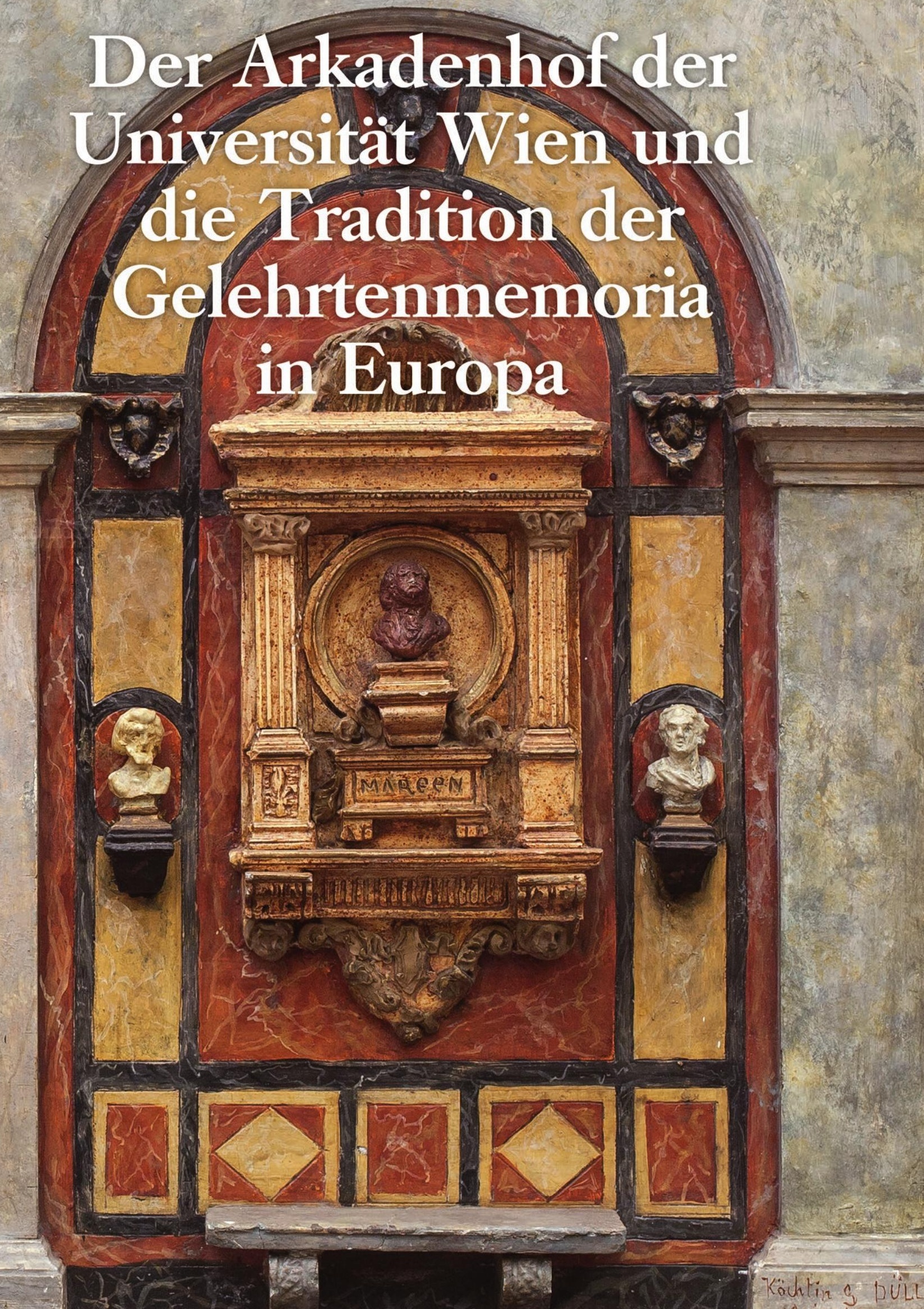




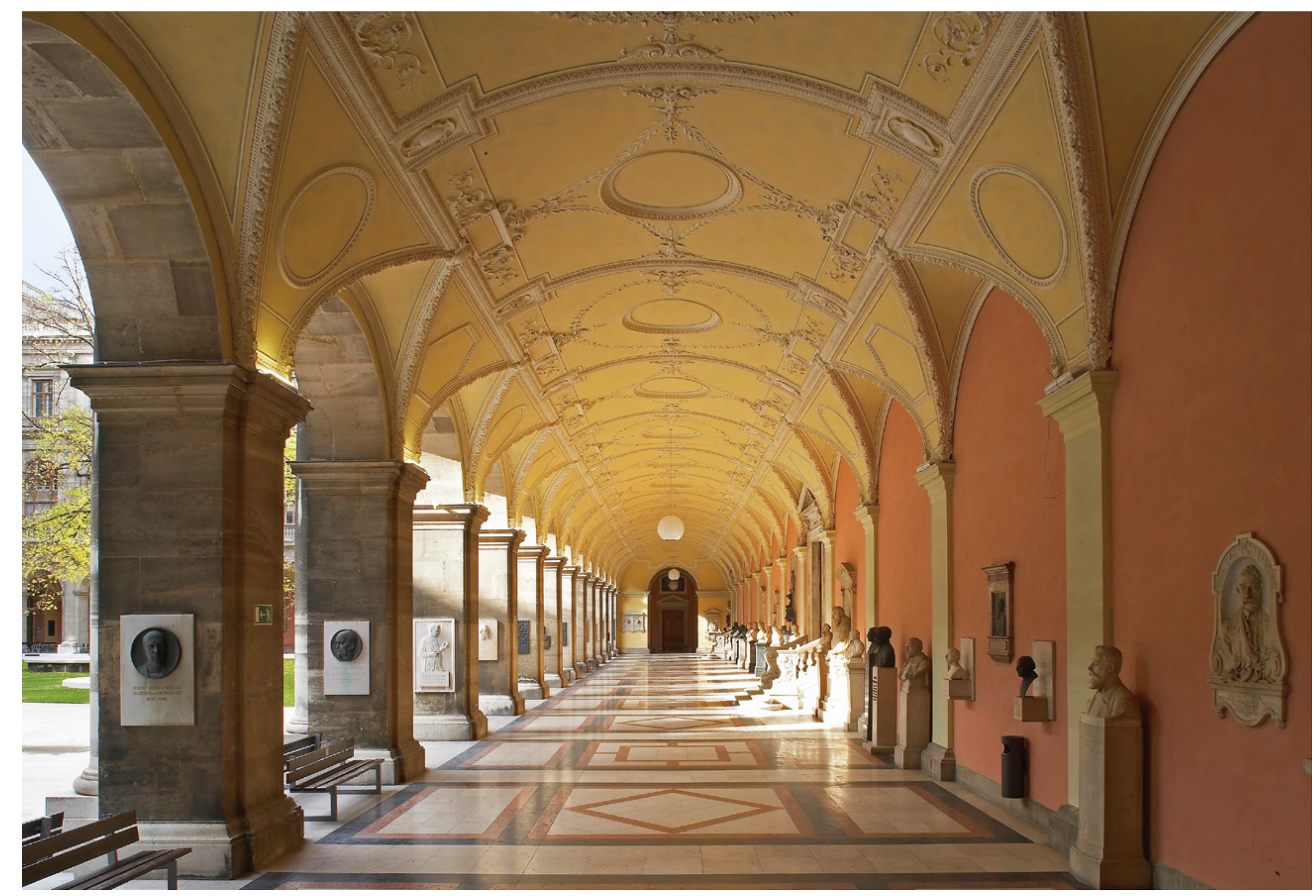




\section{böhlau}




\title{
WIENER JAHRBUCH FÜR KUNSTGESCHICHTE
}

\author{
Herausgegeben vom \\ Bundesdenkmalamt Wien \\ und vom Institut für Kunstgeschichte \\ der Universität Wien
}

BAND LXIII/LXIV 


\section{DER ARKADENHOF DER UNIVERSITÄT WIEN UND DIE TRADITION DER GELEHRTEN- MEMORIA IN EUROPA}

Herausgegeben von Ingeborg Schemper-Sparholz, Martin Engel, Andrea Mayr und Julia Rüdiger 
Das Wiener Jahrbuch für Kunstgeschichte setzt folgende Zeitschriften fort: Jahrbuch der kaiserl. Königl. CentralCommission zur Erforschung und Erhaltung der Baudenkmale (Jg. I/I856-IV/I860); Jahrbuch der k. k. ZentralKommission für Erforschung und Erhaltung der Kunst- und historischen Denkmale (NF I/I903-NF IV/I906); Kunstgeschichtliches Jahrbuch der k. k. Zentral-Kommission für Erforschung und Erhaltung der Kunst- und historischen Denkmale bzw. Jahrbuch des Kunsthistorischen Institutes der k. k. Zentral-Kommission für Denkmalpflege bzw. Jahrbuch des Kunsthistorischen Institutes (Bd. I/I907-Bd. XIV/I920); Jahrbuch für Kunstgeschichte (Bd. I[XV]/I92 I f.). Es erscheint unter dem Titel Wiener Jahrbuch für Kunstgeschichte seit dem Band II (XVI)/I923.

Gedruckt mit Unterstützung durch:

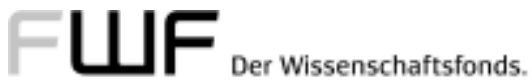

Veröffentlicht mit Unterstützung des

Austrian Science Fund (FWF): PUB 383-G24

Open Access: Wo nicht anders festgehalten, ist diese Publikation lizenziert unter der Creative-Commons-Lizenz

Namensnennung 4.0; siehe http://creativecommons.org/licenses/by/4.0/

Historisch-Kulturwissenschaftliche Fakultät der Universität Wien

\section{. wien}

\author{
RedakTion : \\ Für das Bundesdenkmalamt: \\ N.N. \\ Für das Institut für Kunstgeschichte der Universität Wien : \\ Michael ViKTOR SchWARZ \\ Univ. Wien, Rene Steyer, 2013. \\ Vorsatz: Einblick in den nördlichen Arkadengang, Universität Wien, Öffentlichkeitsarbeit. \\ Iris Andraschek (2009), Universität Wien, Öffentlichkeitsarbeit.
}

Umschlagabbildung: Karl Köchlin/Alois Düll, Modell für einen Arkadenabschnitt der Universität Wien, 1890, Gips, farbig gefasst, restauriert, 1988, Archiv der Univ. Wien, UAW Sign. 114.95; Foto: Institut für Kunstgeschichte der

Nachsatz: Arkadenhof der Universität Wien mit Kastaliabrunnen (1910) und Kunstprojekt „Der Muse reicht's“"von

ISSN 0083-9981

ISBN 978-3-205-20147-2

Druck: Holzhausen, Wolkersdorf

Printed in the EU 


\section{INHALTSVERZEICHNIS}

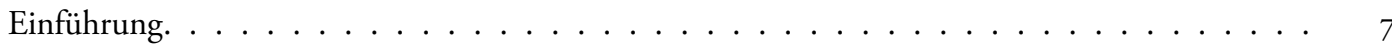

Ingeborg Schemper-Sparholz, Der Arkadenhof im Hauptgebäude der Universität Wien:

Ruhmeshalle, Geschichtsgalerie oder Campo Santo? . . . . . . . . . . . . . . . . . . . II

Maria Pötzl-Malikova, Die Anfänge der Gelehrtenehrung an der Wiener Universität und die Bildnisse des Nikolaus von Jacquin $\ldots \ldots \ldots \ldots \ldots \ldots$

Heidrun Rosenberg, Bilder der Magnifizenz. Die Kaiserliche Rektorengalerie der Universität Wien . . . . . . . . . . . . . . . . . . . . . . 4 47

Andrea Mayr, Das Porträtmedaillon als Form des Gelehrtendenkmals im Arkadenhof

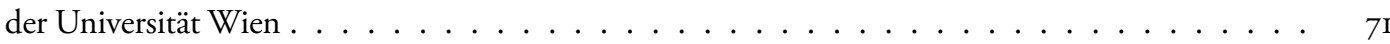

Hubert D. Szemethy, Das Thun-Exner-Bonitz-Denkmal im Arkadenhof der Universität Wien Zur Geschichte des Denkmals anhand von Archivmaterialien . . . . . . . . . . . . . 87

Julia RüDIGER, Medicus in effigie. Repräsentationsformen und -funktionen des Medizinerdenkmals am Beispiel Theodor Billroths . . . . . . . . . . . . . . . . IO

Thomas Maisel, Die „Ausmerzung von Denkmälern“ im Arkadenhof der Universität Wien während der NS-Herrschaft . . . . . . . . . . . . . . . . . . . IIg

Martin Engel, zeitgemäß - die Professorenporträts im Arkadenhof der Universität Wien nach $1945 \ldots \ldots \ldots \ldots \ldots \ldots \ldots \ldots$

Jeanette Kohl, The Salutati Tomb in Fiesole: Animation, Representation and Scholarly Memoria .

Antonella Mampieri, To Fame and Glory: Bologna Municipal Cemetery and its Pantheon. About the Persistence of the Tradition of Celebrating Great Men . . . . . . . . . . . . . . . . . . I69

Elena Catra, Ricordo monumentale ... Le targhe, i busti e i monumenti dell'Accademia di Belle Arti e delle Gallerie di Venezia . . . . . . . . . . . . . . . . . . . . . . . . . . . . I79

Malcolm Baker, A very puissant spurre: Authors, Scholars and the Exemplary Role of the Portrait Bust in the Eighteenth Century . . . . . . . . . . . . . . . . . . I97 
Pietro Conte, Der Körper als Monument. Benthams Auto-Ikone und die Ästhetik des hyperrealistischen Gelehrtenporträts ． . . . . . . . . . . . . . . . . . . . 2 2I3

Sara Ayres, Contemporary Portrait Commissioning in British Universities - Two Case Studies . . 223

Bernd Ernsting, The Portable Scholar's Monument.

Des (Kunst-)Gelehrten Denkmal im Frontispiz seiner Schriften

Hans Christian Hönes, Paper monuments for Antiquaries (Caylus, Winckelmann,

D’Hancarville): Metahistorical Interventions

GrÉgoire Extermann, James Pradier und die Hommage an die Genfer Elite ～. . . . . . . . . . 269

Silvia Schmitt-Maass, Unbequemer Gelehrter, eingehegtes Genie? Eine Büste für Gottfried

Wilhelm Leibniz im Augusteum der Universität Leipzig . . . . . . . . . . . . . . . . . 287

Sigrid Ruby, Gelehrtengedenken in der Universitätsstadt Gießen . . . . . . . . . . . . . . . 303

Angelika Keune, Von Alexander von Humboldt bis Lise Meitner. Denkmalsetzungen von I883 bis 2014 an der Berliner Universität Unter den Linden . . . . . . . . . . . . . . . 3I9

Géza Galavics - Bálint Ugry, Auf der Suche nach Räumen und Formen der Memoria.

Erscheinungsformen der Gelehrtendenkmäler in Ungarn . . . . . . . . . . . . . . 335

Barbara Murovec, Ewige Präsenz der Wissenschaftler im öffentlichen Raum.

Gelehrtendenkmäler in Laibach . . . . . . . . . . . . . . . . . . . . . . . 351

Martin Krummholz, František Palacký im Prager Pantheon und auf dem Platz ． . . . . . . . 367

Plan des Arkadenhofs $\ldots \ldots \ldots \ldots \ldots \ldots \ldots$. . . . . . . . . . . . . . . . . . . .

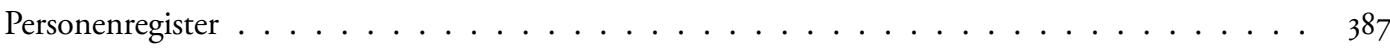

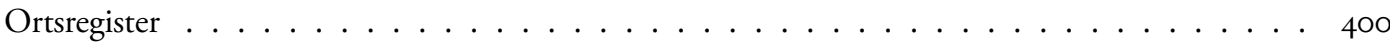

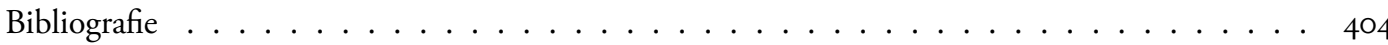




\section{EINFÜHRUNG}

Den Anstoß, sich mit der Gelehrtenmemoria in Europa auseinanderzusetzen, bot das 650-jährige Gründungsjubiläum der Universität Wien. Der bis dahin kaum erforschte Arkadenhof des Universitätshauptgebäudes mit seinen über I50 Professorendenkmälern erwies sich als Forschungsdesiderat für personenbezogene Universitätsgeschichte. Die Basis bot ein vom Jubiläumsfonds der Oesterreichischen Nationalbank gefördertes Forschungsprojekt. Unter meiner Leitung untersuchten Dr. Julia Rüdiger, Mag. Andrea Mayr und Dr. Martin Engel den Arkadenhof als universitäre Gedenkhalle, wobei unter der Mitarbeit von Studierenden das OnlinePortal monuments - das Wiki zu den Denkmälern der Universität Wien (https://monuments.univie.ac.at/) zu sämtlichen Denkmälern erstellt wurde, das jeweils über das Denkmal, den Dargestellten und den/die KünstlerIn informiert.

Im Rahmen des Workshops Scholars' Monuments (Institut für Kunstgeschichte, 24.-26. September 20I4) konnten erste Ergebnisse präsentiert und im Austausch mit WissenschaftlerInnen aus Europa und den USA in einen internationalen Kontext gestellt werden. Die fundierten Beiträge führten zu der Idee, Band LXIII des Wiener Jahrbuchs für Kunstgeschichte diesem Thema zu widmen.

In unserem Forschungsprojekt ging es nicht nur um den historischen Rückblick auf unterschiedliche visuelle Formen der Gelehrtenehrung, sondern aus gegebenem Anlass auch um die Frage, ob das skulpturale Porträt heute noch eine angemessene Form der Auszeichnung für einen Wissenschaftler oder eine Wissenschaftlerin darstellt. Der Arkadenhof der Universität Wien war 2009 musealisiert worden, mit der
Begründung, dass Porträtbüsten keine adäquate Denkmalform mehr darstellen. Von verschiedenen Seiten wurde es aber zunehmend als Mangel empfunden, dass Frauen in der universitären Ehrenhalle keine Berücksichtigung gefunden haben, zumal rund ein Drittel der Denkmäler nach 1945 aufgestellt wurde, also zu einer Zeit als bereits genügend international anerkannte Wissenschaftlerinnen an der Wiener Universität forschten und lehrten. Iris Andrascheks Installation zur vernachlässigten Frauenehrung „Der Muse reicht's“ (2009) kann daher nur als Ausdruck des Protests verstanden werden, nicht als Gedächtnismal für herausragende Wiener Professorinnen. Die Künstlerin illustriert mit ihrem Werk im Grunde Walter Benjamins Bemerkung „Schwerer ist es, das Gedächtnis der Namenlosen zu ehren als das der Berühmten“ (Über den Begriff der Geschichte, 1939). Denkmäler für Namenlose können nicht zu Ikonen und Vorbildern werden, ein Effekt, der nach den Erfahrungen zweier Weltkriege als positiv empfunden wurde.

Der Beschluss des Senats, den Arkadenhof für neue Denkmalsetzungen, speziell für Wissenschaftlerinnen, die an der Universität Wien gelehrt hatten, zu öffnen, entfachte nun erneut die Diskussion um die Denkmalform. Ist das „personifiziert - Denkmalhafte" tatsächlich überholt, wie der Philosoph Burghart Schmidt 2014 in einer Veranstaltung an der Universität Wien meinte, oder sollte die Scheu der Nachkriegsmoderne, Personen Denkmäler zu setzen, überwunden werden? Unterstützt von genderbewussten Gruppen an der Universität Wien bewies Rektor Heinz Engl Mut und schrieb 2015 anlässlich des 650-jährigen Gründungsjubiläums der Universi- 
tät Wien einen Wettbewerb für sieben Denkmäler von international anerkannten Wissenschaftlerinnen aus, die der Universität Wien einst eng verbunden waren.

Der erste Teil des Bandes beleuchtet aus historischer und kunsthistorischer Perspektive den Arkadenhof der Universität Wien. Acht Beiträge mit unterschiedlichen Fragestellungen und methodischen Zugängen beschäftigen sich mit den Professorendenkmälern. In meinem eigenen Beitrag, der sich den Anfängen des Arkadenhofs widmet, werden die ursprünglichen Intentionen der Formgelegenheit universitäre Ehrenhalle und seine Vorbilder in Italien untersucht. Anhand einiger Denkmäler aus den Anfangsjahren wird auch die von der Universität gesteuerte Wahrnehmung durch die zeitgenössischen Medien aufgezeigt. Maria Pötzl-Malikova (München) spürt dem Schicksal einer ursprünglich in der Alten Universität aufgestellten Büste des Naturforschers Nikolaus von Jacquin nach und beschreibt die Anfänge der universitären Professorenehrungen in der 2. Hälfte des I8. Jahrhunderts in Wien. Sind aus der Frühen Neuzeit nur Einzelbeispiele plastischer Professorenbildnisse überliefert, so lässt sich aus dem I7. und I8. Jahrhundert eine gemalte Rektorengalerie rekonstruieren, die Heidrun Rosenberg (Wien) neu interpretiert. Der erste und am häufigsten im Arkadenhof eingesetzte Porträttypus ist das Porträtrelief im scharfen Profil. Andrea Mayr (Wien) untersucht die Bezüge zu Medaillenporträt, Grabmal und Fotografie. Eine Bedeutungssteigerung über die freiplastische überlebensgroße Porträtbüste bis zum ganzfigurigen Monument zeichnet die Denkmalgruppe rund um den Universitätsreformer Leo Graf Thun-Hohenstein aus. Hubert Szemethy (Wien) widmet sich ausgehend von einem Gipsmodell für das Büstenmonument des Philologen Hermann Bonitz dem historisch-politischen Hintergrund ihrer Entstehung. Julia Rüdiger (Wien) untersucht hingegen die unterschiedlichen Intentionen von Repräsentation in den zeitgenössischen und posthumen Denkmal- setzungen für den Chirurgen Theodor Billroth. Eine unrühmliche Phase der Wiener Universitätsgeschichte wird in dem Beitrag von Thomas Maisel, Leiter des Wiener Universitätsarchivs, offengelegt. Quellenkritisch untersucht er die 1938 erfolgte Schändung, aber letztlich auch Bewahrung der Denkmäler von Professoren jüdischer Herkunft. Martin Engel (Wien) stellt die Frage nach der Aktualität der Porträtbüste in den Jahren nach 1945, also in der Zeit der Moderne, wo es zu einem Spannungsverhältnis zwischen dem Anspruch von Erkennbarkeit des Dargestellten und freier Formgebung kommt.

Der zweite Teil des Bandes lenkt den Blick auf die Anfänge der frühneuzeitlichen Gelehrtenehrung und ihre antiken Wurzeln in Italien. Einzelne Beiträge zeigen, wie unterschiedlich diese Tradition in den europäischen Ländern rezipiert wird. Berücksichtigt wurden dabei nicht nur skulpturale Denkmäler, sondern auch die Medien Malerei und Grafik.

Jeanette Kohl (Riverside) widmet ihren Beitrag grundsätzlichen Überlegungen zum Thema Porträtbüste als Körperfragment. Sie verweist auf die antike Memorialkultur und zeigt in einer fundierten Fallstudie zum Salutati-Grabmal in Fiesole das Wiederaufleben des Typus im Quattrocento. Antonella Mampieri (Bologna) erinnert an die Tradition der Gelehrtenehrung in Bologna und konzentriert sich in ihrem Beitrag auf die Grabdenkmäler des I9. Jahrhunderts im Cimiterio Municipale. Das ist in unserem Zusammenhang von Bedeutung, wird doch die Universität Bologna in den Quellen des I9. Jahrhunderts zu den Denkmalsetzungen im Wiener Arkadenhof explizit als Vorbild genannt. Der gehobene soziale Status des Künstlers im I9. Jahrhundert und sein Selbstverständnis als Gelehrter, das letztlich auf Leon Battista Alberti und die Zeit des Quattrocento zurückgeht, ließ auch an den Kunstakademien skulpturale Denkmalensembles entstehen. Elena Catra (Venedig) macht dies am Beispiel der Accademia di Belle Arti in Venedig deutlich. 
In Fortsetzung der Renaissancetradition kommt es im I8. Jahrhundert auch in England zu einer Wiederbelebung der klassischen Porträtbüste, wo sie häufig in Gips vervielfältigt zu einem unverzichtbaren Ausstattungsstück in Colleges, aber auch in privaten Studierräumen wird. Mit Malcolm Baker (Riverside) konnte der beste Kenner dieses Genres für einen Beitrag gewonnen werden. Am Beispiel der Wren Library des Trinity College in Cambridge verweist Baker auf die lange Tradition der Verknüpfung von Autor und Buch in den Bibliotheksprogrammen. Nicht nur Gelehrte, auch Sponsoren und ehemalige Studierende fanden dort Aufstellung. In völligem Widerspruch zur klassisch distanzierten Porträtskulptur entwickelte der Philosoph Jeremy Bentham Ende des I8. Jahrhunderts die außerordentliche Idee, den eigenen Körper als Effigie zu verewigen und für immer am Universitätsleben teilhaben zu lassen. Pietro Conte (Mailand) zeigt in seiner Studie, dass hinter dieser skurril anmutenden Bestimmung ein kunsttheoretisch fundiertes Konzept der hyperrealistischen Autoikone steht. Sara Ayres (London) weist nach, welche Rolle das realistisch gemalte Professorenbildnis noch heute an den Universitäten in Großbritannien spielt.

Zwei Beiträge widmen sich dem Gelehrtenmonument in der Grafik. Seltene bisher unveröffentlichte Beispiele eines „Portable Scholar's Monument" in kunsttheoretischen Schriften der Renaissance stellt Bernd Ernsting (Köln) vor, während Hans Christian Hönes (London) an einigen „Paper monuments for Antiquaries“ des I8. Jahrhunderts die Selbstinszenierung der Autoren (Winckelmann, Caylus, D'Hancarville) in fiktiven grabmalartigen Frontispizen ihrer Schriften behandelt.

Ist im anglikanischen Bereich das Denkmalbewusstsein sehr stark ausgeprägt, wird es im calvinistischen Genf zum Problem. Grégoire Extermann (Genf) zeigt, wie die Genfer Elite das Tabu persönlicher Repräsentation im universitären Raum umgeht und beispielsweise Jean-
Jacques Rousseau, den berühmtesten Sohn der Stadt, durch ein ganzfiguriges Denkmal im öffentlichen Raum ehrt. Eine ähnliche Stellung nimmt Gottfried Wilhelm Leibniz in Leipzig ein. Silvia Schmitt-Maass (Leipzig) erörtert die wechselvolle Geschichte der Aufstellung seiner Kolossalbüste im Augusteum. Sigrid Ruby (Gießen) zeigt wie in der Universitätsstadt Gießen die universitäre Gelehrtenehrung im 20. Jahrhundert wieder aufgenommen und in den Stadtraum eingebunden wurde, wobei dort erstmals auch Frauen als Wissenschaftlerinnen gewürdigt werden. Eine besonders große und noch heute regelmäßig erweiterte Sammlung an Professorendenkmälern besitzt die Humboldt Universität zu Berlin. Die Kustodin Angelika Keune (Berlin) bietet einen Überblick über die Geschichte der Sammlung und stellt die langwierige Entstehungsgeschichte des 20I4 errichteten Denkmals für Lise Meitner vor. Damit setzte Berlin einen Maßstab, wie individuell angemessene Monumente für bedeutende Wissenschaftler und Wissenschaftlerinnen heute aussehen können.

Der Umgang mit Gelehrtenmemoria in den ehemaligen Ländern der Donaumonarchie wird in drei weiteren Beiträgen dargelegt. Géza Galavics und Balint Ugry (Budapest) bieten einen Überblick über die Ehrung von Wissenschaftlern in Ungarn von der Barockzeit bis heute. Die Errichtung von Büstenmonumenten, um etwa die Zugehörigkeit zu einer Korporation auszudrücken oder nationale Identifikation zu stärken, ist dort bis heute selbstverständlich. Dies trifft auch auf Slowenien zu, wo Jože Plečnik, wie Barbara Murovec (Ljubljana) ausführt, am Beginn des 20. Jahrhunderts Büstenreihen vor den Gebäuden der Bildungsinstitutionen in das städtebauliche Konzept Laibachs einplante. Am Beispiel des Laibacher Denkmals für den Slawisten Franz von Miklosich (slow. Miklošič), dem als erstem Lehrstuhlinhaber für slawische Philologie an der Universität Wien auch hier ein Denkmal errichtet wurde, zeigt sie das Erstarken nationaler Kräfte in Slowenien. In Böhmen führte nati- 
onales Denken zur Heroisierung des Historikers František Palacký in dem monumentalen Denkmal in Prag, dessen Genese Martin Krummholz (Prag) darlegt.

Die Beiträge in diesem Band lassen erkennen, dass in Europa unterschiedliche Positionen zur Frage des Personendenkmals und speziell zur Gelehrtenehrung bestehen. Gibt es im englischsprachigen Raum und den Ländern des ehemaligen Ostblocks bis heute keine Scheu, klassische Porträtbüsten im öffentlichen Raum aufzustellen und realistisch gemalte Bildnisse in Amtsräumen aufzuhängen, so wird diese Praxis im deutschsprachigen Raum kritisch hinterfragt. Es besteht hier aber auch mehr Mut zu künstlerischer Freiheit, auch wenn mit Kritik seitens der breiten Öffentlichkeit zu rechnen ist. Als Alternati- ve sind die „sculpture memories“ des Schweizer Künstlers Thomas Hirschhorn zu verstehen, der Individualität aus Artefakten konstruiert.

Allen Autorinnen und Autoren, die zum Gelingen dieses Bandes beigetragen haben, sei an dieser Stelle herzlich gedankt.

Mein besonderer Dank gilt meinen MitarbeiterInnen Martin Engel, Andrea Mayr und Julia Rüdiger, die darüber hinaus wesentlich für die Redaktion dieses Bandes mitverantwortlich waren. Das Jubiläumsbüro der Universität Wien hat dankenswerterweise nicht nur monuments - das Wiki zu den Denkmälern der Universität Wien, sondern auch die Publikation finanziell großzügig unterstützt.

Ingeborg Schemper-Sparholz 


\title{
DER ARKADENHOF IM HAUPTGEBÄUDE DER UNIVERSITÄT WIEN: RUHMESHALLE, GESCHICHTSGALERIE ODER CAMPO SANTO?
}

\author{
Ingeborg Schemper-Sparholz
}

$\mathrm{E}$ ine zufällig erhaltene Postkarte aus der Zeit um 1900 zeigt den südlichen Gang des Arkadenhofes (Juristenseite) der Universität Wien (Abb. I). ${ }^{\mathrm{I}} \mathrm{Zu}$ erkennen sind am letzten Pfeiler nur das I888 enthüllte Porträtrelief für den Juristen und Justizminister Julius Glaser und an der Schnittstelle der Arkadengänge das ganzfigurige Denkmal für den Unterrichtsminister und Bildungsreformer Leo Graf von Thun-Hohenstein. Auf der Rückseite der Karte hat ein anonymer Zeitgenosse das Wachsen des Denkmalensembles verfolgt. Er bezeichnet in Anspielung auf die Regensburger Ruhmeshalle den Arkadenhof als eine Art Walhalla. Die Denkmäler werden 1906 und ergänzend I9I genau in ihrer Reihenfolge aufgelistet. Der Verfasser der Postkarte vermerkt bereits 64 Denkmäler, die er in einem Rundgang, auf der Juristenseite beginnend und sich im Uhrzeigersinn fortbewegend, aufzählt, eine Leserichtung, der sämtliche Beschreibungen bis heute folgen.

Noch vor der I893 erfolgten Aufstellung der prominenten Gruppe der Bildungsreformer (Leo
Graf Thun, Franz Exner, Hermann Bonitz) im linken Eckpavillon präsentierte sich die medizinische Fakultät ihrem internationalen Ruf entsprechend. I889 wurden rechts vom Stiegenaufgang im nördlichen Arkadengang Büstenmonumente für den Anatomen Josef Hyrtl und den Chirurgen Franz Schuh angebracht. Bezug nehmend auf die Universitätsgeschichte stellte man ihnen die Büsten ihrer Vorläufer Gerard van Swieten, Josef Quarin und Andreas Josef von Stifft zur Seite, die sich ursprünglich in der Alten Universität befunden hatten. 1905 wurde van Swieten auf die gegenüberliegende Arkadenwand verlegt, um den Naturwissenschaften als Ahnherr zu dienen (Abb. 2). Es ist dies ein anschaulicher Akt für die Neustrukturierung der Fakultäten, waren doch die Naturwissenschaftler des I8. Jahrhunderts alle zunächst als Mediziner ausgebildet, ehe sie als Vertreter von Einzeldisziplinen der philosophischen Fakultät zugeordnet wurden. ${ }^{2}$ Dieses Beispiel veranschaulicht exemplarisch, dass im Laufe der Geschichte verschiedene Konzepte für

I URL: http://www.metropostcard.com/publishersl.html, abgerufen am 25. Juli 20I5. Die Firma C. Ledermann produzierte zwischen 1899 und 1909 in Wien. Da die Van-Swieten-Arkade noch nicht zu erkennen ist, muss die Aufnahme vor 1904 entstanden sein. Die Beschriftung lautet: $8 m$ breite, mit 5 m breiten Öffnungen dem Hof zugewandte Bogengänge- Die durch Aufstellung der Büsten und Reliefs zu einer Art Walhalla der Universität. Prof. Gestalten umschließen den Hof. Die Wölbungen des Arcadenganges sind mit Ornamenten geziert. Derzeit (November I9, durchgestrichen: März I9II) sind in den Arcaden [...] Standbilder, Büsten und Relief [...]. Es folgen die Namen der Professoren.

2 K. Mühlberger, Das „Antlitz“ der Wiener Philosophischen Fakultät in der zweiten Hälfte des 19. Jahrhunderts. Struktur und personelle Erneuerung. In: Eduard Suess und die Entwicklung der Erdwissenschaften zwischen Biedermeier und Sezession, hrsg. von J. SeIdL (= Schriften des Archivs der Universität Wien I4), Göttingen 2009, S. 67-IO4. 


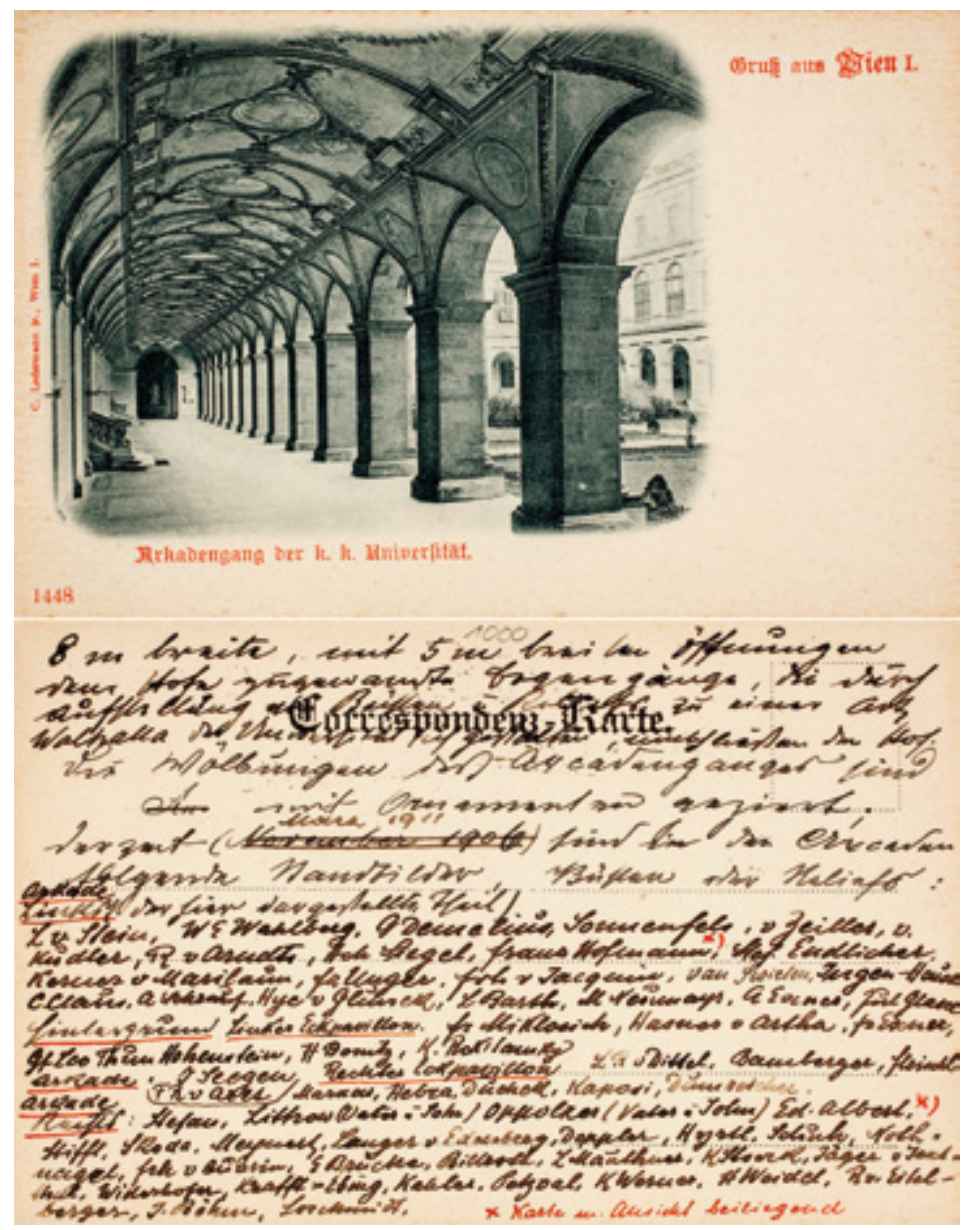

Abb. I: Postkarte, Arkadenhof der Universität Wien, um Igoo, r. und v., Privatbesitz.

die Gestaltung des Arkadenhofes wirksam wurden, sowohl politisch als auch künstlerisch. Im Folgenden soll eine kurze chronologische Darstellung der Denkmalsetzungen erfolgen und die bisherige literarische Bearbeitung derselben erörtert werden. Anhand von Schwerpunkten soll danach Einblick in mögliche vertiefende Forschungsfragen gegeben werden.

In den ersten Jahrzehnten nach seiner Eröffnung erlebte der Arkadenhof seine Hochkonjunktur als Denkmalort, ehe der Erste Weltkrieg eine Zäsur setzte. Eine historische Aufnahme von 1914 zeigt den nördlichen Arkadengang zweckentfremdet als Ruhezone für Kriegsversehrte, denn die Universität diente damals als Militärspital. ${ }^{3}$ Die Pfeiler sind noch unbesetzt. Sie boten sich aber in den folgenden Jahren für die Anbringung von Porträtreliefs an.

Anlässlich des 50-jährigen Jubiläums der Eröffnung des Hauses erschien 1934 eine Festschrift mit dem Titel „Ruhmeshalle der Universität“, verfasst von dem deutsch-national ge-

3 K. Mühlberger, Palast der Wissenschaft. Ein historischer Spaziergang durch das Hauptgebäude der Alma Mater Rudolfina Vindobonensis, Wien/Köln/Weimar 2007, S. 98, Abb. 73. 


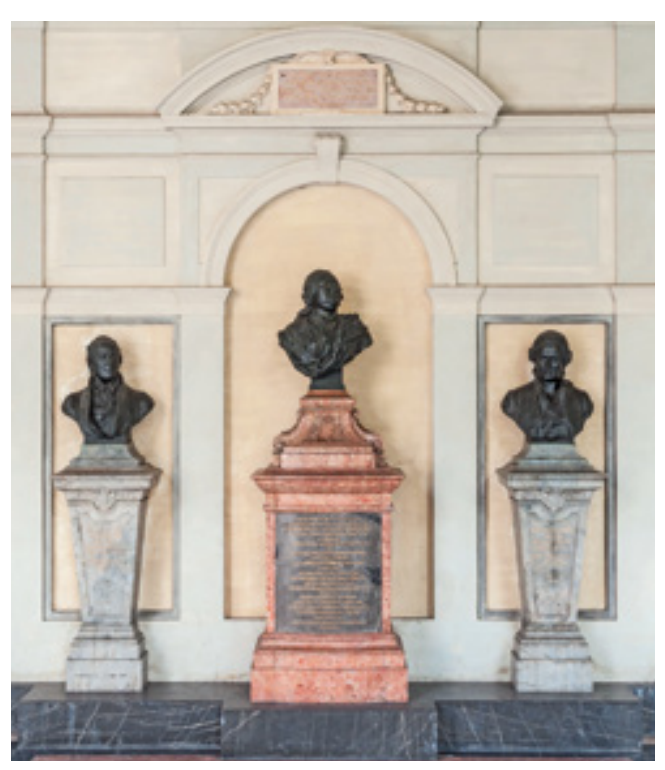

Abb. 2: Wien, Arkadenhof der Universität Wien, Triumphbogen für Nikolaus Jacquin, Gerard van Swieten und Jan Ingen-Housz, Gestaltungskonzept: Karl König, I905.

sinnten Altphilologen und Pädagogikprofessor Richard Meister. ${ }^{4}$ Sie enthält nicht nur eine Geschichte der Universität Wien, sondern ist der erste Denkmalkatalog mit Lichtbildaufnahmen der 95 damals vorhandenen Monumente, mit Angaben zur Person, Bedeutung, zum Künstler und Aufstellungsdatum, wobei auch Denkmäler außerhalb des Arkadenhofes aufgenommen wurden. Vorangestellt sind großformatige Porträtfotos der Unterrichtsminister Anton Rintelen und Kurt Schuschnigg, der zum Erscheinungszeitpunkt des Buches auch schon Bundeskanzler war, sowie der zwischen 1932 und 1934 amtierenden Rektoren und Dekane aller Fakultäten.
Sie präsentieren sich als Nachfolger der Geehrten und somit als Teil der Rubmeshalle.

„Die Denkmäler des Arkadenhofes sollen uns das Stück der Geschichte unserer Universität in lebensvoller Anschauung erhalten, in dem sich ihre beste Tradition verkörpert: die großen Lehrer, ihre Leistungen auf dem Gebiet der Wissenschaft, ihr Wirken für Staat, Volk und Menschheit. So verbinden sie uns Lebende durch die Erinnerung mit der Vergangenheit und verpflichten uns durch das Vorbild zu eigenem Wirken im gleichen Geiste und weisen den kommenden Geschlechtern der Alma Mater den Weg zu dem, was Wissenschaft an Arbeit und Pflicht, Hoheit und Glück in sich birgt."s

Unter den amtierenden Würdenträgern finden sich einige später aus politischen Gründen höchst umstrittene Persönlichkeiten wie der Paläobiologe Othenio Abel und der Historiker Heinrich Srbik. ${ }^{6}$ Die Angaben zu den Denkmälern sind jedoch erstaunlich sachlich. Die Aufnahmen der österreichischen Lichtbildstelle, die erste Fotodokumentation des damaligen Denkmalbestandes, haben historischen Wert, denn viele der hier dargestellten Monumente wurden vier Jahre später beschädigt oder waren zwischen I938 und 1945 abgebaut.7 Bereits 1934 waren Jubiläumsfeierlichkeiten wegen Befürchtung antisemitischer Ausschreitungen vom Unterrichtsministerium untersagt worden. Der Autor verhielt sich aus ideologischen Gründen zwiespältig in Bezug auf Ehrungen. Für eine 1943 geplante Ausstellung, Die Wiener Persönlichkeit des 20. Jahrhunderts aus Kunst und Wissenschaft, äußerte sich der stets opportunistisch agierende Prof. Meister

4 R. Meister, Ruhmeshalle der Wiener Universität. Geschichte der Wiener Universität, Wien I934.

5 Ebenda, S. 70.

6 Bedrohte Intelligenz. Von der Polarisierung und Einschüchterung zur Vertreibung und Vernichtung im NS Regime, Publikation zur Ausstellung der Universität Wien aus Anlass des Jubiläumsjahres 20I5 (hrsg. von ST. MeIsseL, TH. OlechowsKi), S. II, 58. Es ist bezeichnend für die damals noch unaufgearbeitete Universitätsgeschichte der Zwischenkriegs- und Nazizeit, dass 1974 der Antrag gestellt wurde, für Othenio Abel eine Gedenktafel im Arkadenhof zu setzen. 1983 wurde sogar an eine Büste gedacht, die sein Sohn Wolfgang Abel, ebenfalls Paläontologe, nach dem Krieg ungeschoren gebliebener Rassentheoretiker, aber auch Künstler, angefertigt hatte. UAW Senat S 222.56.

7 S. den Beitrag von Th. Maisel in diesem Band. 
ablehnend gegen eine Aufnahme des 1926 verstorbenen Nationalökonomen Friedrich Freiherr von Wieser, weil dieser „nicht rein arisch“ sei.

Wieser erhielt sein Denkmal im Arkadenhof erst 1957. In den Nachkriegsjahren kam es noch einmal zu einer verstärkten Denkmalsetzungsinitiative. ${ }^{8}$ Als Rektor setzte sich Meister für die Aufstellung des Denkmals des Theologen und Politikers Ignaz Seipel ein, dem er sich aus der Zeit des Ständestaates stark verbunden fühlte. Auch als Präsident der Akademie der Wissenschaften folgte Meister dem Beispiel der Universität Wien und ließ in der Aula des Akademiegebäudes, der ehemaligen Universität, Büstenmonumente der Präsidenten aufstellen, u. a. von Eduard Suess, der sein Rektorat schon I889 wegen antisemitischer Anfeindungen vorzeitig beendete und der im Arkadenhof kein Denkmal hat, obwohl er nicht nur ein in- ternational anerkannter Geologe, sondern auch als Liberaler universitätspolitisch aktiv war. ${ }^{9}$

Ein aktualisiertes Verzeichnis der Denkmäler im Arkadenhof ist das Buch von Thomas Maisel (2007). ${ }^{10}$ Die Monumente wurden im restaurierten Zustand neu aufgenommen. 88 Denkmäler waren nach 1934 noch dazugekommen. Diese informative Publikation war Ausgangspunkt für das Projekt „Ge(l)ehrte Köpfe“, dessen Ergebnisse in der elektronischen Wiki-Plattform monuments - das Wiki zu den Denkmälern der Universität Wien allgemein zugänglich sind und laufend korrigiert und ergänzt werden. ${ }^{\text {II }}$

Im Folgenden werden einige der Ergebnisse für grundsätzliche Fragestellungen nach dem Typus des universitären Ehrenhofes und der Rolle des Professorendenkmals in den Jahren um I900 in Wien herangezogen. ${ }^{22}$

\section{G E S C H I C H T S G A LE R I E, RU H M E S H A L L E \\ ODER CAMPOSANTO-DIE IDEE}

Der Arkadenhof des historistischen Hauptgebäudes der Universität Wien gehört mit seinen über I5o Denkmälern zu den größten universitären Gedenkräumen Europas. ${ }^{13}$ Er liegt im Zentrum des palastartigen Neorenaissancebaues an der Ringstraße und bildet die Schnittstelle der Kommunikationswege, die von der Aula zu den seitlichen Treppenhäusern und einst direkt zur Bibliothek führten (siehe Plan Abb. Vorsatz und Einblick Abb. Frontispiz). Der Arkadenhof ist eingebunden in ein Bildprogramm, das an der Hauptfas- sade I28 berühmte Gelehrte als Nischenfiguren, Medaillons und Namenstäfelchen präsentiert. Sie folgen einer hierarchischen Ordnung von antiken Philosophen über Gelehrte des Mittelalters und der Frühen Neuzeit bis hin zu berühmten Zeitgenossen, die nicht aus den Ländern der Habsburgermonarchie stammten. Geordnet nach den klassischen vier Fakultäten verkörpern sie die Universitas litterarum Vindobonensis, wie die Inschrift unterhalb des Giebelreliefs mit Darstellung der Geburt der Minerva verkündet. ${ }^{14}$ Im Hof sollten

8 Vgl. den Beitrag von M. Engel in diesem Band.

9 Mühlberger, Das „Antlitz“ der Wiener Philosophischen Fakultät (zit. Anm. 2), S. 95-IOI.

Io Th. MaIsel, Gelehrte in Stein und Bronze. Die Denkmäler im Arkadenhof der Universität Wien, Wien 2007.

II URL: https://monuments.univie.ac.at, abgerufen am 29. August 2016.

I2 Für Hinweise und anregende Diskussion sei an dieser Stelle meinen MitarbeiterInnen Martin Engel, Andrea Mayr, Julia Rüdiger und den Studierenden der Übung im Studienjahr 2013/14 gedankt, besonders Caroline Mang, Cizgdem Özel und Julia Strobl.

I3 Zum Universitätsgebäude s. zuletzt: Stätten des Wissens. Die Universität entlang ihrer Bauten I365-20I5 (Hg. von J. RüDiger und D. SchweIZer), Wien 2015.

I4 J. RÜDIGER, Begegnung mit dem steinernen Autor. Die Gelehrten an der Fassade der Wiener Universität, in: Autor- 
nun ausgezeichnete Professoren geehrt werden, die seit der Universitätsreform nach 1848 hier gelehrt haben und in Zukunft lehren würden. Kollegen und Studierende werden so mit der Geschichte ihrer Universität konfrontiert, repräsentiert durch die Porträts ihrer Vertreter. Es war die Idee des Architekten Heinrich von Ferstel bzw. seines Schwagers und Nachfolgers Karl Köchlin und ihres kunsthistorischen Beraters Rudolf Eitelberger von Edelberg. Der Kunsthistoriker Eitelberger hat sich massiv für die Bedeutung der Porträtplastik im öffentlichen Raum eingesetzt.

Das Porträt ist zweifach wichtig für das Publicum; für das Staatsleben und für das Familienleben. Der Staat bedarf der Porträtstatuen und Büsten nicht blos des Rubmes, sondern auch der Selbsterhaltung wegen; denn er braucht seine Geistesheroen, seine Staatsmänner als geistige Stützen und die Erinnerung an dieselben. Es handelt sich sowohl darum, die Todten zu ehren, als auch die Lebenden zu erinnern, dass das staatliche Gebäude, in dem sie wohnen, die Frucht der Bemühungen jener Männer sei, deren Leben Jahrhunderte zurückreicht und noch Jahrbunderte nachwirkt. Alle gebildeten Nationen haben daher, solange sie ein Bewußtsein ihrer Grösse und Würde sich erhalten haben, das Andenken solcher Männer nach ihrem Tode durch Porträtstatuen zu ehren gesucht, aber sie haben sich gescheut mit lebenden Personen Idolation zu treiben. Denn der Cultus der Lebenden verlangt ein Mass und eine ethische Schranke, die zu überschreiten, feingebildete und die Würde der Menschheit achtende Nationen scheuen. ${ }^{15}$

Geschichte lernen über Porträtreihen war ein Erziehungskonzept der Aufklärung, das im Denkmalverständnis des Historismus fortlebt. ${ }^{16}$ Leistung und Fortschritt sollten durch die Darstellung einzelner Persönlichkeiten sichtbar gemacht werden. So begegnet man in Wien entlang der Ringstraße Feldherren, Dichtern, Musikern in Einzeldenkmälern, aber kaum Gelehrten. Sie wurden in die Bauplastik der Bildungsbauten integriert. Eitelberger kritisiert die Aufstellung von Naturforschern in der Dachzone des Naturhistorischen Museums, wo sie kaum wahrnehmbar sind, für ihn ein Beispiel für die Geringschätzung der Porträtplastik. ${ }^{17}$

Der Begründer des Instituts für Kunstgeschichte an der Universität Wien trug nach I848 im Zuge der Bildungsreform unter Leo Graf von Thun-Hohenstein zum wachsenden Ansehen der Universitätsprofessoren bei. ${ }^{18}$ Die erstrebte Freiheit in Forschung und Lehre, die zu einer Differenzierung der Wissensgebiete an den Fakultäten führte, förderte das Bedürfnis der Professoren nach Selbstdarstellung als Vertreter ihrer

schaft. Konzeptionen, Transformationen, Diskussionen (hrsg. von H. BANnERT/E. KLECKER), Wien 20I3, S. 223246.

I5 R. v. Eitelberger, Das Porträt, Vortrag gehalten im n.ö. Ständehaus in Wien I86o, in: Gesammelte Kunsthistorische Schriften, III, Wien I884, S. 213-2I4.

I6 Aus einem wohl getroffenen Porträt den Charakter des Dargestellten abzulesen fördere die eigene Hochachtung und Würdigung seiner Verdienste, denn das Wissen um das Aussehen eines Gelehrten wecke bei dem Betrachter das Bedürfnis, sich eingehender mit dessen Schriften zu beschäftigen, und schaffe letztlich einen Anreiz, der ihn zur Nacheiferung anspornt, heißt es bei Johann Jakob Brucker (I696-I770), der Mitte des I8. Jahrhunderts eine Bildnisvitenfolge zeitgenössischer Gelehrter aller Fakultäten herausgab, illustriert durch Mezzotinto-Porträts des Augsburger Stechers Johann Jakob Haid. Johann Jaков BRUCKer, Ehrentempel der Deutschen Gelehrsamkeit, in welchem die Bildnisse gelehrter, und um die schönen und philologischen Wissenschafften verdienter Männer unter den Deutschen aus dem XV. XVI. und XVII. Jahrhunderte aufgestellet, und ihre Geschichte, Verdienste und Merckwürdigkeiten entworfen sind, Augsburg 1747.

I7 R. v. Eitelberger, Die Plastik Wiens in diesem Jahrhundert, in: Gesammelte Kunsthistorische Schriften, I, Wien I879, S. I46-I48.

i8 T. v. Borodajkewicz, Aus der Frühzeit der Wiener Schule der Kunstgeschichte. Rudolf Eitelberger und Leo Thun, in: Festschrift für Hans Sedlmayr (Hg. v. K. Oettinger und M. Rassem), München 1962. Vgl. auch den Beitrag von $\mathrm{H}$. Szemethy in diesem Band. 
neu geschaffenen Institute und nach Anerkennung ihrer Disziplin als exakte Wissenschaft. Die Denkmalsetzungen im Wiener Arkadenhof spiegeln die Bestrebungen der Fakultäten wider, ihre neu gegründeten Lehrkanzeln zu repräsentieren. Die einerseits aus dem Propädeutikum Philosophie (ehem. Artistenfakultät) und einem Teilbereich der Medizin („Hilfswissenschaften“) abgespaltenen naturwissenschaftlichen Fächer hatten ein besonderes Bedürfnis, ihre Selbständigkeit zu demonstrieren. Die Philosophische Fakultät war nun erstmals den Fakultäten der Theologen, Juristen und Mediziner gleichgestellt.

Durch die Orientierung am preußischen Bildungssystem und der Mobilität vieler Professoren wie z. B. Hermann Bonitz kann in Wien die Kenntnis der Denkmalinitiativen in Berlin und deren deutschen Städten vorausgesetzt werden. Dort findet sich schon früher das heroisierte Bild des Universitätsprofessors. An der Berliner Universität wurden seit I833 Porträtbüsten, Medaillen und Gemälde regelrecht gesammelt, von Kaiser Wilhelm I. wurde I876 sogar die Aufstellung ganzfiguriger Denkmäler von Alexander und Wilhelm Humboldt gegenüber den Feldherren unter den Linden gestattet. ${ }^{19}$ Das Konzept des Arkadenhofes in Wien sah individuell gestaltete Denkmäler vor, vereinigte die Professorenschaft aber auch als Korporation im geschlossenen Raum.

Schon in der frühen Planungsgeschichte des
Universitätsneubaues spielte das Gedenken eine Rolle, doch sollte es zunächst traditionsgemäß im sakralen Raum angesiedelt werden.

Eitelberger, dem die Darstellung vaterländischer Geschichte im personalisierten Denkmal ein großes Anliegen war, hatte zunächst eine andere Idee. In der frühen Planungsphase, in der die Votivkirche nach dem Entwurf Ferstels von Universitätsbauten umgeben werden sollte, hätte sie auch die Aufgabe einer Universitätskirche erfüllt. Das Innere sollte - nach Vorstellung Eitelbergers - zu einer Denkmalkirche umgestaltet werden. Die Seitenkapellen zwischen den Pfeilern in den Seitenschiffen, die Wandflächen an dem Kapellenkranz in der Apsis verlangten laut Eitelberger nach Monumenten, „wie solche in Italien und in Frankreich üblich sind, wie man sie in S. Croce in Florenz, in S. Giovanni e Paolo und ai Frari in Venedig, in Santa Maria del Popolo und in St. Peter in Rom und überall sieht, wo man den Geist der Heroen pflegt, nur in Wien nicht. Das schöne Grabmal des Arztes und Gelehrten Johann Peter Frank befindet sich auf einem Friedhof, der zur Demolierung bestimmt ist." ${ }^{\text {"o }}$ Solche Pantheon-Ideen tauchen in Wien schon Ende des I8. Jahrhunderts in $\mathrm{Zu}-$ sammenhang mit der Regotisierung der Augustinerkirche, aber auch als eine mögliche Nutzung der Karlskirche auf. ${ }^{21}$ I 823 stellte die Juridische Fakultät vergeblich ein Ansuchen an die nieder-

I9 A. Keune, Gelehrtenbildnisse der Humboldt-Universität zu Berlin. Denkmäler, Büsten, Reliefs, Gedenktafeln, Gemälde, Zeichnungen, Graphiken, Medaillen, Berlin 2000, S. 9-II.

20 R. v. Eitelberger, Ferstel und die Votivkirche, in: Gesammelte Kunsthistorische Schriften, I, Wien i879, S. 320. J. P. Frank (I745-I82I), der von Josef II. aus Pavia nach Wien berufen worden war, reformierte das Allgemeine Krankenhaus, war Pionier auf dem Gebiet der Sozialmedizin, Begründer der Hygiene als universitäres Fach. Er wurde auf dem Währinger Ortsfriedhof beigesetzt. Nach dessen Schließung (1873) wurde das klassizistische Grabmal von Leopold Kiesling (1822) auf den Wiener Zentralfriedhof (Ehrengräber Gr. 32 A Nr. 3) übertragen. A. SMETANA, Grabdenkmäler des Wiener Klassizismus - Ein Beitrag zur Erforschung der Sepulkralkultur zwischen 1788 und I840, ungedr. Dipl.-arbeit Wien 2008, Kat. 28, S. 176. - Eine verschollene Büste Franks von Johann Martin Fischer befand sich im Allgemeinen Krankenhaus. C. Wurzbach, Biografisches Lexikon des Kaiserthums Österreich, IV, Wien I858, S. 245 .

2I Carl Bertuchs Tagebuch vom Wiener Kongress (hrsg. v. H. Freiherr von Egloffstein), Berlin i9i6, S. 98: „[...] Carls Kirche, wo ich das Locale zu einem Denkmal Mozarts besehe. Diese Kirche wäre ganz zu einem Pantheon für Wien geeignet. In den Schwibbogen der Seitenaltäre wäre dieses gut anzubringen [...]“ Danke für den Hinweis an Gernot Mayer. 


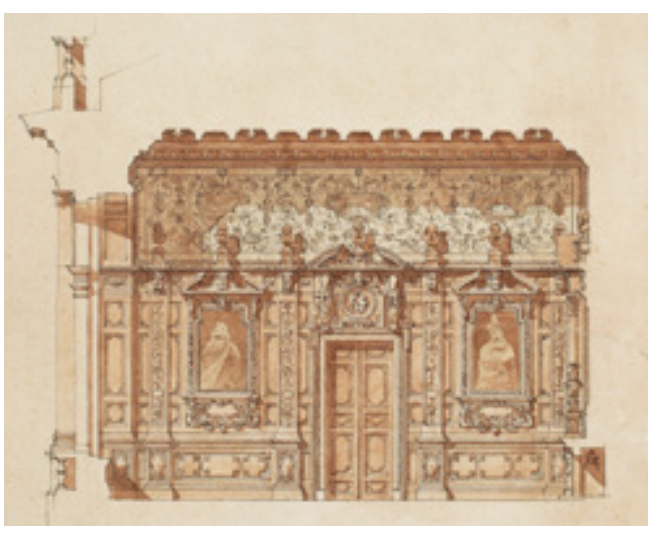

Abb. 3: Heinrich von Ferstel, Entwurf für die Ausstattung eines Festraumes der Universität Wien, Tuschezeichnung, koloriert, I872-I877, UAW.

österreichische Landesregierung, in der barocken Universitätskirche ein Denkmal für den Juristen Franz Anton von Zeiller errichten zu dürfen. ${ }^{22}$

Nach Eitelberger hätte sich der gelehrte Professor als Teil der vaterländischen Geschichte unter Feldherren, Literaten und Musiker gemischt - sakralisiert durch die Aufstellung im Kirchenraum wie in Westminster Abbey oder im römischen Pantheon. Dieses Konzept war im Zeitalter des Liberalismus aber nicht mehr aktuell.

Im neuen Haus am Ring sollten die Herren am Ort ihres Wirkens verewigt werden als ständig wachsende Gruppe, als Korporation, wie sie in Form gemalter Porträts bis dahin in den Hörsälen und im Consistorialsaal verteilt waren.

Es gab wohl Überlegungen, Büstenreihen in die Dekoration der repräsentativen Räume einzubinden, doch ist das Programm nicht überliefert. Zeichnungen Ferstels von 1873 zeigen die Festräume gegliedert durch ein ornamenta-

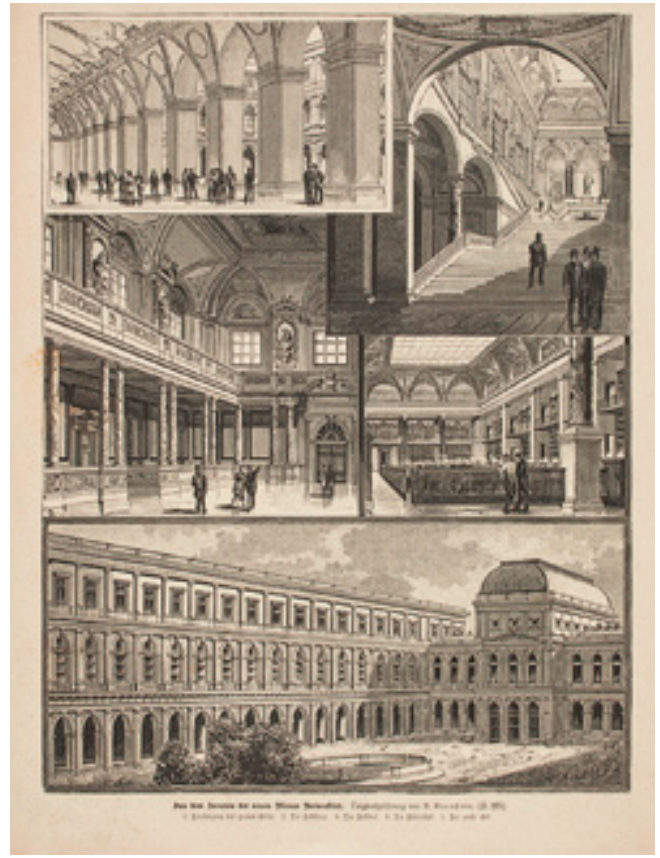

Abb. 4: Die neue Universität Wien, Holzstich nach Zeichnung von A. S. Kronsteiner, I888, Privatbesitz.

les Rahmensystem im Stil der deutschen Renaissance und Bilder, die offenbar Szenen aus der Universitätsgeschichte in Konnex mit den Habsburgern darstellen (Abb. 3). ${ }^{23}$ Über dem Gesims sind Reihen von Porträtbüsten zu erkennen, bei denen es sich wohl um Gelehrte handeln sollte. Auch im Dekorationssystem des großen Festsaales waren Büsten vorgesehen, wie noch heute die tiefen ovalen Nischen zwischen den Fenstern vermuten lassen $(\mathrm{Abb} 4) \cdot{ }^{24}$ Solche gleichförmige Büstenreihen von Gelehrten stehen in der Tradition von Bibliotheksausstattungen. ${ }^{25}$ Vermutlich war an eine allmähliche Füllung der Nischen

22 S. den Beitrag von Maria Pötzl-Malikova in diesem Band. Zeiller erhielt erst I89ı eine Büste von Emanuel Pendl im Arkadenhof.

23 H. Ferstel, Entwürfe für Ausstattung des Hauptgebäudes der Universität, Nr. 9, Fenster, Decken, Festräume, Tuschezeichnung, koloriert, um I872-1877, UAW, Inv. I09.II2.9.

24 Auf dem I888 datierten Holzstich nach einer Zeichnung von August Stefan Kronsteiner sind tatsächlich Büsten zu erkennen.

25 In der Universitätsbibliothek waren keine Porträts vorgesehen. Zu Porträtreihen in Universitätsbibliotheken s. den Beitrag von M. Baker in diesem Band. 


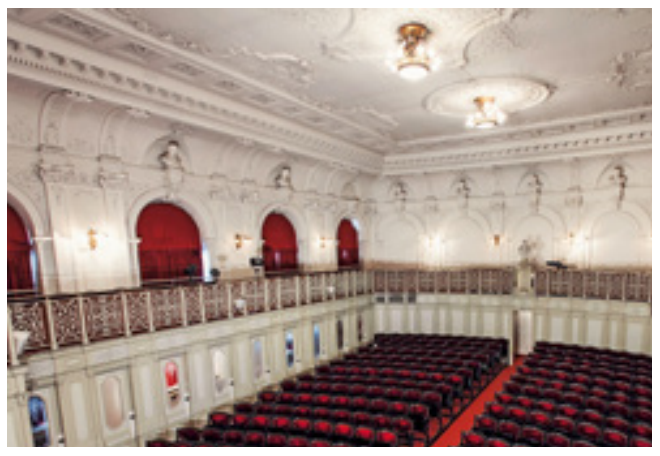

Abb. 5: Wien, Haus der Ärzte (Billroth-Haus), Sitzungs-

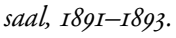

mit Honoratioren der Universität Wien gedacht wie im kurz darauf entstandenen Sitzungssaal im Haus der Gesellschaft der Ärzte (Abb. 5). ${ }^{26}$

Schließlich sollte der Arkadenhof zur universitären Ehrenhalle werden, [...] wie dies auch In der Bologneser Universität, im campo santo zu Pisa usw geschehen ist [...]. ${ }^{27}$ Damit ist die neue Orientierung angesprochen. Es ist nicht mehr die sakrale Pantheonidee, sondern die universitäre Gedenkkultur in Italien, wo seit dem I4. Jahrhundert Erinnerungszeichen für Universitätsangehörige, seien es Studenten oder Professoren, in den Universitätsgebäuden gesetzt wurden. ${ }^{28}$ Im Palazzo Bo in Padua und im Palazzo dell' Archiginnasio in Bologna - beides Orte, die Ferstel und Eitelberger besucht hatten - sind in den Arkadengängen eine Überfülle an Epitaphien für Professoren und Studenten erhalten bzw. wurden nach Kriegszerstörung rekonstruiert. Mit der Orientierung an diesen italienischen Vorbildern ist deutlich gesagt, dass man keine vereinheitlichende Struktur einer Büstengalerie wollte, wie sie etwa in der Regensbur- ger Walhalla vorgegeben ist. Laut Senatsprotokoll sei es

[...] ratsam, kein Zukunftsprogramm auszuarbeiten, vielmehr von Fall zu Fall das Erforderliche zu erörtern und festzustellen, damit auf diesem Wege von einer eintönigen Regelmäßigkeit Umgang genomen [sic] und sukzessive die Ausschmückung der Felder der Arkaden je nach Beschaffenheit der herzustellenden Denkmäler vor sich gehe [...]. ${ }^{29}$

Der Walhalla vergleichbar ist aber die Idee eines in die Zukunft gerichteten Konzepts. Der Arkadenhof ist kein abgeschlossenes Denkmal, das nur längst verstorbene Geistesheroen würdigt, sondern soll allen, die hier täglich den Geistesheroen begegnen, Anreiz sein, durch Leistung auch einmal hier verewigt zu werden.

Der zweite Ort, der im Senatsprotokoll angesprochen wird, ist der Campo Santo in Pisa, der eine Fülle an Gelehrtendenkmälern enthält, u. a. für Francesco Algarotti. Hier verleiht die Bindung des Denkmals an die Grabstätte im Kontext eines kreuzgangähnlichen Raumes dem Ensemble wiederum sakralen Charakter. Der arkadierte Bogengang diente im I9. Jahrhundert als Vorbild für Friedhofsarchitektur. So ruhen der Pathologe Carl von Rokitansky († I878) und der Dermatologe Ferdinand Hebra ( $†$ I880), die beide im Arkadenhof durch ein Büstendenkmal vertreten sind, unter den neugotischen Arkaden des Hernalser Friedhofs. ${ }^{30}$ An einigen Denkmälern wird in der Ädikulaform die Verwandtschaft zwischen Grabmal und Denkmal deutlich. Mehrfach findet man dieselbe Porträtdarstellung des Geehrten am Grabmal und am Denkmal. Wenn heute angesichts der

26 A. BeYER, Das Haus der Gesellschaft der Ärzte in Wien. Billroth-Haus. Eine Untersuchung zur Baugeschichte und Ausstattung, MA-Arbeit Kunstgeschichte, Universität Wien 2016.

27 Senatsprotokoll UAW S. 87.I., 7. 6. I887.

28 Vgl. den Beitrag von A .Mampieri in diesem Band.

29 Senatsprotokoll UAW S. 87.I, 7. 6. I887.

30 Die Arkadengrüfte am Wiener Zentralfriedhof (I879-I88I) wurden von geadelten großbürgerlichen Familien finanziert. Als einziger Professor ist daher der Augenarzt Ludwig Mauthner aus der Wiener Industriellenfamilie dort bestattet. Seine Büste im Arkadenhof schuf Rudolf Weyr I899. 
Porträtbüsten im Arkadenhof abwertend von einem „Friedhof“ gesprochen wird, zeugt die- se Auffassung vom Unverständnis für eine einst anspruchsvolle Denkmalform.

EIN VORBILDHAFTES ENSEMBLE：DIE GELEHRTENDENKMÄLER IN DEN ARKADEN DER UNIVERSITÄT PAVIA

Die Universität Pavia wird im Senatsprotokoll von 1885 nicht ausdrücklich genannt, dürfte aber im Bewusstsein der Verantwortlichen für den Arkadenhof gewesen sein. Bis I859 gehörten die Universitäten Mailand und Pavia zum habsburgischen Herrschaftsgebiet. Sie wurden unter der Regierung von Maria Theresia und Joseph II. grundlegend reformiert und entwickelten sich zu Musteruniversitäten, sodass sie die traditionsreichen Universitäten Bologna und Padua - und erst recht Wien - am Ende des I8. Jahrhunderts an renommierten Professoren und Studentenzahlen weit übertrafen. Bedeutende Gelehrte wie der Physiker Alessandro Volta, der Augenarzt Antonio Scarpa und der später in Wien das Allgemeine Krankenhaus reformierende Arzt Johann Peter Frank wurden von Kaiser Joseph II. nach Pavia berufen und ihre Forschungen finanziell unterstützt, sodass hier lange vor Wien das Modell der Verbindung von Forschung und Lehre verwirklicht wurde. Dies gelang im $\mathrm{Zu}-$ ge der verwaltungstechnischen, ökonomischen und bildungspolitischen Reformen in der Lombardei, die behutsam unter Maria Theresia begonnen und in straffer zentralistischer Form unter Joseph II. fortgeführt wurden. Staatskanzler Fürst Kaunitz setzte sich persönlich für die Berufungen von Professoren ein und schlug bei den Planungen der Universitätsumbauten Änderungen vor. Er vertraute dem Gubernator Graf Firmian, der zentralen Persönlichkeit der aufgeklärten Kreise in Mailand, und Freiherr von Sperges, der von Wien aus den Schriftver-

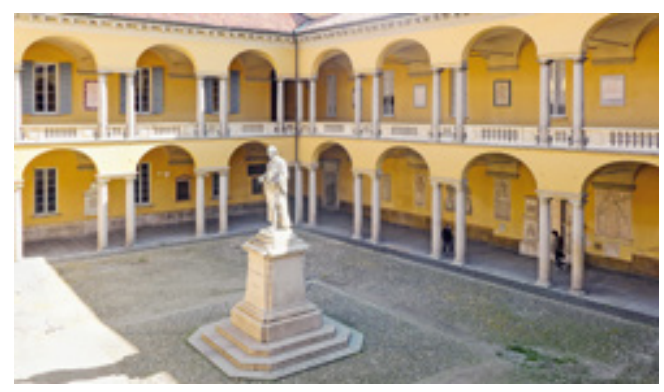

Abb. 6: Pavia, Universität, Cortile di Volta.

kehr führte. ${ }^{3 \mathrm{I}}$ Von Wien aus kontrolliert wurde auch der Ausbau der Universität. Die Architekten Giuseppe Piermarini und Leopoldo Pollack systematisierten und erweiterten eine Anlage aus mehreren miteinander kommunizierenden Höfen des 17. Jahrhunderts, sodass dort jeder Fakultät ein eigener Hof zugehörig war (Abb. 6)..$^{32}$

Im Zuge der Umbauten entstand die Idee, die altehrwürdige Geschichte der Universität durch Installation der bereits in einem Lapidarium gelagerten Steine abgebrochener Denkmäler in den Hofarkaden sichtbar zu machen. Es entspricht dem historischen Verständnis der Aufklärung und dem Bedeutungswandel des Grabdenkmals im Klassizismus, aber auch der josephinischen Kirchenpolitik, dass damals Grabdenkmäler bedeutender Gelehrter, die mit der Universität verbunden waren, den Kirchen entnommen und in die Höfe der Universität übertragen wurden. So blieben wertvolle Denkmäler erhalten wie Reliefs mit dozierenden Professoren des Bologneser Typus, z.B. für den Rechtsgelehrten Francesco

3I A. Wandruszka, Österreich und Italien im I8. Jahrhundert, Österreich Archiv. Schriftenreihe des Arbeitskreises für Österreichische Geschichte. Wien 1963, S. 47-83. P. Fraccaro, L'Università di Pavia, Pavia 1957, S. 137-215.

32 G. Tibiletti, Monumenti e Cimeli dell'Ateneo Pavese, Pavia i96i; L. Erba/A. Morani, Monumenti e Lapidi conservati nel Palazzo Centrale dell'università di Pavia, Pavia 1977. 


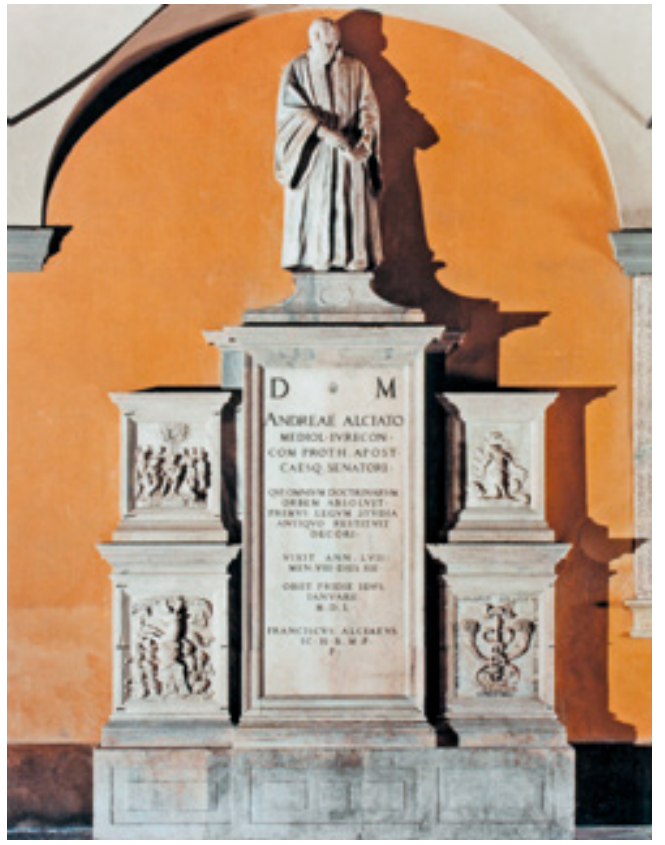

Abb. 7: Cristoforo Lombardo, Denkmal für Andrea Alciati, IssI, Pavia, Universität, Cortile di Volta (ehem. in Pavia, San Epifanio).

Ripa da Sannazaro oder das Monument mit einer ganzfigurigen Statue für den Emblematiker Andrea Alciato (Abb. 7-9). ${ }^{33}$ Seit dem Quattrocento ist hier der skulpturale Typenvorrat vorhanden, aus dem bis heute im Denkmalbereich geschöpft wird: vom Porträtmedaillon über das Büstenmonument bis zur ganzfigurigen Statue. Die historischen Monumente waren Ausgangspunkt für die seit 1786 regelmäßig unter den Arkaden aufgerichteten Professorenepitaphien. Wie in Wien wurden in Pavia bis in jüngste Zeit Gedenktafeln, die teilweise auch mit Porträts versehen sind, angebracht.

Den spezifischen Ort für die Ehrung von Anatomen markiert in Pavia das anatomische Theater. Dieser Raum zeigt am direktesten die

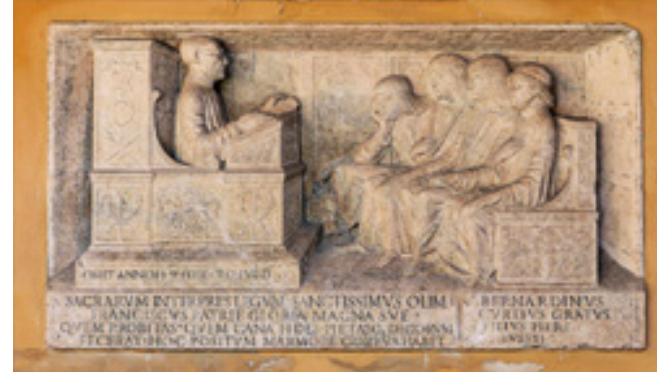

Abb. 8: Pavia, Universität, Cortile di Volta, Epitaph für den Juristen Francesco Corti, † I495.

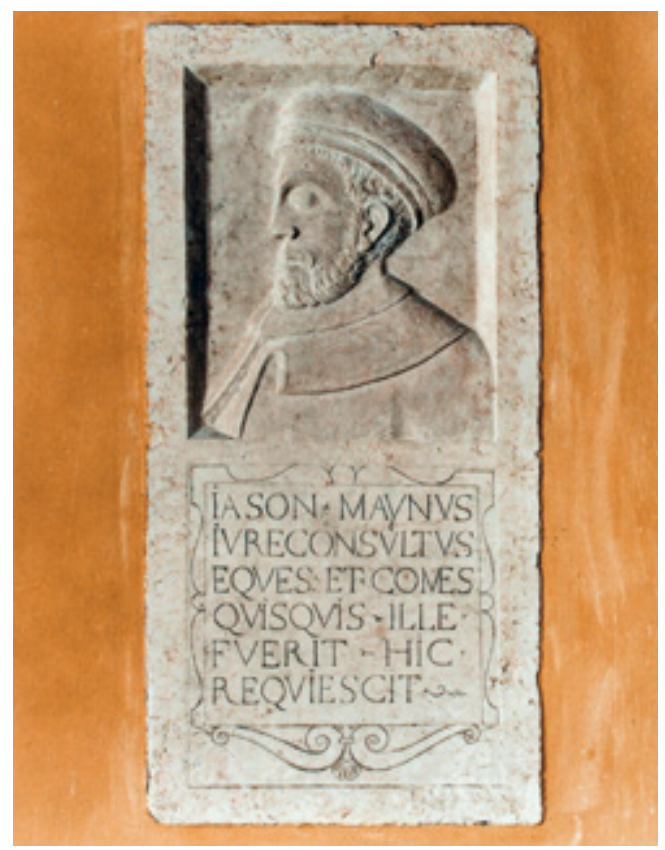

Abb. 9: Pavia, Universität, Cortile di Volta, Epitaph für den Juristen Giason del Maino, † ISI 19 .

enge wissenschaftsgeschichtliche Beziehung zwischen Wien und Pavia am Ende des I8. Jahrhunderts. Sie geht nicht zuletzt auf das einflussreiche Wirken des Militärchirurgen Alessandro Brambilla zurück, der Joseph II. auf seiner Europareise

33 Die Universität gab anlässlich des 650-jährigen Gründungsjubliäums die in Bild und Text vorbildliche mehrbändige Dokumentation der Denkmäler heraus: Il cortile di Volta dell'Università die Pavia. Maestri e studenti: arte e memoria (hrsg. von M. T. Mazzilli Savini (mit Beiträgen von L. Erba, Ch. Pagani), Milano 20II-L. Erba (Hg.), Il Cortile di Medici e degli Artisti e il Teatro Anatomico dell'Università di Pavia (Katalog: Ch. Pagani), Pavia 2012. 


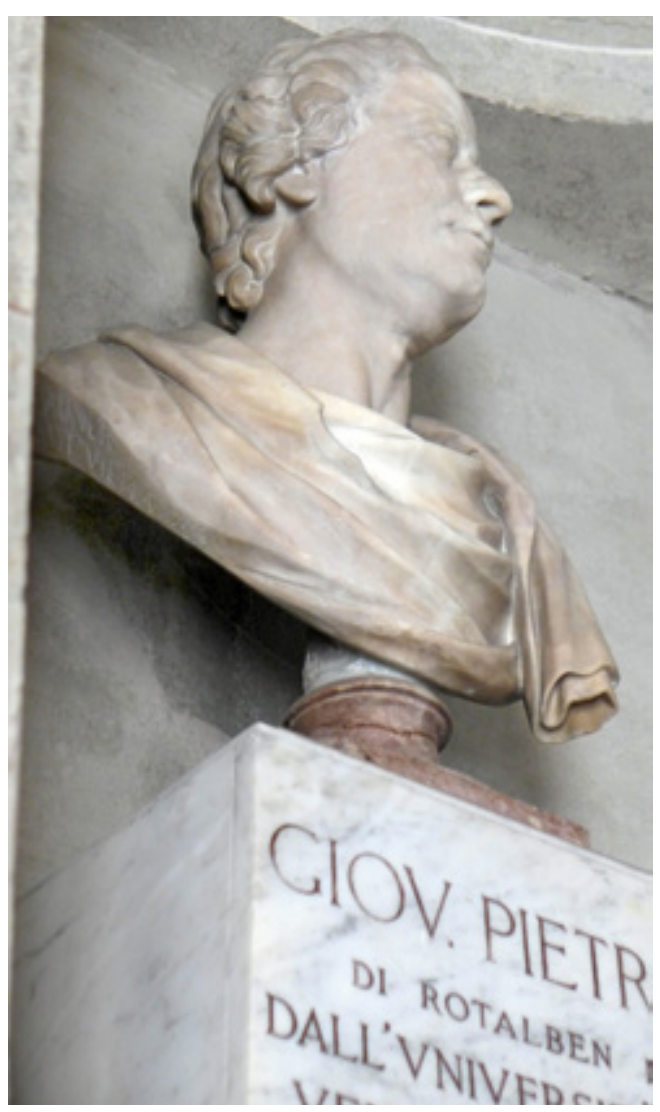

Abb. Io: Franz Anton Zauner, Denkmalbüste für Alessandro Brambilla, Marmor, I789, Pavia, Universität, Anatomisches Theater (Sockel zugehörig zum Denkmal für J. P. Frank).
I769 begleitet und ihn beim Besuch der Universität Pavia auf die Bedürfnisse der medizinischen Lehre und Forschung hingewiesen hatte. Die in Folge errichtete militärchirurgische Anstalt Josephinum in Wien war ein Musterprojekt, das wiederum für Pavia vorbildhaft war, als Antonio Scarpa das anatomische Theater neu errichtete. Der Architekt Leopold Pollack übernahm nach Empfehlung aus Wien das Konzept eines hemizyklisch ansteigenden Auditoriums und einer durchlichteten Fensterwand mit Porträts berühmter Anatomen. Der Raum wurde unter Napoleon neu dekoriert. I950 ließ der Althistoriker und Rektor Plinio Fraccaro in den Nischen des Hemizykels auf einheitlichen Sockeln eine Büstenreihe installieren, die auch ältere Porträtplastiken aufnahm. Darunter befinden sich die Marmorbildnisse von Brambilla und Johann Peter Frank, deren Sockel mit den erklärenden lateinischen Inschriften irrtümlich vertauscht sind (Abb. Io). ${ }^{34}$ Die Büste Brambillas, eine Stiftung von Joseph II. wurde 1789 aus Wien nach Pavia gesendet. Die im Stil des idealisierenden römischen Frühklassizismus konzipierte Skulptur ist signiert mit Franz Anton Zauner fecit Vienna I789, ist also ein kaum bekanntes Werk des wichtigsten Bildhauers des Klassizismus in Wien. ${ }^{35}$

DIE UMSETZUNG DER IDEE. EIN ENSEMBLE ENTSTEHT: FERSTEL/ KÖ CHLIN, C A R L KÖNIG, Z UMBUSCH, T ILGNER, KUNDMAN N UND DAS PROFESSORENKOLLEGIUM - KR ÄFTEMESSEN DER FA K ULT ÄT E N

Am 8. Mai I885 - ein Jahr nach Ferstels Tod wurde vom Senat die Artistische Kommission eingesetzt, deren Aufgabe es sein sollte, als separates Gremium den Senat bei der Ausschmü- ckung des Universitätsgebäudes, also auch des Arkadenhofes, zu beraten. $\mathrm{Zu}$ den Professoren unter dem Vorsitz des Strafrechtlers Wilhelm Emil Wahlberg gehörten als Beiräte auch

34 Erba, Il Cortile di Medici (zit. Anm. 33), S. I52-I53, I68-I69.

35 I. Schemper-Sparholz, Ge(l)ehrte Köpfe, Zu den Anfängen ehrenhalber aufgestellter Büsten in Wien, in: Blickwechsel. Die Bildnisbüste in der Epoche der Aufklärung, Wissenschaftlicher Beiband zum Anzeiger des Germanischen Nationalmuseums (hrsg. von M. KAMMEL), in Druck. 


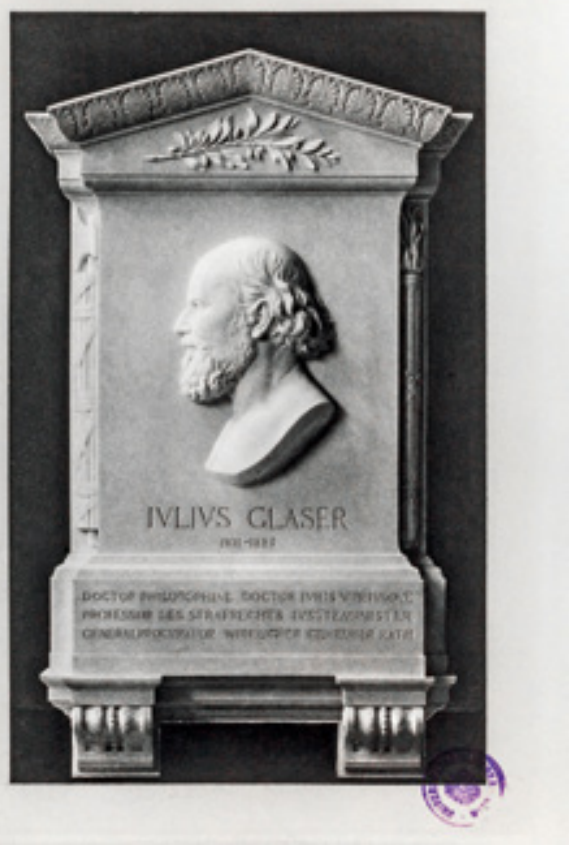

Abb. II: Kaspar Zumbusch, Denkmal für den Juristen Prof. Julius Glaser, Frontispiz aus: Julius Glaser, Bibliographisches Verzeichnis seiner Werke (hrsg. W. Glaser), Wien I888.

Oberbaurat Köchlin und die führenden Wiener Bildhauer Zumbusch, Kundmann und Tilgner. In der Sitzung vom 19. Juni 1885 wurden die Richtlinien für die Ausschmückung des Arkadenhofes festgelegt - nur Universitätsprofessoren sollten dort geehrt werden, in den übrigen Räumen dürften nach Genehmigung durch den Senat auch andere Personen Denkmäler erhalten. Köchlin sollte eine Skizze der [...] Ausschmückung des Arkadenhofes mit Büsten, Statuen, Gedenktafeln ${ }^{36}$ vorlegen. Nach dem Tod Eitelbergers im April I885 schien der Archäologe Otto Benndorf als Mitglied der Artistischen Kommis- sion die stilistische Orientierung in Richtung eines archäologischen Klassizismus vorgegeben zu haben, wie an den Denkmälern von Kundmann und besonders Zumbusch zu erkennen ist (Abb. II). ${ }^{37}$ Benndorf stand in enger Verbindung $\mathrm{zu}$ Zumbusch, der ihn zu Ausgrabungen in Samothrake und Limyra begleitete.

Köchlin fertigte 1890 gemeinsam mit dem Bildhauer Alois Düll ein Modell zweier Arkadenabschnitte an (Abb. I2)..$^{38}$ Das Farbmuster erinnert an die Wandgestaltung im Innenhof des Österreichischen Museums für Kunst und Industrie, wie sie das Präsentationsblatt Ferstels von 1873 zeigt: eine Felderteilung durch rot und grün marmorierte Platten. ${ }^{39}$ Der Senat sprach sich aber gegen die Färbung der Wandflächen aus. Das Modell zeigt Büsten über Konsolen und jeweils im Zentrum ein architektonisch gerahmtes Büstenepitaph. Nach einstimmigem Beschluss sollten Standbilder in ganzer Person nur für hervorragende Personen, die nicht der Universität angehört $t^{\circ}$ haben, zulässig sein. Entsprechend dem hierarchischen Verständnis von Porträtplastik wurden Standbilder für den Kaiser und für Mitglieder des Kaiserhauses vorgesehen.

Eine Hommage an das Haus Habsburg wurde immer wieder angedacht, ist doch die Geschichte der Universität eng mit dem Haus Habsburg verbunden. Das Deckenfresko der Alten Universität (I765) zeigt die Fakultäten noch unter dem Schutz des Kaiserpaares Maria Theresia und Franz I. Stephan. Die Ehrung im neuen Haus beschränkte sich schließlich auf das Standbild des regierenden Kaisers Franz Joseph, das aber nicht zentral in der Aula, sondern im linken Treppenhaus Aufstellung fand. Es sollte von Standbildern Rudolfs IV, des Stifters, und Maria

36 UAW S Z247I I985.

37 M. Kolisкo, Caspar von Zumbusch, Wien I931, S. 62-63. Vgl. das Porträtrelief für Glaser und die Stele für Leopold Hasner von Artha, Benndorf begründete die umfangreiche Abgusssammlung des archäologisch-epigrafischen Seminars in Wien, die auch als Vorbildsammlung in Betracht zu ziehen ist.

38 Gips, farbig gefasst, $\mathrm{H}: 52 \mathrm{~B}: 67 \mathrm{~cm}, \mathrm{~T}: 25 \mathrm{~cm}$. UAW Sign. II4.95.

39 Heinrich von Ferstel. Bauten und Projekte für Wien (Ausstellungkatalog Hermesvilla), Wien I984, Kat. I38, S. 70.

40 UAW, S.Z. 3057 ex I897/8. I884/5 Sitzung Nr. II vom 19. Juni I885. 


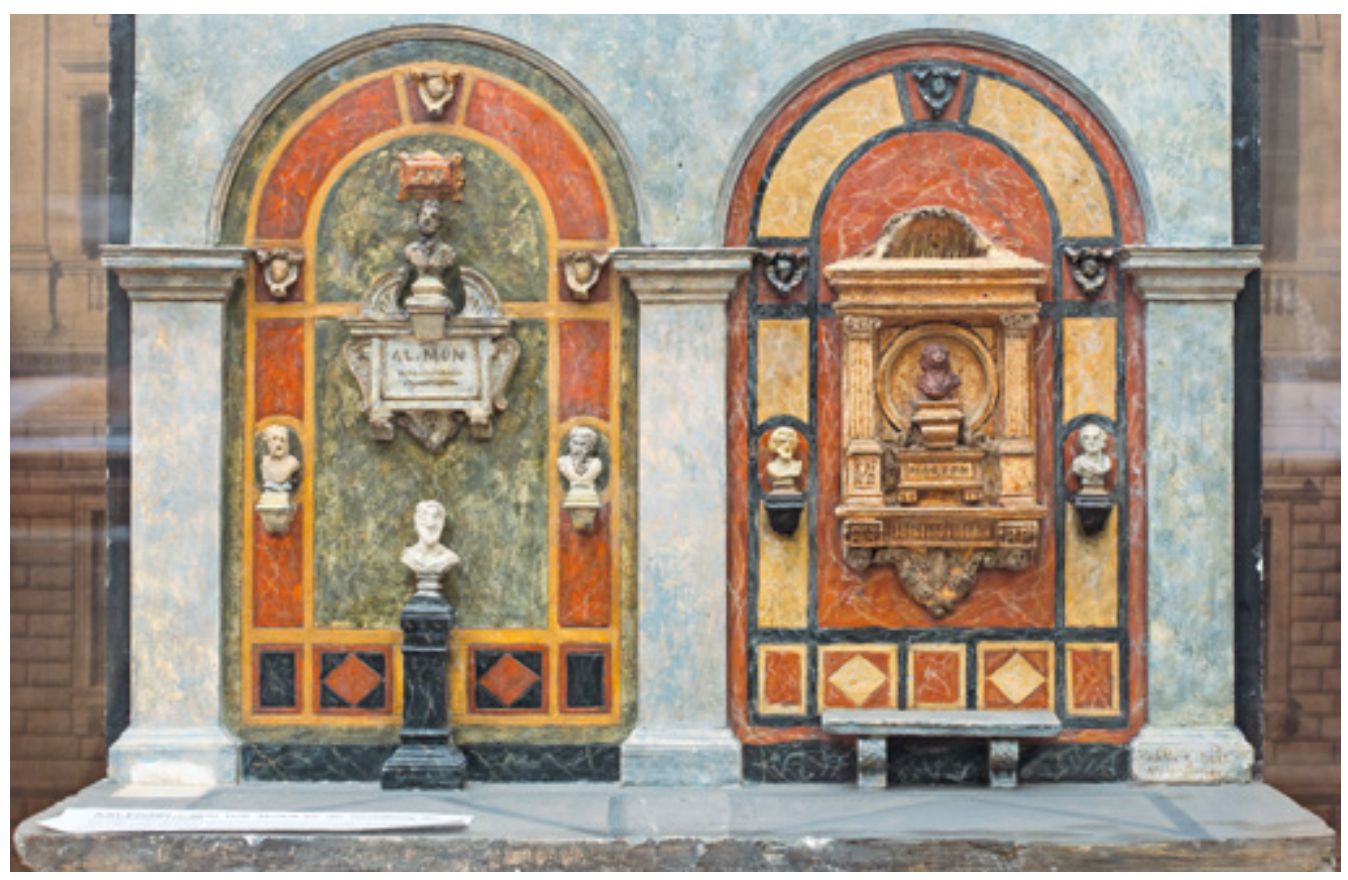

Abb. I2: Karl Köchlin/Alois Düll, Modell für einen Arkadenabschnitt der Universität Wien, I89o, Gips, farbig gefasst, restauriert, 1988 .

Theresias flankiert werden. Die Statuen wurden schließlich im Festsaal aufgestellt. Im Arkadenhof hingegen erhielt der Minister für Kultus und Unterricht Leo Graf Thun als Einziger ein ganzfiguriges Standbild am Ende des Juristenganges in dem pavillonartigen Eckraum und bildet mit den Büsten der Schulreformer Hermann Bonitz und Franz Exner eine Denkmalgruppe. ${ }^{4 \mathrm{r}}$

Auffallend lange wurde die Wand der Bibliotheksseite von Denkmälern ausgespart. I9I2 schlug der Historiker und damalige Rektor Oswald Redlich vor, an dieser Stelle Inschriftentafeln alternierend mit Porträtmedaillons oder
Büsten hervorragender Lehrer anzubringen, die noch nicht in der Ehrenhalle vertreten waren. ${ }^{42}$ Er nennt Heinrich von Langenstein, Thomas Ebendorfer, Georg von Peuerbach, Konrad Celtis, Johann Cuspinian, P. Nikolaus Avanzini, Paul Sorbait, Karl von Martini und Josef von Sonnenfels (von dem allerdings bereits eine Büste vorhanden war), Johann Peter Frank, Lorenz Gasser und Maximilian Stoll. ${ }^{43}$ Redlich stellte aber auch zur Diskussion, Porträtmedaillons jener habsburgischen Fürsten anzubringen, deren Regierung für die Universität von besonderer Bedeutung gewesen ist, also der Gründer

4I S. den Beitrag von H. Szemethy in diesem Band.

42 UAW S. 87.4.6. Brief Redlichs an die Artistische Kommission 23. O2. I9I2.

43 Heinrich von Langenstein (I325-I397), Theologe, Reorganisator der Universität, Thomas Ebendorfer (I388-I464), Theologe, Gesandter Friedrich III., Georg von Peuerbach(I423-I46I), Astronom, Wegbereiter des Koperinikanischen Weltbildes, Konrad Celtis (I459-1508), Humanist, Johannes Cuspinian (I473-1529), Humanist, Nikolaus von Avancini (I6II-I686), Jesuitendichter, Paul Sorbait (I624-I69I), Pestarzt, Karl von Martini (I726-I800), Rechtsphilosoph, Josef von Sonnenfels (1732-I8I7), Jurist, Johann Lorenz Gasser (1723-1765), Anatom, Johann Peter Frank (1745-I82I), Arzt, Maximilian Stoll (I742-1787), Arzt. 


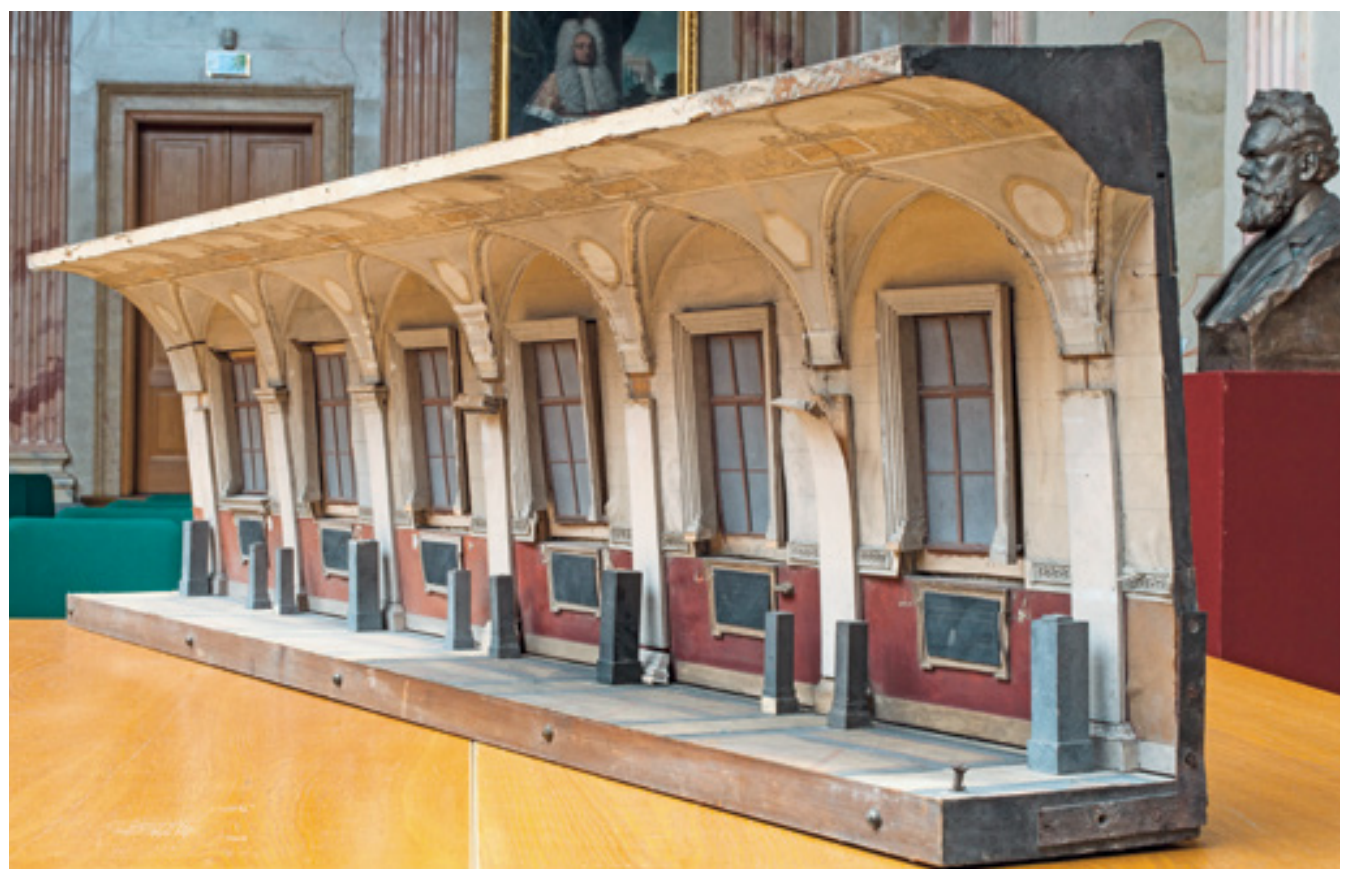

Abb. 13: Karl König, Modell für die Gestaltung der Bibliothekswand im Arkadenhof der Universität Wien, 19I2, Holz, Papier, UAW.

Herzog Rudolf IV., Herzog Albrecht III., Maximilians I. als besonderen Förderer der Humanisten, Kaiser Ferdinands I., der die Universität den Jesuiten übergab, Kaiser Ferdinands II, der Reformerin Maria Theresia, Kaiser Josephs II., Kaiser Franz' I. und des regierenden Kaisers Franz Joseph I. Der Architekt Karl König, Nachfolger Köchlins als Bauberater der Universität, wurde am 27. März I9I2 vom Senat beauftragt, ein $\mathrm{Mo}$ dell der ganzen Bibliothekswand mit den projek- tierten Inschriftentafeln, Postamenten und Büsten aus Pappe herstellen zu lassen. ${ }^{44}$ Ein mit dieser Idee weitgehend übereinstimmendes Modell konnte jüngst im Universitätsarchiv aufgefunden werden (Abb. I3). ${ }^{45}$ Durch den Ersten Weltkrieg und das Ende der Monarchie wurde diese Idee obsolet und die Bibliotheksseite des Arkadenhofes nahm nun auch Professorendenkmäler auf.

MEDIZINER, NAT URFOR SCHER, DICHTER, JUR ISTEN, K ÜNSTLER

Schon am I9. Juni 1885 hatte das medizinische Professoren Collegium wegen Aufstellung eines Hyrtl Denkmals und eventuell eines Gruppendenk- mals für die medicin. Celebritäten Rokitansky, Skoda, Schuh u. Oppolzer ${ }^{4}$ angefragt. Im Gespräch war auch die Aufnahme von Büsten der Dichter

\footnotetext{
44 Senatsakten UAW S. 87.4.6.

45 Modell für die Denkmalgestaltung der Bibliothekswand im Arkadenhof der Universität Wien, I9I2, UAW Depot, Holz, verschraubt, beklebt mit bemaltem Papier: L: 163,8 cm, H: 42,3 cm, T: $18 \mathrm{~cm}$. Für den Hinweis bedanke ich mich herzlich bei Caroline Mang.

46 UAW S Z247I 1985.
} 
Nikolaus Lenau und Anastasius Grün, die jedoch im Gebäude untergebracht werden sollten, denn laut Senatsbeschluss sollte der Arkadenhof ja Universitätsprofessoren vorbehalten sein. Die beiden im Vormärz für akademische Freiheit eintretenden Literaten erhielten ihr Denkmal von Carl Schwerzek wenige Jahre später als Trabanten des Schillerdenkmals vor der Akademie der Bildenden Künste. ${ }^{47}$ Aus Ungarn bzw. Slowenien stammend vertraten die beiden Dichter die deutsche Sprachkultur in der Vielvölkermonarchie und eigneten sich daher auch als Identifikationsfiguren für die Universität Wien, deren Professoren vor dem Ersten Weltkrieg vorwiegend aus diesem Raum stammten. Eine Positionierung an der Universität wäre zudem ein Bekenntnis zu einer politisch liberalen Haltung gewesen. Der studierte Jurist Anastasius Grün hatte im Übrigen I865 das Ehrendoktorat der Wiener Universität erhalten.

Die mit den Professoren gut vernetzten Künstler nützten ihre Position in der artistischen Kommission. In der Sitzung am 30. Juni trugen Tilgner, Zumbusch und Kundmann ihr Anliegen vor, an einem geeigneten Platz in der Universität ein Denkmal für den Erbauer Heinrich von Ferstel anzubringen. Man einigte sich auf das sog. Atrium, den Vorraum zum Festsaal. Mit seiner aufwendigen Rahmenarchitektur steht dieses Büstendenkmal von Tilgner den Professorenmonumenten keineswegs nach (Abb. I4). So wie diese zeugt die Präsentation des geadelten Architekten von dem Bemühen der Künstler, den Aufstieg in die sog. Zweite Wiener Gesellschaft erreicht zu haben.

Die Ehre, als Erste ein Denkmal zu erhalten, wurde aber den Juristen zuteil. Wenige

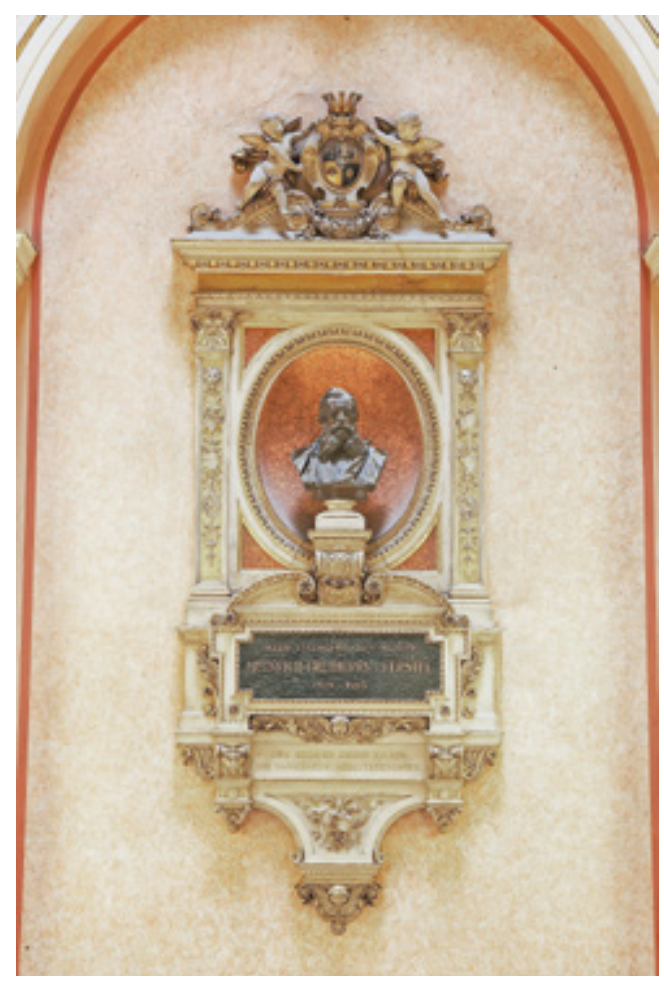

Abb. I4: Viktor Tilgner, Julian Niedzielski u.a., Denkmal für Heinrich v. Ferstel, 1885, Universität Wien, Atrium vor dem kleinen Festsaal.

Monate nach dem Tod ihres Gatten, des Strafrechtlers und liberalen Politikers Julius Glaser, stellte die Witwe I886 direkt an den Senat den Antrag auf Errichtung eines Denkmals, das sie bei Kaspar von Zumbusch in Auftrag gab und selbst finanzierte (Abb. II). ${ }^{4}$ Für die Verwirklichung des Projekts war sicher nicht ungünstig, dass der Strafrechtler Emil Wahlberg Vorsitzender der Artistischen Kommission war. Im November 1887 wurde das Denkmal bereits in der

47 Es wäre zu untersuchen, ob ein Zusammenhang mit den Hermendenkmälern am Schillerplatz besteht. Schwerzek (Schwerczek) hat einige Arbeiten für den Universitätsbau ausgeführt, u.a. I885 die Statue Rudolph IV. im Festsaal, möglicherweise hätte er auch die Büsten von Lenau und Anastasius Grün meißeln sollen. Die klassizistischen Hermen sind den Kundmannbüsten von Exner und Bonitz (1893) auffallend ähnlich.

Wilhelmine Glaser sorgte für den Nachruhm ihres Gatten auch dadurch, dass sie posthum seine Erhebung in den erblichen Freiherrenstand erreichte. Im Jahr der Denkmalenthüllung gab sie die Schriften ihres Mannes heraus: W. v. GLASER (von der Hand der treuen Gattin): Julius Glaser. Bibliographisches Verzeichnißseiner Werke, Abhandlungen, Gesetzentwürfe und Reden. (Vorr.: Josef Unger), Wien I888. 


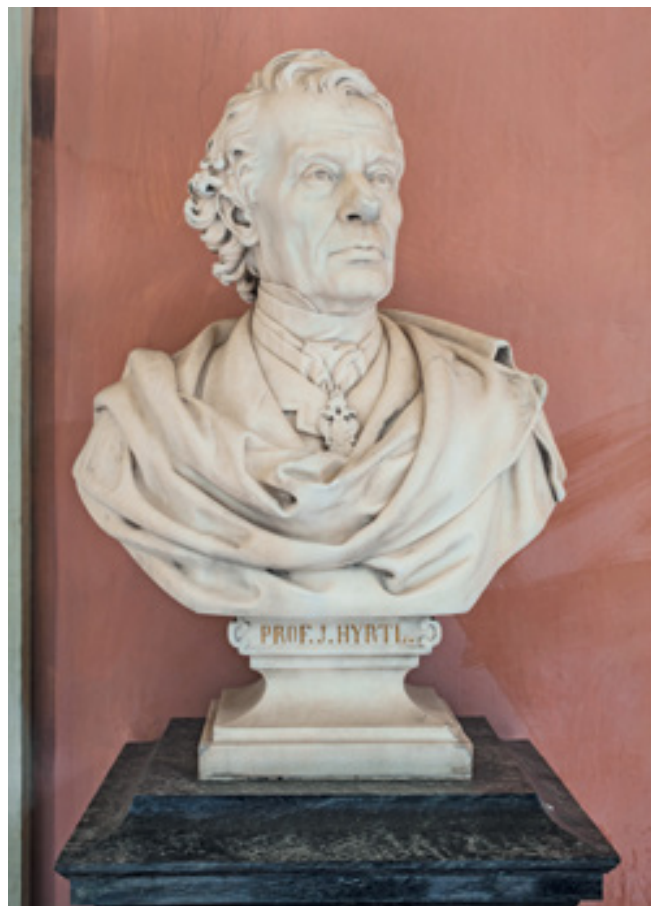

Abb. 15: Johann Kalmsteiner, Denkmalbüste für den Anatomen Prof. Josef Hyrtl, Marmor, 1887, Universität Wien, Arkadenhof.

Neuen Freien Presse als nahezu vollendet angekündigt, detailliert beschrieben und gelobt. Der Kopf, in eine Marmorwand als Relief eingelassen, frappiert durch außerordentliche Porträttreue, die echte Denkerstirne bot dem Plastiker ein ganz besonders günstiges Feld, sie ist in nahezu vollendeter Weise ausgearbeitet. Der Ausdruck des Profils ist edel belebt und gibt den Geist und Edelsinn des Redners und Denkers getreulich wieder. So hat man Glasers Kopfvon der Galerie des Abgeordnetenhauses in der berühmten Schulrede, so in den großen Reden des General Procurators gesehen. Glücklicher konnte der Künstler den unvergeßlichen Gelehrten, Lehrer und Redner nicht auffassen. ${ }^{49}$
Zu diesem Zeitpunkt waren auch die Büsten der Mediziner Hyrtl und Schuh bereits fertig, doch wurden sie deponiert, um erst I889, ein Jahr nach der Feier für Glaser, in einem wohl inszenierten Festakt enthüllt zu werden (Abb. I5). Die ausführlichen Berichte in der Presse, besonders in der klerikalen Zeitschrift Das Vaterland, stellen den Auftritt des geehrten Hyrtl in den Mittelpunkt. Für die Festgäste war es ein besonderes Erlebnis, den greisen Anatomen lebend neben seinem jüngeren Abbild zu sehen: Als die ehrwürdige Erscheinung des großen Anatomen sichtbar wurde, dessen Kopf heute von einem langen weißen Vollbarte umrahmt wird und der infolge eines langjährigen Augenleidens einen großen grünen Schirm trägt, da ertönte brausender Jubel..$^{50}$ Anwesend waren nicht nur Vertreter des Ministeriums für Kultus und Unterricht, das die beiden Denkmäler finanziert hat, sondern der gesamte Senat und viele Professoren, die selbst wenige Jahre später hier ein Denkmal erhalten sollten - Miklosich, Braun von Fernwald, Dittel, Stoerk und der Hyrtl-Schüler Eduard Albert, der die Laudatio auf die beiden Mediziner hielt. Darin verwies er auf Ferstel, der meinte, in den Arkaden sei die Gelegenheit geboten, die Geschichte der Universität in künstlerischer Form zu illustrieren; in Statuen, Büsten, Inschriften, vielleicht auch in Gemälden seien hier die hervorragenden Personen und Ereignisse dieser Hochschule zu verewigen. ${ }^{\text {II }}$

Albert würdigte auch van Swieten, dessen Büste aus dem Allgemeinen Krankenhaus hierher übertragen und zwischen den Büsten von Schuh und Hyrtl angebracht wurde. Die Männer, denen die heutige Feier gilt, reihen sich dem großen Van Swieten würdig an. Hyrtl hat es offenbar genossen, die Errichtung seines eigenen Denkmals im Arkadenhof zu erleben, eine Ehre, die er sich durch eine Stipendienstiftung erworben hatte..$^{52}$ Er dankte in ei-

49 Neue Freie Presse, Nr. 8343, 17. November 1887.

50 Das Vaterland, 3I. Mai I889, S. 3.

5I Local-Anzeiger der Presse, I. Juni I889, S. 9. Abdruck der Festrede Eduard Alberts.

52 Die Denkmalenthüllungen waren protokollarisch festgelegte Ehrenrituale mit ausgesuchten Festgästen, Blumen- 
ner frei gehaltenen Rede in lateinischer Sprache, in der er betonte: [...] mit welcher Freude ich die frohe und unvermutete Kunde empfangen habe, dass ich [...] in die Reihe der Männer aufgenommen wurde, deren lebensechte Büsten aus Marmor gemeißelt, diese glänzende und erhabene Stätte der Wiener Gelehrtenwelt zieren werden und die Erinnerung an die Männer, die durch die Förderung und Vollendung der Wissenschaften sich hochverdient machten, nach ihrem Tod bis in die kommenden Jahrhunderte bewahren werden. 53

Die Marmorbüste von Johann Kalmsteiner zeigt den Geehrten noch rüstig im togaartigen Universitätstalar - ausgezeichnet mit dem I865 verliehenen Ritterkreuz des Ordens der Eisernen Krone 2. Klasse. Es verweist nicht so sehr auf den Mediziner, sondern auf den international anerkannten Gelehrten und universitären Würdenträger im Jahr seines Rektorats. Die Büste wurde nach seinem Tod auch an anderen Orten aufgestellt, wo an das soziale und politische Engagement Hyrtls erinnert werden sollte - vor dem von ihm gestifteten Waisenhaus in Mödling (1902) und in Reliefform im ehemaligen niederösterreichischen Landhaus (1895).

Während alle Büsten des I8. Jahrhunderts zu Lebzeiten entstanden und die Geehrten an den Zeremonien der Enthüllung teilnahmen, wurde dies in Zeiten der Denkmalflut problematisch empfunden. Im Sinne der eingangs erwähnten Bemerkung Eitelbergers war schon I885 festgelegt worden, dass erst fünf, seit 1926 zehn Jahre nach dem Tod ein Denkmal im

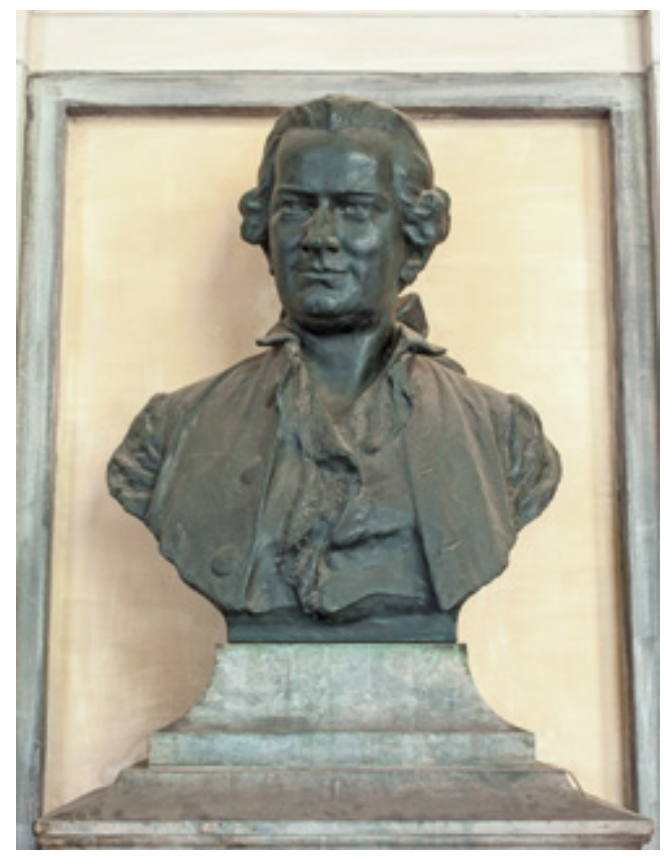

Abb. I6: Franz Seifert, Denkmalbüste für Jan Ingen-Housz, Bronze, I905, Arkadenhof der Universität Wien.

Arkadenhof zulässig sei. ${ }^{54}$ Der Fall Hyrtl blieb eine Ausnahme.

Privaten Initiativen, wie sie die Witwe Glaser unternahm, wurden durch die Verordnungen der Artistischen Kommission Grenzen gesetzt, wenn auch finanzielle Unterstützung gewünscht war, denn der Universität sollten keine Kosten erwachsen.

Dass aber Interessen einzelner wissenschaftlicher Disziplinen für Veränderungen innerhalb

schmuck, musikalischer Begleitung und Elogen, die ein Nachfolger im Fach hielt. Die Festreden wurden meist publiziert und enthielten oft eine Abbildung des Denkmals. Als biografische Skizzen waren sie in humanistischer Tradition ein literarisches Porträt.

$53[\ldots]$ quanto gaudio laetum et inopinatum nuncium accperim, me ab Inclyto et Venerabili Senatu Academico illis Universitatis Viennensis Professoribus clarissimis et celberrimis adscriptum fuisse, quorum imagines vivae, marmore exsculptae, spledidam hanc et aufgustam usarum Viennesium sedem condecorabunt, et virorum de scoemtoari, aigmenmtp et perfectione optime meritorummemoriam, post fata superstitem, per ventura saecula conservabunt, zit. Der Anatom Joseph Hyrtl I8Io-I894 (hrsg. v. Marktgemeinde Perchtoldsdorf), Wien I99I, mit Beiträgen von R. J. Gasser u.a., S. I6I.

54 Eitelberger, Das Porträt (zit. Anm. I5). Eitelberger selbst hatte sein bescheideneres Erinnerungsmal, ein Porträtrelief von Zumbusch, am selben Tag wie die Mediziner in einer kleinen Feier erhalten, die weit weniger Aufsehen erregte. 
der Denkmalanordnung und der Hinzufügung von Personen eine Rolle spielten, kann das folgende Beispiel zeigen. Die Naturwissenschaften, die bis 1976 zur philosophischen Fakultät gehörten, strebten immer stärker nach öffentlicher Anerkennung ihrer Leistungen. Internationale Kongresse in Wien boten eine gute Gelegenheit, sich zu präsentieren. So trachtete der Pflanzenphysiologe Julius Wiesner, seine Monografie über den Arzt und Naturforscher Jan Ingen-Housz 1905 beim 2. Internationalen Botanikerkongress in Wien vorzustellen (Abb. I6). ${ }^{55} \mathrm{Er}$ verband dies mit dem Wunsch nach Aufstellung einer Büste des niederländischen Naturforschers, der von Maria Theresia nach Wien geholt worden war, um ihre Kinder gegen die Pocken zu impfen und der hier einige Jahre lebte und forschte, aber nie der Universität angehört hatte. Die zu diesem Anlass geschaffene Büste von Franz Seifert wurde mit einer ebenfalls neu konzipierten Büste Nikolaus Jacquins von Leopold Schrödl und der Büste van Swietens von F. X. Messerschmidt zu einer Denkmalgruppe der Niederländer verbunden. Die Messerschmidt-Büste wanderte also von den Medizinern zu den Naturwissenschaftlern. Stilistisch hielt sich Karl König, der die neue Konzeption entwarf, bei den Porträts und den
Sockelformen an eine neobarocke Formensprache. Auch bei der Entscheidung für das Material Bronze wurde auf die ältere Metallbüste Rücksicht genommen. Die Zusammengehörigkeit wurde zusätzlich durch eine triumphbogenartige Gliederung der Arkadenrückwand betont. Die lateinischen Inschriften verfasste der Altphilologe Eugen Bormann. Eine am Bogenscheitel angebrachte, bis jetzt in der Forschung nicht beachtete Tafel hebt die besondere Stellung van Swietens hervor: IVNXIT HONORATIO PRIDEM BATAVO POPVLARES ET MERITI SOCIOS AVSTRIA GRATA DVOS: MDCCCCV (Abb. 2).56

Als Vertreter des I8. Jahrhunderts unter den Juristen wurde Josef von Sonnenfels in den Arkadenhof aufgenommen. Da offenbar kein zeitgenössisches skulpturales Porträt in der Universität vorhanden war, schuf Alois Düll ı89r die Büste des aufgeklärten Universalgelehrten in enger Anlehnung an die klassizistische Büste von Franz Anton Zauner (Akademie der Bildenden Künste, Wien). Sein Denkmal wurde I89i auf der Juristenseite gemeinsam mit den Büsten für Franz Anton von Zeiller und Josef Kudler enthüllt, die sich in bürgerlicher Kleidung des Vormärz präsentieren. ${ }^{57}$

\section{GE(L)EHRTE KÖPFE. DER KULT DES GENIALEN SCH ÄDELS IN} WIEN: FRANZ JOSEPH GALL UND FRANZ KLEIN, JOSEF HYRTL UND DER SCH ÄDEL MOZARTS

Die freiplastische Büste ist mit mehr als 80 Exemplaren die am häufigsten vorkommende Denkmalform im Arkadenhof, gefolgt von rund 50 reliefierten Porträtmedaillons, die sich meist auf den Kopf des Dargestellten beschränken. Als
Zwitterform ist der aus einer kreisrunden $\mathrm{Ni}$ sche freiplastisch herausragende Kopf im Typus der antiken imago clipeata einzuordnen, z.B. am Doppeldenkmal der Astronomen Johann und Theodor Oppolzer (V. Tilgner I890). In einigen

55 J. Wiesner, Jan Ingen-Housz. Sein Leben und Wirken als Naturforscher und Arzt, Festgabe zum II. internationalen botanischen Kongreß in Wien 1905, Wien 1905, mit Abbildung der Büste als Frontispiz und näherer Beschreibung der Denkmalsetzung, S. 224.

56 Das dankbare Österreich stellte zwei Landsleute und ebenso verdienstvolle Männer dem Geehrten, der einst aus den Niederlanden kam, zur Seite (übers. von E. Ottmayr).

57 W. LustKandL, Rede auf Sonnenfels und Kudler gehalten am I7. Juli I89i bei der Enthüllung der in den Arkaden der Universität Wien aufgestellten Büsten derselben, Wien I89o. 


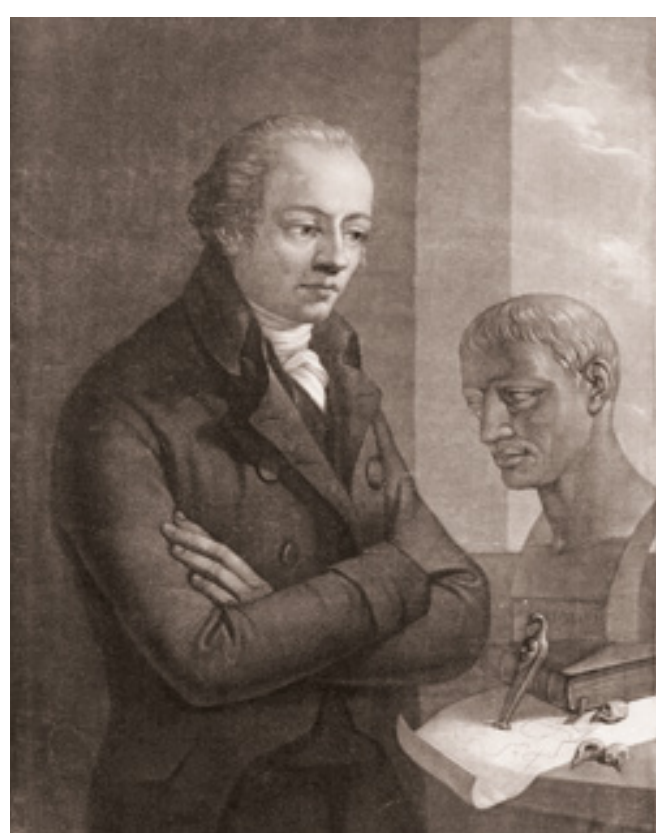

Abb. 17: F. Lenthe, nach Joseph Grassi, Franz Gall mit Büste Haydns, Mezzotinto, Bildarchiv der Österreichischen $\mathrm{Na}$ tionalbibliothek.

Fällen wählte man den alten Bologneser Typus des Gelehrten hinter dem Rednerpult in freiplastischer Form als Halb- bis Dreiviertelfigur (Brücke, Billroth, Sickel, Stefan) und weckte dadurch die Illusion eines ganzfigurigen Denkmals, obwohl I885 festgelegt worden war, dass ganzfigurige Denkmäler im Arkadenhof für Professoren nicht in Frage kommen. Am weitesten wagte sich der Bildhauer Anton Hanak vor, der Emil Zuckerkandls Porträtfigur unterhalb des Knies abschneidet. In diesen Fällen war eine genauere Charakterisierung durch Gestik und Attribute möglich. Die Beschränkung auf den Kopf ist jedoch nicht unbedingt als Abwertung zu sehen, sondern kann im Gegenteil in der Semantik des Klassizismus als Auszeichnung für einen geistig
Schaffenden betrachtet werden. So meint noch Schopenhauer, [...] Männern von Genie. also Dichtern. Philosophen. Künstlern, Gelehrten; als welche eigentlich nur mit dem Kopfe der Menschheit gedient haben. gebührt bloß eine Büste, die Darstellung des Kopfes..$^{58}$

Die Vorstellung, dass sich in der Physiognomie und in der Schädelform die geistigen Fähigkeiten eines Menschen abzeichnen und infolge ablesen lassen, hatte im I8. Jahrhundert durch die Theorien von Lavater und Gall allgemeine Verbreitung erfahren. Sie spielten auch im späten I9. Jahrhundert eine wichtige Rolle. Lebendund Totenmasken berühmter Zeitgenossen wurden abgenommen, um ihre authentischen Züge zu bewahren. Die medizinhistorische Sammlung im Josephinum verwahrt zahlreiche Totenmasken von bedeutenden Vertretern der Wiener Medizinischen Schule. Auch Schädel wurden gesammelt, inspiriert von dem Phrenologen Franz Gall, der an deren Form Begabungen und Charaktereigenschaften zu erkennen glaubte (Abb. 17). ${ }^{59}$ In Kombination mit abgenommenen Masken dienten sie häufig als Vorlage für Büstendenkmäler. Der Bildhauer Franz Klein, der während Galls Lehrtätigkeit in Wien in dessen Auftrag Gesichtsmasken abnahm und Schädel abformte, schuf auf diese Art auch seine Büsten. ${ }^{60} 1826$ entstand so die nüchterne Büste von Andreas Josef von Stifft, die I889 in den Arkadenhof der Universität übertragen wurde (Abb. I8). Im 19. Jahrhundert wuchs aufgrund der Darwin'schen Entwicklungslehre auch das anthropologische Interesse an den Schädeln. Rudolf Pöch, ab I9I9 ordentlicher Professor der neu gegründeten Lehrkanzel für Anthropologie und Ethnographie an der Universität Wien, erwarb im Laufe seiner Forschungsreisen etwa eine um-

58 A. Schopenhauer an das Komitee für ein Goethe-Denkmal in Frankfurt I837, zit. nach R. Selbmann, Dichterdenkmäler in Deutschland. Literaturgeschichte in Erz und Stein, Stuttgart 1988, S. 65.

59 Auch die Gehirne mancher Professoren wurden dort aufbewahrt. URL: http://www.springermedizin.at/ artikel/18575-julius-wagner-jauregg-begruender-der-fiebertherapie, abgerufen am 30. August 2016.

60 S. Krasa-Florian, Franz Klein, ein Bildhauer des Klassizismus, in: Mitteilungen der Österreichischen Galerie I4, I970, S. 99-I49. 


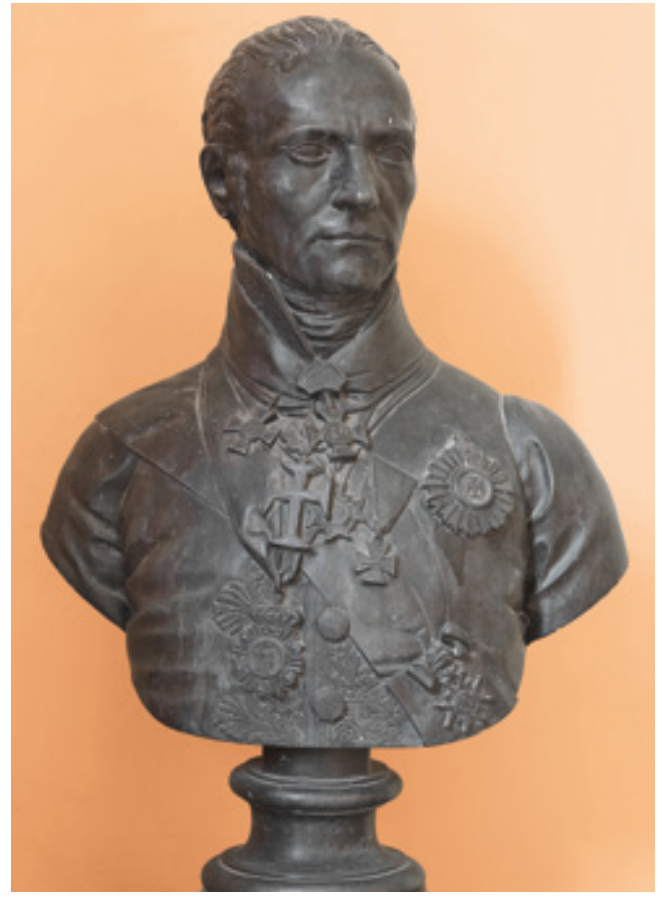

Abb. I8: Franz Klein, Denkmalbüste für den Mediziner Andreas von Stiff, Blei-Zinn-Legierung, I826, Arkadenhof der Universität Wien (ehem. Alte Universität, Consistorialsaal).

fangreiche Schädelsammlung, die teils noch heute im Besitz der Akademie der Wissenschaften und des Naturhistorischen Museums ist. ${ }^{61}$

Als Beispiel sei hier noch einmal der Anatom Josef Hyrtl genannt. Hyrtl übernahm die von van Swieten der Universität Wien verehrte vergleichend-anatomische Sammlung und baute sie nach ihrer Zerstörung I848 mit eigenen Präparaten aus. Mit der Korrosionsanatomie, deren Produkte er I873 auf der Wiener Weltausstellung präsentierte, erlangte er internationale Anerkennung. Hyrtl verstand sich als Humanist und Gelehrter im Sinne der Aufklärung -

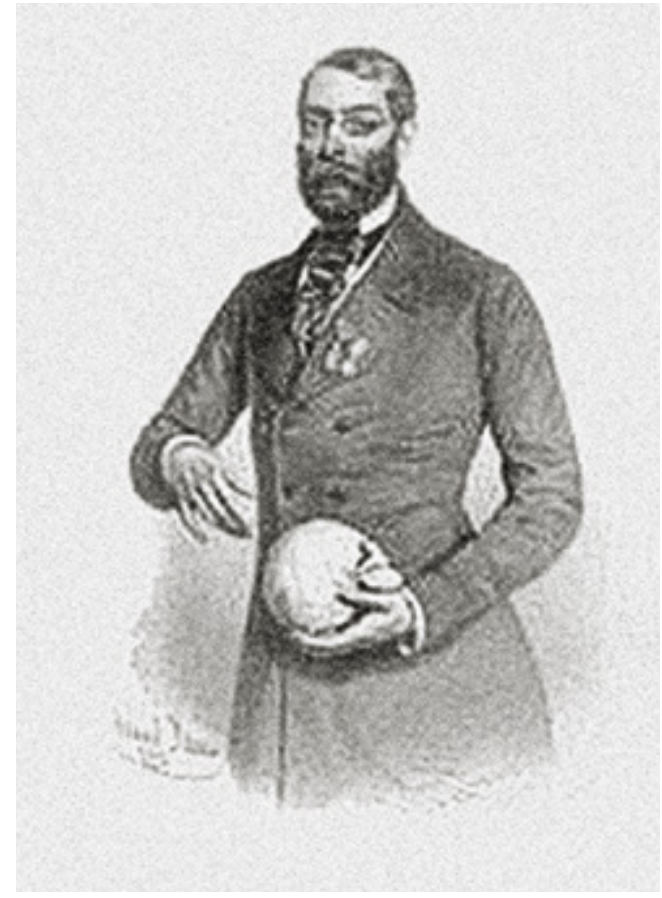

Abb. 19: Prof. Josef Hyrtl, Lithografie von E. Kaiser, UAW.

er wandte sich gegen ein rein materialistisches Verständnis des wissenschaftlichen Fortschritts. Seine Schädelsammlung war teils medizinisch, teils anthropologisch, teils von einem romantisch anmutenden Geniekult motiviert. ${ }^{62}$ In der Sammlung befanden sich der Schädel einer $\mathrm{Mu}$ mie, der eines römischen Legionärs aus Carnuntum und als kostbarste Reliquie der angebliche Schädel von Mozart. Sein Bruder hatte ihn von einem Totengräber am St. Marxer Friedhof bekommen. Hyrtl war von seiner Echtheit überzeugt und hütete ihn wie einen Schatz bekrönt mit einem Lorbeerkranz. ${ }^{63}$ In einer Lithografie

6I URL: http://www.landesmuseum.at/pdf_frei_remote/ANNA_83_0743-0762.pdf, S. 754, abgerufen am 30. August 2016.

62 Zit. Anm. 53. Hyrtl verkehrte freundschaftlich mit dem Mediziner und Literaten Paul Frankl, dem Initiator des Schiller-Denkmals in Wien, mit dem er 1865 gemeinsam der Enthüllung des Denkmals für ihren Medizinerkollegen Türck im Allgemeinen Krankenhaus beiwohnte.

63 Dies erinnert an Goethe, der in seinem Arbeitszimmer den Schädel von Schiller der Büste des Dichters von Johann Heinrich Dannecker gegenüberstellte. J. Endres, Knochenreste. Versuch einer begrifflichen Differenzierung (im 
ließ sich Hyrtl in Betrachtung eines Totenschädels porträtieren (Abb. I9), eine für einen Anatomen durchaus passende Pose, wie das Denkmal für seinen Kollegen Karl Langer von Edenberg (Alfonso Canciani 1903) im Arkadenhof zeigt, doch hinter der pathetischen Geste, die auch an die Rolle des Hamlet erinnert, sind zusätzlich Vanitasgedanken zu vermuten. In seinen Tagebuchaufzeichnungen berichtet Hyrtl, wie er auf Reisen gerne die Grabmäler berühmter Anatomen aufsuchte, unter anderem in Bologna. Er notierte zu dem Grabstein des Mondino de Luzzi aus dem I4. Jahrhundert in Santi Vitali ed Agricola: ein Professor auf der Kanzel umgeben von seinen Zuhörern. ${ }^{64}$

Auch der Pathologe Carl von Rokitansky bewahrte den Schädel eines berühmten Mannes in seinem Institut auf. I852 war der Schädel Josef Haydns auf abenteuerliche Weise bei ihm gelandet. Schüler Galls hatten ihn aus dem Grab ent- wendet und in einem Holzkästchen auf Samt gebettet versteckt. ${ }^{65}$

Die Semantik des Schädels und die besondere Beziehung, die Mediziner professionsbedingt dazu entwickelten, mag die Fülle an Medizinerporträts in Form von Medaillen und Büsten erklären, die im I8. und I9. Jahrhundert entstanden. ${ }^{66}$ Man wollte auch die eigene Physiognomie der Nachwelt überliefern. Carl Freiherr von Rokitansky, Pathologe und Philosoph, der erste Rektor aus der Medizinischen Fakultät, auch Präsident der Akademie der Wissenschaften, wurde schon 1874 zu seinem 70. Geburtstag mit einer lebensgroßen Marmorbüste von Viktor Tilgner geehrt, von der er selbst fünf Kopien anfertigen ließ ${ }^{67}$ Er wurde 1885 unter den ersten zu Ehrenden für den Arkadenhof genannt, erhielt sein Büstendenkmal von Emmerich Alexius Swoboda aber erst 1898.

\section{DIE ALIBIFRAU: MARIE VON EBNER-ESCHENBACH}

Die Frau ist im Arkadenhof aufgrund ihrer soziokulturellen Stellung im 19. Jahrhundert lediglich in ihrer traditionellen Rolle als $\mathrm{Mu}$ se des männlichen Gelehrten vertreten - in der Nymphe Kastalia als Quelle der Inspiration und als weiblicher Genius, der in barocker Manier dem Mediziner Ernst von Brücke huldigt (Otto König I894). Auf diesen Sachverhalt reagierte das 2009 entstandene Kunstprojekt Iris
Andrascheks, das in Form einer Granitintarsie den Schatten der Muse als Silhouette einer rebellierenden Frau wiedergibt. Es konnte in der Entstehungszeit des Arkadenhofes keine Frau als Universitätsprofessorin geehrt werden, da die Möglichkeit eines Studiums an der Universität Wien von Frauen erst gegen Ende des I9. Jahrhunderts mühsam erkämpft wurde, ab I897 an der philosophischen, I900 an der medizinischen

Anschluss an Goethe), in: Kritische Berichte, 3, 2008, S. II-I2. An der Universität Pavia kann man noch heute in der medizinhistorischen Sammlung den mumifizierten Schädel von Carlo Scarpa gegenüber seiner klassizistischen Büste als Supraporten bewundern.

64 Zit. nach Der Anatom Josef Hyrtl (zit. Anm. 53), S. 34-35.

65 URL: http://www.meduniwien.ac.at/homepage/fileadmin/pdfs/News/hintergrundinformation_haydn_schaedel. pdf, abgerufen am 28. Juni 20I5. Der Schädel wurde 1954 in Eisenstadt beigesetzt, ein Gipsabguss befindet sich im Historisch-pathologischen Museum im Narrenturm in Wien.

66 S. z.B. die Medaillensammlung Brettauer, Institut für Numismatik und Geldgeschichte der Universität Wien.

67 Carl Freiherr von Rokitansky (I804-1878). Pathologe, Politiker, Philosoph. Gründer der medizinischen Schule des I9. Jahrhunderts. Gedenkschrift zum 200. Geburtstag (hrsg. v. H. Rumpler/H. DenK), Wien/Köln/Weimar 2005, S. I8I. Das Original befindet sich heute im Wiener Institut für Geschichte der Medizin, Josephinum. Für das Medizinerporträt s. auch den Beitrag zu Th. Billroth von J. Rüdiger in diesem Band. 


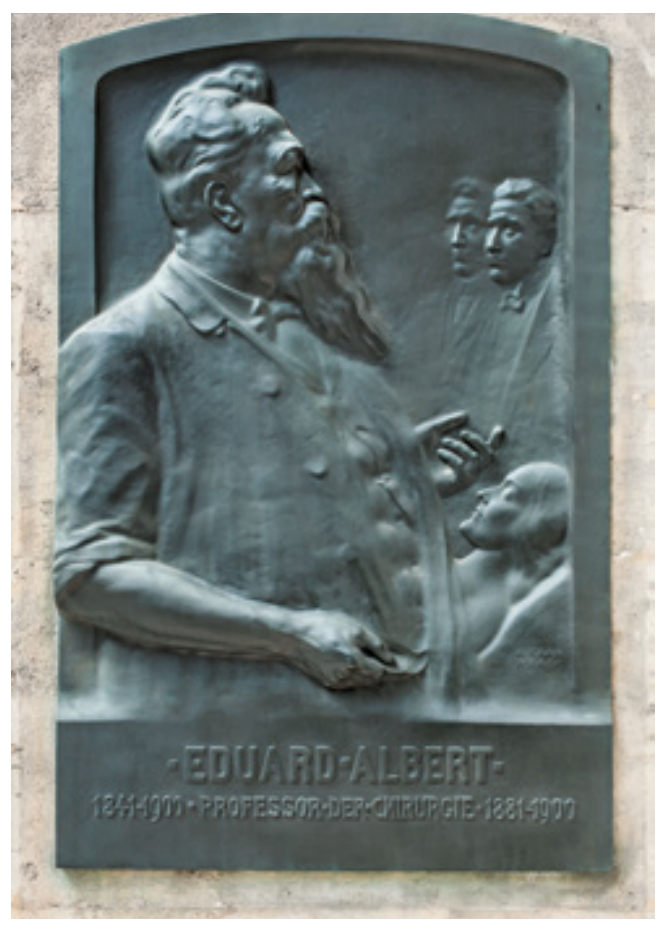

Abb. 20: Arthur Kaan, Denkmal für den Mediziner Prof. Eduard Albert, I9og, Bronze, Arkadenhof der Universität Wien.

und erst 1919 an der juridischen Fakultät. ${ }^{68}$ Ein Gegner des Frauenstudiums war unter anderem der in seinem Fach höchst erfolgreiche Chirurg Eduard Albert, der einzig Männern die Fähigkeit kultureller Leistung zubilligte. Auf seinem Denkmal (1909) doziert er vor rein männlicher Zuhörerschaft, während eine Patientin als Gegenstand wissenschaftlicher Erörterung auf einer Bahre ruht (Arthur Kaan 1909) (Abb. 20). Der Druck der Frauenbewegungen war stark, die Gattinnen der honorigen Herren waren vielfach in Frauenvereinen tätig, ihre Töchter strebten an die Universität. Juristen wie Edmund Bernatzik und der Historiker Theodor Sickel unterstützten die freie Berufswahl als im Staatsgrundgesetz von I867 verankertes Recht.

Die erste und einzige erfolgreiche Initiative für die Ehrung einer Frau ging von dem Germanistikprofessor Anton Bettelheim aus, der enge Kontakte zum Bund österreichischer Frauenvereine pflegte. Er beantragte 1900 anlässlich des 70. Geburtstages der anerkannten österreichischen Dichterin Marie von Ebner-Eschenbach die Verleihung des Ehrendoktorats, obwohl diese nie an einer Universität studieren konnte und wohl auch nie danach gestrebt hatte. Die geborene Gräfin Dubsky hatte in Mähren eine adelige Erziehung genossen, verkehrte später in Wien als gebildete Frau in der großbürgerlichen Gelehrtengesellschaft mit den Familien Exner, Billroth, Fleischl-Marxow und Bettelheim.

Der Verfechter der österreichischen Literatur trug auch publizistisch zum Ruhm der Schriftstellerin bei, indem er zwei Biografien der Dichterin verfasste und darin ihre bisherigen Ehrungen dokumentierte. ${ }^{69}$ Zehn Jahre nach ihrem Tod beantragte Bettelheim im Juni 1923, die Anbringung eines Denkzeichens in der Universität, um auf die 1900 erstmalig erfolgte Verleihung des Ehrendoktorats an eine Frau zu erinnern (Abb. 2I).$^{70}$ Das Denkmal beinhaltet als einziges Epitaph keine Porträtdarstellung. Die Inschrift nennt Namen, Herkunft und ihre Auszeichnung als Ehrendoktorin der Universität Wien. Ironischerweise war es das Denkmal des dem Frauenstudium einst kritisch gegenüberstehenden Eduard Albert, das der neuen Gedenktafel weichen und an andere Stelle versetzt werden sollte.

68 W. HeindL/M. Tichy, „Durch Erkenntnis zu Freiheit und Glück ... “. Frauen an der Universität Wien (ab I897), Schriften des Universitätsarchivs, Universität Wien, 5, Wien I990.

69 Marie von Ebner-Eschenbach (* 13. 09. I830, auf Schloss Zdislavice, Tschechien, $\dagger$ I2. 3. I916, Wien), geboren als Marie Freiin Dubsky, war eine der bedeutendsten deutschsprachigen Schriftstellerinnen des 19. Jahrhunderts. Die Gedenktafel für Marie von Ebner Eschenbach befindet sich an der Innenseite eines Pfeilers im rechten Arkadengang. Die hochrechteckige Tafel besteht aus gelblichem Osliper Sandstein. https://monuments.univie.ac.at/index. php?title=Denkmal_Marie_von_Ebner-Eschenbach, abgerufen am 2. August 20I5.

70 UAW, Senat $S$ 93.22. 


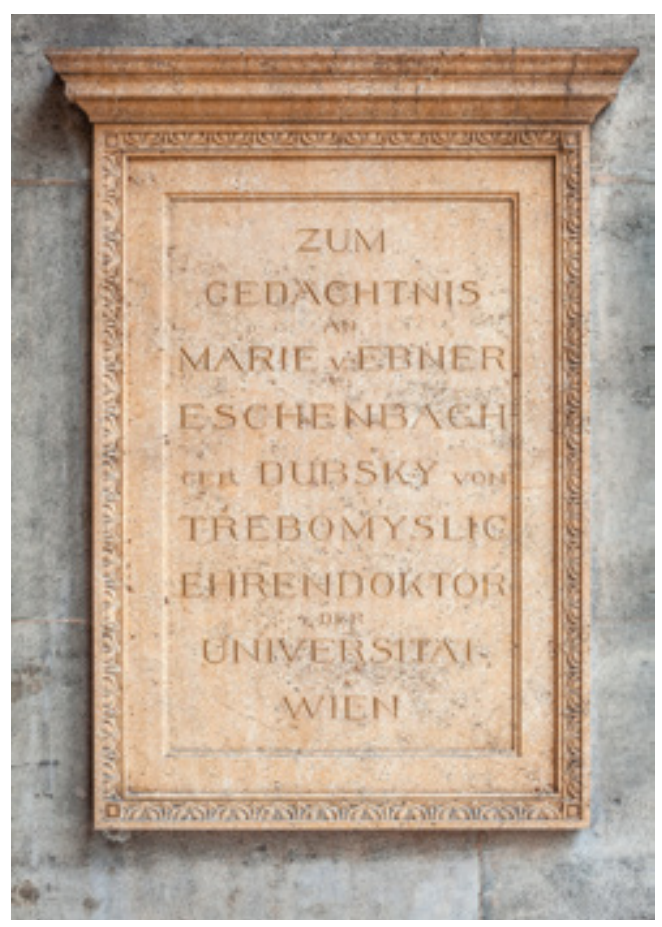

Abb. 2I: Gedenktafel für Marie von Ebner-Eschenbach, 1925, Osliper Sandstein, Arkadenhof der Universität Wien.

Bei der feierlichen Enthüllung am 27. Juni 1925 sprach Marianne Hainisch, die Begründerin der Frauenbewegung in Österreich, auf Wunsch Bettelheims einige Gedenkworte. Es ist bemerkenswert, dass für die Feier ein Porträt vermisst wurde. Daher lieh die Universität nur für diesen Anlass aus den städtischen Sammlungen eine polychrome Büste des römischen Bildhauers Raffaele Zaccagnini, der die Dichterin während ihres Romaufenthaltes porträtiert hatte (Abb. 22). ${ }^{7}$ Dass der Dichterin im Arkadenhof letztlich keine den übrigen Professoren gleichrangige porträtplastische Ehrung zukam, erscheint aus der ursprünglichen Intention Bettelheims, der lediglich ein Denkzeichen für die

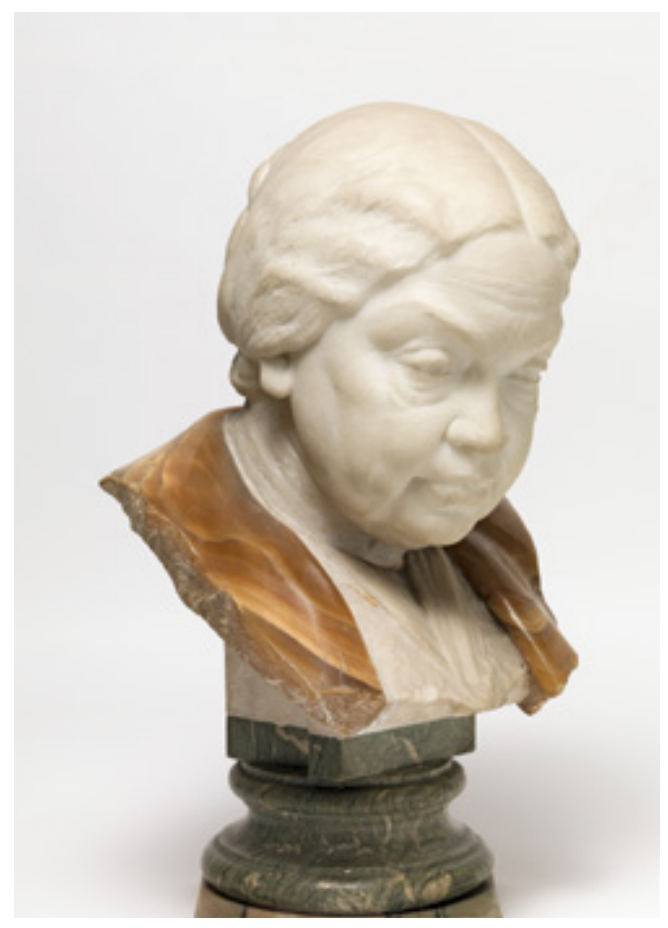

Abb. 22: Raffaele Zaccagnini, Büste der Dichterin Marie von Ebner Eschenbach, Marmor und Achat, I905, Wien Museum.

Verleihung der Ehrendoktorwürde beantragte, erklärbar. Demgegenüber ist es erstaunlich, dass Wissenschaftlerinnen die 2. Hälfte des 20. Jahrhunderts hindurch bis zuletzt von Ehrungen ausgenommen waren.

An den italienischen Universitäten findet man schon wesentlich früher Ehrenbezeugungen für einzelne Frauen, die - allerdings nur auf der Basis privater Studien - akademische Grade erreichten und Ausnahmeerscheinungen blieben. Vielleicht begünstigte gerade die Außergewöhnlichkeit einer solchen Karriere die jeweiligen Denkmalsetzungen. In Padua erinnert eine ganzfigurige Statue an Elena Lucrezia Cornaro Piscopia († I684), in Bologna wurde eine Medaille für

7I Die Dichterin lernte den Bildhauer in Rom kennen. A. Bettelheim, Marie von Ebner Eschenbach. Wirken und Vermächtnis, Leipzig 1920. Diese Büste befindet sich im Depot des Wien Museums. I. Schemper-Sparholz/C. MANG, „Gedächtniswerk“-Zu den plastischen Bildnissen der Marie von Ebner-Eschenbach, in: Innsbrucker Beiträge zur Kulturwissenschaft N. F. I4, erscheint 2017. 
die Physikerin Laura Bassi geprägt († I778), in Pavia erhielt Maria Pellegrina Amoretti 1956 anlässlich ihres 200. Geburtstages eine Gedenktafel im Cortile di Volta der Universität. Sie war 1777 die erste promovierte Juristin in Italien.

\section{R E S Ü M E E}

Ruhmeshalle, Geschichtsgalerie, Campo Santo - das bedeutet Ehren, Lernen, Gedenken. Alle diese Aspekte sollten die Denkmäler im Arkadenhof der Universität Wien der Nachwelt vermitteln. Wie an einigen Beispielen gezeigt werden konnte, hatte diese Form der Memorialkultur einen hohen Stellenwert im Universitätsleben. Es lag im Interesse der Initiatoren, die Denkmäler durch Publikation in der Presse und als Autorenbildnisse in wissenschaftlichen Publikationen über den elitären Kreis der Universität hinaus bekannt zu machen (Glaser, IngenHousz).

Deutlich wurde, dass nicht nur Leistung bestimmte, wer wann in den Olymp erhoben wurde. Es ist unbestritten, dass mit den hier genannten Professoren Gelehrte von internationalem Ansehen ausgezeichnet werden sollten. Aber ist die Auswahl tatsächlich repräsentativ? Im Wissen um die restriktive Universitätspolitik der Zwischenkriegszeit, das Konkurrenzdenken, die ideologisch gesteuerten Besetzungsstrategien, die antisemitischen Diskriminierungen haben einige bedeutende Gelehrte kein Denkmal, die es wohl verdient hätten, wie etwa Guido Adler, der Begründer des musikwissenschaftlichen Instituts, oder der Geologe Eduard Suess, dessen mehrbändiges Werk „Das Antlitz der Erde“ (I928) internationale Anerkennung erfuhr. In der jüngeren Vergangenheit betrifft dies auch weibliche Professoren. Das Geschichtsbild wird also erst vollständig, wenn man die Lücken im Arkadenhof mitberücksichtigt.
Dem langjährigen Ausbleiben von Denkmälern für weibliche Gelehrte im Arkadenhof wurde im Zuge des 650-jährigen Gründungsjubiläums der Universität entgegengewirkt. 20I5 hat die Universität Wien beschlossen, den Arkadenhof für neue Denkmäler, speziell für Wissenschaftlerinnen, zu öffnen. Ein Wettbewerb wurde ausgeschrieben. Die mit der Ausführung betrauten KünstlerInnen experimentieren mit unterschiedlichen Materialien und Gestaltungsmöglichkeiten, von Metall, Glas, Fotografie sowie von traditioneller Büstenform und Relief bis zu freskoartiger Verschmelzung des Abbildes mit der Putzoberfläche der Pfeiler. In allen Fällen ist die individuelle Erkennbarkeit der Dargestellten gewährleistet und wird in der formalen Gestaltung die fachliche Spezialisierung berücksichtigt. Seit ihrer feierlichen Enthüllung am 30. Juni 2016 erlauben die Denkmäler nun die Frage des Personendenkmals neu zu diskutieren. Die Möglichkeit der Fortsetzung ist gegeben. ${ }^{72}$

Abbildungsnachweis: Abb. I, 2, 3, 4, 5, II, I2, 13, I4, I5, I6, I8, 20, 2I: Institut für Kunstgeschichte der Univ. Wien, K. Pani/A. Plankensteiner/R. Steyer; Abb. 6: I. Schemper; Abb. 7, 8, 9: Repro aus: Il Cortile di Volta dell'università di Pavia (hrsg. v. M. T. Savini), Milano 20II, S. I00, I05, I07; Abb. IO: Repro aus: Il cortile dei medici e degli artisti e il teatro anatomico dell'università di Pavia (hrsg. v. L. Erba), Pavia 20I2, S. I52; Abb. I7: Bildarchiv der Österreichischen Nationalbibliothek; Abb. 19: UAW; Abb. 22: Wien Museum

72 Die KünstlerInnen Catrin Bolt, Jessica Richter und Thomas Baumann gewannen die Ausschreibung. Im Umfrageverfahren an den Fakultäten waren die Entwicklungspsychologin Charlotte Bühler, die Physikerinnen Lise Meitner und Bertha Karlik, die Mathematikerin Olga Taussky-Todd, die österreichisch-chilenische Archäologin Grete Mostny Glaser, die Sozialpsychologin Marie Jahoda und die Romanistin Elise Richter als primär denkmalwürdig ausgewählt worden. https://monuments.univie.ac.at/, abgerufen am 3I. Jänner 2017. 


\title{
DIE ANFÄNGE DER GELEHRTENEHRUNG AN DER WIENER UNIVERSITÄT UND DIE BILDNISSE DES NIKOLAUS VON JACQUIN
}

\author{
Maria Pötzl-Malikova
}

$I^{2}$ m späten I8. Jahrhundert begann eine neue Ära der Bildnissetzung an der Wiener Universität. Der entscheidende Schritt dafür war das Ansuchen des Rektors und des Consistoriums der Universität vom 27. September 1778 an die Kaiserin Maria Theresia um die Bewilligung, daß nach Gewohnheit anderer Universitäten, Porträts der um die Universität und Facultät besonders verdienten Männern in den gewöhnlichen Hörsaale aufgehenget werden dürfen. ${ }^{\mathrm{I}}$ Einen Monat darauf kam die Nachricht über die allerhöchste Erlaubnis, nach Wunsch der Kaiserin sollte es aber lediglich auf Privatkosten der Professoren geschehen. Die erhaltenen Dokumente zu dieser Entscheidung demonstrieren nicht nur das neue Selbstwertgefühl des höchsten Bildungsinstituts und die Hervorhebung der persönlichen Verdienste, sondern markieren in Wien zugleich eine Wende in der Denkmalsetzung, die immer mehr zum gesellschaftlichen Anliegen wurde. Bis dahin hatte nur der Herrscher das Recht dazu, im öffentlichen Raum einer verdienten Persönlichkeit durch die Aufstellung ihres Bildnisses seine „huldvolle Anerkennung“ und den Dank für die geleisteten Dienste auszudrücken. Durch ihre Entscheidung verzichtete die Kaiserin daher auf eines ihrer bisherigen herrscherlichen Privilegien.

In der Universität waren vorher Bildnisse nur im Consistorialsaal üblich, wo sie vor allem eine repräsentative Funktion hatten. Hier hing das Porträt des jeweiligen Herrschers für representatio in effgie und barocke ganzfigurige Bildnisse der Rektoren. ${ }^{2}$ Außerhalb dieses Raumes gab es nur eine Ausnahme: Im medizinischen Hörsaal ließ Maria Theresia 1763 ein Porträt des Gerard van Swieten aufhängen, und zwar für seine Verdienste um die Reorganisation der Universität im Sinne des aufgeklärten Absolutismus, als höchste staatliche Lehranstalt. Sechs Jahre danach, I769, als die Kaiserin der Überzeugung war, dass ihr van Swieten bei einer Pockeninfektion das Leben gerettet hatte, ließ sie an dieser Stelle eine Büste des Mediziners aufstellen (Abb. I). ${ }^{3}$ Dieses Denkmal war daher in erster Linie Ausdruck ihres persönlichen Dankes, die Anerkennung der wissenschaftlichen Leistungen war zweitrangig. Die Art der Aufstellung - eine schlichte schmucklose Nische ohne

I Siehe die Antwort der Niederösterreichischen Regierung vom 23. Okt. 1778 (Universitätsarchiv Wien, weiter: UAW), Consistorialarchiv, Fasz. I, Nr. 22I ex 1778 (CA I.O.232) publiziert in: G. NATTER, Icones Rectorum. Werden und Eigenart der Rektorengalerie an der Universität Wien, Ms. (Phil. Diss. an der Leopold-Franzens-Universität Innsbruck), Wien/Innsbruck 1988, S. 250-25I, Nr. 4.3.I.I.

2 Ebenda, S. I2-2I. Vgl. dazu auch: H. Rosenberg, Bilder der Magnifizenz. Zur Rektorengalerie der Wiener Universität, im vorliegenden Band.

3 Die Büste, ein Werk F. X. Messerschmidts, befindet sich als Dauerleihgabe der Wiener Universität im Belvedere Wien (Inv. Nr. Lg. I8). Siehe auch M. Pötzl-Malikova, Franz Xaver Messerschmidt. Monographie und Werkverzeichnis, Belvedere (A. Husslein-Arco (Hg.). Werkverzeichnisse, Bd. 4), Wien 2015, S. 45-47, 237-240, Kat. Nr. 25. 


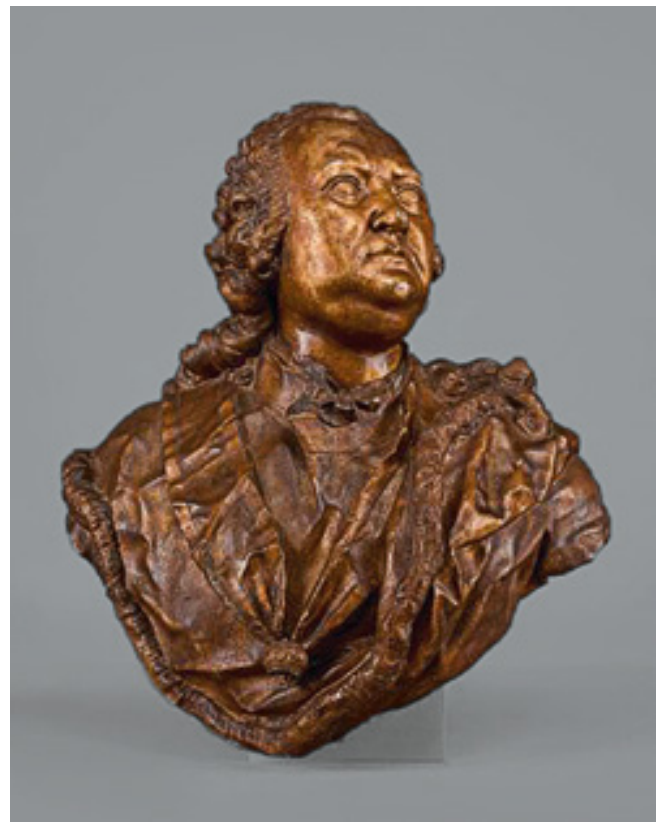

Abb. I: Franz Xaver Messerschmidt, Gerard van Swieten, I769, Blei-Zinn-Legierung, vergoldet, Galerie Belvedere Wien.

zusätzliche Insignien - und das gewählte Material zeugen von der nach wie vor strikten Einhaltung einer genauen Rangordnung bei einer solchen Denkmalsetzung. ${ }^{4}$

Die Initiative zum erwähnten Ansuchen im Jahre 1778 kam von der Juristischen Fakultät. Der Erste, der solche Porträts zur Verfügung gestellt hat, war auch ein Jurist, Joseph Valentin Eybel, Professor des Kirchenrechts. Die Namen der zehn Dargestellten sind bekannt, die Künstler jedoch nicht und bis auf ein Gemälde sind die Bildnisse inzwischen verschollen. ${ }^{5} \mathrm{Nach}$ dem Wortlaut des allerhöchsten Erlaubnisses scheint es, dass Maria Theresia an eine posthume Ehrung gedacht hat. ${ }^{6}$ Die Ausgezeichneten waren aber meist Kollegen von Eybel, die noch an der Universität lehrten. Für Eybels zwiespältige Haltung bei der getroffenen Auswahl spricht in der erhaltenen Liste, dass an der ersten Stelle Papst Clemens XIV. figurierte, zugleich in ihr jedoch auch ein prominenter Aufklärer, der Professor für Zivilrecht Joseph von Sonnenfels, zu finden ist.

Die Widmung Eybels war sicher nicht einmalig, aber über weitere umfangreichere private Geschenke von Ölporträts sind wir bisher nicht informiert. Bei Büsten wissen wir nur von wenigen, einzelnen Aufträgen. Sie hatten mehr eine offizielle Funktion und waren daher für den Consistorialsaal bestimmt. Für diesen Raum schuf I802 Johann Martin Fischer die Metallbüste des Joseph von Quarin ${ }^{7}$ und I826 fertigte Franz Klein ebenfalls aus Metall (wohl einer Zinnlegierung) die Büste des Andreas Josef von Stifft. ${ }^{8}$ Beide Dargestellten waren Leibärzte der kaiserlichen Familie und bekleideten bedeutende öffentliche Ämter, darunter auch die eines Rektors. Der Anlass für ihre Ehrung mit einem dreidimensionalen Bildnis lag wohl noch immer außerhalb ihrer direkten Verdienste um die Universität und bewegte sich in traditionellem Rahmen. Für die Entstehung der Büste von Quarin war sicherlich sein Anteil, als Rektor, an der Bildung des Ersten Wiener Aufgebots im Jahre

4 Siehe bei den Aufträgen Maria Theresias den Unterschied zwischen der Büste des Fürsten Joseph Wenzel I. von Liechtenstein aus feuervergoldeter Bronze und der des Van Swieten, die aus Blei-Zinn-Guss ist und die ursprünglich wahrscheinlich auch nicht vergoldet, sondern nur bronziert war. Lit.: PöтzL-Malikova (zit. Anm. 3), S. 239.

5 UAW, Consistorialarchiv, Fasz. I., Nr. 22I ex 1778, Verzeichniß A. Zitiert in: Natter, Icones (zit. Anm. I), S. 25I. Das einzige bis heute erhaltene Bildnis aus dieser Stiftung stellt Joseph von Sonnenfels dar und wird von Natter als ein Werk des Anton Graff bezeichnet (Ebenda, S. 77-79, I50, Nr. R/g 2I).

6 In der unter Anm. I zitierten Quelle heißt es: [...] womit auch die Verwandschaft des verstorbenen dabey nichts einwende [...] als ein solches Bildniß allenfalls gemißhandlet werden könnte.

7 Näheres darüber in: I. Schemper-Sparholz, Ge(l)ehrte Köpfe in Wien. Zu den Anfängen ehrenhalber aufgestellter Büsten in Wien, in: F. M. Kammel (Hg.), Blickwechsel. Die Bildnisbüste in der Epoche der Aufklärung (im Druck, siehe S. 22).

8 Ebenda. 
I797 wesentlich, bei jener von Stifft, des Direktors des Allgemeinen Krankenhauses und Reorganisators des Sanitätswesens, war wohl vor allem die Genesung des Kaisers Franz I. von einer schweren Krankheit ausschlaggebend. In den Akten des Unversitätsarchivs ist auch die private Stiftung einer Büste vermerkt. ${ }^{9}$ Der Landes-Protomedicus Eduard Guldener von Leber widmete I825 der Universität eine Gipsbüste des Obersten Kanzlers und Ministers Graf Franz von Saurau von Franz Klein. Der Grund für diese Schenkung waren die Verdienste Sauraus beim Aufgebot des Jahres 1797. Die Büste war daher ebenfalls für eine Aufstellung im Consistorialsaal bestimmt, in dem bereits eine Art Gedenkstätte für dieses Aufgebot errichtet wurde, mit Fahnen und den Gemälden des kaiserlichen Ehepaares und eines weiteren Protagonisten des Aufgebots, des Herzogs Ferdinand von Württemberg. ${ }^{10}$ Zwei Jahre später verlangte der Bildhauer Franz Klein Sauraus Gipsbüste zurück, um nach ihr für die Universität eine Büste aus weißem Metall (Zinn) zu verfertigen. ${ }^{\text {II }}$ Nach dem Tod von Franz Anton von Zeiller, Professor des Naturrechtes, versuchte man $1829 \mathrm{ihm}$ ein Denkmal in der Universitätskirche zu errichten, in der so ein Pantheon für hervorragende Wissenschaftler entstehen sollte. $^{\text {I2 }}$ Nachdem dies gescheitert war, plante man 1732 eine Büste Zeillers im großen Universitätssaal aufzustellen. Damals überlegte man das erste Mal, alle weiteren, bis dahin existierenden Büsten (van Swieten, Quarin, Stifft, Saurau) in diesem Saal zu vereinigen, der besser zugänglich war als der Consistorialsaal. Das Ansuchen wur- de jedoch von der Niederösterreichischen Landesregierung abgelehnt. ${ }^{13}$ Bis zum Jahre 1848 , in dem das 1756 erbaute Universitätsgebäude aufgehört hatte, der Lehre zu dienen, ist hier kein weiterer ähnlicher Versuch unternommen worden, in einem zugänglichen Raum die existierenden Büsten gemeinsam aufzustellen. Welche Porträts, ob Gemälde oder Büsten sich im Jahre 1722 in der Universität befanden, erfahren wir aus der Publikation von Franz Heinrich Böckh. ${ }^{14}$ Außerdem verzeichnet I82I auch ein Inventar an die 30 Bilder in verschiedenen Räumen dieser Institution. ${ }^{\text {Is }}$

Nach I8oo kam es bei der Widmung der Bildnisse von verdienten Professoren für die einzelnen Hörsäle der Universität zu einem verstärkten Engagement der Studenten. Um ein Denkmal ihrer innigsten Hochachtung und Dankbarkeit ${ }^{6}$ gegenüber ihrem Professor zu stiften, haben sich Hörer eines bestimmten Faches und bestimmten Jahrgangs zusammengetan, ein Bildnis des verehrten Professors besorgt und der Universität gewidmet. Bevor das Bild an die Wand des entsprechenden Hörsaales kam, wurde es mit einem kleinen Fest in einem der Festsäle präsentiert. Einer der Studenten hielt dabei die Lobrede und manchmal wurde auch eine dazu komponierte Kantate gespielt. Beliebt und verbreitet war diese Art besonders unter den Medizin- und Jurastudenten. Sie entspricht in vielem schon den im I9. Jahrhundert üblichen Gewohnheiten bei einer Denkmalsetzung, in der die Initiative meist „von unten“ kam. Im Universitätsarchiv sind mehrere Akten über solche Unterfangen erhalten geblieben, weil

9 UAW, Fasz. I., Nr. 602 ex I825 (CA I.0.615).

IO F. H. BöскH, Wiens lebende Schriftsteller, Künstler und Dilettanten im Kunstfache. Ein Handbuch für Einheimische und Fremde, Wien I822, S. 332-333.

II UAW, Fasz. III., Lit. K, Nr. 257 ex 1827 (CA 3.1783). Die Büste ist seit Langem verschollen.

I2 UAW, Fasz. I. Nr. 626 ex I832 (CA I.o.639). Siehe dazu: Schemper-Sparholz (zit. Anm. 7).

I3 Ebenda. Im Gesuch wurde vor allem darauf hingewiesen, dass bei Feierlichkeiten diese Büsten auch andere Besucher, vor allem aber die Studenten zum Nacheifern zu sehen bekamen.

I4 BöскH (zit. Anm. IO), S. 332-333.

I5 G. Natter, Die Gemälde der Universität Wien. Eine historische Dokumentation, Ms., Wien 1988, S. 7.

i6 Ebenda, S. 133, Nr. P I07 (Zitat beim Porträt des Professors der Pathologie Karl Hartmann, das von den Studenten gestiftet wurde). 


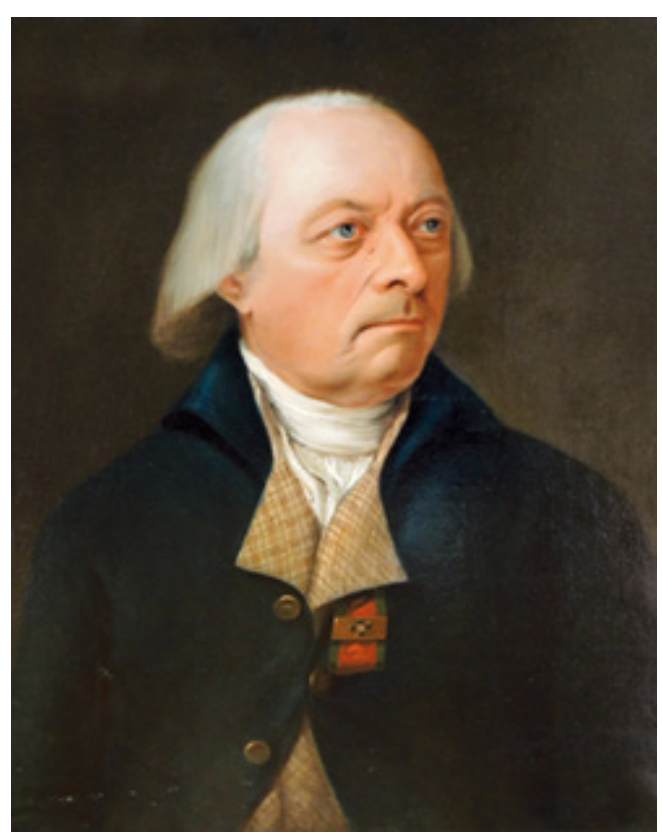

Abb. 2: Unbekannter Maler: Nicolaus von Jacquin, nach I806, Öl auf Leinwand, Bibliothek des Botanischen Instituts der Universität Wien.

das Professorenkollegium seine schriftliche $\mathrm{Zu}$ stimmung dazu geben musste. Die erste solche Widmung ist aus dem Jahr I804 bekannt. Das Bildnis stellt den Juristen Joseph Anton Petzek dar, der in diesem Jahr gestorben war. ${ }^{17}$ Es ist das einzige bekannte Bild, bei dem man eine posthume Ehrung voraussetzten kann. Sonst feierten die Studenten mit diesen Porträts ihre damaligen Lehrer. Einzelne dieser Bildnisse sind bis heute noch in verschiedenen Räumen der Universität vorhanden. ${ }^{18} \mathrm{Im}$ Jahre I823 wurden solche Ehrungen der Studenten verboten, besonders wenn es um einen aktiv wirkenden Professor ging (man erklärte sie als eine Art von Bestechung). ${ }^{19}$ Der Stein des Anstoßes, bei dem wahrscheinlich persönliche Rivalitäten eine Rolle spielten, war ein

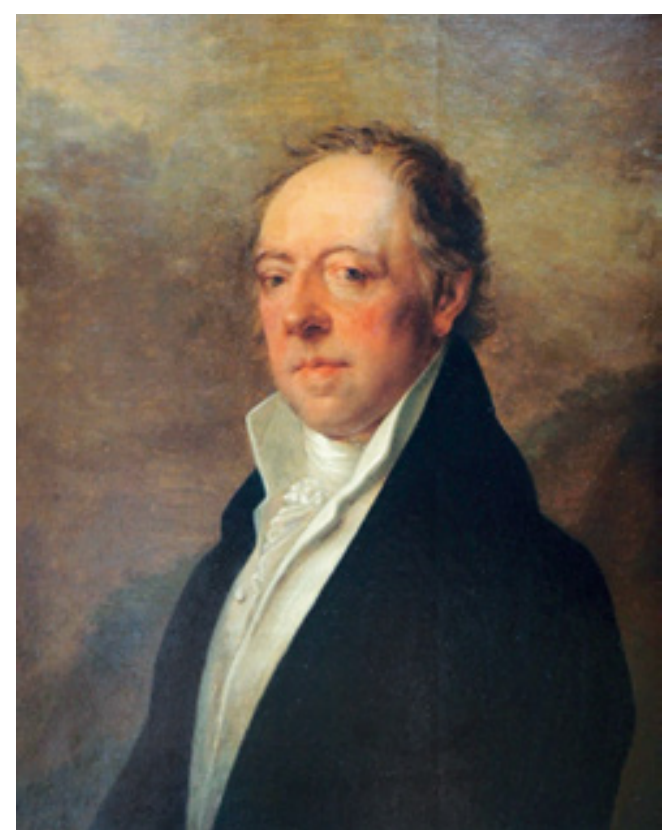

Abb. 3: Heinrich Friedrich Füger, Joseph von Jacquin, I8II, Öl auf Leinwand, Bibliothek des Botanischen Instituts der Universität Wien.

Bildnis des Professors der klassischen Philologie Anton Stein von Leopold Kupelwieser. Die Studenten legten gegen das Verbot eine Beschwerde bei der Landesregierung ein, wurden aber abgewiesen. Man sah in diesem Aufbegehren die Wirkung eines von den fremden Universitäten herüberwehenden verderblichen Zeitgeistes.

Unter jene Professoren, die eine solche Würdigung erlebt haben, gehörten auch der berühmte Botaniker und Professor der Chemie an der Medizinischen Fakultät Nikolaus von Jacquin (1727-1817) und sein Sohn und Nachfolger Joseph von Jacquin (1766-I839). Wir erfahren darüber aus einem Umlaufbogen aus dem Jahre I8I2..$^{20}$ Das Professorenkollegium war einstimmig dafür. Differenzen schienen nur darüber be-

7 Ebenda, S. 24I, Nr. P 207.

I8 Ebenda, an verschiedenen Orten.

I9 Die erhaltenen Akten im UAW, Consistorialarchiv und im Allgemeinen Verwaltungsarchiv des Österr. Staatsarchivs sind in extenso wiedergegeben und kommentiert in: NatTeR, Icones rectorum (zit. Anm. I), S. 252-256, Nr. 4.3.I.2 und 4.3.I.3.

20 UAW, Consistorialakten, Fasc. I, Nr. 4I8 ex I8I2 (CA I.0.430). Der Umlaufbogen über das Gesuch der Medizinstudenten ist ohne Datum, man kann ihn aber in das Jahr I8I2 datieren. 
standen zu haben, ob dabei Musik gespielt oder eine Lobrede, begleitet von Pauken und Trompeten, gehalten werden soll.

In der Bibliothek des Botanischen Institutes der Wiener Universität befinden sich - bisher kaum beachtet - zwei gleich große Bildnisse des Vaters und des Sohnes Jacquin in gleichem Rahmen, die man meiner Meinung nach mit den Bildern identifizieren kann, die I8I2 die Studenten der medizinischen Fakultät der Universität feierlich gewidmet haben. ${ }^{21}$ Sie wurden bisher nicht mit diesem Ereignis in Verbindung gebracht. Das eine Bild - des Sohnes - ist ein so gut wie unbekanntes Porträt von Friedrich Heinrich Füger, signiert und datiert mit I8II (Abb. 3). ${ }^{22}$ Das andere - des Vaters - ist unsigniert und entstand wahrscheinlich früher (Abb. 2). Der terminus post quem ist das Jahr I806, denn in diesem Jahr erhielt dieser den Stephansorden, der auf der Kleidung Jacquins zu sehen ist. ${ }^{23}$ Von Günter (Tobias) Natter wird dieses Porträt von einem bisher nicht näher bestimmten Maler ebenfalls als ein Werk Fügers bezeichnet, ${ }^{24}$ was sicher nicht zutrifft. Von beiden Porträts existieren Kopien von Adelheid Kerner, der Tochter des Professors Anton Kerner von Marilaun. ${ }^{25}$

Im Jahr I8II malte Friedrich Heinrich Füger tatsächlich ein Porträt des Nikolaus von Jacquin in etwa ähnlicher Größe, das aber nach der angege-

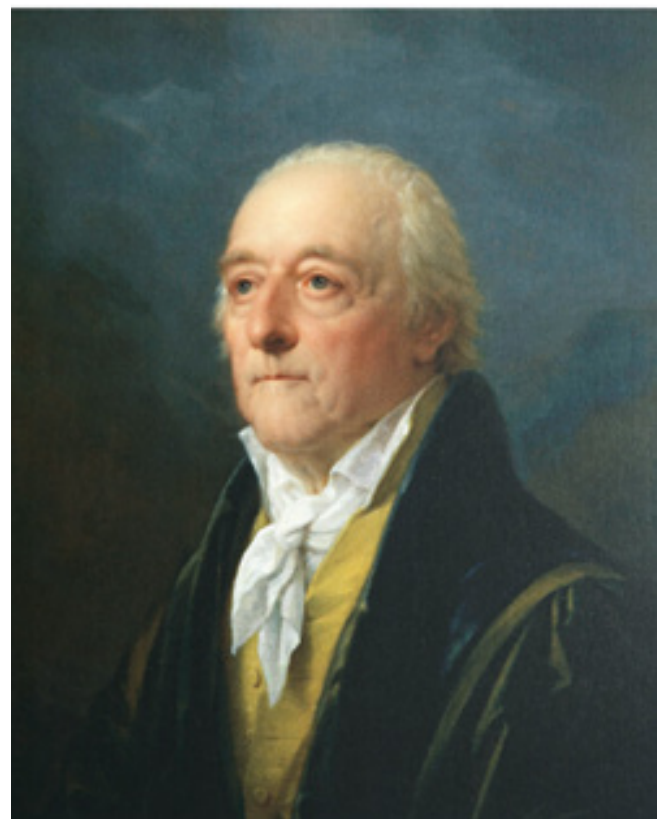

Abb. 4: Heinrich Friedrich Füger, Nicolaus v. Jacquin, I8II, Öl auf Leinwand, Privatbesitz.

benen Provenienz in der Literatur im Familienbesitz blieb (Abb. 4).$^{26}$ Dieses Bildnis wurde ein Jahr später, I8ı2, von Vinzenz Kininger als Schabblatt herausgegeben und ist dadurch bald sehr populär geworden. Für die Wiener Universität ist es insofern von Bedeutung, als es ein beliebtes Vorbild für spätere Porträts des Nikolaus von Jacquin wurde.

2I Ich danke Herrn Mag. Mathias Svojtka, Mitarbeiter der Bibliothek des Botanischen Institutes der Wiener Universität, für den Hinweis auf diese Werke und für seine vielseitige Unterstützung bei meinen Nachforschungen.

22 Natter, Die Gemälde (zit. Anm. I5), S. I54, Nr. P I26, mit Abb. Die Angaben zum Bild sind hier sehr knapp, die Signatur wird zwar erwähnt, das Bild ist jedoch in das Jahr I8I2 datiert. Seine Maße sind nach Natter: 69 x $54 \mathrm{~cm}$. Über die mögliche Identifizierung dieses Bildes mit jenem, das die Studenten I8ı2 gewidmet hatten, wird hier nicht diskutiert.

23 Für die Bestimmung dieses unauffälligen Zeichens danke ich Frau Dr. Sabine Grabner.

24 Natter, Die Gemälde (zit. Anm. I5), S. 157, Nr. P 129, mit Abb. Seine Maße sind nach Natter: 69 x 54 cm, also gleich dem Bild des Sohnes, Joseph von Jacquin. Die Zuweisung dieses nicht signierten Bildes an Füger wird hier nicht begründet und die Möglichkeit, dass dieses Porträt mit jenem identisch sein kann, das die Studenten I8I2 der Universität gewidmet haben, wird hier nicht diskutiert.

25 Natter, Die Gemälde (zit. Anm. I5), S. 155, Nr. P 127, mit Abb. und S. 158, Nr. 130, mit Abb. Die Bilder befanden sich 1988 im Sitzungssaal der Philosophischen Fakultät.

26 R. KeIL, Heinrich Friedrich Füger I75I-I8I8, Wien 2009, S. 382, VW 557. Das von Füger signierte und mit I8II datierte Bild, das sich heute in Privatbesitz befindet, ist mit 6I x 49,5 cm etwas kleiner als die beiden erwähnten Bildnisse von Vater und Sohn Jacquin in der Bibliothek des Botanischen Institutes in Wien. 
Nikolaus von Jacquin wurden am Beginn des 19. Jahrhunderts zwei weitere Ehrungen gewidmet, die unser Interesse verdienen. Sie scheinen einmalig zu sein. Sie illustrieren anschaulich, wie unterschiedlich solche Feiern in der Wiener Universität in dieser Zeit sein konnten und zugleich welche wesentliche Rolle dabei Werke bildender Kunst gespielt haben.

Die erste dieser Ehrungen war mit der Totenfeier des im Oktober I8I7 verstorbenen Nikolaus von Jacquin verbunden. Wir erfahren über sie aus einer Beschreibung dieses Ereignisses, die in einer als selbständiges Bändchen publizierten Trauerrede zu finden ist. ${ }^{27}$ Danach nahmen am 9. Juni I8I8 der Senat, die Mitglieder der vier Fakultäten und eine große Anzahl von Trauergästen an einer Seelenmesse in der Universitätskirche teil und begaben sich dann in den großen Saal der Universität, um die Trauerrede anzuhören. Dort stand auf einem großen, neun Schuh hohen Sarkophag mit einer Inschrift eine angeblich sehr ähnliche Büste des Verstorbenen, die der geschickte Bildhauer Herr Leonhard Posch, vor mehreren Jahren verfertigte. Stufen, die dorthin führten, waren mit exotischen Blumen geschmückt. Rechts stand eine Statue der Hygieia, links waren Jacquins Werke - 36 Prachtbände - aufgetürmt. Das ganze Arrangement war mit weiteren Blumen, die Bezug zu Jacquin hatten, geschmückt. Sie wurden vom Gärtner Schott aufs Zierlichste geordnet. Aus der Publikation erfahren wir auch, wer diese ganze Aufstellung auf Aufforderung des damaligen Dekans entworfen hat - es war Joseph Fischer der k. k. Kammerkupferstecher und Vorsteher der fürstl. Esterházy'schen Kunstsammlungen.

Der Entwurf von Fischer ist leider bisher verschollen. Neuerdings wurde von Dr. Johann

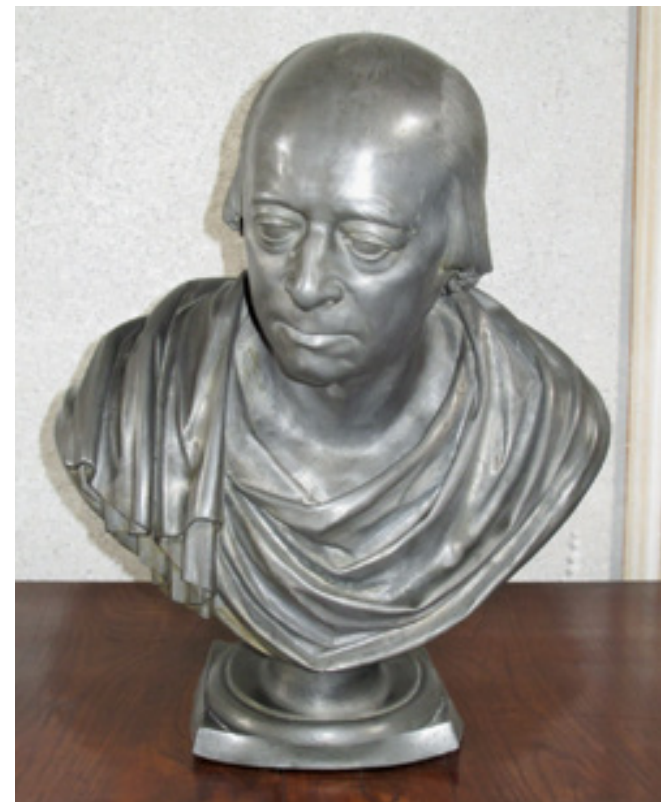

Abb. 5: Leonhard Posch (zugeschrieben), Nicolaus von Jacquin, vor 1803, Metallbüste (Blei-Zinn-Legierung), Schloss Kačina bei Kutná Hora (Kuttenberg).

Kräftner jedoch eine unsignierte Metallbüste des Nikolaus von Jacquin entdeckt, die man mit der damals aufgestellten Büste von Leonhard Posch identifizieren kann (Abb. 5). Sie befindet sich in der Bibliothek des klassizistischen Schlosses Kačina bei Kuttenberg (Kutná Hora), das der Graf Johann Rudolf Chotek in den Jahren I802I822 nach den Plänen des Dresdner Architekten Schuricht hat erbauen lassen. ${ }^{28}$ Über die Entstehungsgeschichte dieser Büste sowie ihr weiteres Schicksal ist bisher nichts bekannt. ${ }^{29}$ Man kann mit ziemlicher Sicherheit annehmen, dass sie in Wien noch zu Lebzeiten Jacquins entstanden ist. Wahrscheinlich nicht auf eine offizielle Bestellung hin, denn darüber hätten wir Informatio-

27 Rede zur Gedächtnissfeyer des Hoch- und wohlgebornen Herrn Nic. Jos. Freyherrn v. Jacquin, gehalten im Saale der Hohen Schule am 9. Juni I8I8 von Joh. Nep. Raimann, Wien, o. J. [I818], S. 28.

28 I. Cerman, Chotkové. Př́běh úřednické šlechty, Praha, o. J. [2008], S. 448-458. Für die freundliche Aufnahme im Schloss, in dem sich heute ein volkskundliches Museum befindet, und die vielseitige Unterstützung meiner Recherchen danke ich dem Museumsdirektor Dr. Pavel Novák und dem Kurator der Gemäldesammlung des Schlosses Kačina Mag. Martin Vlček.

29 In der tschechischen Fachliteratur wurde diese Büste bisher kaum zur Kenntnis genommen. Nur eine lokale Traditi- 
nen aus der zeitgenössischen Presse, es war eher ein Privatauftrag der Familie. Bis zum Beginn des Ersten Weltkrieges befand sie sich offenbar in Wien, ${ }^{30}$ dann verlieren sich ihre Spuren. Interessant ist in diesem Zusammenhang ein erhaltener undatierter Brief aus Wien, adressiert wohl an den Grafen Chotek, in dem die Jacquin-Feier im Jahre I8I8 mit ähnlichen Worten beschrieben wurde wie in der genannten Broschüre. ${ }^{31}$

Der aus Tirol stammende Bildhauer Leonhard Posch (I750-183I) war ein Schüler und Mitarbeiter von Johann Baptist Hagenauer, der mit ihm 1774 nach Wien kam. Er ist bisher vor allem als Schöpfer veristischer Wachsbüsten bekannt, die er zusammen mit Joseph Graf Deym alias Müller für die kaiserliche Familie und für das Wachskabinett Deyms verfertigt hatte. ${ }^{32}$ Gelegentlich hat er jedoch auch konventionelle Porträtbüsten geschaffen. Ein Beweis dafür ist eine Büste des Erzherzogs Carl aus patiniertem Gips, die I8oI entstanden ist. ${ }^{33}$ Später widmete er sich vor allem der Modellierung von Porträtmedaillons. Begonnen hat er mit diesen schon in Wien, die meisten schuf er aber außerhalb Wiens, vor allem in Berlin, wo er sich I8I4 endgültig niederließ. ${ }^{34}$

Während seiner Wiener Zeit war Posch mit der Familie Jacquin mehrmals in Kontakt. I792, in der Zeit der Mitarbeit von Deym, entstand das erste, naturalistisch aufgefasste Porträtmedaillon von Nikolaus von Jacquin. Mit I8O2 datiert ist eine grafische Wiedergabe einer Medaille, auf der Vater und Sohn Jacquin idealisiert, mit schönen Locken und antikisierendem Umhang dargestellt sind. ${ }^{35}$ Die Büste in Kačina wäre die einzige bisher bekannte Büste von Posch aus Metall (Blei-Zinnguss) und müsste vor I803 entstanden sein. Danach war der Bildhauer dauernd auf Reisen, die ihn nach Hamburg, Berlin, Paris und zuletzt wieder nach Berlin führten.

Posch war kein Metallbildhauer, sondern ein ausgesprochener Wachsbossierer und das verrät auch die Büste Jacquins. Ihre Wände sind zu massiv, zu schwer und haben das Einknicken des sicher später angebrachten Metallsockels verursacht. Eine so dicke Metallschicht wie hier ist bei einem geübten Metallbildhauer kaum denkbar und ist daher ein wichtiges Indiz für Poschs Autorschaft. Die Gestaltung von Jacquins Antlitz ist so wie bei Poschs Büste des Erzherzogs Carl einem moderaten Realismus verpflichtet, der sich um Ausgleich zwischen der Wiedergabe der einmaligen Erscheinung und ihrer klassizistischen Idealisierung bemüht. Auffallend ist die Ähnlichkeit mit dem Bildnis Jacquins in der Bibliothek des Wiener Botanischen Instituts, die bis zu den charakteristischen glatt geschnittenen Haaren reicht. In der zeitlos gehaltenen, togaähnlichen Draperie des Büstenabschnittes ist der Einfluss von Zauners Büste des Joseph von Sonnenfels aus dem Jahre 1787 merkbar. ${ }^{36}$

Im Umlaufbogen, in dem alle Mitglieder der vier Fakultäten um Spenden für die Totenfeier für Nikolaus von Jacquin ersucht wurden, heißt es, dass wenn finanzielle Mittel übrig bleiben, sie für die Verfertigung eines Porträts des Verstorbe-

on weiß zu berichten, dass Nicolaus von Jacquin den englischen Park beim Schloss entworfen hat und Graf Chotek ihm daher zur Ehre dieses Bildnis hat errichten lassen. Diese „Erklärung“ entbehrt jeder historischer Grundlage.

3I Für die freundliche Vermittlung dieses Briefes, der sich im Chotek-Archiv in Prag befindet, danke ich Herrn Mag. Vlček. Der Verfasser des Briefes ist Johann Wilhelm Ridler, Direktor der Universitätsbibliothek in Wien.

32 O. Kurz, Hagenauer, Posch and Mozart, in: The Burlington Magazine, vol. IIo, Nr. 783 (June I968), S. 327-328.

33 A. Forschler-Tarrasch: Leonhard Posch, Porträtmedailleur und Bildhauer 1750-I83I, Berlin 2002, S. 2I, mit Abb. Die Büste ist hier als verschollen angegeben.

34 Ebenda, S. 27-33.

35 Ebenda, S. II4, mit Abb.

36 Abb. in: H. Burg, Der Bildhauer Franz Anton Zauner und seine Zeit, Wien 1915, Taf. VI. bei S. I4I.

37 UAW, Consistorialarchiv, Fasz. I. Nr. 49I ex I8I8 (CA I.0.504). 


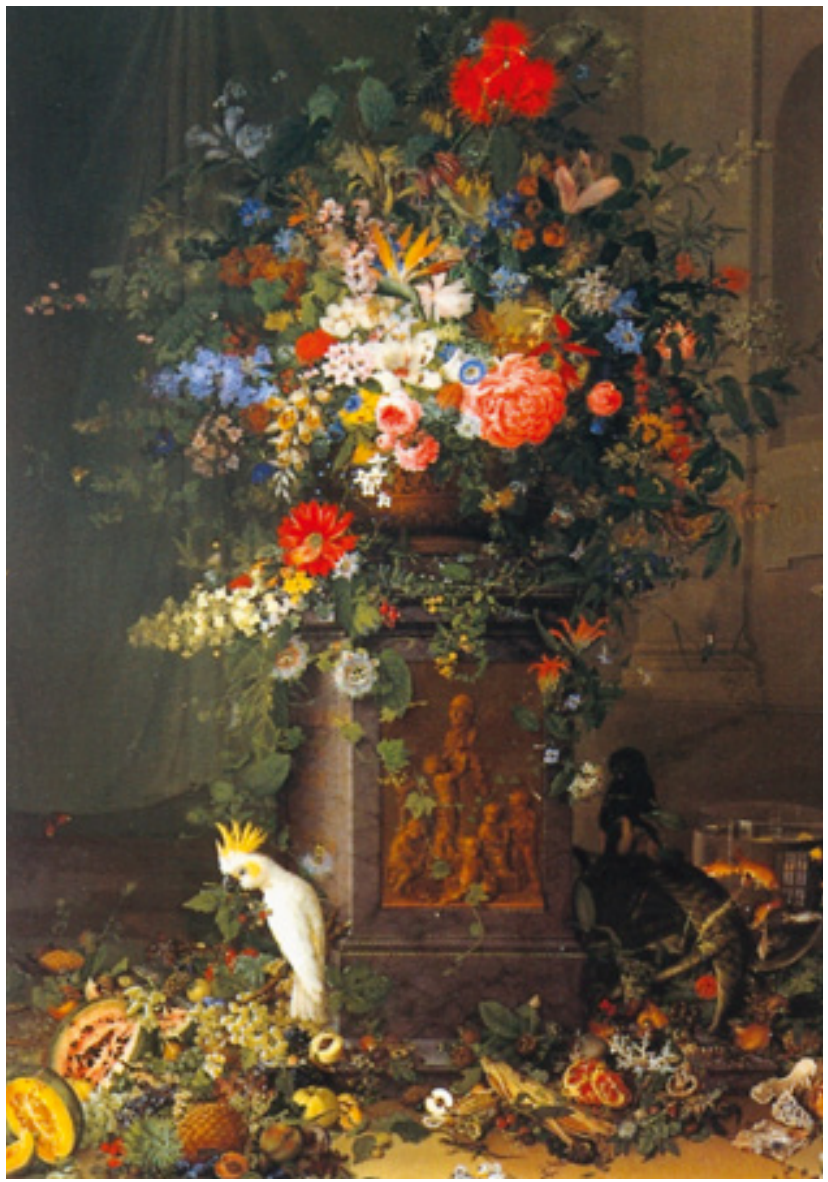

Abb. 6: Johann Knapp, "Jacquins Denkmal", I822, Öl auf Leinwand, Österreichische Galerie Belvedere Wien.

nen benützt werden sollten, das in den Consistorialsaal kommen soll. ${ }^{37}$ Geld ist dann wohl geblieben und davon wurde ein weiteres Bildnis Jacquins angeschafft. Das nach I8I8 entstandene Gemälde kann man mit jenem Bild identifizieren, das von Bernard von Guérard (1771-1836, in Wien: 1793-I826), einem damals sehr geschätz- ten Porträtmaler, stammt. ${ }^{38}$ Es wurde sicherlich für den Consistorialsaal bestimmt, da auf ihm Nikolaus von Jacquin mit der Rektorenkette dargestellt ist. ${ }^{39}$ Der wohl später angebrachten Inschrift am Bildrahmen, dass dieses Bild die Studenten der Pharmazie im Jahre I8I2 der Universität geschenkt hatten, kann man schwer

38 Natter, Die Gemälde (zit. Anm. I5), S. 156, Nr. P 156. Zu dem vor allem als Miniaturmaler sehr geschätzten Guérard siehe den einführenden Aufsatz von Ruth Pollin über Eugene von Guérard, den Sohn des Bernard von Guérard, in dem auch viel über den Vater geschrieben wird, publiziert in: R. Pollin/M. Varcoe-Cocks (Hg.), Eugene von Guérard, Nature revealed (Ausst.-Kat. National Gallery of Victoria, Melbourne 2oII, S. I-3, 44-45). Für den freundlichen Hinweis auf diese Publikation und ihre Vermittlung danke ich Frau Dr. Sabine Grabner.

39 Nicolaus von Jacquin war nur kurz, im Studienjahr 1808/1809, Rektor gewesen.

40 Siehe Anm. 38. Schon Günther Natter meldet Zweifel an dieser Angabe an. 
Glauben schenken. ${ }^{40}$ Nicht zu vereinbaren mit diesem Bild ist auch die Behauptung Böckhs, dass das Porträt Jacquins im Consistorialsaal ein Bild von Johann Baptist Lampi sei. ${ }^{4 r}$

Ein außergewöhnliches Huldigungsbild an Nikolaus von Jacquin wurde im Festsaal der Universität bei einer Feier des 4 . Todestages des Wissenschaftlers I82I ausgestellt (Abb. 6) und I822 vollendet. Es stammt vom Blumen- und Tiermaler Johann Knapp (1778-I833) und war bei seiner Entstehung viel beachtet. In Hormayrs Archiv wurde es mit besonderer Aufmerksamkeit beschrieben, ${ }^{42}$ und der Maler wird lobend von Franz Heinrich Böckh genannt. ${ }^{43}$ Auch der Bamberger Bibliothekar Joachim Heinrich Jäck, der gerade in Wien anwesend war, erwähnt es in seiner Reisebeschreibung. ${ }^{44}$ Das Bild blieb aber nicht in der Universität, aus dem Nachlass des Künstlers kam es I835 in die kaiserliche Gemäldegalerie. Heute hängt es im Oberen Belvedere in der ständigen Exposition von Werken der österreichischen Künstler des 19. Jahrhunderts. ${ }^{4}$

Das Bild von Knapp ist ein kunstvoll arrangiertes überdimensionales Stillleben und eine botanische Illustration zugleich. ${ }^{46}$ Auf einem viereckigen Steinsockel, quasi einem Piedestal, steht hier eine große Vase mit Blumen. Sie sind genau wiedergegeben und stellen alle 24 Gattungen des Linnéschen Systems dar. Seitlich sieht man in einer Wandnische die Urne Carl von Lin- nés - ein Hinweis darauf, dass sich Jacquin für diesen damals noch umstrittenen Forscher sehr eingesetzt hat und daher von Zeitgenossen auch „österreichischer Linné“ genannt wurde. Am Piedestal sieht man ein Relief mit der Büste Jacquins. Sie ist umgeben von Putti, die sie bekränzen oder verschiedene Geräte in den Händen halten. Sie symbolisieren die vielen Interessen Jacquins. Um das Piedestal liegen verschiedene Früchte und Muscheln, man sieht einen Papagei und ein Äffchen, ein Glas mit Fischen - Anspielung an die große fünfährige Forschungsreise Jacquins in die Karibik in den Jahren I755-I759. Das Bild ist nicht nur eine Hommage an Nikolaus von Jacquin als Forscher, sondern auch als wichtigen Anreger für die Entwicklung der wissenschaftlichen botanischen Illustration. ${ }^{47}$

Das Porträt Jacquins, das man auf dem Sockel sieht, folgt dem Bildnis von Füger, das Knapp wohl vom grafischen Blatt Kiningers gekannt hat. Viele weitere Jahre ist dieses Bild die populärste Darstellung von Nikolaus von Jacquin geblieben, und zuletzt lieferte es auch das Vorbild für Leopold Schrödl, der 1905 dessen Büste für die Arkaden der Universität geschaffen hat (Abb. 7). ${ }^{4}$ Von Bedeutung für die Bewahrung der Erscheinung Nikolaus von Jacquins war parallel dazu weiterhin auch die Büste, die sich heute auf dem Schloss Kačina befindet. Aus dem Familienbesitz kam I887 ein patinier-

4I Bӧскн (zit. Anm. IO), S. 333.

42 Johann Baptist Rupprecht, Jacquins Denkmal durch den Blumenmaler Knapp. Aus: Wanderung durch die Ateliers hiesiger Künstler, in: Archiv für Geographie, Historie, Staats- und Kriegskunst, Jg. I2, Wien I82I. Abgedruckt in: Johann Knapp, Jacquins Denkmal (Bildheft I der Östereichischen Galerie), Wien 1976, S. 5-I3.

43 Вӧскн (zit. Anm. Io), S. 334.

44 Wien und dessen Umgebungen beschrieben vom Bibliothekar Jäck aus Bamberg, in: Reise nach Wien, Triest, Venedig, Verona und Innsbruck unternommen im Sommer und Herbste I82I von Jäck und Heller, Weimar I822, S. I89.

45 Öl auf Leinwand, 216,7 x I63 cm. Wien, Belvedere, Inv.-Nr. 3631.

46 G. Frodu, Der Wiener Blumenmaler Johann Knapp und die botanische Illustration seiner Zeit, in: Johann Knapp, Jacquins Denkmal (zit. Anm. 42), S. 30-50.

47 Siehe dazu: M. Petz-Grabenbauer, Zu Leben und Werk von Nicolaus Joseph Freiherr von Jacquin, in: Wiener Geschichtsblätter, Jg. 50, 1995, H. 3, S. I40-I44.

48 T. Maisel, Gelehrte in Stein und Bronze. Die Denkmäler im Arkadenhof der Universität Wien, Wien/Köln/Weimar 2007, S. 16, 47, Nr. 35, mit Abb.

49 F. v. Hauer, Jahresbericht für I887, in: Annalen des k. k. naturhistorischen Hofmuseums, Bd. III, I888, S. 82. Zu- 


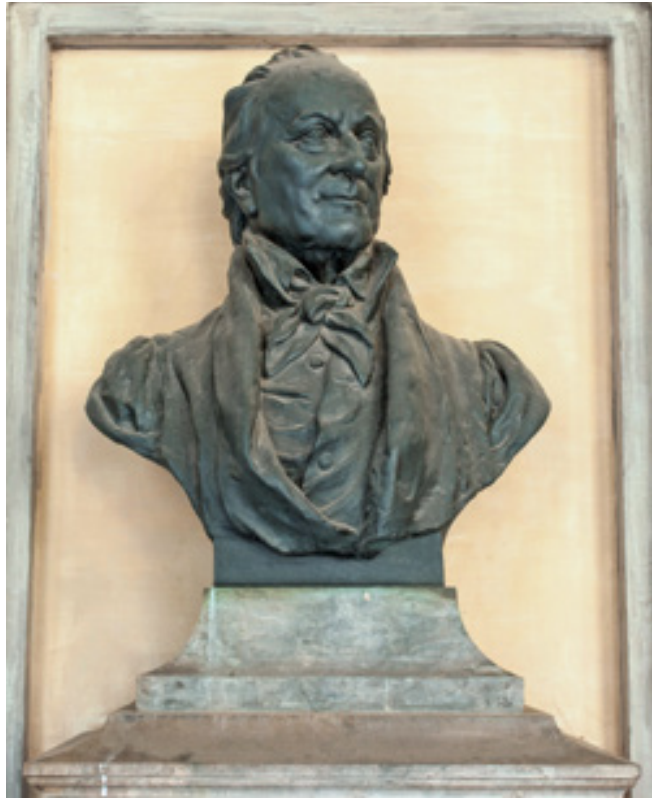

Abb. 7: Leopold Schrödl, Nicolaus Joseph von Jacquin, I905, Bronze, Arkadenhof der Universität Wien.

ter Gipsabguss von diesem Werk in die Sammlungen des Naturhistorischen Museums, ${ }^{49}$ der 2000 auf der Ausstellung „Lothringens Erbe“ in der Schallaburg gezeigt wurde..$^{\circ}$ Diese Büste, die auf keinem eingeknickten Sockel steht, vermittelt besser als das heute gebeugte Original den ursprünglichen aufrechten Aufbau des Werkes.

Im Eigentum der Universität befand sich im I9. Jahrhundert außerdem eine lebensgroße seit Langem verschollene Marmorbüste des Nikolaus von Jacquin, über die bisher nichts Näheres bekannt ist. Sie war 1877 auf der großen histo-

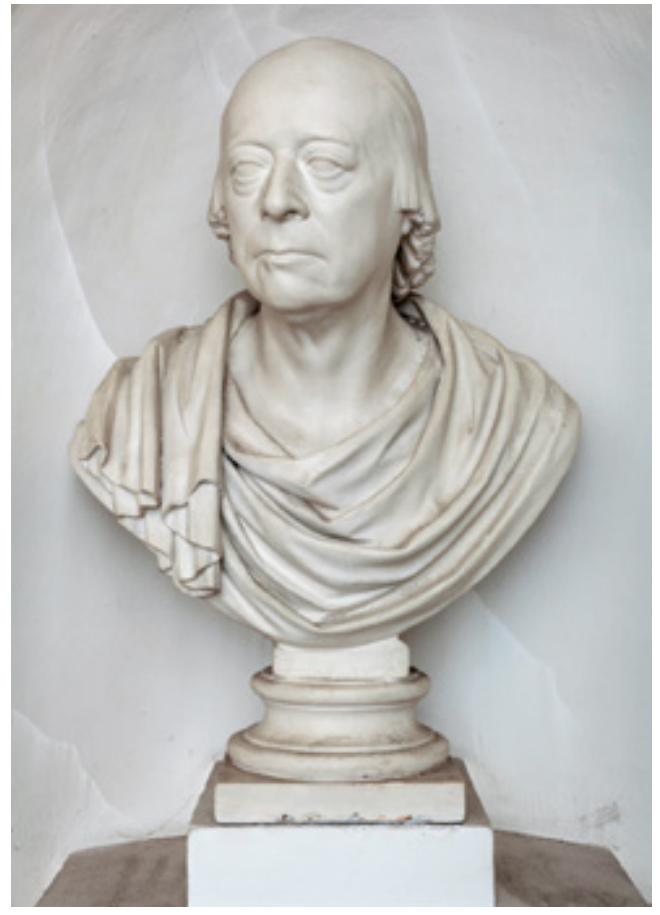

Abb. 8: Unbekannter Bildhauer, Nicolaus von Jacquin, I905, Gipsabguss der Büste in Schloss Kačina, altes Foyer des Botanischen Instituts der Universität Wien.

rischen Kunstausstellung der Akademie der bildenden Künste als ein Werk eines unbekannten Künstlers, der sie um I825 geschaffen hatte, ausgestellt. ${ }^{\text {sI }}$ Auf Ersuchen der Künstlergenossenschaft sollte sie auch I880 auf der von ihr veranstalteten Porträtausstellung gezeigt werden, ${ }^{\text {s2 }}$ im Katalog fehlt sie jedoch. Ob dieses Werk der Büste von Kačina oder dem Porträt von Füger folgte oder ob es sogar eine andere, dritte Dar-

sammen mit dieser Büste bekam das Museum aus dem Familienbesitz auch eine Gipsbüste des Sohnes, Joseph von Jacquin.

50 R. Zedinger (Hg.), Lothringens Erbe. Franz Stephan von Lothringen (I708-1765) und sein Wirken in Wirtschaft, Wissenschaft und Kunst der Habsburgermonarchie (Ausst.-Kat. Schallaburg 29. April-29. Oktober 2000), S. 20I, Nr. 9.I7. Die bronzierte Gipsbüste befindet sich heute im Archiv des Naturhistorischen Museums in Wien, Inv.-Nr. I66.

5I K. k. Akademie der bildenden Künste, Katalog der historischen Kunst-Ausstellung I877, S. 5 , Nr. 35.

52 UAW, Akademischer Senat, Sonderreihe (Akten der Artistischen Kommision), Karton 53, S. 87: Gesuch der Genossenschaft der bildenden Künstler Wiens an das Rektorat um die Leihgabe von Büsten des Jacquin, Stifft (von F. Klein), Joseph II. und Quarin (beide von J. M. Fischer) sowie einer Reihe von Ölgemälden, vom I2. Oktober I880, unterschrieben vom Architekten Carl von Hasenauer. 
stellungsmöglichkeit der Erscheinung von Nikolaus von Jacquin geboten hat, wissen wir nicht. Die bisher kaum beachtete Büste aus Kačina, die hier Leonhard Posch zugeschrieben wurde, blieb bis über die Jahrhundertwende noch immer aktuell. Das beweist ihr Gipsabguss, der im Foyer des neu erbauten Botanischen Institutes am Rennweg 1905 aufgestellt wurde und sich dort bis heute noch befindet (Abb. 8).53

\section{Abbildungsnachweis}

Abb. I, 6: Österreichische Galerie Belvedere Wien; Abb. 2, 3, 8: Institut für Kunstgeschichte der Univ. Wien, R. Steyer/A. Plankensteiner, 20I5; Abb. 7: Institut für Kunstgeschichte der Univ. Wien, A. Plankensteiner, 2013; Abb. 4, 5: Archiv der Autorin.

den relevanten Publikationen über die Errichtung des neuen Botanischen Institutes ist der Name des Bildhauers, der den Abguss verfertigt hat, nicht erwähnt. Dieser Abguss sowie jener, der sich im Naturhistorischen Museum befindet, zeugen davon, dass sich das Vorbild, die Originalbüste im Schloss Kačina, damals noch in Wien befand. 


\title{
BILDER DER MAGNIFIZENZ. DIE KAISERLICHE REKTORENGALERIE DER UNIVERSITÄT WIEN
}

\author{
Heidrun Rosenberg
}

\section{SECHZEHN BESONDERE PORTRÄTS}

$I^{n}$

n der gesamten Universitätslandschaft nimmt die Wiener Reihe von 16 ganzfigurigen Porträts eine Sonderrolle ein. Heute schmücken sie Räume, die so repräsentativ wie exklusiv sind: Sie hängen im Rektorenzimmer, im Senatssaal, im Festsaal und im ehemaligen Jesuiten-Refektorium, dem Schausaal des Universitätsarchivs. Monumental präsentieren sie die Dargestellten

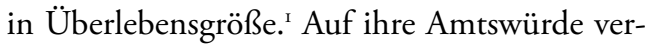
weisen Tracht und Insignien wie Zepter, Siegel und Ring. Die Gemälde tun dies nicht immer mit derselben Vollständigkeit oder Deutlichkeit, doch waren sie für die „stuba consistorialis" gedacht, in der ihr universitärer Rang einzuschätzen war, und auch die Inschriften ließen keinen Zweifel daran. ${ }^{2}$ Die porträtierten Rektoren entstammen den drei höherrangigen Fakultäten der Rechtswissenschaft, der Medizin und der Theologie, nicht aber jener der Artisten, obwohl diese in Wien die meisten Mitglieder zu verzeichnen hatte. Das Rektorenamt alleine genügte offensichtlich nicht, um in die illustre Reihe aufgenommen zu werden. Ins Auge springen Hinweise auf zusätzliche Verdienste und den hohen, teils adligen Status der Männer. Sie reichen von roten Absätzen und Wappen über
Ehrenketten bis hin zu üppigen Allonge-Perücken und feinsten Spitzenjabots. Draperien, Säulen und Marmorböden stellen die Honoratioren in ein hochherrschaftliches Ambiente. In den Bildlegenden werden die meisten von ihnen als „perillustris et magnificus“ geehrt. Dazu erfahren wir von teils glänzenden Karrieren im Dienst des Staates: Neben dem kurzfristigen Rektorenamt haben sich die Porträtierten einen Namen auf Hof-, Reichs- und Landesebene gemacht, etwa als Leibarzt oder Marschall, als höchste kaiserliche Hof- und Regierungsräte, als Ständevertretungen oder in der Funktion von Ordensführern.

Qualität und Erhaltungszustand der Ölgemälde sind heterogen. Einzelne Bilder überraschen mit einer Güte, die sich selten bei Porträtreihen von Amtsinhabern findet: Traditionsstiftung über eine normierte Bilderreihe scheint nicht das einzige Ziel. Vielmehr wirbt eine politische Elite gezielt mit den Mitteln der Kunst um Prestige.

Mit Ausnahme eines Bildes, das im 19. Jahrhundert vermutlich aus raumgestalterischen Gründen hinzugefügt wurde, ist die Wiener Serie zwischen 1672 und 1756 entstanden. ${ }^{3}$ Ihre Genese fällt damit in eine Zeit starker Konkurren-

I Die Ölgemälde messen zwischen 224 und $260 \mathrm{~cm}$ in der Höhe und 117,5 und $\mathrm{I} 3 \mathrm{I} \mathrm{cm}$ in der Breite.

2 Siehe Die Matrikel der Universität, Bd. VII I7I5/I6-I745/46 (hrsg. von K. MüHLBERGER), Wien 2OII, S. I37.

3 UAW Akademischer Senat, Sonderreihe IO2 (Schachtel 65), Josef Prem erhält am 30. 8. I883 eine Quittung über 
zen um die Gunst des Kaisers. Dies zu einem Zeitpunkt, als sich der Hof seinerseits durch Bildungspolitik und kulturelles Kapital zu profilieren beginnt: So finden sich seit I666 wiederholt prachtvolle Ehrenimmatrikulationen des Herrscherhauses in den Geschäftsbüchern der Universität. ${ }^{4}$

Mit der Wertschätzung universitärer Autonomie legte sich seit dem ausgehenden I9. Jahrhundert ein Schatten über einen derart höfischen Auftritt der Universitätsangehörigen. Erst 1988 hat Günter (Tobias) Natter das Thema der sogenannten „Wiener Rektorengalerie“ im Rahmen seiner Dissertation über den Gesamtbestand der Rektorenporträts aufgegriffen. ${ }^{5}$ Grundlegend für die Einschätzung des sozialen Klimas und der Nobilitierungspraxis im Umfeld der Universität sind darüberhinaus die Beiträge Kurt Mühlbergers. ${ }^{6}$

Auf Basis dieser Erkenntnisse lohnt es sich, das Thema nochmals aufzunehmen: Im Zenit steht weiterhin die Frage nach den Motivationen für die ungewöhnliche Gemäldereihe: Wer unter den jährlich rotierenden Amtsinhabern wurde für ein Porträt ausgewählt? Weshalb sind die Artisten nicht vertreten? Wem dient die Repräsentation der Rektoren und was teilen die Bildnisse über das in ihnen so offensichtlich verhandelte Verhältnis von Universität und Kaiserhof mit? Der Untersuchungsgegenstand führt also an die Schnittstelle verschiedener historischer Disziplinen. Die folgenden Ausführungen beginnen mit einer kurzen Entwicklungsgeschichte des Rektorenamtes, um dann den Fokus auf die Situation in Wien zu richten. Da die Gemäldereihe dem Prinzip individueller Profilierung verpflichtet scheint, empfahl sich ein exemplarisches Vorgehen, das mit dem ersten programmatischen Einzelbild von I672 einsetzt. Diese punktuelle Nahsicht eröffnet schließlich die stilgeschichtliche Argumentationsbasis für die These, dass die Porträts mit dem Interesse einer Nobilitierungsbestätigung in den großen Werkstätten im Umfeld des Machtzentrums in Auftrag gegeben wurden. ${ }^{7}$ Im Anschluss daran wird die Genese der Bilderreihe rekonstruiert.

die Restaurierung von I6 lebensgroßen Porträts. Nach der Neuhängung I886 ist in seinem Arbeitszeugnis vom I6. November desselben Jahres (Akademischer Senat, Protokolle der artistischen Kommission, I884-I, Sonderreihe 58) allerdings die Rede von 17 lebensgroßen Universitätsrektoren: G. NATTER, Icones Rectorum, Diss. Wien/Innsbruck I988, S. I47 katalogisiert dieses dazugekommene Bild als „Unbekannt“. Den Dargestellten zeichnet zwar ein Zepter aus, eine Inschrift aber fehlt und die Qualität ist auffallend gering. Vermutlich wurde das Bild von Prem - im Zuge der Neuhängung - dazu gemalt.

4 Die erste kaiserliche Ehrenimmatrikulation geht auf Leopold I. und das Jahr 1666 zurück: Matrikel der Ungarischen Nation (Liber Natio Hungaricae I628-1772, Kodex NH 2 fol. 6a. In erzherzoglichem Rang trug sich vor ihm bereits Ferdinand IV. ins Matrikelbuch der Österreichischen Nation ein. Kodex NA 2 fol. 4.

5 Natter, Icones Rectorum (zit. Anm. 3), zur Rektorengalerie S. I2-2I, 79-82, IO2-IIO, 240-242.

6 Die Matrikel der Universität Wien, VI, (I689-1715) (hrsg. von K. MüHlberger), Wien 1993 und Die Matrikel der Universität Wien, VII, (I7I5/I6-I745/46) (hrsg. von K. MüHLbERGER), Wien 2OII; K. MüHlberger, Promotion und Adelsverleihung im frühneuzeitlichen Österreich. Zur Nobilitierungspraxis der Wiener Philosophischen Fakultät im I7. und I8. Jahrhundert, in: Examen, Titel, Promotionen. Akademisches und staatliches Qualifikationswesen vom I3. zum 2I. Jh. (hrsg. von R. C. Schwinges), Basel 2007, S. 575-624.

7 Natter, Icones Rectorum (zit. Anm. 3), S. 8o vermutet die Künstler aus dem Kreis der an der Universität immatrikulierten „cives academici“, wird aber nicht fündig. 


\section{DER WANDEL DES REKTORENAMTES: VOM „PRIMUS INTER PARES“ ZUM „PRINCEPS ACADEMIAE“}

Seit dem beginnenden I3. Jahrhundert ist zu beobachten, wie sich die Gruppe der Universitätsangehörigen neben Adel und Kirche gleichrangig und ebenso überregional zu positionieren weiß. ${ }^{8}$ Nicht Geblütsrecht oder Weihe, sondern Eid und Leistung zählen zu den legitimierenden Voraussetzungen. Das steigende soziale Ansehen findet schließlich Ausdruck in einer eigenen materiellen Kultur und besonderen symbolischen Kommunikationsformen wie den Insignienverleihungen. ${ }^{9}$ Politisches Haupt dieser Gruppe ist der Rektor. Meist nicht länger als ein Semester übt er nach innen wie nach außen die Jurisdiktion über die „universitas“ aus. Graduierungen bedeuteten einen unverlierbaren sozialen Rang. Den Doktorhut etwa reiht Marian Füssel unter die Symbole von überzeitlicher Dauer. ${ }^{10} \mathrm{An}$ ders das Rektorenamt: Diese „Verfassungsfigur ersten Ranges "II bildete sich zwar als institutionelle Spitze im Ritual $a b,{ }^{12}$ doch die Kurzfristigkeit einer Amtsperiode und die Verpflichtung auf das genossenschaftliche Ethos eines „primus inter pares" hemmten zunächst die Ausbildung eines eigenen Standesbewusstseins, das bildwürdig hätte werden können. Zudem ließ die niedrige Vergütung bei gleichzeitig hoher Arbeitsbelastung diese Position wenig attraktiv erscheinen. ${ }^{13}$ Unter wachsendem Einfluss der Obrigkeiten entwickelte sich jedoch im 15 . Jahrhundert aus dem ehedem gleichberechtigten Führungsorgan ein Herrschaftsorgan über die Universität. Führungslegitimation schöpfte der hohe Amtsträger nun aus sozialen Qualitäten, aus seinen Netzwerken und seinem repräsentativen Auftreten. An einigen Universitäten etablierten sich sogar Adels- und Ehrenrektorate, die bisweilen von Fürstensöhnen übernommen wurden. ${ }^{14}$ Zentrales Herrschaftszeichen wurde das Zepter, daneben erhielten Siegel, Matrikelbuch und Statuten eine wichtige Bedeutung. Angesichts der regional unterschiedlichen sozialen Räume und Herrschaftsstrukturen, mit denen sich die Universitäten im Zuge wachsender Institutionalisierung verbanden, ist die Frage nach Selbstbewusstsein und Selbstdarstellung eines Rektors individuell und lokal zu stellen.

8 L. Bовнм, Libertas Scholastica und Negotium Scholare. Entstehung und Sozialprestige des akademischen Standes im Mittelalter, in: Universität und Gelehrtenstand I400-I80o, Büdiger Vorträge I966 (hrsg. von: H. RösskeR und G. FranZ ), Limburg 1970, S. I5-6I.

9 Ebenda, S. 48. Zu dem Thema der Gelehrtenkultur liegen rezente Beiträge vor, etwa: A. von Huelsen-Esch, Gelehrte im Bild. Repräsentation, Darstellung und Wahrnehmung einer sozialen Gruppe im Mittelalter, Göttingen 2006, oder M. Füssel, Akademische Rituale. Deposition, Promotion und Rektorwahl an der vormodernen Universität, in: Spektakel der Macht. Rituale im Alten Europa 80o-I8oo (hrsg. von B. STollberg-Rilinger et al.), Darmstadt 2008, S. 39-43.

IO M. FüsSEL, Ritus Promotionis. Zeremoniell und Ritual akademischer Graduierungen in der frühen Neuzeit, in: Examen, Titel, Promotionen. Akademisches und staatliches Qualifikationswesen vom I3. bis zum 2I. Jahrhundert (hrsg. von C. Schwinges), Basel 2007, S. 4II-450, hier S. 437.

II C. Schwinges, Rektorwahlen. Ein Beitrag zur Verfassungs-, Sozial- und Universitätsgeschichte des alten Reiches im I5. Jahrhundert, Sigmaringen 1992, hier S. 9.

I2 R. KInK, Geschichte der kaiserlichen Universität zu Wien, 2 Bde., Wien I854. Hier Bd. 2, Nr. I2, Statuten der Universität im Ganzen aus dem Jahr 1385, S. 82.

I3 Füssel, Akademische Rituale (zit. Anm. 9), S. 42.

I4 Schwinges, Rektorwahlen (zit. Anm. iI), S. I3 


\section{VOM KAISER GEKÜSST: „REKTORSEIN“ IN WIEN ${ }^{\text {IS }}$}

"Nahent pey unserm herczoglichen palas ${ }^{\text {"I6 }}$ so formuliert Rudolf IV. im deutschen Stiftungsbrief vom I2. März 1365 den Wunschort für seine Stiftung. Die Identifikation der Dynastie mit ihrer Gründung blieb bestehen und als die Habsburger den Kaiserthron besteigen konnten, sollte sich dies auch nobilitierend auf das Prestigeobjekt ihrer Vorfahren auswirken: Signifikanten Ausdruck fand diese Entwicklung nicht zuletzt I558, als anlässlich der Krönung Kaiser Ferdinand I. ein Rektorenzepter angeschafft wurde. Die Spitze zierte die Kaiserkrone und bald schmückten auch sechs Porträts des Kaiserhauses die Aula der Universität. ${ }^{17}$ Mehr noch: In der ersten Geschichte der Wiener Universität (1559) wird Kaiser Friedrich II. als großes Vorbild eines Universitätsstifters gepriesen. ${ }^{18}$ Die von einem Herzog gestiftete Universität war nun kaiserlich geworden. Steigende Besucherzahlen mit einem wachsenden Anteil aus dem Reich waren die Folge. Trotz Hofnähe finden sich erstaunlich wenige Adelige unter den Inskribenten. ${ }^{19}$ Nicht Wien, sondern Ingolstadt oder Dillingen blieben die wichtigsten Universitäten für die katholische Nobilität der habsburgischen Territorien. ${ }^{20}$

Macht und Ansehen des Rektorenamtes wuchsen parallel zur Integration des Jesuitenordens. Um die Bildungssituation zu stabilisieren und im Sinne des Hofes zu konfessionalisieren, hatte Ferdinand I. schon verhältnismäßig früh (I55I) den Orden in Wien angesiedelt. ${ }^{21}$ Auf kaiserliches Geheiß wurde das Kolleg I623 der Universität inkorporiert. ${ }^{22}$ Wenige Jahre später wurden die Amtszeiten von Rektor und Fakultätsdekanen auf ein ganzes Jahr verlängert. ${ }^{23}$ Schließlich wurde seit dem ausgehenden 17. Jahrhundert üblich, was an anderen Universitätsorten schon lange gang und gä-

I5 Kaiser Karl VI. begrüßt bei seinem ersten öffentlichen Auftritt Rektor von Schlittern mit Handkuss. Siehe Theatrum Europaei I9ter Theil. Ausführlich fortgeführte Friedens- und Kriegs-Beschreibung, ... Frankfurt I723, S. I57/I58, I7I2.

I6 Universität Wien Stiftungsbrief 1365 (Ausgabe Csendes): Transkription Speer 20I4, Abschnitt [I.] http://repertorium.at/qu/1365_wienuniversitaet.html, Abruf I2.05.20I5. Bekanntlich ist diese örtliche Zuweisung Wunschdenken geblieben.

I7 J. Amann-Bubenik, Merkur besucht die Universität Wien. Zur Dichterkrönung des Petrus Paganus in: , Neulatein an der Universität Wien (hrsg. von C. Gastgeber und E. Klecker), Wien 2008, S. I43-I75, insb. S. I48-I49 und 173: In der 1560 gehaltenen Rede des Petrus Paganus werden sechs in der Universitätsaula hängende Porträts erwähnt: Friedrich III., Maximilian I., Karl V., Ferdinand I., Maximilian II und in einem Doppelporträt dessen Brüder Ferdinand und Karl.

I8 Catalogus rectorum et illustrium virorum archigymnasii Viennensis, Wien I559, S. I7

I9 A. Kohler, Bildung und Konfession. Zum Studium der habsburgischen Studenten an Hochschulen aus dem Reich 1560-1620, in: Bildung, Politik und Geschichte. Studien zur Geschichte des europäischen Bildungswesens vom I6. bis zum 20. Jahrhundert. (Wiener Beiträge zur Geschichte der Neuzeit, Bd. 5) (hrsg. von G. KLIngenstein / H. Lutz / G. STOurZH), S. 64-I23, hier S. 94.

20 M. Rosa di Simone, Die Zulassung zur Universität, in: Von der Reformation bis zur französischen Revolution (hrsg. von W. RuegG), S. 235-262, hier: S. 255. Der Anteil der adeligen Studenten nimmt erst später zu, bleibt aber in Wien eher gering: Mühlberger, Matrikelbuch Bd. VI, (zit. Anm. 6) S. XIII und Bd. VII S. XV, verzeichnet für den Zeitraum zwischen 1689/99 und I715/16 einen - bereits gestiegenen - Anteil von 21\%, für den Zeitraum zwischen $1715 / 16$ und 1745/46 einen Anteil von 26,5\% adliger Universitätsbesucher.

2I H. Karner/W. Telesko, Die Jesuiten in Wien. Zur Kunst- und Kulturgeschichte der österreichischen Ordensprovinz der Gesellschaft Jesu im 17. und I8. Jahrhundert, Wien 2003.

22 J. WRBA, Der Orden der Gesellschaft Jesu im alten Universitätsviertel von Wien, in: Das alte Universitätsviertel in Wien I385-1985 (hrsg. von K. Mühlberger/G. Hamann/F. Scacel), Wien I985, S. 55 ff.

23 Kink, Geschichte der kaiserlichen Universität (zit. Anm. I2), Bd. II, S. 467-468. 


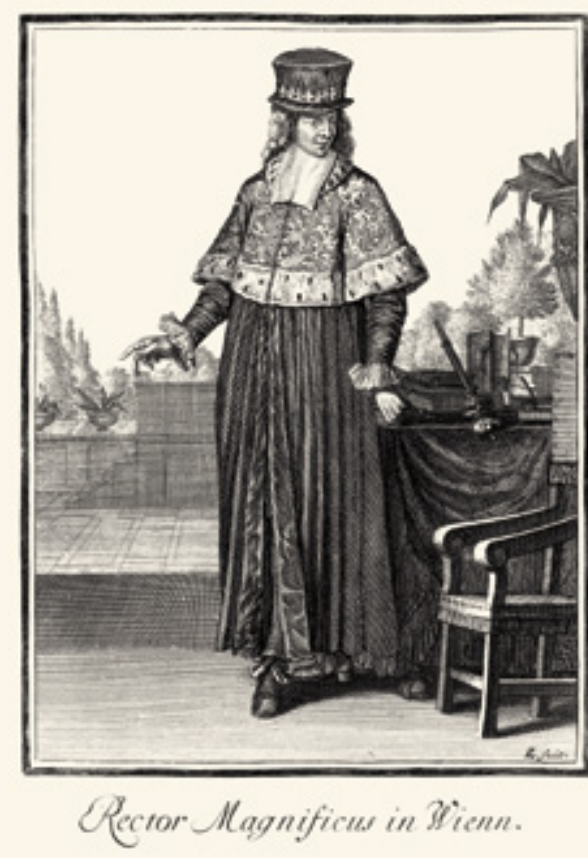

Abb. I: Johann Christoph Weigel "Rector Magnificus in Wienn", Kupferstich aus: Abraham a Sancta Clara, Neueröffnete Welt-Galleria: worinnen sehr curios und begnügt unter die Augen kommen allerley Aufzüg und Kleidungen unterschiedlicher Stände und Nationen: Forderist aber ist darinnen in Kupffer entworfen Die Kayserl. Hoffstatt in Wienn, Nürnberg I703. be war: ${ }^{24} \mathrm{Zu}$ Beginn einer neuen Amtsperiode finden sich in der Wiener Matrikelführung des Rektorates besonders gestaltete Schmuckblätter. ${ }^{25}$ Aufschlussreich ist, dass in dieser Bildpropaganda Zepter zu „arma pacis“ umgedeutet werden. ${ }^{26}$ Den Künsten des Friedens wurde in der konfliktträchtigen Zeit des beginnenden I8. Jahrhunderts in Wien höchste Bedeutung beigemessen und es scheint, dass hier die Vertreter der Universität in eine neue Rolle hineinwuchsen: Insbesondere 17II-I7I2, in der kritischen Interimszeit zwischen dem plötzlichen Tod Josephs I. und dem Regierungsantritt Karls VI., spielten Universitätsrektoren, wie die porträtierten Paul Christoph von Schlittern (Abb. 5b) oder Georg Friedrich Schickh (Abb. 7a), als Konsulenten bei Hof und Regierung eine wichtige Rolle. Auch in den Staats- und Standeskalendern wird das Konsistorium der Universität seit 1702 im Anschluss an den Stadtrat aufgeführt ${ }^{27}$ und selbst nach ihrer Amtsperiode verloren die einstigen Rektoren ihr Ansehen als politische Berater nicht. ${ }^{28}$

Dass der Wiener Rektor tatsächlich als eine eigene Klasse gesehen wurde, bestätigt die 1703 erschienene illustrierte Ständelehre des Abraham a Sancta Clara. ${ }^{29}$ (Abb. I) Elegant gekleidet mit Doktorhut, Epomis, und Talar lässt er dort Bü-

24 Beispielsweise in Basel oder in Erfurt.

25 E. Klecker, Universität und Hofbibliothek unter Karl VI, in: biblos 2OI4, 2, S. 8; Mühlberger, Matrikel Bd. VI (zit. Anm. 6), S. X; MüHlberger, Matrikel, Bd. VII (zit. Anm. 6), S. XI-XIII. Prominentes Beispiel für außergewöhnlich reich illuminierte seitenfüllende Rektorenblätter sind die Rektoratsmatrikel in Basel, die ab I46o geführt wurden: http://www.e-codices.unifr.ch/de/description/ubb/AN-II-ooo3/, abgerufen am I8. Juli 2015.

26 Matrikelblatt zum Rektorat des Jakob Ignaz von Focky I720/I72I, UAW M9 fol. 69a.

27300 Jahre Karl VI. I7II-I740. Spuren des letzten Habsburgers, Begleitbuch zur gleichnamigen Ausstellung im Österreichischen Staatsarchiv (hrsg. von S. Seitschek/H. Hutterer/G. Theiner), Wien 20II, S. 93. Das Publikationsorgan eines Hof- und Staatskalenders erscheint in Wien ab 1702. Die „Wiennerische Universität“ wird dort auf S. 3 im Anschluss an die Stadträte angeführt und nimmt im ersten Erscheinungsjahr I3 Seiten ein.

28 Der Rektor des Studienjahres 1708, Anton Josef von Öttl (Abb. 3d), ist beispielsweise in den Handelsvertrag von Passarowitz involviert, der zwischen Karl VI. und Sultan Ahmed Han geschlossen wurde. Vgl. dazu OeStA/AVA FA Paar Akten 55.55 vom II. 8. I7I8 und den publizierten Handels- und Schifffahrtsvertrag zwischen Carolus VI. und Sultan Ahmed Han, Wien (Schönwetter) I718.

29 Abraham a Sancta Clara, Neu-eröffnete Welt-Galleria: worinnen sehr curios und begnügt unter die Augen kommen allerley Aufzüg und Kleidungen unterschiedlicher Stände und Nationen: Forderist aber ist darinnen in Kupffer entworfen Die Kayserl. Hoffstatt in Wien. Nürnberg 1703, Stiche von Johann Christoph Weigel. 


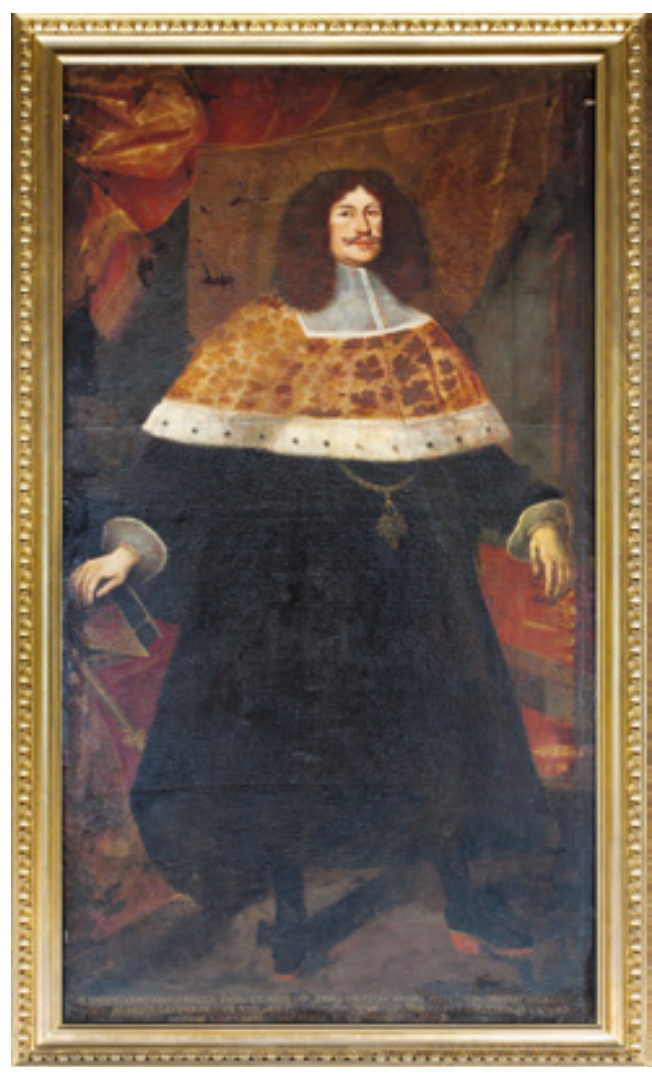

Abb. 2a: Benjamin von Block ?, Christian Rechperger, († I676), Rektor I672, aus älterem Adel. Doktor der Philosophie und der Medizin, Kaiserlicher Rat und Leibarzt, Öl auf Leinwand, $260 \times 13 \mathrm{~cm}$, Universität Wien, Hauptgebäude, Senatssaal.

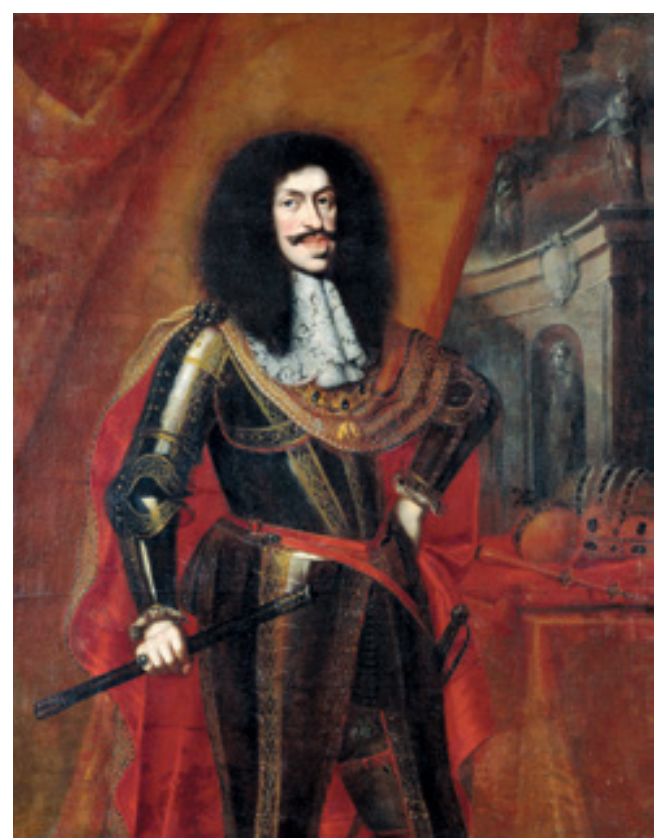

Abb. 2b: Benjamin von Block, Kaiser Leopold, um I672, Kunsthistorisches Museum, Inv. Nr. GG 6745 .

cher und Zepter hinter sich. Auf der Terrasse eines Palastes im Freien stehend, weist er auf die Welt als Ort seines Wirkens. Die Führungsspitze der Wiener Universität behielt Autonomie als ein eigener politisch-elitärer Zirkel und auch die Tatsache, dass nicht alle Rektoren aus ansässigen Familien stammten, war ein Garant der Unabhängigkeit. ${ }^{30}$

\section{BILDER DER MAGNIFIZENZ：DIE REKTORENPORTR ÄTS ALS}

\section{S T A T US I N S Z E N I E R U N G}

Spannungen lagen in der Luft, wenn eine solchermaßen gestärkte Universitätsleitung auf das jesuitische Lehrpersonal traf. Denn der Orden hatte neben dem Kolleg die Leitung der Artistenfakultät übernommen. Die Lehrkanzel war teuer bezahlt: Im Gegenzug hatten die Mitglieder der Societas Jesu nämlich auf das Rektorenamt verzichtet. ${ }^{3 \mathrm{I}}$ Und obwohl nun auf ihren Schultern der Hauptanteil des Studienbetriebes lastete, ${ }^{32}$ erhielten sie innerhalb der universitä-

30 Sehr dominant tritt das beispielsweise in der Bildlegende des Porträts Rektor Blümers entgegen: „heinricus Angelis nobilis de Blümer westphalus phliae et medicinae [...].“

3I Natter, Icones Rectorum (zit. Anm. 3), 9.

32 Mühlberger, Matrikel VII (zit. Anm. 6), S. I5. 
ren Hierarchie wenig Ansehen und nur bedingt Mitspracherechte. Juristen und Mediziner rückten in Wien sogar mehr und mehr von der Forderung eines vorausgehenden unter jesuitischer Aufsicht absolvierten Magisteriums artium ab. ${ }^{33}$ Andererseits darf nicht übersehen werden, dass sowohl Jesuiten wie auch das Universitätskonsistorium gleichermaßen vom Kaiser protegiert wurden. Dass eine solche Situation Konkurrenz und Profilierungsnöte, vielleicht aber auch Innovationsschübe entfachen würde, war zu erwarten.

Einen immer wieder keimenden Konflikt boten die Nobilitierungsverfahren: Seitdem Bildungs- und damit Elitenförderung für den Herrscher an Attraktivität gewonnen hatte, war es durchaus üblich, Adelsprädikate auch an herausragende Gelehrte zu verleihen. ${ }^{34}$ Doktoren der Medizin wie der Jurisprudenz wurden sogar mit der Polizeiordnung von I67I der städtischen Nobilität gleichgestellt. ${ }^{35}$ Vor dem Hintergrund einer Pädagogik, die ohnehin auf Wettbewerb und Belohnungssystem ausgelegt war ${ }^{36}$, bemühte sich auch der Jesuitenorden Adelsprivilegien zu verleihen und konnte - sicherlich nicht ohne Rückendeckung des Kaisers - Erstaunliches durchsetzen. ${ }^{37}$

Es ist sicherlich kein Zufall, dass die Rektorenporträts, die die hohe Abkunft ihrer Amtsträger so bedeutsam ins Bild setzen, in diesem Klima entstanden sind. Schon der „Prototyp“ des ersten Bildnisses, das Porträt des kaiserli- chen Leibarztes und wichtigen Beraters Rechperger, gilt einem gebürtigen Adeligen. Vor ihrer Universitätslaufbahn sind noch sechs weitere der dargestellten Rektoren dem Adelsstand zuzurechnen. Manche der Bildnisse sind sicherlich als Zeugnisse weiterer Standeserhebungen zu lesen: Neun der sechzehn Porträts erwähnen in der Inschrift den nobilitierenden Doktortitel und fünf davon präsentieren zusätzlich ein Adelswappen, darunter ein Domherr, zwei Ordensführer und die beiden in den Ritterstand aufgestiegenen Rektoren Blümer (Abb. 5a) und Schlittern (Abb. 5b). Insgesamt lassen sich neun Standeserhebungen oder Wappenbesserungen nachweisen..$^{38}$ Nicht verwunderlich scheint vor diesem Hintergrund, dass die Bildlegende unter dem Porträt des Rektors Paul von Schlittern auch den ehrenvollen Empfang des neu gekrönten Kaisers 1712 mitteilt. ${ }^{39}$

Die meisten der Porträts der höher nobilitierten Rektoren fallen in die beginnende Regierungszeit Karls VI. Mag sein, dass das Rektorat zunehmend den Charakter einer sozialen Aufstiegschance und Karriereleiter in Ämter des Hofes gewonnen hat. Was die Bilder allerdings nicht zeigen, sind Rektoren in ihrer Tätigkeit als Forscher, Lehrer, Wissenschaftler. Das fällt umso mehr auf, als sich der mehrmalige Rektor und Abt Gottfried Bessel in seinem Rektorenporträt außerhalb der Universität mit Globus und Büchern darstellen ließ (Abb. $4^{\mathrm{b}}$ ). ${ }^{40} \mathrm{Im}$

33 Mühlberger, Promotion und Adelsverleihung (zit. Anm. 6), S. 583.

34 M. Füssel, Ritus promotionis (zit. Anm. IO), S. 4I5. Die Verleihung akademischer Grade zählte zu den kaiserlichen Reservatrechten. Vgl. auch 300 Jahre Karl VI. I7II-I740. Spuren des letzten Habsburgers, Begleitbuch zur gleichnamigen Ausstellung im Österreichischen Staatsarchiv (hrsg. von S. SeitscheK/H. Hutterer/G. Theiner), Wien 2OII, S. 72. UAW/CA r.o.I59 Recht der Universität auf Adelsverleihungen. Erwähnt wird darin, dass die Doktoren der Medizin und der Jurisprudenz in der Polizeiordnung Leopolds I. der städtischen Nobilität gleichgestellt werden.

36 Mühlberger, Promotion und Adelsverleihung (zit. Anm. 6), S. 607.

37 Ebenda, Anhang II, S. 6I6-622.

38 Vgl. K. F. von Frank, Standeserhebungen und Gnadenakte für das deutsche Reich und die Österreichischen Erblande, Bd. I-5, Schloss Senftenegg 1967-I974.

$39 \ldots$ anno I7I2 rect. magnif. neo-coronatum ... imp. Carolum VI. viennae reducem excepit." Vgl. Anm. I5.

40 Stift Göttweig, Inv.-Nr. 53: Das Gemälde (Öl/Lwd., 240 x I62 cm) ist datiert und signiert: Roman Helmshoysen I7I6, und hängt heute über der Kaiserstiege, vgl. Abb. 4b. 


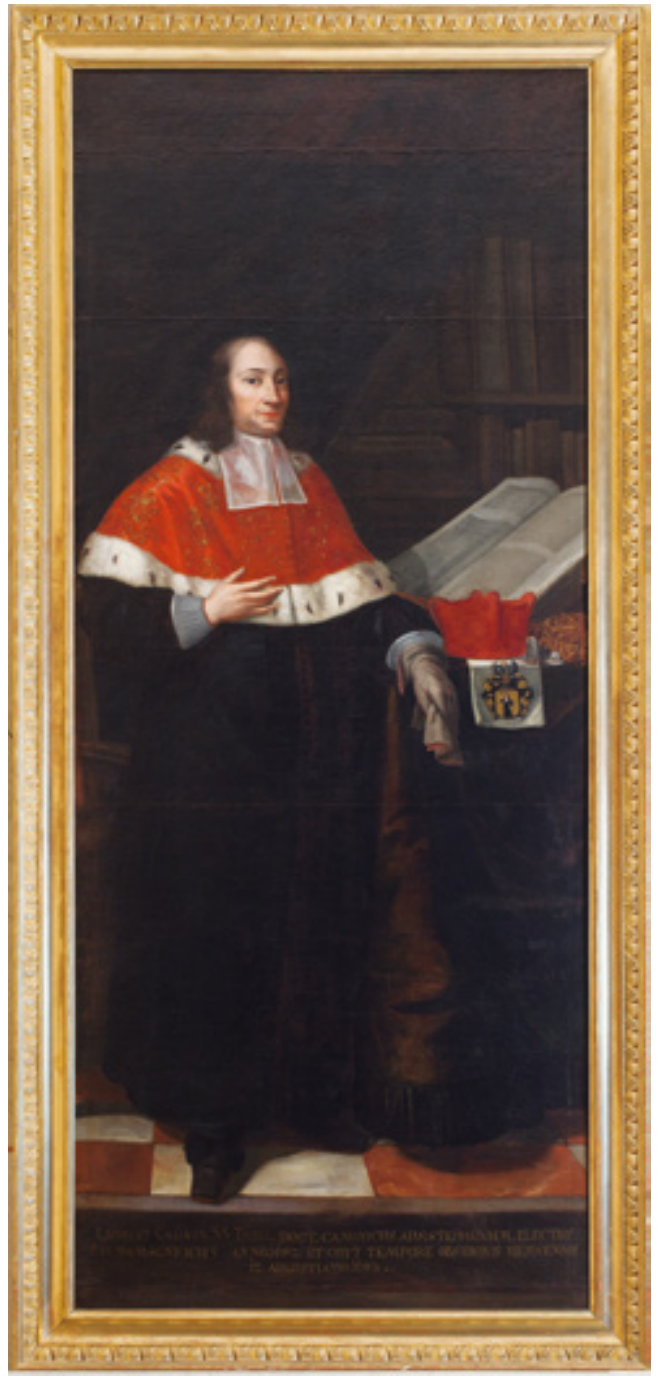

Abb. 3a: Unbekannt, Laurentius Grüner, (I641?-1883), Rektor I682, aus älterem Adel, Doktor der Theologie, Domherr zu St. Stephan und Obrist des Aufgebotes der Universität gegen die Türkenbelagerung I683, Öl auf Leinwand, $264 \times 109 \mathrm{~cm}$, Universität Wien, Schausaal des Archivs der Universität in der Postgasse.

Raum der Universität blieb die Identifikation mit der Wissenschaft jedoch den Jesuiten vorbehalten. Vermutlich liegt in diesem Vorurteil das Ausbleiben von Porträts der Artistenrektoren begründet. Dieser Ausschluss bleibt insofern bemerkenswert, als nicht jesuitische Artisten die im Gegensatz zu den Jesuiten durchaus den

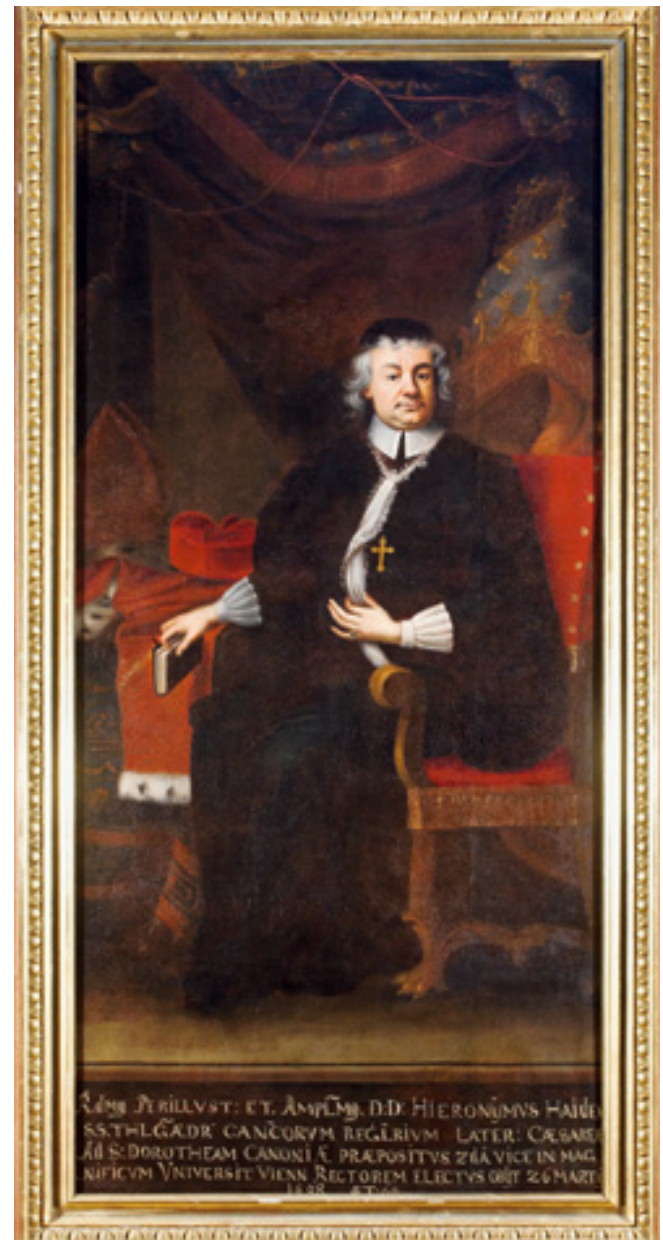

Abb. 3b: Unbekannt, Hieronymus Hayden, († I698), Rektor I674 und I694, aus altem Adel, Doktor der Theologie, Kaiserlicher Rat, Propst des Augustiner Chorherrenstifts St. Dorothea in Wien, Öl aufLeinwand, $258 \times 118 \mathrm{~cm}$, Universität Wien, Hauptgebäude, Festsaal.

Posten eines Rektors bekleiden konnten - über die Zeitspanne von 17 Amtsperioden den größten Anteil der Rektorate übernommen haben. Es spricht deshalb einiges dafür, dass die Rektorenporträts in Wien eine bewusste Abgrenzung zu einer besonders starken, jesuitisch geführten Artistenfakultät intendieren. 


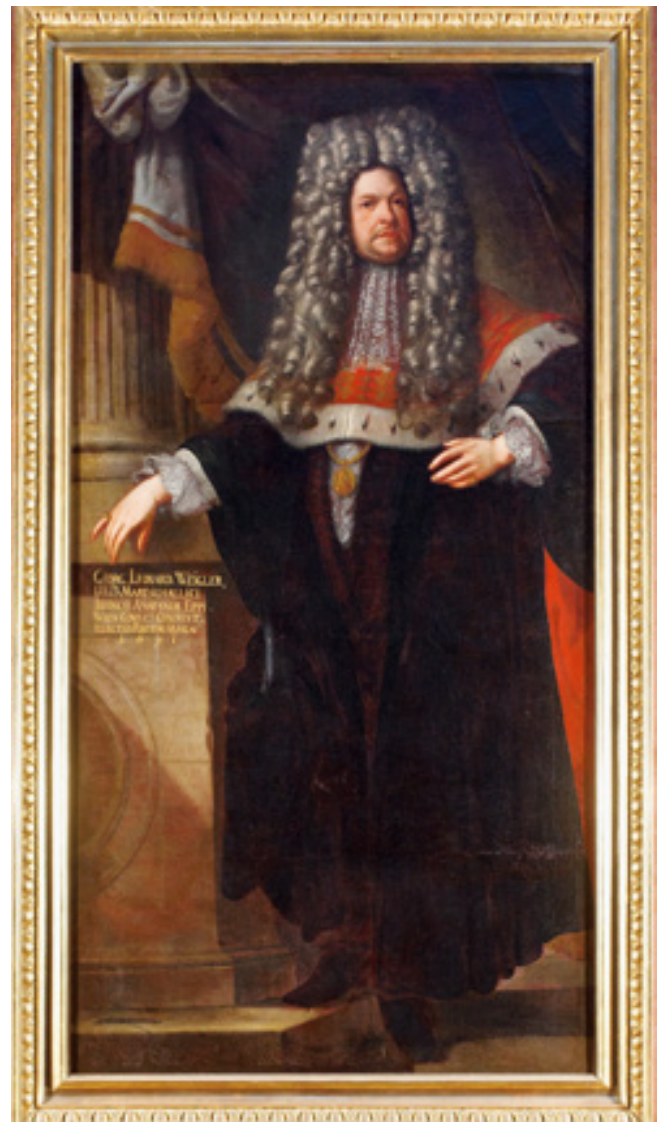

Abb. 3c: Unbekannt, Georg Leopold Weigler, († I716), Rektor 1691, Erhebung in den Freiherrenstand 1702, Doktor beider Rechte, Marschall und Assessor beim Bischöflichen Gericht, kaiserlicher Hofkriegsrat und ungarischer Hofrat, Öl auf Leinwand, $222 \times 114,5 \mathrm{~cm}$, Universität Wien, Hauptgebäude, Festsaal.

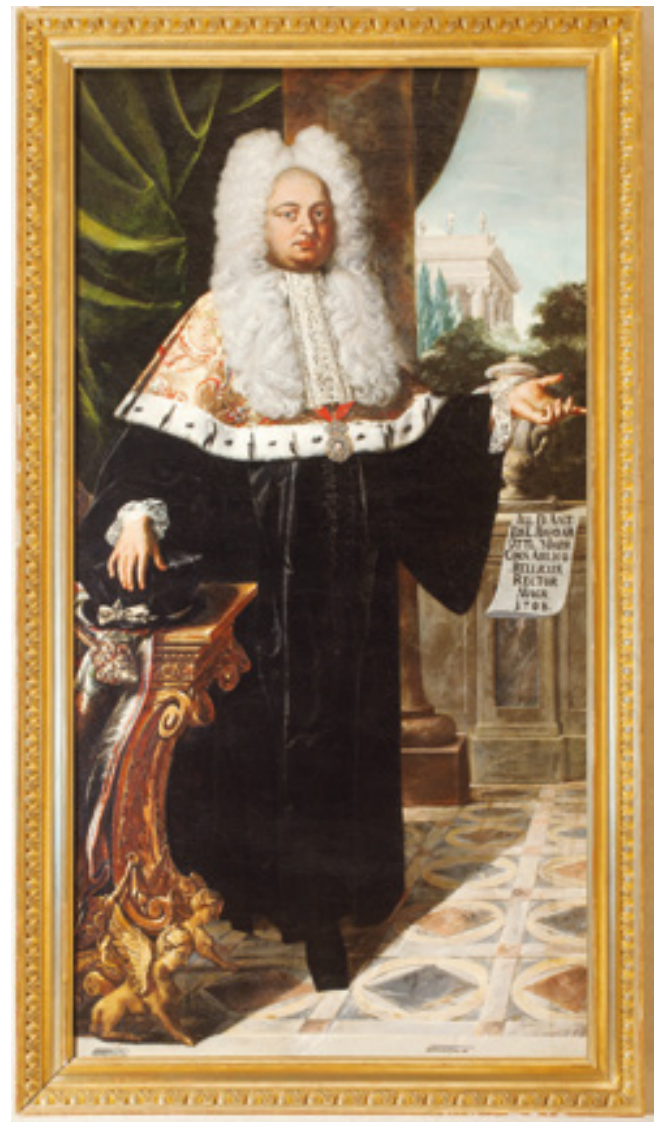

Abb. 3d: Unbekannt, Joseph Anton von Öttl, († I735) Rektor 1707, aus älterem Adel, Doktor beider Rechte, kaiserlicher Hofkriegsrath und geheimer Refendarius, Öl auf Leinwand, 224 XI7,5cm, Universität Wien, Schausaal des Archivs der Universität in der Postgasse.

\section{EIN ARZT, EIN THEOLOGE UND EIN JURIST}

Nehmen wir an dieser Stelle die These auf, dass die aufstrebende Universitätselite nach Porträtmalern sucht, die über ein entsprechendes Wissen zur visuellen Distinktion verfügt. Ilsebill Barta beschreibt, wie das von jeher eng mit dem sozialen Raum des Hofes verbundene Porträt in der Residenzstadt Wien zu Beginn des I8. Jahrhunderts eine enorme Demokratisierung erfuhr. ${ }^{4 \mathrm{I}}$ Wo anders als in den großen Porträtwerkstätten im Umfeld des Hofes waren solche Kompetenzen auch für den Auftraggeber eines Rektorenbildnisses zu finden? Leider weist die Erforschung der zeitgleichen Porträtmalerei in Wien noch erhebliche Lücken auf, hat sie doch mit dem erschwerenden Umstand zu tun, dass sich die höfische Kunstszene aus einem interna-

4I I. BARTA, Familienporträts der Habsburger. Dynastische Präsentation im Zeitalter der Aufklärung, Wien 2008, insb. S. 23-3I. 


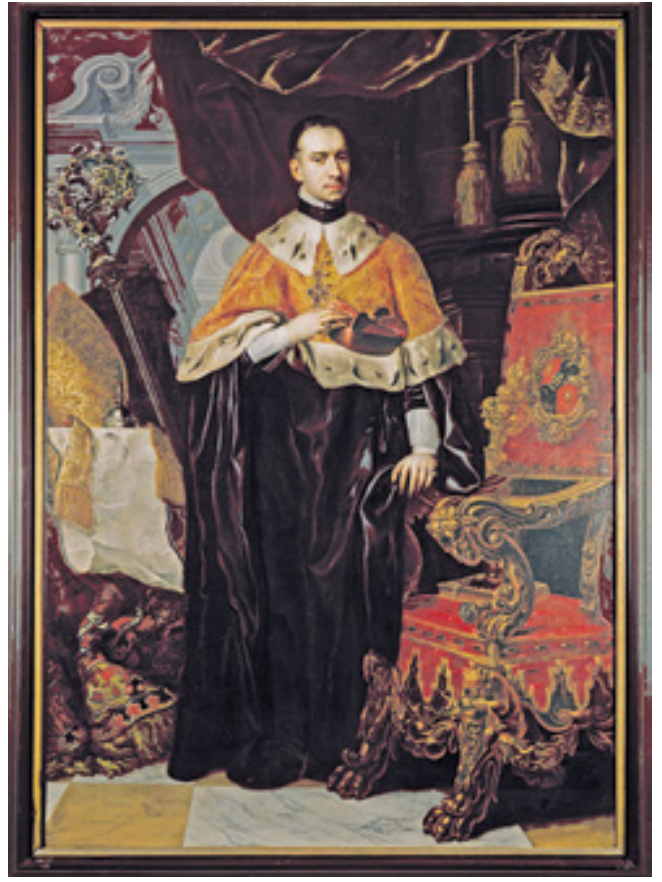

Abb. 4a: Werkstatt Johann Kupetzky, Berthold von Dietmayr, (I670-1739), Rektor 1706, aus älterem Adel, Doktor der Theologie, Abt des Benediktinerstiftes Melk, Primas der niederösterreichischen Stände, Präses des Prälatenstandes und kaiserlicher Rat, Öl auf Leinwand $256 \times$ I20 $\mathrm{cm}$, Universität Wien, Hauptgebäude, Festsal, nach I709.

tionalen Einzugsbereich rekrutierte und insbesondere Bildnisse das Ressort reisender Porträtvirtuosen war. ${ }^{42}$ Die folgenden Zuschreibungen sind deshalb nur als Richtungsweisung für weitere Forschungen zu verstehen.

Das älteste nachweisbare und zugleich größte Ganzkörperporträt (Abb. 2a) zeigt den Träger eines doppelten Doktortitels: Christian Rechperger († 1676). Sowohl im Fach der Philosophie

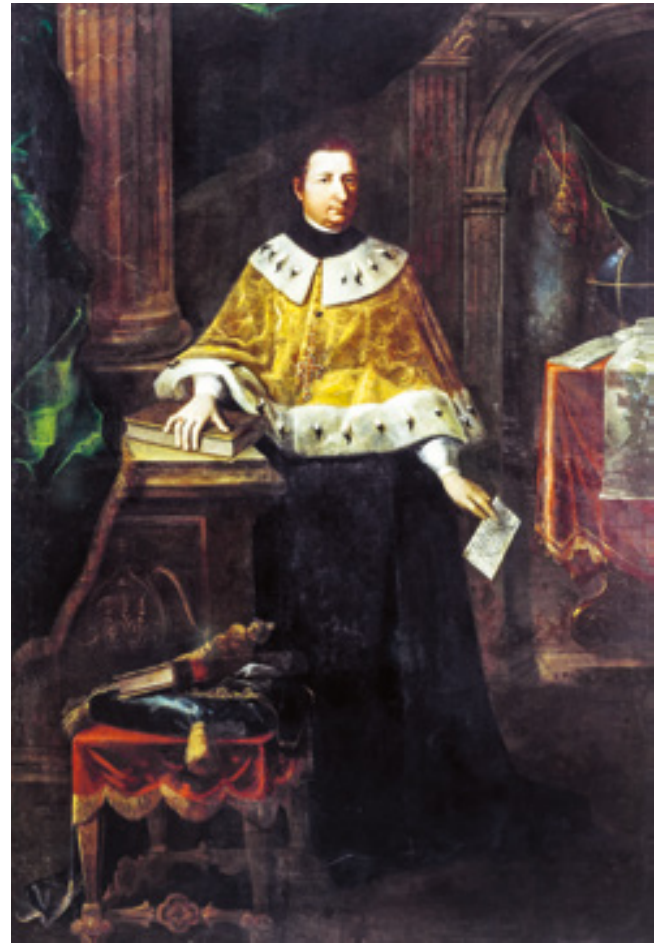

Abb. 4b: Roman Helmshoysen, Gottfried Bessel im Rektorenornat (I716), Abt in Göttweig, Nachweis vgl. Anm. 40, Stift Göttweig.

wie auch in der Medizin war er promoviert worden. Anfang des 17. Jahrhunderts geboren, war er Spross einer Hof wie Universität gleichermaßen verbundenen Adelsfamilie und nicht der letzte in der Reihe der Universitätsgelehrten mit diesem Namen. ${ }^{43}$ Seine Karriere verlief steil: Noch im Jahr seiner Promotion zum Doktor der Medizin fungierte er I640 als Prokurator der österreichischen Nation. Drei Mal wurde er zum Dekan der me-

42 Vgl. F. Polleross, „Damit mein Contrefait zur Gedachtnuss in Hauss verbleibe“. Adelsporträts des 17. und I8. Jh., in: Adel im I8. Jh. Umrisse einer sozialen Gruppe in der Krise (hrsg. von G. Ammerer/E. LobenweIn/M. SCHEUTZ), Innsbruck 20I5, S. 222-255; Aufgeklärt bürgerlich. Porträts von Gainsborough bis Waldmüller I750-1840 (hrsg. von S. Grabner/M. Krapf), München 2008; NAtTER, Icones Rectorum (zit. Anm. 3), S. 8I und BarTA, Familienporträts der Habsburger (zit. Anm. 40), S. 9 I.

43 Ein Hans Wilhelm Rechperger führte von 1592 bis 94 provisorisch die Geschäfte des Burggrafen der Hofburg. Möglicherweise ist er ident mit dem Träger desselben Namens, Wilhelm Rechperger, der als Wiener Doktor der Philosophie und Medizin, als kaiserlicher Mathematiker und als Professor an der Universität tätig war. Ebenfalls ein Wilhelm von Rechperger war als Rektor während der Verhandlungen der Sanctio pragmatica von I623 federführend. 


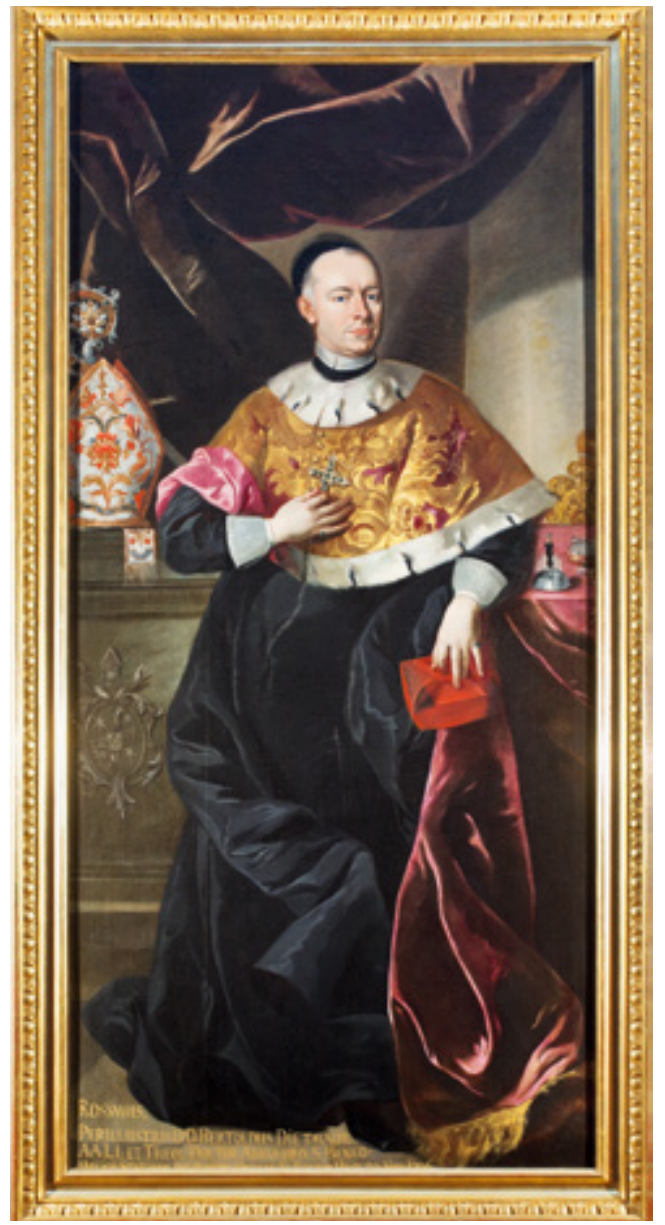

Abb. 4c: Werkstatt Johann Kupetzky, Berthold von Dietmayr, (1670-1739), Rektor 1706, aus älterem Adel, Doktor der Theologie, Abt des Benediktinerstiftes Melk, Primas der niederösterreichischen Stände, Präses des Prälatenstandes und kaiserlicher Rat, Öl auf Leinwand, 224,5 X I57 cm, Stift Melk. I709.

dizinischen Fakultät gewählt und im Studienjahr 1672/73 bekleidete er zugleich das Amt des Rektors. Daneben versah er seine Dienste als Leibarzt und enger Berater des Kaisers Leopold I. Er war verantwortlich für das Wohl von Kaiser und Staat: In Zeiten der Pest erfuhren Experten der Gesunderhaltung ein ganz besonderes Ansehen.

Auch wenn das Bildnis nicht gut erhalten ist, so lässt sich ein prachtvolles Ambiente erahnen. Ein roter Vorhang und möglicherwei-

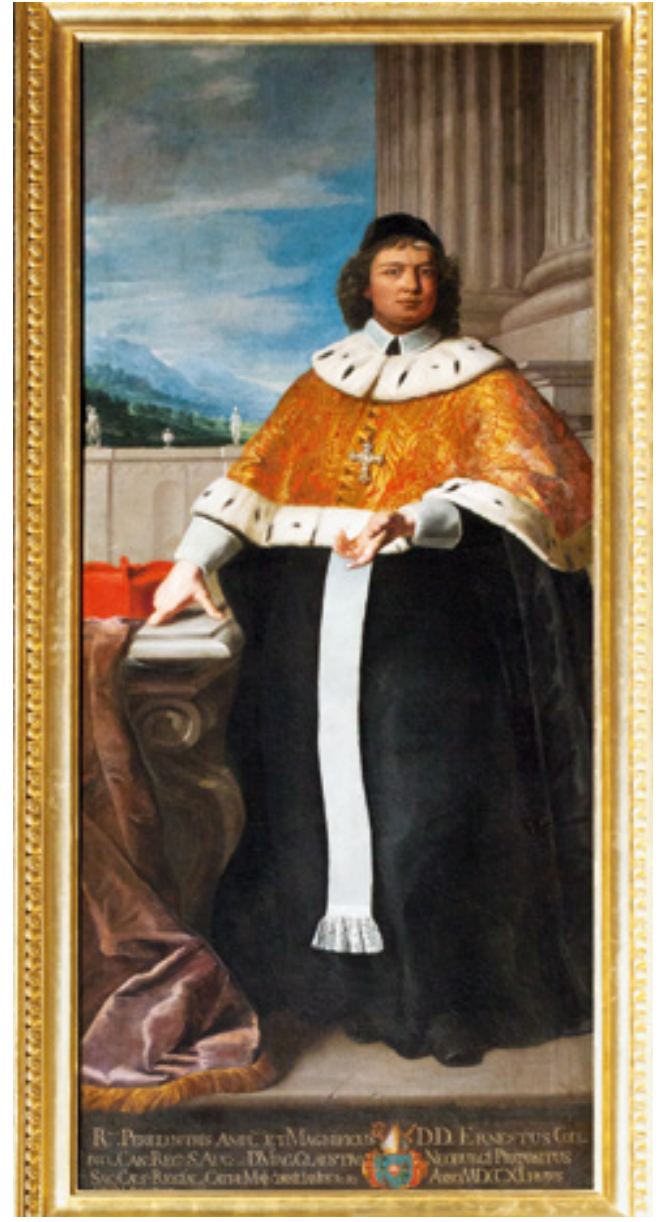

Abb. 4d: Werkstatt Johann Kupetzky ?, Ernst Perger (I6671748), Rektor 1710, aus älterem Adel, Doktor der Theologie, Propst des Augustiner Chorherrenstiftes Klosterneuburg, kaiserlicher Rat und ständiger Deputierter der niederösterreichischen Stände, Öl auf Leinwand, $256 \times 101,5 \mathrm{~cm}$, Universität Wien, Hauptgebäude, Rektorenzimmer.

se eine Standarte hinterfangen die dunkle Gestalt. Rechperger präsentiert sich breitbeinig im Talar und füllt nahezu die gesamte Bildfläche aus. Seine Schultern bedeckt die bordeauxrote Epomis des Rektors. Golden ist die Kollane, die darunter hervortritt. Ein Medaillon mit dem Profil eines Gekrönten lässt eine kaiserliche Ehrenbezeugung vermuten. Aus feinen transparenten Geweben ragen Rechpergers Antlitz und seine Hände, die dunklen Locken fallen offen 
auf die Schultern und insbesondere der sorgfältig geformte Bart lässt deutlich das Vorbild Kaiser Leopolds I. erkennen. Weiteren Hinweis auf seinen hohen Stand geben die roten Absätze seines Schuhwerks, ein Privileg des höheren Adels. Beherrschung und Gelassenheit strahlt der kaiserliche Leibarzt aus: eine Hand ruht auf einem Geschäftsbuch. Eher beiläufig - ragt daneben ein Zepter ins Bild. Angesichts der akademischen Würden Rechpergers hätte man einen Doktorhut erwarten können. Explizit formuliert jedoch nur die Bildlegende den Anlass des Gemäldes. In antiken Versalbuchstaben sind Name, akademische Grade und höfische Würden zu lesen. Erst dann folgt der Verweis auf das Rektorenamt. ${ }^{44}$ Die genaue Nennung des Wahltages steigert die Dokumentarkraft des Gemäldes und schenkt der Institution Präsenz: Es ist der 25. November, der Namenstag der Heiligen Katharina, der Patronatsheiligen der Artisten, ein bedeutender Festtag im Kalender der Wiener Universität. Ein stilistischer Vergleich mit dem um I672 entstandenen Porträt Kaiser Leopolds im Kunsthistorischen Museum (Abb. 2b) legt den Gedanken nahe, dass beide Bildnisse aus der Werkstatt desselben Malers stammen, des Kaiserlichen Kammermalers Benjamin von Block. Dieser ließ sich zwar ab 1670 in Nürnberg nieder, doch sein Bruder lebte weiterhin in Wien. Im Jahr I672, dem Rektorat Rechpergers, erhielt er den Auftrag, den Kaiser zu porträtieren. Aus einem späteren Dokument geht hervor, dass er neben den Porträts des Kaisers und der Kaiserin noch diejenigen von 560 fürstlichen Personen mit besonderer „Lebensgleiche“ hergestellt habe. ${ }^{45}$

Mehr über die Person gibt das Porträt des Melker Abtes Berthold von Dietmayr (I670-
I739) preis (Abb. 4c). Als Vorzeigeschüler von den Benediktinern an die Universität nach Wien entsandt, schloss er zügig sein Studium ab. Mit nur dreißig Jahren wurde er bereits zum Abt des Klosters Melk gewählt, ein Jahr später promovierte er. Schon während seine ganzen Anstrengungen dem Neubau von Kirche und Kloster galten, wurde er 1706 zum Rektor der Universität Wien ernannt. Gleichzeitig initiierte er in Melk eine Gelehrtenakademie und war Cancellarius sowie Superintendent des Kaisers. ${ }^{46}$ Wie Rechperger war Dietmayr von adligem Stand und wir begegnen ihm ebenfalls in einem prachtvollen Innenraum. $\mathrm{Zu}$ seiner Rechten zieht eine kostbare bestickte Infel den Blick auf sich. Darüber ist der Bogen einer Pastorale zu erkennen. Die steinerne Brüstung, auf der der geistliche Kopfschmuck ruht, ist dezent mit seinem Abtswappen reliefiert. Zu seiner Linken deuten Glocke und Uhr auf Beherrschung von Zeit und Personal hin. Im Hintergrund darüber und offensichtlich später dazu gesetzt, befinden sich die goldenen Dolden des Rektorszepters als Pendant zu den Insignien seines Kirchenamtes. Jenes besetzte er auf Lebenszeit, dieses nur für ein Jahr. Der Kampf um die rechte Balance zwischen beiden Ämtern wird noch auf der Leinwand ausgetragen.

Dietmayr trägt eine schwarze Ordenskappe und ist in einen dunklen, bodenlangen Mantel gehüllt. Golden setzt die Epomis die Rektorswürde ins Bild. Graue Schläfen und Falten an seiner Nasenwurzel geben das Bild eines aufmerkenden Denkers. Eine leichte Bewegung durchzieht seinen Körper. Der Abt fasst mit der Rechten an das Kreuz über der Brust, in der Linken hält er mit zierlicher Geste sein rotes Birett. Die Legende des Gemäldes scheint nachträglich eingefügt. ${ }^{47} \mathrm{Sie}$

44 Christianus. Rechperger phil. Et med. doctor iuratus regni Bohemiae physicus sac. -/ caes. Maistat. Leopoldi I consil. Et proto-medicus electus est in rectorem univer -/ sitatis viennensis die 25. Novemb. anno I672.

45 OeStA/AVA Adel RAA 34.47. Bestätigung und Wappenbesserung. Blocks. Vgl. auch Polleross, Adelsporträts (zit. Anm. 4I), S. 24I.

$46 \mathrm{NDB}_{3}$ (1957), S. $675 \mathrm{f}$.

47 Rdssmus, -/ perillustris d.d. Bertoldus Dietmayr. -/a.a.l.l. et theol. Doctor abbas ord. s. Bened. -/Melicij. Statuu, inf. primas el. Rector univ. 30 nov. 1706. 


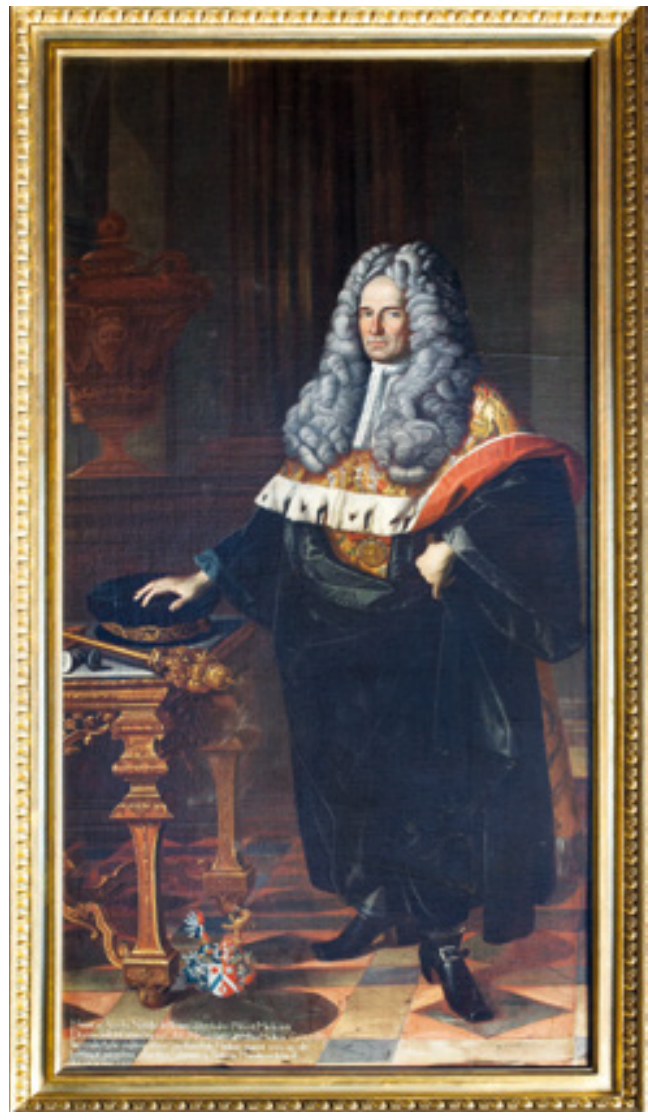

Abb. 5a: Werkstatt Johann Kupetzky?, Heinrich Angelus Blümer († 1732), Rektor 1716, Erhebung in den Ritterstand I7I5, Doktor der Philosophie und der Medizin, kaiserlicher Rat, Leibarzt und Protomedicus des Reichshofrats, Öl auf Leinwand, $260 \times 122,5 \mathrm{~cm}$, Universität Wien, Hauptgebäude, Senatssaal.

ähnelt im Aufbau jener auf dem Gemälde Rechpergers und auch hier wird am Ende das Datum der Rektorenwahl genannt. Dieses Mal fand sie am 30. November 1706 statt, dem Festtag des heiligen Andreas, Hauptheiliger des Ordens vom goldenen Vlies. Zu Beginn des Studienjahres gelegen, sollte sich dieses Datum als idealer Wahltermin bewähren..$^{4}$ Es wird auf fünf weiteren Rektorenporträts genannt.

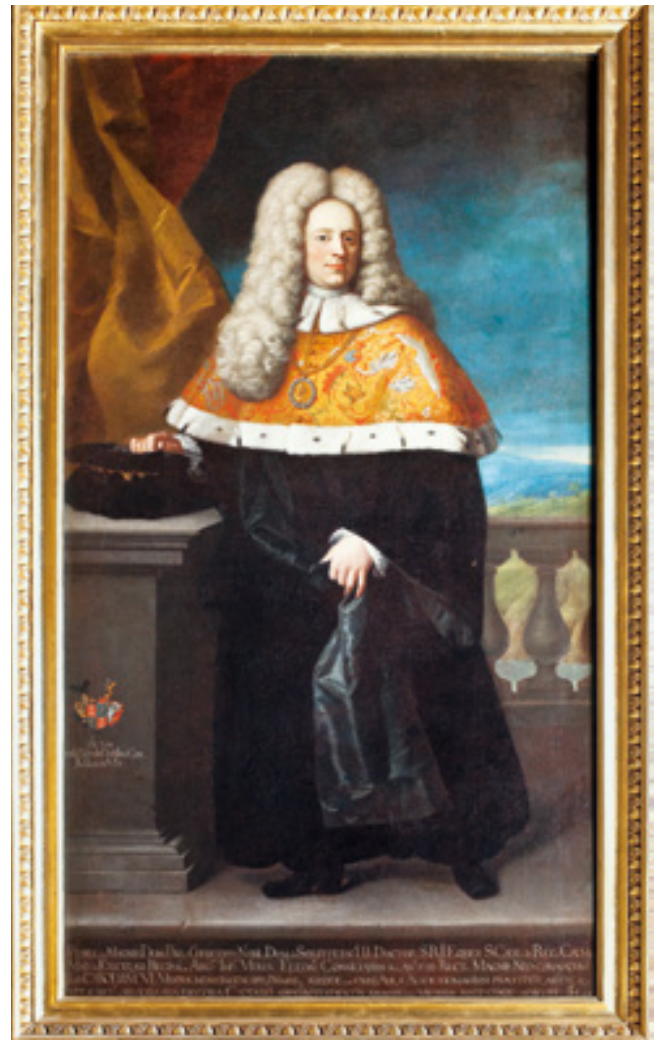

Abb. 5b: Werkstatt Johann Kupetzky?, Paul Christoph Schlittern († I7IS) Rektor I7II, Erhebung in den Ritterstand I7I2, Doktor beider Rechte, niederösterreichischer Regimentsrat, kaiserlicher Rat unter Leopold I und Hofrat seiner Witwe, Öl auf Leinwand $246 \times 125,5 \mathrm{~cm}$, Universität Wien, Hauptgebäude, Senatssaal, I720.

Im Kloster Melk befindet sich noch ein weiteres Porträt des Abtes im Rektorenornat (Abb. 4a). Für die Zuschreibung beider Porträts ist wichtig, dass in der Historiografie des Konvents der Name des böhmischen Künstlers Johann Kupetzky (I666-I740) überliefert ist. ${ }^{49}$ Umso interessanter ist der Vergleich beider Bildnisse: Schon allein vom Format ist der Anspruch des Bildnisses im Konvent ein anderer. Es weicht von

48 Mühlberger, Matrikel Bd. VI, (zit. Anm. 6), S. VII.

49 I. Keiblinger, Geschichte des Benedictiner-Stiftes Melk in Niederösterreich, seiner Besitzungen und Umgebungen, Bd. I, Wien I85I, S. 943, Anm. I. Vgl.: A. Nyari, Der Porträtmaler Johann Kupetzky. Sein Leben und seine Werke, 
dem entschiedenen Hochformat in der Universität ab, wirkt größer und scheint an diesem Ort keine Legende zu benötigen. Links gibt es den Blick auf das ehrgeizige Bauvorhaben des Abtes frei. Die Vergleichsmomente zwischen beiden Bildnissen liegen auf der Hand: Auch in Melk steht der Abt zwischen den Insignien beider Ämter. Die Körperhaltung variiert ein ähnliches Muster: So hält Dietmayr in seiner angewinkelten Rechten im Melker Bild das Birett vor Brust und Abtskreuz, mit seiner Linken stützt er sich auf die Seitenlehne des Abtstuhles. Hier liegen Geschäftsbuch und das Sapientia-Siegel der Universität. Das Abtswappen Dietmayrs ziert die Rückenlehne, daneben wird das Rektorenzepter sichtbar. Ein markanter Unterschied zwischen beiden Porträts manifestiert sich auch im Alter des Porträtierten: Das Wiener Gemälde zeigt den Abt deutlich gereift. Könnte man von einer sehr freien Werkstatt-Wiederholung aus einem Atelier in Wien sprechen, die den anderen Kontext miteinbezieht und sich in die zaghaft begonnene Reihe würdevoller Rektorenpersönlichkeiten setzt? Hier soll in erster Linie Institutionsgeschichte geschrieben werden. Das Universitätsgemälde fällt deshalb weniger repräsentativ aus, die selbstverständlichen Universitätsinsignien sind zurückhaltender gestaltet und scheinen sogar etwas unbeholfen und später eingefügt, die Infel hingegen leuchtet prachtvoll. Es ist auffällig, wie sehr die Präzision auseinanderdriftet, mit der etwa Hände und Gesicht gegeben sind oder auch den einzelnen Details von Infel, Glocke und Birett die behutsame Beschreibung eines Stilllebens gilt. ${ }^{5 \circ}$
Momente persönlichen Ehrgeizes lassen sich der Gestalt Dietmayrs nicht absprechen. Anders in dem Porträt des Juristen Georg Friedrich von Schickh († 1727). Es zählt zu den qualitätsvollsten aller Rektorenporträts in Wien (Abb. 7a). Entstanden scheint hier die Inkunabel einer neuen Gattung, das Porträt eines Staatsmannes, der - ohne Rüstung und mit Verhandlungsgeschick - die militärischen Großtaten des Feldherren ablöst. Seine Schlachten führte er am Konferenztisch. Wer war Georg Friedrich von Schickh? Was seine Laufbahn in der Universität betrifft, finden wir ihn I694 im Amt des Dekans der juridischen Fakultät, I695 bekleidete er das Amt des Rektors. I7Io wurde er nicht nur in den erblichen Ritterstand erhoben, sondern erhielt für sich und seine Familie auch das Prädikat „Edler, Freiherr von“. Interessant sind die überlieferten Argumente für seine Nobilitierung: ${ }^{\text {II }}$ Vernunft, Erfahrung, Adel, Loyalität und langjährige Treue. Die Staatskarriere wog also weit schwerer als die Universitätskarriere. Schickh hatte zunächst in verschiedenen Funktionen der Kaiserlichen und Königlichen Statthalterei von Niederösterreich gedient, dann gelang der Karriereschritt in die geheime österreichische Hofkanzlei. Zu seiner größten Leistung zählt das Engagement für die Pragmatische Sanktion von I713, denn es war Schickh, der das Gesetz zu Papier brachte, mit dem Kaiser Karl VI. die Unteilbarkeit und Untrennbarkeit aller habsburgischen Erbkönigreiche und Länder festlegte. ${ }^{52}$

Ähnlich wie Christoph Weigel den Wiener Rector Magnificus im Stich vorgestellt hat

Wien/Pest/Leipzig I889, S. II7. Nicht bei: E. A. SAFARIK, Johann Kupetzky (I666-I740). Gesamtwerk (hrsg. von Z. KazlePKa), Brno 2014.

50 Am Beispiel der Werkstatt von Meytens hat Georg Lechner jüngst beschrieben, wie sich die Zusammenarbeit in einer arbeitsteiligen Ateliersituation gestaltete: Martin Meytens, der Jüngere (hrsg. von A. Husslein-Arco/G. LeCHNER), Wien 20I4, S. I6 und 17.

5I UAW Konsistorial-Akten S IO2, Schachtel 65 (Recherchen Schrauffs).

52 http://www.verfassungen.de/at/at/-I8/pragmatischesanktionı3.htm (Zuletzt besucht: 10.05.2017). Das Protokoll über die Sitzung des geheimen Rats vom 19. April 1713 dokumentiert die Anwesenheit von Schickh in Gegenwart des Kaisers und des Prinzen Eugen. 


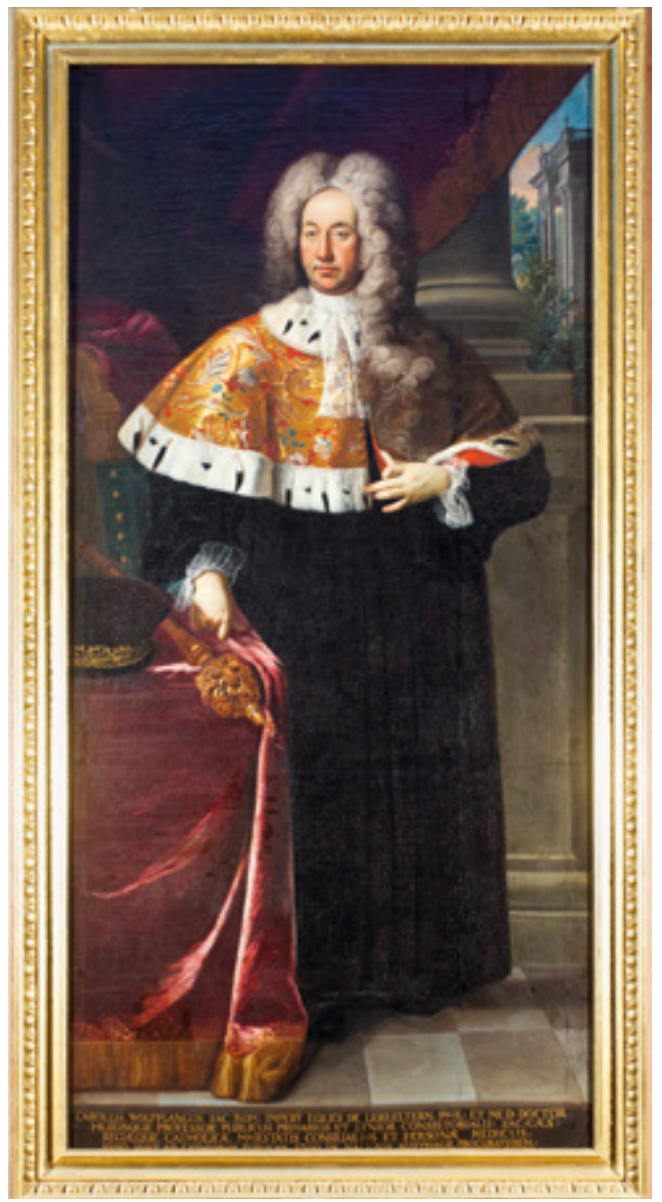

Abb. 6a: Werkstatt Johann Kupetzky?, Karl Wolfgang Lebzeltern, († 1732) Rektor 1712, Erhebung in den Ritterstand I7I8, Doktor der Philosophie und der Medizin, Kaiserlicher Leibarzt und Hofrat, Öl auf Leinwand $257 \times 122 \mathrm{~cm}$, Universität Wien, Hauptgebäude, Festsaal, nach I7I8.

(Abb. I), erscheint Schickh auf einer hoch gelegenen Palastterrasse mit Ausblick auf eine weite Landschaft. Anders als seine Kollegen tritt er dem Betrachter frontal in den Blick. Die graue, wallende Perücke eines mächtigen Hofmannes rahmt das Gesicht einer charismatischen Persönlichkeit: ernst, wissend, stolz und unberührbar ein herausforderndes Gegenüber, dem sich nicht ausweichen lässt. Die Intensität des Blickes wie

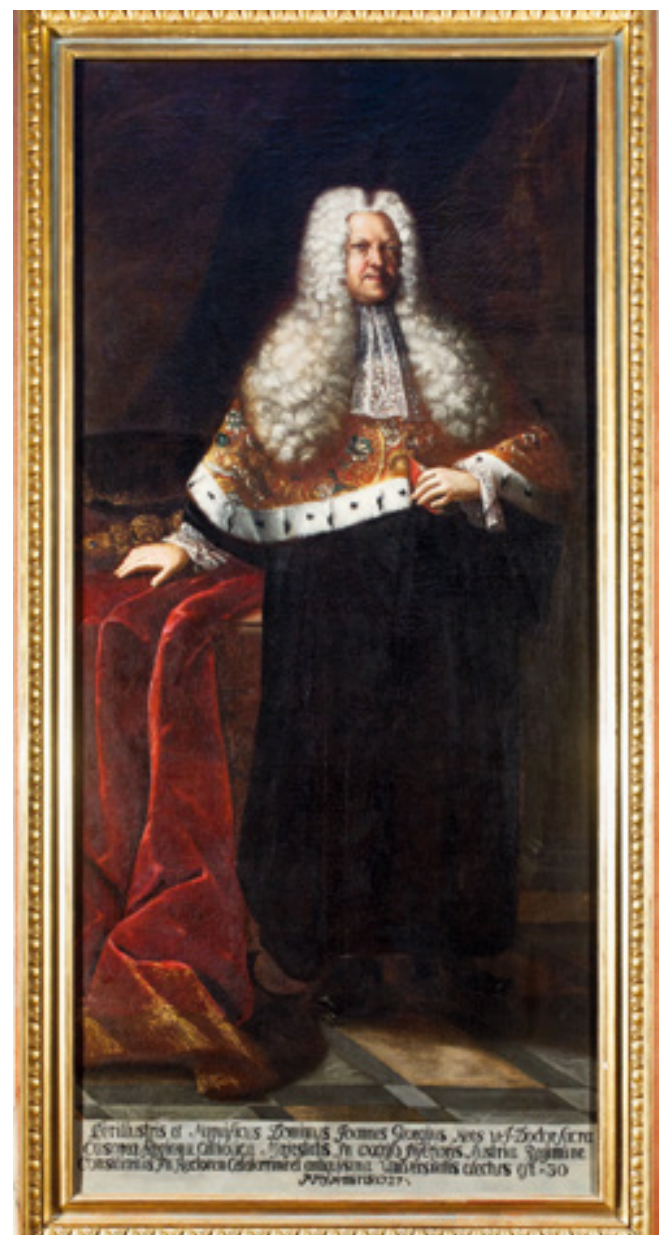

Abb. 6b: Unbekannt, Johann Georg von Kees, (1673-1754), Rektor 1727, Erhebung in den Adelsstand 1753, Doktor beider Rechte, niederösterreichischer Regierungsrat und Landschreiber, Öl auf Leinwand, $258 \times 119,5 \mathrm{~cm}$, Universität Wien, Hauptgebäude, Festsaal.

der ganze Gesichtsschnitt mit hoher Stirn, langer Nase und schmallippigem Mund, schließlich auch die Malweise erinnern an ein weiteres, Kupetzky zugeschriebenes Porträt im Belvedere, das man bisher mit Feldmarschall Guido Graf von Starhemberg in Verbindung gebracht hat (Abb. 7b). ${ }^{53}$ Nachweisen lässt sich diese Identifizierung nicht und es verwundert, dass sich der Feldmarschall auf dem Bildnis des Belvede-

53 Johann Kupetzky, Porträt eines Adligen (Guido Graf Starhemberg?), Öl/Lwd. 95, 5 x 76 cm, Belvedere, Inv.-Nr. 


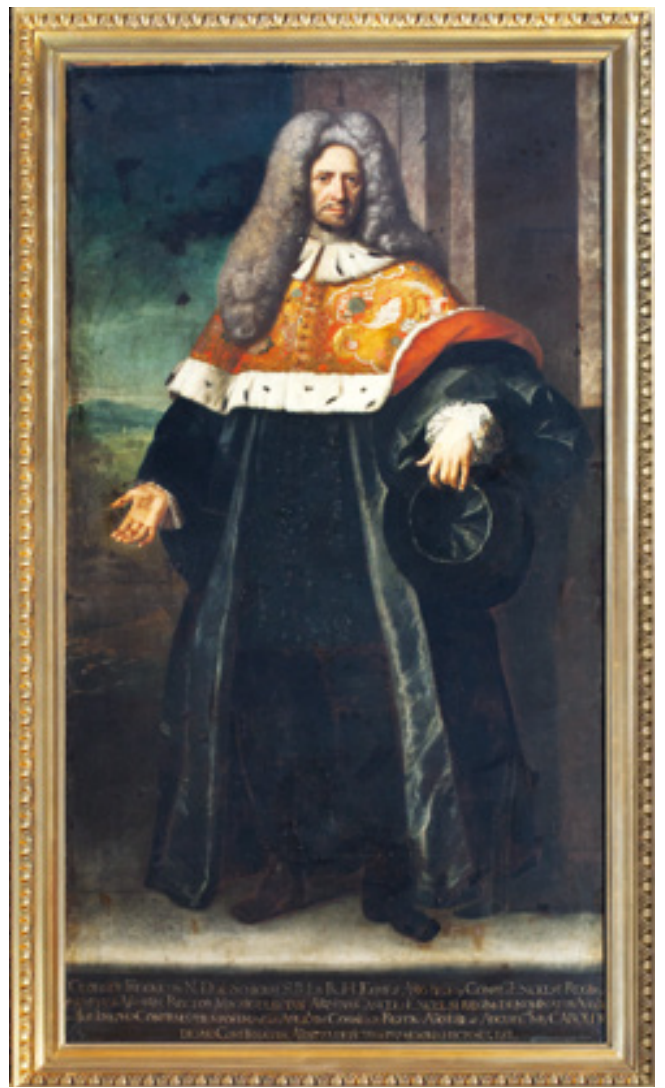

Abb. 7a: Werkstatt Johann Kupetzky?, Georg Friedrich von Schickh († I719) Rektor I695, Erhebung in den Ritterstand I7IO, Doktor beider Rechte, wirklicher Hofrat und Referendar der geheimen Hofkanzlei, federführend bei der Sanctio pragmatica I7I3, Öl auf Leinwand, $239 \times 125 \mathrm{~cm}$, Universität Wien, Hauptgebäude, Senatssaal, 1722.

re ohne Rüstung, doch mit der Pelzschaube eines Gelehrten zeigt. Die Ähnlichkeit beider Porträts legt vielmehr den Gedanken nahe, dass ein und dieselbe Persönlichkeit dargestellt ist: Georg Friedrich von Schickh. Eines fällt auf dem Rektorenbildnis ins Auge: In seiner Linken hält der

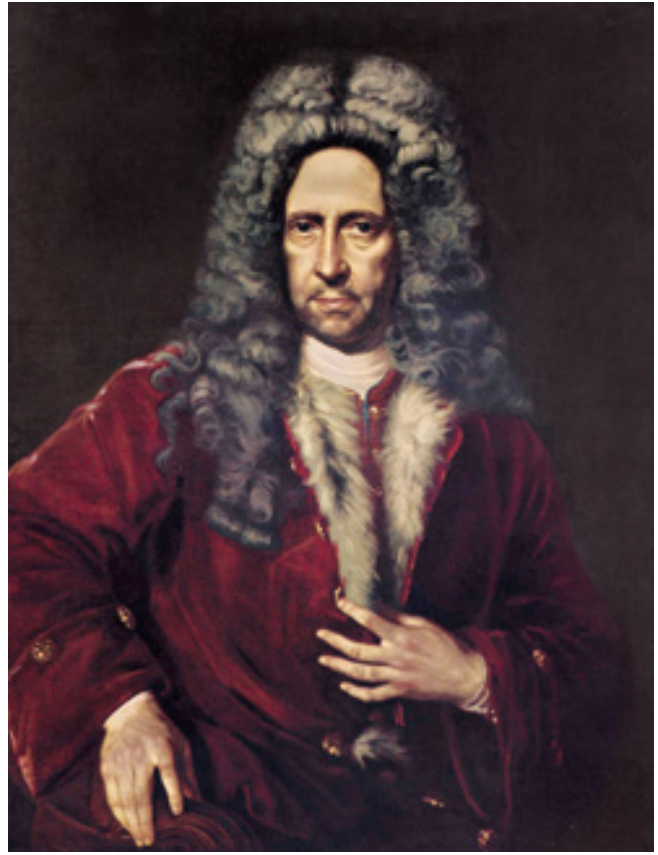

Abb. 7b: Johann Kupetzky, Porträt eines Adeligen, vermutlich Guido Graf Starhemberg oder Georg Friedrich von Schickh (?), Öl auf Leinwand, 95,5 $\times 76 \mathrm{~cm}$, Österreichische Galerie Belvedere Wien, Inv.-Nr. 4268.

Jurist den samtenen Doktorhut, das Rektorenzepter aber fehlt. Die Bildlegende verweist dagegen auf die hohe Stellung unter zwei Kaisern. Es ist der Staatsmann, dem man ein Denkmal setzen möchte, das Rektorat dagegen scheint nur eine Episode: ... anno 1722 depictus \& pro memoria huc deposit est lautet die Legende des Bildes. Schickh starb erst 1727, doch möglicherweise bedingt durch den Tod seiner Frau scheint ihn sein eigenes Ableben um 1722 intensiv beschäftigt zu haben und so verfasste er am 3. Januar 1723 ein Testament. ${ }^{54}$ Sein Wunsch war es, am Grabe seiner Frau in der Gruft der Schotten-

4268 (Abb. 7b) Das Gemälde ist weder signiert noch datiert und wurde 1948 aus dem Besitz Ignaz Graf von Attems erworben. SAfarik, Johann Kupetzky (zit. Anm. 48), S. 72, Kat.-Nr. I9I. Barocke Meisterwerke im Belvedere (hrsg. von A. Husslein-ArCo), Wien 2008, S. I54-I55, Kat.-Nr. 72. Als sicherer Referenzpunkt für die Zuschreibung beider Gemälde soll hier das I7II entstandene signierte Selbstbildnis des Malers in der Nationalgalerie Prag dienen. Siehe dazu Safarik, Johann Kupetzky (zit. Anm. 48), S. 5I, Kat.-Nr. I43. Prag, Narodni Galerie Inv.-Nr. O 2657

54 UAW CA VA Fasc. 40 Nr. II. Aus dem Testament geht hervor, dass seine Frau, die noch I7I8 ihr eigenes Testament verfasst hatte, jetzt verstorben war. Ich danke Ingeborg Schemper für den Hinweis auf Grab und Testament. 
kirche mit einem Epitaph bedacht zu werden. Der Sohn erfüllte den Auftrag, doch auch in der dort angebrachten Inschrift sucht man vergebens nach einer Erwähnung seiner Universitätskarriere oder gar des Rektorates.

\section{EINE „RUHMESHALLE“ ENTSTEHT}

Wer wurde in den "Heldenreigen“ in der stuba consistorialis aufgenommen? Wie verhält sich die kleine Gruppe der porträtierten Rektoren zu den tatsächlichen Besetzungen? In der Bestellung des Rektorenamtes sahen die Statuten einen turnusmäßigen Wechsel der Fakultäten vor. In den Rektorenlisten über die Jahre I689 bis $1745 / 46$ verteilen sich die 57 Rektorate neben den genannten 17 artistischen Amtsperioden auf I5 Mediziner, I4 Juristen und I3 Theologen. Auch wenn Verluste unter den barocken Rektorenporträts nicht auszuschließen sind, lässt sich damit die Aussage treffen, dass der tatsächliche Verteilungsschlüssel der Rektorate nicht in den barocken Rektorenbildnissen reflektiert wird. Eindeutig rangieren dort die Juristen (8) vor Ärzten (4) und Theologen (4). 55 Wenn die Porträts nur auserwählten Rektoren gelten, die jenseits ihres Amtes und des Handlungsraumes der Universität besondere Ehren erwerben konnten, stellt sich folgende weitere Frage: Wann und von wem werden Entschlüsse für die Herstellung und Hängung eines Porträts gefasst? Ändern sich die Ideale dessen, was als vorbildlicher Rektor gilt? Die Einzelanalysen haben bereits einige wenige Anhaltspunkte eingebracht. Um die Entstehungsdynamik der „barocken Rektorengalerie“ nachzuzeichnen, möchte ich nun die Auftragsanlässe diskutieren und schließlich die verschiedenen Perspektiven zusammenführen, die freilich nur auf einer ungefähren Chronologie der Bilder basieren. Solange keine weiteren Quellen aufgefunden werden, sind exakte Datierungen der Porträts nicht möglich.
Im Falle des Rektors Karl Wolfgang Lebzeltern (Abb. 6a) wissen wir genau, dass das Porträt nicht im Anschluss an sein Rektorat im Jahr I7I2 in Auftrag gegeben wurde, sondern als Statusbestätigung erst nach seiner Ernennung zum Reichsritter, die in der Inschrift berücksichtigt wird..$^{56}$ Andere Inschriften vermerken das Sterbedatum wie im Falle Grüners (Abb. 3a) und Haydens (Abb. 3b) oder verweisen explizit auf die Memorialfunktion des Gemäldes, wie im Falle der beiden Porträts, die die prominentesten Rektoren, Schlittern und Schickh, würdigen (Abb. 5b und Abb. 7a). Die Witwe des Rektors von Schlittern ist vermutlich nicht nur die Stifterin eines Porträts: Vorher vermachte sie bereits dessen aus eigenen Mitteln angefertigte „Epomiden Rectoralem zu (s)einer Gedächtnis der Universität“. Die Universität nimmt dankend an und versichert, sich auch noch gegen ihre Kinder und Puppilarien erkenntlich zu zeigen. ${ }^{57}$ 1720 erfolgte dann die Aufstellung seines Gemäldes und wir lesen unterhalb des Wappens, wer den Auftrag erteilt hat: „Pietas perillustris coniugis statuit." Die Stifterin setzt nicht nur ihrem Gemahl, sondern sich selbst ein Denkmal. Die goldene Epomis aber, die Schlittern auf seinem Porträt trägt, finden wir auf den Rektorenporträts von Lebzeltern, Schickh, Nettinghofen und Ruckh wieder. Über die Bilder teilt sich so mit, dass die Gemeinschaft der Universitätsangehörigen ein überschaubarer und über Jahre gut vernetzter Kreis war. Das familiäre Prinzip traditionaler Gesellschaften hatte auch an der Wiener Universität Einzug gehalten. Weitere prosopo-

55 UAW CA I.O.I2I: Doch auch dieses Wahlverfahren wurde bisweilen vom Kaiser beeinflusst, so erklärte Kaiser Karl VI. am 2. 9. 1720 die Wahl für ungültig und ernannte den Juristen Johann Conrad Kramer zum Rektor.

56 NATter, Icones Rectorum (zit. Anm. 3), S. I39.

57 UAW S IO2, Schachtel 65, 3. Juni I7I8 


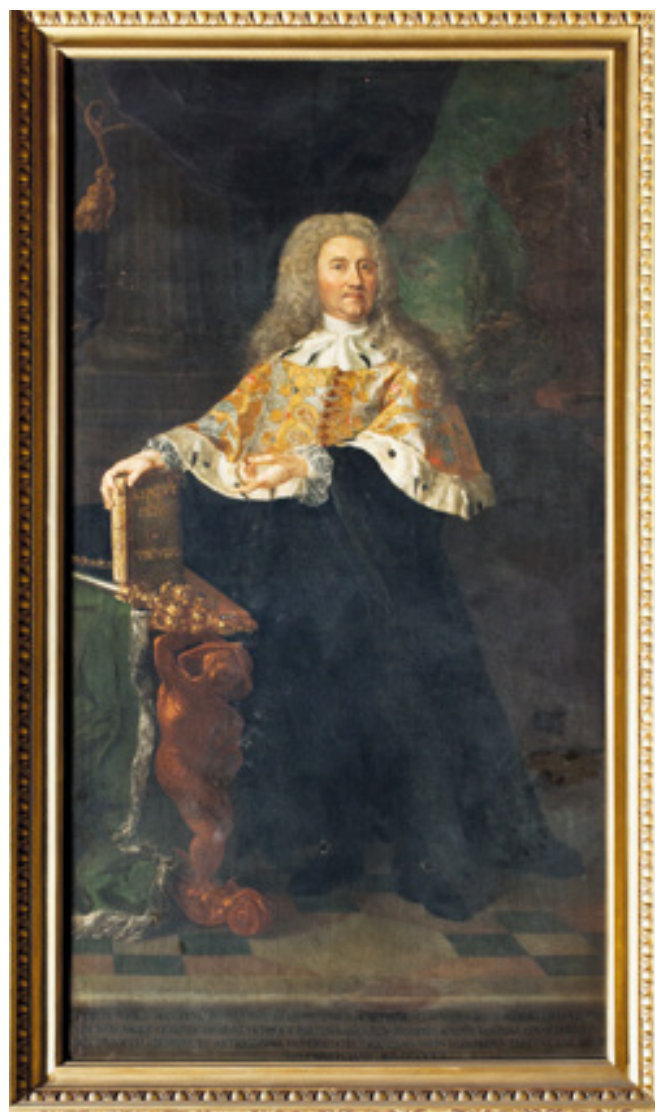

Abb. 8a: Jakob Boodewyns, Johann Adam von Nettinghofen, auch Nettekoven (†I738), Rektor I73I, Erhebung in den böhmischen Ritterstand I732, Doktor beider Rechte, niederösterreichischer Regierungsrat, Öl auf Leinwand, 235,5 X I23 cm, Universität Wien, Hauptgebäude, Senatssaal.

grafische Forschungen scheinen lohnend, doch lässt sich auch nach dem bisherigen Forschungsstand für die porträtierten Rektoren in nicht wenigen Fällen ein persönlicher Kontakt untereinander nachweisen: Rektor Weigler war sowohl Promotor Rektor Öttls (I690) wie Rektor Schlitterns (I693). Rektor Öttl wiederum ist der Wit-

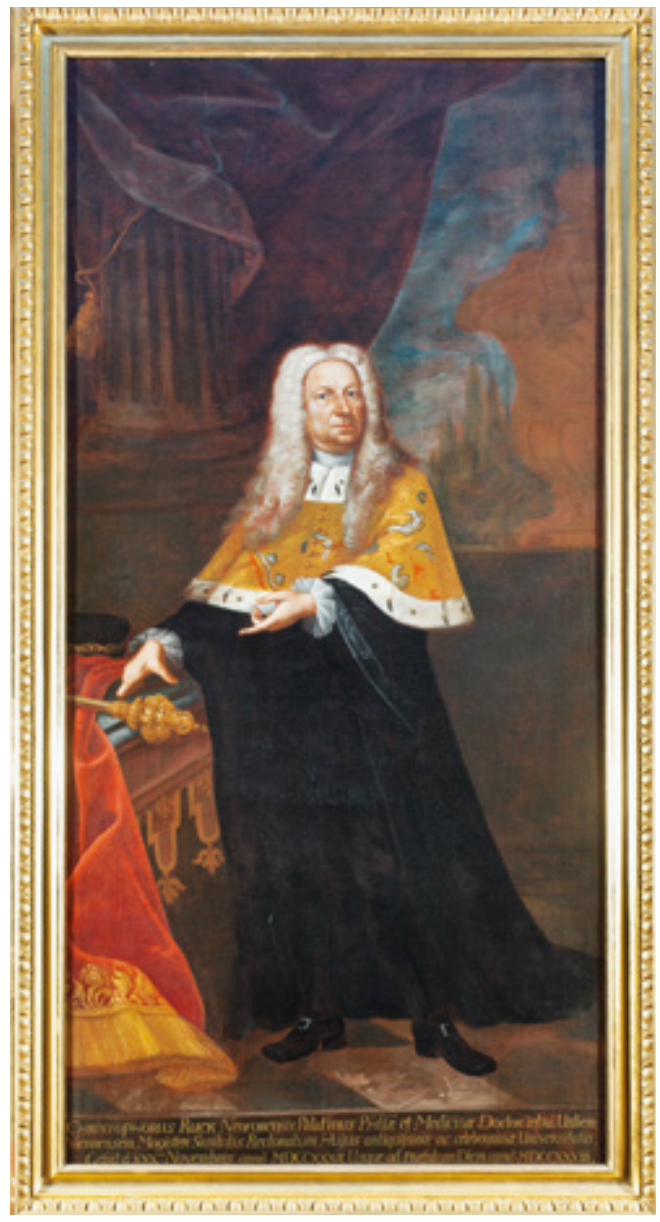

Abb. 8b: Sebastian Linckh, Christoph Ruckh († I744), Rektor 1732, aus älterem Adel, Doktor der Philosophie und der Medizin, Hofrat und "Magister sanitatis“, Öl auf Leinwand, $253 \times 122 \mathrm{~cm}$, signiert und auf I734 datiert, Universität Wien, Hauptgebäude, Festsaal.

we von Schlittern freundschaftlich verbunden. ${ }^{58}$ Auch Rektor von Nettinghofen und Rektor von Spaun arbeiten gemeinsam als Kollegen.99 Alle fünf gehörten der Juristischen Fakultät an. Die Rektoratsmatrikel, die an oberste Stelle den Rek-

58 UAW S I02, Schachtel 65, Exzerpt Schraufs zu „Schlütter“ (= Schlittern). Act. D. Jurid. Coll. Fasc. I. Lit. S. Brief Anton Roman von Öttls in der Funktion des Univ. Syndicus und Notarius vom 3. Juni I7I8 an die Gattin Schlütters: Polixena Catharina Edle Frau von Schlüttern, geb. von Schott.

59 UAW CAr.2.52, Reform der Universität und des Studienbetriebs - Forderungen der Universität an das k. k. Ärar; Neubesetzung des Superintendenten: In diesen Akten über den Zeitraum von 1725-1732 treten von Spaun wie von Nettinghofen als Kommissäre auf. 
tor und seine Verwandten setzen, belegen die Bedeutung von Familienbanden. Eines der Rektorenporträts gilt sogar der Würdigung von Vater und Sohn: So rühmt die Inschrift auf dem Bildnis für Rektor von Spaun nicht nur den Dargestellten, sondern auch dessen Vater, der - nach erfolgreicher Universitätskarriere - I72I in den erblichen Reichsritterstand erhoben worden war (Abb. 9a). Das Interesse der „Gelehrten-Dynastien" wird bei der Beauftragung und der Finanzierung die Hauptrolle gespielt haben.

In Bezug auf die Genese der Bildergalerie lässt sich bezweifeln, ob das Vorhaben einer Reihe von Anfang an intendiert worden ist. Die Abstände zwischen den Aufträgen sind zunächst groß. Mag sein, dass dies den knappen Ressourcen einer Kunstszene zu schulden ist, um die es in Zeiten äußerer Bedrohungen durch Pest und Türkenkrieg schlecht bestellt war. Erinnern wir uns an den Maßstäbe setzenden und vielleicht Verpflichtung weckenden Auftakt des ersten Porträts um I672. Es galt dem kaiserlichen Leibarzt Rechperger (Abb. 2a). Erst mit größerem Abstand folgt dann das Porträt des Theologen und Domherrn Laurentius Grüner um I683 (Abb. 3a). Dieses ist das einzige Porträt, das den Rektor in die Umgebung einer Bibliothek stellt. Es folgen vermutlich die Porträts der beiden Juristen, Weigler (Abb. 3c) und dessen Schüler Öttl. (Abb. 3d) Der Blick hat sich auffällig gewendet: Beide Rektoren werden über die Bildlegende durch ihre bei Hofe hoch angesehenen Ämter definiert. In der Reihe der Porträts ist Öttls das erste, das Palast und Park im Hintergrund zeigt. Pointiert weist er mit seiner Linken den Betrachter darauf hin. Die gesuchte Dramaturgie der Handgesten fällt auch auf allen folgenden Porträts auf und verstärkt den Anschein der Handlungsfähigkeit. Mit den Bildnissen der beiden Ordensführer, dem Melker Benediktiner Dietmayr (Abb. 4c) und insbesondere dem Klosterneuburger Augustiner-Chorherren Perger (Abb. 4d) setzt gleichzeitig ab ca. I709 eine Qualitätssteigerung der Bildnisse ein. Auch werden die zeitlichen Abstände zwischen den Aufträgen dichter: Die Porträts der Rektoren Dietmayr (Abb. 4c), Perger (Abb. 4d), Blümer (Abb. 5a), Schlittern (Abb. 5b), Lebzeltern (Abb. 6a) und Schickh (Abb. 7a) weisen stilistisch und qualitativ eine gewisse Nähe auf und fallen in die Zeitspanne, in der der Maler Johann Kupetzky in Wien tätig war (I709-I723). Wie eine Bestätigung für eine solche Zuschreibung an Kupetzky liest sich der auffällige größere Einschnitt der Reihe kurz nach I722. Das in dieses Jahr datierte Bildnis Schickhs scheint das letzte Rektorenporträt aus der Werkstatt Kupetzkys vor seiner Abreise nach Nürnberg zu sein.

Erst nach einem längeren Zeitraum entstand das nächste Rektorenporträt. Es liegt in deutlich schlechterer Qualität vor. Das nach 1727 zu datierende Porträt zeigt den niederösterreichischen Regierungsrat und Landschreiber Kees (Abb. 6b). Neue Impulse scheint dann die Reihe unter dem engagierten Rektorat des Regierungsrates Nettinghofen 1731/32 zu gewinnen, der im selben Jahre in den böhmischen Ritterstand erhoben wurde. ${ }^{60}$ In dem ungewöhnlich ausführlichen Protokoll über sein Amtsjahr wird vermerkt, dass am 28. August 1732 eine Umhängung der effigies der Rektoren in der stuba consistorialis stattgefunden hat. Ziel war eine Aktualisierung der Ordnung der Bilder, deren Zahl bereits auf mindestens 13 angewachsen war. Das Porträt des letzten Rektors möge seinen Vorgängern vorangestellt werden, empfiehlt Nettinghofen. ${ }^{61}$ Es

60 J. G. Megerle von Mühlfeld, Österreichisches Adelslexikon des I8. und I9. Jh., enthaltend alle von I7OI bis I820 von den Souveränen Österreichs wegen ihrer Verdienste um den Kaiserstaat in die verschiedenen Grade des deutscherbländischen oder Reichsadels erhobenen Personen. Ergänzungsband, Wien I824, S. I8I.

6I Mühlberger, Matrikel VII (zit. Anm. 6), S. I37/fol. 22Ib-222a: Sitzung vom 30. Nov. I732 TOP 7: (28. August I732): “[...] ut propter effigierum ordinem, quae a magnificis rectoribus ad stubam consistorialem offeruntur, ordo servetur, ut ultimi cujusvis domini rectoris effigies antecessorum effigiebus praeponatur.“ 
wird wohl sein eigenes gewesen sein, mit dem die Reihe der letzten vier Porträts beginnt. Sie sind signiert: Jacob Boodewyns, Sebastian Linck, Maximilian Josef Hannl und Christoph Schomburg lauten die Namen der Künstler. Hannl zählt zu den engeren Mitarbeitern Kupetzkys. Unter diesen letzten vier Porträts fällt die Tendenz zur Pendant-Bildung auf: Die Porträts von Nettinghofen (Abb. 8a) und Ruckh (Abb. 8b), wie die Porträts von Spaun (Abb. 9a) und Fraisl (Abb. 9b), ähneln einander in den Körperstellungen. Die Eintragung der Hängungsmaßnahmen in das Matrikelbuch, die bewusste Entscheidung, sich selbst in eine Reihe zu setzen, und die zunehmenden formalen Bezüge der Porträts untereinander deuten darauf hin, dass die Bilderreihe nun in die Phase einer bewussten Verstetigung getreten ist.

Auffällig bleibt, dass nach dem Rektorat des Klosterneuburger Propstes Ernest Perger (I7IO/I7II) kein weiteres Porträt einem Ordensführer oder Domherren gewidmet wurde, obwohl die Hälfte der Rektorate in den Jahren zwischen $1715 / 16$ und 1745/46 aus dieser sozialen Gruppe besetzt worden ist. Es sind die Juristen und einige ausgewählte Mediziner, die die Geistlichkeit verdrängen.

Die Strategie, über eine wachsende Bilderreihe ihrer Mitglieder die Soziabilität und Identität einer Gemeinschaft über Raum und Zeit hinaus zu stärken, haben viele Gruppen verfolgt. $\mathrm{Zu}$ denken ist beispielweise an die prominenten Papstreihen am Langhausgewände von St. Paul vor den Mauern oder in der Lateransbasilika, die dann ein Echo in den vielen Abts- bzw. Prälatenreihen verschiedener Klöster finden sollten. Stabilisierend legt sich ein gleiches formales Schema über individuelle Einzelbildnisse. Es ist naheliegend, hier eine Inspirationsquelle für die Rektorenreihe zu suchen, zumal unter den frü- heren Rektorenbildnissen drei der porträtierten Rektoren Ordensführer waren. Vieles spricht jedoch dafür, dass sich in den Bildnissen vor allem das Vorbild des nahen Kaiserhofes und sein besonderes Verhältnis zu Porträt und Porträtreihen in Skulptur und Malerei spiegelt. Schließlich hatte die spanische Hoftracht den Körper von Kopf bis Fuß in einen Zeichenträger verwandelt. Das Ganzkörperporträt bot sich geradezu als ein ideales und dazu noch mobiles Medium an, das sich mit Erfolg seit dem beginnenden I6. Jahrhundert an den habsburgischen Höfen etabliert hatte. Wie erwähnt war auch die Universitätsaula damals mit Porträts der Kaiserfamilie bestückt worden. Was in diesen Bildern zählt, sind höfische Kleidung, Pose, Gebärdensprache, Ambiente. In den Rektorenporträts folgen auf evidente Weise die nicht geistlichen Dargestellten der modischen Haartracht des Hofes und übernehmen mit dem Porträt Weiglers die Perücke. Darüber hinaus nehmen sie Körperhaltungen ein und vollführen ein Schauspiel an weisenden und präsentierenden Gesten, das sich an dem Repertoire jeweils aktueller Repräsentationsbildnisse des Kaiserhofes orientiert, bisweilen sogar enger, als es der innovationssuchende Adel tut. Ein weiterer Indikator ist der seriöse Verismus, mit dem die Gesichtszüge mancher Rektoren wiedergegeben werden: Hier kann einerseits die Arbeitsteilung einer großen Hofwerkstatt, andererseits die Porträttheorie zum Verständnis beitragen: „Helden tragen Charakterköpfe“, lassen sich die Empfehlungen de Piles' (I708) für das Porträtieren von führenden Persönlichkeiten paraphrasieren. ${ }^{62}$

Zusammengefasst ist die erhaltene Reihe der Rektorenporträts eine gewachsene, adaptive und selektive: Aus verschiedenen Quellen lässt sich vermuten, dass die Gemälde gestiftet wur-

62 DE PILEs, Cours des peintures par principes, Paris I708 (Leipzig 1760), S. 213. Zur Innovationsfreudigkeit des Adels im beginnenden I8. Jh.: Polleross, Adelsporträts (zit. Anm. 42), S. 238.

63 NATter, Icones Rectorum (zit. Anm. 3), S. 15, verweist auf eine Quelle aus dem Jahr 1733: UAW Hauptmatrikel M9 fol. 22I, 222. 


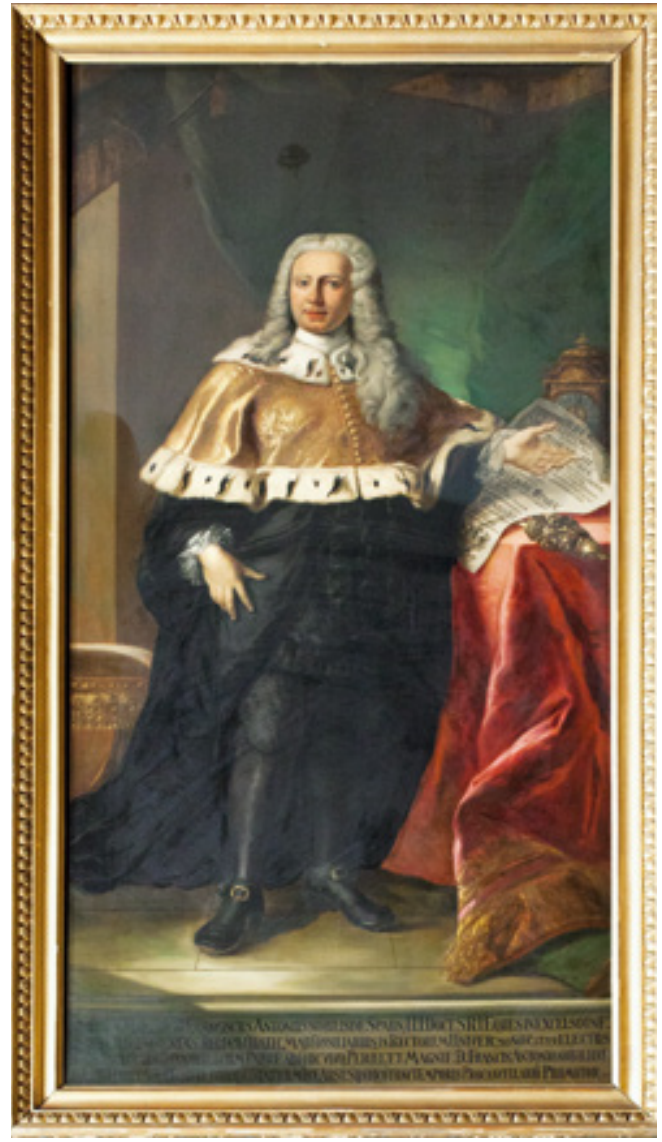

Abb. 9a: Josef Prem nach Maximilian Joseph Hannl, Franz Anton Spaun, († 1746), Rektor I739, I72I war sein Vater in den Reichsritterstand erhoben worden, was das Bild mitteilt. Doktor beider Rechte, niederösterreichischer Regierungsrat, Öl aufLeinwand, $260 \times 127,5 \mathrm{~cm}$, Universität Wien, Hauptgebäude, Rektorenzimmer.

den. ${ }^{63}$ Unterschiedlich und individuell scheinen die Interessen, die zu einem Auftrag geführt haben können. Persönliche, familiäre und institutionelle Interessen sind zu erkennen. Natürlich musste die Anfertigung eines Porträts über entsprechende wirtschaftliche Ressourcen gedeckt sein. Die schwachen Vermögensverhältnisse der Universität und diesbezüglich fehlende Nachweise in der Buchführung machen es wahrscheinlich, dass die Finanzierung eher von den entsprechenden Familien oder Orden geleistet wurde. Während in der frühen Zeit mehrere der

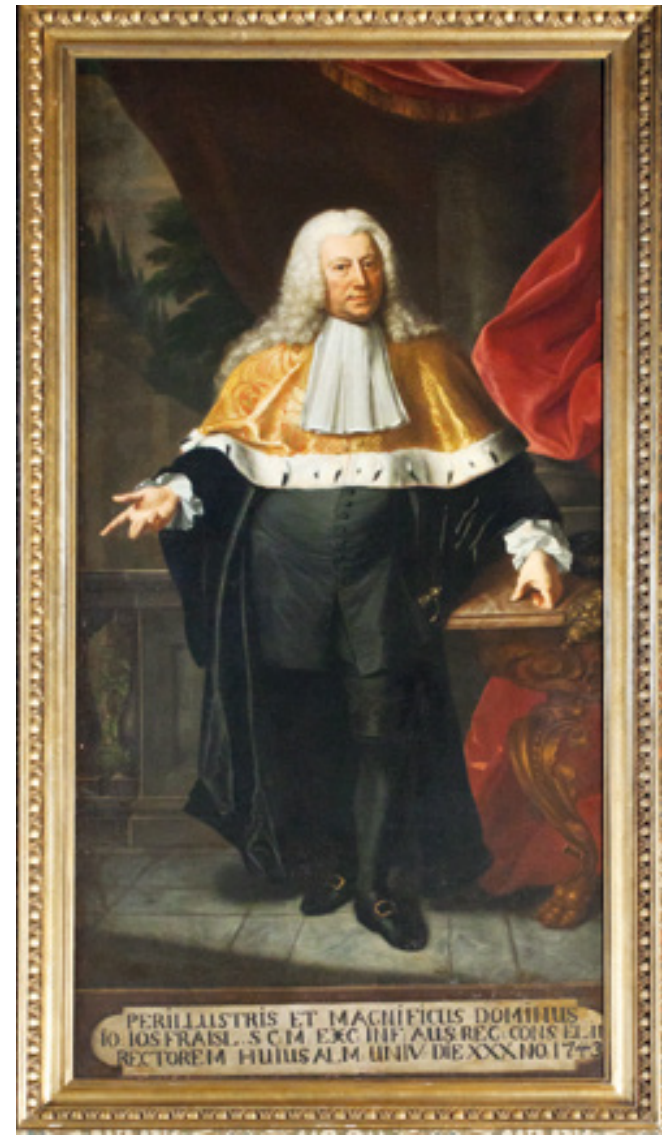

Abb. 9b: Christoph Schomburg, Johann Joseph Fraisl, († 1789), Rektor 1743, Erhebung in den Adelsstand 1756, niederösterreichischer Regierungsrat und Kanzleidirektor, Öl auf Leinwand, $257 \times 123,5 \mathrm{~cm}$, Universität Wien, Hauptgebäude, Rektorenzimmer.

dargestellten Rektoren einen klerikalen Hintergrund aufweisen, nehmen Bedeutung und Profilierungswunsch der Juristen an der Universität unter Karl VI. zu. Unter den Porträtierten finden sich höchst einflussreiche und bei Hof angesehene Staatsmänner wie Rektor Schlittern und Rektor Schickh. Ihre Familien konnten sich einen Porträtisten aus dem Umkreis des Hofes leisten. Die Stiftung des Gemäldes musste nicht mit dem vorgegebenen Anlass, dem Jahr des Rektorates, zusammenfallen, zumal manche der Gelehrten dieses Amt öfters innehatten. Vielmehr 


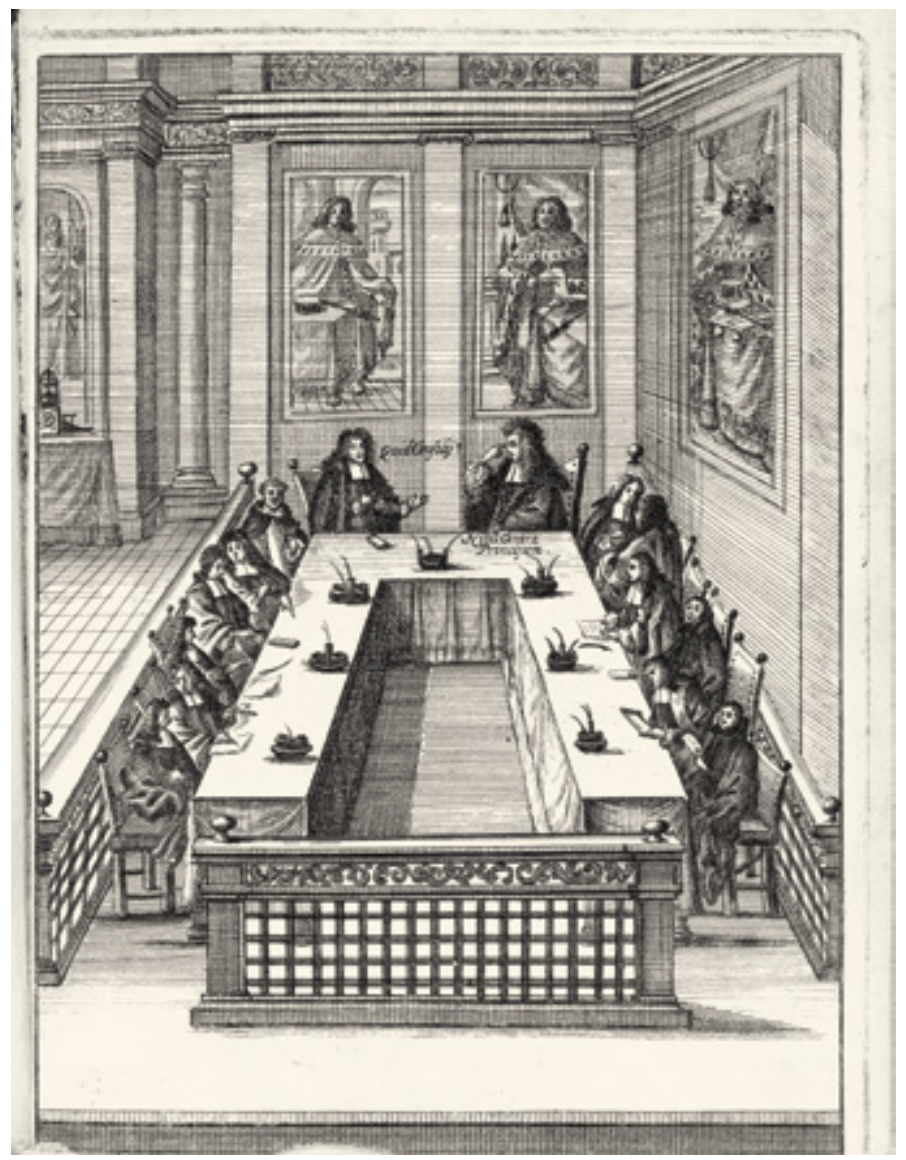

Abb. ıо: Georg Christoph Eimmart, Blick in den Konsistoriumssaal der Universität in der Sonnenfelsgasse, Kupferstich aus: Hohann Ferdinand Josef von Albrecht, Calendarium academicum celeberrimae et antiquissimae universitatis Viennensis ..., Wien 1693.

konnte sie nachträglich oder sogar posthum erfolgen. Entsprechend wechseln die zeitlichen Distanzen zwischen den erhaltenen Gemälden. Das jeweils neue Porträt musste sich an der länger werdenden Reihe messen. Der Konformitätsdruck wird sich gesteigert haben und lässt sich in manchen Fällen durch formale Übernahmen oder durch eine Pendantbildung belegen. ${ }^{64}$ Dennoch ist gerade der Variantenreichtum der Porträts ein bemerkenswertes Charakteristikum. Es dokumentiert sich darin der Respekt vor der Leistung des Einzelnen wie eine neue Sensibi- lisierung für das Individuelle. Die porträtierten Rektoren mögen den Universitätsangehörigen als Vorbild gedient haben, sie bilden jedoch weder die tatsächliche Gruppe der Rektoren ab, die annähernd turnusmäßig aus den verschiedenen Fakultäten gewählt wurden, noch repräsentieren sie den wirklichen Alltagsbetrieb der Universität, der in erster Linie von den Jesuiten getragen wurde und sich auf die Lehre konzentrierte. Was sie zeigen, sind die intellektuellen Ressourcen, die Wissenspflege an der Universität für Hof und Reich bedeuten konnte. Wie

64 So wiederholt Rektor Ruck die Körperhaltung von Rektor Nettinghofen. 
an keiner anderen Universität zeigen diese Porträts, dass sich der Kaiser auf diese Riege prominenter Ratgeber stützen konnte. Der Hinweis auf politische Verdienste am Kaiserhof steigerte das Prestige der Magnifizenzen auf doppelte Weise, denn ein Kaiserhaus, das mit seinem kulturellen Kapital zu triumphieren suchte, gewann mit dem Ansehen ihrer Universitätsrektoren. In der Frage nach dem Verhältnis von Universität und Hof hat sich die Forschung bisher vornehmlich auf die theresianischen Reformen konzentriert. Die Rektorenporträts zeigen, dass die Universität bereits unter Karl VI. ein beachtenswertes Thema gewesen ist. ${ }^{65}$

Die Vereinigung der Universität mit dem Jesuitenkonvikt hatte eine neue Bauphase eingeleitet, die erst 1654 abgeschlossen werden konnte. Es bleibt ein deutliches Zeichen der Distinktion, dass die Universitätsleitung selbst nicht im akademischen Kolleg untergebracht wurde. Rektorat, Konsistorium, Kanzleien und Archiv residierten ab 1629 und weiterhin bis 1884 in der Sonnenfelsgasse 19. ${ }^{66}$ Einen Beleg für die Hängung im exklusiven Sitzungssaal des Universitätskonsistoriums liefert eine Radierung des Nürnberger Kupferstechers Georg Christoph Eimmart. Sie findet sich in dem Calendarium academicum antiquissimae ac celeberissime Universitatis Viennensis von $1693^{67}$ (Abb. Iо).
Das letzte ganzfigurige Rektorenporträt scheint 1746 entstanden zu sein. ${ }^{68}$ Die Reihe wurde jedenfalls auseinandergerissen, Rektorenbildnisse dienten jetzt auch anderen Räumlichkeiten zum Schmuck, etwa in dem neu erbauten Universitätsgebäude von Jadot (1753-55). Laut einem Inventar von I82I scheinen die meisten Rektorenbildnisse nun auf dem Dachboden der Sonnenfelsgasse zu lagern. ${ }^{69}$ Lediglich drei der Porträts lassen sich im Konsistoriumssaal nachweisen. ${ }^{70}$ Die Universität weiß diesen Besitz so wenig zu schätzen, dass sie u.a. freigebig das Porträt des Rektors von Spaun seinen Nachfahren aushändigt.

Ein anderer fand mehr Interesse daran: Graf Hans Wilczek (I837-1922). Er habe, so überliefert der Bericht einer Sitzung des akademischen Senats vom I4. II. I884, der Universität I6 Porträts alter Rektoren in Lebensgröße geschenkt. Graf Wilczek war als Unternehmer höchst erfolgreich und stand in engster Verbindung zum Kaiser. Neben seinen vielfältigen Interessen engagierte er sich als Kunstmäzen, als Kurator und Museumsplaner..$^{71}$ Sicherlich war ihm nicht entgangen, dass 1876 aus den Ateliers der RestaurirSchule im K. K. Belvedere zwölf Ahnenbilder in Lebensgröße für den neu adaptierten Speisesaal Erzherzog Rudolfs in der Hofburg geliefert worden waren, zumal ihn mit dem Kronprinzen ein engeres persönliches Verhältnis verband. ${ }^{72}$ Wie

65 Vgl. G. Kuingenstein, Vorstufen der theresianischen Studienreform in der Regierungszeit Karl VI., in: MIÖG 76 (1968), S. 327-377. Nicht zu vergessen ist auch, dass Karl VI. bereits Pläne für eine Akademie der Wissenschaften in Auftrag gegeben hatte. Vgl. dazu: Seitschek/Hutterer/Theimer, 300 Jahre Karl VI. (zit. Anm. 35), S. 247, Kat.Nr. VII/8: Pläne zur Errichtung einer Akademie.

66 K. Mühlberger, Universität und Jesuitenkolleg, in: Karner/Telesko, Die Jesuiten in Wien, Wien 2003, S. 35, Anm. 106. Vgl. auch WrBA, Das alte Universitätsviertel, Wien 1985: I. August I624 Grundsteinlegung für Collegium und Kirche, Übersiedelung am I8. I. I625.

67 Johann Ferdinand Josef von Albrecht, Calendarium academicum celeberrimae et antiquissimae universitatis Viennensis: ad multos annos complectens Univ. Rectores, Candellarios, superintendentes Caesareos, ab anno M.DC. LXX ..., Wien I693. Vgl. zu Albrecht: KLECKER, Universität und Hofbibliothek (zit. Anm. 25), S. I2-I3.

68 Vgl. dazu Anm. 2

69 Natter, Icones Rectorum (zit. Anm. 3), S. I4.

70 UAW I05.P 276: (Archivierungsgeschichte des Porträts Josefs von Sonnenfels.)

7I Zu den prominentesten Projekten zählen das Heeresgeschichtliche Museum und Burg Kreuzenstein: I874-1906.

72 W. Telesko, Die Wiener Hofburg I835-I9I8. Der Ausbau der Residenz vom Vormärz bis zum Ende des „Kaiserforums“, Wien 20I2. Zum Ahnensaal: S. 273-275. 
Telesko vermutet, schwang bei diesem Anciennitätsbeweis auch die Profilierung gegenüber der neuen „Kaiserstadt“ Berlin mit. Baumeister der Hofburg war Hasenauer, mit dem Wilczek ebenfalls in guter Verbindung stand.

Ausgestellt auf der „Historischen Ausstellung der Stadt Wien I883“wurde nur eines der Bildnisse der Rektorengalerie (Abb. 3a). Das Engagement Wilczeks wurde geschickt inszeniert und in der Presse kommentiert. Einige Tage nach Eröffnung besuchten Erzherzog Rainer und Erzherzogin Marie die Ausstellung. Anlässlich dieses hohen Besuches übergab der Graf „das lebensgroße Ölgemälde des Doktor Grüner, Rektors der Wiener Universität I883“. Daraufhin entschied der Senat der Universität, das Geschenk Wilczeks anzunehmen.

Es war also eine Initiative des Hofes, die die Universität auf ihren Schatz an Porträts aufmerksam machte. Der reiche Privatier Graf Hans von Wilczek, der mit ihm eng verbundene Univer- sitätsarchivar Karl Schrauf, der Ordinarius der Kunstgeschichte Rudolf Eitelberger und der akademische Maler an der Restaurir-Schule im K. K. Belvedere H. Josef Prem sind im Folgenden die entscheidenden Personen im Hintergrund. Auf Beschluss des Universitätssenats im November $1884^{73}$ sorgen sie soweit möglich für die Identifikation der Porträtierten, für Aufarbeitung, Rahmung und tatkräftige Ergänzung. Die Wiederentdeckung geschieht zu einem denkbar günstigen Zeitpunkt, denn im selben Jahr, I884, öffnet das neue Universitätshaus am Ring seine Pforten.

Abbildungsnachweis: Abb. I, 2a, 3a-d, 4c-d, 5a-b, 6ab, 7a, 8a-b, 9a-b, ıо: Institut für Kunstgeschichte der Univ. Wien, K. Pani/R. Steyer, 2orI; Abb. 2b: KHMMuseumsverband; Abb. 4a: Stift Melk (P. Jeremia Eisenbauer); Abb. 4b: Stift Göttweig; Abb. 7b: Österreichische Galerie Belvedere Wien.

73 UAw, Akademischer Senat SR S87. I.I Akten der artistischen Kommission, Schachtel 53: I4. II. I884 


\title{
DAS PORTRÄTMEDAILLON ALS FORM DES GELEHRTENDENKMALS IM ARKADENHOF DER UNIVERSITÄT WIEN
}

\author{
Andrea Mayr
}

$\mathrm{D}$ e Ausstattung des Arkadenhofs als Ehrenhalle bedeutender Professoren der Wiener Universität begann mit dem I888 enthüllten Denkmal für den Juristen und Politiker Julius Glaser, das in Form eines antikisierenden Marmorreliefs in Profilansicht ausgeführt wurde (Abb. I). ${ }^{\mathrm{I}}$ Den größten Teil des heute mehr als I50 Denkmäler umfassenden Ensembles bilden die als Porträtbüste auf Postamenten gefertigten Werke, die sich an den äußeren Wandseiten der drei Arkadengänge befinden. Einen geringeren Anteil stellen die - meist eingefasst von hochrechteckigen Tafeln - an den Pfeilerinnenseiten der Arkaden in etwa gleicher Höhe angebrachten Porträtreliefs dar. Ihre Modellierung erhält durch das von der Hofinnenseite seitlich einfallende Licht eine gesteigerte Wirkung.

Neben den vollständig aus Marmor gearbeiteten Reliefs beinhalten einige das Porträt des Geehrten im Profil in Form eines bronzenen Medaillons, das durch seine Form und Gestaltung an Medaillen denken lässt. Seit ihrer Wiederentdeckung in der Renaissance war die Medaille ein Mittel herrschaftlicher Repräsentation. So wurden anlässlich größerer Ereignisse wie der Geburt

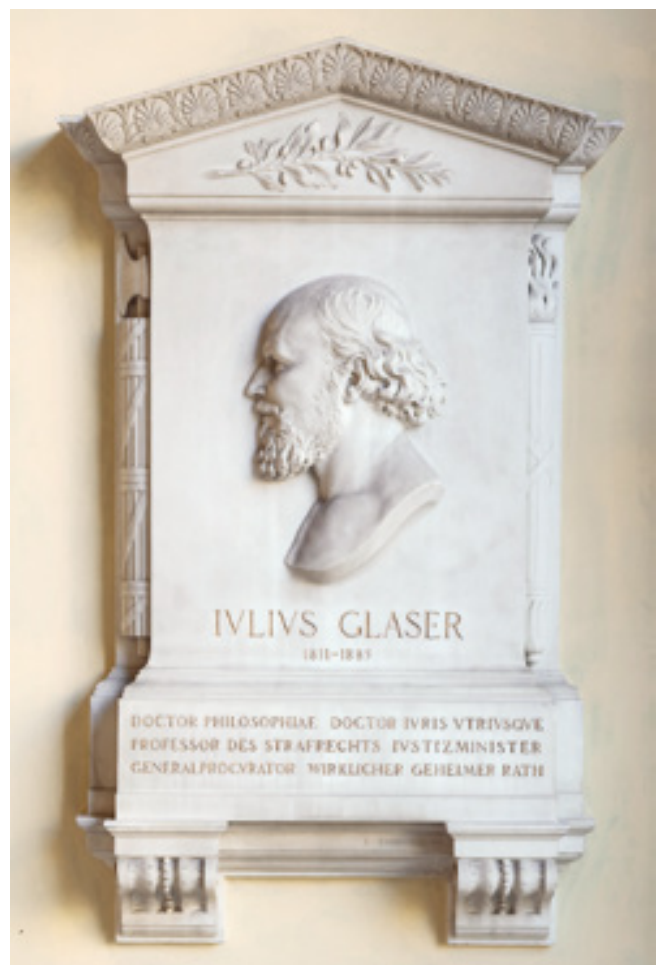

Abb. I: Kaspar von Zumbusch, Denkmal mit Porträtrelief für Julius Glaser (I83I-I885), I888 enthüllt, Arkadenhof der Universität Wien. eines Monarchen, Vermählung und Krönungs-

I Vgl. den Eintrag zum Denkmal für Julius Glaser auf monuments - das Wiki zu den Denkmälern der Universität Wien - https://monuments.univie.ac.at/index.php?title=Denkmal_Julius_Glaser, abgerufen am Io. Februar 20I5 und T. MAISEL, Gelehrte in Stein und Bronze, Wien 2007, S. 57. 
feierlichkeiten sowie kriegerischer Erfolge und Friedensschlüsse prunkvolle Porträt- und Schaustücke hergestellt. Schon vor Ende der Monarchie entdeckten neben der Aristokratie verstärkt private Auftraggeber aus dem Bürgertum, Industrielle, Wissenschaftler und Persönlichkeiten des öffentlichen Lebens dieses Medium zur Betonung der eigenen Individualität und zur Verewigung ihrer Taten. ${ }^{2}$ Persönliche Ereignisse aus dem Leben, wie Hochzeit, Geburt, Jubiläum und Tod, wurden in diesen Präsenten mit Ewigkeitswert festgehalten. ${ }^{3}$ Das Archiv der Universität Wien bewahrt eine umfangreiche Sammlung an Medaillen zu Jubiläen, Kongressen, Gesellschaften, sowie Auszeichnungen von einzelnen Persönlichkeiten auf. ${ }^{4}$ Diese stehen in direkter Verbindung zu den Denkmälern, da sie zumeist Personen zugeordnet werden können, die ebenfalls durch ein Denkmal im Arkadenhof vertreten sind. In ihrer Form und Gestaltung erinnern sie an das entsprechende Medaillon des Denkmals. Es stellt sich daher die Fra- ge nach der vorbildhaften Funktion der Medaille für das Großformat. Gleichzeitig wird die unterschiedliche Wirkung zwischen Klein- und Großform deutlich. Weiters findet sich das Porträtmedaillon häufig auch am Grabmal des Geehrten wieder, wie an zahlreichen Grabdenkmälern am Wiener Zentralfriedhof beobachtet werden kann. Im Folgenden soll untersucht werden, ob das wiederholte Einsetzen des Profilporträts nur aus Sparsamkeitsgründen erfolgte oder ob nicht der erhöhte Wiedererkennungswert der markanten Züge auch eine Rolle spielte. Um nach dem Grad der Idealisierung im Medaillon zu fragen, liefern Porträtfotografien der geehrten Persönlichkeiten Anhaltspunkte zur Gegenüberstellung. In vergleichender, quellenkritischer Analyse der Denkmäler, Medaillen, Grabmäler und Porträtfotografien wird nach den Ausdrucksmöglichkeiten des Typus Porträtmedaillon und seiner Rezeption gefragt.

\section{KASPAR VON ZUMBUSCH (I830-I9I5) UND ARNOLD HARTIG (I $878-$ I972)}

Die beiden Bildhauer Kaspar von Zumbusch und Arnold Hartig stehen im Zentrum dieser Studie. Da beide Künstler zu unterschiedlichen Zeiten tätig waren und daher auch ungleiche Stile vertreten, erscheinen ihre Werke aus dem Arkadenhof für einen kunsthistorischen Vergleich besonders interessant.
Kaspar von Zumbusch, geboren in Westfalen, studierte die Bildhauerkunst bei Johann Halbig am polytechnischen Institut in München. ${ }^{5}$ Nach Studienaufenthalten in Italien wurde Zumbusch durch mehrere Auftragsarbeiten in Freising, Augsburg und München bekannt und 1872 an die Akademie der Bildenden Künste nach Wien berufen. Bis I90I war er als Professor an der Akademie tätig, zahlrei-

2 Vgl. K. Schulz, Künstler, Graveure, Medailleure, in: Geld. 8oo Jahre Münzstätte Wien, (Kat. zur Ausstellung im Kunstforum Bank Austria Wien, 27. Juni-2I. August 1994), Katalogredaktion Christian Bauer, Evelyn Benesch, Wien I994, S. 232 und L. Hölbling, Medaillen der Wissenschaft, Die Sammlungen des Archivs der Universität Wien (Schriftenreihe des Universitätsarchivs, Universität Wien, I3. Band, hrsg. von Kurt Mühlberger und Franz Skacel), Wien I998, S. I5.

3 W. STEguweit, Europäische Medaillenkunst von der Renaissance bis zur Gegenwart, Münzkabinett Staatliche Museen zu Berlin - Preußischer Kulturbesitz, Berlin 1995, S. 53.

4 Hölbling, Medaillen der Wissenschaft (zit. Anm. 2), S. 23-I39.

5 M. Poch-Kalous, Wiener Plastik im 19. Jahrhundert, in: Geschichte der bildenden Kunst in Wien, Wien I970, S. 213 . 
che Bildhauer der nachfolgenden Generation besuchten seine Klasse, darunter Emanuel Pendl, Theodor Charlemont, Edmund Hofmann von Aspernburg, Hans Bitterlich und Josef Müllner. ${ }^{6}$ In den Jahren I886-88 und I899-I90I war Zumbusch Rektor der Akademie, von der Universität Wien erhielt er I9II das Ehrendoktorat.7 Bis zum Ausbruch des Ersten Weltkriegs gehörte er hier als beratendes Mitglied der „Artistischen Kommission" des Akademischen Senats an. ${ }^{8}$ Als bedeutender Bildhauer der Ringstraßenzeit wurde er vor allem für monumentale Denkmäler im öffentlichen Raum bevorzugt, darunter das Beethoven-Denkmal (1874-80), das Maria-TheresiaDenkmal (1874-88) und die Figur Kaiser Franz Josephs im Stiegenaufgang des Universitätshauptgebäudes (I883). ${ }^{9}$ Im Arkadenhof existieren insgesamt neun Denkmäler des Bildhauers. Nach dem Denkmal für Julius Glaser I888 wurde bereits I889 die Bronzeplakette mit Marmorrahmung für Rudolf Eitelberger enthüllt. Im Jahr I897 folgte das Denkmal für Theodor Billroth, das ihn stehend an der Kanzel zeigt, I899 das Denkmal mit Bronzebüste über einem Marmorrelief für Anton Hye von Gluneck und das Marmorrelief für Leopold Hasner von Artha. ${ }^{\text {IO }}$ I9I2 wurde die Bronzebüste für Adolf Mussafia hier enthüllt und 1928 die Bronzebüste für Josef Unger. Es folgten die beiden Denkmäler mit bronzenen Porträtmedaillons für Ernst Ludwig
1932 und für Leopold Schrötter von Kristelli 1937. Nicht alle wurden vom Künstler für den Arkadenhof geschaffen, worauf später noch eingegangen wird. In seiner Formensprache neigte Zumbusch dazu, die anfangs neobarocken Einflüsse „zugunsten eines realistisch-sachlichen Stils mit klassizistischer Färbung " ${ }^{\text {"II }}$ zu unterbinden. In seinen Porträts blieb Zumbusch sachlich und verzichtete auf allzu bewegte Formen, wie an den Büsten und Reliefs im Arkadenhof gut sichtbar wird. Er bevorzugte stets die Arbeit in Stein, der Bronzeguss war für ihn lediglich „Abguss. " ${ }^{22}$ Durch seine mehr als 30-jährige Lehrtätigkeit an der Akademie prägte er nachfolgende Bildhauergenerationen. Im Winter 1930/3I wurde im Künstlerhaus Wien eine Gedächtnisausstellung mit Porträtbüsten, Gipsstudien und Marmorreliefs veranstaltet. ${ }^{13}$ Die von Zumbusch geschaffenen monumentalen Denkmäler an der Wiener Ringstraße tragen bis heute zur großen Bedeutung in der Öffentlichkeit bei.

Der Bildhauer Arnold Hartig, geboren in Brand bei Tannwald, arbeitete hauptsächlich als Medailleur. Schon während seiner Lehrzeit in Gablonz an der Neiße befasste er sich mit dem Zeichnen lebensgroßer Porträts. Sein Interesse an der Medaillenkunst brachte ihn ab I898 durch ein Staatsstipendium an die Wiener Kunstgewerbeschule zu dem Medailleur Stefan Schwartz, unter dem er hauptsächlich mit Kupfertreib-

6 Einige dieser Bildhauer sind auch im Arkadenhof vertreten. Eine Liste mit I3I Schülern findet sich bei M. KolIsKo, Caspar von Zumbusch, Wien 1932, S. 123-I24.

7 Poch-Kalous, Wiener Plastik im 19. Jahrhundert (zit. Anm. 5), S. 216.

8 Vgl. Marsel, Gelehrte in Stein und Bronze (zit. Anm. I), S. I6. In dieser Funktion war er bei der bis I9I4 erfolgten, relativ raschen Ausstattung mit Denkmälern, bei der auch ältere Büsten, wie die von Gerard van Swieten, Andreas Josef von Stifft oder Josef Quarin in den Arkadenhof verlegt wurden, beteiligt. Siehe hierzu den Beitrag von I. Schemper in diesem Band.

9 Siehe hierzu W. Krause, Die Plastik der Wiener Ringstraße, Von der Spätromantik bis zur Wende um I9oo, mit I87 Abbildungen und 4 Textfiguren, Wiesbaden 1980, S. 63-67, S. I83-I85 und Poch-Kalous, Wiener Plastik im I9. Jahrhundert (zit. Anm. 5), S. 2II-2I7.

IO Für das Denkmal für Theodor Billroth siehe den Beitrag von J. Rüdiger in diesem Band.

II Krause, Plastik der Wiener Ringstraße (zit. Anm. 9), S. I85.

I2 Poch-Kalous, Wiener Plastik im 19. Jahrhundert (zit. Anm. 5), S. 215.

I3 Vgl. Künstlerhaus Wien, Gedächtnisausstellung Kaspar von Zumbusch, Herbstausstellung 22. November I9306. Jänner I93I, Wien I930, S. 39-43. 
arbeiten beschäftigt war und der ihn, nach Hartigs Überlieferung, „,von der Medailleurkunst immer ferngehalten [hat]. ${ }^{\text {"I4 }}$ I9O3 verließ er die Kunstgewerbeschule und arbeitete als freischaffender Künstler in Wien. Nach Ausstellung einiger seiner Werke im Künstlerhaus wurde er dessen Mitglied und konnte sich durch zahlreiche Porträtaufträge erfolgreich als bildender Künstler etablieren. Während des Ersten Weltkriegs arbeitete er als Kriegsmedailleur, erst danach wieder selbständig. Im Gegensatz zu Kaspar von Zumbusch umfasst das Euvre von Arnold Hartig hauptsächlich Medaillen, Plaketten und Münzen für private wie staatliche Auftraggeber und nur wenige Großplastiken. Besondere Beachtung erfuhr er für seine Fähigkeit, lebensnahe Porträts der dargestellten Personen nach dem Modell zu liefern. Bei persönlichen Sitzungen in seinem Atelier verzichtete Hartig auf Zeichnungen und modellierte das Bild unmittelbar in Wachs, danach setzte er es in Gips und schließlich in Metall um. ${ }^{\text {Is }}$ Stilistisch ist Hartig in seinen anfänglichen Werken in Wien vom ausgehenden Jugendstil und Sezessionismus geprägt, verwendet zwar im- mer wieder dekorative Elemente, immer aber in Kombination mit realitätsnahen Porträts. ${ }^{16}$ Seine Fähigkeit, traditionelle, wirklichkeitsabbildende Porträts zu schaffen, brachte Hartig zahlreiche Aufträge ein. Hartigs künstlerische Ausdrucksform kennzeichnete seit den I930er-Jahren eine Tendenz zur Konventionalität, da er sich bei der Bildformulierung immer wieder nach dem jeweiligen Auftraggeber richtete, was besonders im Spätwerk zu einer deutlichen Abnahme des künstlerischen Anspruches führte. ${ }^{17} \mathrm{Ab}$ den I95oer-Jahren wurde er seitens der Universität Wien für den Arkadenhof für fünf Denkmäler beauftragt. Nach den beiden Denkmälern für die Theologen Franz Martin Schindler und Rudolf von Scherer, die im Jahr I95I enthüllt wurden, folgten jene für Gustav Riehl 1954, für Karl Landsteiner 196I und für Alfons Dopsch 1964. Hartig wählte in allen eine formal sehr ähnliche Gestaltung, er zeigt den Geehrten im Porträtprofil im Rahmen eines dunklen bronzenen Medaillons, das von einer hellen Steinplatte eingefasst wird.

\section{DIE DENKM ÄLER FÜR ERNST LUDWIG UND LEOPOLD SCHRÖTTER VON KRISTELLI VON KASPAR VON ZUMBUSCH}

Das Denkmal für den Chemiker Ernst Ludwig (I842-1915) befindet sich an der Innenseite des vorletzten Pfeilers im rechten Arkadengang (Abb. 2). Ludwig war seit dem Jahr I874 or-

I4 A. Hartig, Aus meinem Leben, Vom Bauernjungen zum Künstler, Erlebnisse mit porträtierten Persönlichkeiten, Wien I964, S. I8.

I5 Hartig, Aus meinem Leben (zit. Anm. I4), S. 20-24; Gemäß B. Prokisch, Der Nachlass Arnold Hartig im Museum Lauriacum in Enns, Katalog, Teil I: Das Medaillenwerk, Linz/Wien 2005, S. 2I-22, hatte Hartig als Metalle Bronze und bronziertes Eisen verwendet, während des Zweiten Weltkrieges auch Zinn und eine nicht identifizierte Legierung. Prokisch erwähnt ein erhaltenes Wachsmodell einer Kriegsfürsorge-Medaille auf Erzherzogin Isabella. Im Akt zu dem Denkmal für Alfons Dopsch ist eine genaue Kostenaufstellung Hartigs an den Senat der Universität erhalten. Darin enthalten sind die Kosten für die Vergrößerung aus Paraffin, die von einem Gipsgießer in ein Negativ und Positiv gegossen werden sollte. Anschließend sollte der Bronzeguss des Medaillons und die Einfassung in eine Platte aus Untersberger Forellenmarmor erfolgen. Vgl. Akt im Archiv der Universität Wien (UAW), zit. UAW Senat S 222.40, Kostenaufstellung des Künstlers Hartig an das Institut für Wirtschafts- und Sozialgeschichte zu Handen des Vorstandes, Univ.-Prof. Alfred Hoffmann, 27. November 1963.

i6 B. Prokisch, Der Nachlass des Medailleurs Arnold Hartig (I878-1972). Bericht über eine Lehrveranstaltung, in: Mitteilungsblatt des Instituts für Numismatik und Geldgeschichte, SoSe 2005, Wien 2005, S. 24-25.

I7 Zitiert nach Proкisch, Der Nachlass des Medailleurs Arnold Hartig (zit. Anm. I6), S. 26. 


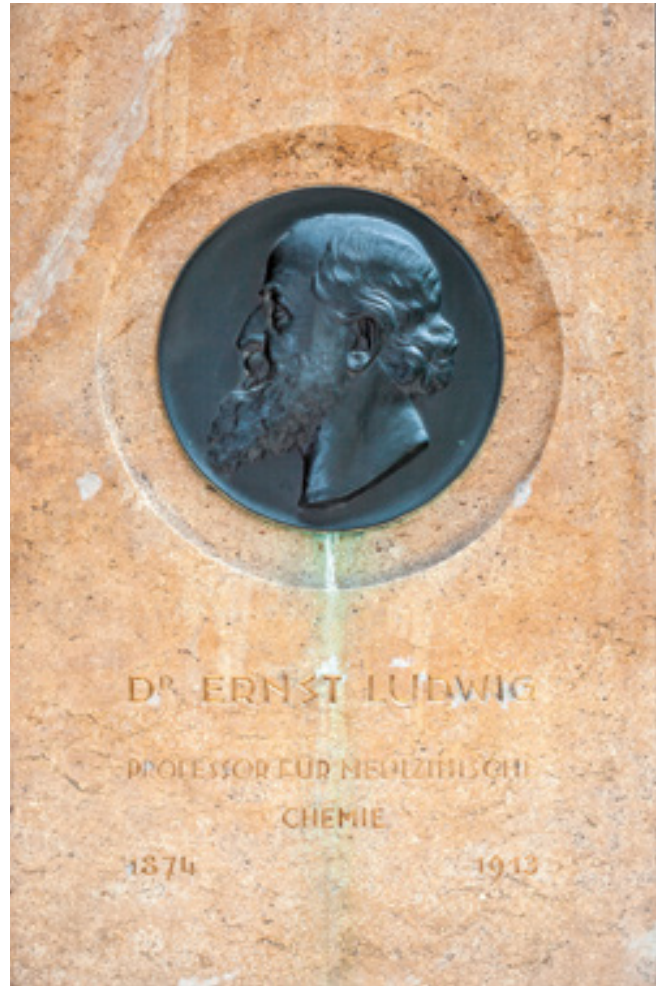

Abb. 2: Kaspar von Zumbusch, Tafel aus Osliper Stein mit Porträtmedaillon aus Bronze für Ernst Ludwig (I842-I9IS), 1932 enthüllt, Arkadenhof der Universität Wien.

dentlicher Professor für analytische und organische Chemie an der medizinischen Fakultät. Ein Schwarz-Weiß-Negativ nach einer Fotografie von Fritz Luckhardt zeigt Ludwig als älteren Mann mit Bart, das Haar zurückgekämmt, den Kopf leicht nach links gewandt, in dunklem Anzug, mit hellem Hemd und dunkler Krawatte (Abb. 3). Ernst Ludwig befasste sich mit der Analyse der Stoffe Arsen und Quecksilber und entwickelte unter anderem ein Verfahren zur Feststel-

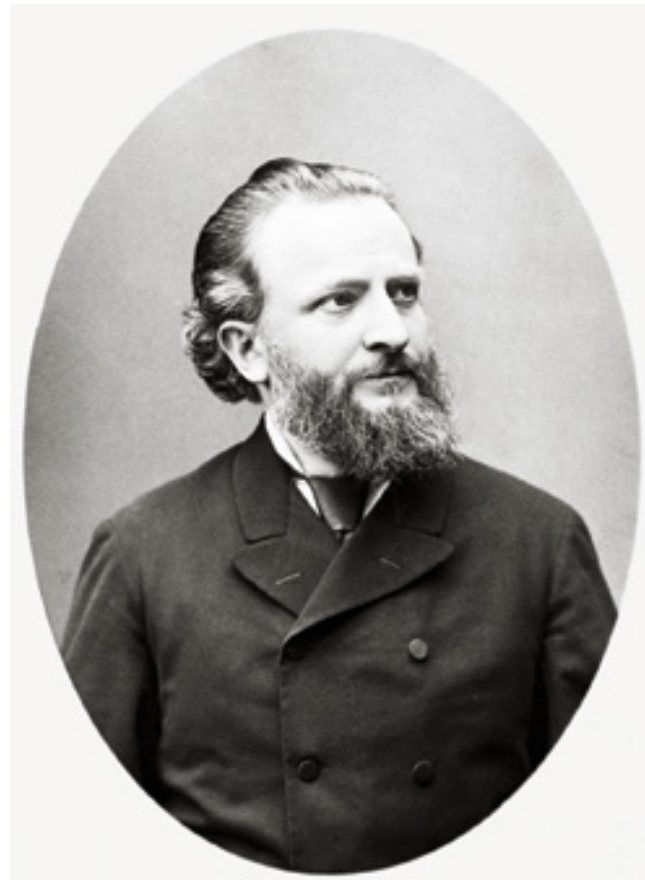

Abb. 3: S/W-Repronegativ nach einer Fotografie von Fritz Luckhardt, Ernst Ludwig in Oval, o. J., Österreichische Nationalbibliothek, Inv.-Nr. NB 53453 .

lung der Harnsäure im Harn. Er war Mitglied der Kaiserlichen Akademie der Wissenschaften in Wien, Dekan der medizinischen Fakultät in den Jahren I886/87 und I890/9I und im Jahr I892/93 Rektor der Universität Wien. ${ }^{18}$ I9I5 starb Ludwig in Wien. Im Jahr I93I stellte auf Wunsch der Familie Ludwigs ein Professorenkollegium den Antrag für ein Denkmal im Arkadenhof der Universität. ${ }^{19}$ Wie aus den Akten des Universitätsarchivs hervorgeht, befand sich das Medaillon bis dahin im Besitz der Familie und wurde für das Denkmal zur Verfügung gestellt. ${ }^{20}$ Die zuständi-

I8 Maisel, Gelehrte in Stein und Bronze (zit. Anm. I), S. 80. Vgl. den Eintrag zu Ernst Ludwig bei monuments - das Wiki zu den Denkmälern der Universität Wien, https://monuments.univie.ac.at/index.php?title=Ernst_Ludwig, abgerufen am 18. Februar 20I5.

I9 UAW Senat S 90.22, Antrag der Professoren Fürth, Chvostek und Hochstetter für ein Denkmal für Ernst Ludwig an das Professorenkollegium der medizinischen Fakultät der Universität Wien vom 7. Mai I93I.

20 UAW Senat $S$ 90.22, Schreiben des Rektors an den Vorsitzenden der artistischen Kommission des akademischen Senats Gustav Riehl vom 24. Oktober I93I. 


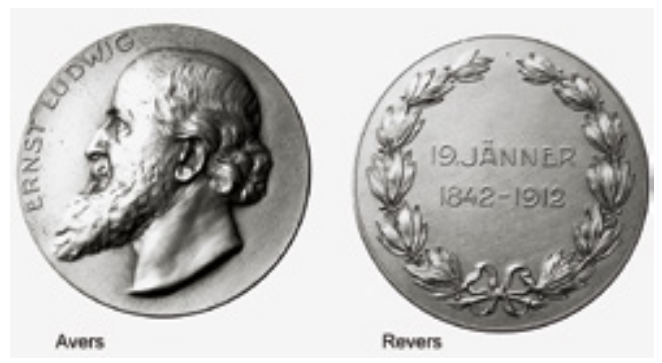

Abb. 4: Kaspar von Zumbusch, Medaille für Ernst Ludwig, I9I2, Ø 55 mm, UAW Sign. 102.2.3.

ge artistische Kommission forderte, dass bei der Konzeption hinsichtlich Größe und Format auf umliegende Denkmäler Bezug genommen werden soll. ${ }^{21} \mathrm{Da}$ als Anbringungsort der Platz gegenüber der Marmortafel für den Gynäkologen Rudolf Chrobak des Bildhauers Edmund Hellmer von 1927 ausgewählt wurde, sollte die rahmende Steintafel für das Medaillon formal entsprechend gestaltet sein..$^{22}$ Die von der beauftragten Wiener Steinmetzfirma Hauser hergestellte hochrechteckige und matt geschliffene Tafel aus hellem Sandstein - Osliper Stein - weist in der oberen Hälfte eine kreisrunde, muldenartige Vertiefung auf, in die das Medaillon eingelassen wurde. ${ }^{23}$ In der unteren Hälfte wurde eine in Gold gefasste Inschrift hinzugefügt, die den Namen und das Tätigkeitsfeld Ernst Ludwigs bezeichnet, sowie die Jahreszahlen I874 und I9I3 für die Dauer seiner Lehrtätigkeit an der Universität Wien.

Das von Zumbusch angefertigte bronzene Medaillon weist an der Unterseite des Halsansatzes die Signatur und Datierung „C.v.Z.I9I2“ auf und wurde demzufolge zwei Jahre vor dem Tod
Ernst Ludwigs hergestellt. Der Künstler zeigt den Chemiker entsprechend seinem Alter als älteren Mann mit Bart, das gelockte Haar streng nach hinten und über das Ohr gekämmt, deutlich im Profil und mit knappem Halsabschnitt. Zumbusch verzichtete im Gegensatz zu Glaser auf die Darstellung eines Brustbildes in klassischer Nacktheit und konzentriert sich auf den Kopf in Profilansicht. Die Gestaltung entspricht Zumbuschs historisierendem und idealisierendem Stil, die strenge Form verleiht dem Porträt Würde und Idealität. Gleichzeitig werden damit die Verdienste um die chemische Wissenschaft geehrt. Die Ansicht des Kopfes im strengen Profil unterstreicht den antikisierenden Charakter des Medaillons. Im Vergleich zu dem bereits erwähnten Porträt von Luckhardt erscheint Ludwig im Medaillon deutlich idealisiert und durch den leicht nach oben gerichteten Kopf und in die Ferne schweifenden Blick von der Umwelt entrückt. Gleichzeitig charakterisiert der Bildhauer ihn durch lebensnah gestaltete Details, wie etwa den Bart und den im Bereich der Augen und am Hals vertieften fein gearbeiteten Falten.

Aus dem Entstehungsjahr des Medaillons 1912 stammt eine von Zumbusch anlässlich des 70. Geburtstages für Ernst Ludwig gefertigte Bronzemedaille (Abb. 4). ${ }^{24}$ Auf dem Avers befindet sich dessen Profilporträt nach links mit Vorund Nachname als Umschrift, auf dem Revers ein gebundener Lorbeerkranz, der im Mittelfeld das Geburtsdatum „I9. Jänner“ und die beiden Jahreszahlen „I842-I9I2“ einfasst. Bereits auf den ersten Blick wird deutlich, dass das Porträt auf

2I UAW Senat S 90.22, Schreiben des Rektors Hans Uebersberger an den Dekan der medizinischen Fakultät Roland Grassberger vom 20. Juli I93I.

22 UAW Senat S 90.22, Auszug aus dem Protokoll der Sitzung des akademischen Senats unter der Leitung von Prof. Dr. Gustav Riehl vom i6. Februar 1932.

23 Vgl. UAW Senat S 90.22, Rechnung Firma Eduard Hauser (Inhaber Robert Hauser) an die Universitäts-Gebäudeinspektion, Wien, vom 30. Juni 1932. Bei M. Kolısko, Caspar von Zumbusch (zit. Anm. 5), S. Io6 wird aus der Korrespondenz zwischen der Firma E. Hauser und Zumbusch zitiert. Darin ersucht Hauser den Bildhauer um die Fortsetzung ihrer erfolgreichen Zusammenarbeit und die Verwendung des ihm bekannten Materials. Die Firma E. Hauser war im Besitz der Laaser Brüche.

24 Vgl. Hölbling, Medaillen der Wissenschaft (zit. Anm. 2), S. 99, Nr. I84 und Abbildung der Medaille aufTafel 6I. 


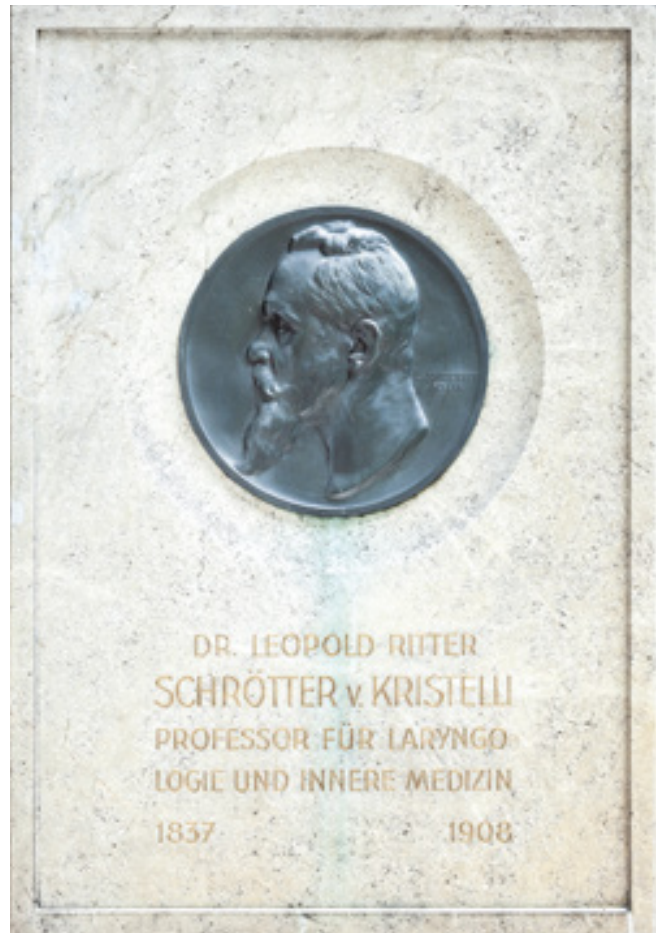

Abb. 5: Kaspar von Zumbusch, Tafel aus Osliper Stein mit Porträtmedaillon aus Bronze für Leopold Schrötter von Kristelli (I837-1908), I937 enthüllt, Arkadenhof der Universität Wien.

der Vorderseite eindeutig Parallelen zum Abbild des Chemikers im Medaillon aufweist. Daher ist davon auszugehen, dass Zumbusch bei beiden Werken auf ein einziges Modell - evtl. aus Gips oder Wachs - zurückgegriffen hat. Dieses meist lebensgroß entworfene Gipsmodell ließ sich mithilfe einer Reduktionsmaschine auf die Größe einer Medaille verkleinern und ebenso auf die eines Medaillons vergrößern. ${ }^{25}$ Durch die große Ähnlichkeit der beiden Werke erzeugt das Porträt des Chemikers eine erhöhte Wiedererkennbarkeit beim Betrachter. Da mehrere Personen im Besitz einer solchen Medaille sein konnten,

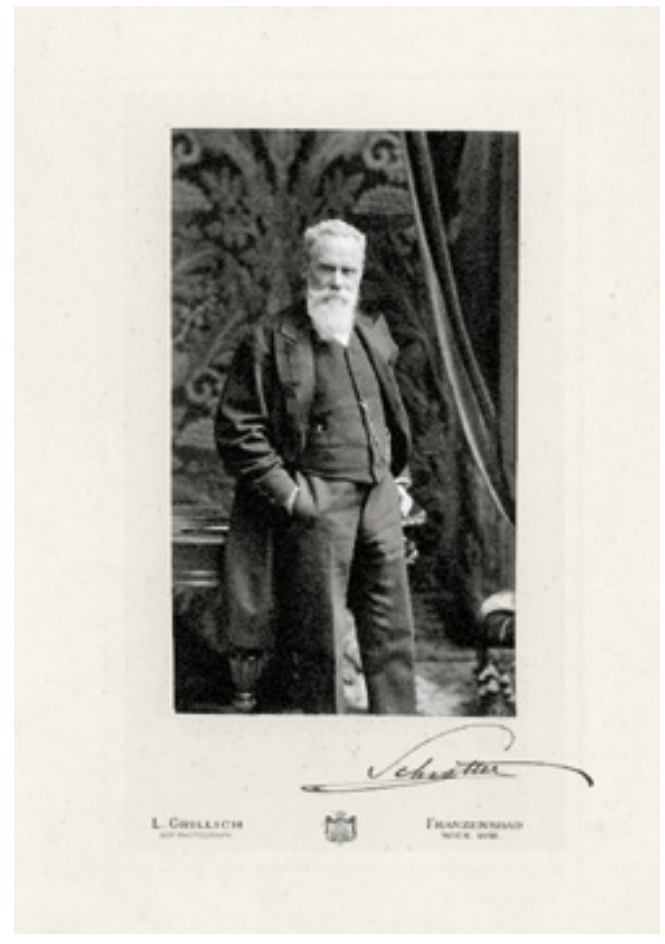

Abb. 6: Ludwig Grillich, Bildnis Leopold Schrötter von Kristelli in vorgerückten Jahren (fast ganze Figur stehend, etwas rechts; die Rechte im Hosensack), eigenhändiger $\mathrm{Na}$ menszug, o. J., Österreichische Nationalbibliothek, Inv. $-N r$. Pf $104.048: E(2)$.

war damit auch das Porträt des Geehrten entsprechend verbreitet.

Das zweite Denkmal, das ein Medaillon Zumbuschs beinhaltet, ist dem Mediziner Leopold Schrötter von Kristelli (I837-1908) gewidmet (Abb. 5). Dieser war weltweit der erste Dozent der Laryngologie und ein Pionier in der Endoskopie der Atemwege und im Kampf gegen Lungentuberkulose. ${ }^{26}$ Eine Fotografie in schwarzweiß von dem Fotografen Ludwig Grillich zeigt ihn im Anzug stehend vor einem halbhohen Tisch und einer angedeuteten Draperie im Hintergrund (Abb. 6). Die rechte Hand steckt in der

25 Mittels Reduktionsmaschine wird der Entwurf eines Gipsmodells maßstabsgetreu auf die Patrize übertragen. Bis zur Einführung dieser Reduzier- oder Reduktionsmaschine wurden die Münz- und Medaillenbildnisse nach einer Zeichnung von den Stempelschneidern direkt in den Stempel geschnitten. Vgl. T. KROHA, Großes Lexikon der Numismatik, Gütersloh 1997, S. 378.

26 F. Czeike, Historisches Lexikon Wien, 5, Wien 1997, S. I49. 
rechten Hosentasche seines dunklen Anzugs, mit der linken Hand hält er sich an der Hosentasche fest, er trägt ein helles Hemd, darüber eine dunkle Weste, an der die Kette der Taschenuhr sichtbar ist, und einen knielangen dunklen Mantel. Der weiße Vollbart und das schüttere, zurückgekämmte Haar lassen auf ein fortgeschrittenes Alter schließen. Seine gerade Haltung ist betont streng, er blickt den Betrachter direkt an, dadurch erhält das Porträtfoto offiziellen Charakter. Ab i870 war er Vorstand der neu errichteten Klinik für Laryngologie, ab I875 außerordentlicher Professor für Kehlkopf- und Brustkrankheiten und ab I885 ordentlicher Professor für Innere Medizin an der Universität Wien. ${ }^{27}$

Das bronzene Reliefmedaillon wurde von Zumbusch im Jahr 1907 angefertigt und zeigt den Mediziner im Profil. Bis zur Errichtung des Denkmals in der Universität befand es sich im Besitz der Familie Schrötter von Kristelli. ${ }^{28}$ Wie aus den Senatsakten des Kunstausschusses im Universitätsarchiv hervorgeht, sollte das Medaillon mittels rahmender Steintafel, welche in Größe, Material und Beschriftung jener für Ernst Ludwig entsprechen sollte, eingefasst und danach an geeigneter Stelle im Arkadenhof angebracht werden. Als Material sollte ebenfalls Osliper Stein aus dem Burgenland verwendet werden, da dieser in kürzester Zeit eine Färbung ähnlich der Pfeiler des Arkadenhofs annehmen würde und die preisgünstigere Variante darstellte. Den Auftrag erhielt wieder die Wiener Stein- metzfirma Hauser. ${ }^{29}$ Als Ort entschied man sich für die Pfeilerseite gegenüber des 1928 im Arkadenhof enthüllten und von dem Bildhauer Josef Müllner gestalteten Denkmal für den Philologen und Anglisten Jakob Schipper..$^{30}$ Damit befand es sich nur eine Pfeilerarkade entfernt und in unmittelbarer Nähe des Denkmals für Ernst Ludwig. Anlässlich des Ioo. Geburtstages von Schrötter von Kristelli am 30. Jänner 1937 fand die Enthüllung des Denkmals im Arkadenhof statt. $^{31}$

Das dunkle, bronzene Medaillon wurde auch hier durch eine muldenartige, kreisrunde Vertiefung in die helle Steintafel eingelassen. Zumbusch wählte für das Porträt im Medaillon - wie schon bei Ernst Ludwig - eine idealisierende Darstellung und zeigt den Mediziner als älteren Mann mit Bart im Profil nach links. Als dekoratives Element wird die Kontur des Medaillons durch eine Profilierung betont. Das Bildnisporträt befindet sich zentral im Mittelfeld. Das Medaillon ist signiert und datiert: „C.v.Z. f. 1907.“ Zusätzlich ist im Nackenbereich unterhalb des Namens der Zusatz „AET. LXX.“ sichtbar. Mit diesen beiden Angaben wird nicht nur auf das Entstehungsjahr 1907 verwiesen, sondern auch auf den 70. Geburtstag des Mediziners, der den Anlass für die Darstellung bot. Die feine Modellierung des Barts, der Haare und die insgesamt abgeschwächte Reliefhöhe tragen zu einem malerischen Gesamteindruck bei. In der unteren Hälfte der Steinplatte befindet sich die in Gold

27 Ebd. und den Eintrag zu Leopold Schrötter von Kristelli auf monuments - das Wiki zu den Denkmälern der Universität Wien, https://monuments.univie.ac.at/index.php?title=Leopold_Schrötter_von_Kristelli, abgerufen am I8. Februar 2015 .

28 UAW Senat S 91.3, Schreiben des Rektors Prof. Dr. Oswald Menghin an den Dekan der medizinischen Fakultät, Univ.-Prof. Dr. Wilhelm Karl, vom 29. Juli 1936.

29 UAW Senat S 91.3, Beiblatt zum Schreiben von Oberbaurat Prof. Leopold Bauer an den akademischen Senat der Universität Wien vom 24. Juli 1936. Die Kosten des Denkmals wurden von der medizinischen Fakultät getragen. Vgl. hierzu UAW Senat S 91.3, Schreiben des Rektors an den Dekan der medizinischen Fakultät, Univ.-Prof. Dr. Wilhelm Karl, vom 25. Jänner 1937.

30 UAW Senat S 9I.3, Protokoll der Sitzung des akademischen Senats unter der Leitung von Hofrat Univ.-Prof. Dr. Gustav Riehl vom i9. März 1936.

3I UAW Senat S 91.3, Schreiben des Rektors an Oberbaurat Prof. Ludwig Bauer vom 23. Dezember 936. 


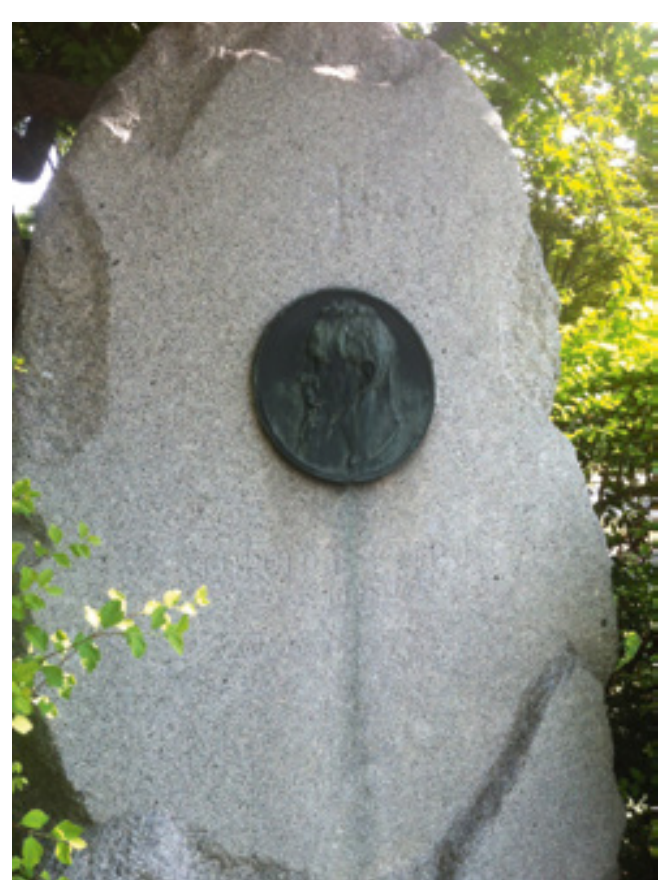

Abb. 7: Kaspar von Zumbusch, Grabmal auf dem Wiener Zentralfriedhof für Leopold Schrötter von Kristelli, Gruppe I4A, Nr. I9, Rohling aus Syenit mit Porträtmedaillon aus Bronze.

gefasste Inschrift, die den Namen und die Tätigkeit Schrötter von Kristellis angibt, sowie - in diesem Fall anders als bei dem zuvor besprochenen Denkmal - die Lebensdaten des Dargestellten: I837-1908. Wie schon das Reliefporträt für
Ludwig erinnert auch das Medaillon für Schrötter von Kristelli an antike Münzen- und Medaillenporträts. Die Konzentration auf das Porträtprofil mit heroisch nacktem Hals unterstützt diese Assoziation. Leopold Schrötter von Kristelli starb 1908 in Wien. Sein Ehrengrab auf dem Wiener Zentralfriedhof trägt ein auf einem Rohling aus Syenit montiertes Bronzemedaillon, das von Zumbusch stammt (Abb. 7). ${ }^{32}$ Dieses wurde I 907 gefertigt und 1909 auf das Ehrengrab übertragen. ${ }^{33}$ Aufgrund der eindeutigen Parallelen zwischen den beiden Medaillons ist davon auszugehen, dass beide nach einem Modell gegossen wurden. Beide zeigen den Geehrten im Profilporträt nach links. Dadurch steht das Denkmal in direkter Verbindung zum Ehrengrab und erhält durch das idente Porträt einen gesteigerten Wiedererkennungswert. Den wesentlichen Unterschied stellt die Denkmalform dar, da die Anbringung auf einem Rohling für den Arkadenhof undenkbar gewesen wäre. Hier wurde die Form eines Epitaphs bevorzugt und umliegende Denkmäler für die Gestaltung miteinbezogen. Im direkten Vergleich zur Schwarz-Weiß-Fotografie von Grillich kann in beiden Medaillons der idealisierende Zug in der Wiedergabe des Mediziners beobachtet werden. Das strenge Profil nach links, der leicht nach oben gerichtete Blick und die klassische Darstellung verleihen dem Porträt eine würdevolle Wirkung.

\section{DIE DENKM ÄLER F ̈̈R GUSTAV RIEHL UND KARL LANDSTEINER VON ARNOLD HARTIG}

Parallelen und Unterschiede zu den soeben besprochenen zwei Denkmälern lassen sich in den Werken des Bildhauers und Medailleurs Arnold Hartig beobachten. Nach den beiden Denkmälern für Rudolf von Scherer und Franz Martin
Schindler folgte das Denkmal für den Dermatologen und Rektor der Universität Wien im Jahr I92I/22, Gustav Riehl (I855-I943). Es befindet sich in der letzten Arkade des rechten Arkadengangs und wurde von einem Professorenkolle-

32 Das Ehrengrab befindet sich in der Gruppe i4 A, Nummer I9 und wurde 1909 enthüllt. Siehe Kleine Chronik vom 7. Juni I909, [...] Grabdenkmalsenthüllung, In: Wiener Zeitung, Nr. I29, 8. Juni 1909, S. 3; W. KitLitschka, Grabkult \& Grabskulptur in Wien und Niederösterreich, St. Pölten/Wien 1987, S. 9I-99. 


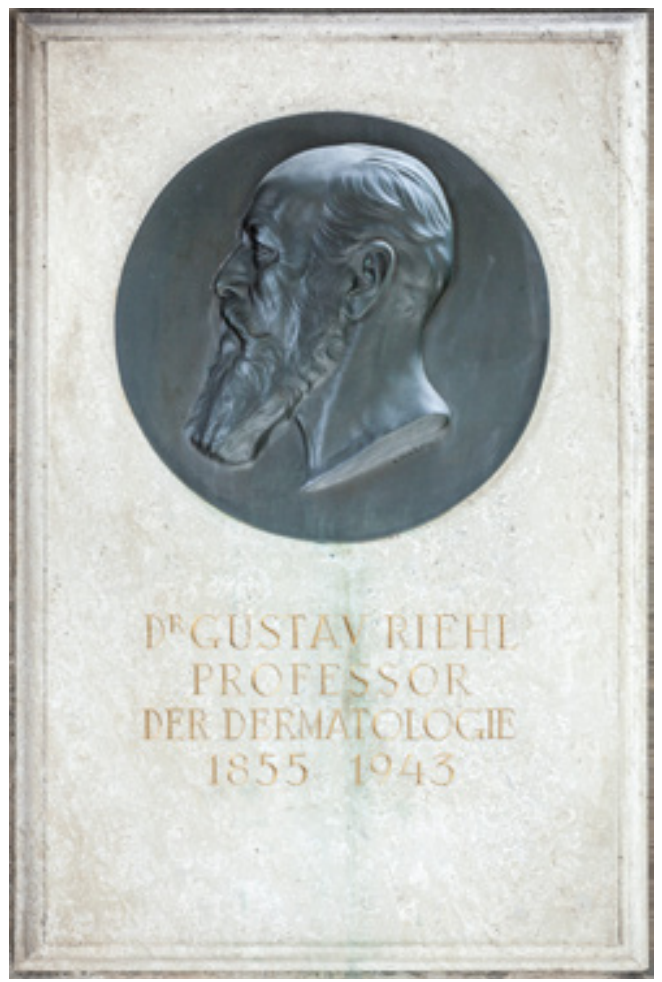

Abb. 8: Arnold Hartig, Steintafel mit Porträtmedaillon aus Bronze für Gustav Riehl (1855-1943), 1954 enthüllt, Arkadenhof der Universität Wien.

gium der medizinischen Fakultät im Juni 1954 beantragt (Abb. 8) ${ }^{34}$ Riehl war ab I88o als Assistenzarzt im Allgemeinen Krankenhaus in Wien tätig. ${ }^{35}$ Nach seiner Habilitation für Dermato- logie und Syphilidologie wirkte er ab I898 als außerordentlicher Professor an der Universität Leipzig. 1902 wurde Riehl Vorstand der Universitäts-Hautklinik im Allgemeinen Krankenhaus in Wien. ${ }^{36}$ Sein Verdienst liegt insbesondere in der pathologischen Histologie von Hautkrankheiten und in der Einführung einer eigenen Radiumstation. ${ }^{37} \mathrm{Im}$ Jahr 1914 wurde er in die Artistische Kommission der Universität berufen und übernahm bis 1937 deren Vorsitz. ${ }^{3}$ Während dieser Zeit fanden auch die beiden oben genannten Denkmalerrichtungen mit den gestifteten Zumbusch-Medaillons im Arkadenhof statt. Riehl war auch mit dem Sohn des Bildhauers, Leo Zumbusch, in Kontakt, da dieser ebenfalls Dermatologe war und sie gemeinsam den in drei Teilen zwischen 1923-25 erschienenen „Atlas der Hautkrankheiten " herausgaben. ${ }^{39}$ In einer Schwarz-Weiß-Fotografie ist der Mediziner leicht nach links in Dreiviertelansicht abgebildet, sein Gesicht dem Betrachter frontal zugewandt (Abb. 9). Riehl blickt den Betrachter direkt und mit fixierendem Blick an. Die sehr ausdrucksstarke Fotografie zeigt ihn hier als älteren Mann mit Vollbart und kahlem Kopf, mit dunklem Anzug mit Jacke und Weste, hellem Hemd und weißer Krawatte. Bei der Errichtung des Denkmals im Jahr 1954 entschied sich der akademische Senat für ein Porträtmedaillon und vergab den Auftrag an Hartig noch im selben Jahr..$^{40}$ Er schien

33 Vgl. Kolisкo, Caspar von Zumbusch (zit. Anm. 5), S. I38.

34 MaIsel, Gelehrte in Stein und Bronze (zit. Anm. I), S. 77; UAW Senat S 222.23, Schreiben des Dekans der med. Fak., Prof. F. Brücke, an die artistische Kommission des akademischen Senats vom 25. Juni I954. Interessanter Aspekt hier: Die Abstimmung über die Errichtung des Denkmals zu Ehren Riehls erfolgte nicht einstimmig, sondern wurde nur knapp befürwortet.

35 Stichwort „Gustav Riehl“, in: Professorenkatalog der Universität Leipzig (20I3), online via http://www.uni-leipzig. de/unigeschichte/professorenkatalog/leipzig/Riehl_956/, abgerufen am 8. September 2014. UAW Senat S 265.4.I25, Personalblätter der medizinischen Fakultät aus dem Jahr 1942. 1985), S. 155 .

38 UAW Senat S 88.I, Wahl von Gustav Riehl in die artistische und von Anton Weichselbaum in die Gebäude-Kommission, I9I4/I5 und UAW Senat S 9I.II, Gustav Riehl legt seine Stelle als Mitglied des Kommissionsausschusses zurück, I937.

39 Vgl. Morgenstern, Riehl Gustav (zit. Anm. 38), S. I55. Inwieweit Gustav Riehl mit Leo Zumbusch bei der Errichtung der Denkmäler in Kontakt war, wäre noch zu untersuchen, und ob Riehl je mit Caspar von Zumbusch in Kontakt war. 


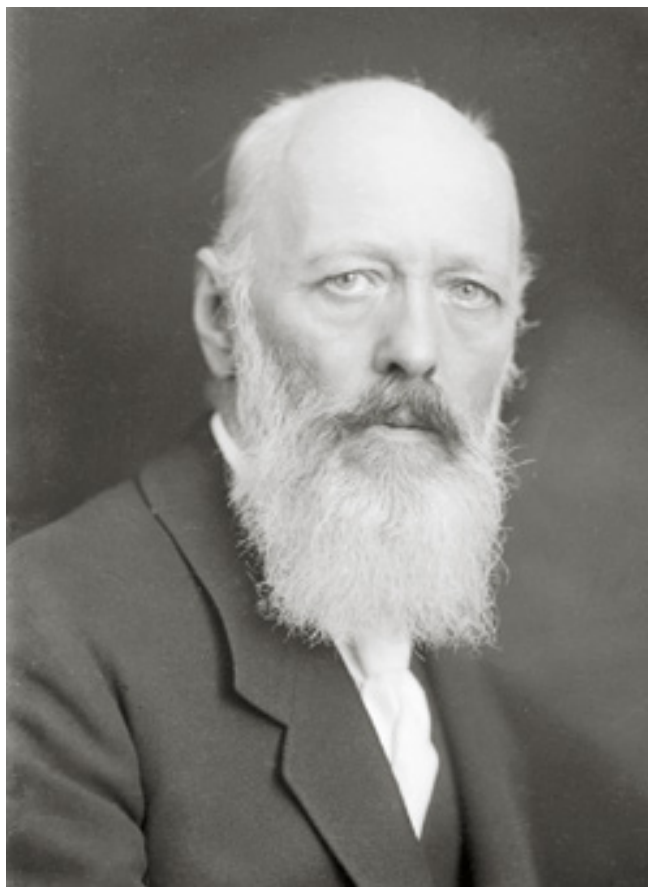

Abb. 9: Wilhelm Hlosta, Porträtfotografie Gustav Riehl, o. J., Österreichische Nationalbibliothek, Inv.-Nr. 222.224.

als ausführender Künstler schnell festzustehen, da er bereits zu Lebzeiten Riehls vom Rektorat den Auftrag erhalten hatte, eine Gedenktafel mit überlebensgroßem Porträt für Riehls Hörsaal anzufertigen. An dieser soll der Künstler anhand mehrerer Sitzungen in seinem Atelier gemeinsam mit Riehl gearbeitet haben. ${ }^{4 \mathrm{I}}$ Für den Arkadenhof wurde das Medaillon in eine am Rand profilierte Steintafel der Fa. Eduard Hauser eingelassen. ${ }^{42}$ Das Porträt zeigt Riehl im Profil nach links mit längerem Vollbart, ohne Kleidung, den Kopf leicht nach oben und den Blick ins Unbe-

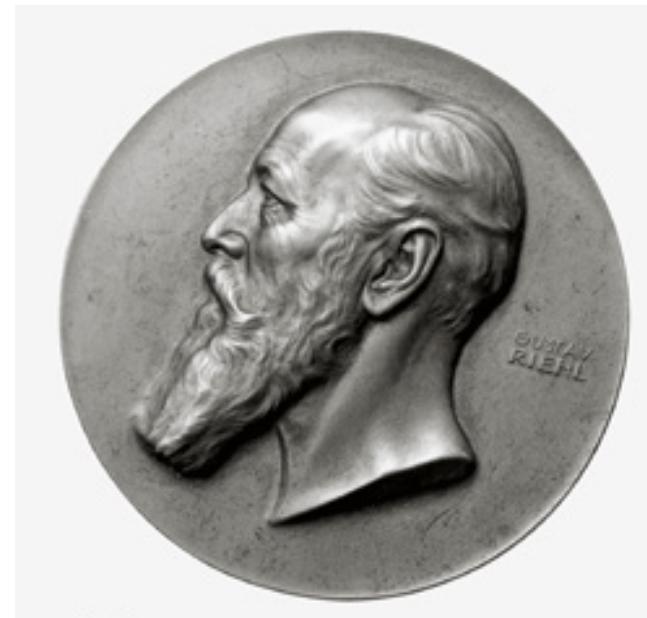

Abb. Io: Arnold Hartig, Medaille für Gustav Riehl, o. J., $\varnothing 60 \mathrm{~mm}$, UAW Sign. 102.3.7.

stimmte gerichtet. Es weist keine Attribute auf, die ihn als Mediziner oder als Rektor ausweisen würden. Erst durch die in Gold gefasste Inschrift in Versalien in der unteren Hälfte der Steintafel wird er als Professor der Dermatologie mit entsprechendem Titel, Vor- und Zuname sowie seinen Lebensdaten identifizierbar. Im Vergleich zur Fotografie arbeitete Hartig im Medaillon abstrakter und reduzierter, das Profilbild wirkt statisch und gleichzeitig durch die heroische Nacktheit idealisiert. Eine von Hartig knapp dreißig Jahre früher gefertigte Bronzemedaille aus dem Jahr 1925 zeigt den Dermatologen ebenfalls in Profilansicht (Abb. Io). ${ }^{43}$ Die Medaille wurde von Hartig anlässlich des 70. Geburtstages von Gustav Riehl geschaffen. Die im Durchmesser $60 \mathrm{~mm}$ große Prägemedaille weist auf dem Avers neben dem Porträt den Namen des Dargestell-

40 UAW Senat S 222.23, Schreiben des Rektors Leopold Schönbauer an den Dekan Franz Brücke vom I. Juli 1954.

4I Vgl. Hartig, Aus meinem Leben (zit. Anm. I4), S. 50; Der Hörsaal war, wie das Fach Dermatologie, bis zur Übersiedlung ins neue AKH Teil der II. Wiener Hautklinik und im Hof 2 des Alten AKH untergebracht. Heute befindet sich dort das Institut für Japanologie (Hof 2.4). Es gibt bisher keinen Hinweis, ob sich das Relief erhalten hat. An der Außenwand befindet sich heute noch das bronzene Porträtmedaillon für den Dermatologen Ferdinand Hebra, bez. Grienauer und Köttendorfer, mit Inschrift.

HöLbLING, Medaillen der Wissenschaft (zit. Anm. 2), S. I08, Nr. 207. 


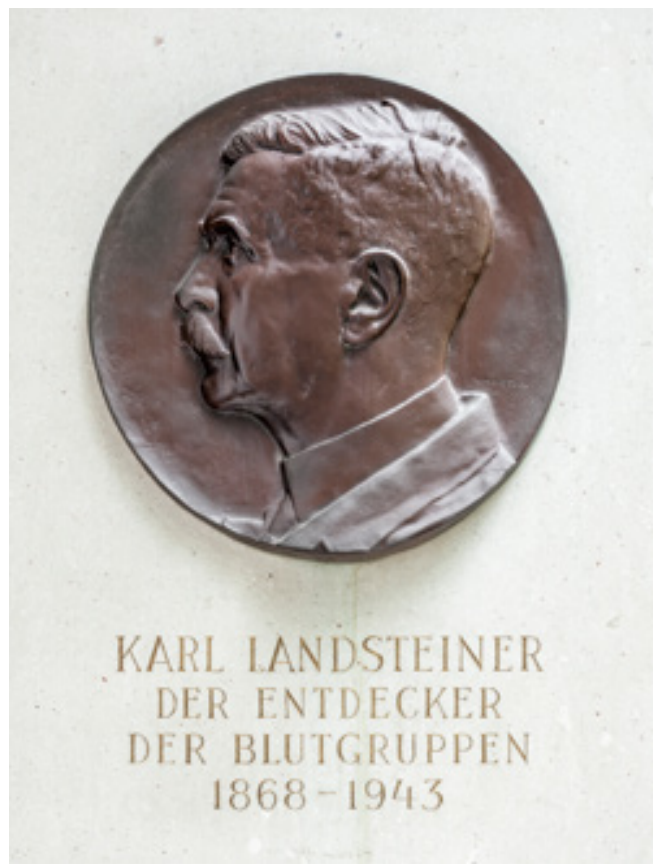

Abb. II: Arnold Hartig, Denkmal mit Porträtmedaillon aus Bronze für Karl Landsteiner (I868-1943), I96I enthüllt, Arkadenhof der Universität Wien.

ten und die Signatur des Künstlers auf. ${ }^{44}$ Hartig dürfte bei seiner Gestaltung des Porträtmedaillons für den Arkadenhof das Wachs- oder Gipsmodell der Medaille zur Vorlage genommen haben, wie dies auch schon bei Kaspar von Zumbusch der Fall war. Beide Porträts weisen dieselben individuellen physiognomischen Merkmale in der Darstellung des Dermatologen auf, wie an dem längeren Vollbart, dem zurückgekämmten Haar und der Modellierung des Gesichts zu erkennen ist. Der knappe Halsabschnitt und die Silhouette sind in beiden Bronzearbeiten ident und unterstützen die Annahme, dass hier von ein- und demselben Modell ausgegangen wurde. Geht man weiters davon aus, dass auch hier die Medaille einem breiteren Publikum bekannt war, so erhöht sich der Wiedererkennungswert des Medaillonporträts im Denkmal damit deutlich.

Ein weiteres Werk von Arnold Hartig ist das Denkmal für den Anatomen und MedizinNobelpreisträger Karl Landsteiner (I868-I943) (Abb. Io). Er studierte Medizin in Wien und promovierte im Jahr I89r. Danach arbeitete er an mehreren Instituten, etwa bei Max Gruber (Hygiene) und Anton Weichselbaum (Pathologie) an der II. medizinischen und I. chirurgischen Klinik in Wien. Er habilitierte sich 1903 für Pathologie in Wien und wurde I9II zum außerordentlichen Professor ernannt. ${ }^{45} 1919$ ging Landsteiner in die Niederlande und wurde 1922 an das Rockefeller-Institut in New York berufen. Dort war er bis zu seinem Tod im Jahr 1943 tätig. Für seine Verdienste im Bereich der Serologie und Immunologie - Landsteiner entdeckte das Blutgruppensystem $\mathrm{ABo}$, mit dem er sich bereits 1900 als Assistent am pathologisch-anatomischen Institut in Wien befasste - wurde ihm am Io. Dezember 1930 der Nobelpreis für Medizin verliehen. ${ }^{46}$ Damit wurde ihm die höchste Auszeichnung für seine Forschungstätigkeit zuteil. Auf dem Zweiten Österreichischen Medizinischen Kongress in Salzburg 1948 erinnerte man an die Verdienste Landsteiners und am 30. August 195I wurde eine Inschriftentafel aus Stein im Wilhelminenspital in Wien zu Ehren Landsteiners enthüllt. ${ }^{47}$ Das auf Antrag des Dekans der medizinischen Fakul-

44 Vgl. Hölbling, Medaillen der Wissenschaft (zit. Anm. 2), Tafel 69, Abb. 207; Das Revers der Medaille ist leer. Vgl. Prokisch: Nachlass Arnold Hartig im Museum Lauriacum (zit. Anm. I5), S. 34.

45 W. Gerabeck, Enzyklopädie Medizingeschichte, Berlin 2005, S. 822.

46 Landsteiner war seit 1922 am Rockefeller-Institut in New York tätig und nicht mehr in Wien. Der Vorschlag an das Nobelpreis-Komitee kam von Julius Wagner-Jauregg, der selbst 1927 den Nobelpreis für Malariatherapie bei progressiver Paralyse erhalten hatte. Siehe P. Speiser/F. G. SMeKal (Hg.), Karl Landsteiner. Entdecker der Blutgruppen und Pionier der Immunologie, Biographie eines Nobelpreisträgers aus der Wiener Medizinischen Schule, mit I26 Abbildungen, 2. Aufl., Wien 1975, S. 72.

47 Siehe Speiser/Smekal, Karl Landsteiner. Entdecker der Blutgruppen (zit. Anm. 46), S. 88, Abb. 60. 


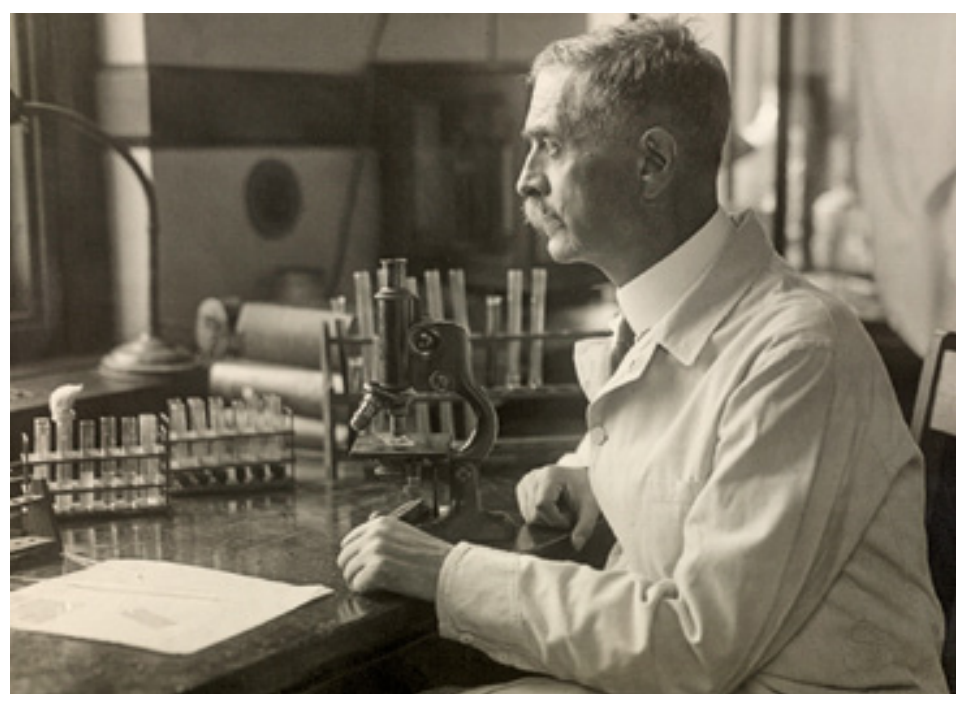

Abb. I2: Underwood \& Underwood, Fotografie in s/w mit dem Arzt Karl Landsteiner sitzend am Tisch, um 1930, Österreichische Nationalbibliothek, Inv.Nr. Pf. $4699: D(2)$.

tät beantragte Denkmal für den Arkadenhof sollte hier 196I anlässlich des 8. Kongresses der Europäischen Gesellschaft für Hämatologie und im 6o. Jahr nach der ersten Publikation Landsteiners über die klassischen Blutgruppen enthüllt werden. ${ }^{4}$ Hartig fertigte ein Gipsmodell des Porträtreliefs an, das vom Senat der Universität in dessen Atelier begutachtet und schließlich bewil-

ligt wurde. ${ }^{49} \mathrm{Als}$ Aufstellungsort einigte man sich bereits in der Sitzung zuvor, dass dieser ,im rechten Winkel beim Medizinischen Dekanat auf einem Pfeiler, wo die Sonne von rechts einfällt" sein soll.5० Das bronzene Porträtmedaillon zeigt Karl Landsteiner im Profil nach links, Mantelrevers, Hemdkragen und Krawatte sind deutlich herausgearbeitet. Es wurde in eine helle Tafel

48 Vgl. den Eintrag zum Denkmal für Karl Landsteiner auf monuments - das Wiki zu den Denkmälern der Universität Wien, https://monuments.univie.ac.at/index.php?title=Denkmal_Karl_Landsteiner, abgerufen am 20. März 20I5, UAW Senat S 222.36, Auszug aus dem Protokoll über die 2. Sitzung des akademischen Senats vom I4. Jan. I96I. Das Denkmal wird von dem Dekan der Medizinischen Fakultät, ord. Univ.-Prof. DDr. Heinrich Hayek beantragt. Senator Prof. Chiari betont, dass die Kostenfrage des Denkmals bereits geklärt sei. Gemeinsam mit dem Vorstand des Kunstausschusses Prof. Kiehler beraten sie über den Ort der Anbringung der Gedenktafel. Sowohl bei SpeISER/ SMEKAL, Karl Landsteiner. Entdecker der Blutgruppen (zit. Anm. 46), S. 89 als auch bei D. AngetTer: Die österreichischen Medizinnobelpreisträger, Wien 2003, S. 56 wird ein weiteres Relief am Institut für Blutgruppenserologie der Universität Wien - vormals Serologisches Laboratorium des Pathologisch-Anatomischen Institutes der Universität Wien - erwähnt, das ebenfalls im Jahr I96I enthüllt worden sein soll. Dort befindet sich seit 1990 aber nur eine, vom Institut für Blutgruppenserologie der Universität Wien links des Haupteingangs am ehemaligen PathologischAnatomischen Institut („Indagandis Hof“, Hof Io/AAKH, Spitalgasse 4, heute Zentrum für Hirnforschung) angebrachte Messingtafel mit Text, die die Verdienste und die Bedeutung Landsteiners ehrt. Das Relief konnte bisher nicht nachgewiesen werden.

49 UAW Senat S 222.36, Auszug aus dem Protokoll über die 3. Sitzung des Akademischen Senats vom 25. März 196I. Bei Speiser/SmeKal, Karl Landsteiner. Entdecker der Blutgruppen (zit. Anm. 46), S. 90, Abb. 62 könnte es sich aufgrund der Modellierung und Erscheinung der Oberfläche um das Gipsmodell des Porträtmedaillons handeln. In der englischen Übersetzung der Publikation von 1975 zeigt diese Abbildung das Relief deutlich weicher modelliert. Vgl. P. Speiser/F. G. Smekal (Hg.), Karl Landsteiner. The discoverer of the blood-groups and a pioneer in the field of immunology, Biography of a Nobel Prize winner of the Vienna Medical School, engl. Transl. by R. Rickett, Wien I975, S. 86, Fig. 62.

50 UAW Senat S 222.36, Auszug aus dem Protokoll über die 2. Sitzung des akademischen Senats vom I4. Jan. I96I. 
aus Stein eingelassen, darunter befinden sich in Gold gefassten Versalien sein Vor- und Zuname, der Zusatz „Der Entdecker der Blutgruppen“ sowie die Lebensdaten $1868-19433^{.1}$ Die Signatur des Künstlers „A. Hartig“ ist an prominenter Stelle rechts neben dem Nackenbereich Landsteiners sichtbar. Das Denkmal selbst besitzt keinerlei Attribute oder Symbole als Hinweis auf das Fachgebiet des Dargestellten, so wird dieser hauptsächlich durch die Inschrift identifizierbar. Landsteiner wird hier auch deutlich als Nobelpreisträger für die Entdeckung der Blutgruppen ausgewiesen und nicht etwa als Professor an der Universität Wien, wie das bei anderen Denkmälern der Fall ist. Zudem weist das Medaillon eine Referenz an die Nobelpreismedaille von dem schwedischen Bildhauer und Medailleur Erik Lindberg auf, die seit I90I auf der Vorderseite das Profilporträt Alfred Nobels nach links beinhaltet. ${ }^{52}$ Im Euvre Hartigs gibt es keine Medaille Landsteiners, auf dessen Modell oder Vorstufe er sich später als Vorlage für das größere Medaillon beziehen hätte können. ${ }^{53}$ Hartig selbst stand auch nicht in Kontakt mit Landsteiner, dieser war seit 1929 in New York und verstarb dort
1943. ${ }^{54}$ Da zur Konzeption des Medaillons keine Modellsitzung mit dem zu Porträtierenden stattfinden konnte, musste der Künstler auf Fotografien zurückgreifen. Eine Serie von vier Porträtfotografien, datiert auf den I. November 1930, zeigen Landsteiner am Rockefeller Institute for Medical Research in New York.5s Diese beinhalten Nahaufnahmen des Mediziners in weißem Arztkittel gekleidet in unterschiedlichen Positionen, sowohl frontal im Porträt als auch an seinem Arbeitstisch sitzend im Dreiviertelprofil. Auf dem Tisch befinden sich Reagenzgläser in unterschiedlichen Größen, Bücher und ein Mikroskop, als essenzieller Bestandteil seiner Wissenschaft, arrangiert. Die Aufnahmen repräsentieren Landsteiner unmittelbar in seiner Tätigkeit als Forscher. $\mathrm{Zu}$ diesen Fotografien dürfte auch jene Aufnahme gehören, die Landsteiner im Profil nach links in gleicher Umgebung zeigt, zwischen seinen auf der Tischfläche abgelegten Händen befinden sich das Mikroskop, daneben Reagenzgläser und ein Blatt Papier (Abb. II)..$^{66}$ Hartig waren diese Aufnahmen mit Sicherheit bekannt, da das Medaillon eindeutige Parallelen zu genau dieser Fotografie aufweist. Beson-

5I Über das genaue Material der Tafel - welcher Stein oder Marmor - wird in dem Aktenkonvolut UAW Senat S 222.36 nicht berichtet. Darin wird das Denkmal als Gedenktafel mit Relief bezeichnet.

52 Die Rückseite ziert eine allegorische Darstellung der Medizin, bestehend aus einer weiblichen Figur mit offenem Buch in ihrem Schoß, die das Wasser von einem Felsen sammelt, um den Durst eines kranken Mädchens zu stillen. Für eine Abbildung siehe http://www.nobelprize.org/nobel_prizes/about/medals/index.html, abgerufen am I7. Juni 2015.

53 Für die Auskunft danke ich Herrn Dr. Harreither, Leiter des Museum Lauriacum in Enns, das den künstlerischen Nachlass Arnold Hartigs verwahrt. Ihm zufolge gibt es im Archiv kein Objekt mit Bezug zu Karl Landsteiner.

54 Vgl. Hartig, Aus meinem Leben (zit. Anm. I4); in seiner Autobiografie wird Landsteiner nicht erwähnt. Zum gesamten Medaillenbestand in Hartigs Werk siehe Proкisch: Nachlass Arnold Hartig im Museum Lauriacum (zit. Anm. I5), S. 4-68.

55 Die fünf Fotografien in s/w sind als Teil der Sammlung Bettmann gekennzeichnet, das Copyright liegt bei Corbis Images, http://www.corbisimages.com/stock-photo/rights-managed/BEo4I879/dr-karl-landsteiner?popup=I, abgerufen am 30. April 20I5; Zitat Bildunterschrift: „Original caption: II/I/30-New York: Closeup of Dr. Karl Landsteiner, famous bacteriologist and pathologist, who has just been announced as the winner of the I930 Nobel prize for medicine. Dr. Landsteiner was photographed as he was continuing with his research work at the Rockefeller Institute for Medical Research this morning. [...]."

56 Diese Fotografie findet sich abgedruckt in s/w auch bei Speiser/SmeKal, Karl Landsteiner. Entdecker der Blutgruppen (zit. Anm. 46), S. 34, Abb. 19. Die Bildunterschrift weist jedoch darauf hin, dass hier Karl Landsteiner in seinem Laboratorium im Pathologisch-Anatomischen Institut der Universität Wien abgebildet ist, wo er die epochale Entdeckung der Blutgruppen des Menschen um 1900 machte. Betrachtet man die Fotografie jedoch genauer, so passen 
ders auffallend ist dabei, dass der Bildhauer nicht nur den Kopf mit dem etwas nach oben gerichteten Blick, den Scheitel, das gekämmte Haar sowie Landsteiners Gesichtsausdruck übernommen hat, sondern auch die Kleidung, Hemdkragen und Mantelrevers. Bei genauer Begutachtung stimmen die Konturen am Medaillon mit jenen des weißen Arztkittels, dem Hemd darunter und dem Krawattenknoten, welche Landsteiner in der Fotografie trägt, überein. Folglich versucht Hartig im Porträt des Medaillons eine realitätsgetreue Wiedergabe des Nobelpreisträgers und unterstreicht diese mit einem idealisie- renden Zug, der durch die betonte Strenge im Profil und den in die Ferne gerichteten Blick unterstützt wird. Durch die Parallelen zu der Fotografie und aus der Presse bekannten Fotografien erhöht sich beim Betrachter der Wiedererkennungswert des Porträtmedaillons. Ein weiteres Porträt Karl Landsteiners in Form einer S/WFotografie von 1925 befindet sich seit 2006 in der von der Agentur Photoglas in Zusammenarbeit mit dem Institut für Zeitgeschichte realisierten Installation der Nobelpreisträger in der Aula des Hauptgebäudes der Universität Wien. ${ }^{57}$

\section{R E S Ü M E E}

Anhand von ausgewählten Denkmälern aus dem Arkadenhof und ihrer Entstehungsgeschichte untersucht die Studie die Rolle des Porträtmedaillons als Form des Gelehrtendenkmals. Mittels kunsthistorischen Vergleichs der Medaillons der beiden Bildhauer Kaspar von Zumbusch und Arnold Hartig zu Medaillen aus dem Archiv der Universität Wien, zu Porträtfotografien der Dargestellten oder zu Grabdenkmälern am Wiener Zentralfriedhof werden verschiedene Entwicklungen in der jeweiligen Repräsentation aufgezeigt. Die beiden Medaillons von Zumbusch entsprechen der idealisierenden, antikisierenden Formensprache des Künstlers und verzichten dennoch nicht auf charakteristische Merkmale der geehrten Persönlichkeit. Beide Medaillons sind Werke des Historismus und zeigen den Geehrten in heroischer Nacktheit und in einer auf den Kopf reduzierten klassischen Gestaltung. In der Entstehungsgeschichte dieser Denkmäler spielte die Anerkennung des
Ringstraßenbildhauers und Schöpfers von bereits sieben Werken im Arkadenhof eine wesentliche Rolle. Im Unterschied dazu wurde der Medailleur Arnold Hartig als naturnaher Porträtist seitens der Universität zur Anfertigung von fünf Denkmälern mit Porträtreliefs beauftragt. In seinen Medaillons übernimmt er die traditionelle Form, sie zeichnen sich aber durch eine realistischere und zeitgemäße Wiedergabe des Dargestellten aus. Unterschiede in der Gestaltung zwischen Zumbusch und Hartig finden sich sowohl in der Wahl des Büstenabschnitts als auch in der Wiedergabe der Kleidung. So präsentieren sich die Porträts von Ernst Ludwig und Leopold Schrötter von Kristelli noch traditionell in heroischer Nacktheit auf den Kopf konzentriert. Während in Hartigs Medaillon für Gustav Riehl noch eine Orientierung an dieser klassischen Gestaltung beobachtet werden kann, zeigt das Medaillon für Karl Landsteiner den Mediziner mit Arztkittel als forschenden Wissenschaft-

das darin gezeigte Interieur und das Alter des Dargestellten zu den Fotografien von I930. Dafür spricht auch, dass eine weitere sehr ähnliche Fotografie am 20. November 1930 in der Wochenzeitung „Das interessante Blatt“, Ausgabe Nr. 47, S. 2, veröffentlicht wurde. Hier mit dem Untertitel „Der Oesterreicher Dr. Karl Langsteiner [sic], Träger des Nobelpreises für Medizin für 1930, bei seinen Arbeiten im Laboratorium des Rockefeller-Instituts in New York. “ Darin wird Landsteiner mit Blick ins und der Hand am Mikroskop gezeigt. Der Bezug zur Fotoserie der Sammlung Bettmann ist klar zu erkennen.

57 Siehe hierzu http://geschichte.univie.ac.at/de/artikel/nobelpreis-und-universitaet, abgerufen am I8. Juni 2015. 
ler bis knapp zum Schulteransatz. Die Übernahme dieses Porträtausschnitts aus der Fotografie ist deutlich erkennbar. Die Entscheidung der Universität für ein Medaillon hängt eng mit der Wahrnehmung dieses Typus zusammen, da es in einer Entwicklung, in der die Form der vollplastischen Büste in Frage gestellt wurde, als eher neutral und zeitlos gesehen wurde. Die Artistische Kommission konnte bei Hartig neben den Gipsmodellen auch Belegexemplare in Form von Medaillen begutachten, womit bereits im Vorhinein absehbar war, wie das spätere Porträtrelief aussehen wird. Damit konnte auch die zu Beginn formulierte Frage nach der Vorbildfunktion im Kleinformat für das größere Arkadenhof-Medaillon durch zuvor geschaffene Medail- len belegt werden. Ziel dieser Studie war es, die Denkmäler anhand der Quellen zur Biografie des Dargestellten in Verbindung mit Archivalien zur Entstehungsgeschichte zu untersuchen. In der Zusammenschau mit Professorenporträts und Medaillen konnte dabei die Repräsentation des Geehrten im Porträtmedaillon als Form des Gelehrtendenkmals beleuchtet werden.

Abbildungsnachweis: Abb. I: Fotostudio F. Pflügl; Abb. 2, 5, 8, II: Institut für Kunstgeschichte der Univ. Wien, R. Steyer/K. Pani, 20I4; Abb. 3, 6, 9, I2: Bildarchiv der Österreichischen Nationalbibliothek; Abb. 4, Io: Medaillensammlung der Universität Wien, Archiv der Universität Wien; Abb. 7: Fotografie d. Autorin 2015. 


\title{
DAS THUN-EXNER-BONITZ-DENKMAL IM ARKADENHOF DER UNIVERSITÄT WIEN - ZUR GESCHICHTE DES DENKMALS ANHAND VON ARCHIVMATERIALIEN
}

\author{
Hubert D. Szemethy
}

A usgangspunkt meiner Beschäftigung mit der Geschichte des Denkmals für die großen Reformer des österreichischen Bildungswesens nach 1848 war der ,Fund' einer $24,5 \mathrm{~cm}$ hohen, $19 \mathrm{~cm}$ breiten und II $\mathrm{cm}$ tiefen Gipsbüste, die im Studienjahr 2008/o9 beim Ausräumen eines Zimmers am Institut für Alte Geschichte und Altertumskunde, Papyrologie und Epigraphik der Universität Wien in einem Kasten hinter allerlei wissenschaftlicher Literatur und Aktenordnern zum Vorschein kam (Abb. I-4).

Wie das auf der Rückseite eingeschriebene „C. Kundmann" klarmachte, musste es sich um ein Werk des bekannten österreichischen Bildhauers und Professors an der allgemeinen Bildhauerschule der Wiener Akademie der bildenden Künste, Carl Kundmann, ${ }^{1}$ handeln. Die originale Büste war mir aus einer früheren $\mathrm{Ar}$ beit über den aus Hannover stammenden George Niemann bekannt ${ }^{2}$ und ist Teil des Thun-Exner-Bonitz-Denkmals (auch: Denkmal für Graf Leo Thun-Hohenstein). Sie befindet sich im Oktogon in der südwestlichen Ecke des Arkadenhofes der Universität Wien und stellt den Philologen Hermann Bonitz dar (Abb. 5-6).
Was mich nach der Identifizierung der kleinen Gipsbüste zu interessieren begann, war ihre Geschichte, insbesondere ob bzw. wie sie in die Entstehungsgeschichte des Thun-Hohenstein-Denkmals passt und wieso sie an unserem Institut, gelandet' ist. Diese Fragen erforderten die Aufarbeitung der Geschichte des Denkmals, vom Anlass über die ersten Ideen und Planungen bis hin zur großartigen Enthüllung des Denkmals am 24. Mai I893, einem Tag, der - ohne dass er für die Universität ein besonderer Feiertag gewesen wäre - zu einem bildungspolitischen Festtag wurde, wie ihn Wien längere Zeit nicht mehr erleben sollte.

Die Quellen, aus denen sich Material zu dieser Thematik erschließen lässt, sind Archivalien im Archiv der Universität Wien (Akten der Artistischen Kommission des Akademischen Senats), im Österreichischen Staatsarchiv (Allgemeines Verwaltungsarchiv/Finanz- und Hofkammerarchiv), in der Handschriftensammlung der Wienbibliothek im Rathaus (Teilnachlass Carl Kundmann) und in der Sammlung von Handschriften und alten Drucken der Österreichischen Nationalbibliothek (Nachlass Miklosich, Nachlass Benndorf).

I W. Krause, Die Plastik der Wiener Ringstraße von der Spätromantik bis zur Wende um 1900, Wiesbaden I980; W. Krause, Kundmann, Karl, in: Neue Deutsche Biographie I3, Berlin 1982, S. 289 f.; I. Beier, Carl Kundmann, ungedr. Dipl.-Arb., Univ. Wien 1994. - Herrn Prof. Walter Krause danke ich für die Möglichkeit der Einsichtnahme in eine unvollendet gebliebene Dissertation über Carl Kundmann von Bettina Norman-Audenhove. 

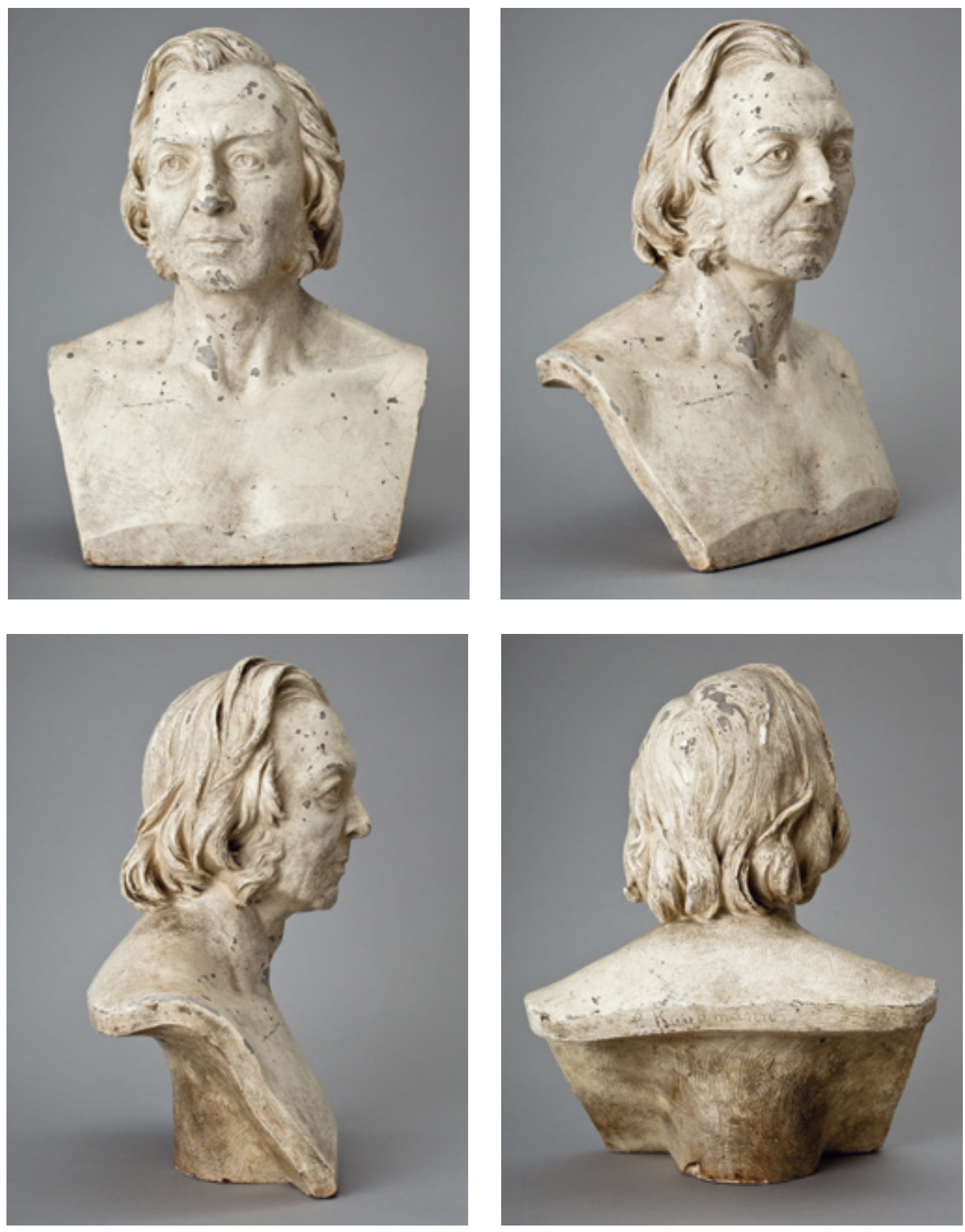

Abb. I-4: Carl Kundmann, Gipsbüste von Hermann Bonitz, Sammlung des Instituts für Alte Geschichte und Altertumskunde, Papyrologie und Epigraphik, Inv.-Nr. Sooo7. 


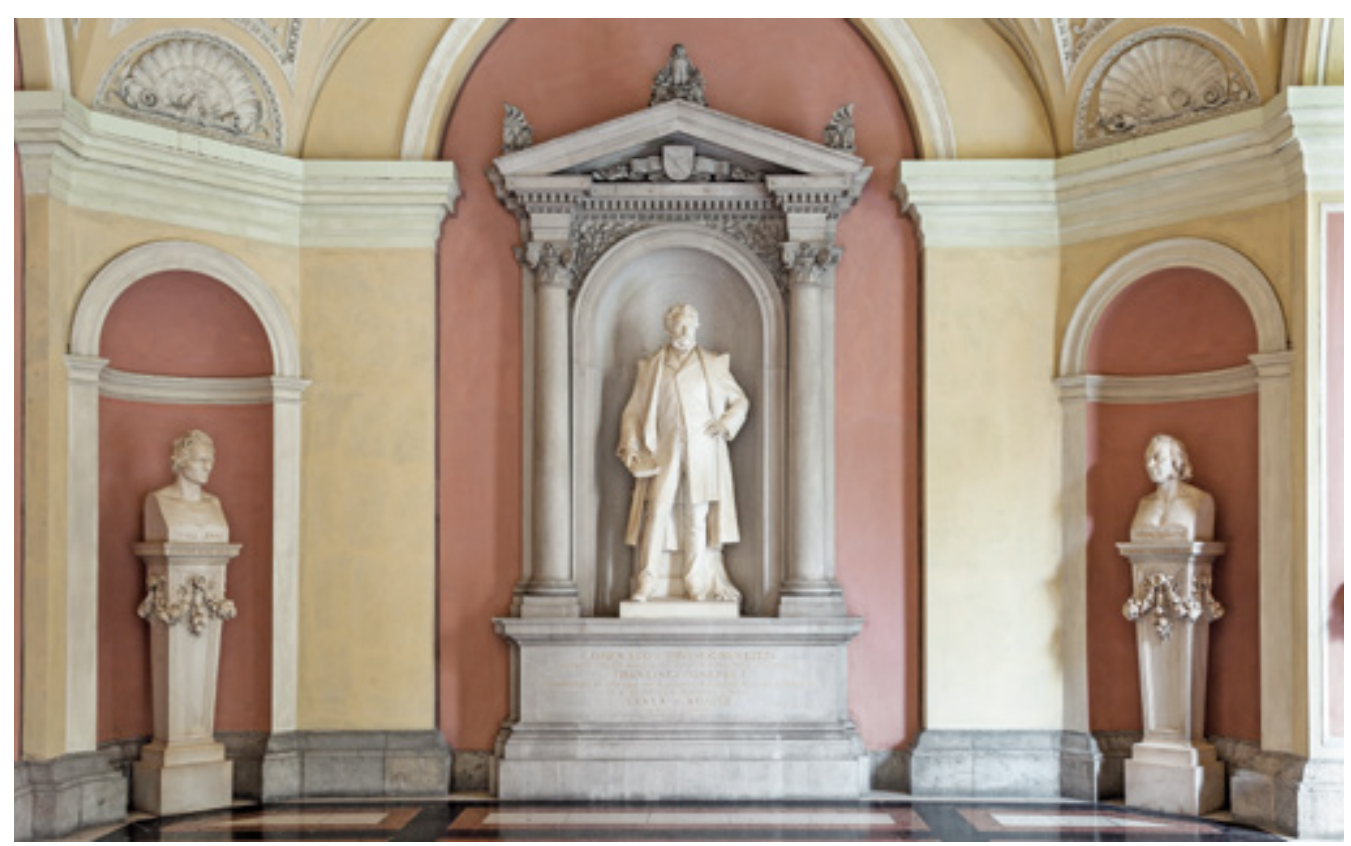

Abb. 5: Carl Kundmann, Thun-Exner-Bonitz-Denkmal im Arkadenhof der Universität Wien.

A N L A S S

Anlass für die Errichtung dieses Monuments waren die im Jahr 1888 erfolgten Todesfälle von Hermann Bonitz in Berlin (am 25. Juli) und Graf Leo Thun-Hohenstein in Wien (am 17. Dezember). Mit Franz Serafin Exner, der schon I853 in Padua verstorben war, waren das jene drei Männer, denen die Reformen der Universitäten und Gymnasien in der Habsburgermonarchie ab I849 zu verdanken waren.

Diese erfolgten unter der politischen Verantwortlichkeit des I8II in Tetschen/Děčín geborenen und I849 zum Minister für Cultus und
Unterricht ernannten Graf Leo Thun-Hohenstein, dessen Amtszeit bis Oktober I860 dauerte. Seine unmittelbaren Mitarbeiter und Ratgeber waren der 1802 in Wien geborene Philosoph Franz Serafin Exner, dessen Entwurf der Grundzüge des öffentlichen Unterrichtswesens in Oesterreich (Wien $\left.\mathrm{I}_{848}\right)^{3}$ Basis für die Neuorganisation der Gymnasial- und Universitätsstudien wurde. Dazu trat der I8I4 in Langensalza in Thüringen geborene Philologe Hermann Bonitz, der 1849 unter Vermittlung von Exner als Professor für Klassische Philologie nach Wien berufen wur-

2 H. Szemethy, From Samothrace to Spalato/Split. The architectural drawings of ancient buildings and sites by George Niemann (I84I-I9I2), in: Cogitata Tradere Posteris. Figurazione dell'Architettura antica nell'Ottocento/The representation of ancient architecture in the XIX ${ }^{\text {th }}$ century: Atti della Giornata Internazionale di Studio „La documentazione grafica dei monumenti antichi nell'Ottocento. Tra tecniche e ideologia (Catania, 25 novembre 2009)“ (hrsg. von F. Buscemi), Rom 20I0, S. 87-I09. - Zu George Niemann s. R. Schachel, Österreichisches Biographisches Lexikon 7, Wien I978, S. I2I; J. BorchHardt, Georg(e) Niemann I84I-I9I2, in: Archäologenbildnisse. Porträts und Kurzbiographien von Klassischen Archäologen deutscher Sprache (hrsg. von R. Lullies/W. Schiering), Mainz I988, S. 80. 
Abb. 6: Carl Kundmann, originale Büste von Hermann Bonitz im Arkadenhof der Universität Wien.

de, wo er bis 1867 wirkte. Auf diese drei Männer geht das 8-klassige Gymnasium und die Einführung der Matura als Studienberechtigung zurück; durch sie erfolgte eine Orientierung an den preußischen Universitäten und rückte die Philosophische Fakultät gleichberechtigt neben die Juridische, Theologische und Medizinische Fakultät, weshalb sie als Begründer der Philosophischen Fakultäten gelten; durch sie wurde Lehr- und Lernfreiheit gewährt, die Forschung mit der Lehre verbunden und die Verwaltung der Universitäten der Professorenschaft übertragen, wurden Universitäten von reinen Lehrund Ausbildungsanstalten zu wissenschaftlichen Einrichtungen. ${ }^{4}$ Ihnen wurde das Denkmal gewidmet, um dessen Geschichte es im Folgenden

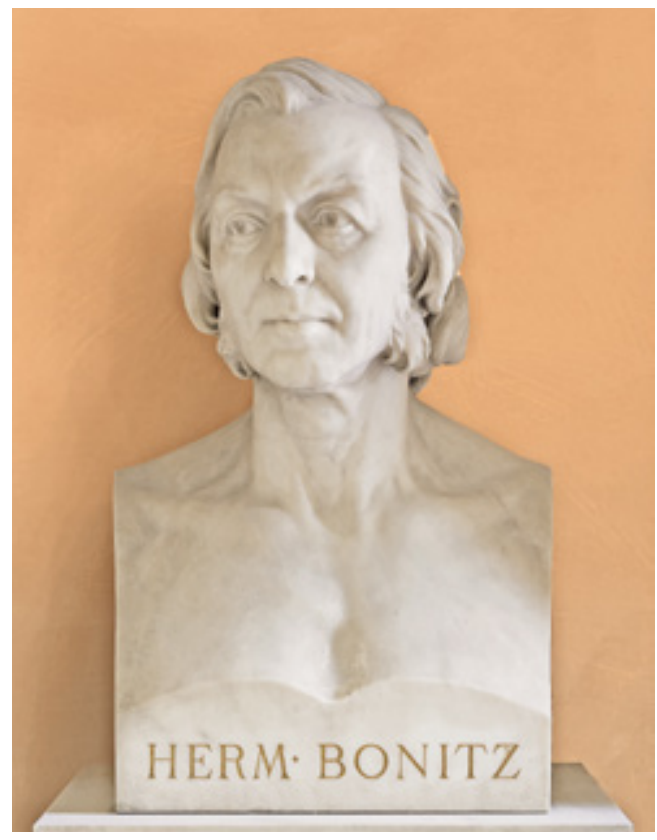
geht.

\section{P L A N U N G}

Nicht lange nach dem Ableben Thun-Hohensteins bildete sich in Wien eine freiwillig zusammengetretene Gesellschaft von Männern aus allen Kreisen Wiens, welche der Pflege des höheren Bildungswesens in Oesterreich berufsmäßig nahe standen. Diese Gruppe machte sich Gedanken, in welcher Weise durch ein Monument der großen Reformen [des] Ministers und seiner Hauptmitarbeiter Franz Exner und Hermann Bonitz die Erinnerung an die Erneuerung des höheren Unterrichtswesens in Oesterreich würdig zu verewigen sei. 5

4 Zu diesen Protagonisten und Reformen s. F. SAlomon, Graf Leo Thun-Hohenstein, Franz Exner und Hermann Bonitz. Beiträge zur Geschichte der österreichischen Unterrichtsreform, Wien I893; R. HansLIK, Das österreichische humanistische Gymnasium in seinem Werden und gegenwärtigen Sein. Festvortrag anläßlich der Hundertjahrfeier der Reform durch Franz Exner und Hermann Bonitz, gehalten an der Wiener Universität, Wien I95I; H. LeNTZE, Die Universitätsreform des Ministers Graf Leo Thun-Hohenstein, Wien I962; R. Meister, Entwicklung und Reformen des österreichischen Studienwesens, Wien 1963; R. LeITner, Das Reformwerk von Exner, Bonitz und Thun: Das österreichische Gymnasium in der zweiten Hälfte des I9. Jahrhunderts - Kaderschmiede der Wiener Moderne, in: Zwischen Orientierung und Krise. Zum Umgang mit Wissen in der Moderne (hrsg. von S. Rinofner-KreIDL), Wien u. a. 1998, S. 17-69; W. Ogris, Die Universitätsreform des Ministers Leo Graf Thun-Hohenstein. Festvortrag anläßlich des Rektorstages im Großen Festsaal der Universität Wien am I2. März I999, Wien I999; Ch. Aichner/B. Mazohl, La riforma scolastica di Thun-Hohenstein I849-I860, in: La scuola degli Asburgo. Pedagogia e formazione degli insegnanti tra il Danubio e il Po (I773-19I8) (hrsg. von S. Polenghi), Torino 20I2, S. I79-209; Die Thun-Hohenstein'sche Universitätsreform I849-I86o. Konzeption - Umsetzung - Nachwirkungen (hrsg. von CH. Aichner/B. Mazohl), Wien/Köln/Weimar 2017.

5 Entwurf eines Schreibens von Franz von Miklosich an Paul Gautsch von Frankenthurn, Minister für Cultus und Unterricht, vor dem oder am I9. Jänner I890, Beilage zu Protokoll Nr. 2828 ex I89I/92 des Akademischen Senats 
In der konstituierenden Versammlung des Denkmalkomitees am 2. Jänner I889 um 4 Uhr Nachmittag im Professorensaal der philosophischen Fakultät nahmen Vertreter der Wiener Universität (der Archäologe Otto Benndorf, der Althistoriker Eugen Bormann, der Jurist Adolf Exner, der Philosoph Theodor Gomperz, die Philologen Wilhelm von Hartel, Emanuel Hoffmann und Karl Schenkl, der Slawist Franz von Miklosich, der Geologe Eduard Suess und der Theologe Hermann Zschokke), des k. k. Ministeriums für Cultus und Unterricht (Sektionschef Graf Vincenz Baillet-Latour und die Ministerialräte Benno von David und Erich Wolf), der Akademie der Wissenschaften (Präsident Alfred von Arneth), der Akademie der bildenden Künste (Josef Mathias Trenkwald) und der österreichischen Gymnasien (Alois von Egger-Möllwald, Pius Knöll, Victor Langhans) teil. Karl Köchlin war als künstlerischer Berater anwesend. Zum Obmann der Denkmalkommission wählte man den emeritierten Professor für slawische Philologie, zweimaligen Dekan und Rektor der Universität Wien 1853/54, Franz Ritter von Miklosich.

Von Anfang an war geplant, ein gemeinsames Denkmal für die drei Männer zu schaffen, die das jetzige Unterrichtswesen begründet haben, diesseits wie auch jenseits der Leitha, aufgestellt in der Wiener Universität. Da die Mittel für derartige Denkmäler an sich von den Komitees selbst aufzubringen waren, ${ }^{6}$ plante man zuerst drei Büsten oder Medaillons mit einer verbindenden Inschrift. Doch nachdem Graf Latour in Vertretung des Ministeriums die Erklärung abgegeben hatte, der Minister hätte großes persönliches Interesse an dem Denkmal bekundet und legt Gewicht darauf, daß es in würdigster Weise zu Stande komme, und überdies unter allgemeinem Beifall kundtat, das Ministerium würde die gesamten Kosten für das Denkmal übernehmen, war von so einem der Form nach bescheidenen Denkmal aus drei Büsten keine Rede mehr.

Für weitere Beratungen wurde noch in der konstituierenden Sitzung aus dem Kreis des großen Denkmalkomitee ein engeres ,artistisches Comité" gewählt - bestehend aus Miklosich (Praeses), Arneth, Latour, Benndorf, Egger, Exner, Hartl, Schenkl und Trenkwald.?

Unmittelbar nach Schluss der konstituierenden Versammlung trat das "artistische Comité “ zusammen, das auf Antrag von Latour von einem künstlerischen Beirat unterstützt werden sollte, nämlich dem Bildhauer Kaspar von Zumbusch und dem Architekten Karl Köchlin. Beide keine Unbekannten: Zumbusch hatte sich durch das Beethoven-Denkmal und das Denkmal für Maria Theresia in Wien einen Namen gemacht, und Köchlin war Mitarbeiter Heinrich Ferstels und nach dessen Tod mit der Bauleitung und Fertigstellung des Neubaus der Universität betraut.

Dieses engere Comité beschloss, keine Konkurrenz auszuschreiben. Ob ein, zwei oder gar mehrere Künstler gemeinsam das Denkmal ausführen sollten, war anfangs offen. Die Wahl fiel schließlich auf einen Künstler, auf Carl Kundmann, den Schöpfer des Schubert-Denkmals, mehrerer Statuen im Heeresgeschichtlichen Museum und später Mitgestalter der Hofmuseen und des Burgtheaters. Das Denkmal sollte nach Meinung des Ministeriums aus einer Statue des Ministers und zwei Kolossalbüsten bestehen. Die Gesamtkosten schätzte das Ministerium auf I5.000 Gulden. Notwendige Behelfe wären möglichst sofort zu beschaffen, z. B. Bilder, Fotografien, eventuell Totenmasken, wie es eine von

der Universität Wien (UAW, AAK S 96/9). Das originale amtliche Dokument vom I9. Jänner I89o befindet sich im Österreichischen Staatsarchiv (ÖSTA, AVAFHKA, CUM, U-Präs. I22 ex I89o).

6 Th. Maisel, Gelehrte in Stein und Bronze. Die Denkmäler im Arkadenhof der Universität Wien, Wien u. a. 2007 , S. I2.

7 S. dazu Protokoll I der Sitzung vom 2. Jänner I889 (ÖSTA, AVAFHKA, CUM, U-Präs. I22 ex I89o, Beilage).

8 S. dazu Protokoll II a. und b. der Sitzung vom 2. Jänner 1889 (ÖSTA, AVAFHKA, CUM, U-Präs. I22 ex I890, Beilage). 
Exner gab - von ihm muss damals auch schon eine Büste existiert haben. Bei der Darstellung der Personen sollte die Zeit ihrer vollen Wirksamkeit [...] in Betracht kommen, also etwa das Jahr 1850.

Da sich das Comité bewusst war, dass der Aufstellungsort für die Form des Denkmals mitentscheidend sei - Benndorf hatte in der Sitzung das Quarré bei der Stiege, die zur Bibliothek führt, vorgeschlagen -, wurde für den 6. Jänner I889 eine Begehung festgesetzt, um einen geeigneten Platz für das Denkmal zu finden. ${ }^{8}$

Diese Begehung durch Miklosich, Exner, Latour, Schenkl, Zumbusch und Köchlin - man traf sich um I Uhr Mittag vor dem Archaeologisch-Epigraphischen Seminar ${ }^{9}$ - ergab zwei Möglichkeiten: zum einen die linke, südwestliche Ecke der Arkaden, wo sich eine in das Depot der Universitätsbibliothek führende Thüre befand. Falls das Denkmal hier versetzt würde, müsste diese Türe zugemauert werden, was aber problemlos geschehen könne, da sie - laut Protokoll - weder für die Bibliothek noch für die Communication überhaupt irgend einen Werth besitzt..$^{10} \mathrm{Als}$ zweiter möglicher Aufstellungsort kam die linke Seite des Atriums vor dem Festsaal auf der Seite der juridischen Fakultät in Frage. Für beide Plätze sollte Kundmann Skizzen entwerfen und sie der nächsten Sitzung des ,artistischen Comités' vorlegen, zu der der Künstler auch einzuladen sei. ${ }^{\text {II }}$

Diese fand am Himmelfahrtstag, den 30. Mai I889, statt. Einige Tage zuvor hatte Kundmann Benndorf sein Kommen zu dieser Sitzung mitgeteilt, musste gleichzeitig jedoch bemerken daß meine Angaben über Herstellungskosten noch nicht ganz genau sein können. Auch hatte er angekündigt, am 29. Mai seine ausgearbeiteten Skizzen zu Benndorf in die archäologische Sammlung der Universität zu bringen. ${ }^{12}$ Offenbar war es ihm ein Anliegen, die Entwürfe vorher mit Benndorf durchzusprechen. ${ }^{13}$

In besagter Sitzung legte Kundmann zwei Skizzen vor, die den Akten leider nicht beiliegen, aber die kursorischen Beschreibungen im Protokoll helfen uns, eine Vorstellung von ihnen zu bekommen. Der Standbild-Entwurf zeigte demnach in einem architektonischen Aufbau in der Mitte das Standbild des Grafen Thun, während rechts und links zwei Hermen mit den Büsten von Exner und Bonitz angebracht sind. Die zweite Skizze stellte in einem Relief, das architektonisch umkleidet und im Giebel mit einer Figur der Wissenschaft geschmückt ist, den Grafen Thun in seinem Bureau sitzend dar; rechts vor ihm steht Exner im Begriffe einen Vortrag zu halten, links hinter ihm steht Bonitz dem Vortrage gespannt folgend.

Kundmann erläuterte seine Ideen, die er mit diesen Entwürfen verfolgt hatte, und die Details der Ausführung. Hinsichtlich der Wahl zwischen beiden Entwürfen waren die Meinungen der Komiteemitglieder sehr geteilt. Trenkwald, Zumbusch und Köchlin stimmten sofort für die Reliefskizze. Trenkwald meinte, das Relief zeige eine wärmere Auffassung und mehr Leben; die Idealfgur im Giebel rücke dasselbe schon aus der Sphäre des Genrehaften. Latour sprach sich dagegen für

9 Heute ist in diesen Räumlichkeiten das Institut für Alte Geschichte und Altertumskunde, Papyrologie und Epigraphik untergebracht.

IO Im nördlichen Teil der Arkaden existiert eine vergleichbare Tür noch heute.

II S. dazu Protokoll III der Begehung der Universität vom 6. Jänner I889 (ÖSTA, AVAFHKA, CUM, U-Präs. I22 ex ı890, Beilage).

I2 Brief Kundmanns aus Wien an Benndorf, 25. Mai I889 (ÖNB, HAD: Autogr. 650/2-6).

I3 Den Rat Benndorfs schätzten auch andere Künstler, z. B. Caspar von Zumbusch, der Benndorf um seine Meinung zum Entwurf für das Radetzky-Denkmal (Brief Zumbuschs aus Wien, 5. Oktober I886 [ÖNB, HAD: Autogr. 666/4-Io]; Postkarte Zumbuschs aus Wien, 26. Mai I888 [ÖNB, HAD: Autogr. 666/4-I7]) bzw. für das GlaserDenkmal bat (Brief Zumbuschs aus Wien, 3I. Oktober 1887 [ÖNB, HAD: Autogr. 666/4-I5]).

I4 Das Vorherige zusammengefasst nach Protokoll IV der Sitzung vom 30. Mai I889 (ÖSTA, AVAFHKA, CUM, UPräs. I22 ex I890, Beilage). 
die Standbildskizze aus, die Reliefskizze bringe die Bedeutung des Monuments nicht so zur Geltung wie die Standbildskizze, er wünsche sie aber nur noch einfacher gestaltet. [...][Die Darstellung der Reliefskizze führe] das Bureau des Ministers [...] in den Bereich des gewöhnlichen Lebens, über welchen er das Denkmal erhoben wünsche. Auch Exner schloss sich Trenkwald an und wies darauf hin, dass sich der Künstler selbst für die Reliefskizze entscheide und man daher vor allem den Intentionen desselben folgen solle. Gerade das Relief bringe den eigentlichen Gedanken des Denkmales, die Vereinigung der drei Männer zur Schaffung des großen Werkes, zur Geltung; zudem sei es, was künstlerische Schönheit betrifft, dem anderen Entwurfe weit überlegen. Mit ihm einer Meinung waren ferner Benndorf, der das Relief in größserem Maßstab ausgeführt wünschte, damit der monumentale Charakter noch mehr hervortrete, und Hartel, da sich für die inneren Räume der Universität [...] keine Darstellung mehr [eigne] als die, welche in dem Relief ihren Ausdruck finde. Kundmann, der das Relief präferierte, wies im Verlauf der Besprechung darauf hin, dass es so möglich sein werde den Köpfen der Persönlichkeiten mehr Leben einzuhauchen; die Scene werde so wahrhaft dramatisch werden.

Als Miklosich nach langer Diskussion abstimmen ließ, herrschte nur über den Aufstellungsort Einigkeit: der genannte Platz im Arkadenhof. Was die Form des Denkmals anging, stimmten lediglich der Vertreter des Ministeriums, Graf Latour, und Arneth für das Standbild, alle anderen für das Relief. Latour hielt jedoch umgehend fest, dass eine letztgültige Entscheidung beim großen Komitee liege, dem Künstler solle aber hinsichtlich der Details keine weitere Directive gegeben werden. ${ }^{\mathrm{I}}{ }^{4}$ Latour spielte offenbar auf Zeit.
Wenige Tage später, so ist einem Brief Kundmanns an Benndorf zu entnehmen, wurde der Künstler ins Ministerium gebeten. Der Unterrichtsminister selbst hatte den Wunsch ausgesprochen, die beiden Skizzen für das Leo ThunDenkmal in Augenschein zu nehmen. Ich werde also morgen persönlich vorsprechen und anfragen, wohin die beiden Entwürfe gebracht werden sollen; $d a$ dieselben nur für I-2 Tage verlangt werden, so dürfte ja bald etwas über die Anschaunng S[einer] E[xcellenz] bekannt werden. .5

Interessanterweise ist von da an - entgegen dem Abstimmungsergebnis des ,artistischen Comités ' - nur mehr ein einziges Mal vom Reliefentwurf die Rede, und zwar in einem Brief Kundmanns an Miklosich vom 13. Juli I889. Diesem ist zu entnehmen, dass Kundmann tags zuvor einen vergleichenden Beleuchtungsversuch im Octogon der Arkaden und im Atrium in Gegenwart der Professoren Trenkwald und Niemann ausgeführt hatte und dabei feststellen musste, daß sich meine Voraussicht vollkommen erfüllt hat. Die Beleuchtung im Octogon hat sich für das Relief-Projekt ungünstig erwiesen, sodaß ich, nachdem dieser Platz einstimmig gewählt wurde, dasselbe überhaupt zurückziehen müßte, und nur das Andere, mit der Statue und den beiden Büsten, für geeignet erklären könnte. ${ }^{16}$

$\mathrm{Zu}$ seiner eigenen Orientierung wünschte er von Miklosich Einsicht in das Protokoll der Sitzung vom 30. Mai I889, die ihm Miklosich sogleich ermöglichte. Kundmann plädierte daraufhin mit Rücksicht auf die herrschenden, divergirenden Ansichten, die Sitzung des großen Comite's bis zum Herbste zu vertagen. ${ }^{17}$ Er gewann dadurch Zeit, in den Ferien und den Monaten danach an unterschiedlichen Modellentwürfen für die Standbildgruppe zu arbeiten.

Brief Kundmanns aus Wien an Benndorf, 5. Juni I889 (ÖNB, HAD: Autogr. 650/2-7).

Brief Kundmanns aus Wien an Miklosich, I3. Juli I889 (ÖNB, HAD: Autogr. 135/132-I).

Brief Kundmanns aus Wien an Miklosich, I8. Juli I889 (ÖNB, HAD: Autogr. 135/132-2).

Brief Kundmanns aus Wien an Miklosich, 26. November I889 (ÖNB, HAD: Autogr. 135/132-3).

Schreiben Kundmanns aus Wien an Benndorf, laut Stempel auf dem „Karten-Brief zur pneumatischen Expressbe- 
Wir gehen wohl nicht allzu falsch in der Annahme, dass seit Juni I889 von seiten des Ministeriums, des Finanziers des Denkmals, ,sanfter Druck auf den Künstler - und in weiterer Folge wohl auch auf die Comité-Mitglieder - ausgeübt wurde. Nur so lässt sich erklären, dass von nun an nur mehr von der Standbildgruppe die Rede ist; nur so lassen sich auch Widersprüche im Schlussprotokoll zu den Einzelprotokollen der vorangegangenen Sitzungen erklären.

Ende des Jahres traten die Planungen in die entscheidende Schlussphase. Kundmann hatte am 26. November persönlich die 3 Denkmal-Entwürfe in der archäologischen Sammlung der Universität aufgestellt. ${ }^{18}$ Bereits am Tag danach jedoch ließ er das neue Modell, das er für die sichere Größenbestimmung der beiden Hermen in seinem Atelier brauche, damit ich die Wirkung im Zusammenhang studiren kann, ${ }^{19}$ wieder aus der Sammlung abholen. Am 6. Dezember war Kundmann mit seinen Entwurfsarbeiten schließlich fertig und hatte das umgearbeitete neue Projekt wieder in der archäologischen Sammlung zur Aufstellung gebracht. ${ }^{20}$

Die endgültige Entscheidung über das Denkmal fiel in zwei Sitzungen. In der letzten Sitzung des ,artistischen Comités' am I5. Dezember I889 präsentierte Kundmann dieses neue Modell, welches in der Mitte die Statue des Grafen Thun, in zwei Seitenflügeln die Büsten Exners und Bonitzens in Hermenform darstellt. Ohne sich auf ei- ne neuerliche Diskussion einzulassen, erklärte Latour daraufhin, daß das Modell bei weitem mehr entspricht als das frühere und auch den Intentionen Seiner Excellenz des Herrn Ministers entsprechen dürfte. Er verspricht hierüber Seiner Excellenz $z u$ berichten und dessen Entschließung mitzutheilen. Auf Antrag Exners erklärte sich das Komitee mit diesem neuen Modell einverstanden. ${ }^{2 I}$ Wie zu erwarten war, wurde diese Ansicht auch in der Sitzung des Gesamtkomitees, in welcher das neue Modell Kundmanns ausgestellt war, am Sonntag, I2. Jänner I890, vom artistischen Ausschuss vertreten und von allen Anwesenden einstimmig angenommen. ${ }^{22}$ Aus dem Protokoll dieser Sitzung geht überdies hervor, dass sich dieses neue Modell Kundmanns von dem früheren dadurch unterscheidet, daß die im Gebäude an jener Stelle vorhandenen Nischen für das Denkmal benutzt werden.

Erstmals wurde in dieser Sitzung auch die Frage des Zeitpunkts der Fertigstellung behandelt, denn Hartel, dem sich Benndorf und Bormann anschlossen, hatte die Idee ausgesprochen, die Enthüllung des Denkmals mit der etwa für das Jahr I893 geplanten Versammlung der deutschen Philologen und Schulmänner in Wien in Verbindung zu bringen. Und da der Künstler, der nicht an alle Einzelheiten des Modells gebunden war, für die Ausführung drei Jahre berechnete, war eine Verbindung der zwei Ereignisse durchaus naheliegend und sinnvoll. ${ }^{23}$

förderung" vom 27. November I889 (ÖNB, HAD: Autogr. 650/2-8).

20 Brief Kundmanns aus Wien an Miklosich, Ir. Dezember I889 (ÖNB, HAD: Autogr. 135/132-4).

2I Zusammengestellt nach Protokoll VII der Sitzung vom I5. Dezember I889 (ÖSTA, AVAFHKA, CUM, U-Präs. I22 ex I890, Beilage).

22 Dass im Vorfeld dieser entscheidenden Sitzung mit dem Ministerium und wohl auch unter den Komitteemitgliedern das Einvernehmen gesucht wurde, darüber legt ein Schreiben von Miklosich aus Wien an Benndorf vom Io. Jänner 1890 (ÖNB, HAD: Autogr. 653/3-3) beredtes Zeugnis ab: „Ein Schreiben Kundmann's lässt mich vermuthen, dass der Minister dem geänderten Modell zustimmt: ist diese Vermuthung richtig ? Wenn ja, will ich für Sonntag den I2. d[ieses Monats], I2 Uhr, das (große) Denkmahl-Comité [sic] zu einer Sitzung berufen und zwar im archäologischen Museum. In dieser Sitzung würden Sie namens des artistischen Comités den Antrag stellen, dass das Denkmahl-Comité [sic] seine Zustimmung ausspreche. Wollen Sie gütigst mir durch die Überbringerin mittheilen, ob Sie mit diesen Anordnungen einverstanden sind."

23 Protokoll VIII der Sitzung vom I2. Jänner 1890 (ÖSTA, AVAFHKA, CUM, U-Präs. I22 ex I89o, Beilage).

24 ÖSTA, AVAFHKA, CUM, U-Präs. 122 ex I89o.

25 Vgl. die Berichte vom 20. November I890 (ÖSTA, AVAFHKA, CUM, U-Präs. 2I38 ex I89o), 28. Februar (ÖSTA, 
In seinem Schlussbericht vom 19. Jänner I89o teilte Miklosich als Vorsitzender der Denkmalkommission das Ergebnis der Beratungen dem Minister für Cultus und Unterricht, Paul Gautsch von Frankenthurn, mit, wonach Kundmann der Auftrag erteilt werden solle, in Entsprechung des gebilligten Modells, d. h. ein lebensgroßes Standbild des Ministers Thun in der Mitte, flankiert von Kolossalbüsten von Exner und Bonitz in bereits existierenden Mauernischen. Die Ausführung solle in Marmor erfolgen und das Denkmal in der südlichen Ecke des Arkadenhofes aufgestellt werden.

Kundmann übermittelte daraufhin dem Ministerium zwei Kostenvoranschläge (für die Statue, die rahmende Architektur und die Hermen), die sich - abhängig vom Material der Architektur (Karstmarmor bzw. Salzburger Marmor) - auf I6.000 bzw. 17.600 Gulden beliefen. Am I9. März I890 nahm der Minister das Ergebnis der Beratungen mit lebhafter Befriedigung zur Kenntnis und erklärte sich bereit, die von Kundmann veranschlagten Kosten in Höhe von I6.00o Gulden zu übernehmen, wobei dieser Betrag auf drei aufeinanderfolgende Jahre verteilt werde, und erteilte Kundmann den Staatsauftrag. Hinsichtlich des Materials entschied sich der Minister dafür, die Statue, Büsten und Hermen in Carrara-Marmor und die Architektur in Karstmarmor ausführen zu lassen. Bezüglich der Details wollte er sich mit dem ständigen ,artistischen Comité“ der Universität ins Einvernehmen setzen. ${ }^{24}$ Nachdem Kundmann den Staatsauftrag in Händen hielt, wandte er sich zu einem uns nicht näher bekannten Zeitpunkt betreffs der architektonischen Ausgestaltung an George Niemann. Niemann wirkte damals an der Akademie der bildenden Künste als Professor für Perspektive und architektonische Stillehre, hatte als Architekt und Bauforscher an den archäologischen Expeditionen Alexander Conzes und Otto Benndorfs in Samothrake und Gjölbaschi-Trysa mitgewirkt und zeichnete für die architektonische Gestaltung einiger Ehren- und Grabdenkmäler in Wien verantwortlich.

PHASE DER AUSFÜHRUNG UND VORBEREITUNGEN ZUR E N T H Ü L L U N G

Regelmäßig wird Kundmann vom Ministerium aufgefordert, schriftlich Mitteilung über den Stand der Arbeiten zu geben (Abb. 7). ${ }^{25}$ Wir wissen trotz dieser jeweils nur kurzen Berichte ziemlich genau über den Arbeitsfortschritt Bescheid. Detaillierte plastische Modelle der Büsten und des Standbildes wurden angefertigt, danach mittels Punktierung in Laas im Südtiroler Vinschgau in Stein übertragen, ehe sie in Wien im Ate- lier Kundmanns in Reinbearbeitung kamen. Wir kennen ferner vom i6. Juli I89i einen Kostenvoranschlag der Tiroler Marmor- und PorphyrWerke der Union-Baugesellschaft in Wien, über welche Kundmann das Steinmaterial besorgte, und wissen somit Bescheid über die Kosten eines Marmorblocks samt Punktieren und Reinausführung (Abb. 8). ${ }^{26}$

AVAFHKA, CUM, U-Praes. 470 ex I89I) und I5. Oktober I89I (ÖSTA, AVAFHKA, CUM, U-Präs. I878 ex I89I), I8. Juli (ÖSTA, AVAFHKA, CUM, U-Präs. I5I5 [Beilage zu 2304] ex I892) und I8. Dezember 1892 (ÖSTA, AVAFHKA, CUM, U-Präs. 2538 ex I892). S. auch die diesbezüglichen Entwürfe (Wienbibliothek im Rathaus, Handschriftensammlung, H.I.N. I04.522, I09.I24, I04.557) bzw. Abschriften (UAW, AAK S 96/9).

26 Wienbibliothek im Rathaus, Handschriftensammlung, H.I.N. I04.563/2. Selbst eine handschriftliche Kalkulation Kundmanns über das Gesamtprojekt ist erhalten (Wienbibliothek im Rathaus, Handschriftensammlung, H.I.N. I04.563/I4).

27 Vgl. Verhandlungen der achtzehnten Versammlung deutscher Philologen, Schulmänner und Orientalisten in Wien 


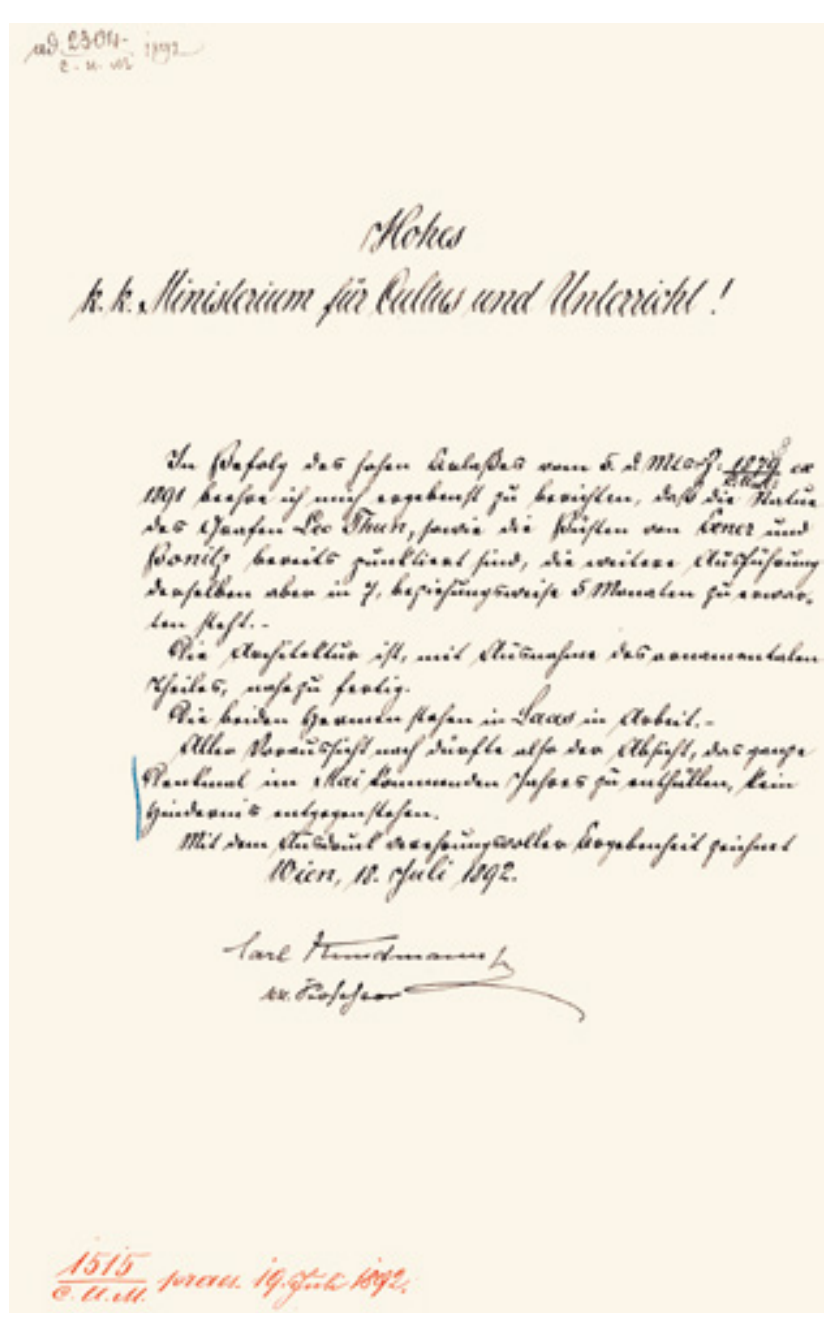

Abb. 7: Bericht Carl Kundmanns an das Ministerium vom I8. Juli I892 (ÖSTA, AVAFHKA, CUM, U-Praes. ISIs [Beilage zu 2304] ex I892).

Nachdem in München anlässlich der 4I. Versammlung Deutscher Philologen und Schulmänner vom 20. bis 23. Mai I89I Wien als nächster Veranstaltungsort dieses Zusammentreffens beschlossen worden war, lief in der Hauptstadt der k. k. Monarchie alles auf eine Zusammenlegung der Enthüllung des Thun-Hohenstein-Denkmals mit dieser renommierten, seit 1838 regelmäßig stattfindenden Versammlung hinaus, die sich der Erörterung wissenschaftlicher Fragen genauso widmete wie den Methoden des Unterrichts an Gymnasien und Universitäten, und auch über eine eigene pädagogische Sektion verfügte. Wien war erstmals und zuletzt I858 Austragungsort dieser hochkarätigen Fachtagung gewesen. ${ }^{27}$

Am 27. Februar I893 - die Arbeiten am Denkmal waren von Kundmann fast abgeschlossen -

vom 25. bis 28. September 1858 , Wien 1859 .

28 Beilage zu Protokoll Nr. 1742 ex I892/93 des Akademischen Senats der Universität Wien (UAW, AAK S 96/9). 


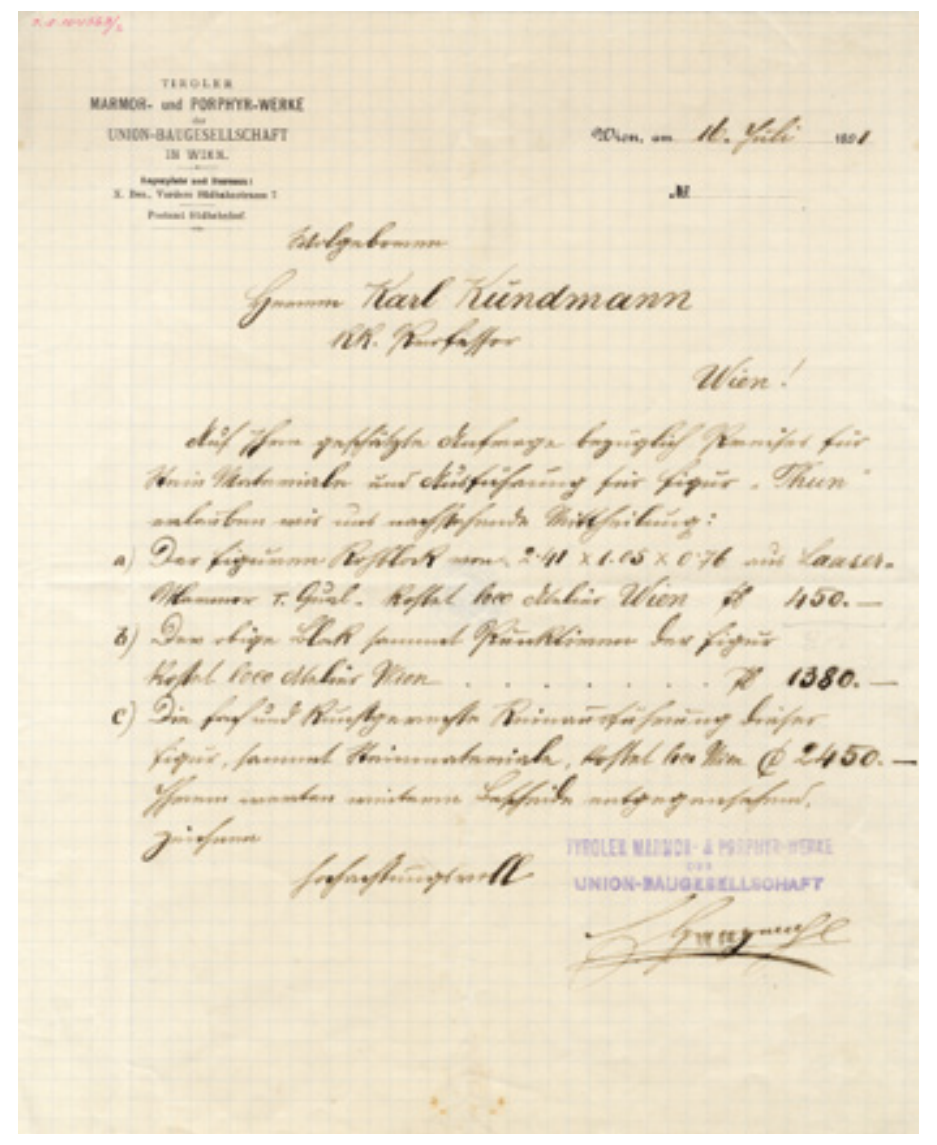

Abb. 8: Kostenvoranschlag der Union-Baugesellschaft in Wien (Wienbibliothek im Rathaus, Handschriftensammlung, H.I.N. 104.563/2).

wandte sich Minister Gautsch an Ernst Ludwig, Rektor der Wiener Universität, mit dem Ersuchen, die Veranlassung zu treffen, daß mir ehestens der Entwurf einer Inschrift, deren Genehmigung ich mir vorbehalte, vorgelegt werde. ${ }^{28}$ Wilhelm von Hartel arbeitete unverzüglich einen Entwurf aus, musste sich beim Konzipieren der Inschrift aber sehr beeilen, weil der Rektor diese schon am 3. März in der Senatssitzung vorlegen wollte. Dieser Entwurf fand unter Vorbehalt einer Überprüfung und eventuellen Richtigstellung die ungeteilte Zustimmung des Senats.

Der Archivar Karl Schrauf übernahm es, die Inschrift anhand von Akten im Unterrichtsmi- nisterium und gedruckten biografischen Quellen zu überprüfen. Diese Überprüfung war auch notwendig, denn Hartel waren in der Eile einige Fehler unterlaufen. So hatte er sich im Jahr geirrt, in dem Exner aus Prag von seiner ordentlichen Professur für Philosophie als Ministerialrat ins Unterrichtsministerium nach Wien wechselte, bei der Nennung des Kaisers vergaß er auf das „Francisci“ vor „Josephi“, und Bonitz hatte er einen falschen Vornamen angedichtet: Eduard statt Hermann.

Die überarbeitete Version wurde dem Ministerium zur Genehmigung vorgelegt, welches am 29. März dem Rektor mitteilte, wie die Inschrif-

29 Beilage zu Protokoll Nr. 2032 ex 1892/93 des Akademischen Senats der Universität Wien (UAW, AAK S 96/9). 


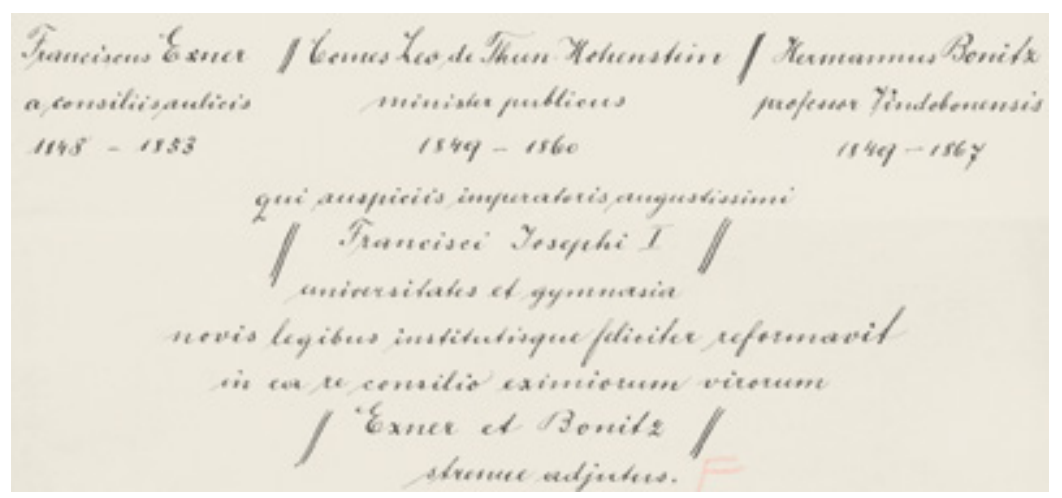

Abb. 9: Ausschnitt aus dem Schreiben des Ministers Gautsch an den Rektor der Universität Wien vom 29. März I893.

ten (mit kleinen Änderungen) offiziell zu lauten hätten (Abb. 9). ${ }^{29}$

Der Tag der Enthüllung, der 24. Mai I893, rückte immer näher, und man entnimmt den Akten die Hektik der letzten, emsig getätigten Vorbereitungen. Eine Liste von Persönlichkeiten, welche bei Univ[ersitäts-]Feierlichkeiten eingeladen zu werden pflegen, wird erstellt - und mehrmals überarbeitet. Einladungskarten (6oo Stück aufweißem, 200 Stück auf blauem Papier - letztere für Damen) werden beim Verlag Adolf Holzhausen bestellt ${ }^{30}$ und versendet - an das Ministerium, Behörden und Anstalten, an Dekanate und Zeitungsredaktionen. Holzhausen hat in diesen Tagen überhaupt kräftig zu schaffen. Denn auch die Festrede von Hartel zur Enthüllung des Denkmals ${ }^{31}$ wird von Holzhausen in IOo० Exemplaren gedruckt und muss von der Universität versendet werden.

Im Zuge des Versetzens des Denkmals bemerkt Kundmann Anfang Mai, dass die Wände des Oktogons vollständig neu bemalt werden müssten, und bittet, diese Arbeit mit möglichster Beschleunigung bewerkstelligen zu lassen. ${ }^{32}$ Der Rektor unternimmt daraufhin eine Begehung des Arkadenhofes, stellt in der Tat fest, daß der Arkaden-Gang [...] was die Bemalung anbetrifft, sich in einem sehr schadhaften Zustande befindet, ${ }^{33}$ und ordnet umgehend eine Übertünchung an. Eine Militärkapelle wird für die musikalische Untermalung der Feierlichkeiten im Arkadenhof bestellt.

Eine derart groß angekündigte Enthüllung eines Denkmals erfordert eine perfekte Planung. Rektor Ludwig tut sein Bestes und lässt eine Festordnung für den 24.ten Mai I893 erarbeiten. ${ }^{34}$ Darin wird penibel festgelegt, welche Personengruppen wo sitzen bzw. stehen sollten, von wo der Eintritt in den Festsaal und wie der Abgang in die Arkaden zu erfolgen habe und wo Ordner und Diener zu postieren seien.

30 Protokoll Nr. 2199 ex 1892/93 des Akademischen Senats der Universität Wien, 26. April und I. Mai I893 (UAW, AAK S 96/9).

3I W. v. Hartel, Festrede zur Enthüllung des Thun-Exner-Bonitz-Denkmals, gehalten in der I. Hauptsitzung der 42. Versammlung deutscher Philologen und Schulmänner am 24. Mai I893, den Festgästen überreicht vom Rector und Senat der Universität, Wien I893.

Schreiben Kundmanns aus Wien an das Rektorat der Universität Wien, 2. Mai I893, Beilage zu Protokoll Nr. 2289 ex I892/93 des Akademischen Senats der Universität Wien (UAW, AAK S 96/9).

33 Protokoll Nr. 2289 ex I892/93 des Akademischen Senats der Universität Wien, 3. Mai I893 (UAW, AAK S 96/9).

34 Beilage zu Protokoll Nr. 2199 ex 1892/93 des Akademischen Senats der Universität Wien (UAW, AAK S 96/9).

35 K. MüHlberger, Palast der Wissenschaft. Ein historischer Spaziergang durch das Hauptgebäude der Alma Mater 


\section{E N T H Ü L L U N G}

Die professionelle Vorbereitung ließ die Feierlichkeiten rund um die Enthüllung des Thun-ExnerBonitz-Denkmals am Mittwoch, den 24. Mai I893 um Io Uhr Vormittag, reibungslos ablaufen. Auf der Einladungskarte (Abb. Io) war als Ort der Begrüßungen und der von Hartel gehaltenen Festrede die Aula angegeben, womit in den ersten Jahren nach der Besiedlung des neuen Gebäudes gelegentlich der Große Festsaal bezeichnet wurde, ${ }^{35}$ wo diese Programmpunkte auch tatsächlich stattfanden, und zwar im Rahmen der ersten allgemeinen Sitzung der 42. Versammlung deutscher Philologen und Schulmänner unter den Präsidenten Hartel und Egger-Möllwald. Vielen Gästen, die schon 35 Jahre zuvor, im Jahr I858, an diesem Zirkel gelehrter Leute in Wien teilgenommen hatten, müssen die Veränderungen in der Reichshauptstadt und der Universität seither enorm vorgekommen sein, sie müssen sich wie in einem anderen, einem ,neuen', jungen 'Wien gefühlt haben - und haben dies in ihren Ansprachen und gegenüber Pressevertretern auch zum Ausdruck gebracht. ${ }^{36}$

Die Denkmalenthüllung fand nicht, wie sonst üblich, im überschaubaren akademischen Umfeld Wiens statt. Sie war vielmehr ausgezeichnet durch eine hochrangige, internationale Gelehrtenschaft - insgesamt 948 Personen waren zur Versammlung angemeldet -, ausgezeichnet darüber hinaus durch die Anwesenheit von Ministerpräsident Taaffe, mehreren Ministern und Statthaltern, weiteren hohen Vertretern des Staates, der Stadt und der Wissenschaft sowie Angehörigen der Familien der durch das Denkmal Geehrten, die, wie Hartel in seiner Festrede be-

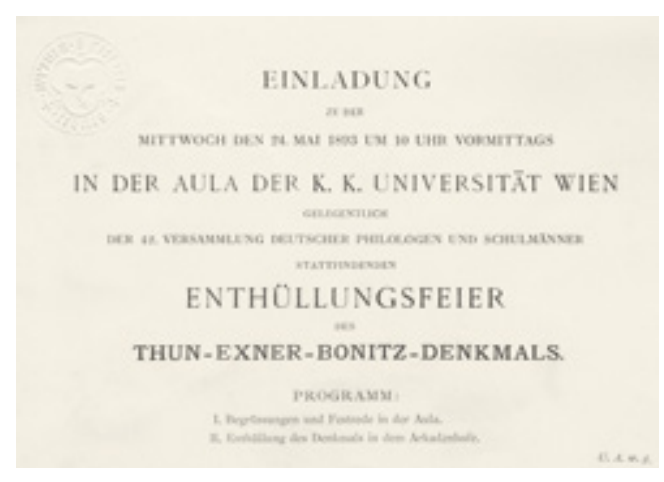

Abb. Iо: Einladung zur Eröffnungsfeier des Thun-ExnerBonitz-Denkmals.

tonte, in unserem Vaterlande eine neue Epoche des geistigen Lebens durch ibre Schöpfungen eröffnet haben. ${ }^{37}$ Die ihnen verdankte Reform sei von durchgreifender Wirkung auf die gesammte Cultur Öterreichs gewesen. ${ }^{3}$ Hartels Festrede wurde daher bewusst in diesem Kreise berühmter und bewährter Vertreter der Wissenschaft und Schule gehalten ${ }^{39}$. Nach diversen Begrüßungsworten und der Festrede Hartels sah das Programm den Gang in den Arkadenhof und die Enthüllung des Thun-Hohenstein-Denkmals vor.

Unmittelbar danach fand in der Aula die Enthüllung noch eines weiteren Monuments statt, nämlich der nach Entwürfen von Camillo Sitte in Marmor ausgeführten Rektorentafeln, auf denen die Namen aller Rektoren seit der Gründung von 1365 bis I 892 verzeichnet waren (Abb. II). Karl Schrauf hatte sie aus den im Universitätsarchiv befindlichen Originalakten und eigenhändigen Unterschriften der Rektoren zusammengestellt. ${ }^{40}$

Rudolphina Vindobonensis, Wien u. a. 2007, S. 67.

36 Vgl. die zahlreichen Berichte über die Versammlung in den Tageszeitungen.

37 Hartel, Festrede (zit. Anm. 3I), S. 4.

38 Ebenda, S. 5.

39 Ebenda, S. 4.

40 K. Schrauf, Die Gedächtnistafeln der Wiener Universitäts-Rectoren 1365-I893, Wien 1893. Auch diese Listen wurden vom Verlag Holzhausen in einer Auflage von Iooo Exemplaren gedruckt.

4I W. von Hartel in seiner Rede zur Begrüßung der Gäste, s. Verhandlungen der zweiundvierzigsten Versammlung 


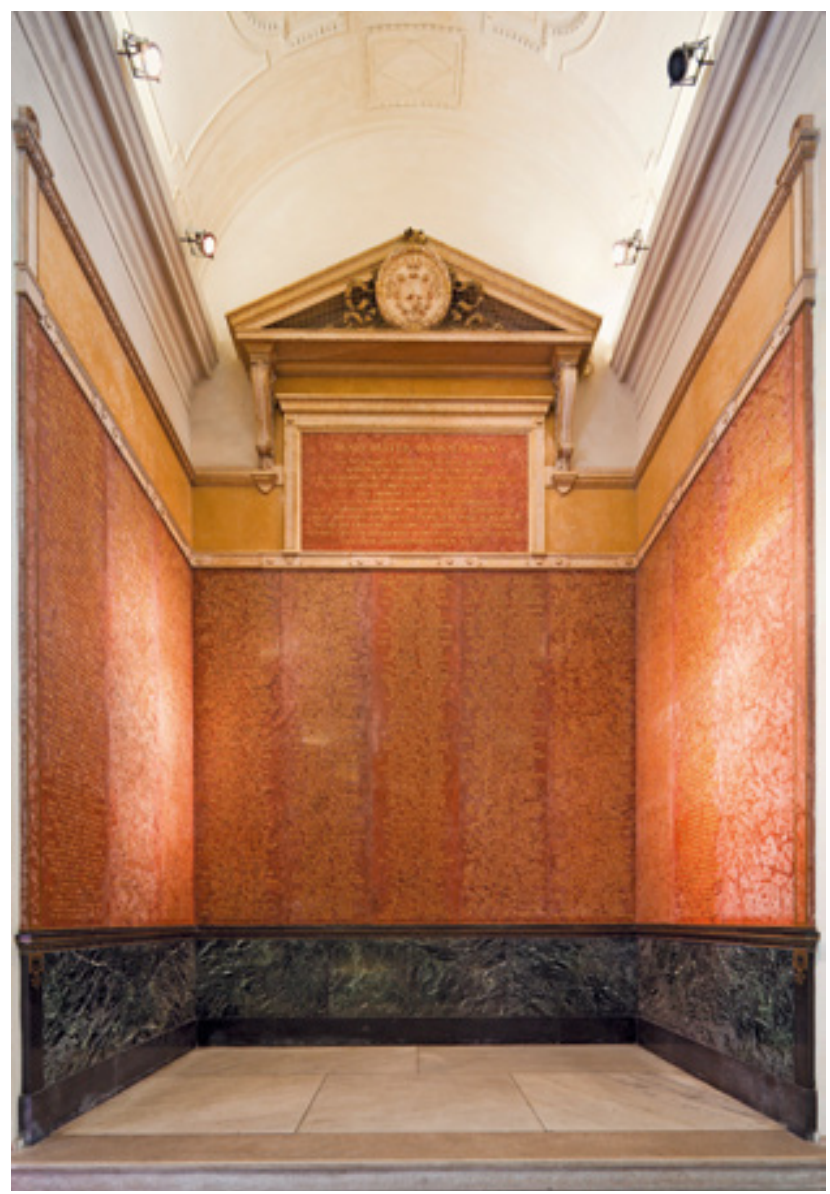

Abb. II: Rektorentafeln in der Aula des Hauptgebäudes der Universität Wien.

Dieser Programmpunkt zeigt, dass der 24. Mai 1893 von der Alma Mater Rudolphina als ein besonderer Tag aufgefasst wurde. Die beiden Denkmäler - die Rektorentafeln in der Aula und das Thun-Hohenstein-Denkmal im Arkadenhof - wurden zwar nicht von Anfang an gemeinsam geplant, aber sie wurden bewusst aufeinander bezogen, bewusst unmittelbar aufeinanderfolgend enthüllt. Denn durch die Aufstellung der Rektorentafeln wurde das Geburtsjahr der alten, durch die Enthüllung des Thun-Denkmals das Wiegen- fest der neuen Universität gefeiert. ${ }^{4 \mathrm{I}}$ Und wie die 42. Versammlung deutscher Philologen und Schulmänner Themen der universitären Wissenschaft und des schulischen Unterrichts zu verbinden wusste, so ist auch das Thun-Hohenstein-Denkmal Ausdruck dafür, dass Wissenschaft und Lehre, Universität und Mittelschule, nur in enger Fühlung und in treuem Zusammenwirken miteinander ihre hohe staatliche Mission zu erfüllen vermögen. ${ }^{42}$

deutscher Philologen und Schulmänner in Wien vom 24. bis 27. Mai I893 (Leipzig I894), S. 6.

42 Ebenda, S. 6.

43 Mühlberger, Palast der Wissenschaft (zit. Anm. 35), S. Ioo. 


\section{WEITERE DENKM ÄLER IM S ÜDLICHEN OKTOGON}

Kurt Mühlberger hat die Thun-Exner-BonitzDenkmalgruppe vor Kurzem als „monumentale Gruppe der Wiener Universitätsreformer" ${ }^{43}$ bezeichnet, und Thomas Maisel hat sie etwa zur gleichen Zeit als „universitätspolitisches Bekenntnis “ ${ }^{44}$ gewertet. Mit Verweis auf das bereits Dargelegte und mit Hinweis auf das hinter dem Denkmal stehende Komitee sowie die Inschrift selbst scheint mir diese universitätspolitische Dimension zu eng begriffen. Diese Gruppe ist mehr. Sie ist ein Denkmal für die beispiellose Entfaltung des gesamten Unterrichtswesens nach I848, für Universitäten und Gymnasien gleichermaßen, ist Ausdruck eines allgemeinen bildungspolitischen Anspruchs, der sich auch aus den Eröffnungs- und Schlussreden der 42. Versammlung deutscher Philologen und Schulmänner deutlich herauslesen lässt.

Dafür sprechen meines Erachtens auch die weiteren Denkmälerweihungen, die in den nächsten Jahren dieses Oktogon füllen.

Der erste, der hier dazustieß-am 4. Juli I897-, war der im März I89I verstorbene Franz von Miklosich. Adolf Exner hatte eine Büste für ihn beantragt, die hier aufgestellt werden sollte, um die Zugehörigkeit des Prof. Dr. Miklosich zu den Gelehrten Thun, Exner u[nd] Bonitz zu documentiren. ${ }^{45}$

Carl von Rokitansky kam am 5. Juni I898 dazu. Er war Professor für pathologische Anatomie, unbedingter Unterstützer der Thun'schen Reformen, ${ }^{46}$ mehrfacher Dekan, erster frei gewähl- ter Rektor $1852 / 53$ und langjähriger Präsident der Akademie der Wissenschaften. Dem Akt im Universitätsarchiv ist zu entnehmen, dass er der Thun'schen Periode angehört, sich vielfach um den Unterricht verdient gemacht hätte und seine Verdienste durch die Aufstellung der Büste neben Thun-Exner-Bonitz am besten gewürdigt würden. ${ }^{47}$

Zuletzt wurde am 9. Juli I899 das Relief des auf einem Sessel sitzenden Leopold Hasner von Artha hier angebracht, nachdem sich das beantragende Komitee mit gutem Grund für den Standort neben dem bereits bestehenden ThunHohenstein-Denkmal entschieden hatte. ThunHohenstein hatte Hasner „I849 eine eigens für ihn geschaffene außerordentliche Professur für Rechtsphilosophie“48 in Prag angeboten. I867I870 war er als Minister für Cultus und Unterricht verantwortlich für die Erlassung des Reichsvolksschulgesetzes und damit in gewissem Sinne Fortsetzer des Thun'schen Reformprozesses.

Innerhalb weniger Jahre haben sich damit um die Thun-Hohenstein-Gruppe weitere Denkmäler versammelt, die alle mit den bildungspolitischen Reformen Thun-Hohensteins in Verbindung zu bringen sind. Diese Denkmäler in der südwestlichen Ecke des Arkadenhofes stellen damit ein Ensemble des ausgehenden 19. Jahrhunderts dar - bestehend aus einer Statue, vier Büsten und einem Relief -, das auf die bildungspolitischen Weichenstellungen der Mitte des 19. Jahrhunderts verweist -

44 Maisel, Gelehrte in Stein und Bronze (zit. Anm. 6), S. I6.

45 UAW, AAK S 95/9. Dazu muss man wissen: Miklosich war I849 auf Antrag Thuns, eines überzeugten Förderers philologischer Studien, zum ersten Professor für slawische Philologie an der Universität Wien ernannt worden und stand Bonitz und Exner freundschaftlich sehr nahe. Vgl. auch den Beitrag von B. Murovec in diesem Band.

46 Vgl. G. Winckler, Carl von Rokitansky als Rektor der Wiener Universität, in: Carl Freiherr von Rokitansky I8041878. Pathologe, Politiker, Philosoph, Gründer der Wiener Medizinischen Schule des I9. Jahrhunderts (hrsg. von H. Rumpler/H. DenK), Wien u. a. 2005, S. 45-50.

47 UAW, AAK S 95/19.

48 H. L. Miкоletzky, Hasner Ritter von Artha, Leopold, in: Neue Deutsche Biographie 8, Berlin 1969, S. 38.

49 Ich danke Herrn Kollegen W. Krause für seine Expertise nach Autopsie während der Scholars'-Monuments-Tagung. 
und aus welchem die Statue Thun-Hohensteins, die einzige ganzfigurige lebensgroße Statue unter den Denkmälern des Arkadenhofes, hervorsticht.

Kehren wir abschließend nochmals zum Ausgangspunkt zurück: Die eingangs vorgestellte Gipsbüste von Bonitz ist jedenfalls kein Entwurfsmodell. Messpunkte sind an ihr nicht auszumachen. Das Kabinettformat und der Ölüberzug sprechen vielmehr für eine verkleiner- te Replik ${ }^{49}$. Warum sie sich im Institut für Alte Geschichte und Altertumskunde, Papyrologie und Epigraphik fand, muss bis auf Weiteres offenbleiben.

Abbildungsnachweis: Abb. I-4: Institut für Kunstgeschichte der Univ. Wien, R. Steyer; Abb. 5: Institut für Kunstgeschichte der Univ. Wien, R. Steyer/A. Plankensteiner, 20I4; Abb. 6: Fotostudio F. Pflügl; Abb. 7: ÖSTA; Abb. 8: Wienbibliothek im Rathaus; Abb. 9, ıо: UAW. 


\title{
MEDICUS IN EFFIGIE. REPRÄSENTATIONSFORMEN UND -FUNKTIONEN DES MEDIZINERDENKMALS AM BEISPIEL THEODOR BILLROTHS ${ }^{1}$
}

\author{
Julia RüdigeR
}

$\mathrm{D}$ ie sogenannte Denkmalflut des ausgehenden I9. Jahrhunderts schlug in Wien große Wellen. Davon zeugen nicht nur die zahlreichen Monumente für Musiker, Literaten und Staatsmänner im Stadtraum, sondern auch die Medizinerdenkmäler im Umkreis der Universität und des ehemaligen Allgemeinen Krankenhauses. Dem Chirurgen Theodor Billroth sind neben seinem Ehrengrab am Wiener Zentralfriedhof zahlreiche Denkmäler und Büsten vor und in seinen wichtigsten Wirkungsstätten gewidmet. Drei ganz unterschiedliche Billroth-Porträts bilden den Ausgangspunkt für die folgende Fallstudie, in der ich untersuche, inwiefern sich die intendierte Denkmalaussage in der Gestaltung niederschlägt. Die Analyse spannt sich zwischen der Büste vor dem Rudolfinerhaus (Abb. I), dem Denkmal im Arkadenhof der Universität Wien (Abb. 2), die beide kurz nach Billroths Tod von dem Bildhauer Kaspar von Zumbusch gearbeitet wurden, und der Statue (Abb. 3), die zu Billroths 50. Todestag im Februar 1944 im großen Hof des ehemaligen Allgemeinen Krankenhaus errichtet wurde. Bemerkenswert sind hierbei die formalen und ikonografischen Unterschiede in den Ausführungen. Die Varianten weisen darauf

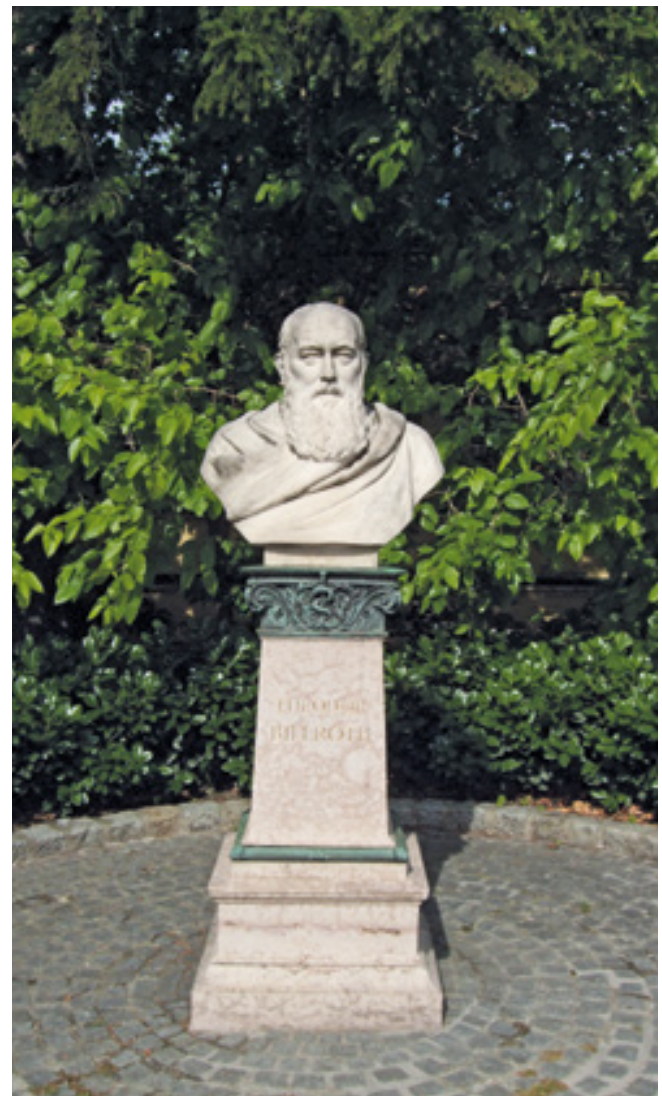

Abb. I: Kaspar von Zumbusch, Denkmalbüste für Theodor Billroth, I895, Rudolfinerhaus, Wien.

I Dieser Artikel kombiniert und vertieft zwei unterschiedliche Vorträge der Autorin zum Thema Medizinerdenkmal. Zum ersten den im Rahmen des Workshops Case Studies of Medical Portraiture im Juli 2013 am King's College London gehaltenen Vortrag „Surgeons' portraiture in historical context: monuments to Theodor Billroth“ und zum zweiten den bei der Wiener Tagung Scholars' Monuments. Historical meaning and cultural significance im September 


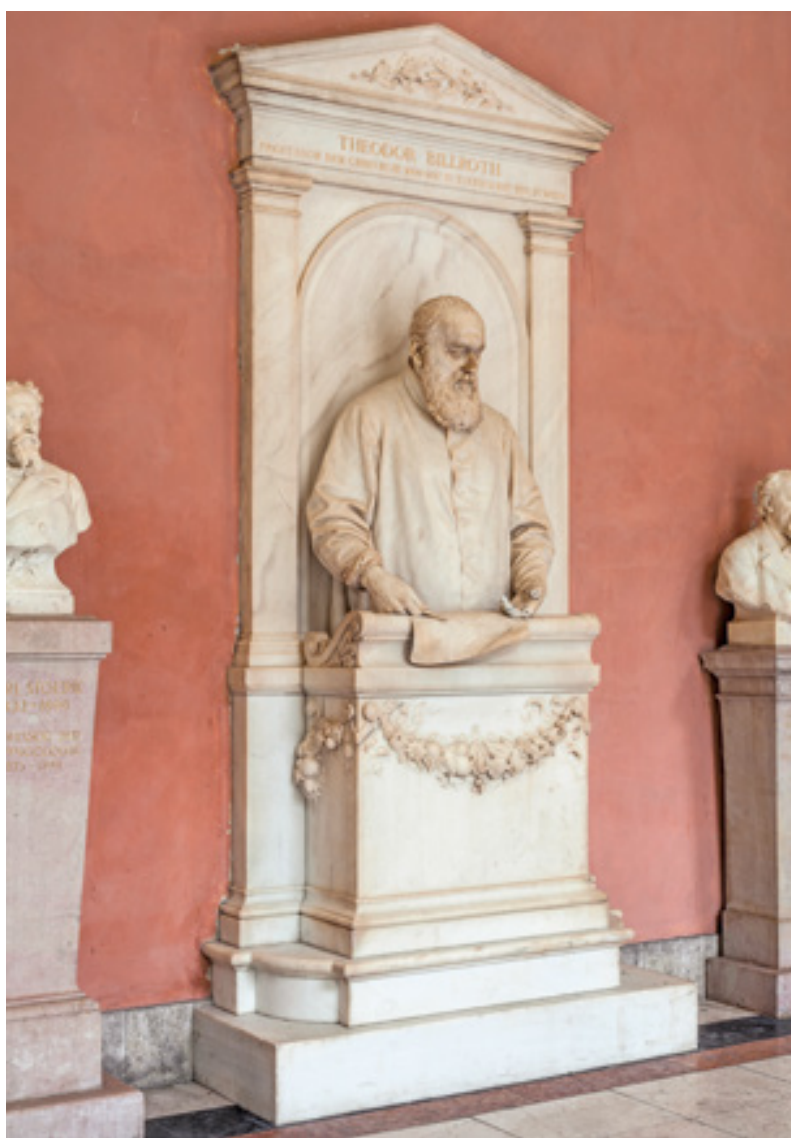

Abb. 2: Kaspar von Zumbusch, Denkmal für Theodor Billroth, I897, Marmor, Arkadenhof der Universität Wien.

hin, dass keine stereotypen Bildnisse gefordert waren, sondern dass vielmehr der jeweilige Kontext die Gestaltung der Monumente beeinflusste. Im Vergleich der Denkmäler entstehen daher die folgenden Fragen: Zu welchem Zweck wurden diese Denkmäler aufgestellt? Welche Charakteristika erachtet eine Institution zu welchem historischen Zeitpunkt als repräsentativ? Und wie werden die institutionellen Vorgaben künstlerisch umgesetzt?

Zum Zeitpunkt der Aufstellung mögen die ursprünglichen Denkmalsintentionen für zeitgenössische Rezipienten eindeutig oder zu- mindest lesbar gewesen sein. Doch über die Generationen geht diese Lesbarkeit verloren, sodass sie erst mittels Archivalien und einer genauen Betrachtung der Werke selbst wiederhergestellt werden kann. Gerade im Falle von Gelehrtendenkmälern spielt die Kenntnis der jeweiligen Wissenschaftsgeschichte eine entscheidende Rolle für das Verständnis der gewählten Darstellungsform. Dies berücksichtigend verstehe ich meinen wissenschaftlichen Ansatz vorrangig als kulturhistorisch. Der Medizinhistorikerin Mary E. Fissell folgend stelle ich die Frage nach der (sich wandelnden) Bedeutung der Denk-

$20 I 4$ vorgetragenen Beitrag „Die (zwei) Körper des Arztes. Repräsentationsformen und -funktionen des Medizinerdenkmals“. 


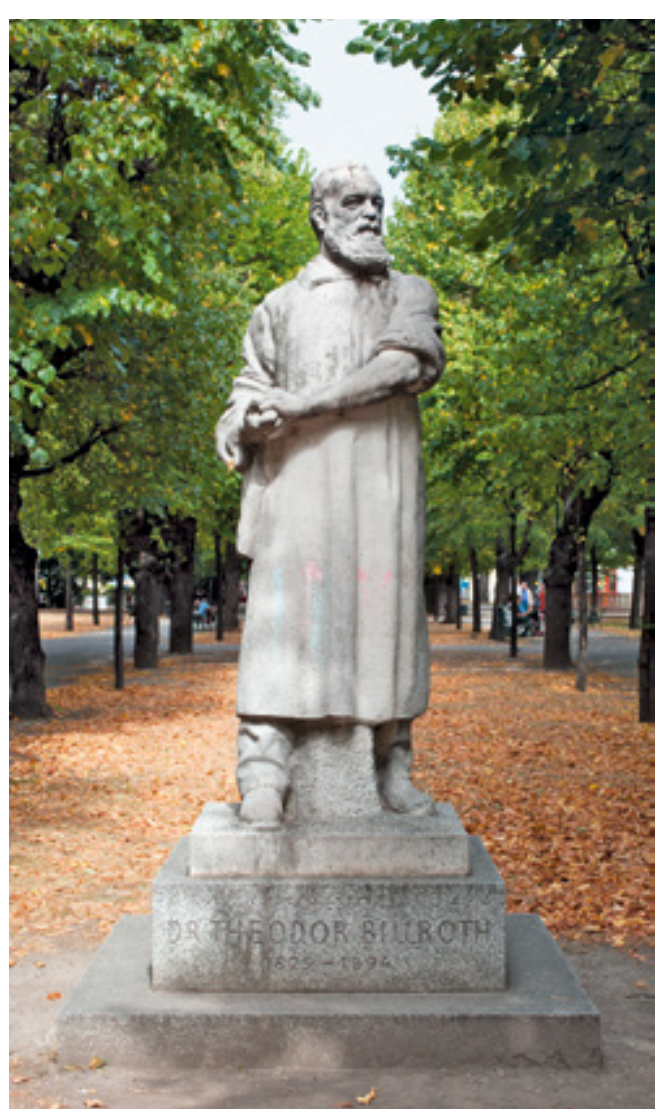

Abb. 3: Michael Drobil, Denkmalstatue für Theodor Billroth, 1944/49, Hof I des ehemaligen Allgemeinen Krankenhauses, heute Campus der Universität Wien.

mäler. Denn Bedeutung und Zweck eines kulturellen Erzeugnisses sind weder zwingend inhärent noch andauernd, sondern sie entstehen in stets wiederkehrenden Prozessen des making of meaning. ${ }^{2}$ Demnach muss für die Erforschung eines Denkmals die ursprünglich intendierte Bedeutung durch Quellenmaterial und durch eine rezeptionsästhetische Analyse der künstlerischen Form wieder freigelegt werden. Für Medizinerdenkmäler gilt gleichermaßen, was Thomas Nipperdey für nationale Denkmäler postuliert hat, dass diese ,im wesentlichen von etablierten Kräften " errichtet werden. ${ }^{3}$ In Nipperdeys Sinne waren diese vor allem politischer Natur. Im akademischen Kontext sind die etablierten Kräfte vordergründig jedenfalls die Vorstände, Dekane und Rektoren, die sich jeweils für die Vertreter bestimmter wissenschaftlicher Schulen einsetzen. Allerdings war die Wiener Medizinische Fakultät in der zweiten Hälfte des I9. Jahrhunderts in zwei politische Lager gespalten, ${ }^{4}$ daher können auch politische Beweggründe eine Rolle gespielt haben. Für Denkmalserrichtungen während des Zweiten Weltkriegs sind über die reine Memoria hinausgehende propagandistische Zwecke kaum auszuschließen. So muss für jedes der Denkmäler hinterfragt werden: Wer sind die etablierten Kräfte, die das Denkmal errichten? An welches Publikum wenden sie sich und mit welcher Botschaft?

In den Standardwerken der Porträtforschung gelten vor allem die zeitgenössische Porträtpraxis, der soziale Kontext des dargestellten Wissenschaftlers und der Aufstellungskontext als grundlegend für die ikonologische oder rezeptionsästhetische Beurteilung der Denkmäler. In der rezeptions- und funktionsorientierten Untersuchung der Billroth-Denkmäler spannt sich die Analyse zwischen der Biografie des Dargestellten, der zeitgenössischen Porträtkultur und der beauftragenden Institution.

2 M. E. Fissell, Making Meaning from the Margins. The New Cultural History of Medicine, in: Locating Medical History. The Stories and Their Meanings (hrsg. von F. Huisman/J. H. WARNER), Baltimore/London 2004, S. 365.

3 Th. Nipperdey, Nationalidee und Nationaldenkmal in Deutschland, in: Historische Zeitschrift, Bd. 206 H. 3 (Juni I968), S. 53I.

4 T. Buklijas, Surgery and national identity in late nineteenth-century Vienna, in: Studies in History and Philosophy of Biological and Biomedical Sciences, 38 (2007), S. 769.

5 L. Jordanova, Defining Features. Scientific and Medical Portraits 1660-2000, London 2000, S. 25-26; R. KanZ, Dichter und Denker im Porträt. Spurengänge zur deutschen Porträtkultur des I8. Jahrhunderts, München I993, S. I2. 
Die Begründung für eine Ehrung liegt vor allem in den medizinischen Leistungen. Diese wissenschaftshistorischen Zusammenhänge bilden die Grundlage für das Verständnis der bildhaften Hinweise in der Gestaltung des Denkmals. Die zeitgenössische Porträtkultur bedingt, welche künstlerischen Formen hierfür möglich waren. Schließlich geht die Untersuchung der idealen Rezeption, also der von der stiftenden Institution intendierten Aussagefunktion des Denkmals, im Zusammenhang mit seinem Aufstellungsort nach. Dieser Punkt basiert auf der Überzeugung, dass die Funktion von Denkmälern eine zweifache ist. Nicht nur sichert ein Denkmal dem Dargestellten memoria, sondern die Tugenden und Leistungen werden durch das Denkmal auf die stiftende Institution projiziert. Demzufolge, so die These dieses Artikels, werden je nach Auftraggeber und Institution die jeweilig passends- ten Tugenden oder Merkmale in der Denkmalgestaltung wirkungsvoll in Szene gesetzt.

Das Billroth-Denkmal im Ensemble der Professorendenkmäler im Arkadenhof der Universität zielte von Beginn an auf ein anderes Publikum ab als jenes vor dem Spital Rudolfinerhaus. Wenn auch die Statue im Hof des Allgemeinen Krankenhauses in einem ähnlichen institutionellen Kontext, nämlich vor einem Krankenhaus, errichtet wurde, lässt der Aufstellungszeitpunkt im Februar 1944 unter der Naziherrschaft erahnen, dass hier nicht allein Billroths medizinische Leistungen im Vordergrund standen. Anhand dieser drei Denkmäler werde ich aufzeigen, zu welch unterschiedlichen künstlerischen Ergebnissen die Ehrungen von Medizinern kommen können und inwieweit medizinhistorische und politische Einflüsse hierbei nachweisbar sind.

\section{DAS WIRKEN THEODOR BILLROTHS}

Theodor Billroth $\left({ }^{*}\right.$ 26. April I829-7. Februar 1894) gilt als Europas führender Chirurg des späten 19. Jahrhunderts und als Protagonist der fortschreitenden Verbesserung der wissenschaftsbasierten Medizin. Nach seinem Studium in Greifswald, Göttingen und Berlin, wo er von seinen Mentoren nicht nur in Medizin, sondern auch in einer wissenschaftlichen Methodik unterrichtet wurde, arbeitete er als Assistenzarzt an der Berliner Charité unter seinem Lehrer Bernhard von Langenbeck. Im Januar I860 wurde er als Direktor der Chirurgischen Klinik an die Universität Zürich berufen. Im Jahr I867 folgte Billroth schließlich dem Ruf an die Universität Wien auf die 2. Chirurgische Lehrkanzel. ${ }^{6}$

Billroths Arbeit zeichnet sich insbesondere dadurch aus, dass er systematisch die chi- rurgische Praxis und Nachsorge in Zusammenhang mit parallelen wissenschaftsbasierten Forschungen sah. So begann er in Zürich mit der Aufzeichnung von Patientendaten, Krankheits- und Heilungsverläufen. Die wissenschaftliche Analyse dieser Aufzeichnungen diente ihm zur Überprüfung und stetigen Verbesserung seiner Therapiemethoden. Mit der empirischen Ausrichtung der medizinischen Praxis reihte sich Billroth nahtlos in die Tradition der Ersten und Zweiten Wiener Schule der Medizin ein, die zuerst unter Gerard van Swieten (1700-1772) und Andreas Josef von Stifft (1760-1836) und später unter Carl von Rokitansky (1804-1878) und Joseph Skoda (I805-I88I) die Grundlagen für die evidenzbasierte, moderne Medizin legten. ${ }^{7}$

6 W. Genschorek, Wegbereiter der Chirurgie. Johann Friedrich Dieffenbach/Theodor Billroth, Leipzig I982, S. II7I22.

7 E. Kandel, Das Zeitalter der Erkenntnis. Die Erforschung des Unbewussten in Kunst, Geist und Gehirn von der Wiener Moderne bis heute, München 20I2, S. 44-46; Genschorek, Wegbereiter (zit. Anm. 8), S. I52. 
Während des Deutsch-Französischen Kriegs I870/7I wirkte Billroth freiwillig bei der Errichtung von Kriegslazaretten auf preußischer Seite mit. Seine dortigen Erfahrungen nutzte er, um nach den Ursachen des Wundbrands zu forschen. Denn Wundinfektionen stellten die größte medizinische Problematik sowohl in der Behandlung verwundeter Soldaten als auch in der postoperativen Nachsorge ziviler PatientInnen dar.

Seit den späten I86oer-Jahren kursierten Theorien über die Ursachen des Wundbrands und dessen Bekämpfung. Basierend auf Louis Pasteurs Keimtheorie empfahl der englische Arzt Lord Joseph Lister die großflächige Behandlung der Räume bzw. der Raumluft mit Karbolsäure. ${ }^{8}$ Billroth zweifelte jedoch lange an Listers Theorie und deren Wirksamkeit. Erst im Jahr I878 führte Billroth antiseptische Methoden und insbesondere das Tragen von reinen OP-Kitteln bei seinen Operationen verpflichtend ein. ${ }^{9}$ Dadurch wurde Billroth zu einem der Pioniere der Antisepsis in Wien. Die keimfreie Wundbehandlung hob die Überlebensrate seiner PatientInnen signifikant. ${ }^{\text {Io }}$

Insgesamt basierte der Erfolg der medizinischen und im Speziellen der chirurgischen Praxis in der zweiten Hälfte des I9. Jahrhunderts auf zwei Neuerungen: Zum einen erlaubten überhaupt erst die Fortschritte der Anästhesie ab den I840er-Jahren größere, schmerzfreie Eingriffe. Zum anderen brachten die Kenntnis und die Akzeptanz antiseptischer Methoden einen Durchbruch gegen postoperative Wundinfektionen.

Mit seinem Engagement für das Rudolfinerhaus, das als Lehrkrankenhaus für die erste Krankenpflegerinnenschule konzipiert war, setzte Billroth weitere Akzente in der medizinischen Nachsorge. Neben seinen chirurgischen Leistungen trat er stark für die universitäre Lehre ein und war dadurch bei einem Großteil der Studenten sehr beliebt. Im medizinischen und wissenschaftlichen Kontext gilt Billroth daher als herausragender Forscher und Arzt, dem die moderne Medizin enorme Fortschritte verdankt.

Aufgrund seiner antisemitischen Äußerungen und Agitation muss er im historischen Diskurs als ambivalente Persönlichkeit gesehen werden. In seiner Schrift „Über das Lehren und Lernen der medicinischen Wissenschaften an den Universitäten der deutschen Nation" beklagte er die Überfüllung der Hörsäle mit jüdischen Studierenden, denen er rassisch begründet die Voraussetzungen zur wissenschaftlichen Kompetenz absprach. ${ }^{\text {II }}$ Mit dieser Aussage heizte er die seit dem Börsenkrach 1873 bereits höchst

8 Th. Schlich, Asepsis and Bacteriology: A Realignment of Surgery and Laboratory Science, in: Medical History, Vol. 56/3 (2012), S. 309 .

9 Genschorek, Wegbereiter (zit. Anm. 8), S. i87. Siehe auch K. Lovecky/B. Panning, ... nicht einmal ein Tröpfchen Blut. Adalbert Seligmanns Gemälde „Der Billroth'sche Hörsaal im Allgemeinen Wiener Krankenhaus“, in: Wiener Geschichtsblätter, 68. Jg., Heft 3 (2013), S. 229; S. AвEND, Götter in Weiß. Arztmythen in der Kunst, Hilden 20I0, S. 130-136.

Io Billroths spektakulärste Operation war die erste erfolgreiche Magenresektion im Jahr I88I, bei der er einer Patientin einen $44 \mathrm{~cm}$ großen Tumor aus der Magenwand entfernte. Siehe Genschorek, Wegbereiter (zit. Anm. 8), S. 203-204.

II Th. Billroth, Über das Lehren und Lernen der medicinischen Wissenschaften an den Universitäten der deutschen Nation. Eine Culturstudie, Wien I875, S. I49-I53; F. SeEbacher, Das Fremde im „deutschen“ Tempel der Wissenschaften. Brüche in der Wissenschaftskultur der Medizinischen Fakultät der Universität Wien, Wien 20II, S. IoI; O. Ratнкоцв, Gewalt und Antisemitismus an der Universität Wien und die Badeni-Krise I897. Davor und danach, in: Der lange Schatten des Antisemitismus: Kritische Auseinandersetzungen mit der Geschichte der Universität Wien im I9. und 20. Jahrhundert (hrsg. von O. RathкоLB), Göttingen 20I3, S. 7I-72; F. SeEbacher, „Der operierte Chirurg". Theodor Billroths Deutschnationalismus und akademischer Antisemitismus, in: Zeitschrift für Geschichtswissenschaft 54 (2006), S. 317-338. 
angespannte Situation gegenüber den jüdischen Mitbürgern an und traf damit nicht nur bei den deutschnationalen Burschenschaftern auf begeisterte Anhänger. ${ }^{12}$ Erst I89r konnte er den sowohl bei antisemitischen Anhängern als auch bei ministerialen Gegnern erzeugten Aufruhr durch seine Ehrenmitgliedschaft im „Verein zur Ab- wehr des Antisemitismus" wieder besänftigen. Nachweislich blieben seine Äußerungen in antisemitischen Kreisen in Erinnerung. Diese Schattenseite in Billroths Biografie ist entscheidend für das Verständnis des Denkmals, das 1944 zur Aufstellung kam.

\section{DIE BILLROTH-DENKM ÄLER VOR I 900}

Über Jahrhunderte waren Porträtbüsten und Denkmäler der gesellschaftlichen Elite vorbehalten und entwickelten sich erst seit dem späten I8. Jahrhundert zum Medium der bürgerlichen Repräsentation. ${ }^{13}$ Das Neue Wiener Tagblatt beklagte im Jahr 1867, dass diese Entwicklung in Österreich besonders schleppend vor sich ginge, aber dass auch hier die Zeit kommen müsse, wo den bürgerlichen Verdiensten und den großen Erfindern Monumente gesetzt würden. ${ }^{14}$ Seit der Mitte des I9. Jahrhunderts war Wien geprägt von der Anlage der Ringstraße, den seit Jahrhunderten größten Eingriff in die Urbanistik der Stadt. Hier boten sich sowohl an den entstehenden Plätzen als auch an den Fassaden der Monumentalbauten zahlreiche Möglichkeiten für die Ehrungen von Mitgliedern des Kaiserhauses, von verdienstvollen Militärs, aber schließlich auch von Komponisten und herausragenden Vertretern des Bürgertums. Diese sprunghafte Entwicklung rief innerhalb kürzester Zeit auch Kritiker auf den Plan, die die „Selbstbedenkmalungs-Arroganz" der Wiener Gesellschaft und die darauffolgende „Denkmal-Pest“ beklagten. ${ }^{\text {Is }}$

Einer der vielbeschäftigten Bildhauer war Kaspar von Zumbusch (1830-1915), der, nach seiner Ausbildung an der Polytechnischen Schule in München, in Wien zahlreiche Denkmäler im öffentlichen Raum geschaffen hat. Besonders prestigeträchtige Aufträge waren jene für das Beethoven-Denkmal und das prächtige Maria-Theresien-Denkmal an der Ringstraße. Für die Ehrung der Wiener Gelehrten wurde im Jahr I885 im Arkadenhof des Universitätsneubaus an der Ringstraße ein Memorialraum eingerichtet. ${ }^{16}$ Hier sollten die bedeutenden Wissenschaftler der Universität posthum geehrt werden und durch ihre Anwesenheit in effigie den nachkommenden Generationen als Vorbild und Ansporn dienen. Der gesellschaftliche Bedarf einer solchen bürgerlichen Ehrenhalle spiegelt sich nicht nur in dem oben zitierten Artikel wider, sondern zeigt sich besonders in der Resonanz. Obwohl der Senat als erste Bedingung stellte, dass der Universität aus den Denkmalserrichtungen keine Kosten erwachsen sollten, fanden sich schon bis zur Jahrhundertwende private Stifter, meist die Professorenwitwen, die Kollegen oder die Schülerschaft, die für die Aufstellung von ungefähr vierzig Denkmälern sorgten.

Das Denkmal für Billroth hatte der renommierte Bildhauer Zumbusch im Jahr I897 voll-

I2 Seebacher, Das Fremde (zit. Anm. I3), S. 84-86.

I3 P. Zitzlsperger, Die Büste als Porträt. Historische und theoretische Überlegungen, in: Die obere Hälfte. Die Büste seit Rodin (hrsg. von D. Brunner et al.), Heidelberg 2005, S. 24.

I4 Neues Wiener Tagblatt, 20. Oktober 1867, zit. nach W. Telesko, Kulturraum Österreich. Die Identiät der Regionen in der bildenden Kunst des I9. Jahrhunderts, Wien/Köln/Weimar 2008, S. I65-166.

I5 F. Kürnberger, Ein Aphorismus zur Denkmal-Pest unserer Zeit, in: Die Gegenwart. Wochenschrift für Literatur, Kunst und öffentliches Leben, Io (30. März I872), S. I54-156.

I6 Th. MaIsel, Gelehrte in Stein und Bronze, Wien 2007, S. II. 
endet. Mediziner und Bildhauer hatten sich spätestens Mitte der I88oer-Jahre kennengelernt, als Billroth eine Büste des Kronprinzen Rudolf, des kaiserlichen Protektors der Krankenanstalt Rudolfinerhaus, bestellt hatte. Noch zu Billroths Lebzeiten erhielt der Künstler den Auftrag, eine Porträtbüste von dem Mediziner zu schaffen. Diese überreichten Billroths Schüler im Jahr I892 der Berliner Charité, wo sie sich noch heute befindet. ${ }^{17}$ Spätestens nach der Fertigstellung dieser ersten Büste machte Billroth sich besagter Selbstbedenkmalungs-Arroganz schuldig, indem er an Zumbusch schrieb, dass er damit rechne, dass ihm nach seinem Tod ein Denkmal im Arkadenhof der Universität Wien, wo seit 1888 eine Ehrenhalle mit den Büsten der herausragendsten Professoren eingerichtet worden war, gewidmet würde. ${ }^{18}$ Aus diesem Grund hätte er testamentarisch verfügt, dass Zumbusch das Denkmal ausführen solle. Das nötige Honorar übersandte er gleichzeitig an den Künstler, damit unter seinen Schülern und Kollegen keine Sammlungen durchgeführt werden mögen. ${ }^{19}$ Nach Billroths Tod vollendete Zumbusch als erstes jenes Bildnis, das am 26. April I895 feierlich vor dem Rudolfinerhaus enthüllt wurde. ${ }^{20}$ Die weiße Marmorbüste auf einem hohen Sockel ähnelt der Berliner Büste von I892, weist aber dennoch in einigen Details Unterschiede auf. Wie in der ersten Büste nach dem Leben sitzt auch hier der Haaransatz weit hinten und tiefe Falten umspielen die Augen, dennoch wirken im späteren Porträt die Gesichtszüge noch stärker idealisiert. Denn die Tränensäcke wirken weniger tief, die Wangen runder und glatter und der Bart noch länger. Statt der weichen Stofflichkeit der Berliner Büste gestaltete Zumbusch den drapierten
Stoff hier kräftiger, sodass die Assoziation zur Toga des antiken Gelehrten deutlicher hervortritt. Damit stellte Zumbusch den Mediziner in die Tradition des Gelehrtenporträts all'antica, deren Form das Modell durch idealisierte und zeitlose Darstellung in die Ewigkeit einschreiben sollte. ${ }^{21}$ Auf die Errungenschaften des Dargestellten nimmt diese Art der Gestaltung jedoch keinen Bezug. Lediglich im bronzenen Kapitell des Sockels verweist ein kleiner Äskulap auf die Profession des Porträtierten.

Einen ikonografischen Kontrast bildet das Denkmal im Arkadenhof der Universität. Im Gegensatz zu seinen früheren Werken nutzte Zumbusch hier die gestalterischen Möglichkeiten zur Gänze aus. In einer reduzierten Ädikula steht Billroth hinter einer Lehrkanzel, als wäre er gerade im Begriff zu dozieren. Billroths kräftiger, überlebensgroßer Körper füllt den Raum zwischen Wand und Kanzel vollständig aus, die erhöhte Position des Denkmals verleiht dem Abbild zusätzliche Autorität als Hochschullehrer. Während die Geste seiner linken Hand diesen Eindruck des Lehrenden unterstützt, hält seine rechte ein Skalpell, um auf seine Errungenschaften in der Chirurgie aufmerksam zu machen. Zwischen seinen Händen auf der Lehrkanzel liegt die anatomische Zeichnung des Beckenknochens mit dem oberen Abschnitt des Femurs, die offenkundig auf Billroths Erfolge bei Knochenoperationen anspielt, wie er sie in Zürich begonnen und in Wien systematisch verfeinert hatte. Mit diesen Attributen verweist das Denkmal auf die unterschiedlichen Aufgabenbereiche von Billroths Professur. Die Kanzel und die anatomische Zeichnung an sich verweisen auf die theoretische Vermittlung medizinischer Kennt-

I7 Siehe A. Keune, Gelehrtenbildnisse der Humboldt-Universität zu Berlin. Denkmäler, Büsten, Reliefs, Gedenktafeln, Gemälde, Zeichnungen, Graphiken, Medaillen, Berlin 20I0, S. 68; siehe auch M. KoLIsкo, Caspar von Zumbusch, Zürich/Leipzig/Wien I93I, S. 69-70.

I9 Kolisкo, Zumbusch (zit. Anm. 19), S. 79-80.

20 Kolisko, Zumbusch (zit. Anm. 19), S. 86.

2I F. M. Kammel, Charakterköpfe. Die Bildnisbüste in der Epoche der Aufklärung, Nürnberg 2OI3, S. IO3-IO4. 
nisse, wohingegen das Skalpell sowohl für Billroths chirurgische Fertigkeit als auch für dessen praktische Vermittlung an die Studierenden steht.

In Billroths Kleidung spiegelt sich diese Dualität von theoretischem und praktischem Lehren ebenfalls wider. Denn im Gegensatz zu den vorherigen Porträts trägt Billroths Abbild hier den Chirurgenkittel, der ihn eindeutig als praktizierenden Mediziner kennzeichnet. Mehr als ein Jahr vor der Enthüllung des Denkmals beschreibt ein knapper Pressebericht aus dem Atelier Zumbuschs das fast vollendete Tonmodell: „Man wähnt, Billroth lebend vor sich zu sehen. Die überlebensgroße Statue stellt den berühmten Chirurgen auf der Lehrkanzel, im Operationskittel stehend derart dar, daß hinter der Kathederbrüstung der Oberleib nur bis über die Hüften zu sehen ist. Die auf dem Katheder ruhende rechte Hand hält ein Operationsmesser. ${ }^{\text {"22 }}$ Die Beschreibung der Skulptur deutet darauf hin, dass die Kombination von Lehrkanzel und Operationskittel nicht selbstverständlich ist. Neben dem anerkennenden antikisierenden Typus von Gelehrten in Toga waren die Gelehrten in ihren Porträts seit dem Humanismus meist in Talar und Doktorhut abgebildet. ${ }^{23}$ Da sich die Medizin bis ins I8. Jahrhundert als Lehrbuchwissenschaft entwickelt hatte, entsprachen die Medizinerporträts weitgehend dieser allgemeinen Darstellungstradition mit Talar und Büchern als Attributen. Nur die Anatomengruppenbildnisse bilden hier eine Ausnahme, doch auch hier tragen die Anatomen entweder ihre akademische Amtstracht oder aber in Ausnahmefällen nob- le Kleidung und Dreispitz. ${ }^{24}$ Noch in der zweiten Hälfte des 19. Jahrhunderts wurden sowohl die Operationen als auch die Sektionen in Straßenkleidung durchgeführt. Die Einführung des Operationskittels als erfolgreiche Maßnahme der Antisepsis erfolgte in Wien erst I878. Billroth bekannte hierzu im Jahr I889: ,Alle Chirurgen tragen jetzt die antiseptische Uniform, das Individuelle tritt gewaltig in den Hintergrund. Mit reinen Händen und reinem Gewissen wird der Ungeübteste jetzt weit bessere Resultate erzielen als früher der berühmteste Professor der Chirurgie." ${ }^{25}$ Die neue Standeskleidung der medizinischen Gelehrten weist Billroth als einen zeitgemäßen und innovativen Chirurgen aus, der selbst großen Anteil an der Einführung der antiseptischen Maßnahmen in den Wiener Operationssälen hatte. Seine Befürchtungen um den Verlust der Individualität erfüllen sich zumindest in seinem Denkmal nicht, da die wuchtige Statur, die porträthaften Züge und der aufmerksame Blick sein Standbild unverkennbar machen.

Im Arkadenhof-Denkmal wurden also zwei wesentliche Charakteristika eines erfolgreichen, erinnerungswürdigen Chirurgieprofessors in einem Porträt zusammengefasst. Zum einen der Medizinprofessor, der in theoretischen Vorlesungen sein fundiertes Wissen an die Studenten weitergibt und zum anderen der lehrende Chirurg, bei dem die Studenten im Operationssaal die praktischen Fähigkeiten durch Anschauung und Erproben erlernen. Die Vorlesungen am Katheder hielt Billroth, so muss man annehmen, im bürgerlichen dunklen Anzug mit Gilet

22 Neue Freie Presse, I9. Januar I896, Nr. II280, S. 6.

23 Kanz, Dichter und Denker (zit. Anm. 7), S. 25; M. FüsseL, Talar und Doktorhut. Die akademische Kleiderordnung als Medium sozialer Distinktion, in: Frühneuzeitliche Universitätskulturen. Kulturhistorische Perspektiven auf die Hochschulen in Europa (hrsg. von B. Krug-Richter/R. E. Mohrmann), Köln/Weimar/Wien 2009, S. 248-249.

24 Kanz, Dichter und Denker (zit. Anm. 7), S. 44; M. Kemp/M. Wallace, Spectacular Bodies. The Art and Science of the Human Body from Leonardo to Now, Berkeley/Los Angeles/London 2000, S. 3 I.

25 Zit. nach W. EcKart, Illustrierte Geschichte der Medizin: Von der französischen Revolution bis zur Gegenwart, Berlin/Heidelberg 20II, S. I43; siehe auch L. Schönbauer, Das Medizinische Wien. Geschichte - Werden - Würdigung, Berlin/Wien I944, S. 29I. 


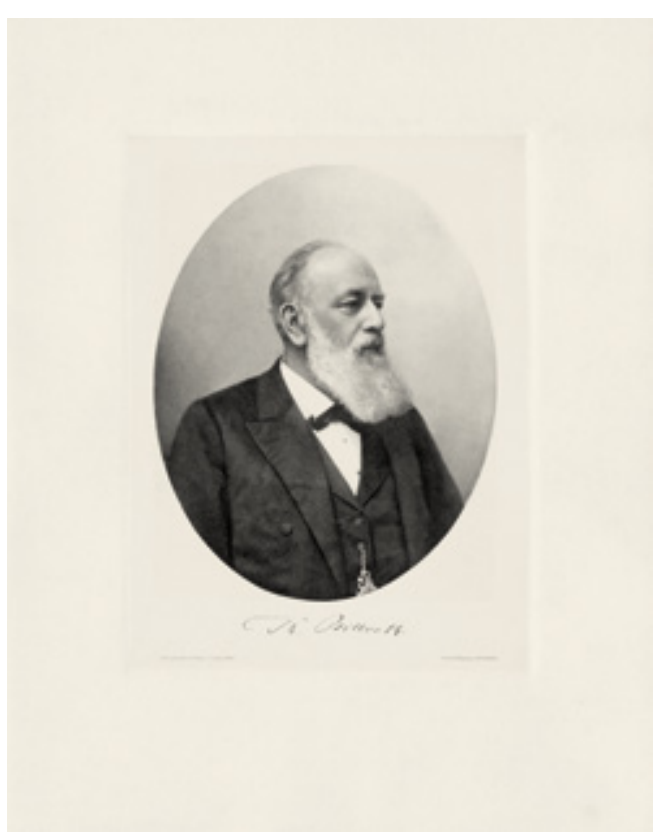

Abb. 4: Porträtfotografie von Theodor Billroth, undatiert, Österreichische Nationalbibliothek.

und Fliege, so wie er auf zahlreichen fotografischen Porträts zu sehen ist [Abb. 4]. Mit Kittel und Skalpell hingegen ist der Professor ausgerüstet für den Operationssaal, wie ihn das Porträt von I892 darstellt [Abb. 5]. Wie der Blick auf andere Medizinerdenkmäler im Arkadenhof der Universität Wien, beispielsweise diejenigen von Karl Langer von Edenberg (enthüllt 1903) oder Emil Zuckerkandl (enthüllt I924), ${ }^{26}$ zeigt, entwickelte sich die ,antiseptische Uniform“ zur modernen Ausstattung des Mediziner-Standesporträts. Statt eines magister in cathedra, der sich dem Betrachter in Talar und Doktorhut als Teil des Geistesadels präsentiert, zeigen die neuen Standesporträts den modernen Mediziner im Kittel als medicus in cathedra.

Die anatomische Zeichnung vor Billroth wirkt auf den ersten Blick widersprüchlich, da sie gerade nicht diejenigen chirurgischen Erfolge verbildlicht, für die er am meisten gefeiert wur-

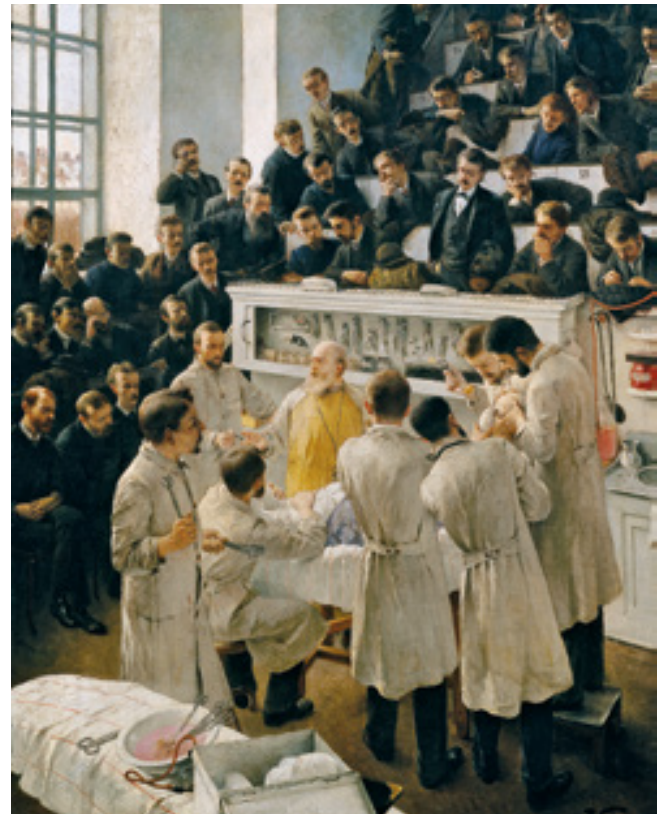

Abb. 5: Adalbert Franz Seligmann, Der Billroth'sche Hörsaal im Wiener Allgemeinen Krankenhaus, I888/go, Österreichische Galerie Belvedere Wien.

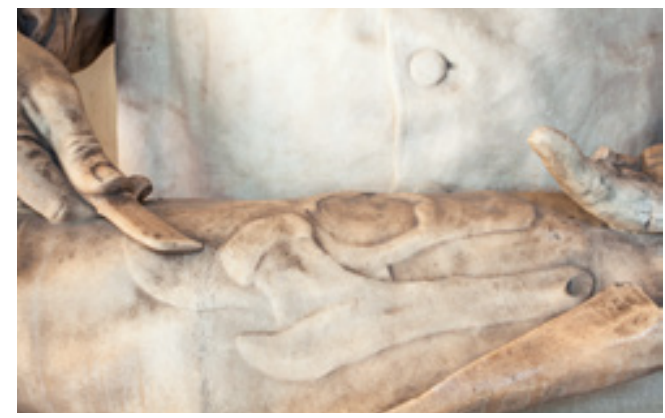

Abb. 6: Kaspar von Zumbusch, Denkmal für Theodor Billroth, I897, Marmor, Detail Anatomische Zeichnung, Arkadenhof der Universität Wien.

de. Nicht die nach ihm benannten Magenresektionen oder seine Kehlkopfoperation sind hier dargestellt, sondern stattdessen ein Beckenknochen und ein Oberschenkelknochen, der durch eine Osteotomie verkürzt wurde [Abb. 6]. Billroth hatte nach eigenem Bekunden bereits in Zürich ein großes Interesse für Knochenopera-

26 Th. Maisel, Gelehrte in Stein und Bronze, Wien 2007, S. 73 und 84. 
tionen entwickelt und I868 in Wien seine erste subkutane Osteotomie einer schief geheilten Unterschenkelfraktur durchgeführt. ${ }^{27}$ Aber nicht nur das Motiv der Zeichnung, sondern auch deren Gestaltung ist ungewöhnlich. Üblicherweise wird etwas Gezeichnetes in der plastischen Darstellung durch Einritzen dargestellt, wie beispielweise bei plastisch dargestellten Grundrissen. ${ }^{28}$ Der Bildhauer Zumbusch arbeitete stattdessen das Motiv in dem Bildvehikel des marmornen Blatts Papier als Hochrelief heraus. ${ }^{29}$ Auf die Erkennbarkeit des Bildobjekts, des Knochens, hat dieser bildtheoretische Kniff keine Auswirkung. Dennoch referiert die Differenz in der bildgebenden Ausarbeitung der marmornen Zeichnung, nämlich Hochrelief statt Ritzung, auf eine tiefere Aussage des Denkmals.

Im Jahr I870 veröffentlichte Billroth einen Artikel über die Praxis der Osteotomie, wobei er auf seinen Berliner Lehrer Bernhard von Langenbeck verwies, der ihm zufolge mit der Stichsäge hier besonders geschickt gewesen sei. ${ }^{3 \circ} \mathrm{Da}$ Billroth eingestehen musste, dass er es selbst „nie zu der Fertigkeit in Anwendung der Stichsäge“ bringen konnte, stellte er das für ihn viel geeignetere chirurgische Werkzeug vor, nämlich den Meißel. So schrieb er, dass er in zahlreichen Operationen ohne Säge und Bohrer allein mit dem Meißel auskam und die Heilungserfolge noch dazu - aufgrund des verwendeten Werkzeugs überdurchschnittlich gut seien. Allerdings stellte er fest, dass die gebräuchlichen chirurgischen Meißel nicht annähernd so geeignet waren wie diejenigen, die er schließlich für seine Osteotomien verwendete: die Bildhauermeißel.

Ich liess mir von einem Bildhauer eine Adresse für gute englische Meissel hier in Wien geben; für neun Gulden bekam ich ein ganzes Paket voll Meissel aller Arten, von denen ich mir die brauchbarsten Formen auswählte, und sie mit einem dicken Holzstiehl versehen liess; ein tüchtiger Holzklöppel, wie ihn die Bildhauer führen, gehört auch zu diesem Zweige der plastischen Kunst. ${ }^{3 r}$

Bedeutsam ist, dass Billroth seine knochenchirurgischen Fertigkeiten an dieser Stelle bewusst denen von Bildhauern gleichsetzt. Durch gezielt gesetzte Kerben und Schnitte mit seinen verschiedenen Bildhauermeißeln gelingt es dem Chirurgenkünstler, die verkrümmten Beine seiner Patienten neu zu formen. Durch diese Semantik der künstlerischen Fertigkeiten setzt sich Billroth von den Medizinerhandwerkern ab und betont seine Genialität. Die plastische Herausbildung der Zeichnung im Marmor als Bildvehikel macht deutlich, wie fein sich mit den Methoden und Werkzeugen der Bildhauerei das harte Material bearbeiten lässt, und versinnbildlicht wiederum die Parallelität zu Billroths Bearbeitung der Knochen. Wenn der Bildhauer Zumbusch also in seinem Werk auf Billroths Knochenoperationen anspielt, so ist dies nur vordergründig ein Hinweis auf den medizinischen Inhalt und viel mehr eine bildtheoretische Ehrerbietung gegenüber dem Künstlerkollegen in diesem Zweige der plastischen Künste, mit dem er bei dessen zahlreichen Besuchen im Atelier sicherlich auch über die Vorzüge des Bildhauermeißels in ihren beiden Professionen, zum einen der Bildhauer und zum anderen der Mediziner, zu sprechen kam. Ein detailreiches Epitaph in Marmor von einem der angesehensten Bildhauer Wiens erscheint daher als die optimale Form der Ehrung für den verstorbenen Professor.

In diesem Sinne ist es Zumbusch mit dem Arkadenhof-Monument gelungen, diejenigen

27 Th. Billroth, Ueber die Verwendung vom Bildhauermeissel bei Osteotomien, in: Wiener Medizinische Wochenschrift, Nr. I8 (I2. März I870), Sp. 28I.

28 Vgl. beispielsweise das Ludwig-Denkmal von Max Widnmann und Ludwig Schwanthaler, München I862: Grundriss in der Hand der Personifikation der Baukunst.

29 Zur bildtheoretischen Terminologie: W. Pichler/R. Ubl, Bildtheorie zur Einführung, Hamburg 2OI4, S. $20-42$.

30 Billroth, Osteotomien, Sp. 282.

3I Billroth, Osteotomien, Sp. 284. 
Vorzüge Billroths zu vereinen, die für die Universität am wesentlichsten waren. Es kombiniert den modernen, innovativen Chirurgen mit dem engagierten Hochschullehrer und betont zusätzlich auf subtile Weise durch die Hochrelief-Zeichnung Billroths künstlerische Meisterschaft in seinem Beruf. Im Arkadenhof der Universität Wien ehrte man so den verdienstvollen Professor mit einem Monument, das insbesondere seine akademischen Errungenschaften und seine Verdienste für die Lehre hervorhebt. Aber umgekehrt spiegelte dieses eindrucksvolle Denkmal Billroths Ruhm zurück auf die Institution, an der er wirkte. Der Anblick der Denkmäler für verdienstvolle Professoren im Arkadenhof der Universität sollte den Besuchern einen Eindruck des hohen Rangs der Universität vermitteln und bei den Universitätsangehörigen den Ehrgeiz fördern, diesen ausgezeichneten Vorgängern nachzufolgen.

\section{DAS BILLROTH-STANDBILD VON I944/I 949}

Im dritten Denkmal, das hier genauer besprochen werden soll, werden wiederum ganz andere Eigenschaften Billroths in den Vordergrund gerückt [Abb. 3 und 7]. Anlässlich des 50. Todestages des Chirurgen wurde das Standbild im Februar 1944 feierlich im großen Hof des damaligen Allgemeinen Wiener Krankenhauses enthüllt. Zum Zeitpunkt der Enthüllung befand sich das „Großdeutsche Reich“ unter dem Regime der Nationalsozialisten im fünften Kriegsjahr, was sämtliche Ressourcen, auch im Allgemeinen Wiener Krankenhaus, massiv verknappte. ${ }^{32}$ Daher weist die bisherige Forschung zu dem Denkmal immer darauf hin, dass das Werk zunächst nur in Gips ausgeführt werden konnte und erst im April I949 in Marmor errichtet wurde. ${ }^{33}$ Die Tatsache selbst, dass während einer akuten Not an Heizmaterial, Verbandsmaterial, Glasfenstern und einer Vielzahl an anderen infrastrukturellen Ausstattungen überhaupt ein Denkmal errichtet wurde, wurde meines Erachtens bisher zu wenig hinter- fragt. Was versprachen sich die etablierten Kräfte von einem Standbild des seit 50 Jahren verstorbenen Chirurgen, das sie im Rahmen eines großen Medizinerkongresses mitten im Krieg enthüllten?

Über die Planung des Denkmals sind nur wenige Fakten bekannt, da bisher im Archiv des Allgemeinen Krankenhauses keine diesbezüglichen Dokumente gefunden wurden. Bereits im Jahr 1942 wurde der bereits im Austrofaschismus erfolgreiche Bildhauer Michael Drobil mit der Ausführung einer Statue beauftragt. ${ }^{34}$ Bemerkenswert ist, dass die Herstellung der Marmorstatue nicht an den finanziellen Mitteln scheiterte, sondern an der Tatsache, dass der Marmor nicht lieferbar war. ${ }^{35}$ So wurde 1944 an Billroths 50. Todestag vorerst die in Gips modellierte Fassung des Standbildes von dem Chirurgen und späteren Rektor Wolfgang Denk enthüllt. Ein Foto dieser Gipsfigur ist zeitgleich in der Medizingeschichte des Chirurgen Leopold Schönbauer publiziert worden. ${ }^{6}$ Schönbauer war 1939

32 Wiener Stadt- und Landesarchiv, Direktionsakten des Allgemeinen Krankenhauses, M. Abt. 209-AKH, B2 - Aktenindex 1944 .

33 B. Grois, Das Allgemeine Krankenhaus in Wien und seine Geschichte, Wien 1965, S. 204; R. Burgstaller/ H. Posch, Zeitgenössische Kunst und Geschichte im Alten Allgemeinen Krankenhaus. Eine Dialogführung durch den Campus der Universität Wien, in: Update! Perspektiven der Zeitgeschichte (hrsg. von L. ERKer et al.), Innsbruck/Wien/Bozen 20Io, S. 749 .

34 Der exakte Vorgang der Beauftragung konnte bisher nicht archivalisch belegt werden, weder die Akten der Medizinischen Fakultät, des Senats noch des Allgemeinen Krankenhauses geben darüber Aufschluss.

35 Grois, Das Allgemeine Krankenhaus (zit. Anm. 33), S. 204.

36 Schönbauer, Das Medizinische Wien (zit. Anm. 27) (1944); L. Schönbauer, Das Medizinische Wien. Geschichte - Werden - Würdigung (überarbeitete Fassung), Wien 1947. 


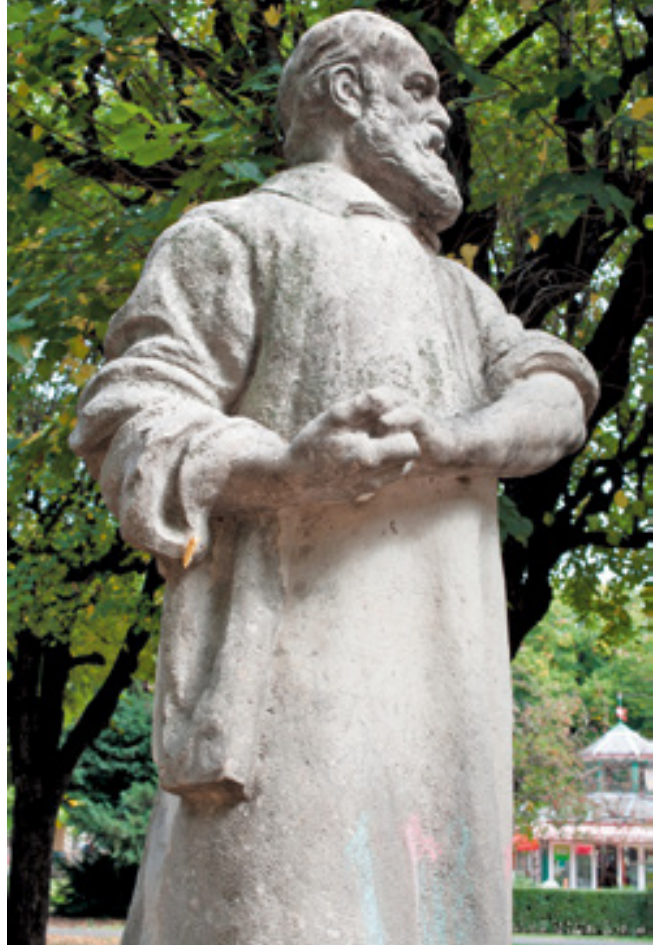

Abb. 7: Michael Drobil, Denkmalstatue für Theodor Billroth, 1944/49, Hof I des ehemaligen Allgemeinen Krankenhauses, heute Campus der Universität Wien.

zum Leiter der I. Chirurgischen Klinik ernannt worden. ${ }^{37}$ Durch seine Anwartschaft und spätere Mitgliedschaft in der NSDAP war er in zahlreichen maßgeblichen Universitätsgremien vertreten. ${ }^{38}$ Kurz vor Kriegsende schloss sich Schönbauer nach eigenen Angaben einer Widerstandgruppe im Allgemeinen Krankenhaus an und wurde daraufhin, trotz seiner Beteiligung an medizinischen NS-Verbrechen, zum Direktor des Allgemeinen Krankenhauses gewählt und hielt diese Stelle bis 1960. ${ }^{39}$ In seiner Funktion als Direktor gab Schönbauer den Anstoß, dass Drobil, der seine Künstlerkarriere nach 1945 ebenfalls bruchlos fortsetzen konnte, das Standbild in Marmor vollendete, und dieses am I2O. Geburtstag Billroths, dem 26. April 1949 an derselben Stelle auf der Achse im großen Hof des ehemaligen Allgemeinen Krankenhauses (heute Hof I des Universitätscampus) errichtet wurde. ${ }^{40}$

Die Statue zeigt den Arzt auf einem dreistufigen Sockel aufrecht stehend. Während sich sein Körper frontal zur Achse ausrichtet, blickt Billroth mit einer Wendung des Kopfes aufmerksam nach links. Seine Hände treffen sich auf der Höhe seiner rechten Hüfte und die Finger sind so zusammengefügt, als würde sich die Figur gerade die Hände waschen oder desinfizieren. Dies offenbar mit so viel Gründlichkeit, dass das Muskelspiel der Unterarme unter den hochgekrempelten Ärmeln seines Chirurgenkittels deutlich zu erkennen ist.

Im Gegensatz zu dem idealisierenden Werk Zumbuschs, das den Medizinprofessor in einer Synthese seiner positiven Eigenschaften zeigte, wirkt diese Statue wie ein dreidimensionaler Schnappschuss, der den tatkräftigen Chirurgen genau in dem Moment einfängt, in dem er sich auf dem Weg zum Operationssaal befindet. Dieser Charakter des schnell eingefangenen Bildes wird durch die raue Behandlung des Marmors, an dessen Oberfläche sich die Spuren des Meißels noch deutlich abzeichnen, betont. Dennoch ist auch dieses Werk nicht frei von Idealisierung. So wirkt Billroths Körper deutlich schlanker und agiler als in Zumbuschs Darstellung. Durch die kompositorische Gegenüberstellung der Hän-

37 Burgstaller/Posch, Zeitgenössische Kunst und Geschichte (zit. Anm. 33), S. 750.

38 I. ArIas, Felix Mandl. Chirurg im Wiener Gemeinderat/Leopold Schönbauer. Chirurg und Abgeordneter zum Nationalrat, in: Universität - Politik - Gesellschaft (hrsg. von M. Ash/J. EHMER), Göttingen 2015, S. 324-325.

39 M. Hubensdorf, Medizinische Fakultät I938-1945, in: Willfährige Wissenschaft. Die Universität Wien 1938 bis 1945 (hrsg. von G. Heiss et al.), Wien 1989, S. 250; Burgstaller/Posch, Zeitgenössische Kunst und Geschichte (zit. Anm. 33), S. 750, I. ArIAs, Die Medizinische Fakultät von 1945 bis 1955: Provinzialisierung oder Anschluss an die westliche Wissenschaft?, in: Zukunft mit Altlasten. Die Universität Wien 1945 bis 1955 (hrsg. von M. GrandNER et al.), Innsbruck/Wien u .a. 2005, S. 76-77.

40 Grois, Das Allgemeine Krankenhaus (zit. Anm. 33), S. 204; Burgstaller/Posch, Zeitgenössische Kunst und Geschichte (zit. Anm. 33), S. 749. 
de auf der rechten Seite und den aufmerksamen Blick zur linken Seite entsteht eine Spannung, die den Eindruck vermittelt, dass Billroth sich in der Bewegung nach links befindet, um einen Schritt zu seiner nächsten Aufgabe zu machen. Trotz der Betonung der Handbewegung scheint dieses Denkmal nicht die medizinische Bedeutung der Handdesinfektion zum Inhalt zu haben, sondern muss im Kontext seiner Errichtung während des Zweiten Weltkriegs betrachtet werden. Als personifizierte Parole wendet es sich direkt an den durch den Haupteingang eintretenden Kriegsarzt. Aber wodurch wurde Billroth zur idealen Projektionsfläche der nationalsozialistischen Propaganda während des Krieges?

Die Medienberichte, die anlässlich des Kongresses und der Denkmalsenthüllung veröffentlicht wurden, bieten einen erhellenden Einblick in die Wahrnehmung des bereits 50 Jahre zuvor verstorbenen Chirurgen während der NSZeit. All diesen Pressestimmen ist gemein, dass sie nicht auf Billroths politische Gesinnung oder seine Rolle als Wegbereiter des Antisemitismus eingehen, sondern ihn vorrangig als herausragenden Mediziner feiern. Seine antisemitische Grundhaltung kann im Jahr 1942 keinesfalls als Alleinstellungsmerkmal gegolten haben, vielmehr als Voraussetzung. Die weltanschauliche Gleichgesinntheit wird a priori angenommen.

Das nationalsozialistische Propagandaorgan widmete Billroth und dem Chirurgenkongress einen reichsweiten Artikel und drei weitere in der Wiener Ausgabe. Bereits am Samstag, dem 5. Februar 1944, berichtete Der Völkische Beobachter über die Eröffnung des Chirurgenkongresses im Billrothhaus, wo eine Gedenkausstellung für Billroth zu sehen war. ${ }^{4}$ Diese Ausstellung war von dem damaligen Direktor des Instituts für Geschichte der Medizin an der Universität Wien, dem aktiven NSDAP-Mitglied Fritz Lejeune, zusammengestellt worden. Besonders hervorgehoben wurde in dem Bericht, die außerordentlich interessante „Bildersammlung Billroths selbst, die er im Deutsch-Französischen Krieg I870/7I angelegt hat. [...] Stolz prangt vor seiner Büste das Eiserne Kreuz, das er in diesem Feldzug erwarb. " ${ }^{22}$ Ideologisch abgerundet wurde diese Eröffnungsveranstaltung mit einem wehrmedizinischen Vortrag eines Geschwaderarztes. Am 6. Februar 1944 schrieb der genannte Fritz Lejeune in seiner Würdigung über Billroth als den Fürsten der Chirurgie, ,der die neuzeitliche Chirurgie zu kaum begreiflicher Höhe, ja sozusagen zur Vollendung " führte. ${ }^{43} \mathrm{Im}$ Weiteren begnügte sich der Medizinhistoriker mit einer jubelnden Nacherzählung der wichtigsten Lebens- und Karriereabschnitte des verstorbenen Chirurgen. An demselben Tag erschien zusätzlich in der Wiener Ausgabe ein weiterer Bericht vom „Wiener Chirurgentag im Zeichen Billroths"..44 Zu der Tagung im überfüllten Vortragssaal im Billrothhaus kamen auch hochrangige Gäste aus der politischen Ebene, allen voran der Mediziner, Gauleiter und Reichsstatthalter von „Niederdonau“ Hugo Jury sowie der Gauamtsleiter für Volksgesundheit Walter Ekhart. In den Vorträgen wurden wiederum Billroths Errungenschaften gepriesen und seine Bedeutung als „,beispielhafter Sanitätsoffizier“ und „Betreuer der Gemeinschaft und dies umso mehr im Kriege" betont. ${ }^{45}$ Am folgenden Tag, Montag, den 7. Februar, informierte wieder der Völkische Beobachter von der feierlichen Enthüllung des Billroth-Denkmals im Allgemeinen Krankenhaus. ${ }^{46}$ Die Prominenz dieser Ver-

4I Völkischer Beobachter, Jg. 1944, Nr. 36, Wiener Ausgabe, Samstag, 5. Februar 1944, S. 5.

42 Ebd.

43 F. Lejeune, Zu seinem fünfzigsten Todestag. Theodor Billroth zum Gedächtnis, in: Völkischer Beobachter, Jg. I944, Nr. 37 (Sonntag, 6. Februar 1944), S. 3.

44 Völkischer Beobachter, Jg. 1944, Nr. 37, Wiener Ausgabe, Sonntag, 6. Februar 1944, S. 8.

45 Ebd.

46 Völkischer Beobachter, Jg. 1944, Nr. 38, Wiener Ausgabe, Montag, 7. Februar 1944, S. 6. 
anstaltung wird durch die zusätzliche Schlagzeile „Blaschke überbrachte die Wünsche Baldur von Schirachs", also der anwesende Bürgermeister und NSDAP-Mitglied Hanns Blaschke war vom Gauleiter und Reichsstatthalter von Wien beauftragt, die „hohe medizinische Schule Wiens" zu würdigen und „den Stolz dieser Stadt, das Werk eines Billroth für sich in Anspruch nehmen zu dürfen", zu betonen. ${ }^{47}$

Der hohe Aufwand, der für die Gedenktagung zu Billroths 50. Todestag betrieben wurde, dient als Indiz für das große Vertrauen, das offenbar nicht nur die Medizinische Fakultät, sondern auch die Führungsriege der ansässigen NSDAP in Billroth als Identifikationsfigur hatte. So wird das Standbild in diesem letzten Artikel im Völkischen Beobachter als das „Denkmal eines Siegers“ charakterisiert: „Das Standbild zeigt Billroth im Ärztemantel, in einer Stellung, als hätte er eben als Sieger über Leben und Tod eine Operation beendet, aufrechten Hauptes und leuchtenden Blickes, die Hände zufrieden ineinander verschlungen. " 48

Basierend auf einem publizierten Gespräch ${ }^{49}$ mit dem Bildhauer Drobil kam der Reporter des Völkischen Beobachters zu der Interpretation, dass es sich bei der Statue um eine Momentaufnahme nach der Operation handelt. Doch die dynamische Drehung der Skulptur weist meines Erachtens darauf hin, dass in diesem Fall nach der Operation gleichsam vor der Operation ist. Die Figur blickt - noch während sie ihre Hände desinfiziert von der vorangegangenen Operation - bereits aufmerksam zur nächsten Aufgabe und scheint dabei bereits einen Schritt nach vorn zu machen.

Ein kleinformatiger Konkurrenzentwurf für das Denkmal von dem Bildhauer Karl Stemolak unterstreicht, dass die Dynamik offenbar ganz im Sinne der gewünschten Denkmalsintention

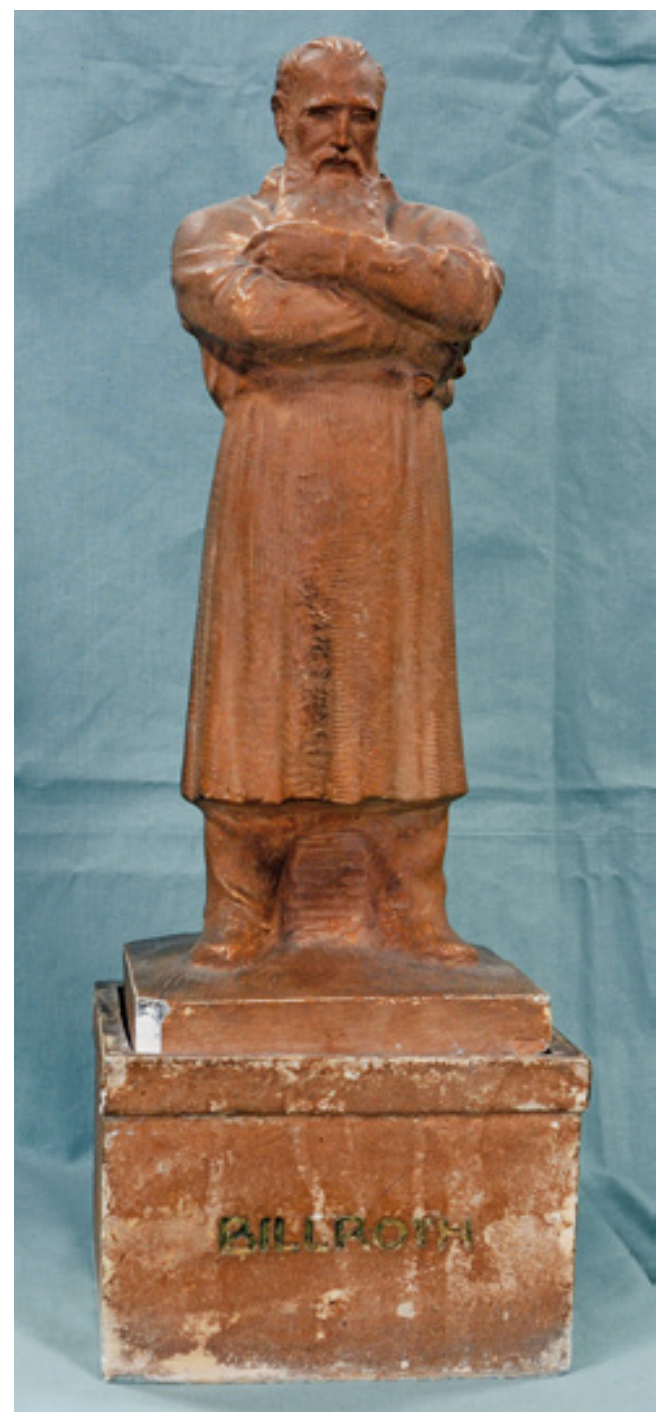

Abb. 8: Karl Stemolak, Entwurffür die Denkmalstatue für Theodor Billroth,1942, Josephinum, Medizinische Universität Wien.

war [Abb. 8]. Dieser Entwurf, der sich in der Sammlung des Josephinums befindet, ${ }^{50}$ zeigt einen wuchtigen Billroth, der breitbeinig stehend die Arme vor der Brust verschränkt. Statt eines

47 Ebd.

48 Ebd.

49 Volkszeitung, I5. Dezember 1943, S. 2.

50 Mein Dank für diese Informationen gilt dem Josephinum - Sammlungen der medizinischen Universität, namentlich Ruth Koblicek und der Leiterin Christiane Druml. 


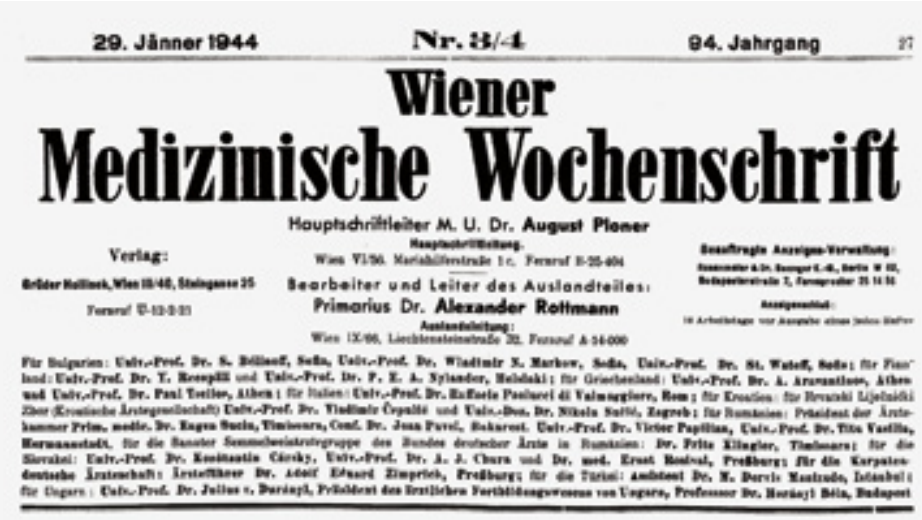

Billroth als Kriegsehirurg während des Sommers 1870

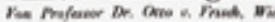

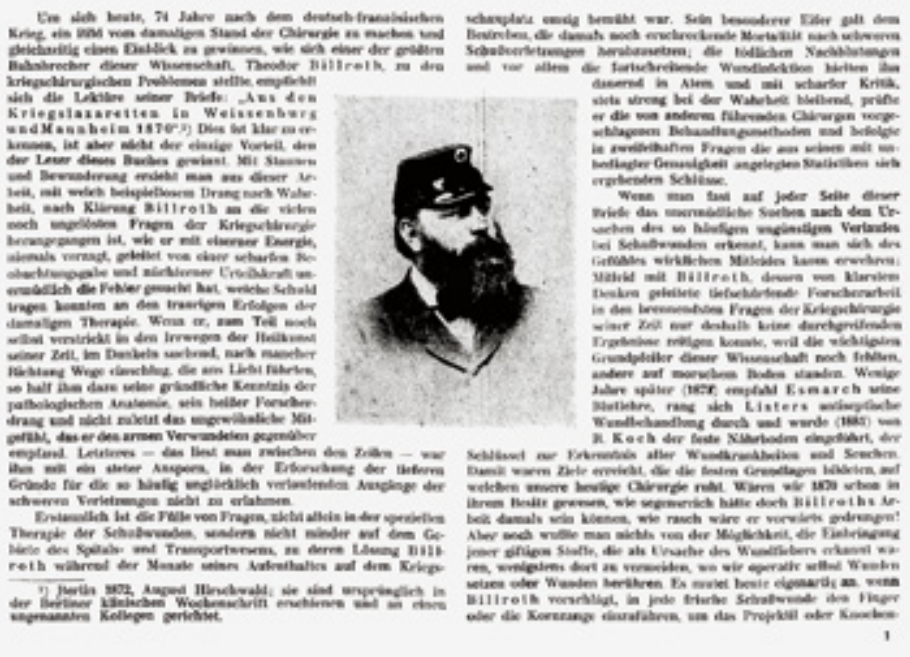

Abb. 9: Titelblatt der Wiener Medizinischen Wochenschrift vom 29. Jänner 1944.

agilen Chirurgen vermittelt dieses unausgeführte Modell von Stemolak das Bild eines starken, aber vielleicht nicht energischen Mediziners. In der ausgeführten Fassung von Drobil stattdessen schreitet der Chirurg tatkräftig zur nächsten Operation.

Ein bereits im Januar 1944 erschienener Beitrag in der Wiener Medizinischen Wochenschrift stützt diese These [Abb. 9]. Der vierseitige Leitartikel mit dem Titel Billroth als Kriegschirurg während des Sommers I870 hebt diese eine Pha- se der Billroth'schen Karriere hervor und lobt in zahlreichen Variationen dessen Entschlossenheit und Forschergeist: „Ohne Zaudern“, mit „beispiellosem Drang nach Wahrheit“, „mit eiserner Energie, niemals verzagt" und „sein heißer Forscherdrang “.'s Besonders, dass er ,an die vielen noch ungelösten Fragen der Kriegschirurgie herangegangen ist" und dabei nicht nur um die Therapie der Schusswunden, sondern auch um die Verbesserungen „auf dem Gebiete des Spitals- und Transportwesens" bemüht gewesen

5I O. von Frisch, Billroth als Kriegschirurg während des Sommers 1870, in: Wiener Medizinische Wochenschrift, Jg. 98, Nr. 3/4, 29. Jänner 1944, S. 27-28. 
ist, wurde hervorgehoben und als Zeichen von „ungewöhnlichem Mitgefühl“ und „wirklichem Mitleid“ gedeutet. ${ }^{52}$ Und schließlich fasst der Autor Otto von Frisch zusammen, welchen Nutzen die zeitgenössische Medizin aus diesem Porträt Billroths ziehen kann: „Aber die Zähigkeit seines von echter Menschenliebe geleiteten Wollens, seine Fähigkeit, die Ergebnisse seiner scharfen Beobachtungen kritisch zu ordnen [...], ließ Billroth in seinem unermüdlichen Suchen Richtungen einschlagen, die uns als Wegweiser für unsere moderne Chirurgie dienen können." ${ }^{33}$

Der Bezug, den der Autor zwischen den widrigen Bedingungen zu Zeiten Billroths, als die- ser noch nicht einmal über ein funktionierendes antiseptisches Mittel verfügte und dennoch mit so viel Eifer versuchte die Lage zu meistern, und der zeitgenössischen Kriegssituation ist unverkennbar. Der möglicherweise kriegsmüde Arzt im unterversorgten Allgemeinen Krankenhaus sollte durch das Vorbild Billroths neuen Mut fassen und ebenfalls versuchen mit unermüdlichem Eifer und echter Menschenliebe die medizinische Versorgung zu gewährleisten. In eben diesem Sinne ist das Denkmal im Allgemeinen Krankenhaus, das eben zu widrigsten Zeiten dort errichtet wurde, zu verstehen.

\section{R E S Ü M E E}

Der Vergleich dieser drei Denkmäler für den Mediziner Theodor Billroth zeigt, dass jedes für einen spezifischen Kontext konzeptioniert wurde, um die institutionellen Denkmalsintentionen darzustellen. Im Aufstellungskontext Krankenhaus vor dem Rudolfinerhaus kann sich der Bildhauer Zumbusch darauf verlassen, dass der Dargestellte auch in Toga als Mediziner identifiziert wird. Im Rahmen des Arkadenhofs hingegen muss derselbe Künstler seinen Billroth ganz explizit als Mediziner und Pionier der Antisepsis auszeichnen, um ihn aus der großen Anzahl der anderen Gelehrtendenkmäler herauszuheben. Die besondere Dynamik des Billroth-Standbilds im Allgemeinen Krankenhaus wird wiederum nur im zeithistorischen Kontext verständlich als Versuch, die letzten Kräfte der kriegsmüden Ärzte zu mobilisieren. Die Tatsache, dass heute vielerorts nur mehr das Nachkriegsdatum 1949 des später ausgeführten Marmordenkmals genannt wird, verzerrt die Wahrnehmung der ursprünglichen, durch NS-Propaganda geprägten Denkmalsintention. Dies führt schließlich dazu, dass ausgerechnet dieses Denkmal heutzutage zur Il- lustration von Billroth-Biografien verwendet wird.

Einst als wertvolles Mittel der Memoria und der politischen Einflussnahme geschätzt, verfügt das Bildnis in effigie - einmal wirklich angesehen - noch immer über ungeahnte kommunikative Kräfte. Umso wichtiger erscheint es mir, Denkmäler auch heute in der kunsthistorischen Forschung ernst zu nehmen, sie durch rezeptionsästhetische sowie archivalische Forschung hinsichtlich ihrer eigentlichen Denkmalsintention zu analysieren und somit für die Betrachter wieder lesbar zu machen.

Abbildungsnachweis: Abb. I: Fotografie der Autorin; Abb. 2: Institut für Kunstgeschichte der Univ. Wien, R. Steyer/K. Pani, 20I4; Abb. 3, 7: Institut für Kunstgeschichte der Univ. Wien, R. Steyer, 20II; Abb. 6: Institut für Kunstgeschichte der Univ. Wien, A. Plankensteiner, 2OI3; Abb. 4: Österreichische Nationalbibliothek, Inv. Nr. PORT_00000548_oI; Abb. 5: Galerie Belvedere, Wien, Inv. Nr. 796; Abb. 8: Ruth Koblizek, Josephinum, Medizinische Universität Wien; Abb. 9: Wiener Medizinische Wochenschrift, Österreichische Nationalbibliothek.

52 VON Frisch, Billroth als Kriegschirurg (zit. Anm. 5I), S. 27.

53 Ebenda, S. 30. 


\section{DIE „AUSMERZUNG VON DENKMÄLERN“IM ARKADENHOF DER UNIVERSITÄT WIEN WÄHREND DER NS-HERRSCHAFT}

Thomas Maisel

$I^{2}$ m November 1938, ziemlich genau acht Monate nach dem sogenannten „Anschluss“ und der nationalsozialistischen Machtergreifung in Österreich, begann man an der Universität Wien, Denkmäler jener Professoren, die als Juden oder „jüdische Mischlinge“ betrachtet wurden, aus dem Arkadenhof zu entfernen. Insgesamt wurden siebzehn Büsten und Reliefs abmontiert und im Hauptgebäude der Universität eingelagert. $\mathrm{Zu}$ diesem Zeitpunkt waren das ca. sechzehn Prozent aller im Arkadenhof vorhandenen Denkmäler.

In seinem Bericht an das Ministerium für innere und kulturelle Angelegenheiten bezeichnete der damalige Rektor Fritz Knoll diesen Vorgang

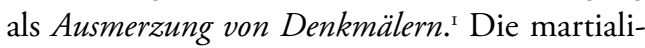
sche Diktion, die hier zum Ausdruck kommt, war nicht unbedingt typisch für jenen Mann, der seit 1937 NSDAP-Mitglied war $^{2}$, am 15. März 1938 vom späteren Gauleiter Odilo Globocnik zum kommissarischen Rektor der Universität Wien bestellt wurde ${ }^{3}$ und unter dessen tatkräftiger Führung die Selbstgleichschaltung der Wiener Universität und die "Säuberung“ des Lehrkörpers erstaunlich effektiv und rasch durchgeführt wurden. Sein offizieller, im Druck erschienener Bericht über diese Ereignisse, vorgetragen anlässlich der Amtsübergabe an den neuen Rektor Eduard Pernkopf 1943, ist zwar voll von zeittypischem deutschnationalen Anschlusspathos und Worten von der großen Aufgabe, mit der sich Knoll konfrontiert sah, die massenhafte Vertreibung von aus rassistischen und politischen Motiven unliebsamen Professoren und Dozenten erwähnte er jedoch fast nur beiläufig: Der Lehrkörper der Wiener Universität wurde entsprechend der Verordnung über das Berufsbeamtentum weiter von ungeeigneten Personen befreit. ${ }^{4}$ Die Entfernung von Denkmälern erwähnte er mit keinem Wort, was auffällig erscheint, da der Arkadenhof mit seinen dort jeweils ergänzten Denkmälern in den Jahrzehnten zuvor immer in den Berichten scheidender Rektoren genannt wird.

In der Geschichte des Arkadenhofes als zentraler Ort der Gelehrtenmemoria an der Universität Wien stellt die Entfernung von Denkmälern einen singulären Fall dar. Es gab dafür, anders als

I Archiv der Universität Wien (UAW), Schreiben des Rektors Fritz Knoll an das Ministerium für innere und kulturelle Angelegenheiten vom 7. November 1938, Akademischer Senat der Universität Wien (Senat), G.Z. I84 aus I938/39, ONr. 2.

2 M. GRÜTTNER, Biographisches Lexikon zur nationalsozialistischen Wissenschaftspolitik, Heidelberg 2004, S. 93.

3 UAW, Senat G.Z. 669 aus $1937 / 38$.

4 Die feierliche Rektorsinauguration der Universität Wien 1943 (Wiener wissenschaftliche Vorträge und Reden, hrsg. von der Universität Wien), Brünn/München/Wien I944, S. I4. 
bei der Entlassung von Mitgliedern des Lehrkörpers, keine Präzedenz und auch keine rechtliche oder statutarische Grundlage. Anders verhielt es sich bei der Aufstellung von Denkmälern: Dazu waren bereits kurz nach Eröffnung des neuen Hauptgebäudes I885 vom Akademischen Senat Regelungen beschlossen worden. Bevor es zu einer Ehrung für einen Professor in Form eines Denkmals kam, sollte eine Frist von fünf Jahren nach dessen Tod verstrichen sein. Diese Frist wurde 1926 auf zehn Jahre verlängert, es waren jedoch Ausnahmen davon möglich. ${ }^{5}$ Die Anträge für eine Denkmalaufstellung mussten von der zuständigen Fakultät nach fachlichen Kriterien darauf geprüft werden, ob eine solche Würdigung angemessen wäre. Nach einer positiven Beurteilung war es dann die Aufgabe des Akademischen Senats, für oder gegen den Antrag zu stimmen. Die Kunstkommission des Senats - zu dieser Zeit als Artistische Kommission bezeichnet - sollte über die künstlerische Eignung des Denkmals befinden und auch den geeigneten Platz im Arkadenhof festlegen. Für die Entfernung eines bereits bestehenden Denkmals existierten hingegen keine Regelungen.

Die Vorgänge bei der Entfernung von Denkmälern aus dem Arkadenhof weisen in ihrem Ablauf Analogien zur unmittelbar nach dem „Anschluss“ einsetzenden sogenannten „Säuberung" des Lehrkörpers auf. Dabei folgte auf eine relativ kurze Phase spontanen Terrors - etwa durch Verhaftungen und Hausdurchsuchungen ${ }^{6}$ - und spontaner Vertreibungen von jüdischen oder den Nazigegnern zuzurechnenden Universitätsmitgliedern die ,geordneten“ und den An- schein der Legalität erweckenden Enthebungen und Entlassungen, welche vom neuen Unterrichtsminister Menghin und den neu ernannten Universitätsfunktionären gesteuert wurden. ${ }^{7}$ Der erste Schritt erfolgte durch die Vereidigung der dazu berechtigten Universitätsprofessoren als Beamte am 22. März 1938. Zugelassen war nur, wer nicht als Jude galt. Dem folgte am 6. April der Widerruf der Lehrbefugnis der jüdischen Privatdozenten durch Erlass des Unterrichtsministeriums. Einen vorläufigen Abschluss vor der feierlichen Wiederaufnahme des Vorlesungsbetriebes am 25. April bildeten für jede Fakultät eigens formulierte Erlässe des Unterrichtsministers, in dem all jene Universitätslehrer aufgeführt wurden, die zu beurlauben, zu entlassen oder auf andere Weise von ihrer Lehrverpflichtung zu entbinden seien. ${ }^{8}$ Die Abgrenzung des von diesen Maßnahmen betroffenen Personenkreises erforderte jedoch zuvor die Mitwirkung aller Instanzen der Universität, insbesondere auch der Dekanate, die mit der Erstellung von Namenslisten und den damit verbundenen Erhebungen beauftragt waren. Auch das ganze restliche Jahr war man mit ungeklärten Fällen befasst, ehe 1939 im Zusammenhang mit der Implementierung der „Dozenten neuer Ordnung" eine weitere Vertreibungswelle einsetzte.

Rektor Fritz Knoll war von der Wichtigkeit dieser Aufgabe überzeugt, hat jedoch die Schwierigkeiten und die Arbeitsbelastungen, welche der gleichzeitige organisatorische und personelle Umbau der Universität nach dem „Führerprinzip“ mit sich brachten, bei passender Gelegenheit gerne betont. „Wir leben hier immer noch in einem Wirbel“" und „Wir haben eine unge-

5 T. MaISEL, Gelehrte in Stein und Bronze. Die Denkmäler im Arkadenhof der Universität Wien, Wien/Köln/ Weimar 2007, S. II.

6 A. Massıczek, Die Situation an der Universität Wien März/April I938, in: Forschungen und Beiträge zur Wiener Stadtgeschichte, 2, I978, S. 222.

7 Siehe dazu etwa K. MüHlberger, Dokumentation Vertriebene Intelligenz 1938. Der Verlust geistiger und menschlicher Potenz an der Universität Wien von 1938 bis 1945, Wien, 2. Aufl. 1993, S. 7-9; A. Müller, Dynamische Adaptierung und „Selbstbehauptung“. Die Universität Wien in der NS-Zeit, in: Geschichte und Gesellschaft, 23/4, 1997, S. 595-607.

8 Müller, Dynamische Adaptierung (zit. Anm. 7), S. 602. 
heure Arbeit zu leisten, was vor allem mit dem riesigen Personalstand der Universität zusammenhängt", formulierte er im April 1938 in einem Schreiben an seinen Grazer Rektorenkollegen. ${ }^{9}$ Auch noch Jahre danach, als er 1943 über seine Amtszeit Rechenschaft ablegte, erwähnte er die beträchtlichen Schwierigkeiten, welche bei der Umstellung unserer Universität auf die neuen Verhältnisse zu bewältigen waren. ${ }^{10}$

Diese Zitate stehen auch in Bezug zu den Vorgängen im Zusammenhang mit der Entfernung von Denkmälern aus dem Arkadenhof. Der von Knoll konstatierte „Wirbel“ in der Universität hat sich teilweise auch in der Aktenführung des Rektorats niedergeschlagen. Im konkreten Fall hatte dies zur Folge, dass nicht alle Vorgänge zur Entfernung der Denkmäler vollständig dokumentiert sind. Der zweite Aspekt, die Schwierigkeiten aufgrund hoher Arbeitsbelastung, wird von Knoll auch im eingangs zitierten Bericht an das Ministerium besonders hervorgehoben. Dieser Bericht ist eine wesentliche Quelle für die hier geschilderten Ereignisse. Er war nicht für die Öffentlichkeit bestimmt und sein Verfasser war bemüht, sich in der Frage der Denkmäler von Juden und ,jüdischen Mischlingen" gegen den offensichtlich befürchteten Vorwurf zu wappnen, er könnte dabei säumig oder nachlässig gewesen sein. Knolls Rechtfertigung diente die anfangs zitierte martialische Diktion, welche Tatkraft suggerieren sollte und die Betonung der äusserst starken Beanspruchung der Dekanate durch die verschiedensten dringenden

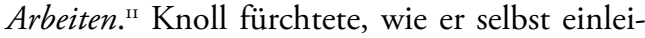
tend formulierte, dass über die Entfernung der Denkmäler im Ministerium unrichtige Vorstellungen $^{\text {I2 }}$ entstehen könnten.

Laut diesem Bericht, der am 7. November I938 verfasst wurde, ist die Initiative zur Ent- fernung der Denkmäler vom Nationalsozialistischen Studentenbund an der Universität Wien ausgegangen. $\mathrm{Zu}$ einem nicht näher bestimmten Zeitpunkt - Knoll schreibt: schon vor längerer Zeit - wäre der Studentenführer an der Universität Wien, Robert Müller, bei ihm vorstellig geworden und hätte das Ersuchen vorgebracht, so bald wie möglich die Denkmäler jüdischer Professoren in den Arkadengängen entfernen zu lassen. Knoll erklärte dazu, dass er selbst schon diese Absicht gehabt hätte, dass jedoch dringendere Angelegenheiten Vorrang haben müssten. Auf das Insistieren des Studentenführers antwortete Knoll, dass vor irgendwelchen Maßnahmen die einwandfreie Feststellung, wer von den betreffenden Professoren jüdischer Abstammung gewesen ist, erforderlich wäre, was vielfach mit Schwierigkeiten verbunden sei. Er schlug daher vor, die nötigen verlässlichen Daten mit Hilfe des Sippenamtes [Gau-Amt für Sippenforschung der NSDAP] einzuholen. Die Vorarbeiten dazu wären von den Dekanaten vorzunehmen. Die Vorgangsweise bei den Denkmälern wäre demnach der „Säuberung" des Lehrkörpers recht ähnlich gewesen, und auch die zuvor praktizierte Regelung bei der Aufstellung von Denkmälern mag hier Berücksichtigung gefunden haben, nur dass die Fakultäten in diesem Fall nicht die Würdigkeit, sondern die Unwürdigkeit eines Denkmals festzustellen hätten.

Tatsächlich hat der Rektor am 5. September I938 ein Rundschreiben an die fünf Dekane verschickt, in dem er darum ersuchte, Denkmäler jener Professoren im Arkadenhof, aber auch in anderen Universitätsräumlichkeiten, namhaft zu machen, die Juden oder jüdische Mischlinge waren. ${ }^{13}$ Aus dem Bericht vom 7. November wird klar, dass dies erst nach dem Gespräch mit dem Studentenführer geschehen sein kann. Die ers-

9 Zitiert nach Müller, Dynamische Adaptierung (zit. Anm. 7), S. 599.

IO Feierliche Rektorsinauguration 1943 (wie Anm. 4), S. I4.

II UAW (zit. Anm. I).

I2 UAW (zit. Anm. I).

I3 UAW, Senat G.Z. I250 aus I937/38, ONr. I. 
ten Rückmeldungen trafen schon nach wenigen Tagen von den beiden theologischen Fakultäten ein: Es waren „Fehlmeldungen“ - keines „ihrer“ Denkmäler wäre davon betroffen. Erst mehr als ein Monat später, am I7. Oktober 1938, antwortete der Dekan der Philosophischen Fakultät, Viktor Christian, und berichtete nach eingeholten Informationen, dass folgende Denkmäler im Arkadenhof und in Institutsräumlichkeiten seiner Fakultät von Juden oder jüdischen Mischlingen vorhanden wären: Im Arkadenhof die Chemiker Adolf Lieben und Guido Goldschmiedt, der Romanist Adolf Mussafia, der Botaniker Julius Wiesner und der Musikwissenschaftler Eduard Hanslick; in Institutsräumlichkeiten der Geologe Eduard Suess und der Pharmazeut Josef Herzig. ${ }^{14}$ Von den beiden restlichen Fakultäten, der Medizinischen und der Rechtswissenschaftlichen, gab es vorerst keine Rückmeldungen.

Auch im Aktenbestand der Philosophischen Fakultät haben diese Vorgänge ihren schriftlichen Niederschlag gefunden. Es ist daraus jedoch nicht ersichtlich, auf welche Weise die gewünschten Informationen beschafft worden waren. ${ }^{\text {Is }}$ Eine Befassung des Sippenamtes ist nicht belegt. Dafür, dass es trotz hoher Arbeitsbelastung schon so bald eine detaillierte Rückmeldung des philosophischen Dekans gegeben hat, kann es m. E. nur eine Erklärung geben: Nicht penible Recherchen zur „arischen“ oder „nicht-arischen“ Abstammung der durch Denkmäler geehrten Professoren, sondern das in der Professoren- und Studentenschaft kommunizierte Wissen über tatsächliche oder vermutete jüdische Abstammung lebender oder verstorbener Kollegen bildete die Grundlage für die Erstellung der Namensliste. Dieses tatsächliche oder vermutete Wissen entstammte den antijüdischen und antiliberalen Traditionen, welche an der Universität Wien seit dem I9. Jahrhundert deutlich feststellbar sind und sich spätestens in den Anfangsjahren der Ersten Republik radikalisierten und zu einer Bewegung des universitären Antisemitismus formierten. ${ }^{16}$ In kaum einem anderen Bereich des gesellschaftlichen Lebens hatten antisemitische und deutschnationale Tendenzen schon viele Jahre vor 1938 so starke Resonanz und - vor allem in der Studentenschaft - so radikale Anhänger wie auf akademischem Boden. ${ }^{17}$ Informelle antisemitische Netzwerke Wiener Professoren und Dozenten hatten zum Ziel, akademische Karrieren von Wissenschaftlern, denen jüdische Abstammung und/ oder Sympathien für den Sozialismus unterstellt wurden, zu verhindern. ${ }^{18}$ Lobbys dieser Art konnten schon lange vor dem „Anschluss“ rassistische und konservative Kriterien bei Lehrstuhlbesetzungen durchsetzen. ${ }^{19}$ Ihnen war es ein Anliegen, den postulierten „deutschen Charakter“ der Wiener Universität durchzusetzen. Schon

4 UAW (zit. Anm. I3), ONr. 7 .

I5 UAW, Dekanat der phil. Fakultät, D.-Zl. I278 aus 1937/38.

I6 Müller, Dynamische Adaptierung (zit. Anm. 7), S. 605.

I7 Vgl. dazu zuletzt: Der lange Schatten des Antisemitismus. Kritische Auseinandersetzungen mit der Geschichte der Universität Wien im 19. und 20. Jahrhundert (hrsg. von Oliver Ratнкоцв), Zeitgeschichte im Kontext, 8, Göttingen 2013 .

i8 Vgl. dazu T. Olechowski/T. Ehs/K. Staudigl-Ciechowicz, Die Wiener Rechts- und staatswissenschaftliche Fakultät I9I8-I938 (Schriften des Archivs der Universität Wien 20), Göttingen 20I4, S. 67-72. Demnächst auch K. TAschwer, Geheimsache Bärenhöhle. Wie ein antisemitisches Professorenkartell der Universität Wien nach I9I8 jüdische und linke Forscherinnen und Forscher vertrieb, in: Alma mater antisemitica. Akademisches Milieu, Juden und Antisemitismus an den Universitäten Europas zwischen 1918 und 1939, Wien 2015. Der Beitrag ist in einer Langversion online verfügbar: http://www.academia.edu/4258095/Geheimsache_B\%C3\%A4renh\%C $3 \%$ B6hl e._Wie_ein_antisemitisches_Professorenkartell_der_Universit\% $3 \%{ }_{3} \mathrm{~A} 4 \mathrm{t}$ _Wien_nach_1918_j\%C3\%BCdische_und_ linke_Forscherinnen_und_Forscher_vertrieb._2013_, abgerufen am I. Dezember 2014).

I9 O. Rathкоцв, Die Rechts- und Staatswissenschaftliche Fakultät der Universität Wien zwischen Antisemitismus, 
im späten I9. Jahrhundert war die von Antisemiten behauptete „Verjudung der Universität“ Thema von Reichstagsreden. ${ }^{20}$ Dazu war es unter den Prämissen des völkischen Antisemitismus notwendig zu wissen, wer als Jude gelten sollte und wer nicht. Diese Fragen wurden auch in der Tagespresse offen artikuliert. Im Zweifel konnten mithilfe von antisemitischen biografischen Nachschlagewerken, wie dem in mehreren Auflagen erschienenen „Semi-Kürschner“ oder dem „Semi-Gotha“, gesuchte und gewünschte Antworten gefunden werden. ${ }^{21}$

Der NS-Studentenschaft waren die Maßnahmen des Rektors jedenfalls zu zeitraubend und langwierig. Noch bevor alle Dekanate die gewünschten Informationen liefern konnten, erschien am 4. November 1938 ein Vertreter des Studentenführers bei Rektor Knoll und urgierte, dass endlich etwas in dieser Angelegenheit geschehen müsse. Als Begründung gab er an, dass am II. November in der Säulenhalle (Aula) der Universität die Langemarck-Feier stattfinden würde, dass in diesem Rahmen auch eine Rundfunkübertragung in den Arkadenhof geplant sei und dass dort deshalb unbedingt mindestens vorläufige Maßnahmen getroffen werden müssten. Der Vertreter der Studentenführung erwähnte ausdrücklich die Untragbarkeit des Standbildes von Emil Zuckerkandl, weil es durch seine jüdischen Handbewegungen die Studierenden gerade$z u$ herausfordere. ${ }^{22}$

Für die deutschvölkischen und die nationalsozialistischen Studenten spielte der politische Langemarck-Mythos vom an der Westfront kämpfenden und den Heldentod sterbenden Studenten eine herausragende Rolle. An der Universität Wien wurde nach deutschem Vorbild ein „Langemarckstudium“ eingerichtet: ein Vorbereitungsstudium, das parteitreue Nationalsozialisten aus der Unterschicht förderte. In der Säulenhalle (Aula) der Universität befand sich der „Siegfriedskopf ${ }^{\prime \prime}$, das sogenannte Heldendenkmal für die Gefallenen des Ersten Weltkrieges, welches 1923 unter maßgeblicher Mitwirkung der Deutschen Studentenschaft errichtet worden war. Es verweist auf die Siegfriedmythologie der Nibelungensage und die „Dolchstoßlegende“ des Ersten Weltkriegs. Für die deutschvölkischen Studenten, welche von der Deutschen Studentenschaft, in der die nationalsozialistischen Studierenden seit I93I die Mehrheit stellten, repräsentiert wurden, war dieses Denkmal Kristallisationspunkt ihrer universitätspolitischen Präsenz. ${ }^{23}$ Ziel war es, in der Auseinandersetzung um ein Studentenrecht in der Ersten Republik einen Numerus clausus für jüdische Studierende durchzusetzen. Insbesondere Anfang der Dreißigerjahre waren Veranstaltungen und Demonstrationen um den Siegfriedskopf Ausgangspunkt für gewalttätige Zusammenstöße, in deren Verlauf regelrecht Jagd auf jüdische und sozialdemokratische Studierende gemacht wurde. $\mathrm{Zu}$ solchen Ausschreitungen kam es auch regelmäßig im Zusammenhang mit dem samstägigen Bummel von schlagenden Burschenschaften im Arkadenhof. ${ }^{24}$

Für die Langemarck-Feier 1938 waren beide symbolträchtigen Orte, die Aula mit dem Sieg-

Deutschnationalismus 1938, davor und danach, in: Willfährige Wissenschaft. Die Universität Wien I938-1945 (hrsg. von G. Heiss/S. Mattl/S. Meissl/E. Saurer/K. Stuhlpfarrer), Wien 1989, S. 197-200.

20 J. S. BLoch, Erinnerungen aus meinem Leben, Wien/Leipzig I922, S. 26I-262.

2I G. Hufenreuter, Völkischer Antisemitismus, in: Handbuch des Antisemitismus (hrsg. von W. Benz), Bd. 3, Berlin/New York 20Io, S. 342.

22 Alle Zitate aus: UAW (zit. Anm. I).

23 Zu Langemarck-Mythos und Siegfriedskopf vgl. die Website des Forum Zeitgeschichte: http://www.univie.ac.at/de/ universitaet/forum-zeitgeschichte/gedenkkultur/siegfriedskopf/\#cı2oI, abgerufen am I. September 2014.

24 M. Grandner/G. Heiss/E. Klamper, Im Kampf um das Haupt des deutschen Helden Siegfried, in: FORUM, 37/444, I5. Dez. 1990, S. 62. 
friedskopf und der Arkadenhof, von Bedeutung. Das Zentrum der Feier bildete der Siegfriedskopf, wo das Rednerpult aufgestellt war. An der Feier sollten Studierende aller Wiener Hochschulen teilnehmen, darüber hinaus Abordnungen der Wehrmacht und verschiedener NS-Teilorganisationen sowie hohe Repräsentanten der NS-Hierarchie in Österreich. ${ }^{25}$ Einen Höhepunkt stellte die Liveübertragung der Rundfunkansprache des Reichsstudentenführers Scheel vom Friedhof im belgischen Langemarck dar, die, so wie wohl auch die vor Ort gehaltenen Reden, in den Arkadenhof mit Lautsprechern übertragen wurde. ${ }^{26}$ Die Feier war zur Gänze eine Veranstaltung der Reichsstudentenführung, an welcher der Rektor der Universität Wien selbst nur als Gast teilgenommen hat. Die NS-Studentenführung agierte hier so, als ob sie über das Hausrecht an der Universität Wien verfügen würde. Es gab kein formales Ansuchen an den Rektor zur Abhaltung der Feier, er wurde lediglich darüber informiert, dass sie stattfinden würde. ${ }^{27}$

Das Drängen der Studentenführung auf die Entfernung von Denkmälern noch vor Abhaltung der unmittelbar bevorstehenden Langemarck-Feier zwang den Rektor Fritz Knoll zur Zusage, dass dies umgehend von ihm veranlasst und noch vor Abschluss der von ihm beauftragten Recherchen durch die Dekanate erfolgen werde. Doch schon am folgenden Tag, am Samstag, den 5 . November 1938, wurde diese Absprache von den Studenten durch einen Gewaltakt torpediert. Sie beschädigten und beschmierten mehrere Denkmäler vermeintlich jüdischer Professoren im Arkadenhof:

- Das Denkmal von Emil Zuckerkandl, welches nach Ansicht der Nazi-Studenten durch seine ,jüdischen Handbewegungen“" provozierte, wurde umgestürzt und beschädigt;

- die Denkmäler von Joseph von Sonnenfels, Julius Wiesner, Heinrich Bamberger, Moriz Kaposi und Guido Goldschmiedt wurden zum Teil schwer beschädigt;

- und alle diese sowie die Denkmäler von Adolf Mussafia, Julius Glaser, Ernst (von) FleischlMarxow und Gustav Bickell mit Eisenlack beschmiert. ${ }^{28}$

An diesem Vorkommnis lassen sich die Spannungen und die Rivalitäten unter den Repräsentanten der NS-Hierarchie an der Universität deutlich ablesen. Als jemand, der von der Größe und Wichtigkeit der Aufgabe, die „Gleichschaltung" der Universität Wien unter dem Anschein geordneter Verhältnisse durchzuführen, überzeugt war, fühlte sich Rektor Knoll vom Gewaltakt der Studenten brüskiert. In seinem Bericht warf er ihnen vor, nicht nur einige jüdische Denkmäler übersehen zu haben, sondern auch, dass sie das Denkmal eines „Ariers“ beschädigt hatten, nämlich jenes des Orientalisten Gustav Bickell. Wie Knoll vermutete, war es entweder die Aufschrift „Professor der Semitologie“ oder die Verwechslung des Namens Bickell mit dem jüdisch klingenden Namen Pick, die dazu den Anlass gegeben hätte. ${ }^{29} \mathrm{Ob}$ die Studenten in diesem Fall tatsächlich so ahnungslos waren, wie Knoll unterstellte, kann jedoch auch in Frage gestellt werden. Bickells Name stand nämlich in Verbindung mit dem katholischen Antijudaisten August Rohling, dessen Werk „Der Talmudjude“ im Nationalsozialismus als Standardwerk des Antisemitismus anerkannt war. Bickell hatte Rohlings jüdische Ritualmordthese als „reinste[n], auf grober Unwissenheit beruhende[n] Schwindel" bezeichnet, was als einer der Nachweise gilt,

25 Vgl. etwa den Bericht in der Neuen Freien Presse, Nr. 26644 W, I2. II. 1938, S. 7.

26 UAW, Senat G.Z. 1336 aus $1937 / 38$.

27 UAW (zit. Anm. 26).

28 UAW, Bericht der Universitäts-Gebäude-Inspektion vom 7. II. 1938, Senat G.Z. I84 aus 1938/39, ONr. I.

29 UAW (zit. Anm. I). 
die Rohlings Fälschungen und Entstellungen vor Gericht entlarvt hatten. ${ }^{30}$ Im Aktenbestand der Universität Wien gibt es jedoch keinen Hinweis darauf, dass dieser Sachverhalt den NS-Studenten bekannt gewesen wäre. Ebenso könnte die Darstellung syrischer Schriftzeichen, die als hebräisch fehlgedeutet worden sein könnten, und eines siebenarmigen Leuchters im Zierrahmen des Mosaiks den Anlass für die Beschädigung gegeben haben.

Die Studentenführung hatte ihr Ziel erreicht: Noch am selben Tag gab Knoll dem Gebäudeinspektor den Auftrag, bis auf eines alle beschädigten Denkmäler entfernen zu lassen. Das mit Eisenlack beschmierte Mosaikdenkmal von Gustav Bickell sollte hingegen wieder instand gesetzt werden. ${ }^{31}$

Schon am nächsten Werktag stellte Rektor Knoll den Studentenführer Robert Müller zur Rede, welcher zugestand, dass die gewaltsame Aktion gegen die Denkmäler mit seinem Wissen und seiner Zustimmung geschehen sei. Knoll machte ihm schwere Vorwürfe: Wenn er, Müller, nicht in der Lage sei, die Disziplin unter den Studierenden aufrechtzuerhalten, dann wäre es besser, in Hinkunft überhaupt keine Absprachen mehr zu treffen. Müller hat diese Vorhaltungen offenbar kommentarlos hingenommen. ${ }^{32}$ Dass Knoll disziplinäre Maßnahmen gegen die Studenten in Erwägung gezogen hätte, ist nirgendwo überliefert.

In diesem Zusammenhang muss natürlich auf die zeitliche Koinzidenz der geschilderten Ereignisse an der Universität Wien mit den
Novemberpogromen von 1938 und ihrer Vorgeschichte hingewiesen werden. Die LangemarckFeier, welche durch jüdische Denkmäler nicht gestört werden sollte, fand nur einen Tag nach den von oben gesteuerten Gewaltexzessen der sogenannten „Reichskristallnacht" statt. Schon in den Wochen zuvor waren die Maßnahmen zur Eliminierung von Juden aus dem öffentlichen Leben verschärft worden und in Wien häuften sich seit Oktober antisemitische, pogromartige Ausschreitungen in einer Weise, die an den Terror der ersten „Anschluss“-Tage erinnerten. ${ }^{33}$ Auch an der Universität Wien wurden mit Beginn des Wintersemesters 1938/39 antisemitische Maßnahmen verschärft: Ausnahmslos alle Juden wurden vom Studium ausgeschlossen und die bis dahin bestehenden Ausnahme- und Numerus-clausus-Regelungen aufgehoben. ${ }^{34}$ In diesem Kontext betrachtet, fügt sich der „Denkmalsturm " an der Universität Wien in die Reihe von gewalttätigen Aktionen ein, welche in den Novemberpogromen kulminierten.

Unmittelbar nach der Anweisung zur Entfernung beschädigter Denkmäler beauftragte Rektor Knoll die Gebäudeinspektion, auch die von den Studenten übersehenen, jedoch im Bericht der Philosophischen Fakultät genannten Denkmäler von Adolf Lieben und Eduard Hanslick abzubauen..$^{35}$ In kurzer Folge ergingen weitere Anweisungen, wobei auch die Studentenführung wieder aktiv wurde: Sie beantragte die Entfernung der bei ihrer Gewaltaktion verschont gebliebenen Denkmäler für Carl und Anton Menger, für Josef Unger, Karl Stoerk und Leopold Oser. Knoll be-

30 Vgl. dazu Bцoch, Erinnerungen (zit. Anm. 20), S. 99-Ior (das Zitat Bickells dort auf S. Ioo). Vgl. auch den Artikel „Bickell, Gustav Wilhelm Hugo“ in: Encyclopaedia Judaica 4, Berlin 1929. Zu Rohling vgl. S. Plietzsch, TalmudPolemik, In: Handbuch des Antisemitismus (zit. Anm. 2I), Bd. 3, S. 3 I4.

3 I UAW, Amtsvermerk vom 9. II. 1938, Senat G.Z. I84 aus 1938/39, ONr. 3.

32 UAW (zit. Anm I).

33 G. Botz, Nationalsozialismus in Wien. Machtübernahme und Herrschaftssicherung 1938/39, Buchloe, 3. Aufl. 1988, S. 397-404.

34 H. Posch/D. Ingrisch/G. Dressel, „Anschluss“ und Ausschluss i938. Vertriebene und verbliebene Studierende der Universität Wien (Emigration - Exil - Kontinuität. Schriften zur zeitgeschichtlichen Kultur- und Wissenschaftsforschung, hrsg. v. F. STADLER, Bd. 8), Wien/Berlin 2008, S. II4-II5. 
stätigte diese Aufträge, obwohl er bis zu diesem Zeitpunkt keine Bescheinigung durch die Dekanate über deren jüdische Abstammung erhalten hatte. Eine Steinmetzfirma montierte in den Tagen unmittelbar vor der Langemarck-Feier am II. November die Denkmäler ab und lagerte sie in Depoträumen des Hauptgebäudes ein. Erst einige Wochen danach wurden auch die Sockel und Postamente abgetragen und weggeräumt. ${ }^{36}$

In dem Bericht der Gebäudeinspektion werden fünfzehn demontierte Denkmäler aufgelistet, wobei auffallend ist, dass das Denkmal für Carl Menger dort nicht aufscheint, sehr wohl jedoch das für seinen Bruder Anton. ${ }^{37}$ War dies lediglich ein Versehen oder befand sich das Denkmal für den berühmten Nationalökonomen zur Zeit der Langemarck-Feier tatsächlich noch im Arkadenhof? Es muss während der NS-Herrschaft entfernt worden sein, da es nach 1945 bei den wieder aufgestellten Denkmälern genannt wird. ${ }^{8}$ Es gibt im Bestand des Universitätsarchivs jedoch keine weiteren Dokumente, welche die Frage des genauen Zeitpunkts klären könnten. Belegt ist hingegen die Tatsache, dass es auch nach der Denkmalsdemontage vom November 1938 in der Professorenschaft Zweifel an der jüdischen Abstammung der Familie Menger gab. Der kommissarische Dekan der rechtswissenschaftlichen Fakultät legte am I4. November 1938 Schriftstücke vor, die bereits im Zusammenhang mit der Aufstellung des Denkmales von Carl Menger im Jahr 1928 entstanden waren und die dessen ,arische" Abstammung belegen sollten. ${ }^{39}$ Dies wirft ein weiteres Schlaglicht auf das von Antisemitis- mus geprägte Klima an der Universität zur Zeit der Ersten Republik: Aus Sorge davor, mit der Errichtung eines Denkmals für einen möglicherweise jüdischen Professor Ausschreitungen deutschvölkischer Studenten zu provozieren, hatte man Belege gesammelt, welche eine „arische“ Abstammung des Geehrten nachweisen und „falsche Gerüchte“ widerlegen sollten. Rektor Knoll fürchtete daraufhin, möglicherweise selbst einen Fehler begangen zu haben, und betraute das Amt für Sippenforschung der NSDAP mit weiteren Nachforschungen zur Abstammung der Familie Menger. ${ }^{40}$ Obwohl das Rektorat sogar bereit war, die Kosten der erforderlichen Archivrecherchen zu übernehmen, blieb die Anfrage jedoch ohne Erledigung. ${ }^{4 \mathrm{I}}$ Es handelt sich in diesem Zusammenhang um den einzigen dokumentierten Fall, in dem bei Denkmälern tatsächlich amtliche Erhebungen zur möglichen jüdischen Abstammung der Geehrten eingeleitet wurden.

Das Beispiel Menger belegt die Sorge des Rektors und mancher Professoren um die Traditionen der Universität, mit denen man in einer Zeit des Umbruchs nicht leichtfertig umgehen wollte, weil sie einen wesentlichen Teil ihres „symbolischen Kapitals“ bildeten. ${ }^{42}$ Ähnliche ebenso erfolglose Interventionen wie im Falle Menger gab es bei den Denkmälern für Julius Wiesner und Eduard Suess. Letzteres musste auf Druck der Studentenführung aus den Räumen des Geologischen Instituts entfernt werden. ${ }^{43}$ Schon zuvor war das Denkmal für den Chemiker und Pharmazeut Josef Herzig im alten Chemiegebäude abgetragen worden. ${ }^{44}$

\footnotetext{
UAW, Bericht der Universitäts-Gebäude-Inspektion vom 24. II. 1938, Senat G.Z. I250 aus 1937/38, ONr. I3. UAW (zit. Anm. 36).

8 UAW, Wiederaufstellung der im Jahr 1938 aus den Arkaden entfernten Denkmäler, Senat G.Z. 454 aus 1944/45.

9 Vgl. dazu den Schriftverkehr in UAW, Senat G.Z. I84 aus 1938/39, ONr. 7.

40 UAW, Schreiben von Rektor Fritz Knoll an das Sippenamt der Gauleitung Wien der NSDAP vom 25. II. 1938, Senat G.Z. I84 aus $1938 / 39$, ONr. 8.

4I UAW, Senat G.Z. I84 aus 1938/39, ONr. 9 u. I2-I3.

42 Müller, Dynamische Adaptierung (zit. Anm. 7), S. 599.

43 UAW, Dekanat der phil. Fakultät, D.Zl. 1278 aus 1937/38.

44 UAW (zit. Anm. 3I).
} 
Erst im Juli 1939 folgte eine schriftliche Reaktion des medizinischen Dekans Eduard Pernkopf auf Knolls Rundschreiben vom September 1938. Er war vom NS-Dozentenbund an der Universität Wien und dieser vom Institut für Geschich- te der Medizin darauf hingewiesen worden, dass auch der Ophthalmologe Ludwig Mauthner $J u$ de gewesen wäre. ${ }^{45}$ Auch dessen Denkmal wurde daraufhin aus dem Arkadenhof entfernt. ${ }^{46}$

\section{BESCHÄDIGTE UND AUS DEM ARKADENHOF ENTFERNTE DENKM ÄLER}

\begin{tabular}{|c|c|c|c|}
\hline Denkmal & Nummer ${ }^{47}$ & Schäden und Beschmierungen am 5.11.1938 & Entfernung \\
\hline Josef v. Sonnenfels & 4 & Kleine Beschädigungen, Eisenlack & 7.-10.11. 1938 \\
\hline Julius v. Wiesner & 71 & $\begin{array}{l}\text { Büste beschädigt, Eisenlack (Aufschriften auf } \\
\text { Sockel) }\end{array}$ & 7.-10. 11.1938 \\
\hline Adolf Mussafia & 44 & Eisenlack (Sockel) & 7.-10.11.1938 \\
\hline Heinrich v. Bamberger & 70 & Beschädigt (Büste und Sockel), Eisenlack & 7.-10.11. 1938 \\
\hline Emil Zuckerkandl & 85 & Umgestürzt & 7.-10. 11. 1938 \\
\hline Moriz Kaposi & 118 & Stark beschädigt, Eisenlack (Sockelinschriften) & 7.-10.11. 1938 \\
\hline Julius Glaser & 52 & Eisenlack & 7.-10.11. 1938 \\
\hline Guido Goldschmiedt & 62 & Stark beschädigt, Eisenlack & 7.-10.11. 1938 \\
\hline $\begin{array}{l}\text { Ernst Fleischl v. Mar- } \\
\text { xow }\end{array}$ & 84 & Eisenlack & 7.-10. 11. 1938 \\
\hline Gustav Bickell & 150 & Eisenlack & Nicht entfernt \\
\hline Adolf Lieben & 61 & -- & 7.-10. 11.1938 \\
\hline Eduard Hanslick & 46 & -- & 7.-10.11. 1938 \\
\hline Carl Menger & 3 & -- & $\begin{array}{l}\text { Nov. } 1938 \text { oder } \\
\text { später }\end{array}$ \\
\hline Anton Menger & 14 & -- & 7.-10. 11. 1938 \\
\hline Josef Unger & 65 & -- & 7.-10.11. 1938 \\
\hline Karl Stoerk & 129 & -- & 7.-10. 11. 1938 \\
\hline Leopold Oser & 146 & -- & 7.-10.11. 1938 \\
\hline Ludwig Mauthner & 126 & -- & 28.7 .1939 \\
\hline
\end{tabular}

Damit war die „Ausmerzung von Denkmälern“" im Arkadenhof der Universität Wien abgeschlossen. Allem Anschein nach war dies keine Maß- nahme, deren sich die Universität besonders rühmen wollte. Nur in den internen chronikalischen Aufzeichnungen ${ }^{49}$, nicht jedoch im darauf

45 UAW, Dekanat der mediz. Fakultät, G.Z. 2048 aus 1937/38.

46 UAW, Senat G.Z. I250 aus 1937/38

47 Denkmalnummer in Maisel, Gelehrte (zit. Anm. 5).

48 Laut Bericht der Universitäts-Gebäude-Inspektion vom 7. II. I938, UAW (zit. Anm. 28). 
gründenden gedruckten Rechenschaftsbericht $t^{50}$ des Rektors Knoll, wird davon etwas erwähnt.

Das Hauptgebäude wurde im Krieg durch Bombentreffer zum Teil schwer beschädigt; von den Denkmälern - sowohl den entfernten als auch den im Arkadenhof verbliebenen - sind keine durch Kriegsereignisse verursachten Schäden überliefert. Im Rahmen der Wiederaufbauarbeiten nach Kriegsende wurde vom Akademischen Senat der Universität Wien schon am I2. Mai 1945 beschlossen, alle von den Nazis entfernten Denkmäler wieder im Arkadenhof an ihrem angestammten Platz aufzubauen. ${ }^{\text {II }}$ Nur für das am schwersten beschädigte Denkmal, jenes von Guido Goldschmiedt, sind Restaurierungsarbeiten dokumentiert. ${ }^{52}$ Die Rückführung der Denkmäler in den Arkadenhof konnte im Laufe der Jahre 1945 und 1946 abgeschlossen werden. Im 1947 erschienenen Rektorsbericht stellte Ludwig Adamovich fest, dass „die während der nationalsozialistischen Herrschaft entfernten Büsten ehemaliger Mitglieder des Lehrkörpers wieder auf ihren alten Plätzen aufgestellt" waren. ${ }^{53}$

In der Geschichte der Universität Wien während der NS-Zeit bildet die „Arisierung“ der Gelehrtenmemoria einen symbolischen Akt, der in direkten Zusammenhang mit der Vertreibung von Studierenden und Mitgliedern des Lehr- körpers gestellt werden kann, auch wenn er keine vergleichbaren Dimensionen menschlichen Leids und der Vernichtung von Existenzen zur Folge hatte. Die geschilderten Ereignisse werfen ein Schlaglicht auf die Verhältnisse an der Universität Wien im Jahr 1938, welche durch die Rivalität zwischen einer radikal antisemitischen NS-Studentenschaft auf der einen und dem Rektor sowie Teilen der Professorenschaft auf der anderen Seite gekennzeichnet waren. Übereinstimmung herrschte im Ziel der „Säuberung " der Universität von als jüdisch geltenden und politisch missliebigen Personen. Aus offensichtlicher Sorge um die Traditionen der Universität und um den Anschein geordneter Verhältnisse aufrechtzuerhalten, missbilligte jedoch der Rektor den Radau-Antisemitismus und die willkürlich erscheinenden Gewaltaktionen der NS-Studenten. Nicht die Zerstörung der Denkmäler, sondern deren sachgerechte Entfernung nach eingehender Prüfung war seine Absicht gewesen. Deren Restaurierung und Rückführung nach Kriegsende wurde von der Universität im Rahmen von Wiederaufbauarbeiten und der Beseitigung von Kriegsschäden im Hauptgebäude durchgeführt. Die Maßnahme diente der raschen Wiederherstellung eines Status quo vor dem „Anschluss" und war von keinen feierlichen Akten begleitet.

\footnotetext{
UAW, Chronik zum Jahresbericht 1938/39, Senat G.Z. 4 aus 1939/40.

Rektorsinauguration 1943 (zit. Anm. 4).

UAW, Senat G.Z. 454 aus $1944 / 45$.

UAW, Akademischer Senat, Sonderreihe, Senat S 222.2.

Bericht über den Studienbetrieb an der Wiener Universität vom Sommersemester 1945 bis zum Sommersemester 1947 (hrsg. von der Universität Wien), Wien I947, S. 4I.
} 


\title{
ZEITGEMÄSS - DIE PROFESSORENPORTRÄTS IM ARKADENHOF DER UNIVERSITÄT WIEN NACH 1945
}

\author{
Martin Engel
}

$\mathrm{D}_{\mathrm{t}}^{2}$ as plastische Porträt wurde im 19. und frühen 20. Jahrhundert vor allem in bürgerlichen Kreisen sehr geschätzt und sicherte die Existenz zahlreicher Bildhauer. Mit den gesellschaftlichen Umbrüchen infolge der beiden Weltkriege änderten sich die Nachfrage und die Wertschätzung dieser Form der Ehrung einzelner Personen. Das gilt vor allem auch für das Gelehrtenporträt. Der Usus, dem geschätzten Lehrer und Kollegen anlässlich eines Jubiläums eine Porträtbüste oder eine Porträtmedaille zu stiften, kam völlig aus der Mode. Trotz der anhaltenden Krise der Porträtplastik, die zumindest in Österreich und Deutschland feststellbar ist, wurden im Arkadenhof der Universität Wien seit 1945 rund 50 Professoren mit bildhauerischen Denkmälern geehrt. Vielfach werden sie pauschal als unzeitgemäß abgetan und nicht selten ebenso pauschal ob ihrer künstlerischen Qualität kritisiert. Vergessen wird dabei oft, dass es sich zumeist um Werke bedeutender österreichischer Bildhauer handelt.

Beginnen möchte ich meine Studie, die auch ein grundlegender Beitrag zur Geschichte der österreichischen Porträtplastik im 20. Jahrhundert sein soll, mit den Porträts von zwei österreichischen Gelehrten, die nicht nur wissenschaftsgeschichtlich von größtem Interesse sind, sondern mit ihren Ideen auch den Lauf der Welt beeinflusst haben. Anhand dieser beiden Beispiele werde ich die grundsätzlichen Fragestellungen zur modernen Porträtkunst entwickeln. Geleitet wird meine Untersuchung von den drei klassischen Kriterien, an denen sich die spannungsreichen Wechselwirkungen zwischen den Wünschen der Auftraggeber einerseits und den künstlerischen Zielen der Bildhauer andererseits am besten aufzeigen lassen: von der Wiedererkennbarkeit, der Angemessenheit und vom künstlerischen Ausdruck.

Von den beiden ausgewählten Wissenschaftlern, Sigmund Freud (I856-I939) und Karl Popper (1902-1994), gibt es berühmte und oft reproduzierte Porträtfotos. Sie sind bestens geeignet, um sich ein Bild von den beiden Personen zu machen (Abb. I und 2). Fotos dieser Art wurden angefertigt, um als Frontispiz den Büchern der berühmten Autoren beigefügt zu werden. Heute findet man sie zuhauf im Internet, vorwiegend zur Illustration von Wikipedia-Artikeln.

Generell lässt sich sagen, dass die Fotografie hinsichtlich der Erinnerung an einzelne Personen allen anderen Medien den Rang abgelaufen hat. Im Zeitalter der „Selfies“ verfügt jeder über unzählige Aufnahmen, sowohl von sich selbst als auch von seinen Freunden und Verwandten. Zumeist handelt es sich dabei um mehr oder weniger gelungene Schnappschüsse, denn nur wenige von uns gehen in ein Fotostudio, um ein professionelles Porträtfoto von sich machen zu lassen, ein Porträtfoto mit künstlerischem Anspruch, das perfekt ausgeleuchtet den Porträtierten bestens in Szene setzt. Solche Porträtfotos gibt es vor allem von denjenigen, die Wert auf ihr Image legen müssen: Politiker, Unternehmer, Schauspieler, Schriftsteller, Künstler etc. Das Porträtfoto 


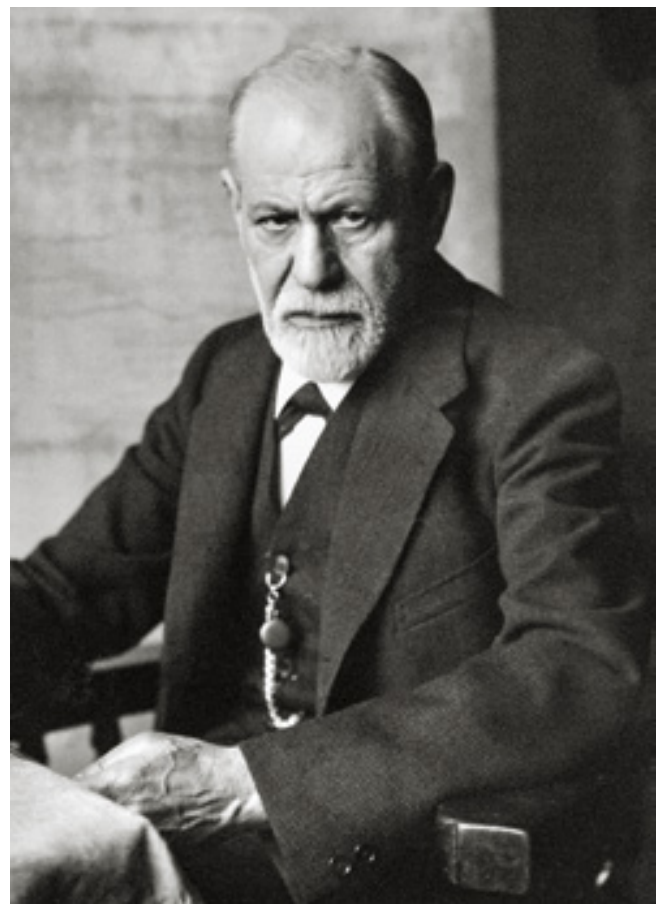

Abb. I: Ferdinand Schmutzer, Porträtfoto des 70-jährigen Sigmund Freud, 1926.

von Sigmund Freud, das der Wiener Fotograf und Porträtmaler Ferdinand Schmutzer (I8701928) im Jahr 1926 aufgenommen hat, ist so ein perfektes Foto. ${ }^{2}$ Es zeigt Freud am Tisch sitzend. Seine Körperhaltung ist relativ entspannt, doch sein Blick ist streng und durchdringend. Mit dem Wissen um Freuds wissenschaftliche Leistung ist man geneigt, in diesem Blick den Blick in die menschliche Psyche zu sehen. Die ganze Aufmerksamkeit ist auf die Augen gerichtet. Der Rest der Physiognomie ist nebensächlich. Den sorgsam gestutzten Bart und die etwas asymmetrische Lippe nimmt man bei Weitem nicht so intensiv wahr.

Das Porträtfoto von Karl Popper ist zwar nicht im Atelier entstanden, es ist aber genauso perfekt. Dem Fotografen gelingt es, Popper in einem nachdenklichen Moment festzuhalten und man ist bereit, die ganze wissenschaftliche Leis-

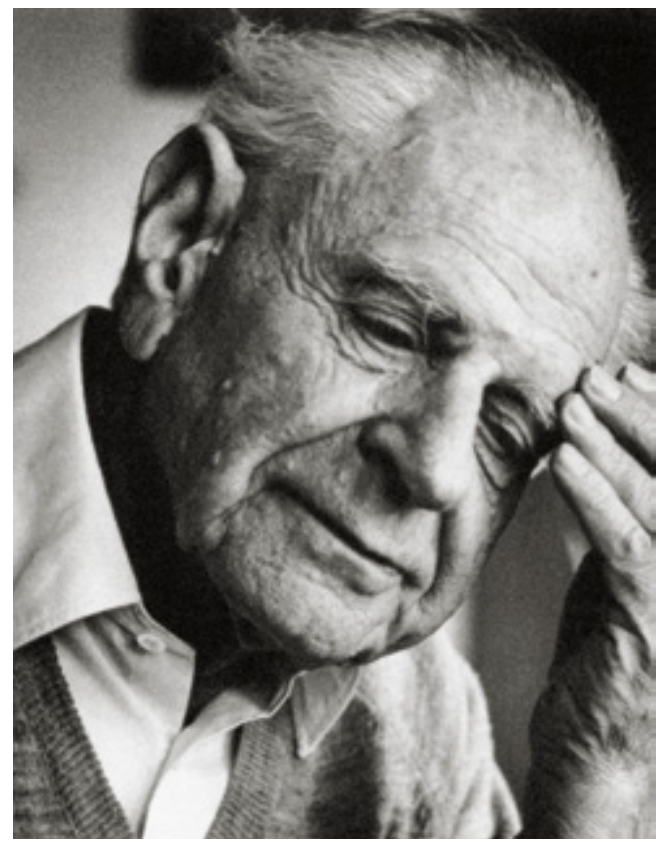

Abb. 2: Porträtfoto von Karl Popper.

tung Karl Poppers durch dieses Porträtfoto wahrzunehmen. Den Kopf geneigt, die linke Hand an der Stirn, den Blick nach innen gekehrt bleibt der Porträtierte für sich. Der Blick des Betrachters kann leicht über das ganze Gesicht wandern und die einzelnen Partien, den Mund, die Augen, die Haare, die großen Ohren und die Falten geruhsam wahrnehmen. Wenn man das Porträtfoto lange genug anschaut, dann überträgt sich die fast meditative Ruhe Poppers auch auf den Betrachter.

Die unterschiedlichen Qualitäten dieser beiden Porträts sind offensichtlich, doch beide sind gleichermaßen in der Lage, unsere Wahrnehmung von den abgelichteten Personen weitgehend zu bestimmen und das mit dem Anspruch der Objektivität der fotografischen Technik.

Einen ganz anderen Eindruck vermitteln die Büsten dieser beiden Wissenschaftler im Arkadenhof der Universität Wien (Abb. 3 und 4). Die

I A. Hanreich, Ferdinand Schmutzer (I870-I928): der fotografische Nachlass, Diss. Wien 2012. 


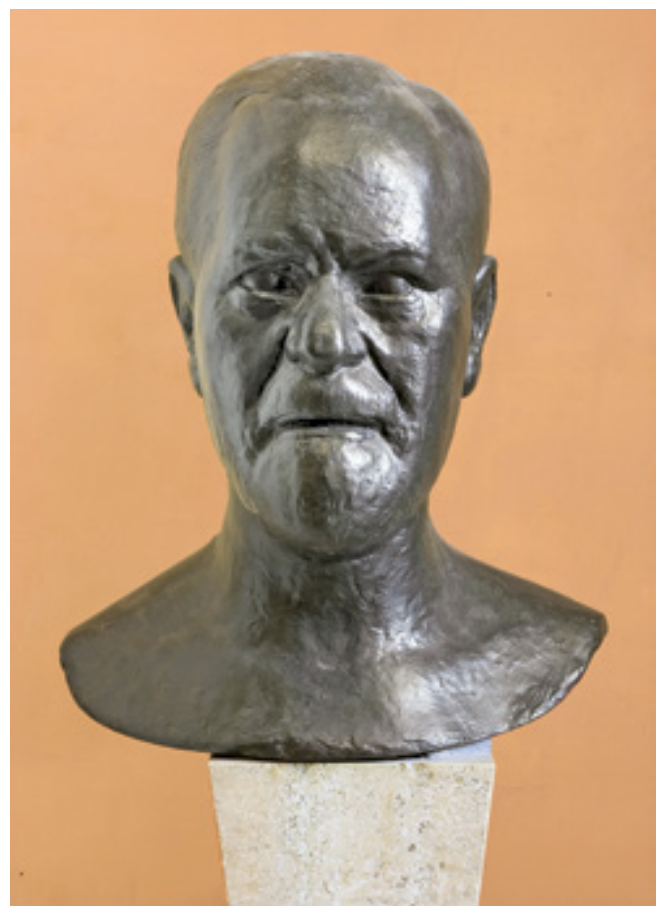

Abb. 3: Paul Königsberger, Die Porträtbüste von Sigmund Freud im Arkadenhof der Universität Wien.

Bronzebüste von Sigmund Freud wurde 1955 im Arkadenhof aufgestellt. Die Büste von Karl Popper wurde am 7. Juli 2002 anlässlich einer Tagung zu seinem Ioo. Geburtstag enthüllt. Es ist das zurzeit letzte Professorendenkmal, das im Arkadenhof aufgestellt wurde. ${ }^{2}$

Problemlos lässt sich Karl Popper in dem von Christine Pillhofer (* ${ }^{*}$ 954) geschaffenen Porträt wiedererkennen. Die großen Ohren, das kahle Haupt, der breite zu einem Lächeln geformte Mund, alle vorhin beschriebenen Merkmale sind lebensnah modelliert, selbst die Falten fehlen nicht.

Das liegt vor allem daran, dass das Porträt posthum entstanden ist und die Künstlerin nicht nach dem lebenden Modell gearbeitet hat, sondern sich - nolens volens - an den vorhande-

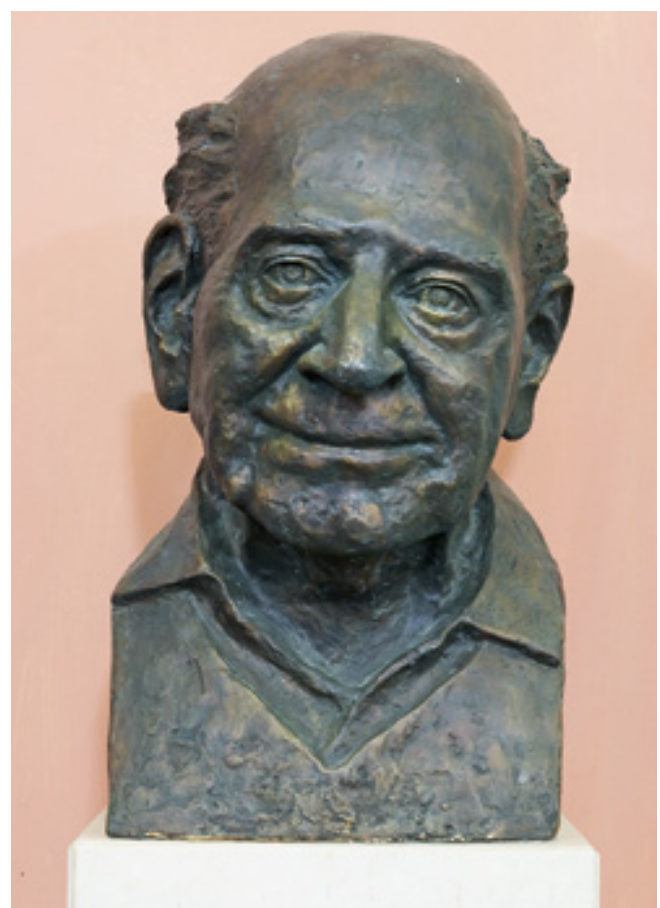

Abb. 4: Christine Pillhofer, Porträtbüste von Karl Popper im Arkadenhof der Universität Wien.

nen Fotos orientieren musste. Offensichtlich benutzte sie vor allem jene Fotoserie, aus der auch die zuerst betrachtete Aufnahme stammt. Von dort übernahm sie jedenfalls das Motiv der legeren Kleidung mit offenem Hemd und Pullover. Da es schwierig ist, die wissenschaftliche Leistung eines Geisteswissenschaftlers in einer Porträtbüste angemessen zum Ausdruck zu bringen, konzentriert sich die Bildhauerin auf das für Karl Popper charakteristische milde Lächeln. Sie verzichtet auf jede Idealisierung und belässt es bei der naturnahen Formgebung. Es gelingt ihr jedoch nicht, die vorhin genannten ästhetischen Qualitäten der Fotografie nachzubilden.

Ganz anders die Porträtbüste von Sigmund Freud. Die Porträtähnlichkeit ist nicht so offensichtlich und wenn wir nicht gerade eben das Foto

2 Das Universitätsjubiläum gab den Anstoß, die längst überfällige Ehrung von Wissenschaftlerinnen nachzuholen und einen künstlerischen Wettbewerb für sieben neue Denkmäler auszuschreiben. Auf diese neuen Denkmäler, die am 30. Juni 2016 feierlich enthüllt wurden, konnte hier nicht mehr eingegangen werden. 


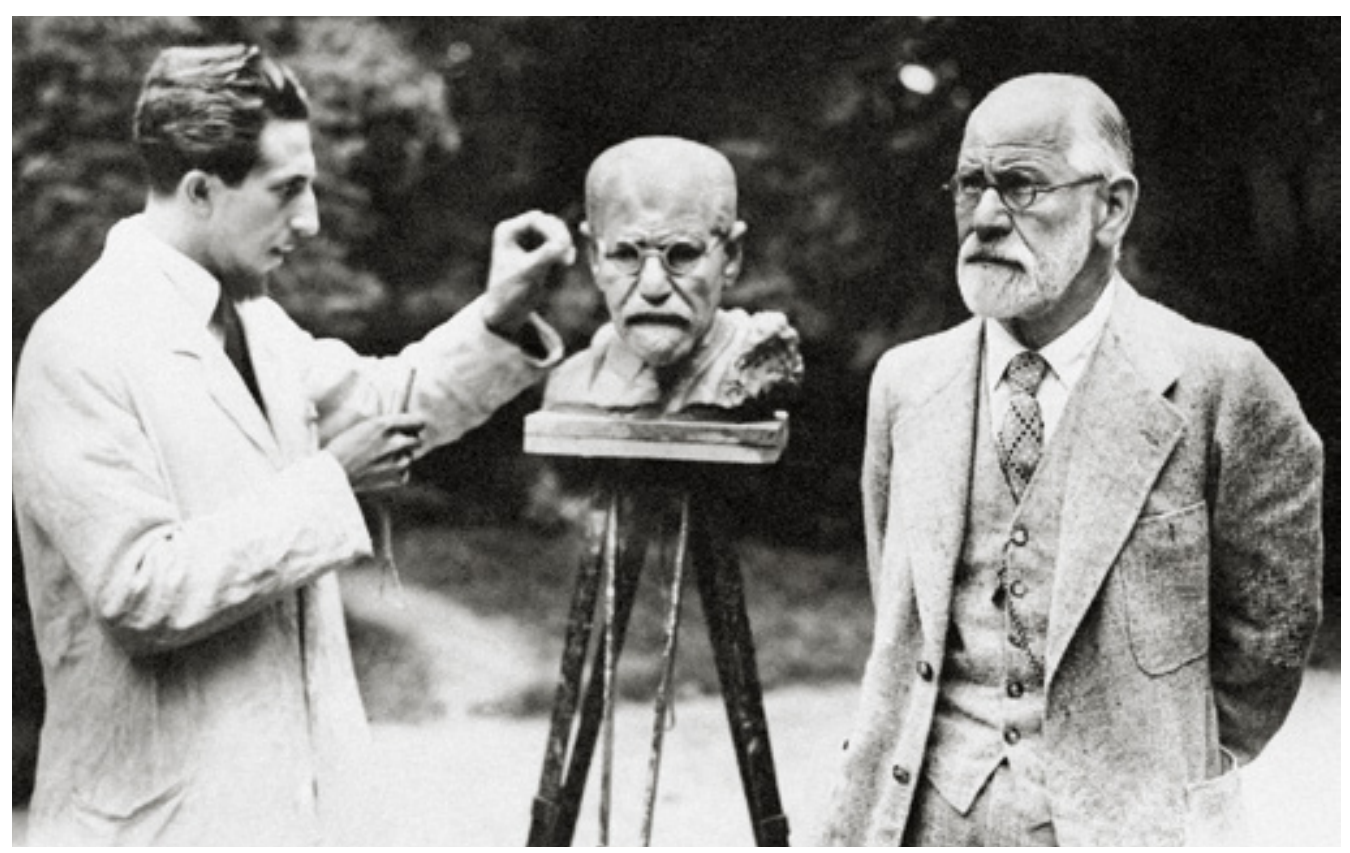

Abb. 5: Oscar Nemon bei der Arbeit, Porträtsitzung in Sigmund Freuds Sommersitz in der Khevenbüllerstraße in Pötzleinsdorf, I93I.

mit Freuds intensivem Blick und seinem schiefen Mund betrachtet hätten, wäre es wohl vielen schwer gefallen, Freud wiederzuerkennen. Gleichwohl handelt es sich bei dem Porträt um die Kopie jener Büste, die Max Eitingon - ein vermögender Schüler Freuds - im Jahr 1920 von dem heute weitgehend unbekannten Bildhauer Paul Königsberger (* um I890) anfertigen ließ und Freud zum 65. Geburtstag schenkte. Freud selbst schrieb Eitingon in einem Brief, wie er dem Bildhauer Modell saß und dass die Büste erstaunlich richtig sei und allen sehr gefalle. ${ }^{3}$ Zudem ist sich Freud auch bewusst, dass die Büste nicht für den Moment, sondern für die Nachwelt geschaffen wurde.

Freud ist unbekleidet dargestellt. Auf den ersten Blick scheint es, als verwende der Bild- hauer den klassischen Topos lediglich, um den Dargestellten zu idealisieren und ihn über die Zeit und deren Moden zu erheben. Im Fall von Sigmund Freud lassen sich Blöße und Nacktheit aber auch als Sinnbild für die von ihm entwickelte Psychoanalyse deuten. Auch der schwer zu definierende Gesichtsausdruck gibt Raum für Spekulationen in diese Richtung. Leider haben wir von dem Bildhauer Paul Königsberger fast keine anderen Werke, um seine künstlerische Handschrift genauer bestimmen zu können.

Von Sigmund Freud gibt es vier weitere Porträtplastiken von dem kroatischen Bildhauer Oscar Nemon (1906-1985), der zunächst in Brüssel und ab 1938 in England Karriere als Porträtist machte (Abb. 5). Eigenen Angaben zufolge ver-

3 U. MAY, Fundstücke zur Freud-Biographik in der Exilpresse, in: Luzifer Armor, Heft 38 (19. Jg. 2006): Blicke auf Freud, S. I44-I47. - Über die Entstehung der Büste berichtet Freud auch in einem Brief vom 22. Juli I920 an seine Tochter Anna, in: S. Freud/A. Freud, Briefwechsel 1904-1938, hrsg. von I. Meyer-Palmedo, Frankfurt a. M. 2006, Anm. 746.

4 Zur Biografie Oscar Nemons und zur Entstehung der Büsten Sigmund Freuds siehe die Internetseiten des „Estate of Oscar Nemon“ (http://oscarnemon.org.uk, abgerufen am I0. 8. 20I5). 
suchte Nemon schon Mitte der Zwanzigerjahre, als er sich vergeblich um einen Studienplatz an der Wiener Akademie der Künste bewarb, ein Porträt von Freud anfertigen zu dürfen. Dies gelang jedoch erst I93I durch Vermittlung des Wiener Arztes und Psychoanalytikers Paul Federn (I87I-I950). Bemerkenswert ist, dass das Interesse des Bildhauers mit dem Wunsch der Freunde und Schüler Freuds zusammenfiel. Der Bildhauer suchte ein attraktives Modell und nutzte die Berühmtheit Sigmund Freuds geschickt für die Entfaltung seiner eigenen Karriere. Zumindest sprechen die Fotos, die er bei einer der Sitzungen anfertigen ließ, für diese Vermutung. Die Auftraggeber hatten hingegen ein eindrucksvolles Präsent zum 75. Geburtstag des Gelehrten. Offenbar war es in akademischen Kreisen auch nach dem Ersten Weltkrieg noch durchaus üblich, dass man Porträtbüsten für den privaten Gebrauch anfertigen ließ. Freud wählte für sich eine in Holz geschnitzte Version dieser Büste, die sich heute im Freud Museum in Hampstead befindet.

Hinsichtlich des Kriteriums der Angemessenheit der Büste ist nun interessant, dass sich die Initiatoren und Antragsteller der Ehrung Sigmund Freuds im Arkadenhof für die in formaler Hinsicht modernere, von Paul Königsberger modellierte Büste entschieden haben. Die Entscheidung geht auf keinen Geringeren als Ernest Jones (I879-1958) zurück, der einer der ersten Schüler Sigmund Freuds war und dann sein Freund und wichtigster Biograf wurde. Jones stiftete die Kopie der Büste, die ab 1936 in der Universität Jerusalem aufgestellt war und heute - ob im Original oder in Kopie ist derzeit nicht zu entscheiden - im Wiener Freudmuseum in der Berggasse I9 zu sehen ist.

Am Beispiel der beiden Büsten von Sigmund Freud und Karl Popper zeigen sich die grundsätzlichen Unterschiede zwischen dem Porträt nach dem lebenden Modell und dem posthumen Porträt nach einem Foto. Während die Porträtplastik nach dem lebenden Modell allein aufgrund des direkten Kontaktes zwischen dem Künstler und dem Dargestellten sich für vielfältige Interpretationen anbietet, wird die posthume Porträtplastik vor allem an den vorhandenen Porträtfotos gemessen, wobei die Wiedererkennbarkeit zu einem wichtigen Qualitätskriterium wird.

Da von den meisten Gelehrten des 19. Jahrhunderts, wenn überhaupt, nur ein fotografisches Porträt existiert, konnte das plastische Porträt noch zu einer Art Ikone für den Dargestellten werden. Im 20. Jahrhundert übernimmt das Porträtfoto die maßgebliche Rolle für das Erinnern und Gedenken. Symptomatisch ist, dass die Biografien der berühmten Wissenschaftler des 20. Jahrhunderts mit zahlreichen Aufnahmen aus den unterschiedlichen Lebensabschnitten illustriert werden können. Die vielen Fotos sind zwar in der Lage, die Entwicklung eines Gelehrten zu veranschaulichen, aber sie verhindern die Herausbildung eines Idealbildes. Sigmund Freud ist ein frühes Beispiel für diese Entwicklung, die letztlich zur Krise der Porträtplastik und deren weitgehenden Entwertung als Erinnerungsobjekt führte. Im Folgenden wird der Manifestation dieser Krise im Arkadenhof der Universität Wien nachgegangen.

Die Errichtung des Denkmals für Sigmund Freud im Jahr 1955 fällt in eine Zeit, in der überraschend viele Professorendenkmäler im Arkadenhof aufgestellt worden sind. Die Statistik gibt einen ersten Überblick über die zeitliche Verteilung der Denkmalsenthüllungen in dem untersuchten Zeitraum vom Ende des Zweiten Weltkriegs bis 2015. (Abb. 6) In der langen Zeitspanne von 70 Jahren wurden im Arkadenhof 46 Denkmäler für herausragende Mitglieder der Professorenschaft errichtet. Hinzu kommen das Mahnmal für die vertriebenen Mediziner von Günther Wolfsberger (1998), die Neugestaltung des „Siegfriedskopfes" von Bele Marx \& Gilles Mussard (2006), das Denkmal „Der Muse reicht's“ von Iris Andraschek (2009) sowie die temporären Aufstellungen des Denkmals „Anonymisier- 


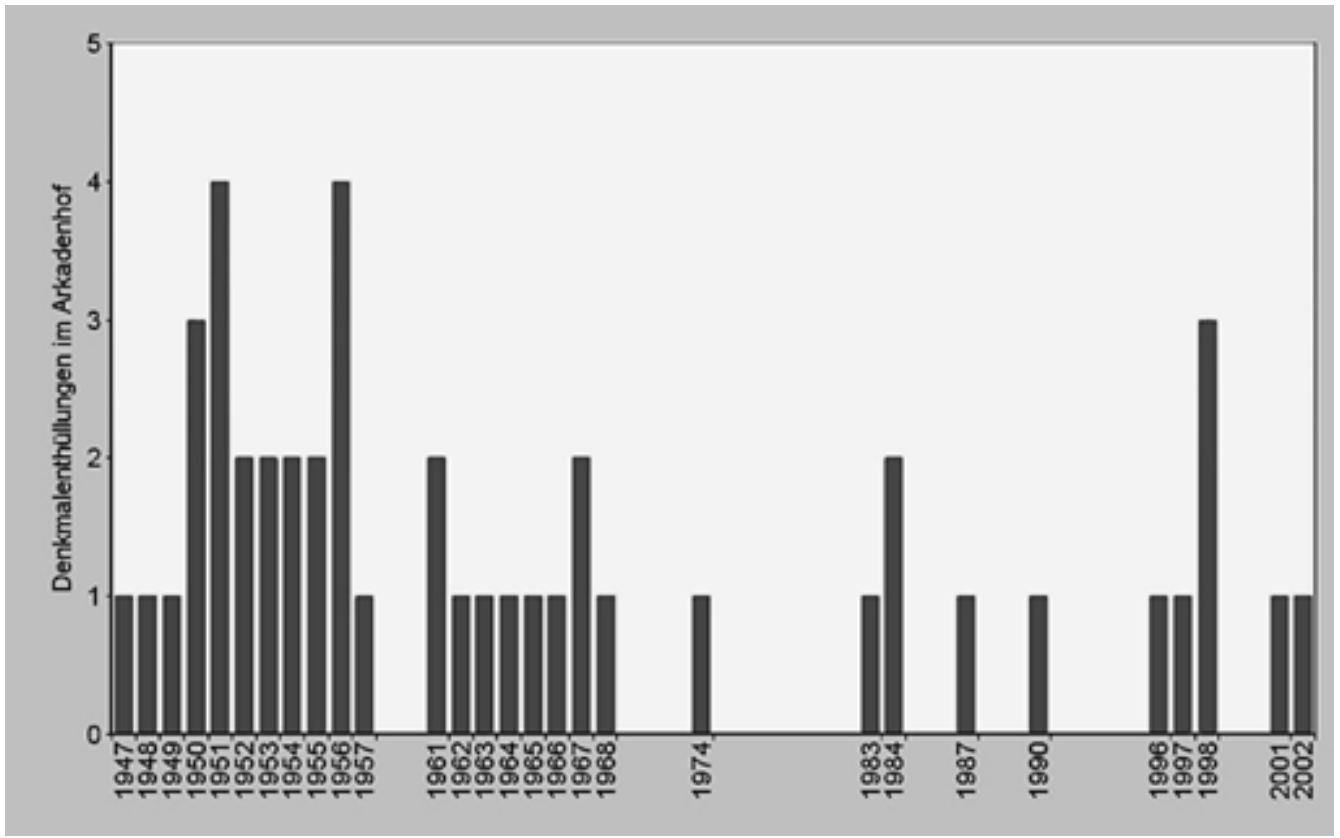

Abb. 6: Statistische Erfassung der Denkmalenthüllungen seit 1945.

te Wissenschaftlerinnen 1700-2005“ von Elisabeth Penker (2005) und der „Radical Busts“ von Marianne Maderna (2015), die in dieser Statistik nicht berücksichtigt sind. ${ }^{5}$

Die Statistik verrät auf den ersten Blick, dass die Denkmalerrichtungen zeitlich sehr ungleich verteilt sind und sich vor allem auf die beiden ersten Jahrzehnte nach dem Zweiten Weltkrieg konzentrieren. Allein in den elf Jahren von 1947 bis 1957 fanden 24 Denkmalenthüllungen statt. Das heißt, im Durchschnitt kamen jedes Jahr zwei neue Denkmäler hinzu. In den Jahren 195 I und 1956 gab es sogar jeweils vier Denkmalenthüllungen. Diese Werte reichen beinahe an die Denkmalhäufigkeit in der Zeit vor dem Ersten Weltkrieg heran und liegen höher als in den I920er- und I93oer-Jahren. Zum Vergleich: In der Zeit von I888 bis I9I8 wurden im Schnitt 2,5 Denkmäler pro Jahr errichtet, während in den 20 Jahren von 1919 bis 1938 im Schnitt nur I,4 Denkmäler enthüllt wurden. Statistisch gesehen wurden also in der ersten Dekade nach dem Zweiten Weltkrieg pro Jahr mehr Denkmäler enthüllt als in der Zwischenkriegszeit.

In den Jahren 1958 bis 1960 gab es eine erste Unterbrechung von drei Jahren, die bislang nur festgestellt, aber nicht erklärt werden kann. In den darauffolgenden acht Jahren wurden wieder kontinuierlich ein bis zwei Denkmalsenthüllungen pro Jahr durchgeführt. Die 600-Jahr-Feier der Universität Wien im Jahr 1965 hatte offenbar keinen Einfluss auf die Zahl der Denkmalenthüllungen im Arkadenhof.

Der große Bruch bei der Ehrung herausragender Professoren ist ab dem Jahr 1968 festzustellen. Dieser Bruch geht einher mit dem gesellschaftlichen Wandel, der auch die Universität Wien erfasste. Bislang konnte noch nicht geklärt werden,

5 Diese Denkmäler sind in der Selbstdarstellung der Universität Wien fest verankert und auf deren Internetseiten gut dokumentiert (https://monuments.univie.ac.at, abgerufen am 23. Jänner 20I7). 
ob die Professorenschaft selbst den Wandel mitvollzogen hat und die traditionelle Form der Personenehrung als nicht mehr zeitgemäß erachtete oder ob die Professorenschaft, die ja als Antragsteller eine wichtige Funktion bei den Denkmalerrichtungen hat, in der Defensive war und deshalb keine neuen Denkmäler mehr beantragt wurden. In diesem Zusammenhang ist zu erwähnen, dass vier Denkmalanträge aus den Jahren 1965 bzw. I967 nicht mehr realisiert wurden, wobei nur in einem Fall politische und moralische Bedenken für das Nichtzustandekommen ausschlaggebend waren: beim Antrag eines Denkmals für den Historiker und Nationalsozialisten Heinrich von Srbik (I878-195I). ${ }^{6}$ Das Denkmalwesen an der Universität Wien, das bis dahin mit erstaunlicher Gleichmäßigkeit funktionierte, kam jedenfalls zum Stillstand. Seither sind Denkmalsetzungen im Arkadenhof Einzelfälle, auch wenn sich um die Mitte der 1980er-Jahre eine kurze Wiederbelebung abzeichnet. Eine letzte kurze Blüte bei den Denkmalenthüllungen gibt es in den späten I99oerJahren in der Ära von Rektor Alfred Ebenbauer und in den Jahren 2001 und 2002, also am Beginn des zwölf Jahre dauernden Rektorats von Georg Winckler. Seit 2002 werden zwar immer wieder Denkmalswünsche diskutiert, aber seit dem Erlass im Jahre 2009, dass der Arkadenhof in seiner jetzigen Form „musealisiert“ werden soll, erübrigt sich ja auch das Stellen von neuen Anträgen.

Wenden wir uns zunächst den Denkmälern der ersten Blütephase zu und der Frage, welche
Fächer geehrt wurden. An der Spitze stehen, wie könnte es anders sein, die Mediziner mit acht Denkmälern. ${ }^{7}$ Die zweite große Gruppe bilden die Theologen mit fünf Denkmälern, wobei zu bemerken ist, dass es im Arkadenhof insgesamt nur acht Denkmäler für Theologen gibt. ${ }^{8}$ Die Philologen sind mit drei Denkmälern vertreten. ${ }^{9}$ Hinzu kommen die Denkmäler für den Chemiker Rudolf Wegscheider (1949), den Biologen Hans Molisch (1950), den Philosophen Franz Brentano (1952), den Juristen Max Hussarek von Henlein (1954), den Kunsthistoriker Julius von Schlosser (1955), den Mineralogen Friedrich Becke (1956) und die beiden Ökonomen Eugen von Böhm-Bawerk (I950) und Friedrich von Wieser (1957). Von diesen 24 Gelehrten waren mindestens fünf auch in einer politischen Spitzenfunktion tätig. Es sind dies die Professoren Ignaz Seipel (1950), Heinrich Lammasch (1953), Julius Tandler (1956) und die bereits genannten Eugen von Böhm-Bawerk (1950) und Friedrich von Wieser (1957).

Beim zweimaligen Bundeskanzler Ignaz Seipel (I872-1932) heißt es im Antrag lapidar, dass die katholisch-theologische Fakultät auf Anregung des Rektors die Bitte äußerte, eine seit Langem im Hörsaal stehende Büste „auf einem angemessenen Platz in den Arkaden zur Aufstellung“ zu bringen. Rektor war in diesem Studienjahr 1949/1950 der konservative Richard Meister, der nicht in der NSDAP gewesen war und als politisch unbelastet galt. ${ }^{10}$ Meister hatte schon

6 Für den Hinweis auf die nicht realisierten Denkmäler danke ich Andrea Mayr. Mit den drei anderen Denkmälern sollten der Numismatiker Joseph Hilarius Eckhel (I737-1798), der Mathematiker Wilhelm Wirtinger (I865-I945) und der Jurist Alexander Hold-Ferneck (I875-1955) geehrt werden. Universitätsarchiv UAW, Senatsakten S 222.43, 44,45 und 48 .

7 Ich nenne nur die Namen der geehrten Mediziner und das Jahr der Denkmalsenthüllung. Die übrigen Informationen zu den einzelnen Denkmälern finden sich auf den Internetseiten der Universität Wien (wie Anm. 5): Eduard von Hofmann (1947), Anton von Eiselsberg (1950), Ernst Fuchs (195I), Julius von Wagner-Jauregg (I95I), Hans Horst Meyer (1953), Gustav Riehl (1954), Sigmund Freud (1955), Julius Tandler (1956)

8 Die Theologen: Ignaz Seipel (1950), Rudolf von Scherer (1951), Martin Schindler (195I), Max Hussarek von Heinlein (1954), Heinrich Swoboda (1956).

9 Die Philologen: Hans von Arnim (1948), Rudolf Much (1952), Vatroslav von Jagic (1954).

io Zu seiner Biografie siehe: F. Graf-Stuhlhofer, Opportunisten ..., in: Wiener Klinische Wochenschrift IIO, I998, S. I52-I57. 
früher bei der Gestaltung des Arkadenhofs mitgewirkt und bereits 1932 ein erstes kleines Büchlein über die Professorendenkmäler verfasst. Die vorhandene Büste wurde von der Artistischen Kommission allerdings als wenig geeignet eingeschätzt und der Kunsthistoriker Otto Demus, der damalige Leiter des Bundesdenkmalamtes, beauftragt, nach einem besseren Porträt zu suchen. Schließlich wurde ein Werk aus dem Nachlass des Bildhauers Josef Engelhart (I864I94I) aufgestellt. ${ }^{\text {II }}$

Sechs Jahre später erhielt auch der Mediziner Julius Tandler (1869-1936), der als sozialdemokratischer Abgeordneter Mitglied der Wiener Landesregierung war und sich für die Einführung der Sozialhilfe und die Schaffung sozialer Einrichtungen starkmachte, wohl auch aus Proporzgründen ein Denkmal im Arkadenhof. Den Auftrag erhielt Josef Riedl (1884-1965), der die Arbeit an diesem Porträt mehrfach in seinem Tagebuch erwähnt. ${ }^{\text {I2 }}$

Offensichtlicher ist das Wirken des Ministeriums beim Denkmal für den Juristen und letzten Ministerpräsidenten der Monarchie Heinrich Lammasch (1853-1920) (Abb. 7). Satzungsgemäß wurde der Antrag zwar von drei Professoren der Rechtswissenschaft gestellt, die Finanzierung und die Auswahl des Künstlers lagen jedoch beim Bundesministerium für Unterricht. Interessant ist in unserem Zusammenhang, dass wiederum Otto Demus mit der Auswahl des Künstlers beauftragt wurde und in diesem Fall den 65-jährigen Josef Humplik (I888-1958) vorschlug.

Bei den beiden Ökonomen, dem Finanzminister Eugen von Böhm-Bawerk (I85I-I9I4) und dem Nationalratsmitglied Friedrich von Wieser (I85I-1926), ist der Fall etwas komplexer. Bereits I936 stellte die Rechts- und Staatswissenschaftliche Fakultät den Antrag, ein Doppeldenkmal

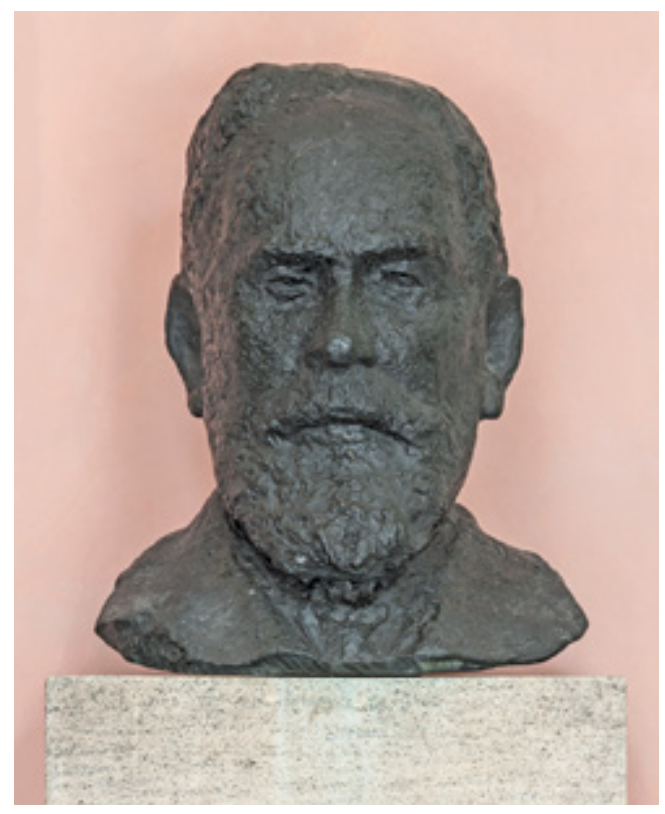

Abb. 7: Josef Humplik, Denkmal für Heinrich Lammasch, Arkadenhof der Universität Wien.

für die beiden Vordenker der Österreichischen Schule der Nationalökonomie im Arkadenhof errichten zu dürfen. In den Akten zu diesem Denkmal wird kein Grund genannt, warum die Realisierung nicht recht vorankam. Da der Zeitraum zwischen der Antragstellung und der Enthüllung oft mehrere Jahre dauert, ist es sehr wahrscheinlich, dass die Realisierung des Doppeldenkmals nach dem Regierungswechsel 1938 unmöglich wurde, denn es gab Gerüchte, dass

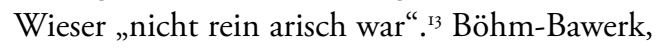
der als der wichtigere der beiden gilt, wurde bereits 1950 mit einem Einzeldenkmal geehrt. Das Denkmal für Friedrich von Wieser folgte sieben Jahre später.

Die Verzögerung bei den beiden zuletzt genannten Denkmälern führt zu der Frage, ob es bedingt durch Faschismus und Krieg einen

II UAW S 222.IO, GZ 358.

I2 R. Riedl (Hg.), Leben und Schaffen des Bildhauers Josef Riedl, Frankfurt a. M. 2005, S. 273-276.

I3 Graf-Stuhlhofer zitiert ein Schreiben von Richard Meister an den Regierungsrat Ludwig Berg aus dem Jahr 1943. Siehe: Graf-Stuhlhofer, Opportunisten ..., (wie Anm. IO), S. I55 und I57. 

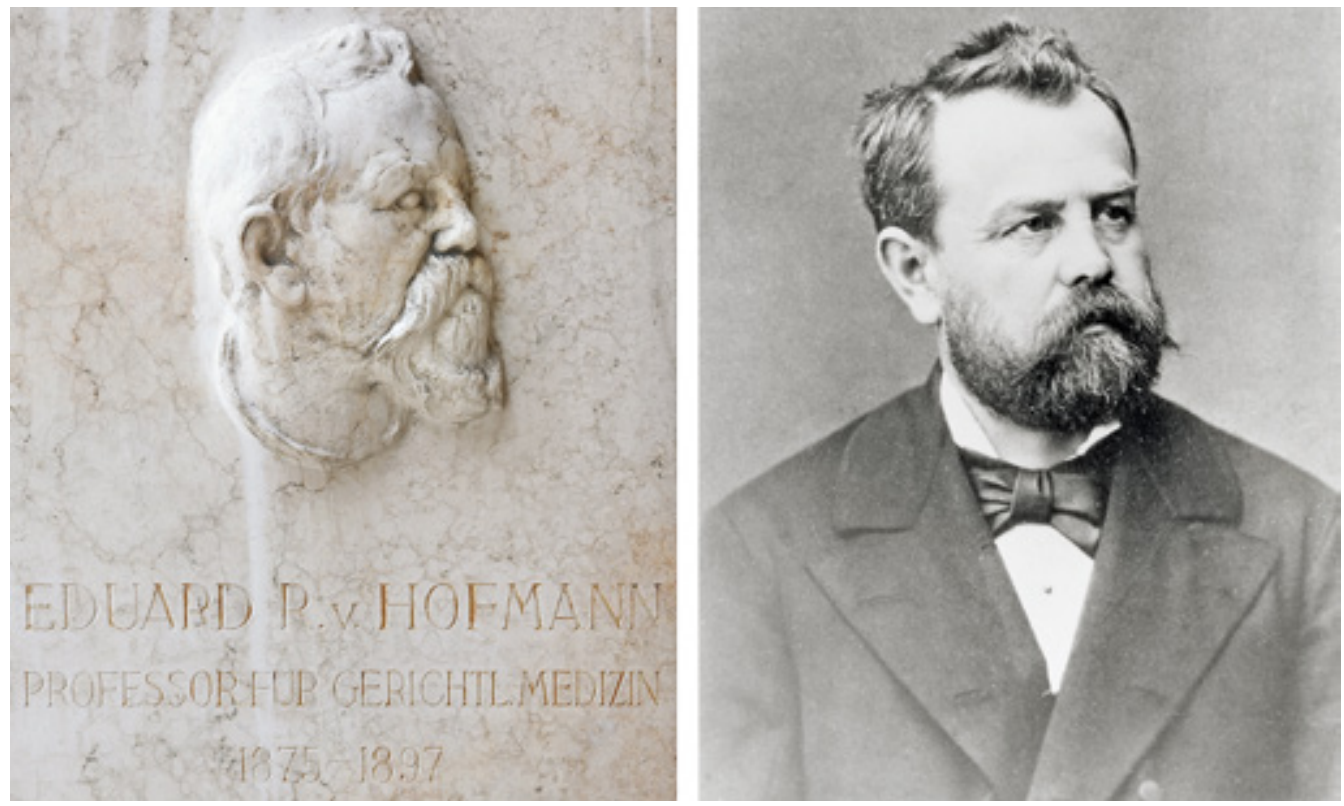

Abb. 8: Michael Drobil, Denkmal für Eduard von Hofmann im Arkadenhof der Universität Wien/Porträtfoto von Hofmann.

gewissen Denkmalstau gegeben hat, der zu der signifikanten Denkmalhäufung geführt haben kann. Aktenkundig ist nur ein weiterer Fall, bei dem Planung und Realisierung aus politischen Gründen unterbrochen wurde. Das Denkmal für den Philosophen Franz Brentano (I8381917), der mit der Jüdin Ida von Lieben verheiratet war, war bereits fertiggestellt und das Datum der Enthüllung für den 26. April 1938 festgelegt, als Anfang April der Termin auf unbestimmte Zeit verschoben wurde. Die zwischenzeitlich eingelagerte Büste des Bildhauers Theodor Georgii (I883-1963) wurde am I2. Mai 1952 enthüllt.

Ganz anders ist der Sachverhalt bei dem Denkmal für den Gerichtsmediziner Eduard Ritter v. Hofmann (1837-1897), mit dem das Denkmalwesen an der Universität Wien nach dem Zweiten Weltkrieg wieder in Gang gebracht wurde (Abb. 8). Der Wunsch, Hofmann zu seinem 50. Todestag im Jahr 1947 mit einem Denkmal zu ehren, entstand noch zur Zeit des nationalsozialistischen Regimes. Im November 1945 erinnerte der damalige Rektor der Universität Wien,
Prof. Ludwig Adamovich, der unter Schuschnigg Justizminister und ab 1946 Präsident des Verfassungsgerichtshofes war, das Dekanat der medizinischen Fakultät an dieses Vorhaben. Sein Engagement erklärt sich aus verwandtschaftlichen Gründen, denn Adamovich war mit der Enkelin von Hofmann verheiratet. Im Juni 1946 erfolgte die formgerechte Antragstellung seitens der medizinischen Fakultät. Bereits in der nächsten Sitzung des Akademischen Senats am 6. Juli 1946 wurde der Antrag einstimmig genehmigt. Rektor Adamovich wandte sich daraufhin an den Bildhauer Michael Drobil (1877-1958) und bat ihn, einen Entwurf anzufertigen und diesen der Kunstkommission zur Begutachtung vorzulegen. Im September 1947 wurde der Entwurf im Zimmer des Rektors aufgestellt. Adamovich und der mit der Denkmalerrichtung beauftragte Prof. Reuter fanden den Entwurf so gelungen, dass auf das Gutachten der Kunstkommission verzichtet wurde und Drobil sofort mit der Ausarbeitung in Marmor beauftragt wurde. 

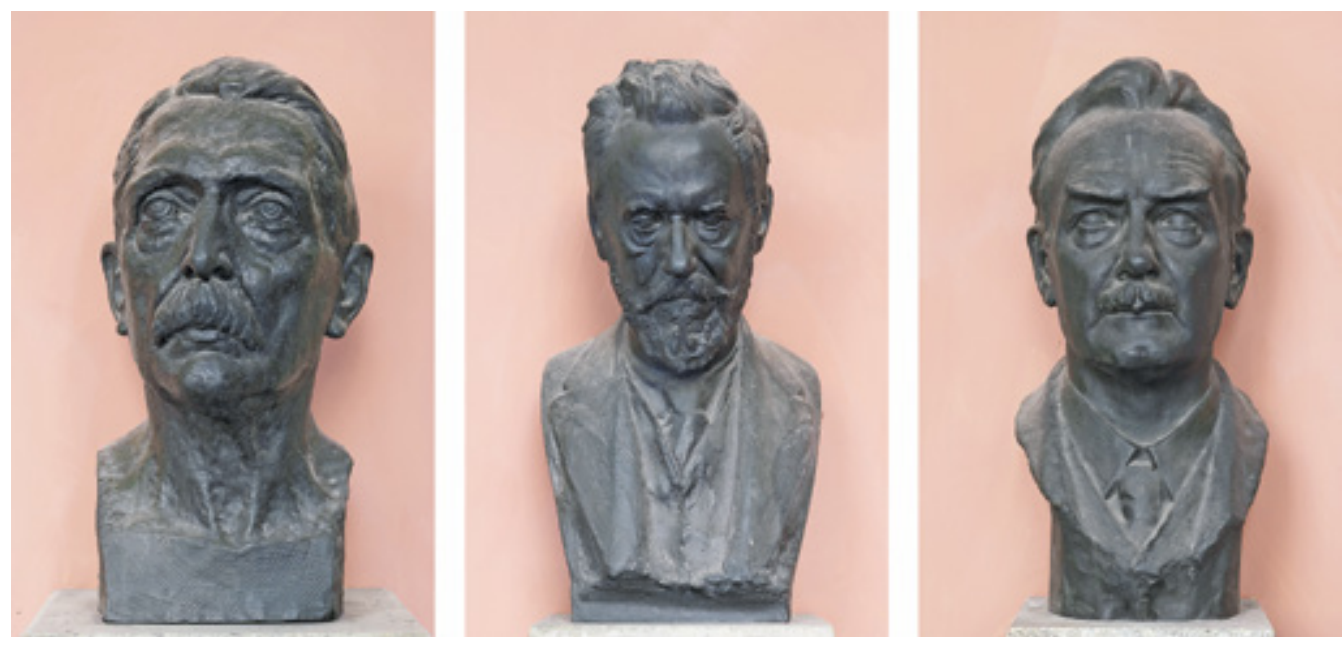

Abb. 9: Franz Barwig, Denkmal für Hans von Arnim; Heinricht Zita, Denkmal für Rudolf Wegscheider; Franz Seifert, Denkmal für Hans Molisch, Arkadenhof der Universität Wien.

Die Mitglieder der Kunstkommission werden in diesem Akt nicht namentlich genannt. Vermutlich hatte Prof. Meister, der zugleich den Wiederaufbaufond verwaltete, den Vorsitz in der Kunstkommission inne und fühlte sich durch diese Entscheidung nicht übergangen. Jedenfalls gab es keinen Protest wegen der Entscheidung für Drobil, der seit I93I als Nachfolger seines Lehrers Edmund von Hellmer an der Wiener Akademie der Künste lehrte. Man kannte Drobil, der bereits 1935 das Denkmal für den Meteorologen Josef Maria Pernter im Arkadenhof und I944 das Denkmal für Theodor Billroth im Hof I des AKH geschaffen hatte. ${ }^{14}$ Drobil lieferte, anknüpfend an seine Zeit bei der Wiener Secession, ein modern anmutendes Kunstwerk und bewältigte die Schwierigkeit, dass es von Eduard von Hofmann offenbar nur ein akzeptables Porträtfoto gibt, dadurch, dass er den Geehrten, ähnlich wie bei einer Medaille, als stark erhabenes Relief darstellte. Unverkennbar handelt es sich um ein Denkmal mit posthumer Porträtdarstellung.

Das führt wieder zurück zu der eingangs entwickelten Unterscheidung zwischen den Denkmälern, bei denen Porträtbüsten verwen- det wurden, die noch zu Lebzeiten der Geehrten entstanden sind, und den Denkmälern, deren Gestaltung komplett nach fotografischen Vorlagen erfolgte. Diese Unterscheidung ist deshalb so wichtig, weil sich daran die fundamentale Kritik an den Professorendenkmälern entzündet, auf die ich später näher eingehen werde.

Bei den 24 Denkmälern, die wir gerade im Blick haben, werden bei mehr als der Hälfte Büsten eingesetzt, die nach dem lebenden Modell entstanden sind. Dazu gehören die Denkmäler für den Altphilologen Hans von Arnim (1948), den Chemiker Rudolf Wegscheider (1949) und den Biologen Hans Molisch (1950), die zu den ersten gehören, die nach dem Zweiten Weltkrieg im Arkadenhof errichtet wurden (Abb. 9).

Im Falle Hans von Arnims erklärte sich die Familie bereit, die Büste eines ungenannten Bildhauers zur Verfügung zu stellen. Bereits im ersten Antragschreiben vom I4. August 1947 wurde auf die künstlerische Qualität dieser Büste hingewiesen, die sich bestens für die Aufstellung im Arkadenhof eigne. Auch von der Kunstkommission wurde die für den privaten Bereich geschaffene Büste als denkmalfähig akzeptiert.

I4 Siehe dazu den Beitrag von J. Rüdiger in diesem Band, S. IO3-II8. 

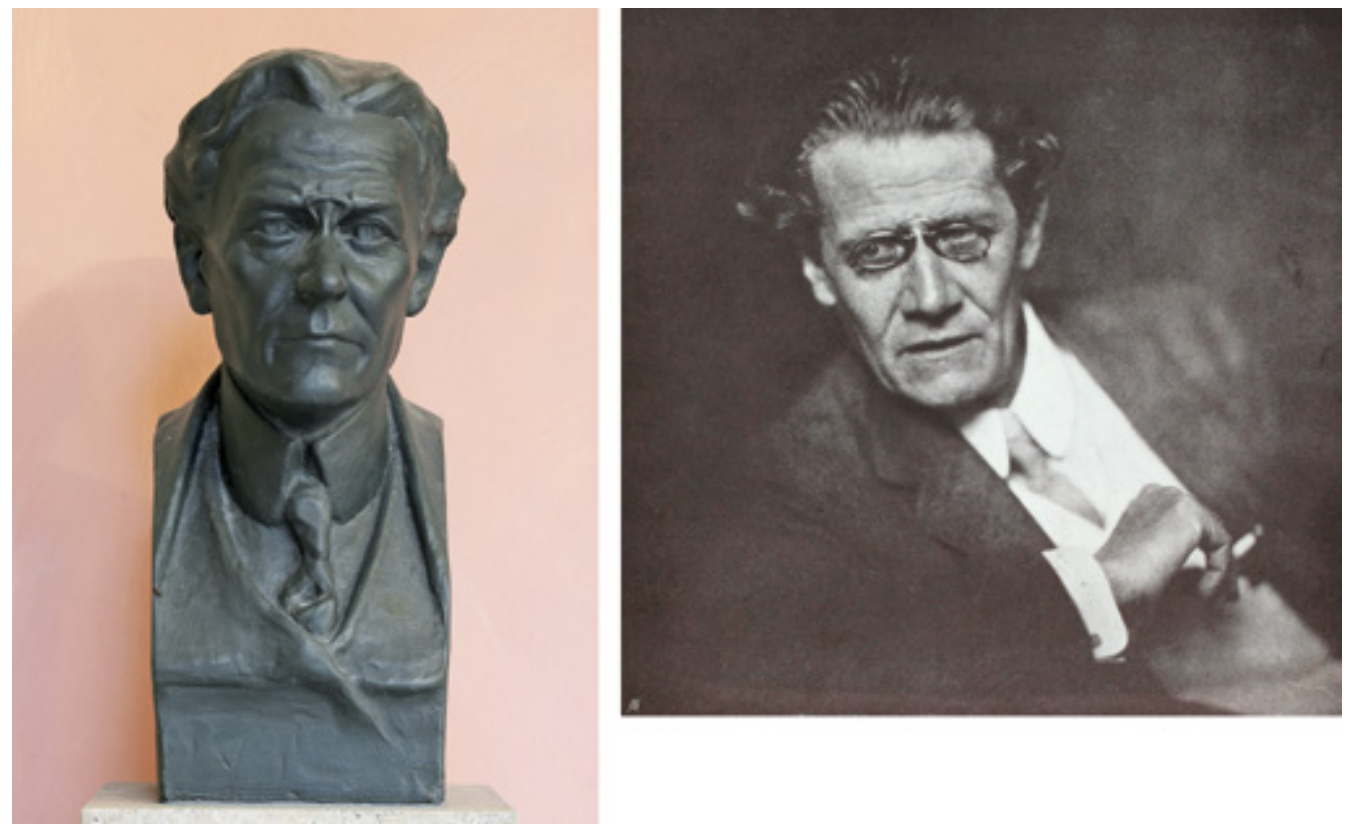

Abb. Io: Josef Thorak, Denkmal für Julius Schlosser im Arkadenhof der Universität Wien/Porträtfoto von Schlosser.

Das Denkmal für Rudolf Wegscheider wurde aus dem I. Chemischen Institut in den Arkadenhof überführt. Die 1926 modellierte Büste, die auch an Wegscheiders Ehrengrabmal auf dem Grinzinger Friedhof verwendet wurde, hatte der Bildhauer Heinrich Zita (I882-I95I) noch zu Lebzeiten Wegscheiders angefertigt. In seiner Rede anlässlich der Enthüllung lobte Richard Meister, zu diesem Zeitpunkt Rektor der Wiener Universität, dieses lebensvolle Denkmal, dessen Qualität sich nicht nur in der Wiedergabe der natürlichen Physiognomie, sondern auch [in der Wiedergabe] dessen, was dieser Physiognomie ihre Vollendung gegeben hat, des Geistes Rudolf Wegscheiders, ${ }^{15}$ zeige.

Beim Denkmal für Hans Molisch wurde die Kopie der Büste verwendet, die heute noch im Nachfolgeinstitut des Pflanzenphysiologi- schen Instituts, dem Faculty Center of Ecology, zu finden ist. Wie bei den beiden anderen Denkmälern ist die Darstellung auf den Kopf konzentriert, der Brustbereich ist so weit reduziert, dass gerade mal Hemd, Krawatte und Weste sowie der Kragen des Jacketts zu sehen sind. Der schmale Sockel hat den Vorteil, dass die Büste relativ wenig Platz beansprucht und leicht in der Wohnung aufgestellt werden kann. Die undatierte Büste stammt von dem Bildhauer Franz Seifert (I866-I95I). Ein zufälliger Fund von drei Postkarten, die derzeit im Internet zum Kauf angeboten werden, belegt, dass Molisch mit Seifert persönlich bekannt war und sich schon 1922 bei der Auftragsvergabe zum Denkmal für den Chemiker Guido Goldschmiedt für Seifert eingesetzt hatte. ${ }^{16}$ Wohl aus dieser Zeit stammt auch das Porträt von Hans Molisch.

I5 G. Schörner, Der österreichische Realismus am Beispiel eines Künstlerlebens - Heinrich Zita. Der Bildhauer und seine Zeit, Wien (Eigenverlag) 1987, S. II2.

I6 Drei Postkarten von Hans Molisch an den Bildhauer Franz Seifert wurden 2015 von der Autografenhandlung Kotte angeboten (www.autographenhandlung.de; abgerufen am Io. August 2015). 
Als letztes Beispiel dieser Gruppe zeige ich das 1955 enthüllte Denkmal für Julius Schlosser (1866-1938), nicht nur weil Julius Schlosser Kunsthistoriker war, sondern weil die Büste von Josef Thorak (I889-1952) stammt (Abb. IO). In den Akten wird Thoraks Name nicht genannt, sondern nur nebulös berichtet, dass die Witwe eine Büste zur Verfügung stelle. Josef Thorak war neben Arno Breker der Lieblingsbildhauer von Adolf Hitler und stand sogar auf der Liste der „gottbegnadeten Künstler“, deren Leben unbedingt zu schützen sei.

Die Frage nach der Angemessenheit bekommt hier eine ganz andere Wendung. Dabei ist aber zu berücksichtigen, dass Schlosser als Direktor der Skulpturenabteilung des heutigen Kunsthistorischen Museums ein besonderes Interesse an der Porträtplastik hatte und mit Thorak seit Langem freundschaftlich verbunden war. Schlosser überzeugte Thorak, sein Studium in Berlin fortzusetzen und machte ihn bereits I9I5 mit dem Berliner Museumsdirektor Wilhelm v. Bode bekannt, der 1929 eine erste Schrift über den damals 40-jährigen, erfolgreichen Bildhauer veröffentlichte. Diese freundschaftliche Verbindung zwischen Schlosser und Thorak war wohl auch die Grundlage dafür, dass Thorak die Porträtbüste modellierte, die Schlosser im Alter von etwa 55 Jahren zeigt. Wenn diese Annahme stimmt, dann ist die Büste um das Jahr I92I entstanden, also in der Zeit, in der Schlosser den Ruf an die Universität Wien angenommen hat. Möglicherweise ist sie aber erst nach dem Tod von Schlosser im Jahr 1938 entstanden, denn eine Kopie dieser Büste schmückt auch sein Ehrengrab auf dem Wiener Zentralfriedhof. In einer Würdigung von Schlossers wissenschaftlichen Leistungen bezeichnete Renate Wagner-Rieger die Büste ohne weitere Begründung als ,ein Jugendwerk von Thorak“ “. ${ }^{17}$
Nach diesen Porträts, die allesamt einer eher naturalistischen Kunstauffassung verpflichtet sind, möchte ich nun die Aufmerksamkeit auf die künstlerische Handschrift, das dritte Kriterium meiner Untersuchung, lenken. Sie erlangt vor allem bei den Denkmälern mit posthumen Porträts eine zunehmende Bedeutung. An der bereits erwähnten Büste des letzten k. k. Ministerpräsidenten Heinrich Lammasch lassen sich einige Merkmale der neueren Porträtauffassung zeigen (Abb. 7). Das Gesicht wird nicht mehr in allen Details ausgeformt, was besonders bei den Augen auffällt, auch die Oberfläche wird nicht mehr der Haut entsprechend geglättet, wodurch der additive Aufbau aus einzelnen Tonklumpen, also der Herstellungsprozess selbst, zur Schau gestellt wird. Insgesamt gibt der Bildhauer Josef Humplik (1888-1958), der in der Zwischenkriegszeit einige Künstler, Schauspieler und Musiker porträtiert hatte, dem Dargestellten einen entrückten, eher heiteren Charakter. Die Bedeutung des Amtes und das Gewicht der Verantwortung, die Lammasch zu tragen hatte, macht er nicht wirklich sichtbar.

In ähnlicher Weise gestaltet der an der Wiener Akademie der bildenden Künste ausgebildete kroatische Bildhauer Ivan Mestrovic (1883-1962) das Denkmal für den Slawisten Vatroslaw v. Jagic (I838-I923) (Abb. II). In einem Brief bedauert Mestrovic, dass er den ihm persönlich bekannten Jagic nicht schon früher, also zu dessen Lebzeiten, porträtiert hat, denn sein erster Entwurf sei ihm nicht gerecht geworden. Für den zweiten Entwurf stehe ihm nun ein weiteres Foto, das Jagic zwar in höherem Alter zeige, auf dem aber die Gesichtszüge etwas genauer zu sehen sind, zur Verfügung. ${ }^{18}$ Erkennbar ist, wie Mestrovic die fotografische Vorlage zwar ziemlich genau umsetzt, sich aber gleichzeitig von der realistischen Darstellung löst, indem er die

\footnotetext{
I7 R. Wagner-Rieger, Julius von Schlosser - zur hundertsten Wiederkehr seines Geburtstages (23. September), in: Neue Züricher Zeitung, 26. 9. 1966 , Nr. 4045 (I08).

I8 UAW Senat S 222.22.
} 

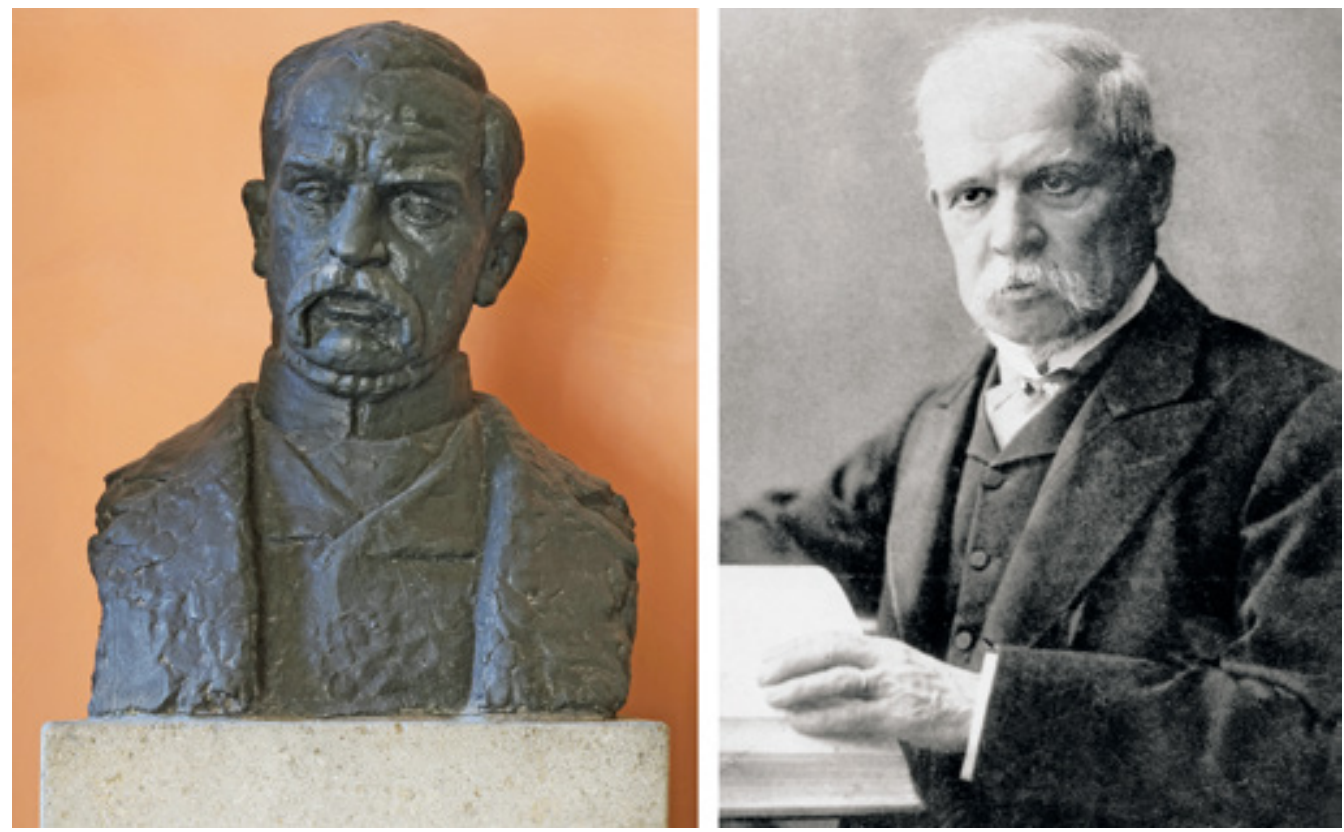

Abb. II: Ivan Meštrović, Denkmal für Vatroslav v. Jagic im Arkadenhof der Universität Wien/Porträtfoto von Jagic.

Details nicht mehr ausarbeitet, die Oberflächen nicht glättet und stattdessen den Prozess des Modellierens sichtbar lässt.

Noch stärker ist die persönliche Handschrift beim Denkmal für den Gynäkologen Semmelweis von Alfred Hrdlicka (1928-2009) ausgeprägt (Abb. I2). Semmelweis und seine Bedeutung für die moderne Geburtshilfe gehört in Österreich und insbesondere in Wien zum allgemeinen Bildungsgut. Sein Ioo. Todestag im Jahr 1967 war der äußere Anlass für die Errichtung des Denkmals im Arkadenhof. Leider findet man in den Akten keinen Hinweis darüber, wer den Bildhauer Alfred Hrdlicka vorgeschlagen hatte und wie die Wahl auf ihn fiel. Die Tatsache, dass Hrdlicka mit der Erstellung des Denkmals beauftragt wurde, zeugt aber von Mut und künstlerischem Gespür seitens der Auftraggeber. Hrdlicka war damals 37 Jahre alt und hatte die ersten großen Erfolge seiner Karriere. Im Jahr zuvor sorgte er als Vertreter Österreichs bei der Biennale in Venedig für Aufsehen und etwa zur gleichen Zeit entstand das Denkmal für Dr. Karl Renner an der Wiener Ringstraße, das heiße Diskussionen auslöste. Und nicht zuletzt war Hrdlicka ein bekennender Kommunist. Man wusste also, worauf man sich bei diesem Künstler einließ, und wurde nicht enttäuscht. Hrdlicka lieferte ein Relief, das den Porträtierten in schweren, ja beinahe groben Formen zeigt. Ein kantiger Schädel, dessen kahler Scheitel mit dem mächtigen Unterkiefer korrespondiert. Schnauzbart und Mund bilden eine undifferenzierte Masse. Einzig die kleinen, wachen Augen sind mit scharfen Linien aus dem Stein gemeißelt und ziehen die Aufmerksamkeit auf sich. Der Vergleich mit dem offiziellen Foto von Semmelweis, das sicherlich als Vorlage gedient hatte, zeigt, welche Gestaltungsfreiheit sich Hrdlicka erlaubte und was für ein zeitgemäßes Denkmal - im Sinne von zeitgenössischer Kunst - er geschaffen hat.

Trotz allem: Das 1967 enthüllte Denkmal bildet quasi den Endpunkt des traditionellen Denkmalwesens im Arkadenhof der Universität Wien. Im Zuge des gesellschaftlichen Wandels, der sich nicht nur in den studentischen 

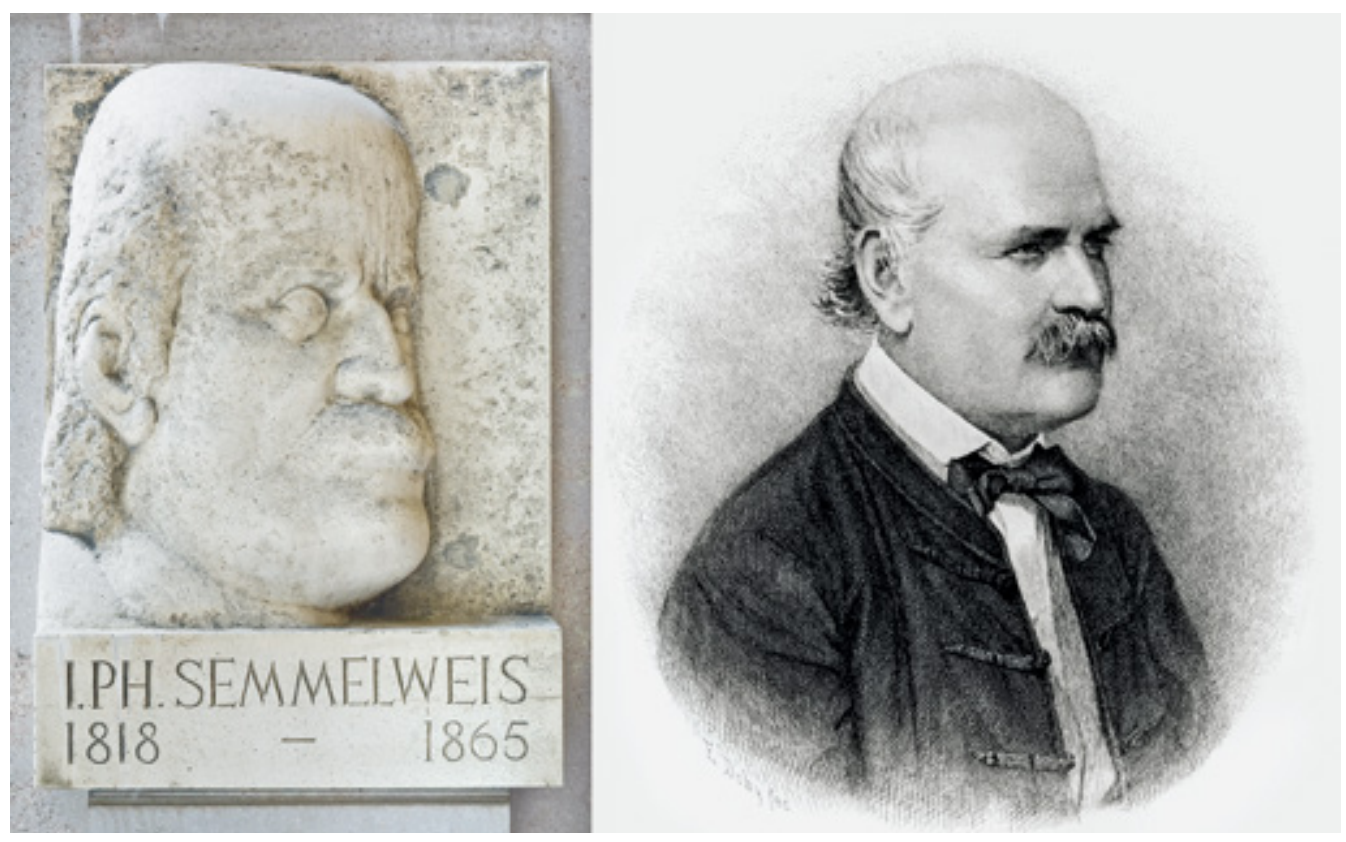

Abb. I2: Alfred Hrdlicka, Denkmal für Ignaz Philipp Semmelweis im Arkadenhof der Universität Wien/Porträtlithografie von Semmelweis.

Unruhen manifestierte, änderte sich auch die Einstellung zur Ehrung einzelner Personen. In den i96oer- und 7oer-Jahren war der Strukturalismus en vogue und in den Geistes- und Geschichtswissenschaften standen nicht mehr die einzelnen Akteure und deren Biografien im Zentrum der Forschung, sondern strukturalistische Erklärungsversuche. ${ }^{19}$ Der Zweifel an den Einflussmöglichkeiten und der moralischen Integrität des Individuums wirkte sich ebenso negativ auf die Ehrung herausragender Persönlichkeiten aus wie die ideologischen Kämpfe, die innerhalb der Universität ausgefochten wurden.

Symptomatisch ist die Sitzung der Kunstkommission am 28. November 1973. Zu verhandeln waren zwei Anträge zur Errichtung eines Denkmals für den Philologen Fürst Nikolai Sergejewitsch Trubetzkoy (I890-I938) und für den Nobelpreisträger Erwin Schrödinger (I886196I). ${ }^{20}$ Den Vorsitz hatte in schöner Tradition der inzwischen 7I-jährige Ordinarius für Kunstgeschichte Otto Demus (1902-1990), der schon 20 Jahre zuvor beim Denkmal für Heinrich Lammasch den Künstler auswählen durfte. Ebenfalls vom Institut für Kunstgeschichte waren anwesend Gerhard Schmidt (I924-20IO), dem in dieser Sitzung der Vorsitz der Kunstkommission übertragen wurde, und Renate WagnerRieger (I92I-1980) sowie als Künstlerischer Beirat der Architekt Ernst Hiesmayr (1920-2006), der zu dieser Zeit mit der Planung und dem Bau des Juridicums der Universität Wien beauftragt war, und der Künstler Ferdinand Welz (I9152008). Die Sitzung ist leider nicht im Wortlaut überliefert, im Protokoll ist nur vermerkt, dass es eine „lebhafte Debatte“ war, in deren Verlauf

I9 J. Eckel, Der Sinn der Erzählung. Die narratologische Diskussion in der Geschichtswissenschaft und das Beispiel der Weimargeschichtsschreibung, in: J. EcKel/Th. EtZemüLler (Hg.), Neue Zugänge zur Geschichte der Geschichtswissenschaft, Göttingen 2007, S. 20I-230, hier S. 204 f.

20 UAW Senat S 222.5I. 
Hiesmayr „stärkste Bedenken gegen die Anbringung von Tafeln und Plaketten an den Pfeilern des Arkadenhofes angemeldet" hat. Die Erregung darüber, dass die Kunstkommission viel zu spät und in der Regel mit fertigen Kunstwerken konfrontiert wird, war so groß, dass er auch „eine grundsätzliche Revision der bisherigen Praxis und die Entwicklung eines neuen Konzeptes" anregte. ${ }^{21}$ Trotz des Ärgers wurde das Denkmal für den Linguisten Trubetzkoy, der in seinen Wiener Jahren die Theorie der Phonologie entwickelte und einer der wichtigen Vordenker des Strukturalismus ist, dessen Schriften auch heute noch relevant sind, genehmigt. Im Fall des Denkmals für Erwin Schrödinger wurde in der Kommission „die Problematik der Herstellung posthumer Porträts behandelt" und Ferdinand Welz, „der auf Wunsch des Bundesministeriums für Wissenschaft und Forschung [...] bereits an einem unverbindlichen Vorschlag arbeitet[e]", wurde gebeten, mit Prof. Hiesmayr und dem Antragsteller Prof. Pietschmann die verschiedenen Möglichkeiten zu überdenken und zu einer einvernehmlichen Lösung zu kommen. Der Entwurf solle dann in der nächsten Sitzung der Kommission vorgestellt werden.

In der Sitzung vom 30. April 1974 stellte Renate Wagner-Rieger dann das Konzept vor, die Denkmäler neu zu gruppieren, um „einzelne Joche vollkommen von Denkmälern zu räumen und für eine einheitliche Künstlerische Gestaltung nach zeitgemäßen Gesichtspunkten zu reservieren." Aufgrund dieses Vorschlags wurde allerdings der Bericht Hiesmayrs über das projektierte Denkmal für Erwin Schrödinger vertagt, weil man erst die Ergebnisse dieser Initiative abwarten wollte. Was aus den Plänen der Kunstkommission geworden ist, ist bislang nicht geklärt. Vermutlich wurde das Ganze mit dem üblichen Kostenargument verworfen. Die Stellungnahme zum beantragten Denkmal für Schrödinger war damit aber erst mal blockiert.
Weitere Verzögerungen führten schließlich dazu, dass das Denkmal am 9. Juni 1976 nicht im Arkadenhof, sondern, rechtzeitig zu den Feierlichkeiten anlässlich des 50. Jahrestages der Entdeckung der Schrödinger-Gleichung, am Institut für theoretische Physik aufgestellt wurde. Der Akademische Senat, der dieser Änderung zustimmen musste, plädierte aber für die Übersiedlung der Büste in den Arkadenhof, sobald dieser „umgestaltet" sei. Sechs Jahre später brachte das Institut für theoretische Physik die Schrödinger-Büste wieder in Erinnerung und beantragte erneut deren Aufstellung im Arkadenhof. Nach der Genehmigung durch den Akademischen Senat am 28. Oktober 1982 wurde die Frage des Aufstellungsorts erneut aufgerollt und Alternativen vorgeschlagen, sodass die feierliche Enthüllung erst am 2. April 1984, also mehr als zwölf Jahre nach der ersten Antragstellung, stattfinden konnte.

Rückblickend ist der Streit um dieses Denkmal nur mehr schwer nachvollziehbar. Vermutlich richtete sich der Widerstand auch weniger gegen die Gestaltung der Büste als gegen die Art und Weise, wie sie durchgesetzt werden sollte. Hiesmayrs Kritik entzündete sich allerdings am „Problem der Herstellung posthumer Porträts“. Schauen wir also, wie es in diesem Fall um die genannten Kriterien Wiedererkennbarkeit, Angemessenheit und künstlerischer Ausdruck steht.

Ferdinand Welz zeigt Erwin Schrödinger durchaus realistisch und lebensnah als einen Mann des 20. Jahrhunderts (Abb. 13). Bei genauerer Betrachtung und beim direkten Vergleich mit einer Fotografie erkennt man die Idealisierung, mit der Welz diese Büste gestaltet hat. Die Brille fehlt, sodass die sehenden Augen voll zur Wirkung kommen. Der harte Haaransatz betont die eckige Stirn, während die Haare in breiten Strähnen geordnet sind. Die Kleidung ist stark vereinfacht: Das Sakko hat kein Revers. Die bei einem offiziellen Porträt obligatorische Krawatte fehlt und das Hemd hat nicht einmal Knöp-

2I UAW Senat S 222.5I. 

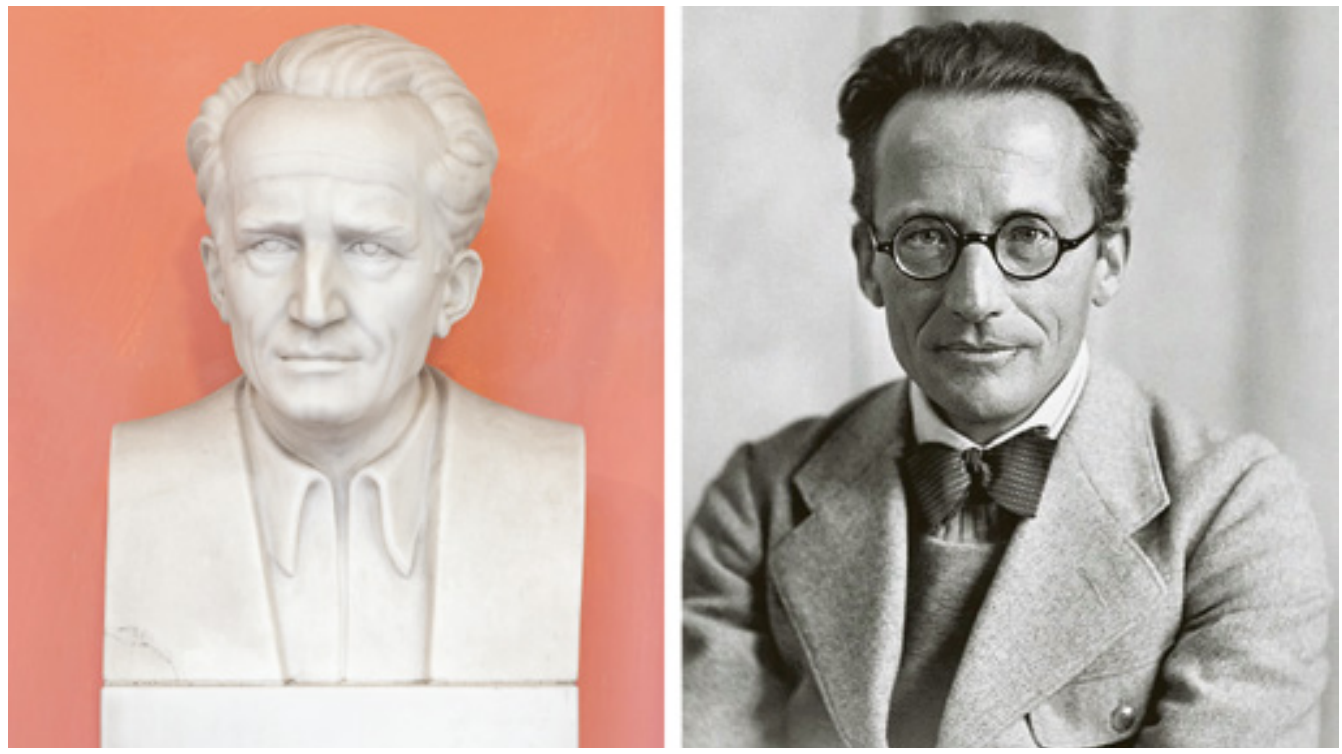

Abb. 13: Ferdinand Welz, Denkmal für Erwin Schrödinger im Arkadenhof der Universität Wien/Porträtfoto von Schrödinger.

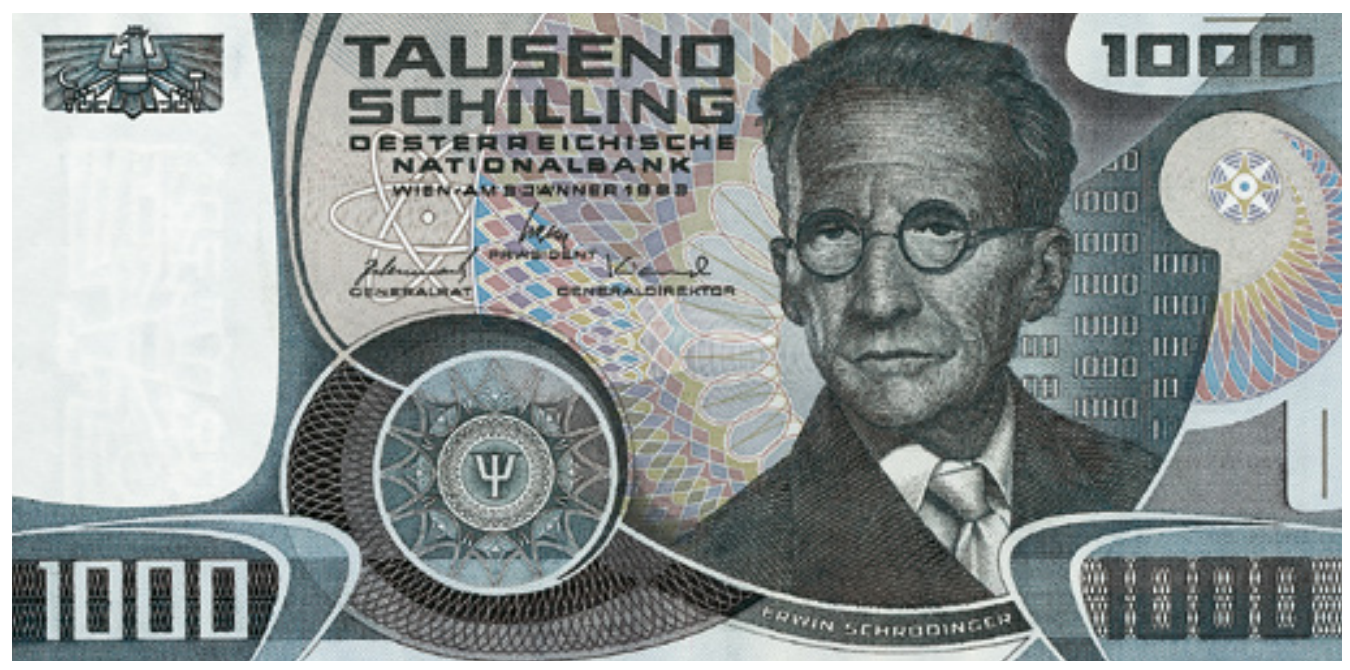

Abb. I4: 10oo-Schilling-Note mit dem Porträt von Schrödinger.

fe. Stattdessen laufen zwei Stoffkanten glatt nach unten und lenken die Aufmerksamkeit wieder zurück zum Gesicht. Die posthum entstandene Porträtbüste zeigt Schrödinger etwa in dem Alter, in dem er die nach ihm benannte Schrödinger-Gleichung entdeckt hatte. Welz gestaltet die Büste allerdings mit einer gewissen Strenge und Kühle und gibt den Nobelpreisträger viel stärker als den nach innen gekehrten Denker wieder, als der er auf den zahlreichen Fotos, die es von ihm gibt, erscheint. Die Büste zeigt Schrödinger auf eine völlig andere Weise, als er den meisten Österreichern bekannt war und ist: Sein Porträt zierte ab 1983 auch die Iooo-Schilling-Banknote. Schrödinger erscheint dort älter und weitaus asketischer (Abb. I4). 


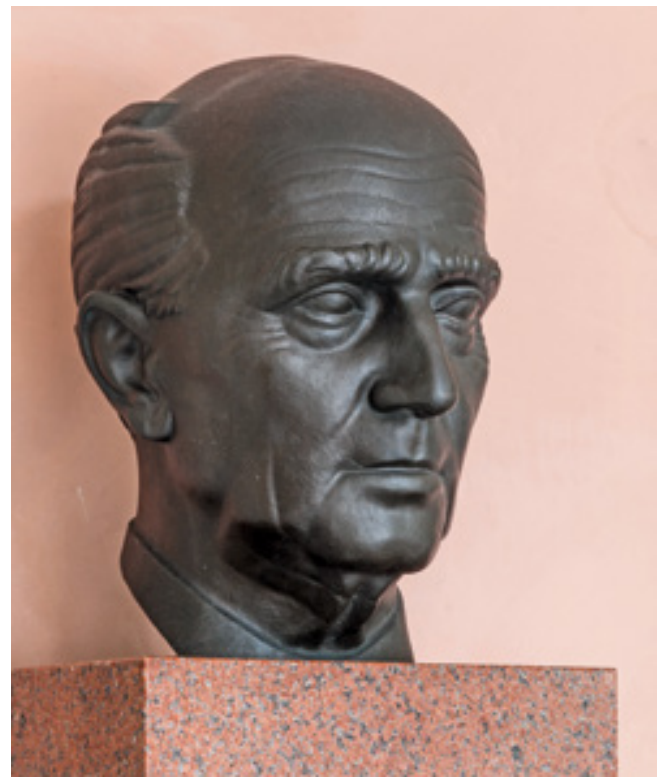

Abb. 15: Denkmal für Hans Kelsen im Arkadenhof der Universität Wien.

Ferdinand Welz erhielt noch drei weitere Aufträge für Denkmäler im Arkadenhof der Universität Wien. Alle seine Denkmäler zeichnen sich durch eine starke Idealisierung und eine glatte Ästhetik aus (Abb. I5). Welz entwickelte seine künstlerische Handschrift vor allem in der Medaillenkunst. Seit I955 leitete er an der Akademie der bildenden Künste in Wien die Meisterschule für Medailleurskunst, in den I97oer-Jahren war er dort auch Rektor und Prorektor und emeritierte im Jahr 1985 im Alter von 70 Jahren. Beim Denkmal für Hans Kelsen (I88I-I973), der maßgeblich an der Ausarbeitung der Österreichischen Bundesverfassung mitgewirkt hatte, gab die „artistische Kommission“, zu deren Vorsitzendem Prof. Filitz vom Institut für Kunstgeschichte ernannt worden war, erneut zu bedenken, dass das Aufstellen von Denkmälern „überholt“ sei. Dennoch wurde die Aufstellung vom Akademischen Senat genehmigt. Die Finanzierung war durch

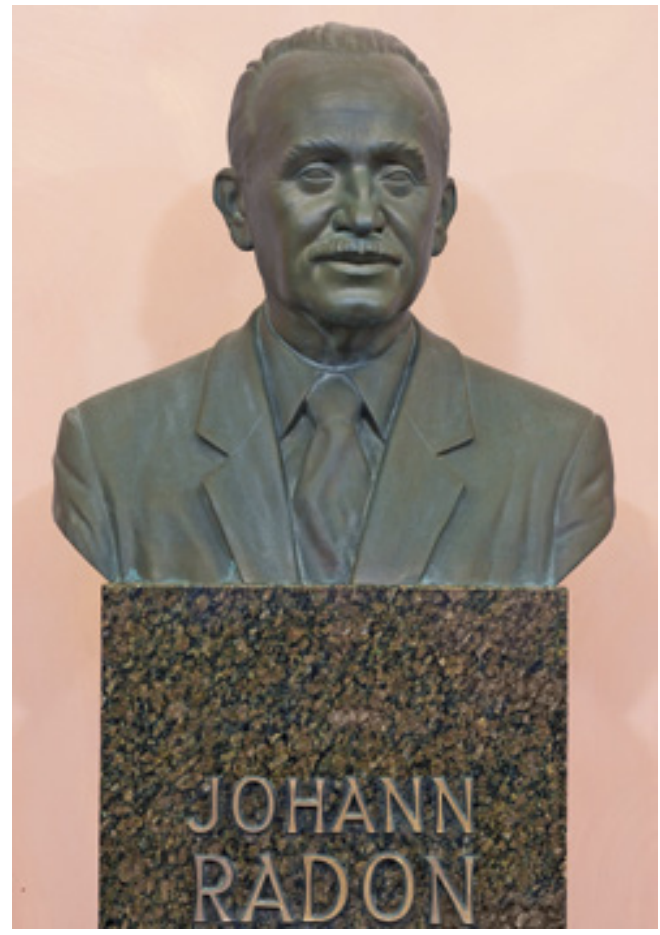

Abb. I6: Ferdinand Welz, Denkmal für Johann Radon im Arkadenhof der Universität Wien.

das Hans Kelsen-Institut gesichert. Interessant ist, welche Wirkung diese recht kalte Büste außerhalb der Universität Wien hatte. Auf Wunsch des damaligen Präsidenten des italienischen Verfassungsgerichtshofes La Pergola steht heute eine Kopie dieser Büste in der Universität von Bologna. 1987 wurde sie vom Präsidenten des österreichischen Verfassungsgerichtshofes, Ludwig Adamovich jr., dem Rektor der Universität Bologna übergeben. ${ }^{22}$ Der ehemalige Bundespräsident Heinz Fischer, der im Jahr 1984 als Minister für Wissenschaft und Forschung an den Enthüllungsfeierlichkeiten teilgenommen hatte, wünschte sich eine weitere Kopie, die er 2007 in seinen Amtsräumen im Leopoldinischen Trakt der Hofburg aufstellen ließ. ${ }^{23}$ Beim Denkmal für den Mathematiker Johann Radon (I887-1956)

22 R. Walter, Bleibende Erinnerungszeichen an eine Rechtslehre, in: T. Olechowski u. a. (Hg.), Grundlagen der österreichischen Rechtskultur. Festschrift für Werner Ogris zum 75. Geburtstag, Wien 20I0, S. 552-553.

23 R. Walter (wie Anm. 22), S. 545. 


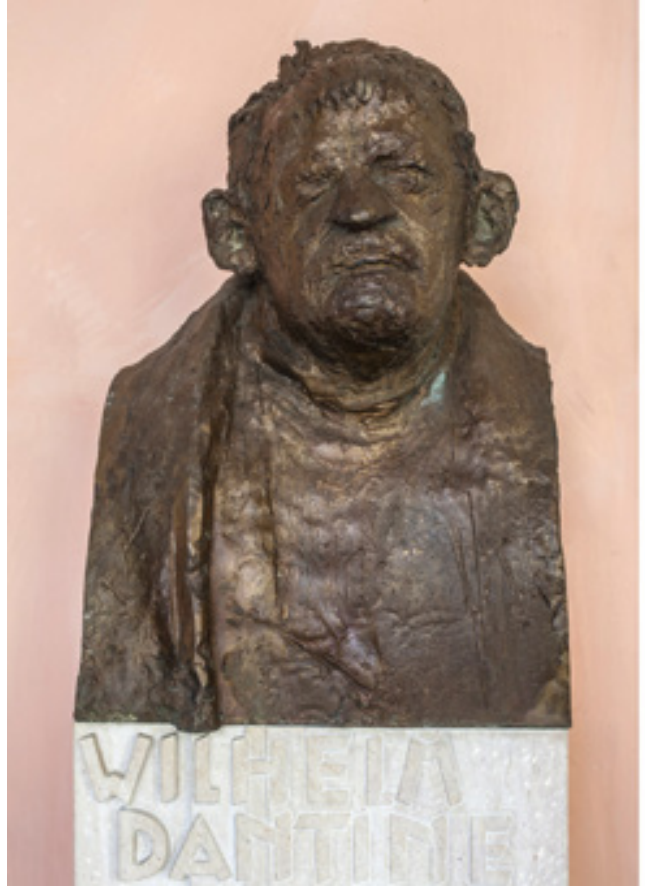

Abb. 17: Denkmal für Wilhelm Dantine im Arkadenhof der Universität Wien/Porträtfoto von Dantine.

(Abb. I6), das 1987 enthüllt wurde, meldete sich die artistische Kommission wieder zu Wort und empfahl - noch bevor ein Künstler gesucht und gefunden wurde -, dass die neue Büste den bereits aufgestellten Denkmälern angepasst werden soll, damit sie ein passendes Gegenstück zu den bereits geehrten Professoren bildet. Mit dieser Position verhinderte die Kommission allerdings die allfällige Modernisierung des künstlerisch gestalteten Professorendenkmals im Arkadenhof. Obwohl in den I980er-Jahren auch andere Künstler, wie Alfred Hrdlicka oder Josef Zenzmaier, als Porträtbildhauer bekannt waren, fiel die Wahl erneut auf Ferdinand Welz, der wiederum eine seiner strengen Porträtplastiken lieferte, die sich problemlos in den Gesamtbestand der Professorendenkmäler einfügt.

Nur kurz erwähnen möchte ich die drei Denkmäler für Tomas Masaryk, Karol Kuzma-

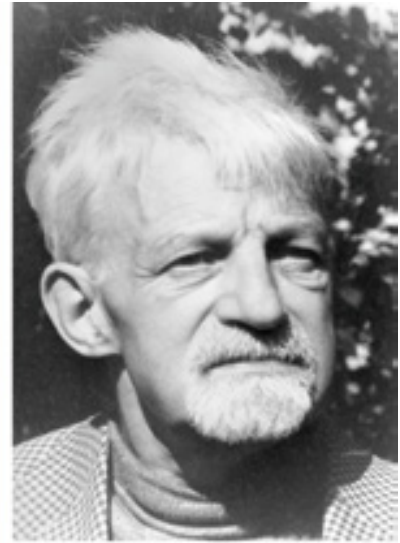

ny und Jan Kollar, die in der Ära von Rektor Ebenbauer aufgestellt wurden. Deren Entstehung ist im Zusammenhang mit den Entwicklungen in der postsozialistischen Tschechoslowakei zu sehen, was eine gesonderte Untersuchung wert wäre. Viel wichtiger sind mir im Hinblick auf die Entwicklung der österreichischen Porträtplastik die beiden Denkmäler für den evangelischen Theologen Wilhelm Dantine und den Philosophen Sir Karl Popper (Abb. 4 und 17).

Aus den Akten zur Errichtung des Denkmals für Wilhelm Dantine, die an der Fakultät für evangelische Theologie vorhanden sind ${ }^{24}$, geht hervor, dass der Bildhauer Josef Zenzmaier (* 1933) auf Vorschlag des Dekans Prof. Gottfried Adam von Rektor Georg Winckler direkt mit der Herstellung der Büste beauftragt worden ist. In dem Schreiben vom 2. Juli 200 I wird Zenzmaier um einen Kostenvoranschlag gebeten und gefragt, ob die Büste bis zum Oktober fertig sein kann. Mitte August teilte Zenzmaier mit, dass er

24 Prof. Rudolf Leeb hat mir die Akten zugänglich gemacht, wofür ich ihm herzlich danke. 
mit Prof. Adam und Hofrat Dr. Mühlberger einen Standort ausgesucht habe, und erklärte sich bereit, die Bronzebüste samt Sockel für I45.000 Schilling ( $€$ IO.0oo) bis Ende Oktober fertigzustellen. Ein Modell wurde nicht gefordert, aber vereinbart, dass der Bildhauer vorab eine Zeichnung liefere. Beratend wurde der Architekt Prof. Wilfried Posch von der Kunstuniversität Linz hinzugezogen, der in einer Besprechung am 5. September 200I darauf hinwies, „dass der Kreis der in Frage kommenden Künstler, die eine für den Arkadenhof der Univ. Wien passende Büste anfertigen würden, ein sehr beschränkter ist."

Zenzmaier, ein bekannter österreichischer Bildhauer, hatte bereits einige Porträtplastiken geschaffen, unter anderem für Stefan Zweig, Clemens Holzmeister und Erwin Ringel. ${ }^{25}$ In einem Interview berichtete der damalige Senatsvorsitzende Prof. Hoyer, dass bei der Denkmalenthüllung die Enttäuschung vieler Anwesender zu spüren war. ${ }^{26}$ Offenbar wurden die Erwartungen, die in dieses Denkmal gesetzt wurden, nicht erfüllt. Wenn wir nun die drei Kriterien Wiedererkennbarkeit, Angemessenheit und künstlerischer Ausdruck auf dieses Denkmal anwenden, dann überwiegt ganz eindeutig der künstlerische Ausdruck. Im Grunde lieferte Zenzmaier nichts anderes als eine sehr persönlich geprägte Interpretation seines bruchstückhaften Wissens über den Dargestellten. Dies wird an einer Anekdote deutlich, die Prof. Hoyer mit launigen Worten erzählte und die ich frei wiedergebe. Auf seine Frage, warum Dantine so große Ohren bekommen habe, antwortete der Künstler, weil ihm immer wieder gesagt wurde, dass Dantine ein besonders guter Zuhörer war.

Ich will nicht verschweigen, dass mein erster Eindruck von diesem Denkmal nicht zweifellos gut war. Ich empfand es aufgrund der geradezu respektlosen Gestaltung als nicht angemessen.
Je länger aber die Auseinandersetzung mit diesem Denkmal dauert, umso größer wird meine Zustimmung, auch wenn hinsichtlich der drei genannten Kriterien der an die Entstehungszeit gebundene künstlerische Ausdruck stark in den Vordergrund gerückt ist. Die Porträtbüste wird dadurch jedoch in weit größerem Maß als üblich zu einem eigenständigen Kunstwerk und kann damit den oft empfundenen Mangel an Authentizität bei posthum entstandenen Porträtbüsten überspielen.

Die offen oder versteckt vorgetragene Kritik an den zuletzt aufgestellten Büsten und die Zweifel an der Richtigkeit dieser Form der Würdigung wissenschaftlicher Leistungen war wohl so groß, dass Rektor und Senat im Jahr 2009 den Entschluss gefasst haben, die traditionelle Gelehrtenehrung mit Denkmälern im Arkadenhof zu beenden. Unter ganz anderen Vorzeichen, nämlich im Hinblick auf die Gleichbehandlung beider Geschlechter, knüpft die Universität Wien jedoch wieder an diese alte Form der Gelehrtenehrung an, indem sie im Rahmen des 650-jährigen Jubiläums die Entscheidung getroffen hat, die Musealisierung des Arkadenhofes aufzuheben und einen Wettbewerb unter den österreichischen BildhauerInnen auszuschreiben, um endlich mit der seit Langem geforderten Ehrung von Wissenschaftlerinnen zu beginnen.

Abbildungsnachweis: Abb. I, I2: Wikipedia; Abb. 2, 6: Sammlung Engel; Abb. 3, 13, I6: Öffentlichkeitsarbeit Universität Wien, Foto: Franz Pfluegl; Abb. 3, 4, 8, 9, ıо, II, I2, I3, I6: Fotostudio F. Pflügl; Abb. 7: Institut für Kunstgeschichte der Univ. Wien, R. Steyer/A. Plankensteiner, 20I4; Abb. 15: Institut für Kunstgeschichte der Univ. Wien, R. Steyer/A. Plankensteiner, 20I4; Abb. I7: Institut für Kunstgeschichte der Univ. Wien, K. Pani, 20I4; Abb. 5: Estate of Oscar Nemon; Abb. 8: Österreichische Nationalbibliothek; Abb. I4: Österreichische Nationalbank.

25 Josef Zenzmaier. Zum 70. Geburtstag, (Ausstellungskatalog hrsg. vom Salzburger Museum Carolino Augusteum), Salzburg 2003.

26 Interview mit Prof. Jörg Hoyer am 2. Sept. 2014. 


\title{
THE SALUTATI TOMB IN FIESOLE: ANIMATION, REPRESENTATION AND SCHOLARLY MEMORIA
}

\author{
Jeanette Kohl
}

\author{
And marble's language, Latin pure, discreet... ${ }^{1}$ \\ EX-ANTE: IMAGINATION / FRAGMENTATION
}

According to Pliny the Elder, the first portrait sculpture came into being under the impression of an impending loss. The Corinthian potter $\mathrm{Bu}-$ tades of Sikyon's daughter drew the silhouette of her lover, who was preparing to leave, on the wall. Butades, who was touched by his daughter's grief, modeled upon this outline the boy's portrait in clay, which he then fired in the oven along with the tiles he made for a living. ${ }^{2}$ This well-known Urszene of portraiture is motivated by the impulse to compensate for an anticipated absence by means of a bodily likeness, a medium of Fernanwesenheit ${ }^{3}$, which fills the silhouette on the wall with three-dimensional materiality. Love, loss, and the desire for a bodily praesentia in absentia thus mark the beginnings of mimetic sculpture. The ersatz body, however, is by nature deficient. The image and its physical presence implicate the absence of the sitter and thus its own illusion. As a medium of memory, the sculpted portrait is also a matrix of oblivion.

The substitution of absence in the image of a bust portrait, an art form that traditionally served as a medium of memory-generating presence, goes along with another deficit - that of bodily integrity. Busts are reductions in form and shape of the human sitter, and as such they are visual synecdoche: the isolated part implies the entirety of a human being. As 'intentional fragments', bust portraits are characterized by a gap, a vacancy in the spot where the body should be, making our perception of such objects an oscillating act between utter familiarity (with the 'human head') and discomfiture (with the lack of 'body'), touching upon both the illusion of presence and the distance of memoria, authenticity and artifice. ${ }^{4}$ Their essentially ambivalent position between representation and presentification, deadness and artistic vivification, rigid limitation (as fragments) and challenging imita-

I R. Browning, The Bishop Orders his Tomb, verse 98, cit. The Poems of Browning. Volume Two: I84I-I846 (ed. J. WOOLFord/D. Karlin), New York I99I, p. 270.

2 N. Suthor, Caius Plinius Secundus d.Ä.: Trauerarbeit/Schatten an der Wand, in: Porträt (ed. Rudolf PreimesBerger/Hannah Baader/Nicola Suthor), Berlin 1999, pp. II7-I26.

3 Thomas Macho defines faces as 'Medien der Fernanwesenheit' in the digital age, in reference to a term by Manfred Fassler. T. Масно, Das prominente Gesicht. Notizen zur Politisierung der Sichtbarkeit, in: Politische Inszenierungen im 20. Jahrhundert. Zur Sinnlichkeit der Macht (ed. S. R. Arnold/C. Fuhrmeister/D. Schiller), Vienna I998, p. I72.

4 For the typology and materiality of bust portraits and the viewer-object relation see J. KoHL, Sichtbar sein. Materialität und Facialität frühneuzeitlicher Porträts, in: Trajekte I7 (Zeitschrift des Zentrums für Literatur- und Kultur- 
tion makes them rather puzzling objects with a strong physical and psychological appeal to the beholder. Busts are memorials and mementos per se - 'Denkmäler in des Wortes eigentlichster Bedeutung' (Burger 1904) - confronting us with faces and heads of the past, activating our response en face.

To the beholder, busts intuitively represent a state of being 'undead': 'Tu vivi e in te non puo la morte', you live and death can do no harm to you, as the paradox is addressed concisely in Antonio Tebaldeo's cycle of sonnets on a female marble bust of ca. I493.5 By substituting human transience with more durable materials, busts are placeholders between life and death, heads representing spiritedness, achievements, beauty, social standing, intellect, and virtues in the monadic seclusion of fragmented torsos. The rigorous cut, perhaps most pronounced in the multitude of Quattrocento busts divided horizontally at chest height, leaves behind all the formidable movability of the human body in favor of a rigidly defined immobile body-box. And the more minutely lifelike the artistic rendering of face and poise, the more alien and irritating is its state of bodily incompleteness. We understand that it is an artwork hinting at the entire person, yet we cannot help being puzzled by its obvious reduction. ${ }^{6}$ This irritation is essentially motivated by the bust's bodily presence as opposed to painted portraits. Beholder and bust share the same space, the same 'reality' (even though they might be a millennium apart). The divided body image of a bust portrait seems to have a life of its own, yet it is not responsive. The representation of all that defines the exceptional human being in the sculptural pars pro toto of his 'upper half' throws us back onto ourselves and our imagination in completing the image of the totus homo. The intentionally chosen fragment, at least in the case of Renaissance busts, references man's integrity and relies upon the observer's imagination to complete the picture. What is mute, immobile, controlled, clearly contoured, cut and incomplete in the realm of the Renaissance's prevailing 'aesthetics of effect' (Wirkungsästhetik) generates more effectively than any other form of art the liveliness, presence, and much lauded, quasibreathing presence of the individual. ${ }^{7}$

forschung: Ausdruck. Erscheinung. Affekte) IO, 2008, pp. I7-24; J. KoHL, Gesichter machen. Büste und Maske im Florentiner Quattrocento, in: Marburger Jahrbuch für Kunstwissenschaft 34, 2007, pp. 77-IOO; J. KoHL, Talking Heads. Reflexionen zu einer Phänomenologie der Büste, in: Kopf/Bild. Die Büste in Mittelalter und Früher Neuzeit (ed. J. Kohl/ R. MüLler), Munich/Berlin 2007, pp. 9-30.

5 A. Tebaldeo, Rime, Bd. 2, Teil I, Rime della vulgata (ed. T. Basile), Modena I992, p. 358, sonnet 226.

6 Irving Lavin discusses the essential difference between antique and Renaissance bust portraits. While the marble and stone objects from Roman antiquity are usually conceived as self-contained formal entities designed for frontal viewing and mounted on a pedestal to emphasize their status as representative artworks, the vast majority of Renaissance busts from the Quattrocento are more pronouncedly three-dimensional bodily objects whose 'unartful fragmentation' - as if amputated below the shoulders - hints at the absent body and thus at the entire person (totus homo). I. LaVIn, On the Sources and Meaning of the Renaissance Portrait Bust, in: The Art Quarterly XXXIII, no. 3, I970, pp. 207-226.

7 The paradoxical effort of capturing the dynamics of the living human body in the static medium of an image has, since antiquity, also been understood along the lines of techniques of memorization. The immobile image serves as an incentive for mechanisms of 'enlivenment' in the beholders imagination. Cicero's advice in the Rhetorica ad Herennium points to the usefulness of imagines agentes - unusual, eye-catching images with the potential for agency, which create a presence by hinting at what is absent. Cicero, Rhetorica ad Herennium, III, 22, 37, see also P. MatusSEK, Bewegte und Bewegende Bilder. Animationstechniken im historischen Vergleich, in: Kunst der Bewegung. Kinästhetische Wahrnehmung und Probehandeln in Virtuellen Welten (ed. C. Lechtermann/C. Morsch/H. WENZEL), Bern 2004, pp. I-I3. 


\section{SINGULARITY / INTEGRATION}

While bust portraits clearly celebrate the transient individual in an enduring form, they have also since Roman antiquity been exponents of ancient lineage and genealogy. Individuality and homogeneity of family representation were closely intertwined, in particular in Republican Rome and again in the Renaissance, both periods in which galleries of busts were common. ${ }^{8}$ Series of busts portraying eminent thinkers of the past and present came fully in vogue in the eighteenth century, with ambitious projects such as the commission of twenty-six marble busts for Trinity College in Cambridge, of which ten were executed by Roubiliac between I75I and $1766 .{ }^{9}$ The Vienna University's Arkadenhof with its 150 monuments to illustrious scholars and thinkers of the late nineteenth century marks an ambitious peak in the development of such galleries of bust portraits of famous men (and quite rarely, women) as far as their number is concerned, but also in their variety of types. ${ }^{\text {Io }}$ Based on ideas not unlike those of painted galleries of uomini illustri and donne famose, so popular in palazzi, residences and town halls all over Europe since the fourteenth century, the gallery display of series of busts (in the case of Vienna, a pantheon of eminent scholars) harks back to the warp and weft of early modern ruler representation - emperors, princes, mercenaries and wealthy merchants who would integrate themselves and their fabricated biographies into the mythological tex- ture of the ancient epics of superheroes. Fictitious genealogies, like the descent from Romulus and Remus, Hercules, Caesar, and Alexander the Great, were an integral part of early modern ruler iconography and biography. Genealogy here was no longer bound to consanguinity, instead it developed into a cultural order, one that was not genetically but generically determined. Merit and fame brought about by virtuous accomplishment became the core ingredient for the male elite's right to participate in fabricated lineages. The idea of distinct individual fame (a thought pattern rooted in 'vertical' ideologies of individuals surpassing each other in history) joins the concept of meritocratic genealogies (the horizontal idea of lineage) in galleries of famous men. These 'synthetic' rather than genetic lineages, before the eighteenth century mainly instrumentalized in political iconography, find their more modern and 'enlightened' counterparts in the galleries of scholars, artists and authors. They are hybrid attempts in evoking a homogeneity of the intellect, much of which is owed to the firm belief in the concept of the 'genius' so deeply rooted in Western cultures.

Scholarly memoria - Gelehrtenmemoria - has always had many faces: from author's images in manuscripts and prints to the act of writing proper (if understood as an inscription into the collective memory of cultures); as well as from the portrait bust as part of intellectual galleries to

8 See, among others, G. LAHusEn: Zur Funktion und Rezeption des römischen Ahnenbildes, in: Mitteilungen des deutschen archäologischen Instituts, Römische Abteilung (Römische Mitteilungen) 92, I985, pp. 26I-289; H. FLower, Ancestor Masks and Aristocratic Power in Roman Culture, New York 1996.

9 For an excellent and comprehensive overview of bust portraiture in eighteenth century England see M. BAKER, The Marble Index. Roubiliac and Sculpted Portraiture in Eighteenth-Century Britain, New Haven 20I4, here for the representation of groups pp. 277-317.

io T. Meisel, Gelehrte in Stein und Bronze. Die Denkmäler im Arkadenhof der Universität Wien, Vienna 2007. See also the activities of the group of art historians under I. Schemper-Sparholz at Vienna University and their research projects on the Vienna monuments. For a conference review of 'Scholar's Monuments: Historical Meaning and Cultural Significance' see https://www.academia.edu/9738439/Review_Scholars_Monuments._Historical_ Meaning_and_Cultural_Significance (last accessed March I6, 2015). 
the singular image of the deceased on his tomb. At times these forms mix, as in the case of bust portraits on sepulchral monuments. One such case will be the focus of the following investigation.

\section{SIMILE AL VIVO QUANTO SIA POSSIBILE: A SCHOLAR'S TOMB AS 'THINK SPACE'}

In his major publication on the history of Italian tomb monuments, Fritz Burger's Die Geschichte des Florentinischen Grabmals of 1904, the author emphasizes the key position of the monument to Leonardo Salutati in the Fiesole Cathedral (Fig. I): For the first time ever in the Renaissance, Burger states, a tomb monument appears as 'Denkmal in des Wortes eigentlichster Bedeutung', as a memorial in the truest sense of the word. ${ }^{1}$ Denkmal literally translated means as much as: a monument to think about - and a place that is both one of remembrance and one to remember. Burger's brief observation about the Salutati monument as a think-space, uttered more than a century ago, provides a keynote for the following short case study, which presents some new suggestions on the Salutati Chapel's iconography and reevaluates the remarkable tomb's visual strategies in engaging the beholder; it does so in an intriguingly innovative way, using the aesthetics and the appeal of bust portraiture to 'produce' and 'perform' the perpetual memoria of an eminent cleric and scholar.

Surprisingly, the Salutati tomb - unique and aesthetically appealing as it is - is not discussed in most standard publications on tomb monuments. ${ }^{12}$ It is briefly mentioned in a few

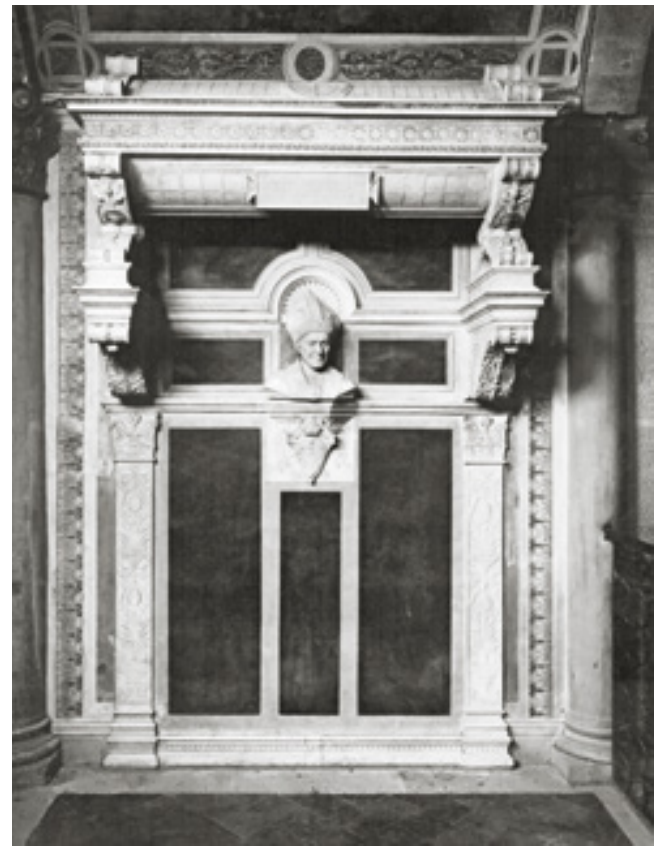

Fig. I: Mino da Fiesole, Tomb monument for Leonardo Salutati, I464-I466, marble, Cathedral San Romolo, Fiesole.

publications dedicated to its sculptor, Mino da Fiesole, where it is generally characterized as a problem case with an obscure iconography. ${ }^{13}$ Part of the reason for this lack of attention might be its somewhat remote place in the

II F. Burger, Geschichte des florentinischen Grabmals von den ältesten Zeiten bis Michelangelo, Strassburg I904, p. 217. Despite a multitude of publications on individual tombs, there is no more recent comprehensive publication dedicated to Renaissance tomb monuments in Florence.

I2 It is briefly mentioned in P. Schubring, Die italienische Plastik des Quattrocento, Berlin I9I9, p. I63 and in J. Poeschke, Die Skulptur der Renaissance in Italian, vol. I: Donatello und seine Zeit, Munich 1990, p. I43. J. PopeHennessy in his canonical volume Italian Renaissance Sculpture, London 1958, discusses in his chapter on The Humanist Tomb the monuments to Benozzo Federighi and Margrave Hugo - both by Mino da Fiesole - but does not mention the Salutati tomb. The same applies for more recent publications, which discuss Renaissance tombs, such as J. T. Paoletti/G. M. Radke, Art in Renaissance Italy, London 1997.

I3 It is briefly discussed in G.C. Sciolla, La scultura di Mino da Fiesole, Turin 1970, and in S. E. Zuraw, The Sculp- 


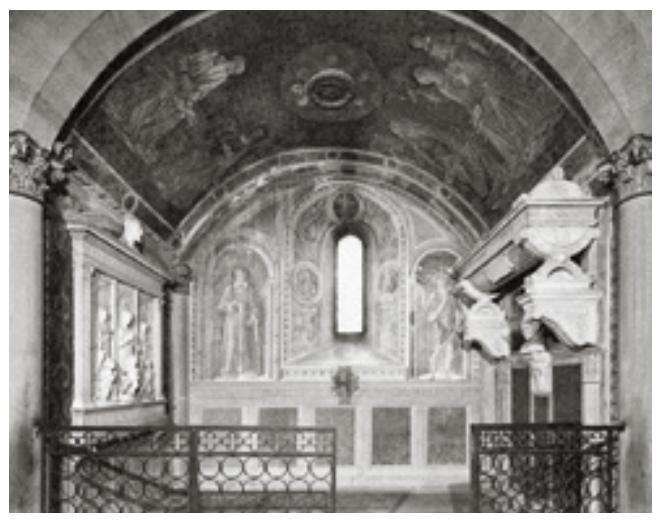

Fig. 2: Cosimo Rosselli (fresco paintings) and Mino da Fiesole (altarpiece and tomb), chapel of Leonardo Salutati, Bishop of Fiesole, Cathedral San Romolo, Fiesole.

cathedral of Fiesole just outside of Florence. Yet the monument also raises a set of intricate problems related to its rather unconventional form and iconography, in particular in its interplay between tomb and marble altarpiece in the same chapel (Fig. 2). ${ }^{\mathrm{I}} \mathrm{A}$ thorough analysis of the Salutati monument is further hindered by a scarcity of sources. In the following, I will introduce several suggestions about the largely unprecedented form of the monument, the way in which it engages with the visitor and beholder, and about the iconography of the mar- ble altarpiece, which has not been interpreted conclusively at all.

The Salutati tomb's innovative design and nonstandard iconography, its intelligent use of spatial relations and the way in which the newly discovered agency of bust portraiture all'antica is turned into its key feature, form an elaborate statement of Leonardo Salutati's selfconception as an eminent humanist and bishop. They build on a particular set of religious ideals, which help us identify and understand the Salutati tomb as one of the most remarkable and stunning - albeit overlooked - monuments in the history of Renaissance art and a true scholar's monument.

The chapel's commissioner, Leonardo Salutati, hailed from an important Florentine family whose brightest star was his famous grandfather, Florentine chancellor and notary Coluccio Salutati (I33I-I406). ${ }^{\text {Is }}$ Coluccio, an avid collector of ancient book manuscripts and the undisputed protagonist of early humanism in Florence, was one of the most influential thinkers of the Trecento. ${ }^{16}$ His grandson Leonardo, born in or around I400, was raised in this climate of humanist intellectual curiosity and the spirit of Renaissance political pragmatism his

ture of Mino da Fiesole, New York 1993. Zuraw states: 'The most inexplicable part of the Salutati chapel is the tomb itself', p. 24I. Older publications, such as D. Angeli, Mino da Fiesole, Florence igos and H. Lange, Mino da Fiesole. Ein Beitrag zur Geschichte der florentinischen und römischen Plastik des Quattrocento, Munich I928, emphasize the tomb's extraordinary sculptural and artistic quality, the highly innovative ornamentation and the striking presence of its portrait bust. It is all the more puzzling that there is not one single article dedicated to the monument among the many publications on tomb sculpture from the I980s onward.

I4 It poses questions similar to those raised by the monument and chapel to the cardinal of Portugal in San Miniato al Monte in Florence, a much better known church than the Fiesole cathedral. The Salutati Chapel's altarpiece has been subject to several attempts in identifying its iconography, all of which are not satisfactory. It has never been analysed as part of the chapel or in relation to the tomb. See Angeli, Mino da Fiesole (cit. n. I3); Lange, Mino da Fiesole (cit. n. 13); Sciolla, La scultura di Mino da Fiesole (cit. n. I3); Zuraw, The Sculpture of Mino da Fiesole (cit. n. I3), pp. 232-273, 78I-800.

I5 Leonardo's father, Coluccio's son, was Francesco Salutati. For Coluccio see 'Coluccio di Pierio di Salutati' in: Catholic Encyclopedia, New York 1913, vol. 13, http://en.wikisource.org/wiki/Catholic_Encyclopedia_(I913)/Coluccio_ di_Pierio_di_Salutati (last accessed on March 6, 20I5). For the family history see also the comments by G. MAZzUChelli in F. Villani, Le Vite d'Uomini Illustri Fiorentini, Florence I847, pp. 74-79 (vita di Coluccio Salutati).

i6 R. Witt, In the Footsteps of the Ancients: The Origins of Humanism from Lovato to Bruni, Boston 200o, pp. 292-337. Coluccio is one of the protagonists in S. Greenblatt's Pulitzer Prize-winning The Swerve. How the World Became Modern, New York 20II. 
grandfather had cultivated. ${ }^{17}$ Although we do not know much about his life and he would never become the political heavyweight his grandfather had been, Leonardo was a highly successful notary and an influential cleric both in Rome and in Florence.$^{18} \mathrm{He}$ became canon of the Florence bishopric in 1438 and served as chierico di camera under Pope Eugene IV in Rome. ${ }^{19}$ In I450, during the papacy of Nicholas $\mathrm{V}$, he was consecrated Bishop of Fiesole. In I462, Leonardo purchased the chapel in the nave of the Fiesole cathedral and made provisions for a tomb monument and altar to be built in the chapel, which is dedicated to his namesake, San Leonardo. ${ }^{20}$ Mino da Fiesole, who had just returned from Rome to Florence in I464, was given the commission. Both the tomb monument and the chapel's altarpiece were practically finished when Salutati died on November 17, I466. ${ }^{21}$

The Salutati monument was executed during the heyday of ambitious commissions for tombs of eminent Florentine humanists and city officials. It dates from shortly after the monuments to Leonardo Bruni (I45O, by Bernardo Rossellini) and Carlo Marsuppini (I453-I455, by Desiderio da Settignano) in Santa Croce, and before Mino's tombs in the Badia Fiorentina: the Giugni monument of $1466-68$ and the tomb for Margrave Hugo of I47I-8I. ${ }^{22}$ Construction on the famous and no less innovative chapel and monument to the cardinal of Portugal in San Miniato al Monte (I460-68) was well underway after the young cardinal's untimely death in August of I459. ${ }^{23}$

While Mino's reception of the important monuments to Bruni and Marsuppini is quite evident in his Badia tombs, the Salutati monument sets an entirely new tone. ${ }^{24}$ It does not follow the predominant type of mid-century tombs with a framing triumphal arch suggesting a niche. ${ }^{25}$ Instead it reinterprets the more traditional type of the sepolcro in aria popular in the Trecento and combines it with the rath-

I7 As the Encyclopedia Brittanica, http://www.britannica.com/EBchecked/topic/519977/Coluccio-Salutati (last accessed March 6, 20I5), has it, Coluccio's 'Latin letters to other states were so effective that the tyrannical Duke of Milan, one of the targets of his scorn, said that a thousand Florentine horsemen were less damaging than Salutati's epistles.'

I8 G. Ansaldi, Cenni biografici die personaggi illustri della città di Pescia e suoi dintorni, Pescia I872, pp. 249-255. Archivio Biografico Italiano, F. 877, pp. 249-255. See also L. Martines, The Social World of the Florentine Humanists, 1390-I460, Toronto 20II, p. I49.

I9 S. SAlvini, Catalogo Cronologico de 'Canonici della Chiesa Metropolitana Fiorentina, Florence I782, p. 40.

20 The earliest extant document in relation to the chapel is dated February 26, I462. See A.M. BANDINI, Lettere XII. Della Città di Fiesole e suoi Contorni, Siena I80o, p. I79. n. I2: 'Per rogito di Ser Andrea Die a di 26. Febbraio I462 Mons. Salutati dota la Capella di S. Leonardo posta nella Cattedrale di Fiesole (...).' Zuraw, The Sculpture of Mino da Fiesole (cit. n. 13), p. 783 mentions that the document is still in the archives of the Fiesole cathedral.

2I For date and chronology see in parricular F. Caglioti, Mino da Fiesole, Mino del Reame, Mino da Montemignaio: un caso chiarito di sdoppiamento di identità artistica, in: Bolletino d'Arte 76, no. 67, I991, p. 23 and n. 29. Leonardo bequeathed the chapel to his nephew Benedetto and his male descendants, and should the line become extinct, to the Florentine Arte di Cambio; see ibid.

22 S. Zuraw, The Public Commemorative Monument: Mino da Fiesole’s Tombs in the Florentine Badia, in: Art Bulletin 80, 1998, pp. 452-477.

23 L. A. Косн, The Early Christian Revival at S. Miniato al Monte: The Cardinal of Portugal Chapel, in: Art Bulletin 78, 1996, pp. 527-555; M. Hansmann, Die Kapelle des Kardinals von Portugal in S. Miniato al Monte. Ein dynastisches Grabmonument aus der Zeit Piero de’Medicis, in: Piero de’Medici 'il Gottoso' (I4I6-69). Kunst im Dienste der Mediceer (ed. A.Beyer/ B. Boucher), Berlin I993, pp. 29I-3i6; F. Hartt, The Chapel of the Cardinal of Portugal, I434-I459, at San Miniato in Florence, Philadelphia 1964.

24 The tomb's unusual type is briefly mentioned in Angeli, Mino da Fiesole (cit. n. 13), p. II4; see also Lange, Mino da Fiesole (cit. n. I3), pp. 8-I4, who emphasizes 'wie weit sich Mino von den Grabmaltypen seiner Zeit emanzipiert', ibid, p. Io.

25 Different types of wall-mounted tombs are discussed in Burger, Geschichte des florentinischen Grabmals (cit. n. II), in particular pp. 59-80 for sarcophagi on corbels. 


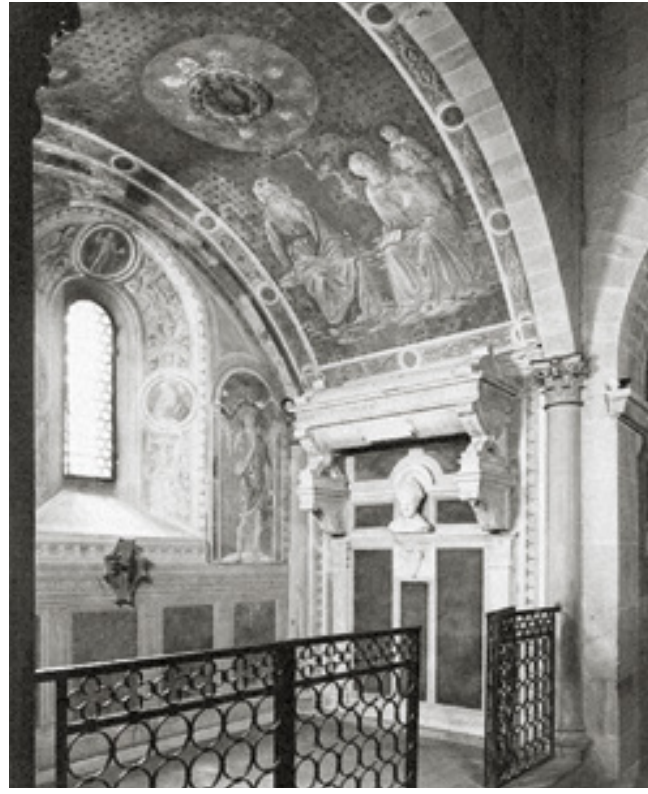

Fig. 3: Cosimo Rosselli (fresco paintings) and Mino da Fiesole (altarpiece and tomb), view of the Salutati Chapel toward the tomb, Cathedral San Romolo, Fiesole.

er novel feature of a lifelike bust portrait on a tomb (Fig. I). ${ }^{26}$ While the lower part with its three vertical red markers is set completely flat against the wall, the monument's upper register is decidedly sculptural and voluminous, with its protruding consoles and the elegant, classicizing sarcophagus on top (Fig. 3). ${ }^{27}$ The sarcophagus in aria creates a baldacchino of sorts, with the bishop's elevated corpse projected into the chapel space. ${ }^{28}$ Salutati's coat of arms in marble is set well visible against the shorter red middle

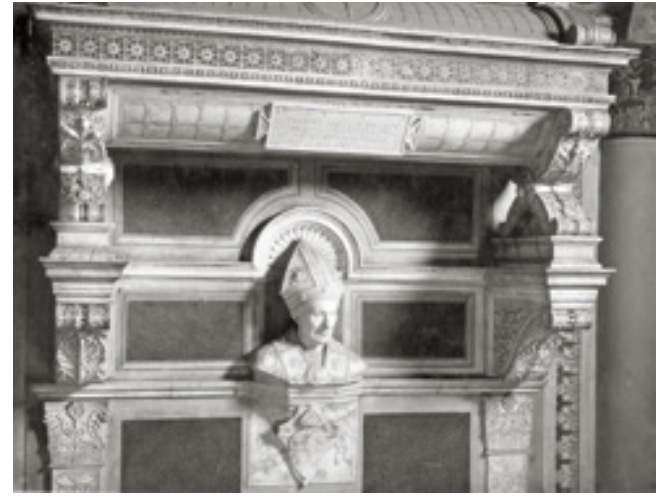

Fig. 4: Mino da Fiesole, Salutati tomb (detail): bust, coat of arms, sarcophagus with inscription.

marker. On top of it sits the bishop's remarkable portrait bust (Fig. 4). There is a simple tabula ansata in the centre of the sarcophagus' lower tub, bearing the inscription: OSSA LEONARDUS SALUTATUS CIVILIS PONTIFICII QS (OLIM) IURIS CONSU(L)TUS EP(ISCOP) US QS (OLIM) FESU(LANUS) VIVENS SIBI POSUIT, VALE LECTOR ET ME PRECIBUS ADIUVA. MCCCLXVI, which translates as, 'Here rest the bones of Leonardo Salutati, former Bishop of Fiesole, learned in canon and civil law, who had this erected for himself while still alive. Farewell reader, and may your prayers help me. I466.' Salutati also emphasizes his status as 'iuris consultus' on the altarpiece on the opposite side of the chapel facing the tomb, where we read: LEONARDUS DE SALUTATIS EP(ISCOPU)S FESULANUS IURIS CONSULTUS. ${ }^{29}$

26 Portrait busts on different types of tombs turn into a genuine fashion from the sixteenth century onwards. For an overview see A. Grisebach: Römische Porträtbüsten der Gegenreformation, Leipzig 1936. While Grisebach dates the beginning of this trend to the Quattrocento he does not mention the Salutati tomb.

27 In terms of its aesthetic qualities and its emphasis on the flat wall against which an elevated antique-like sarcophagus is mounted on corbels, the Salutati tomb compares perhaps best to the tomb for Orlando de'Medici in SS. Annunziata and to the much lesser known tomb for Antonio degli Agli in S. Maria dell'Impruneta. U. MidDELDORF, A Forgotten Florentine Tomb of the Quattrocento, in: Raccolta di Scritti, that is Collected Writings, vol. III: 1974-I979, Florence 198I, pp. 69-74 and fig. 70; for the Orlando Medici tomb (I456-58) see A. Markham Schulz, The Sculpture of Bernardo Rosselino and his Workshop, Princeton 1977, p. I26.

28 The sarcophagus measures $2.097 \mathrm{~m}$ in length and $0.792 \mathrm{~m}$ in height. See O. H. Giglioli. Catalogo delle cose d'arte e di antichità d'Italia - Fiesole, Rome 1933, pp. I28s, and Sciolla, La scultura di Mino da Fiesole (cit. n. I3), p. 63.

29 The double mention in both inscriptions is certainly a conscious choice, and it indicates the importance of his 


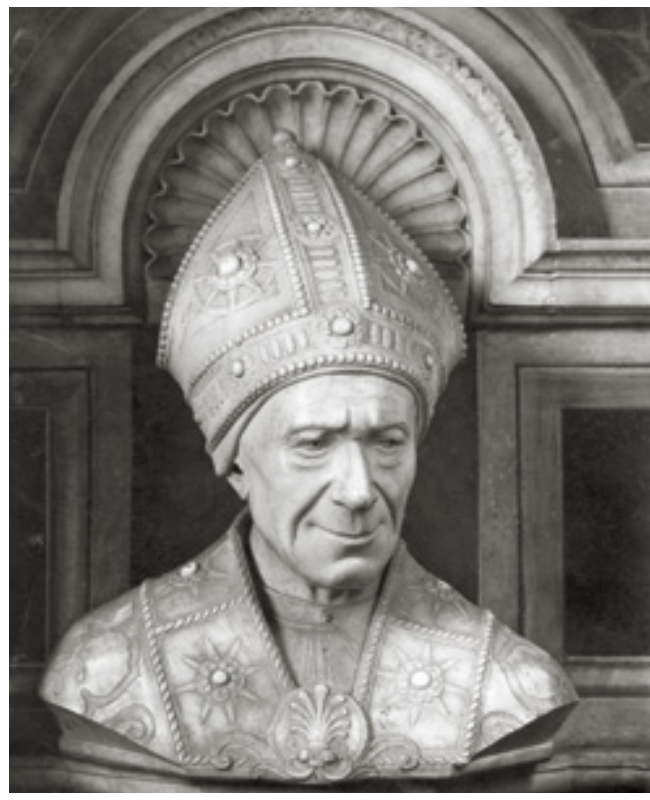

Fig. 5: Mino da Fiesole, Salutati tomb (detail): portrait bust (1464-I466), marble.
Coat of arms, bust and inscription are in the monument's central axis. They form three distinguished and significant components, all of which evoke the deceased's presence in different ways. The bust is clearly staged as the centrepiece of the entire composition. ${ }^{30}$ It is a sculptural masterpiece, creating a vibrant presence of the bishop that is lifelike yet not overly veristic, the iconic portrait of a man of moderation and contemplation..$^{31}$ Mino, whose fame is largely based on his production of trendsetting portrait busts, fully displays his remarkable artistic talent with the bust of Salutati. In turning the bishop's head slightly to one side, the artist succeeds in creating a vivid impression of the humanist and scholar, infusing life into the somewhat rigid and fragmentary nature of bust portraits (Fig. 5)..$^{32}$ The bust's pupils are marked by drill holes, an antique feature which helps to direct the bust's line of sight towards those who enter the chapel; the bishop pensively greets the visitors. With what

education in canon and civil law. His grandfather Coluccio is the author of a famous treatise, De nobilitate legum et medicinae, in which he discusses the primacy of jurisprudence over medicine. He understands jurisprudence as part of the more intellectually oriented 'humanities', actively creating its subjects of inquiry, whereas medicine is merely empirical. Coluccio's humanistic concept favours jurisprudence, and those who practise it possess ethical and moral authority. See in particular the preface by E. KessLer in: Coluccio Salutati. Vom Vorrang der Jurisprudenz oder der Medizin / De nobilitate legum et medicinae (Latin-German ed., translation and commentary by P. M. SCHENKEL), Munich I990, vol. 25, pp. VII-XXV.

30 Burger, Geschichte des florentinischen Grabmals (cit. n. II), p. 217 keenly observes that the entire tomb architecture serves one main purpose, which is to provide a monumental frame for the life-size bust of the deceased staged in its centre.

3I If compared to the busts of the famous Florentine physician Giovanni Chellini (of I456 by Antonio Rosselino) and Pietro Mellini (of 1474 by Benedetto da Maiano), the difference in concept becomes evident. The busts of Chellini and Mellini are naturalistic to the point where beard stubble, moles and even the pores of the skin are made visible. Chellini's bust is most certainly sculpted after a life mask. Like Leonardo Salutati's bust, it bears an inscription (albeit hidden within the bust's hollow base) hinting at the sitter's profession: MAGisteR IOHANES MAGistRI. ANTONII DE SancTO MINIATE DOCTOR ARTIVM ET MEDICINE. MCCCCLVI. The two objects' painstaking lifelikeness contrasts with the smoother liveliness of the bishop's portrait. For the Chellini bust see R. LiGHTBOwN, Il busto di Giovanni Chellini al Museo Victoria \& Albert di Londra, in: Bollettino dell'Accademia degli Euteleti 26, 1962/63, pp. 13-24; for Mellini see D. CARL, Benedetto da Maiano. A Florentine Sculptor at the Threshold of the High Renaissance, Turnhout 2005, 2 vols., vol. I, pp. I78-82.

32 M. Marek, 'Virtus' und 'fama'. Zur Stilproblematik der Porträtbüsten, in: Piero de'Medici 'il Gottoso' (I4I6-69) (ed. A. Beyer/B. Boucher), Berlin 1993, pp. 34I-368. Marek points out that Mino sets a new standard with the bust in that it is not ostentatiously veristic and rather creates a psychological realism, 'ein Extrakt jener Züge und Eigenschaften der Persönlichkeit', which is so important for individual memoria. Poise, pathognomy and the directed look represent the deceased's virtus in a highly lifelike manner. 
one might call 'restrained naturalism', Mino emphasizes the horizontal furrows on the forehead, the pronounced cheekbones and characteristic naso-labial folds. The bust is one of the most remarkable sculpted portraits of Renaissance art. ${ }^{33}$ Vasari, who is the first to mention the bust, praises the heightened degree of skillful realism in the service of commemorative presentification: Mino lo ritrasse in pontificale, simile al vivo quanto sia possibile. ${ }^{34}$ In a conceptual twist, the traditional personifications of the virtues so common on Quattocento tomb monuments are given up in favour of a focus on the bishop's presence in a sculpted portrait: It is the bust itself that demonstrates inner virtue and wisdom as they manifest on the bishop's face. This is indeed the first sculpted portrait of a Renaissance humanist in the true sense of the word. Mino responds to the artistic challenge of rendering visible 'personality' and inner qualities in a block of marble by drawing forth (pro-trahere) a person's character from underneath the surface of their appearance. ${ }^{35}$

The sparse use of common allegorical iconography on the tomb directs the observer's attention to the bishop's portrait, which is further accentuated by the way in which the bust is framed, sheltered by strong, beautifully carved consoles and set into a system of horizontal and vertical moldings and markers on the back wall (Fig. I). Placed against a geometric composition reminiscent of a diagrammatic abbreviation of the human figure with outstretched arms, it ap-

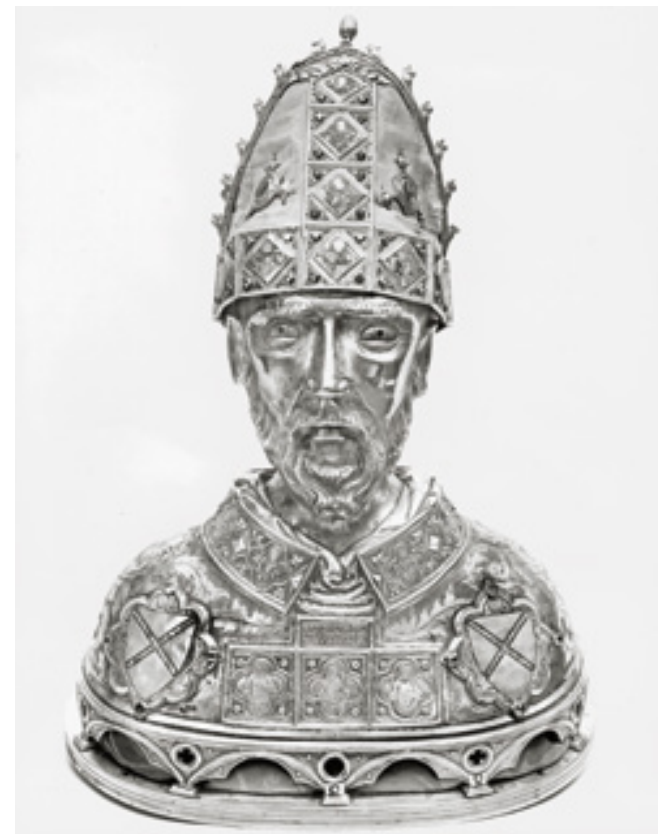

Fig. 6: Andrea Arditi, Reliquary bust of San Zenobio, circa I33I, silver, Cathedral Santa Maria del Fiore, Florence.

pears that the tomb also makes a reference to the crucified Christ, bearing eucharistic and eschatological implications. The bust, a classical pars pro toto object, references antiquity particularly by its slightly angular cut at the bottom; yet it also refers to the totus homo and, by means of its geometrically structured backdrop, the complete human body. ${ }^{36}$

While a bishop's bust in an antique style and on a tomb monument would have been perceived as rather novel in the I460s in Fiesole,

33 The striking aesthetic qualities of the bust 'qui est parmi les plus belles de cette période' are emphasized by AngELI, Mino da Fiesole (cit. n. 13), p. 59.

34 '...e per questo gli fu allogato a fare nel vescovado di Fiesole, a una cappella vicina alla maggiore, a man dritta salendo, un'altra sepoltura per il Vescovo Lionardo Salutati, vescovo di detto luogo, nella quale egli lo ritrasse in pontificale, simile al vivo quanto sia possibile.' G. VAsari, Le Opere (ed. G. Milanesi), 9 vols., Florence 1906, vol. 3, p. I22, as part of the vita of Mino da Fiesole.

35 For different concepts of portraiture from its beginnings to thethe twentieth century see Porträt, I999 (cit. n. 2).

36 The term totus homo originates from Pauline anthropology and appears in the Italian Renaissance above all in Giannozzo Manetti's treatise De dignitate et excellentia hominis, where it is discussed in the context of the dichotomy of body and soul. It was first related to Renaissance portraiture by Lavin, On the Sources and Meaning of the Renaissance Portrait Bust (cit. n. 6), p. 208s. 
there are both earlier and contemporaneous examples of bishop's busts. It is safe to assume that the tradition of reliquary busts had a decisive impact on the development, 'resurrection' and boom of bust portraiture in the Quattrocento. ${ }^{37}$ Everyone in Florence was familiar, for example, with the reliquary bust of San Zenobius by Florentine goldsmith Andrea Arditi (Fig. 6). ${ }^{38}$ While most of these busts were still rather hieratic, with Donatello's San Rossore being an early exception in its pronounced lifelikeness, they were perceived and venerated as 'alive', active through their sheer presence as containers of holy body parts and particles. ${ }^{39}$ Salutati's bust is an agentive image along the lines of this well-established representational tradition, yet in a slightly modified way. Salutati's moral and intellectual authority is given presence through physical likeness in a character portrait masterly executed by Mino, who succeeds in producing and presenting the image of a Renaissance humanist. The reminiscences to both antiquity (in its form and material) and traditional religious image concepts (in that it is a bishop's bust with a mitre similar to Trecento and Quattrocento reliquaries of saintly bishops) reproduce and address in one single object the status of its sitter as a venerated humanist bishop. The fact that the bust was originally gilded in most of its ornamental parts (traces are still visible) must have additionally underlined its inherent reference to the bust reliquary tradition. Salutati was met with unusual veneration during his tenure in Fiesole - Bargilli reports 'un culto come Beato' ${ }^{\circ}$ - and his mitre served as a 'talismano miracoloso' after the bishop's death; ${ }^{41}$ it is kept in the cathedral's tesoro until today.

The direct address of the viewer in an epitaph is a rather common rhetorical strategy to be found on both ancient Latin and Greek tomb inscriptions. The stock phrase qui transis is found frequently, combined with the wish for commemoration and the peaceful rest of the mortal remains. ${ }^{42}$ The farewell to the passerby, sometimes as a combination of ave viator and vale lector, can also be found on several English and German tombs of the late Renaissance and Baroque periods. ${ }^{43}$ Unprecedented, at least to my knowledge, is the epitaph's address to the visitor in combination with a portrait bust. This smart combination of a sculpted portrait 'simile al vi-

37 Ibid. See also MareK, 'Virtus' und 'fama' (cit. n. 32), p. 346 and KoHL, Kopf/Bild (cit. n. 4), pp. 9-30.

38 The gilded silver reliquary of ${ }_{133 \mathrm{I}}$ is in the Museo dell'Opera di S. Maria del Fiore in Florence, see L'oreficeria nella Firenze del Quattrocento (exhibition catalogue), Florence 1977, pp. I76-I78; also G. WINTER, Zwischen Individualität und Idealität. Die Bildnisbüste. Studien zu Thema, Medium, Form und Entwicklungsgeschichte, Stuttgart 1985, pp. I05-IO7 and fig. 27; J. Poeschke, Donatello. Figur und Quadro, Munich I980, pp. 3Is. and n. 9I, p. IO4. For bust reliquaries and their perception see S. B. Montgomery, The Use and Perception of Reliquary Busts in the Later Middle Ages, Ann Arbor 1997 and C. HaHn, Speaking Reliquaries, in: Gesta 36, no. I, 1997, pp. 20-3I.

39 For the reliquary of San Rossore see J. Koнl, No one in particular. Donatello's San Rossore, in: Inventing Faces. Rhetorics of Portraiture Between Renaissance and Modernism (ed. M. Körte/S. Weppelman et AL.), Berlin 20I3, pp. 15-28. Donatello's remarkable bust reliquary of San Rossore (Museo San Matteo, Pisa) of I428 represents a transitional stage, mediating between the Trecento reliquary of San Zenobio and objects like the Salutati bust portrait. See again Winter, Zwischen Individualität und Idealität (cit. n. 38), p.Io9.

40 F. Bargilli, La Cattedrale di Fiesole, Florence i883, p. 67.

4 I O. H. Giglioli, La mitria del vescovo Leonardo Salutati nel Duomo di Fiesole, in: Rivista d'Arte 9, I9I6, p. 5.

42 See e.g. the examples in Rest Lightly: An Anthology of Latin and Greek Tomb Inscriptions (ed. P. J. SHORE), Wauconda/Illinois 1997, p. 42. In Ovid's epitaph, we find a combination of 'qui transis' - the call to the traveller passing by - with 'molliter ossa cubent' (may the bones rest softly) similar to that on Salutati's tomb. 
vo quanto sia possibile' with a learned address in Latin 're-activates' the bishop's presence in an unprecedented way. As we have seen, busts being allusive fragments generally evoke the presence of the entire person. In the case of the Salutati bust, which so clearly refers the beholder to bishop's reliquaries, we also find a distinct reference to the antique bust portrait in its slightly oblique lower cut between arms and body. This double coding produces a twofold effect of presence, visually and verbally: the presence of the bones (also referred to in one of the inscriptions) and the presence of the mind (underscored by the invitation for prayer and commemoration). The bust's formal reminiscence to antique commemorative and genealogic bust portraits also hints at Salutati's lineage, his family tradition and humanist background. And last but not least, the salutation VALE LECTOR ET ME PRECIBUS $A D I U V A$, brought forth by the living presence of the bust, denotes the speaker proper: 'Leonardus Salutatus'. His family name is literally inscribed into the monument's image concept and its commemorative function.

\section{A NOVEL QUATTROCENTO ICONOGRAPHY}

While this is not the place to discuss the entire chapel's painted imagery in detail, it must be mentioned that the frescoes by Cosimo Rosselli of 1465 (which pose their own set of problems ${ }^{44}$ ) comprise a Sybil, a figure of Daniel fighting the lion, John the Baptist and Saint Leonard, and a Christ Child (Fig. 2). ${ }^{45}$ The vault is painted with seated figures of the Four Evangelists (Fig. 3). The paintings, in their iconographic combination another uncommon choice, embed the tomb monument in the larger context of the four stages of individual salvation history as they correspond to the four stages of religious law: ante legem, sub lege, sub gratia, in pace. Saint Augustine in his writings prominently discussed these stages of salvation history, pointing towards the fact that humans are largely driven by their appetites, which only law can cure: law initiates the process of redemption by creating a consciousness of $\sin .{ }^{46}$ Redemption, however, comes only through Christ. We will see that Augustine is a central figure for the Salutati Chapel's overall religious and humanistic concept.

The Salutati Chapel also houses a marble altarpiece, likewise executed by Mino, whose iconography poses several questions (Fig. 7). In an antique-like framework, six figures are interacting in an unusual sculptural version of a sacra conversazione. ${ }^{47}$ The relief gradually develops from rilieveo schiacciato in the upper parts towards almost three-dimensional figures in the lower register (in that it reverses the spatial and sculptural concept on the other side of the tomb). In the center we see the Virgin Mary, the Christ Child seated on the stairs in front of her and blessing San Giovannino next to him

44 Both the cathedral and the Salutati Chapel underwent a restoration campaign in the early I88os. The frescoes were heavily repainted; see Giglioli, Catalogo delle cose d'arte e di antichità d'Italia (cit. n. 28), pp. I33-I35.

45 Zuraw, The Sculpture of Mino da Fiesole (cit. n. I3), pp. 783-786; A. PadoA Rizzo, La Cappella Salutati nel Duomo di Fiesole e l'attivita giovanile di Cosimo Rosselli, in: Rivista d'Arte XXVI, I950, pp. II6s.

46 The four stages of salvation history are at the core of Saint Augustine's teachings. They are discussed in his Expositio quarundam propositionum ex epistula apostolic ad Romanos (Commentary on statements in the letter of Paul to the Romans). See the helpful summary and commentary in: Augustine Through the Ages. An Encyclopedia (ed. A. FitzGerald/J.C. Cavadini), Grand Rapids,MI 1999, pp. 345-346.

47 It is located on the wall opposite the tomb. A sculpted altarpiece is, again, rather unusual in the I46os in Florence and surroundings. There are several Tuscan Gothic altarpieces in marble, yet the painted altarpiece prevails in the early Renaissance. See U. Middeldorf, Quelques sculptures de la Renaissance en Toscane occidentale, in: Revue de l'Art XXXVI, 1976, pp. 7-26. 


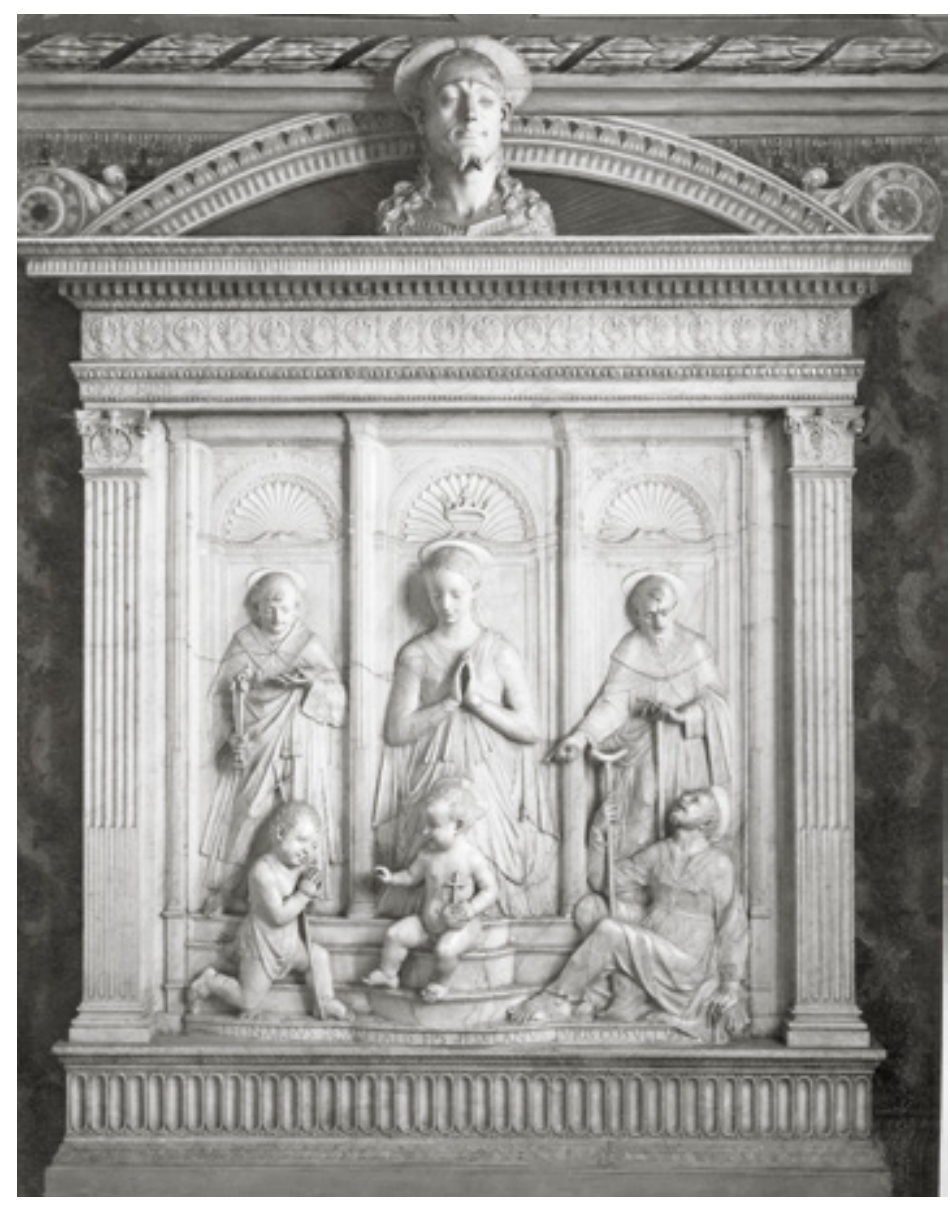

Fig. 7: Mino da Fiesole, Altarpiece for Leonardo Salutati, 1464-I466, marble, Cathedral San Romolo, Fiesole.

(Fig. 8)..$^{8}$ Through their looks, posture and gestures they form a referential triangle within the altarpiece's rather traditional, compartmentalized architectural backdrop. Mino's much more conventional arrangement in his formally similar altarpiece for Diotisalvi Neroni in the Florentine Badia is given up in favour of an interactive and narrative scene transgressing the boundaries of convention (Fig. 9). ${ }^{49}$ The central group of Mary and the children is flanked on the left by Saint Leonard of Noblac, Salutati's patron saint (Fig. 7)..$^{\circ} \mathrm{He}$ is reading 'aloud' from the scriptures. Speech and interaction are also brought forth through the two figures on the panel's right side:

48 The iconography of the meeting of an infant Christ with a little Saint John the Baptist is a genuine Quattrocento invention, see M. Aaronberg Lavin, Giovannino Battista: A Study in Renaissance Religious Symbolism, in: Art Bulletin 37, I955, pp. 85-IOI.

49 For the Badia altarpiece see Lange, Mino da Fiesole (cit. n. I3), pp. 29s. (cit. n. I3); Sciolla, La scultura di Mino da Fiesole (cit. n. 13), pp. 68-72; Zuraw, The Sculpture of Mino da Fiesole (cit. n. 13), pp. 767-78o.

50 Saint Leonard of Noblac is usually depicted as a young deacon with iron chains reading from an open book. In this the altarpiece follows iconographic convention; see G. KaftaL, Iconography of the Saints in Tuscan Painting, Florence 1952, col. 627-634. 


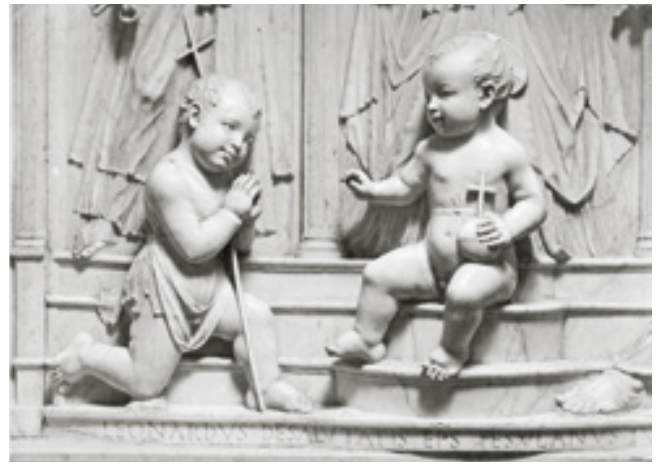

Fig. 8: Mino da Fiesole, Altarpiece for Leonardo Salutati (detail): Christ Child with San Giovannino.

A standing figure seems to give advice to a seated man in sandals in front of him. Both have been interpreted in a number of ways, of which the most commonly discussed possibilities are Saint Remigius arguing with an Arian bishop, ${ }^{5 \mathrm{I}}$ and Saint Anthony the hermit with a beggar at his feet. ${ }^{52}$ Others have identified an antique wayfarer in the seated figure, and Zuraw suggests Saint Benedict for the standing saint and either Saint Romuald or Joseph for the seated figure. ${ }^{33}$ Milanesi's simple observation in the Vasari commentary that the seated man seems to be a saint, '... un vecchio che all'aureole che gli cinge il capo sembra santo', should at least exclude speculations about a beggar or 'cripple'; the figure has a nimbus. ${ }^{54}$

Part of the problem in identifying the dossale's iconography results from the way in which different iconographic strands, image types, and

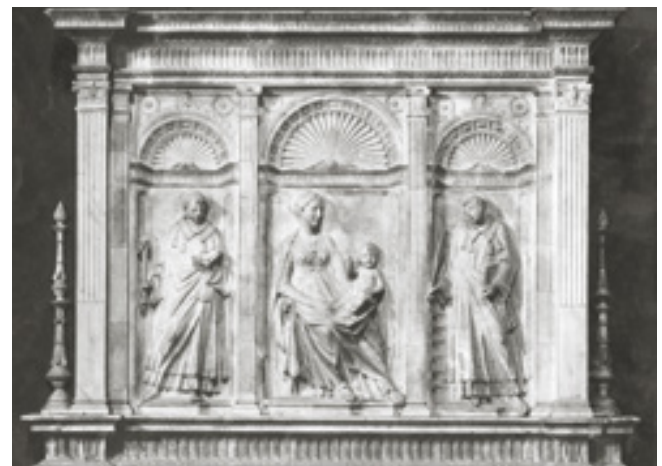

Fig. 9: Mino da Fiesole, Altarpiece for Diotivalvi Neroni, circa 1466, marble, Badia Fiorentina

forms of interaction are fit into what at first sight appears to be a rather conventional tripartite marble panel. The individual and nonstandard combination of formal and iconographical elements poses a series of challenges to the modern interpreter: The Adoration of the Virgin motif is combined with the 'new iconography' of bambino Gesù blessing the little San Giovannino, and the combination of three vertical panels leads into a horizontal set of stairs that opens up the religious scenery towards the beholder in both an architectural and narrative way. However, the picture does become clearer and less puzzling when we understand tomb and altarpiece as two parts of an ensemble with a coherent, mutually dependent message.

This assumption is emphasized by the twofold mention of Salutati's status as jurisprudent. The reference as 'iuris consultus' appears prom-

5I BANDINI, Lettere XII (cit. n. 20), p. I79: ‘...nella nicchie laterale vi sono collocati i Santi Leonardo vestituo da Diacono, e Remigio suo maestro, ai di cui piedi si osserva giacente in atto di alzarsi un vecchio schiavo con maravigliosa attitudine.' M. Reymond, La Sculpture florentine au XV siècle, Florence I897, p. 96; and A. Guerri, Fiesole e il suo Comune. Fiesole 1897 (reprint Florence 1978), p. 52. This identification is also found in descriptions of the altar from the nineteenth century; see Zuraw, The Sculpture of Mino da Fiesole (cit. n. I3), p. 794. See also M. Horster, Dem 'Florentiner Wanderer', in: Beiträge zur Ikonographie und Hermeneutik. Festschrift für Nikolaus Himmelmann, Mainz I988, pp. 5II-5I4.

52 Schubring, Die italienische Plastik des Quattrocento (cit. n. I2), p. I63; Lange, Mino da Fiesole (cit. n. I3), p. 27.

53 Zuraw, The Sculpture of Mino da Fiesole (cit. n. I3), p. 794-798; Horster, Dem 'Florentiner Wanderer' (cit. n. 5I), p. 5II-5I4.

54 Vasari-Milanesi (cit. n. 34), vol. 3, p. I22. 


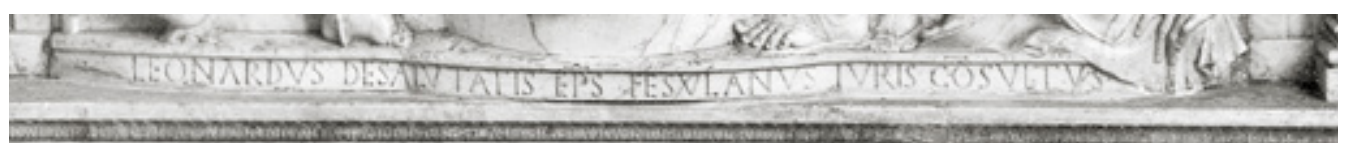

Fig. Io: Mino da Fiesole, Altarpiece for Leonardo Salutati (detail): inscription.

inently on the inscriptions of tomb and altarpiece, where we read LEONARDUS DE SALUTATIS EP(ISCOPU)S FESULANUS IURIS CONSULTUS (Fig. Io). Salutati had a good reason to emphasize his juristic background. It was, after all, Leonardo's grandfather Coluccio, who in his famous treatise De nobilitate legum et medicinae discussed the concept that jurisprudence was a part of the study of humanities and as such, superior to the merely physical sciences such as medicine. 55 The argument that civic law is an articulation of the divine law and hence closely tied to moral philosophy and humanism is propagated heavily in Coluccio's treatise..$^{56}$ In this frame of reference, jurisprudents were deemed to hold a key position, intellectually as well as in moral terms. Coluccio had emphasized that jurisprudents represented a doctrine based on permanent principles both in connection to Christian and Aristotelian thought. ${ }^{57}$ His treatise was part of the attempts of early humanists (Petrarch, Leonardo Bruni, Poggio Bracciolini, Maffeo Vegio and others) to upgrade the social image of jurisprudence, attempts which also reflected and prevailed in the patronage of Leonardo Salutati's contemporaries..$^{58}$

For the self-definition of notaries and jurisprudents of the fourteenth and fifteenth centuries, Saint Jerome was the key historical reference and figure of identification. 99 The Hieronymianus treatise by Bolognese jurisprudent Giovanni d'Andreae (I342) helped significantly in establishing the prominent cult around the church father. ${ }^{60}$ As part of the ascetic ideal of monastic

55 See the preface by E. Kessler in: Coluccio Salutati (cit. n. 29), pp. VII-XXV.

56 D. R. Kelley, Vera Philosophia: The Philosophical Significance of Renaissance Jurisprudence, in: Journal of the History of Philosophy I4/3, July 1976, pp. 267-279.

57 See M. Lobban, A History of the Philosophy of Law in the Common Law World, I600-1900, vol. 8 of A Treatise of Legal Philosophy and General Jurisprudence (ed. E. Pattaro), Dordrecht 2007, p. 57.

58 See A. von HüLSEN-Esch's well-researched publications on the representation of humanists, in particular jurisprudents: Gelehrte im Bild. Repräsentation, Darstellung und Wahrnehmung einer sozialen Gruppe im Spätmittelalter, Göttingen 2006, pp. 163-203, in particular pp. I83-193; A. von HüLSEN-Esch, Kleider machen Leute. Zur Gruppenrepräsentation von Gelehrten im Spätmittelalter, in: Die Repräsentation der Gruppen: Texte, Bilder, Objekte (ed. O.G. OeXle/A. von Hülsen-Esch), Göttingen 1998, pp. 225-258. Laura Goldenbaum has recently analysed the 'self-fashioning' of Mariano Sozzini, a Sienese jurisprudent, and the way in which concepts of law, authenticity and authority are reflected in his bronze gisant, now in the Museo del Bargello in Florence. L. Goldenbaum, Der Zeugniswert des Körpers oder anima forma corporis. Der quattrocenteske Bronzegisant des Sieneser Rechtsgelehrten Mariano Sozzini, in: kunsttexte 4, 20IO. http://edoc.hu-berlin.de/kunsttexte/20Io-4/goldenbaum-laura-5/PDF/ goldenbaum.pdf (last access March 13, 2015). There are other manifestations of the status of jurisprudents and humanist-bishops and their attempts to create an improved social identity, in particular in the tombs of humanists and lawyers in late medieval Bologna, see R. Wolff, Zur 'Gruppe' der Gelehrtengrabmäler des Mittelalters in Oberitalien, in: Creating Identities. Die Funktion von Grabmalen und öffentlichen Denkmalen in Gruppenbildungsprozessen, Kassel 2007, pp. 219-230.

59 E. F. Rice, Saint Jerome in the Renaissance, Baltimore/London I985; C. Wiebel, Askese und Endlichkeitsdemut in der italienischen Renaissance, Weinheim 1988; B. Ridderbos, Saint and Symbol. Images of Saint Jerome in Early Italian Art, Groningen 1984; A. Pöllmann, Von der Entwicklung des Hieronymus-Typus in der älteren Kunst, in: Benediktinische Monatsschrift 2, 1920, pp. 438-522.

60 See also HüLSEN-Esch, Kleider machen Leute (cit. n. 58), p. 228. 
reform movements in the later Middle Ages and early Renaissance, Jerome experienced a tremendous thrust of popularity as a Christian Leitfigur, the prototypical hermit and ascetic. ${ }^{61}$ The order of Saint Jerome was established and pushed by the foundation of the Eremiti di S. Girolamo a Fiesole, supported later on by ample financial support of Cosimo de' Medici. ${ }^{62}$

The veneration of Saint Jerome in the Italian Renaissance, in particular by scholars and jurisprudents, is amply documented. ${ }^{63}$ Pope Eugene IV massively supported the observant movement and promoted the foundation of the Fiesole order in I44I, initially under the rule of Saint Augustine. ${ }^{64}$ During that time, Leonardo Salutati was one of his closest administrators. When Leonardo became bishop of Fiesole in 1450 , he was behind the monastery's architectural and spiritual expansion. ${ }^{65}$ The cult of Saint Jerome was in fashion, not just in Fiesole. When Cardinal Guillaume d'Estouteville, one of the major diplomats and global players at the papal court in the midfifteenth century, commissioned a marble ciborium and altar for Santa Maria Maggiore in Rome in the early I460s, the commission went to no other than Mino da Fiesole. ${ }^{66}$ D'Estouteville was made cardinal in 1439 by Eugene IV. Leonardo, who entered the papal court that same year, must have known him well. ${ }^{67}$ D'Estouteville, who 'for thirty seven years (...) was protector of the Order of Saint Augustine', ${ }^{68}$ commissioned from Mino and his workshop a large-scale marble altar

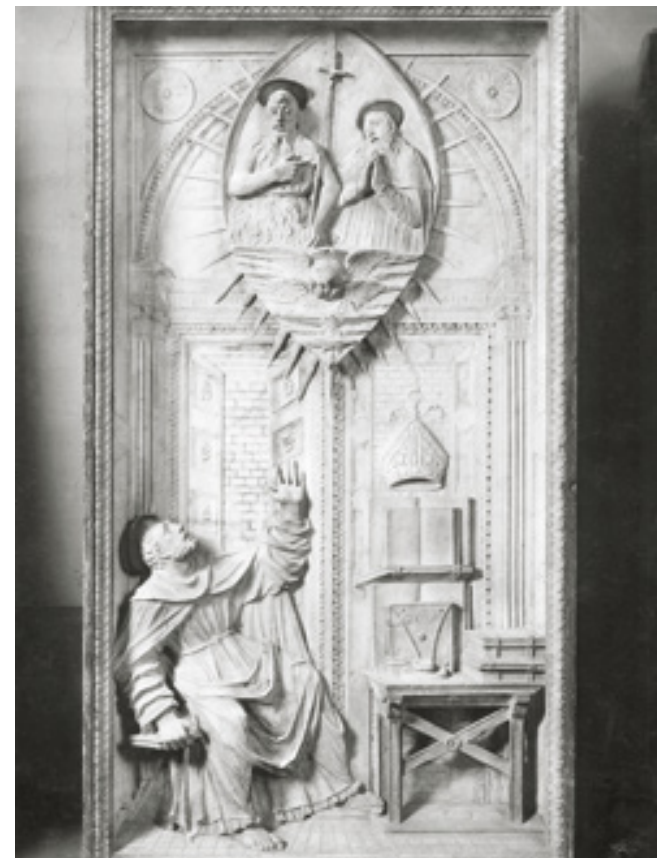

Fig. II: Mino da Fiesole, Saint Gerome altarpiece for Cardinal Guillaume d'Estouteville, relief panel with Saint Augustine's vision of Saint John the Baptist and Saint Jerome, I46I-I464, marble, Museo Nazionale Palazzo Venezia, Rome.

(I46I-63) dedicated to Saint Jerome with a series of reliefs depicting scenes of the life and miracles of Saint Jerome: Jerome in his study, Jerome chastening himself in the image of Christ Crucified, Jerome miraculously curing an injured lion, and finally, a scene in which Jerome has a vision (Fig. II). The episode is from the pseudo-letters

6I Wiebel, Askese und Endlichkeitsdemut (cit. n. 59), p. 5, 33.

62 Ibid, p. 29. See also G. Raspini, Gli Eremi nella Diocesi di Fiesole, Fiesole 198I, pp. 8-I4. In I405 in the poor hermitage of Beato Carlo da Montegranelli, which had become a popular location of veneration, the Congregazione degli Eremiti di San Girolamo a Fiesole was founded. Several decades later, Cosimo de' Medici had a large convent built in 1450 for the Hieronymites.

63 D. Russo, Saint Jérome en Italie. Étude d'Iconographie et de Spiritualité (XIIe - XVe siecle), Paris/Rome 1987.

64 Wiebel, Askese und Endlichkeitsdemut (cit. n. 59), p. 29.

65 For the relations of Pope Eugene IV and Leonardo Salutati with the observant movement of Fiesole see S. AND J. Horner, Walks in Florence, Florence I884, 2 vols., vol. 2, p. 315.

66 Zuraw, The Sculpture of Mino da Fiesole (cit. n. I3), pp. I50-I93, 62I-649.

67 For Guillaume d'Estouteville see The Cardinals of the Holy Roman Church. Biographical Dictionary. http://www2. fiu.edu/ - mirandas/biosi439.htm (last accessed March I5, 2015).

68 Ibid. 
of Saint Jerome written in the thirteenth century. ${ }^{69}$ It describes how Saint Jerome and Saint John the Baptist appeared to Saint Augustine in a religious vision shortly before his death. It is possible that d'Estouteville's fine marble bust, likewise by Mino, was originally meant to be placed on the altar of Saint Jerome, 'as a perpetual reminder not only of his patronage of the altar itself, but also as a sign of his continued devotion to ot the saint.' ${ }^{70}$

In light of Leonardo Salutati's emphasis on his career and status as iuris consultus on both his tomb and altarpiece, his almost certain knowledge of d'Estouteville's ambitious Saint Jerome altarpiece in Santa Maria Maggiore (Fig. II), and both the relevance of Saint Jerome for Quattrocento notaries and for the Diocese of Fiesole, I would like to suggest a new identification of the two figures communicating with one another on the Salutati Altarpiece's right side, an identification that situates both tomb and dossale in its proper scholarly context.

It is quite striking and typical of Mino that in both scenes - the marble relief for d'Estouteville's altar of Saint Jerome and the figures in relief on the Salutati Altarpiece - the artist applies the exact same types in depicting the saints (compare figs. 7 and II). Both reliefs show similar gestures, postures and facial features of the seated saint, with his open mouth including visible teeth, to emphasize a form of visibile parlare, of dialogue made visible, further stressed by the saint's fine- ly carved ear in the Salutati Chapel. Both seated figures wear sandals and a simple tunic with a girdle, both have short, curly hair and a remarkably full, curly beard. Mino, it seems, brought this figure with him from Rome, where he had been working on the cardinal's Saint Jerome altarpiece up until the Salutati commission. Yet, if what we see is indeed a seated Saint Augustine, looking up in surprise to what he sees possibly Saint Jerome in his vision, then Salutati's is a much more innovative interpretation of the scene than its Roman counterpart, where Saint John the Baptist and Saint Jerome appear in a mandorla behind a cherub's head and stylized clouds.

There are several good reasons to assume that the Salutati Altarpiece shows a combination of Saint Augustine with the much-venerated Saint Jerome. As we know, Leonardo Salutati was very close to the congregation of the Hermits of Saint Jerome in Fiesole; he was a member of the Buca di San Gerolamo, an important brotherhood named after its foundation site in the monastery of San Gerolamo in Fiesole. ${ }^{71}$ Jerome was a Modeheiliger - a saint in vogue in the fifteenth century and extremely popular among humanists, scholars, and jurisprudents. Veneration for Jerome and Augustine were closely intertwined in pre-Reformation Europe. ${ }^{72}$ Cardinal d'Estouteville's predilection for both Jerome and Augustine is expressed in the fact that he named his two sons after these saints. ${ }^{73}$ What is more,

69 Kaftal, Iconography of the Saints in Tuscan Painting (cit. n. 50), p. 531.

70 Zuraw, The Sculpture of Mino da Fiesole (cit. n. 13), p. 648. Already Vasari notes a portrait of the cardinal on the altar, see ibid, p. I54. This would make a direct influence on Salutati's tomb monument and altarpiece even more probable.

7I See L. Sebregondi, Tre confraternite fiorentine, Florence 1991. Vespasiano da Bistecci reports that several eminent Florentine city officials, clerics and artists (the two Florentine bishops Amerigo Corsini and Saint Antoninus, as well as Pope Paul II and Luca della Robbia) were members of the Buca di San Gerolamo, see H. BrocKHaus, Forschungen über Florentiner Kunstwerke, Leipzig I902, pp. III-II2.

72 B. Намм, Hieronymus-Begeisterung und Augustinismus vor der Reformation. Beobachtungen zur Beziehung zwischen Humanismus und Frömmigkeitstheologie (am Beispiel Nürnbergs), in: Augustine, the Harvest, and Theology (I300-I650). Essays Dedicated to Heiko Augustinus Oberman in Honor of his Sixtieth Birthday (ed. K. Hagen), Leiden I990, pp. I27-235.

73 Zuraw, The Sculpture of Mino da Fiesole (cit. n. 13), pp. 638s. 


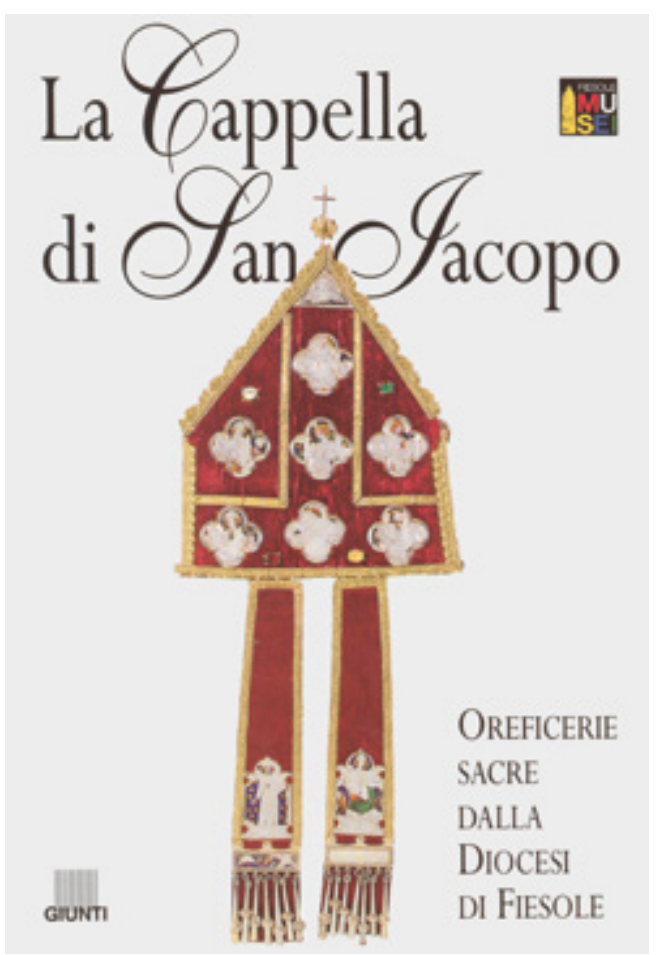

Fig. I2: Mitre of Bishop Leonardo Salutati, cloth, silver, enamel, mid-fifteenth century: Saint Jerome on the application of the left fascia and possibly Saint Augustine on the right, Fiesole Cathedral Treasury.

the standing figure of Saint Jerome represents the same type of saint with long beard and a cardinal's mozzetta. He points to the two interacting children, the bambino Gesù greeting San Giovannino, a gesture that seems to reverse the pointing of Saint John the Baptist toward Saint Jerome in the d'Estouteville relief panel. Saint John was understood as a precursor of Christ, Saint Jerome as his successor and translator. ${ }^{74}$ The subject of Augustine seeing Saint Jerome and Saint John the Baptist in his last hour, when Jerome announces Augustine's impending death, is the topic of several predella paintings from the later fifteenth century in Florence and Fiesole by Lu-

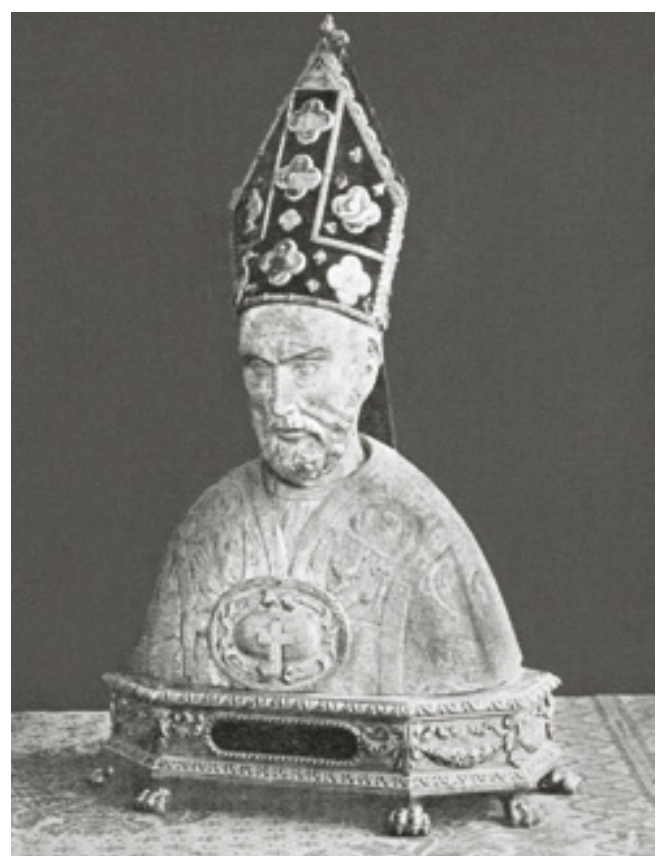

Fig. 13: Bust of Saint Romulus with Leonardo Salutati's mitre, 1584, Cathedral San Romolo, Fiesole.

ca Signorelli, Benozzo Gozzoli, Matteo di Giovanni and others - a clear reflection of the episode's popularity for altarpieces. ${ }^{75}$

I would also argue that the position of the two saints in the Salutati Altarpiece right on top of the inscription 'iuris consultus' is no coincidence. Here, an immediate visual link is created between the learned bishop, his name, his family tradition established by his grandfather Coluccio's engagement with the leading faculty of jurisprudence, and his main two religious figures of identification. These assumptions are further backed up by a closer look at a more ephemeral but nonetheless important object of self-representations: Leonardo Salutati's mitre, which as we have learned, was venerated as a miracle working 'relic' after his death (Fig. 12). ${ }^{76}$ The object's main body features twelve silver enameled

74 Wiebel, Askese und Endlichkeitsdemut (cit. n. 59), pp. 27-28.

75 R. Jungblut, Hieronymus. Darstellung und Verehrung eines Kirchenvaters, Tübingen 1967, p. 35.

76 See before, p. 158 and Giglioli, La mitria del vescovo Leonardo Salutati (cit. n. 4I), pp. 57-60. 
quatrefoils with images of the Virgin Mary and Archangel, Saint John the Baptist, Saint Peter and Paul, Saint Romulus (the cathedral's patron saint), Saint Zenobius and other unidentified saints. The two infule or fasciae in red velvet have two larger silver plaques with translucent enamel, one of which shows Saint Jerome in the act of beating his chest with a stone. The second one shows the figure of a bishop saint, possibly
Saint Augustine. ${ }^{77}$ On the annual Saint Romulus feast day, the mitre, which is usually kept in the Fiesole cathedral's tesoro, is mounted to the reliquary of Saint Romulus, a silver-plated copper bust from the sixteenth century (Fig. I3). While the Salutati Altarpiece's iconography certainly deserves further investigation, I would hope that my suggestions are a step in the right direction and serve as the basis for future studies. ${ }^{78}$

\section{A FINALSALUTE}

The overall concept of the Salutati Chapel's iconography and typology are novel and clearly show the patron's intellectual handwriting. Mino da Fiesole was a fine sculptor, certainly one of the most gifted portrait sculptors of the Renaissance period, yet the chapel's design is the work of a learned humanist. Typologically, it clearly departs from the standard mid-fifteenth century tombs to be found in Florence and surroundings. It is a highly individual memorial with its portrait bust articulating both this individuality and an awareness of antique standards of representation. Yet it is also a monument that emphasizes group identity by means of its emphasis on the patron's social status and profession. He is shown as bishop in his portrait yet identified as jurisprudent in the inscriptions and the iconography as suggested here. In this way it combines ideas of intellectual and ethical lineage with the Renaissance patron's aspiration to stand out.

The Salutati tomb is also a monument into which the patron's family name is inscribed, literally and metaphorically, by means of the greeting bust. Moreover, the witty reflection of family identity extends to the identity of its individual member, Leonardo, the lion-like. Everyone familiar with Christian iconography will have understood that the lion was Saint Jerome's faithful companion as a hermit. It is Giovanni d'Andrea who is usually credited with introducing the motif of the lion to images of Saint Jerome as a scholar and theologian in the mid-fourteenth century. ${ }^{79}$ The combination harkens back to the popular story of Jerome's brave act of removing a thorn from an injured lion's paw. The story was known throughout the Middle Ages (through Vincent of Beauvais's Speculum Historiale and the Legenda Aurea) as an allegory of the extinction of carnal sensations. ${ }^{80}$ In this perspective, Leonardo not only implicitly references the leonine iconography connected with Saint Jerome; he also alludes to the hermit interpreter of Divine Law, Saint Jerome, as a healer of humankind in need of interpretation and salvation, thus again pointing to his own profession and its moral, social, and theological status. In his burial chapel the humanist bishop and jurisprudent addresses us with his presence and likeness

77 Ibid, p. 6o. I was unable to see the mitre in person during my last visit to Fiesole.

78 I am preparing to include a more detailed analysis in my upcoming publication on Florentine Renaissance bust portraits (in preparation for 2018).

79 See Rice, 1985, pp. 64-68 and G. Ring, Saint Jerome Removing the Thorn from the Lion's Paw, in: Art Bulletin 27, 1945, p. 190. See also H. Friedman, A Bestiary for Saint Jerome: Animal Symbolism in European Religious Art, Washington D.C., p. 229; D. SALter, Holy and Noble Beasts: Encounters with Animals in Medieval Literature, Cambridge 200I, p. II-24.

80 SAlter, Holy and Noble Beasts (cit. n. 79), pp. I3-I5. 


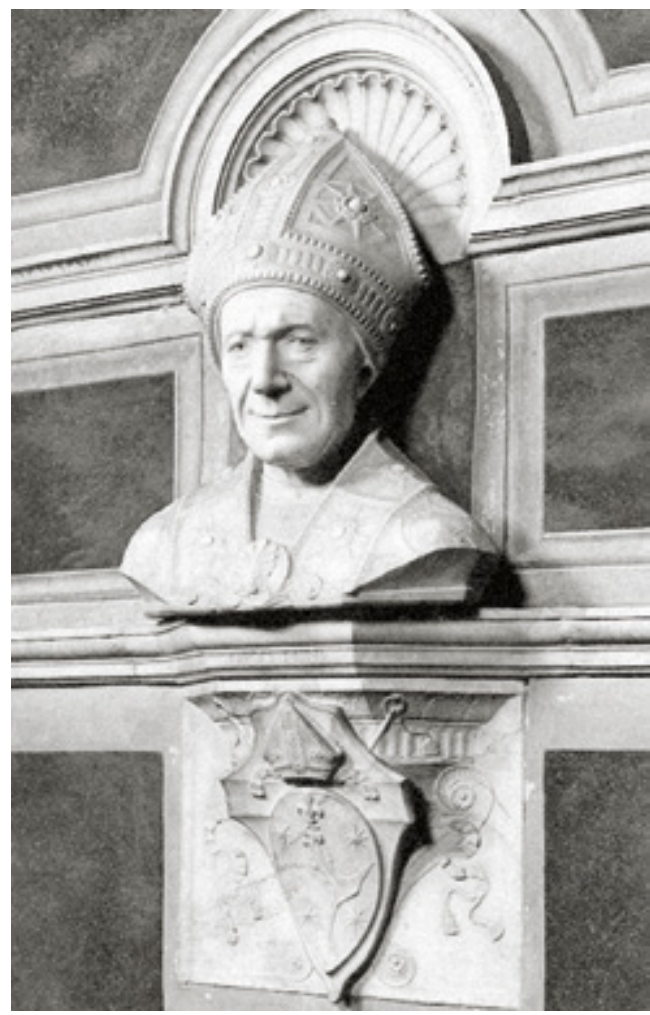

Fig. I4: Mino da Fiesole, Tomb of Leonardo Salutati (detail): coat of arms below the bust with lion's paw holding a giglio. as a saluting lion - Leonardus Salutatus. His coat of arms, prominently positioned underneath his bust, sets the final keynote: a lion's paw holding the giglio fiorentino (Fig. I4). As an iconography custom-tailored to represent a humanist theologian, jurisprudent, and descendent of an intellectual Florentine nobility, it forms a truly novel concept of scholarly memoria and a unique theopolitical statement in the Salutati Chapel. ${ }^{8 \mathrm{r}}$

Photographic acknowledgements: Fig. I-II, I4: Photo Library, Kunsthistorisches Institut in Florence, MaxPlanck-Institute; Fig. I2: La cappella di San Jacopo. Oreficerie sacre dalla diocese di Fiesole. Pianta guida. Giunti Ed., Florence 2000, cover photo; Fig. 13: Odoardo H. GIGLIOLI, La mitria del vescovo Leonardo Salutati nel Duomo di Fiesole, in: Rivista d'Arte 9, I916, p. 57

8I One part of the chapel's interior went unmentioned in this essay: a bust of Christ positioned in the shallow lunette above the altarpiece. Zuraw discusses it in her 1993 dissertation at length and in regard to a possible theological meaning expressing the deceased's beatific vision. The bust is most likely by Mino, yet it is completely unclear if it was designed for the chapel or is a later addition. Vasari does not mention a bust of Christ in his brief description of the chapel. He does, however state that Mino 'fece per lo medesimo vescovo una testa di Cristo, di marmo, grande quanto il vivo e molto ben lavorato, la quale fra l'altre cose dell'eredità rimaso allo spedale degl'Innocenti', VASARIMilanesi (cit. n. 34), vol. 3, p. I22. It is quite possible that the bust was installed in the chapel during interventions of the late seventeenth century, when the sarcophagus was opened and the bishop's body was found 'tutto incorrotto' and looking much like the bust, as a commentary remarks; see Zuraw, The Sculpture of Mino da Fiesole (cit. n. I3), p. 783. It also seems to be of a different kind of marble, slightly more yellow than the other marble elements in the chapel. Given the lack of further evidence of its original position and whereabouts I decided to exclude it from my observations. 


\title{
TO FAME AND GLORY: \\ BOLOGNA MUNICIPAL CEMETERY AND ITS PANTHEON. ABOUT THE PERSISTENCE OF THE TRADITION OF CELEBRATING GREAT MEN
}

\author{
Antonella Mampieri
}

In I886, when Luigi Serra (Bologna, I846-I888) painted the great plafond depicting Irnerius, his mind must have been full with the rumours, projects and ideas for the solemn celebration of the eighth centenary of the University foundation that took place in I888 (Fig. I). I The large painting bears all the symbols of scholarship and embodies the values of Bologna University at the end of the nineteenth century. The mythical first professor of the local school of law, Irnerius, is depicted by Serra seated upon his cathedra, writing his notes in a huge codex. Serra combines here the realistic style fashionable at the end of the nineteenth century (the man bent over his book pensively considering the text, the books gathered around him in an untidy mass expressing his hard intellectual work, the clothes carefully studied on costume repertoires and the Roman-Cosmatesque gold decoration encrusting the steps and throne, the contrast between Gothic and capital fonts on the scroll and on the inscription under Irnerius' feet) with the sym-

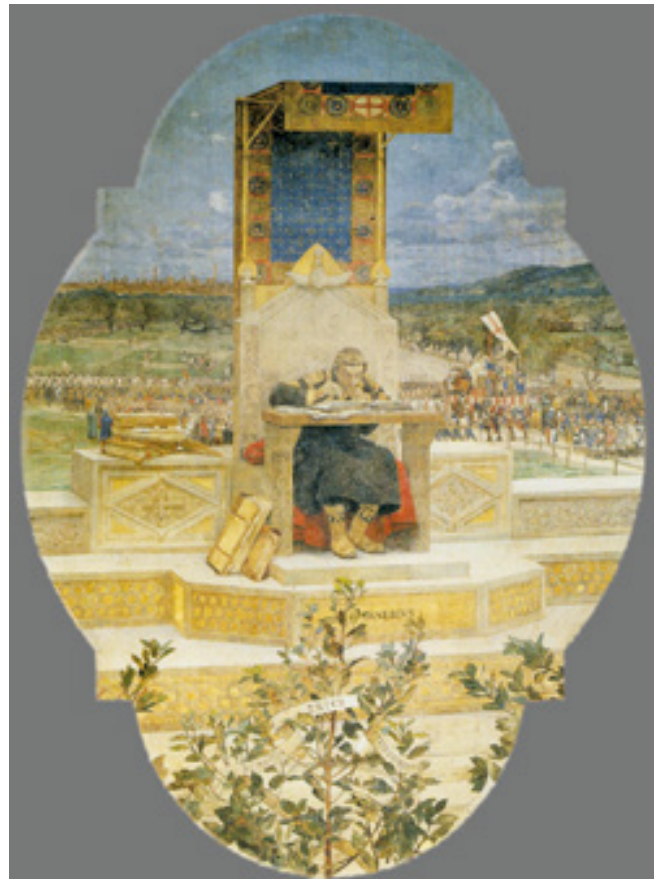

Fig. I: Luigi Serra, Irnerius writing his notes on the Corpus Iuris, I886, painting, Bologna, City Hall. bolism creeping into poetry and the arts during

I The painting, originally placed in the middle of the ceiling of the Hall of Honour of the Provincia di Bologna, hosted at that time in the town hall, is today exhibited on the first floor of the same building. Serra was commisioned for this last and significant work in I886 and following his usual studio practice, he made a great number of sketches and drawings in order to reach the complex, allegorical result that was going to be enthusiastically celebrated by his contemporaries, especially by the Nobel prize winner poet Giosue Carducci. See A. ZACCHI, Temi sacri, storici e allegorici, in: Il Segno e il colore. Nell'atelier di Luigi Serra (exh. cat. Bologna, Galleria d'Arte Moderna), Cinisiello Balsamo 2003, p. III and p. 203. 


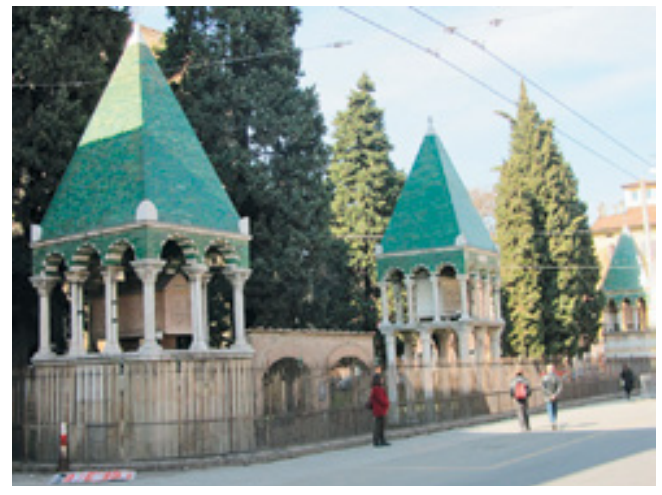

Fig. 2: Bologna, San Francesco, churchyard, Monuments of Rolandino dei Romanzi, Odofredo and Accursio, thirteenth century.

the same years (the laurel bush in the foreground with the scroll celebrating Bologna mater Studiorum, the landscape with the far away medieval town, its skyline pointed with towers alluding to a well known poem by Giosue Carducci). But it is especially the seated figure of the university professor dominating the painting that connects past and present in a sort of long term persistent tradition that starts with the monumental tombs of the glossatori (Fig. 2).

The tradition of building significant monuments to celebrate the scholars of Bologna University dates back to the second half of the thirteenth century, as its first monumental tomb of the doctor of law Odofredo, still extant in the churchyard of San Francesco, testifies very well. Its shape, a high basement on which the cell stands on columns, crowned by a canopy and hosting the sarcophagus, was probably inspired, as Renzo Grandi notes in his highly specialized studies on the subject, by the imperial tombs in Palermo, especially by that of Frederick II of Swabia. ${ }^{2}$ At the same time, the pyramid symbolizing long-lasting memory is a clear citation from the Roman tombs of Caius Cestius and Julius Caesar. From this early model derived the subsequent monuments of Rolandino de' Romanzi, dated 1284 and in the same churchyard, and of Rolandino de' Passeggeri on the square of San Domenico, the last (beginning of fourteenth century) and the best preserved of the group. ${ }^{3}$

All these imposing architectural structures are evidence of the social role conquered by that time by the scholars of the oldest university in Europe and of the need felt by their heirs and colleagues to make their memory eternal by building a memorial that had to be more than a tomb; in these specific cases a proper monument not very different in luxury and size from those erected to kings, emperors and popes. A significant parallel between these customs can be noticed even in the decoration of the sarcophagus, at first inspired by Roman models and later intended as a double celebration of both the body and the soul of the deceased. Therefore the sarcophagus of Rolandino de' Passeggeri is decorated on one side with the life-size figure of the notary as a gisant, while on the opposite side is

2 R. Grandi, I monumenti dei dottori e la scultura a Bologna (I267-I348), Bologna 1982.

3 See also R. Grandi, Le tombe dei dottori bolognesi: ideologia e cultura, in: Università e Società nei secoli XII XVI, Atti del IX Convegno Internazionale di studio (Pistoia, 1979), s.l. 1983, pp. 429-445; R. Grandi, La Scultura nel Medioevo, in Storia Illustrata di Bologna, Repubblica di San Marino 1987, vol. 2, pp. 26I-280; R. Grandi, Dottori, scultori, pittori: ancora sui monumenti bolognesi, in: Skulptur und Grabmal des Spätmittelalters in Rom und Italien, Akten des Kongresses 'Scultura e monumento sepolcrale del tardo Medioevo a Roma e in Italia' (Roma 1985), Wien I990, pp. 353-365; R. GRANDI, 'Ad modum doctoris': nuove considerazioni ai margini dei monumenti funerari del medioevo bolognese, in Di fronte all'aldilà. Testimonianze dall'area bolognese, atti del convegno di studi (Bologna 2002), Bologna 2004, pp. I69-185. The present state of the tombs is the result of a heavy, even if philological, restoration carried out by Alfonso Rubbiani between the end of the nineteenth century and the beginning of the twentieth. See A. Rubbiani, La chiesa di san Francesco e le tombe dei Glossatori, Bologna i899; A. RubBIANI, i veri e i falsi storici (exh. cat. Bologna I98I), Casalecchio di Reno I98I. 
carved one of the first representations of the professor teaching his students. This scene, characterized by a strong proportional contrast between teacher and pupils that emphasizes once more the former's predominant social role, evolves soon into a frontal representation with the professor seated on his cathedra in the middle of the sarcophagus' front and at his sides the pupils sitting at their desks and listening to his words. Princely dressed in his long robe and toque, the scholar dominates the viewer; he is framed by the architectural structure of the cathedra, symbol of his knowledge and prestige, on which stands open a huge book. The pupils gather at his sides, some of them sit at their desks as before, but now the classroom is so crowded that some have to stand against the wall in the background. The love for description, a special feature of Gothic style and especially of Bolognese painting in the second half of the fourteenth century, takes the lead and depicts characters, attitudes and clothing in a very lively and detailed way. A good example of this stage is the arca of the jurist Giovanni d'Andrea in the Museo Civico Medievale of Bologna and originally in the Church of San Domenico (Fig. 3). ${ }^{4}$

In the sixteenth century, the building of the palace of the Archiginnasio as an official seat for the University succeeded in unifying under one roof the schools which up to that date were scattered in different places, and granted the papal government a stricter control over their work. In the same years the distinction between funeral monument and memorial becomes clearer. The Archiginnasio is entirely decorated with memorials dedicated to professors and students of Bologna University, while the habit of burying in churches still produced a small number of elegant Renaissance funeral monuments. The

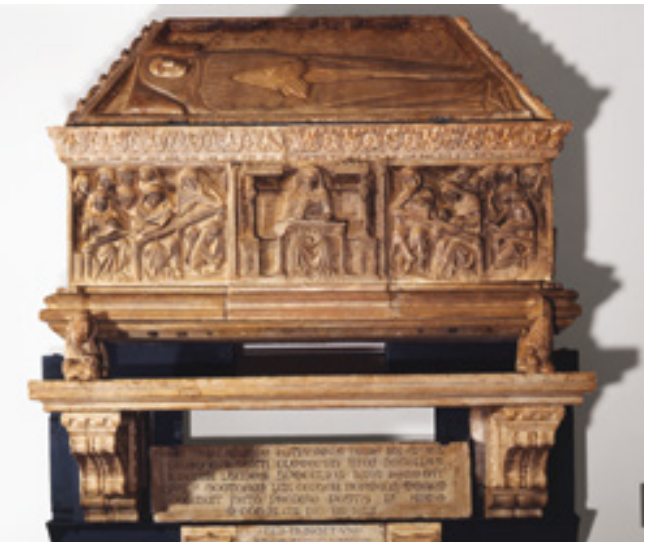

Fig. 3: Jacopo Lanfran, Bologna, Arca di Giovanni d'Andrea, Museo Civico Medievale, ca. 1348 .

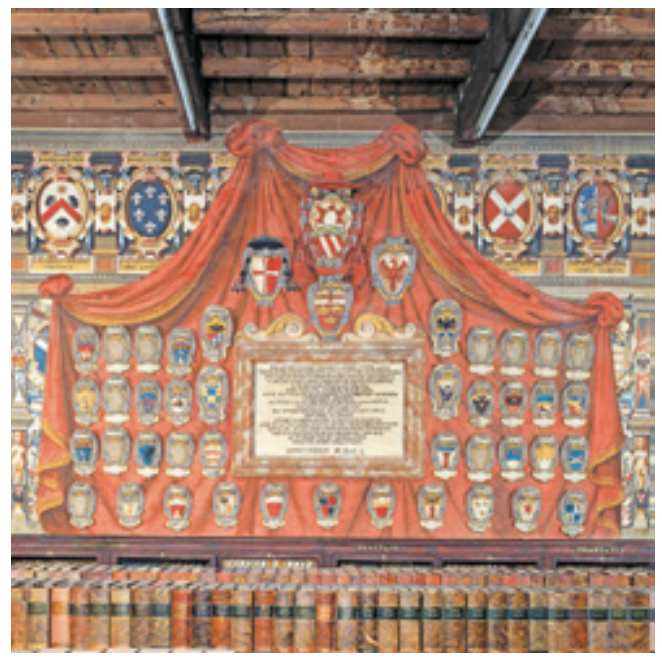

Fig. 4: Bologna, Archiginnasio, Aula 6 dei Legisti, eastern wall.

memorials erected in the arcades of the upper and lower courtyards and in the classrooms of the Archiginnasio are characterized by their size (Fig. 4). They often extend to the whole wall and are generally painted, or at least they are a com-

4 The famous professor of canon law Giovanni d'Andrea Calderini was also secretary for several popes. He died in Bologna during the 1348 black death epidemic. About his arca, its attribution history and historical notes see Grandi, I monumenti (cit. n. 2), pp. I63-I67.

5 About the history and decoration of the Archiginnasio see L'Archiginnasio: il Palazzo, l'Università, la Biblioteca, Bologna 1987; Biblioteca Comunale dell'Archiginnasio (ed. P. Bellettini), Firenze 200I. 


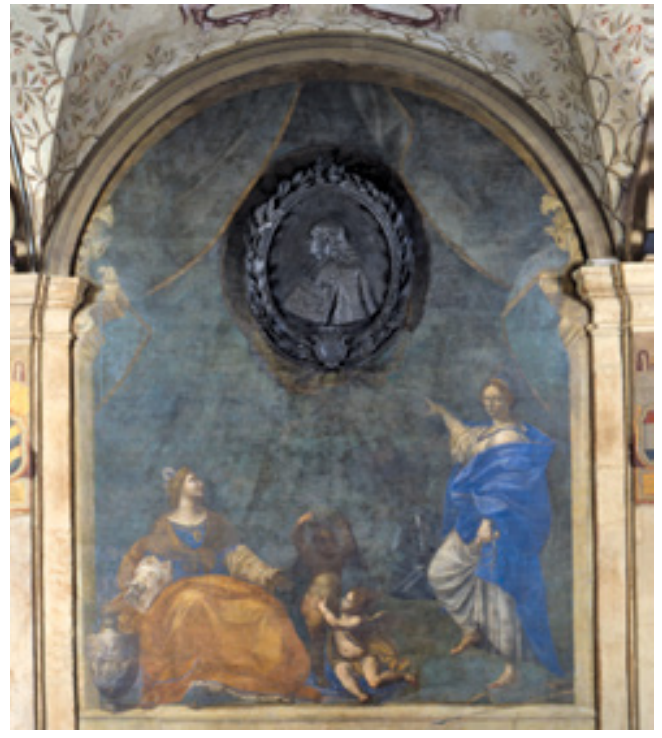

Fig. 5: Donato Creti and Giuseppe Maria Mazza, Memorial to Gerolamo Sbaraglia, Bologna, Archiginnasio, upper courtyard, oil on wall and bronze portrait bas-relief.

bination of plastic sculpture and painting, thus underlining the pre-eminence accorded in Bologna to painting in relation to sculpture, and at the same time the economic reasons attached to a choice that was both practical and fast. One example for all is the memorial of Gerolamo Sbaraglia, painted by the Bolognese artist Donato Creti (Cremona, I67I - Bologna, I749) in 1713. Here the profile of the celebrated physician, cast in bronze after the wax model by the sculptor Giuseppe Maria Mazza (Bologna, I653-I74I), is framed by a complex allegory showing the de-

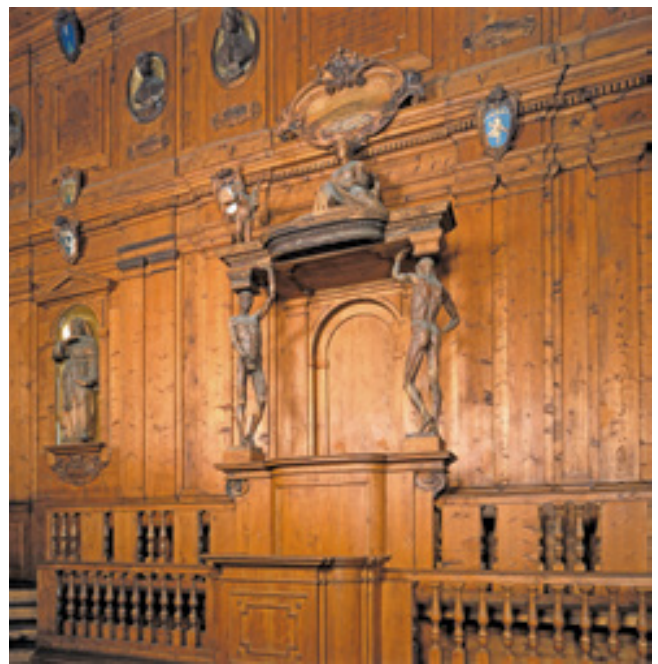

Fig. 6: Bologna, Archiginnasio, The Anatomy Theatre.

ceased's main virtues of Reason and Experience pointing or looking at him for inspiration (Fig. 5). ${ }^{6}$ Inside the same building, the Anatomy Theatre, built in 1673 by Antonio Levanti and heavily damaged by bombing in the the Second World War, offered another good opportunity of celebrating modern physicians such as Marcello Malpighi and Gaspare Tagliacozzi, whose wooden statues placed in the niches on the walls stood side by side with those of famous 'colleagues' from Antiquity, like the Roman Galen and the Greek Hippocrates (Fig. 6). ${ }^{7}$

In I7I4, the opening of the Istituto delle Scienze, and a few years before that of the Acca-

6 About the Sbaraglia memorial see R. Roli, Il Creti a Palazzo: il lascito Collina Sbaraglia al Senato di Bologna (I744), in: Arte a Bologna: Bollettino dei Musei Civici d'Arte Antica, I, I99I, pp. 47-57; R. Grandi, Un Creti a metà (o qualcosa d'altro), ibidem., pp. I3I-I32.

7 Marcello Malpighi (Crevalcore, Bologna, I628 - Rome, 1694) was one of the first physicians to stand for the empirical method. His revolutionary studies on the nervous system and on the lungs opened up new perspectives in modern medicine. Gaspare Tagliacozzi (Bologna, 1545-1599) was the inventor of a plastic surgery technique that enabled doctors to reconstruct mutilated noses and faces. The wooden statues in the Archiginnasio Anatomy Theatre portray twelve famous doctors from antiquity to modern times in full figure (Hippocrates, Galen, Fabrizio Bartoletti, Girolamo Sbaraglia, Marcello Malpighi, Carlo Fracassati, Mondino de' Liuzzi, Bartolomeo da Varignana, Pietro d'Argelata, Costanzo Varolio, Giulio Cesare Aranzio and Gaspare Tagliacozzi). On the upper level are placed the busts of twenty anatomists. The allegorical statue of Anatomy sits on the canopy over the professor's cathedra, held by two impressive wooden statues of ecorchés drawn by Ercole Lelli (Bologna, I70I-1766) and carved by Silvestro Giannotti (Lucca, I680 - Bologna, I750). 
demia Clementina of Fine Arts, moved a great part of the scientists' attention from the Archiginnasio to the new seat of the institution, Palazzo Poggi. Here, thanks to General Luigi Ferdinando Marsili, a collector and a man of science as well as a diplomat and an expert in strategy, and to Pope Benedict XIV, both academies were endowed with many extremely modern camere that attracted the attention of princely and academic visitors from all over the world. Contacts with the French Académie des savants and with the Royal Academy of Sciences made the Bolognese Istituto one of the most renowned bodies in Europe working with empiricism and experiments. Especially celebrated were the Museo delle Navi with its wooden models of the most modern vessels sailing the seas, and the Anatomy cabinet with its hyper-realistic wax statues of Adam and Eve (flanked by their anatomic selves ecorchés, showing superficial as well as deep muscles and skeletons) and also hosting a great number of detailed preparazioni of systems and organs made by two well known specialists in the field, Anna Morandi (Bologna, I7I4-I774) and her husband Giovanni Manzolini (Bologna, I70o1755). ${ }^{8}$ Thanks to Pope Benedict XIV the Istituto also owned a rich collection of prints, antique statues and plaster casts, including a complete series of models of life-size terracotta wombs to teach doctors as well as midwives how to master all the most modern techniques and tools to help child birthing. Extremely updated devices enabled scientists to experiment with optics, light and sound and, thanks to the Specola, the astronomical observatory built over Palazzo Poggi's

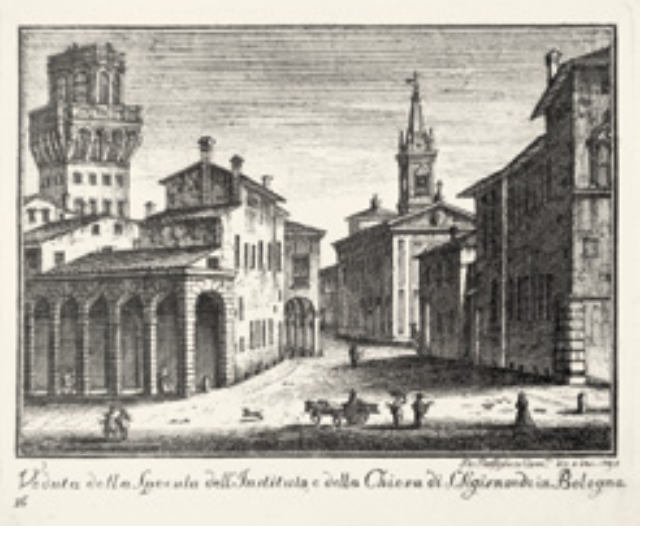

Fig. 7: Pio Panfili, Veduta della Specola dell'stituto, etching, Bologna, Collezioni Storiche della Fondazione Cassa di Risparmio di Bologna.

roof, Eustachio Manfredi was able to write his works on the stars (Fig. 7). ${ }^{9}$

The patronage granted to both academies justifies the erection of memorials inside the building to commemorate its founders, General Marsili and Pope Benedict XIV. The memory of professors was preserved especially through their painted portraits, generally in standard measures and hanging on the palace walls, a practice that would increase with the unification of the University and the two academies in the same building and become official after Napoleon's reformation of Italian universities in 1805 . The original nucleus of this collection of portraits of great men, today divided between the Biblioteca Universitaria and the University of Bologna, starts with the bequests to the Istituto of many local private collections of portraits, encouraged by Pope Benedict XIV. These portraits

8 Pope Benedict XIV commissioned the eight wax statues designed by Ercole Lelli and made by sculptors specialized in anatomical preparations, while the wax systems by Anna Morandi and Giovanni Manzolini, together with their works for the gynecologist Giovanni Antonio Galli were bought by the Bolognese Senate for the university laboratories. About these anatomy artists see R. Messbarger, The Lady Anatomist: the Life and Work of Anna Morandi Manzolini, Chicago 2010.

9 For a general knowledge on the Bolognese Istituto delle Scienze see I Materiali dell'Istituo delle Scienze (exh. cat. Bologna, Accademia delle Scienze), Bologna 1979; Guide to Palazzo Poggi Museum: Science and Art (ed. W. Tega), Bologna 2002. 


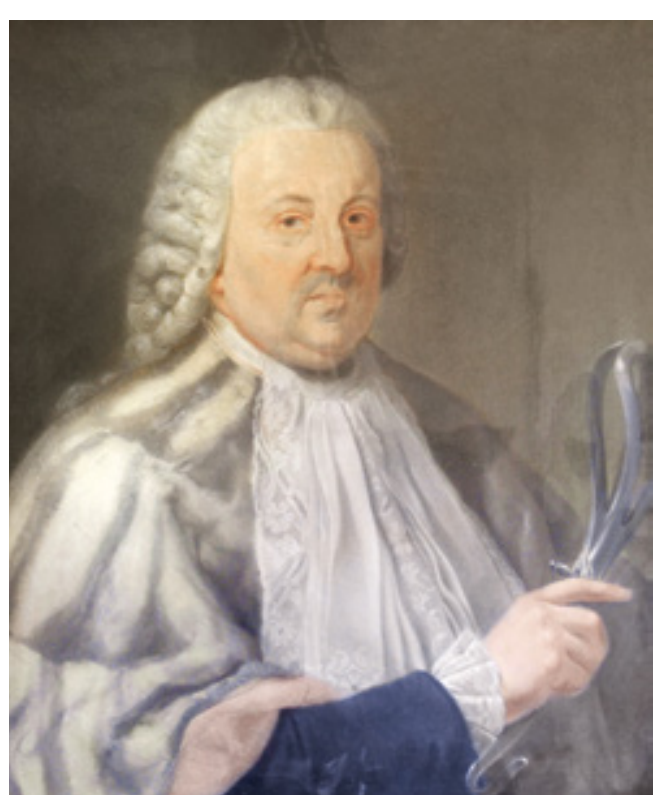

Fig. 8: Angelo Crescimbeni, Portrait of Giovanni Antonio Galli, Bologna, Museo di Palazzo Poggi.

depicted not only university professors, but also musicians, artists, members of the local nobility and scientists; not all of them were members of the Studio, but rather of the Accademia delle Scienze or of both institutions (Fig. 8). ${ }^{\text {I }}$

For the same reason only few of the carved memorials inside Palazzo Poggi were dedicated to famous university professors. Most of them were instead celebrations of kings and popes (Benedict XIV and Pius VII, Vittorio Emanuele II and Umberto I of Savoy), some were dedicat- ed to founders of academies or benefactors, such as Francesco Pannolini, Luigi Ferdinando Marsili, and the Duke of Curlandia. ${ }^{\text {II }}$

The few memorials dedicated to scholars are still visible in the loggia on Palazzo Poggi's first floor. One of them, the monument of the physician Luigi Galvani carved in marble by the neoclassical sculptor Giacomo De Maria (Fig. 9) only slightly differs from the early marble monumental tombs dedicated to the illustrious deceased inside the new public cemetery of Bologna, La Certosa. Opened in I8or in order to satisfy the modern need of burial outside the city gates, the public cemetery was a refurbishment and adaptation of Bologna's charter house, founded in I334 and abandoned by the monks in 1797 after the Napoleonic suppressions. The claims by the nobility and the bourgeoisie for distinguished tombs inside the cemetery were satisfied, enabling them to buy special areas for monumental sepulchres. A comparison between the memorial of Luigi Galvani in Palazzo Poggi and the tomb of the nobleman and scientist Prospero Malvezzi shows striking similarities, such as the employment of rare and antique marbles mostly imported from Rome and the adoption of a lay symbolic language, in which the female figures representing the virtues in Galvani's monument are paralleled by the Genius of Knowledge surrounded by scientific paraphernalia (Fig. Io). The same visual analysis can be applied to more modest monuments, like the tomb of the cele-

Io G. Gandolfi, Imagines Illustrium Virorum: la collezione dei ritratti dell'Università e della Biblioteca Universitaria di Bologna, Bologna 20 o.

II The merchant Francesco Pannolini was the creator of a college for poor but talented university students. His marble bust, today in the Collezioni Comunali d'Arte of Bologna, comes from the Istituto delle Scienze. It was commissioned in Rome from the Bolognese sculptor Agostino Corsini by Pope Benedict XIV (A. MampIERI, Roma- Bologna. Le statue dei santi Pietro e Paolo per il completamento della facciata della Metropolitana di S. Pietro, in: Benedetto XIV e la facciata della cattedrale di Bologna (ed. R. Terra/ G. Cavina), Ferrara 2008, pp. 39-53). Ernst Johann Biron, Duke of Curlandia, was so impressed during his stay in Bologna by the organisation of the institute that he promoted an annual prize for young artists attending the Accademia Clementina, namely, the Premio Curlandese. For this reason the academy dedicated to him a memorial planned by the architect Angelo Venturoli (Medicina, Bologna, I749 - Bologna, I82I) and carved by the neoclassical sculptor Giacomo De Maria (Bologna, I760-I838). See I concorsi Curlandesi: Bologna Accademia di Belle Arti 1785-I870 (exh. cat. 1980) ed. C. PoppI and E. FARIOLI. 


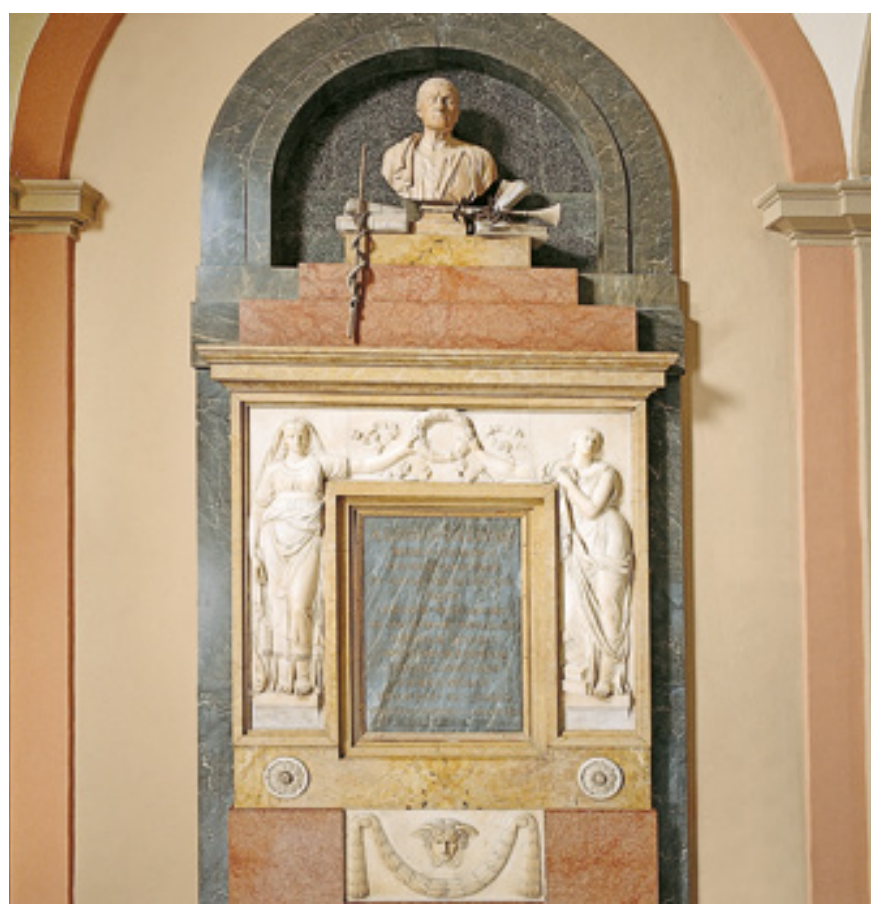

Fig. 9: G. Maria, Monument to Luigi Galvani, Bologna, Museo di Palazzo Poggi.

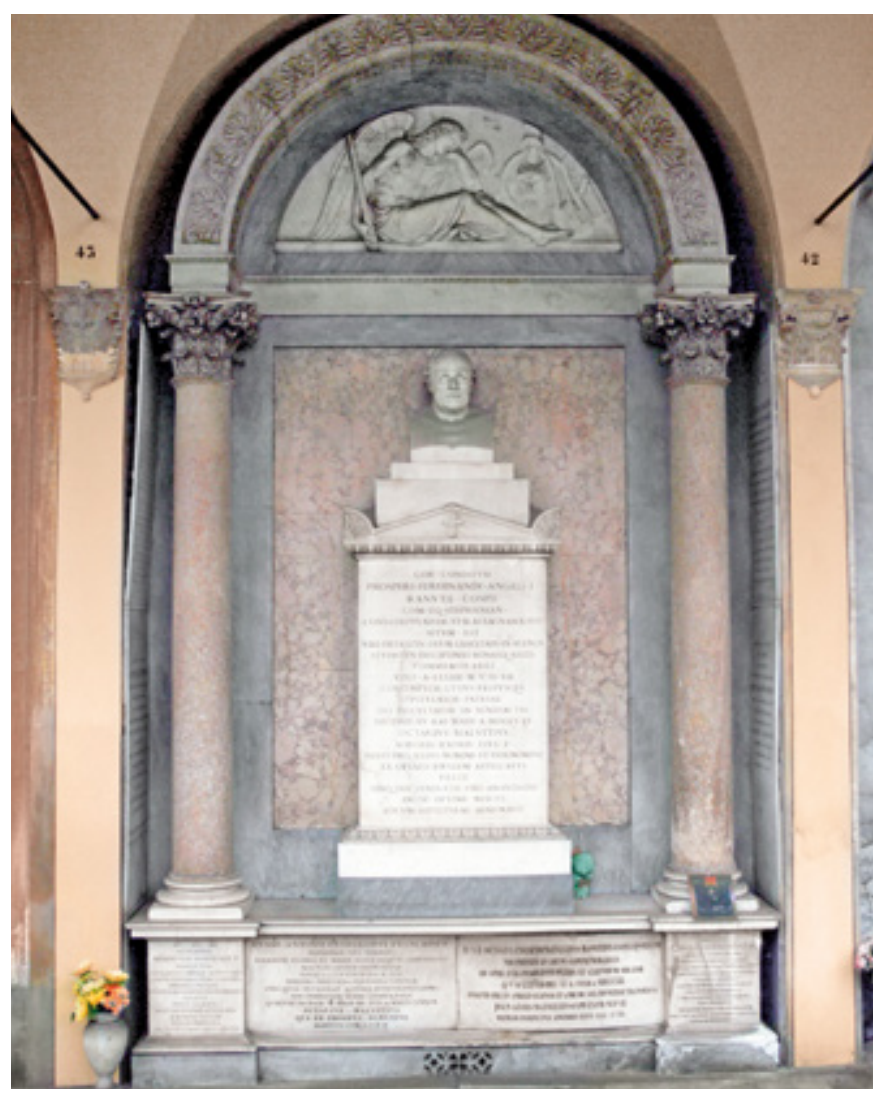

Fig. Io: G. De Maria, Tomb of Prospero Malvezzi, Bologna, Municipal Cemetery. 


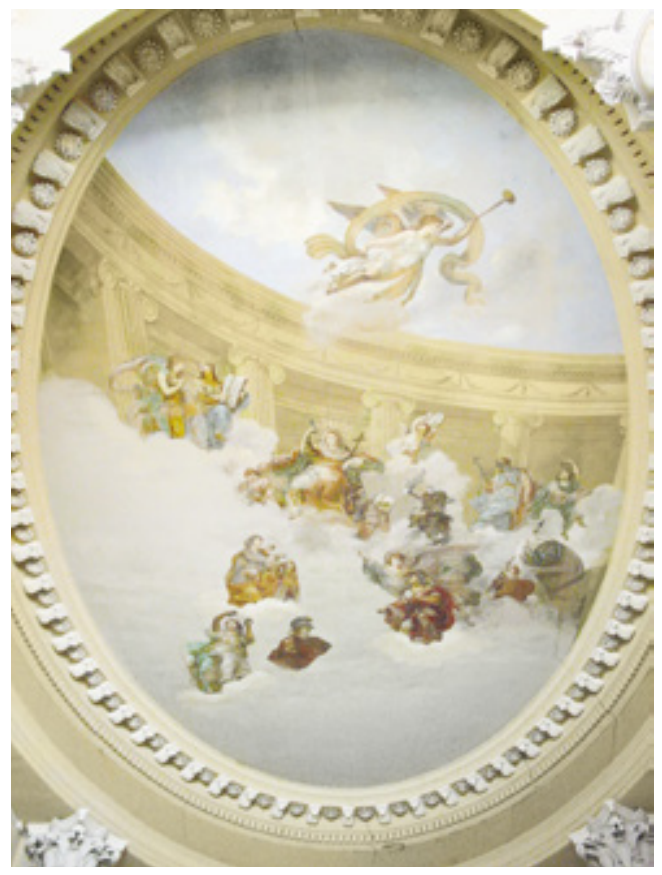

Fig. II: Filippo Pedrini, Bologna introduced to the Triumphant Catholic Religion by Wisdom in the presence of the Arts and Sciences, Bologna, Municipal Cemetery, Pantheon. brated woman professor of Greek Literature Clotilde Tambroni in the same cemetery, and the monument of her colleague Laura Bassi in Palazzo Poggi's loggia.

In the same cemetery, the earliest painted funeral monuments call to mind the memorials in the Archiginnasio. The tomb of the famous physician Tarsizio Riviera can be compared with the monument of Marcello Malpighi. The figural language is the same, as well as the use of lay virtues and allegories still coming from Ripa's Iconography. While Malpighi's memorial is hosted in a deep niche in perspective, Riviera's pyramid stands in the foreground against a lively garden background. Both works are an homage to the illusionistic tradition of Bolognese quadratura painting. ${ }^{\mathrm{I}}$

In 1828 the papal administration of the cemetery favoured the creation of a hall dedicated to the illustrious men who had helped the development of Bologna. Also on this occasion they were not only university professors, even if the institution was very well represented. The

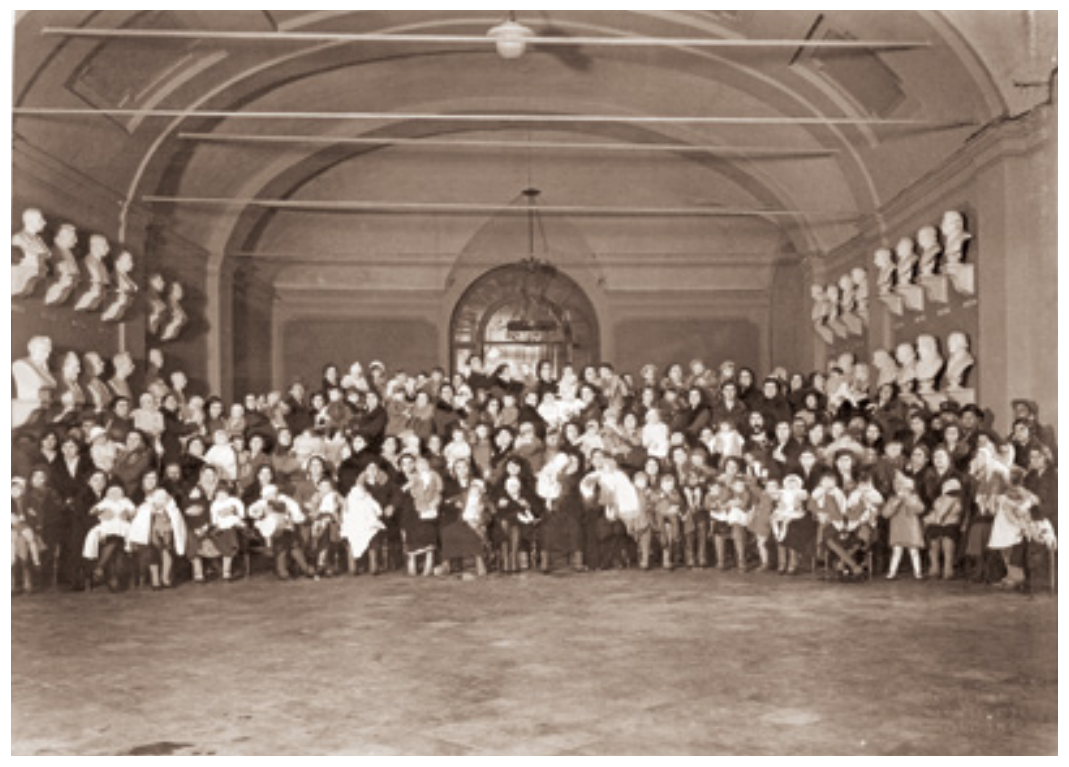

Fig. 12: The busts of the Bolognese Great Men in Sala d'Ercole, 1933, Bologna, Municipal Archive.

I2 For Bologna Municipal Cemetery and its tombs: La Certosa di Bologna: immortalità della Memoria (ed. G. PESCI), Bologna 1998 . 


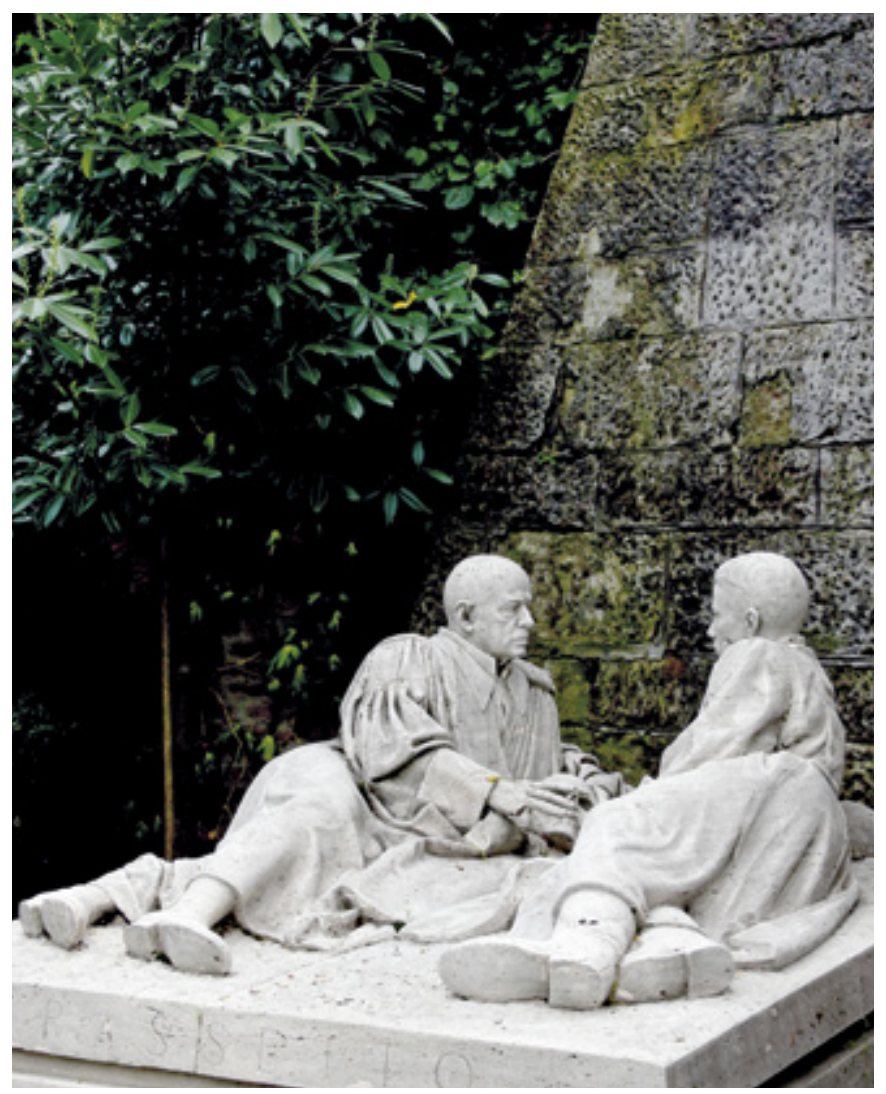

Fig. 13: Farpi Vignoli, Tomb of Fabio and Flavio Frassetto, I95I, Bologna, Municipal Cemetery.

names of the illustrious citizens were selected by the municipality after a thorough examination of their works, merits and curricula. They were honoured with the gift of a sepulchre in the crypt under the hall floor and with the dedication of a marble bust on a bracket of the same stone placed on the walls of the Pantheon. The sculptures were the work of local artists chosen by the local government among the professors and pupils of the local Academy of Fine Arts. This Hall of Fame, today a room for lay funerary ceremonies and therefore dramatically changed, stood on the area formerly occupied by the cell of the Car- thusian prior, enlarged with the elimination of the subdivision between the ground and first floors. The original square plan was changed into an oval shape framed by pairs of Corinthian columns supporting a vault. On the ceiling, the painter Filippo Pedrini represented an allegory of Wisdom introducing Bologna to the Catholic religion in the presence of the Sciences and the Arts while Fame blew her trumpet above their heads (Fig. II). ${ }^{\text {I3 }}$

In 1927 when the Pantheon was officially closed, the marble busts of the great men were moved to the first floor of the town hall, inside

I3 A. Mampieri, Filippo Pedrini e la decorazione della Sala degli Uomini Illustri e Benemeriti del cimitero comunale della Certosa, in: Aperto. Bollettino del Gabinetto dei Disegni e delle Stampe della Pinacoteca Nazionale di Bologna, n. 2, http://www.aperto.gdspinacotecabo.it/?q=node/477 


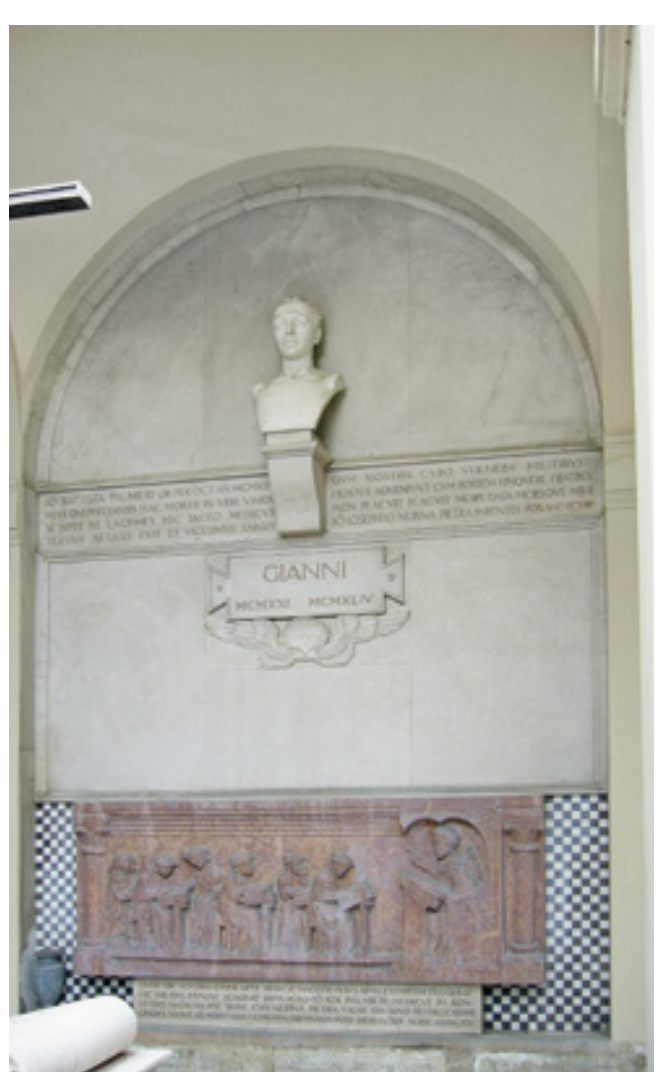

Fig. I4: Luigi Saccenti, Tomb of Giovanni Battista Palmieri, I940, Bologna, Municipal Cemetery.

the Sala d'Ercole. We can still see them in the background of an old photograph dated 1933 (Fig. I2). Moved in 1934 to a public park, they were progressively maimed and damaged by vandalism and war and had to be stored in the Modern Art Gallery by the I970s to save them from complete annihilation. Some of them have been recently restored and are now back in the town hall, some are still in storage waiting to be restored.

While the Pantheon celebrated the town's great men, the habit of building impressive funerary monuments to university professors continued, adopting a modern artistic language and at the same time employing citations from the past. This is clearly visible in two significant tombs. In the monument of the professor of anthropology Fabio Fassetto, carved in 1950 by Farpi Vignoli, the two gisants lay vis à vis looking into each other's eyes, the professor is clad in a toga and rests his hand on a skull while his son Flavio wears a Second World War uniform, alluding to his premature death (Fig. I3). In the tomb of the professor of medicine Giovanni Battista Palmieri, the lower part of the monument frames a modern copy of the medieval relief of the professor of anatomy Mondino de' Liuzzi’s sepulcral monument, thus ideally bringing us back to the start of the celebration of Bolognese scholars and their medieval monumental tombs (Fig. I4).

Photographic acknowledgements: Fig I: Mambo, Bologna; Fig. 2: by the author; Fig. 3: Museo Civico Medievale, Bologna; Fig. 4, 5, 6: Biblioteca Comunale dell'Archiginnasio,Bologna; Fig. 7: Collezioni d'Arte e di Storia della Fondazione Cassa di Risparmio di Bologna; Fig. 8: Musei Universitari di Palazzo Poggi, Bologna; Fig. 9, Io, 13, I4: Museo Civico del Risorgimento, Bologna, Photo Roberto Martorelli; Fig. I2: Municipal Archive, Bologna

I4 Both tombs depict university professors, but while the first one stresses the family bond between father and son and employs the academical toga only to underline the social role of professor Frassetto in parallel with his son's military uniform, in Palmieri's monument the connection is between the university professor's celebration in a sort of unbroken line. See La Certosa di Bologna (cit. n. I2) pp. 298-9 and p. 314.; La Certosa di Bologna: guida (ed. G. Pesci), Bologna 20oI. 


\title{
RICORDO MONUMENTALE ... LE TARGHE, I BUSTI E I MONUMENTI DELL'ACCADEMIA DI BELLE ARTI E DELLE GALLERIE DI VENEZIA
}

\author{
Elena Catra
}

Chi ha visitato le Gallerie dell'Accademia di Venezia, descriverebbe il museo come una pinacoteca, se non fosse per la presenza del così detto Vestibolo, un luogo di passaggio arricchito dalle sculture di Giacomo De Martini ${ }^{1}$, Antonio Giaccarelli ${ }^{2}$ e Rinaldo Rinaldi ${ }^{3}$ eseguite tra gli anni dieci e venti dell'Ottocento.

Quando il conte Leopoldo Cicognara nel I808, alla morte di Almorò Pisani, assunse l'incarico di Presidente della rifondata Accademia di Belle Arti si trovò impegnato nel restauro dell'edificio della Carità (Chiesa e Scuola) per adibirlo a istituto d'arte e collezione. Passarono quasi dieci anni prima che l'edificio fosse inaugurato e aperto al pubblico. Nel I8I7 Cicognara inaugurando la Galleria, dopo essersi soffermato a lungo sull' Assunta di Tiziano, asseriva:

E quanto con si adatta ordinanza vedete a far corona a questo patrio giojello, e quanto contiensi in altre quattro sale adiacenti, ove e marmi, e bron$z i$, e tavole, e tele stanno egualmente distribuitet
Quanto affermato dal presidente e riportato nei cataloghi delle Gallerie, ove si elencano gli oggetti esposti, ci fa intendere che si mirava a uno studiato equilibrio tra pittura e scultura. Questa armonia venne meno sul finire del XIX secolo, quando l'allora direttore Giulio Cantalamessa riorganizzò le Gallerie a vantaggio della pittura, relegando nei depositi la quasi totalità delle sculture. Sono infatti diverse le opere che vengono ricordate dalle fonti e oggi non reperibili nella loro collocazione originaria, o perché rimosse (quelle attualmente visibili negli spazi delle Gallerie dell'Accademia) e spostate di collocazione (quelle negli spazi dell'ex Accademia), oppure perché addirittura eleminate o sostituite. ${ }^{5}$

Come vedremo, dal I8I7 in poi, nelle sale delle Gallerie e successivamente negli spazi adibiti alla scuola, prenderanno posto monumenti, busti e lapidi che andranno a celebrare donatori, grandi artisti del passato e del presente, imperatori, sovrani, nonché professori di spic-

I Giacomo De Martini (Venezia, I793 - I84I). Per un profilo cfr. E. CaTra, Canova come Fidia: le metope e i fregi per il Tempio di Possagno, in Canova. L'ultimo capolavoro. Le metope del Tempio, (catalogo della mostra di Milano, Galleria di Piazza Scala, 3 ottobre 20I3 - 6 gennaio 20I4), (a cura di M. Ceriana / F. Mazzocca / E. Catra), Cinisello Balsamo 2013, pp. 37-38.

2 Antonio Giaccarelli (Venezia I799 - I838). Per un profilo cfr. F. De Boni, Biografia degli artisti, Venezia I840, p. 420.

3 Rinaldo Rinaldi (Padova I793 - Roma I873). Per un profilo sullo scultore si veda: M.A.G. [Giovanni Antonio Moschini], Alla ornatissima signora T.C.E., a Padova, in: Giornale sulle scienze e lettere delle provincie venete, VIII/7, I825 e M. S. Lilli, Rinaldo Rinaldi, in: Antologia delle Belle Arti, IV, I3-I4, I980, pp. 94-IOO.

4 L. Cicognara, Prolusione, in: Discorsi letti nella grande aula dell'I.R. Accademia di Belle Arti in occasione della solenne apertura di una delle sue nuove Gallerie, e della pubblica distribuzione dei Premii..., Venezia I8I7, p. I3.

5 Si sono perse le tracce dei Busti di Federico Moja, Davide Rossi e dell'Imperatore Ferdinando I. 


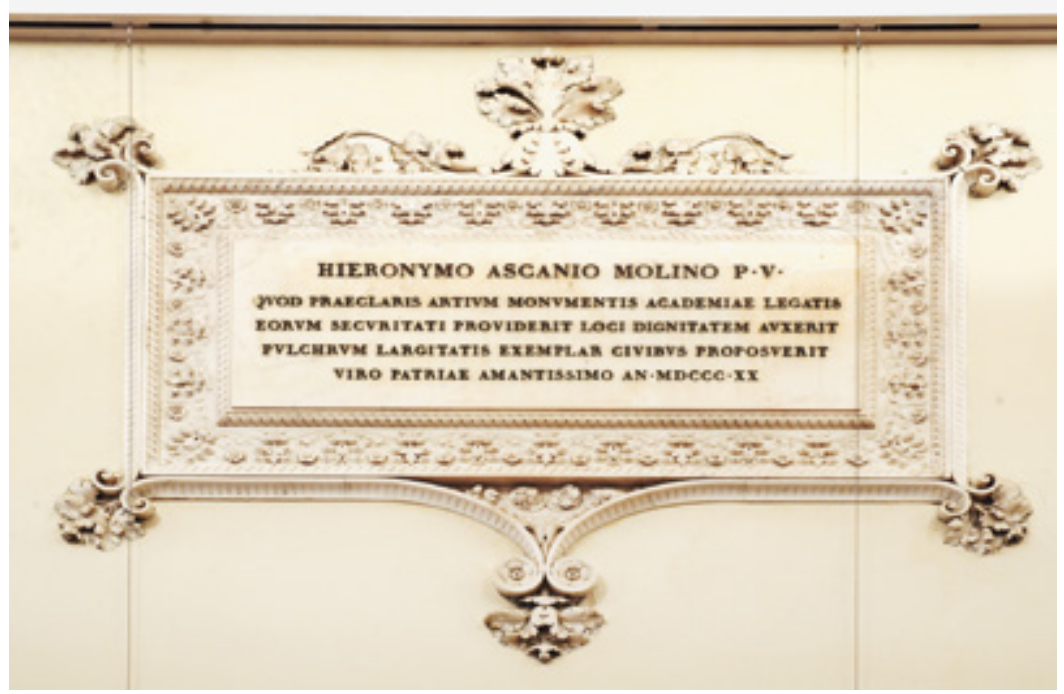

Fig. I: Giacomo Spiera, Targa in Onore di Ascanio Molin, marmo, I819-1820, Venezia, Gallerie dell'Accademia.

co dell'Accademia. Tutte queste opere di diversa estrazione pervennero alle Gallerie tramite comitati costituiti dalla stessa Accademia o da privati, come pure grazie a donazioni di singoli collezionisti.

Possiamo ricostruire la storia dell'arricchimento del patrimonio statuario dell'Accademia - inizialmente di marmi e poi, nella seconda metà del XIX secolo, prevalentemente di bronzi - attraverso lo spoglio dei documenti conservati all'Archivio storico dell'Accademia di Belle Arti, che in alcuni casi conserva anche i disegni preparatori e i progetti per gli apparati relativi al monumento.

Parallelamente a quello di Milano - lo Statuto dell'Accademia veneziana nella prima versione del I803 (riaggiornato sotto il governo austriaco) prevedeva nelle 'diposizioni generali' al punto 9:

L'Accademia giudica, e risolve per l'erezione di un monumento di marmo, oltre la lapide decretata dalla Legge 4 Settembre I802 (Anno I) a chiunque aumenta considerabilmente la suppellettile o la dote dello stabilimento. ${ }^{6}$

Questa è l'unica disposizione ufficiale relativa ai monumenti in marmo da erigere in Accademia, ma chiaramente si riferisce solo ai personaggi che avrebbero effettuato cospicue donazioni.

$\mathrm{Al}$ contrario, in tutta la storia dell'Accademia di Venezia, furono in seguito apposte solo due lapidi di questo tipo, nonostante le numerose donazioni importanti.

L'unica lapide ancor oggi visibile nelle sale delle Gallerie - anche se non più nella sua ubicazione originaria - è quella dedicata a Girolamo Ascanio Molin [Fig. I], di cui si conservano ancora i documenti relativi alla commissione ed esecuzione. Un anno dopo la firma del verbale di consegna da parte del legato Molin7, il 25 aprile i8r7 l'Accademia e il Governo si accordarono per la realizzazione di una solenne lapide in onore del donatore. Scelto come luogo più adatto il Vestibolo ${ }^{8}$, nel I8I9 lo scalpellino Giacomo Spie-

6 Statuto Napoleonico, in: Elena Bassi, La R. Accademia di Belle Arti di Venezia, Firenze 194I, pp. I84-I85.

7 Il verbale porta la data I4 agosto I8I6.

8 AABAVe, Atti, I820, b. I5, c. $\mathrm{N}^{\circ}$ I90 Venezia, 9 Novembre 1820. 


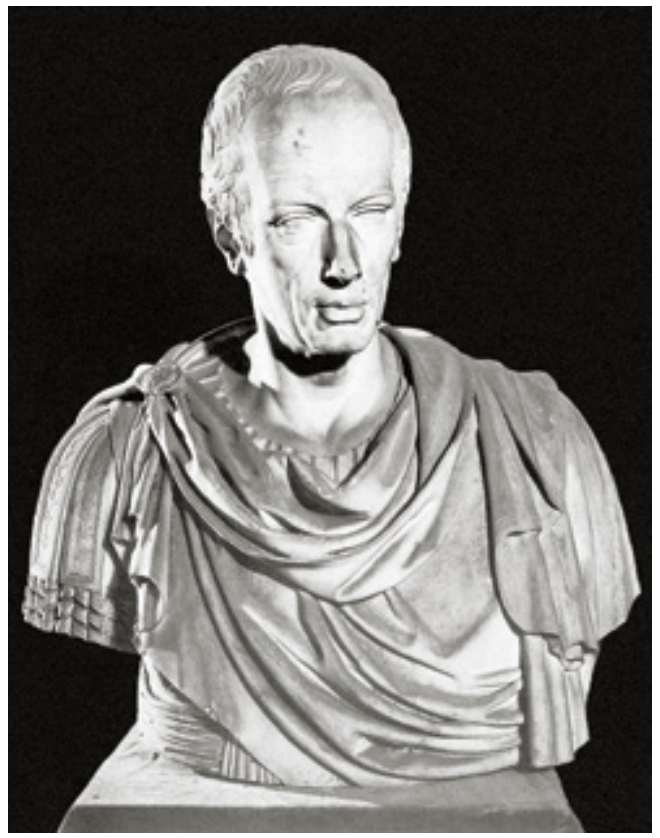

Fig. 2: Angelo Pizzi, Busto dell'Imperatore Francesco I, marmo, I8I7, Venezia, Gallerie dell'Accademia (depositi).

ra ${ }^{9}$, a cui era stato affidato il lavoro, consegnò i disegni preparatori e il preventivo di spesa; nel I82I il monumento fu inaugurato.

Nel I820 fu quindi dedicata una lapide al reggente d'Inghilterra Giorgio IV in ricordo della donazione di ventitré calchi delle statue e bassorilievi del Partenone, appartenenti alla collezione di Lord Elgin, di cui oggi non si trova traccia, essendone andati persi persino i documenti in merito alla realizzazione. ${ }^{\text {I }}$

Oltre a quelle di Girolamo Ascanio Molin e di Giorgio d'Inghilterra, numerose furono le

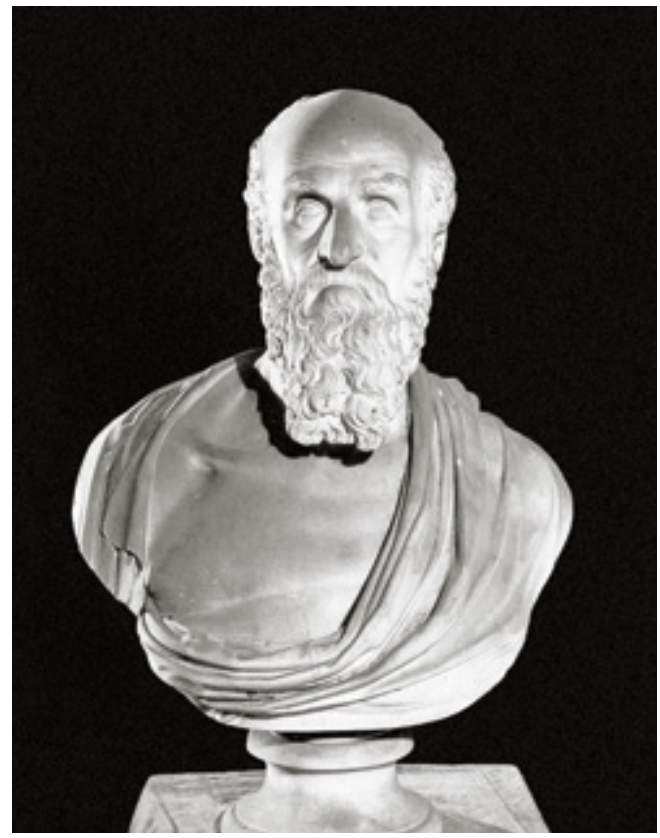

Fig. 3: Rinaldo Rinaldi, Busto di Tiziano, marmo, I816, Venezia, Gallerie dell'Accademia.

cospicue donazioni in favore dell'Accademia: tra queste si ricordano quelle di Massimiliano I Giuseppe Wittelsbach re di Baviera (I823), Girolamo Contarini (1838), Maria Felicita Berand Hellmann, vedova di Bernardino Renier (I850) e la collezione di Giacomo Manfrin (1856). Per nessuna di queste pare sia stato eretto alcun monumento in memoria.

Nello stesso I8I7 nella Sala delle Riunioni Accademiche o delle Sedute venivano raccolti ed esposti gli oggetti e le immagini più preziose appartenenti all'Accademia. ${ }^{\text {II }}$ Qui, contornato da

9 Giacomo Spiera (Venezia, I792-I874), per un profilo completo si veda E. CaTra, Canova come Fidia (vedi n. I), pp. 37,43 .

Io E. BAssi, La Regia Accademia di Belle (vedi n. 6), p. 48. La targa recitava: RELIQVAE PHIDIACI OPERIS / E PARTHENONE ATHENARVM GYPSO DESVMPTAE / MDCCCXX. / EX MVNIFICENTIA REGIS ANGLIAE. Cfr. Antonio Emmanuele Cicogna, Corpus delle iscrizioni di Venezia e delle isole della laguna veneta di Emmanuele Antonio Cicogna ovvero riepilogo sia delle Iscrizioni edite pubblicate tra gli anni I824 e I853 che di quelle inedite conservate in originale manoscritto presso la Biblioteca Correr di Venezia e dal 1867, anno della morte dell'insigne erudito, rimaste in attesa di pubblicazione, a cura di P. Pazzi, Venezia 200I, p. I759.

II Per un catalogo delle opere contenute nella sala si veda: Catalogo delle Opere d'Arte contenute nella Sala delle Sedute dell' I.R. Accademia di Venezia, Venezia, I854. 
busti antichi e del Cinquecento, venne collocato il Busto dell'Imperatore Francesco I realizzato dal professore di scultura Angelo Pizzi [Fig. 2]. ${ }^{12}$ Nella stessa sala, qualche anno dopo, presero posto due opere di Giacomo De Martini e Rinaldo Rinaldi, realizzate quali saggi per il secondo anno di "alunnato" a Roma; si trattava di due busti che rappresentavano rispettivamente: Venezia adornata del Corno Ducale ${ }^{\mathrm{I3}}$ e Tiziano [Fig. 3]..$^{\mathrm{I}}$ Con il ritratto di questo grande artista veneto prendeva avvio la celebrazione dei cosiddetti "padri” dell'arte veneziana. Non è un caso che la serie di ritratti si aprisse con la figura di Tiziano: a lui Cicognara aveva dedicato il suo primo elogio nel $1^{809^{15}}$ e per tutto il secolo fu celebrato come il pittore esemplare, modello per i giovani, assieme allo scultore Canova.

Se lo Statuto disciplinava l'accoglimento di monumenti in onore dei mecenati dell'Accademia, nel I822 un avvenimento storico - la morte di Canova - aprì la strada all'erezione di monumenti in onore non solo dei collezionisti e donatori, ma anche di personaggi famosi legati all'Accademia per avervi svolto un ruolo importante.

Antonio Canova morì a Venezia la mattina del 13 ottobre I822. ${ }^{16}$ Il giorno seguente, alcuni medici eseguirono l'autopsia del cadavere. Una lettera scritta la mattina stessa annunciava:

Oggi faranno la sezione del cadavere, il quale sarà mandato a Possagno dopo essere stato imbalsamato; il suo cuore all'Accademia di Belle Arti, che gli innalzerà un monumento ${ }^{I 7}$

I funerali di Canova furono celebrati in forma solenne il 16 ottobre nella Basilica di San Marco e l'orazione funebre fu letta dal conte Leopoldo Cicognara, allora Presidente dell'Accademia di Venezia. Lo stesso giorno dei funerali, la commissione dell'Accademia, sotto l'egida di Cicognara, aprì i registri per la raccolta di fondi, al fine di edificare un mausoleo in onore del sommo scultore, con il contributo di tutte le nazioni europee.$^{18}$ Inoltre:

Nel giorno del pubblico lutto per la morte di Antonio Canova, splendor dell'Europa e più particolarmente di Venezia, l'Accademia di Belle Arti decreta erigere un pubblico monumento, il più degno che per lei si potesse [...]. Frattanto quest'Accademia, ambiziosa di segnalare se stessa senza l'intervento di alcun estraneo sussidio, erige nel proprio recinto un segnale di devozione destinato a racco-

I2 Cfr. Elenco degli oggetti di belle arti disposti nelle cinque sale apertansi nell'agosto del I8I7 nella R. Accademia in Venezia, Venezia I8I7, pp. 3I-32. Il busto dell'Imperatore Francesco I si trova oggi nei depositi delle Gallerie dell'Accademia. S. M. Marconi, Gallerie dell'Accademia di Venezia. Opere d'arte dei secoli XVII, XVIII, XIX, Roma I970, p. 232 (n. 576) e fig. 576. Per un profilo su Angelo Pizzi si veda E. NoÈ, Lo scultore Angelo Pizzi (Milano I775-Venezia I8I9), in: Saggi e memorie di storia dell'arte, n. 36, 20I2, pp. 235-3I4.

I3 Cfr. S. M. Marconi, Gallerie dell'Accademia (vedi Nota. I2), p. 228 (n.556) e fig. 554.

I4 Ivi, p. 233 (n. 578 ) e fig. 578.

I5 L. Cicognara, Elogio di Tiziano Vecellio, in: Discorsi letti nella R. Veneta Accademia di Belle Arti per la distribuzione de' premi, Venezia, Venezia I809, pp. 3-29. Sulla fortuna di Tiziano nel XIX a Venezia si veda in particolare: V. Gransinigh, Aspetti della fortuna critica, iconografica e artistica di Tiziano a Venezia nella prima metà dell'Ottocento, testi di specializzazione, Università degli Studi di Udine, I998-I999.

I6 Lettera di un anonimo a Giuseppe Monico pubblicata da R. VArese, Prefazione, in: P. A. Paravia, Notizie intorno alla vita di Antonio Canova giuntovi il catalogo cronologico di tutte le sue opere, Venezia (Ristampa anastatica, Bassano del Grappa, 20oI, p. XCIV) e P. ZANNINI, Storia della malattia per cui è morto Antonio Canova, Venezia I822.

I7 Per i dettagli sull'intera vicenda del Monumento ad Antonio Canova all'Accademia di Belle Arti di Venezia si veda E. NoÈ, Il Monumento a Canova dell'Accademia di Venezia, in La mano e il volto di Antonio Canova. Nobile semplicità, serena grandezza, (catalogo della mostra, Possagno, Museo Gipsoteca Antonio Canova), (a cura di M. Guderzo), Treviso 2008, pp. 93-97.

I8 ASVe, Governo Veneto, I823, b. 2174, f. XVI 2/7, Rubrica Accademia delle Belle Arti, Oggetto Monumento Canova e L. Cicognara, Lettera sul monumento da erigersi in Venezia alla memoria di Antonio Canova, del co. Cicognara presidente della I.R. Accademia di Belle Arti, all'egregio Sig. Ab. Gio. Battista Canova, Venezia li 25 Dicembre I822, Venezia I822. 


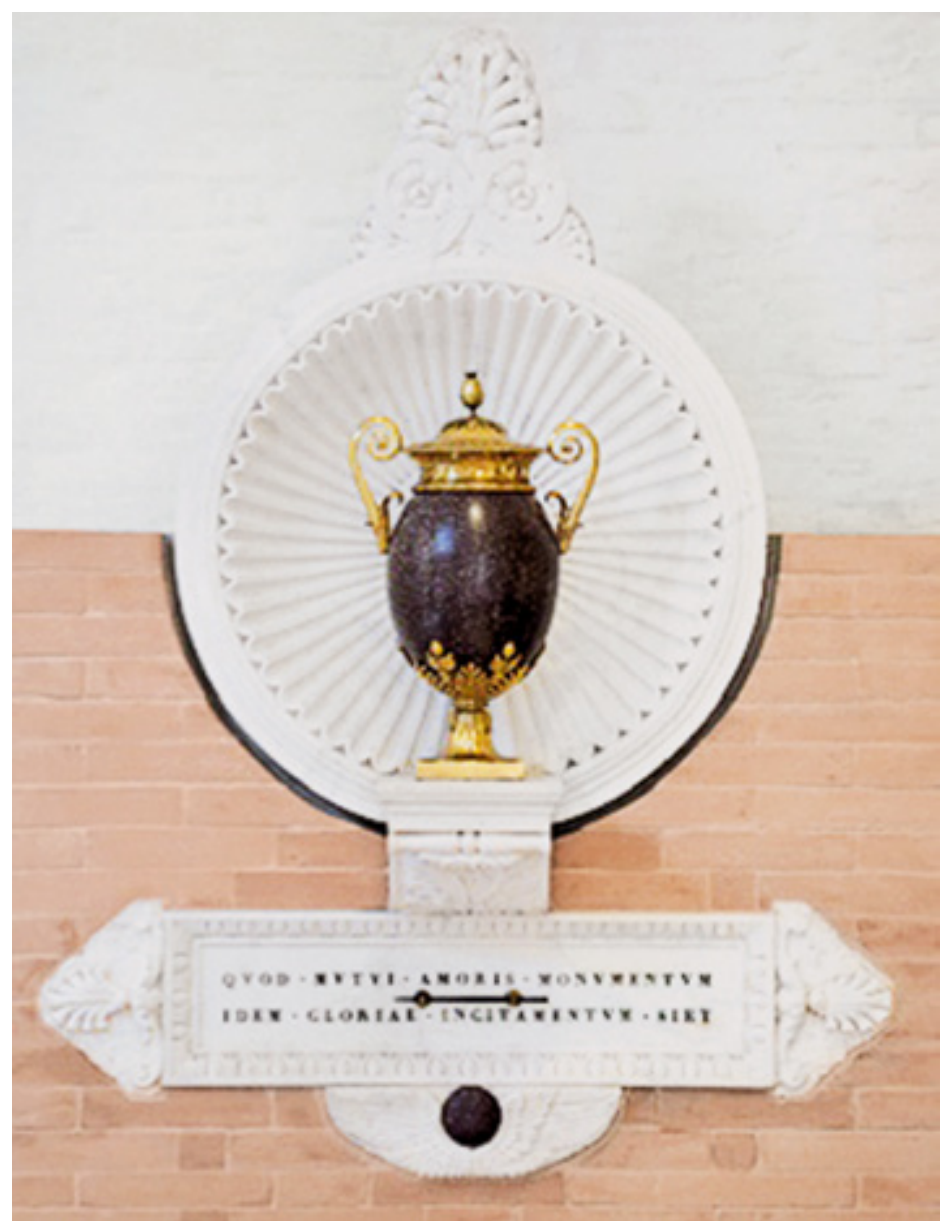

Fig. 4: Giuseppe Borsato/Bartolomeo Bongiovanni, Monumento alla mano di Antonio Canova, porfido, marmo e bronzo, Venezia, Gallerie dell'Accademia.

gliere e custodire il cuore del suo amorosissimo concittadino e fratello. ${ }^{19}$

Il monumento promesso, contenente il cuore di Canova, fu collocato nella sala delle Riduzioni, corrispondente all'odierna sala III delle Gallerie e venne inaugurato il $2 \mathrm{I}$ gennaio $\mathrm{I} 824$, con un discorso di Cicognara. ${ }^{20}$ Esso consisteva in un'urna ovale - di porfido rosso antico prove- niente dal Tesoro di San Marco - disegnata da Giuseppe Borsato con applicazioni in bronzo dello scultore Bartolomeo Bongiovanni [Fig. 4].

Una stampa del monumento, visto come memoria del reciproco amore tra Canova e gli accademici, nonché, per questi ultimi, quale incitamento alla gloria, fu edita nella guida accademica del $1826 .{ }^{2 \mathrm{r}}$

I9 M. Missirini, Vita di Antonio Canova Libri Quattro, Prato I824, pp. 450-I5I.

20 Si vedano: L. Cicognara, Allocuzione letta dal sig. Conte Leopoldo cav. Cicognara, Presidente della R. Accademia veneta nel dì 2I gennaro I824, giorno in cui fu dedicato il piccolo monumento da i soci Accademici all'immortale Canova, Venezia s.d. [I824] e "Gazzetta Privilegiata di Venezia", n. I9, 24 gennaio I824.

2I Guida per la Reale Accademia delle Belle Arti in Venezia, con alcune notizie riguardanti lo stabilimento stesso, Venezia I826, pp. 20-2I. 


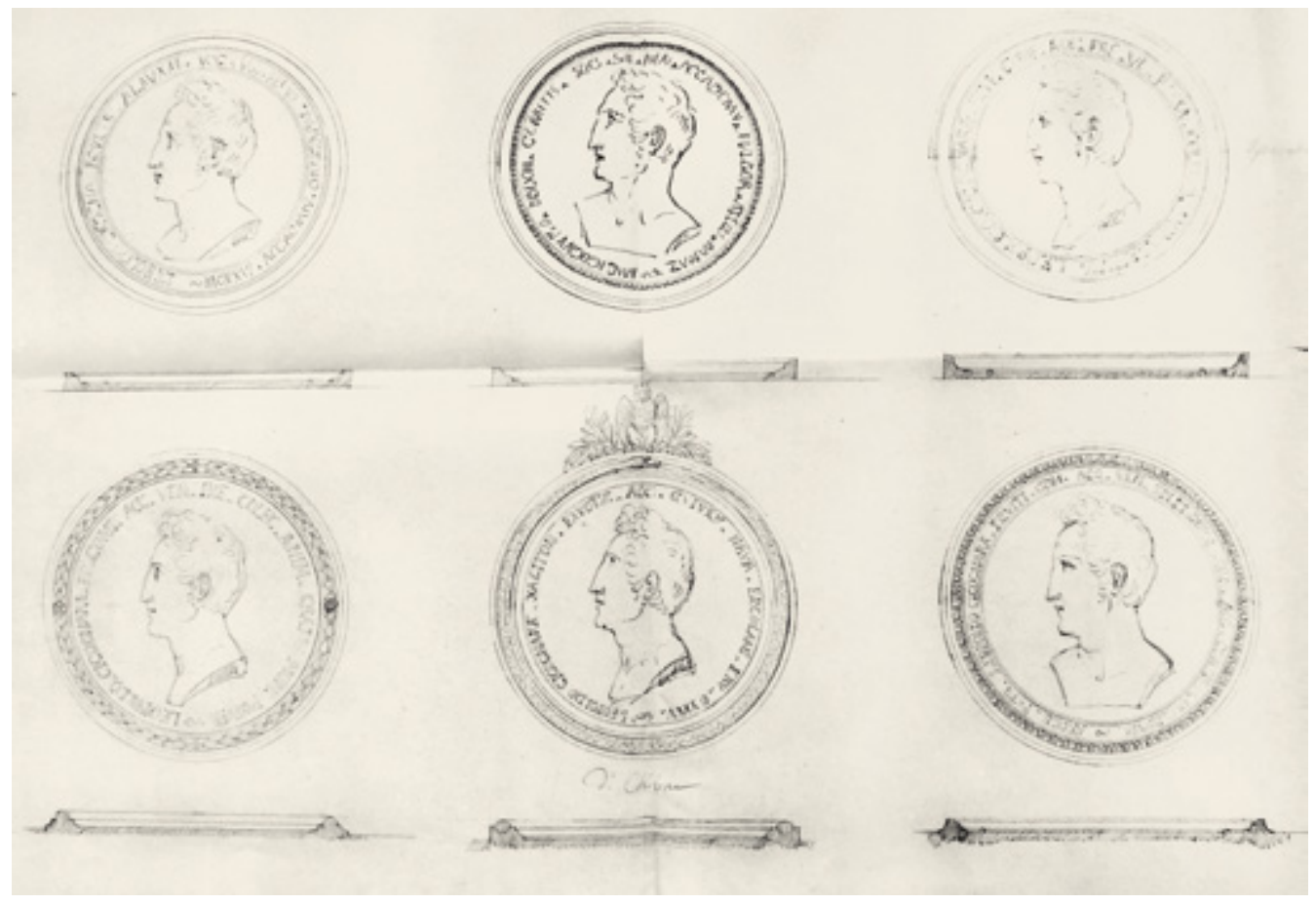

Fig. 5: Luigi Zandomeneghi, Disegni preparatori per il Medaglione di Leopoldo Cicognara, Venezia, Archivio dell'Accademia di Belle Arti.

Nel 1827, in seguito alla inaugurazione ai Frari del grande monumento a Canova, si decise di trasferirne anche il cuore in quella sede, e di collocare invece nel monumento in Accademia la mano destra del sommo scultore. L'avvenimento ebbe luogo il 9 luglio I828, sostituendo nella dedica incisa sull'urna la parola COR con la parola DEXTERA. ${ }^{22}$

Questi primi monumenti si inserivano nelle celebrazioni neoclassiche, quali si verificavano anche a Milano con l'obiettivo di esaltare le singole personalità di quello stile, indipenden- temente dal valore e dalle loro peculiarità estetiche. ${ }^{23}$

$\mathrm{Si}$ era intanto polemicamente dimesso nel I826 da Presidente dell'Accademia Leopoldo Cicognara. Gli accademici, che pur avendolo avversato, gli dovevano riconoscenza per il prestigio con il quale egli aveva ricoperto il suo ruolo, decisero di rendergli omaggio dedicandogli un medaglione marmoreo con il suo profilo contornato da un uroboro, ossia il serpente che si morde la coda, e la scritta: LEOPOLDO CICOGNARA PRAESIDI BENEMERENTI ACADEMICI [Fig. 5].

22 L'intero processo verbale è stato pubblicato da E. Nò̀, Il Monumento a Canova (vedi Nota. I7), pp. 94-95. Come riferito da Noè il monumento venne smantellato nel 1946 dalla Sala della Riduzioni per essere trasferito nel Tablino palladiano, spazio ufficialmente di pertinenza dell'Accademia di Belle Arti. Ora il monumento privo del suo contenuto, in ottemperanza ad una clausola dell'epoca, è stato rimontato da Tobia Scarpa. Su quest'ultimo argomento si veda M. Ceriana, Da un taccuino di lavoro: note per una sala canoviana alle Gallerie dell'Accademia, in: Canova. L'ultimo capolavoro (vedi Nota. I), pp. 72-74.

23 Cfr. F. Poli, Le statue, i busti, e i monumenti del Palazzo di Brera, in: Due secoli di scultura, (a cura di G. Maria AcCame / C. Carritelli / M. Meneguzzo), Milano 1995, pp. IOO-IO5. 
L'opera realizzata da Luigi Zandomeneghi fu inaugurata nel 1826 . Il medaglione è stato citato per la prima volta nel I828 nella Guida per la Reale Accademia delle Belle Arti in Venezia con alcune notizie riguardanti lo stabilimento stesso ${ }^{24}$, e dalla quale apprendiamo che l'opera venne collocata nella Sala delle riunioni accademiche. ${ }^{25}$ Vennero dunque a ritrovarsi nello stesso luogo il memento di colui che aveva realizzato l'apertura della nuova Accademia rifondata da Napoleone e quello di colui che da Roma ne era stato il nume tutelare: ossia Cicognara e Canova.

In uno strano silenzio, venne eretto nel I828 il Monumento a Giannantonio Selva, colui che, grande amico di Cicognara e Canova, aveva ricoperto la cattedra di architettura e si era occupato dei lavori di ristrutturazione dello stabile dell'Accademia, fino alla morte avvenuta nel I8I9. Quello stesso anno l'Accademia gli dedicò uno degli Elogi, consueti a fine anno accademico, nel quale si riporta:

L'effigie del Selva posta in fronte al presente Elogio è cavata dal busto scolpito in marmo statuario dal sig. Giacomo de Martini distinto alunno di questa R. Accademia per far parte di un cenotafio che una società di amici dell'estinto sta per innalzargli nella descritta novella Chiesa di santa Chiara. ${ }^{26}$

La Chiesa di Santa Chiara o anche del Ss. nome di Gesù, che in quegli anni veniva portata a termine per essere consacrata nel I834, non vide la realizzazione del monumento di De Martini e nemmeno quello che avrebbe dovuto realizzare Antonio Bosa. Forse quella 'società di amici', di cui non conosciamo i componenti, per celebrare Giannantonio Selva ritenne più consoni gli spazi dell'Accademia che egli stesso aveva restaurato. ${ }^{27}$

Con il monumento a Selva si inaugurò la prassi - propria di altre iniziative simili in Italia - che i monumenti eretti in Accademia venissero per la maggior parte commissionati da sottoscrittori privati, coadiuvati da comitati composti da docenti, allievi, e amici dell'arte appartenenti al colto mondo della società veneziana. Il Monumento a Selva funse anche da modello per i successivi: nella prima metà del secolo si usò dedicare una semplice targa con una iscrizione cui veniva sovrapposto il busto del defunto.

Gli anni Trenta non videro aggiungersi altro monumento, se si esclude la donazione nel 1837 da parte dello scultore Antonio d'Este ${ }^{28}$ di un autoritratto, affinché l'Accademia lo collocasse nel-

24 La Guida riporta a p.I7: "Volendo poi gli Accademici dimostrare il loro attaccamento verso il cessato Presidente Co. Leopoldo Cicognara hanno fatto scolpire dal Professore signor Luigi Zandomeneghi la Medaglia in marmo che qui si vede, portante la sua effige, intorno alla quale si legge: Leopoldo Cicognara Praesidi Benemerenti Academici”. Il Medaglione venne successivamente spostato e collocato nel corridoi d'Ingresso alla Pinacoteca come riportato dal Catalogo degli oggetti d'arte esposti al pubblico nella R. Accademia di Belle Arti in Venezia, Venezia I869, p. 5. Ora si trova nei depositi delle Gallerie, cfr. S. M. Marconi, Gallerie dell'Accademia (vedi Nota. I2), p. 235 (n. 583) e fig. 583.

25 Una stampa del monumento compare negli Atti del I834 quando alla morte di Cicogna gli venne dedicato un Elogio. Cfr. A. Diedo, Discorso funebre in memoria del co. Leopoldo Cicognara Presidente emerito della I. R. Accademia di Belle Arti in Venezia, in: Discorsi letti nella I.R. Accademia di Belle Arti in Venezia per la distribuzione dei premi, Venezia I834.

26 A. Diedo, Elogio del prof. Gio. Antonio Selva letto nel dì 8 Agosto I8ı9, p. 32. Nel frontespizio è riprodotto in incisione il Busto di Selva.

27 Il busto in gesso si trova nei depositi delle Gallerie dell'Accademia mentre il Monumento marmoreo con la targa "IO ANTONIO SELVA VENETO / HIC DOCTORI ARCHTECTVRAE / PIETATE SCIENTIA MODESTIA EXIMIO / SOCIETAS AMICORVM / MDCCCXXVIII” si trova ora negli spazi dell'ex Accademia al termine di un corridoio che porta al cortile maggiore.

28 Per alcune notizie su Antonio d'Este si veda: S. ZIZI, Un esempio di bottega romana: lo studio di Antonio d'Este (1754-1837), testimonianze documentarie, in: Abitare il Museo: le case degli scultori, (Atti del Terzo Convegno Internazionale sulle Gipsoteche, Possagno, 4-5 maggio 20I2), (a cura di M. Guderzo), Vicenza 20I4, pp. $25-38$. 


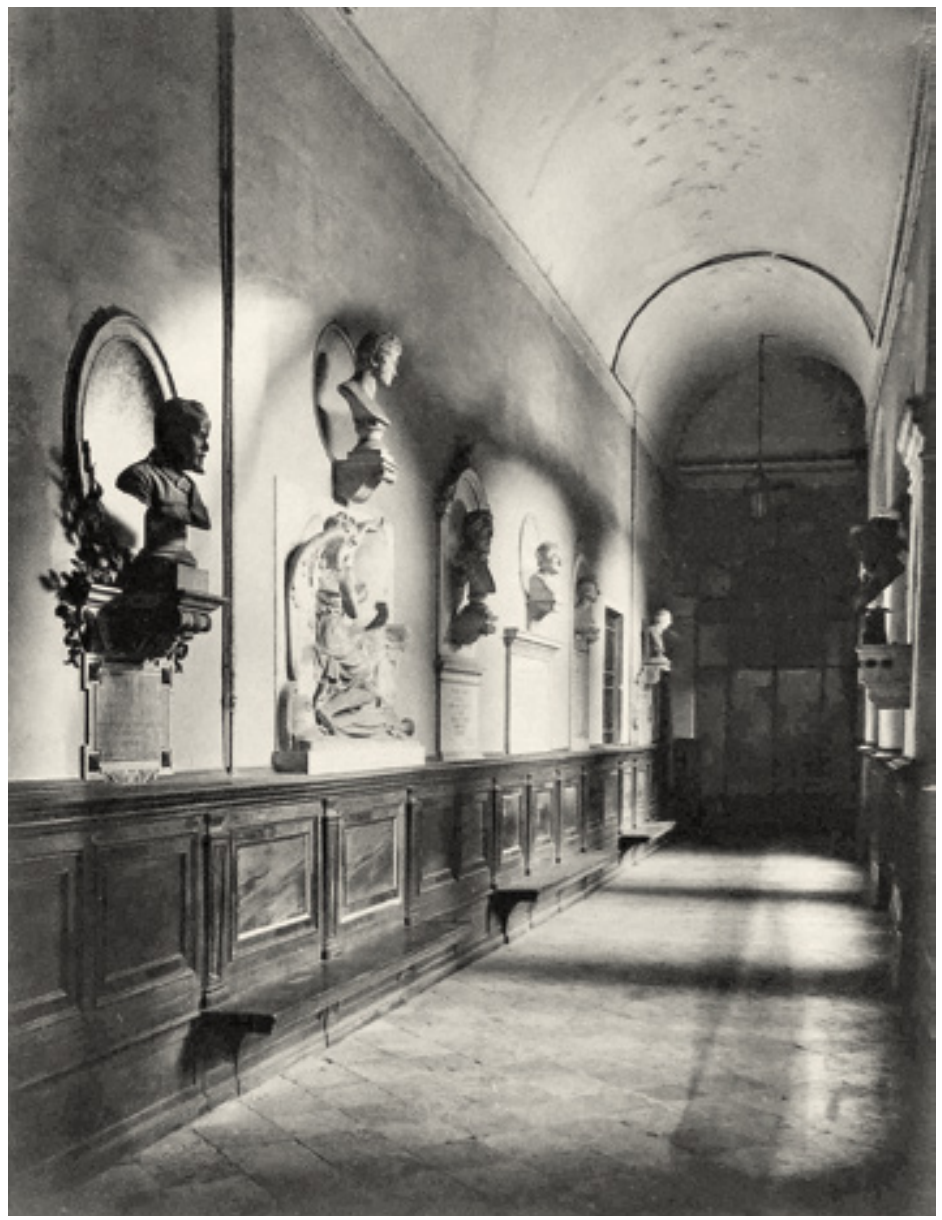

Fig. 6: Autore ignoto, Loggia terrena dell'Accademia di Belle Arti con i monumenti ai professori, foto, post 1928, Venezia, Archivio dell'Accademia di Belle Arti.

la sala che già accoglieva il cenotafio di Antonio Canova. ${ }^{29}$ Il busto pervenne qualche tempo dopo e lo ritroviamo per la prima volta citato nel- la Guida del $1845 .{ }^{30}$ Si dovette invece aspettare il I844 perché venisse innalzato quello alla memoria di Teodoro Matteini. Matteini fu per mol-

29 Per una scheda dell'opera si veda E. Nok̀, Autoritratto di Antonio d'Este, in: Ritratti e autoritratti d'artisti, (catalogo della mostra, Venezia, Gallerie dell'Accademia), (a cura di G. Nepi Scirè), Milano 2005, n. I5. Nella stessa sala a fianco del monumento a Canova prese posto anche il Busto di Odorico Politi realizzato dal friulano Giuseppe Bernardi. Per qualche notizia in merito si veda: S. M. Marconi, Gallerie dell'Accademia (vedi n. I2), p. 223 (n. 542) e fig. 542. La prima citazione dell'opera appare nel catalogo del I854: Catalogo delle Opere d'Arte contenute nella Sala delle Sedute dell' I.R. Accademia di Venezia, Venezia I854, p. 4. Il passo riporta: “A fianchi del descritto monumento veggonsi, posti su rocchi di colonna, due busti in marmo. Quello a destra del riguardante porta l'effige dello scultore Antonio D'Este, e fu da lui stesso eseguito e donato a quest'Accademia; l'altro, rappresentante il defunto prof. di pittura Odorico Politi, è opera del vivente scultore Giuseppe Bernardi, e fu offerto in dono all'Accademia dalla famiglia dell'illustre professore".

30 A quanto risulta dai dati d'archivio il busto venne proposto all'Accademia dallo stesso scultore nel I837 qualche mese 


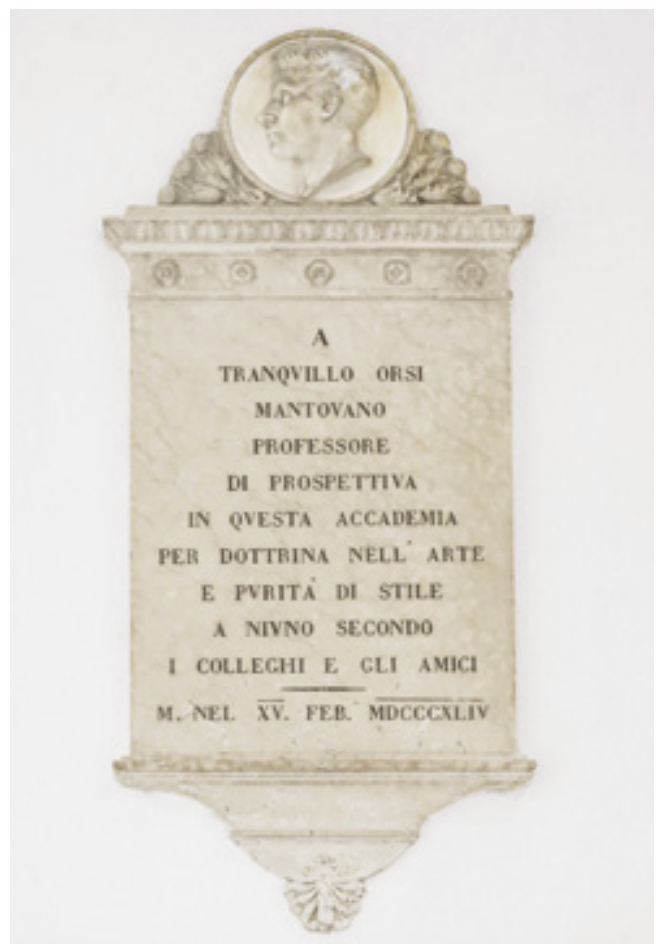

Fig. 7: Autore ignoto, Monumento a Tranquillo Orsi, marmo, I844, Venezia, Gallerie dell'Accademia.

ti anni maestro di pittura e nel I84I, a dieci anni dalla morte, l'Accademia gli dedicò un Elogio nel quale lo scrivente si augurava di poter vede- re l'effige del Matteini immortalata in marmo [Fig. 6]. ${ }^{31}$

Tre anni più tardi il monumento venne inaugurato. In questo stesso arco di tempo - anche se non ci rimangono documenti a riguardo - sappiamo che si inaugurarono anche i monumenti ai professori di scultura e prospettiva Angelo Piz$\mathrm{zi}^{3^{2}}$ e Tranquillo Orsi [Fig. 7].33

Alla fine degli anni Quaranta la commemorazione dei professori subì una momentanea battuta d'arresto a causa dell'insurrezione contro la dominazione austriaca. Nel 1847 a Venezia, in concomitanza con il IX Congresso degli Scienziati Italiani si dette avvio ad un "Panteon veneto" su modello di quello avviato da Canova a Roma per celebrare le glorie del passato e, più in particolare, della cultura storica locale. Si trattava di una glorificazione che andava oltre ai personaggi legati ad un determinato istituto, secondo la tradizione ancora in uso nell'Accademia veneziana.

Grazie alla supplica di tre artisti, che si appellarono al Governo provvisorio per ottenere il finanziamento di alcune opere, essendo rimasti senza commissioni a causa della guerra, il Governo si impegnò per il finanziamento di un ciclo pittorico e di una serie di medaglioni in marmo che dovevano raffigurare i grandi maestri della

prima di morire, cfr.: AABAVe,, Protocollo I837, 7 luglio I837, Gio. [sic] Antonio d'Este dona suo busto per sala dove sorge Cenotafio Canova; 19 luglio 1837, viene accolto il dono di Antonio d'Este.

3 I A. Diedo, Elogio di Teodoro Matteini già professore di pittura, in Atti della Imp. Regia Accademia di Belle Arti in Venezia per la distribuzione de' premi negli anni I84I-4I, Venezia I84I, p. 22. Una breve scheda dell'opera si trova pubblicata in: N. Gori BuCCI, Il pittore Teodoro Matteini (I754-I83I), Venezia 2006, pp. 277, 424. Il Monumento, come si evince dalle foto storiche e dai cataloghi, si trovava assieme ai monumenti della prima metà del XIX secolo nel corridoio che dall'entrata dell'Accademia portava alla scala a chiocciola. La targa posta al di sotto del busto riporta: A TEODORO MATTEINI PISTOJESE / CHE QVI PRIMO TENNE LA CATTEDRA DI PITTURA / E CHE AGLI ALVNNI / PADRE ED AMICO AFFETTVOSISSIMO / SVLLA VIA DEL BELLO E DEL VERO / L'ARTE RICONDVCEVA / MDCCCXLIV

32 Antonio Marsure, Busto di Angelo Pizzi, marmo, iscrizione: ANGELO PIZZI. Come in altre occasioni è durante l'Elogio a lui dedicato nel I842 che Diedo spera di vederlo eternato. Cfr. A. Diedo, Elogio del prof. Angelo Pizzi, in: Atti della Imp. Regia Accademia di Belle Arti in Venezia, Venezia, Antonelli, I843, p. I7. Si veda anche E. Nok̀, Lo scultore (vedi n. I2), p. 292, 293.

33 La targa del Monumento a Orsi riporta: A / TRANQVILLO ORSI / MANTOVANO / PROFESSORE / DI PROSPETTIVA / IN QVESTA ACCADEMIA / PER DOTTRINA NELLARTE / E PVRITA' DI STILE / A NIVNO SECONDO / I COLLEGHI E GLI AMICI / M. NEL XV. FEB MDCCCXLIV. Per un profilo di Tranquillo Orsi (Mantova, I79I - Venezia, I844), cfr. M. I. BIGgi, ad vocem, Orsi Tranquillo, in: La Pittura nel Vento. L'Ottocento, vol. II, (a cura di G. Pavanello), Milano 2003, p. 78 o. 


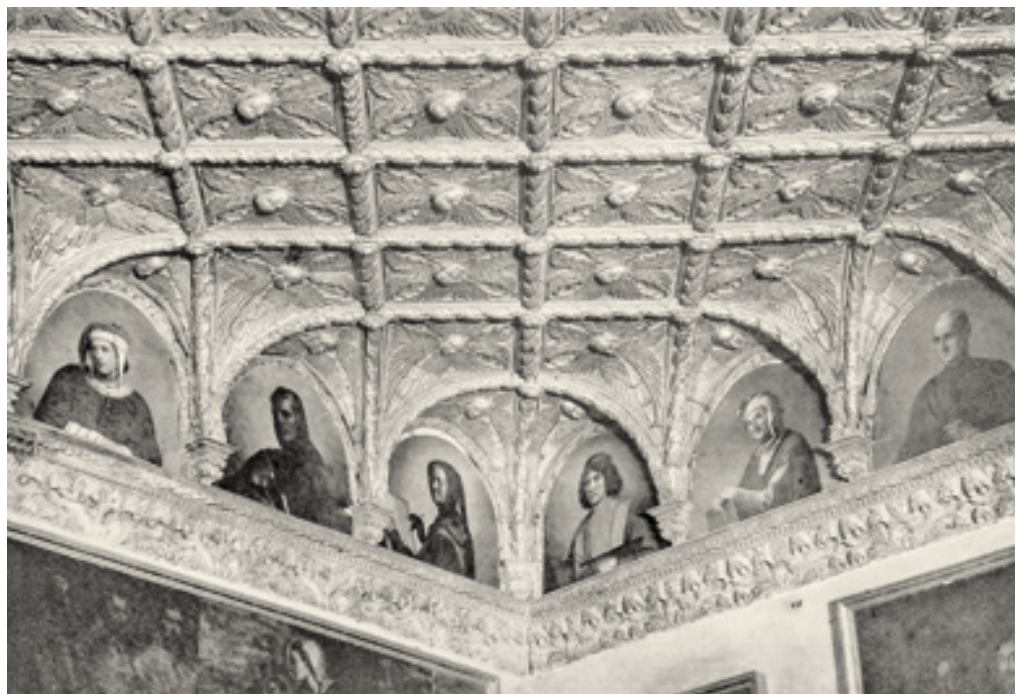

Fig. 8: Soffitto della Sala dell'Assunta alle Gallerie dell'Accademia, Venezia, Gallerie dell'Accademia (particolare con i ritratti dei Maestri veneziani), da Paoletti Pietro, La scultura e l'architettura del Rinascimento a Venezia, 1893 Venezia, in Fondazione Giorgio Cini, Venezia.

Scuola Veneziana: questa risoluzione riuscì a procurare lavoro a un buon numero di artisti. ${ }^{34}$ Già nei decenni precedenti era stata avviata un'impresa analoga in Accademia. ${ }^{35}$ Prese quindi avvio un ciclo di 70 tele, e non più affreschi, che venne collocato nella Sala dell'Assunta, impresa che si concluse sotto la supervisione di Pietro Selvatico e del Governo Austriaco [Fig. 8] . Questa decorazione pittorica scomparsa nel "depositorio" delle Gallerie quando l'architetto Carlo Scarpa intervenne per il nuovo allestimento del museo, faceva da magniloquente sfondo al succedersi di tele dei grandi del passato appese alle pareti e dava volto agli artisti a cui a partire dal I807 il presi- dente o i soci avevano dedicato l'elogio che veniva letto durante le premiazioni. L'iniziativa veneziana anticipò imprese simili e più famose come il Premio Mylius a Milano. ${ }^{36}$

Nel I853 la commemorazione riprese con l'inaugurazione di due monumenti voluti dal Consiglio Accademico a proprio carico, e continuò così l'erezione di nuove opere scultoree negli anni a seguire [Fig. 9-Io]. Il primo fu il monumento ad Antonio Diedo, il segretario morto nel I847, del quale lo scultore Luigi Zandomeneghi aveva realizzato il busto già nel I848. ${ }^{37}$ La scultura venne collocata tra l'ingresso della Scuola di Pittura e una finestra situata presso la scala a

34 Su questo argomento ritornerò in altra sede.

35 Si vedano le diverse guide dell'Accademia in cui, allorché si descrivono la Sala Prima e Sala Seconda viene riportato: "Sala prima - Il soffitto è dipinto con molta intelligenza ed amore dal Signor Tranquillo Orsi Professore Supplente di Prospettiva, ed i busti dei Pittori della Veneta scuola dal Signor Odorico Politi Membro di questa Accademia. [...] Sala seconda - Anche questo soffitto fu dipinto dal nominato sig. Orsi, ed i Busti che rappresentano le immagini di alcuni Pittori Veneziani dal signor Giovanni Dariff Socio Onorario di questo Stabilimento”.

36 Per qualche cenno sul Premio Mylus si veda: D. Pescarmona, I monumenti commemorativi, in: Le raccolte storiche dell'Accademia di Brera, (a cura di G. Agosti / M. Ceriana), Firenze 1997, pp. I60, 165 (n. 4).

37 AABAVe, b. I35, f. Monumento Diedo. In questo fascicolo si conserva moltissima documentazione che ci permette di ricostruire nel dettaglio tutti i particolari artistici e burocratici dell'esecuzione dal I848 al I853. Il Comitato Promotore era composto dai proff. Francesco Lazzari, Federico Moja e dai consiglieri Alvise Pigazzi, Giuseppe Salvadori, Giovanni Battista Cecchini. Nello stesso fascicolo si conservano gli elenchi dei contributori. 


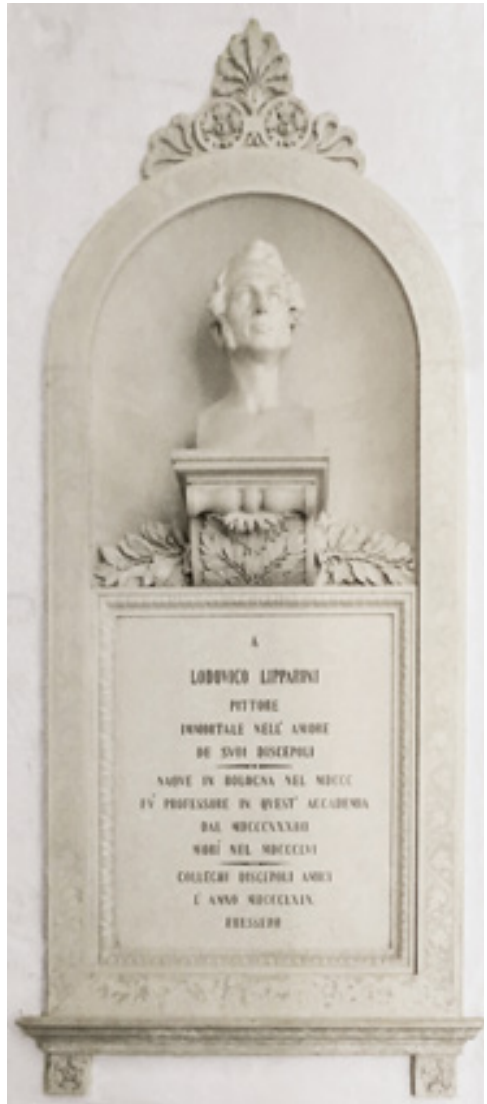

Fig. 9: Antonio Dal Zotto, Ludovico Lipparini, marmo, I859, Venezia, Gallerie dell'Accademia.

chiocciola che portava al piano superiore e alla Pinacoteca. Il monumento venne realizzato e progettato da Zandomeneghi e dallo scalpellino Giacomo Spiera [Fig. II].

Gli accademici affidarono al promettente allievo Luigi Borro il Busto di Giovanni Bellini per collocarlo nella "stanza che s'apre a destra di chi guarda l'Assunta di Tiziano”. Il Consiglio diede al giovane artista come indicazione per la riuscita dell'opera di "rifarsi alle immagini più note di

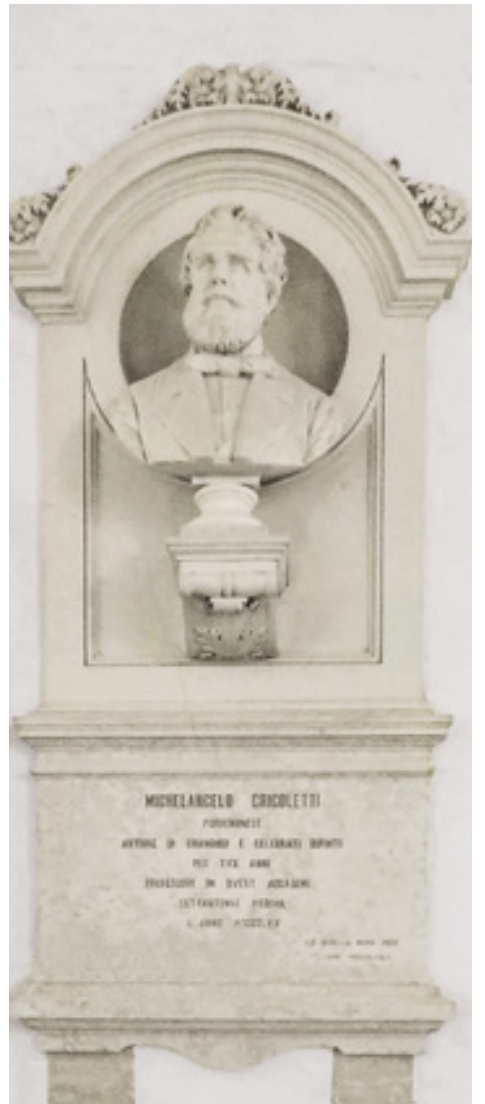

Fig. Io: Emilio Marsili, Monumento a Michelangelo Grigoletti, marmo, I874, Venezia, Gallerie dell'Accademia.

Bellini e alla medaglia di Vittore Gambello conservata al Museo di San Marco". ${ }^{38}$ Qualche anno più tardi, nel I872, nella stessa sala prese posto anche il Busto di Sebastiano del Piombo opera di Lorenzo Moretti Larese. ${ }^{39}$

L'anno seguente Luigi Ferrari ${ }^{40}$, allora professore di scultura, realizzò il busto dell'Imperatore Francesco Giuseppe "consacrato dal Consiglio Accademico, in ricordanza di esultazione pel salvamento dei preziosi giorni dell'Augusto Impe-

38 AABAVe, b. 75, f. Busto Bellini, Luigi Borro.

39 AABAVe, b. I6I.

40 Luigi Ferrari (Venezia I8Io-I894) per un profilo si veda: E. CATra, Bartolomeo (I780-I844) e Luigi Ferrari (I8IOI894), in: “Abitare il Museo." (vedi n. 28), pp. 6I-73. 


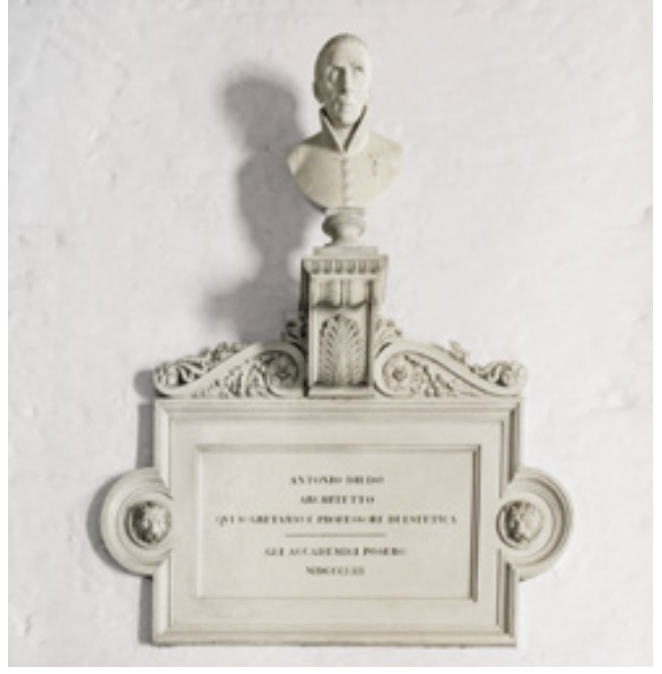

Fig. II: Luigi Zandomeneghi e Giacomo Spiera, Monumento ad Antonio Diedo, marmo, I848-1853, Venezia, Gallerie dell'Accademia.

rante dall'attentato I8 febbraio I853" [Fig. I2].41 Quando l'Imperatore fu in viaggio ufficiale in laguna nel 1856 ringraziò personalmente l'Accademia per l'omaggio. ${ }^{42}$

Con l'annessione di Venezia all'Italia, a Luigi Ferrari, considerato lo scultore ufficiale dell'Accademia, venne affidata l'esecuzione dei busti di Vittorio Emanuele II (1874) ${ }^{43}$ e di Re Umberto I (I887-I889). ${ }^{44}$

Dagli anni Novanta in poi vennero realizzati, in onore di vari artisti, solamente "ricordi" che furono allogati nei corridoi interni dell'Accademia di Belle Arti e furono tutti eseguiti in bronzo: carattere che li distingue da quelli relativi ai

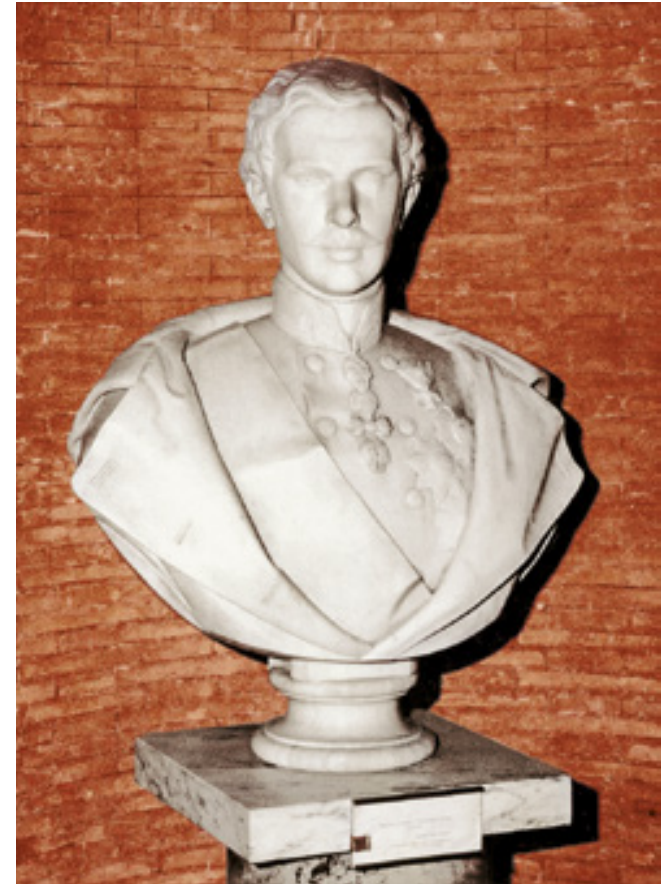

Fig. I2: Luigi Ferrari, Busto dell'Imperatore Francesco Giuseppe, marmo, I853, Roma, Museo Nazionale del Risorgimento.

maestri e personaggi della prima metà del secolo [Fig. 13]. Purtroppo nessuno di questi monumenti, sia in bronzo che in marmo, si trova oggi nella collocazione originaria. Presumibilmente nella seconda metà del XX secolo, essi furono collocati nel cortile esterno, privati delle lastre decorative, e quindi delle targhe e delle suppellettili, decontestualizzati, per renderli più vicini al gusto novecentesco [Fig. I4]. ${ }^{45}$

4I Così si legge nel Catalogo degli oggetti d'arte esposti al pubblico nella I.R. Accademia di Belle Arti in Venezia, Venezia 1856 , p. 36.

42 Con l'Annessione di Venezia all'Italia il busto venne relegato nei magazzini e in una data ancora imprecisata fu affidato in deposito esterno al Museo Nazionale del Risorgimento di Roma dove ancora oggi si trova esposto. Per una scheda completa dell'opera si veda: E CATra, Dalla Bottega alla Accademia. La famiglia degli scultori Ferrari a Venezia nell'Ottocento, Tesi di dottorato, Università Ca' Foscari - IUAV, a.a. 20I2-20I3, pp. 272-273.

43 Ead, p. 285.

44 Ead. p. 297-298. Dal I887 al I935 vennero esposti in Accademia dopo la lor collocazione a Palazzo Reale i Busti di Napoleone e della moglie Maria Luigi realizzati da Angelo Pizzi, su questi due busti si veda: E. Noè, Lo scultore (vedi n. I2), p. 263-264.

45 Nel 1922 quando fu inaugurato l'ultimo busto in onore di Luigi Nono i monumenti si trovavano ancora tutti nelle logge, lo spostamento all'esterno è sicuramente posteriore a questa data. 


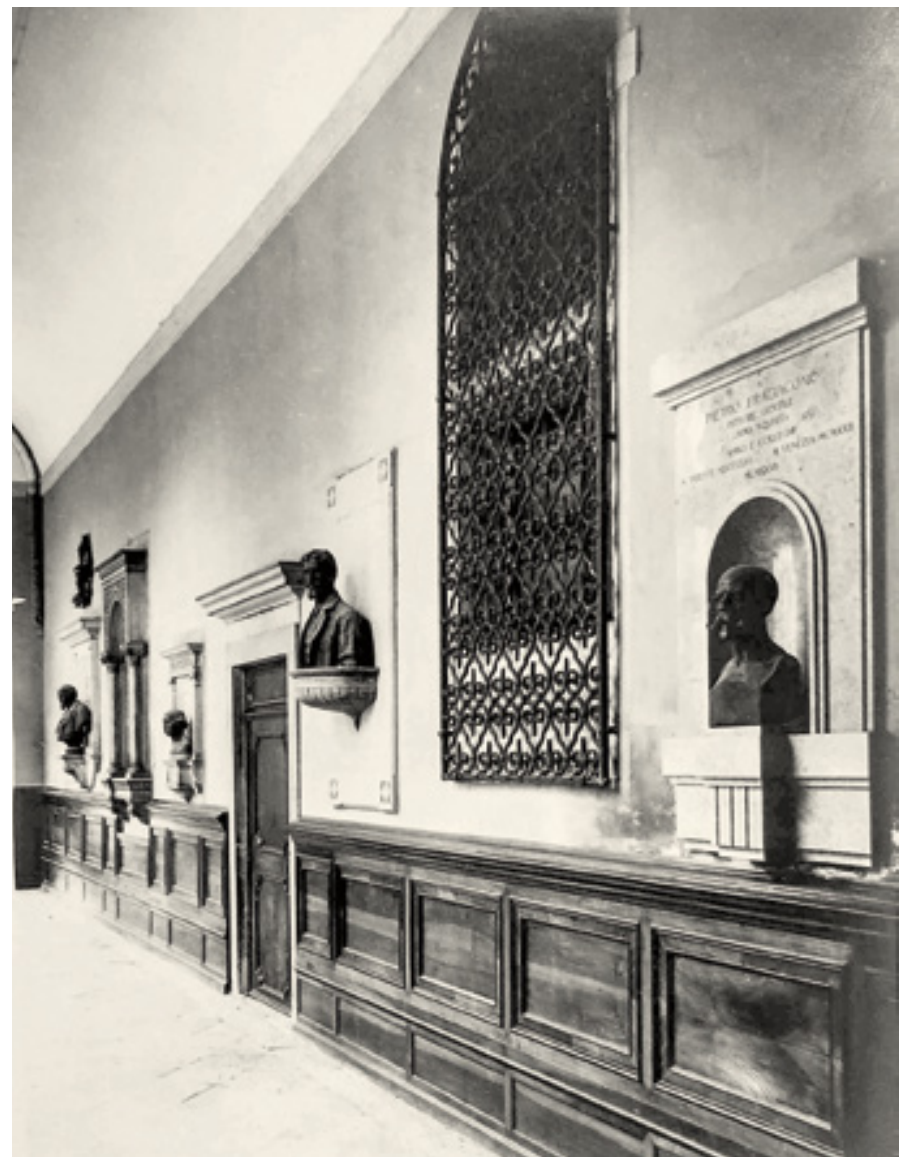

Fig. 13: Autore ignoto, Loggia terrena dell'Accademia di Belle Arti con i monumenti ai professori realizzati dopo il I897, foto, post 1928, Venezia, Archivio dell'Accademia di Belle Arti.

Il primo monumento inaugurato il I2 giugno I89o fu quello in onore del prematuramente scomparso Giacomo Favretto (Venezia I8491887). Il "Circolo Artistico Veneziano", nella persona del suo Presidente Gugliemo Ciardi inviò la seguente richiesta:

Il Circolo Artistico Veneziano, fattosi iniziatore delle offerte per un ricordo al compianto collega Giacomo Favretto, presenta a Codesta on.le Presidenza il progetto, che sta ora in via di esecuzione, e che si desidererebbe fosse collocato nell'Atrio del R. Istituto di Belle Arti, e precisamente, fra l'entrata alla scuola del Nudo, ed il ricordo dello scultore A. Pizzi. ${ }^{46}$

Giovedì I2 giugno I89o venne inaugurato il "Ricordo"; durante la cerimonia tennero un breve discorso Ciardi come presidente del comitato promotore, Luigi Ferrari come presidente dell'Istituto di Belle Arti, il Sindaco di Venezia Riccardo Selvatico e Pompeo Gherado Molmenti in rappresentanza degli amici del pittore. ${ }^{47} \mathrm{Il} \mathrm{Bu}$ -

46 AABAVe, b. I3, Collegio Accademico, Atti, I888-1889, c. 6Io.

47 I discorsi che vennero letti durante la cerimonia sono stati pubblicati in: Per Giacomo Favretto, in: Gazzetta di Venezia, venerdì 23 giugno I89o. 


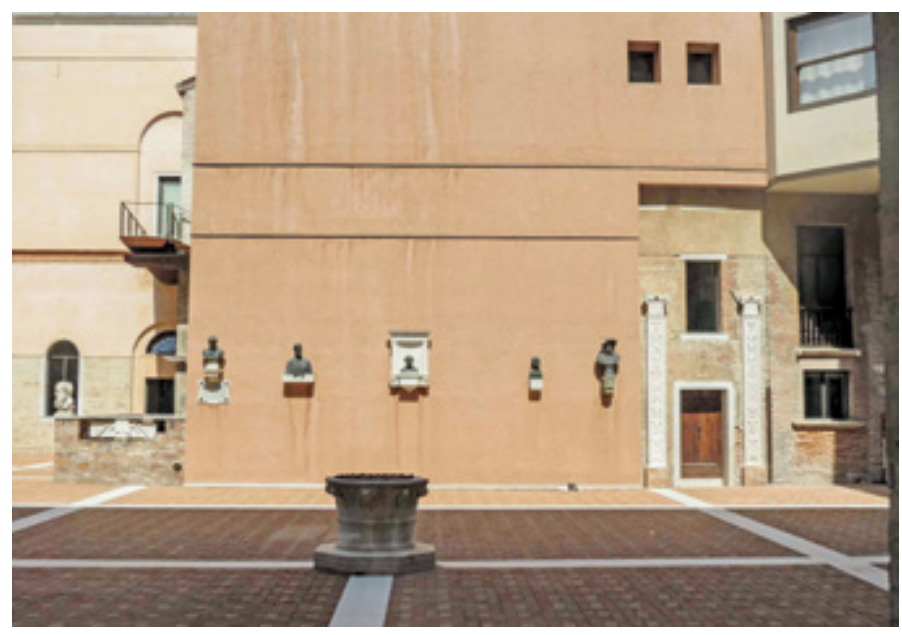

Fig. I4: Cortile esterno con la ricollocazione dei monumenti bronzei, Venezia, Gallerie dell'Accademia.

sto venne realizzato dall'amico Urbano Nono..$^{48}$ Negli anni seguenti vennero inaugurati i monumenti a Raffaele Cattaneo ${ }^{49}$, Giacomo Franco ${ }^{50}$, Pompeo Marino Molmenti ${ }^{\text {}}$, Luigi Nono ${ }^{52}$, Pietro Fragiacomo. Tutti ad esclusione di quello di Giulio Carlinis ${ }^{3}$, presero posto in una delle Logge terrene dell'Accademia, laterale rispetto a quella dove sono collocati i busti marmorei.

Nel 1904, in occasione della traslazione della salma dello scultore Luigi Ferrari, i giornali vene- ziani annunciarono che per iniziativa dello scultore Antonio Dal Zotto, presidente del "Comitato per un ricordo al comm. Ferrari”, si sarebbe posto nelle logge terrene dell'Accademia un busto in onore dello scultore scomparso. ${ }^{54} \mathrm{Di}$ questo busto realizzato dallo scultore Soranzo non rimane alcuna documentazione.

Il 24 maggio 1922, in occasione dell'anniversario dell'entrata d'Italia nella guerra I9I5-I9I8, nell'atrio dell'Accademia si aggiunsero due Lapi-

48 Il Busto venne fuso in bronzo dal modello di Urbano Nono da Michieli, mentre la parte decorativa oggi andata perduta è stata disegnata da Pellegrino Oreffice ed eseguita da Sacchetto. Un riproduzione del monumento si trova nel numero del 22 giugno I89o dell'”Illustrazione Italiana”. La targa riportava: “A / GIACOMO FAVRETTO / AMMIRATO E RIMPIANTO / OVE APPRESE GLI INIZI DELLARTE I SUOI AMICI POSERO / N. I3 AGO. I849 - M. I2 GIU. ำ887”.

49 I documenti relativi al monumento Cattaneo si trovano in: AABAVe, Collegio Accademico, b. I4, Atti, I890-I89I, f. I890, n.II90 in data 7 luglio I89o e I6 dicembre I889; Collegio Accademico, b. I5, Atti, I892; Collegio Accademico, b. I6, Atti, I893-1895, f. 1893, n. II90.

so In coincidenza dell'inaugurazione venne pubblicato l'opuscolo: C. Borto, Giacomo Franco architetto, s.d. [I897]. Si veda anche: A Giacomo Franco, in: Gazzetta di Venezia, n. 328, lunedì 29 novembre 1897.

5I Per l'occasione venne pubblicato l'opuscolo: Pompeo Marino Molmenti pittore. In occasione dello scoprimento del Ricordo Monumentale nella Loggia terrena della R. Accademia di Belle Arti. Venezia 22 maggio, I898, Venezia I898. All'interno è pubblicata una riproduzione fotografica del Monumento. Si veda anche: All'Accademia. Per un ricordo a P. M. Molmenti, in: Gazzetta di Venezia, n. I40, lunedì 23 maggio I898.

52 AABAVe, b. 517, Oggetti diversi, 1916-1925, f. 1922, n. 395-396, Inaugurazione del Busto di Luigi Nono. Si veda anche: Gli Amici dei Monumenti alle "Gallerie” riordinate, in: Gazzetta di Venezia, n. I39, martedì I3 giugno 1922.

53 Il monumento si trovava originariamente nella loggia terrena di fronte al monumento ad Angelo Pizzi. Il busto venne realizzato dallo scultore Gerolamo Bortotti (Belluno I849 - Venezia, I925) e fuso dalla fonderia F.lli PIN.E..

54 Cfr. Per un ricordo al comm. Luigi Ferrari, in: La Difesa, venerdì / sabato, I8 / I9 novembre I904. 
di a carattere diverso rispetto a tutte le altre. La Prima Guerra Mondiale aveva lasciato il segno anche su quest' istituzione artistica e l'Accademia volle ricordare i suoi studenti caduti durante la Guerra. " Lo stesso giorno si commemorarono con un'altra lapide anche i maestri e gli allievi che avevano reso eccelsa l'Accademia veneziana nel mondo. ${ }^{56}$

L'apposizione di ricordi e targhe scemò drasticamente negli anni successivi: furono inaugurate infatti solo due targhe: quella a Gino Fogolari negli anni Quaranta e quella a Giuseppe De Logu nel 1986, su iniziativa del Comune. ${ }^{57}$

I monumenti, divenuti mute presenze di personaggi sconosciuti che, a detta dei maestri e degli allievi, avevano portato al decadere dell'Arte e non rappresentavano più validi modelli da seguire, vennero dimenticati, spostati, senza curarsi dell'armoniosa vicinanza che per più di un se- colo li aveva accomunati e animati come da un dialogo.

In questi mesi gli spazi dell'ex Accademia di Belle Arti stanno per essere riallestiti per ampliare l'area espositiva delle Gallerie dell'Accademia. Parte della collezione scultorea e i monumenti celebrativi saranno così nuovamente visibili al grande pubblico e torneranno ad essere testimoni del glorioso passato dell'Istituto.

\section{Elenco delle abbreviazioni}

AABAVe, Archivio dell'Accademia di Belle Arti di Venezia

ASVe, Archivio di Stato di Venezia

BCMC, Venezia Biblioteca Civico Museo Correr

55 BCMC, Carte Bordiga, Discorsi e comunicazioni, f. 28, Inaugurazione della lapide in onore degli studenti dell'Accademia di Belle Arti caduti in guerra. Si tratta del discorso pronunciato da Giovanni Bordiga, presidente dell'Accademia di Belle Arti, in onore di Silvio Giobbe, Angelo Astolfoni, Paolo Stivanello Gussoni, Vincenzo Negroni, Giuseppe Brandolini, Salvatore Briamo, Silvio Rota, Giuseppe Vecchiet. Si veda anche: L'Istituto di Belle Arti di Venezia onora i suoi caduti in guerra, in: "Gazzetta di Venezia", n. I23, giovedì 25 maggio 1922.

56 La targa il giorno dell’inaugurazione riportava i nomi di: Piazzetta G. Battista, Pittoni G. Battista, Diziani Gaspare, Diziani Antonio, Diziani Giuseppe, Tiepolo G. Battista, Pasquetti Fortunato, Canal Antonio (Canaletto), Colonna Megozzi Girolamo, Joli Antonio, GAspari Pietro, Battaglioli Francesco, Zais Giuseppe, Zuccarelli Francesco, Bonazza Francesco, Temanza Tommaso, Guardi Francesco, Maggiotto Domenico, Maggiotto Francesco, Moretti Giuseppe, Marieschi Giacomo, Angeli Giuseppe, Guarana Giacomo, Tiepolo Giov. Domenico, Novelli Pier Antonio, Morlaiter Giov. Maria, Morlaiter Michelangelo, Longhi Pietro, Longhi Alessandro, Antonio Gai, Marchiori Giovanni, Bernardi Torretti Giuseppe, Selva Giov. Antonio, Pizzi Angelo, Canova Antonio, Pellegrini Domenico, Zandomeneghi Pietro, Zandomeneghi Luigi, Diedo Antonio, Matteini Teodoro, Bagnara Francesco, Cicognara Leopoldo, Lipparini Lodovico, Politi Odorico, Schiavoni Natale, Demin Giovanni, Caffi Ippolito, Selvatico Estense Pietro, Grigoletti Michelangelo, Cremona Tranquillo, Moia Federico, Borro Luigi, Hayez Francesco, Favretto Giacomo, Cattaneo Raffaele, Zona Antonio, Blaas Carlo, Orso Tranquillo, Carlini Giulio, Franco Giacomo, Ferrari Luigi, Selvatico Riccardo, Boito Camillo, Molmenti Pompeo Marino, Bresolin Domenico, Rotta Antonio, Rotta Silvio, Kirchmayr Cherubino, Ciardi Guglielmo, Dal Zotto Antonio, Zezzos Alessandro, Nono Luigi, Fragiacomo Pietro.

57 Il monumento si compone di un'unica lastra marmorea nella quale si trova un piccolo medaglione bronzeo con il ritratto di profilo e la scritta: A / GIVSEPPE DE LOGV / STORICO DELLARTE / CHE IN QUESTA ACCADEMIA / DAL 1929 AL 1933 / E DOPO L'ESILIO / DAL 1945 AL 197I / PROFVSE GLI IDEALI DELLARTE / E DELLA LIBERTA' ( IL COMVNE DI VENEZIA / P / 1986. 
I. Angelo Pizzi, Busto dell'Imperatore Francesco I, marmo, I8I7, Sala delle Riduzioni Accademiche.

2. Rinaldo Rinaldi, Busto di Tiziano, marmo, I8ı6, Sala delle Riduzioni Accademiche.

3. Giacomo De Martini, Venezia con il Corno Ducale, marmo, I817, Sala delle Riduzioni Accademiche.

4. Giacomo Spiera, Targa in Onore di Ascanio Molin, marmo, I819-I820, Vestibolo. Iscrizione: HIERONYMO ASCANIO MOLINO P V / QVOD PRAECLARIS ARTIVM MONVMENTIS ACADEMIAE LEGATIS / EORVM SECVRITATI PROVIDERIT LOCI DIGNITATEM AVXERIT / PVLCHRVM LARGITATIS EXEMPLAR / CIVIBVS PROPOSVERIT / VIRO PATRIAE AMANTISSIMO AN MDCCCXX /

5. Giuseppe Borsato / Bartolomeo Bongiovanni, Tablino di Antonio Canova, porfido, marmo e bronzo, Sala delle Riduzioni Accademiche. Iscrizione: DEXTERA MAGNI CANOVAE

6. Antonio D'Este, Autoritratto, marmo, I8I2, Sala delle Riduzioni.

7. Luigi Zandomeneghi, Medaglione di Leopoldo Cicognara, marmo, I826, Sala delle Riduzioni Accademiche. Iscrizione: LEOPOLDO CICOGNARA PRAESIDI BENEMERENTI ACADEMICI

8. Giacomo De Martini, Monumento a Giannantonio Selva, marmo, I828, loggia terrena. Iscrizione: IO ANTONIO SELVA VENETO / HIC DOCTORI ARCHTECTVRAE / PIETATE SCIENTIA MODESTIA EXIMIO / SOCIETAS AMICORVM / MDCCCXXVII
9. Antonio Marsure, Monumento ad Angelo Pizzi, marmo, post I842, loggia terrena. Iscrizione: ANGELO PIZZI.

Io. Innocenzo Fraccaroli, Teodoro Mattini, marmo, I844, loggia terrena. Iscrizione: A TEODORO MATTEINI PISTOJESE / CHE QVI PRIMO TENNE LA CATTEDRA DI PITTURA / E CHE AGLI ALVNNI / PADRE ED AMICO AFFETTVOSISSIMO / SVLLA VIA DEL BELLO E DEL VERO / L'ARTE RICONDVCEVA / MDCCCXLIV

II. Autore ignoto, Monumento a Tranquillo Orsi, marmo, I844, Loggia terrena a destra. Iscrizione: A / TRANQVILLO ORSI / MANTOVANO / PROFESSORE / DI PROSPETTIVA / IN QVESTA ACCADEMIA / PER DOTTRINA NELL'ARTE / E PVRITA' DI STILE / A NIVNO SECONDO / I COLLEGHI E GLI AMICI / $\mathrm{M}$. NEL XV. FEB MDCCCXLIV

I2. Giuseppe Bernardi, Ritratto di Odorico Politi, marmo, (prima metà del XIX secolo).

13. Luigi Zandomeneghi e Giacomo Spiera, Monumento ad Antonio Diedo, marmo, I848-I853, loggia terrena. Iscrizione: ANTONIO DIEDO / ARCHITETTO / QVI SEGRETARIO E PROFESSORE DI ESTETICA / GLI ACCADEMICI POSERO / MDCCCLIII

I4. Luigi Borro, Busto di Giovanni Bellini, marmo, I853, Sala a destra dell'Assunta.

I5. Luigi Ferrari, Busto dell'Imperatore Francesco Giuseppe, marmo, I853, Sala a sinistra dell'Assunta. Iscrizione: IMP ET REGI / FRANCISCO IOSEPHO I / QVOD / XII K MART MDCCCLIII / SICARII FERRO PETITVS / IMPERII SECVRITATI / POPVLORVM Q ADFECTVI / DIVINT-

* Le collocazioni indicate sono quelle originali 
VS SERVATVS / FVERIT / ACADEMICI / LAETITIAE CAVSSA / ALOYSIO FERRARI / SCVLPTORE.

16. Antonio Dal Zotto, Ludovico Lipparini, marmo, I859, loggia terrena.

17. Iscrizione: A / LODOVICO LIPPARINI / PITTORE / IMMORTALE NELLAMORE / DE SVOI DISCEPOLI / NAQVE IN BOLOGNA NEL MDCCC / FV PROFESSORE IN QUEST'ACCADEMIA / DAL MDCCCXXXIII / MORI` NEL MDCCCLVI / COLLEGHI DISCEPOLI AMICI / L'ANNO MDCCCLXIX / PRESSERO

I8. Lorenzo Moretti Larese, Busto di Sebastiano del Piombo, marmo, 1872, Sala a destra dell'Assunta.

19. Luigi Ferrari, Busto del Re Vittorio Emanuele II, marmo, I874.

20. Emilio Marsili, Monumento a Michelangelo Grigoletti, marmo, 1874, loggia terrena. Iscrizione: MICHELANGELO GRIGOLETTI / PORDENONESE / AVTORE DI GRANDIOSI E CELEBRATI DIPINTI / PER XXX ANNI / PROFESSORE DI QVEST ACCADEMIA / SETTANTENNE MORIVA / L'ANNO MDCCCLXX / LA SORELLA MARIA POSE / L'ANNO MDCCCLXXIV.

2I. Luigi Ferrari, Busto del Re Umberto I, marmo, I888-I889.

22. Urbano Nono e Pellegrino Oreffice, $M o$ numento a Giacomo Favretto, bronzo, I890, loggia terrena.

23. Iscrizione: A / GIACOMO FAVRETTO / AMMIRATO E RIMPIANTO / OVE APPRESE GLI INIZI DELLAARTE I SUOI AMICI POSERO / N. I3 AGO. ${ }^{\circ}$ I849 - M. I2 GIU. ${ }^{\circ} 887$.

24. Autore ignoto, Monumento a Raffaele Cattaneo, marmo, bronzo, mosaico, I892-I893, loggia terrena verso il cortile. Iscrizione: RAFFAELE.CATTANEO / ARCHITETTO / DEGLI STUDI DELLARTE CRISTIANA / VALENTE CVLTORE / CON
SINGOLARE ERVDIZIONE / E / CRITICA ARGVTA / SAPIENTEMENTE SCRISSE / SVLL'ARCHITETTURA ITALIANA / DEL SESTO SECOLO AL MILLE / N. MDCCCLXI M. MDCCCLXXXIX

25. Ugo Zannoni / Rinaldo Vincenzo, Monumento a Giacomo Franco, bronzo e marmo, I897, loggia terrena verso il cortile. Iscrizione: A GIACOMO FRANCO ARCH ${ }^{\circ}$ / ALLIEVI ED AMICI / VERONA I8I8 VENEZIA I895

26. Carlo Lorenzetti / Costante Biasutti / Luigi Gaggio, Monumento a Pompeo Marino Molmenti, bronzo, I898, loggia terrena verso il cortile. Iscrizione: POMPEO MARINO MOLMENTI / PITTORE E MAESTRO / I DISCEPOLI E GLI AMICI / N. I2 NOV. MDCCCXIX M. I6 DEC. MDCCCXCIV

27. Gerolamo Bortotti, Monumento a Giulio Carlini, bronzo, prima della fine del XIX secolo, loggia terrena.

28. Angelo Franco, Busto di Domenico Fadiga, marmo, post 1912, entrata dell'Accademia. Iscrizione: DOMENICO FADIGA / SEGRETARIO DELLACCADEMIA DI BELLE ARTI / DAL 28 GENNAIO I856 AL I AGOSTO I9I2 / MVNIFICO BENEFATTORE DEGLI STVDI.

29. Mario Nelli, Comunicato del generale Diaz per la Vittoria della Prima Guerra Mondiale, bronzo, I9I8, entrata dell'Accademia.

30. Urbano Nono, Monumento a Luigi Nono, bronzo, I922, loggia terrena verso il cortile. Iscrizione attuale: LVIGI NONO / MAESTRO NELL'ARTE E NELLA VITA / N. II DIC. MDCCCL - XV OPT. MCMXVIII

31. Autore Ignoto, Lapide in onore degli studenti dell'Accademia di Belle Arti caduti in Guerra, marmo antico, 1922, entrata dell'Accademia.

32. Autore ignoto, Lapide in onore dei maestri e scolari dell'Accademia, marmo antico, I922, entrata dell'Accademia (collocazione attuale). 
33. Carlo Lorenzetti, Monumento in onore di Pietro Fragiacomo, bronzo, 1926, loggia terrena verso il cortile. Iscrizione originale: PIETRO FRAGIACOMO / PITTORE GENTILE / ANIMA SQUISITA / AMICI E COLLEGHI / N. TRIESTE MDCCCLVI M. VENEZIA MCMXXII / MCMXXVI

34. Autore ignoto, Lapide in ricordo di Gino Fogolari, pietra, I94I ca., Chiesa. Iscrizione: GINO FOGOLARI / I875 194I / STUDIOSO E CRITICO INSIGNE DELLA PITTURA VENETA SPRINTENDENTE A VENEZIA PER OLTRE UN TRENTENNIO / LE GALLERIE DELLACCADEMIA DA LUI CURATE E ARRICCHITE CON INFINITO AMORE VOGLIONO QUI RICORDARE
35. Romano Vio, Monumento in onore di Giuseppe de Logu, marmo e bronzo, 1986, cortile d'accesso dell'Accademia. Iscrizione: A / GIVSEPPE DE LOGV / STORICO DELLARTE / CHE IN QUESTA ACCADEMIA / DAL 1929 AL 1933 / E DOPO L'ESILIO / DAL I945 AL I97I / PROFVSE GLI IDEALI DELL'ARTE / E DELLA LIBERTA“ / IL COMVNE DI VENEZIA / P / 1986.

Photographic acknowledgements: Fig. I, 2, 3, 4, 7, 8, 9, Io, II, I4: Gallerie dell'Accademia, Venezia; Fig. 5, 6, I3: Archivio dell'Accademia di Belle Arti, Venezia; Fig. I2: Museo Nazionale del Risorgimento, Rome 


\title{
A VERY PUISSANT SPURRE: AUTHORS, SCHOLARS AND THE EXEMPLARY ROLE OF THE PORTRAIT BUST IN THE EIGHTEENTH CENTURY
}

\author{
Malcolm Baker
}

$\mathrm{T}$ he splendid array of portrait busts which adorns the Arkadenhof in the University of Vienna celebrates the intellectual achievements of that institution through its long history. In doing so, however, this series of images draws on a number of earlier traditions. Such a concentration of busts might be seen as one manifestation of the cult of monuments that formed so characteristic a feature of German-speaking lands and their culture during the nineteenth century. ${ }^{\mathrm{I}}$ The proliferation of sculpted images of great men and they are usually men - throughout Europe during this period provides a wider contemporary context in which to view this particular assemblage of busts. But while this is undeniably a striking feature of nineteenth century public art throughout Europe, this collective celebration of scholarly achievement has its roots in traditions of sculptural commemoration established long before then.

The genre of the bust had, of course, long been associated with writers and thinkers, and these were just as frequently represented in this way as were emperors and rulers. From ancient Greece onwards, one of the principal roles of sculpture was to commemorate illustrious men and celebrate their achievements. While it was the Romans rather than the Greeks who did this through the form of the bust, as opposed to the full length statue, the subjects who were represented were often Greek writers or thinkers, including Homer of course, whose bust became one of the most frequently reproduced classical images and helped to reinforce the association of busts with authorship. One way in which the Arkadenhof display works as an institutional celebration of scholarship is that all the images are sculptural, so continuing and amplifying the tradition that began with busts of Homer. But another equally significant feature of this assemblage is that these sculptural images form part of a series, at least in a very loose sense. The writers and thinkers celebrated here are represented through their proximity by being gathered together within a single space. In this respect, the Arkadenhof draws on another well-established tradition - that of the series of author portraits, often in the form of a sequence of painted portraits.

Long before, these portraits of dead and living writers and scholars had formed two of the categories of famous men represented in the

I H.A. Pohlsander, National Monuments and Nationalism in $19^{\text {th }}$ Century Germany, Bern 2008; K.A. Lang, Monumental unease: monuments and the making of national identity in Germany, in: Imagining modern German culture, I889-I9Io. Studies in the history of art (ed. F. Forster-Hahn), Washington D.C. 1996, pp. 274299. For the earlier German tradition of busts representing writers, see R. Kanz, Dichter und Denker im Porträt: Spurengänge zur deutschen Porträtkultur des I8. Jahrhunderts, Munich I993. 
celebrated collection gathered together by Paolo Giovio at Como. ${ }^{2}$ Here these subjects were not placed in a library or indeed in an academic institution but formed part of a far more extensive series of great men worthy of emulation. Like the many series of portraits of rulers, providing a visual representation of continuity through lineage, such groups of 'worthies' were to be found in many public spaces during the sixteenth and seventeenth centuries. Poggio Bracciolini in his De nobilitate (I440) had indeed recommended the emulation of Roman practices in setting up images of wise men as exemplars. ${ }^{3}$ However, as Justus Lipsius had already recognized in I602, representations of authors were especially relevant in the setting of a library. ${ }^{4}$ Gathering together the references made by classical authors to portraits in libraries, Lipsius had regretted that this had not been adopted in modern times. This was, however, soon to change. In the early I6oos the Bodleian Library in Oxford was decorated by an extensive series of painted author portraits, and by the late seventeenth century, series of author portraits were becoming a familiar way of arranging images in a library, just as the bust had become almost a natural way of celebrating authorial fame. It was above all in the eighteenth century that these two traditions - that of representing famous men in series and that of representing authors in the form of busts - took on its most visible and familiar form. This was the Enlightenment library populated by busts of writers where such images served as exemplars for the members of an academic institution. This paper will focus on the use of au- thor busts in one particular case - the Wren Library at Trinity College, Cambridge. ${ }^{5}$ But before turning to this eighteenth-century academic library with its series of exemplary busts of writers and scholars, something needs to be said about the changing place of the bust as a genre in the eighteenth century.

Portrait busts had of course occupied a prominent place in visual culture from the Renaissance onwards, and the expressive power of the bust had been richly exploited long before the eighteenth century, not least in the hands of Bernini. But the busts of Bernini and Algardi are in a sense exceptions in the way that they functioned as independent images. More often busts formed part of architectural settings and were viewed from afar or were integral components of funerary monuments. During the eighteenth century, however, the bust became both more prominent and even ubiquitous, especially in France and Britain. The bust emerged from its niche to become an independent form. ${ }^{6}$ At the same time, it became far more ambitious aesthetically. No longer an image to be glanced at from afar, the bust was increasingly viewed closely, an image to be given concentrated and sustained attention. Correspondingly, the way in which busts - especially in Britain and France - were finished changed. Surfaces became more subtly modulated; their details, gradations of plane and the carving of the marble more highly worked; their execution being predicated on the viewer's close attention. These shifts were in part associated with a new engagement on the part of at least some viewers with the processes

F. Haskell, History and its Images, New Haven / London I99I, pp. 26-79.

P. Bracciolini, De vera nobilitate (ed. D. Canfora), Rome 2002.

J. Lipsius, De Bibliothecis Syntagma, Antwerp i6o2.

5 This paper draws on material presented in more detail in M. BAKER, The Portrait Sculpture, in: The Making of the Wren Library (ed. D. McKiтterick), Cambridge I995, pp. IIO-I37.

6 For a fuller discussion of this phenomenon, see M. BAKer, The Marble Index. Roubiliac and Sculptural Portraiture in Eighteenth-Century Britain, New Haven / London 20I4, especially pp. 13-25. The Trinity College busts are discussed on pp. 30I-318. 


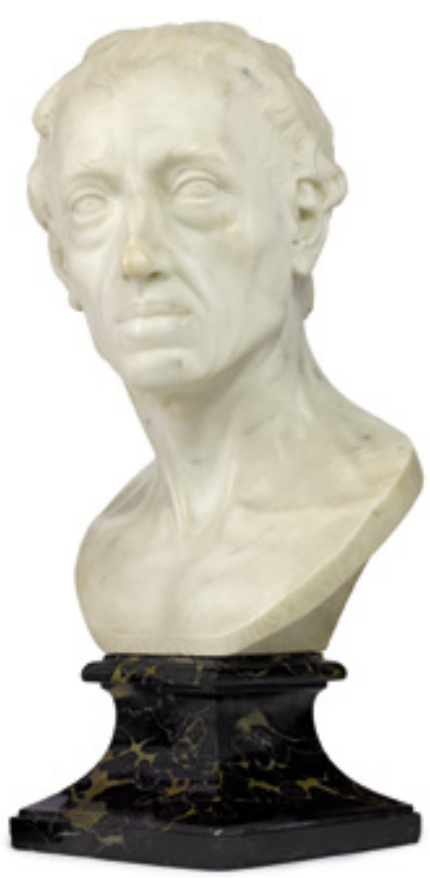

Fig. I: Louis-François Roubiliac, Alexander Pope, 1740, marble. Private collection.

of perception, and involved what Michael Baxandall called a 'Lockean mode of viewing. ${ }^{7}$ At the same time, through Enlightenment writings about the nature of personal identity - not least those of Locke and Hume - the bust could be approached in a different way as the image of an individual, a distinctive personality. With their subtly finished surfaces, the finest busts such as Roubiliac's Alexander Pope - invite close viewing by informed eyes (Fig. I) ${ }^{8}$ But within eighteenth-century culture, such aesthetication was balanced by commodification and the same busts were widely reproduced in plaster and other materials as multiples. The bust could stand alone as a distinctive image representing and celebrating someone whose achievements were distinctive and singular. On the other hand, in most cases such images did not stand alone. Pope's bust, for example, was very often paired with another celebrated 'worthy', such as Newton, forming part of a sequence which served as a visual representation of a literary canon.

The bust as a genre also worked through repetition and the use of shared format and conventions. The use of the same format signalled belonging to a group. Of course, most portraits involve a play between the duality of likeness and type, an oscillation between individual and group identity. But the relatively restricted range of conventions used for the bust makes this even more pertinent to an understanding of how this genre works as a mode of representation. The shared use of the same conventional format is foregrounded when busts are assembled as a series, in which individual likenesses are balanced by what they share.

In the case of busts of writers or scholars displayed together within an institutional context, this duality takes on particular significance. The point of setting up a bust of a writer or scholar is to celebrate that person's distinctive achievement - what sets him or her (though it is usually him) apart. What is emphasised here is indeed distinction. At the same time, the placing of a bust of a writer or scholar alongside others using a similar format registers belonging, either to a literary canon or an academic institution. What were the various groups to which the subjects represented belonged? Were they being celebrated as writers, as philosophers, or simply as having associations with those institutions where they were set?

There were often other tensions in play too. As well as becoming an image which was accorded close and sustained attention, the portrait bust in the eighteenth century frequent-

7 M. BaXandall, Patterns of Intention, New Haven / London 1985, pp. 76-79; for the 'Lockean viewing' of sculpture, see BAKER, The Marble Index (cit. n. 6), pp. 56-65.

8 Baker, The Marble Index (cit. n. 6), pp. 26I-276; M. Baker, Busts and Friendship: The Identity and Context of William Murray's Version of Roubiliac's Bust of Pope, in: Sculpture Journal, XXII, 2013, pp. 65-76; M. BAKER, Fame and Friendship. Pope, Roubiliac and the Portrait Bust, Waddesdon 2014, pp. 74-95. 


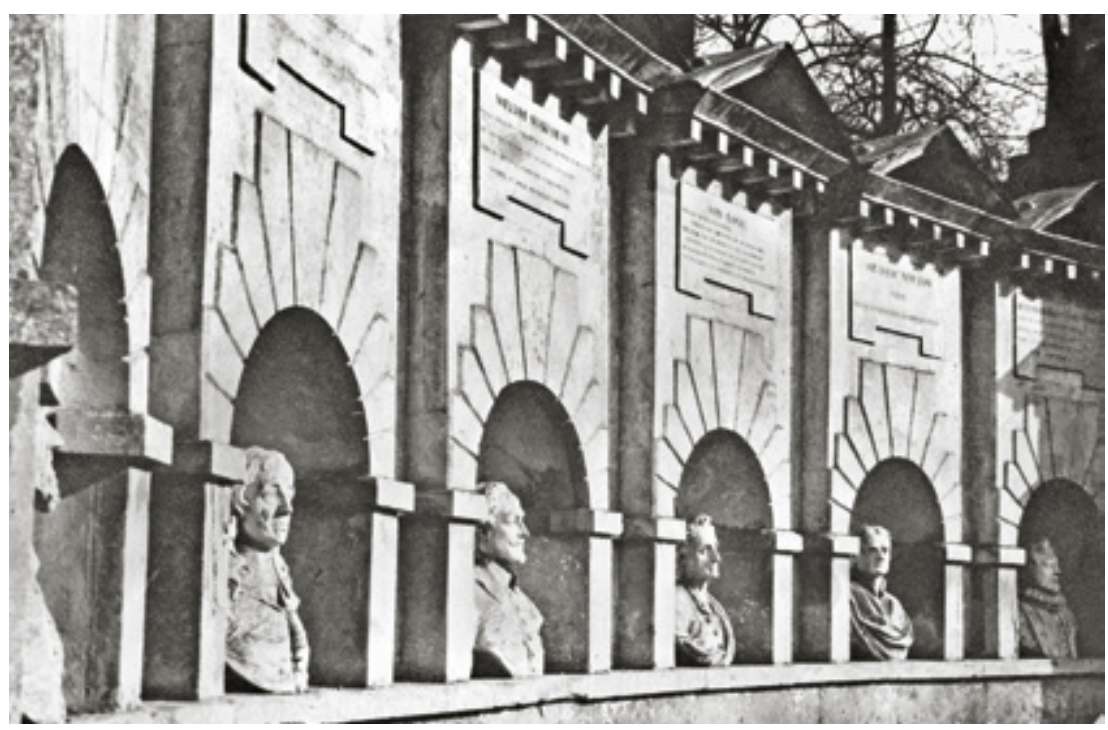

Fig. 2: William Kent (with busts by Michael Rysbrack and Peter Scheemakers), The Temple of British Worthies, ca. I735, stone. Stowe House, Buckinghamshire.

ly made use of a heightened illusionism. These veristic, illusionistic effects emphasised the image's immediacy, suggesting the fleeting and momentary. The momentary effect was of course at odds with sculpture's association with permanence. This seeming contradiction was articulated in the way such images were apprehended by the attentive viewer, who was at one and the same time taken in by the animation and immediacy of the illusionistic effects of carving, while being made aware of the marble bust's nature as a made artifact through its insistent materiality, not least through the obvious marks of the chisel. In the more successful examples, the balance between illusionism and materiality was such that part of the pleasure of looking at a marble bust involved a conscious play with the very process of perception. Yet a further twist to the way such images work occurs when, as with so many of these images, the subject represented is an historical figure. Here an historicising image is invested with the effects of immediacy and animation.

These were some of the factors involved in the making and viewing of portrait busts in the eighteenth century and, in particular, with those series or sequences of busts representing writers or scholars, most of them long dead. The viewing of such images was complicated and enriched when different examples were juxtaposed and displayed to form a series within an academic institution with which the subjects had belonged. How did they work within such a setting and in what sort of interior were they to be seen together?

The celebration of great men through sculptural images did not, of course, have to be an institutional matter and did not necessarily require an institutional setting. One early eighteenthcentury grouping of portrait busts consisted of those images of natural philosophers Newton and Locke, assembled by Queen Caroline for her Hermitage at Richmond. Just a few years later, two of these figures were included among the writers and thinkers who constituted one half of the Temple of British Worthies at Stowe. Here, these exemplars of the vita contemplativa, accompanied by Milton, Shakespeare and Pope among others, were balanced by a series of monarchs who represented the vita activa as well as, collect- 


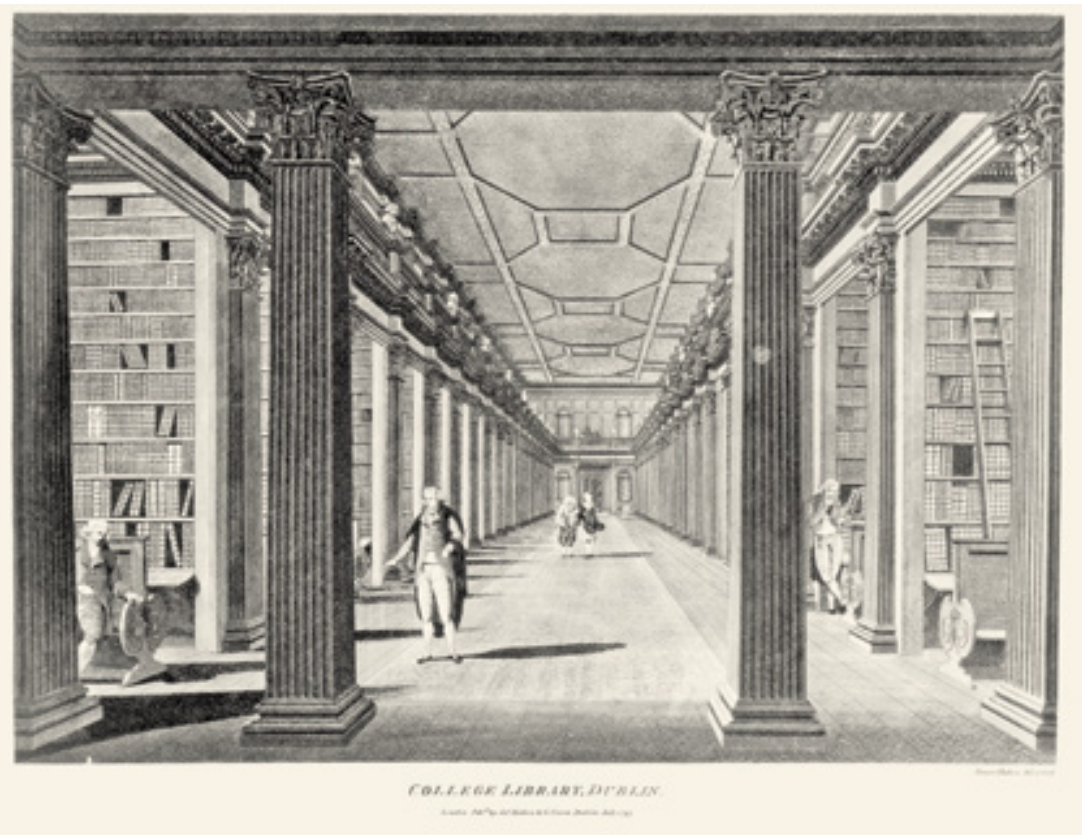

Fig. 3: The Long Room, Trinity College, Dublin. Engraving from James Malton, A Picturesque and descriptive View of the City of Dublin, I797.

ively, the upholders of what were seen as English liberties (Fig. 2).9

But the setting in which such series of busts of writers and thinkers were more prominent was the library. Increasingly, libraries in private houses were furnished with paintings or busts of authors. When Pierre-Jean Grosley in the midI76os visited the library of Lord Morton's London house, he described how

the several faculties and branches of science, which are elsewhere distinguished by simple inscriptions, are represented by a basso-relievo in painting, which unites in several groupes the most eminent men in each faculty, both amongst the ancients and moderns: the centre of each basso-relievo pre- sents the picture of some Englishman, who appears to hold the first rank in that particular branch of science. ${ }^{\text {IO }}$

The library of the physician Dr Richard Mead included busts of Milton, Shakespeare and Pope, and we know that as the friend of Pope, Halley and Newton, he placed their portraits in his house near the Busts of their great Masters, the antient Greeks and Romans. ${ }^{\text {II }}$

By far the most extensive series of author busts were, however, to be found in the libraries of public institutions, such as those being erected in the seventeenth and eighteenth centuries by colleges in Oxford, Cambridge and Dublin (Fig. 3). ${ }^{12}$ Here a visual articulation of a literary

9 For Queen Caroline's Hermitage, see J. Colton, Kent's Hermitage for Queen Caroline at Richmond, in: Architectura, II, I974, pp.I8I-I90; for the Temple of British Worthies, see K. EustacE, Stowe and the Development of the Historical Portrait Bust, in: Apollo, CXXXXVII, i998, pp. 3I-40.

P.J. Grosley, A Tour to London, London 1776, p.196.

II M. Maty, Authentic Memoirs of the Life of Richard Mead M.D., London I755, p. 63.

I2 On the Dublin example, see M. BAKer, The making of portrait busts in the mid-eighteenth century: Roubiliac, Scheemakers and Trinity College, Dublin, in: Burlington Magazine, CXXXVII, 1995, pp. 82I-83I. 
canon was being expanded into a broader scholarly pantheon, as well as (as we shall see) a visual register of an institution's history. Far from being a British phenomenon, this was of course a pattern of sculptural display being developed elsewhere in Europe, seen for instance in the Aula magna in Bologna from 1756 onwards. Of course, the association of a library with portraits might be seen as a logical extension of the connection between collections of books with collections of prints or of medals, all of which might be housed together. ${ }^{13}$ The shift to what we recognise as a familiar eighteenth-century configuration of a library with author busts is to be seen in late seventeenth-century France.

If Lipsius had already suggested that the moderns should imitate the ancients in their uses of busts in libraries, more practical advice as to how to do this was offered in two late seventeenth-century texts about the formation and organisation of libraries: Gabriel Naudés Advis pour dresser une bibliothèque of 1627 and Claude Clément's Musei sive bibliothecae of I635. According to Naudé, who cited antique precedents in Pliny and Suetonius of libraries decorated with lively statues of all the gallant men, it was desirable to include good Copies drawn from such are as are most famous in the profession of Letters; that thereby a man may at once make judgement of the wit of authors by their Books, and by their bodies; figure, and physiognomy by these Pictures and Images, which joyn'd to the description which may have made of their lives, may serve, in my opinion, as a puissant spurre to excite a generous and well-born Soul to follow their track and to continue firm and stable in the wayes and beaten paths of some noble enterprise and resolution. Naudé does not give any detailed advice about the placing of busts, but Clément was rather more specific about their disposition, recommending that the bookcases ... are surmounted by statues of men distinguished in the discipline for which the bookcase is intended. ${ }^{I 4}$ This well-established tradition of using portraits of earlier authors could therefore be employed to articulate the relationship between ancient and modern authors, to represent a literary canon through images, and even to function as a visual key to the library's contents.

By the end of the seventeenth century, the Bibliothèque Sainte-Geneviève contained no less than 26 busts, several of which are shown in engravings of 1692 as placed on tapering plinths against the pilasters dividing the bookcases (Fig. 4). Although other French libraries were also decorated with busts, the Bibliothèque SainteGeneviève remained by far the most celebrated and widely known example, its collection of sculptural portraits growing steadily throughout the eighteenth century. Some of these were of ancients, others of the French royal house; but a considerable proportion were of relatively modern sitters. In some cases they were given by the sculptors - most notably those by Girardon and Caffieri - but many of this last category were donated by relatives or descendants of those commemorated. The library thus became, according to Piganiol de la Force in 1765 , 'a sort of temple of memory where the parents and friends of illustrious men of all kinds hasten to place their portraits'. ${ }^{15}$

It is in the college libraries in Britain, however, where we see this tradition of commemorating worthies - writers and thinkers - by busts being more fully developed. The richness and complexity of the use of busts with an academic institution is best illustrated by the case of Trin-

I3 The association of a library with an interior decorated with busts was even implicit in Duke Albrecht V's setting up in 1566 of the Antiquarium in Munich, with its busts on the lower floor and the library above.

I4 G. NAUdE, Advis pour dresser une bibliothèque, Paris 1627; the English quotations used here are from John Evelyn's translation: J. Evelyn, Instructions concerning erecting of a library, London I66I; C. CLEMENT, Musei sive bibliothecae, 1635 .

I5 Piganiol De La Force, Description of Paris, vol. 6, Paris I765, p. 92. 


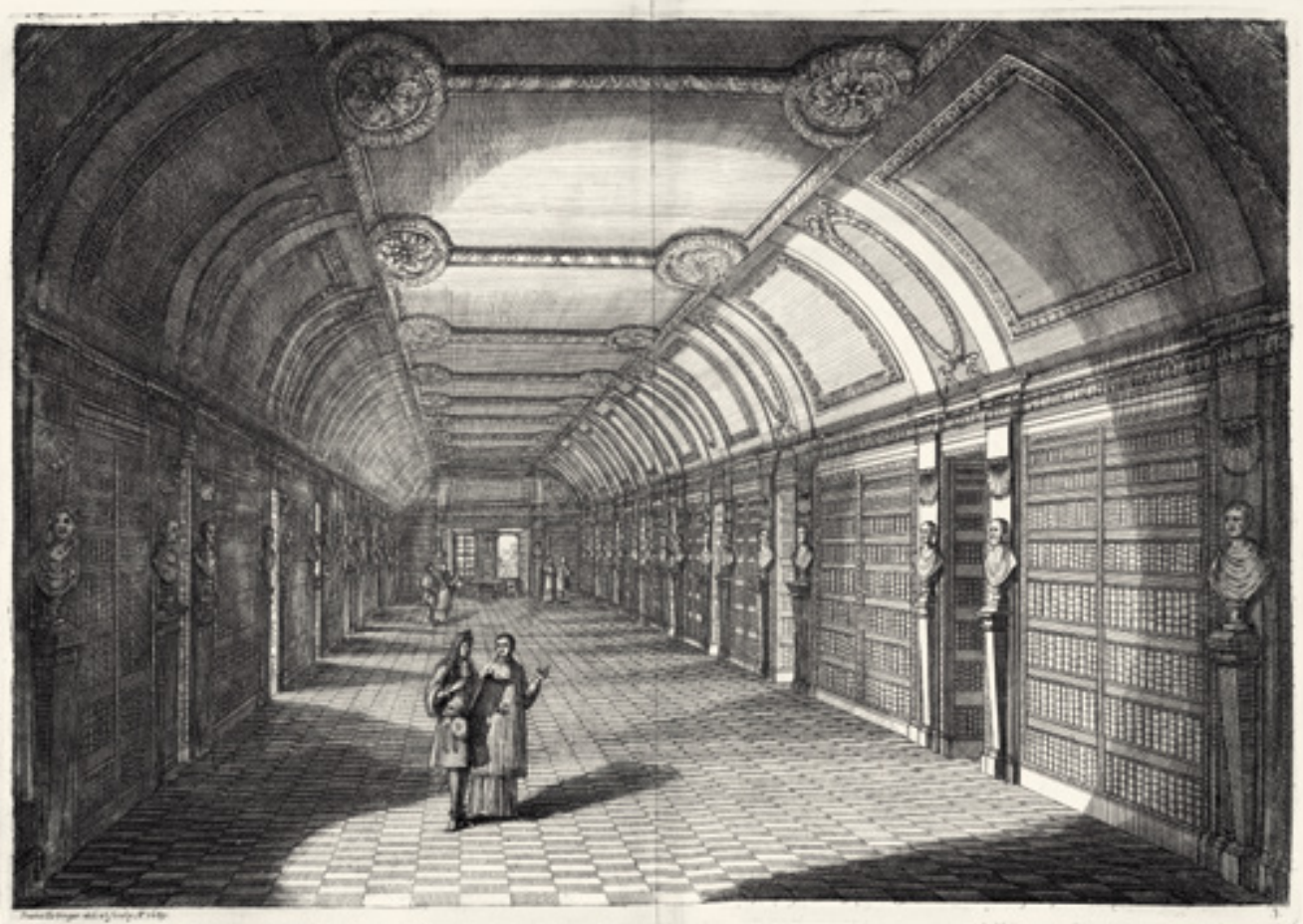

Fig. 4: Interior of the Bibliothèque Sainte-Geneviève, Paris. Engraving by François Erlinger, I689.

ity College, Cambridge, where the Master, Robert Smith, fashioned what was effectively a visual history of the college through portrait busts (Fig. 5 and 6). Here those represented were not just writers and scholars. Nor was the magnificent late seventeenth-century library, designed by Sir Christopher Wren, the only space involved.

Although Wren had envisaged the decoration of the library with sculpture, it occurred only much later in the 1750 . In addition to 26 plaster busts of ancient and modern authors given around 1755 , no less than 13 marble busts were commissioned for the college between I75I and 1763, including ten executed by Louis-François Roubiliac, the leading sculptor working in mideighteenth-century Britain. Significantly, most of these images were historicising. This remarkable group of busts includes some examples of virtuoso carving as well as many images which draw on a variety of historical visual sources, but at the same time achieve effects of exceptional immediacy and animation. Their relationship to each other, as well as the evidence for their original settings, raises issues about the way in which traditional practices for displaying images of illustrious figures from the past were being reworked for new ends.

The earliest documentation for this commission - or, more properly, this series of commissions - is found in a letter of 25 July 1753 from Mrs Elizabeth Montagu to her husband. Mrs Montagu writes about meeting Dr Smith with whom she

fell into discourse upon some embellishments \& ornaments to be added to the fine library at Trinity College; there are to be 26 busto's put up, 13 in memory of the Ancients, 13 of moderns. These are to be casts in plaister of Paris, but Mrs Middleton talks of a fine Marble Busto of Dr Middleton [the librarian of Cambridge Univer- 


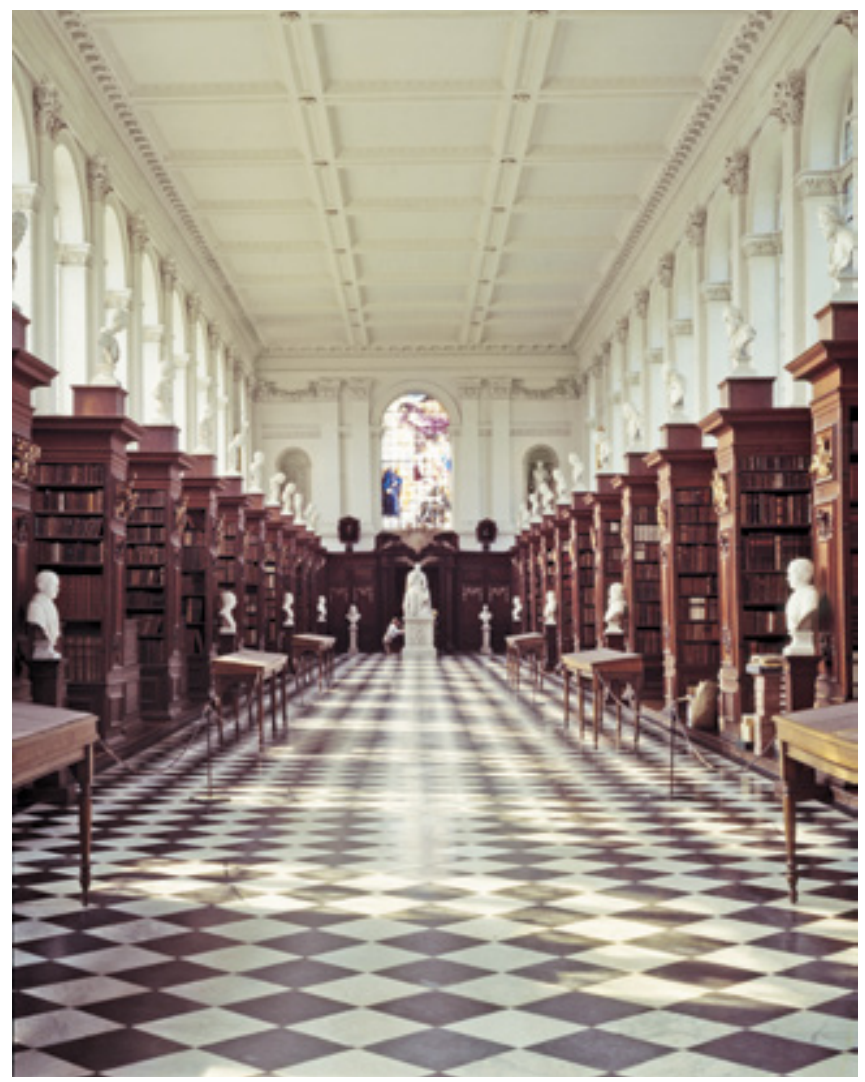

Fig. 5: Sir Christopher Wren, The Wren Library, Trinity College, Cambridge, ca. 1685 with later sculptural additions.

sity] to be done by Roubilliac [sic], which I think very proper, as he was so eminent there should be a public memorial of him \& as he was long $l i$ brarian it is proper that it should be in that place. There are to be likewise 48 portraits of considerable persons that have been of the College. I think Dr Smyth is very right in all this, so fine a Temple of the Muses should be adorn'd with all the arts of the ingenious as we as the Studious Nine, especially in an age that honors the polite arts more than the severe science ${ }^{16}$

Although the bust of Dr Middleton mentioned by Mrs Montagu seems never to have been made, ten busts of other subjects were to be executed by Roubiliac. The earliest of Roubiliac's busts, representing Bacon and Newton, had already been given in I75I, two years before Mrs Montagu writes about Smith's plans. Two further busts representing John Ray and Francis Willoughby were recorded as gifts from another donor in $175 \mathrm{I}$ (Fig. 7 and 8). However, the bust of Ray was not made until 1755 , since on 17 th January of that year Roubiliac, at the request of the Revd Dr Smith, was given permission by the Trustees of the newly founded British Museum to make a Draught from the picture of Mr John Ray

I6 Elizabeth Montagu to Edward Montagu, 25 July 1753, Huntington Library, Elizabeth Montagu MSS. The plaster busts mentioned here were given by Dr Hooper before his death in I763; see BAKER, The Portrait Sculpture (cit. n. 5), p. II7. 


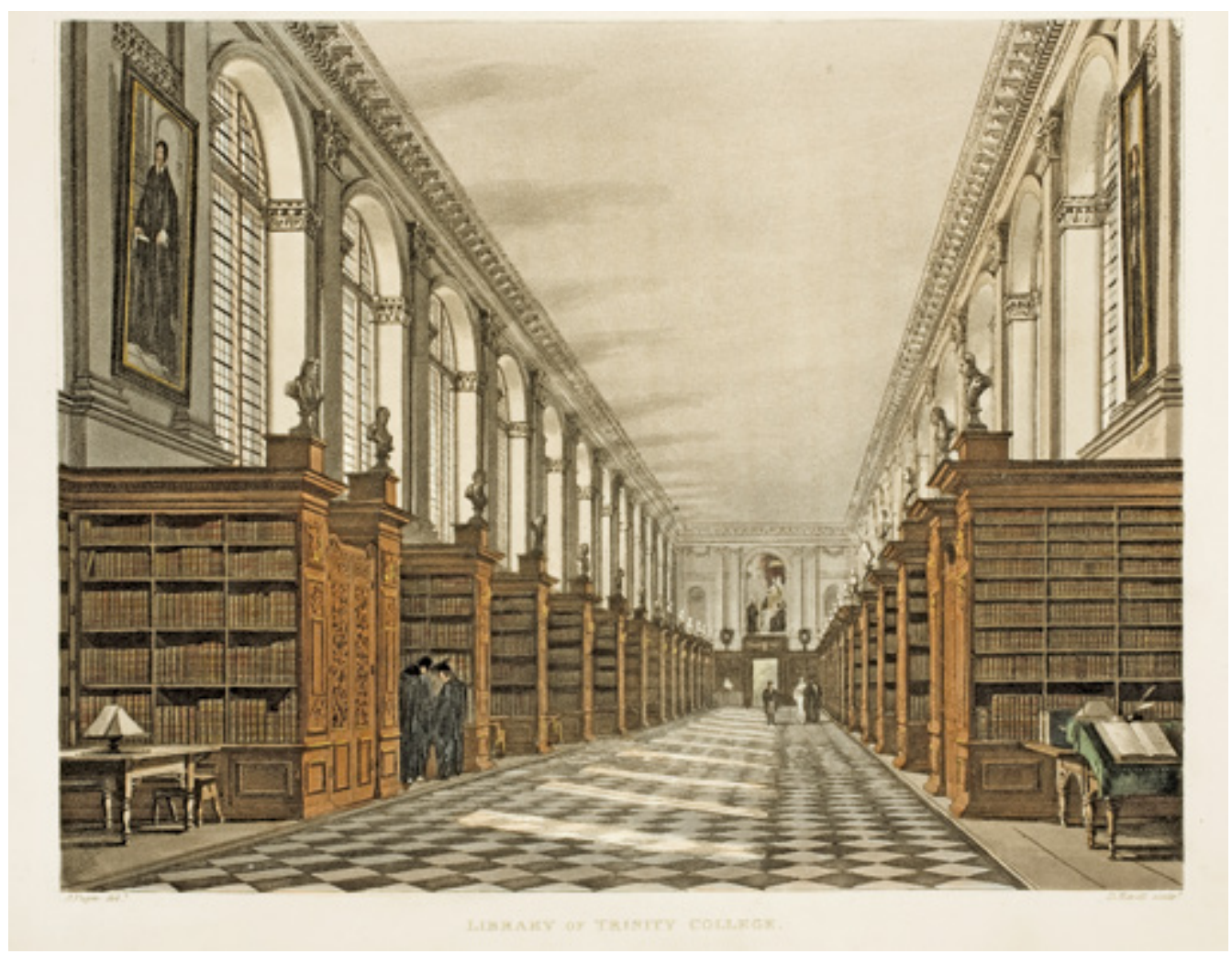

Fig. 6: Interior of the Wren Library with busts of Francis Bacon and Sir Isaac Newton at the far end, Trinity College, Cambridge, I8I5, aquatint. From R. Ackermann, A History of the University of Cambridge.

... in Order for the making of a Busto of him to be placed in the said College (Fig. 9). ${ }^{\text {I7 }}$

The two busts of Ray and Willoughby illustrate well how Roubiliac could use a variety of earlier visual sources and then create a likeness of an historical figure that has all the immediacy and animation of an ad vivum portrait. That of Willoughby seems to have been based on a late seventeenth-century portrait (probably made accessible to Roubiliac by the sitter's descendants), which shows him holding a book. ${ }^{18}$ The painted source is, however, enlivened by the treatment of the hair and collar so as to suggest that they are caught by a breeze from the sitter's right hand side, to which Willoughby turns his head. Ray's image is rather more static. The lower part of this bust in fact replicates a pattern used for a contemporary figure: Jonathan Tyers, the proprietor of Vauxhall Gardens and very much still living (Fig. I0). ${ }^{\text {I9 }}$ The introduction of the collar and the chiselling of the inner side of the drapery enveloping the bust - a feature introduced in the marble version but not yet present on the model means that there is no disparity between bust and head. In this case, the head is based on the portrait (then in the British Museum) but, here

I7 British Museum, MS, Trustees General Minutes, II, p. 240.

I8 For a fuller analysis of this relationship see BAKER, The Marble Index (cit. n. 6), pp. 304-306.

I9 On the use of replication in the making of models, see BAKER, The making of portrait busts (cit. n.I2); BAKER, The Marble Index (cit. n. 8), pp. 193-200. 


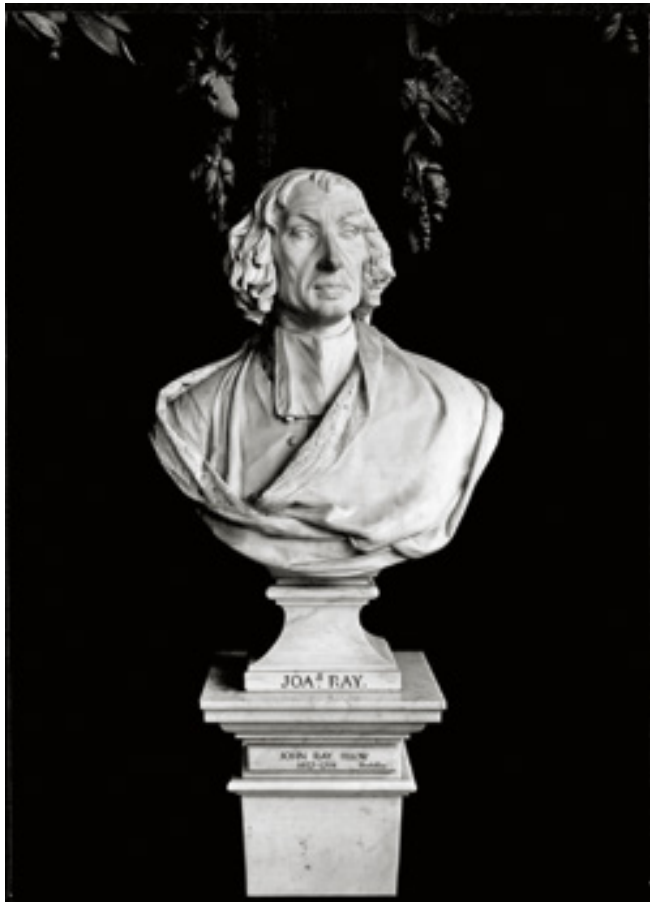

Fig. 7: Louis-François Roubiliac, John Ray, I75I-55, marble. Trinity College, Cambridge.

again, the modifications are significant and effective. Strikingly, the hair is no longer clumped together on either side of the face but broken up into separate strands, articulated through deep undercutting and very visible drill-work, while the face itself is more lined, the furrowed brow being used to suggest the concentration of study. The animation of an historicising image takes another form in the bust of Robert Cotton, given in 1757 (Fig. II). This image, with its agitated and deeply undercut ruff, bearded head and dramatically arched eyebrows and drilled eyes, is among Roubiliac's most virtuoso marbles.

Alongside these historicising busts were a number of portraits of more or less contemporary figures, such as Baron Trevor, Lord Whitworth and Thomas Bentley, the controversial former Master of the College.

The busts commissioned from Roubiliac for Trinity do not conform to a single, familiar type. Instead, they represent the full range

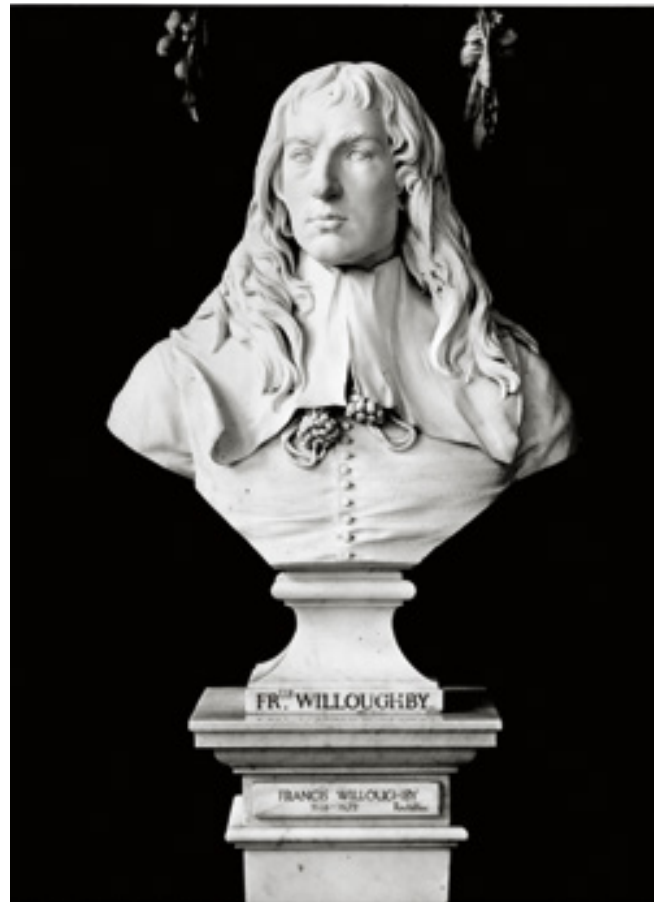

Fig. 8: Louis-François Roubiliac, Francis Willoughby, I75I55, marble, Trinity College, Cambridge.

of modes and formulae employed by the sculptor in his sculptural portraiture. While a single bust or statue, prominently displayed, might attract attention and help to add to the sculptor's renown, the opportunity to execute a series of ambitious busts as well as a major statue for display in a space that was as much public as private meant that Roubiliac's sculptural portraiture could be seen in all its variety. This set of linked commissions involved a network of patrons, with Smith and his Vice-Master at Trinity, Richard Walker, prompting and coordinating what was in effect a collective programme. As a result, these works are quite exceptional.

The bust of Francis Willoughby, for example, was given by Edmund Garforth who had married Wiloughby's great-granddaughter, while that of Baron Trevor was donated by his daughter and that of Baron Whitworth by his nephew. Where the donors were male, most had been undergraduates at the college, so that 


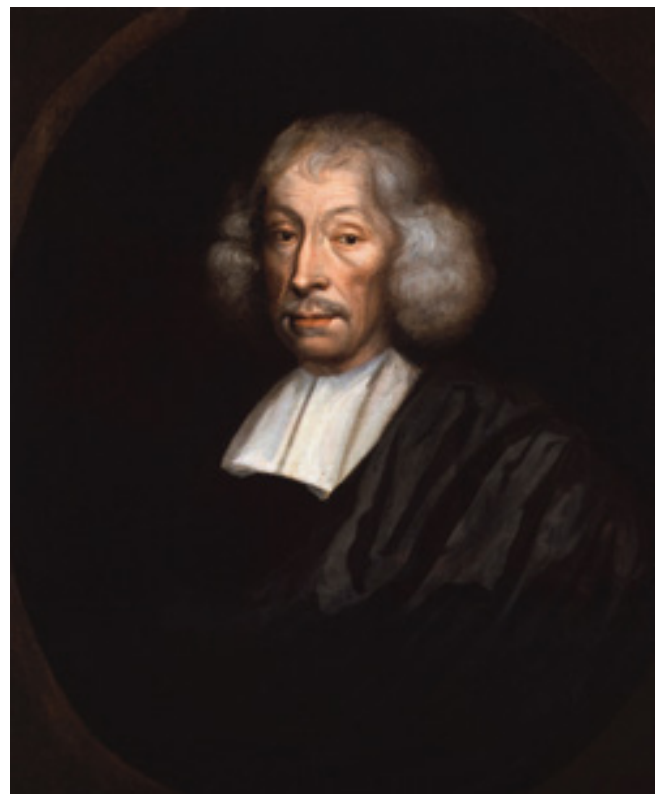

Fig. 9: John Ray, late seventeenth century, oil on canvas. $\mathrm{Na}$ tional Portrait Gallery, London (formerly, British Museum).

the connection was more than an historical one concerning the sitter. The commissioning of these busts was, however, not the only way in which distinguished former members of the college were being commemorated and celebrated. Around the same time in the early 1750s, when the first busts were being commissioned, a number of painted portraits were also being given to the college, in a few cases by the same donors. Edmund Garforth, for example, gave portraits of Bentley and Barrow, as well as the busts of Ray and Willoughby.

Although the documentation is scant, as Smith's papers do not survive, it would seem that from around 1750, a scheme developed for peopling the college with images of its illustrious former members. While a range of different individuals are named as donors, the person primarily responsible for this ambitious plan for constructing the college's visual institutional history was Robert Smith, who as Master was more conciliatory than his predecessor, Richard Bentley, and seems to have been concerned to sta-

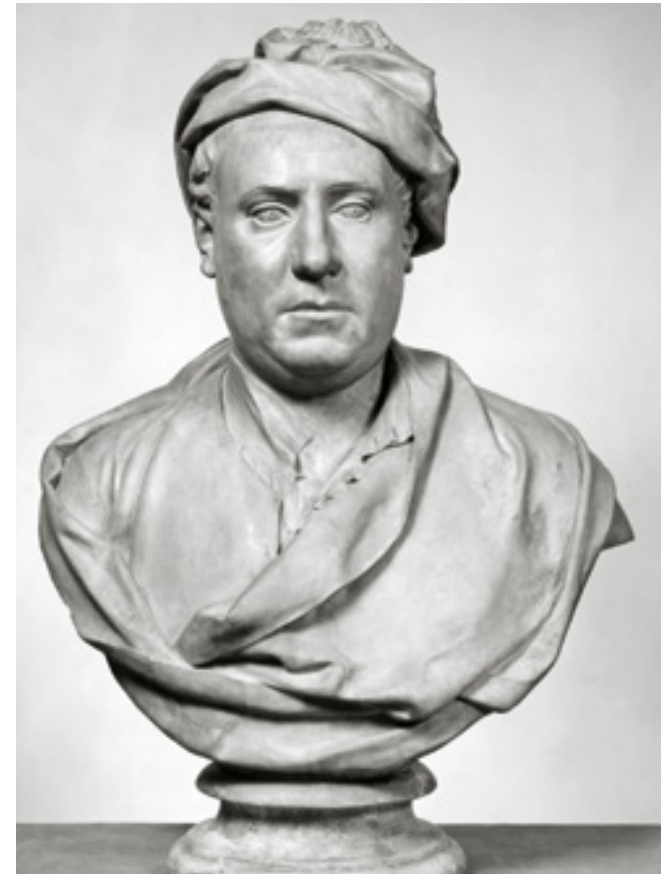

Fig. Io: Louis-François Roubiliac, Jonathan Tyers, ca. 1738 , terracotta. Victoria and Albert Museum, London.

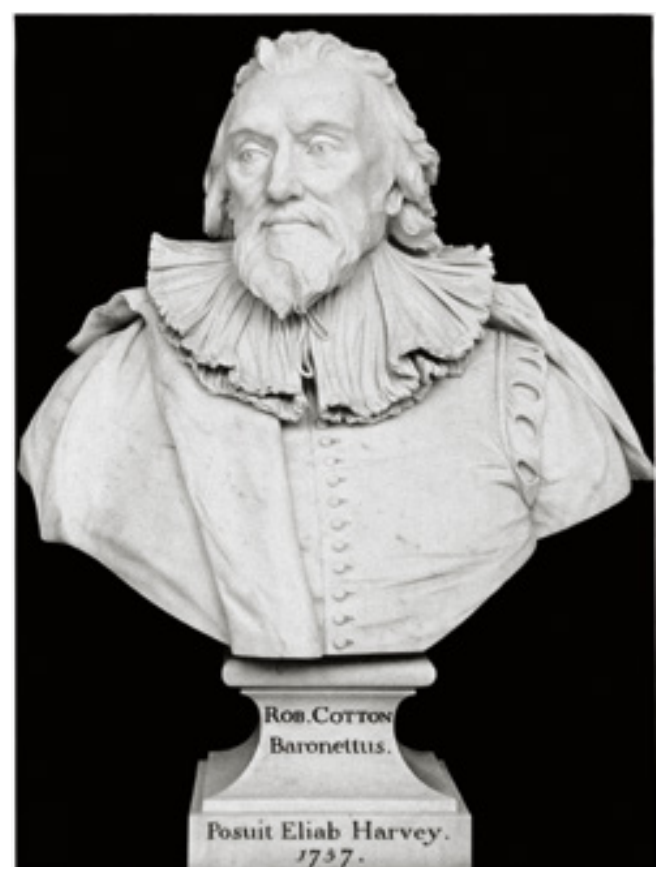

Fig. II: Louis-François Roubiliac, Robert Cotton, 1757, marble. Trinity College, Cambridge. 


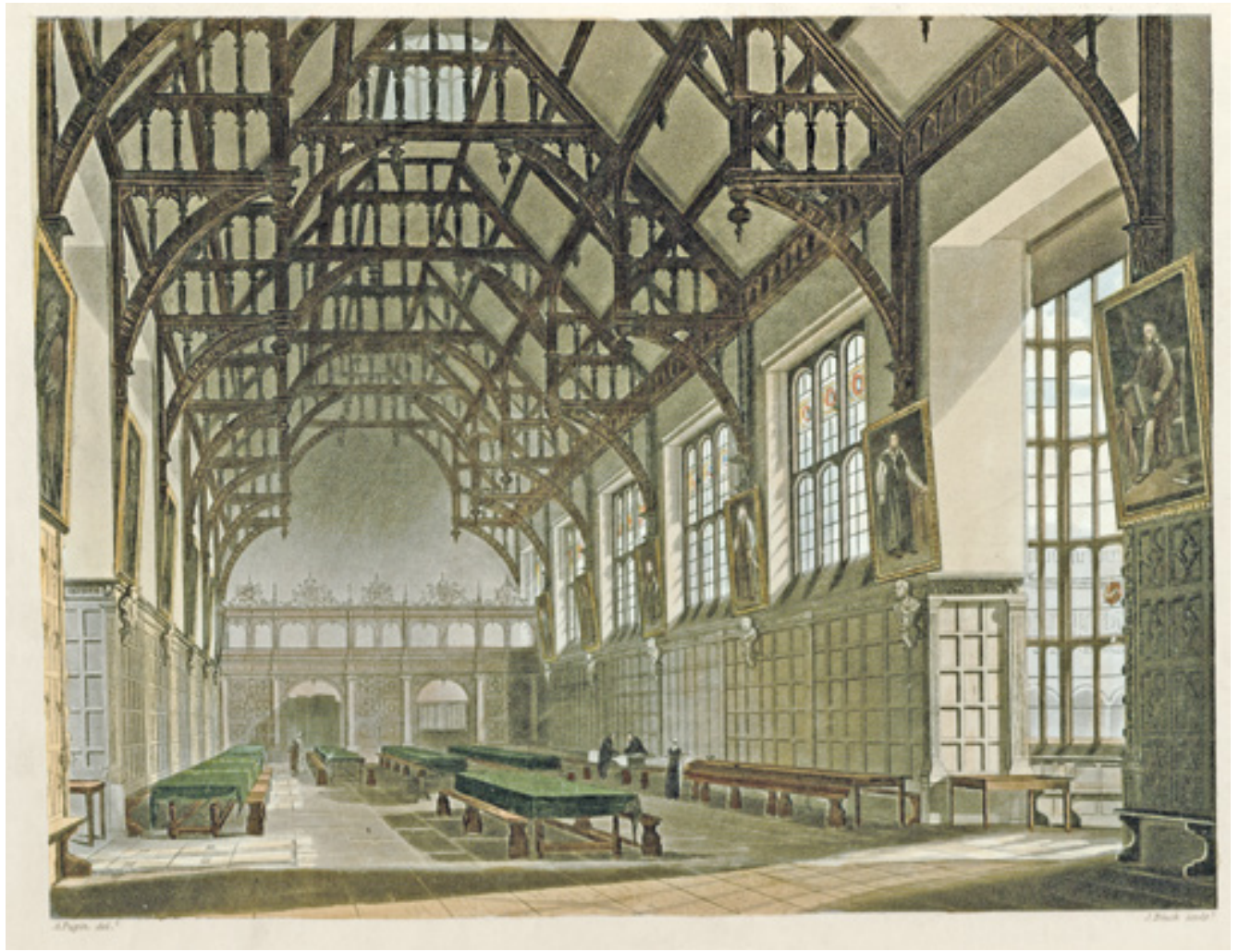

Fig. I2: The Hall, Trinity College, Cambridge, I8I5, aquatint. From R. Ackermann, A History of the University of Cambridge.

bilize and consolidate. The energy he expended in the collecting and display of busts and painted portraits is a register of this approach as well as an expression of the college's collective identity as he conceived it. But Smith did not apparently act alone. A significant role was also apparently played by Trinity's Vice-Master, Richard Walker. Like Smith, Walker was a supporter of Bentley and a long-standing member of the College, serving as Vice-Master between 1734 and his death in 1764 . While Smith's interests were in mathematics and optics, Walker's were above all botanical and in this he followed on from Ray and Willoughby. Best known for his donation of the University's Botanic Gardens in 1760, it may well have been Walker who championed the inclusion of the busts of Ray and Willoughby. Here, then, we see an ambitious scheme - one which we may assume was devised by Smith being realised by him and Walker. It is not surprising that by the mid-I770s, the revised edition of Cantabrigia Depicta could state:

These portraits of learned members are such and so many as no college can equal. Indeed had Locke happened to have had his education here, this group might have made head against any university on any subject of literature. ${ }^{20}$

How were these various images displayed and how meaningful were any of the groupings and juxtapositions? Although the busts placed at the end of each book press now line the sides of the Wren library, so repeating at floor level the series

20 Cantabrigia Depicta, Cambridge 1763. 


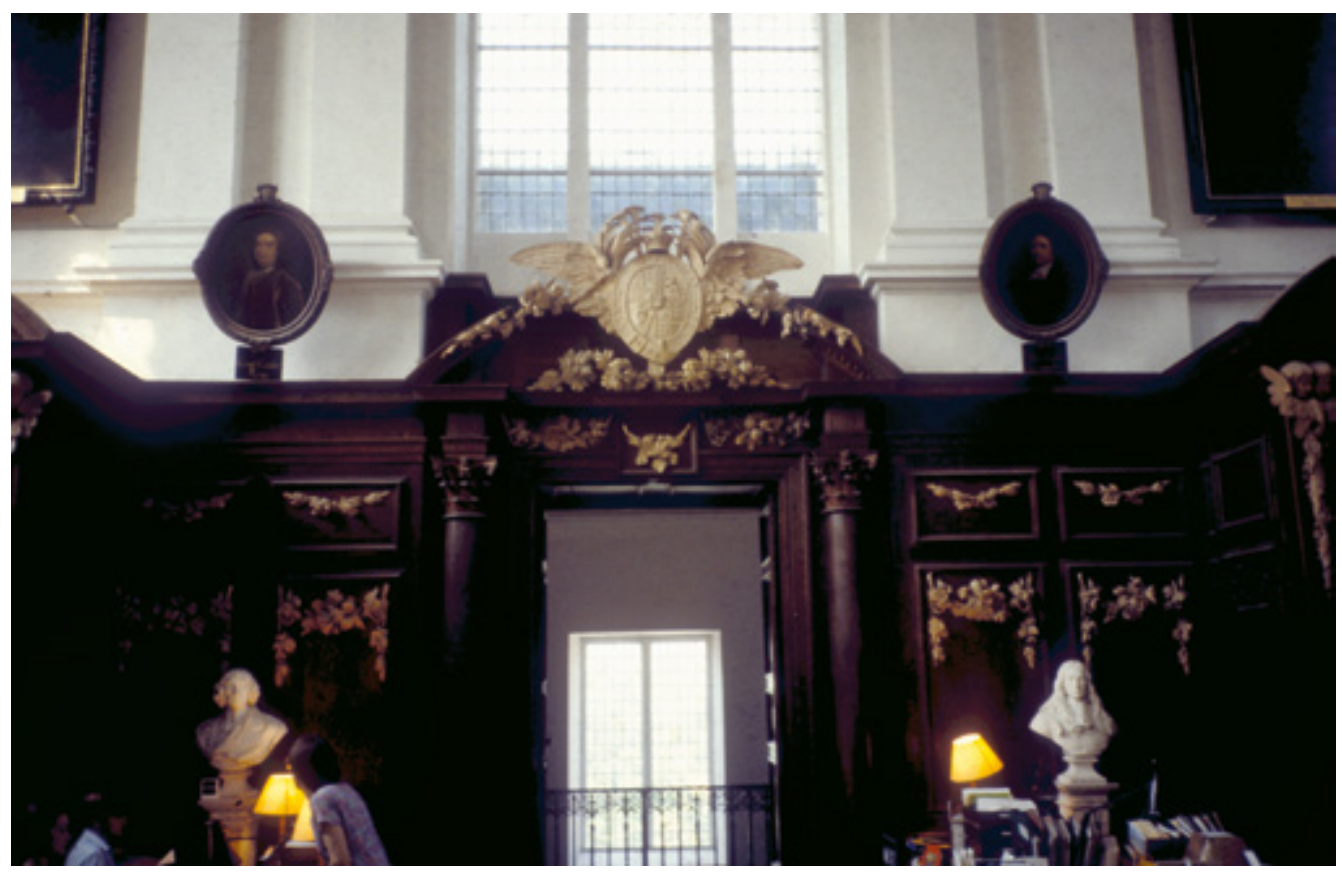

Fig. 13: North end of the Wren Library with busts of Ray and Willoughby in situ.

of plasters above, when given around 1755 only a few of them were displayed in this interior in the eighteenth century. The majority of the marble portraits - though the guidebooks are generally silent on this point - were displayed, along with many painted portraits, elsewhere at Trinity (Fig. I2). Together with the painted portraits, the busts formed part of a larger scheme of commemoration that ran throughout the college's principal spaces. A more specific programme, however, is discernible in the original arrangement of busts in the library, as this is described in late eighteenth-century accounts. The 1763 edition of the Cantabrigia Depicta mentions the plaster busts on the top of the bookcases but more specifically adds a reference to the 4 beautiful Busts on marble Terms, two at each end, of the celebrated Ray, Willoughby, Bacon, and Newton. Set on their paired pedestals these four busts remain in their original position (Fig. 13). ${ }^{2 \mathrm{I}}$ The busts commissioned for the library were evidently conceived as a distinctive group, reflecting the particular academic interests of Smith and Walker as well as their shared commitment to the physical sciences (or 'New Philosophy') developed at Cambridge with the encouragement of Bentley and Barrow.

By the 1750 , the research activity of Newton's time had ceased, allowing Heberden to comment more generally that the resident Fellows of the University were incrusted with the corroding rust of inactivity. But, while the earlier experimental advances could not be matched, the mid-eighteenth century was significant as a period in which Newtonianism and natural philosophy became integrated into a reformed curriculum at Cambridge and the 'holy alliance' between Newtonian science and Anglican theology found institutional expression in the Whig university. Trinity was at the centre of these developments and, in Gascoigne's words, 'formed

2I The images of Bentley and Barrow might also have been introduced into the library during the eighteenth century. 
a catalyst for the cultivation of scientific activity within the university as a whole'..$^{22}$

Smith's choice of subjects for the library needs to be interpreted in relation to these concerns. In one sense, the prominence given to the images of Newton and Bacon may be seen as an attempt to make the most of the college's illustrious scientific past at a period when new research in the experimental sciences, like undergraduate numbers, were at a low ebb, just as the inclusion of Ray and Willoughby might be associated with the not wholly successful attempts made by Richard Walker (who might indeed have suggested the commissioning of the busts) to re-establish botanical studies through his foundation of the University's Botanical Garden. But Smith's additions to the imagery of library and the chapel are better understood as the visual equivalent to his popularising of experimental science through the publication of accessible textbooks. The place of science within the Cambridge curriculum was being consolidated not only through the publication of these works but also through the presence of scientists' images in the library where they were read.

Quite apart from this particular grouping of images, the commissioning and use of the busts is interesting in that most of the sitters represented in this form already had a presence in the college as painted portraits. What then, we may ask, was to be gained by commissioning images of the same figures as more expensive marble busts? These commissions must presumably have been undertaken on the assumption that a representation in sculptural form added something or worked in a different way. Of course, given that at least some of these busts were from the start intended for display in the library, such images might be seen in terms of their traditional role as appropriate ornaments for a library, as recommended by Naudé. Without doubt, Smith

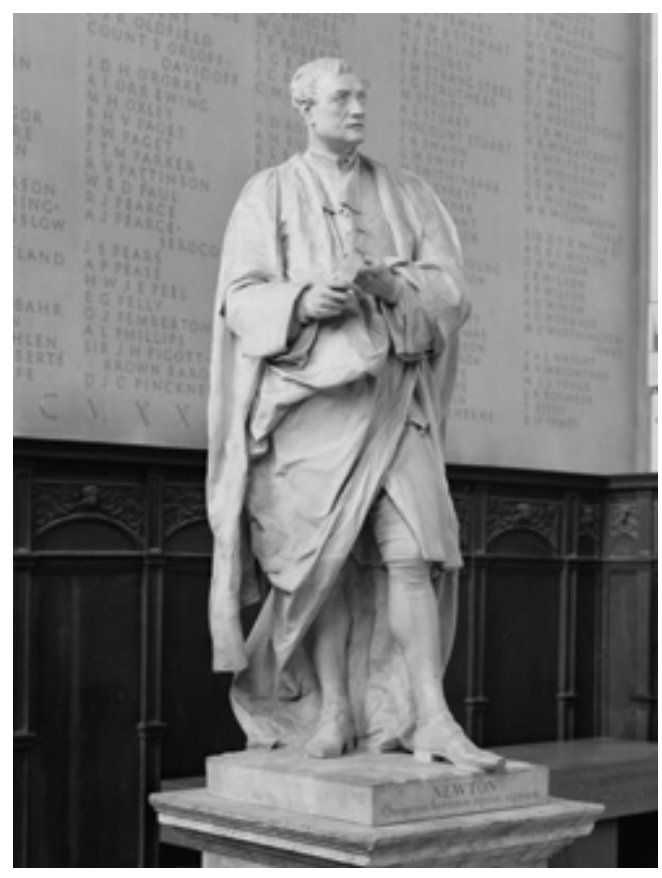

Fig. 14: Louis-François Roubiliac, Sir Isaac Newton, I755, marble, Trinity College, Cambridge.

and Walker would have been well aware of earlier examples of libraries adorned with busts of ancient and modern authors, not to mention cases where family members contributed busts of figures from an institution's past history, as at the Bibliothèque Sainte-Geneviève.

However, since the busts produced as part of Smith's ambitious plans were intended for display not just in the library but throughout the college, the significance of commissioning sculptural images should perhaps be understood not simply in terms of a tradition of library busts. Instead, the busts at Trinity seem to have been commissioned and executed on the assumption that the sculptural portrait was not simply an alternative or supplement to a painted image but carried with it a different cluster of associations, and a perhaps heavier weight of meaning. Such images, after all, were intended to celebrate the

22 J. Gascoigne, Cambridge in the Age of Enlightenment: Science, Religion and Politics from the Restoration to the French Revolution, Cambridge I988, p. 78. 
great and illustrious. If Smith's aim was to signal the importance of Trinity through an institutional history involving many of the great men of the country's past, then sculpture was the more appropriate mode by which to represent them. If the sculptural portrait was being accorded a new centrality by the mid-eighteenth century, no example illustrates this more powerfully than the series of busts executed for Trinity.

Nowhere is the new attention being given to sculpture clearer than in the commissioning, making and reception of the statue of Newton in the ante-chapel at Trinity (Fig. I4). Commissioned from Roubiliac by Robert Smith himself and erected in 1755 , this full-size, freestanding marble figure of Trinity's most eminent alumnus is certainly the most notable image within Smith's ambitious visual history of the College.

As soon as it had been put in place the statue was receiving admiring attention. A long and discerning account was given by John Nevile, Fellow of Emmanuel College, in his letter of I8 July 1755 to his friend Cox Macro, and this indicates the statue's place within Smith's larger scheme.

After describing the pose, dress and attributes of the statue, Nevile goes on to give a critical reading of the figure. He pays close attention to the way the drapery has been represented, and the role that the surface of the marble and the way in which it is polished play here. But above all he concentrates on the face:

A sublime Thought is surprisingly well express'd in ye Face, in wh One sees vast Penetration, wthout anything gloomy yt disgusts One, So far from it, $y t$ there are evident Marks of ye greatest Openness \& Ingenuity \&, at the same Time, Such a Joy appears in every Feature, as if ye Philosopher was rejoycing at some noble Discovery, He had just then made. ${ }^{23}$
It is assumed here that the viewer should look, above all, at the face, and that the way in which the sculpture was conceived and executed prompts such attention. The same idea was present much later in Wordsworth's celebrated description of

Newton with his prism and silent face,

The marble index of a mind for ever

Voyaging through strange seas of Thought, alone. ${ }^{24}$

In this respect, the statue as executed by Roubiliac assumes the same mode of viewing as a bust. While very much a public image, as statues were, of course, more so than any other mode of representation, Roubiliac's figure of Newton assumes a close and attentive viewing more usually associated with sculptural images that were to be seen at closer quarters. Despite its grandeur and authority it has an almost unexpected intimacy, effected through not only the composition - the set of the head, as well as the stance - but above all through the surface modulations of the carving, as Nevile seems to recognise.

The work's situation - its framing or staging, as it were - is in itself ambiguous.

A church in the eighteenth century was of course a public space, but a college chapel was public in a different way. In some ways, as part of the college, it was more private than a parish church but, at the same time, the chapel was but one of a series of connected social spaces, along with the hall and the library. This indeed was how the chapel was presented in contemporary guidebooks by which the visitor would be taken through a sequence of rooms, including the chapel.

In the late 1750 , then, a visitor to Trinity would have seen a combination of portraits, painted and sculptural, distributed throughout the college. The sheer number of recently

23 John Nevile to Cox Macro, I8 July 1755, British Library, Add. MS 32556-325557. For a transcription of the full description see BAKER, The Marble Index (cit. n. 6), pp. 344-45.

24 W. Wordsworth, The Prelude [1850], in: The Poetical Works of Wordsworth (eds. T. Hutchinson and E. De SeLINCOURT), Oxford I936, Book III, lines 6I-63. 
commissioned images would have left the viewer in no doubt as to the importance being attached to the college's past and its distinguished former members. But the unusual prominence of the sculptural portraits among this rich array must also have been striking. While sequences of busts were a familiar enough feature of many libraries by this date, no institution was so richly adorned with marble images of its collective past. The Newton statue belongs to this continuum of sculptural portraiture, employed to articulate in a very telling way the authority and achievement of the college's members and to make visible a powerful sense of the institution's history and identity. Together with celebrating the college's past - and most notably the achievement of Newton - the prominent display, especially in the library, of figures associated with advances in natural philosophy demonstrate an ideological commitment to the new sciences, their role in the Cambridge curriculum and the pioneering role that Trinity and its eighteenth-century Masters played in establishing this. At the same time, other sculptural portraits that were displayed throughout the college celebrated the college's history by representing former members who were not necessarily scholars. In fact, this was a hybrid assemblage, albeit one in which scholarly achievements figured prominently.

But what might we deduce from the example of Trinity College Cambridge, and the other cases I mentioned earlier, about the way in which writers and scholars were commemorated in academic institutions in the eighteenth century? We have seen here how assemblages or se- quences of busts celebrating writers and thinkers became more common during the eighteenth century and by mid-century were being seen as a necessary component of academic interiors especially the library. Predominantly historicising, the busts which populated such interiors sometimes represented pantheons of writers and thinkers, and were consciously considered to be exemplars, those who served as a puissant spurre. While at Trinity the combination of certain subjects could sometimes function as a visual register of an academic vision or agenda within the distinctive space of the library, the distribution of busts throughout the college intermingled with painted portraits shows that the arrangements were frequently more contingent and less programmatic. Furthermore, the assemblages of portrait busts need not be limited to scholars but could commemorate instead notable figures in the college's history or even benefactors. Although the eighteenth century saw a new and collective use of portrait busts within academic institutions of Enlightenment Britain and indeed Enlightenment Europe, it was only in the nineteenth century, most notably in the Arkadenhof in Vienna, that writers, thinkers and scholars were fully and properly celebrated in sculptural form.

Photographic acknowledgements: Fig. I: owner; Figs. 2, II, I3: author; Figs 3, 5, 6, I2: Trinity College, Cambridge; Figs. 7, 8, 14: Conway Library, Courtauld Institute of Art, London; Figs. 4, Io: V\&A Images; Fig. 9: National Portrait Gallery, London. 


\title{
DER KÖRPER ALS MONUMENT. BENTHAMS AUTO-IKONE UND DIE ÄSTHETIK DES HYPERREALISTISCHEN GELEHRTENPORTRÄTS
}

\author{
Pietro Conte
}

$\int$ eremy Bentham muss ein sehr vorausschauender und eher pessimistischer Mensch gewesen sein, wenn es wahr ist, dass er am 24. August 1769, gerade volljährig geworden, entschieden hat, sein Testament zu verfassen. Das, was ihn sorgte, war nicht die Verteilung seiner Reichtümer, sondern das Schicksal seiner sterblichen Überreste, die er einem Chirurgen für eine öffentliche Sezierung anvertrauen wollte: ein großartiger Beitrag zum wissenschaftlichen Fortschritt und ganz sicher demjenigen würdig, der später die moderne Theorie des Utilitarismus begründen würde.

Hinter der persönlichen Sorge eines einzelnen Menschen steckt jedoch ein viel generelleres Problem, dasselbe welches Jahrzehnte später, am 4. Februar I832, in einem seltsamen Brief auftaucht, in dem Goethe den Preußischen Ministerialbeamten Peter Beuth ermahnt, einen Anatomen, einen Plastiker und einen Gipsgießer nach Florenz zu senden, wo sie die Geheimnisse der Herstellung anatomischer Wachsmodelle erlernen und nach Berlin - der Stadt, wo Wissenschaften, Künste, Geschmack und Technik vollkommen einheimisch in lebendiger Thätigkeit sind ${ }^{\mathrm{H}}$ - importieren sollten. Auf diese Weise könnten die Medizinstudenten die innere Gestalt des menschli- chen Körpers untersuchen, ohne den Leichnam zu berühren. Goethes Erachtens nach erwies sich die Wachsfigur als ein würdiges Surrogat, das auf ideelle Weise die Wirklichkeit ersetzt. ${ }^{2}$ Die Gründe für diese Anfrage sind identisch mit jenen, die Bentham dazu trieben, sein Testament zu machen, und sie werden deutlich, als Goethe am Ende seines Briefes einige Nachrichten wiedergibt, die Friedrich Alexander Bran, Journalist und Leiter der „Miszellen aus der neuesten ausländischen Literatur", veröffentlicht hatte. Der Titel klang stark beunruhigend: London Asphyxiators. Und auch der Inhalt war es nicht weniger. Man liest von den Auferstehungsmännern, Leichenräubern, die, mangels frischer Körper, die exhumiert und geheim an die Krankenhäuser für anatomische Studien hätten geliefert werden können, entschieden hatten, die Wartezeit zu verkürzen und sich unmittelbar in Mörder zu verwandeln: Von ihren Eltern verlassene Kinder, die von Betteln oder Spitzbübereyen lebten, kamen nicht wieder an die Orte, die sie gewöhnlich besuchten. Man zweifelt nicht daran, daß auch sie als Opfer der Habgier jener Ungeheuer gefallen sind, die sich um jeden Preis zu Lieferanten der Sectionsäle machen wollen. ${ }^{3}$ Das Vorgehen der Mörder war immer gleich: Die Unglücklichen wurden

I J. W. von Goethe, Plastische Anatomie, in: Goethe's Werke. Vollständige Ausgabe letzter Hand, 6o Bde., Stuttgart/ Tübingen I827-I842, Bd. 44, S. 6 I.

2 Ebenda, S. 60.

3 Ebenda, S. 64. 


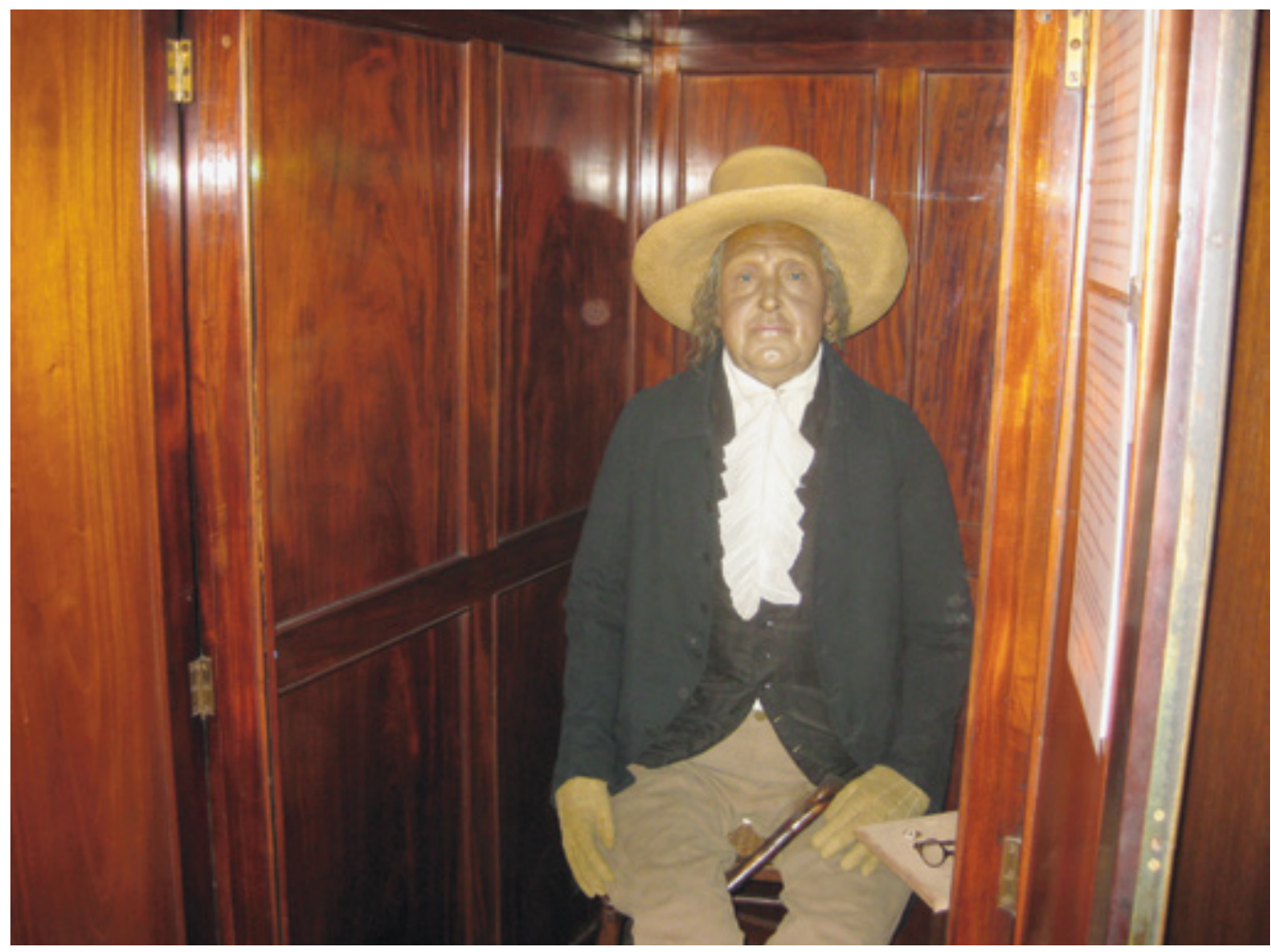

Abb. I: Jeremy Bentham, Auto-Icon, I832. University College London.

beschattet, narkotisiert und erstickt, damit keine augenfällige Spur des gewaltsamen Aktes hinterlassen wurde.

Zusätzlich zu der Empörung gegenüber diesen Aktionen, die die Hauptstadt und andere englische Städte geißelten, äußerte Goethe die begründete Befürchtung, dass die teuerste Rechnung nicht die Verbrecher, sondern die Wissenschaftler bezahlen würden: Die Reaktion gegen die Leichenräuber habe schrittweise zu einer geringeren Verfügbarkeit von legal aufgetriebenen Kadavern geführt sowie zur anschließenden Einschränkung der Sezierpraktiken. In diese Richtung habe sich auch die öffentliche Meinung entwickelt, die immer geneigter sei, die Todesstrafe abzuschaffen: Man denkt an die Verbesserung des Zustandes entlassener Verbrecher, man er- zieht verwilderte Kinder zum Guten, und schon findet man es höchst unmenschlich, Fehler und Irrtbümer auf das Grausamste nach dem Tode zu bestrafen. Landesverräther mögen geviertheilt werden, aber gefallene Mädchen in tausend Stücke anatomisch zu zersetzen, will sich nicht mehr ziemen. ${ }^{4}$

Es handelt sich dabei gewiss nicht - unnötig, es zu sagen - um ein Plädoyer für die Todesstrafe, sondern um die Sorge den wissenschaftlichen Fortschritt betreffend, der in den Jahrhunderten viel Nutzen aus den anatomischen Beobachtungen gezogen hat. Goethe spürte die Notwendigkeit, etwas zu tun, auch weil das Sezieren von Leichen als Teil des Medizinstudiums in Deutschland wie auch in England einen sehr schlechten Ruf genoss. Von religiösen und im Volksglauben verankerten Vorbehalten

4 Ebenda, S. 6I-62. 
abgesehen, mochte dies auch damit zusammenhängen, dass seit Heinrich VIII. eine bestimmte Zahl hingerichteter Verbrecher für medizinische Zwecke zur Verfügung gestellt wurde. Dieses Verfahren fand seine Bestätigung im „Murder Act“, einem Gesetz von 1752, welches es erlaubte, den von einem Mord befleckten Leichnam der öffentlichen Autopsie zu unterziehen. In der breiten Öffentlichkeit galt das Sezieren also als eine über den Tod hinaus verlängerte Form des Bestrafens. Goethes Brief und Benthams Testament belegen ihren Willen, gegen diesen Irrglauben vorzugehen.

Goethe und Bentham starben beide in kurzem Abstand voneinander I832, bevor sie ihre Anstrengungen prämiert sehen konnten: Genau in demselben Jahr segnete das House of Lords den „Anatomy Act“ ab, der die Sezierung aus dem Kreis der zu bestrafenden Post-mortem-Praktiken strich und es Medizinern und Forschern ermöglichte, sich den zur Verfügung stehenden Verstorbenen anzunehmen und so das Problem des Auftreibens der Kadaver zum größten Teil zu lösen. Bentham hatte sich also höchstpersönlich zur Verfügung gestellt, damit den anatomischen Studien ein unverzichtbarer Wert für den Fortschritt der wissenschaftlichen Erkenntnisse anerkannt werden konnte: Er hatte dabei nicht nur seinen Namen, sondern auch seinen Körper hergegeben, weil er sich schon als Junge fragte, ob und wie er auch nach seinem Tod noch von einem Nutzen für die Gesellschaft sein könnte.

Dies reichte ihm jedoch nicht. Sollte sein wissenschaftlicher Beitrag auf dem kalten Tisch eines Operationssaals, unter den Augen von Dutzenden von Menschen, enden? War es möglich, dass es nichts anderes gab, um der wissenschaftlichen Sache zu dienen? Solche Fragen müssen die Gedanken des englischen Philoso- phen für lange Zeit aufgewühlt haben, bis er sich I824 dazu entschloss, seinem Testament ein Kodizill hinzuzufügen. Nachdem er die Absicht bestätigt hatte, den eigenen Leichnam in the most public manner sezieren und die Weichteile für zukünftige Studien konservieren zu lassen, beeilte sich Bentham, neue Instruktionen zu geben: As to the head \& rest of the skeleton, it is my desire that the head may by preparation after the New Zealand manner be preserved, \& the entire skeleton with the head above it \& connected with $i t$, be placed in a sitting posture, \& made up into the form of a living body, covered with the most decent suit of clothes. And whereas it has occurred to me that some of my friends may be eventually disposed to meet at a club in commemoration of my birth \& death, my desire is, that in that case order may be taken by my executor, for such my skeleton seated in an appropriate chair, to be placed, on the occasion of any such meeting, at one end of the table after the manner in which, at a public meeting, a chairman is commonly seated. ${ }^{6}$

Es ist der erste Anklang an das, was hier als Effigy ${ }^{7}$ definiert, später aber zur Auto-Ikone umgetauft wird, ein Neologismus, der in der letzten Version des Testaments erstmals auftaucht. Der Autor dieser Seiten, die der Philosoph lediglich gegenzeichnet, ist in der Tat ein Arzt, Thomas Southwood Smith: Er wird es sein, der die Grabrede zur Erinnerung an Bentham hält und der in den darauffolgenden Tagen mit der Behandlung seiner sterblichen Reste fortfährt. Fünfundzwanzig Jahre später sollte Southwood Smith seinem Kollegen William Munk in einem Brief das angewandte Verfahren erklären und dabei zeitgleich die problematischen Aspekte herausstellen: I endeavoured to preserve the head untouched, merely drawing away the fluids by placing it under an air pump over sulphuric acid. By this means the

\footnotetext{
5 J. Bentham, Codicil to Bentham's Will, 29 March and 9 October 1824, in: Bentham’s Auto-Icon and Related Writings (hrsg. von J. E. CRimmins), Bristol 2002, S. 5-7: 6.

6 Ebenda.

7 Ebenda.
} 
head was rendered as hard as the skulls of the New Zealanders; but all expression was of course gone. ${ }^{8}$

Das Gesicht war also nicht mehr präsentabel, aber eine Lösung war schnell gefunden: Wenn der Kopf aus Fleisch und Blut mittlerweile unpräsentabel war, blieb nichts anderes, als einen anderen zu modellieren, ein Bild zu konstruieren, das als Ersatz des Vorbildes gelten könnte. Das Material? Eine obligatorische Wahl: Wachs - der Stoff der Ähnlichkeit par excellence, das anthropomorphe Material schlechthin, das Medium der Metamorphose und des Zwischenstadiums. ${ }^{9}$ Ohne weiter zu zögern, wandte man sich an Jacques Talrich, einen Chirurgen, der sich für den Bau anatomischer Puppen begeisterte: einen Arzt also, den Southwood Smith aber als distinguished French artist ${ }^{\circ}$ definierte, der sich von einigen Porträts Benthams derart inspirieren ließ, dass er ein fast lebendiges Bild erschaffen konnte.

Nachdem sie ursprünglich von Southwood Smith in seinem Studio aufbewahrt wurde, sollte die Auto-Ikone nach einigen Abenteuern am University College ihre aktuelle Bleibe finden. In einem Brief aus dem Jahr I850 berichtete Lord Henry Brougham die akademischen Autoritäten über Southwood Smiths Anfrage, Benthams Effigie im Inneren des Colleges aufzubewahren, und der Ton lässt dabei keine Zweifel: [It is] the most valuable wax figure I ever saw [...]. The likeness is so perfect that it seems as if alive. ${ }^{\text {II }}$

Die Betonung liegt dabei noch einmal auf der außergewöhnlichen mimetischen Treue, die durch den Einsatz des Wachses möglich geworden war, und von diesem Blickwinkel aus wäre nicht einmal Bentham - der sich jedoch gewünscht hät- te, sich direkt, ohne jegliche Vermittlung in sein eigenes Bild zu verwandeln ${ }^{12}$ - enttäuscht gewesen: Die Grenzen des Hyperrealismus bis ins Extreme rückend, verliert sich in der Tat jede Distanz zwischen Kopie und Modell. Das Abbild ersetzt das Modell und nimmt stellvertretend seinen Platz ein, so wie beispielsweise die Tatsache zeigt, dass die Vitrine, in der die Auto-Ikone ausgestellt wurde, für eine gewisse Zeit beide Köpfe beherbergte, sowohl den Kopf aus Fleisch und Blut, als auch sein wächsernes Abbild. Auf den Schultern des Philosophen thronte allerdings dieser letzte, während der „andere“ (der sich plötzlich und paradoxerweise in das Doppelte des Doppelten verwandelt hatte) auf der Erde zwischen den Füßen seines Eigentümers ruhte: Manna für die Studenten des Colleges, die in verschiedenen Gelegenheiten sich dabei vergnügten, den Kopf zu rauben und um Lösegeld zu bitten oder ihn in einem Schließfach im Bahnhof von Aberdeen wieder auftauchen zu lassen, bis die Verwaltung ihn in einem sicheren Archivraum und ab dem Jahr 2005 in einem Safe des Archäologischen Instituts des Colleges aufbewahrte.

Nichts, was Bentham nicht bereits schon vorhergesehen hatte: Ridiculed it will be, of course, schrieb er prophetisch in Auto-Icon, einem Pamphlet, das zu seinen Lebzeiten unveröffentlicht blieb, aber posthum in dreißig Kopien von seinem Freund John Hill Burton gedruckt wurde. Der Untertitel, Further Uses of the Dead to the Living, verdeutlichte Benthams Obsession, auch als Toter in gewisser Weise nützlich zu sein. Die Auto-Ikone - dieses seltsame Denkmal, dieses in Lebensgröße, von den üblichen Gelehrtenbüsten so verschiede-

8 Th. S. Smith, Brief an W. Munk (I4. 6. 1857), in: W. Munk, The Roll of the Royal College of Physicians of London, 3 Bde., London I878, Bd. 3, S. 237 (Anm.).

9 S. darüber G. Didi-Huberman, Ähnlichkeit und Berührung. Archäologie, Anachronismus und Modernität des Abdrucks, Köln 1999 .

Iо Sмiтн, Brief an William Munk (zit. Anm. 8).

II University College London, Minutes of the Proceedings of the Council, zit. nach C. F. A. Marmoy, The „AutoIcon" of Jeremy Bentham at University College, London, S. 83.

I2 S. darüber D. Bindman, The Skeleton in the Cupboard: Jeremy Bentham's Auto-Icon, in: The Old Radical. Representations of Jeremy Bentham (hrsg. von C. Fuller), London 1998, S. 9-2I. 
ne Bildnis - ist durchaus nicht einfach der makabre Scherz eines Intellektuellen, sondern stattdessen Ausdruck eines präzisen kulturellen Projekts. Nachdem er die Herkunft des Begriffes „Auto-Ikone" geklärt hatte - The word "auto" has been made familiar to English ears by its use in ,autobiography" (why should there not be "auto-tanatography“?), "autograph" ecc. ${ }^{13}$-, stürzt sich der Gelehrte in eine Lobrede auf seine Kreatur und definiert sie als a man who is his own image, ,ein Mensch, der sein eigenes Ebenbild ist" ${ }^{.}{ }^{4}$ Es handelt sich dabei um das extremste Beispiel einer Monumentalisierung des Körpers, die in einer Metamorphose endet, die diametral entgegengesetzt zu jener der Galatea (der Statue, in die sich Pygmalion verliebt hatte) ist: Dort wurde eine unbeseelte künstliche Figur zum Leben erweckt, hier wird im Gegenteil eine Person aus Fleisch und Blut in ihr eigenes Ebenbild umgewandelt. Thus every man would be his own monument; and if copies were wanting, a cast in plaster would supersede the necessity of sculpture. ${ }^{\mathrm{IS}}$

Benthams Meinung nach hatte der Auto-Ikonismus unzählige Vorteile. Aus ökonomischer Sicht ließe er Beerdigungen, Beisetzungen und Einäscherungen überflüssig werden, Zeremonien, die von Bentham als gleichbedeutend mit verhassten und unnützen Formen der Versteuerung gesehen wurden. Aus pädagogischen Gründen würde er es gestatten, Tempel der Ehre oder der Schande ${ }^{16}$ zu errichten, die die Respekt oder Schmach verdienenden Auto-Ikonen aufnehmen und den Besuchern vorbildliche oder abzulehnende Modelle anbieten könnten. Das Voranschreiten der Zeit (mit den sozialen, politischen und moralischen Veränderungen, die damit stets einhergehen) könnte auch zu perspektivischen Umschwüngen führen und bewirken, dass zuvor verschmähte Auto-Iko- nen anschließend verehrt würden und umgekehrt - eine Tatsache, die sich als außerordentlich interessant aus Sicht der Ideen- und Kulturgeschichte erweisen sollte. Man sollte auch nicht vergessen, dass Bentham diese Überlegungen genau zu der Zeit entwickelt, in der Marie Grosholtz (alias Madame Tussaud) auf dem Höhepunkt ihrer Karriere angekommen ist und in ganz England ihre Wanderausstellung herumführt, die nicht nur aus Helden und strahlenden Persönlichkeiten bestand, sondern vor allem aus Mördern, Halsabschneidern, Vergewaltigern und grands voleurs: Die von dem Philosophen erdachten Tempel der Lobrede und Schande sind also gar nicht so abwegig und es ist kein Zufall, dass in Auto-Icon explizit Bezug auf ein anderes berühmtes Wachsfigurenmuseum, das der Mrs. Salmon, genommen wird.

Dies ist aber nicht alles. Von einem wissenschaftlichen Blickwinkel aus ist es in erster Linie die Phrenologie, die Vorteil aus den Auto-Ikonen hätte ziehen können: Explizit die Begründer des Faches, Johann Gaspar Spurzheim und Franz Joseph Gall zitierend, unterstreicht Bentham, dass ihre Schüler so endlich auf Selbstporträts zählen könnten, die vollkommen identisch mit den Originalen wären. Und Bentham hätte es gewiss Freude bereitet, zu wissen, dass es im Laufe des I9. Jahrhunderts nicht an tief schürfenden Studien gefehlt hat, die versucht haben, zwischen seinen außergewöhnlichen intellektuellen Gaben und den anatomischen Charakteristiken seines Schädels einen Bezug herzustellen. Die Ergebnisse sind allerdings nicht sonderlich ermutigend gewesen: „Jeremy Bentham's head is closely identical with that of the mediocre or average Englishman. [...] If judged by head-capacity, Bentham would have been simply mediocre" ${ }^{\text {.17 }}$

I3 J. Bentham, Auto-Icon. Or, Farther Uses of the Dead to the Living. A Fragment. From the MSS. of Jeremy Bentham, in: Bentham's Auto-Icon (zit. Anm. 5), S. I-2I: 2.

I4 Ebenda.

I5 Ebenda, S. 4 .

I6 Ebenda, S. 6.

i7 M. A. Lewenz K. Pearson, On the Measurement of Internal Capacity from Cranial Circumferences, in: Biometri$\mathrm{ka}, \mathrm{III} / 4$, I904, S. 366-397, 394 
Ein weiterer, nicht weniger wichtiger Vorteil, der durch die Auto-Ikonen möglich wurde, bezieht sich auf das Gedenken, indem der Bau einer Galerie von Porträts die teuren Stein- und Marmordenkmäler überflüssig machen und Reiche und Arme demokratisch auf dieselbe Stufe stellen würde. Gibt es denn kein ausreichend großes Gebäude, um die Auto-Ikonen als Ganzkörperfigur auszustellen? Sicher könnte man sich mit den auf wenigen Brettern eines mittleren Wandregals ausgelegten alleinigen Köpfen der Auto-Ikonen bereits begnügen, die bestens das exzellente pedigree des Hausherren auszeichnen.

An diesem Punkt eilen die Gedanken Jahrhunderte zurück bis hin zu dem sogenannten ius imaginum, dem Recht, das die nobiles hatten, Wachsbilder der Ahnen, die zu kurulischen Ämtern gelangten, im Atrium aufzustellen und bei feierlichen Gelegenheiten, wie Leichenbegängnissen, zur Schau zu stellen. Diese Praxis, die Julius von Schlosser - mit allen Risiken, aber auch der Faszination des Anachronismus - in seiner bahnbrechenden Geschichte der Porträtbildnerei in Wachs mit unserem heutigen Brief$a_{d e l^{8}}$ verglich, ist seit der republikanischen Zeit nachgewiesen und im II. Jahrhundert $\mathrm{n}$. C. von Polybius in einer komplizierten und festgelegten Form beschrieben worden:

Denn so oft unter ihnen irgend ein berühmter Mann diese Welt verlassen hat, wird er bei seiner Leichenbestattung, außer andern Ehrenbezeugungen, auf den Rednerplatz, wie sie es nennen, herausgetragen, zuweilen stehend, damit ihn Jedermann sehen könne, seltner liegend. Hier steht das ganze Volk versammelt umher, und sein Sohn, wenn er einen schon herangewachsenen Sohn nachgelassen hat, und dieser zugegen ist, oder einer von seinen Blutsverwandten, besteigt die Rednerbühne, und hält eine Lobrede auf den Verstorbenen, wor- in er die von ihm in seinem Leben verrichteten edlen Handlungen erwähnt. Und so geschieht es, daß das ganze Volk sich an das Geschehene lebhaft erinnert, sich es wieder vor Augen stellt, und so innig davon gerührt wird, daß die Trauer mehr öffentlich, als bloß dem Geschlechte des Verstorbenen eigen zu sein scheint. Hierauf bestatten sie die Leiche des Verstorbenen; und hernach stellen sie sein Bildnis an dem scheinbarsten Orte des Hauses auf, und schließen es in hölzerne Schreine ein. Dies Bildnis aber ist das Antlitz des Verstorbenen mit ganz vorzüglicher Ähnlichkeit gearbeitet, sowohl der Form, als der Unterschrift nach. Dergleichen Bilder aber tragen sie auch bei öffentlichen Opferfeyerlichkeiten umher, und schmücken sie aufs schönste. Wenn aber irgend ein angesehenes Mitglied des Hauses stirbt, so tragen sie das Bild mit zum Leichenbegängniß, und bekleiden es so, wie es seiner Größe und seinem Range gemäß ist. [...] Schöner kann für einen ehrliebenden und edelmüthigen Jüngling kein Anblick sein. Denn die Bilder solcher Männer zu sehen, die durch Tugend berühmt worden sind, und sie wie lebend und beseelt vor sich zu sehen, ist ohne Zweifel das edelste Schauspiel. ${ }^{19}$

Die Frage nach den imagines maiorum ist bekanntlich ein sehr verzwicktes Problem, wobei die teils weit entfernten Interpretationen gerade durch den Nachdruck auf den performativen Wert dieser Porträts vereint werden, der durch die vom Einsatz des Wachses möglich gemachte Adhärenz an das Modell akzentuiert wird: „Die Ahnen sind hier, sie sind in Form von Masken, die ihr Aussehen am präzisesten wiedergeben, angekommen. [...] Der Verstorbene gelangt nicht nur metaphorisch ad maiores: die Ahnen sind tatsächlich dort, um ihn zu begleiten. Man stirbt in Anwesenheit seiner Vergangenheit".${ }^{20}$ Hier sind wir also erneut bei der Frage der Anwesenheit, der Präsenz, der eigentli-

I8 J. von Schlosser, Geschichte der Porträtbildnerei in Wachs. Ein Versuch, in: Jahrbuch der Kunsthistorischen Sammlungen des Allerhöchsten Kaiserhauses, XXIX, I9IO-I9II, S. I7I-258, hier 178.

I9 Polybios, Historiae VI, 52, II-54; zit. nach J. von Schlosser, Geschichte (zit. Anm. 17), S. I79.

20 M. Bettini, Antropologia e cultura romana. Parentela, tempo, immagini dell'anima (i986), Roma i999, S. I86 (Übersetzung des Autors). 
chen kulturellen Konstante, welche die verschiedenen Bereiche und Gebräuche der Keroplastik durchdringt: Die imagines sind von einer eigentümlichen agency gekennzeichnet, sie sind konkret benutzbar, um die Abwesenden zu vergegenwärtigen, so als ob diese "lebend und beseelt" wären. Wenn man den Begriff „Bild“ als fiktive Reproduktion auffasst, sollte man gewiss präzisieren, - so paradox es auch klingen mag - dass das imago kein Bild ist, da es sich nicht um die einfache Darstellung eines Gesichts, sondern um das Gesicht selbst handelt: Ergebnis eines Abdrucks und als solcher auf eine materielle Spur zurückführbar, steht es mit dem Original in metonymischer, nicht metaphorischer Beziehung und bringt daher also „die reelle Präsenz des Dinges ${ }^{{ }^{\prime 2 I}}$ mit sich.

In diesem Kontext scheint die Auto-Ikone nicht mehr nur eine bizarre Idee oder ein makabrer Spaß zu sein, sondern das Ergebnis von tausendjährigen Versuchen der Vergegenwärtigung - um Jean-Pierre Vernants Begriff der présentifcation zu zitieren - von abwesenden Personen (z. B. der Toten) oder Wesen (z. B. der Gottheiten). In all diesen Versuchen hat das Wachs stets eine Protagonistenrolle eingenommen: Dank seiner Geschmeidigkeit (welche es ihm ermöglicht, jedwede Form anzunehmen) und Farbe (jener der Haut sehr ähnlich) ist Wachs seit jeher der Stoff, der die größte Nähe zum Modell ermöglicht; aus diesem Grund ist es so oft verwendet worden, um Bildnisse von Gelehrten oder prominenten Persönlichkeiten (Herrschern usw. ${ }^{22}$ ) herzustellen.

Bevor Bildnisse an eine Person erinnern, haben sie die Funktion, sie zu repräsentieren, sie zu vergegenwärtigen. Dabei ist die Ähnlichkeit zwischen dem Porträtierten und seinem Bildnis, sowohl in äußeren physiognomischen Merkmalen als auch in der Erfassung der Persönlichkeit, entscheidend. Diesbezüglich kommen weitere sitzende Ganzkörperporträts in den Sinn, deren unglaubliche Ähnlichkeit von vielen kuriosen Anekdoten unterstrichen wird: Als er die auf einem Thron sitzende Effigie von Ferdinand III. von Habsburg (I608-I657) beschreibt, stellt Joachim von Sandrart fest, dass sie dem Herrscher in Fleisch und Blut so ähnlich ist, daß einest der Ungarische Canzler und Bischof von Neutra, als er in der Käyserlichen Schatzkammer herum geführet worden und in das Zimmer kommen, wo diese Käyserliche posirte Bildnis geseßen / die sich bey seiner Ankunft aufgerichtet / das Haupt und die Augen hin und her gewendet / sich über solche unverhofte Käyserliche Gegenwart entsetzet I auf die Knie nidergefallen und um Verzeihung gebetten/ daß er sich erkühnet ohne Befehl dahin zu kommen / auch so lang kniend verblieben/ biß der Schatzmeister ihne aufgehoben / gelachet / und den Betrug offen und kundbar gemacht. ${ }^{23}$ Das Wachs ist in der Lage, dem dargestellten Subjekt einen erstaunlichen Grad der "Gegenwart" - so wie es bezeichnenderweise der deutsche Text wiedergibt - zuzuerkennen, eine Präsenz, die auch zu weitaus dramatischeren Resultaten führen kann als dem der tragikomischen Anekdote von Sandrart: In seinem Altes und neues Berlin behauptet Georg Küster, dass ein gewisser General, der sich vor der Effigie Friedrichs I. von Preußen (1657-1713) befand, diesem Bilde, da es in des Königs Zimmer auf einen Stubl gesetzt worden, seine Reverenz gemacht [habe], weil er geglaubt, es sey der König. Da

2I F. Dupont, L'autre corps de l'empereur-dieu, in: Ch. Malamoud/J.-P. Vernant (Hg.), Corps des dieux, Paris I986, S. 23I-252, hier 33I (Übersetzung des Autors).

22 Siehe u.a. M. Kretzschmar, Herrscherbilder aus Wachs. Lebensgroße Porträts politischer Machthaber in der Frühen Neuzeit, Berlin 2014.

23 J. von Sandrart, Academie der Bau-, Bild- und Mahlerey-Künste (I675), hrsg. von A. R. Peltzer, München I925, S. 235, später zitiert von W. BRÜCKNER, Bildnis und Brauch. Studien zur Bildfunktion der Effigies, Berlin I966, S. 158 und von D. Freedberg, The Power of Images. Studies in the History and Theory of Response, Chicago/London 1989 , S. 222-224. 
ihm nun nicht geantwortet worden, hat er es für eine Ungnade gehalten, ist darüber erschrocken und nach einigen Tagen gestorben. ${ }^{24}$

So unwahrscheinlich diese Geschichten erscheinen mögen, sollten sie allerdings doch aufgrund ihres typischen Erzählcharakters ernst genommen werden: Schon Ernst Kris und Otto Kurz, beides Schüler Schlossers, unterstrichen, dass das Problem der Wahrhaftigkeit einzelner Behauptungen bzw. Anekdoten vollkommen irrelevant ist. Das, was zählt, ist nur ihre Wiederkehr. ${ }^{25}$ Und wiederkehrend sind diese Anekdoten ganz gewiss. 193I veröffentlicht der russische Erzähler Jurij Nikolaevič Tynjanow einen seiner bedeutendsten Texte, Die Wachsfigur, einen historischen Roman, der in Sankt Petersburg zur Zeit des Untergangs der langen Reformzeitperiode von Peter dem Großen spielte. Mit dem Tod des Herrschers, I725, erlegt sich der Künstler Francesco Bartolomeo Rastrelli die Aufgabe auf, eine Effigie in Wachs und Eichenholz zu realisieren. Nachdem er ein Loblied auf die Wachsplastik gesungen hatte (Es gibt eine Kunst, die schön und wahr ist, in der das Kunstwerk nicht vom Modell zu unterscheiden ist ${ }^{6}$ ), macht sich der Bildhauer an die Arbeit und realisiert eine dem Original außergewöhnlich treue Skulptur, die anschließend in Begleitung von drei Hunden und einem Papagei auf einem eleganten Sessel unter einem Baldachin in einem Zimmer der lokalen Kunstkammer positioniert wird. Das Ergebnis ist erstaunlich: Wie sollte man dem Abbild begegnen? Vieles konnte nicht vor ihm ausgesprochen werden; denn alles an der Wachsperson war ähnlich, sie war das Ebenbild. ${ }^{27}$ Wiederum fällt die Betonung auf die unheimliche Präsenz der Wachsfigur, die nicht wie ein Porträt, nicht wie ein Denkmal, sondern wie eine Person wahrgenommen wird. Es handelt sich dabei tatsächlich um ein Wahrnehmungsproblem, zumal die Effigie von Peter dem Großen - die nach wie vor in der Hermitage aufbewahrt wird - in dem Roman von Tynjanow mit verborgene[n] Federn ${ }^{28}$ ausgestattet ist, die ihr erlauben, sich zu erheben, wenn jemand bewusst oder unbewusst auf den Mechanismus an einem bestimmten Punkt auf dem Boden tritt.

Mit der Auto-Ikone bekommt aber die Ähnlichkeit ganz und gar Identität. Das Bild repräsentiert nicht, sondern präsentiert. Es ist beispielsweise eine verbreitete Überzeugung, dass die Auto-Ikone an allen Ratssitzungen des University Colleges teilgenommen habe und Bentham als present but not voting deklariert wurde. Hierbei handelt es sich normalerweise um urbane Legenden, die einfach als solche erkennbar sind, auch wenn mitunter Zweifel zurückbleiben: Manche Gelehrte behaupten, dass die Auto-Ikone tatsächlich bei einem offiziellen Treffen des Bentham Club im Jahr 1953, bei der Einweihung der International Bentham Society und bei der Feier für den 250. Jahrestag der Geburt des Gelehrten anwesend gewesen sein soll. Ob es sich dabei um wirklich vorgekommene Er-

24 G. G. Küster, Altes und neues Berlin, 4 Bde., Berlin 1737-1769, Bd. 3, S. 54I. Schon D. Fassman, Leben und Thaten des Allerdurchlauchtigsten und Großmächtigsten Königs von Preußen Friederici Wilhelmi, 2 Bde., Hamburg/ Breßlau 1735-I74I, Bd. I, S. 850) hatte die beeindruckende Lebensähnlichkeit des Porträts hervorgehoben, das dermassen natürlich gemachet und getroffen [ist], daß man gleichsam mit einem kleinen Schrecken befallen, und mit Respect gegen das Bild erfüllet wird, so offt man dasselbe ins Gesichte bekommet. Siehe darüber F. ОтTEN, Neue Quellen zur Datierung einer Wachsfigur Friedrichs. I, in: Zeitschrift des Deutschen Vereins für Kunstwissenschaft, XLII, I988, S. 77-8I; H. Bredekamp, Vom Wachskörper zur Goldkrone. Die Versprechung der Effigies, in: Preußen I7or. Eine europäische Geschichte, 2 Bde., Berlin 200I, Bd. 2, S. 353-357.

25 Siehe E. Kris/O. Kurz, Die Legende vom Künstler. Ein geschichtlicher Versuch, Wien 1934.

26 J. Tynjanow, Die Wachsperson (I930), deutsche Übersetzung in: Aufzeichnungen auf Manschetten. Sonderbare Geschichten von Bulgakow bis Schukschin, Leipzig 1987, S. 257-352.

27 Ebenda, S. 325 .

28 Ebenda, S. 325 
eignisse oder um schlichte Fiktionen handelt, hat im Grunde wenig Bedeutung, weil es aus einem kulturgeschichtlichen Gesichtspunkt entscheidend ist, dass das Ereignis auch nur gedacht wurde: Wie Johann Jakob Bachofen einmal feststellte, auch wenn ein überliefertes Ereignis in Wirklichkeit gar nicht oder nicht so geschehen ist, bewahrt die Idee, dass dieses Ereignis geschehen oder in einer bestimmten Form geschehen ist, seine Gültigkeit wegen des typischen Charakters der Beschreibung. ${ }^{29}$ Die Mitglieder des Collegerates müssen allerdings anderer Ansicht gewesen sein, weil sie entschieden haben, jeden Zweifel zu zerstreuen und den Mythos in Realität zu verwandeln: Anlässlich der Pensionierung des Rektors konnte die Auto-Ikone am 9. Juli 2013 endlich an der vorgesehenen Versammlung teilnehmen, von der, um Missverständnisse zu vermeiden, eine umfangreiche fotografische Dokumentation festgehalten wurde.

Bentham wäre glücklich darüber gewesen. Die Effigie mit dem Gesicht aus Wachs, ketzerische Erbin der tausendjährigen Versuche, das Abwesende zu vergegenwärtigen, verbringt ihre paradoxe posthume Existenz zwischen dem stän- digen Erblühen neuer Studien und dem kontinuierlichen Pilgern zahlreicher Neugieriger aus der ganzen Welt. Es gibt sogar eine digitale hochaufösende Version namens virtual auto-icon, die dank elektronischer Datenverarbeitung gedreht und vergrößert werden kann; ein Vorgehen, welches immer häufiger im Rahmen der Kunst und Kunstwerke benutzt wird. Es ist genau wie ein sublimes Kunstwerk, wie Bentham seine AutoIkone verstanden wissen wollte: In the Fine Arts, identity is the source and standard of similitude. What resemblance, what painting, what statue of a human being can be so like him, as, in the character of an Auto-Icon, he or she will be to himself or herself. Is not identity preferable to similitude?30 Ganz sicher eine provozierende Frage, die allerdings die zweihundert Jahre spätere Epoche des Readymade und das radikal zur Diskussion gestellte Problem der nur scheinbar unbestrittenen Grenzen zwischen Mimese, Nachahmung, Abdruck und Kunst vorwegnimmt.

Abbildungsnachweis: Abb. I: University College London.

29 Siehe J. J. Bachofen, Die Sage von Tanaquil. Eine Untersuchung über den Orientalismus in Rom und Italien (I870), Basel 195I, bes. S. 49-5I.

30 Bentham, Auto-Icon (zit. Anm. I2), S. 3. S. darüber F. Druffner, Identität statt Ähnlichkeit. Jeremy Benthams „Auto-Icon“, in: Zeitschrift für Ideengeschichte I/3, 2007, S. 84-96. 


\title{
CONTEMPORARY PORTRAIT COMMISSIONING IN BRITISH UNIVERSITIES - TWO CASE STUDIES
}

\author{
Sara Ayres
}

$T^{h}$ his paper focuses on the contemporary production of scholars' monuments in British universities, specifically, the painted portrait and its display within academic spaces. ${ }^{\mathrm{I}}$ It offers a detailed discussion of two cases of contemporary academic commissioning undertaken in 20III2. Both portraits were commissioned via and undertaken by artist members of the Royal Society of Portrait Painters (RP): the first, of Sir Tim Wilson DL, Emeritus Professor at the University of Hertfordshire is by Brendan Kelly (Fig. I); the second, of Professor William Brown, Master of Darwin College between 2000 and 2012, is by Geoffrey Hayzer (Fig. 2).

Within the academic context, the scholar's monument is a unique, durably material object which records not only the appearance of an honoured individual, but the triangulation of interpersonal relationships between that individual and the portrait's commissioner and its artist. The portrait's value lies not only in the commissioner's or commissioning group's esteem for the person whose living presence is represented. It is also encoded in the vision, skill and time of the

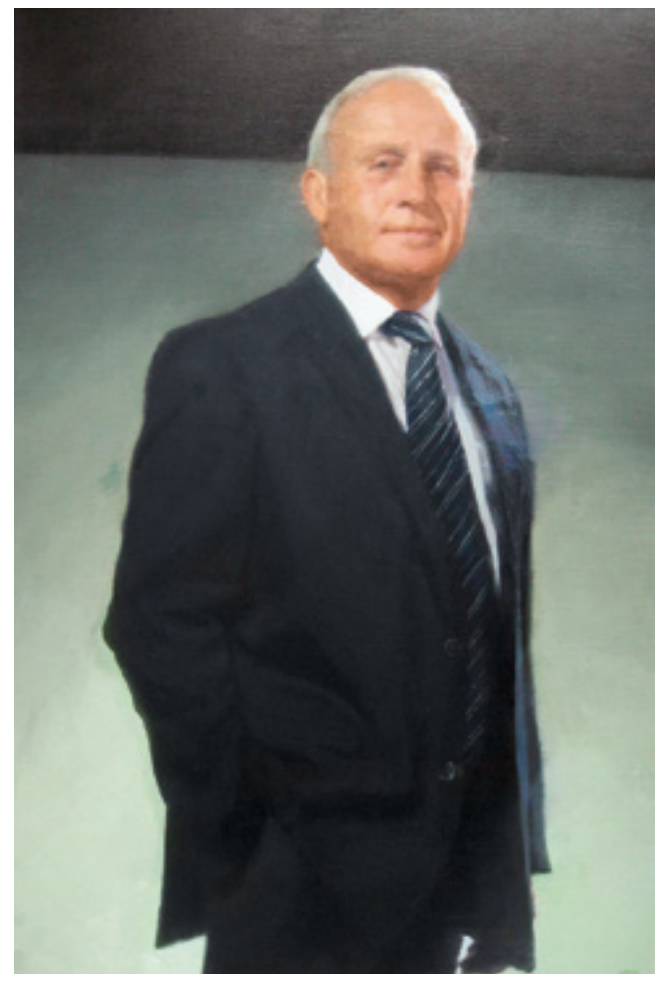

Fig. I: Brendan Kelly, Sir Tim Wilson, 2012, $120 \times 70 \mathrm{~cm}$, oil on canvas. University of Hertfordshire. artist, the portrait's temporal durability, and its

I Within Britain, this practice appears to have originated in the Oxbridge Colleges and then replicated elsewhere. Existing literature on scholars' monuments in university collections includes J. Jones, The Portraits of Balliol College, Oxford 1990; R. Lane Poole, Catalogue of Portraits in the Bodleian Library, completely revised and expanded by K. Garlick, Oxford 2004; Fitzwilliam Museum, Cambridge Portraits: from Lely to Hockney, Cambridge I978; J. Weatherburn Goodison, Catalogue of Cambridge Portraits, Cambridge i955; H. Guest, On the shoulders of Giants: Portraits from the University of Cambridge, Cambridge 2008; D. TALвот Rice, The University Portraits, Edinburgh 1957; J. H. Burnett / D. Howarth / S. D. Fletcher, The University Portraits: Second Series, Edinburgh 1986. Other literature in English on scholars' portraits includes P. FARA, Framing the Evidence: Scientific 


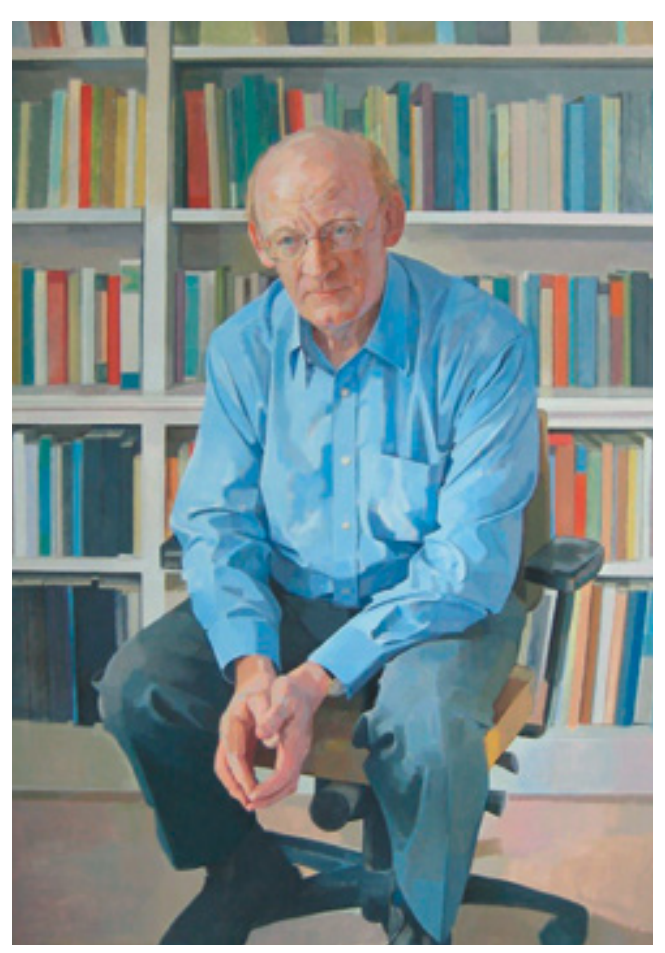

Fig. 2: Geoffrey Hayzer, Professor William Brown, 20I2, I47 $x I I 2 \mathrm{~cm}$, oil on canvas. Darwin College, Cambridge.

spatialisation in relation to the objects and audiences alongside which it will be housed. The portrait functions as substitute for the scholar, as his or her memorial and as a guarantor of the continued significance of the past within the con- stantly changing field of the present. The motivations for commissioning a portrait are thus inextricably linked with collective memory and cultural tradition: both in terms of preserving and honouring existing patterns of commissioning and also in terms of their initiation. This paper will argue that the scholar's monument acts as a reflexive object in which college sees the parameters of its own status identity delineated and, furthermore, that the social practice of portrait commissioning occupies a performative role within the academic institution.

The University of Hertfordshire attained University status in 1992, having been established as a technical college in 1952 and designated a Polytechnic since 1959. Darwin was established as a constituent college of Cambridge University in 1964 . While Darwin instituted a tradition of commissioning scholars' monuments - that is, portraits of Masters - from its inception, the University of Hertfordshire began to commission painted portraits of its Vice Chancellors in 20II, commencing with the portrait of Sir Tim Wilson. The case studies consider both institutions' motivations for commissioning contemporary scholars' monuments and the nature of the collective, cultural investment this type of memorialisation represents.

Biography and Portraiture, in: The History and Poetics of Scientific Biography (ed. T. SöDERQVIST), Aldershot 2007, pp.7I-92; L. Jordanova, Defining Features: Scientific and Medical Portraits 1660-2000, London 2000.

2 Creativeworks London is in turn supported by the Arts and Humanities Research Council in the UK. The Researcher in Residence scheme is one of a number of initiatives managed by Creativeworks London aimed at creating opportunities for collaboration between 38 London-based universities, colleges, museums, libraries and archives and London's entrepreneurs in the digital media, advertising, music, performing or visual arts, publishing, design or fashion sectors. The schemes aim to create knowledge transfer between London's creative economy and the academy, to spark synergies, growth and innovation. The Researcher in Residence scheme is particularly oriented towards unlocking the skills, knowledges and expertise of doctoral candidates and early career researchers for small cultural and creative companies, to enable these companies to solve a problem, undertake targeted research or to address a specific business need. It is also intended that the researcher gains, for example, the valuable experience of applying their skills and expertise to a 'real-world' scenario, or the opportunity to develop new perspectives on their own research questions. See <http://www.creativeworkslondon.org.uk/phd-in-residence-scheme/>

3 The Society was formed in I89I and became the Royal Society of Portrait Painters in I9II, which continues today under the patronage of Queen Elizabeth II. Early members included John Everett Millais, John Singer Sargent, Lawrence Alma Tadema, George Frederick Watts and James McNeil Whistler. 
These original case studies are derived from an enquiry undertaken during a short period I spent as a Researcher in Residence at the RP from October 2013 to January 20I4, a position funded by Creativeworks London. ${ }^{2}$ RP's mandate is to encourage the appreciation, study and practice of the art of portraiture. ${ }^{3}$ The strategy for furthering this aim includes facilitating the commissioning of portraits, which is handled by its in-house commissioning service. Analysis of the activities of the commissioning service between 2000 and 2012 formed the focus of the Creativeworks research residency. Today, there are 57 artist members belonging to the Royal Society of Portrait Painters, many of whom receive commissions through the commissioning service. The RP applied to the Researcher in Residence scheme primarily in order to enquire into the current state of the market for portrait commissions and to inform its strategic marketing plan, and secondly to provide a basis for thinking about how to secure a sustainable future for the formally commissioned painted portrait in an age of ubiquitous born-digital imagery. ${ }^{4}$

The research design included an analysis of ten years' invoices, a focus group with RP artists and a series of seven in depth interviews with private and organisational commissioners. The examination of invoicing records showed that while individual, private commissions constitute the basis of roughly half of RP's commissions, within the remainder, the education sector is most significant source. Therefore, academic commissions formed the focus of the qualitative enquiry. The research sought to understand motivations for commissioning within academia; the composition of the purchasing cell responsible for initiating, developing and completing academic portrait commissions; and how portraits were used and displayed by academic institutions, once delivered into their care. The research demonstrated that even within a period dominated by new media, and born-digital images, the painted portrait remains an object of unique cultural significance to the commissioning academic institution, a significance which underwrites the financial investment involved in its production. ${ }^{5}$ However, it was also found that portraits are made, used and displayed in ways that are driven by specific institutional needs and priorities.

British universities and colleges both ancient and modern are holders of highly significant collections of artworks. ${ }^{6} \mathrm{New}$ commissions for

4 Primary research conducted with commissioners demonstrated that the experience of commissioning and sitting for a portrait can be very pleasurable and affirming. The experience of forming a relationship with the artist is often considered to be as important and valuable a part of the commission as the production of the portrait itself. Yet primary research also indicated that the commissioning of a portrait is a process fraught with risk for the commissioner, the sitter and the artist. Should the relationship be unproductive, communication misfire and the resulting object disappoint, the outcome can be experienced as highly traumatic by all those involved. In many respects, the risks involved are balanced by the personal confidence of artists, sitters and commissioners, whose personal achievements ensure that they encounter one another within the commission as equals.

5 The significance of the portrait object perhaps makes it inevitable that commissioning is a process fraught with risk. The commissioning service at the RP is therefore highly valued by both artists and commissioners and sitters for the security it brings to the process of portrait commissioning. The RP brand offers confidence to commissioners and sitters that the outcome of the project will be of a high quality. RP membership offers artists the security of knowing a commission will be well managed through to completion. There is also the added benefit for both parties of the opportunity of seeing the work hung during the Annual Exhibition at the Mall Galleries in London. RP's brand value for commissioners lies in the sense that its involvement in commissioning acts as a guarantee that potential risks will be ameliorated and the pleasures of commissioning maximised.

6 The Worldwide Database of University Museums \& Collections lists 175 university museums and collections in the UK, yet the University of Hertfordshire art collection is not included in the list (neither is that of Darwin College). The somewhat low profile of such collections certainly within Britain has recently begun to be explored in a recently 
scholars' monuments enter into an already established community of objects of artistic, historic, scientific or cultural value - the university collection, the core of which may often be preserved for didactic purposes. Scholars have proposed a variety of taxonomies for university collections. Cornelia Weber suggests that the commissioned portrait forms part of 'collections which bear witness to the history of universities. ${ }^{7}$ James Hamilton suggests two categories of object into which the commissioned portrait might fall: commemorative - portraits of distinguished individuals of the university's past; and decorative - works acquired to hang in public or private spaces of the university. ${ }^{8}$ While the task of the commissioned portrait is certainly commemorative, and forms part of the institution's history and heritage, and will often, but not always, be hung, this paper suggests additional tasks for which the commissioned portrait may also be responsible.

The case studies are detailed and analysed below. Direct quotations from the interviews conducted with lead commissioners are reproduced with the interviewees' kind permission. As the commissioner and the sitter are very often not the same person in university commissions, I interviewed Chris McIntyre, Dean of Cultural Affairs and the Director of UHArts at the University of Hertfordshire, and at Darwin, I interviewed the serving College Bursar, Peter Brindle, who administered the portrait commission in consultation with the College Fellowship.

THE HERTFORDSHIRE PORTRAIT：BRENDAN KELLY SIR

TIM WILSON DL, EMERITUS PROFESSOR, UNIVERSITY OF HERTFOR DSHIRE ( 2 OI 2 )

Sir Tim Wilson DL was Vice-Chancellor of the University of Hertfordshire between 2003 and 2010 and was Pro-Vice Chancellor when the University made its transition from Hatfield Polytechnic to fully-fledged University in 1992. Sir Tim was appointed Knight Bachelor for services to Higher Education and to business in the 20II New Year's Honours List.

His portrait measures $120 \mathrm{~cm} \times 70 \mathrm{~cm}$ and is a half-length standing portrait with a neutral background, which appears to depict a rear wall joining with a ceiling, resulting in a strong sense for the viewer of a low positionality in relation to the subject. The subject is depicted wearing a business suit. The tonal palette of the painting is restricted and focused on greys, blacks and whites. The artist was inspired by the Japanese compositional technique known as Notan, meaning literally, 'light and shade', which seeks to harmonize light and dark tones. The painting was painted from a photograph, one of several hundred shot by Kelly in the television studios on the University of Hertfordshire's campus, in which a state-of-the-art lighting system has been installed. ${ }^{9}$

emerging literature which catalogues them and analyses their functions internally and externally to the university. See L. Drysdale, A World of Learning: University Collections in Scotland, Edinburgh I990; V. Tandy, Boom and Bust: Why we Can't Afford to be Complacent about Local Authority Museums and University Collections, in: Museums Journal, I07:II, 2007, pp. I6-I7; K. Arnold-Forster, `A Developing Sense of Crisis’: A New Look at University Collections in the United Kingdom, in: Museum International, 52:207, 2000, pp. IO-I4; J. Hamilton, The Role of the University Curator in the I990s in: Museum Management \& Curatorship, I4:3, I995, pp. 73-79; Betrayal Of Trust, in: Burlington Magazine, 135, 1993, p. 3.

7 C. Weber: University Collections, in: Europäische Geschichte Online (EGO), Mainz 20I2-I2-I9. URL: http:// www.ieg-ego.eu/weberc-20I2-en URN: urn:nbn:de:0159-20I2I2170I [2014-09-17].

8 J. Hamilton, The Role of the University Curator in the I99os, (cit. n. 6).

9 Email from Brendan Kelly to Annabel Elton, 22 September 2014. 
While the portrait was the first that Hertfordshire has commissioned to memorialise one of its leading scholars, the University has been collecting fine art since its designation as a Polytechnic in 1959. As Chris McIntyre explained: The University acquired or inherited a number of artworks when it was originally established, and in its days as a polytechnic. Often, at the establishment of a new institution in those days, the provision of artworks was part of the establishment process and, typically, a college might get a Barbara Hepworth, a Reg Butler and a couple of Ben Nicholsons, as your starter for ten, as it were. There are now 450 pieces of work in our collection. ${ }^{10}$

Hertfordshire, in common with other public institutions formed and funded in the I950s, benefited from the post-war period's investment in modern art by British artists for public buildings and new audiences. The Hertfordshire collection, which has been added to over the years, now forms a significant aspect of the institution's identity and cultural capital. Policy determines that the collection is displayed in public areas of the campus, rather than private offices. The careful acquisition of objects forming the University's art collection also formed the platform and the precedent for the new commission of the painted portrait.

Alongside cultural confidence, financial capital also naturally supports the commissioning of the contemporary scholar's monument. We're in the top 500 international institutions now and doing well economically, with no risk of failing financially."

It was a common theme among the interview sample (and indeed, within the few catalogues published on University portraits) that a commissioned portrait is a signifier of robust fiscal health. The University-commissioned, scholar's portrait can thus be straightforwardly regarded as an investment in an institution's symbolic capital resulting from a fiscal surplus.

The University of Hertfordshire emphasises education for business and has done so since its inception. The purchasing cell for this commission consisted of the Board of the University, which includes not only scholars, but also corporate leaders. If we were to propose something very challenging, it might satisfy academic staff and the bright young minds of the research constituency but it would not necessarily feel right for the board ...I didn't want elements of iconography and obscure symbols, ... something that fit with the approach we take to the collection which features international, post-war British and European artists. We needed someone who worked in a way that was clean and modern. ${ }^{12}$

The board devolved total responsibility for the project to the lead commissioner, Chris McIntyre, whose experience and expertise was judged sufficient to produce recommendations and to manage the commission as effectively, a personal project. He in turn remained very mindful of the Board's needs and concerns and the nature of the collection the portrait would enter into.

Within the wider University doubts were expressed that a painted portrait was needed, a reflection that portrait commissioning is not (yet) a tradition within the institution. There was an inevitable sense, even in a University of that size, why do we need to spend money on this? Isn't a photograph good enough? ${ }^{13}$

Why wouldn't a photograph be absolutely 'good enough' - especially in a new, modern University with an excellent reputation for technical expertise in fields ranging from aircraft engineering to new media? Eric Guthey and Brad

IO Interview with Chris McIntyre at the RP, I4 October 2013.

II Interview with Chris McIntyre.

I2 Interview with Chris McIntyre.

I3 Interview with Chris McIntyre. 
Jackson have persuasively argued that top executive and CEO [photographic] portraits form a genre of images, which they refer to as 'the family photo album of corporate capitalism.' ${ }^{\mathrm{I} 4}$ Such images, which often appear on company websites or on the covers of business journals, stand in iconographic relation to one another - the CEO photographic portrait can be recognised at a glance. Guthey and Jackson argue that, while striving for a sense of authentic identity which audiences can relate to, the CEO photographic portrait is paradoxically hampered by its own conventions, which only serve to highlight its careful construction as a particular kind of image and the contingent, ephemeral nature of its medium. Similarly to many diffuse multinational organisations, the photograph lacks a singular concrete location where it might be said to be found, making its authenticity claims problematic and elusive. ${ }^{\text {Is }}$

While CEO photographic portraiture has burgeoned with the rise of digital media, the RP's experience is that fewer portraits of CEOs have been commissioned by corporations in the last two decades. We may speculate that this may be due to a number of reasons: the effect of recessions which have taken place during this period; a perception of what is modern or fashionable; a preference for contemporary art with more obvious investment or resale value; or even a need to symbolise the increasingly diffuse and immaterial nature of multi-national organisations, electronic money and digital communications. CEO portraits, like multi-national organisations, are required to be available in all places at all times, to be responsive to the immediacy and hyper-visuality of the Internet, and perhaps portfolios of photographic portraits meet such representational needs better than the more static, finished nature of painted portraits. The photographic portrait may be fraught with ambiguity as to its authenticity, but it is easily adaptable in case of change - reproduced, retouched, or even replaced. Perhaps the materiality and the objecthood of a portrait are a little more difficult to quickly disavow, without attendant and potentially controversial iconoclastic connotations.

The finished portrait of Sir Tim presents us with a painted image of the man in a photographically realistic style. It constitutes a kind of formal bricolage between the genre of CEO portrait photography and the traditional professorial painted portrait. Iconographically, it is recognisable as a CEO photographic portrait, but materially, it is a painted portrait, and as such partakes of a centuries-old, elite academic tradition. Its materiality (and the attendant expense) conveys a seriousness of intent regarding this object's commissioning and production, which the ephemeral nature of a photograph might not necessarily be able to equal. The painted portrait's materiality announces itself as an investment for the longue durée. I've been having some really interesting conversations with some staff about memorialising people and what you might do in a digital environment. How do you get some kind of permanence out of it? And there's a heritage issue. Hertfordshire does not have a long history as a university but we're at the point where we can start that history, so yes, it's conservative, it's traditional. ${ }^{16}$

If the painted portrait is a somewhat anachronistic object producing symbolic capital generated by a financial surplus, it is also a memorial form that is widely practised by universities in Britain. Every commissioned portrait contributes to the preservation of a memorial language, building the stabilisation and legitimacy of the organisation (and the community of

\footnotetext{
I4 E. Guthey / B. Jackson, CEO Portraits and the Authenticity Paradox, in: Journal of Management Studies, 42:5, July 2005, pp. 1057-I080, (p. 1058).

I5 Ibid, pp. I069-I070.

I6 Interview with Chris McIntyre.
} 


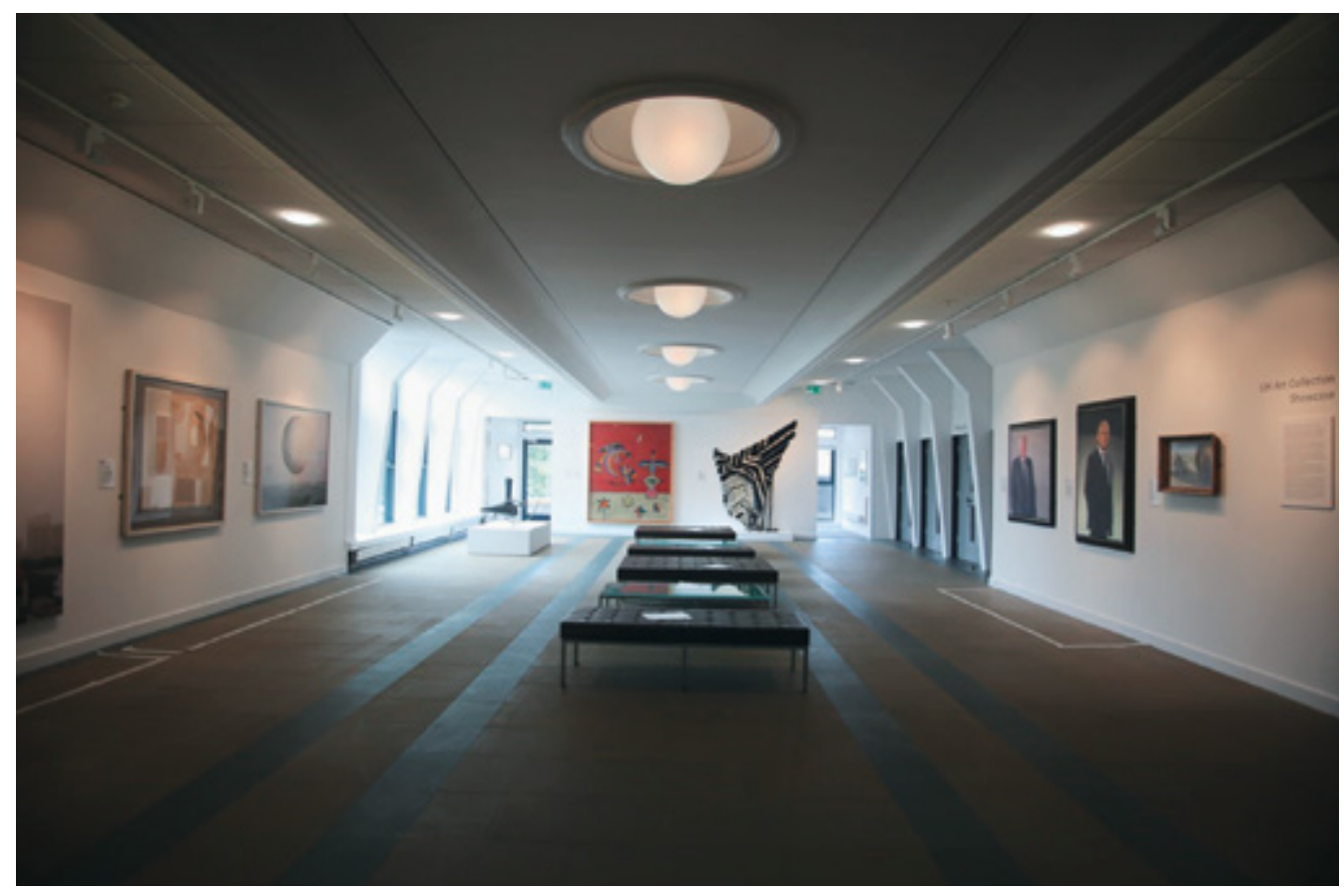

Fig. 3: UH Art Collections Showcase Gallery. The portrait of Sir Tim Wilson can be seen second from right.

organisations within which it operates). Within the academic spatial context, accumulating portraits form a kind of visual archive of an organisation's leadership, and portrait collections inventory an accumulation of institutional honour. The financial barriers alone ensure commissioned, painted portraiture remains an elite form for an elite few. If photographs and born-digital imagery are ubiquitous, painted portraits are rare. A painted portrait is a privileged utterance. With this portrait, the 'new' University of Hertfordshire signals its occupation of the symbolic territory of the 'traditional' university. The motivations for commissioning a portrait are inextricably linked with tradition - defined here as an active accumulation of heritage assets - but this particular portrait may also be regarded as a public statement of achievement and ambition. That picture is a quite cool but psychologically accurate portrait of Tim in a certain circumstance.
Many people in the University will recognise it. He's actually more jovial than that in reality. ... As the studies were done, he was thinking about the seriousness of the job, the work he's doing in $H E$, in terms of the reputation of that work for the country, and how we are exposed all around the world. ${ }^{17}$

The mnemonic technique of the portrait underscores what has been described as the vicarious nature of cultural memory; it is a performance of an interpersonal encounter between artist and sitter from which the viewer is always excluded, always spectating from the outside after the fact of the process of painting. Yet the painted portrait has often been thought to offer a uniquely truthful means of apprehending the subject. The act of gazing upon the portrait allows the viewer a borrowed sensation of relationship to the individual portrayed. The material construction of the portrait, which contains so many hours of skilled labour and so many

I7 Interview with Chris McIntyre. 
hours of concentrated regard, offers us the illusion of a direct inhabitation of the artist's knowledge of that person. ${ }^{18}$ Commissioners canvassed across the research residency made the point that the relationship of the artist to sitter is very important to its success - obviously so - but there is something about the painted portrait and its time investment which represents a special distillation of that interaction, which an instantaneous photograph perhaps cannot equal, even when taken by an intimate of the subject. The painted portrait offers the viewer the fantasy of acquiring a portion of time lived and now past, the time spent by the artist with the sitter.

Audiences for the Hertfordshire portrait may be mapped over three tiers: the first consists of the University board and their peers; the second, the wider University of faculty, staff and students; and the third consists of an international network of academic peers, in research and ad- ministration; present, past and future students; opinion formers and decision makers in business and government internationally. This portrait is externally facing and reputation building; again, it has this in common with photographic CEO portraiture. Its status as a painted portrait signals Hertfordshire's intention to articulate its history and heritage as a university institution, using the object-language traditionally reserved for creating such histories. At the time of writing, the portrait has been very recently hung in a purpose built gallery showing a range of artworks in the University's collections (Fig. 3). it remains a little too soon to speculate on its reception in relation to the audiences mapped above. However, as the case study below seeks to demonstrate, the performative effect of a scholar's monument is not predicated so much on its reception, but rather on the institution's possession of its material, unique presence in academic space.

\section{THE DARWIN PORTRAIT: GEOFFREY HAYZER PROFESSOR WILLIAM BROWN (2OI 2)}

Professor William Brown's academic research focuses on industrial relations and the minimum wage. He was Master of Darwin from 2000 to 2012 and was awarded the CBE in 2002. He is well known as a respected mediator of national-level negotiations between trade unions and employers.

The portrait is full length, measures $147 \mathrm{~cm}$ $\mathrm{x} I \mathrm{I} 2 \mathrm{~cm}$ and shows the subject seated in front of a background of bookshelves. The palette is blue, in keeping with the tonal range of the portraits of Masters that Darwin has commissioned in the past and alongside which this portrait is now displayed. In contrast to many leadership portraits, Hayzer presents us with an image al- most of diffidence. ${ }^{19}$ Rather than the conventional point of view constructed by a leadership portrait, which shows the subject raised above the upward gaze produced by a low viewpoint, Professor Brown is shown looking upwards from a lower position than we might ordinarily expect from a scholar's monument. We can even see a section of the floor carpet of what is presumably Professor Brown's office. The figure appears compressed into the base of the frame; his hands appear large and awkward. He is seated on a very ordinary office chair.

Geoffrey Hayzer is clearly working in a very different iconographic register to Brendan Kelly. Interviews revealed that there are differen-

I8 A mythic assumption, given that portraits are sometimes produced posthumously, or from photographs, as in this case.

I9 The conventions of leadership portraiture are observed in E. Griffey/B. JACKson, The Portrait as Leader: Commissioned Portraits and the Power of Tradition, in: Leadership, 6:133, 2010, pp. 133-157. 
ces in the planned usages of and audiences for the Hertfordshire portrait and the Darwin portrait, which may be seen to have affected their markedly different styles. The Darwin portrait is firstly addressed to a much smaller and spatially restricted audience than the Hertfordshire portrait. Secondly, the address conveyed in the Darwin portrait is also personal (rather than, potentially global), from one individual to another, perhaps from the Master to a student, or a Fellow. During our interview, Peter Brindle related some of the immediate responses to the portrait drawn from those acquainted with the subject: Some people felt it was a bit dour. Willy's a happy sort of guy. But, in actual fact, if you look closely, he's just smiling. I've worked with him for twelve years and it's like a viva! He's stitting there giving you a severe 'listening to' and he's about to ask the penetrating question that's going to be extremely difficult to answer. Just doing the work of the college, the life of the college. ${ }^{20}$

Thirdly, it is a portrait of a very particular, contingent kind of authority. Somewhere in the middle is when you're mostly in control and at the height of your powers, so the portrait represents you when you're most in control of the college. One or two Masters don't stay. They come here to be a $C E O$, and it's absolutely not. You lose a lot when they take votes. Things have to be finessed through. In some of the Colleges the Fellowship will not allow things to go through. Fellowships and collegiate organisations are, it's a talking shop. It's a discursive arrangement of equals who have a voice whether or not they have expertise. You have to get people on side. ${ }^{2 \mathrm{I}}$

While the Dean I interviewed at Hertfordshire had essentially acted as the core decisionmaker for the Hertfordshire portrait, as the key to the entire purchasing cell, the Bursar at Darwin had to effectively answer to the Fellowship. One of the ways the Fellowship makes its views known is by participating in committees. The Paintings Committee is a sub-committee of the Buildings and Grounds Committee. This committee included senior professionals from Cambridge art institutions Kettle's Yard and the Fitzwilliam Museum.

The portrait's presence within the College is particularly important during the Master's decade-long service because the relationship of the Fellowship to the finished portrait is perceived to be current and living. Masters' portraits are commissioned of living and acting Masters - they are not posthumous or even post tenure. The portrait acts daily as a proxy for the Master's embodied presence and his authority. The people who actually commission it, receive it and live with it are the Fellowship. Not just today's but in perpetuity because when the Master leaves office, trotting off round the world doing field trips and things, the Master is there because of the portrait. They're there much more frequently in the portrait than in the flesh, so to speak. ${ }^{22}$

In this way, as Griffey and Jackson have pointed out, the role of the leadership portrait may be participatory, not merely commemorative, or mimetic. ${ }^{23}$ At the same time, the importance of the tradition means that portrait commissioning forms an essential part of the practice of college life; even an essential aspect of being a college. I mean, cost is serious, because Darwin is not rich. It's about the 24th best funded of 3 I Cambridge Colleges]. So it's doing more with less. So money is always a problem. But if you decide something's got to be done. And you've got to have a portrait of your Master. The five portraits we've got go

20 Interview with Peter Brindle at the RP, 7 November 2013.

2I Interview with Peter Brindle.

22 Interview with Peter Brindle.

23 E. Griffey / B. Jackson, The Portrait as Leader: Commissioned Portraits and the Power of Tradition, (cit. n. 2I), p. I34. 


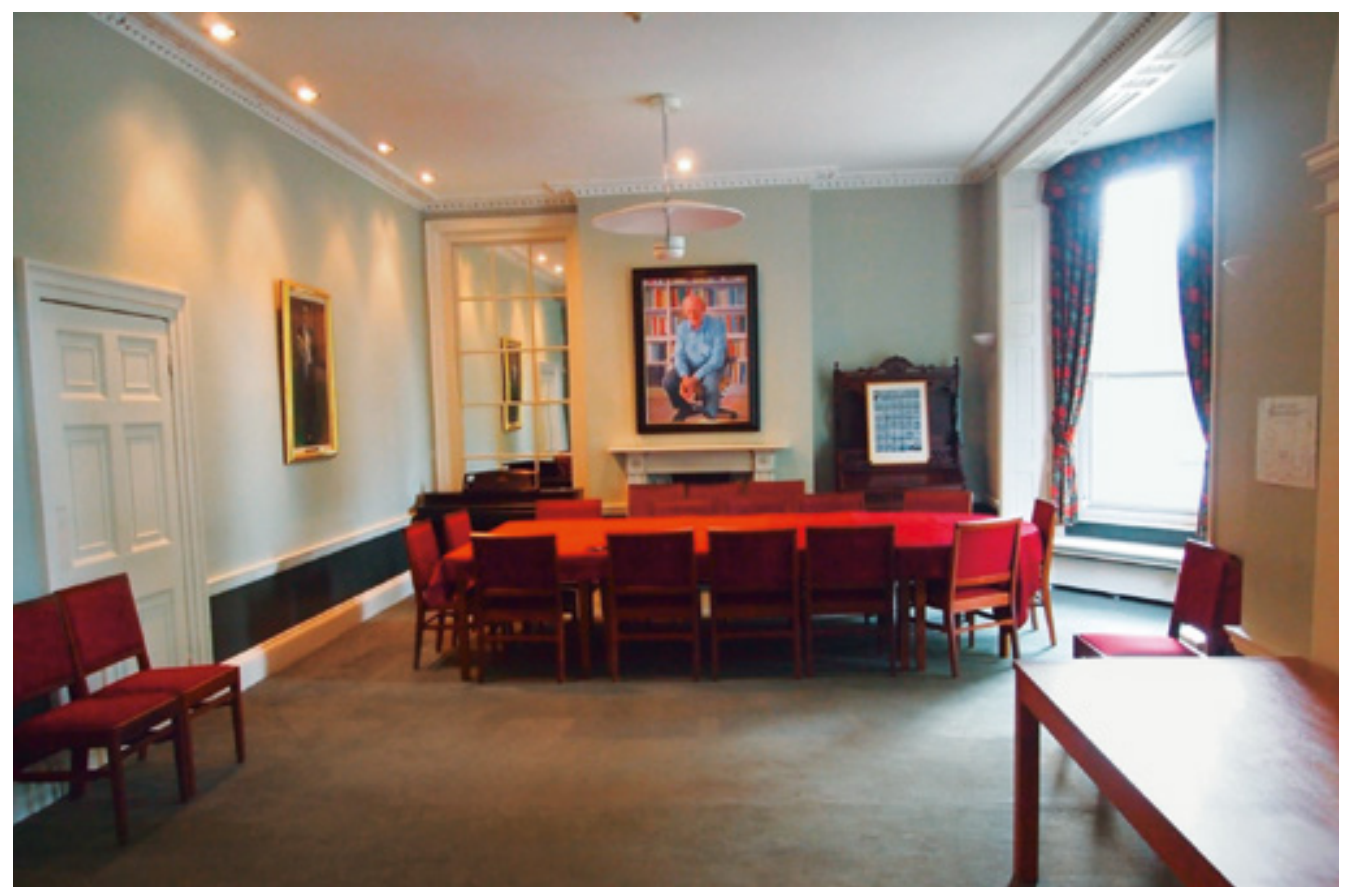

Fig. 4: Committee room in Darwin College, Cambridge.

from head and shoulders to full length. The college has got a bit richer, can afford a bit more. ${ }^{24}$

Figure 4 shows the Darwin portrait in situ (Fig. 4). This room in Darwin College is used for meetings, conferences and symposia. It is not usually open to the public, students or even the Fellowship - it is not a room that people may use on an informal basis. This room contains all the portraits of the Masters and as such, the room acts as a kind of repository or archive for the College's symbolic capital. Certain Fellows have asked that these portraits be moved to the dining hall, because they remember the Masters and want to be able to tell their stories about those Masters during dinners and to use the portrait as part of their storytelling performances. The
Bursar told me that he personally opposed this, as he was primarily concerned with maintaining the portraits' good condition. When the Master retires, his or her portrait accedes to an auratic memorial object, and from the Bursar's point of view, cannot therefore be used informally by storytellers engaged in oral transmission of Darwin's heritage to students - in other words, in the process of transferring communicative (unstable, disorganised, non-specialised) memory to the collective. ${ }^{25}$ These are portraits which need to exist, but do not need to be seen as part of everyday collective College practice. The portraits are characterised by their distance from the everyday, they are cultural formations of fixed memory points. Their subjects become 'figures of

24 Interview with Peter Brindle. Again, wealth was a pre-condition for the production of this type of portrait; this excerpt also highlights the payment structures entailed in portrait commissioning, which depend not just on the reputation of the painter, but on the size of the portrait, the amount of the subject's body which is included, the complexity of the background and the number of objects included.

25 W. Kansteiner, Finding Meaning in Memory: A Methodological Critique of Collective Memory Studies, in: History and Theory, 41:2, 2002, pp. 179-197, (p. 182). 
memory' in a double sense. ${ }^{26}$ This demonstrates that the function of the commemorative portrait or scholar's monument is not purely or primarily epideictic, despite the visuality of its objecthood. In other words, it is an auratic, ritual object rather than an object for exhibition.

As students are acquiring an education at Darwin College they are also acquiring an identity associated with it - perhaps we might say that those who do not need to acquire this identity do not need to see or even to know about these portraits. ${ }^{27}$ The College itself is a coalescing site of memory, which becomes more weighted with every commissioned portrait. Each portrait is a formal and structured reinvestment in the College's significance; the portraits trace the boundaries of a site of memory which is primarily addressed to those who inhabit the College as students, Fellows or staff (and alumni). Jan Assmann has described this structure in relation to cultural memory: 'The supply of knowledge in the cultural memory is characterized by sharp distinctions made between those who belong and those who do not, i.e., between what appertains to oneself and what is foreign. Access to and transmission of this knowledge is not controlled by what Blumenberg calls "theoretical curiosity," but rather by a "need for identity" as described by Hans Mol. ${ }^{28}$

The Masters' portraits are material monuments created for the reflexive remembrance of a specific community. The uniqueness of the site increases in line with this ongoing symbolic reinvestment. What Assmann has called a specif- ic society's 'unity and peculiarity' we might call the College's 'Darwin-ness' or 'Darwinicity'. ${ }^{29} \mathrm{~A}$ scholar's monument within the context of this College is a kind of commemorative storage receptacle, providing a stable point of reference against which the college and its members can map out their discrete identity. The portrait's role and function in this context may be regarded as performative.

In this respect, the scholar's monument is an objectivised means of transmission in the culturally institutionalized heritage of the particular kind of society we call a college or university. ${ }^{30}$ Within this society, commissioning becomes a specialised practice, of which the RP becomes a part. ${ }^{35}$ The location of the portraits in the Common Room indicates their importance; an importance signified by their restricted context of display. By contrast, the portrait of the College's primary benefactor, Max Rayne (1968-9) by Graham Sutherland, is placed in the College dining hall, a high traffic and possibly, higher risk area for a painting's display. ${ }^{32}$ Such distinctions indicate the weight of the symbolic worth attached to portraits of Masters, even when they are painted by lesser-known artists than Sutherland. ${ }^{33}$

Within an age of digital media and ubiquitous born-digital imagery, the sense of difference, uniqueness and importance encoded in the object of the painted portrait entrenches and valorises it as a conveyance of cultural and collective memory - of tradition - within the academic institution. Aleida Assmann writes that, 'the different systems of the mass media culture

26 J. Assmann, Collective Memory and Cultural Identity, in: New German Critique, 65, I995, pp. I25-I33 (p. I29).

27 Members of the public can arrange to see the College portraits by appointment. The 'public' for such portraits is highly restricted; a point also made by L. Jordanova, Defining Features: Scientific and Medical Portraits, pp. 29-30, (cit. n. I).

28 J. Assmann, Collective Memory and Cultural Identity, p. I3O (cit. n. 28).

29 Ibid.

30 Ibid.

3 I Ibid, p. I3I.

32 Reproduced in Fitzwilliam Museum, Cambridge Portraits: from Lely to Hockney, pp. 22-23, cat. 38, (cit. n. I).

33 Also discussed as 'practices of portraiture' by L. Jordanova, Defining Features: Scientific and Medical Portraits, p. I4O, (cit. n. I, 29). 
and the totalitarian state converge: both shut out the past and create an absolute present. [...] In the world of mass media, the consciousness of a past silently evaporates in the cycles of continuous production and consumption. ${ }^{34}$ In many respects Darwin's painted scholar's portraits form a nub of resistance to the ephemeral, absolute present created by the mass media. The painted college portrait acts as a point of material resistance to this cycle of continuous production and consumption, as a canonical, authoritative link to the college's past, and series of portraits perform continuity with the past.

Such portraits hover between potentiality and actuality. The Darwin portrait's display emphasises its potentiality - the room in which it is contained acts similarly to an archive. Yet the room also remains sufficiently open to always remain exposed to the mode of actuality. The portrait's transference to the dining hall - a true actuality, in which it might participate as a representation across 'the whole spectrum' of memory-making - seems unlikely. 35 The Hertfordshire portrait, in its public display and in the likelihood of its wide reproduction, operates primarily in the mode of actuality and is intended to be adopted, reused and exchanged within (mass) media culture across a wide spectrum of reception. ${ }^{36}$ As the subjects and the making of each portrait recede from the collective memory, both will be absorbed into the history of each institution. ${ }^{37}$

Photographic acknowledgements: Figure r: Chris McIntyre, University of Hertfordshire; Figure 2: Geoffrey Hayzer. By kind permission of the Masters and Fellows of Darwin College, Cambridge; Figure 3: Chris McIntyre, University of Hertfordshire; Figure 4: Sara Ayres. By kind permission of the Masters and Fellows of Darwin College, Cambridge.

34 A. Assmann, Texts, Traces, Trash: The Changing Media of Cultural Memory, in: Representations, 56, 1996, pp. I23-I34, (p. I32).

35 It seems likely that for a scholar's monument to transition into the mode of actuality in the wider world of mass media culture, the subject must first pass into the cult of celebrity. An interesting discussion of a scholarly celebrity may be found in J. Browne, Looking at Darwin: Portraits and the Making of an Icon, in: Isis, I00:3, 2009, pp. 542570. For most scholars, the deaccessioning of their portrait from a college collection is usually forbidden firstly by the probable terms of its accessioning, and secondly by the very low likelihood of its ever being sold on the open market (as told to me informally by an ex-Sotheby's employee). If the portrait performatively materialises the scholarly heritage and status of the college, the college seems to be the only possible home for the majority of scholars' monuments.

36 W. Kansteiner, Finding Meaning in Memory, (cit. n. 27), p. I82.

37 The author would like to thank Annabel Elton, Head of Commissions at the RP, for her advice during the research and writing of this paper. 


\title{
THE PORTABLE SCHOLAR'S MONUMENT. ${ }^{1}$ DES (KUNST-)GELEHRTEN DENKMAL IM FRONTISPIZ SEINER SCHRIFTEN*
}

\author{
Bernd Ernsting
}

$\mathrm{D}_{\mathrm{p}}^{\mathrm{c}}$ es Gelehrten Wissen überdauert, sofern publizierend er selbst oder spätestens seine nachlaßpflegenden Fachkollegen dafür Sorge tragen, seine eigene, seine irdisch-leibliche Existenz; das eine wird mit Drucklegung statisch und durch Auslieferung zum bleibenden Gemeingut, die andere bekanntermaßen mit dem Ableben transitorisch bis zum Staubzerfall. Sein Wissen mag fortwirken oder mangels anhaltender Rezeption am Gestade des Vergessens versanden doch was erinnert jenseits seiner Schriften an seine Persönlichkeit, wo erscheint und wo verbleibt sein Bild, hier speziell dasjenige zur öffentlichen Wahrnehmung sich bietende und zumal das aus ehrenwollender Absicht ihm errichtete? Manchmal fehlt gar seine bildlich authentische Porträtüberlieferung. Im öffentlichen Profanraum oder am (akademischen) Ort ihres (lehrenden) Wirkens wurde bis zum 19. Jahrhundert einzelnen Gelehrten des Humanismus kaum je ein plastisches Denkmal gesetzt. Ersterer blieb von jeher und fast ausnahmslos den Repräsentanten schier- und geistlich-weltlicher Macht vorbehalten, den Akteuren von politischer Wirkung aus friedliebender wie aus militärischer Ambiti- on. Derweil versammelten Universität und Kolleg - falls überhaupt, dann über längere Zeiträume akkumulierend statt aktualisierend - die gemalten Bildnisse ihrer einst rühmlichen Mitglieder in akademischen Ahnengalerien, die zuvörderst auf die Meriten der Korporation in toto, weniger auf die Verdienste des Einzelnen zielten und schon gar nicht plausibel unterstellen konnten, dieser habe seine persönliche Leistung in das Wirken wiederum einzelner Nachfolger im Lehramte tradiert.

Im ehrenvollsten Falle wurde ihnen das Epitaph im Sakralraum errichtet, den sie mit Vertretern anderer Berufe und Stände teilten; von jenen distanzierte man sich mittels des ikonographischen Apparates und demonstrierte - nahm eine Kirche mehrere solcher Gelehrtenepitaphien auf - zugleich den Korpsgeist des selbstbewußt geistigen Standes. Nach mehr als vier Jahrzehnten Lehrtätigkeit (Philosophie und Medizin) und zeitweiser Rektorenschaft verstarb I49I Pietro Roccabonella (* um I427). ${ }^{2}$ (Abb. I) Als handele es sich hier in San Francesco Grande zu Padua gar nicht um ein Funeralmonument, sondern um eine Genreschilderung des

* Auf Wunsch des Autors und in Vereinbarung mit den Manuskriptrichtlinien erscheint dieser Beitrag einheitlich in alter Rechtschreibung.

I Der Titel rekurriert auf Edward Kienholz' (1927-1994) Installation „The Portable War Memorial“ von I968 im Kölner Museum Ludwig, Inv.-Nr. ML I06I, Neg. 135 685. Der Vortrag basierte auf einer ausführlicheren Textversion; Isabel Hufschmidt unterstützte den Verf. bei Recherchen und Bildbeschaffungen.

2 Bartolomeo Bellano (I437 oder I438-I496 oder I497) und Andrea Briosco, gen. il Riccio (I470-I532). Danese 


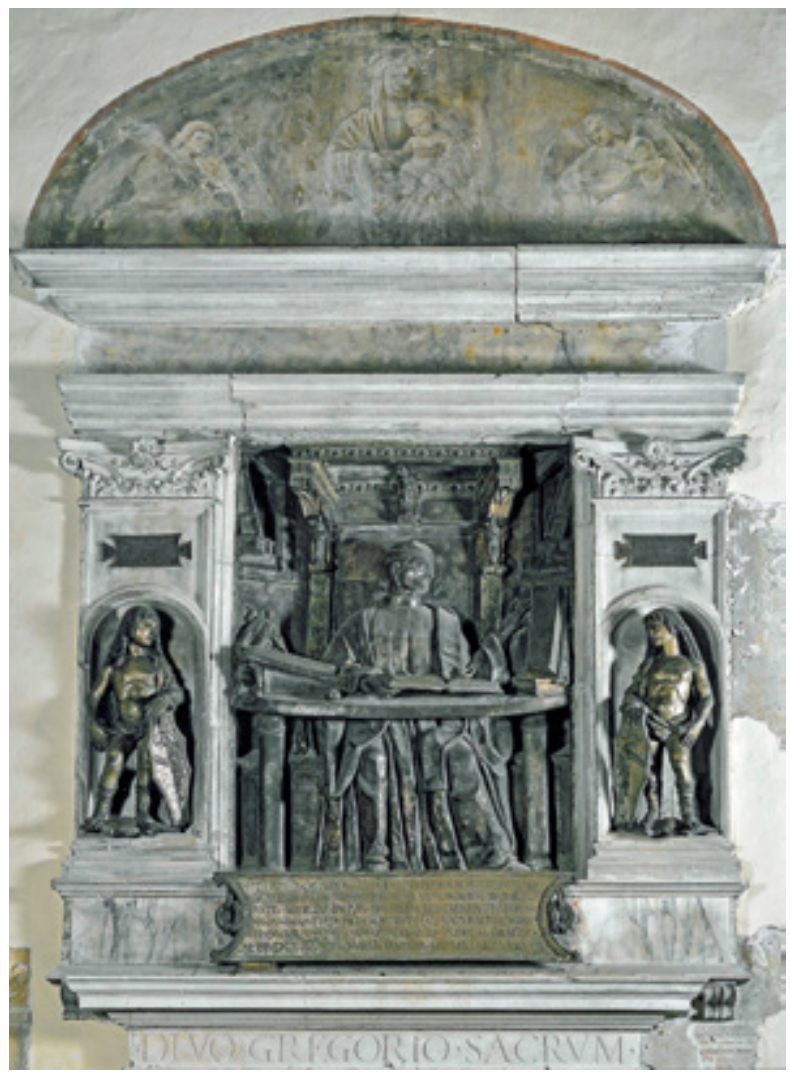

Abb. I: Bartolomeo Bellano und Andrea Briosco, Epitaph für Pietro Roccabonella, 1497-1498, Padua, San Francesco Grande.

Gelehrten ad vivum, sowohl in seinem studiolo wie simultan im Hörsaal, so zeigt ihn das seinige mitten im Dasein agierend: In voller Figur und mit dem Scholarengewand bekleidet sitzt er dem Betrachter vis-à-vis hinter dem Studiertisch (studiolo) auf ehrfurchtgebietender Kathedra (Hörsaal) und von Bücherborden flankiert; sein zwischen drei geöffneten Bänden prüfend wandernder Blick demonstriert die wissenschaftliche Maxime des stets vergleichenden Wahrnehmens aller relevanten Phänomene und ihrer diversen Deutungen, bevor das eigene Urteil sich bildet und der Gelehrte zur Feder (mittlerweile: in die Tasten) greift - welche konsequenterweise hier (noch) fehlt. Mithin ist dieses Personaldenkmal zugleich plastisch-didaktisches Manifest wissenschaftlicher Methodik, und zu deren konsequenter Anwendung mahnt der Forscher wie der Lehrstuhlinhaber noch post mortem zeitgenössische und nachgeborene Betrachter. Solche Exempel imaginieren den Verstorbenen in der scheinlebendigen Präsenz seines wissenschaftlichen Wirkens, in vita activa begriffen.

Ausgerechnet ein nordalpines, ein österreichisches Monument belegt diesen Gedanken des aus dem Jenseits fortlehrenden Dozenten, zeigt subterran gewissermaßen in Bein, was oberirdisch die Epitaphien behaupten. In einer Kryp-

Cattaneo da Colonnata I5I2-1572. Scultore, poeta, architetto, 2 Bde. und CD-ROM, Fosdinovo 20I3, hier: Bd. 2 (R. M. Galleni Pellegrini, C. Andrei und L. Passeggia), S. 252, Abb. 153. 


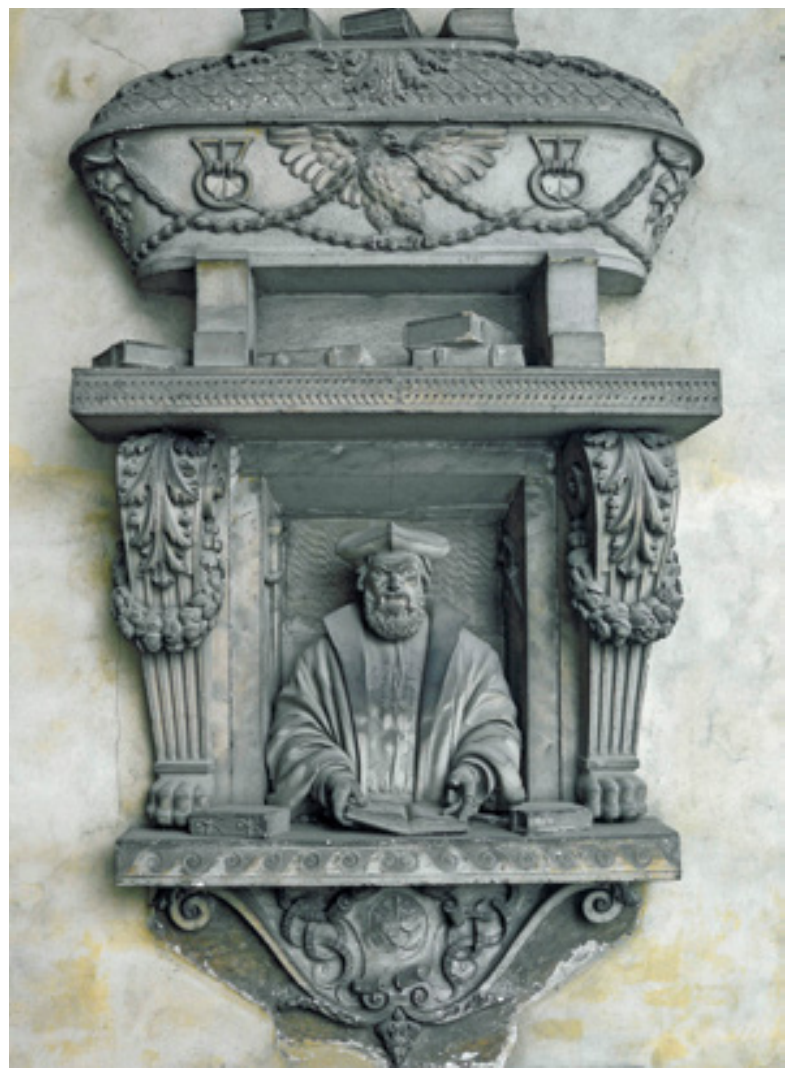

Abb. 2: Vincenzo und Gian Gerolamo Grandi, Epitaph für Giovanni Antonio de Rossi, I545, Padua, Basilica del Santo.

ta unter dem Sacellum der Salzburger Benediktiner-Universität wurden seit dem zweiten Drittel des I7. Jahrhunderts insgesamt zwölf geistliche wie weltliche ihrer Professoren uneingesargt in vollständiger Gewandung beigesetzt. ${ }^{3}$ Beiderseits des tonnengewölbten Raumes saßen sie in ursprünglich raumwärts offenen Wandnischen auf Mauerbänken, die aufrechte Oberkörperhaltung durch einen stützenden Querbalken gesichert, sämtlich dem Hochaltar des liturgischen Saales zu ihren Häupten zugewandt. Die Sitzbestattung hat eine zwar rare, aber alte Tradition und scheint nach den Worten des Franziskanerpredigers Serenus Schatter ( $†$ I744) besonders für Professoren gerade diese lebensbezügliche Bedeutung gehabt zu haben: „Schulen die Gräber, desswegen seyn vor Zeiten die Todte in ihren Gräbern gesessen, wie anjetzo die Professores sitzen auf ihren Cantzlen: Cadavera sepeliebantur sedentia tanquam in cathedra, [...] dardurch anzudeuten, wasgestalten der Tod und die Todte beste Lehrmeister seyn. ${ }^{\text {" }}$ Nun sitzen hier im postmortalen Kollegium die Lehrer selbst beisammen wie einstens die Schüler vor ihnen, auf-

3 Gymnasium Mortis. Das Sacellum der Universität Salzburg und seine Sitzgruft (hrsg. von Ch. Brandhuber und U. Schachl-Raber), Salzburg/Wien/Berlin 20I4, S. I39-I48 (sitzend Beigesetzte S. 150-199), mehrere Abb.: Innenansicht mit Nische S. I4I, Grundriss S. I42.

4 S. Schatter, Fama Sancta Oder Heiliger Rueff. Das ist: Lob- und Ehren-Predigen, [...], sambt zweyen LeichPredigen, Augsburg 1728, S. 985 . 


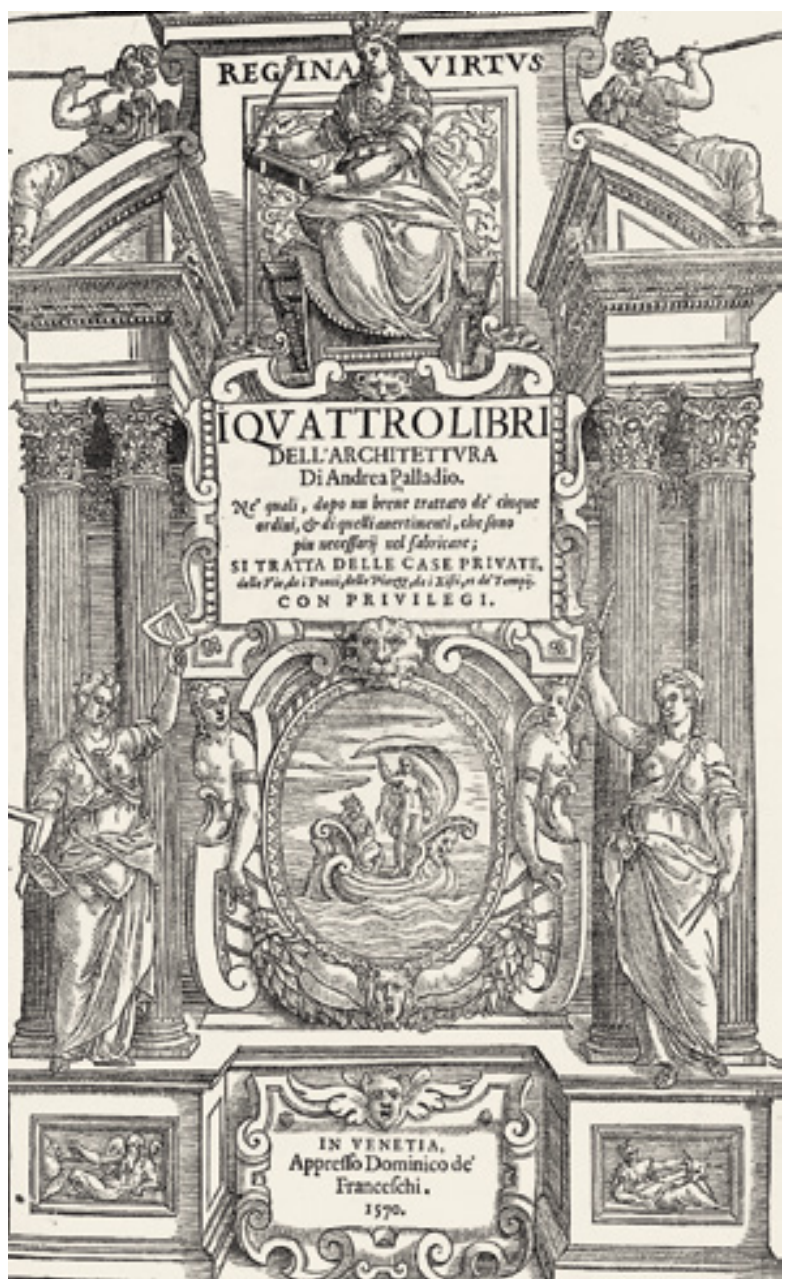

Abb. 3: Andrea Palladio, I quattro libri dell'architettura, I570.

gesucht jedoch nur noch, sobald ein neuer sich ihnen beigesellte.

Der Regelfall, um das grabmalattributive Buch wiederum aufzuheben, sah dieses nicht im rezeptiven Gebrauch, sondern zuvörderst als emblematischen Indikator für Forschen und Wissen eingesetzt. Daß sich letzteres in der steinernen Jenseitsbibliothek buch-stäblich zum Nebenmonument schichten bzw. zur Gelehrsamkeitspyramide auftürmen kann, demonstriert das
Kenotaph für Giovanni Antonio de Rossi, gen. Rubeus (I488-I544), im zweizonigen Aufbau seiner Schriftenlager auf drei Ebenen (Abb. 2). 5 Der wiederum ins aufgeschlagene Buch verweisende Gelehrte - Autorität stützt sich auf schriftliche Überlieferung - hat wie bei einer Promotionsdisputatio weitere Bände in gleichsam assistenzieller Funktion neben sich auf der Brüstung deponiert, weitere vier liegen anscheinend achtlos verstreut zu Füßen des Scheinsarkophags da-

5 Padua, Basilica del Santo. Vincenzo Grandi (I493-I577 oder 1578) und sein Neffe Gian Gerolamo Grandi (I508i560). Galleni Pellegrini, Andrei und Passegia 2013 (wie Anm. 2), S. 254, Abb. I55. 


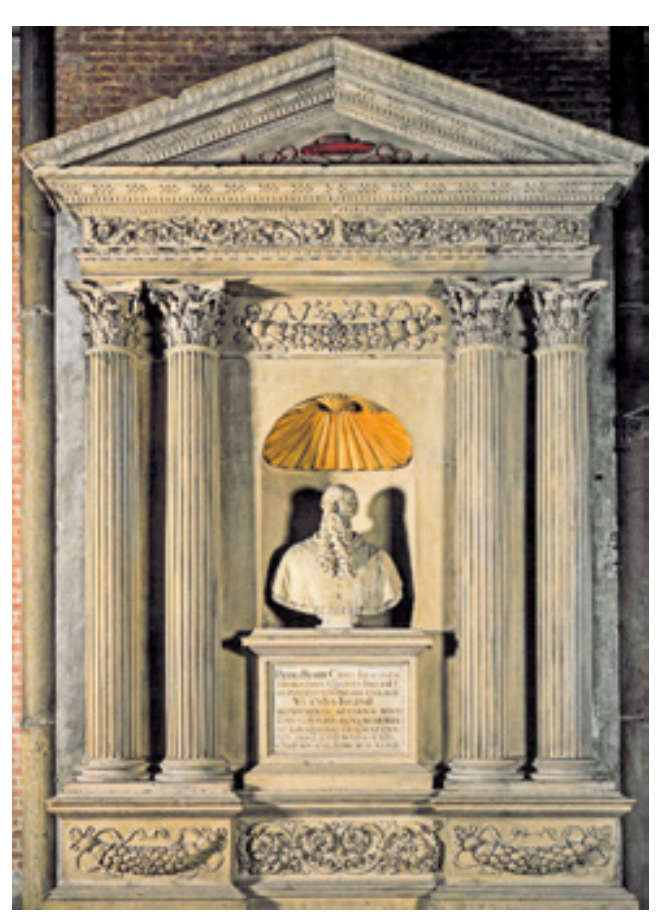

Abb. 4: Danese Cattaneo und Michele Sanmicheli (?), Epitaph für Pietro Bembo, I549, Padua, Basilica del Santo.

rüber, und dessen Deckel schließlich wird, wie um das in Wirklichkeit ja leere Grab zu siegeln, mit nochmals drei gewichtigen Folianten belastet. Hier wie in anderen Grabdenkmälern auffallend ist, daß deren in Architektonik und plastischer Figuration strenge Symmetrie entlang einer vertikalen Spiegelachse ausschließlich, aber eben unübersehbar durch die teils disparat verstreuten Bucharrangements konterkariert wird - ausgerechnet die Speichermedien geordneter Erkenntnis tumultieren chaosstiftend durch die architektonisch-plastische Harmoniewelt ihres publikumswirksamen Bühnenbildes.

Hielt zuvor das Bronze- oder Steinbuch auf attributivem Wege Einzug ins (Grab-)Denkmal, so umgekehrt dieses, und zwar nicht minder imaginär, ins Buch: In architektonischer Rahmung erinnern viele Innentitel neuzeitlicher Druckwerke sowie die Frontispize des Autorenbildnisses jene Funeralarchitekturen aus Renaissance und Barock, die ihrerseits die antike Ehrenpforte rezipieren, die zur Ädikula formulierte, wahlweise bogen- oder giebelüberfangene, manchmal mit Architrav überdeckte Säulenstellung. Diese bei den Säulenordnungen seiner Quattro libri dell'architettura aufgreifend, setzte sie I570 Andrea Palladio (I508-I580) im eigenen Werktitel in doppelsäulige Szene um; schon 1549 waren sie geradezu rigid kanonisch beim Paduaner Denk-, also nicht etwa Grabmal des tatsächlich in Rom beigesetzten Pietro Bembo (I470I547) erschienen. ${ }^{6}$ (Abb. 3 und 4) Ohne weitere buchgeschichtliche Ausführung sei erinnert, daß die ersten gedruckten Bücher den Titel nur im Typensatz kannten, dem sich alsbald der bildgraphische Holzschnitt in Gestalt von Emblemata und Druckerzeichen beigesellte. Das später eingeführte Autorenbildnis konnte in Gegenständigkeit zum Titel über den Buchfalz hinweg auf diesen blicken, so im Profil und posthum beim New Kreütterbuch eines Hieronymus Bock, genannt Tragus (1498-I554).7 Das Frontispiz - die Architektur mit dem Fronton des Gebäudes teilt sich diesen Begriff mit dem gebundenen Bucheals dem Titel links gegenüber gestelltes Blatt entwickelte sich seit der Mitte des I6. Jahrhunderts. In großer Themenbreite mochte seine Darstellung den Inhalt des Werkes bildhaft andeuten, zunehmend reich befrachtete Allegorien oder eben das Bildnis seines geistigen Urhebers aufweisen oder ihm sogar das in Wirklichkeit niemals bzw. das nur minder prächtig vergönnte Epitaph setzen. ${ }^{8}$

6 Galleni Pellegrini, Andrei und Passegia 2013 (wie Anm. 2), S. II3, Abb. 38.

7 Kreutterbuch, darin underscheidt Nammen und Würckung der Kreutter, Stauden, Hecken und Beumen sampt ihren Früchten [...], Straßburg 1577, Frontispiz (Holzschnitt) von David Kandel (um I520-1525 - [nach] I592).

8 Z.B. das reale Kenotaph von I7I2 für Caspar Ziegler (I62I-I690) in der Schloßkirche Wittenberg; dagegen opulent sein graphisches in: Casparis Zigleri [...] Disceptationes selectae argumenti varii ex Iurisprudentia Romano-Germanica forensi, [...], Leipzig I7ı2, Frontispiz (Radierung?) von unbekanntem Künstler. 
Im Allgemeinen ist beiden, dem Grabmal wie dem Frontispiz, des Verfassers Bildnis oft als vollplastische Büste, manchmal als Relief eingestellt. Gegenüber den dreidimensional existierenden überwiegen die graphisch erfundenen Büsten nach Zahl, seltenst mag die eine der anderen als (Reproduktions-)Vorlage gedient haben. Zumeist kompensiert das dem transportablen Buch eingebundene, das hierdurch mobile Denkmal ein dem Autor in ortsgebundener Haptik eben nicht vergönntes. Im Falle seiner Frontispiz-Präsenz im gedruckt zu lesenden Buche amalgamiert er immerhin untrennbar mit dem eigenen Lebenswerk; er testiert mit Verfassernamen und verbürgt sich qua bildlichem Identitätsnachweis für seine autonome Autorenschaft. Der nicht zuletzt auch autoritäre Charakter dergestalter Anwesenheit ist offenkundig und hat seine Vorbilder wie Begleiterscheinungen in der Edition antiker und schon qua Altehrwürdigkeit ihrer Schriften quasi sanktionierter Autoren; wo deren Bildnis nicht etwa durch halbwegs gesicherte antike Zeugnisse in Büste, Kopf oder Gemme überliefert war, wurde es bedarfsweise erfunden und in der Buchgraphik als eben ein solches Bild mehr pro- als reproduziert. So kombiniert eine Pariser Cicero-Ausgabe des Jahres 1544 den Titel mit einem „Porträt“ des Autors im Clipeus. ${ }^{9}$ Jene Zeit wußte noch keine antike Physiognomieüberlieferung sicher mit dem Schriftsteller zu verbinden - mithin wurde sie in freier Anlehnung an mehr oder minder beliebig gewählte, antike Bildnisköpfe frei erfunden und in Kombination mit dem Buchtitel die auktoriale Realitätsgewißheit von dessen historischer Existenz unterstrichen. ${ }^{\text {. }}$
Verband der Vitruv-Übersetzer Jean Martin ( $\dagger$ 1553) den Buchtitel mit einem frei durch den Bildhauer Jean Goujon (um I5IO - um I566) erfundenen Bildnis des antiken Architekturtheoretikers und -praktikers, welches jenen mittels Kostüm und Barttracht als französischen Zeitgenossen des I6. Jahrhunderts in Paris einbürgert, dann mit kulturpolitischer Absicht: Die Autorität dieser Lehre wird legitimistisch unmittelbar aus der Antike, also ohne italienische Umwege, in eine Gegenwart adaptiert, die gerade die letzten Gotizismen ihrer Architekturtradition abstreift und eine nationale, originär französische

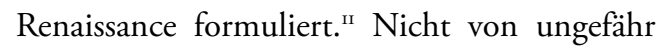
ist diese Ausgabe durch Martin seinem König, Henri II. (I5I9-I559), zugeeignet. Wie bedeutsam solch genealogische Herleitungen zur Behauptung zeitgenössisch aktueller Kompetenz waren, mögen zwei ebenso jeweils sich auf $\mathrm{Vi}$ truv berufende Beispiele andeuten. Im ersten Falle betrifft es Giacomo Barozzi, gen. Vignola (I507-I573), der einem handwerklichen Milieu ohne humanistisch tiefreichende Bildung entstammte und als erfahrener Praktiker erstmals frühestens 1562 mit seinen Regola delli cinque ordini d'architettura den Baumeistern dreier folgender Jahrhunderte ein solides Rüstzeug ohne theoretischen Unter- oder Überbau an die Hand gab; kein anderes Architekturwerk erfuhr so viele Auflagen und Bearbeitungen. Britischer Pragmatismus mag nun 1703 dazu geführt haben, die durch Claude Perrault (I6I3-I688) I674 komprimierte Vitruv-Bearbeitung mit einem gleichfalls kondensierten Vignola zu verbinden - und beider Büsten konsequenterweise auch den Sockel teilen sowie, ungeachtet der Zeitkluft ihrer Daseinsfristen, sie auf diesem Diskussionspodium

9 Les epistres familiaires de Marc Tulle Cicero, [...], nouvellement traduites de Latin en François par Estienne Dolet [...], Paris I544, Titel.

Io Solches steigernd, Cicero mit signifikanter (cicer - Kichererbse) Wangenwarze, antikisch gewandet, anachronistisch jedoch im Gelehrtenstubeninterieur des I6. Jh. schreibend: M. Tullii Ciceronis epistolae familiares selectae [...], Venedig I547, Abb. S. 329, Holzschnitt von unbekanntem Künstler.

II Architecture ou art de bien bastir, de Marc Vitruve Pollion autheur Romain antique. Mis de Latin en Francoys, par Ian Martin [...]. Pour le Roy treschrestien Henry II, Paris 1547, Titelblatt von unbekanntem Künstler. 


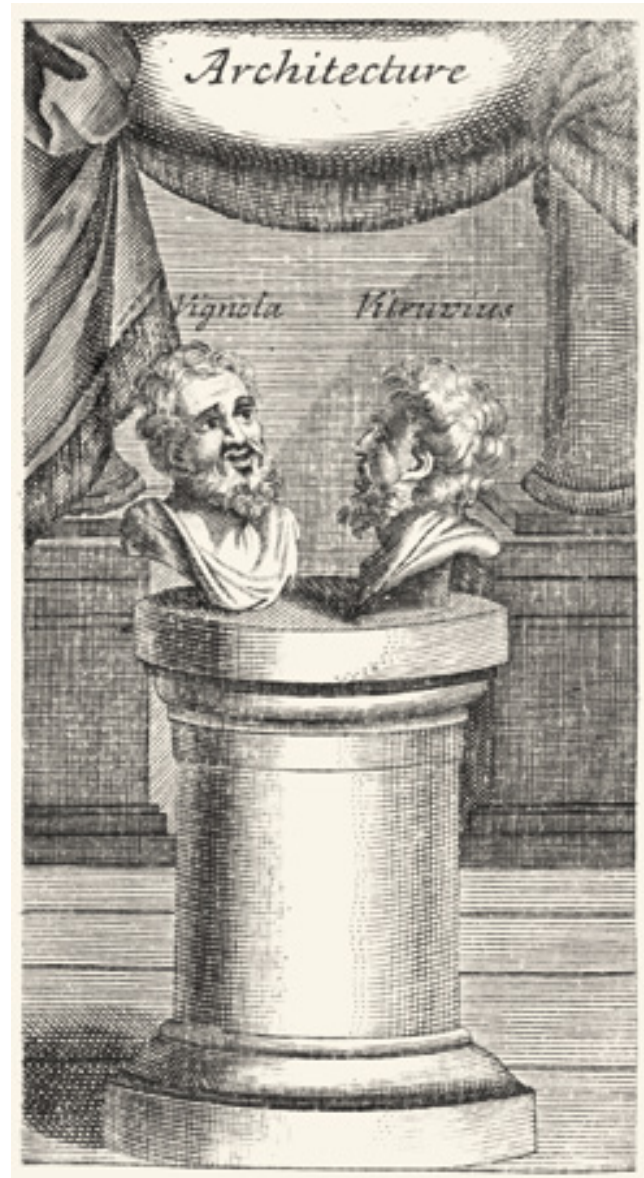

Abb. 5: Claude Perrault und Joseph Moxon, The Theory and Practice of Architecture, 1703 .

in einen erkennbar angeregten Dialog eintreten zu lassen. ${ }^{\mathrm{I}}$ (Abb. 5) Bleibt es bei diesem vereinzelten Beispiel eines gemeinsamen Pantheons, innert dessen der Nachgeborene auf denselben Altar wie sein Vorläufer und Vorbild erhoben wurde, so übernahm Vitruv doch gelegentlich das Patronat über das Werk eines späteren Adepten, der sich dann selbstverständlich auf ihn berief. So pochte der posthume Neuherausgeber von Samuel Marolois' (I572-I627) Perspective auf die antike Architektenautorität, deren wiederum frei phantasierte Büste man zuoberst der Architektur des gestochenen Titelblattes in den üblicherweise frei belassenen Sprenggiebel platzierte. ${ }^{13}$ (Abb. 6) Von dort nimmt Vitruv die dankbaren Blickes bekundete Huldigung der geradezu überattribuierten Personifikationen jener Künste entgegen, die angeblich von ihm, als Malerei in Wahrheit hingegen von Marolois, profitieren, für den Vitruv hier zu bürgen hat. Diesmal ist die Seligsprechung unübersehbar, steht doch die Tabernakelarchitektur dem Hochaltar ähnlich frei im Inneren eines renaissancistischen (Sakral-)Raumes.

Jenseits irdischer Leibesvergänglichkeit gilt das literarische Vermächtnis des Gelehrten als tendenziell ewiges des Geistes und seiner geernteten Früchte, im Druckwerk als Denkmal stolz der Leserschaft kommender Generationen dargebracht. Im Lesen erweckt der Rezipient dessen Verfasser zum Leben; entsprechend sind die dem Buch beigebundenen Bildnisse stets, doch keineswegs selbstverständlich, ad vivum; gleichzeitig bilden deren realexistierenden Büstenbildnisse zum Zeitpunkt der Bucherscheinung noch lebender Autoren die rare Ausnahme. Zur Ehre der Altäre - und mit Spätbarock und Frühklassizismus mehren sich szenische Arrangements mit zeremonieller Bekränzung solcher recht vivid wirkender Büsten über aufragenden Sockeln - wird man in der Regel erst post

I2 C. Perrault, Abrégé des dix livres d'architecture de Vitruve, Paris i674. Im Jahr zuvor hatte er die ausführliche Version publiziert: Les dix livres d'architecture de Vitruve. Corrigez et traduits nouvellement en François [...], Paris I673. - The Theory and Practice of Architecture, or Vitruvius and Vignola abridgd. [...], London I703, Frontispiz (Kupferstich) von unbekanntem Künstler.

I3 Samuel Maroloys deß weitberühmbten Mathematici und Ingenieurs Perspectiva. [...], Amsterdam I629, Titel (Kupferstich) von Isaeck van Aelst (erwähnt zwischen 1629 und I663). Ebd. im selben Jahr eine Ausgabe in frz. Sprache. - Die noch auf Hans Vredemann de Vries (I527 - [nach] 1604) als Marolois' Quelle verweisende Erstausgabe war I6r9 in Amsterdam ohne Frontispiz erschienen. 


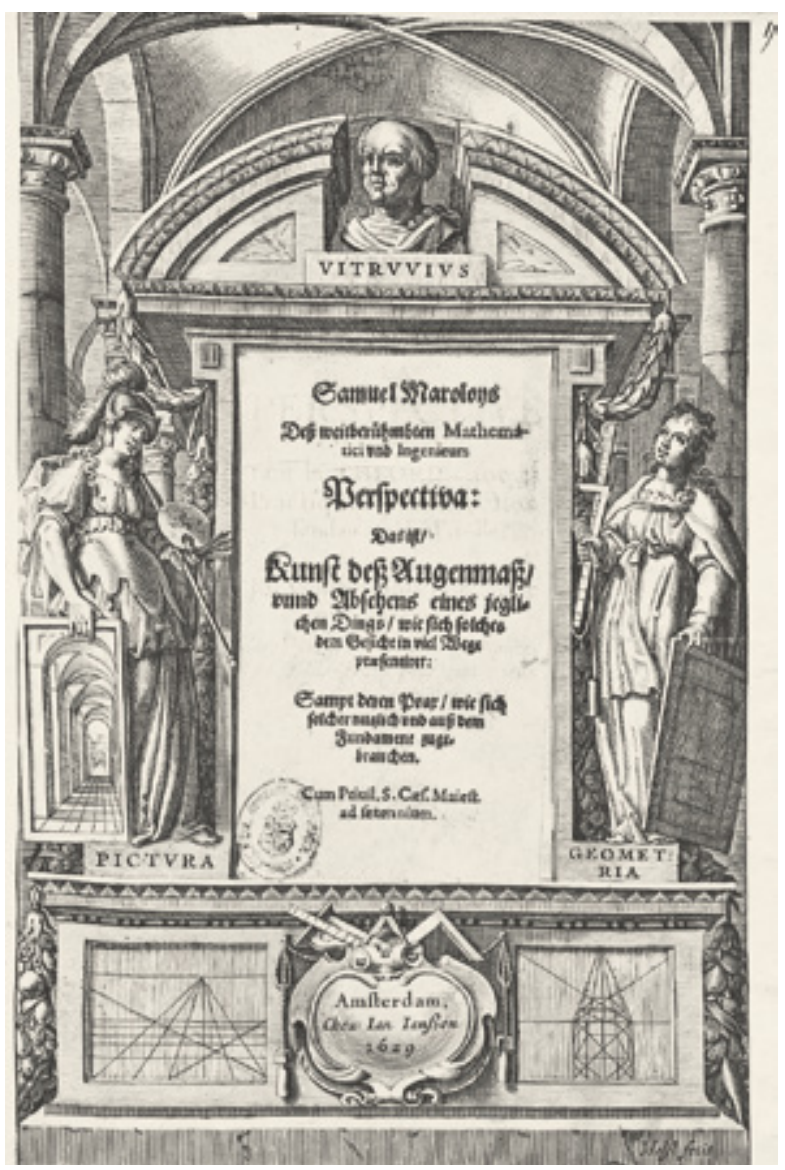

Abb. 6: Samuel Marolois, Perspectiva, I629.

mortem erhoben. Bei den meisten Büstenporträts in der Buchgraphik ist eine Tendenz zum Volloder Dreiviertel- bis Halbprofil zu konstatieren. Den humanistischen Autoren vermochten deren Nachdrucker, aber auch deren Nachfolger im Fache das Eingangsbildnis ihrer Werke in variantenreicher Form zum Denkmal zu formulieren: Die posthum edierte Mailänder Stadtgeschichte des eher als Emblematiker bekannten Andrea Alciato (I492-I550) verzichtet aufs separate Frontispiz und inszeniert im Titel eine prunk- volle Rahmung, zuoberst derer Herkules und Minerva höchstselbst des Autors Bildnis in ihrer Mitte tragen - demnach auch er ein Olympier. ${ }^{14}$ (Abb. 7) Der dagegen nüchternen Materie angemessen erscheint die Frontispiz-Büste vor neutralem Grund in Franz Karl Conradis (I7OI-I748) Schrift über den längst verflossenen, den juristischen Berufskollegen Alciato. ${ }^{15}$

Die Mailänder Autorenapotheose Alciatos ist keineswegs singulär und konnte sich sogar über verschiedene Editionen in einer Klimax

I4 Rerum patriae Andreae Alciati I. C. [= Iuris Consultus] celeberrimi. Libri IIII. [...], Mailand I625, Titel (Kupferstich) von Giovanni Paolo Bianchi (Ende I6. Jh.-1645 oder I646).

I5 Francisci Caroli Conradi Parergorum libri quatuor, [...], Helmstedt 1740, Frontispiz (Kupferstich) von Johann Christoph Sysang ([vor] I703-I757). 


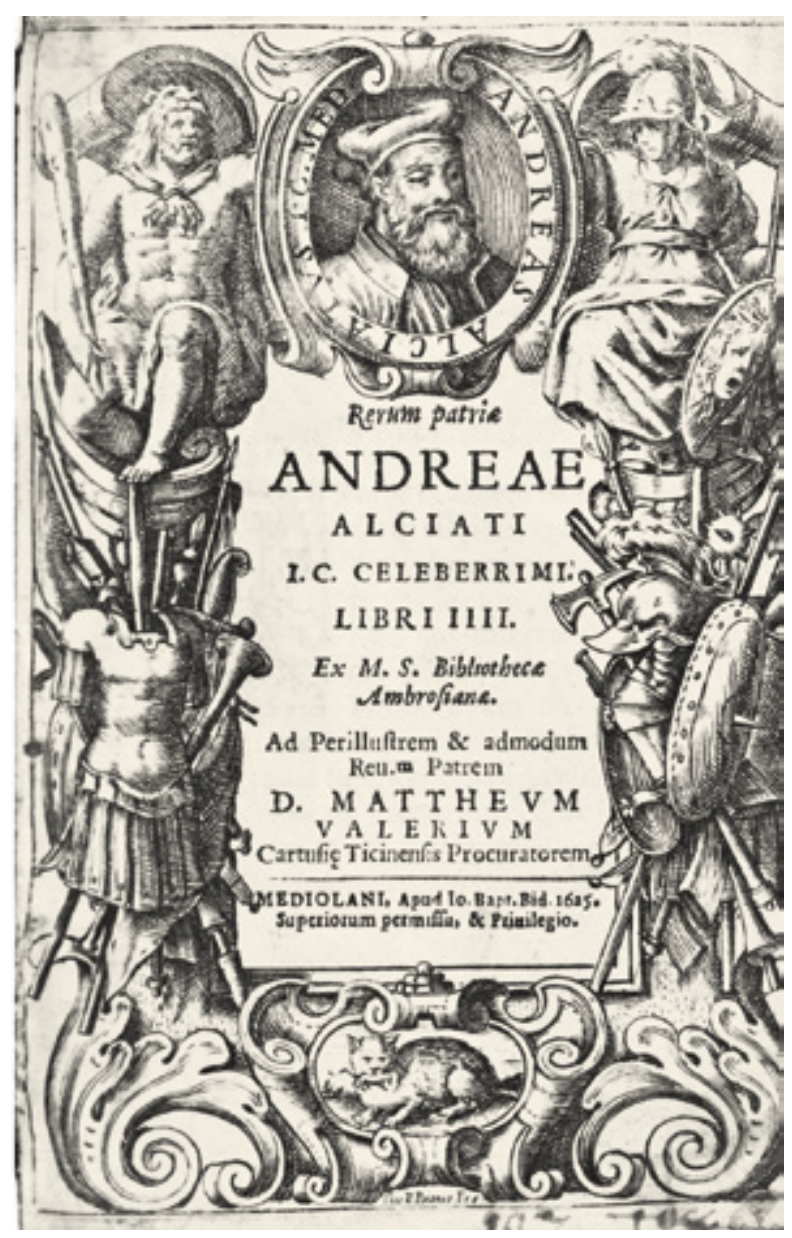

Abb. 7: Andrea Alciato, Rerum patriae, I625.

vom Dies- ins Jenseits sinnsteigern. Im Falle des gerühmten Altphilologen und Rechtsphilosophen Justus Lipsius (I547-I606) begann dessen Erhöhung bereits zu seinen Lebzeiten. Im Jahre I605 gab er in erster und akribisch kommentierter Auflage die Schriften Senecas heraus. Dessen Bildnis erscheint singulär keineswegs titelnah, sondern erst zwischen der Widmung an den soeben zum Papst gewählten Paul V. (I552-I62I) und der Vorrede an den Leser. Schlägt nun dieser das Buch am Beginn auf, begegnet ihm zunächst panoramisch eine gestochene Doppelseite. (Abb. 8) Auf dem Buchtitel rechts eine ganze Phalanx antiker Götter, Heroen und geistiger
Autoritäten in gleich zweigeschossiger Ehrenhalle, die relativ klein wiedergegebenen Bildnisköpfe in Art von Gemmen inszeniert: Oben wird Pallas Athene von Herkules und Odysseus flankiert, während unten Seneca selbst und Epiktet auf Personifikationen von Ehre und Tugend blicken, darüber sich als ganzfigurige Assistenten die beiden Stoiker Zenon von Kition und Kleanthes von Assos dem gedruckten Titeltext zuwenden und Zeugnis ablegen, daß es mit dem von Lipsius begründeten Neustoizismus seine philosophiegeschichtlich begründete Richtigkeit habe. Links des Falzes befindet sich das Frontispiz mit aufwendigem Dekor in freier Groteskenma- 


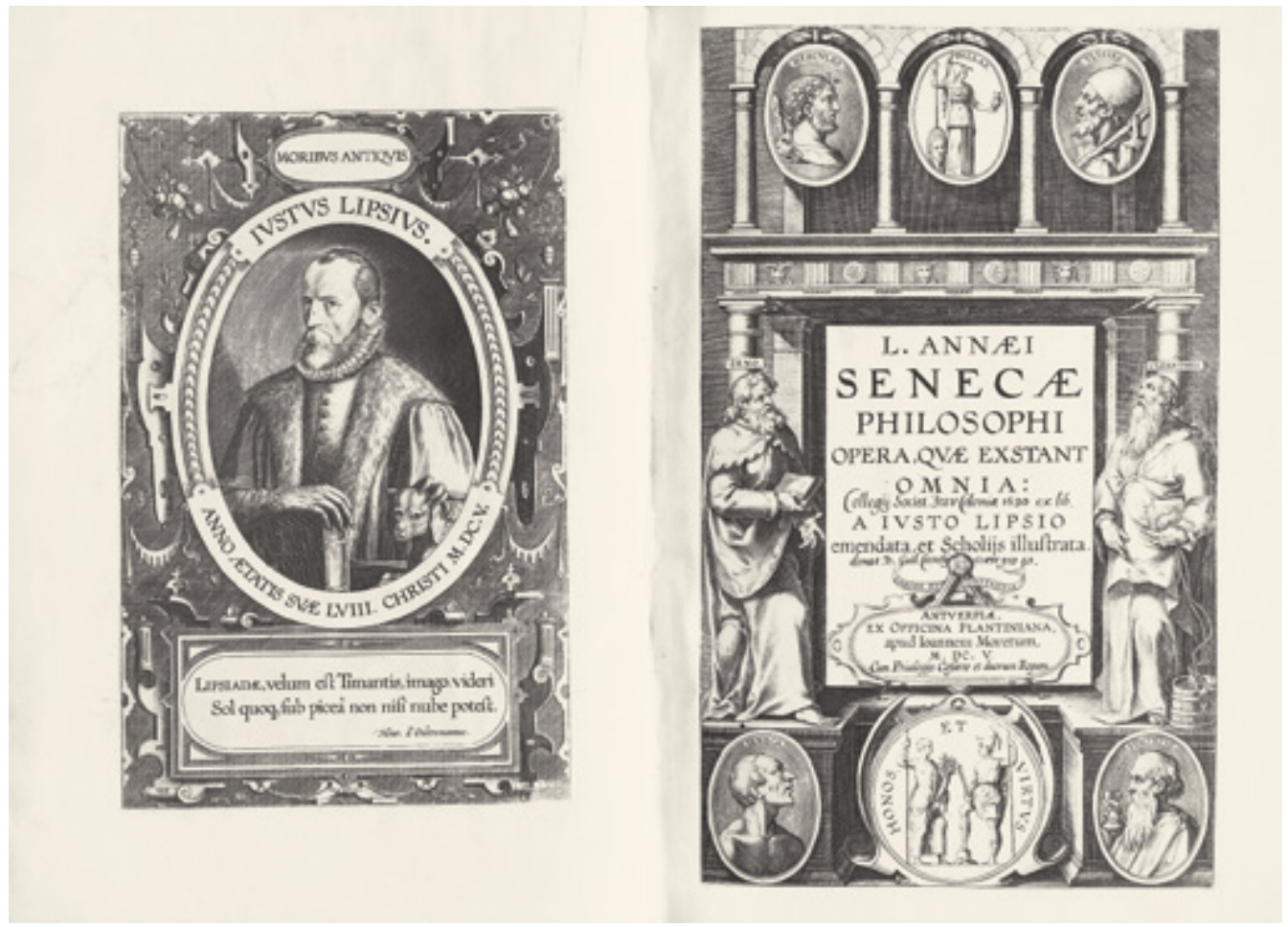

Abb. 8: Justus Lipsius, L. Annaei Senecae Philosophi opera, I6o5, Frontispiz und Titel.

nier, der den großformatigen Clipeus mit des Autors Bildnis trägt, gestochen durch Theodor Galle (157I-1633). Zwar folgen Oberkörperwendung und Physiognomie dem Lipsius-Auftritt in Peter Paul Rubens' (I577-I640) Gemälde „Die vier Philosophen ", ${ }^{16}$ doch sollen die neu hinzuerfundenen Attribute und die Gestik im Verein mit dem textlichen Hinweis auf das 58 . Lebensjahr die Präsenz des Dargestellten als eines vital agierenden Zeitgenossen unterstreichen. Nicht ungewöhnlich ist dessen Hand auf dem Buche, unkonventionell jedoch die Beigabe eines zweiten Lebewesens, hier des Hündleins, das den Betrachter blickparallel zu seinem Herrchen aus den Augenwinkeln fixiert und damit in ers- ter Linie dessen Vividität suggeriert. ${ }^{17}$ Denn ausgerechnet dieser Spaniel und langjährige Lipsius-Gefährte Saphyrus ist - hier nun zugleich des G/gelehrten Hundes Memorial im Frontispiz - zum Zeitpunkt seines Kupferstichbildnisses längst tot, war er doch I6or in einem Sudkessel kochenden Wassers verunfallt. Der eigenen, dem Quintus Ennius entlehnten und in einer allen Gebildeten verständlichen Abkürzung zitierten Devise „moribus antiquis [res stat Romana virisque]"18 gab Lipsius - denn selbstverständlich er selbst verantwortete dieses Frontispiz - noch jenen Hymnus bei, den ihm sein Zeitgenosse Henricus d'Oultremannus (* $\left.{ }^{*} 546\right)$ in dessen eigenem Todesjahr i6os für diese Bucheröffnung

I6 Um I6IO-I6I2, Florenz, Palazzo Pitti, Galleria Palatina, Inv.-Nr. 85.

I7 Buchfern hatte schon 1587 Melissa, dieses Lieblingshundes Vorgängerin, den damals vierzigjährigen Gelehrten in seinem durch Chrispin De Passe (1564-1637) gestochenen Bildnis begleitet, welches seitenverkehrt und unter Hinzufügung eines anderslautenden Distichons einen Stich von Hendrick Goltzius (I558-16I6) wiederholt.

I8 „Sitten aus alter Zeit geben Roms Staat Bestand wie die Männer“. 


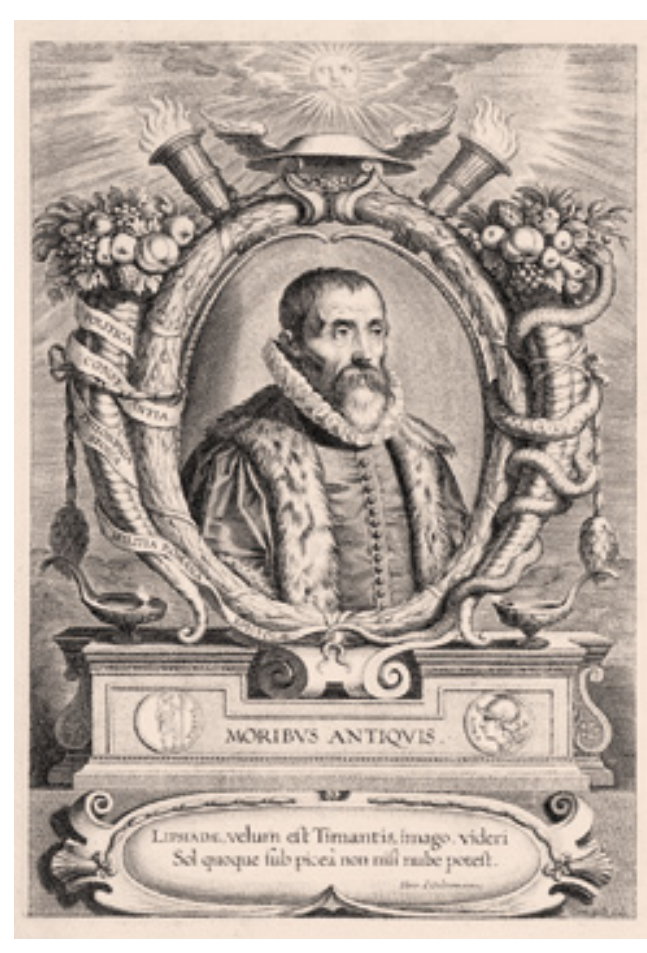

Abb. 9: Justus Lipsius, L. Annaei Senecae Philosophi opera, I6I5.

hinterließ. ${ }^{19}$ Spielt der erste Vers auf die Schleiergeschichte des griechischen Malers Timanthes an, so führt der zweite weiter aus, daß kein erinnerndes Kunstwerk, keine Eloge jemals die wissenschaftliche Größe und Bedeutung des hier Gefeierten angemessen umfassend zu würdigen vermöge. ${ }^{20}$ Und damit ist eben nicht der Römer Seneca, sondern dessen niederländischer Herausgeber Lipsius gemeint.

Blickte dieser (und blickte sein Hund) in der Lebzeitausgabe noch recht untypisch nicht etwa auf das Titelblatt, sondern nach links heraus und damit dem buchöffnenden Leser gewissermaßen ,ansprechend“ entgegen, dann änderte sich mit der zweiten, posthum I6I5 erschienenen Ausgabe so manches. ${ }^{21}$ (Abb. 9) Kaum prächtiger konnte dieses endliche, mit dem Tode „verdiente“ Denkmal ausfallen, das der Verleger Balthasar (I) Moretus (I574-I64I) eigens im Vorwort textlich erläuterte. Nunmehr nach Zeichnung Peter Paul Rubens' stach diesmal Cornelis Galle d. Ä. (I576-1650) dieses Zimmerdenkmal raffinierter Assemblage aus Malerei und plastischem Trägerkonstrukt: Die persönliche Devise nach Ennius rückte nach unten zum Bildsockel zwischen die Medaillons einer Virtus und einer Roma. An ihre Stelle trat die im Oultremannus-Vers zitierte Sonne ans Firmament; beide umklammern gewissermaßen das Personendenkmal. Darunter das suggeriertermaßen gemalte, nunmehr hundlose Bildnis im hochovalen Kontur der schlanken Zierleiste, das ganze prachtvoll eingefaßt von einem "geschnitzten“ Ehrenblattkranz, den seinerseits zwei Füllhörner flankieren; symbolisch für das vollendete Lebenswerk, für die eingefahrene Ernte quellen

19 „Lipsiadae velum est Timantis imago. Videri Sol quoque sub picea non nisi nube potest“. Timanthes hatte in seinem Gemälde der Opferung der Iphigenie in Aulis die Gesichtszüge der Beteiligten in steigerndem Ausdruck ihres Schmerzes dargestellt und schließlich dem Hauptbetroffenen, Agamemnon, mangels Möglichkeit zur weiteren physiognomischen Ausdrucksintensivierung das Antlitz mit einem Schleier verhüllt.

20 Aus der Angabe von Oultremannus als Urheber der Zeilen ist neben philologischer Akkuratesse vor allem Lipsius' (Selbst-)Bescheinigung zu erlesen, durch einen seinerseits bestreputierten Gelehrten gewürdigt worden zu sein. Von Lipsius existiert eine nur vage mit „I7. Jh.“ datierte Alabasterbüste von unbekannter Hand im Justus Lipsiuscollege in Leuven: Voorbeldige busten. Het borstbeeld in de Nederlanden I600-I800 (hrsg. von Valérie Herremans); Ausst.-Kat. Antwerpen, Koninklijk Museum voor Schone Kunsten I2. 9.-I4. I2. 2008, Köln 2008, Abb. S. 52 und Abb. 2 auf S. 56.

2I L. Annaei Senecae Philosophi opera, quae exstant omnia, a Iusto Lipsio emendata et scholiis illustrata. Editio secunda, atque ab ultima Lipsi manu, Antwerpen 16I5, Frontispiz und Titel. - J. DE LANDTSheEr, Pius Lipsius or Lipsius Proteus?, in: Between Scylla and Charybdis. Learned Letter Writers navigating the Reefs of religious and political Controversy in early modern Europe (hrsg. von J. De Landtsheer und H. Nellen), Leiden u. a. O. 20II, S. 303349; zum I605 durch Theodor Galle gestochenen Bildnis S. 303-304. 


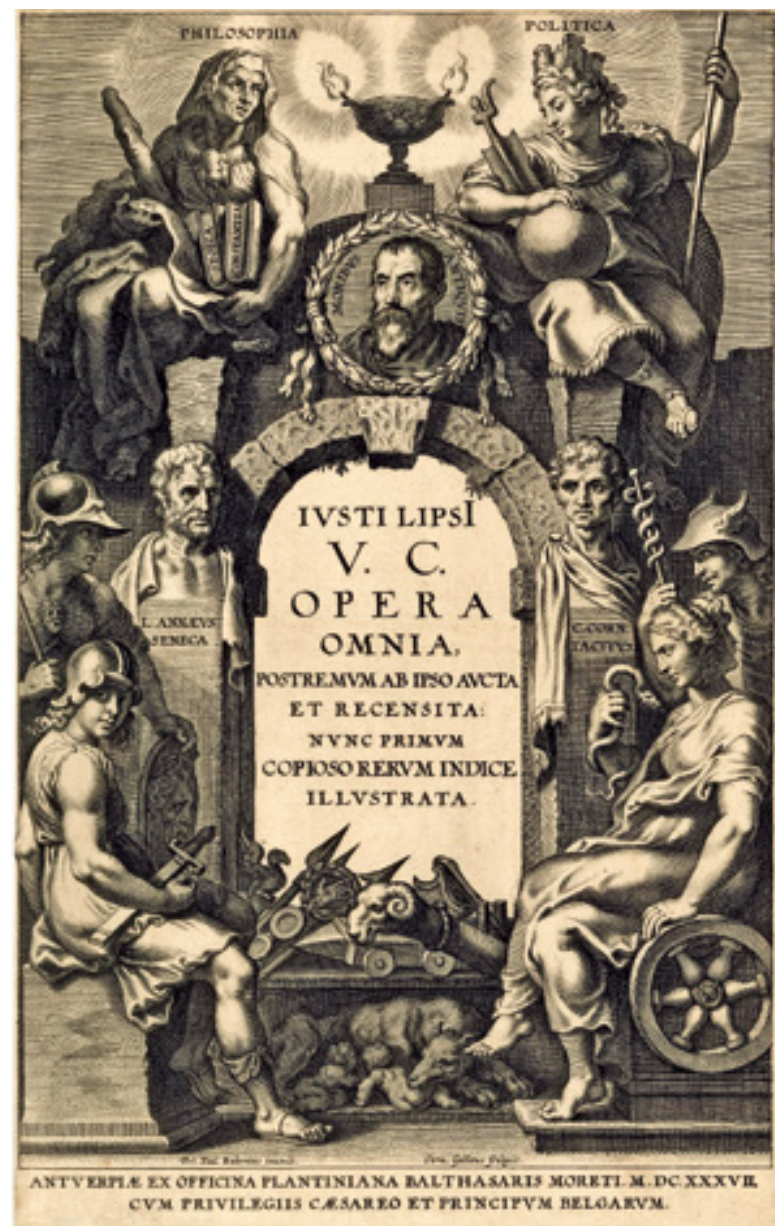

Abb. Iо: Justus Lipsius, Opera omnia, I637.

sie über vom eingesammelten Streuobst aus dem Frontispizfond der I6oser-Edition. Dem Kranze ist das linke Füllhorn mittels eines Bandes sinnbildlich der Doctrina, der Gelehrsamkeit, angeflochten, welches die zentralen Forschungs- und Lehrgegenstände des Autors kurztitelt, während die Schlange der Prudentia das rechte Horn umwindet und daraus von den Früchten der Erkenntnis nascht. Gekreuzte Fackeln hinterfangen das „Gemälde“, welches der Flügelhut des Hermes (wohl des wissenschaftsweisen Trismegistos?) krönt. Antikische Öllampen beiderseits des Rahmens als irdisch-ewige Lichter eines Gedenkens im Diesseits tragen zum texterläuter- ten, zum apotheotischen Bühnenlicht aus Sonnen- und Fackelschein bei. Verzicht auf Attribut und Assistenz im Porträt sowie dessen Blickwendung zum Titelblatt verbinden den Herausgeber - doch eben nicht Autor! - Justus Lipsius und Buchinhalt diesmal stärker denn zuvor miteinander. Denn inzwischen sind ja beide Beitragenden (vom treuen Hunde Saphyrus ganz zu schweigen) im Jenseits angelangt. Im Buchinneren widerfuhr immerhin nunmehr auch dem eigentlichen Autor Gerechtigkeit, Senecas Kopf nach einem antiken Büstenfragment in Mauerwerksnische sowie ein Stich nach der gleichfalls durch Rubens gemalten Selbstmordszene ersetz- 
ten sein noch nicht so „authentisches“ Einzelbildnis von $1605 .{ }^{22}$

Die Verschmelzung von Persönlichkeit und literarischem Verdienst erreichte schließlich 1637 in dritter Stufe der Glorifizierung mit den Opera omnia ihren memorialen Höhepunkt, wobei erneut Rubens die Zeichnung zu jenem alleinigen Blatt lieferte, in dem Frontispiz und Titeldruck jetzt eins wurden. ${ }^{23}$ (Abb. Io) Den offenen Triumphbogen - es existieren Abzüge des Stiches ohne den bibliographischen Schrifteindruck schmückt oben der aus Blättern gewundene Ehrenkranz; in der Reduzierung des Porträtausschnitts von der vormals gezeigten Halbfigur auf nunmehr den Kopf mit Büstenanschnitt ist der Rückzug des Dargestellten in jene mittlerweile rein geistige, erd- und leibentrückte Sphäre evident, in der er jedenfalls weiterhin seiner Devise der „moribus antiquis“ "treu bleibt. Die nunmehr identischen Größenverhältnisse seines „gemalten " und der plastischen Bildnisse Senecas sowie diesmal Publius Cornelius Tacitus' bezeugen seine Ankunft in diesem Olymp der großen Geister, wo er gemäß triangulärer Komposition solch akademischer Dreifaltigkeit auch gleich präsidiert. Seitlich einer im Sockel säugenden römischen Wölfin assistieren Athena/Minerva ebenso wie Hermes/Merkur und die weibliche Personifikation einer janusköpfigen (dialektischen?) Klugheit; über allem strahlt oben, dem Haupte Lipsius' entwachsend, die zweiflammige Leuchte der Wissenschaft, flankiert von Philosophie und Politik als den beiden literarischen Hauptgegenständen des Verblichenen. ${ }^{24}$

Mancherlei Indizien sprechen dafür, daß die Präsenz ihres Bildnisses im eigenen Buchwerk, und zwar schon zu ihren Lebzeiten, besonders für solche Autoren bedeutsam wurde, die entweder selbst nicht dem humanistisch vollumfassend gebildeten Stande entstammen oder bzw. und zugleich sich nicht abstrakter Wissenschaft zuwenden, sondern im einen oder anderen Sinne dem praktisch anwendbaren Wissen verpflichtet sind. Unter ihnen ist die Zahl der Architekten und bezeichne man sie hilfsweise so - der ,anwendenden" Antiquare und Historiographen ihres Berufsstandes auffallend hoch. Exemplarisch unter den erstgenannten seien der schon als Dialogpartner Vitruvs identifizierte Vignola sowie Palladio betrachtet. Über Barozzis Regola delli cinque ordini d'architettura herrscht zwar hinsichtlich der Ersterscheinung 1562 oder 1563 bibliographisch Uneinigkeit, doch erfolgte sie jedenfalls zu des Autors Lebzeiten und zeigt ihn auf dem Titelblatt in Halbfigur ad vivum, wobei die Nähe zu einigen der eingangs zitierten Paduaner Gelehrtenepitaphien unübersehbar ist. ${ }^{25}$ (Abb. II und 2) Schon zu Lebzeiten erhob sich der Dargestellte selbst, aus eigener Veranlassung, zur Ehre des Altares, den er hier einem Sanktuarium einstellte. Dem praktischen Baumeister, der sich aus seinem Metier heraus auf die Brüstung seines (Atelier-)

22 Auf dem Blatt nach dem Titel und vor dem Moretus-Vorwort findet sich der ganzseitige Kupfer Galles (wie Anm. 2I) nach dem Rubens-Gemälde „Der sterbende Seneca“ von I6ı2 oder I6I3 (München, Bayerische Staatsgemäldesammlungen, Alte Pinakothek, Inv.-Nr. 305), wenig später eingefügt ein Stich auf Grundlage von Rubens' Zeichnung nach dem antiken Kopf des Pseudo-Seneca, der als Bildwerk in verschiedenen Variationen überliefert ist, und von dem der Maler 1608 eine römische Marmorversion des I. Jh. n. Chr. aus Italien nach Antwerpen mitgebracht hatte; diese hatte er schon in seinem Gemälde der „Vier Philosophen“ (wie Anm. I6) einer Wandnische eingestellt. Herremans 2008 (wie Anm. 20), S. 94, Kat.-Nr. 35 (Eintrag von B. van Beneden), Abb. S. 95.

23 Iusti Lipsi V. C. [= Vir Clarissimus] opera omnia, postremum ab ipso aucta et recensita, nunc primum copioso rerum indice illustrata, Antwerpen I637, Titel, gestochen von Cornelis Galle d. Ä. nach Zeichnung von Peter Paul Rubens.

24 Zwischen die Seiten V und VII des Vortextes wurde ein weiteres, von Theodor Galle gezeichnetes und gestochenes Ehrenblatt mit Lipsius' Porträt integriert, diesmal wieder im Büstenausschnitt und mehr ad vivum, seine Persönlichkeit basierend auf der Modestia und lebenslang begleitet von Virtus und Doctrina, und hierfür geehrt durch Gloria und gepriesen durch Fama. 


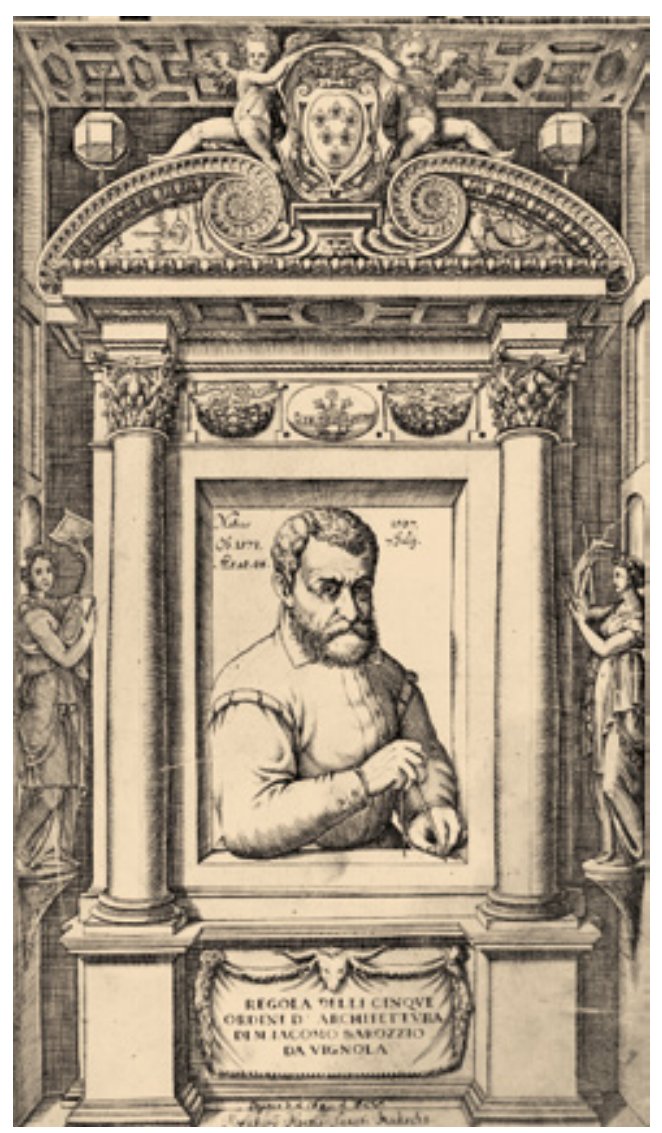

Abb. II: Vignola, Regola delli cinque ordini d'architettura, I562 oder I563/nach I572.

Fensterausblicks lehnt und zirkelnd den Leser fixiert, auch seinen Assistenzfiguren (die funktionalikonologisch den ,assistierenden“ Büchern der Paduaner Gelehrtendenkmäler entsprechen) sind jedoch keinerlei Bücher abstrakten Wissens attribuiert, sondern konkrete Gerätschaften eines zünftig bauplanenden und -realisieren- den Wirkens. Höchstwahrscheinlich vermochte er selbst nicht einmal jene griechischen Schriften zu deuten, welche den Schmuckbändern oben und seitlich des Wappens der Farnese, seiner Fördererfamilie, eingewebt sind. Der Buchinhalt, durch und durch in Kupfer gestochen, ist baumeisterlich pragmatisch, konzentriert sich auf die graphische Darstellung grundlegender architektonischer Verhältnisse und erläutert deren Anwendung im jeweils knappen Text unter Verzicht auf theoretische Auslegung oder geschichtliche Herleitung. Im Falle Vignolas wandelte sich naturgemäß erst mit dem Todesjahr 1573 das Titelporträt zum eigentlichen Denkmal; so gravierte man ihm unter Verwendung der originalen Erstausgaben-Titelkupferplatte anläßlich einer wiederum undatierten Ausgabe die Lebensdaten sowie das erreichte Alter von 66 Jahren bei und widmete das zu Lebzeiten genommene und verbreitete Bildnis hierdurch um zum Epitaph. ${ }^{26}$ (Abb. II) Das Bild des Autors, mit dem Titel verwoben und durch ihn selbst auf - wie sich zeigen sollte - ewig mit seinem hilfreichen Vademecum auch für den „ungebildeten“ Baumeister verbunden, sollte über zahlreiche Ausgaben bis ins frühe 19. Jahrhundert dasselbe bleiben. Es änderten sich die gegebenenfalls beigegebenen Wappen, es mutierte die Rahmenarchitektur, im seitenverkehrenden Nachstich blickte er manchmal nach links statt wie ursprünglich rechts - doch der Inhalt blieb weitestgehend so identisch wie das Verfasserbild diesem verknüpft. Sein Zirkel als Ausweis der Planungskompetenz wurde zum Vorbild für Bildnisse von Architekten und artverwandten Berufen überhaupt. ${ }^{27}$

25 Regola delli cinque ordini d'architettura di M. Iacopo Barozzio da Vignola, o. O. (Rom), o. J. (I562 oder I563), Titel (Kupferstich) von unbekanntem Künstler. Vgl. zur Abb. II die posthume Ausgabe, wie Anm. 26.

26 Regola delli cinque ordini d'architettura di M. Iacopo Barozzio da Vignola, o. O., o. J. (identisch mit der Ausg. von I562 oder 1563; wie Anm. 25), o. J. (nach 1572), Titel (Kupferstich) von unbekanntem Künstler, unter Beigravur der Lebensdaten.

27 Z.B. der premier jardinier du Roy Claude Mollet d. Ä. (I557-I647): Le jardin de plaisir, [...]. Composé \& divisé en onze chapitres par André Mollet, [...], Stockholm I65I, Kupferstich von Michel Lasne (vor I59I, oder 1595-I667) zwischen Widmung und Vorrede. - Auch der Holzbildhauer Giovanni Battista Montano (I534-I62I): Giovanni Battista Soria, Li cinque libri di architettura di Gio. Battista Montani Milanese, Rom I684, S. (7), Kupferstich 
Vignolas eigentlich fragwürdige Akademisierung erfolgte sowohl erst posthum als auch himmelsleitersprossenweise und gipfelte in der Büstenaufstellung in der bühnenbildgerechten Ehrenhalle eines Perspektivtraktats. ${ }^{28}$ Wenn hingegen Claude-Nicolas Ledoux (1736-I806) gegen Ende seines Lebens die Praxis mancher Berufskollegen aufgriff, das eigene architektonische Wirken samt ihrer Utopie gebliebenen Projekte selbst zu publizieren und dem Leser neben Wort und Werk im Abbild auch die eigene Erscheinung zu vermitteln, so vertraute der Autor nicht seinen Nachkommen, sondern nahm seine eigene Denkmalsetzung persönlich und zwar in ganz alleine seinem Sinne beizeiten selbst vor. ${ }^{29}$ Und hier kommt ein Aspekt ins Spiel, der letztlich allen im Buchtitel oder -frontispiz errichteten Verfasserdenkmälern eignet: Über Auflagendruck und -verbreitung finden diese mobilen wie multiplizierten Monumente eine weitaus größere Bildgegenwärtigkeit, als die ortsfest unikale Büste und selbst deren plastische Massenreproduktion es je vermöchten. Die surrogate „Papierbüste“ agiert nämlich in großer, zugleich zielgruppenspezifisch limitierter Öffentlichkeit, indem sie sich an explicit „ihren“ Leser wendet. In distribuierter Auflage wie Einzelexemplar zwischen mehreren dieser Leser geteilt, wird das Buch und wird das im Frontispiz vorgebundene Autorendenkmal - Gemeingut einer supranationalen und territorial unbegrenzten Gelehrtenrepublik.
Im Bücherschrank schließlich, in der Bibliothek sockeln diese Frontispizbüsten im Pantheon, figurieren sie in einer Walhalla allein der Denker.

Jegliche Bildnisvoraussetzung fehlte lange Zeit einem anderen Architekten, dessen (Nach-) Wirkung sich erst nahezu zwei Jahrhunderte nach seinem Tode, dann allerdings auch transkontinental, entfalten sollte. Die Lebzeitausgabe von Palladios Quattro libri dell'architettura war 1570 noch ohne sein Bildnis erschienen, und auch die identischen Neudrucke von 158 I, I60I und I6I6 lassen ein solches vermissen, obschon doch bereits die I58Ier-Ausgabe im ersten Jahr nach seinem Tode aktuellen Anlaß zur Einfügung desselben geboten und mit dem post mortem jene Vorbedingung gerade zum Büstenbildnis erfüllt hätte, an welche sich - wie gezeigt - seine Berufsstandskollegen nur ausnahmsweise hielten. Als es im frühen I8. Jahrhundert mit der Wiederentdeckung Palladios und der Entwicklung des sich auf ihn berufenden Neo-Palladianismus zu einem erkennbaren Bedürfnis kam, sich ein Bild von ihm zu machen und ihm mittels eines solchen auch ein Denkmal zu setzen, da waren die zunächst englischen Herausgeber und Verleger gehalten, ein solches zu erfinden. Die erste neben italienisch- auch englischsprachige Ausgabe der Quattro libri erschien, bearbeitet vom Architekten Giacomo Leoni (I6851746), I715 in London..$^{\circ}$ (Abb. I2) Der gebürtige Venezianer war über eine Anstellung beim pfäl-

von Jérôme David (wohl zwischen 1590 und I60o-nach I634) nach Francesco Villamena (I564 oder um I565-I624). Zum Stich (Ausgabe Rom I69i [I684]) jüngst E. Leuschner, in: Architektur- und Ornamentgraphik der frühen Neuzeit. Migrationsprozesse in Europa (hrsg. von S. Frommel und E. Leuschner), Ausst.-Kat. Erfurt, Universität, Forschungsbibliothek Gotha 5. 6.-3I. 7. 20I4, Rom 2014 (Hautes etudes histoire de l'art, hrsg. von S. FrommEL und J.-M. Leniaud), S. io6, Kat.-Nr. 48, Abb. S. I07. Dort auch der Hinweis auf die Attribute in den Zwickeln.

28 Le due regole della prospettiva pratica di M. Iacomo Barozzi da Vignola, con i commentarii del R. P. M. [= Reverendo Padre Maestro] Egnatio Danti [...], Rom 1583, Frontispiz (Kupferstich) von Alberto Cherubini (nicht identifiziert).

29 L'architecture considerée sous le rapport de l'art, des mœurs et de la législation par C. N. Ledoux, Paris I804, Frontispiz (Kupferstich) von Charles Nicolas Varin (I74I-I8I2).

30 L'architettura di A. Palladio, divisa in quattro libri [...]. Aggiuntevi in oltre alcune note, ed osservazioni di Inigo Jones. Il tutto riveduto, disegnato, \& novamente posta in luce da Giacomo Leoni Veneziano, architetto [...] (Bd. I) The Architecture of A. Palladio; in four Books [...] to which are added several Notes and Observations made by Inigo Jones, never printed before. Revis'd, design'd, and publish'd by Giacomo Leoni, a Venetian, [...] translated from 


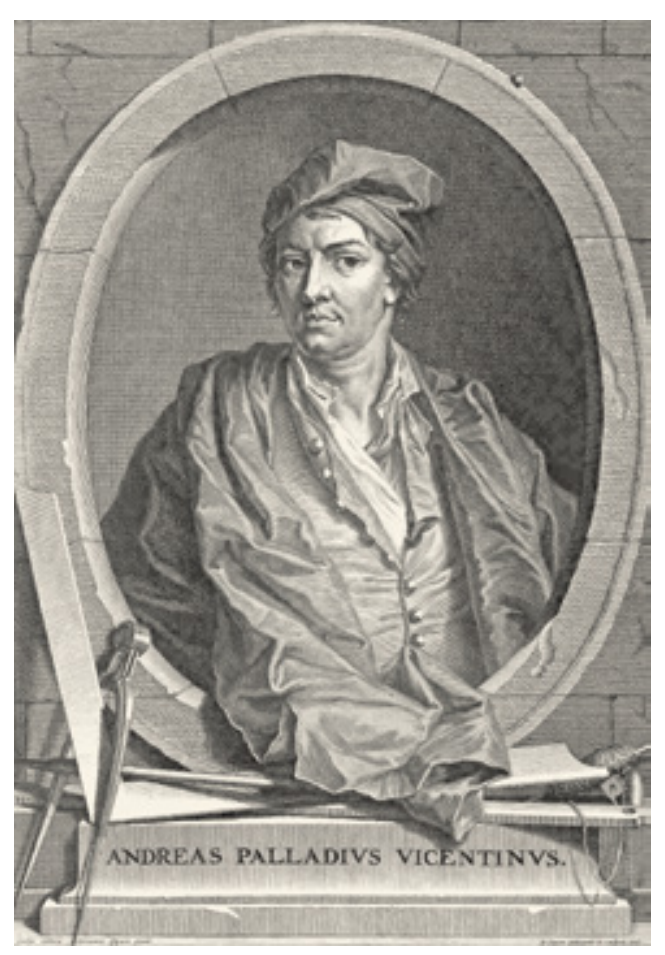

Abb. I2: Giacomo Leoni, L'architettura di A. Palladio, I7IS, Frontispiz.

zischen Kurfürsten schließlich im Gefolge von Richard Boyle (1694-1753), dem dritten Earl of Burlington und vierten Earl of Cork, nach England gelangt und sollte sich bei dessen Engagement zugunsten der Sammlung und Edition von Palladios Schriften und Zeichnungen als effizienter Mitarbeiter bewähren. Diese für England editio princeps verlangte geradezu nach einem Porträt Palladios, und da ein solches nicht als authentisch überliefertes zur Verfügung stand, wurde es kurzerhand phantasiert: Im Frontispiz erscheint der Architekt bartlos und im Kostüm der Zeit um I70o, und zwar im leger getra- genen Hausmantel mit der auch nur im Studio üblichen Kopfbedeckung des lose zur Mütze geschlungenen Schals; in England nannte man diese Tracht des informel oder indoor dress seinerzeit en négligé. Nicht ein Mann der Gesellschaft, der öffentliche Repräsentant seiner selbst, ist hier imaginiert, sondern nachdrücklich der aufgeklärte, autonome, zuvörderst seiner Berufung lebende und agierende Künstler. Als wenig später Burlington Gartenskulpturen für seinen palladianisch entworfenen Landsitz Chiswick House beauftragte, folgte eine ganzfigurige PalladioStatue schon diesem Porträttypus; gemeinsam mit ihrem Pendant, dem mit van Dycks (1599I64I) Bildnis entlehnten Gesichtszügen vorgestellten Inigo Jones (um I572 oder 1573-165I oder 1652), formuliert sie am Beginn des Außentreppenaufgangs, sprechenderweise im Basisbereich der darüber aufsteigenden Villa, das architektonisch-ästhetische Manifest des Bauherrn..$^{31}$ Derselbe flämische Bildhauer Michael Rysbrack (zwischen [vor] I684 und 1694-1770) schuf in Burlingtons Auftrag außerdem zwei Büsten dieser Architekten, und daß sein eigenes Selbstbildnis von ca. 1730 auffällig an die Palladio-Büste erinnert, belegt erneut jenen genialischen Charakterzug, den der Burlington-Kreis der historischen Persönlichkeit ihres italienischen Patrons zuwies. ${ }^{32}$ Das Frontispiz der Ausgabe von I7I5 zeigt zwar Palladio ad vivum, doch der aus Steinen gefügte Clipeus erinnert, wiewohl einer Mauerwand eingelassen, weniger an einen Fensterausschnitt als an den Rahmen eines Porträts, zumal er sich unten auf einen Sockel stützt und dieser neben mancherlei Berufsutensilien - der Zirkel darf auch hier nicht fehlen - des Dargestellten vor allem dessen Namen in Versa-

the Italian Original (Bd. 2, zugleich mit frz. Titel), 2 Bde., London I715, hier: Bd. I, o. S., Kupferstich von Bernard Picart (I673-I733) nach Zeichnung von Sebastiano Ricci (I659-1734). Die Erscheinungsdatierung im Titel auf I715 ist zu bezweifeln, da einige der Stiche von I7I6 (darunter das Frontispiz) bzw. I7I7 datieren. - In Den Haag erschien I726 dasselbe in frz. Sprache.

3I M. I. Weвb, Michael Rysbrack. Sculptor, London I954, Abb. 38 und 39, S. 89.

32 Zu den Architektenbüsten Webb 1954 (wie Anm. 3I), S. IO2 (Palladio), Abb. 36 und 37, S. 80. - Zum Selbstbildnis Herremans 2008 (wie Anm. 20), S. I8I, Kat.-Nr. 106 (Eintrag V. Herremans), Abb. S. (I80). 


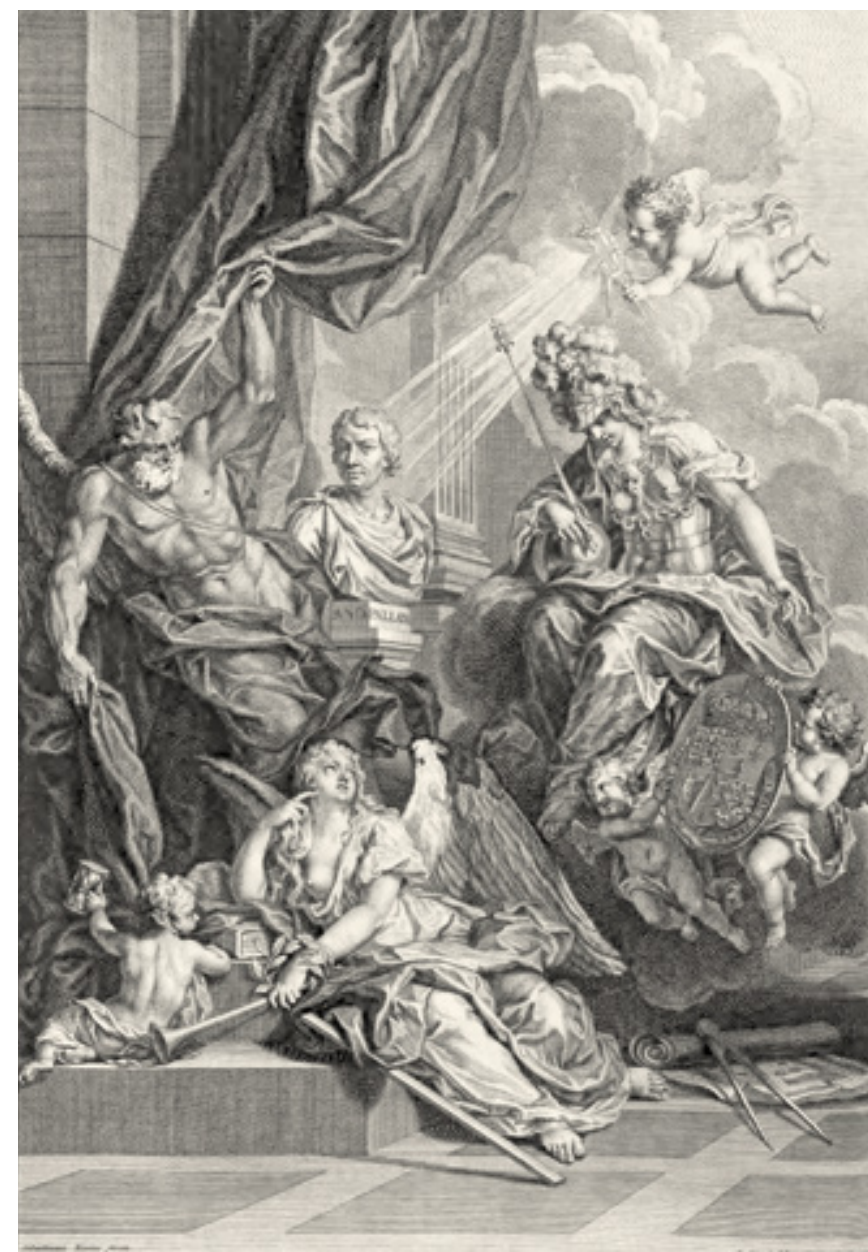

Abb. 13: Giacomo Leoni, L'architettura di A. Palladio, I7I5, Huldigungsblatt.

lien trägt. (Abb. I2) Das englische Denkmal eines anscheinenden und lebenden Zeitgenossen, in Wirklichkeit eines längst verstorbenen italienischen Architekten ohne jede bildliche Persönlichkeitsüberlieferung, die aber - bis heute offenbar unbelegt - einem der wichtigsten venezianischen Maler seiner Zeit zugeschrieben wird: Das Blatt vermerkt kühn „Paulus Caliary Veronensis Efigiem pinxit", also Paolo Veronese (I528-I588), als Maler der Stichvorlage. ${ }^{33}$ Wenige Seiten später, der Widmung an König George I. (I660-I727) gegenübergestellt, gelangt Palladio dann tatsäch- lich erstmals zur Ehre der Altäre: Diesmal angeblich nach einem Gemälde (auch dieses ansonsten nicht dokumentiert) von Sebastiano Ricci zeichnete und stach Picart die pathetische Apotheose des Architekten, der als antikisch drapierte Büste auf einem Sockel und nunmehr selbstverständlich barhäuptig erscheint, im Sinne seiner hier zelebrierten Wiederentdeckung soeben durch Chronos enthüllt und dem überirdischen Lichte wie dem Leserauge dargeboten, zu Füßen seines Piedestals eine geflügelte Fama mit bereitgehaltenem Lorbeerkranz. (Abb. 13)

33 Als Zeichner und Stecher erscheint wiederum Bernard Picart. 


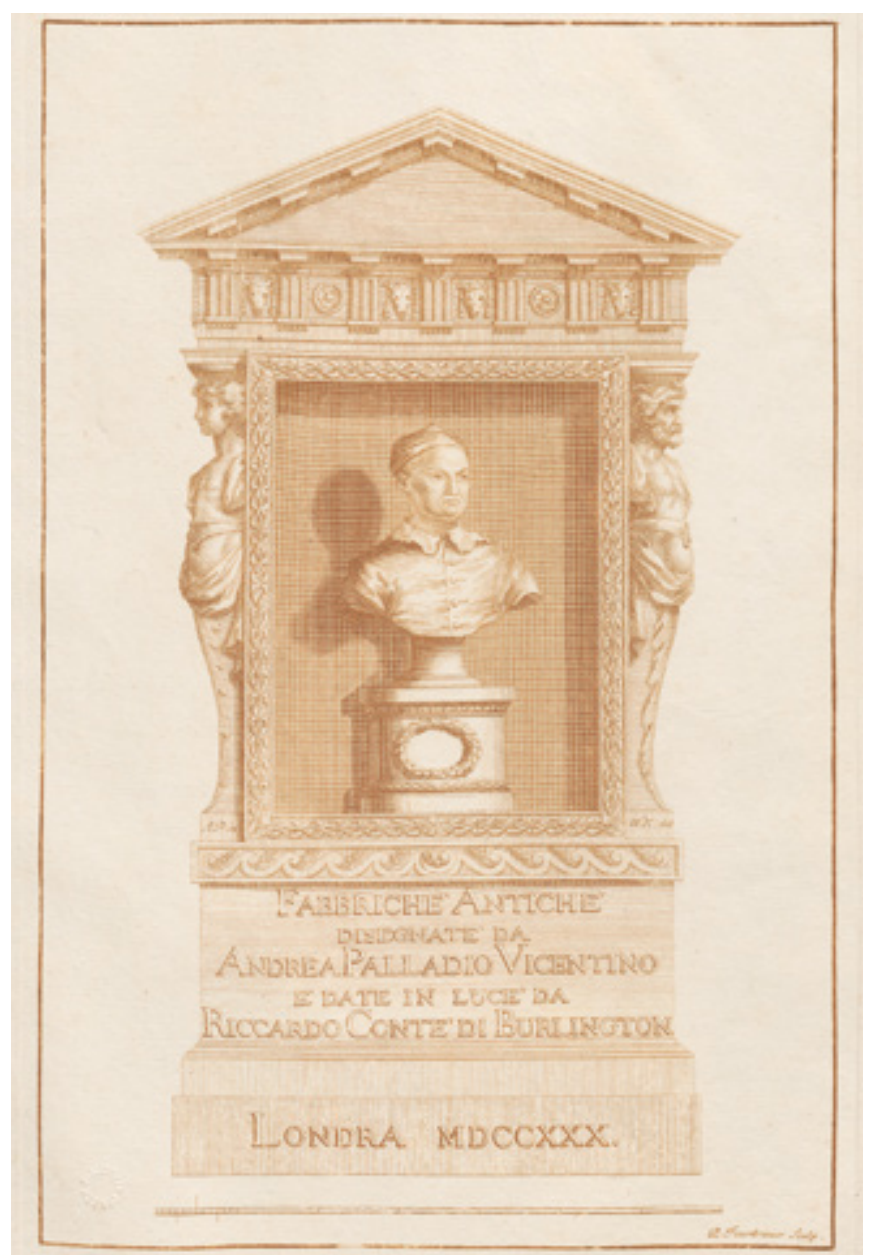

Abb. I4: Richard Boyle, Fabbriche antiche disegnate da Andrea Palladio, I730, Frontispiz.

Der im Frontispiz, im Widmungsblatt und mittels der Rysbrack-Büste formulierte Porträttypus wurde wegweisend für die folgenden britischen Palladio-Ausgaben, allemal für Burlington selbst, der 1730 im Frontispiz seiner Edition der von ihm erworbenen Palladio-Zeichnungen diesem das Büstendenkmal in einer streng renaissancistischen Tabernakelarchitektur errichtete, ihn aber gleichzeitig in einem von (Markus-)
Löwen bewachten Schmuckmedaillon oberhalb der Vorrede an den Leser „wie gemalt“ auftreten ließ. ${ }^{34}$ (Abb. I4) Colen Campbell (I676-1729), durch seinen Vitruvius Brittanicus, or the British Architect (drei Bände, 1715-1725) als Fachautor ausgewiesen und nicht erst durch die Fassadenüberarbeitung des Londoner Burlington House seit I7I7 dessen Eigentümer Richard Boyle verbunden, translozierte die Büste aus der Huldi- 


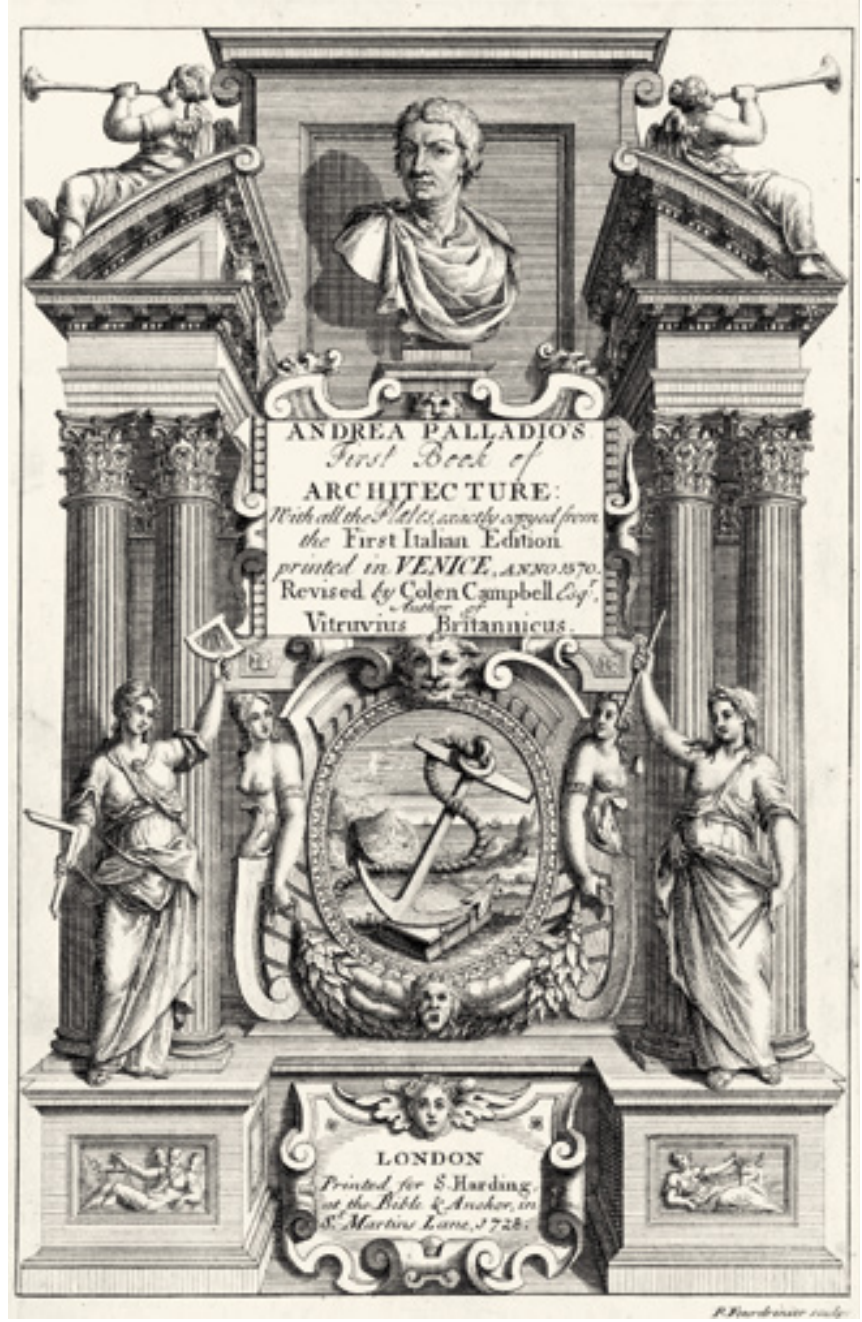

Abb. 15: Colen Campbell, Andrea Palladio's first Book of Architecture, I728.

gungsszene von I7I5 in seine Ausgabe von Palladios erstem Buch zur Architektur. ${ }^{35}$ (Abb. I5) Hierbei folgte er absolut getreu dem Titelblatt der originalen Palladio-Ausgaben von 1570 bzw. I58I, verwies jedoch die seinerzeit dort herrschende Regina Virtus ihres Thrones und setzte statt ihrer des Architekten Büste ein. Palladios
Name sollte seitdem zum britischen Synonym für Architektur überhaupt werden und selbst dort, wo es weniger um ästhetische Reflexion als um pragmatische Anwendung bis hin zur Mörtelrezeptur ging, das Patronat über Baumeister und Bauherren übernehmen: So erlebte William Salmons (um 1703-1779) Palladio Londoniensis,

35 Andrea Palladio's first Book of Architecture. With all the Plates exactly copyed from the first Italian Edition printed in Venice, anno I570, revised by Colen Campbell Esq.r, Author of Vitruvius Britannicus, London I728, Titel (Kupferstich) gestochen (wie dann in Burlingtons I730er-Ausgabe der Fabbriche antiche; wie Anm. 34) von Paul Fourdrinier. 
or the London Art of Building seit seiner Londoner Erstausgabe von 1734 allein bis 1767 sieben Auflagen - denen allesamt so sehr Palladios Bildnis wie der inhaltlich eingehende Bezug auf jenen fehlt.

Aufgeweckt durch die englischen Bemühungen um Palladios Andenken begannen auch italienische Antiquare sich mit ihrem Landsmann $\mathrm{zu}$ befassen, wobei sie ihre eigene Akribie in der Quellenforschung betonten und damit implizit den Briten einen Mangel an solcher unterstellten. Was zunächst dazu führte, die von der Insel übermittelten Bildvorstellungen zum angeblich wahrhaftigen Aussehen Palladios - tatsächlich wohl aus gutem Grunde - zurückzuweisen und nach Alternativen zu forschen. Wie bestellt, tauchte nun plötzlich ein heute in der Villa Valmerana nahe Vicenza bewahrtes Gemälde minderer Güte auf, wohl eine Kopie durch Francesco Boldrini (I762-I825), der das nicht überkommene Original (existierte ein solches überhaupt je) mit Palladios Namen in Verbindung brachte und es dessen befreundetem Zeitgenossen Giovanni Battista Maganza (1513-1586) zuwies: als glatzköpfiger und kurzbärtiger Alter so gar nicht der insularen Vorspiegelung eines dynamisch-jugendlichen Künstlers entsprechend, aber vielleicht schon hierdurch als „seriöser" und innerhalb der Bildnisreihe anderer Architekten seiner Zeit als adäquater empfunden; und selbstverständlich durfte der Vignola-Zirkel auch hier nicht fehlen. In nahezu allen italienischen Palladio-Ausgaben des I8. Jahrhunderts bis hin zur 1762 durch Tommaso Temanza (I705-I789) unter Beigabe zweier bislang unveröffentlichter Schriften vorgelegten Architektenbiographie figuriert nun geradezu kanonisch dieses Porträt. Und zwar nur noch zweimal als seitenverkehrter Nachstich des Gemäldes, ${ }^{36}$ ansonsten regelmäßig als ein daraus extrahiertes und seitdem nicht minder observant repetiertes Büstenbild. ${ }^{37}$ Denn nach der plastischen und literarisch-bildlichen Denkmalsetzung jenseits des Ärmelkanals mußte selbstverständlich auch im Heimatland ein solches her, und sei es einstweilen nur auf dem illusionierenden Wege der Graphik - ein öffentliches, haptisches Denkmal sollte Palladio erst I859 gewidmet werden. ${ }^{38} \mathrm{Um}$ die historische Würdigung machte sich bis dahin vor allem Ottavio Bertotti Scamozzi (1719-1790) verdient, der diese nicht minder denn die britische Palladio-Version fragwürdige Büste wiederholt an den Buchbeginn stellte. Im ersten Band seines kompendiösen Werküberblicks wird sie frei auf einen zweistufigen, ehrenhalber mit Festons behängten Sockel, dem das Clipeusbildnis einer lorbeergeschmückten Athena eingelassen ist, und vor einer mandorlaartigen Dunkelnische des ansonsten leeren Fonds effektvoll ins Licht gesetzt. ${ }^{39}$ Wenige Jahre später auch in seiner Neubearbeitung der erstmals durch Burlington unternommenen Publikation hinterlassener Palladio-Zeichnungen zu den römisch-antiken Thermen. ${ }^{\circ \circ}$ (Abb. I6 und I4) Und

36 Del teatro olimpico di Andrea Palladio in Vicenza. Discorso del Signor Giovanni Montenari Vicentino, Padua I733, Frontispiz (Kupferstich) von Francesco Zucchi (1692-I764) nach Zeichnung von G. B. Marioli (nicht identifiziert). Dasselbe, allerdings mit Änderung des Grundrisses im aufgerollten Plan und ohne Zeichner- und Stecherangabe, durch Enea Arnaldi Accademico Olimpico, Vicenza 1769, Frontispiz (Kupferstich).

37 Vita di Andrea Palladio Vicentino egregio architetto scritta da Tommaso Temanza architetto [...] aggiuntevi in fine due scritture dello stesso Palladio finora inedite, Venedig 1762, Vortitel (Kupferstich) von nicht identifiziertem Künstler.

38 Skulptur von Vincenzo Gajassi (um I8II-I86I) in Vicenza neben der Basilica Palladiana.

39 Le fabbriche e i disegni di Andrea Palladio, raccolti ed illustrati da Ottavio Bertotti Scamozzi [...], Bd. I (von 4, bis I783 erschienenen; Titel auch in frz.), Vicenza 1776, Frontispiz (Kupferstich) von Ravenet (nicht sicher identifiziert) nach Zeichnung des Architekten Davide Rossi (1744-I820), der 1793 (laut Privileg, S. VIII) einen allerdings auch auf I776, somit rückdatierenden Nachdruck veranstaltete, dessen identisches Frontispiz er zu dieser Gelegenheit neu durch Pietro Bonato (zwischen 1765 und I775-1820 oder I827) stechen ließ.

40 Le terme dei Romani disegnate da Andrea Palladio e ripubblicate con la giunta di alcune osservazioni da Ottavio 


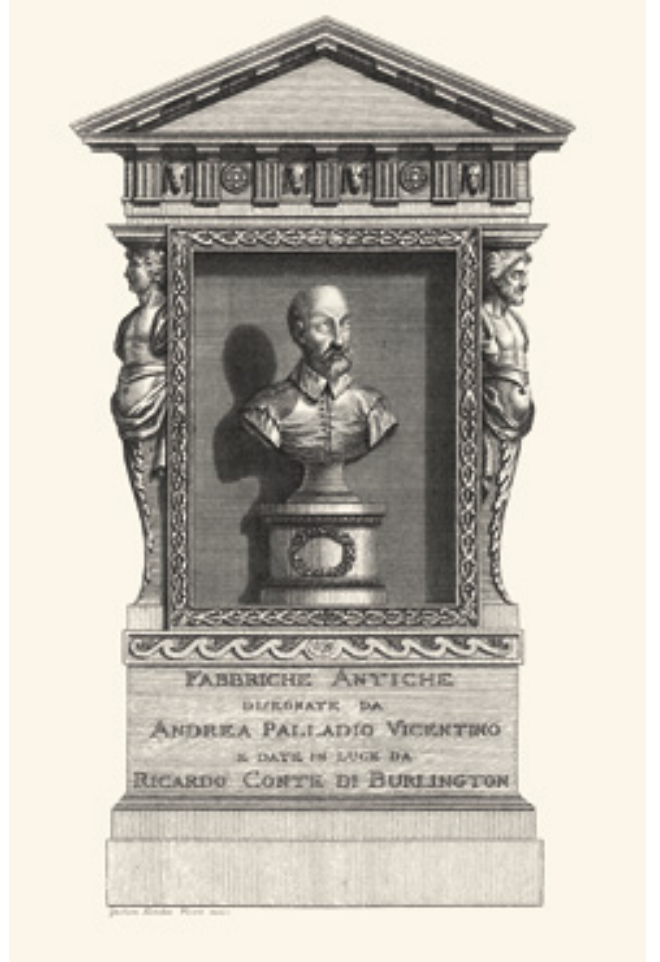

Abb. I6: Ottavio Bertotti Scamozzi, Le terme dei Romani disegnate da Andrea Palladio, 1785. hier kommt der dem Anschein nach einzig belegte Denkmalsturz in der Buchgraphik zur Ausführung, indem nämlich Bertotti Scamozzi ohne erkennbare Notwendigkeit äußerer Art die Architektur samt Sockelinschrift aus dem Frontispiz von Burlington geradezu penetrant exakt kopieren ließ - jedoch dessen Palladio-Büste à la inglese aus dem Tabernakel herausräumte und statt dessen das Bildnis in modo italiano aufstellte! Wissenschaftliche Kollegenkritik ${ }^{41}$ ist schlechterdings kaum radikaler zu veranschaulichen, selbst wenn dem Büstenkostüm das geknöpfte Wams und der Kragen britischen Manufakturfleißes verblieben.

Was wären die Künste ohne ihre Sammler, ohne die ihr Werk Ordnenden und ohne die Kunstwissenschaftler? ${ }^{22}$ Der Beitrag schließt mit einem der jüngeren Begründer moderner Kunstwissenschaft, mit Johann Joachim Winckelmann (1717-I768). Acht Jahre nach dessen gewaltsamem Tode gab die Wiener Akademie seine Geschichte der Kunst des Alterthums heraus. ${ }^{43}$ (Abb. 17) Der Titelkupfer breitet rings um das stark idealisierte Forscherbildnis Gegenstände der verschiedenen Denkmälerarten und Repräsentanten jener historischen Hochkulturen

Bertotti Scamozzi giusta l'esemplare del Lord Co. di Burlingthon [sic] impresso in Londra l'anno I732 [in Wirklichkeit I730; Titel auch in frz.], Vicenza 1785, Frontispiz (Kupferstich) von Gaetano Testolini (erwähnt um I770-I8I8).

4I Zur Kollegenkritik und Eigenwertschätzung: Giorgio Vasari (I5II-I574) formulierte in 2. Ausgabe seiner Künstlerviten das eigene Bildnis größer denn das der gewürdigten Kollegen: Le vite de’ piu eccellenti pittori, scultori, e architettori [...], 2 Teile, Florenz 1568, Holzschnitt im I. Teil vor dem Index. - Karel van Mander (I548-1606) ließ sich zwecks Eternitätssicherung seines Angedenkens durch Hendrik Goltzius (I558-1616 oder I6I7) unter exakter Angabe seines Alters im - noch währenden! - Leben in Form einer Büste ad vivum darstellen: Het schilder-boeck [...] door Karel van Mander schilder, Haarlem I604, Kupferstich von Jan Pietersz. Saenredam (um I565 oder um I565/1566 1607), eingebunden nach dem Privileg.

42 Als Beispiel etwa der Kunsthändler und gelegentlich selbst als Kupferstecher wirkende Pierre-Jean Mariette (I694I774), als Graphiksammler zugleich Begründer einer systematischen Ordnung nach Schulen, im Katalog seiner Nachlaßversteigerung: Catalogue raisonné des différens objets de curiosités dans les sciences et arts, qui composoient le cabinet de feu Mr Mariette [...]. Par F. Basan, graveur, Paris 1775, Frontispiz (Kupferstich) gestochen von Pierre Philippe Choffard (1730-I809). - Noch zu Lebzeiten und inmitten seiner Sammlung Kaspar Friedrich Jencquel (Lebensdaten ungesichert) unter seinem Pseudonym Neickel als Begründer moderner Sammlungsordung: Museographia oder Anleitung zum rechten Begriff und nützlicher Anlegung der Museorum, oder Raritäten-Kammern, [...]. [...] vermehret von D. Johann Kanold [...], Leipzig/Breslau 1727, Frontispiz (Kupferstich) gestochen von Bartholomäus Strahowsky (erwähnt zwischen I712 und 1759).

43 Johann Winkelmanns [sic] Geschichte der Kunst des Alterthums. Nach dem Tode des Verfassers herausgegeben und dem Fürsten Wenzel von Kaunitz-Rietberg gewidmet von der kaiserlichen königlichen Akademie der bildenden Künste, Wien 1776, Titel mit Kupferstich von L. Marck (oder March; nicht identifiziert). 


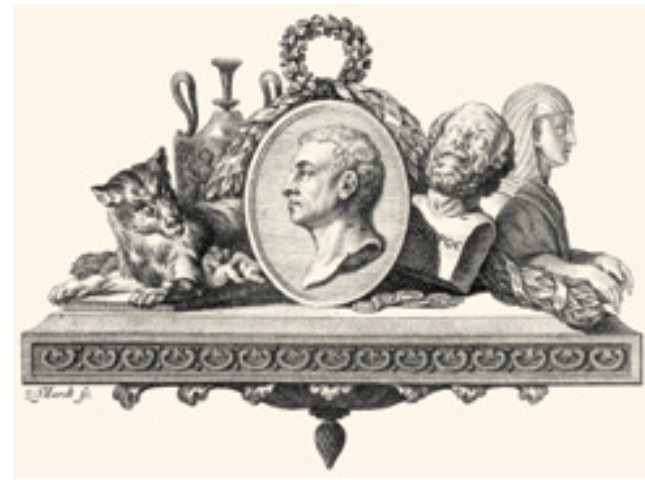

Abb. 17: Johann Joachim Winckelmann, Geschichte der Kunst des Alterthums, 1776.

aus, mit denen der Verstorbene sich befaßt hatte. Die tragende Konsolplatte steht für die Architektur, die Münzen für die Numismatik, die säugende Wölfin für Rom, der Kopf des blinden Homer für Griechenland und für die Texttradition, die Sphinx für Ägypten sowie beide für die Skulptur, die bemalte Vase für die antike Malerei. Das Bildnis selbst ist Zeugnis der Steinschneidekunst und wird von zwei Ehrenkränzen umgeben, der eine geflochten aus mediterranem Lorbeer, der andere gewunden aus den Blättern nordischer Eiche. ${ }^{44}$ In der Kombination von Buchtitel, Bildnis und Bildgegenwärtigkeit seiner Forschungsgegenstände ist dem Gelehrten hier ein Universaldenkmal seines Geistes errichtet, das über die Verbreitung des Werkes Einzug in jede wissenschaftliche Bibliothek nehmen sollte. Die hingegen irdische Vergänglichkeit deutete fünf Jahre später Winckelmanns Freund und zeitweiliger Lehrer Friedrich Adam Oeser (I717-1799) im fingiert realen Monument an, zu dessen Füßen neben dem Lorbeerzweig auch das Knäuel eines zerrissenen Lebensfadens, der Spinnrocken der Parzen liegen.45
Zerrissen, abgerissen ist seitdem die Tradition, das Bildnis des Gelehrten dauerhaft mit den schriftlichen Zeugnissen seines wissenschaftlichen Wirkens zum Denkmal zu verbinden; statt des Frontispizes - es müßte beileibe nicht gleich die apotheotische Büste sein - findet sich schnöde sein briefmarkengroßes Photo im Klappentext des Schutzumschlages. Und indem der Bibliothekar diesen umgehend entsorgt, verhindert er den Zuzug des Autors in jenes Pantheon der Geister, das sich über Jahrhunderte auf den Bücherborden gelehrter und lehrender Institute versammelte. Und gar das posthum errichtete, das plastische Denkmal am öffentlichen Ort? Man stelle sich vor, die Wiener Universität hätte nicht beizeiten über ihren Innenhof eine $\mathrm{Zu}$ wanderungsbegrenzung gegenüber dreidimensionalen Memorabilia verhängt ... die dortige Stein- und Bronzeschar der vorverstorbenen Ge(l)ehrten wäre womöglich kaum kleiner als die Zahl der aktuell immatrikulierten Aspiranten auf künftige solche Würdigungen.

Abbildungsnachweis: Abb. I, 2, 4: Antonio Cozza; Abb. 3: New York, Metropolitan Museum of Art, Library Purchase; Abb. 5: London, British Library Board/7815. aa.35/20I4; Abb. 6: Digitale Sammlungen/Sächsische Landesbibliothek/Optica.24.m, misc.I; Abb. 7, II, I7: Bayerische Staatsbibliothek München; Abb. 8: Köln, USB, Historische Sammlungen; Abb. 9: Universiteit Antwerpen, Bibliotheek Stadscampus, Historische Collecties; Abb. Io: London, The Trustees of the British Museum; Abb. I2, I3: Internet Archive/Smithsonian Libraries; Abb. I4: ETH-Bibliothek Zürich, Sammlung Alte und Seltene Drucke; Abb. I5: London, The Trustees of the British Museum; Abb. I6: Köln, LETTER Stiftung.

44 Das Profilbild geht auf das durch Johann Gottfried Dyck (I750-I8I3) in der Neuen Bibliothek der schönen Wissenschaften und der freyen Künste (3. Bd., Leipzig 1766/1767, hier: erstes Stück, 1766) als Frontispiz publizierte Winckelmann-Porträt zurück, gestochen von Bartolomeo Folin (I730-[nach] I808) nach einer im Leipziger Museum der bildenden Künste bewahrten, auf I764 datierten Zeichnung von Giovanni Battista Casanova (I730-1795).

45 Histoire de l'art de l'antiquité par M. Winkelmann [sic]. Traduite de l'Allemand par M. Huber, Bd. I, Leipzig I78I, Frontispiz nach Zeichnung von Adam Friedrich Oeser und Titel. 


\title{
PAPER MONUMENTS FOR ANTIQUARIES (CAYLUS, WINCKELMANN, D'HANCARVILLE): METAHISTORICAL INTERVENTIONS
}

\author{
Hans Christian Hönes
}

$\mathrm{O}^{n}$ ne of the central aims of the present volume is to contribute to the history of scholars' monuments in halls of honour and pantheons, such as the Viennese Arkadenhof, and to work towards a typology of these spaces of remembrance. Such collective commemorative spaces necessarily extend beyond the individual to a more corporative form of remembrance, no matter how closely the iconography of a monument might allude to the profession and achievements of an individual (as in the case of Theodor Billroth, analysed by Julia Rüdiger). In order to contribute to a contrastive analysis of these ensembles, I would like to focus on a somewhat different constellation, namely on paper monuments that were integrated in the published works of the author they were dedicated to. The monument, in this case, becomes a paratext to the scholarly output of the honoured person.

My article will focus on three such cases: memorials for the Comte de Caylus, Johann Joachim Winckelmann, and Pierre-François d'Hancarville, all three of whom are amongst the most famous antiquaries of the second half of the eighteenth century. This shared profession (or research interest, at least) leads to another quite intricate specificity of these examples: they represent memorials of a historiographer in a work on historiography. Two levels of historical interest and enquiry meet here: the description of the past (as pursued by the historian) and the shaping of the past (as done by the commissioner/designer of a paper memorial - who might readily be synonymous with the former). I wish to argue that in these cases, paper monuments become a metahistorical commentary on the respective author's writings and theories of history. By shaping the remembrance of the historiographer, these monuments relate the latter to the past he describes. The fact that these monuments were designed, on more than one occasion, by the antiquary himself, gives rise to a self-reflexive comment on the epistemological status of the narrative representation of history and the historiographer's own status.
The Comte de Caylus (I692-I765), one of the most prominent, renowned, colourful, and versatile amateurs of his day, is known first and foremost for his enormous seven-volume history of ancient art, the Recueil des antiquités égyptiennes, étrusques, grecques, romaines et gauloises (175267). ${ }^{.}$In the seventh and last volume of his magnum opus (published only posthumously, two

I The range of his activities was, however, extremely vast and went far beyond the realm of antiquarian research. On 


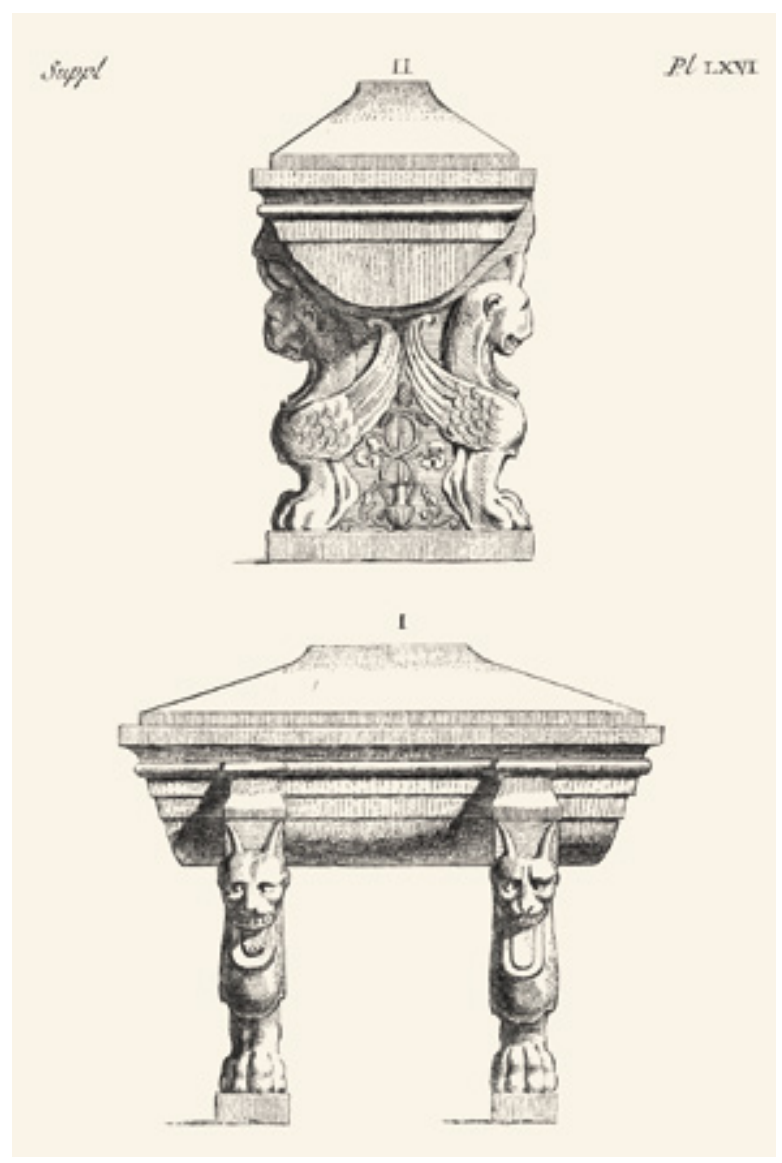

Fig. I: 'Urne dite du comte de Caylus', in Caylus, Recueil (cit. n. 2), p. 236 .

years after Caylus' death), he included a remarkable object (Fig. I). Caylus, who had bought the item some years before, thought it to be a Roman urn dating from the time of Emperor Hadrian, namely, the first half of the second century A.D. ${ }^{2}$ The catalogue entry describing this monument indicates how fascinated the Comte was by the magnificence générale and intelligence of its features, the plus beau porphyre it was made of, as well as by the poli of its intérieur. ${ }^{3}$ Caylus was attracted even more by the iconographic features of the urn than by its craftsmanship. The consoles of the object, in particular, caught his attention. These were decorated with animaux fantastiques, most likely representing some kind of feline animal. In Caylus' eyes, they were indebted to the iconographic model of the Sphinx of the Greek, which the Romans often imitated. ${ }^{4}$

the interplay of these different fields of interest, see the study by J. ReEs, Die Kultur des Amateurs: Studien zu Leben und Werk von Anne Claude Philippe de Thubières, Comte de Caylus (I692-1765), Weimar 2006.

2 [C]ette espece d'urne, dont [...] l'usage ne pouvoit être destiné qu'à un Cénotaphe, ou peut-être à renfermer les cendres d'un personage, sans doute, considerable [... was made] aux environs du regne d'Adrien. (A. C. DE CAYLus, Recueil d'Antiquités Egyptiennes, Etrusques, Grecques, Romaines et Gauloises, vol. VII (Supplement), Paris I767, p. 235ff.)

3 Ibid., p. 235.

4 Ibid. All translations, unless otherwise stated, are mine. 
The Roman sarcophagus is thus citing a Greek iconography, which, in turn, was adopted by the Greeks from another, older civilization: the Greek prototypes bore in themselves an archaic réminiscence Egyptienne, which was transmitted from Egypt, via Greece, to Roman art.

From Egyptian art, to the appropriation of the Sphinx by the Greeks, whose adaptions of this ancient image formed the prototypes for Caylus' Roman sarcophagus, the whole history of ancient art as described in Caylus' Recueil, seems to be condensed in this single object. It virtually mirrors ontogenetically the development of art as a whole. ${ }^{5}$

Precisely in this vein, the Recueil presented the history of ancient art as an uninterrupted continuous development, spanning from Egyptian times to the downfall of the Roman Empire. ${ }^{6}$ As already suggested by the book's full title, Caylus argues for a transmission of the arts in a kind of relay from one nation to the next, thus continuing their uninterrupted development. His Roman urn was virtually the last link in an uninterrupted chain of artistic and symbolic tradition, leading back to the earliest times of art. ${ }^{7}$ Published in the final volume of this long history, the urn might therefore be described as the metonymical synopsis of this history. ${ }^{8}$

One might have already guessed by the somewhat strange praise that Caylus gave to the intérieur of the urn that he had a very special usage for this object in mind. Unlike the rest of his collection of antiques, which he bequeathed to the Royal collections, he wanted to keep this urn all to himself: Caylus selected it to be his sarcophagus in which he wished to be entombed. ${ }^{9}$ This idea was clearly facilitated by the fact that the urn was abandoned, so to speak: there was no inscription documenting to whom this monument once belonged. It was thus free for a new inhabitant. $^{\text {IO }}$

In death, Caylus wanted, quite literally, to become part of the past, or better, to become part of the antiquity whose art and culture he revered so much. During his lifetime, this immediate contact with antiquity was precisely what he lacked. His continuous and somewhat holistic history of ancient art came, as already indicated, to an end with the downfall of the Roman Empire. The modern antiquary had to content himself with a somewhat belated standpoint, from where he could only guess the richness and

5 Caylus repeatedly uses a rhetoric that suggests a 'recapitulation' of the phylogeny of art history as a whole in the 'ontogeny' of the art of the respective nations: Les ouvrages des Etrusques [...] suivent absolument la route à laquelle tous les hommes sont soumis (CAYlus, Recueil (cit. n. 2), vol. V, Paris I762, p. 9I). Cf. D. Syndram, Ägypten-Faszinationen: Untersuchungen zum Ägyptenbild im europäischen Klassizismus bis I800, Frankfurt a.M. 1990, p. 42, who provides a brilliantly concise account on Caylus' idea of history.

6 On les [the arts] voit formés en Egypte avec tout le caractère de la grandeur; de-là passer en Etrurie, où ils acquièrent des parties de détail, mais aux dépens de cette même grandeur; être ensuite transportés en Grèce, où le sçavoir joint à la plus noble élégance, les a conduits à leur plus grande perfection ; à Rome enfin [...] (CAYlus, Recueil (cit. n. 2), vol. I, Paris I752, IX).

7 „Wie in einem Brennglas schien diese zoomorphe Kollage den Entwicklungsgang der alten Kunst selbst noch einmal zu bündeln und dabei deren Transformation nachzuzeichnen." (ReEs, Kultur des Amateurs (cit. n. I), p. 432ff.)

8 Rees, Kultur des Amateurs (cit. n. I), p. 43I.

9 As the editor of this volume informs the reader: M. le Comte de Caylus, qui avoit acheté ce monument, l'a destine à être placé dans le lieu de sa Sépulture à S. Germain l'Auxerrois, \& à lui server de tombeau. En attendant qu'il pût être employé à cet usage, il l'avoit fait dresser dans son Jardin, où il le considéroit souvent d'un oeil tranquille, \& se faisoit un plaisir de le montrer à ses amis (CaYlus, Recueil (cit. n. 2), p. 236). Cf. S. Rocheblave, Essai sur le Comte de Caylus, Paris I889, p. I4O; ReEs, Kultur des Amateurs (cit. n. I), ch. 6.

IO [I]l n'est chargé d'aucune inscription, ainsi on ne peut attribuer [whose ashes were stored in the reputed urn] (CAYLUS, Recueil (cit. n. 2), p. 235); 'Die Urne war nicht nur leer, sondern sie war auch semantisch frei' (ReEs, Kultur des Amateurs (cit. n. I), p. 432). 


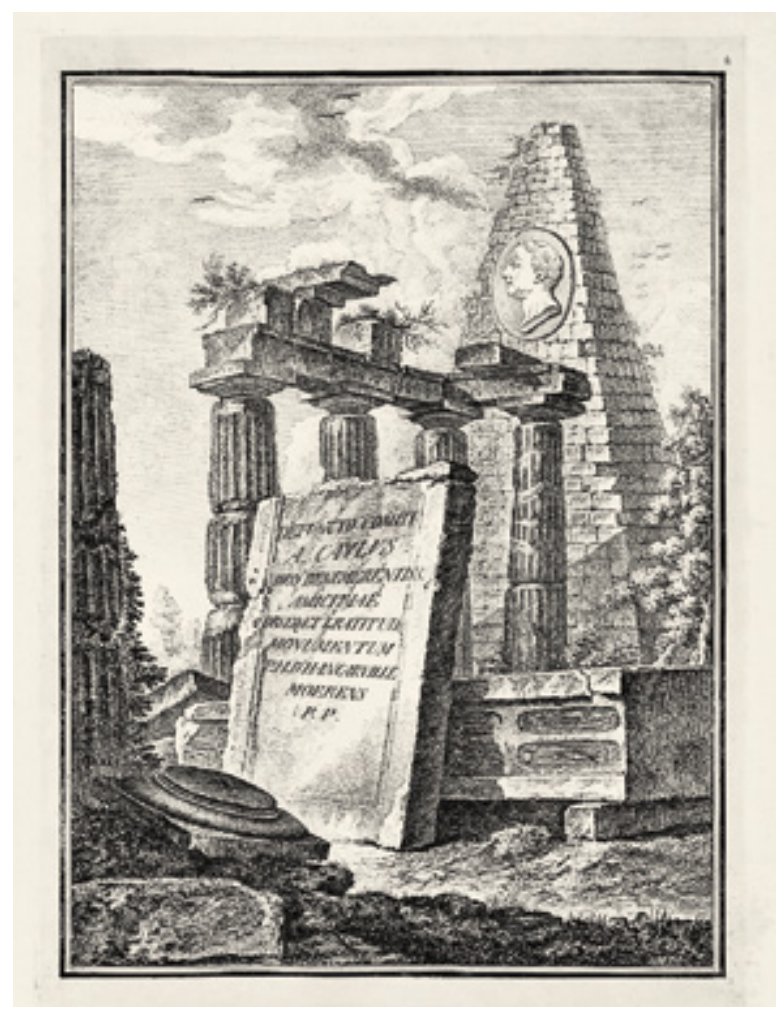

Fig. 2: Anon., Paper Memorial for the Comte de Caylus, in d'Hancarville, Antiquités (cit. n. 25), vol. IV, Naples 1767 [I776], s.p.

splendour of antique art in its full bloom. ${ }^{\text {II }}$ In the preface to the sixth volume of the Recueil, Caylus described this belatedness using a geographical metaphor: The antiquary, he wrote, travels constantly in a distant country, where he is nothing more than an ignorant tourist, a traveller who sees, without seeing, because the incertitude of his knowledge is presenting him with nothing fixed, and the quantity of objects finally irritates and blurs his perception. ${ }^{12}$ His urn (which was indeed integrated into his tomb by his heirs, though only placed on top of his actual sepulchre) functioned as an interface that allowed him to reincarnate himself in the past in order to bridge the temporal gap that separated him from the past. ${ }^{13}$ To a certain degree, Caylus was aiming at an inverted, negative renaissance: He did not envision a rebirth of the past, but a reunification with the past by being buried in it. ${ }^{14}$

II On this motif, see P. Geimer, Die Vergangenheit der Kunst, Weimar 2002.

I2 [The antiquary] voyage constamment dans un pays fort éloigné; il voit sans voir, du moins l'imperfection de son coup d'eil, ou l'incertitude de son sçavoir ne lui présentent rien de fixe, et la quantité des objets l'offusque (CAYLus, Recueil (cit. n. 2), vol. VI, Paris I764, p. VII).

I3 'L'auteur est enterée dans son Recueil.' (P. Griener, La République de l'oeil. L'Expérience de l'art au siècle des Lumières, Paris 20IO, p. 155) 'In dieser Urne, die als römische Arbeit unter Verwendung griechischer Formen nach Ägypten wies, wollte Caylus die Reise in den pays éloigné vollenden’ (ReEs, Kultur des Amateurs (cit. n. I), p. 433).

I4 Cf. Was war Renaissance? Bilder einer Erzählform (exh. cat. München, Zentralinstitut für Kunstgeschichte), Passau 2013, p. 165-168. 
At least some of his contemporaries might have judged this operation a success. This is suggested by an impressive, fictive paper monument for Caylus, printed in the fourth and last volume of Pierre d'Hancarville's Antiquités étrusques, grecques et romaines ( $1767-1776)$, the monumental and highly influential publication of the collection of vases by the British diplomat William Hamilton (Fig. 2). Here, Caylus seems to have virtually arrived in the past. He is entombed in an antique site, in many parts dilapidated und ruinous. His portrait medallion, which also ornamented his actual tomb, is affixed on a very pointed pyramid. The latter does not look very Egyptian, but rather resembles depictions of the Cestius pyramid in Rome. ${ }^{\text {Is }}$ If this identification is correct, it might be appropriate to try to 'read' the architectural fragments displayed in the etching in a diagrammatical way, interpreting their sequence from fore- to background as a kind of timeline: At the bottom, in the foreground, lies a console with Egyptian hieroglyphics, behind it stands a row of Doric columns, i.e., a Greek structure, and the end was represented by the 'Cestius/Caylus-Pyramid', a mock-Roman structure, referring to the original archetypes of Egyptian art, and thus summarizing the whole of the antique history of art. If this is the case, d'Hancarville's paper monument situates the late Caylus in the same chronological framework as he himself did with his own 'urn'.
The motif of such a reverse renaissance was congenially adopted for the remembrance of another, even more famous historian: Johann Joachim Winckelmann. The murder of Winckelmann in Triest in 1768 (about three years after the death of Caylus) was a traumatic shock for the European republic of letters. ${ }^{16}$ The dozens of eulogies written for the greatest antiquary of all time overflow with grief and articulate the feeling of a profound loss. ${ }^{17}$ One of the most successful outcomes of this 'mourning work' was another paper monument designed by Winckelmann's friend Adam Friedrich Oeser, which was printed as a frontispiece in numerous posthumous editions of Winckelmann's History of Ancient Art, such as the French translation by Michel Huber and Gottfried Sel- lius, or the Italian translation by Carlo Fea (Fig. 3). ${ }^{18}$ In front of a large cenotaph, adorned with a portrait medallion of Winckelmann, stands a weeping woman. It is one of the Fates; the remains of the cut thread of life lies on the floor in front of her. The late Winckelmann and his ingenious scholarly mind, one might conclude, is irrevocably lost and gone.

Yet, some solace remained. As is well known, Winckelmann's theory of history suggests a view of ancient art as an ultimately past and unreachable state that could no longer be experienced in its fullness. In this respect, his views were very similar to those of Caylus sketched above. ${ }^{19}$ Famously, in the final scene of his History of Art, Winckelmann formulated this vision

I5 'Aus der Pyramide des Cestius ist ein Monument für den Comte de Caylus geworden' (ReEs, Kultur des Amateurs (cit. n. I), p. 438).

I6 Il fut pleuré de ses amis \& regreté de tous ceux qui sintéressent aux progrès des Arts \& des Sciences. (J. J. WincKeLmanN, Histoire de l'art de l'antiquité (trad. M. HubER), Paris I78I, p. CXXXVI)

I7 See only C.G. Heyne, Lobschrift auf Winckelmann, Leipzig 1778, and Die Kasseler Lobschriften auf Winckelmann (ed. A. Schulz), Berlin i963.

I8 Cf. Das Evangelium des Schönen. Zeichnungen von Adam Friedrich Oeser (exh. cat. Leipzig, Museum der bildenden Künste), München 2008, p. $58 \mathrm{ff}$.

I9 For a comparison of the art theories by Winckelmann and Caylus, see E. DÉcultot, Winckelmann et Caylus. 


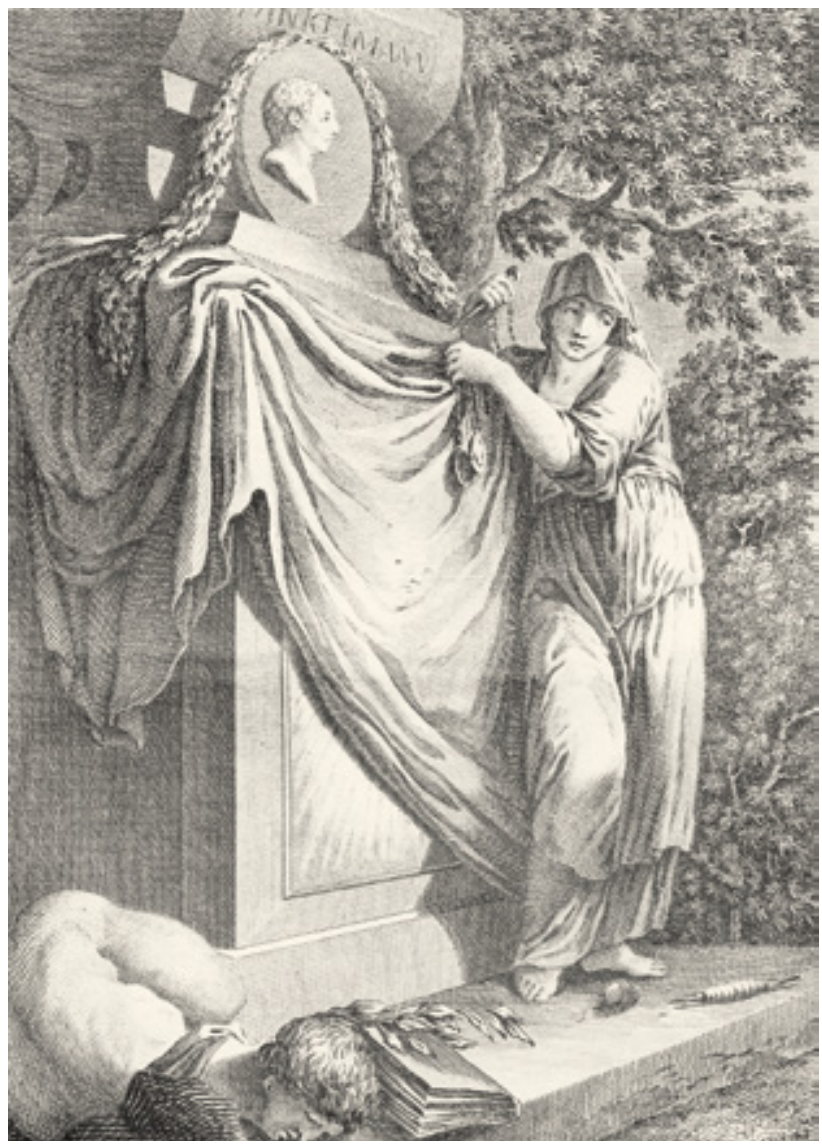

Fig. 3: Christian Gottlob Geyser after Adam Friedrich Oeser, Paper Memorial for Winckelmann, in Johann Joachim Winckelmann, Storia delle arti di disegno presso gli antichi, trad. Carlo Fea, Rome ${ }_{7} 783$, frontispiece.

of a grieving, belated observer, left behind and looking back on the vanished but much desired art of the past. Here, looking back on the lost beauties whose history he had just finished writing, he compares his situation with the situation of a (female) lover, who follows with tearful eyes her departing sweetheart, with no hope of seeing him again, and believes she can glimpse even in the distant sail the image of her lover..$^{20}$ Yet, what remains to be grasped is nothing more than an afterimage, a faint memory of the departed. The same holds weight for ancient art, equally lost in the turmoil of history.

As saddening and devastating as Winckelmann's murder might have been for those who were left behind, his death opened up the pos-

Enquête sur les rapports de l'histoire de l'art au savoir antiquaire, in: Le Comte de Caylus. Les Arts et les Lettres (ed. N. Cronk / K. Peeters), Amsterdam / New York 2004, p. 59-78; F. Queyrel, Caylus, de l'antiquaire à l'archéologue: une méthode différente de celle de Winckelmann, in: L’idée du style dans l'historiographie artistique (ed. S. Frommel / A. Brucculeri), Rome 20I3, p. 23I-239.

20 J.J Winckelmann, History of the Art of Antiquity (trad. H.F. Mallgrave), Los Angeles 2006, p. 35I. See also the brilliant analysis by W. DAvis, Winckelmann Divided, in: IвID., Replications. Archaeology, Art History, Psychoanalysis, University Park, Penn. 1996, p. 257-265. 


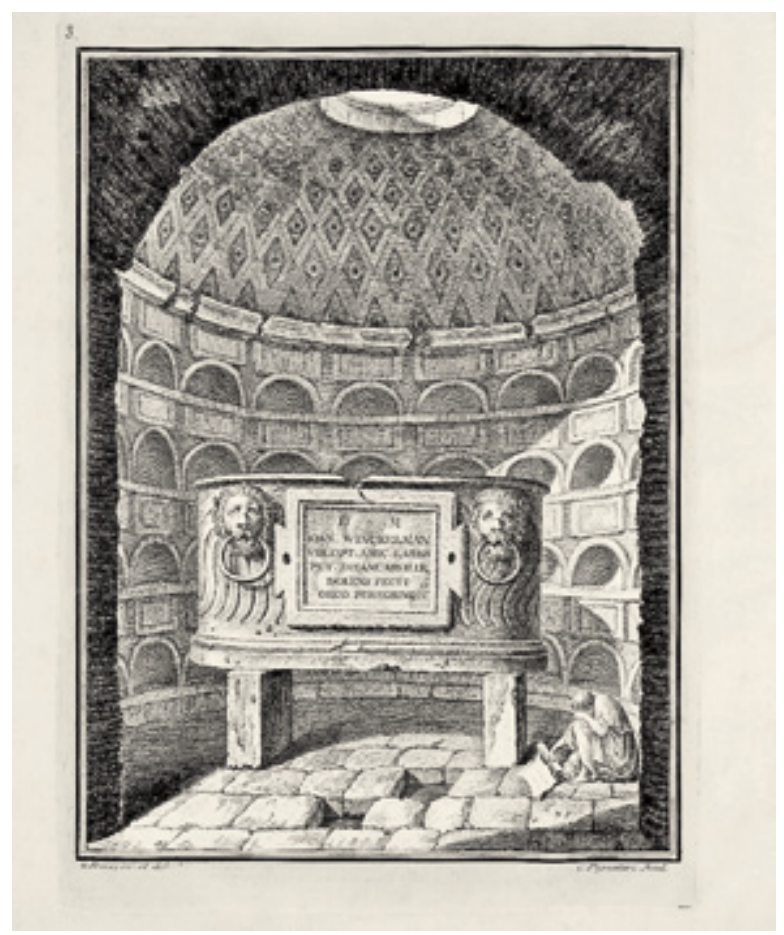

Fig. 4: Carmine Pignatori after Giuseppe Bracci: Paper Memorial for Winckelmann, in d'Hancarville, Antiquités (cit. n. 25), vol. II, Naples 1766 [1770], s.p.

sibility that, through dying, Winckelmann ultimately achieved what he longed for most during his lifetime: to become part of the beloved past, this remote asylum of freedom and beauty. ${ }^{21}$ The ones left behind in this case are his saddened contemporaries, such as the beholder of Oeser's fictive cenotaph. This interpretation is not only suggested by the iconography of his paper monument, alluding to the farewell scene of the History, but also by the wording of several eulogies written on this occasion. As Herder wrote: The dream of your life tumbled down and lay shattered on the ground, as the statue of an Apollo-Mu- sagetes by the hand of a barbarian. ${ }^{22}$ The fate of the history of art and the fate of Winckelmann's life are directly and unambiguously paralleled here.

A similar setup is staged in another print remembering Winckelmann, likewise published in d'Hancarville's Antiquités étrusques, grecques et romaines (Vol. II). Here, one witnesses another scene of mourning taking place in a monumental, Pantheon-like building - apparently a columbarium (Fig. 4). ${ }^{23}$ In the middle of the room stands Winckelmann's very antique-looking cenotaph. Next to it crouches an apparently grieving man, desperate over the loss of Winck-

2I Cf. the brilliant analysis by Daniel Orrells: 'Winckelmann himself came to be viewed like the Geschichte he wrote: he was seen as a timeless, classical figure that transcended the ages, both ancient and modern, and as a man always romantically destined to die young.' (D. Orrells, Burying and excavating Winckelmann's History of Art, in: Classical Receptions Journal 3, 20II, p. I66-I88, here: p. I73ff.)

22 [D]er Traum deines Lebens sank dahin und lag zerschlagen, wie die Bildsäule eines Apollo-Musagetes von der Hand des Barbaren. (J. G. Herder, Lobschrift auf Winckelmann, in: Die Kasseler Lobschriften (cit. n. I7), p. 3I-63, here: p. 60)

23 Michel Huber, who published a modified version of this print in his translation of the History of Ancient Art wrote: 
elmann's life. The most interesting aspect of this paper monument is, however, the fictive inscription on the cenotaph: D.M. / IOAN.WINKELMANN / VIR.OPT.AMIC.KARISS / PET. DHANCARVILLE. DOLENS FECIT / ORCO PEREGRINO.

D'Hancarville, the author of the volume, claims to have built this monument for his amicus carissimus, his dearest friend Winckelmann. What is very unusual, however, is the last line of the inscription. In Roman times, the antique formula orco peregrino was applied when someone died far away from his home in a foreign country, when consequently the exact place and even time of his death remained unknown to his next of kin who erected a memorial for the deceased. ${ }^{24}$ This seems to be quite a fitting formulation for Winckelmann who died in Triest, far away from his native country (Germany), as well as from his elected homeland (Rome). But the orco peregrino might also allude to the popular geographical metaphor of the past as a distant country, not only used by Caylus, but also by d'Hancarville ${ }^{25}$ as well as (more implicitly) by Winckelmann in the 'farewell scene' of his History. Winckelmann vanished in the orco peregrino for good, and he is therefore ultimately relocated to the pays éloigné of the past.
One might imagine that Winckelmann would have been pleased by such an optimistic interpretation of his sad death. At least ideally, his fatal transformation from a lover of the arts to a weeping girl would have been overcome through these eulogies of his contemporaries. The idea that one could change the actual identity of a person by such a 'speech act', by a narrative evocation of a new persona, was certainly no strange concept for Winckelmann. I wish to argue that it is precisely this idea that is reflected in the farewell scene of his History of Art.

As I have mentioned, at the very end of his History, Winckelmann compared himself to a weeping maiden longing for her departed lover. In the sentence before that, he likens himself to someone who, in writing the history of his native land, must touch upon the destruction that he himself has witnessed. Contemplating the collapse of art evoked the very same feelings in Winckelmann. ${ }^{26}$ Both times, he tellingly compares him- self to a character that was once a contemporary of what is now lost. Be it the now destroyed native land, or the departed lover: both were once present in the life of the respective mourner. Ancient art, on the other hand, was ruined quite a while before Winckelmann started writing (or was even born, for that matter), and one might assume that he must have realized this obvious fact a little earlier. However, the logic of Winckelmann's text, one might argue, suggests that it was only due to his historiography that ancient art died.

By writing the history of art as he did, Winckelmann might have regarded himself as ultimately responsible for the outcome of the story. Thus, he enacts his transformation to a weeping maiden at the very moment he realizes what he has done by narrating the history of art beyond its set bounds. The historical distance separating him from antique splendour seems to be an immediate effect of this storytelling; the past only comes

Cette planche représente un Columbarium, ou l'interiéur d'un tombeau, où l'on voit un homme assis dans l'attitude de la tristesse au pié d'un sarcophage de pierre. (WInCKelmann, Histoire de l'art (cit. n. I6), p. CXXXVI)

24 Cf. Orrells (cit. n. 2I), p. I8I.

25 The past, he wrote, is a foreign country, dont la distance est immense de celui que nous habitons (P.-F. D'HANCARviLLE, Antiquités étrusques, grecques et romaines, tirées du cabinet de M. Hamilton, vol. II, Naples I766, p. 9). 


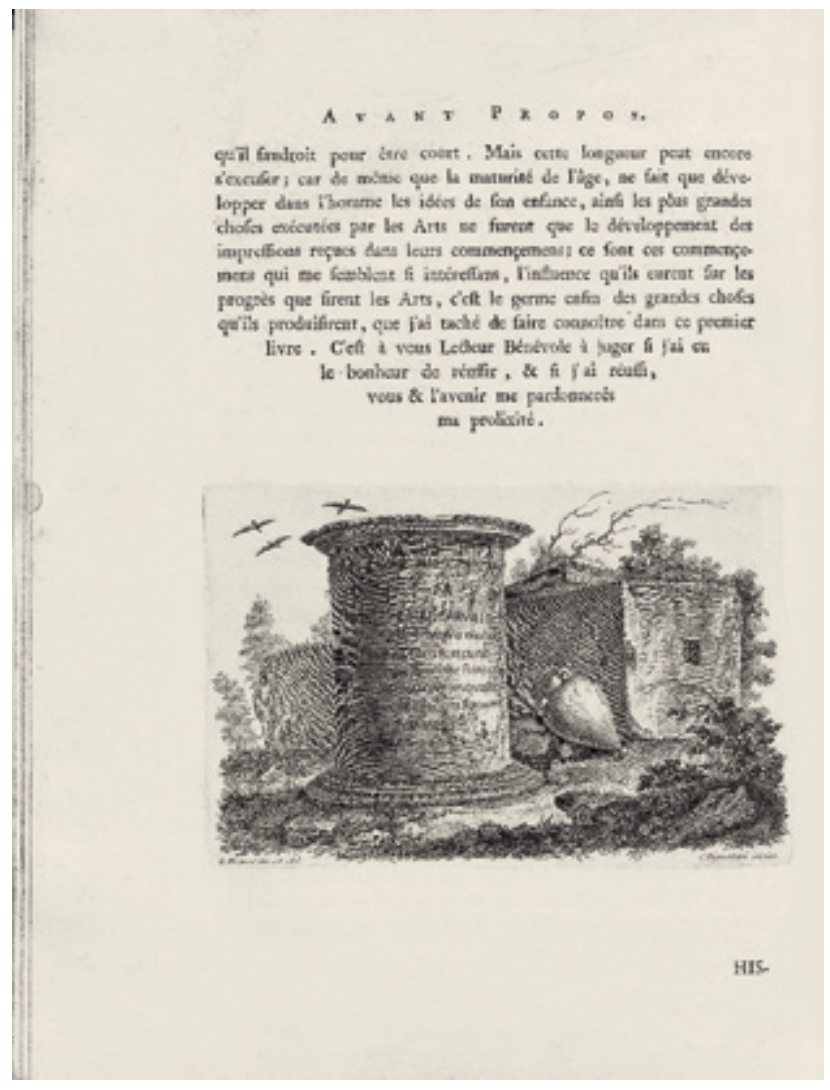

Fig. 5: Carmine Pignatori after Giuseppe Bracci: Paper Memorial for d'Hancarville, in d'Hancarville, Antiquités (cit. n. 25), vol. III, Naples 1767 [I776], s.p. ('Avant-Propos').

into being by being described as such. There are hardly any other passages in art historical literature, which demonstrate such an awareness of the power of the act of writing itself.

By understanding history in this way, one might conclude that this very history could potentially be remodelled once again by recounting it differently. This seems to be, in any case, the conclusion that another follower, interpreter, and contemporary of Winckelmann drew from Winckelmann's identity politics. I am speaking of Pierre-François d'Hancarville, whose extensive occupation with paper monuments for anti- quaries should have already become clear during the course of this essay.

At the beginning of the third volume of the Antiquités, placed as a vignette after the preface, the reader is greeted by another strange paper monument, a little more modest than the two discussed so far (Fig. 5). ${ }^{27}$ What is apparently shown is a dilapidated monument in the middle of a deserted landscape; a couple of circling birds are the only sign of life in the ruinous scenery. Only a short inscription on what seems to be the pedestal of a now lost statue or a funerary altar testifies to who was once remembered by this

27 For an in-depth analysis of this vignette and d'Hancarville's art theory in general, see H.C HöNEs, Kunst am Ursprung. Das Nachleben der Bilder und die Souveränität des Antiquars, Bielefeld 2014. 
monument. But the reader is surprised by the person to whom it is dedicated: The person remembered here is none other than d'Hancarville himself, which is even more surprising considering he was still very much alive when this volume came out and went on wandering this earth for thirty more years. ${ }^{28}$

The intention of the author becomes clearer on reading the preface accompanying his paper monument, where he comments at length on this self-burial. His fictive tomb monument, d'Hancarville writes, is not meant as a memorial for the remembrance of the author but, on the contrary, it represents a symbolic break from his old ideas and writings. D'Hancarville wants, quite literally, to bury his old self. The third volume of the Antiquités is therefore conceived as a critique of the volumes that had the misfortune to precede this one. ${ }^{29}$ Instead of continuing this old way of thinking, he claims to have developed a 'new science' - a science nouvelle. The reader should regard d'Hancarville's previous works and opinions as dead, as if a man who's dead for a fairly long time wrote them. ${ }^{30}$
I wish to argue that the last comment is directed against one specific man who died in fact not so long ago, Johann Joachim Winckelmann, who was some kind of guiding spirit for the first two volumes of the Antiquités. ${ }^{31}$ Winckelmann's theory of art history is overturned in the third volume of the Antiquités; the crucial trait of d'Hancarville's science nouvelle is that he describes art history in a way that is radically different to the cyclical narrative of birth, rise, blossom and decay which Winckelmann put forward.

Instead of describing the downfall of ancient art, d'Hancarville boldly claims that it never ceased to exist. Even the present is connected to the remotest past by a secret influence. ${ }^{32}$ Somewhat in the vein of Aby Warburg,,33 d'Hancarville states that primeval symbols survive to the present. ${ }^{34}$ From the most beautiful sculptures of Greece to modern Christian artworks, they all contain un reste de l'ancienne manière de représenter. ${ }^{35}$ Be they the classical statues of the Dioskuroi and the three Graces, or the Christian cross, or the saints and their attrib-

28 On d'Hancarville's biography, see F. Haskell, The Baron d'Hancarville: An adventurer and art historian in eighteenth-century Europe, in: Oxford, China and Italy. Writings in Honour of Sir Harold Acton on His Eightienth Birthday (ed. E. Chaney / N. Ritchie), London 1984, p. I77-I9I. D’Hancarville, Antiquités (cit. n. 25), vol. III, Naples 1767 [I776], s.p. ('Avant-Propos').

30 Ibid.

3I On Winckelmann's model function for this publication project: D. Constantine, Winckelmann and Sir William Hamilton, in: Oxford German Studies 22, 1993, p. 55-83. On the genesis of the Antiquités: P. Griener, Le Antichità etrusche greche e romane 1766-1776 di Pierre Hugues d'Hancarville, Rome I992; N. Heringman, Sciences of Antiquity, Oxford 2013, ch. 3. On Hamilton's collection: Vases and Volcanoes. Sir William Hamilton and his Collection (exh. cat. London, British Museum), London 1996.

32 [C]es temps si éloignés de nous, se lient avec celui où nous vivons, c'est par la secrete influence quills ont sur les Esprits, que les Siecles se touchent. (D'Hancarville, Antiquités (cit. n. 25), vol. III, Naples I767 [I776], p. 32)

33 He was even called a 'Vorfahre Aby Warburgs' (L. Ritter SANtini, 'Auf dunklen Grund gezogen.' Das Gedächtnis der Bilder, in: Geheimster Wohnsitz. Goethes italienisches Museum (ed. H. Mildenberger et al.), Berlin i999, p. 4I-73, here: p. 52).

Griener, Le Antichità (cit. n. 3I), p. 58; Haskell, The Baron d'Hancarville (cit. n. 28), p. I85; J. Moore, History as Theoretical Reconstruction? Baron D'Hancarville and the Exploration of Ancient Mythology in the Eighteenth Century, in: Reinventing history: the enlightenment origins of ancient history (ed. IвID. et al.), London 2008, p. 137-I67, here: p. I50. D'Hancarville, Antiquités (cit. n. 25), vol. III, Naples 1767 [1776], p. 36. [La] maniere de représenter les Dieux qui commenca dès les temps qui antérieurs à la découverte de la Sculpture subsista toujours avec elle, \& ne finit pas, même par l'extinction de la Religion des Grecs \& des Romains, puisqu'elle existe encore chez nous en mille facons différentes, qu'il seroit trop long de rapporter ici. (Ibid., p. 64) 
utes as depicted in medieval and modern churches: all of them bear remembrances and represent iconographic survivals originating from the earliest times of human art making. ${ }^{36}$

D'Hancarville thus denies the death of ancient art, constitutive for the historiography of Caylus and Winckelmann alike, and instead introduces a new, continuous perspective on art history. Consequently, he argues that the most important topic of enquiry for every historian is that of the origins of art. These very origins are, quite logically, seen as the root and cause of all subsequent events, which stem and evolve from this primal scene and are repeatedly related to it by the aforementioned secret influence. ${ }^{37}$

In light of the hypothesis that the course of history is inescapably determined by its very beginnings, it seems quite ironic that d'Hancarville's new system of a continuous art history, determined $a b$ origine, comes into being only after a radical break with one's own past. Burying and reinventing oneself seems to be the precise opposite to his theory of an ongoing, uninterrupted historical course. Of all things, d'Hancarville denies this formative influence of the origins of art in his own biography and instead authorizes himself to step out of this continuous (biographical) history and to begin anew.

I wish to argue, however, that this quite ironic, arbitrary self-authorization is key to d'Hancarville's historiographic operation. What our author suggests by burying and reincarnating himself is that all origins are arbitrarily imposed events. Arbitrariness is precisely what he attests to the origins of art, too. The beginning of art history, he argues, is marked by the erec- tion of aniconic memorials referring to a certain event or god. These aniconic proto-images might consist, for example, of a rude stone, or the trunk of a tree. The term he uses to denote these objects is signes (signs) and he describes them as presque toujours Arbitraire. ${ }^{8}$ They are not connected to the persons or the events remembered by them through any mimetic resemblance, but are quite randomly and licentiously created by what one might call the artistic license of human beings. The origins of art, this cause of all history and the crucial key that historiography should strive to uncover, are thus quite ironically dubbed to be arbitrary. The all-determining cause of art appears to draw a blank.

This definition can be understood as a strategic and meta-historiographical intervention by d'Hancarville. When the all-determining origins of art become an arbitrary blank, this void can be filled by a manipulative historiographer who subsequently gains control over history as a whole, as he commands the crucial cause of all subsequent events. D'Hancarville elaborated this idea of history in greater detail in his early Essay de politique et de morale calculée (1752). ${ }^{39}$ In this book, he tried to develop a mechanism to calculate the morale of a people in order to equip a state's sovereign with a means to educate and improve society. To achieve this goal, he does not suggest a reform of the present political and moral circumstances and conditions the people are living in, but rather aims towards a manipulation of the motives of human behaviour. The latter, he writes, is quite comparable to a physical equation where the result also depends on what one inserts as the first variable. $4^{\circ}$ The subsequent

36 Ibid., pp. 7, 62, 64, I47ff.

37 [C] e sont ces commencemens qui me semblent si intéressans, l'influence qu'ils eurent sur les progrès que firent les Arts, c'est le germe enfin des grandes choses quils produisirent. (Ibid., s.p. 'Avant-Propos')

38 Ibid., p. 39. See also p. 7 ff.

39 On this basically unstudied text, see M. PApenheim, En ce monde chacun a sa politique: Aspekte einer Begriffsgeschichte von 'politique' in Frankreich vom I6. bis I9. Jahrhundert, in: Politik: Situationen eines Wortgebrauchs im Europa der Neuzeit (ed. W. STEInMETz), Frankfurt a.M. 2007, p. I62-205.

40 Dans la morale, comme dans la phisique, un mouvement en occasionne toujours un autre, qui produit de nouveaux rap- 
arithmetic operations are determined - in human behaviour as well as in history, where the causes of the equation were also defined as arbitrary quantities. D'Hancarville's paper monument staging his self-burial can ultimately be regarded as a visible self-authorization, demonstrating that he is the one capable of defining such an arbitrary new foundation for the course of history.

Furthermore, d'Hancarville takes full advantage of this licence. In fact, one of the most unusual and surprising traits of the Antiquités are the extremely early datings for significant periods of Greek art history. To be more precise, d'Hancarville dates the origins of Greek art about half a millennium earlier than Winckelmann. In doing so, he quite literally pulls the rug from under his opponent's History of Ancient Art by locating the beginning of this history at a far earlier stage than Winckelmann. Ultimately, he is founding history anew by wittily turning Winckelmann's identity politics against himself. Where the latter had to experience how he destroyed the beauties of art by writing their history, d'Hancarville takes the exact opposite stance. By re-narrating art history from its beginnings, he is ultimately able to rewrite and repeal the story of the downfall of art which Winckelmann had institutionalized.
The paper monuments discussed during the course of this essay attempt to situate the commemorated antiquarian in relation to his authored text and the historic occurrences described in it. Ultimately, they attempt to allow him to become part of this very history. In each case, a different rhetorical strategy is used in order to tackle this challenge. Caylus tried to reincarnate himself in the past by appropriating an antique tomb monument, which summarises metonymically (and ontogenetically) the history of art as a whole. The ultimate failure of the realization of this project, however, gives it a rather tragic outcome.

Winckelmann's personas are all modelled metaphorically: He likens himself to a weeping maiden; Oeser places the beholder of his paper memorial in an analogous position of mourning, as embodied by the said lover; and Herder compares Winckelmann's life to a ruined statue. By evoking the reunification of Winckelmann with his lost love, the memorials and eulogies discussed tell a romantic story - but it is a dark romance, 'a drama of self-identification symbolized by the hero's transcendence of the world of experience, his victory over it, and his final liberation from it'. ${ }^{4 \mathrm{I}}$ D'Hancarville, finally, understands history ironically. Unlike Winckelmann and Caylus, he does not try to catch up with the past by inscribing himself to its ending, but instead to its beginning, thus negating the temporal sequentiality that was still respected by the authors of the Recueil and the History of the Art of Antiquity. By undermining the historical roots of Winckelmann's history, d'Hancarville is working on what one might call a satirical 'counter-history'. ${ }^{42}$ If all of the paper monuments discussed seem decidedly self-reflexive in their outlook, d'Hancarville's project is surely the most blatant avowal to the metahistoric mindsets underlying its construction.

Photographic Acknowledgements: Fig. I, 3: Ian Jones; Fig. 2, 4, 5: SUB Göttingen. 


\section{JAMES PRADIER UND DIE HOMMAGE AN \\ DIE GENFER ELITE}

Grégoire ExtermanN

A us kulturellen, aber auch konfessionellen Gründen hatte Genf eine schwierige Beziehung zu dem Porträt im öffentlichen Raum. ${ }^{\text {I Es }}$ ist jedoch das akademische Umfeld, in dem sich diese Repräsentationsform zuerst manifestierte. Im I8. Jahrhundert wurden nur gemalte Porträts von Gelehrten in der akademischen Bibliothek angebracht, ab dem I9. Jahrhundert in skulpturaler Form im Jardin Botanique. Dieser Ort, später Parc des Bastions genannt, wurde schrittweise zum Aufstellungsort universitärer Berühmtheiten.

Die folgende Analyse nimmt die erste Genfer Denkmalgruppe in den Blick: die sechs Büs- ten von Professoren vor dem ehemaligen Gebäude der Orangerie (Abb. I). Es werden die sozialen und künstlerischen Auswirkungen dieser neuen Denkmalform studiert, wobei ich mich auf den Bildhauer James Pradier (1790-I852) konzentriere, der zum Porträtisten der Genfer Eliten wurde.

Die Analyse befasst sich mit der Periode der Restauration, als Genf die ersten Statuen erhält, aber noch mit den Werten des Ancient régime verbunden bleibt, insbesondere mit einer streng oligarchischen Regierungsform. Dieser Sachverhalt verleiht der kleinen Republik eine seltsame Identität in Europa.

GENF ZW ISCHEN ANCIENT RÉGIME UND RESTAURATION: DIE AKADEMISCHE BIBLIOTHEK UND DER FRIEDHOF VON P L A I N PA L A I S

Im I8. Jahrhundert war die monumentale Skulptur in Genf fast inexistent. In Privatbesitz gab es einige wenige Porträtbüsten der Mitglieder der finanziellen Elite, hauptsächlich von Jean-Antoine Houdon (Madame de Thelusson, Madame de Vermenoux, Jacques Necker oder Théodore Tronchin), aber keine im öffentlichen Bereich. ${ }^{2}$ Ursache für diese Situation ist vermutlich eine Abscheu oder zumindest ein Misstrauen der calvinistischen Kultur gegenüber der Bildhauerei.

Ich bin Ilse Schwab, Simone Vögtle und Sarah Kinzel sehr dankbar für die Hilfe mit dem Text. Nicolas Schätti (Centre d'Iconographie Genevoise) verdanke ich die Abbildungen.

I Die Skulptur in Genf ist wenig studiert, deshalb werden hier nur Generalitäten präsentiert. Eine Synthese in: C. LAPAIre, La sculpture à Genève au XIXe siècle, in: Genava, 27, I979, S. IOI-I2I. Für das Thema der Kunst in Genf während der Restauration siehe: M. Natale, Le goût et les collections d'art italien à Genève du XVIIIe au XIXe siècle, Genève 1980; A. Corboz, La „refondation“ de Genève en I830 (Dufour, Fazy, Rousseau), in: Genava, 40, I992, S. 55-85. D. Buyssens, La question de l'art à Genève. Du cosmopolitisme des lumières au romantisme des nations, Genève 2008.

2 LAPAire, La sculpture à Genève (zit. Anm. I), S. IOI. 


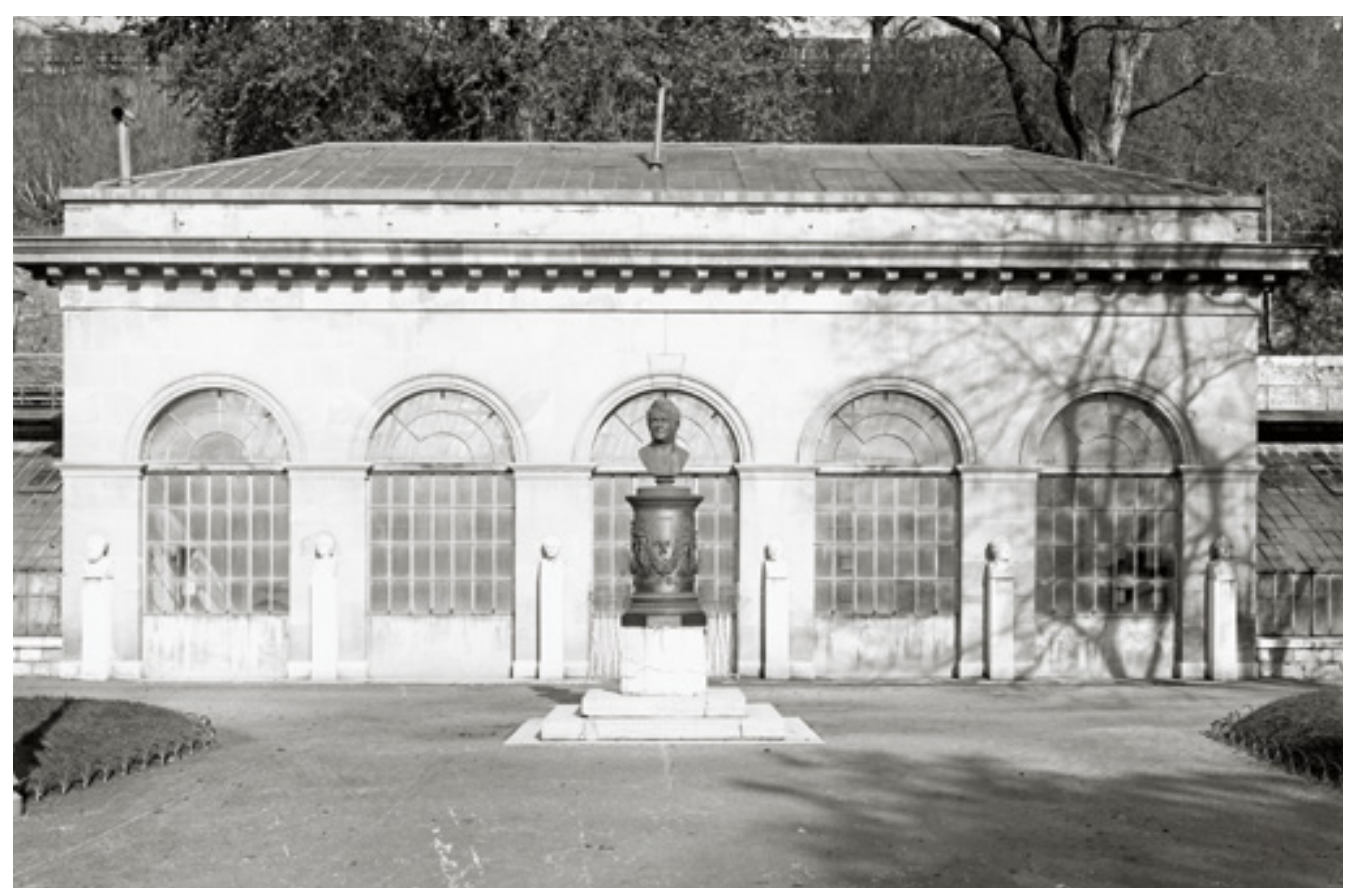

Abb. I: Orangerie, I8I7-I8I8. Genf, Parc des Bastions.

Ihre Vertreter sahen sie vor allem mit dem Katholizismus und der Monarchie verbunden, einem Gesellschaftssystem, das im Widerspruch mit den Werten einer protestantischen Republik stand. Stärker als die religiösen waren vielleicht die moralischen Hindernisse: Das bildhauerische Porträt galt als hochmütig, was eine besonders negative Eigenschaft im Calvinismus war. ${ }^{3}$

Es gab auch konkrete politische Motive. Die Regierungsform war eine maskierte, aber strenge Oligarchie. ${ }^{4}$ Fassaden ohne Skulpturen und Plät- ze ohne Monumente konnten die politischen Ungleichheiten verdecken und somit den sozialen Zusammenhalt bewahren. ${ }^{5}$ In diesem Kontext wurde das Fehlen von Denkmälern positiv betrachtet, da es mit dem Mythos einer Vergangenheit von Bescheidenheit und Einfachheit verbunden schien: „La simplicité et la modestie de nos aïeux" sind Werte, auf die sich die Regierung oft berief, um sich Denkmälerprojekten zu widersetzen. ${ }^{6}$

3 Beispielsweise die Schwestern Henriette und Jeanne-Françoise Rath gaben ihr Vermögen und das von ihrem Bruder Simon Rath an die Stadt Genf, um ein Museum einzuweihen, aber wollten keine Hommage - weder schriftlich noch künstlerisch - für diese Spende: „Mais je dois vous prier, au nom de ma sœur comme du mien, de nous écarter tout à fait de tous les honneurs qui doivent être rendus au donateur et fondateur du Musée: c'est notre désir sincère, notre volonté positive de ne point paraître dans aucune inscription“. (Brief von Henriette Rath an Augustin-Pyrame de Candolle, in Mai I826), in: N. Etienne/V. Chenal, Les demoiselles Rath \& l'institution artistique à Genève autour de I80o, in: Post tenebras luxe (hrsg. von D. BERnARDI), Genève 2009, S. 66-87, 70 (zahlreiche soziale Überlegungen sind hier behandelt).

4 C. Montandon, Le développement de la science à Genève aux XVIIIe et XIXe siècles. Le cas d'une communauté scientifique, Vevey 1975, S. 22-23.

5 Buyssens, La question de l'art (zit. Anm. I), S. I05-IO7.

6 Das Argument der Bescheidenheit wird aufgerufen, z.B. gegen das erste Rousseau-Denkmalprojekt I79I (ebenda, 


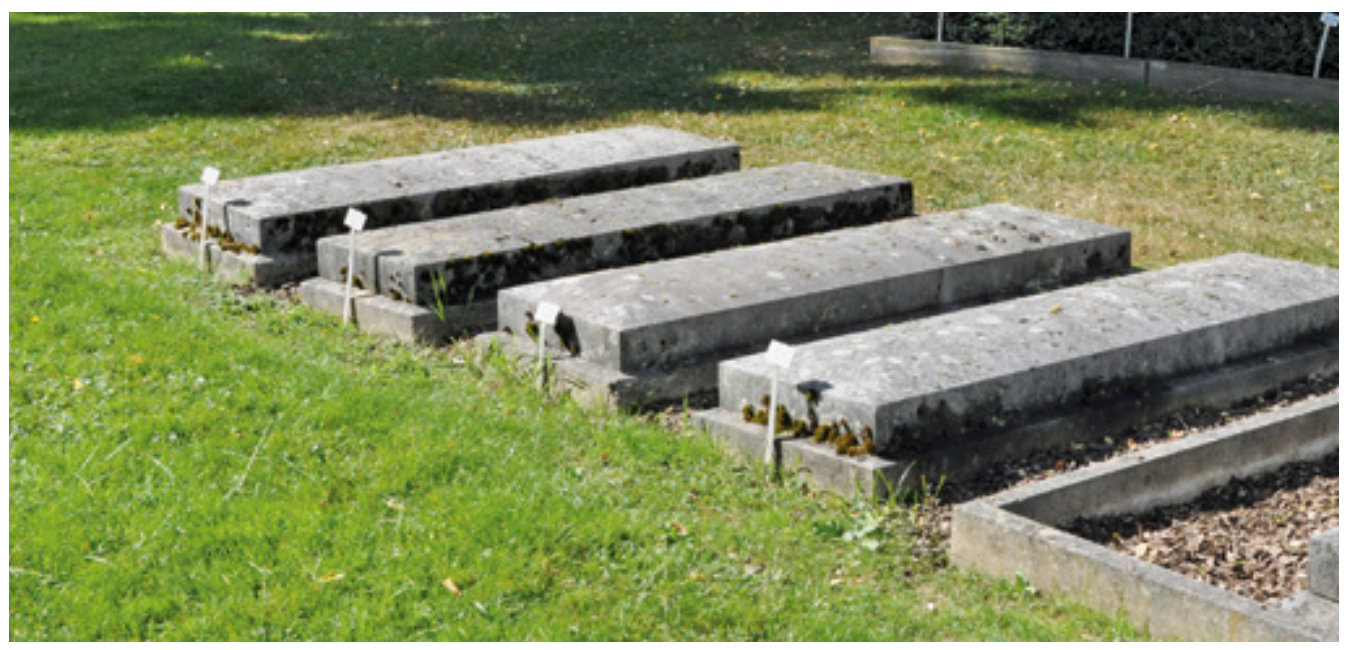

Abb. 2: Grabmäler, erste Hälfte des Ig. Jahrbunderts. Genf, Friedhof von Plainpalais.

Es gibt allerdings eine Ausnahme: das Grab des Duc de Rohan in der Genfer Kathedrale Saint-Pierre (I646). ${ }^{7}$ Als militärischer Alliierter genoss Rohan den Respekt der Genfer Regierung. So stimmte sie zu, dass die Familie des Herzogs nicht nur ein Denkmal, sondern auch eine Statue in der Kirche errichten durfte, was jedoch mitunter zu ideologischem Widerspruch führte. Eine Quelle berichtet, dass I659 katholische Pilger vor dessen Statue gebetet hätten, im Glauben, es sei ein Heiliger. ${ }^{8}$ Man weiß nicht, ob die Geschichte wahr ist oder ob sie nur für die Regierung als Vorwand diente, um den Bau einer Palisade zu rechtfertigen. Es war jedenfalls die einzig existierende Statue in den Genfer Kirchen, d. h. zusätzlich zu Saint-Pierre, Saint-Germain, La Madeleine, la Fusterie und Saint-Gervais, und ihre Qualität war, wie eine historische Aufnahme zeigt, gering. ${ }^{9}$

Wenn das Beten vor einer Statue als Götzendienst betrachtet wurde, so galt dies auch im Hinblick auf Grabmäler. Der historische Genfer Friedhof außerhalb der Stadtmauern im Gebiet Plainpalais bietet dafür deutliche Beispiele. Bis zum 19. Jahrhundert waren Grabmäler inexistent, da der Totenkult verboten war. $^{\text {. }}{ }^{\circ} \mathrm{Un}$ ter der französischen Besetzung wurde $\mathrm{I}^{8} \mathrm{O} 4$ ein Dekret zur Genehmigung der Grabsteine erlas-

S. 235); gegen neue Grabmäler im Friedhof von Plainpalais I8I8 (D. Ripoll, Ci-gît J. C.: la tombe de Jean Calvin au cimetière des Rois, in: Il più dolce lavorare che sia: mélanges en l'honneur de Mauro Natale (hrsg. von F. Elsig/G. Extermann/N. Etienne), Milano 2009, S. 453-457, 453); gegen das Pictet-de-Rochemonts-Denkmal i825 (BuysSENS, La question de l'art (zit. Anm. I), S. 37I); endlich gegen das zweite Rousseau-Denkmalprojekt I826 (ebenda S. 372).

7 J.-A. Godoy, Le mausolée du duc Henri de Rohan (I579-I638): notes sur son effigie et son armure posthumes, in: Genava, 53, 2005, S. I23-I53. Das Wort „Kathedrale“ blieb in der Alltagssprache, obgleich es natürlich keinen Bischof mehr gab.

8 D. Art, La chapelle et le mausolée du duc Henri de Rohan, in: Saint Pierre. Ancienne cathédrale de Genève, Genève I892, S. 9-I42, I05-IO7.

9 Ebenda, S. I06 mit Abbildung. Die heutige Statue ist eine bemerkenswerte Marmorskulptur von Charles Iguel (1827-I897), Schüler von François Rude; siehe, Godoy, Le Monument (zit. Anm. I), S I44-I5I; G. Extermann, Iguel, Charles, in: Artistes à Genève: de I400 à nos jours (hrsg. von K. Tissot), Genève 20IO, S. 332-333.

Io L. Blondel, Le cimetière de Plainpalais, Genève 1957, S. 6. 


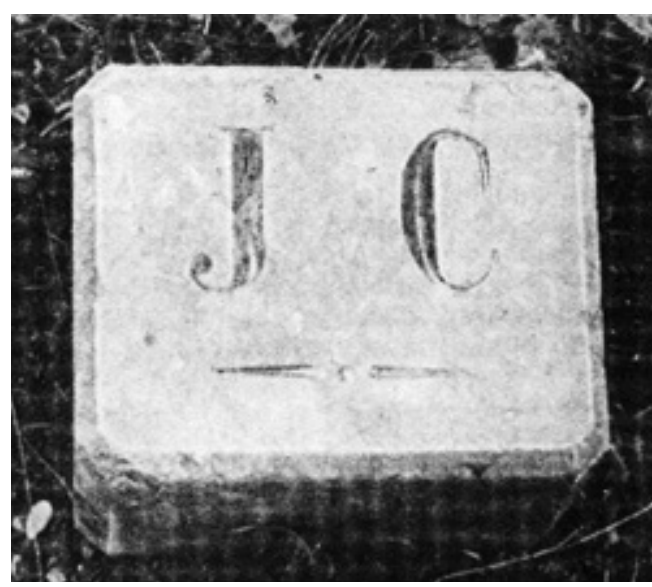

Abb. 3: Calvin's Denkmal, ante I850. Genf, Friedhof von Plainpalais.

sen. ${ }^{\text {II }}$ Die ersten auffallend schlichten Denkmäler entsprachen folgenden Typen: Steinplatten mit Inschrift (Abb. 2), stilisierten Sarkophagen, verkürzten Pyramiden oder verkürzten Säulen.
Ein interessanter Fall ist hierbei jener des Grabsteins für Jean Calvin (1509-1564), den Begründer der Universität, dem zunächst kein Denkmal errichtet wurde, um kultischer Verehrung keinen Raum zu bieten. Im I9. Jahrhundert schuf die Regierung, unter dem Druck holländischer Pilger, ein symbolisches Grab: einen Stein mit den Initialen J. C. (für Jean Calvin, Abb. 3). ${ }^{\text {I2 }}$ Dieses Denkmal ist das bescheidenste aller Grabmäler des Friedhofs und kann als minimalistisches Kunstwerk betrachtet werden. Die Regierung ließ dann später eine Absperrung errichten und eine dichte Bepflanzung vornehmen, vielleicht um die Besucher daran zu hindern, Blumen niederzulegen (Abb. 4). Damit wurde es zu einem symbolischen Grabmal, das einen minimalistischen Kenotaph verdeckt.

Im Gegensatz dazu erweckte das gemalte Porträt nicht dasselbe Misstrauen, wie das in Stein gehauene. ${ }^{13}$ I702, anlässlich der Renovierung der

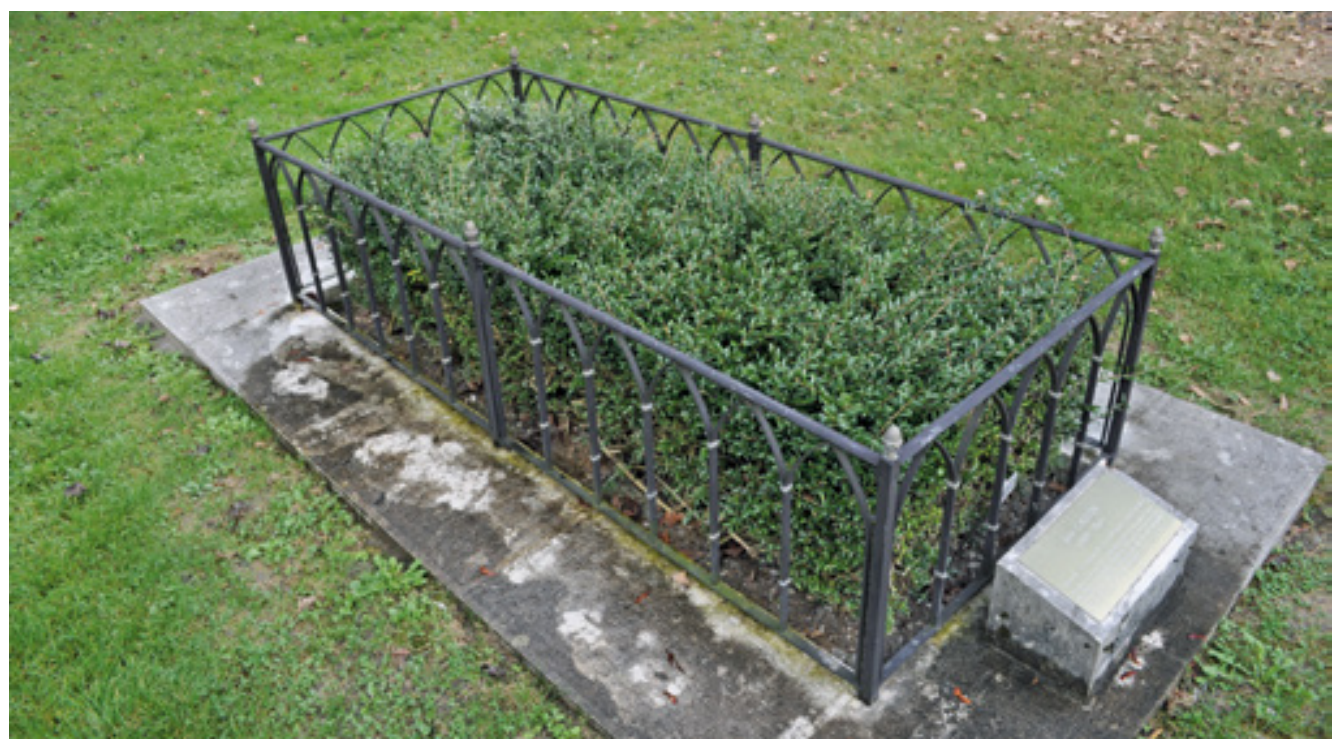

Abb. 4: Calvins Pseudo-Grabmal. Genf, Friedhof von Plainpalais.

II D. Ripoll, Ci-git J. C. (zit. Anm. 6), S. 453.

I2 Solche Inschrift, die unabsichtlich Christusinitialen wiederholt, klingt aber zweideutig. Ebenda, S. 454-455.

I3 D. Buyssens, Introduction; Le premier musée de Genève, in: „La bibliothèque étant un ornement publique ... “ Réforme et embellissement de la bibliothèque de Genève en 1702 (hrsg. von D. Buyssens/T. Dubois), Genève 2002, S. I-6, 9I-I3I, 94-98. Mit der Porträtgalerie erhielt die Bibliothek auch eine Wunderkammer („Cabinet de curiosités", S. IO3-I3I). 


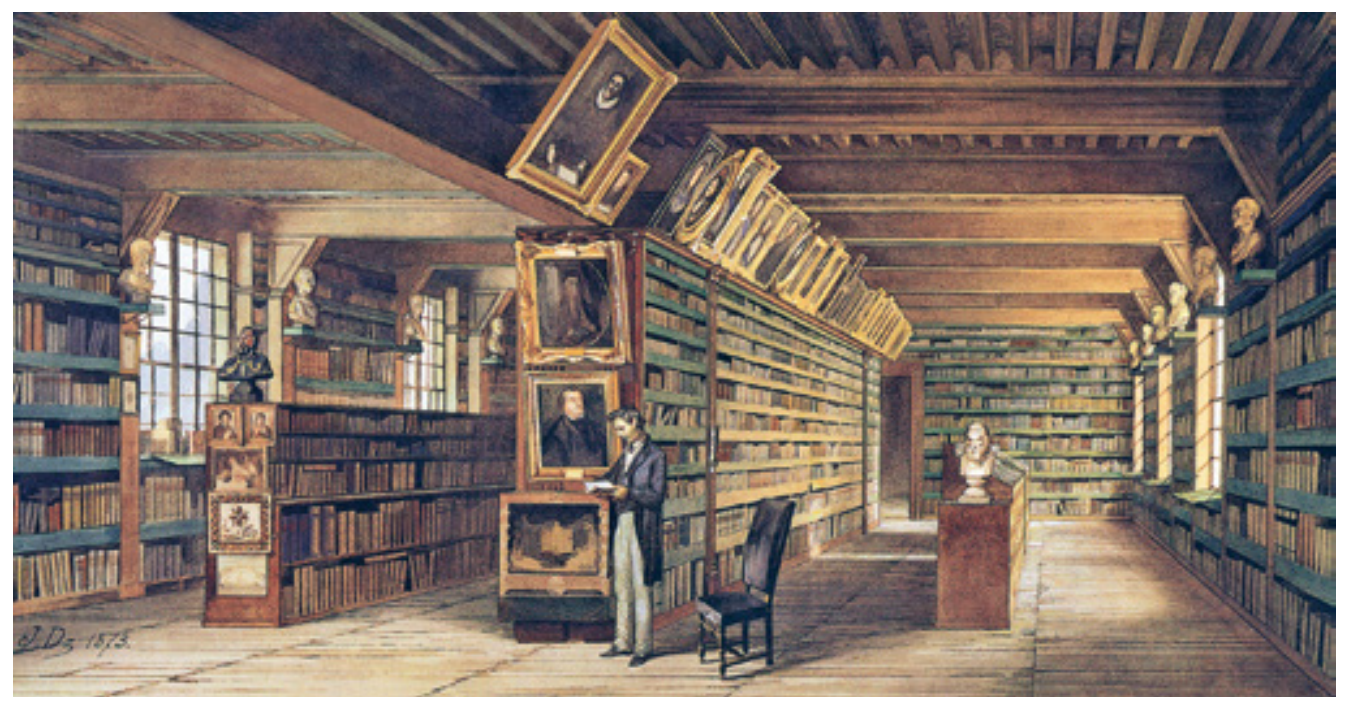

Abb. 5: Jean-Jacques Dériaz, Grande Salle von der Bibliothek von Saint-Antoine, I873, Gouache. Genf, Bibliothèque de Genève, inv. Tabl. 201.

Akademiebibliothek, entschied man sich für gemalte Bildnisse im Rahmen einer neuen Porträtgalerie. Drei gesellschaftliche Gruppen von Honoratioren sind dort vertreten: Pfarrer und Professoren, das heißt Mitglieder der Akademie; Wissenschaftler und Schriftsteller, deren Werke in der Bibliothek vorhanden waren; verbündete Politiker: In dieser Kategorie gibt es auch eine Skulptur, eine Büste von Heinrich IV.

Porträtskulptur kann man in Form von Antikenkopien finden, beispielsweise einer Serie von zwölf römischen Kaisern, die auf Bücherregalen standen. ${ }^{14}$ Man erkennt sie, sowie auch eine Büste von Homer, auf einem späteren Gemälde von Jean-Jacques Dériaz (1873, Abb. 5). is Solche Kopien erinnern uns, dass die Ausbildung im Col- lège, dem Gymnasium, das mit der Universität von Calvin gegründet wurde, nur in lateinischer und griechischer Sprache stattfand. ${ }^{16}$ Antike Kopien gab es aber auch in anderen Bibliotheken, so zum Beispiel in jener von Guillaume Favre (I770-185I), I82I gebaut und mit römischem Buntmarmor, Mobiliar von Percier \& Fontaine und Bronzekandelabern ausgestattet (Abb. 6). ${ }^{17}$

Durch den Einfluss der französischen Kultur entstanden am Ende des I8. Jahrhunderts zwei Porträts von Zeitgenossen. Das erste von Charles Bonnet (I720-I793), einem Genfer Naturwissenschaftler, wurde von Jean Jacquet (I754-I839) gemeißelt (Abb. 7) $\cdot^{18}$ Es lässt den dominanten Einfluss von Houdon erkennen, mit einem milden Naturalismus, der sich im Gesichtsausdruck

I4 Ebenda, S. IoI; Buyssens, La question de l'art (zit. Anm. I), S. 39. Die zwölf Büsten sind ein Geschenk von Jacob Vernet von 1742 .

I5 P. Monnoyeur, Du galetas du XVIe siècle à la grande salle de I702: la bibliothèque du Collège Saint-Antoine, in: „La bibliothèque étant un ornement public“ (zit. Anm. 13), S. 45-79, 73-76.

i6 Montandon, Le développement de la science (zit. Anm. 4), S. 64. Auch L. ThÉvenaz, Histoire du collège de Genève, Genève i896, S. 59-60.

I7 Natale, Le goût et les collections (zit. Anm. I), S. 58.

I8 Buyssens, La question de l'art (zit. Anm. I), S. 24I-242. Die Büste wurde in der Genfer Ausstellung von 1789 präsentiert. C. Magnusson, Jean Jacquet et ses émules obscurs: les sculpteurs d'ornement à Genève au XVIIIe siècle, Doktorarbeit, Université de Lausanne, 20II, S. I94-198. 


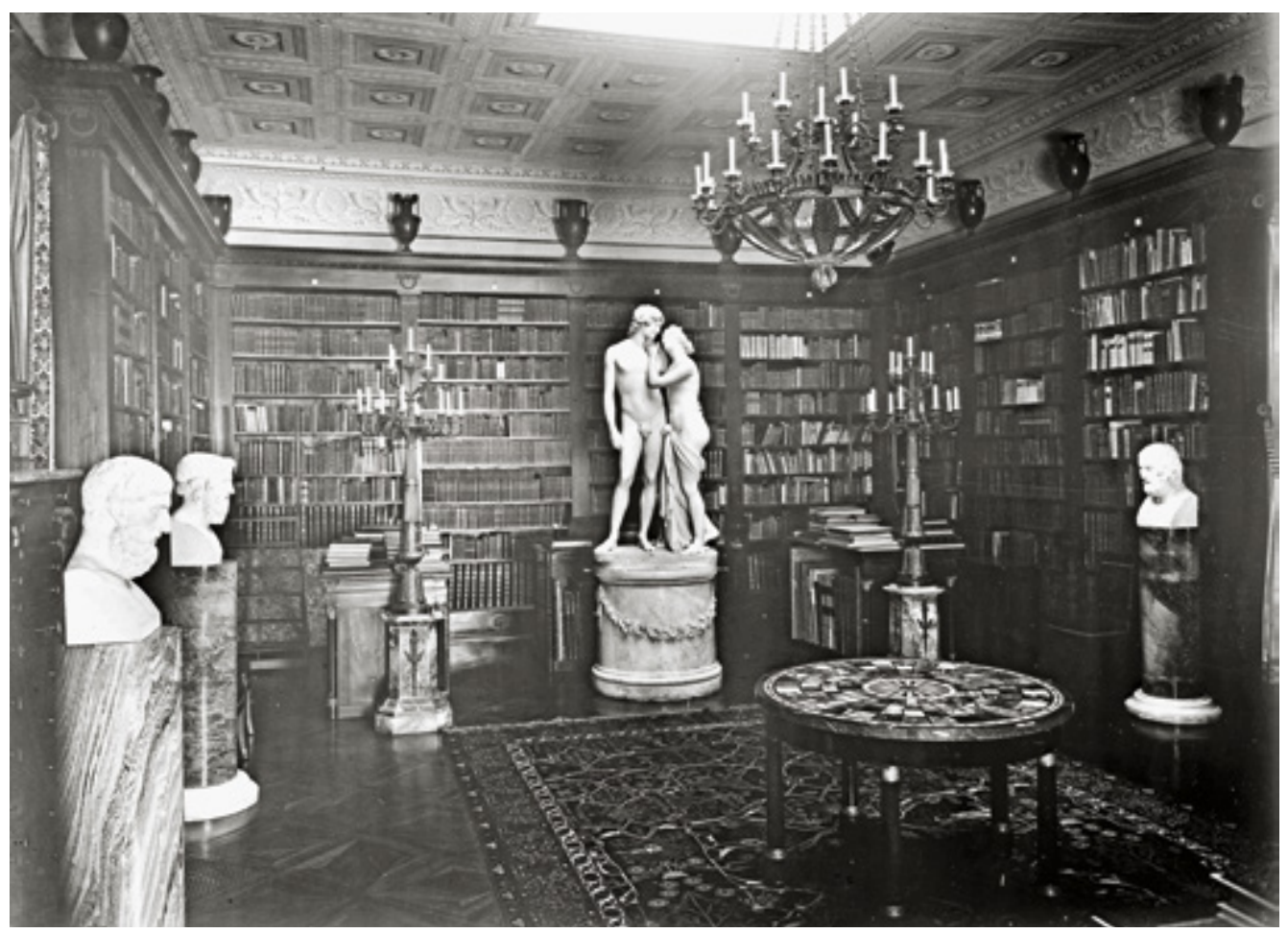

Abb. 6: Bibliothek von Guillaume Favre mit Canovas Gruppe im Zentrum, ante I9II.

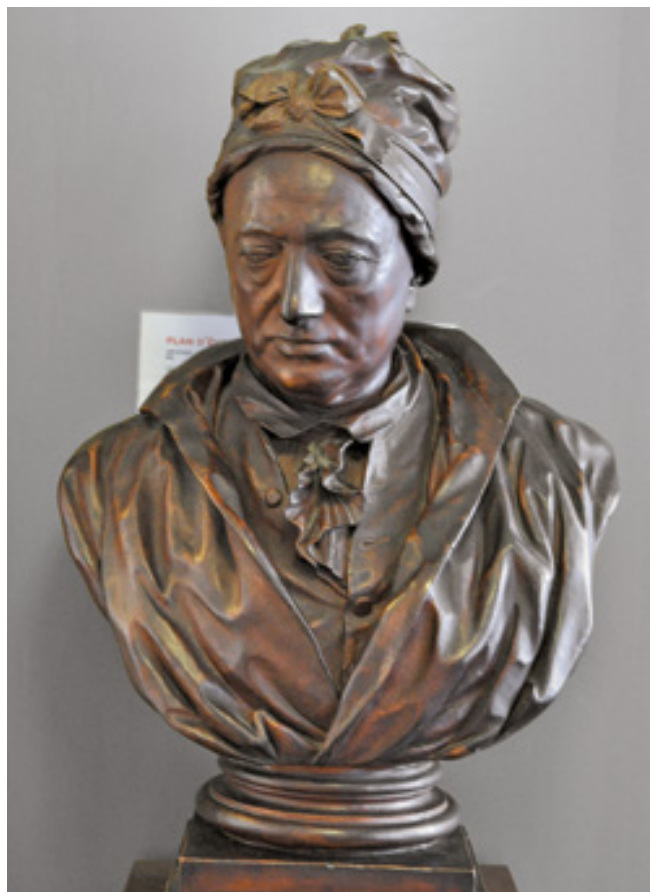

Abb. 7: Jean Jacquet, Büste von Charles Bonnet, ante 1789 , Genf, Bibliothèque de Genève, inv. 0307. 
- Bonnet war fast blind - und in der Hauskleidung des Porträtierten widerspiegelt. ${ }^{19}$ Das zweite Porträt ist tatsächlich von Houdon: Es handelt sich um eine Kopie seiner berühmten Büste von Jean-Jacques Rousseau (1712-1778), der hier als Schriftsteller dargestellt wird. ${ }^{20}$ Diese beiden
Büsten sind die einzigen skulpturalen Darstellungen von Zeitgenossen in der akademischen Bibliothek vor der Französischen Revolution. Ihnen gegenüber findet man einige antike Büstenkopien sowie eine Vielzahl von Gemälden.

\section{NEUE BEGEISTERUNG FÜR SKULPTUR IM XIX. JAHRHUNDERT}

Nach der Revolution und dem Genfer Anschluss an Frankreich (1798-I8I4) verstärkte sich das Interesse der Patrizier an Skulptur und italienischer Kunst. Der Finanzier Jean-Gabriel Eynard (1775I863) ist ein gutes Beispiel für diese Entwicklung: Als überzeugter Bonapartist bereicherte er sich in der Toskana unter Napoleons Schwester Elisa Baciocchi und ließ sich in Genf ein Haus bauen, das erste, das man Palais nannte. ${ }^{21}$ Der Florentiner Giovanni Salucci (I769-I845) zeichnete die ersten Pläne und der ebenfalls aus Florenz stammende Bildhauer Lorenzo Bartolini (I777I850) schuf einige Statuen für die Innendekoration. ${ }^{22}$ Mehr als Bartolini setzte allerdings Antonio Canova neue ästhetische Normen innerhalb dieser internationalen Strömung. Die Genfer Patrizier begeisterten sich für seine Arbeiten und boten ihm die Mitgliedschaft der Genfer Société des Arts an. ${ }^{23}$ Für diese Institution wurden Gipskopien der „Drei Grazien“ und der „Tänzerin“ erworben und der Künstler selbst steuerte dazu eine Kopie seiner „Venus Italica“ bei. ${ }^{24}$ Auch in den Patrizierhäusern fanden sich Marmorkopi-

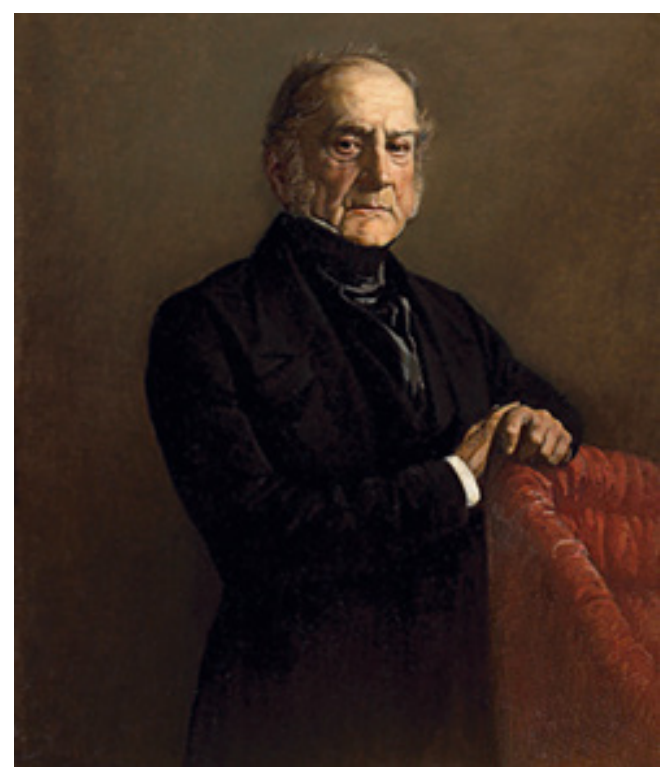

Abb. 8: Barthélémy Menn, Guillaume Favre, I845 ca., Holzmalerei. Genf, Bibliothèque de Genève, inv. 0086.

en, so z. B. in der Villa von François Bartholoni am Genfer Seeufer mit vier Statuen. ${ }^{25} \mathrm{Zu}$ guter Letzt gelang Guillaume Favre I823 in Neapel ein

I9 C. Fontaine-Borgel, A la mémoire du sculpteur Jean Jacquet: 1754-I839, Genève 1887, S. I8-20. Der Autor vergleicht Jacquets Büste zu Greuze, Reynolds, Pigalle und Houdon, was ihre Abhängigkeit vom Französischen künstlerischen Milieu beweist.

20 Man erkennt Rousseaus Porträt in einem der Gemälde von Jean-Jacques Dériaz, siehe. P. Monnoyeur, Du galetas (zit. Anm. I6), S. 76.

2I Über Eynards Tätigkeit in Italien siehe E. Chapuisat, Jean-Gabriel Eynard et son temps, Genève I952, S. 22-39, aber vieles ist noch unbekannt. Über Eynards Palais siehe A. Corboz, Le palais Eynard à Genève: un „design“ architectural en I817, in: Genava, 23, S. 195-275.

22 G. Extermann, Attività di Lorenzo Bartolini in Svizzera, in: Neoclassico, 27-28, 2005 (2007), S. 44-89.

23 Lapaire, La sculpture à Genève (zit. Anm. I), S. Io4.

24 P.-A. Guerretta, Pierre-Louis De la Rive ou la belle nature: vie et oeuvre peint, Genève 2002, S. II7.

25 Die Kopien sind Pauline Bonaparte, Amor und Psyché, Hebe aus dem Modell von Forli und die Danzatrice, siehe J.-J. Rigaud, Renseignements sur les beaux-arts à Genève, Genève i876, S. 356-357. 
Kauf eines originalen Werkes, Venus und Adonis, für seine Bibliothek. Diese sinnliche Gruppe steht in einem merkwürdigen Kontrast zu den ernsthaften Büsten der griechischen Philosophen und zu Favres Charakterstrenge (Abb. 6 und 8). ${ }^{26}$ Das Ensemble der Bibliothek ist jedoch eines der schönsten Beispiele des Neoklassizis- mus in Genf: Es zeigt einerseits den zunehmenden Luxus der Patrizierhäuser zu Beginn des I9. Jahrhundert und andererseits ihren Willen, dem Modell einer künstlerischen Exzellenz zu folgen und sich damit in einer kosmopolitischen Gesellschaft zu positionieren.

\section{GEN FER KOSMOPOLITISMUS}

Für eine kleine Stadt, die ein winziges Gebiet umfasst und die von den enormen Mauern erdrückt wird - die Oberfläche der Festungsmauern ist größer als die Oberfläche der Stadt selbst -, ist die Pflege internationaler Beziehungen lebenswichtig (Abb. 9). ${ }^{27}$

I. Das wichtigste Netzwerk war natürlich das finanzielle. Die Genfer Bankiers, die meistens aus toskanischen und südfranzösischen Flüchtlingsfamilien kamen, verfügten über Niederlassungen in Paris, London und später Berlin und St. Petersburg. ${ }^{28}$

2. Ein weiteres Netz betrifft direkt unser Thema. Es ist das wissenschaftliche, das sich im I8. Jahrhundert verstärkte, aber schon mit Calvin, der Kontakte mit Intellektuellen aus ganz Europa pflegte, entwickelte. Die Genfer Elite investierte massiv in die Naturwissenschaften (Botanik, Physik, Chemie, Mineralogie usw.) und erlangte dadurch großen Ruhm in den europäischen intellektuellen Kreisen. ${ }^{29}$ Dabei wurde das akademische Umfeld vom Genfer Patriziat monopolisiert. Die Elite sah ihre eigenen moralischen Werte in denen der Wissenschaft gespiegelt: der Suche nach der Wahrheit (mit religiösen Nuancen) und der Pflicht, diese Wahrheit zu übermitteln. ${ }^{30}$

3. Das dritte Netzwerk betrifft die Künste. Dieses erweiterte sich stark in den Jahren der Restauration (I815-I846). Dabei ist der Erwerb der Canova-Statue durch Guillaume Favre ein Meisterstück, gelang es hier doch sogar, Zar Nikolaus II., der ebenfalls an der Skulptur interessiert war, zu übertrumpfen. ${ }^{3 \mathrm{I}}$ Hinzuzufügen ist, dass die strengen Formen des Neoklassizismus den calvinistischen Werten entsprachen und sein Antikenkult die Vorliebe für Skulptur förderte.

\section{DAS ERSTE SCHOLAR'S MONUMENT}

Im Jahr I8I7 begann Augustin Pyrame de Candolle (I778-I84I) damit, in der Promenade des Bastions einen botanischen Garten anzulegen.
In diesem ließ er eine Orangerie errichten und dort sechs Büsten von Genfer Naturwissenschaftlern aufstellen (Abb. I ${ }^{32}$. Von links nach

26 Guillaume Favre folgte einer Ausbildung in Geologie wie de Saussure, aber interessierte sich später für zahlreiche und komplexe Forschungsthemen wie: die Literatur der Goten, der Traktat De re militari von Robertus Valturius, die Drückerei in Genf vor der Reformation, die punischen Inschriften usw.

27 Natale, Le goût et les collections (zit. Anm. I), S. I-3.

28 H. LÜThy, La banque protestante en France, de la Révocation de l'Edit de Nantes à la Révolution, I, Paris I959, S. $39-48$.

29 Montandon, Le développement de la science (zit. Anm. 4), S. 68-70.

30 Ebenda, S. 70-77.

3I J. Adert, Notices sur la vie et les écrits de Guillaume Favre, Genève I856, S. 34-36. 

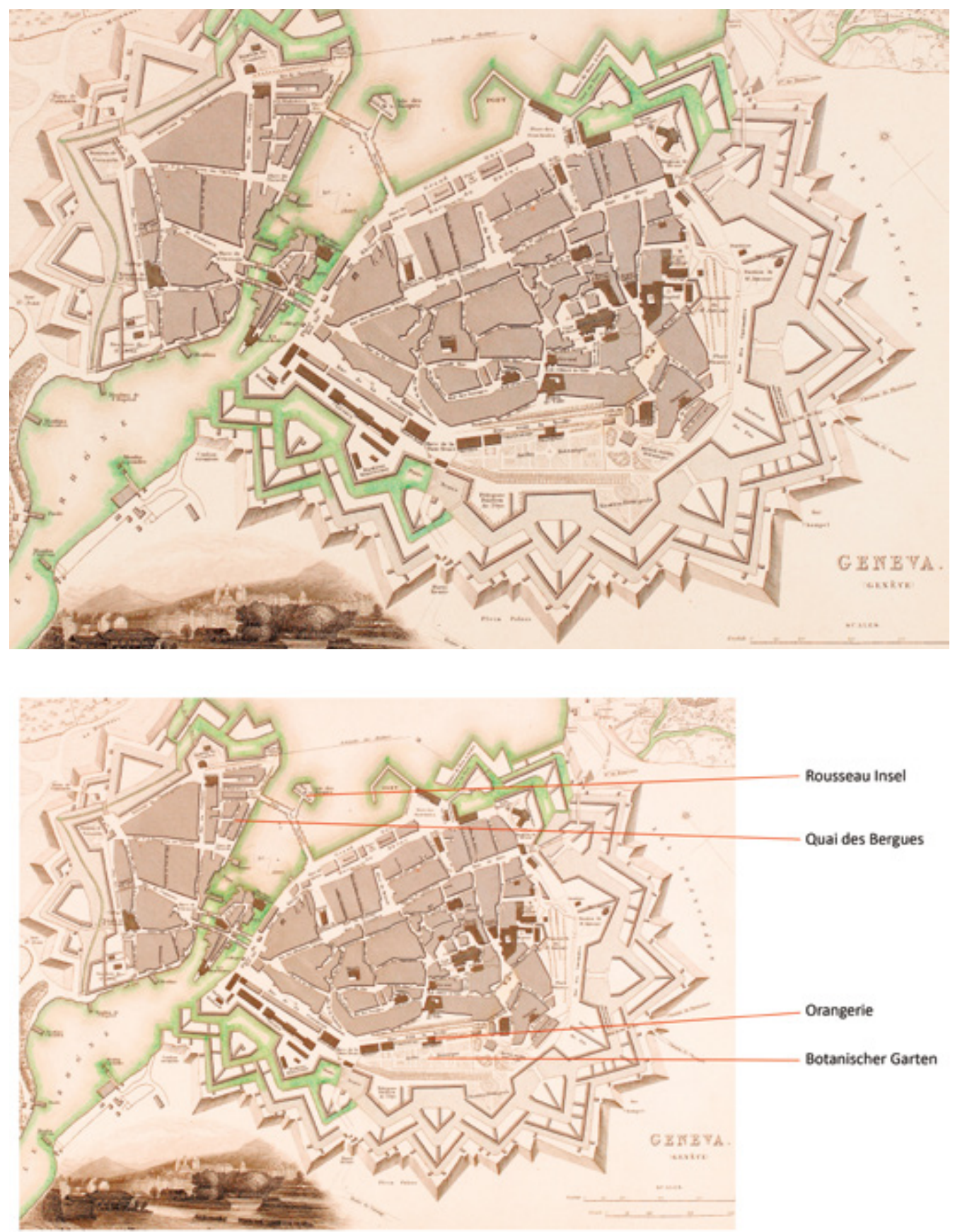

Abb. 9: B. R. Davies, Plan der Stadt Genf, ante 1840. 
rechts: Dominique Chabrey (I6I0-I659), Horace-Bénédicte De Saussure (1740-1799), die schon porträtierten Charles Bonnet \& Jean-Jacques Rousseau, Abraham Trembley (I7IO-I784) und Jean Sénebier (1749-1809).

Verschiedene Künstler arbeiteten an den Büsten. ${ }^{33}$ Für de Saussure wählte man Luigi Zandomeneghi (I778-I850), einen Canova-Schüler, der auch das Grab seines Meisters in Santa Maria dei Frari in Venedig schuf. Eine solche Wahl war natürlich die direkte Folge der Popularität Canovas in Genf. Trembley und Sénebier wurden zwei unbekannten Künstlern aus Carrara anvertraut. Ausschlaggebend hierfür war die
Fürsprache Pellegrino Rossis (I787-I848), Juraprofessor und erster katholischer Akademiker an der Genfer Universität. Rossi stammte aus Carrara und wählte offensichtlich zwei Landsmänner. Ein anderer Bildhauer aus Carrara, Pietro Tenerani (1789-I869), meißelte später eine Büste von Rossi, von welcher eine Kopie der Universitätsbibliothek geschenkt wurde. ${ }^{34}$ Es war ein Auftrag von Rossis Freund, Auguste de la Rive (I80I-I873), Professor für Physik, Rektor und Politiker, dessen Büste aus Marmor auch in der Bibliothek steht. Anhand dieser Porträts lassen sich Verflechtungen im sozialen, beruflichen und familiären Bereich erkennen.

\section{EIN NEUER BILDHAUER: JAMES PRADIER}

Für die Büsten von Rousseau und Bonnet wählte man einen Genfer Künstler, James Pradier (1790-I852).35 Pradier hatte eine beispielhafte Karriere vorzuweisen: Er arbeitete zuerst unter Jean Jacquet an der Genfer École de dessin, dann in Paris unter François-Frédéric Lemot, wo er I8I3 den Prix de Rome gewann. ${ }^{36}$ Da Genf zu dieser Zeit noch Teil von Frankreich war, konnte Pradier die Bourse de pensionnaire erhalten. Zurück in Paris setzte sich sein Aufstieg mit einer Stelle an der École des Beaux-Arts und einem Lehrstuhl am Institut de France fort.

Im Vergleich zu den Büsten von Rousseau und Bonnet in der akademischen Bibliothek erscheint Pradiers Version für die Orangerie heroischer und schlichter zugleich (Abb. 8 und ro). ${ }^{37}$ Seine wenig originelle, einfache Sprache setzte sich durch und machte ihn zum Referenzporträtisten der ersten Hälfte des I9. Jahrhunderts. Als Candolle, der Begründer der Orangerie, I84I starb, beauftragte man Pradier damit, auch seine Büste anzufertigen. ${ }^{3}$ Diese wurde vor den sechs Porträts der Orangerie aufgestellt, wie die eines Professors vor seinen Kollegen (Abb. I). Candolles Porträt ist luxuriöser als die anderen, es ist größer, in Bronze gegossen und steht auf

32 A. Corboz, La place Neuve, composition progressive, in: Le Musée Rath a I5O ans (hrsg. von M. Pianzola), Genève 1976, S. 9-36, 23-24; Natale, Le goût et les collections (zit. Anm. I), S. 8o.

33 A. P. de Candolle, Second rapport sur la fondation et l'état du Jardin Botanique de Genève, fait à l'assemblée générale des Souscripteurs et Donataires de l'Etablissement, le 30 avril I82I, Genève I82I, S. I2-I4. Ich danke Vincent Chenal für den Hinweis zu dieser Publikation.

34 F. GARDy, Les bustes de Rossi et de Cavour conservés à la Bibliothèque de Genève, in: Genava, 8, I930, S. I2I-I27.

35 Ursprünglich Jean-Jacques Pradier: Die Namensänderung ist Beispiel einer verbreiteten, konfessionell bedingten Anglophilie.

36 C. LAPAire, James Pradier (1790-1852) et la sculpture française de la génération romantique, Milano 20IO, mit Bibliografie.

37 Ebenda, S. 249-250, N. I6-17. Pradier wurde ziemlich stark durch Lorenzo Bartolini beeinflusst, cf. G. ExTERMANN, „Un talent digne de Périclès“. Lorenzo Bartolini e la Grecia, in: Lorenzo Bartolini, scultore del bello naturale (Austellungskatalog Florenz, Galleria dell'Accademia, hrsg. von F. Falletti, S. Bietoletti, A. M. Caputo), Firenze 20II, S. 72-85, 76-78.

38 Lapaire, James Pradier (zit. Anm. 36), S. 318-319, N. 196. 


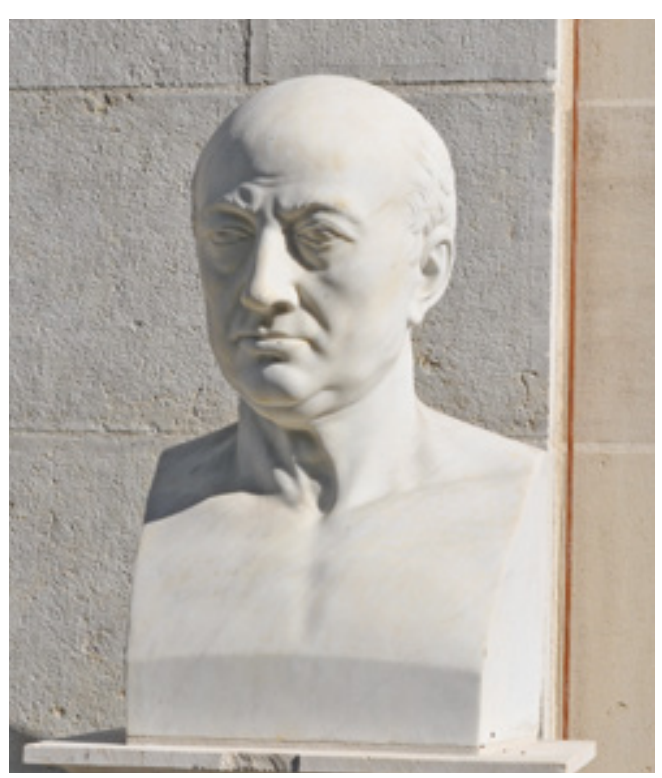

Abb. Io: James Pradier, Büste von Charles Bonnet, I8I9I822, Marmorkopie (Anfang des XX. Jh.). Genf, botanisches Konservatorium.

einem mit Figuren und Girlanden geschmückten Sockel. Es sollte als Modell für weitere Genfer Wissenschaftlerbüsten dienen, welche danach im Parc des Bastions ihren Platz fanden.

Mittels der Büsten wurden die Bastions optisch zum wissenschaftlichen und künstlerischen Zentrum (Abb. II). In der Tat hatte die Société des Arts ihren Sitz nur wenige Meter davon entfernt. Es war ein Verein von Gelehrten und Künstlern, deren Ziel es war, verschiedene soziale Milieus miteinander in Verbindung zu bringen: ${ }^{39}$ die Künstler und Handwerker aus dem Kleinbürgertum und populäre Schichten mit den Wissenschaftlern vom Patriziat. ${ }^{40}$ Viele Büsten von Pradier wurden, bevor sie ihren endgültigen
Platz fanden, von der Société des Arts ausgestellt. Der Künstler fertigte auch I826 das posthume Porträt seines Direktors Marc-Antoine Pictet (1752-I825), Professors für Physik. ${ }^{4 I}$

Dieses wissenschaftliche und künstlerische Zentrum wurde noch verstärkt durch die Einweihung des Musée Rath I825 und später, I875, durch die Errichtung der neuen Universität gegenüber der Orangerie und den Umzug der alten Bibliothek von Saint Antoine. Die Bastions stellten somit eine Verbindung zwischen verschiedenen Bauwerken her, die eine künstlerische und wissenschaftliche Funktion haben (Orangerie, Musée Rath, Universität, Akademische Bibliothek und Société des Arts), und bildeten zugleich eine Bühne für die Porträts von Gelehrten.

Die Architektur der Orangerie mit fünf schmucklosen Arkaden erscheint schlicht und streng. Diese Charakteristik wurde von Zeitgenossen gepriesen, denn sie wurde als für Genf angemessen betrachtet. So schrieb de Candolle: Malgré la modestie appropriée à notre petitesse [sic], il convenait cependant de donner à ce bâtiment une architecture un peu soignée et un style monumental. ${ }^{42}$

Das Gebäude wurde von Guillaume-Henri Dufour (1787-1875) entworfen. Als Ingenieur der École Militaire de Saint Cyr und ehemaliger Kapitän unter Napoleon trieb er die Modernisierung von Genf während der Restauration entscheidend voran. Sein Schüler Samuel Vaucher (1798-1877) errichtete an der Südseite das $\mathrm{Mu}$ sée Rath und die Gebäude der Rue de la Corraterie, und Dufour überwachte den Bau des Palais Eynard, der teilweise von Vaucher geplant wurde. ${ }^{43}$ Im Norden der Stadt plante Dufour die

39 Über die Société des Arts siehe Natale, Le goût et les collections (zit. Anm. I), S. 74-79.

40 Dasselbe Prinzip einer Kooperation zwischen Kunst und Wissenschaft wird im „Discours préliminaire“ der Encyclopédie von Diderot \& d'Alembert ausgedrückt: „les artisans reçoivent l'aide de savants pour perfectionner leur ouvrages“, zit. in D. Buyssens, Galerie de portraits et collections iconographiques, in: Patrimoines de la Bibliothèque de Genève: un état des lieux au début du XXIe siècle (hrsg. von D. Buyssens), Genève 2006, S. I9. 


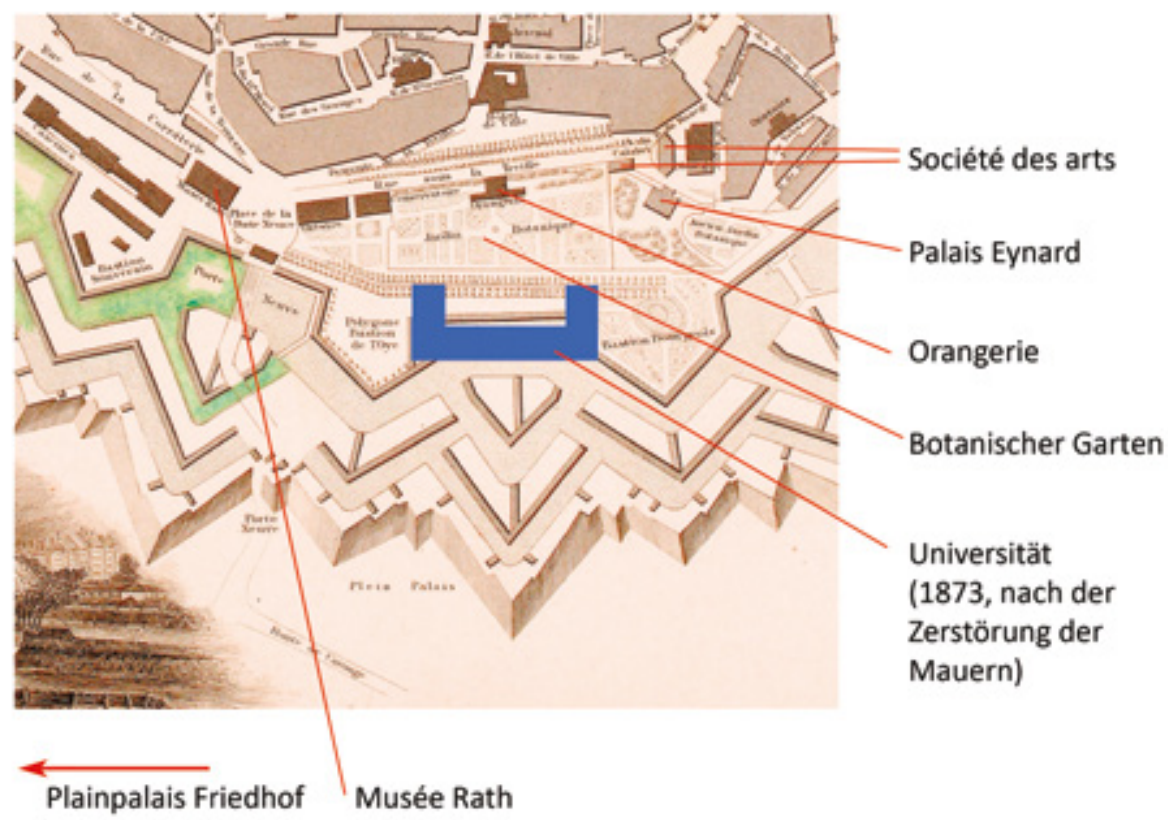

Abb. II: B. R. Davies, Plan der Stadt Genf. Details des botanischen Gartens.

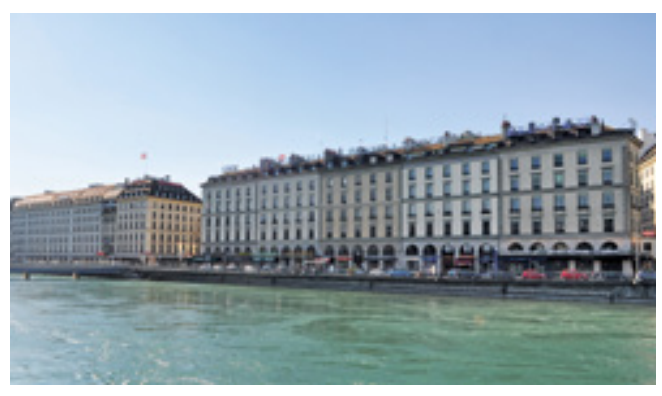

Abb. 12: Genf, Quai des Bergues.
Seeufer (Quai des Bergues und Grand Quai), eine neue Brücke, ein neues Hotel und später, als Höhepunkt, einen Platz für Rousseaus Denkmal ${ }^{44}$. Victor Hugo fand diese Modernisierung abscheulich und beschrieb sie 1839 als un quai blanc, orné d'une ribambelle de grandes casernes blanches que ces bons Genevois prennent pour des Palais (Abb. 12). ${ }^{45}$ Trotzdem ist diese schlichte Architektur charakteristisch für das Erscheinungsbild des internationalen Genfer Neoklassizismus, dessen Vertreter in der Skulptur Pradier war.

\section{DIE AKADEMIKER - MITGLIEDER DES PATRIZIATS}

Außer Rousseau gehörten alle vor der Orangerie dargestellten Professoren zum Patriziat. Das ist wenig überraschend, weil das akademische Milieu, wie oben dargelegt, durch die Repräsentanten dieser sozialen Kategorie monopolisiert wurde. Diese Besonderheit konnte auch auf eine subtile Art die Legitimation der Regierungsform bewirken.

Die akademische Karriere stand theoretisch allen offen, denn das Collège war kostenlos. Aber

44 Corboz, La „refondation“ (zit. Anm. I), S. 65-74.

45 V. Hugo, Euvres complètes. Voyages (hrsg. von G. Rosa, J. Seebacher), Paris 1987, S. 685 (Brief vom 24. September I839). 
diese Ausbildung stellte einen ersten Schritt in Richtung Pfarramt und Regierungsfunktionen dar, Berufe die de facto für die Patrizier reserviert waren. Und eine wissenschaftliche Karriere, ohne ausreichende finanzielle Unterstützung und ohne Zugang zum internationalen Netzwerk, zu dem das Patriziat viele Kontakte hatte, war nahezu unmöglich. Akademische Professoren teil- ten diesen Standpunkt wahrscheinlich nicht und glaubten aufrichtig, dass ihre Stelle der Beweis einer natürlichen Überlegenheit war. ${ }^{46}$ Jedenfalls ist diese Reihe von Büsten vor der Orangerie eine Würdigung der politischen, ökonomischen und intellektuellen Genfer Elite, die sich hier wirkungsvoll selbst inszeniert.

\section{EIN EIN DRINGLING: JEAN-JACQUES ROUSSEAU}

Inmitten dieser steinernen Gesellschaft erscheint Rousseau wie ein Eindringling. Er war kein anerkannter Naturwissenschaftler und gehörte nicht zur Aristokratie. Seine Schriften waren nicht elitär, sondern wurden im Gegenteil von allen Genfer Gesellschaftsschichten gelesen. Seine literarischen Werke haben einen sozialen Protest gegen das Ancien Régime ausgelöst und wurden von einem Großteil der Patrizier als gefährlich angesehen.

Zur Zeit der französischen Revolution wurde in Genf ein Denkmalprojekt für Rousseau vorgeschlagen. Man verwandelte den Parc des Bastions in ein Lycée National für die Parade und weihte hier 1794 eine Büste von Rousseau auf einer Säule ein, ein Werk des Jean Jacquet. ${ }^{47}$ Es war tatsächlich das erste öffentliche Denkmal in Genf, hatte aber nur ein kurzes Leben. Während der Terrorherrschaft 1794 wurden nicht weit entfernt von ihm einige Genfer Patrizier hingerichtet. ${ }^{4}$ Zur Zeit der Restauration wollte die Regierung dieses Monument, Symbol der Revolution, sofort entfernen. Die Einweihung der Orangerie war also ein guter Vorwand.

Die Büste Pradiers, die ebenfalls Rousseau darstellt, wurde hingegen ihrer revolutionären Konnotation entkleidet und inhaltlich neu besetzt. Hier ist Rousseau nicht der Schriftsteller wie in der akademischen Bibliothek, ebenso wenig der Philosoph, wie vormals im Parc des Bastions, sondern ein Botaniker, der in eine Gruppe von Genfer Gelehrten integriert wird, um so ganz ungefährlich - das heißt unpolitisch - zu erscheinen.

Diese reduzierte Version Rousseaus wurde von vielen Genfern als unbefriedigend empfunden, sowohl vom Volk, das ohne politische Einflussmöglichkeiten war, als auch vom liberalen Flügel des Patriziats, der in Rousseau einen besonders verdienten Bürger der Stadt sah. ${ }^{49}$ An den Diskussionen beteiligten sich die bereits erwähnten Jean-Gabriel Eynard, Marc-Antoine Pictet, Guillaume Favre und Guillaume-Henri Dufour. ${ }^{50}$ Es wurde eine Kommission gebil-

46 Montandon, Le développement de la science (zit. Anm. 4), S. 64-68. Diese Theorie kann natürlich nuanciert werden, aber im XVIII. Jahrhundert wurde die Akademie hauptsächlich von Patriziern und Ausländern besucht (ebenda, S. 66).

47 Buyssens, La question de l'art (zit. Anm. I), S. 238-243.

48 E. Golay, Révolutions à Genève: une chronologie, in: Révolutions genevoises (Ausstellungskatalog Genf, Maison Tavel), Genf 1989, S. 7-20.

49 Corboz, La „refondation“ (zit. Anm. I), S. 74-80. Für die politischen Spannungen um Rousseaus Denkmal, siehe I. Herrmann, Genève entre république et canton. Les vicissitudes d'une intégration nationale (I8I4-I846), Genève 2003, S. 385-394; Buyssens, La question de l'art (zit. Anm. I), S. 369-378.

50 Bibliothèque de Genève, Archives de la Société Jean-Jacques Rousseau, ms R. 62. 


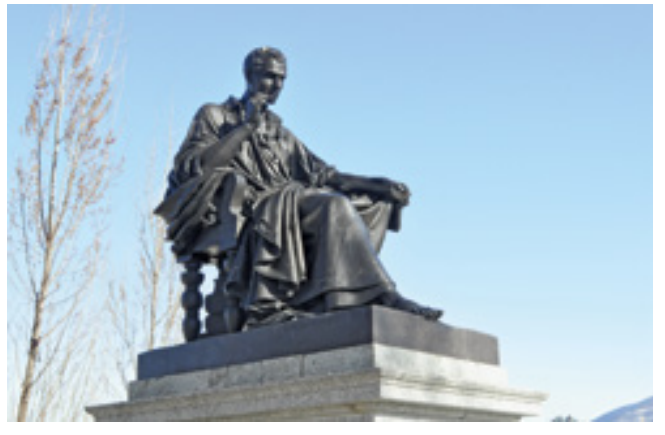

Abb. 13: James Pradier, Rousseaus Denkmal, I828-1835, Bronze. Genf, île Rousseau.

det, um zusätzlich zur Büste eine Statue - nun nicht mehr in der wissenschaftlichen Gemeinschaft des Parc des Bastions, sondern im Herzen der neuen Seefront - zu errichten. Die erneute Wahl Pradiers als ausführenden Bildhauer verwundert kaum, war er doch damals der berühmteste Genfer Bildhauer und hatte Rousseau bereits zuvor porträtiert.

Nach einer öffentlichen Spendenaktion wurde das Denkmal I835 geweiht (Abb. I3). Als Aufstellungsort wählte man die île aux barques, die vormals als Festung gedient hatte, nun aber entmilitarisiert war und den Namen île Rousseau erhielt (Abb. 9). ${ }^{\text {II }}$ Im Gegensatz zu Victor Hugo war Stendhal begeistert von der Modernisierung des Quai des Bergues und bewunderte die neue Statue Rousseaus:

Je vais voir la statue de Rousseau dans la petite île au milieu du nouveau pont; c'est une nouveauté pour moi ; honneur à M. Pradier, artiste genevois! Il voit l'antique, mais il voit aussi la nature; c'est l'homme parmi les contemporains, qui, quelquefois, fait le mieux un bras et une jambe [...]. La statue de Jean-Jacques, comme le peuple dit à Genève, peut avoir huit pieds de proportion. La tête est fort belle, et vue de face, la figure toute entière fait un très bon effet. Jean-Jacques est assis vis-à-vis de ce lac qui lui fut si cher. Qu'il ềt été heureux de savoir quon lui élèverait une statue dans sa patrie, quil crut ingrate, et qu'elle serait ainsi placée. ${ }^{52}$

Aber ihm war gleichfalls bewusst, dass der reaktionäre Flügel der Patrizier diese Statue als unerträglich empfinden würde:

Les gens du haut ont la maladie de la haine. Ils ont été outrés de la belle statue de Pradier, et cependant sans Rousseau, Genève ne serait pas plus célèbre que Hambourg et Amsterdam, ce serait une ville à argent et voilà tout. Si demain l'on déclarait que, moyennant une souscription de quatre mille francs, la statue de Rousseau sera jetée dans le lac, la somme serait souscrite en une heure, le temps matériel d'aller d'une maison à l'autre.

Im Genf des i8. und frühen 19. Jahrhunderts, in dem öffentliche Statuen so selten waren, nahm Rousseau mit vier Porträts - die Büste von Houdon in der Bibliothek, von Jean Jacquet im Parc des Bastions, von Pradier vor der Orangerie sowie Pradiers Bronzestatue auf île Roussean - eine führende Stellung ein. Mit diesem letzten Denkmal außerhalb des akademischen Milieus wurde Rousseau, wie Stendhal schrieb, eine Figur von internationalem Prestige (Genf sei besser als Hamburg und Amsterdam). Sie nimmt damit eine universelle, vorbildhafte Identität an, als der „Bürger von Genf“ d. h. le Citoyen de Genève. 


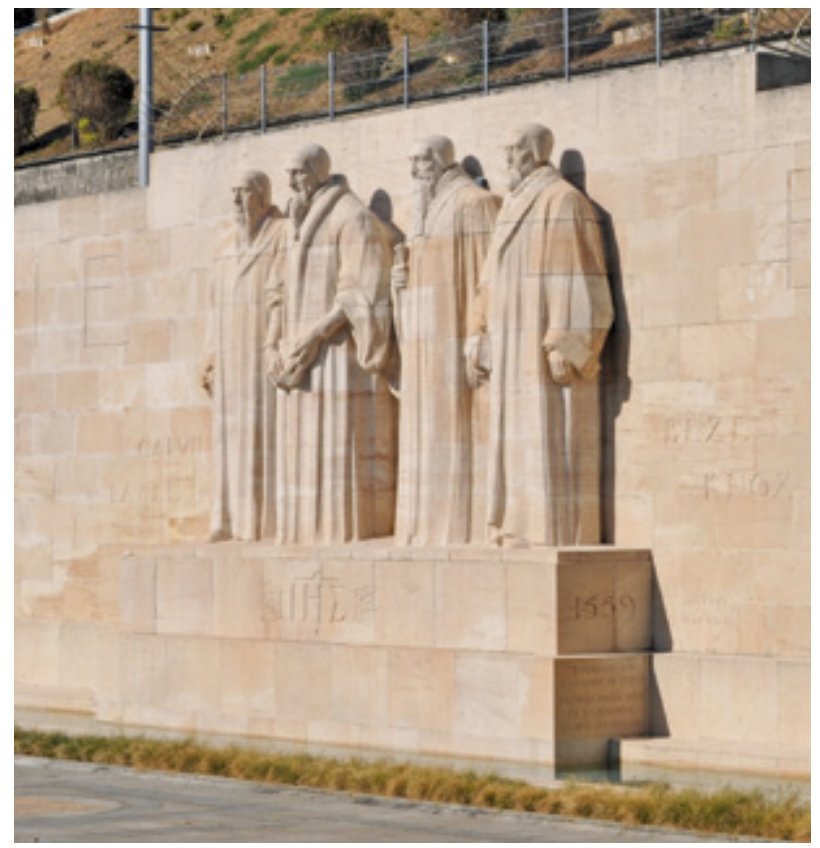

Abb. I4: Paul Landovski, Henri Bouchard, Mur des Réformateurs, I9o8I9I7. Genf, Parc des Bastions.

\section{ALVINS R ÜCKKEHR}

Mit der Zerstörung der Orangerie im Jahre 1906 endet diese Studie..$^{53}$ Anlässlich des 350-jährigen Jubiläums der Universität wurde die Orangerie ersetzt, um ein kolossales Monument zu Ehren Calvins, des Gründers der Akademie, zu errichten. ${ }^{54}$ Der Kontrast könnte kaum größer sein: von dem minimalistischen, ungegenständlichen Steinblock auf dem Friedhof hin zur größten, jemals in Genf geschaffenen Skulptur (Abb. 3, I4). Calvin ist nicht allein. Ihm werden Guillaume Farel, Théodore de Bèze und John Knox zur Seite gestellt, aber er nimmt im Relief durch die zentrale, vorgerückte Positionierung eine hervorgehobene Stellung ein.
Als die Bevölkerung für das allgemeine Wahlrecht demonstrierte, war Rousseau eine notwendige Identifikationsfigur. Später wurde Calvin nach und nach zu einer neuen, starken Referenz. Endpunkt dieser Entwicklung war sein Denkmal im Parc des Bastions. Die Konfrontation zwischen Rousseau und Calvin, dem Philosophen und dem Theologen, bleibt doch sinnvoll: Beide sind eng mit dem akademischen Milieu verbunden; Rousseau ist „der Bürger von Genf“, aber Genf ist „la ville de Calvin“.

53 Die sechs Büsten wurden in das neue botanische Konservatorium am Seeufer umgesiedelt (A. BrulHaRt/E. Deuber Pauli, Ville et canton de Genève, in: Art et monuments, Genève 1985, S. 203). Pradiers Büsten sind Kopien. 


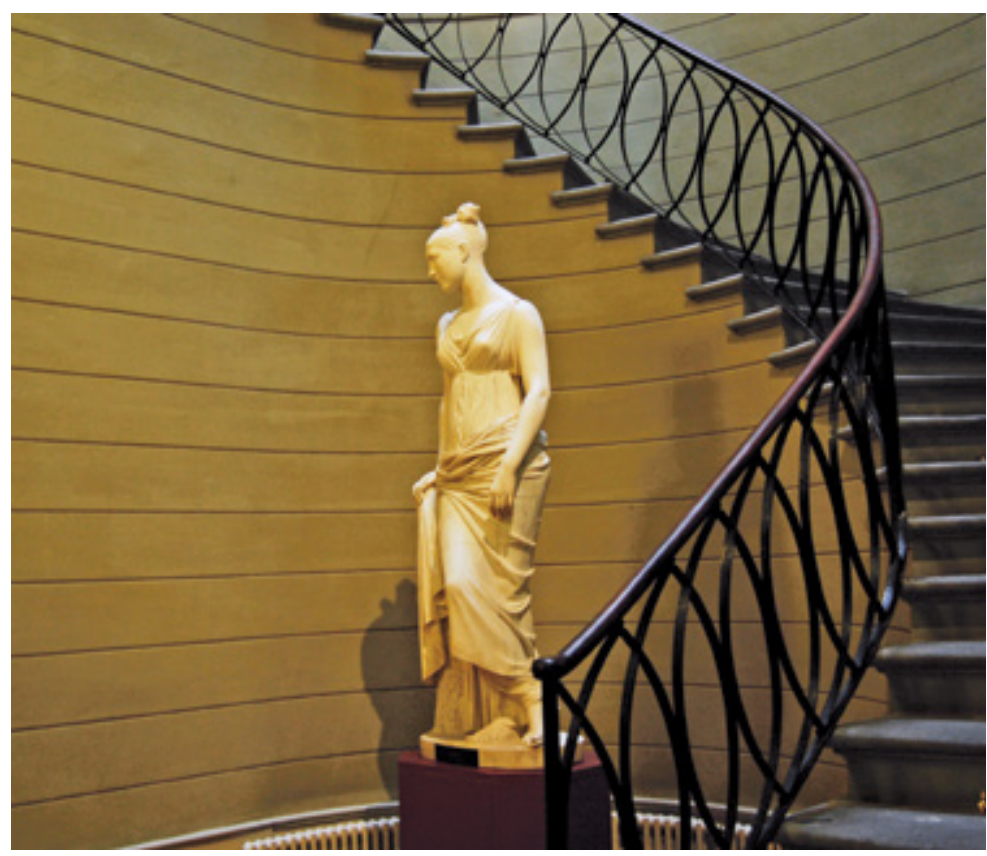

Abb. 15: Lorenzo Bartolini, Anne Lullin, 1823-1826, Marmor. Genf, Palais Eynard.

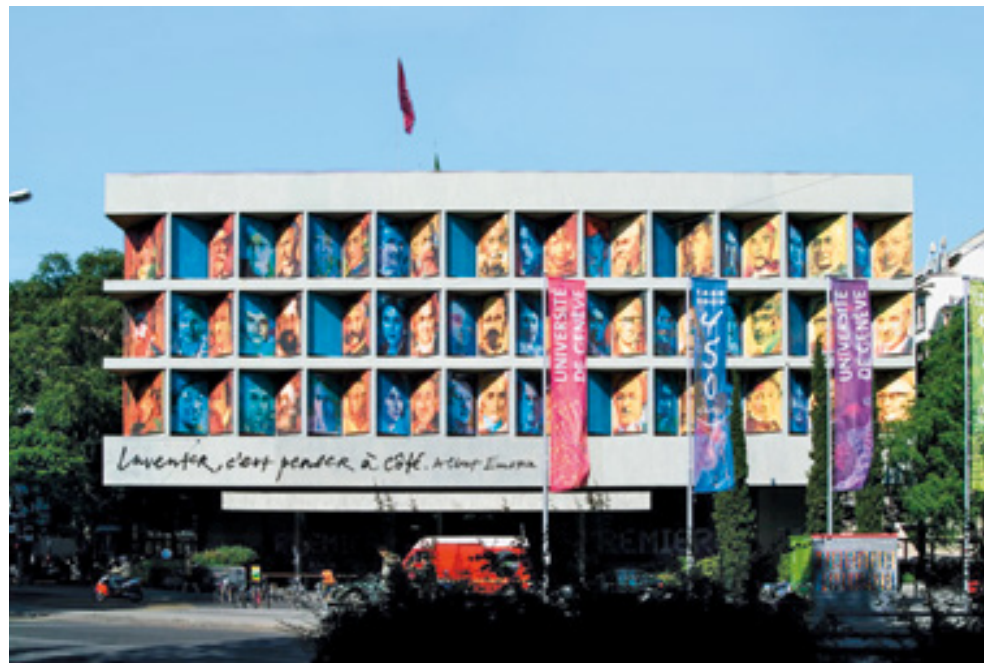

Abb. I6: Roger Pfund, „Faces à faces“, 3. 6-30. 9. 2009. Genf, Uni-Dufour. 


\section{E G A L I T ÄR E R E P I L O G}

Wie zu erwarten sind Frauen in diesem skulpturalen Prozess leider völlig abwesend. Die einzige weibliche Präsenz in der Bibliothek ist eine Büste von Germaine de Staël, Kopie eines Werkes von Friedrich Tieck (I776-I85I).

Es gibt noch ein anderes großartiges Beispiel, nicht aus dem akademischen Milieu, aber im Rahmen des Parc des Bastions: Im neben der Orangerie gelegenen Palais Eynard steht am Fuße der Treppe die Statue der Frau von Jean-Gabriel Eynard, Anne Lullin, ein Werk von Lorenzo Bartolini (Abb. 15).55 Es ist eine der schönsten Statuen des 19. Jahrhunderts in der Schweiz, stilistisch nahe an Ingres' kalligrafischer Form. In Genf ist sie allerdings ein Einzelfall. In der Malerei wurden weibliche Porträts zwar toleriert, Büsten sind dagegen eine Ausnahme und Statuen sind undenkbar. Außer einem schlichten Kommentar von Jean-Jacques Rigaud findet man keine Beschreibung dieses Werkes im I9. Jahrhundert. ${ }^{56}$ Das Schweigen kann hier, wie so oft in Genf, als eine moralische Verurteilung interpretiert werden.

Das letzte Kapitel der Porträtgalerie wurde 2009 anlässlich des 450-jährigen Jubiläums der Genfer Universität geschrieben. Bedeutende Persönlichkeiten der akademischen und intellektuellen Sphäre Genfs wurden an den Mauern des Gebäudes der Uni-Dufour angebracht (Abb. I6). ${ }^{57}$ In diesem Werk des Künstlers Roger Pfund (* I943), entstanden auf Initiative des Bureau de l'égalité, sieht man anhand der bifrontalen Wabenzellen an der modernistischen Fassade

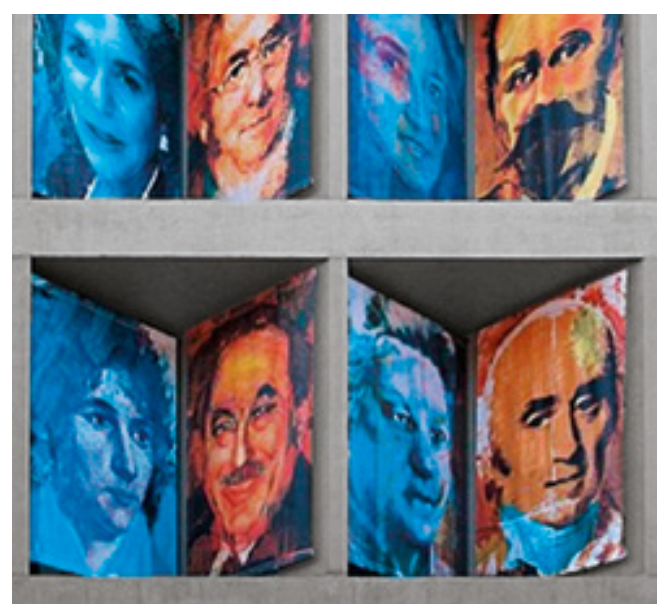

Abb. 17: Roger Pfund, „Faces à faces", Detail.

eine fruchtbare Genderkonfrontation (Abb. I7). Da die Universität erst ab I873 für Frauen geöffnet war, gab es einige leere Flächen, repräsentativ für verpasste Gelegenheiten. ${ }^{8}$ Im I9. Jahrhundert, als der radikale politische Flügel eine Demokratisierung des Studiums anstrebte, war diese Gleichheit gar keine Priorität. Sie ist eine Errungenschaft des 20. Jahrhunderts, welche, selbst zu Beginn des 2I. Jahrhunderts, noch nicht abgeschlossen ist.

Abbildungsnachweis: Abb. I, 5-6, 8-9, II: Centre d'iconographie genevoise; Abb. 2, 4, 7, 10, 12-15: Verfasser; Abb. 3: nach Ripoll (zit. Anm. 6); Abb. 16, 17: nach Mantilleri (zit. Anm. 57).

55 Extermann, Attività di Lorenzo Bartolini (zit. Anm. 22); IDEM, in: Lorenzo Bartolini, scultore del bello naturale (zit. Anm. 37), S. 260-262, N. 36.

56 „A l'entrée du principal salon, on voit d'abord la statue en marbre de grandeur naturelle de Madame Eynard“, J. J. Rigaud, Renseignements sur les beaux-arts à Genève, I, Genève I848, S. 340.

57 Faces à faces 06/o9: Université de Genève et atelier Roger Pfund (hrsg. von B. Mantilleri), Genève 2009.

58 B. Mantilleri/J. Labarthe, Ebenda, S. 2I. 



\title{
UNBEQUEMER GELEHRTER, EINGEHEGTES GENIE? EINE BÜSTE FÜR GOTTFRIED WILHELM LEIBNIZ IM AUGUSTEUM DER UNIVERSITÄT LEIPZIG
}

\author{
Silvia Schmitt-MaAss
}

$\mathrm{B}^{\mathrm{c}}$ eim Festumzug zur Jubiläumsfeier der Universität Leipzig im Jahr 1909 mimten Studenten in Kostümen und Allongeperücken Gottfried Wilhelm Leibniz Abreise aus seiner Heimatstadt (Abb. I). Denn I666 verwehrte die Universität Leipzig dem damals Zwanzigjährigen die Promotion. Dieses Faktum geht auf Zeugnisse von Leibniz zurück, in welchen Biografen Anlass für Spekulationen und Legendenbildungen um den Weggang dieses wohl berühmtesten Studenten der Leipziger Universität sahen. Die nachgestellte Szene ist als Seitenhieb auf die damalige universitäre Praxis zu verstehen. Aus wissenschaftshistorischer Perspektive entbehrt „die Auffassung, Leibniz [...] sei abgeschreckt vom sterilen Traditionalismus der Universität aus seiner Heimatstadt vertrieben worden, [allerdings] [...] der dokumentierbaren Grundlage. "I

Um sein Studium zu vollenden, wandte sich Leibniz der Universität Altdorf zu und kehrte nicht nach Leipzig zurück. Dennoch gibt es bereits in der ersten Hälfte des I8. Jahrhunderts
Versuche, Leibniz ebendort eine ideelle Heimat zu geben. Dabei wirkte Johann Christoph Gottsched wegweisend, indem er ein Leibniz-Denkmal vorschlug. Obwohl sich der kursächsische Gesandte und Mäzen Christian Wolffs, Graf Ernst Christoph von Manteuffel, dafür interessierte, kam es über Entwürfe nicht hinaus. Erst ein Jahrhundert später wurden Bildnisse verwirklicht.

Dieser Beitrag soll erweisen, dass bereits Gottscheds Denkmalpläne das Gedankengut und die Verdienste von Leibniz würdigten und einer Leibniz-Rezeption an der Universität Leipzig den Weg wiesen. Insbesondere bauliche Neuorganisationen führten zu verspäteten Ehrungen in der Aula des Universitätshauptgebäudes, welche Merkmale einer universitären Ehrenhalle aufwies. Die Auseinandersetzung mit der Platzierung der Leibnizbüste soll erhellen, inwiefern ihre Präsenz das Selbstverständnis der Universität innerhalb dieses Raumes unterstrich oder ob sie sogar zeitweise konterkarierend wirkte.

GOT TSCHEDS LEIBNIZ UM I 746

Johann Christoph Gottsched kommt allem Anschein nach als Hauptinitiator des Festaktes zum
Ioo. Geburtstag von Leibniz in Frage. Schließlich ist verbrieft, dass er 1746 in der Bibliothek

I Der junge Leibniz und Leipzig. Ausstellung zum 350. Geburtstag von Gottfried Wilhelm Leibniz im Leipziger Alten Rathaus (hrsg. von D. DörInG, Ausstellungskatalog Leipzig, Rathaus der Stadt Leipzig), Berlin 1996, S. I5, sowie S. 92-93. 


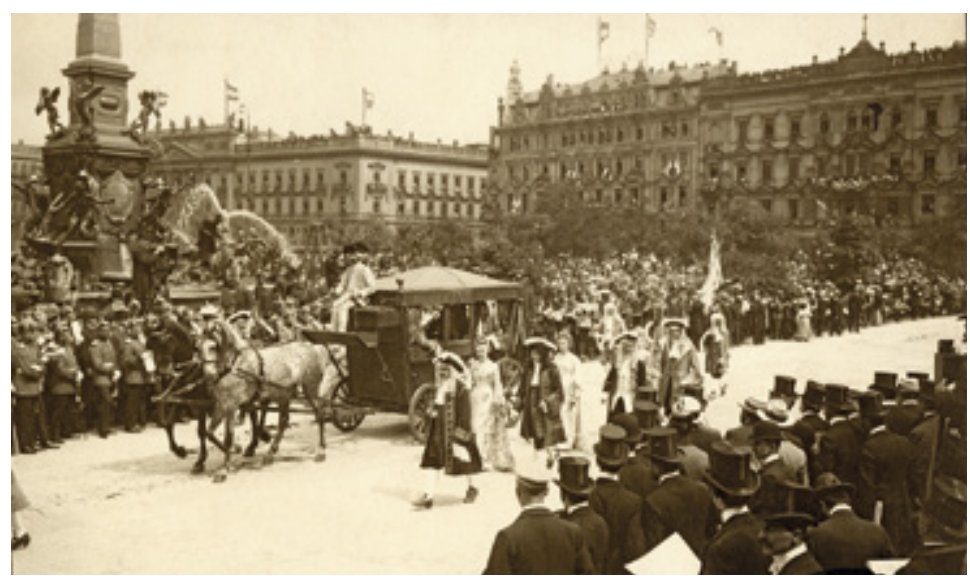

Abb. I: Festwagen zu Gottfried Wilhelm Leibniz' Abreise aus Leipzig, Universitätsjubiläum am 30. Juli 1909, Fotografie, Universitätsarchiv Leipzig (Sign. UAL FS Uooo69).

des Paulinums eine erhaltene Lob- und Gedächtnisrede auf ihn hielt. ${ }^{2}$ Zudem publizierte er in seiner Eigenschaft als Dekan der philosophischen Fakultät am 9. Juli 1746 eine Einladung zu Leibniz' Jubiläumsfeier. ${ }^{3}$ Bei Rednergesellschaften machte Gottsched vehement auf Leibniz' Leistungen aufmerksam und betonte das Ansehen, welches Leibniz bereits im Ausland genoss, und drängte wiederholt auf die Errichtung eines Monuments. ${ }^{4}$

Nicht nur adelige, sondern auch bürgerliche Personen mit Denkmälern zu ehren, forderte Gottsched „schon in seiner Opitzrede von
I739“, die in dieser Hinsicht als „das erste öffentliche Plädoyer"s für die Zurschaustellung eines Gelehrtenbildnisses angesehen wird. ${ }^{6}$ Tatsächlich entwarf er diese Perspektive bereits in der Rezension der Ausgabe von Leibniz’ „Collectanea Etymologica“ von 1732.7 Dem Briefwechsel ist zudem zu entnehmen, dass Gottsched das Erasmusdenkmal von Hendrick de Keyser (1565I62I) auf dem Markt von Rotterdam beispielhaft anführte. ${ }^{8}$ Allgemein ist anerkannt, dass seinerzeit „nur Männer fürstlicher Herkunft für öffentliche Denkmäler in Frage“ kommen. ${ }^{9}$ Dennoch schlägt Gottsched in Leipzig eine bürgerliche

2 J. C. Gottsched, Das Andenken des vor Ioo Jahren in Leipzig gebohrnen Freyherrn Gottfried Wilhelms von Leibnitz, welches in hoher Gegenwart Ihrer Kön. Hoheiten, Beyder ältesten Kön. u. Chursächs. Prinzen, auf der Pauliner-Bibliothek zu Leipzig 1746 den Io May vorgelesen worden, in: Ausgewählte Werke (hrsg. von J. Birke/Ph. M. Mitchell), Bd. I-II, Berlin I968-I995, Bd. I, S. I88-203; vgl. R. Отто, Gottscheds Leibniz, in: Pluralität der Perspektiven und Einheit der Wahrheit im Werk von G. W. Leibniz: Beiträge zu seinem philosophischen, theologischen und politischen Denken (hrsg. von F. BeIderbeck/S. Waldhoff), Leipzig 20II, S. I9I-264, hier S. 257.

3 J. C. GotTsChed, Ad audiendam orationem qua memoria nati ante saeclum viri illustrissimi Godofredi Guilielmi Lib. Bar. a Leibnitz d. IX. mens Iul. A. H. S. MDCCXXXXVI. hor. IX. mat. in auditorio-philosopho. [...] invitat ord. ohilos. decanus, [Leipzig I746], nicht paginiert.

Отто, Gottscheds Leibniz (zit. Anm. 2), 258 f.

5 Ebenda.

6 Vgl. I. Weibezahn, Das Leibnizdenkmal in Hannover. Geschichte, Herkunft und Wirkung, in: Niederdeutsche Beiträge zur Kunstgeschichte, XI, 1972, S. I9I-248; T. H. vON DER DunK, Das Deutsche Denkmal. Eine Geschichte in Bronze und Stein vom Hochmittelalter bis zum Barock. Köln/Weimar/Wien 1999, S. 398. Отто, Gottscheds Leibniz (zit. Anm. 2), S. 258.

8 Ebenda, S. 259, Anm. 375.

9 U. Merkel, Das plastische Porträt im 19. und frühen 20. Jahrhundert. Ein Beitrag zur Geschichte der Bildhaue- 
Gelehrtenmemoria im städtischen Raum vor. Vermutlich wurde sein Vorschlag für ein Leibniz-Denkmal zu jener Zeit als unbequem aufgefasst, schließlich fehlen über die Erhebung von Leibniz in den Adelsstand bis heute zuverlässige Informationen. ${ }^{\circ}{ }^{\circ}$ Hervorzuheben ist außerdem: Gottsched erwog nicht ausdrücklich ein Denkmal in universitären Ehrenhallen oder speziellen Sammlungsräumen. ${ }^{\text {II }}$ Gleichwohl verwies er in dem später von Gotthold Ephraim Lessing kritisierten Gedicht darauf, ${ }^{\mathrm{I2}}$ dass ein Denkmal für Leibniz die jüngere Generation zur Nachah- mung ermuntern würde: Wie kräftig wird sein Ehrenbild / In deiner Söhne Brust den Weisheittrieb erhitzen! Wie mancher Kopf wird dir noch nützen!'13 Doch schon nach Leibniz' Jubiläumsfeier verflüchtigte sich das Interesse an seinem Vorhaben. ${ }^{14} \mathrm{Zu}$ den Gründen zählen offenbar auch Finanzierungsschwierigkeiten der Universität. ${ }^{\text {IS }}$ Verwirklicht wurde nach 1787 - freilich ohne Gottscheds Zutun - ein öffentliches Denkmal für Leibniz in Form einer Marmorbüste in Hannover; jener Stadt, in der Leibniz arbeitete und starb. ${ }^{16}$

\section{DIE LEIBNIZ-EHRUNG VON I 846 (UND I 866 )}

Der von Gottsched angestoßene Plan wurde in Leipzig I836 zur Fertigstellung des neuen Universitätshauptgebäudes, „Augusteum“ genannt, auf dem Gelände des säkularisierten Dominikanerklosters erneut aufgegriffen. Nun war es kein städtisches, sondern ein universitäres Vorhaben, das eng an architektonische Neuerungen knüpft. Noch um I8oo herrschte Platzmangel in den Räumen der Hochschule. Versammlungen mussten in der Universitätskirche St. Pauli abgehalten werden. Eine Trennung wissenschaftlicher Vorgänge aus diesem geistlichen Beziehungsrahmen wurde zwingend notwendig. Der Senat konnte zwar schon ab 1776 auf die sogenannte „Nationalstube ${ }^{\text {“ }_{77}}$ bei der alten Börse (beim alten Rathaus) ausweichen, doch sollte die Universität mit dem Neubau des Augusteums nach

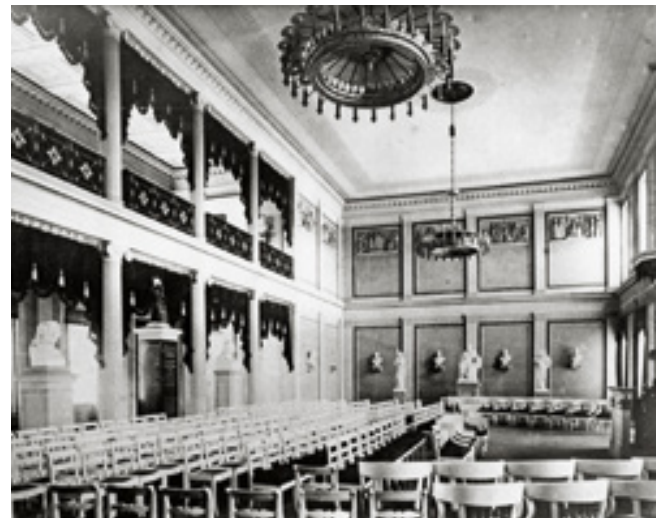

Abb. 2: Leipzig, Aula der Universität Leipzig, Fotografie, nach I870/vor I892, Leipzig, Stadtgeschichtliches Museum Leipzig.

ersten Entwürfen Karl Friedrich Schinkels vollkommen neue und zweckmäßige Räumlichkei-

rei in Frankreich und Deutschland, Berlin I995, S. 42 ff.; Von Der Dunk, Das Deutsche Denkmal (zit. Anm. 6), S. 397.

Io Neues allgemeines deutsches Adelslexikon (hrsg. von E. H. KnEschke ), Bd. 5, Leipzig I864, S. 445.

II Отто, Gottscheds Leibniz (zit. Anm. 2), S. 258.

I2 Ebenda, S. 257, Anm. 365.

I3 Gotтsched, Ausgewählte Werke (zit. Anm. 2), Bd. I, S. 202.

I4 Отто, Gottscheds Leibniz (zit. Anm. 2), S. 257 ff.

I5 A. Janda-Bux, Die Entstehung der Bildnissammlung an der Universität Leipzig und ihre Bedeutung für die Geschichte des Gelehrtenporträts, in: Wissenschaftliche Zeitschrift der Karl-Marx-Universität Leipzig, Gesellschaftsund Sprachwissenschaftliche Reihe 4, 1954/44, S. I43-168, hier S. I44.

i6 Weibezahn, Das Leibnizdenkmal (zit. Anm. 6), S. 398; U. Boeck: Der Leibniztempel, in: Herrenhausen: die Königlichen Gärten in Hannover (hrsg. von M. von KöNIG), Göttingen 2006, S. 245-246.

I7 C. C. Carus Gretschel, Die Universität Leipzig in der Vergangenheit und Gegenwart, Dresden I830, S. 72. 
ten erhalten, wie den Saal der Aula (Abb. 2), der die Funktion einer Ehrenhalle übernahm, Salons für Professoren und weitere Unterrichtssäle. Unter der planerischen Aufsicht Schinkels leitete Albert Geutebrück (I8OI-I863) das Bauvorhaben.

Eine zeitgenössische Beschreibung stellt die I836 fertiggestellte Aula wie folgt dar: Dieser $z u$ akademischen Festlichkeiten, Disputationen und Promotionen bestimmte Saal nimmt [...] die beiden obern Geschosse des Mittelbaus ein. [...] die Decoration [...] ging aus der Construction der Galerieanlage und der äußerlich zwei Stockwerke bildenden Fensterseite hervor. Die Wand- und Pilasterflächen sind mit Stuckmarmor überzogen. Die Pilaster und Simsungen sind weiß, dagegen die Felder grau mit Friesen nach Art des giallo antico. Jene Felder geben Gelegenheit zur Aufstellung von Büsten und zu einem besonderen Schmuck durch Relief. ${ }^{18}$

Ernst Rietschel, Bildhauer und Professor der Sächsischen Akademie der Künste, ließ eine Sitzstatue in Gips aufstellen, die für ein Modell des in Dresden errichteten, überlebensgroßen Denkmals zu Ehren von König Friedrich August I. von Sachsen gehalten wird. ${ }^{19}$ Die vier Personifikationen der Frömmigkeit, Weisheit, Gerechtigkeit und Milde ${ }^{20}$ sind ein zugehöriges Ensemble. Die für die Aula ebenfalls in Gips ausgeführten Standfiguren - im Entwurf der Staatlichen Museen Dresden in deutlich kleinerem Format im Verhältnis zur Sitzstatuette (vgl. Abb. 3) ${ }^{21}-$ sollten das Modell [des] Denkbildes in der Aula umgeben. ${ }^{22}$ Eine historische Aufnahme gibt das Ensemble im Augusteum nur mit zwei flankierenden Figuren im Bild wieder (Abb. 2) und zeigt

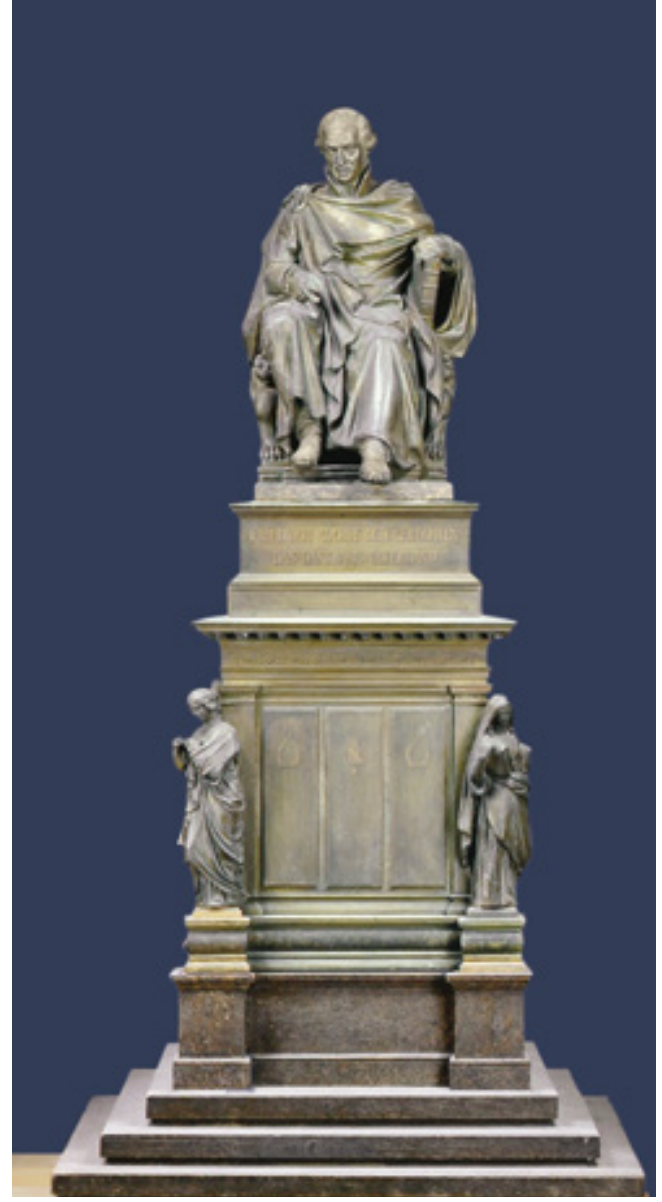

Abb. 3: Ernst Rietschel, Entwurf zum Denkmal für König Friedrich August I. von Sachsen, I827/1831, Gips (fig. Teile), Holz, Dresden, Staatliche Kunstsammlungen Dresden.

auf, dass das ursprünglich raumgreifende Denkmal aus Sitzfigur mit Sockel und vergrößerten Personifikationen an die Wände gerückt werden musste. Das Ensemble knüpfte zweifellos an die noch zu Gottscheds Zeiten vorherrschende Praxis an, städtische Einrichtungen herrschaft-

I8 Anоnym, Das Augusteum und dessen Übergabe an die Universität Leipzig am dritten August I836, Leipzig I836, S. 27 .

I9 Ebenda.

20 Ebenda.

2I E. Rietschel, Entwurf zu dem Denkmal für König Friedrich August I. (den Gerechten) von Sachsen, I827/I83I, Sitzstatuette, Gips (alle figürlichen Teile), Holz (die übrigen Teile), Staatliche Kunstsammlungen Dresden, Skulpturensammlung.

22 Anonym, Das Augusteum (zit. Anm. I8), S. 28-29. 


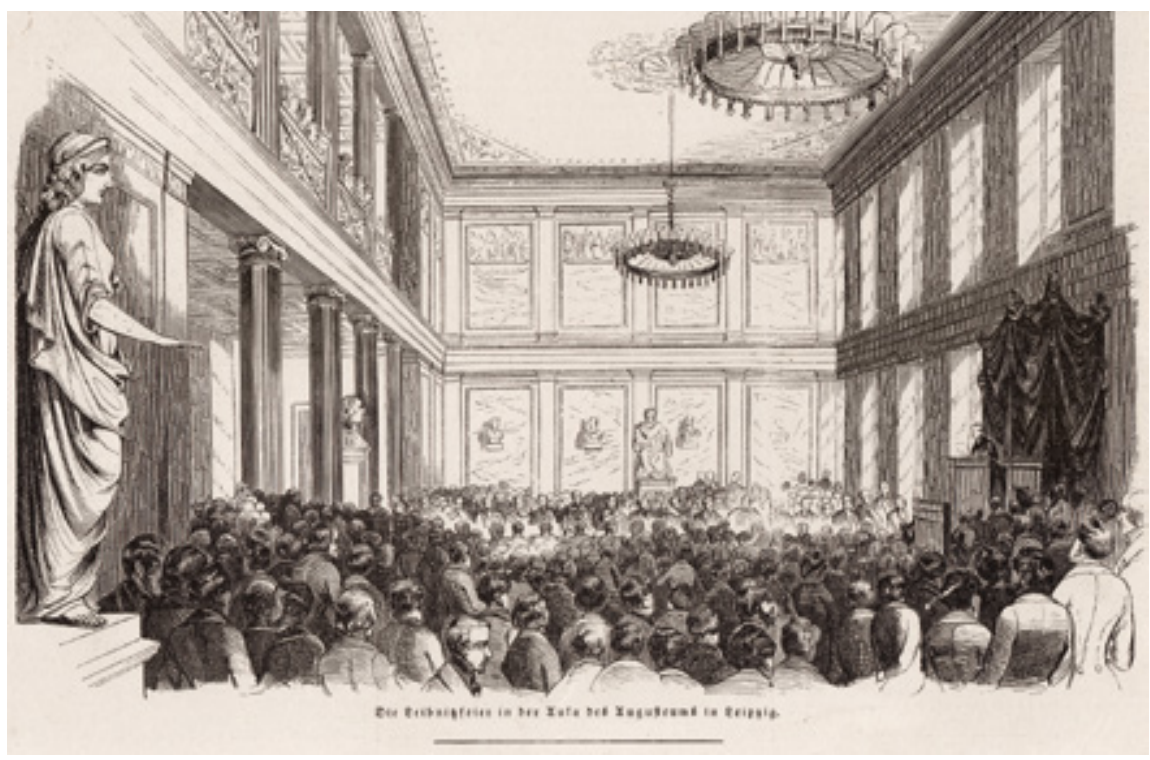

Abb. 4: Feier zu Ehren des 200. Geburtstages von Leibniz am 2I. Juni I846, Illustration, Illustrirte Zeitung (zit. Anm. 3I), S. 44.

lich zu widmen, ${ }^{23}$ daran lässt auch die Beschreibung von 1836 keinen Zweifel, wenn vermerkt wird, dass Marmorbüsten mit Gewand positioniert werden sollen, darunter: Se. Majestät, [der] regierende[n] König Friedrich August sowie weitere Erbprinzen und höfische Adelsträger. ${ }^{24}$ Letztendlich war der Neubau selbst - König Friedrich August I. namentlich gewidmet - in dieser Hinsicht als ein Denkmal zu verstehen. Zwölf Marmorbüsten mit Gewand ${ }^{25}$, die um das Vaterland verdiente Gelehrte ${ }^{26}$ darstellen, waren zusätzlich zur Ausschmückung der Aula geplant. ${ }^{27}$ Nachdem der Senat über ihre künstlerische Ausfüh- rung entschieden hatte, wurden sechs Bildnisse der philosophischen Fakultät zuerkannt, darunter: Joachim Camerarius, Ernst Platner und Christian Fürchtegott Gellert. Die theologische und die juristische Fakultät schlugen weitere vier Personen vor. „Die Medizinische Fakultät verzichtete. ${ }^{\text {"28 }}$ Für die Ehrenhalle wurde eine Leibnizbüste nicht ausdrücklich erwogen ${ }^{29}$ und auch die erhaltenen vielfigurigen zwölf Stuckreliefs der Culturgeschichte der Menschen ${ }^{3 \circ}$ - ebenfalls Arbeiten von Rietschel - lassen keinen expliziten Bezug auf Leibniz erkennen.

23 Das Prozedere stimmt mit der straffen Organisation der Universität überein.

24 Anonym, Das Augusteum (zit. Anm. 18), S. 29.

25 Ebenda; H. ZwaHr, Geschichte der Universität Leipzig I409-2009, Bd. 2, Das neunzehnte Jahrhundert I830/3I1909, Leipzig 20IO, S. I59 ff. Zum Bildprogramm vgl. E. G. Sснміdт, Marmorbüsten der Universitätsaula. Nachbetrachtungen zu einer Ausstellung, in: Mitteilungen und Berichte für die Angehörigen und Freunde der Universität Leipzig, H. 7, 1998, S. 19-20.

26 ZwAHr, Geschichte der Universität Leipzig (zit. Anm. 25), S. I59.

27 Ebenda.

28 Ebenda, S. I60. Vgl. JANDA-Bux, Die Entstehung der Bildnissammlung (zit. Anm. I5), S. I54-I55.

29 „Gottfried Wilhelm Leibniz war nicht darunter und auch keiner der anderen berühmten Studenten. “, ZwAHr, Geschichte der Universität Leipzig (zit. Anm. 25), S. I60.

30 A. Oppermann, Ernst Rietschel, Leipzig I863, S. 402. 


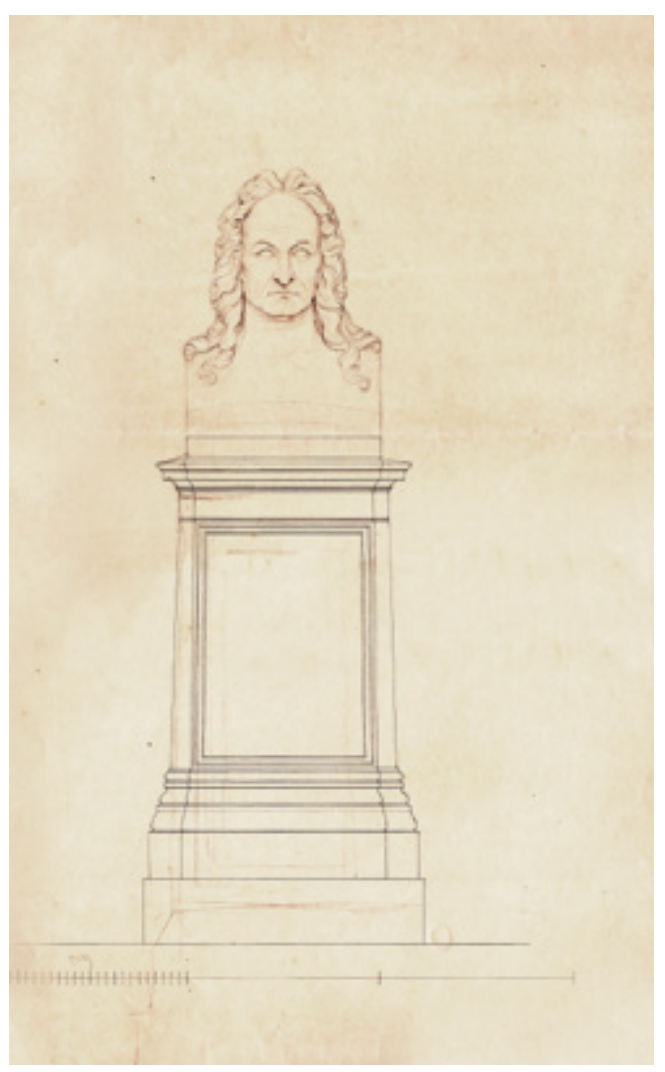

Abb. 5: (Immanuel August) Hermann Knaur, Entwurf für die Leibnizbüste der Universität, um I846, Bleistift und Feder in Dunkelbraun auf gelblichem Karton, $45 \times 33 \mathrm{~cm}$, Leipzig, Stadtgeschichtliches Museum Leipzig.

Konkreten Bedarf nach einer Leibnizbüste für die Aula weckte erst die von der Philosophischen Fakultät ausgerichtete Feier zu Ehren des 200. Geburtstages von Leibniz am 2I. Juni I846 (Abb. 4): ${ }^{31}$ Die Mitglieder halten die Verherrlichung [?] durch die Aufstellung einer Marmorbüste [bzw.] des Modelles einer solchen, [...] für höchst wünschenswerth, und glauben, daß [...] auch für die Gegenwart [ein] ehrenvolles Zeugniß dafür gegeben würde, daß [...] die Achtung vor der Wissenschaft und der wahren geistigen Größe nicht verloren gegangen ist. ${ }^{32}$

Der Leipziger Bildhauer und Rietschel-Schüler Immanuel August Hermann Knaur (I8III872) erhielt daraufhin den Auftrag zur Ausführung der Marmorbüste von Leibniz. ${ }^{33}$ Neben einem Entwurf in Bleistift und Feder (Abb. 5) übersandte er noch einen undatierten Kostenvoranschlag, der den Vergleich von zwei Ausführungen ermöglichte: einer kolossalen Büste und einer lebensgroßen; beide Versionen kalkulierte er zusammen mit einem dazugehörigen Gipsmodell des geplanten Formates. ${ }^{34}$ Der Senat gab am 24. Februar 1846 hierzu etwas hölzern zu Protokoll, daß die Büste Leibnitzens, [...], in colossalen / Maaßstabe ausgeführet werde, das sich / nach sorgfältiger Erwägung der Umstände / und gehörten [?] Gutachtens des Herrn / Baudirector Geutebrück über die Auf-I stellung in der Aula ergeben, daß nur / unter Anlagung eines solchen Maaß- I stabes die Ausführung würdig [...] sayn werde. ${ }^{35}$

Der undatierte Entwurf im Stadtgeschichtlichen Museum Leipzig zeigt den kolossalen Leibnizkopf frontal, anhand einer leicht ausradierten Mittelachse ausgerichtet, auf flacher Plinthe und mehrfach profiliertem, hohen Sockel (Abb. 5). Dieser Sockel ist in zwei Versionen lesbar: zum einen in einer schmaleren, auf ausladende Gesimse verzichtenden Variante, die durch ihren direkten Übergang von der Büste zum Sockel an eine verbreiterte Stele erinnert, und zum anderen in einer ausladenderen Version mit vor-

3I JANDA-Bux, Die Entstehung der Bildnissammlung (zit. Anm. I5), S. I55, Quelle: Acta, die Feier des Geburtstages Leibniz's und Errichtung eines Denkmals für selbigen betr., I845, Univ.-Arch. Leipzig, II/V, 73. Gefeiert wurden Doktorehrungen und Leibniz' Geburtstagsfeier am 2I. Juni I846 und die Gründung der Akademie der Wissenschaften am I. Juli I846. Vgl. Illustrirte Zeitung, I59, VII., Leipzig, I8. Juli I846, S. 43-44. Quelle (zit. Anm. 3I), Bl. I.

33 Zwahr, Geschichte der Universität Leipzig (zit. Anm. 25), S. 165, Anm. 446: „ein von der ,Deputation“ als gelungen akzeptiertes Werk des Bildhauers Knauer."

34 Quelle (zit. Anm. 3I), Bl. II.

35 Ebenda, B1. I2-I2v. 
kragender Plinthe. Unterhalb der Büste ist der Karton gefaltet, sodass beim Umklappen die Betrachtung des Entwurfes ohne Sockelversionen möglich ist. Offenbar hat Knaur das Blatt dazu verwendet, drei unterschiedliche Ansichten der Büste zu präsentieren und die Auswahl des passenden Postamentes vorzubereiten. Dass der Senat sich für den breiteren Sockel entschieden hat, den ein Tischler angefertigt hatte, legen die historischen Aufnahmen der Aula nahe. Wenige Monate später lieferte Knaur das Gipsmodell. Die Darstellung der Leibnizfeier in der „Illustrirten Zeitung" erweist (Abb. 4), ${ }^{36}$ dass es sich zum Zeitpunkt der Feierlichkeiten anstelle des marmornen Leibnizkopfes im Saal befand. Knaur wechselte die marmorne Kolossalbüste erst im darauffolgenden Jahr aus, was er in einem Brief vom I4. Juli I847 selbst anzeigte. ${ }^{37}$

Die Büste zeigt im Gegensatz zum Entwurf ein leicht zur linken Seite geneigtes Haupt, das von der Stellfläche über den oberen Ansatz der Schultern bis hin zur Haartracht aus einem Block gearbeitet ist (Abb. 6). Der würfelähnliche, massiv wirkende Unterteil fungiert auf etwa quadratischem Grundriss als Stellfläche der Büste. Die vordere, glatt geschliffene Partie ziert in Kapitalis die Gravur des Philosophennamens: „LEIBNIZ.“ und schließt oberhalb nahezu halbrund ab. Im Gegensatz zum zeichnerischen Entwurf versah Knaur die Büste nicht mit einer differenzierten Brustfläche. In ihrem Grundaufbau scheint sie sich an antiken Vorlagen zu orientieren. ${ }^{38}$ Leibniz' Blick wirkt wie auf ein feststehendes Ziel in nächster Nähe gerichtet, die Gesichtszüge sind hart und gebieterisch, was insbesondere durch die Denkerfalten an der Stirn und die tiefen Winkel des milde lächelnden Mundes bewirkt wird. Die Umrisse sind hart, was das eckige Kinn betont. Insbesondere der Haaransatz scheint durch das antike Modell be-

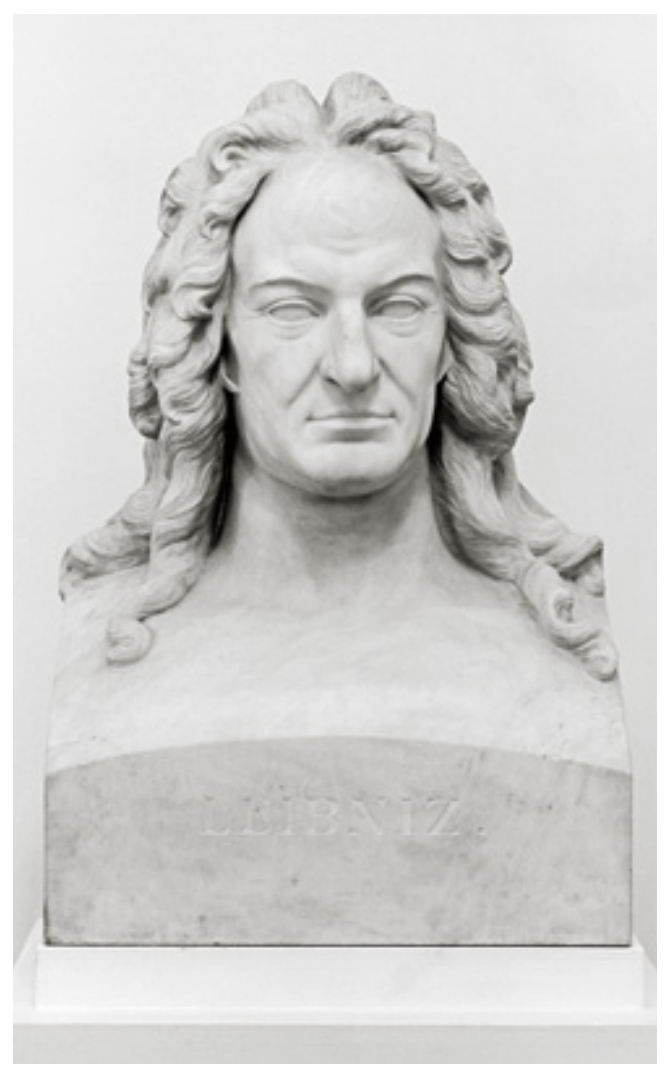

Abb. 6: (Immanuel August) Hermann Knaur, Kolossalbüste des Universalgelehrten Gottfried Wilhelm Leibniz, I847, Marmor, weiß, Objektmaße: $58 \times \mathrm{ca}$. 9I $\times 50,3 \mathrm{~cm}$, signiert und datiert auf der Rückseite links unten „H. KNAUR. fec. I847. “, am Büstenanschnitt bezeichnet „LEIBNIZ. “, Leipzig, Kunstbesitz der Universität Leipzig.

einflusst, schließlich wird Leibniz durch eine hohe Stirn, ohne Allongeperücke und mit offenen Haarsträhnen wiedergegeben. Offenbar hat Knaur versucht, zwei Gegenstände miteinander zu verschmelzen. Zum einen eine Ähnlichkeit mit dem Antlitz des Gelehrten im Rückgriff auf dessen wohl bekanntestes Porträt mit Allongeperücke (Abb. 7) und zum anderen eine idealisierte und antikisch anmutende Darstellungsweise, die eine Wiedergabe im historischen Kostüm

36 Illustrirte Zeitung (zit. Anm. 3I), S. 43-44.

37 Quelle (zit. Anm. 3I), Bl. 36-37.

38 Vgl. U. Merkel, Das plastische Porträt (zit. Anm. 9), S. 38 f. 


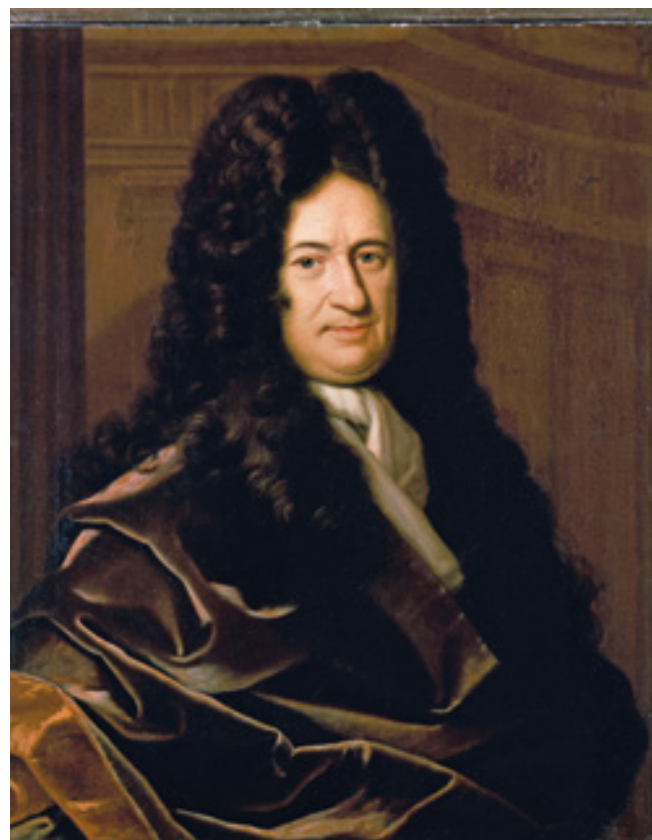

Abb. 7: Christoph Bernhard Francke, Bildnis des Philosophen Gottfried Wilhelm von Leibniz, vor I7I6, Öl auf Leinwand, Braunschweig, Herzog Anton Ulrich-Museum.

oder ähnliches vermeidet, um die Verehrung von Leibniz' geistiger Größe hervorzuheben.

Eher noch als einer Antikenrezeption des in Italien geschulten Bildhauers trug Knaur einem Geniekult Rechnung, der vor allem im Bezug auf Johann Wolfgang Goethe bekannt ist. ${ }^{39}$ Ein Goethebezug wird auch in der Aula des Augusteums evident, da die Leibnizbüste später von einer Goethebüste flankiert wurde (s. unten). Wohl kaum wirkte in Knaurs Werk jene Büste nach, die David d'Anger ein Jahrzehnt zuvor von Goethe angefertigt hatte. Angers jedenfalls charakterisierte den gealterten Goethe mit aufwehender Lockenpracht, tiefen Denkerfalten an der Stirn und verhaltenem Blick, doch mit kolossalen Büstenmaßen..$^{\circ}$ Goethe hatte die von Angers als Geschenk und persönliche Hommage übersandte Büste öffentlich in der Großherzoglichen Bibliothek aufstellen lassen, wo Knaurs Lehrer Ernst Rietschel sie I84I studieren konnte. ${ }^{4 \mathrm{I}}$ Rietschel hatte ,angesichts deren übermächtiger Wirkung gesagt: Sie habe ihn ,mit Erstaunen erfüllt, man hat Mühe, den Eindruck wieder los zu werden, daß er einem [!] nicht des Nachts beunruhigt. “"42 Angers überdimensioniertes Geschenk war ein Kulminationspunkt des Goethekultes. Knaurs Leibnizkopf dagegen verpflichtete sich der klassizistischen Schadow'schen Bildhauerkunst. ${ }^{43}$ Eine autoritäre Wirkung entfaltete die Leibnizbüste somit gleichwohl. Die Leipziger "Illustrirte Zeitung" beschrieb sie als wahren Jupiterkopf [...] einen Geist verkörpernd, der eine Welt von Ideen in sich trägt und zu beherrschen weiß. ${ }^{44}$

Der Rektor der Universität vermerkte über die Aufstellung der Leibnizbüste I847, dass: „die Aufstellung der Büsten solcher Männer wie Leibniz, namentlich in der Aula der Universität, auch von wohltätigem Einfluß auf Geist und Richtung der Studierenden sei[en], indem sie denselben bei jeder akademischen Feier von Neuem vor die Seele führt, daß die ernste Wissenschaft in ihrer klaren ruhigen Macht alle trüben oder leidenschaftlichen Bestrebungen des Tages über-

39 E. Forssman, Goethezeit. Über die Entstehung des bürgerlichen Kunstverständnisses, Berlin I999, S. I28 ff.

40 Die Büste wurde am 28. August I83I in der Großherzoglichen Bibliothek zu Weimar feierlich eingeweiht. Die Festgesänge hierzu erschienen gedruckt: vgl. B. MAAz, Vom Kult des Genies. David d'Angers' Bildnisse von Goethe bis Caspar David Friedrich, München/Berlin 2004, S. 40.

4I Ebenda, S. 39.

42 Ebenda, S. 44. Vgl. Briefwechsel zwischen Rauch und Rietschel (hrsg. von K. EgGers), 2 Bde., Berlin I890-I89I, Bd. 2, S. 9 .

43 Merkel, Das plastische Porträt (zit. Anm. 9), S. 66 ff. Zur Gelehrtenmemoria in der Anna Amalia Bibliothek vgl. B. Werche, Kräuters Skizze des Rokokosaales der Großherzoglichen Bibliothek, in: Anna Amalia, Carl August und das Ereignis Weimar (hrsg. von H. Th. SeEmann), Göttingen 2007 (Klassik Stiftung Weimar, Jahrbuch 2007), S. 244-27I.

44 Illustrirte Zeitung (zit. Anm. 3I), S. 44. 
ragt und überdauert. “45 Diese Worte legten die Einhegung der Leibnizbüste in den universitären Rahmen als steinerne Autorität im Sinne ihrer pädagogischen Wirksamkeit fest. Die Leibnizbüste zielt auf die Bekehrung von Studenten zu Bedachtsamkeit ab und sollte in den zu jener Zeit immer wieder aufflammenden Studentenunruhen der Vormärz-Aufstände als Vorbild funktionieren.

Interessant ist an der Illustration, dass die monumentale Büste dem Rednerpult gegenübergestellt abgebildet wird (Abb. 4), während das Denkmal von König Friedrich August I. von Sachsen zergliedert und an den Rand gedrängt erscheint. Möglicherweise ist das königliche Bildnis für die Aufstellung der Leibnizbüste in der Aula neu platziert worden. Das Königsdenkmal ist schließlich ebenfalls in Gegenüberstellung zum Pult denkbar. Gegen die These mag die übergroße Ausformung der Personifikationen sprechen, die für eine Aufstellung an der Wand konzipiert zu sein scheinen; doch für sie sprechen die kolossalen Dimensionen des Leibnizkopfes auf hohem Sockel, der ein räumliches Gegengewicht zur herrschaftlichen Gewalt und ein beinahe majestätisches Gegenüber zur akademischen Partei formiert. Zudem wendet sich der Kopf in Richtung des königlichen Denkmals und nicht wie im zeichnerischen Entwurf vorgesehen streng frontal in Richtung des Rednerpultes. Wird der Leibnizkopf nicht auch zu einem herausragenden Anwesenden im Publikum? Die im Vordergrund der Illustration wiedergegebene Herrschertugend der „Milde“ mag als Kommentatorin dieser Konstellation gedeutet werden, denn der Aufstellung von Leibniz’ Büste hatte der sächsische König zu- gestimmt. Hier nun konnte Leibniz als bürgerlicher Vertreter der Wissenschaften und Begründer des Akademiewesens im deutschsprachigen Raum zugleich als etwas trotzig wirkender Vertreter der Freiheit der Wissenschaften dem königlich-universitären Rahmen trutzen. Nicht unerheblich erscheint die Tatsache, dass die Feierlichkeiten zu Leibniz' Geburtstag mit der offiziellen Gründung der Sächsischen Akademie der Wissenschaften zusammenfielen. Wie ein Jahrhundert zuvor bereits Gottsched einer Akademiegründung mittels wissenschaftlicher Gesellschaften zugearbeitet hatte, berief sich auch die Akademie der Wissenschaften auf den Gelehrten. ${ }^{46}$ Angesichts von Gottscheds Denkmalsplänen überrascht es kaum, dass Leibniz nicht ensemblehaft erinnert wurde. Vielmehr wurde ein solitäres Denkmal im Raum errichtet, das durch die Gegenüberstellung seine Bezüge zu königlichen Würden und Universitätsgeschichte entfaltet.

Kaum überraschen mag auch, dass die Universität zusätzlich zu diesem Vorgehen zu einem im städtischen Raum positionierten Denkmal riet. Schließlich enthalten die Akten zu den Jubiläumsfeierlichkeiten schon 1846 den „Aufruf zu freiwilligen Beiträgen zur Errichtung eines Denkmals für Leibniz in Leipzig " ${ }^{47}$ an den Stadtrat. Knaur fertigte offenbar ein weiteres Gipsmodell für ein Leibniz-Standbild, das heute im Stadtgeschichtlichen Museum Leipzig erhalten ist. ${ }^{48}$ Gegen ein kostenintensives, städtisches Monument regt sich allerdings in der Leipziger Bürgerschaft zeitgleich Widerstand, ${ }^{49}$ was die verspätete Verwirklichung erklärt. Erst I877 sollte der Bildhauer Ernst Julius Hähnel (I8II-I89I) den Zuschlag erhalten. ${ }^{\circ \circ}$ Zwischen I88I und I883 fer-

45 Zit. nach Janda-Bux, Die Entstehung der Bildnissammlung (zit. Anm. I5), S. I56-I57, Quelle (zit. Anm. 3I), Bl. 3.

46 E. L. Wiemers/G. Wiemers, Planung und Entstehung der Sächsischen Akademie der Wissenschaften zu Leipzig. I704-I846, Göttingen 1996, S. I59-I64. Vgl. Illustrirte Zeitung (zit. Anm. 3I), S. 43.

47 Quelle (zit. Anm. 3I), Bl. I6.

48 Datiert um 1846, lt. Inventar des Stadtgeschichtlichen Museums Leipzig.

49 Etwa in den Ausgaben des Leipziger Tageblattes zum Thema „Leibnizdenkmal“ im Jahr I846.

50 Univ.-Arch. Leipzig, III/V, Nr. 68b (Acta, Errichtung des Leibniz Denkmals betr., I877), Blatt 6-7 mit einem „Triplicat" des Vertrages mit Hähnel. 


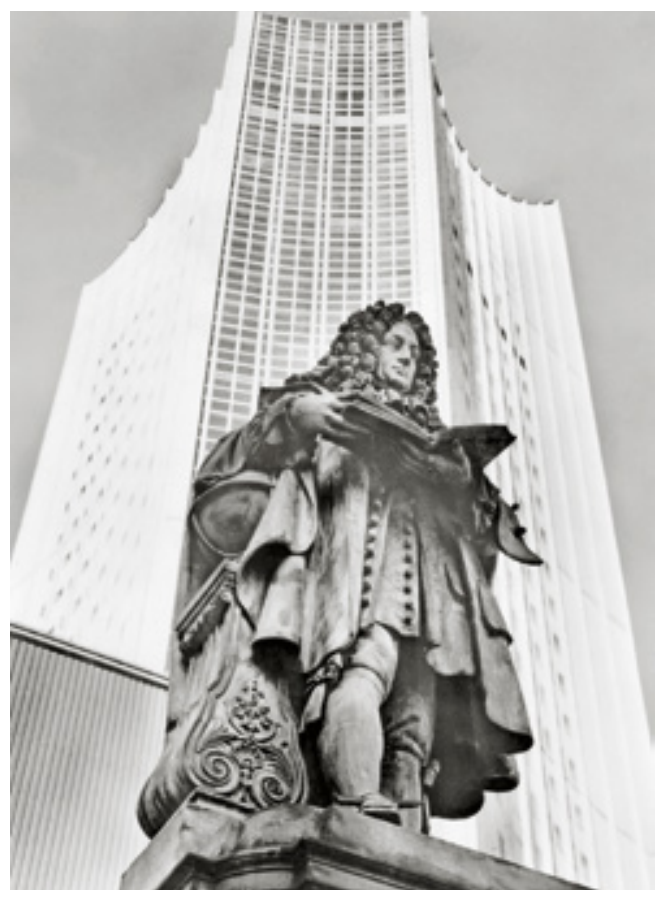

Abb. 8: Ernst Julius Hähnel, Leibnizdenkmal vor dem Hochhaus der ehemaligen Karl-Marx-Universität, Fotografie, 1974, Universitätsarchiv Leipzig (Sign. UAL FS No43048).

tigte er das Modell für den Bronzeguss der überlebensgroßen Figur mit hohem steinernen Sockel und einem Unterbau aus Granit. Die Bronzereliefs am Sockel zeigen Darstellungen der vier alten Fakultäten: Philosophie, Medizin, Theologie und Jurisprudenz. Das Denkmal wurde zuerst am Thomaskirchhof aufgestellt, nach 1900 versetzte man es in den neuen Hof des Universitätsgeländes am erneuerten Paulinum (Abb. 8)..$^{51}$

Noch 1846 stellt die Leibnizbüste in der Aula als Denkmal im Raum ein Einzelstück dar, das in Gegenüberstellung zu den Ensembles aus Mäzenendenkmal und Professorenbildnissen vor allem aufgrund seiner kolossalen Größe hervorsticht. Dies mag als Ungleichgewicht wahrgenommen worden sein, denn I866 wurde es um eine marmorne Goethebüste gleichen Formates

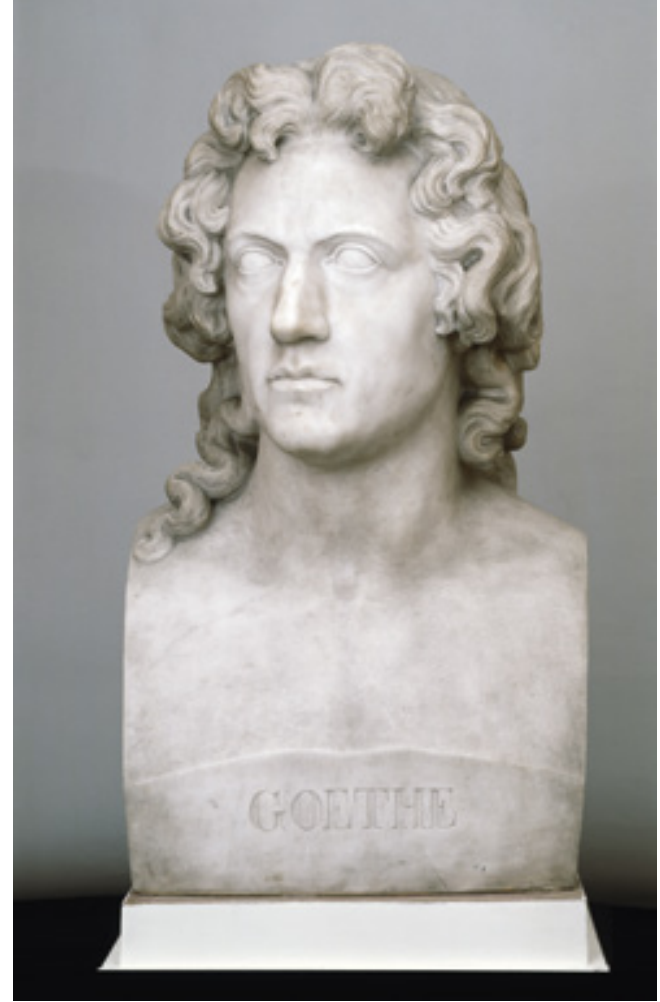

Abb. 9: (Immanuel August) Hermann Knaur nach Alexander Trippel, Kolossalbüste des Johann Wolfgang von Goethe, I866, Marmor, weiß, Objekthöhe: $83 \mathrm{~cm}$, auf der Rückseite signiert und datiert: "HKnaur A I866/nach/Trippel 1787 ", vorn bezeichnet „GOETHE“, Leipzig, Kunstbesitz der Universität Leipzig.

ergänzt, für welche ebenfalls der Bildhauer Knaur verantwortlich zeichnete (Abb. 9). Über die von Knaur mit „I866, nach Trippel“ signierte Büste, die im Zuge der Feierlichkeiten des Goethejubiläums aufgestellt wurde, ist in den Akten des Universitätsarchives leider nichts Näheres zu ermitteln. Allein historische Aufnahmen dokumentieren die Positionierung beider Kolossalbüsten zwischen den ionischen Säulenpaaren, welche die Ehrentribüne der Aula Geutebrücks trugen. Die Büsten flankieren auf der ausgewählten Aufnahme eine „Denksäule für die im Kriege I870/7I gefallenen Commilitonen“ (Abb.

5I Bez. an der Plinthe der Figur u. am Sockel: „Erfunden und modelliert von E. J. Hähnel in Dresden I88I-I883“. 
Abb. ıо: Leipzig, Aula der Universität Leipzig, Fotografie, nach I870/7I, vor I892, Leipzig, Stadtgeschichtliches Museum Leipzig.

Io). ${ }^{52}$ Das Leibniz-Denkmal wird zusammen mit der Goethebüste nun als ein Ensemble erkennbar, das dem bereits angesprochenen Geniekult der Vorjahre entspricht. Ab sofort und auch weiterhin werden die Büsten als zusammengehörig angesehen, denn 1899 werden sie im Zuge der Ausstattung der neuen Wandelhalle gemeinsam

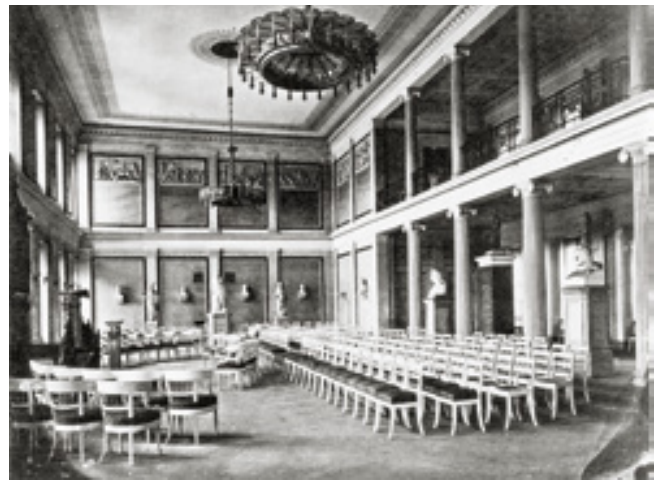
positioniert. ${ }^{33}$

\section{DAS LEIBNIZ-ENSEMBLE NACH I 890}

Arwed Roßbach ließ ab i889 Umbaumaßnahmen durchführen. Die neue Wandelhalle verband die Komplementärgebäude Johanneum und Albertinum mit dem erweiterten Augusteum. Ein Innenhof überbrückt zum Neubau des Paulinums. Die Veränderungen betrafen auch die Büstenensembles. Während man sich zu Beginn des I9. Jahrhunderts gezielt um die Gelehrtenmemoria in der Aula bemüht hatte, entwickelte sich die Aufstellung von immer zahlreicheren Büsten zu einem prestigefördernden Mittel. Die auf Innenansichten der Wandelhalle abgebildeten dunklen Stelen sind für Büsten vorbereitet (Abb. II), die auch auf der oberen Galerie zahlreiche leicht überlebensgroße Professorenbildnisse trugen (Abb. I2). ${ }^{54}$ Diese Flut von Bildnissen machte eine Kontrollinstanz er- forderlich: Eine „Büstenkommission“ sollte den Andrang begrenzen.5 Im Hinblick auf die Leibniz- und Goethebüste wurde diese Kommission ebenfalls herangezogen. In der Folge wurden sie für den Umbau entfernt und I899 in der Wandelhalle platziert. ${ }^{56}$ Die Kollossalbüsten, der Leibnizkopf und sein Pendant, sollten die vorhandenen Professorenbildnisse nun ersetzen.

Ein Jahrzehnt später kam die Büstenkommission noch einmal auf Leibniz zu sprechen, da in der Wandelhalle noch für das Denkmal der 1870/7I Gefallenen der Universität Platz geschaffen werden sollte. ${ }^{57}$ Zusätzlich fertigte Carl Ludwig Seffner 1909, im Jubiläumsjahr der Universität, eine kolossale Büste aus gelblichem Marmor etwa gleichen Formats. Sie zeigt den Dichter Gotthold Ephraim Lessing. ${ }^{58}$ Offenbar sollten die

52 Monument von E. I. Einsiedel (sign. I872), vgl. Janda-Bux, Die Entstehung der Bildnissammlung (zit. Anm. I5), S. I78, Nr. 298.

53 „die beiden, jetzt in der Aula [...] Büsten von Leibnitz u. Göthe aus der Aula in die Halle versetzt werden [...]“, Univ.-Arch. Leipzig, II/III Litt. C, Nr. 8 (Acta Aufstellung von Büsten usw. in der Wandelhalle usw. betr., I897), Bl. IO, Eintr. v. 5. 2. I899.

54 Vgl. R. Bruck, Arwed Rossbach u. seine Bauten, Berlin I904.

55 Janda-Bux, Die Entstehung der Bildnissammlung (zit. Anm. I5), S. 155, Quelle (zit. Anm. 53), Bl. 5 ff.

56 JandA-Bux, Die Entstehung der Bildnissammlung (zit. Anm. I5), S. 178, Quelle (zit. Anm. 53), Bl. Io.

57 „im Erdgeschoss der Wandelhalle das Kriegerdenkmal an die frühere Stelle zurückzustellen und den Büsten andere Plätze einzuräumen“, zit. Quelle (zit. Anm. 53), Bl. 48.

58 A. Janda-Bux, Katalog des Kunstbesitzes der Universität Leipzig mit besonderer Berücksichtigung der Gelehrtenbildnisse, in: Wissenschaftliche Zeitschrift der Karl-Marx-Universität Leipzig. Gesellschafts- und Sprachwissenschaftliche Reihe 4, 1954/44, S. I69-197. 


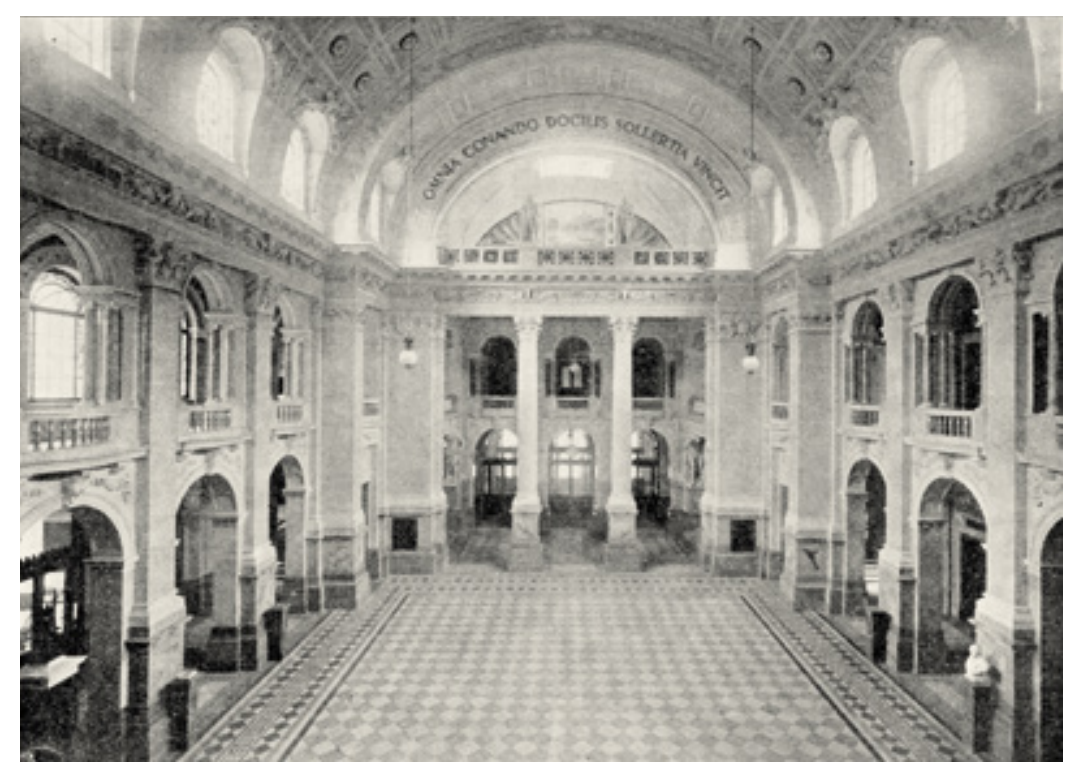

Abb. II: Leipzig, Wandelhalle der Universität Leipzig, Fotografie, um I899 (?), Leipzig, Stadtgeschichtliches Museum Leipzig.

Büsten nunmehr zu einem Set der berühmtesten Studenten der Universität Leipzig erweitert werden; wie die drei Büsten auch heute noch wahrgenommen werden. Für diese These spricht der Briefwechsel des Professors für Archäologie Franz Studniczka, der die Büstenkommission beriet. Seine Skizzen von I9Io zeigen Überlegungen auf, 59 nach welchen ein solches Ensemble zunächst in die Seitenumgänge der Wandelhalle eingepasst werden konnte: Goethe und Lessing sollten den Eingang zum Senatssitzungssaal flankieren. Der Leibnizkopf sollte nach Studniczka vorerst allein [...] links neben der Gedenktafel vor der jetzt die Königsstatue steht [aufgestellt werden] [...] in Erwartung, dass ihnen bald ein Thomasius als Gegenbüste gegeben wird. ${ }^{60}$

Doch zur Erweiterung des Ensembles kommt es nicht mehr. Studniczka, Leiter der Archäologischen Sammlung im Johanneum, lieferte die Begründung: Da ich aber weiss, daß der Kunstkom- mission [...] wenig daran liegt, die Leibnizbüste um jeden Preis in der Wandelhalle zu halten, während im Paulinerhof die grosse Leibnizstatue prangt, erlaube ich mir [...] Möglichkeiten zu anderweitiger würdiger Unterbringung der Leibnizbüste anzuführen. ${ }^{61}$ Hiernach schlug Studniczka unter anderem zur Kostenersparnis vor, den Leibnizkopf in einen der Treppenaufgänge zu versetzen.

Zuvor kursierte immerhin der Vorschlag, die Leibnizbüste wieder an ihren ursprünglichen Platz in die Aula zu versetzen, doch hat sich die Einrichtung seit dem Umbau durch Arwed Roßbach so stark gewandelt, dass die Monumentalbüste in diesen streng bildthematisch bestimmten Rahmen nicht mehr eingepasst werden konnte (Abb. 13). Die Aufgaben der Bildhauerkunst, die Ehrenbüsten und Denkmäler traten in der Aula in den Hintergrund und somit zierte die Leibnizbüste eines der Treppenhäuser der Wandelhalle kurz nach der Fertigstellung des kolossalen Gemäldes von Max

59 Quelle (zit. Anm. 53), Bl. 42, Bl. 50.

60 Ebenda, Bl. 39.

6I Ebenda, Bl. 4I, Brief vom I. Juni I9Io. 


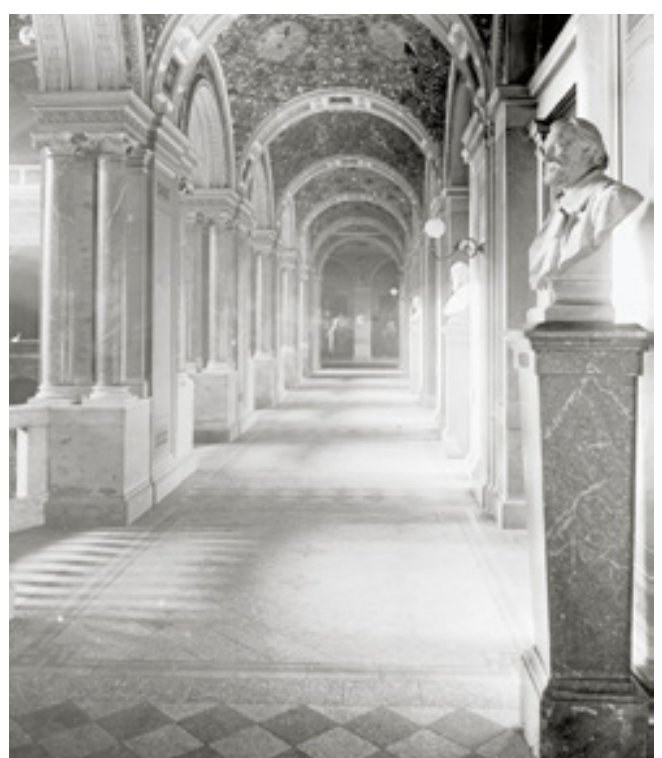

Abb. 12: Leipzig, Wandelhalle der Universität Leipzig, Obere Galerie, Fotografie, nach I899, Universitätsarchiv Leipzig (Sign. UAL FS Noo844).
Klinger für die Aula. ${ }^{62}$ Dort fristete die Büste mit Unterbrechungen während der Kriegszeiten, dann aber bis zu ihrer Inventarisierung von $1954 / 55$ ein Schattendasein. ${ }^{63}$ Allem Anschein nach ist die Büste bis zu der höchst bedauerlichen Sprengung des Gebäudekomplexes von 1968 an diesem Platz verblieben. Während die Leibnizbüste in diesem Jahr schließlich in einem Depot der Universität landete,${ }^{64}$ fielen die durch die Bombardierung von 1943 stark zerstörten Gebäude selbst und zahlreiche dort immer noch vorhandenen Kunstwerke der Sprengung durch das DDR-Regime zum Opfer. ${ }^{65}$ Der öffentliche Raum hielt die Erinnerung an Leibniz allerdings noch durch das Standbild von Hähnel aufrecht, wie eine Aufnahme vor dem Hochhaus der ehemaligen Karl-Marx-Universität veranschaulicht (Abb. 8). Seit der Fertigstellung des neuen Campus am Augustusplatz im Jahre 2009 wird das Denkmal im Innenhof, der

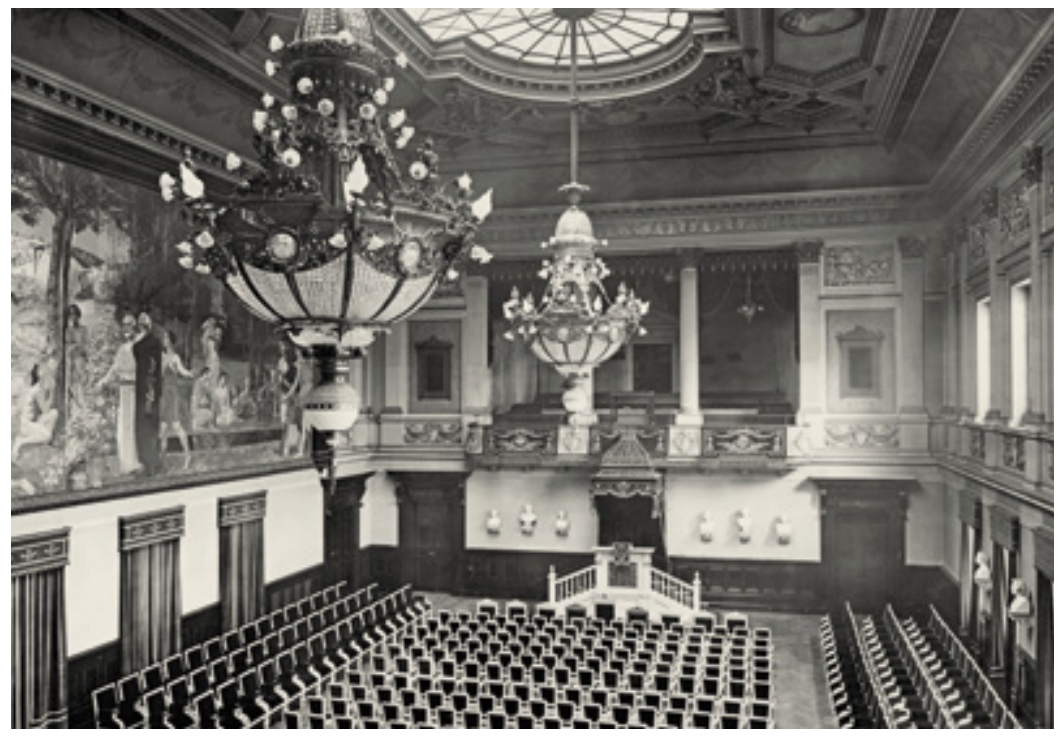

Abb. 13: Leipzig, Aula der Universität Leipzig, nach der Fertigstellung des Gemäldes von Max Klinger „Blüte Griechenlands“, I9I0, Fotografie vor 1945, Universitätsarchiv Leipzig (Sign. UAL FS NoI65I).

62 Quelle (zit. Anm. 53), Bl. 49v.

63 Vgl. Janda-Bux, Katalog des Kunstbesitzes der Universität Leipzig (zit. Anm. 58), S. I78.

64 Nach Auskunft durch Cornelia Junge, Kustodin der Sammlungen der Universität Leipzig.

65 Vgl. den Überblick in: Kulturkampf in Leipzig. Denkschrift zur Wiederaufbaudebatte Universitätskirche St. Pauli (hrsg. von D. Косн/E. Косн), Leipzig 2006, S. I5 ff. 


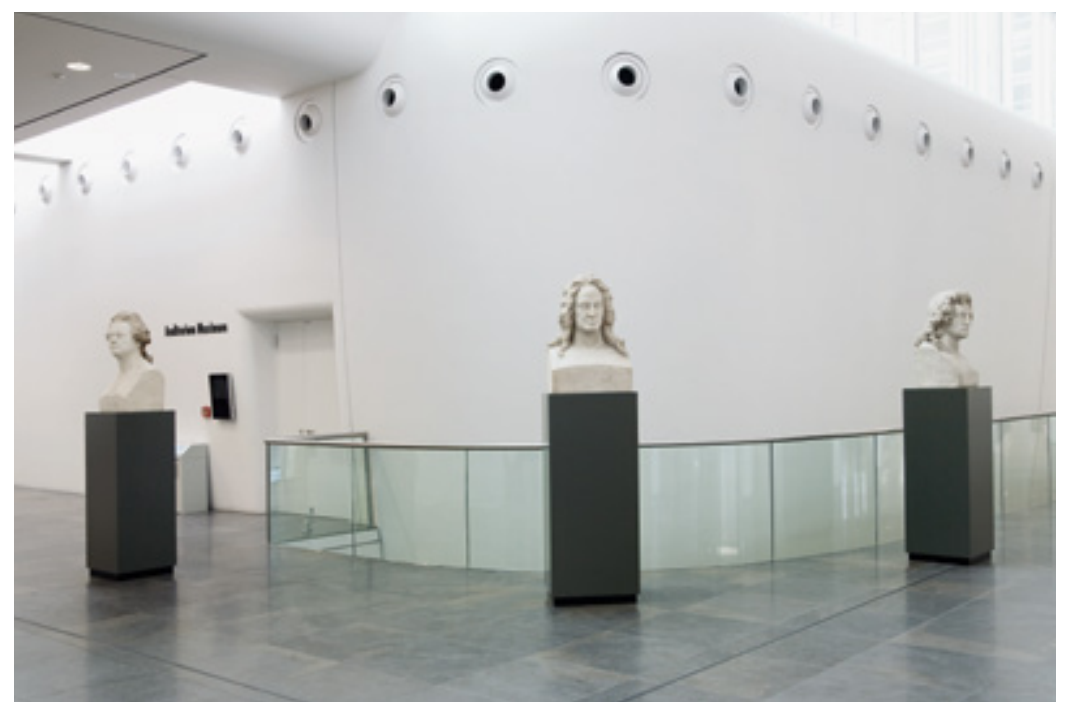

Abb. 14: Leipzig, Foyer des Neuen Augusteums der Universität Leipzig, 2012, Fotografie, Leipzig, Kunstbesitz der Universität Leipzig.

zum „Leibnizforum“ umbenannt ist, nun erneut präsentiert. Gemeinsam mit den Büsten für Goethe und Lessing steht die kolossale Leibnizbüste auf hohen Sockeln in dem erst 2012 wieder eröffneten Neuen Augusteum (Abb. I4).

\section{Z U S A M M E N FAS S U N G}

Im I8. Jahrhundert kam es in Leipzig nicht zu einer Ehrung von Leibniz durch ein öffentliches oder universitäres Denkmal, obschon Gottsched dies propagiert hatte. Erscheint der Vorschlag zu Gottscheds Zeiten wohl aufgrund des bürgerlichen Status des Gelehrten und aufgrund von finanziellen Schwierigkeiten als zu unbequem und unpassend, wirkte Gottscheds Leibnizrezeption auf die Bestückung der universitären Neubauten mit Ensembles maßgeblich ein. I846 wurde im Augusteum mit königlicher Erlaubnis eine kolossale Leibnizbüste als Denkmal im Raum mit dem königlichen Standbild konfrontiert. Anlass der universitären Einhegung war die Jubiläumsfeier zum 200. Geburtstag des Gelehrten im Jahr I846 und die Gründung der Sächsischen Akademie der Wissenschaften. Die Kolossalbüste nahm gegenüber der programmatischen Ausstattung mit Professorenbüsten und Reliefs in Gegenüberstellung zum Modell des königlichen Denkmals eine Sonderstellung ein, da sie anders als die Büsten im Arkadenhof der Universität Wien weniger einer humanistisch orientierten Gelehrtenmemoria als einem goethezeitlichen Geniekult entsprach. Zeitgleich liefen Planungen für ein städtisches Leibniz-Monument. Weniger im Interesse eines Konzeptes der Raumausstattung als im Interesse einer Verehrung autoritärer Vorbilder fügten sich die Leibniz- und Goethebüsten I866 zu einem Ensemble der Aula, das den Geniekult weiterhin unterstrich. Neu- und Umbauten durch Arwed Roßbach führten nach I897 schließlich zur Zerlegung des additiven Programmes in der Aula des Augusteums und leiteten in die Verdrängung nahezu aller Gelehrtenbildnisse in die Wandelhalle über. Davon war auch das Leibniz-Goethe-Ensemble betroffen. Während die Kolossalbüsten 
um 1900 dort offenbar nicht mehr als Vertreter des Geniekultes verstanden wurden, konnte das städtische Denkmal für Leibniz auf dem universitären Gelände eingemeindet werden. Anschließend versetzte man die Leibnizbüste in eines der Treppenhäuser, wo sie bis zur Zerstörung des Gebäudes verblieb. Seit Gottsched ist Leibniz, wenn auch mit unterschiedlichen Akzentsetzungen, als einer der herausragendsten Gelehrten der Universität Leipzig geehrt worden. Unter Berufung auf die Gelehrtenmemoria in der Ehrenhalle der Aula konnte die Leibnizbüste von I846 noch zu Zeiten der sozialistischen Gewaltherrschaft vor der Sprengung von 1968 gerettet werden - wohl im Sinne einer Vereinnahmung des erhaltenswürdigen „humanistischen Erbes“.

Abbildungsnachweis: Abb. I, 8, I2, I3: Universitätsarchiv Leipzig; Abb. 2, 4, 5, Iо, II: Stadtgeschichtliches Museum Leipzig; Abb. 3: Staatliche Kunstsammlungen Dresden; Abb. 6, 9: Kustodie der Universität Leipzig (Aufnahmen: Karin Kranich); Abb. 7: Bildarchiv Preußischer Kulturbesitz; Abb. I4: Kustodie der Universität Leipzig (Aufnahme: Marion Wenzel). 


\title{
GELEHRTENGEDENKEN IN DER UNIVERSITÄTSSTADT GIESSEN*
}

\author{
Sigrid Ruby
}

W er heute nach Gießen fährt, sei es auf der Straße oder mit der Eisenbahn, wird über das Ortsschild oder die Lautsprecherdurchsage darüber belehrt, in eine „Universitätsstadt“ gekommen zu sein. Tatsächlich hat das abseits der Metropolen im ländlichen Mittelhessen gelegene Gießen eine lange Tradition nicht nur als Hauptstadt der Provinz bzw. des Regierungsbezirks, sondern auch als Sitz einer Volluniversität, die immerhin schon 1607 gegründet wurde. Heute ist die Justus-Liebig-Universität die bedeutendste Arbeitgeberin der Stadt, und die Studierenden aller fünf Gießener Hochschulen machen fast die Hälfte der mittlerweile gut 80.00o Einwohner aus. Die Stadt hat damit die unter Umständen höchste Studierendendichte in der Bundesrepublik Deutschland. Mit Fug und Recht, so scheint es, preist sich Gießen als „Universitätsstadt“ und leitet demnach seine Identität maßgeblich von der Hochschule ab. Unweigerlich stellt sich hier die Frage, inwiefern die Universität tatsächlich das semantische Gefüge der Stadt bestimmt und in ihrem Erscheinungsbild ästhetisch erfahrbar wird. Wie steht es insbesondere um die Gelehrtenmemoria an einem solchen Standort mit seiner qua Uni- versität nachgerade institutionalisierten Gelehrtenschaft?

Diese Fallstudie stellt wesentliche Aspekte und Monumente des Gelehrtengedenkens in Gießen von der Frühen Neuzeit bis in die Gegenwart vor bzw. führt sie erstmals in diachroner Perspektive zusammen. ${ }^{\mathrm{I}}$ Die Synopse erlaubt es, ein Set von Fragen struktureller Art zu konturieren. Deren vertiefende Diskussion erfordert allerdings den Vergleich und folglich die Hinzuziehung weiterer Fallstudien, die den Umgang mit der ,beweglichen Masse' Gelehrtenmemoria in anderen (europäischen) Universitätsstädten untersuchen. So ist zu fragen, wie sich das Gelehrtengedenken in Gießen seit dem frühen 17. Jahrhundert veränderte und welche epochenspezifischen Merkmale dabei hervortreten, sodass im Gegenzug besondere, unter Umständen ortstypische Qualitäten benannt werden können. Wann gab es ein gesteigertes Denkmalbedürfnis, wann nicht, und was waren jeweils die Gründe? Welche Rolle spielten und spielen Spezifika des Ortes, die Topografie und binnenräumliche Struktur der Stadt? Welche Medien, Gattungen und Gestaltungselemente wurden und werden bevorzugt eingesetzt? Welche Insti-

Ich danke nachdrücklich der Gießener Historikerin und Journalistin Dagmar Klein M. A. für überaus wertvolle Hinweise zum Thema, für die Bereitstellung von Bildern und Dokumenten und ihren kritischen Sachverstand.

I Eine wissenschaftlich grundierte Zusammenschau der Gelehrtenmemoria in Gießen existiert bislang nicht. Auf einschlägige Studien zu den hier vorgestellten Bildnissen, Denkmälern und Monumenten wird - sofern vorhanden - an den entsprechenden Stellen verwiesen. 
tutionen, Akteure und Interessengruppen waren und sind jeweils involviert? Und welche Schlussfolgerungen lassen sich unter Umständen für die
Zukunft, d.h. für Perspektiven der Gelehrtenmemoria in mittelgroßen Universitätsstädten wie Gießen ziehen?

\section{DIE ANFÄNGE DER GIESSENER UNIVERSITÄT}

Die frühneuzeitlichen Anfänge der Gießener Hochschule sind eng mit der Geschichte der Universität im benachbarten Marburg verknüpft. 1527 hatte Landgraf Philipp der Großmütige (1509-1567) die Marburger Universität als erste lutherische Hohe Schule in Hessen gegründet. Mit dem am I6. Juli I54I ergangenen kaiserlichen Privileg erhielt die Alma Mater Philippina das Graduierungsrecht. Infolge der Erbteilung des Fürstentums in zwei Landgrafschaften 1604 und der zunehmend calvinistischen Ausrichtung Hessen-Kassels, inklusive der Universität in Marburg, erging am I9. Mai I607 das Privileg Kaiser Rudolfs II. zur Gründung der Gießener Universität in der weiterhin der reinen lutherischen Lehre anhängenden Landgrafschaft Hessen-Darmstadt. ${ }^{2}$ Die Academia Giessena bzw. nach ihrem Gründer Landgraf Ludwig V. (I577-I626; Abb. I) benannte Ludoviciana in der Festungsstadt Gießen war demnach eine glaubens- und territorialpolitisch motivierte Gegengründung zur Marburger Universität und im theologischen Disput der Zeit bedeutsam.

Hinsichtlich der Gelehrtenmemoria sind für die Phase der Gießener Universitätsgründung und -etablierung im frühen 17. Jahrhundert vor allem zwei Ensembles anzuführen: zum einen die umfangreiche Folge gemalter Professorenbildnisse in der Universität, zum anderen die

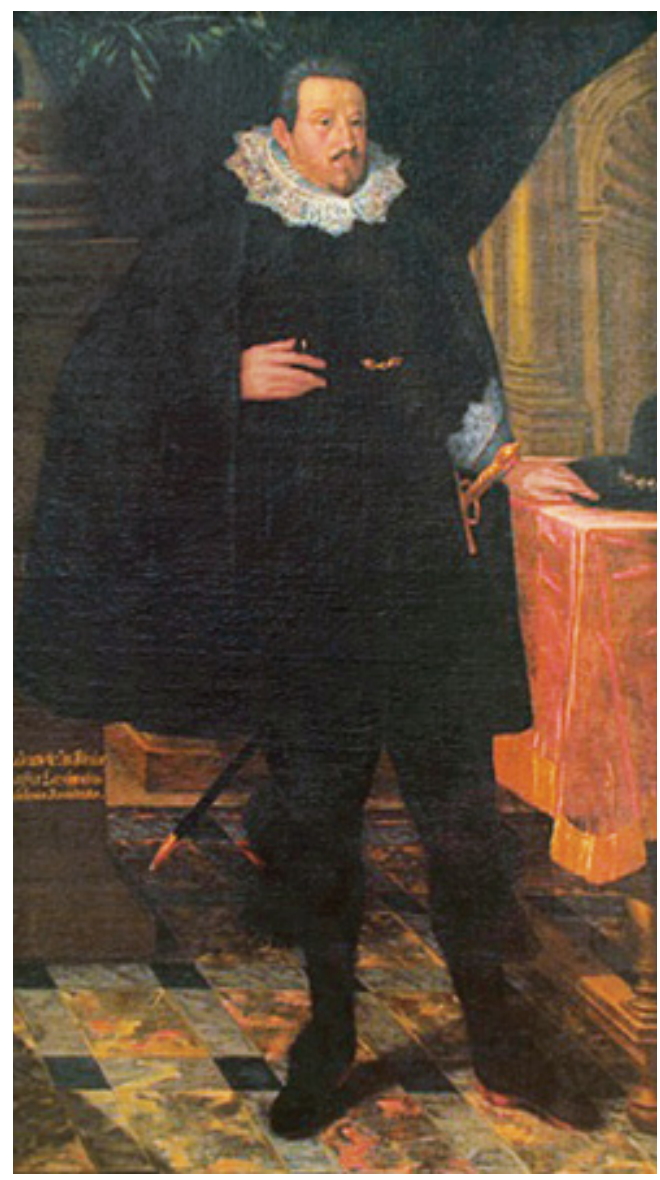

Abb. I: anonym (Christoph Jobst?), Ganzfigurenporträt von Landgraf Ludwig V. von Hessen-Darmstadt, ca. 1624-30, Öl auf Leinwand, [ca. $200 \times$ IIS cm], Universität Gießen. plastischen Grabdenkmäler für die ersten Rek-

2 Zunächst, seit dem I0. IO. I605, hatte es in Gießen ein Gymnasium illustre und ein Pädagogium gegeben. - Zur Geschichte der Gießener Universität vgl. P. Moraw, Kleine Geschichte der Universität Gießen, Gießen I99o (2. Aufl.); E.-M. Felschow/C. Lind, Ein hochnutz, nötig und christlich Werck. Die Anfänge der Universität Gießen vor 400 Jahren. Gießen 2007; E.-M. Felschow/C. Lind/N. Busse, Krieg, Krise, Konsolidierung. Die „zweite Gründung“ der Universität Gießen nach 1945, Gießen 2008.

3 Zur Kultur des Gelehrtenstandes in der Frühen Neuzeit vgl. u.a. M. FüsseL, Gelehrtenkultur als symbolische Praxis. Rang, Ritual und Konflikt an der Universität der Frühen Neuzeit, Darmstadt 20I2. S. a. Die Praktiken der Gelehrsamkeit in der Frühen Neuzeit (hrsg. von H. Zedelmaier/M. Mulsow), Tübingen 20or; Frühneuzeitliche Univer- 


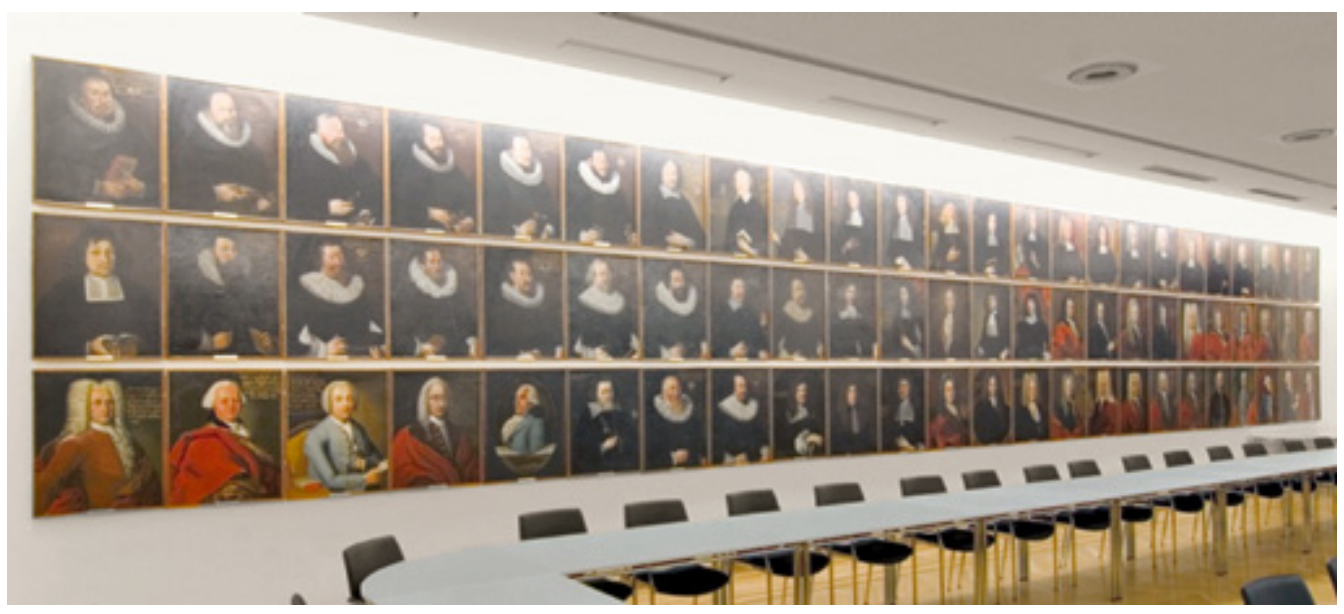

Abb. 2: Gießen, Universitätshauptgebäude, Professorengalerie im Senatssaal, I63I bis Ende I8. Jahrhundert.

toren in der Totenkapelle auf dem Gemeindefriedhof. Beide Ensembles waren wichtig für die symbolische Zurschaustellung und Behauptung des frühneuzeitlichen Gelehrtenstandes als Korporation, und sie zeigen, dass diese noch junge Korporation - zumal in der problematischen Anfangszeit ihres Bestehens - ein ausgeprägtes Repräsentationsbedürfnis besaß bzw. zuerkannt bekam. ${ }^{3}$

Die historische Professorengalerie ist nahezu vollständig erhalten und wird heute in dichter Hängung im Senatssaal des I88o eingeweihten Universitätshauptgebäudes an der Ludwigstraße präsentiert (Abb. 2 und 7). ${ }^{4}$ Sie wurde interessanterweise zu einem Zeitpunkt initiiert, als die Gießener Universität offiziell gar nicht mehr existierte. Denn infolge des hessischen Erbfolge- streits war das Marburger Land I623 wieder dem Haus Hessen-Darmstadt zugesprochen worden, sodass es fortan und bis 1649 wieder nur eine „Samtuniversität“ der hessischen Fürstentümer gab, nämlich die Marburger, mit dezidiert lutherischer Ausrichtung. Bald nach der Hundertjahrfeier der Philippina ordnete Landgraf Georg II. (I605-I66I) von Hessen-Darmstadt per Erlass vom Io. April I629 an, dass wie bey ausländischen auch theils deutschen Universitäten Bildnisse aller Professoren angefertigt würden, und zwar in einer gleichen größ Und Form, mit anzeig de $\beta$ nahmens, auch der Jahrzahl seines altters Und der geburth Christi. Die Bildnisse sollten bey Unserer Universität bracht und erhaltten werde[n]. Der Landgraf verfügte nicht, wo die Porträts hängen sollten, meinte aber: Es werden sich auch mit der

sitätskulturen (hrsg. von B. Krug-Richter/R.-E. Mohrmann), Köln et al. 2009. - Zur visuellen Repräsentation Gelehrter im Mittelalter vgl. A. von HüLSEN-Esch, Gelehrte im Bild. Repräsentation, Darstellung und Wahrnehmung einer sozialen Gruppe im Mittelalter, Göttingen 2006.

4 Zur Gießener Professorengalerie vgl. I. Sснnаск, Beiträge zur Geschichte des Gelehrtenporträts (= Historische Bildkunde 3), Hamburg 1935; S. Rösch, Die Professorengalerie der Gießener Universität. Ikonographische und genealogische Betrachtungen, in: Ludwigs-Universität, Justus-Liebig-Hochschule: 1607-1957. Festschrift zur 350-Jahrfeier, Gießen 1957, S. 433-442; N. Werner, Die Professoren-Galerie und ihre Portraitmaler, in: Panorama - 400 Jahre Universität Gießen - Akteure, Schauplätze, Erinnerungskultur (hrsg. von H. CARL et al.), Frankfurt a. M. 2007, S. 244-249; ders., Professoren-Galerie, in: 375 Jahre Universität Gießen I607-1982. Geschichte und Gegenwart. Ausstellungskatalog, Gießen 1982, S. 50-54; E. Sснміdт, Die Gießener Universitätsmaler Christoph Maximilian Pronner und Friedrich Johann Ludwig Berchelmann und der Kunstmaler Johann Nikolaus Reuling, Gießen 1968. 


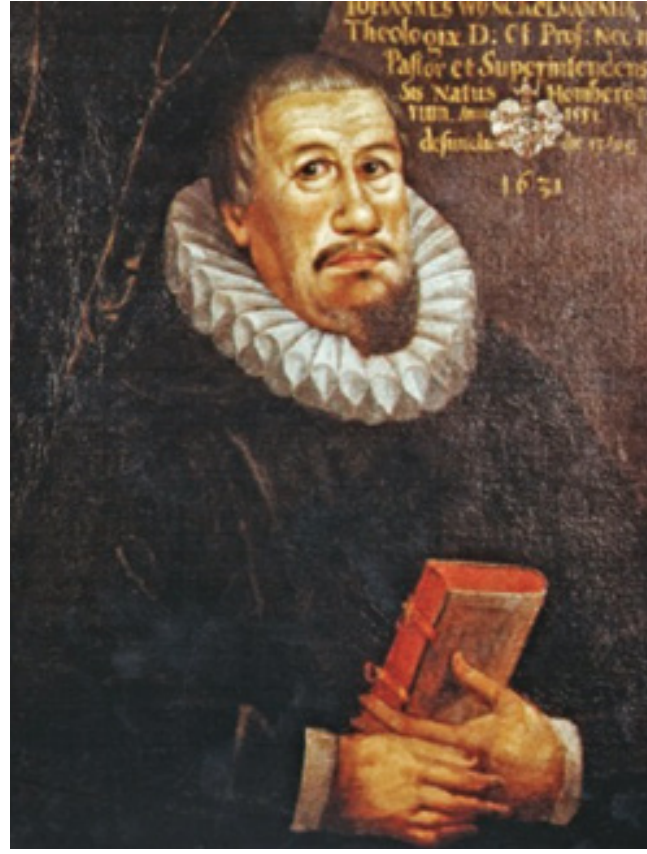

Abb. 3: Johannes B. Becker, Porträt des Theologen Johannes Winckelmann, I55I-I626 (aus der Professorengalerie), I63I, Öl auf Leinwand, ca. $75 \times 60 \mathrm{~cm}$, Gießen, Universitätshauptgebäude.

Zeit gebeu und örter finden laßen, dahin man solche Contrafait füglich könne faßen und Ufhengen..$^{5}$ Die ersten dieser demnach für keinen bestimmten Ort gedachten Bildnisse wurden im Marburger Bibliothekssaal präsentiert und gelangten erst nach dem Westfälischen Frieden mit der vertraglich geregelten Teilung der Universitätsgüter (I650) in das neuerlich zum Universitätsstandort erhobene Gießen. ${ }^{6}$ Hatte Georg II. in der von ihm begründeten Professorengale-

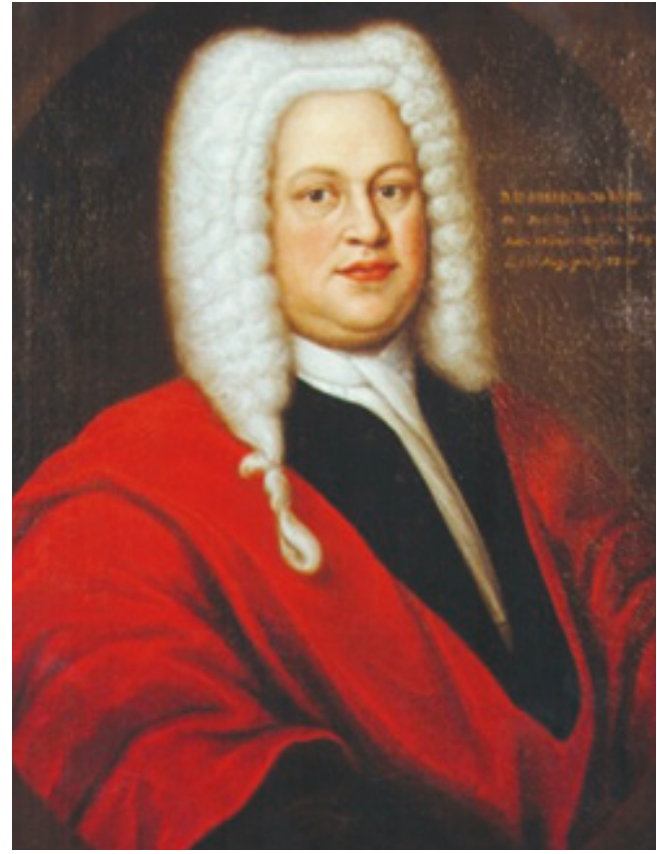

Abb. 4: Christoph Maximilian Pronner, Porträt des Juristen Johann Friedrich Wahl, I693-I755 (aus der Professorengalerie), I736, Öl auf Leinwand, ca. $75 \times 60 \mathrm{~cm}$, Gießen, Universitätshauptgebäude.

rie vermutlich ein Mittel zur Bekräftigung und Stabilisierung der wiedervereinten gesamthessischen Hochschule gesehen, so wurde das Format auch nach deren Teilung an beiden Standorten separat fortgeführt. ${ }^{7}$ I650 waren 23 Bildnisse nach Gießen gelangt, und die Professorengalerie wuchs dort bis in das ausgehende I8. Jahrhundert auf 108 Einzelporträts an, von denen sich immerhin 106 erhalten haben. ${ }^{8}$ Die Hüftbildnisse sind in Öl auf Leinwand gemalt, mes-

5 Universitätsarchiv Gießen, Allg. A. 5. Codex rescriptorium Principalium (Tomus I. I629 April Io), zit. nach C. Graepler, Imagines professorum Academiae Marburgensis. Katalog von Bildnissen Marburger Hochschullehrer aus 5 Jahrhunderten, Marburg 1977, S. XIV. Der Malerlohn wurde anfangs von der Universität bestritten, später Berufene mussten die Hälfte selber zahlen.

6 Vgl. ebd., S. XX.

7 Auch an der 1653 wieder eröffneten Landesuniversität in Marburg griff man das repräsentative Format der Professorenbildnisse auf. Vgl. Graepler, Imagines (zit. Anm. 5); Schnack, Beiträge (zit. Anm. 4). Der Bestand wird aktuell nicht öffentlich präsentiert, sondern - nach Aussage des Leiters des Marburger Universitätsmuseums, Herrn Dr. Christoph Otterbeck - im Depot verwahrt.

8 Analog der Professorengalerie entstand in der Stadt Gießen ab I663, einsetzend mit dem Bildnis von Johann Bal- 
sen durchschnittlich 75 x $60 \mathrm{~cm}$ und können sieben lokalen Künstlern zugeschrieben werden (Abb. 2-4). Dem Erlass des Landgrafen nachkommend, sind die Porträts beschriftet, zumeist in der oberen Bildzone rechts des Kopfes und anfangs auch das Familienwappen integrierend. In Gießen hingen die Bildnisse zunächst im alten, I6II vollendeten Kollegiengebäude und wurden nach dessen Abriss 1838 und einer gründlichen Restaurierung in den 1850 neu errichteten, heute nicht mehr erhaltenen Aulabau überführt. Dort präsentierte sich die Professorengalerie geschlossen, in drei Reihen übereinander gehängt und begleitet von historischen Ganzfigurenporträts der hessischen Landesfürsten. ${ }^{9}$

Seriell angelegte Professorenbildnisse sind ein typisches Repräsentationsmedium der in der Frühen Neuzeit gegründeten protestantischen Universitäten, und der Erlass des hessischen Landgrafen bezeugt seine Kenntnis davon. Vergleichbare Ensembles fanden sich in Tübingen und Leiden, bald auch in Jena, Leipzig und Basel. ${ }^{\circ}$ Aufgrund der wachsenden Zahl der Porträts wurden sie häufig auseinandergerissen und auf unterschiedliche Räume der Universität verteilt, mitunter auch ganz oder in Teilen ins Depot verbannt. In Gießen ist das frühneu- zeitliche Kollegium heute wieder in einem der universitären Repräsentationsräume versammelt, zur Schau gestellt als eine strenge Abfolge formal ähnlicher, gleich großer Bildnisse, deren horizontale Reihung der hierarchischen Ordnung der vier historischen Fakultäten - Theologie, Jurisprudenz, Medizin und Philosophie - und der Chronologie folgt. ${ }^{\text {II }}$ Das im frühen 17. Jahrhundert in Marburg begonnene, I650 nach Gießen transferierte und dort bis in das späte I8. Jahrhundert gewachsene Ensemble steht ästhetischsymbolisch für das korporative Selbstverständnis der Gelehrten als ein Kollegium (universitas) von Gleichgesinnten. Die wuchtige, fakultätenübergreifende Professorengalerie im Senatssaal repräsentiert die lange Tradition der Gießener Universität, die in den hier stattfindenden Gremiensitzungen, Versammlungen, Festvorträgen etc. performativ bekräftigt und fortgeführt wird.

Im Zuge der Wiedereröffnung der Gießener Hochschule nach dem Zweiten Weltkrieg (1946 bzw. 1957) griff man das am Ort bereits etablierte Medium der gemalten Porträtserie insofern auf, als nun - zusätzlich zur abgeschlossenen historischen Professorengalerie - eine auf kontinuierliches Wachstum angelegte Rektoren- und Präsidentengalerie eingerichtet und das tradierte

thasar Schupp, auch eine Ratsherrengalerie (heute Leib'sches Haus; je ca. 30 x $30 \mathrm{~cm}$ groß, auf Holz, Leinwand oder Blech gemalt), die bis I8I4 fortgeführt wurde und das städtische Pendant zur landgräflichen Initiative darstellt.

9 Vgl. Rösch, Professorengalerie (zit. Anm. 4), S. 433; Sснnack, Beiträge (zit. Anm. 4), S. 2I/Anm. 42. Eine ähnliche Hängung, ebenfalls in der Aula, ist für die Marburger Professorengalerie im ausgehenden 19. Jahrhundert bezeugt. Vgl. die Abb. in Graepler, Imagines (zit. Anm. 5), S. XXIII. - Nach Schnack (S. 20) waren die Professorenbildnisse zu ihrer Zeit, d.h. 1935, auf sechs Hörsäle des Universitätsgebäudes und das Dekanat der theologischen Fakultät verteilt.

Io Systematische Untersuchungen zur Professorengalerie als Typus stehen m. W. noch aus. Zu den Leipziger Professorenbildnissen vgl. R. Hiller von Gaertringen/N. Horsch, Incitamenta animi. Die Professorengalerie des I7. und I8. Jahrhunderts der Universitätsbibliothek Leipzig, in: Das Porträt als soziale Praxis (hrsg. von E. KREMs/S. RubY), Berlin, 20I6, S. 28I-299; zu den Tübinger Professorenbildnissen vgl. R. Scholl, Die Bildnissammlung der Universität Tübingen I477-I927, Stuttgart 1927; W. Fleischhauer, Die ,Imagines Professorum Tubingensium‘. Entstehungsgeschichte und Bildnisse, in: Erhard Cellius Imagines Professorum Tubingensium 1596 (hrsg. von H. Decker-Hauff/W. Setzler, Bd. 2 (Kommentar und Text in Übersetzung), Sigmaringen 198I, S. 2I-32; S. KNÖLL, Creating academic communities. Funeral monuments to professors at Oxford, Leiden and Tübingen: $1580-1700$, Equilibris Publ. 2003, S. 59-70; A. Ackermann/St. Freyer (Hg.), Standesgemäß? Jenaer Professorenporträts zwischen Adel und Nichtadel, Weimar 20I5.

II Einige der Professorenbildnisse wurden 1957 im Zuge der 350-Jahr-Feier der Universität aus dem Senatssaal in die Aula und andere Räume transferiert, wo sie dann verblieben. Die erneute Zusammenführung aller erhaltenen Porträts im Senatssaal, mithin die heutige Präsentation, wurde erst 1993 abgeschlossen. 


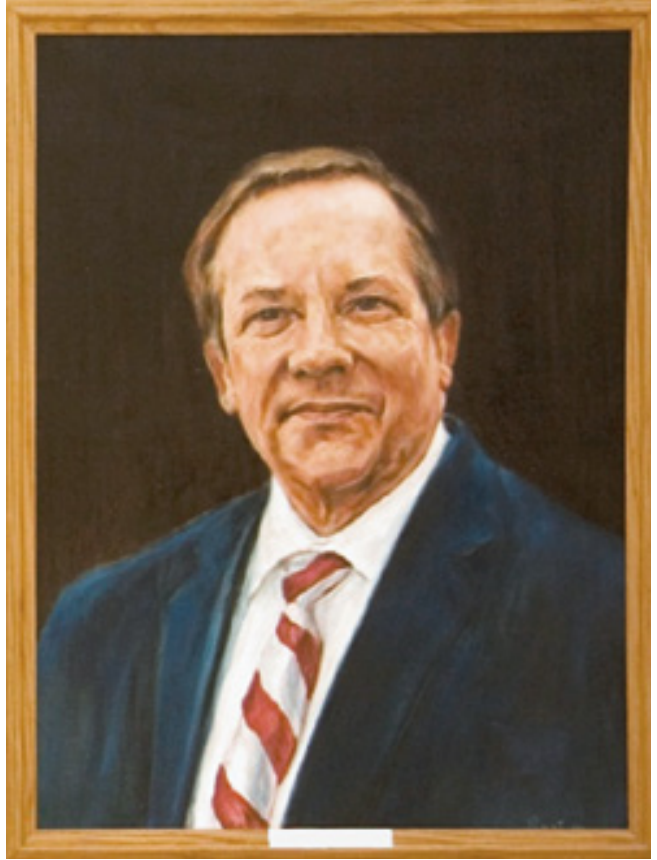

Abb. 5: Rolf Stieger, Bildnis Stefan Hormuth, 1949-2010 (aus der Rektoren- und Präsidentengalerie), 2010, Öl auf Leinwand, Gießen, Universitätshauptgebäude.
Format somit zum Privileg der leitenden Funktionsträger deklariert wurde. Die von unterschiedlichen Künstlern in Öl gefertigten Halbfigurenbildnisse der Rektoren bzw. Präsidenten seit 1946 werden in der 1907 errichteten, dem Universitätshauptgebäude in der Innenstadt angegliederten Aula präsentiert (Abb. 5-7). ${ }^{12}$ Die Porträtfolge umfasst derzeit 2I Bildnisse, die friesartig an einer Längswand der Aula gehängt sind und begleitet werden von zwei historischen Ganzfigurenporträts, die die früheren Landesherrn, den ersten Landgrafen von Hessen-Darmstadt und Gründer der Universität Ludwig V. (Abb. I) sowie den letzten Großherzog von Hessen und Rhein Ernst Ludwig (I868-1937), vorstellen. Überspitzt formuliert, wird heute in der Gießener Universitätsaula weniger der Wissenschaft als vor allem ihres administrativen Managements gedacht. In der Zusammenführung der Rektoren- und Präsidentenbildnisse des 20. und 2I. Jahrhunderts mit relativ größeren Porträts historischer Landesfürsten zeigen sich wiederum

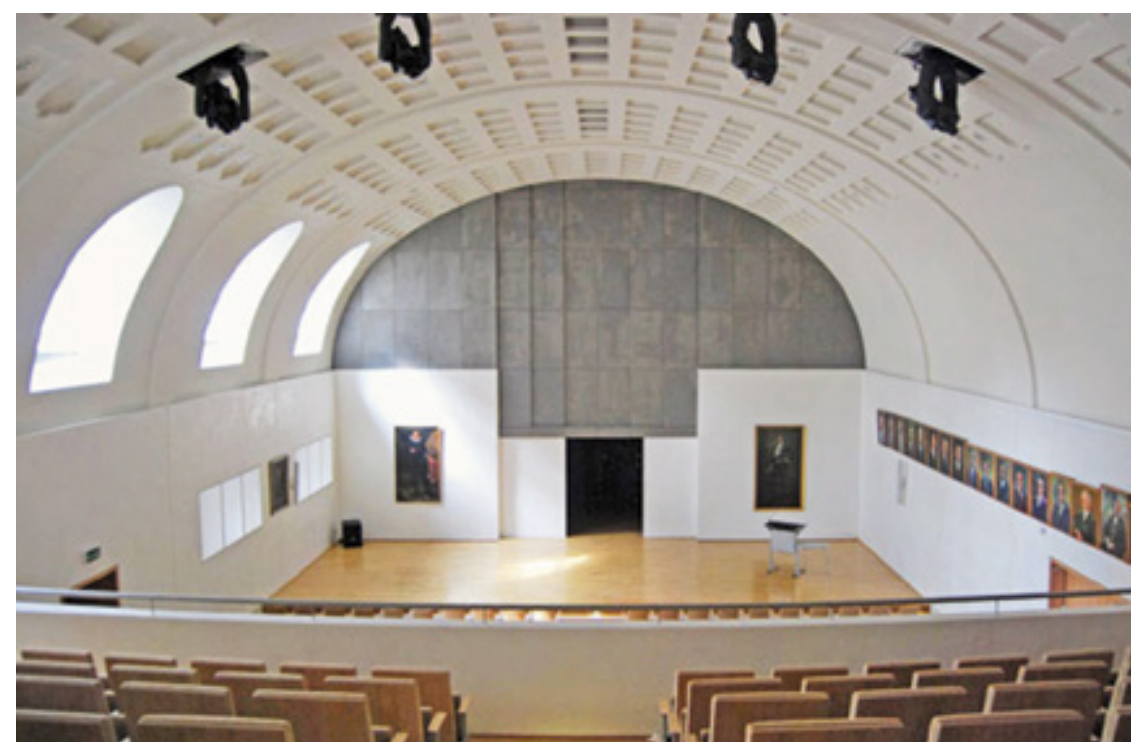

Abb. 6: Gießen, Universitätshauptgebäude, Rektoren- und Präsidentengalerie in der Aula, Ig6oer-Jahre bis 2010 .

I2 Der Großteil der Bildnisse stammt von dem Darmstädter Maler Carl Gunschmann (I895-I984) und dem Hamburger Maler Rolf Stieger (geb. 1960). 


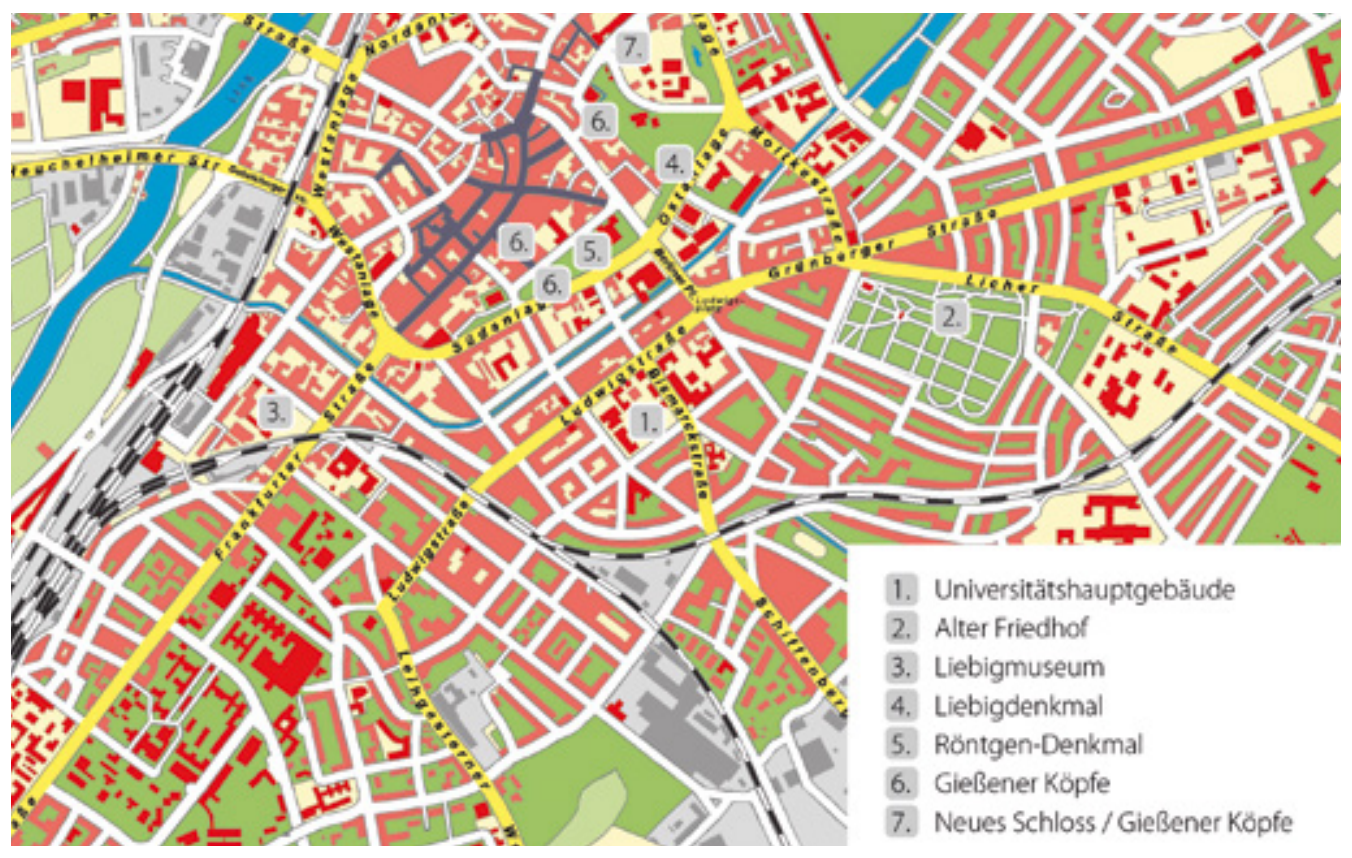

Abb. 7: Topografie der Gelehrtenmemoria in Gießen.

Relikte feudalistischer Herrschaftsbeziehungen, die - wenngleich asynchron und unglaubwürdig inszeniert - einer modernen, auf Selbstverwal- tung gründenden und das Berufungsrecht besitzenden Universität nicht angemessen scheinen.

\section{PROFESSORENGR ÄBER UND - GRABDENKM ÄLER}

\section{AUF DEM ALTEN FRIEDHOF}

In Erfahrung der Pestepidemie 1529 hatte Landgraf Philipp der Großmütige, zusammen mit dem Bau der Gießener Festungswälle 1530-33, auch einen neuen Friedhof (heute Alter Friedhof) im Osten außerhalb der Stadt anlegen lassen (Abb. 7). Erst 1623-25, d.h. während der zeitweiligen Aufhebung der 1607 gegründeten Universität, wurde eine feste Kapelle auf dem Friedhofsgelände (Abb. 8) errichtet. ${ }^{\mathrm{I3}}$ In deren Innerem finden sich repräsentative Epitaphi- en für die drei ersten Rektoren der Ludoviciana (Abb. 9 und Io), die Professoren der Theologie, mithin der ranghöchsten Fakultät, und zugleich Superintendenten der Landgrafschaft Hessen-Darmstadt waren. Die Grabdenkmäler demonstrieren die damals übliche enge personelle Verzahnung von Amtskirche, Hochschuladministration und -lehre.

Das Epitaph des Gründungsrektors Johannes Winckelmann (I55I-I626) ${ }^{14}$ an der südlichen

I3 Die erste, in der Zwischenzeit stark veränderte bzw. historistisch rekonstruierte „Kapelle auf dem Gottesacker“ hatte der Gießener Baumeister und Gastwirt Johannes Ebel zum Hirsch erbaut. Vgl. Denkmaltopographie Bundesrepublik Deutschland. Kulturdenkmäler in Hessen. Universitätsstadt Gießen (hrsg. vom Landesamt für DenkmalpfleGe Hessen), Braunschweig/Wiesbaden 1993; D. KleIn, Die Gießener Friedhöfe. Erinnerungsorte der Universitätsgeschichte, in: Panorama (zit. Anm. 4), S. 250-255.

I4 Johannes Winckelmann war zunächst an der Marburger Universität tätig, wechselte aber infolge der zunehmend 


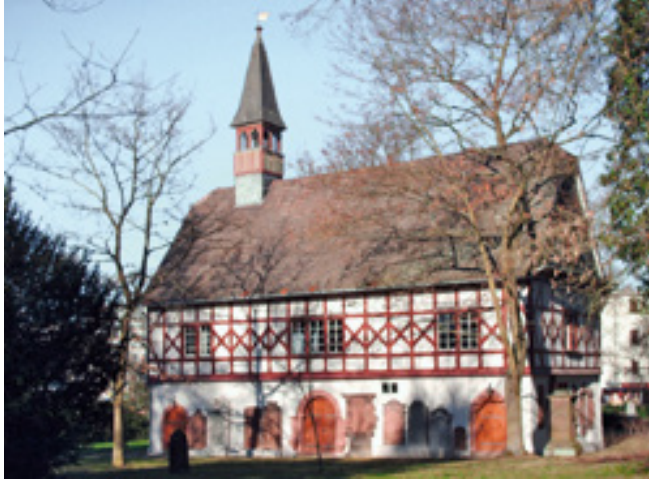

Abb. 8: Johann Ebel, Totenkapelle, I623-25, Gießen, Alter Friedhof

Wand ließ laut Inschrift seine Witwe errichten. Gegenüber wurden die vermutlich ebenfalls von den Familien in Auftrag gegebenen Epitaphien von Winckelmanns Nachfolgern, den Theologen Justus Feuerborn (1587-1656) und Peter Haberkorn (1604-1676), platziert. ${ }^{15}$ Die drei als Hochreliefs aus farbig gefasstem Sandstein gearbeiteten Grabdenkmäler sind im Stil eines ländlichen Barocks gehalten und untereinander sehr ähnlich, sodass das korporative Moment der Amtsfolge betont ist. Das Hauptfeld nimmt jeweils die annähernd lebensgroße, plastisch hervortretende und frontal erfasste Figur des Verstorbenen ein, der offenbar den Bildnissen der Professorengalerie abgeschaute porträthafte Züge trägt (Abb. 3 und 9) und in den üblichen schwarzen Theologentalar („Luthertalar“) mit weißer Halskrause gekleidet ist. In den Händen hält er ein Buch als Zeichen der Gelehrsamkeit, seitlich des Kopfes sind Wappen angebracht. Der architektonische Rahmen ist mit unterschiedlichen farbig gefassten Schmuckelementen versehen.

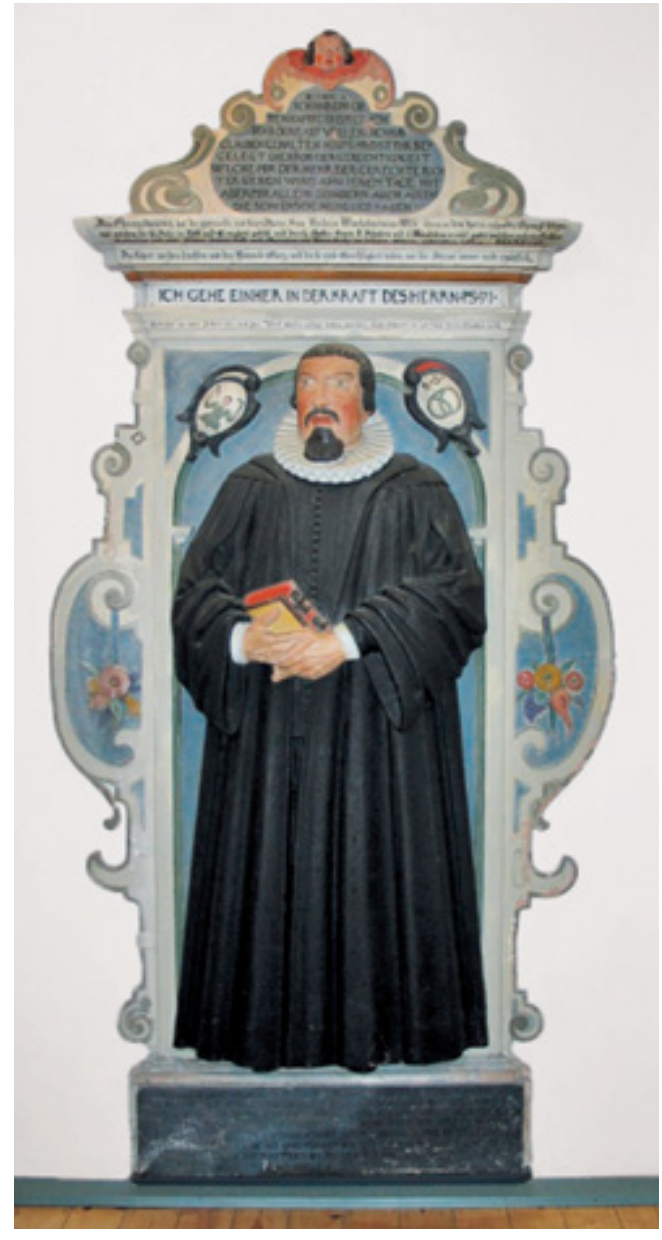

Abb. 9: Adam und Philipp Franck (zugeschr.), Epitaph für Johannes Winckelmann (I55I-I626), nach I626/I63oer-Jahre, Sandstein, farbig gefasst, Gießen, Alter Friedhof, Kapelle.

Inschriften im Sockelbereich und der abschließenden oberen Zone referieren Biografisches und biblische Texte.

calvinistischen Ausrichtung der Hochschule nach Gießen, wo er zunächst die Leitung des Gymnasiums und dann die erste Professur für Theologie an der neuen Ludwigs-Universität übernahm. Winckelmann war in der Folgezeit mehrfach Rektor und wurde I6I2 zudem Superintendent der Landgrafschaft Hessen-Darmstadt. Er wurde am I6. 8. I626 auf dem Gießener Kirchhof beigesetzt. Vgl. H. Нaupt/G. Lehnert, Chronik der Universität Gießen, 1607-1907, Gießen 1907, S. I02

I5 Zu Justus Feuerborn vgl. H. Schüssler, Feuerborn, Justus, in: Neue Deutsche Biographie, Bd. 5, Berlin I96I, S. II5. Zu Haberkorn, dem Nachfolger und Schwiegersohn Feuerborns, vgl. K. Dienst, Haberkorn, Peter, in: Neue Deutsche Biographie, Bd. 7, Berlin 1966, S. 390-39I. 


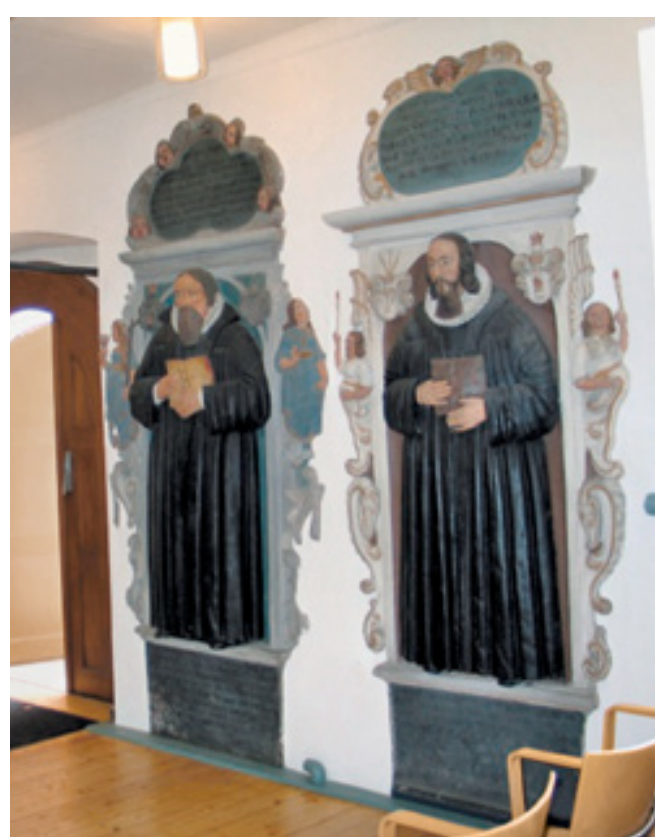

Abb. Io: anonym, Epitaph für Justus Feuerborn (1587-1656), I65oer-Jahre, Sandstein, farbig gefasst/Matthias Wenzel, Epitaph für Peter Haberkorn (1604-I676), I67oer-Jahre, Sandstein, farbig gefasst [Bildplatte $162 \times 83,5 \mathrm{~cm}$, vgl. Graepler 1977, S. 48], I65oer/I670er-Jahre, Gießen, Alter Friedhof, Kapelle.

Die beiden älteren Gießener Epitaphien werden der Bildhauerfamilie Franck, dasjenige Haberkorns dem Künstler Matthias Wenzel zugeschrieben. ${ }^{16}$ Die Brüder Adam und Philipp Franck waren zeitgleich auch im Dienste der hessischen Landgrafen in Marburg tätig und schufen dort unter anderem das Grabdenkmal für den Gründer der Gießener Universität, Landgraf Ludwig V., und seine Gemahlin Magdalena von Brandenburg (Marienkirche $1626-3 \mathrm{I}) .^{17}$ Das Kenotaph des in der Stadtkirche in Darm- stadt bestatteten Ludwig entstand im Auftrag des Sohnes, Georgs II. von Hessen-Darmstadt, und erscheint als ein weiteres kunstpolitisches Bekenntnis dieses Landgrafen zur Einheit Hessens und der Verankerung einer lutherischen „Samtuniversität" in Marburg. Es sollte explizit als eine Kopie des im Chor der Marienkirche unmittelbar benachbarten Epitaphs für Landgraf Ludwig IV. von Hessen-Marburg und seine Gemahlin Hedwig (err. 1590-92) erscheinen und auch dessen theologisch-lutherisches Programm replizieren.

Die drei Rektoren-Monumente in der Gießener Friedhofskapelle entspringen der regionalen Kunstproduktion, und sie schließen typologisch - hinsichtlich des Ganzkörperporträts - sowie werkstatttechnisch - bezogen auf die vermutlich verantwortlichen Künstler - an Bildnisse und Grabdenkmäler vor allem derjenigen hessischen Landgrafen an, die sich explizit zum reinen lutherischen Glauben bekannten und politisch dafür eintraten. Ein diesbezüglich eminent wichtiger Fürst war Ludwig V., der Gründer der Gießener Universität, dessen Marburger Kenotaph die dynastische Verbundenheit mit Ludwig IV. zum Ausdruck bringt, wie auch die Gießener Theologen-Epitaphien durch ihre im Laufe des 17. Jahrhunderts gleichbleibende Gestaltung die Kontinuität des Rektoren- und Superintendentenamtes an ihrem treu der reinen lutherischen Lehre verpflichteten Wirkungsort Gießen anschaulich machen. Im künstlerischen, formal-ästhetischen und raumgreifenden Anspruch bleiben sie hinter den Grabdenkmälern der Landgrafen deutlich zurück, doch offenbart sich hier ein Selbstverständnis der Gelehr-

I6 Vgl. Denkmaltopographie (zit. Anm. I3), S. 383; H. Lonenz, Die Landgrafengräber und der Hochaltar in der lutherischen Pfarrkirche zu Marburg, in: Marburger Jahrbuch für Kunstwissenschaft I, 1924, S. 99-I94, hier S. I76-I77; E. Broscheк, Matthias Wenzel. Ein Beitrag zur mittelhessischen Bildhauerkunst im I7. Jahrhundert, in: Mitteilungen des Oberhessischen Geschichtsvereins 8I, 1996, S. 227-260, hier v. a. S. 240-24I. Zu den Künstlern vgl. H. Th. GräF, Franck, Adam und Franck, Philipp, in: Allgemeines Künstlerlexikon, Bd. 43, München 2004, S. 440 und 457. - Eine präzise kunsthistorische Einordnung der Gießener Epitaphien steht noch aus.

I7 Vgl. M. Lemberg, god erbarme dich uber mich / bruder des begere ouch ich. Die Grablegen des hessischen Fürstenhauses, Marburg 20I0, S. I22-I33; LoRENZ, Landgrafengräber (zit. Anm. I6). 
ten als - zumindest in Gießen glaubenspolitisch höchst streitbarer - Geistesadel, auf das auch Stefanie Knöll in ihren umfangreichen Studien zur frühneuzeitlichen Professorenmemoria wiederholt hinweist. ${ }^{18}$ Funktional und strukturell unterscheidet sich die Anlage der Rektorengrabdenkmäler in Gießen von der Situation in anderen Universitätsstädten der Epoche, denn anders als z.B. in Tübingen gab es hier keine für das Fürstenhaus und hochrangige Universitätsangehörige gleichermaßen dienende Begräbnisstätte bzw. -kirche. Und im Unterschied zu Ox- ford besaß die Ludwigs-Universität auch keine eigene Kapelle, die als exklusive Grabstätte der Professoren und als ein Raum gesteigerter korporativer Repräsentation hätte dienen können. Diese Aufgabe hatte in Gießen die Professorengalerie zu erfüllen, während die Rektoren-Epitaphien in der Kapelle des städtischen Friedhofs den prägnanten und zunächst stark glaubenspolitisch motivierten Nukleus eines in der Folgezeit stetig wachsenden Grabdenkmalensembles bildeten.

IN DIVIDUA LISIERUNGSTENDENZEN IM I 9. JAHRHUNDERT

Im Lauf der Zeit wurde der alte Gießener Friedhof von der Kapelle ausgehend in Richtung Süden und Osten erweitert und nahm bis in das frühe 20. Jahrhundert zahlreiche Grabmäler und Grabdenkmäler auf, darunter viele von Professoren und anderen Mitgliedern der Universität, die zur gesellschaftlichen Elite der Stadt gehörten und über die nötigen Finanzmittel verfügten. ${ }^{19}$ Anders als die Professorengalerie in der Universität und die Rektoren-Epitaphien im Inneren der Friedhofskapelle sind die Grabmonumente im Außenraum kein ästhetisch homogenes oder gar seriell angelegtes Ensemble, sondern ein unsystematisch gewachsener und künstlerisch sehr heterogener Bestand..$^{20}$ Das gilt für nahezu alle Momente der neuzeitlichen bzw. modernen Gelehrtenmemoria in Gießen.
Für das 19. und 20. Jahrhundert lassen sich diverse Maßnahmen aufzeigen, die darauf angelegt waren, die Universität, ihre Funktionsbereiche und Professoren bzw. die Erinnerung daran im innerstädtischen Raum zu verankern. Dazu gehört zum einen die Anbringung von Gedenktafeln, die an die Wohnung oder Wirkungsstätte ehemaliger Professoren erinnern. Des Weiteren wurden zahlreiche Gießener Straßen, Gebäude, Hörsäle, öffentliche Einrichtungen und Plätze nach namhaften Professoren - und später auch Professorinnen - der Universität benannt.

Besonders präsent war und ist der Chemiker Justus Liebig (I803-I873), der I824-I852 an der Ludoviciana lehrte und dessen Namen die Hochschule seit ihrer Wiedereröffnung als Volluniversität 1957 trägt. ${ }^{21}$ Der Chemiehörsaal, Liebigs Labore und seine private Wohnstätte wa-

I8 Vgl. S. KNöLL, Creating (zit. Anm. Io); dies., Funeral monuments to professors in I7th century Oxford, in: Creating Identities. Die Funktion von Grabmalen und öffentlichen Denkmalen in Gruppenbildungsprozessen (hrsg. von R. Sörries), Norderstedt 2007, S. 23I-240; dies., Die Grabmonumente der Stiftskirche in Tübingen, Stuttgart 2007; dies., Vom Ruhm des Geistesadels: Professorengrabmäler in Oxford, Leiden und Tübingen, in: Frühneuzeitliche Universitätskulturen (zit. Anm. 3), S. 273-284.

I9 Zur Entwicklung des Alten Friedhofs in Gießen vgl. Denkmaltopographie (zit. Anm. I3), S. 384-398. Als im ausgehenden 19. Jh. die Kapazitätsgrenzen des Alten Friedhofs absehbar wurden, begann die Stadt mit der Planung des Neuen Friedhofs auf dem Rodtberg im Norden Gießens, der erstmals I903 belegt wurde. Vgl. ebd. S. 373-378.

20 Nur in wenigen Fällen lassen sich offizielle Auftraggeber nachweisen, bei den meisten handelt es sich um private Familiengräber.

2I Vgl. Liebig in Gießen. Vom Außenseiter zum Ehrenbürger (Ausstellungskatalog Gießen, Oberhessisches Museum, hrsg. von L. Brake und F. HärInG), Gießen 2003. 


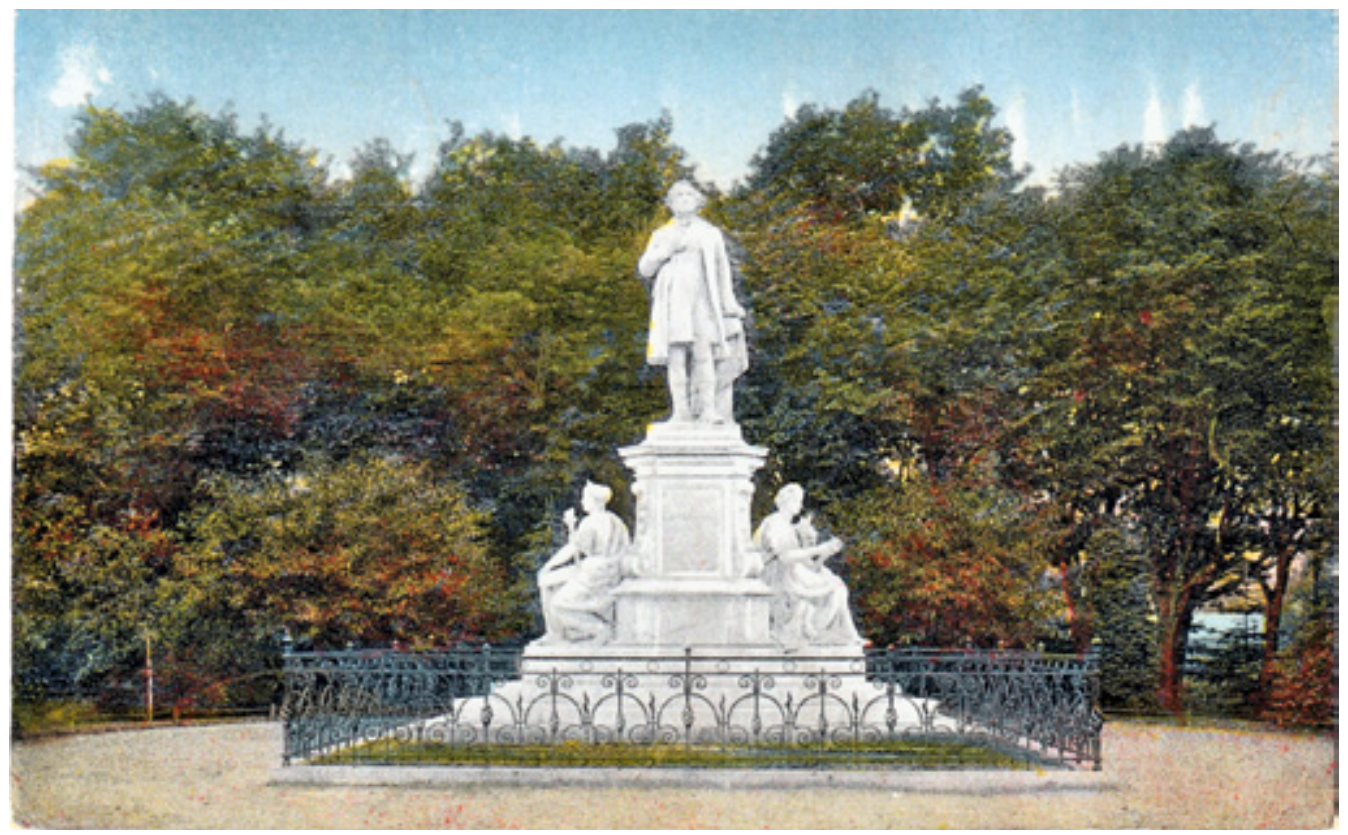

Abb. II: Fritz Schaper, Denkmal für Justus Liebig, I880er-Jahre/I89o enthüllt, weißer Marmor, Figur ca. 3 m, Sockelfiguren ca. I,80 m, Sockel 2,80 m, Gießen, Ostanlage (im 2. WK zerstört; Reproduktion einer historischen Ansichtskarte).

ren in einem der beiden klassizistischen Wachhäuschen der I8I8/ı9 für das großherzogliche Infanterieregiment errichteten und schon I82I nicht mehr gebrauchten „Neuen Kaserne auf dem Seltersberg" untergebracht. Die Labore, die weltweit Vorbildcharakter besaßen und heute als eine Geburtsstätte der modernen Chemie ${ }^{22}$ gelten, wurden mit zum Teil originalen Ausstattungsstücken rekonstruiert und 1920 als Liebigmuseum eröffnet. ${ }^{23}$ Schon Ende des 19. Jahrhunderts hatte man im Osten der neu entstandenen Ring- und Parkanlage, die an die Stelle der ehemaligen Fes- tungswälle rund um die Innenstadt getreten war, ein repräsentatives Liebig-Denkmal aufgestellt (Abb. 7 und II). ${ }^{24}$ Die Errichtung dieses lange Zeit einzigen größeren Denkmals im öffentlichen Raum hatte nicht die Universität betrieben, sondern ein zunächst internationales, dann lokal konzentriertes Komitee von Honoratioren, zu denen Schüler und Nachfolger Liebigs, Gießener Professoren und Unternehmer sowie andere ranghohe Vertreter des Bürgertums gehörten, die gemeinsam zu Spenden aufriefen. ${ }^{25}$ Für den Entwurf konnte der renommierte Berliner Bildhauer

22 Broschüre „Liebig-Museum“, Gießen o. J.

23 Vgl. Liebig in Gießen (zit. Anm. 2I), S. 27-28; Denkmaltopographie (zit. Anm. 13), S. 345.

24 Vgl. Liebig in Gießen (zit. Anm. 2I), S. 25-26; D. KLEIN, Liebig wird leicht übersehen [= Denk-mal: unikunst I], in: uniforum 2/2006, S. 3; Denkmaltopographie (zit. Anm. I3), S. I08-IO9; J. von Simson, Fritz Schaper, I842-I9I9, München 1976, S. I24-I25.

25 Das internationale Zentralkomitee hatte für das Denkmal einen Entwurf von Michael Wagmüller vorgesehen, der den alternden Gelehrten Liebig zeigte und keine Zustimmung in Gießen fand. So kam es dort zu einer Nachsammlung und dem Denkmalentwurf von Schaper. Vgl. von Simson, Schaper (zit. Anm. 24), S. I24. - Siehe auch die Liebig-Denkmäler in München (Michael Wagmüller, I883, Maximiliansplatz) und Darmstadt (Heinrich Jobst, I9I3, Luisenplatz). 


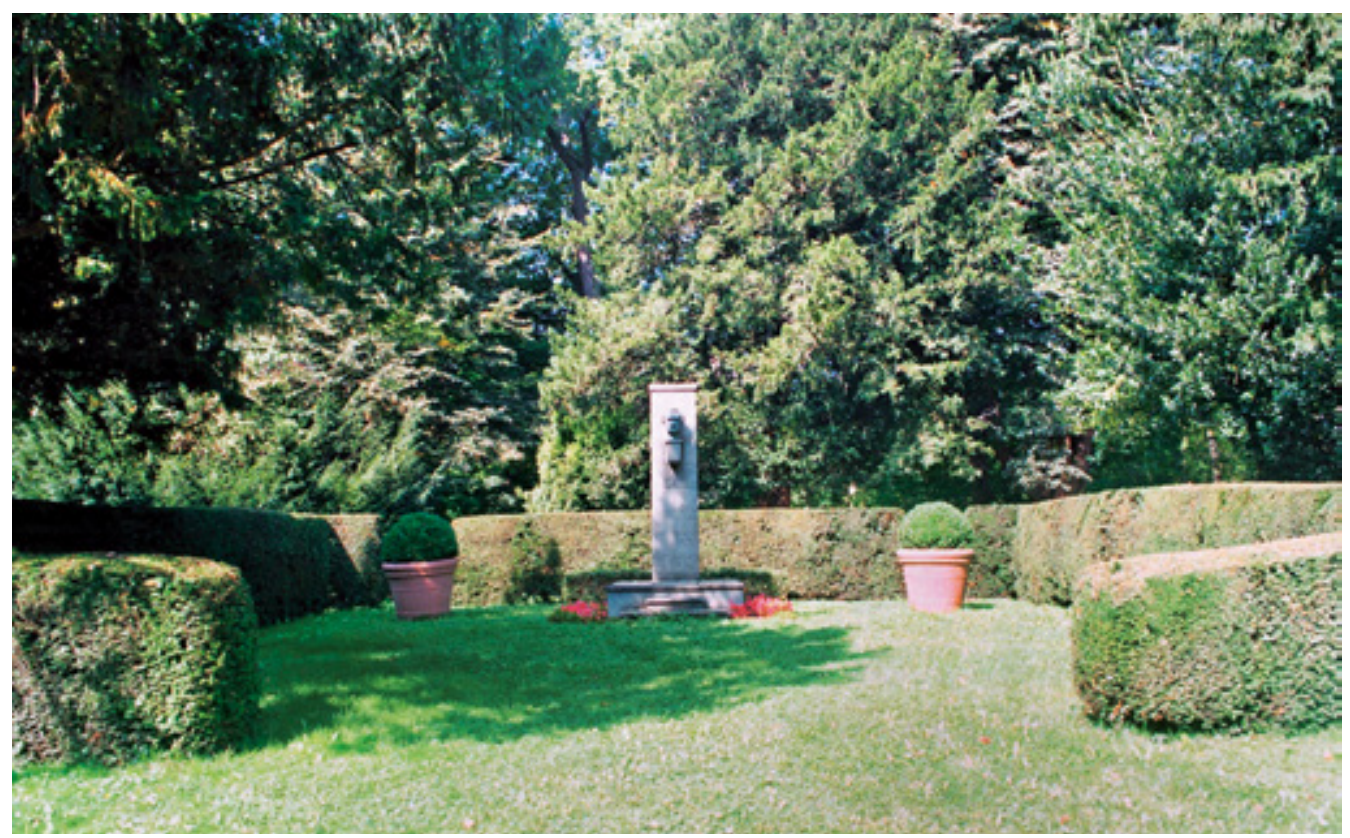

Abb. I2: Denkmal für Justus Liebig, I953, Bronze und Lungstein, Gießen, Ostanlage.

Fritz Schaper (I84I-I9I9) gewonnen werden, der für einen Standort in der baumbestandenen Ostanlage plädierte und sich damit gegenüber dem Denkmalkomitee durchsetzte. Ursprünglich war eine Aufstellung auf dem Platz vor dem Universitätshauptgebäude vorgesehen gewesen. Schaper konzipierte ein pyramidal angeordnetes Monument mit hohem gestuftem Piedestal, auf dem er das lebensgroße Standbild des Gelehrten in zeitgenössischer Kleidung mit langem Gehrock und offenem Mantel, die rechte Hand in napoleonischer Haltung ins Revers gesteckt, platzierte. Dem Wunsche des Denkmalkomitees entsprachen die Ausführung in weißem Marmor ebenso wie die beiden allegorischen Frauenfiguren zu
Seiten des Sockels, links eine Personifikation der Wissenschaft mit aufgeschlagenem Buch und Fackel, rechts die römische Göttin Ceres mit Ähren und Trauben in den Händen. ${ }^{26}$ Das Denkmal wurde im Juli I890 im Beisein des hessischen Großherzogs Ludwig IV. und Liebigs Witwe feierlich enthüllt.

Nach der nahezu vollständigen Zerstörung infolge der Luftangriffe 1944/45 entschloss man sich erst 1953, anlässlich Liebigs 150. Geburtstag, zu einer Wiederaufstellung in sehr reduzierter Form (Abb. I2). Am historischen Standort steht nun in einem Buchsbaumgeviert eine LungsteinStele, an dessen Vorderseite eine bronzene Büste Liebigs - eine Kopie des Marmorkopfes vom

26 Vgl. von Simson (zit. Anm. 24), S. 40; Liebig in Gießen (zit. Anm. 2I), S. 25. - Das Gießener Liebig-Monument orientierte sich an dem zehn Jahre früher für den Berliner Tiergarten geschaffenen, sehr populären Goethe-Denkmal Schapers. Deutliche Analogien bestehen auch zum Peter-von-Cornelius-Denkmal am Rande des Hofgartens in Düsseldorf, das Adolf von Donndorf 1879 fertigstellte. Vgl. K. Brenм, Das Goethe-Denkmal in Berlin, in: Fritz Schaper. Die Wiederentdeckung des Denkmals (Ausstellungskatalog Goch, hrsg. von U. Hinkforth), 2000, S. 39-53; von Simson, Schaper (zit. Anm. 24), S. 22 u. II6-II9. 


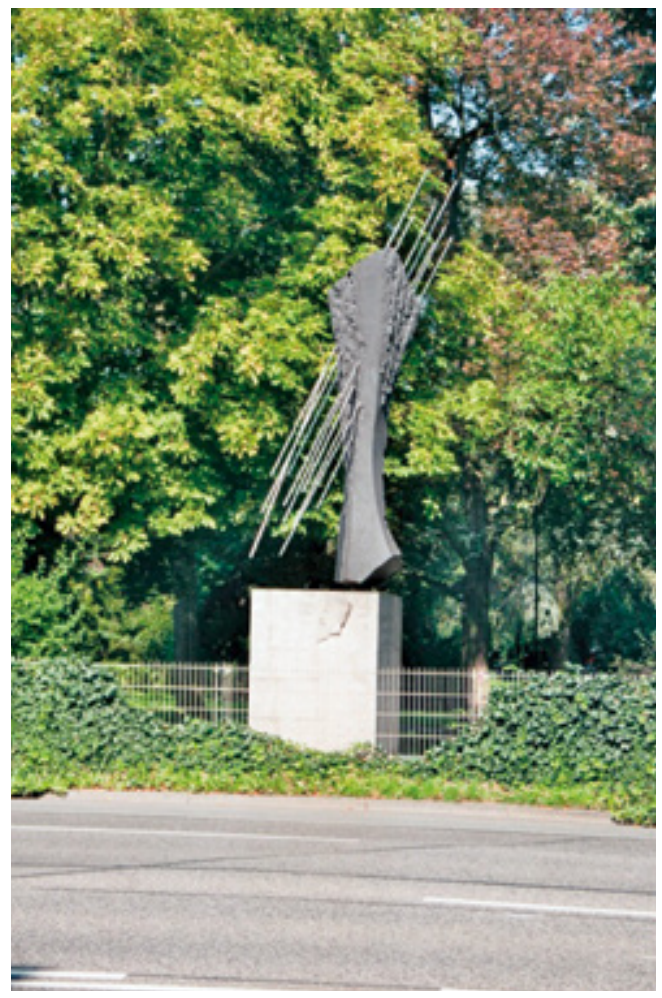

Abb. 13: Erich F. Reuter, Denkmal für Wilhelm Conrad Röntgen, I962, Eisen, Chromnickelstahl, Stein, $5 \mathrm{~m}$ hoch, Gießen, Ostanlage.

Denkmal Schapers - sowie sein Name und die Lebensdaten angebracht wurden. ${ }^{27}$ Das Arrangement hat die Anmutung eines Grab- und Mahnmals. Justus Liebig steht hier symbolisch für die klassische Tradition der ehemals hoch angesehenen Gießener Universität, an die es - nach der Perversion der Wissenschaften in nationalsozia- listischer Zeit - mit der Wiedereröffnung als Justus-Liebig-Universität anzuknüpfen galt. ${ }^{28}$

Explizit auf die modernen Wissenschaften und eine innovative Einzelleistung bezogen ist ein anderes Gelehrtendenkmal der zweiten Nachkriegszeit, das 1962 eingeweihte RöntgenDenkmal (Abb. 7 und I3). Hierfür hatte die Gießener Bürgerschaft, angeführt von einem lokalen Kunsthändler, Finanzmittel gesammelt und einen öffentlichen Wettbewerb ausgeschrieben, den der bekannte Berliner Bildhauer Erich F. Reuter (I9II-I997) gewann. ${ }^{29}$ Sein damals als außerordentlich modern angesehenes, im Volksmund „Hundeknochen“ genanntes Monument besteht aus einem hohen, mit Inschriften und einem Profilbildnis Conrad W. Röntgens (I8451923) versehenen Steinsockel, auf dem ein von Chromnickelstahl-Stäben durchdrungener Metalltorso steht. Die abstrakte Skulptur ist eine anschauliche Darstellung der nach Röntgen benannten Strahlen, deren Entdeckung dem Physiker zwar nicht in Gießen gelang, aber dort von ihm vorbereitet worden war.

Für die Gelehrtenmemoria der jüngsten Zeit stehen die sogenannten „Gießener Köpfe“, ein 2004 von Kulturdezernat und Kulturamt initiiertes Unterfangen (Abb. 7, I4 und 15), dessen Weiterführung aktuell zur Debatte steht. ${ }^{30}$ An verschiedenen Orten der Innenstadt, vorzugsweise in öffentlichen Grünanlagen, wurden in den vergangenen zehn Jahren Bronzeköpfe auf Lungstein-Stelen aufgestellt, um an bedeutende Persönlichkeiten, deren Namen mit Gießen ver-

27 Zunächst war hier der originale Marmorkopf des ursprünglichen Liebig-Denkmals montiert gewesen, der jedoch I969 gestohlen und durch eine bronzene Kopie in der Originalgröße von $40 \mathrm{~cm}$ ersetzt wurde. Vgl. von Simson (zit. Anm. 24), S. I24.

28 Für den Zusammenhang s. a. die in den I95oer-Jahren entstandenen Bronzebüsten der beiden Gründerväter, Landgraf Ludwig V. und Justus Liebig, geschaffen von der in Weimarer Zeit erfolgreichen, von den Nationalsozialisten als „entartet“ diffamierten Bildhauerin Emy Roeder (I890-I97I) im Foyer des Universitätshauptgebäudes an der Ludwigstraße.

29 D. KLEIN, Röntgenstrahlen durchdringen Körper [= Denk-mal: unikunst 2], in: uniforum 3/2006, S. 8; W. SpEITKAмP, ,Sinnbild für unsere wieder aufgebaute Stadt'? Das Röntgen-Denkmal in Gießen, in: Panorama (zit. Anm. 4), S. 272-277; Ernst F. Reuter. Monographie und Werkverzeichnis (hrsg. von A. Karpen), München 2005, S. 72.

30 Ich danke Simone Maiwald, Kulturamtsleiterin in Gießen seit I. 5. 20I3, für die Gelegenheit zur Einsicht der die „Gießener Köpfe“ betreffenden Akten am 13. 2. 2015. 


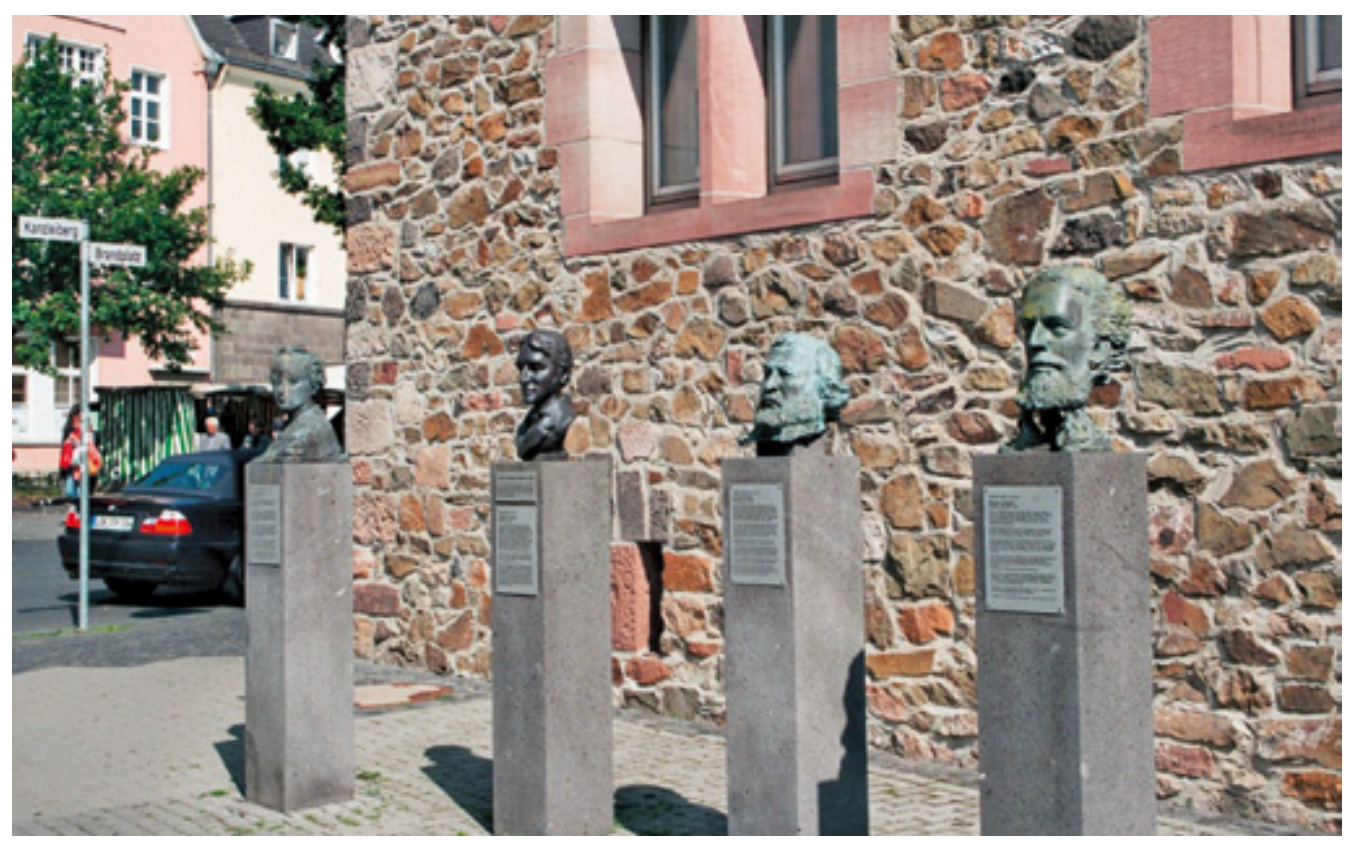

Abb. I4: „Gießener Köpfe“„,Denkmal der politischen Innovation“ von den Bildhauern: Georg Büchner, Ludwig Börne, Carl Vogt, Wilhelm Liebknecht, 2006, Lungstein und Bronze, Gießen, Altes Schloss.

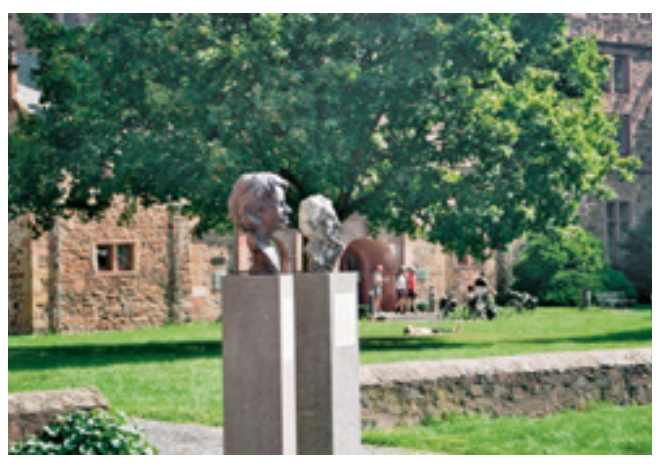

Abb. I5: „Gießener Köpfe“: Thomas Burhenne, Helge Pross, 20II, Bronze; Thomas Duttenhoefer, Horst-Eberhard Richter, 2012, Bronze, Gießen, Neues Schloss.

bunden sind, ${ }^{3 \mathrm{I}} \mathrm{zu}$ erinnern. Die „Gießener Köp-

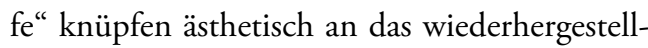
te Liebig-Denkmal an der Ostanlage an, sind aber in ihrem konzeptuellen Ursprung weniger der Gelehrtenmemoria als vielmehr der Erinnerung an die politische Geschichte verschrieben. Das erste Ensemble mit Büsten von Carl Vogt, Wilhelm Liebknecht, Georg Büchner und Ludwig Börne wurde 2006 als ein „Denkmal der politischen Innovation" eingeweiht. Im Laufe der Jahre kamen weitere Büsten von Personen und Künstlern hinzu, auf die man sich in der Kulturverwaltung der Stadt verständigen konnte - ohne dass eine öffentliche Diskussion oder ein Vergabeverfahren stattgefunden hätten. Unten den „Gießener Köpfen“ sind nun auch ehemalige Studenten und Professoren und längst auch einige Frauen. So stehen zum Beispiel neben dem Neuen Schloss mittlerweile zwei Büsten namhafter professores der jüngeren Universitätsgeschichte, der Soziologin Helge Pross (1927-84)

3I Broschüre „Gießener Köpfe“ (hrsg. von der Tourist-Information Gießen), Mai 2013.

32 Für die Errichtung der Büste von Helge Pross hatte der Ortsverband des Frauenclubs „Soroptimist international“ Gelder gesammelt. Es ist der bislang einzige der „Gießener Köpfe“, der auf Spendenbasis und nicht durch städtische Finanzmittel finanziert wurde. 
und des Psychoanalytikers Horst-Eberhard Richter (I923-20II), letzterer auch Ehrenbürger der Stadt. ${ }^{32}$ In der Fußgängerzone wurde eine Dreiergruppe von Frauenbüsten errichtet, die Margarete Bieber, Agnes von Zahn-Harnack und Hedwig Burgheim vorstellen.

Alle „Gießener Köpfe“ entstanden posthum, nach fotografischen oder gezeichneten Vorlagen, und alle sind naturalistisch, häufig mit einem Zug ins Expressive gehalten. Wer für das öffentliche Gedenken im Medium einer Bronze- büste auf Basaltstele auserwählt wird, folgte bislang wechselnden Interessenlagen und Finanzierungsmöglichkeiten. Zurzeit (Winter 20I4/I5) debattiert der Magistrat, ob und wie das Programm fortgeführt werden soll. Dabei geht es sowohl um konzeptuelle und finanzielle Aspekte als auch um Fragen der Beteiligung und der Ästhetik. Wie viele „Gießener Köpfe“ soll es geben? Wie viel Freiraum braucht eine Stadt mit und vor allem - trotz Kunst und Gedenkmonumenten im öffentlichen Raum?

\section{EINE ART FAZIT}

Die Fallstudie zum Gelehrtengedenken in der Universitätsstadt Gießen erlaubt ein paar thesenhaft formulierte Schlussbemerkungen.

I. Bei den Ursachen, Motiven und Effekten der Gelehrtenmemoria ist zu unterscheiden zwischen einer korporativen, individuell-leistungsorientierten oder aber sozial-integrativen Qualität, die wiederum abhängig von der Epoche, den gesellschaftlichen Instanzen und Räumen unterschiedlich ausgeprägt ist. Initiiert durch einen Erlass des Landesherrn stellten sich die Professoren der frühneuzeitlichen Ludwigs-Universität standesbewusst und das Kollektiv betonend im Medium der seriell angelegten Porträtgalerie dar, wie es in der Zeit auch an einigen anderen protestantischen Universitäten zu beobachten ist. Es ging hier in symbolischer und medialer Hinsicht vor allem um die Zurschaustellung des noch jungen Standes der Gelehrten bzw. des neuen Geistesadels als eine beträchtliche und stetig wachsende Korporation, deren Bedeutungsanspruch nicht unwesentlich in der Akkumulation von Tradition durch Amtsfolge gründete. Die Professorengalerie wurde in Gießen im ausgehenden I8. Jahrhundert nicht mehr weitergeführt, der Bestand aber konserviert und das Konzept nach dem Zweiten Weltkrieg abgewandelt wieder aufgegriffen - in Form einer Rektoren- bzw. Präsidentengalerie, die es in Ansätzen schon auf dem Alten Friedhof mit den Superintendenten-
Epitaphien des 17. Jahrhunderts gab. Die Zahl der Universitätsprofessoren war im 19. und erst recht im 20. Jahrhundert zu groß, ihre Organisation zu komplex geworden. Nur ihr oberster Vertreter ist bildwürdig - zunächst noch im Amtstalar, bald schon im ubiquitären Anzug - für die Aufnahme in die repräsentative Porträtfolge. Nicht um Gelehrtheit geht es, sondern um eine exponierte Leitungsfunktion, die allerdings ausschließlich Professoren und neuerdings auch Professorinnen ausfüllen dürfen und deren Kontinuität zur Schau gestellt werden soll.

Dem korporativen Moment der Professorenund Rektorenmemoria, die in der Regel nach innen gerichtet ist und die Mitglieder der Universität adressiert, steht die Anerkennung individueller wissenschaftlicher Leistungen im öffentlichen Raum gegenüber. In der Stadt Gießen ist der Chemiker Justus Liebig der zentrale Protagonist, dem vielfältig, anschaulich und nachhaltig Ehre zu Teil wird, bis hin zur Namensgebung und auch visuell vermittelten corporate identity der 1957 wieder eröffneten Volluniversität. Neben Liebig ist es vor allem Conrad Röntgen, auch er ein Naturwissenschaftler, dessen bahnbrechender Forschung mit einem eigenen Denkmal gedacht wird. Mit aktuellen Erinnerungsinitiativen wie den "Gießener Köpfen" wird von seiten der Stadt versucht, die Perspektive zu weiten und gesellschaftlich integrativ anzusetzen. 
Gelehrsamkeit bzw. wissenschaftliche Verdienste sind nur eines von vielen möglichen Kriterien der Auswahl und des Zugangs. Das Projekt entwickelte sich zu einer Demonstration sozialer Vielfalt, indem nach und nach Leerstellen der erinnerungspolitischen Vergangenheit reflektiert und kompensiert wurden, unter anderem durch die Aufnahme von Professorinnen und anderen Frauen in die Gruppe der "Gießener Köpfe“.

2. Für die Erinnerung an Gelehrte und ihre wissenschaftlichen Leistungen ist der biografische Bezug zum Ort bzw. zur Stadt wesentlich. Aber es gibt unterschiedliche Arten und Intensitätsgrade von topografischer Gebundenheit. Neben Epitaph und Grabmal mit ihren radikal physischen Ortsbezügen existieren Straßennamen, Gedenktafeln und ein Museum zur Erinnerung an Arbeits- und Wohnstätten Gießener Professoren. Die heutigen, zumeist jüngeren Universitätsgebäude dienen als institutionelle Rahmung sowohl für schon länger bestehende und zu konservierende bzw. zu reaktivierende als auch für neu zu gestaltende Monumente der Gelehrtenmemoria. Jenseits davon existiert der innerstädtische Raum als ein Raum verdichteter und stark frequentierter Öffentlichkeit, in dem sich die Stadt mittels Denkmälern, Büsten etc. darstellt und ihrer historischen Dimension versichert. Innerhalb dieser städtischen Erinnerungskultur spielen ehemalige Gießener Gelehrte, Studenten, Professorinnen und Professoren eine wichtige Rolle. Die Stadt präsentiert sich als eine traditionsbewusste Universitätsstadt, bemüht sich aber vor allem in jüngster Zeit um eine Ausweitung des Gedenkspektrums über die Wissenschaften und ihre Klientel hinaus.
3. Jenseits von reinen Inschriften und Ortsbezeichnungen dominierte und dominiert bei der Gelehrtenmemoria die künstlerische Gattung des Porträts. $\mathrm{Ob}$ in ganzer Figur oder in halber, gemalt oder plastisch - der oder die Gelehrte wird vorzugsweise als leibhaftiges Individuum erinnert, über Inschriften identifiziert und der Nachwelt überliefert. Bemerkenswert ist, dass die historisch jüngsten Porträts, nämlich die Folge der Rektoren- und Präsidentenbildnisse in der Universitätsaula und die „Gießener Köpfe“, als in Öl auf Leinwand gemalte Konterfeis und bronzene Büsten, auf ausgesprochen traditionelle Konventionen und Formate der Gattung zurückgreifen. Vor dem Hintergrund stellt Erich F. Reuters abstraktes Röntgen-Denkmal von 1962, das es sich der ästhetischen Kompatibilität zeittypischer Entwicklungen in der modernen Plastik mit naturwissenschaftlicher Erkenntnis verdankt, eine bemerkenswerte Ausnahme dar.

Es bleibt zu resümieren, dass sich die Gelehrtenmemoria zumindest in der Universitätsstadt Gießen nicht als ein Feld künstlerischer Experimentierfreude und Innovation hervortut. Sie pflegt die Traditionen der Künste und der Institutionen und lässt wenig erahnen von all den Neuerungen, für die Gelehrtheit, Wissenschaft und Universität auch stehen könnten.

Abbildungsnachweis: Abb. I, 2, 3, 4, 5: Gießen, Universitätsarchiv; Abb. 6: Gießen, Universitätsarchiv, Foto: Elena Leussidis; Abb. 7: Magistrat der Universitätsstadt Gießen, Vermessungsamt - 35390 Gießen, Vervielfältigungsnr. 2/20I5; Abb. I2, I3, I4, I5: Sigrid Ruby; Abb. 8: Wikipedia/Stefan Flöper; Hinweis auf Freigabe unter der „Creative Commons Attribution-Share Alike 3.0“-Lizenz; Abb. 9, Io, II: Dagmar Klein. 


\title{
VON ALEXANDER VON HUMBOLDT BIS LISE MEITNER. DENKMALSETZUNGEN VON 1883 BIS 2014 AN DER BERLINER UNIVERSITÄT UNTER DEN LINDEN
}

\author{
Angelika Keune
}

$\mathrm{D}$ em französischen Historiker Pierre Gaxotte wird der Ausspruch nachgesagt, dass Denkmäler die Lesezeichen der Geschichte seien. Plastisch, im wahrsten Sinne des Wortes, erzählen sie uns anhand ihrer Entstehungsgeschichte, der Biografie des Geehrten, seiner Leistungen und Erfolge und ebenso durch die Kunstfertigkeit des Künstlers, seiner Formen- und Bildsprache, von vergangenen Zeiten - und von deren Gestalter. Die Humboldt-Universität hat gegenwärtig zehn Denkmäler und neun von ihnen zeigen Männer, Wissenschaftler, die ihre Fachdisziplin nachdrücklich bestimmten, sie oftmals begründeten und sowohl innerhalb als auch außerhalb der Universität historische Entwicklungen maßgeblich beeinflussten. Dargestellt wurden sie von erfolgreichen Bildhauern ihrer Zeit.

Seit dem Sommer 2014 ist die HumboldtUniversität jedoch auch im Besitz eines Denkmals für eine Wissenschaftlerin, die Kernphysikerin Lise Meitner, eine der renommiertesten Naturwissenschaftlerinnen des 20. Jahrhunderts (Abb. I). Es ist damit das erste vollfigurige Denkmal in Deutschland für eine Wissenschaftlerin, und geschaffen wurde es ebenfalls von einer Frau, der Berliner Bildhauerin Anna Franziska Schwarzbach.

Es gibt keine tiefgreifenden und langfristigen gesellschaftlichen Veränderungen ohne gute Vorbilder. Für Generationen von Wissenschaftlern waren Alexander und Wilhelm von Humboldt,

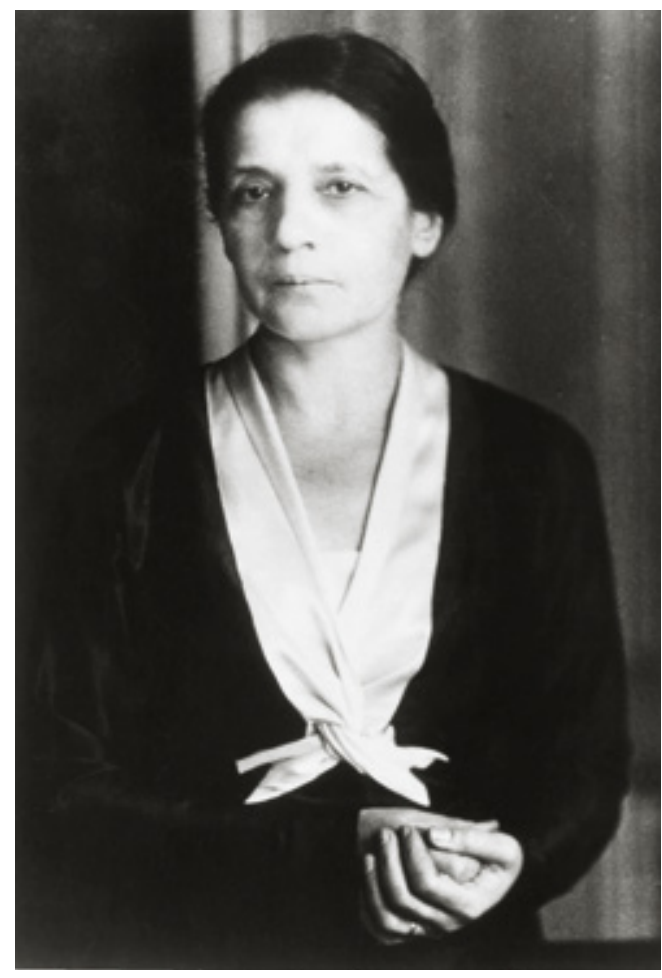

Abb. I: Lise Meitner (I878-1968), Foto, Dreißigerjahre.

Hermann von Helmholtz, Theodor Mommsen und Max Planck als bedeutende Gelehrte solche Vorbilder. Sie wurden nicht nur mit Preisen geehrt, sondern auch mit Ölporträts, Büsten und Denkmälern. Frauen haben in Deutschland erst seit Anfang des 2o. Jahrhunderts, spätestens seit I908 mit ihrer Zulassung zum Studium in Preu- 
ßen, die Möglichkeit der gleichberechtigten Teilhabe an der Wissenschaft. Dieser Weg war und ist lang und mühsam und daher sind bis heute von Wissenschaftlerinnen kaum künstlerische Abbildungen vorhanden und erst recht keine Denkmäler, die der nachfolgenden Frauengeneration Wegzeichen sein könnten.

Als ich 1989 meine Tätigkeit als Kustodin begann, zählten zum Kunstbesitz der HumboldtUniversität fast 400 Kunstwerke, die Wissenschaftler der Universität darstellen, Denkmäler, Büsten, Gemälde, Zeichnungen, aber kein einziges Abbild einer Wissenschaftlerin. Nur eine gemeinsame Gedenktafel für Otto Hahn und Lise Meitner erinnerte am ehemaligen Chemischen Institut an die gemeinsamen Experimente der beiden Wissenschaftler in der Holzbaracke.

Seit den 8oer-Jahren des vorigen Jahrhunderts wurde im Flur vor dem Arbeitszimmer des amtierenden Rektors eine Reihe von Gemälden ehemaliger Rektoren der Universität präsentiert. Anfang der 9oer-Jahre wollte ich wenigstens mit Fotografien auf besondere Frauen der Universi- tät aufmerksam machen. Doch schon die Fotorecherche gestaltete sich schwierig und nicht selten erfolglos: Frauen waren in der öffentlichen, aber auch historischen Präsentation der Universität nicht sichtbar.

Darüber hinaus lehrten mich die folgenden Jahre, dass es noch Jahrzehnte dauern würde, bis es auch von Wissenschaftlerinnen eine nennenswerte Anzahl künstlerischer Abbildungen geben wird.

Als langjährige nebenamtliche Frauenbeauftragte der Humboldt-Universität war es für mich eine herbe Erkenntnis, dass das wissenschaftliche Cuvre von Frauen - der Gegenwart wie der Vergangenheit - keine adäquate künstlerische Präsenz findet, obwohl schon seit den 2oer-Jahren des 20. Jahrhunderts Frauen sich zunehmend auch an der Berliner Universität wissenschaftlich etabliert hatten. Unter diesen Ausnahmefrauen ragte Lise Meitner besonders hervor.

Daher entschloss ich mich 2006, der Universitätsleitung den Vorschlag zur Errichtung eines Denkmals für Lise Meitner zu unterbreiten.

\section{LISE MEITNER - VOM HINTEREINGANG ZUM HAUPTPORTAL}

Für die Berliner Universität, die heutige Humboldt-Universität zu Berlin, hat Lise Meitner, die eine Reihe von Isotopen entdeckte und mit ihrer experimentellen physikalischen Grundlagenforschung maßgeblich zur Erschließung neuer Wissenschaftsgebiete beitrug, eine besondere Bedeutung: I9I2 war sie die erste weibliche Assistentin der Berliner Universität und Preußens, 1922 habilitierte sie sich als erste Physikerin Deutschlands an unserer Universität und 1926 erhielt sie hier ihren Ruf als ao. Professorin für experimentelle Kernphysik. Damit war sie die erste Professorin der Berliner Universität und die erste Professorin für Physik in Deutschland (Abb. 2).

Der Beginn ihrer wissenschaftlichen Laufbahn war exemplarisch für bildungshungrige Frauen in Deutschland wie auch in Österreich. I9OI, mit 23 Jahren, studierte sie als zweite Frau an der Wiener Universität Physik, promovierte hier bei Ludwig Boltzmann und war gemeinsam mit einer weiteren Promovendin damit die zweite Frau im Fach Physik. Angetan von den Gastvorlesungen Max Plancks an der Wiener Universität wollte sie 1907 für einige Semester in Berlin studieren. Doch dann begann sie als „unbezahlter Gast" ihre Zusammenarbeit mit dem Chemiker Otto Hahn in der zum Labor umgerüsteten Holzwerkstatt des Chemischen Instituts der Berliner Universität. Da es zu dieser Zeit in Preußen Frauen noch untersagt war zu studieren, musste sie sich damit einverstanden erklären, die Laborräume des Instituts nicht durch die Vorder-, sondern nur durch die Hintertür zu betreten.

In den Folgejahren machten die beiden Wissenschaftler gemeinsam spektakuläre Entdeckungen, wofür I9I9 beide erstmalig für den Nobel- 


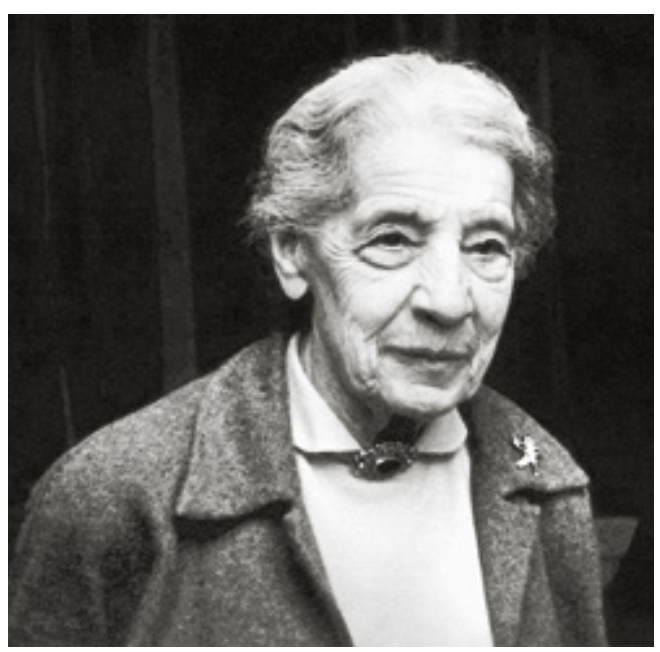

Abb. 2: Lise Meitner, Foto um 1958.

preis nominiert wurden. Schon I913 wurde Lise Meitner als erste Frau Mitglied der Kaiser-Wilhelm-Gesellschaft, was in etwa der Stellung eines Akademiemitglieds entsprach. Von I9I8 bis I938 war sie Leiterin der physikalisch-radioaktiven Abteilung am Kaiser-Wilhelm-Institut für Chemie. In den Zwanzigerjahren erklomm sie stetig die Karriereleiter, jedoch immer einige Stufen und Jahre hinter den männlichen Kollegen zurück. Wie hoch ihr Ansehen in den ersten Jahren ihres wissenschaftlichen Wirkens gestiegen war, ist u.a. daran ablesbar, dass Albert Einstein sie „unsere Marie Curie“ nannte.

I933 endete jäh ihre wissenschaftliche Karriere. Trotz eines Protestbriefes von Otto Hahn wurde auch ihr die Lehrbefugnis wegen ihrer jüdischen Herkunft entzogen, wie tausenden anderen Wissenschaftlern und Wissenschaftlerinnen. Bis 1938 konnte sie jedoch ihre Arbeit am (nicht staatlichen) Kaiser-Wilhelm-Institut mit
Otto Hahn und dem Chemiker Fritz Straßmann an Bestrahlungsexperimenten mit Neutronen fortsetzen. Erst durch den sogenannten „Anschluss" von Österreich verlor sie ihren Status als Ausländerin und galt nun als „deutsche Jüdin" und ihr Leben war in Gefahr. Im Sommer 1938 organisierten daher ihre Freunde zusammen mit ausländischen Kollegen ihre Flucht nach Stockholm. Sie hatte anderthalb Stunden Zeit, um zu packen und um Deutschland nach 3I Jahren zu verlassen.

Hahn und Straßmann setzten die Forschungen ohne sie fort. Doch als ihre Experimente Ergebnisse erbrachten, die sie nicht zu deuten wussten, bat Otto Hahn in einem Brief Lise Meitner: „Vielleicht kannst Du irgendeine phantastische Erklärung vorschlagen."

Und Lise Meitner leitete gemeinsam mit ihrem Neffen Otto Robert Frisch die Veränderung des Urankerns aus dem sogenannten Tröpfchenmodell des Atomkerns ab, berechnete die freigesetzte Energie und deutete damit erstmalig theoretisch und kernphysikalisch die Atomspaltung, wobei sie den Begriff „Kernspaltung“ in den wissenschaftlichen Diskurs einbrachte. ${ }^{2}$

Otto Hahn wurde für diese Entdeckung mit dem Nobelpreis geehrt, eine Auszeichnung, die zweifellos auch Lise Meitner verdient hätte. Fünfmal wurde sie für den Nobelpreis vorgeschlagen, aber niemals berücksichtigt. Unsere Hochachtung vor der Lebensleistung von Lise Meitner kommt aber auch daher, dass sie nicht bereit war, in die USA zu gehen, um an der Entwicklung der Atombombe mitzuwirken, obwohl sie in ihrem schwedischen Exil weitgehend aller Experimentiermöglichkeiten beraubt war. Sie verwendete ihre Kraft vor allem darauf, Kollegen

I Brief von Otto Hahn an Lise Meitner v. 19. I2. 1938, Churchill Archives Centre, in: Lise Meitner zum I25. Geburtstag (Ausstellungskatalog Berlin, Staatsbibliothek zu Berlin, Preußischer Kulturbesitz, Katalognr. I60), Berlin 2003, S. 98 .

2 L. Meitner/O. R. Frisch, Disintegration of Uranium by Neutrons: A New Type of Nuclear Reaction, in: Nature. I43, London, 1939, S. 239-240. In diesem Beitrag vom II. Februar 1939, der erstmalig den Prozess der Atomspaltung beschreibt, wird auch erstmalig der Begriff, fission’ verwendet. 
und Kolleginnen bei der Flucht ins Exil zu unterstützen. ${ }^{3}$ Nach dem Krieg ächtete sie wiederholt öffentlich die Atombombe und verurteilte entschieden ihren Einsatz. Unbestechlich blieb sie ihrer humanistischen Gesinnung treu - ein Vorbild in jeder Hinsicht, denkmalwürdig.

Unser Denkmal für Lise Meitner sollte aber gleichzeitig ein Erinnerungszeichen an die allererste Generation der Wissenschaftlerinnen der Berliner Universität sein sowie an die von den Nationalsozialisten verfolgten jüdischen Wissenschaftlerinnen und Wissenschaftler. Denn Lise Meitner war in vielem die erste, aber nicht die einzige.

In den 2oer-Jahren hatten sich Frauen als Promovendinnen, Dozentinnen und Hochschul- lehrerinnen etablieren können. 1933 kam das Lehr- und später das Studiumverbot für alle, die die Nationalsozialisten als jüdisch einstuften. Davon waren allein zwei Drittel der Wissenschaftlerinnen betroffen. Ehe sie nachhaltige Erfolge erzielen konnten, wurden sie aus der Universität und aus Deutschland vertrieben. Sie hatten nur maximal zehn Jahre Zeit, um zu beweisen, dass Frauen die gleichen wissenschaftlichen Leistungen erbringen können wie Männer. Diese Zeitspanne war zu kurz, um jahrhundertealte Vorurteile zu widerlegen und um eine eigene Tradition, eigene Schulen bilden zu können, mit Studierenden und Doktoranden, die ihren Vorbildern Gemälde, Büsten oder gar Denkmäler widmen.

\section{DIE WISSENSCHAFTLER-DENKM ÄLER VOR DER HUMBOLDT-UNIVERSITÄT ${ }^{4}$}

Demgegenüber wurden männliche Wissenschaftler bereits im 19. Jahrhundert zunehmend denkmalwürdig. I869, anlässlich der Säkularfeier für Alexander von Humboldt, veröffentlichte der Pathologe Rudolf Virchow gemeinsam mit weiteren Persönlichkeiten einen Aufruf zur Schaffung eines Denkmals für den berühmten Universalgelehrten. Virchows Denkmalidee wurde in einer Zeit geboren, in der die Büste als Ehrung bereits gesellschaftlichen Konsens darstellte und die Hoch-Zeit der Denkmalsetzungen begann, nicht nur in Berlin, sondern in ganz Preußen und am Ende des Jahrhunderts im gesamten Deutschland.

Vor der Bauakademie in Berlin war 1869 das Denkmalensemble mit dem Begründer der Landwirtschaftswissenschaften Albrecht Thaer von Christian Daniel Rauch (enthüllt I860), dem Wirtschaftsförderer Christian Wilhelm
Beuth von August Kiss (enthüllt I86I) und dem Architekten Karl Friedrich Schinkel von Friedrich Drake (enthüllt 1869) komplettiert worden und für Friedrich Schiller war bereits der Kunstwettbewerb für ein Denkmal vor dem Schauspielhaus ausgelobt.

In der Berliner Universität wurden seit I832, geregelt durch ein Statut, kontinuierlich die Büsten verdienstvoller Professoren in der Aula aufgestellt. In der zweiten Hälfte des I9. Jahrhunderts war ein gesellschaftliches Klima entstanden, in dem bürgerliche Persönlichkeiten, die Außerordentliches geleistet hatten, nicht nur im internen Kreis, sondern öffentlich geehrt wurden.

Obwohl es Virchow und seinen Mitstreitern gelang, innerhalb eines Jahres I0o.00o Mark Spendengelder aus der ganzen Welt einzusammeln, vergingen I4 Jahre bis zur Fertigstellung, denn noch immer war die Realisierung

3 Beispielsweise unterstützte Lise Meitner die Breslauer Physikerin Hedwig Kohn in die USA zu flüchten. S. Annette Vogt: Vom Hintereingang zum Hauptportal? Lise Meitner und ihre Kolleginnen an der Berliner Universität und in der Kaiser-Wilhelm-Gesellschaft, Stuttgart 2007, S. 224.

4 Ausführlich s. A. Keune, Gelehrtenbildnisse der Humboldt-Universität zu Berlin. Denkmäler, Büsten, Reliefs, Gedenktafeln, Gemälde, Zeichnungen, Graphiken, Medaillen, Berlin 200o, S. 13-39 und S. 47-64. 


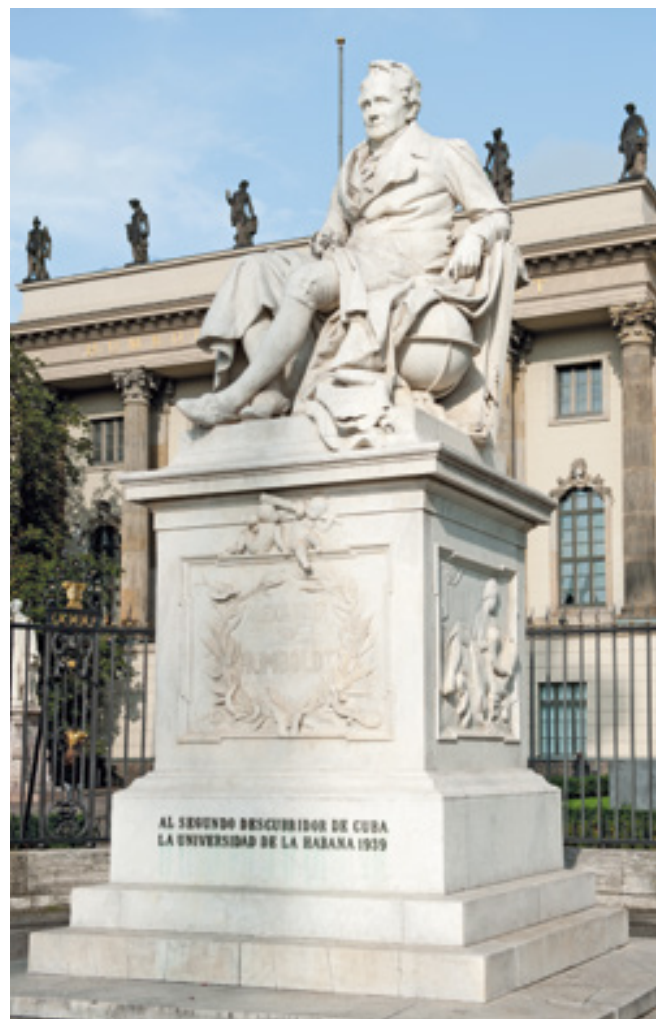

Abb. 3: Berlin, Denkmal für Alexander von Humboldt, vor dem Ehrenhof der Humboldt-Universität zu Berlin, Unter den Linden; Reinhold Begas, Alexander von Humboldt, I883, Carrara-Marmor.

von Denkmalvorhaben von der Zustimmung des Kaisers abhängig. Nachdem ein Gesuch Virchows an den König um einen repräsentativen Standort ohne Antwort blieb, wurde die Universität um einen Aufstellungsort gebeten. Diese stimmte dem Vorhaben unter der Bedingung zu, dass auch für Wilhelm von Humboldt, den Gründer der Universität, ein Denkmal errichtet wird. Weil das gesammelte Geld nur für die Ehrung A. v. Humboldts bestimmt war, wandte sich das Denkmalkomitee an den Kaiser mit der Bitte um finanzielle Mittel für eine Wilhelmvon-Humboldt-Statue. Als Wilhelm I. zwei Jahre später seine Zustimmung gab und die Mittel zur Verfügung stellte, verband er dies mit der Auflage, dass die Statue von Alexander rechts und von

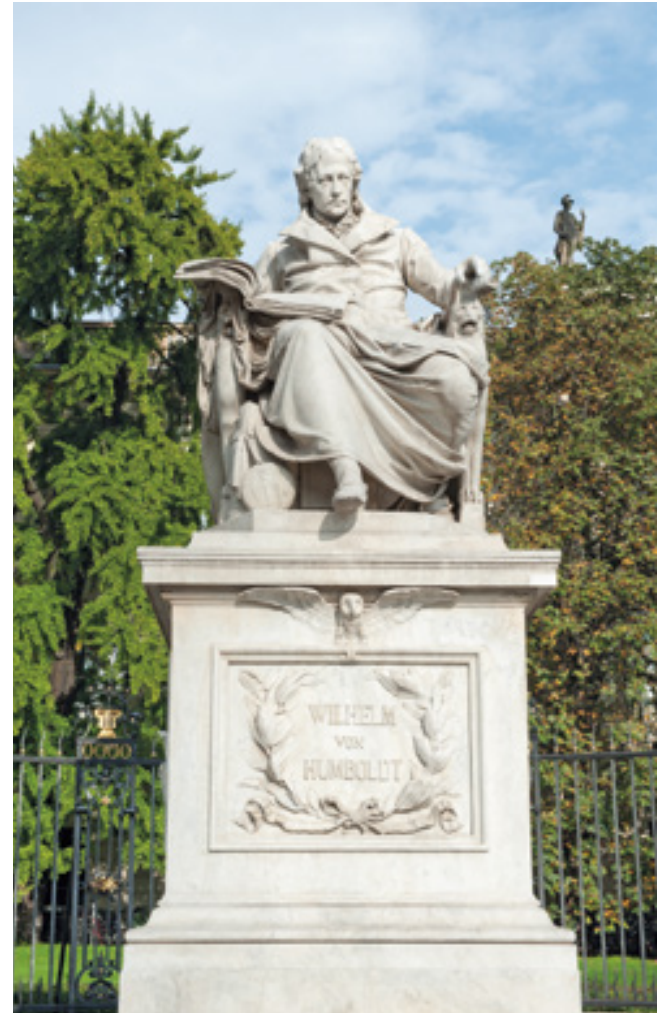

Abb. 4: Berlin, Denkmal für Wilhelm von Humboldt, vor dem Ehrenhof der Humboldt-Universität zu Berlin, Unter den Linden; Martin Paul Otto, Wilhelm von Humboldt, 1883, Carrara-Marmor.

Wilhelm links gegenüber seinem Palais errichtet werden und dass sie nicht höher sein dürften als die der Generäle vor der Neuen Wache.

Geschaffen wurde das Alexander-von-Humboldt-Denkmal von Reinhold Begas, Protagonist eines neuen Bildhauerstils, dessen Denkmäler und Statuen, so wie jene seiner Weggenossen und Schüler, die Denkmallandschaft des Wilhelminischen Deutschlands prägten (Abb. 3). Das Denkmal für Wilhelm von Humboldt wurde vom Bildhauer Paul Otto geschaffen, der erstmalig einen Gelehrten sitzend darstellte und ihn so äußerlich mit Fürsten gleichsetzte (Abb. 4).

Während bei den Humboldt-Denkmälern vom Kaiserhof stark in die Realisierung hinein dirigiert wurde, da man nur höchst ungern 


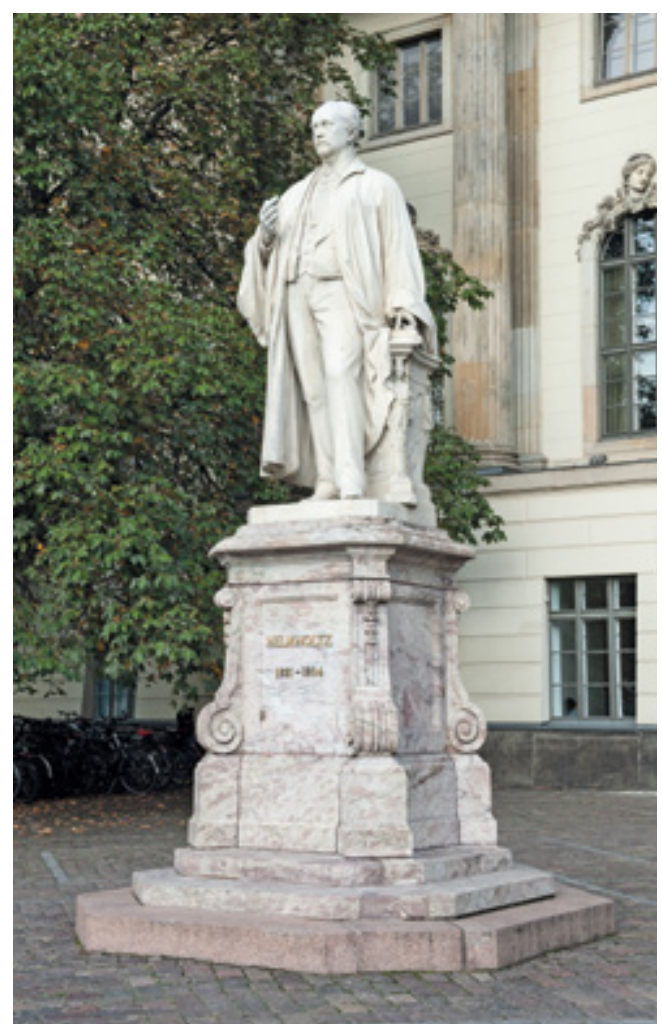

Abb. 5: Berlin, Denkmal für Hermann von Helmholtz, Ehrenhof der Humboldt-Universität zu Berlin, Unter den Linden; Ernst Herter, Hermann von Helmholtz, I899, Figur: Tiroler Marmor, Sockel: Bayerischer Marmor.

dem Freidenker und Demokrat Alexander von Humboldt ein Denkmal errichten wollte, regte der Kaiser, nunmehr Wilhelm II., für den Physiker Hermann von Helmholtz ein Denkmal im Ehrenhof der Universität sogar an und stiftete hierfür Io.0oo Mark (Abb. 5). Dennoch gab es im Akademischen Senat jahrelange Diskussionen, inwiefern ein einzelnes großes Denkmal auch andere verdiente Professoren repräsentieren könnte oder ob das Helmholtz-Denkmal mit den Büsten namhafter Ordinarien umsäumt werden sollte. Diese Idee wurde jedoch verworfen und 1899 das repräsentative $5,20 \mathrm{~m}$ hohe Helmholtz-Denkmal des Berliner Bildhauers Ernst Herter eingeweiht.

Zehn Jahre später standen sich nach ausgiebigen Diskussionen die Denkmäler zweier Pro-

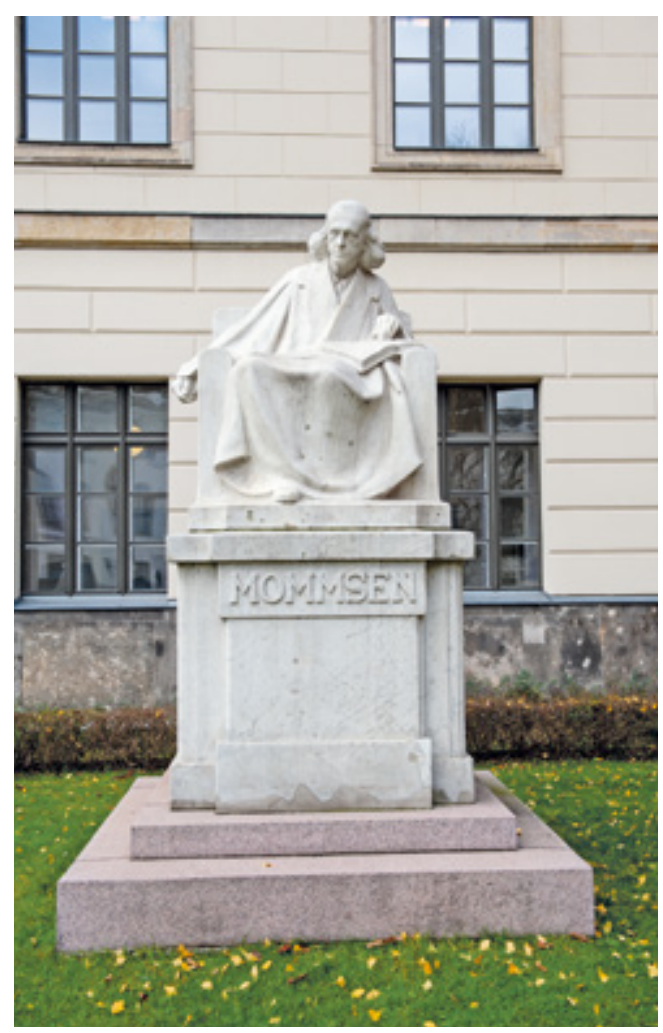

Abb. 6: Berlin, Denkmal für Theodor Mommsen, Ehrenhof der Humboldt-Universität zu Berlin, Unter den Linden; Adolf Brütt, Theodor Mommsen, I9o9, Carrara-Marmor.

fessoren gegenüber, die zu ihren Lebzeiten politische Kontrahenten waren: das Denkmal für den Althistoriker Theodor Mommsen (Abb. 6), der im sogenannten Antisemitismusstreit I879 vehement Partei für seine jüdischen Mitbürger ergriffen hatte und gleiche Chancen im Wissenschaftsbetrieb auch für jüdische Gelehrte forderte, und das Denkmal für den Historiker Heinrich von Treitschke, der den unheilvollen Satz prägte: „Die Juden sind unser Unglück.“ Eingeweiht wurden beide Denkmäler 1909 .

Wenn das Denkmal für Lise Meitner, die aufgrund ihrer jüdischen Wurzeln aus Deutschland vertrieben wurde, heute fast genau an jenem Ort steht, an dem sich einst das Denkmal für Treitschke befand, so ist mir dies eine besondere Genugtuung. 
I950 sollte ein Denkmal für den Physiker Max Planck folgen, doch der Künstler der Plastik, Bernhard Heiliger, wechselte von der Kunsthochschule Berlin Ost, also aus der neu gegründeten DDR, zur Kunsthochschule nach Berlin
West und das Denkmal wurde an die Peripherie Berlins verbannt. 2006 gelang es, das PlanckDenkmal an dem schon 1950 bestimmten Standort im Ehrenhof der Universität aufzustellen (Abb. 7).

\section{VON DER IDEE ZUR DENKMALAUSFÜHRUNG}

Bei der Einweihung des Denkmals für Max Planck, Förderer und Mentor von Lise Meitner, entschloss ich mich endgültig, ein Denkmal für sie zu initiieren. Dabei wollte ich mich an den partizipatorischen Denkmalprojekten der Vergangenheit orientieren, die stets von Universitätsangehörigen, allerdings ausschließlich von Professoren, ins Leben gerufen bzw. von ihnen getragen worden waren und an denen sich zahllose Spender finanziell beteiligten. Ich schlug daher

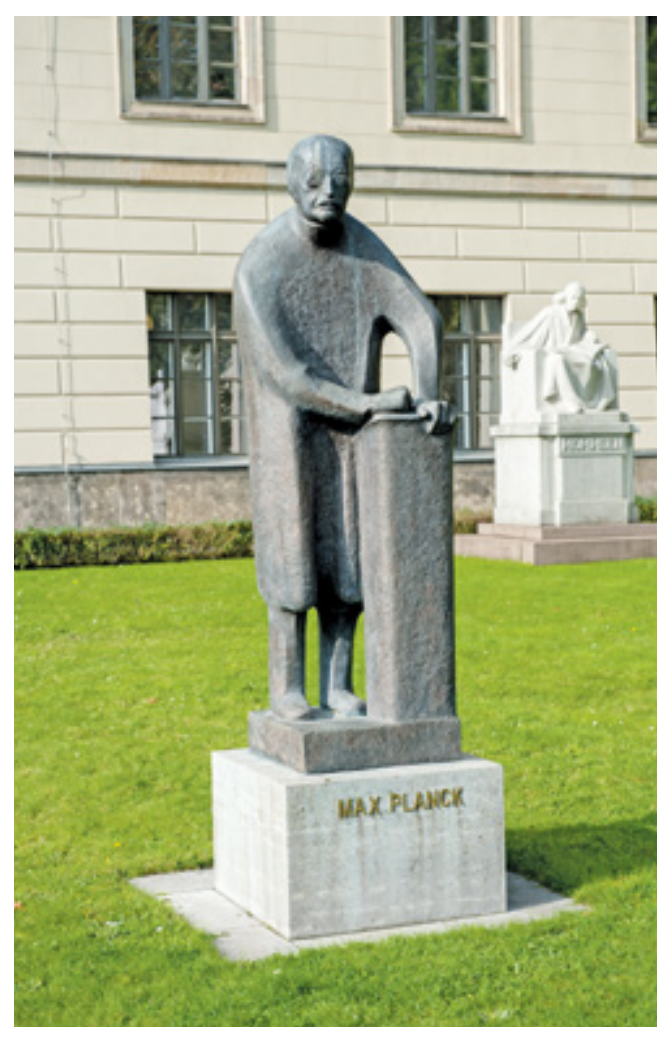

Abb. 7: Berlin, Denkmal für Max Planck, Ehrenhof der Humboldt-Universität zu Berlin, Unter den Linden; Bernhard Heiliger, Max Planck, I948/49, Bronze. der Universitätsleitung vor, einen Spendenaufruf an alle Angehörigen der Universität zu veröffentlichen. Damit wollte ich drei Ziele erreichen:

- eine öffentliche Diskussion über das Denkmal, zur künstlerischen Sichtbarkeit bzw. Unsichtbarkeit von Frauen in der Universität und zur Person Lise Meitners,

- eine Gruppe von Unterstützern und vor allem Unterstützerinnen zu finden, mit der das Projekt realisiert werden kann, und

- die benötigte Summe von Ioo.00o,oo € einzusammeln.

Das damalige Präsidium wollte jedoch weder einen Aufruf verfassen noch eine Diskussion initiieren. Es war der Meinung, dass ich als Erstes einen Hauptsponsor finden sollte. Fast drei Jahre schrieb ich entsprechende Bittbriefe. Aber einen Sponsor, der bereit war, 50.000,00 € oder gar $100.000,00 € \mathrm{zu}$ spenden, konnte ich nicht gewinnen. Dann begann ich die Finanzierung in kleineren Schritten zu realisieren.

Im Laufe der Jahre haben hunderte Menschen, insbesondere Universitätsangehörige, durch Artikel und Mundpropaganda von dem Unternehmen erfahren. Im persönlichen Gespräch habe ich stets Zustimmung erhalten, nie Ablehnung, gleichwohl blieb die Resonanz innerhalb und außerhalb der Universität gering.

Man könnte meinen, dass die Schwierigkeiten nur von den Finanzen abhingen, aber als auch die Einweihung des ersten vollfigurigen Denkmals für eine Wissenschaftlerin in Deutschland, in Anwesenheit der Bildungsministerin der Bundesrepublik und von Persönlichkeiten des Berliner öffentlichen Lebens, kaum medialen Widerhall fand, fragte ich mich: 
- Sind partizipatorische Denkmalprojekte in der heutigen Zeit noch möglich?

- Ist die Bedeutsamkeit von Wissenschaftlerinnen für skulpturale Repräsentationen immer noch nicht gesellschaftlicher Konsens?
- Und ist daher die geringe Resonanz auf das erste vollfigurige Denkmal einer Wissenschaftlerin ein Ausdruck dafür, dass Memorialkultur ausschließlich gesellschaftlich etablierten Kräften zugestanden wird?

\section{DER KUNSTW ET T B E W ER B}

Als die finanziellen Mittel mit hohem Aufwand nach sechs Jahren eingeworben waren, wobei ich in den letzten Jahren intensiv vom neu gewählten Präsidenten und der neu gewählten zentralen Frauenbeauftragten unterstützt wurde, konnte ich endlich mit der Vorbereitung des Kunstwettbewerbs beginnen. Damit dessen Durchführung allen rechtlichen Vorgaben entsprach, hatten wir über ein Auswahlverfahren eine professionelle Wettbewerbskoordinatorin ausgewählt. Der Wettbewerb wurde im Einladungsverfahren als anonymer, einstufiger Realisierungswettbewerb durchgeführt. Wir entschieden uns, ihn europaweit und für Israel auszuschreiben. Am I. Februar 2013 wurde er veröffentlicht und an alle Künstlerverbände verschickt. Insgesamt beteiligten sich 8I Künstler und Künstlerinnen aus Deutschland, Österreich und der Schweiz. Eine Auswahlkommission, bestehend aus Angehörigen der Humboldt-Universität zu Berlin und auswärtigen Kunsthistorikerinnen, wählte am 5. April 2013 vier Künstlerinnen und Künstler sowie eine Künstlergruppe aus, die innerhalb von sechs Wochen einen Denkmalentwurf einreichen konnten.

I4 Tage später fand für sie ein Rückfragekolloquium statt, bei dem ihnen der genaue Wortlaut der Aufgabenstellung für den Denkmalentwurf mitgeteilt wurde. Zuvor hatte es dazu eine ausführliche Diskussion im Preisgericht gegeben, in dem ich mich aber mit meiner Formulierung, das Denkmal erkennbar weiblich und porträthaft zu gestalten, mit dem Ziel, Frauen in der
Wissenschaft sichtbarer zu machen, nicht durchsetzen konnte. Insbesondere seitens der Kunstwissenschaftlerinnen, die die Vorgabe „erkennbar weiblich und porträthaft" als zu einengend empfanden, wurde über die Formulierung heftig diskutiert. Wir einigten uns auf die Formulierung: „Das Denkmal soll die unverwechselbaren Züge der Persönlichkeit Lise Meitner zeigen.“

Der genaue Wortlaut der Wettbewerbsaufgabe lautet daher folgendermaßen: „Lise Meitner repräsentiert mit ihrer Forschungsleistung und ihrer Biographie konkrete Berliner Wissenschafts- und Universitätsgeschichte. In Anbetracht ihrer Lebensleistung soll Lise Meitner ein Denkmal im Ehrenhof der Humboldt-Universität zu Berlin gesetzt werden. Als Jüdin verfolgt und als Frau diskriminiert, gehört Lise Meitner in die Reihe der weltweit anerkannten Berliner Wissenschaftler des Denkmalensembles am historischen Forum Fridericianum.

Das Denkmal soll die unverwechselbaren Züge der Persönlichkeit Lise Meitner zeigen. Die Gestaltung des Lise-Meitner-Denkmals soll sich gegenüber den am vorgegebenen Ort bereits vorhandenen Denkmälern - M. Planck von B. Heiliger (1948/49, Bronze), H. von Helmholtz von E. Herter (I899, Marmor) und Th. Mommsen von A. Brütt (1909, Marmor) - durch ihre Eigenart und ihren zeitgenössischen Ausdruck künstlerisch behaupten."

Am I8. Juni 2013 entschied das Preisgericht über die anonymisierten Entwürfe. Als ich die

5 Auslobungstext Berlin, Nichtoffener Kunstwettbewerb für das Lise-Meitner-Denkmal im Ehrenhof der HumboldtUniversität zu Berlin, Berlin 2013, S. 33. 


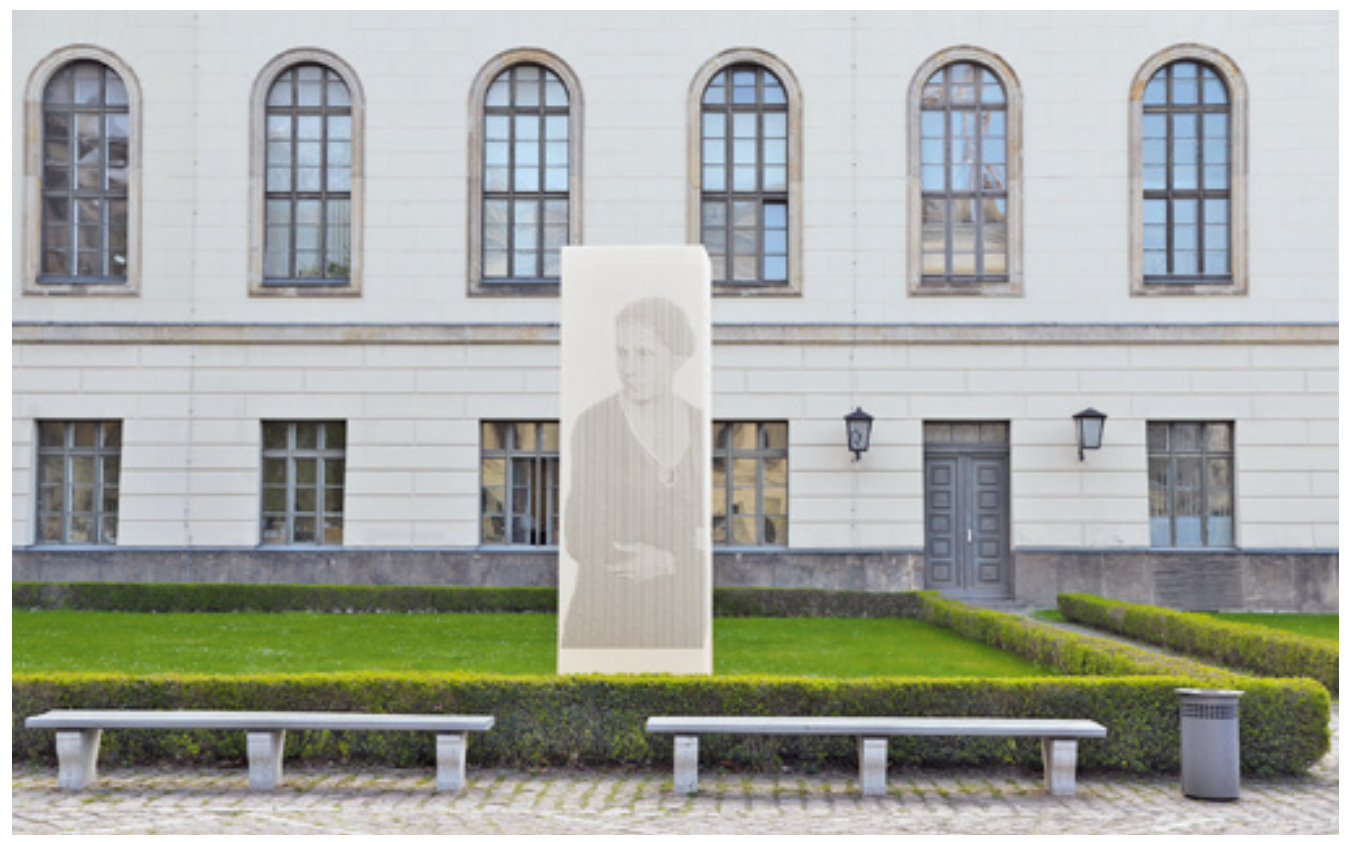

Abb. 8: Modell von Dagmar Pachtner, Landshut, eingereicht zum Kunstwettbewerb für das Lise-Meitner-Denkmal im Ehrenhof der Humboldt-Universität zu Berlin 2013.

Modelle für das Lise-Meitner-Denkmal zu Beginn der Preisrichtersitzung sah, war ich überaus beeindruckt. Bewusst hatte ich vorher keine feste Denkmal-Vorstellung entwickelt. Meine Prämissen waren, dass dieses Denkmal gleichberechtigt im Ensemble der anderen Denkmäler vor dem Universitätshauptgebäude stehen soll und, wie bereits erläutert, dass es erkennbar weiblich sein soll. Alle Künstlerinnen und Künstler waren mit großem Einfühlungsvermögen in die Person Lise Meitners an ihren Denkmalentwurf herangegangen und haben daraus sehr unterschiedliche, aber stets innovative, künstlerische Ideen entwickelt, die in ihrer Bindung an Geschichte und Individualität ebenso ermutigend wie kommunikativ wirkten.

Die Künstlerin Dagmar Pachtner aus Landshut hat eine Stele entworfen, deren Vorderansicht mithilfe der Foto-Gravur-Technik ein Foto von Lise Meitner aus dem Jahre 1937 reproduziert (Abb. 8). Entsprechend dem jeweiligen Lichteinfall beim Vorübergehen ist das Fo- to deutlicher oder undeutlicher erkennbar. Was die Betrachter sehen, hängt vom Lichtspiel auf der Oberfläche ab, also von der Zufälligkeit und Flüchtigkeit des Lichts. Das über Eck gezogene Porträt nimmt die Bewegung der Besucher vom Tor über den Ehrenhof zum Universitätseingang auf. Auf zwei Seiten der Stele war je ein Zitat von Lise Meitner eingraviert. Auch wenn die Materialwahl und die Form des Körpers zunächst als positiver Kontrast wahrgenommen wurden, sahen große Teile des Preisgerichts in der Stele einen für den Ehrenhof zu massiven Körper, insbesondere in Bezug auf das Max-Planck-Denkmal.

Marie Luise Bauerschmidt aus Berlin wählte das fast klassische Ideal der frei stehenden Statue (Abb. 9). Alle Linien und Details, Körper- und Handhaltungen führen auf den gehobenen Kopf zu, dem Zentrum und dem Ausgangspunkt der Gedankenwelt Lise Meitners. Erhobenen Hauptes schaut sie den Betrachter an und scheint doch ein wenig in ihre Welt versunken. Homogen fügt sich die Figur in das Ensemble der anderen 


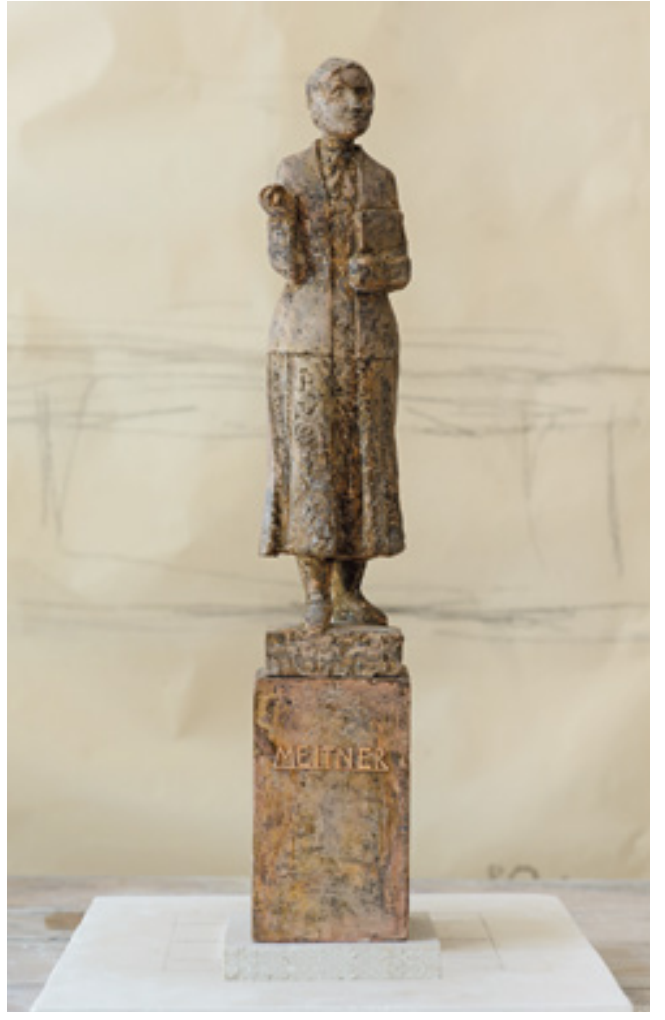

Abb. 9: Modell von Marie Luise Bauerschmidt, Berlin, eingereicht zum Kunstwettbewerb für das Lise-Meitner-Denkmal im Ehrenhof der Humboldt-Universität zu Berlin 2013.

Denkmäler im Ehrenhof. Auch Helmholtz hat seine Hand zum Dozieren erhoben, beide, Meitner wie Helmholtz, schauen ernst und ruhig, bedachtsam scheinen sie ihr Wissen den Zuhörern weiterzugeben. Durch eine kleine Drehung des Kopfes zum Eingang wendet sich die Skulptur dem eintretenden Besucher zu. Nicht nur durch die Darstellung des Rockes, dessen Herausarbeitung Bewegung, aber auch Anmut in die Figur bringt, ist die Plastik erkennbar weiblich. Auch die Zartheit der Darstellung betont das Weibliche. Von großen Teilen des Preisgerichts wurde die Ausführung als zu konventionell bewertet und die Befürchtung geäußert, dass sich die zierliche Plastik nicht gegen die imponierende Ausstrahlung der anderen Denkmäler behaupten könne.

Das dritte Modell, von der Künstlergruppe Mitra Wakil und Fabian Hesse aus München, stellt einen Ausbruch aus der figürlichen Konvention bildhauerischer Arbeit dar (Abb. Io). Nicht in erster Linie durch die Darstellung der Figur, obwohl ihre nicht völlig motivierte Schräglage auch gegensätzlich interpretiert werden kann - ist es Selbstbewusstsein, Lässigkeit oder Unsicherheit? Nein, was hier die bildhauerische Konvention sprengen würde, wäre die angewendete Technik. Die Figur sollte mit 3DAusdruck in grau-blauem Kunststoff, vermischt mit Marmorpartikeln, ausgeführt werden, eine neuartige Technik, die auf die innovativen Entdeckungen und Gedankenmodelle der Physikerin hinweisen soll. Wie aber ist die verwendete Technik am fertigen Kunstwerk ohne zusätzliche Erklärung noch ablesbar? Absicht der Künstler war es, Kopf und Hände auf der Grundlage von Fotografien naturalistisch abzubilden, während andere Teile der Figur als „flüchtiges Rauschen der Partikel ... bewusst verunklart “ ${ }^{\text {" }}$ bleiben sollten. Eine Ewald Mataré zugeschriebene Äußerung, dass die einfachste und zugleich schönste Skulptur der Abdruck eines menschlichen Fußes im Sande sei, klingt hier an und wird konfrontativ einzelnen unbestimmten Formen wie den Marmorrollen, die von einem XYZ-Koordinatensystem inspiriert sind, oder der nicht näher definierbaren Sitzgelegenheit gegenübergestellt. Alle diese Gegenstände sind Bestandteil einer plastischen Szene, von der die Betrachter entscheiden müssen, inwiefern sie miteinander korrespondieren.

Das vierte Modell, der Entwurf des Erfurter Künstlers Thomas Nicolai, präsentiert eine auf einer Bank sitzende Marmorfigur (Abb. II). An der Bank ist ein wolfartiges Tier erkenn-

6 Bericht der Vorprüfung zur Sitzung des Preisgerichts am 18. 6. 20I3, Berlin, Nichtoffener Kunstwettbewerb für das Lise-Meitner-Denkmal im Ehrenhof der Humboldt-Universität zu Berlin, Berlin 2013, Einzelbericht Ioo3. 


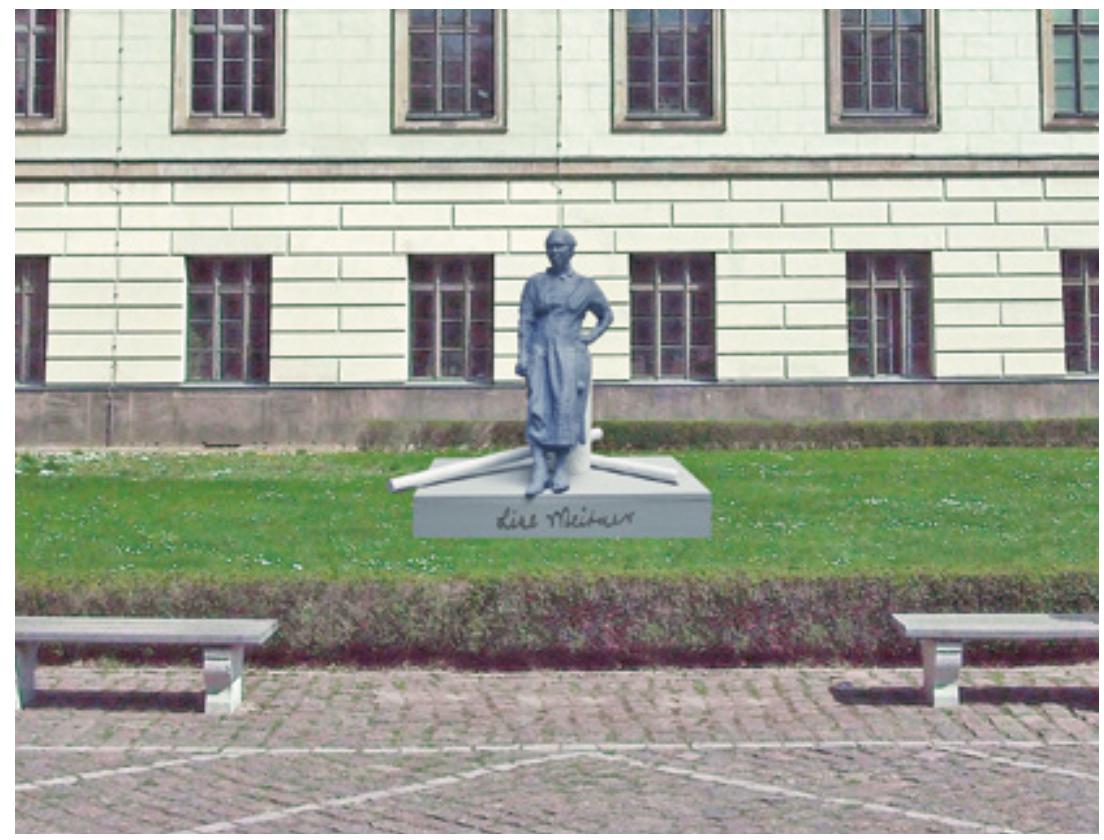

Abb. Iо: Modell der Künstlergruppe Mitra Wakil und Fabian Hesse, München, eingereicht zum Kunstwettbewerb für das Lise-Meitner-Denkmal im Ehrenhof der Humboldt-Universität zu Berlin 2013 .

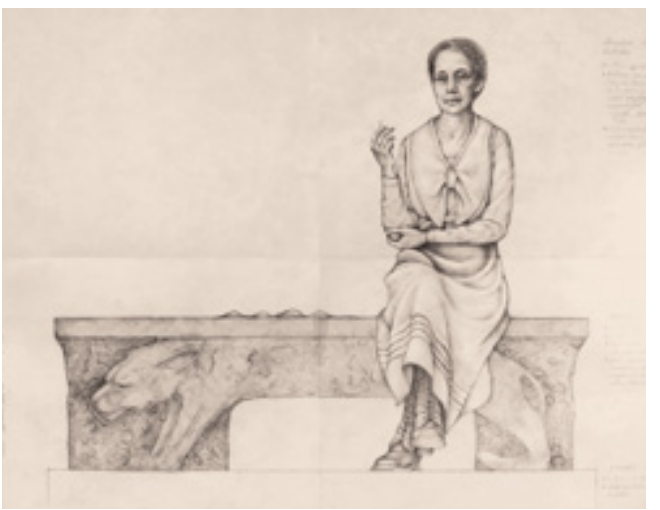

Abb. II: Modell von Thomas Nicolai, Erfurt, eingereicht zum Kunstwettbewerb für das Lise-Meitner-Denkmal im Ehrenhof der Humboldt-Universität zu Berlin 2013.

bar. Auf seiner Entwurfstafel weist der Künstler mit einem Foto auf Ernst Barlachs „Geistkämpfer" von 1927 an der Nikolaikirche von Kiel hin und somit auf die Dechiffrierung der Bankgestaltung. Barlachs Engelsgestalt, mit erhobenem Schwert auf einem wolfartigem Tier mit gesträubten Haaren stehend, soll den Sieg des
Geistes über die dunklen, animalischen Kräfte repräsentieren. Das Preisgericht war beeindruckt von der Entwurfsausarbeitung, insbesondere von der in Marmor geplanten Ausführung der Figur, die damit auf die Materialität der Denkmäler von Helmholtz und Mommsen eingeht, und von der sitzenden Figur, die durch ihre Platzierung auf einem Sockel sich in Augenhöhe zu den Betrachtern befinden würde. Jedoch erschien einer Mehrheit des Preisgerichts das dreiteilige Gesamtensemble des Sockels als zu überladen, da entsprechend dem vorliegenden Entwurf der Sockel zusätzlich noch mit einem Kiesbett umrandet und mit einer Bodenplakette ergänzt werden sollte. Mich überzeugte vor allem hier die Grundidee der sitzenden, auf Augenhöhe mit dem Betrachter kommunizierenden Wissenschaftlerin.

Als ich den fünften Entwurf sah, fühlte ich sofort, dass es dieser Entwurf ist, der am stimmigsten Lise Meitners Leben und Wirken wiedergibt, sich einfügt und gleichzeitig abhebt 


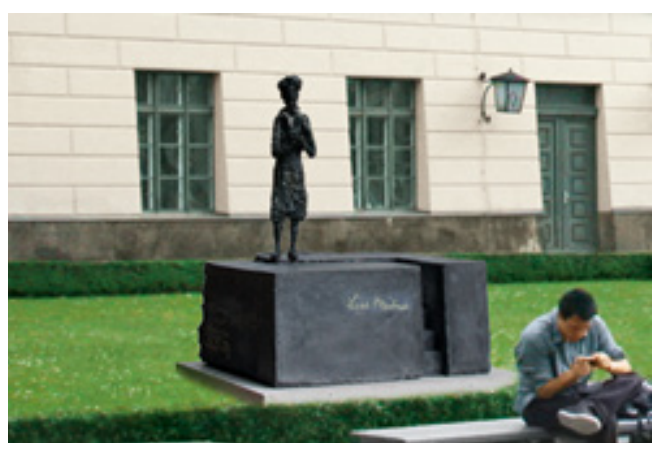

Abb. I2: Modell von Anna Franziska Schwarzbach, Berlin, Wettbewerbssiegerin, eingereicht zum Kunstwettbewerb für das Lise-Meitner-Denkmal im Ehrenhof der HumboldtUniversität zu Berlin 2013.

vom Ensemble der anderen Denkmäler (Abb. I2). Erfreulicherweise sah die Mehrheit des Preisgerichts ebenfalls in der selbstbewusst dastehenden, lebendig wirkenden Figur eine adäquate Widerspiegelung der Persönlichkeit Lise Meitners. Insbesondere der knapp 3,5 $\mathrm{m}^{3}$ große wuchtige Kunststeinsockel mit seinen tief eingeschnittenen Stufen, seinen Unregelmäßigkeiten, Schrägen und Brüchen wurde als ein außergewöhnliches Narrativ bewertet.

Geschaffen wurde das Modell von der namhaften Berliner Bildhauerin Anna Franziska Schwarzbach. In ihrer Modellerklärung schreibt sie, dass sie erkennen musste, dass es kaum Bild- nisse von Wissenschaftlerinnen gibt und zu Lise Meitners Zeiten kaum Professorinnen. „Wie schwer muss es für eine Frau gewesen sein, wissenschaftlich zu arbeiten, wie viel schwerer noch, wissenschaftlich geachtet zu werden. Dies brachte mich auf die Idee, den Sockel möglichst breit zu machen, um in Gedanken der vielen ,Nichtaufgesockelten' gedenken zu können. “7 Und sie führt weiter aus: „Stufe für Stufe schritt Lise Meitner. Es waren immer Einschnitte. Sie beginnt mit dem Status des, unbezahlten Gastes' und inmitten ihrer Forschungen musste sie emigrieren. Die Stufen brechen ab. Sie geht ihren Weg auf der anderen Seite - im Ausland, im Hintergrund - weiter [...]. Sie steht abseits in ihrer kleinen hervorragenden und herausragenden Größe."

In der abschließenden Diskussion ging es insbesondere darum, ob das Denkmal von Anna Franziska Schwarzbach dem aktuellen Kunstund Denkmalsdiskurs standhält. Während einige Mitglieder des Preisgerichts ausschließlich die Stele von Dagmar Pachtner als ein adäquates zeitgenössisches Kunstwerk betrachteten, sah die Mehrheit des Preisgerichts gerade in dem Entwurf von Schwarzbach eine aktuelle Aussage in hoher künstlerischer Qualität und votierte für dessen Realisierung.

\section{K ÜNSTLERISCHER ENTSTEHUNGSPROZESS DES LISE-MEITNER-} DENKM A L S

Es war eine wunderbare Erfahrung für mich, den Entstehungsprozess des Denkmals in allen Einzelheiten verfolgen zu dürfen, zu erleben, wie die Künstlerin am nackten Stahlkreuz allmählich eine Figur formte und wie von dieser Tonfigur eine Gipsfigur abgeformt wird und von dieser wiederum ein Wachsmodell, bis zu dem Zeitpunkt, da sich die glühende Bronze in die Form ergoss, die Figur aus der Schalung herausgeklopft und teilweise ziseliert wurde, wobei die Bildhauerin möglichst viele Arbeitsspuren an der fertigen Bronze belassen hat.

Bei der Arbeit am Denkmal konnte Anna Franziska Schwarzbach auf ihre jahrzehntelange Erfahrung im Bereich des figurativen Arbeitens, der Gedenkplastik und Gedenkmedaille zurück-

7 Bericht der Vorprüfung zur Sitzung des Preisgerichts am 18. 6. 20I3, Berlin, Nichtoffener Kunstwettbewerb für das Lise-Meitner-Denkmal im Ehrenhof der Humboldt-Universität zu Berlin, Berlin 2013, Einzelbericht I005.

8 Ebenda. 


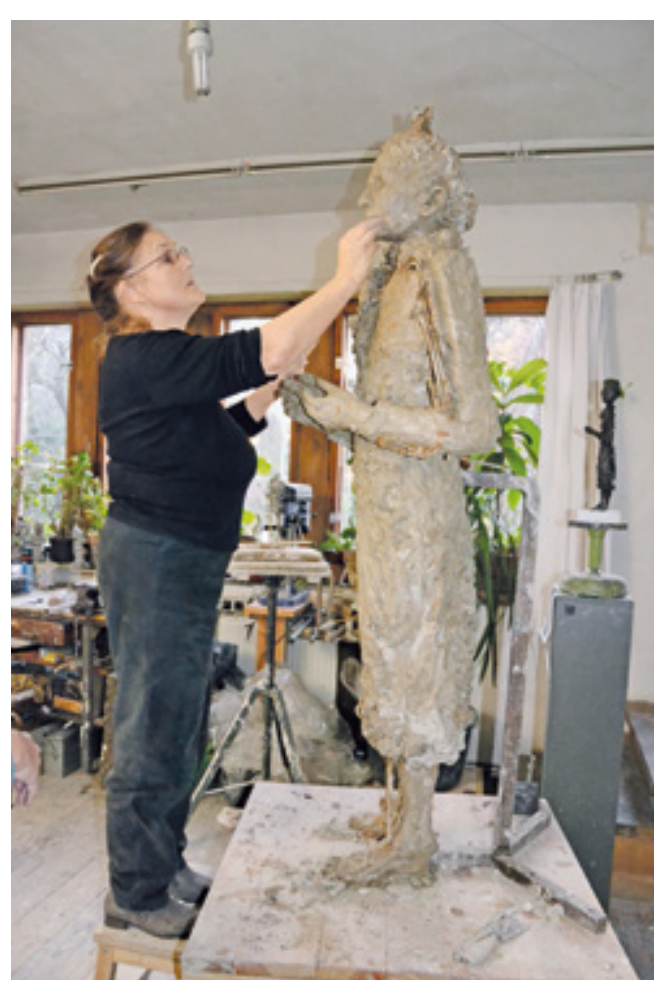

Abb. 13: Die Bildhauerin Anna Franziska Schwarzbach bei der Arbeit am Tonmodell für das Lise-Meitner-Denkmal.

greifen. Ihr breites, außergewöhnliches Euvre umfasst ein Universum menschlicher Wesen, deren Bilder sie formte: von Kindern, Frauen und Männern ihrer unmittelbaren Umgebung bis zu bekannten Persönlichkeiten. Sie formte Geschöpfe der Fantasie, Undinen, Amazonen, trauernde Seelen und weibliche Plagegeister, aber ebenso Symbole weiblichen Widerstandes und weiblicher Größe, wie „Kassandra“ (1982) und "Jeanne d'Arc" (2003), vor allem jedoch Porträts starker Frauen der Vergangenheit und der Gegenwart. Und immer wieder Skulpturen, die an die Vernichtung jüdischer Menschen gemahnen.

Ein Jahr lang hat sich die Künstlerin intensiv mit der Persönlichkeit Lise Meitners auseinandergesetzt, sich in Literatur und Fotos vertieft; Körperhaltung, Augen und Mund sorgfältig studiert und in verschiedenen Techniken, Skizzen, Büsten, Medaillen, ausprobiert - und dabei stän- dige Veränderungen an der Plastik vorgenommen (Abb. I3). Ernsthaftigkeit und Würde gehören ebenso zu Schwarzbachs Bildsprache wie Ironie und Skurrilität. Im Laufe ihres Künstlerlebens bevorzugte sie zunehmend skulpturale Formen des Unabgeschlossenen, der Auslassung, des „non finito“. Die „erzählerische” Bearbeitung des Materials rückte in den Vordergrund, dessen Stofflichkeit, dessen Zufälligkeiten sollen erkennbar sein. So ist ihr eine äußerst bewegte Figur gelungen. Der rechte Fuß zeigt zum Hauptportal des Universitätsgebäudes, das Gesicht zum gegenüberliegenden Eingang des Ehrenhofes, dem Eintretenden zugewandt. Dadurch ist eine Drehung und starke Dynamik in den Körper eingeformt. Die $157 \mathrm{~cm}$ hohe Figur (Lise Meitner war $149 \mathrm{~cm}$ groß) ist leicht nach vorn geneigt, so, als ob sie forschend dem Betrachter ein wenig näher kommen möchte (Abb. I4).

Demgegenüber sind die männlichen Gelehrtendenkmäler des 19. und des 20. Jahrhunderts mit der ausdrücklichen Absicht ihrer Schöpfer in erster Linie repräsentativ angelegt. Sie wirken auffallend statisch. Bei den Humboldt-Denkmälern und bei Mommsen ist die Unbeweglichkeit, das Majestätische schon durch die Sitzhaltung vorgegeben. An der aufrechten Helmholtz-Statue ist keine Bewegung erkennbar. Im hoheitsvollen Gestus, in sich ruhend, steht er den Betrachtern gegenüber. Unterstrichen wird die würdevolle Haltung durch den typischen Kanon der Attribute der Gelehrsamkeit wie Buch, Talar und antike Bildzitate. An der gesellschaftlichen Anerkennung dieser Gelehrten gab es keinen Zweifel. Die Humboldts, Helmholtz, Mommsen, Thaer, Beuth, Schinkel - sie alle eint eine erfolgreiche, geradlinige, ungebrochene Biografie. Sie waren Helden, Helden ihrer Zeit, Heroen des Geistes, und dieses Heldenhafte ist in ihr Denkmal eingearbeitet.

Bei der Lise-Meitner-Figur dominieren in der Körperhaltung, wie auch im Gesichtsausdruck, gleichfalls Selbstbewusstsein und Würde, 


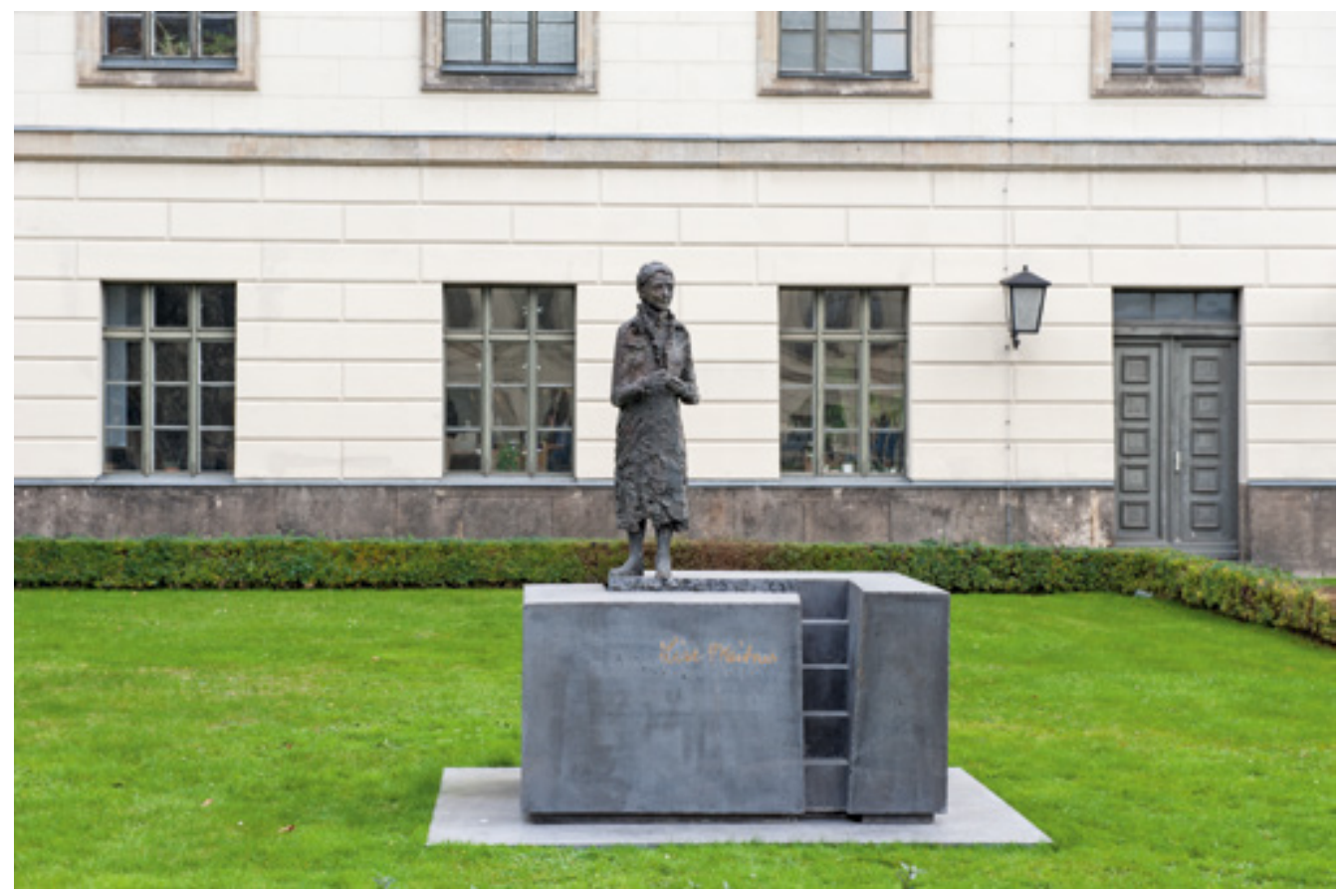

Abb. I4: Berlin, Denkmal für Lise Meitner, Ehrenhof der Humboldt-Universität zu Berlin, Unter den Linden; Anna Franziska Schwarzbach, Lise Meitner, 20I4, Figur: Bronze, Sockel: Kunststein, Gesamtansicht.

aber sie sind gepaart mit einem aufmerksamen, forschenden Gestus und zugleich mit einem Ausdruck von Bescheidenheit (Abb. I5).

Eine besondere künstlerische Leistung ist die Gestaltung des Sockels. Die Tradition des klassizistischen Sockels aufnehmend, hat die Künstlerin ihm eine völlig neue Form gegeben. Das wuchtige Postament entwickelt eine eigene Überzeugungskraft. Es ist zu einem immanenten Teil des Kunstwerkes geworden und bietet bemerkenswertes Potenzial, Erinnerungsarbeit zu leisten. Nur die vordere Seite mit dem Namenszug Lise Meitners in ihrer Handschrift ist spiegelglatt und erinnert in seiner Schräge an jüdische Grabsteine. Unübersehbar eingeschnitten in diese Schräge ist ein Pfad in Form einer Treppe. Schwarzbach will hier auf die gebrochene Biografie Meitners verweisen, ihre Karrierestufen, die plötzlich abbrachen, sodass sie gezwungen wurde, ihren Weg in einer anderen Welt, im Ausland, hier auf der anderen Seite des Sockels, weiterzugehen, denn eine schmale Furche teilt auf der Oberseite denselben. Die auf dem Sockel zierlich wirkende Figur steht erhobenen Hauptes auf dem hinteren Teil des Sockels, doch ihre Fußspitzen berühren noch den vorderen Teil, ihre Vergangenheit, die erste Hälfte ihres Lebens.

Die Formeln an den Sockelseiten wirken einesteils wie eine Klammer dieses Wissenschaftlerinnenlebens: In die linke Seite des Sockels ist eine handschriftliche Formel zum Beschuss von Uran mit Neutronen aus Lise Meitners Tagebuch aus dem Jahr 1935 eingebettet und in die rechte Seite des Sockels das vereinfachte Schema der Kernspaltung. Heute wissend um die gewaltige Zerstörungskraft, die diese Formel widerspiegelt, ist die hintere Sockelseite aufgebrochen wie nach einer Eruption. Doch gleichsam assoziiert die Rückseite des Sockels wie auch das gesamte Postament mit seinen Schrunden, Rissen und Brüchen das 20. Jahrhundert als ein, so Osip Mandelstam, „Wolfshundjahrhundert“ mit 


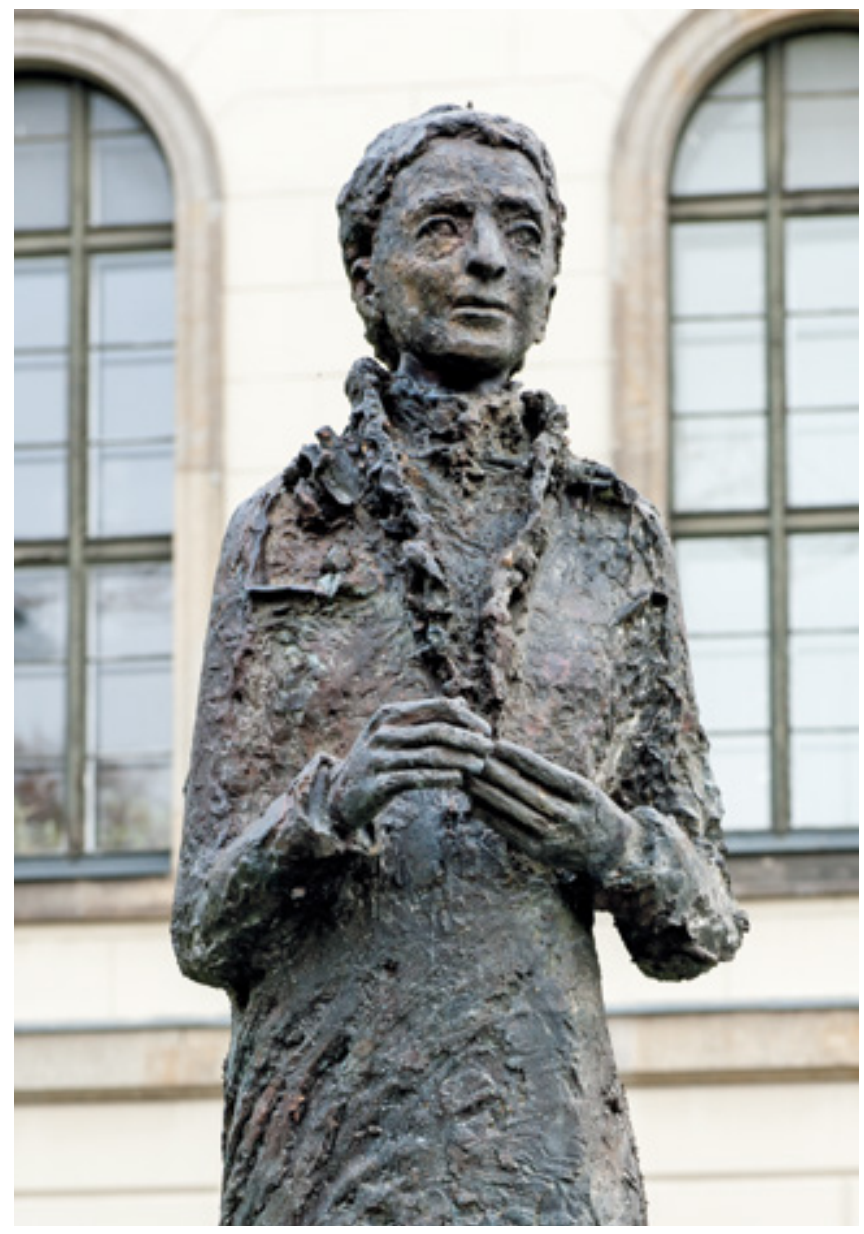

Abb. I5: Berlin, Denkmal für Lise Meitner, Ehrenhof der Humboldt-Universität zu Berlin, Unter den Linden; Anna Franziska Schwarzbach, Lise Meitner, 2014, Figur: Bronze, Sockel: Kunststein, Ausschnitt.

dessen Verheerungen und Grausamkeiten. Meitners Leben ist wie das von Millionen Menschen dieses Jahrhunderts geprägt von nationalsozialistischer Gewalt und Vertreibung. Die Bildhauerin kann sich daher nicht an den Formen der traditionellen Gelehrtendenkmäler, an würdevollen Talaren orientieren. Meitners Kleid, am Halsausschnitt eher verspielt, anklingend an die von der Wissenschaftlerin geliebten Häkelkragen, wird unmerklich immer zerklüfteter und geht allmählich in die Verwerfungen des hinteren Sockelteils über, wird so Bindeglied zur rückseitigen Sockel- seite, die all die Gewalt und Abscheulichkeiten des vergangenen Jahrhunderts symbolisiert.

Die Facetten der gebrochenen Biografie Meitners finden somit ihre Entsprechung in einer ästhetischen Einheit von Figur und Sockel und dem daraus erwachsenen Potenzial für Erinnerungsarbeit, von der glücklichen Erfahrung wissenschaftlichen Arbeitens bis zum Missbrauch wissenschaftlicher Erkenntnisse, von der Erinnerung an jüdische Traditionen bis zum Schmerz über die verlorene Heimat. Der Künstlerin Anna Franziska Schwarzbach ist es gelun- 
gen, die Einzigartigkeit der außergewöhnlichen Persönlichkeit Lise Meitners mit einem großartigen Denkmal zu vergegenwärtigen.

Die Realisierung des Denkmals ist zweifellos eine Erfolgsgeschichte, auch wenn sie nur von sehr wenigen Menschen aktiv realisiert wurde. Den Grund hierfür sehe ich darin, dass es immer noch keine Selbstverständlichkeit ist, Wissenschaftlerinnen gleichberechtigt im Wissenschaftsbetrieb anzuerkennen. Dennoch ist es möglich, überzeugende, spannende Denkmäler auch für Persönlichkeiten mit einer nicht linearen erfolgreichen Biografie zu errichten, auch wenn sie (noch) nicht selbstverständlicher Teil des etablierten gesellschaftlichen Lebens sind.

Am Io. Juli 2014 wurde das Lise-MeitnerDenkmal im Ehrenhof der Humboldt-Universität eingeweiht.

Es bleibt abzuwarten, inwiefern das Denkmalprojekt Lise Meitner seine Wirkung auf nachfol- gende Denkmalplastiken und insgesamt auf die Kultur des Erinnerns entfalten kann. Oder um es mit Worten von Christa Wolf zu sagen: „[...], dass der Mantel der Geschichte zugunsten derjenigen weht, die genug Puste haben, die Windrichtung zu bestimmen."

Abbildungsnachweis: Abb. I, 2: Helmholtz-Zentrum Berlin für Materialien und Energie Berlin; Abb. 3-7, I4I6: Antonia Weiße, Kustodie der Humboldt-Universität zu Berlin, Berlin; Abb. 8: Repro aus Bericht der Vorprüfung zur Sitzung des Preisgerichts am I8. 6. 2013, Berlin, Nichtoffener Kunstwettbewerb für das Lise-Meitner-Denkmal im Ehrenhof der Humboldt-Universität zu Berlin, Berlin 2013, Einzelbericht IOoI; Abb. 9: ebenda, Einzelbericht IOO2; Abb. Io: ebenda, Einzelbericht IOO3; Abb. II: ebenda, Einzelbericht IOO4; Abb. I2: ebenda, Einzelbericht I005; Abb. I3: Silvia Zerbe, HelmholtzZentrum Berlin für Materialien und Energie Berlin.

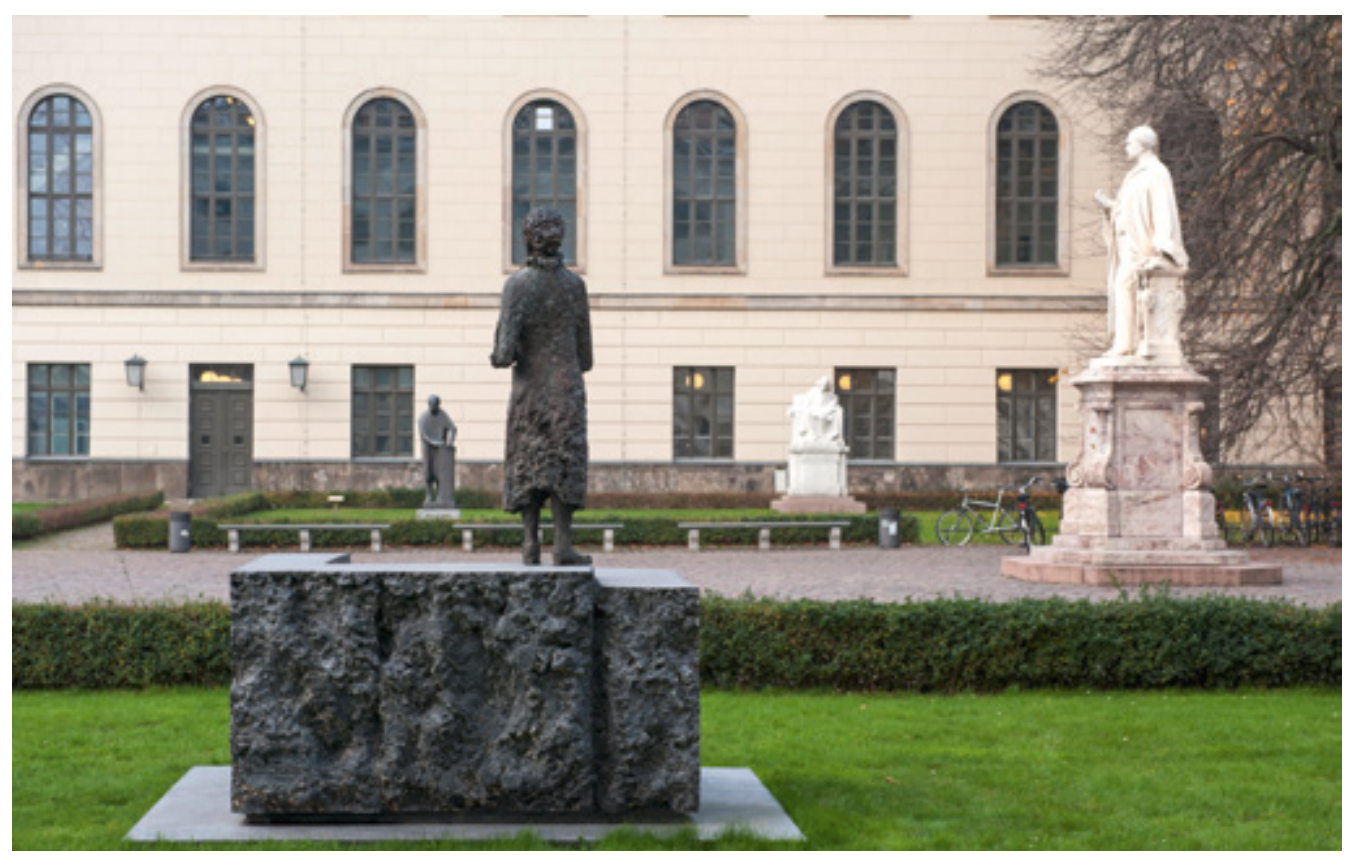

Abb. I6: Rückenansicht mit Kunststeinsockel des Lise-Meitner-Denkmals mit Blick auf die Denkmäler für Max Planck (v.l.n.r.), Theodor Mommsen und Hermann von Helmholtz.

9 Ch. Wolf, Abschied von Phantomen. Zur Sache: Deutschland, in: Ch. Wolf, Auf dem Weg nach Tabou, Köln, I994, S. 33I. 


\title{
AUF DER SUCHE NACH RÄUMEN UND FORMEN DER MEMORIA. ERSCHEINUNGSFORMEN DER GELEHRTENDENKMÄLER IN UNGARN
}

\author{
Géza Galavics - Bálint Ugry
}

$\mathrm{D}_{\mathrm{i}}^{\mathrm{ic}}$ Geschichte der Gelehrtenmemoria durch Ensembles von Kunstwerken lässt sich einerseits als permanente Suche nach den Erscheinungsformen, welche die Gestalt einzelner Gelehrter verewigen, und andererseits als Suche nach den Räumen, welche die Gelehrtenmemoria aufnehmen, beschreiben. Der Aufsatz stellt die Geschichte der Gelehrtenmemoria eines einzigen Landes, Ungarns, vor, und zwar durch die typischsten Beispiele und die charakteristischsten Tendenzen aus einem Zeitraum, der fast zweieinhalb Jahrhunderte umspannt. Nicht, dass sie - als Kennzeichnen einer autochthonen Entwicklung - eine voneinander abzuleitende einheitliche Reihe bilden. Denn ebenso wie die Wissenschaft international ist, sind es auch die Erscheinungsformen der Gelehrtenmemoria. Von wem aber - von welchen Institutionen und wie - diese Denkmäler verwirklicht wurden und welche politischen, wissenschaftlichen und künstlerischen Absichten sich dahinter verbergen, beabsichtigen die Verfasser aus der Geschichte Ungarns und dort aus den Rollen und Verbindungen von Wissenschaften und Gelehrten abzuleiten.

Die Hüter des kollektiven Gelehrtengedenkens waren von Anfang an meist die Universitä- ten. Die verschiedenen Fakultäten umfassten fast die Gesamtheit der Wissenschaften. Es sind die akademischen Fakultäten, die auch in der bildnerischen Repräsentation der Wissenschaften erscheinen. Die Fakultätsdarstellung des - auch in Wien tätigen - Augsburger Malers Franz Sigrist im Universitätsgebäude der nordungarischen Stadt Eger (Abb. I) stellt die Gelehrten der Zeit dar, wie sie sich mit den charakteristischen Instrumenten ihrer Wissenschaft betätigen. Nicht in historisierenden Kostümen wie bei Daniel Gran (Prunksaal der Hofbibliothek, Wien), auch nicht in einem theatralischen Milieu wie bei Gregorio Guglielmi (Neue Aula der Alten Universität, Wien), sondern in zeitgenössischen Kostümen. Das Bild gilt als eine der authentischsten Darstellungen von Wissenschaftlern der Aufklärungszeit, obwohl es keine konkreten Personen, sondern nur Typen darstellt. ${ }^{I}$ Der Auftraggeber Graf Károly Eszterházy (1725-1799) ließ ab den I76oer-Jahren in Eger, seinem Bischofssitz, eine groß angelegte katholische Universität errichten. In dem mehrstöckigen Gebäude entstanden eine umfangreiche Bibliothek, ein repräsentativer Festsaal (verziert mit dem Wandbild von Franz Sigrist), ferner eine Kapelle (mit Fresken von Franz Anton Maulbertsch) und auch

I B. Matsche-von Wicht, Franz Sigrist, I727-I803: Ein Maler des I8. Jahrhunderts, Weissenhorn 1977, S. II2-I25.; J. Jernyei Kiss, Die Welt der Bücher auf einem Deckenbild. Franz Sigrists Darstellung der Wissenschaften im Festsaal des Lyzeums in Erlau, in: Bibliotheken, Dekor 17.-I9. Jahrhundert (hrsg. von F. Barbier/I. Monok/A. De PasQUALE), Budapest/Rom/Paris 20I6, S. I45-I54. 


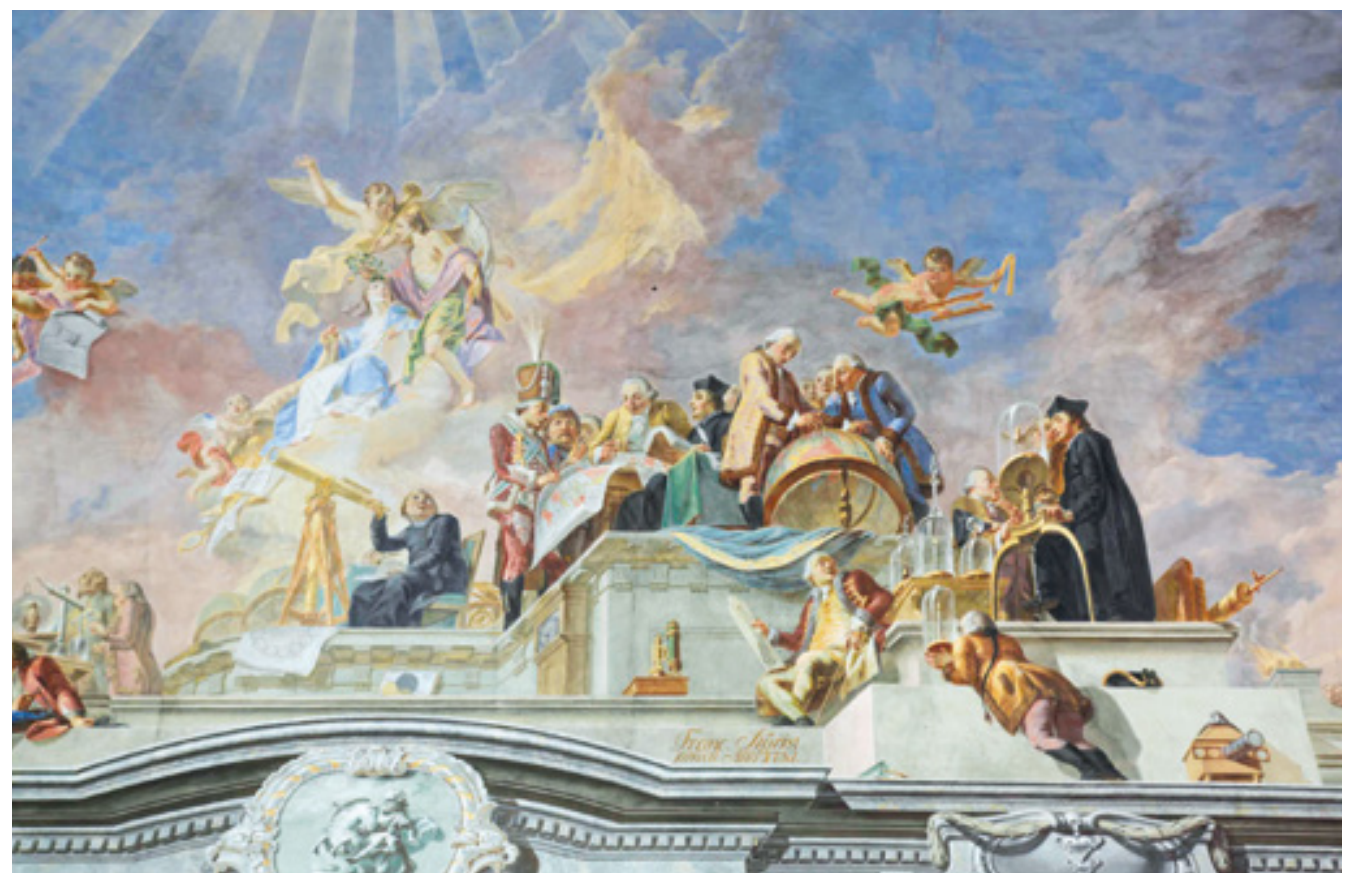

Abb. I: Franz Sigrist, Die philosophische Fakultät, I78I, Deckenmalerei, (Detail), Eger, Lyceum, heute Eszterházy Károly Föiskola, Festsaal.

ein Observatorium, das man mit den modernsten Geräten aus England versah. ${ }^{2}$ In Eger wurde die bildnerische Memoria der Wissenschaftler in der Bibliothek bewahrt. Nicht am Deckenbild, denn das stellt das Konzil von Trient dar (gemalt von Johann Lucas Kracker, I779), sondern in 24 vergoldeten Reliefporträts in Tondoform über den Regalen der geschnitzten Holzarchitektur von Vencel Halblechner (Abb. 2). ${ }^{3}$ Es sind Porträts von Aposteln und Kirchenvätern, Heiligen und Gelehrten, vom Heiligen Augustinus über Galilei und Christoph Kolumbus bis hin zu den Bildnissen von drei ungarischen Wissenschaftlern aus dem I6. und I7. Jahrhundert: István Werbőczy, Miklós Istvánffy, Péter Pázmány.
Es war eine traditionelle Gelehrtengalerie und hatte eine dekorative Funktion. Es gab unter den Porträtierten keinen zeitgenössischen Gelehrten.

Um 1780 bestand die „Universitas“ von Eger aus dem großzügigsten und am besten ausgestatteten Universitätsgebäude in Ungarn, dennoch wurde daraus keine funktionierende Universität. Der Bischof strebte nach einer modernen katholischen Universität, um die Position des katholischen Glaubens und der Kirche zu festigen, das Regierungssystem des aufgeklärten Absolutismus hingegen wollte eine starke staatliche Universität ohne Konfessionsunterschiede. Bischof Eszterházy durfte seine Universität nicht eröffnen. ${ }^{4}$ Die damals bereits I50-jährige Universität des

2 Zur Domus Universitatis in Eger: Az egri Domus Universitatis és Líceum. Oktatás, tudomány, művészet I763-20I3 (hrsg. von T. Petercsák), Eger 20I3 - Aufsätze im Band über die barocke Stadt: I. Bitskey, Eger a barokk kori Közép-Európában, S. 13-39. - Über die Deckenbilder: G. LudÁNYI, Az épület freskói, S. 7I-IO9. - Über die Bibliothek: E. Löfrler, Az egri Főegyházmegyei Könyvtár, S. III-I26. - Über die Sternwarte: T. PETERCSÁk, Specula - Csillagászati Múzeum, S. I5I-167. 


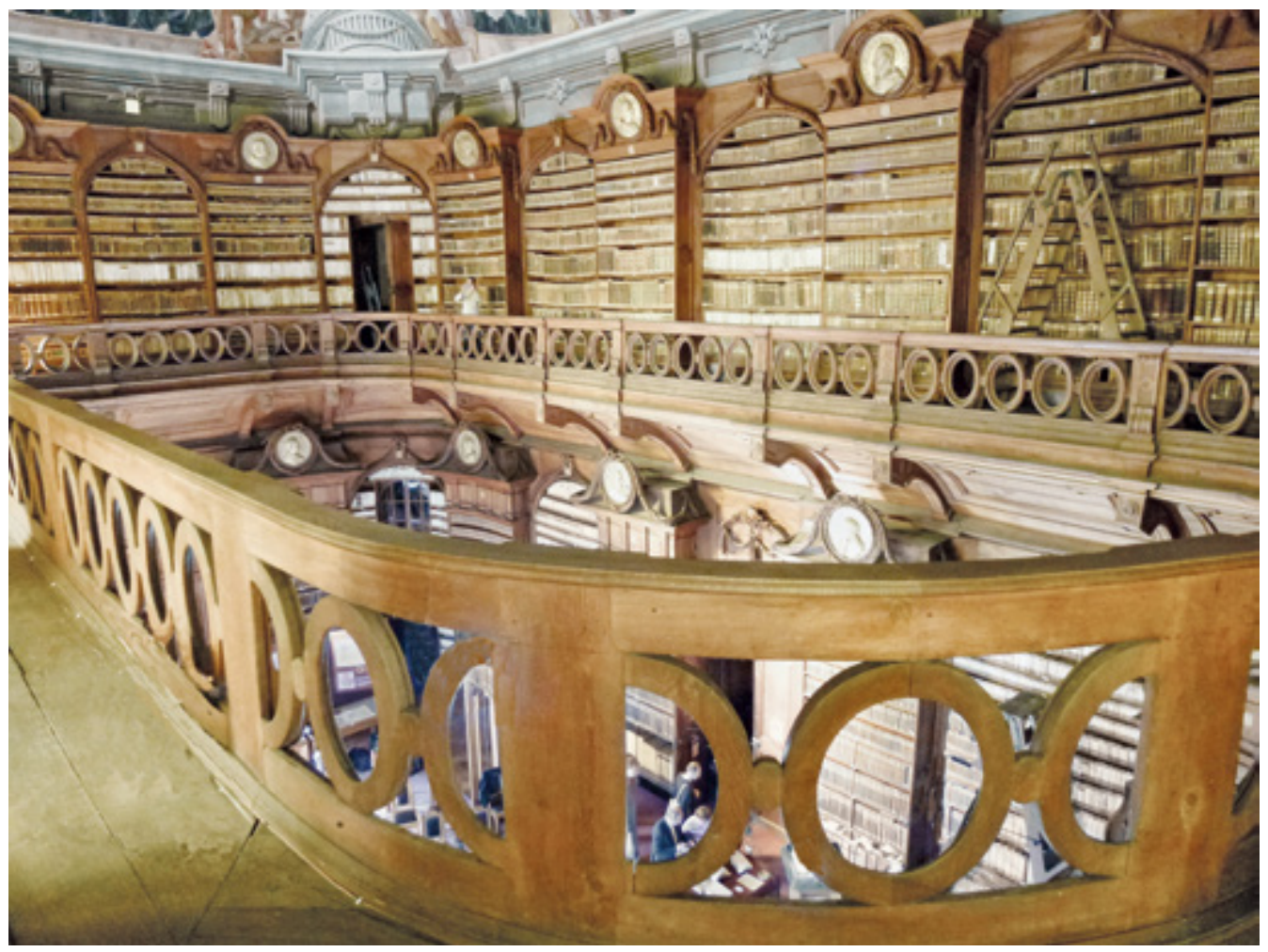

Abb. 2: Eger, Bibliothek des Lyzeums, um 1780 .

Ungarischen Königreichs war zu dem Zeitpunkt gerade nach Buda, in den Königlichen Palast umgezogen, war mit den Mühen der Einrichtung beschäftigt und unseres Wissens nicht mit der korporativen Verewigung ihrer Gelehrtenmemoria. In der Universitätsbibliothek wurde zwar eines der bedeutsamsten mitteleuropäischen Wissenschaftlerdenkmäler der Aufklärungszeit, die Büste des Rechtsgelehrten Martin Georg Ko- vachich (I744-I82I) aufbewahrt (Abb. 3). Kovachich, der zugleich Kustos der Bibliothek war, gab die Porträtbüste bei Franz Xaver Messerschmidt allerdings selbst in Auftrag und stellte sie in seinem eigenen Arbeitszimmer auf.

Aus der „Universitas“ des Bischofs Eszterházy wurde zwar keine funktionierende Universität, aber ihr Kulturprogramm inspirierte den ehemaligen Domherren des Bischofs, Ignác Batthyány

XXVIII. Internationalen Kongresses für Kunstgeschichte/Artistic Exchange. CIHA I5.-20. Juli I992 Berlin (hrsg. von T. W. Gaehtgens), Berlin I993, Band II. S. I85-198. - Zum Verhältnis der katholischen Kirchen und des Staates siehe J. BAHLCKe, Ungarischer Episkopat und Österreichische Monarchie. Von einer Partnerschaft zur Konfrontation (I686-I790), Stuttgart 2005.

5 M. Pötzl-Malikova, Franz Xaver Messerschmidt, Wien 1982, S. 239-240. (Kat.-Nr. 63) - M. Bückling, Der Historiker Martin Georg Kovachich (1782), in: Franz Xaver Messerschmidt 1736-I783 (Ausstellungskatalog Wien, Österreichische Galerie Belvedere), Wien 2002, S. 278-279. (Kat.-Nr. 66) - Ders., „Cognosce et dignosce” - „Erkenne und differenziere", in: Franz Xaver Messerschmidt 1736-I783 (Ausstellungskatalog Wien, Österreichische Galerie Belvedere), Wien 2002, S. 77-85. - M. Pötzl-Malikova, Martin Georg Kovachich (I743-182I) I782, in: Franz Xaver Messerschmidt I736-I783 (Ausstellungskatalog Paris, Musée du Louvre), Paris 20II, S. 93-95. (Kat.-Nr. 


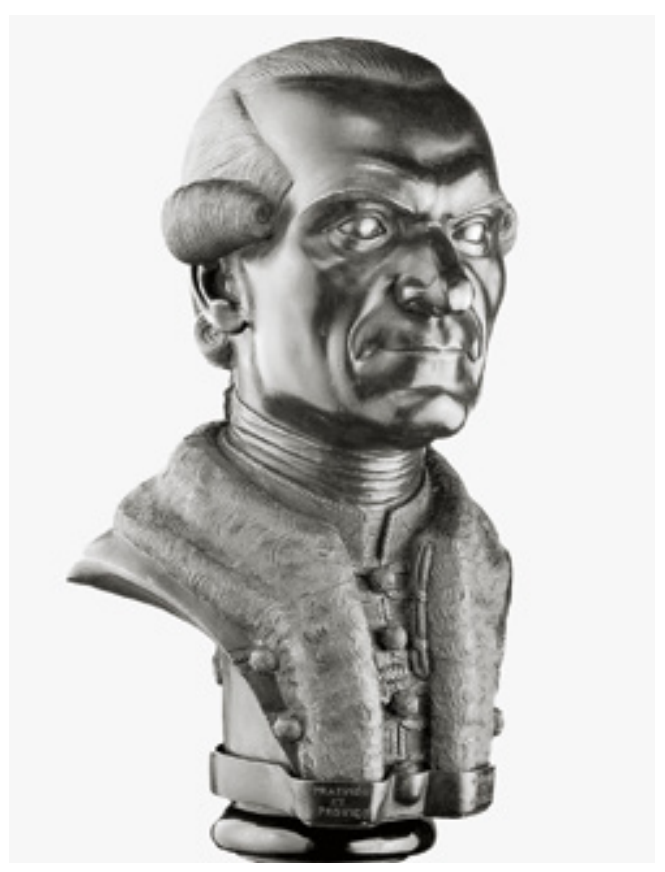

Abb. 3: Franz Xaver Messerschmidt, Martin Georg Kovachich, I782, Zinn, Budapest, Szépmüvészeti Múzeum.

(I74I-I798), der ebenfalls aus einer ungarischen Aristokratenfamilie stammte. Als er Bischof von Siebenbürgen wurde, errichtete er an seinem Bischofssitz Karlsburg (ung. Gyulafehérvár, heute Alba Iulia in Rumänien) zwischen 1792 und I798 eine multifunktionale kulturelle Institution. Er ließ das Innere der aufgelösten Trinitarierkirche in drei Stockwerke teilen und im unteren eine Typographia, im mittleren eine Bibliotheca und im oberen Geschoss eine Urania, eine Sternwarte, anlegen. Das Institut hatte eine umfangreiche Bibliothek, die bis heute erhalten blieb, die Besonderheit aber war das moderne Observatorium. Die Astronomie erlebte in der zweiten Hälfte des I8. Jahrhunderts eine ihrer Glanzperioden und galt vielleicht als eine der internationalsten Wissenschaften ihrer Zeit. Ihre führende Gestalt, der in Ungarn geborene Wiener Jesuit Maximilian Hell, wirkte bei der Einrichtung von mehreren Sternwarten in Ungarn mit. Die dortigen Astronomen waren seine Schüler. Ihre zeitgenössischen Fachkenntnisse bewahrt in Karlsburg nicht nur das erste Jahrbuch der Sternwarte, sondern auch der bis heute erhaltene, repräsentative spätbarocke Innenraum des Observatoriums (Abb. 4). Seine Seitenwände ziert eine Porträtgalerie mit sechzehn hervorragenden Vertretern der astronomischen Wissenschaft in gemalten ovalen Bildnissen (und nicht als Büsten auf Postamenten, wie ursprünglich geplant). Neben Ptolemäus, Kopernikus, Kepler, Tycho Brahe und Maximilian Hell finden sich auch die Porträts zweier damals noch lebender Zeitgenossen, das von Franz de Paula von Triesnecker, der die Sternwarte der Wiener Universität geleitet hatte, ferner das von Gottfried van Swieten. Dieses moderne Selbstbild der Astronomie als Wissenschaft zeigt, dass die Astronomen in Karlsburg den größten Vorfahren der Astronomie folgen. Man plante noch, an einem Deckenbild auch den wohltätigen Einfluss der Astronomie auf den Fortschritt der Menschheit darzustellen. ${ }^{6}$

In der ersten Hälfte des 19. Jahrhunderts erschienen Bildergalerien gemalter Gelehrtenporträts auch in mehreren Bibliotheken Ungarns (Nationalbibliothek in Pest, Bibliothek des Be-

7). - Maria Pötzl-Malikova, Franz Xaver Messerschmidt I736-1783. Biografie und Werkverzeichnis, Wien 20I5, S. IO6 (Kat.-Nr. 65)

6 A. Kovács, Program és műalkotás a I8. század végi Erdélyben. A gyulafehérvári Batthyaneum csillagvizsgálója, in: Stílusok, művek, mesterek. Erdély művészete I690-I848 között. Tanulmányok B. Nagy Margit emlékére (hrsg. von J. ORBÁN), Marosvásárhely/Kolozsvár 20II, S. II7-136. - A. Kovács, The Batthyaneum Observatory of Alba Iulia: A less known iconographic program, in: Batthyaneum: Omagiu fondatorului Ignatius Sallestius de Batthyan (I74I-I798) (hrsg. von D. H. BIRo), Bucureşti 20II, S. I95-2I2; Kupferstiche des ersten Jahrbuchs der Sternwarte zeigten die Fassade, die Pläne der Seitenwand des Innenraums, den Grundriss der Sternwarte, die Deckenmalerei und drei astronomische Werkzeuge: A. Mártonfi, Initia astronomica speculae Batthyanianae Albensis in Transilvania ..., Gyulafehérvár 1798. 

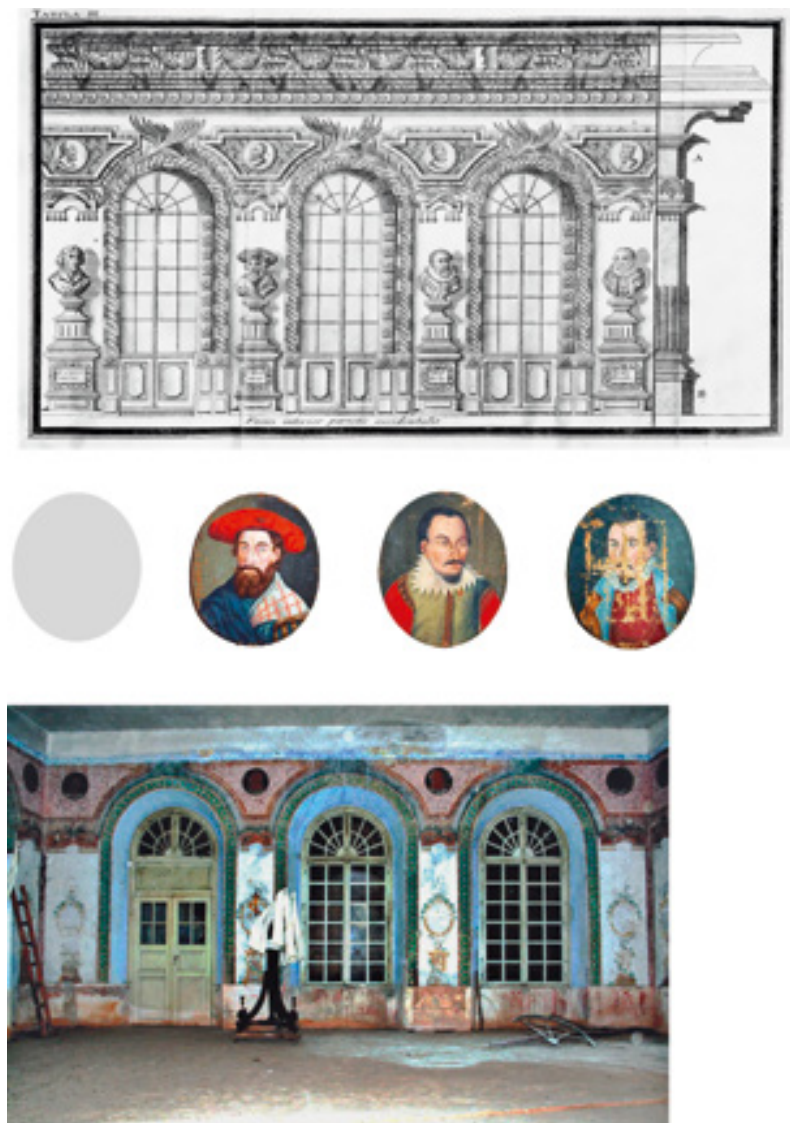

Abb. 4: Geplante Westwand der Sternwarte von Karlsburg (Alba Iulia), I796, Kupferstich

Claudius Ptolemäus, Johannes Kepler, Tycho Brahe, 1799, Öl auf Leinwand, Biblioteca Batthyaneum (Filiala Bibliotecii Nationale a României) Heutiger Zustand der Westwand der Sternwarte.

nediktinerordens in Pannonhalma). ${ }^{7}$ Jedoch in ziemlich sekundärer Rolle, umlaufend an den inneren Gesimsen in den Bibliotheken. Keine kunsthistorische, sondern nur historische Bedeutung kann ihnen beigemessen werden, sie sind zu betrachten als Versuche, den Kanon der Nationalkultur zu schaffen und den Kreis der dazugehörigen Wissenschaftler zu markieren. Die interessierte Öffentlichkeit in Ungarn erreichten in jener Zeit eher die populären Porträtstiche der zeitgenössischen Gelehrten.

Für die ungarische Kultur und Wissenschaft brachten die Jahre zwischen 1862 und 1865 ein durchaus bedeutsames Novum. Am Pester Donauufer wurde der repräsentative Palast der Ungarischen Akademie der Wissenschaften erbaut

7 Zur Nationalbibliothek (ehemalige Pauliner Bibliothek) siehe: P. FARBAKY, Pálos könyvtár vagy nemzeti könyvtár?, in: Művészettörténeti tanulmányok Mojzer Miklós hatvanadik születésnapjára (hrsg. von I. TAKács et al.), Budapest I99I, S. 237-244. - Zur Pannonhalma, wo Joseph Klieber für die Bibliothek zwei Statuen (hl. Stephan, Kaiser Franz I.) und die Dekoration der Decke mit der Gestalt Minervas fertigte - siehe: J. SisA, Klassizistische Bauten des 19. Jahrhunderts. Die Bibliothek und der Turm von Pannonhalma, in: Acta Historiae Artium, XXXVIII, 1996, S. I67-I84. 


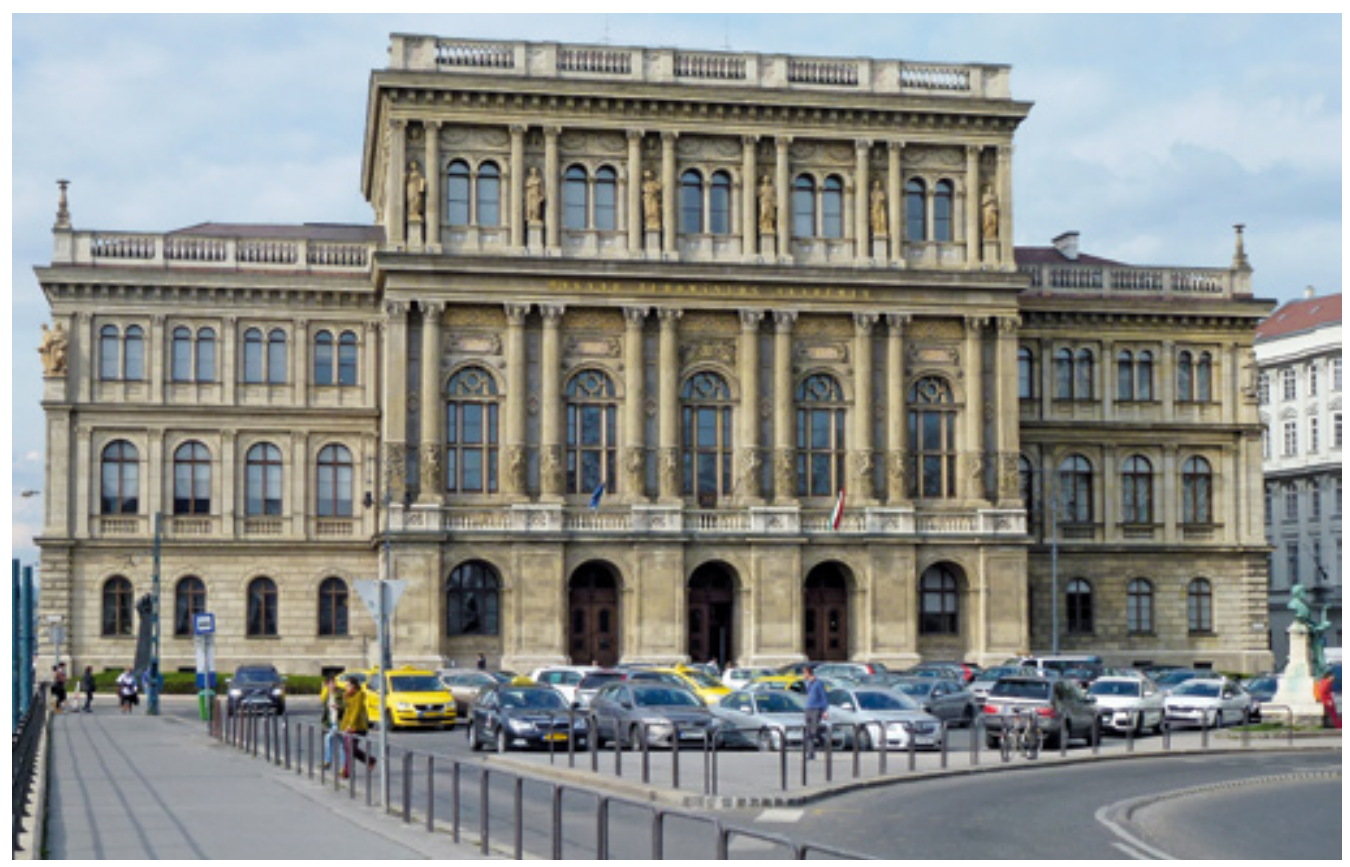

Abb. 5: Friedrich August Stüler, Palast der Ungarischen Akademie der Wissenschaften, Budapest, I862-I865.

(Abb. 5). Dies war für die Wissenschaft ein symbolträchtiges Ereignis. Zu jener Zeit stand schon das Gebäude des Ungarischen Nationalmuseums und das Land hatte auch ein Nationaltheater, aber die Akademie der Wissenschaften hatte noch kein selbstständiges Gebäude. Dem Bau gingen große Erwartungen und eine intensive Diskussion darüber voraus, welcher architektonische Stil sich für den Palast der Wissenschaft eignet. Nach der Meinung des Vorbereitungskomitees war dies auf jeden Fall der gotische, und ungarische Architekten konzipierten entsprechende Entwürfe. Das gut vernetzte Präsidium der Akademie dachte aber anders und erbat Entwürfe von Leo von Klenze aus München und von August Stüler aus Berlin. ${ }^{8}$ Schließlich wurde Stülers Entwurf im Stil der Neorenaissance angenommen. I865 wurde der Palast der Ungarischen Akademie der Wissenschaften eingeweiht. Stüler errichtete nicht nur ein funktionales und repräsentatives Gebäude, sein Entwurf umfasste auch das bauplastische Programm der europäischen Gelehrtenmemoria. Auf der Fassade sollten allegorische Skulpturen die Wissenschaften verkörpern, und an den Ecken der Risalite brachte er ganzfigürliche Gelehrtenstatuen an: Galilei, Newton, Leibniz, Descartes, Raffael und die Skulptur eines ungarischen Gelehrten, Miklós Révai (Abb. 6). ${ }^{9}$

8 A Magyar Tudományos Akadémia palotájának pályázati tervei - Bewerbungspläne für den Palast der Ungarischen Akademie der Wissenschaften. Katalog und Schriftquellen (Ausstellungskatalog Budapest, MTA), Budapest 1996.

9 E. Börsch-Supan/D. Müller-Stüler, Friedrich August Stüler I800-I865, München/Berlin 1997, S. 931. - M. Kemény, A Magyar Tudományos Akadémia palotája, in: A Magyar Tudományos Akadémia és a művészetek a XIX. században - The Hungarian Academy of Sciences and the Fine Arts in the Nineteenth Century (Ausstellungskatalog Budapest, Magyar Nemzeti Galéria), Budapest 1992, S. II8-I25, English: S. 286-290. - J. SisA, A Magyar Tudományos Akadémia székháza, in: Épített örökség a magyar tudomány szolgálatában (hrsg. von G. Gy. PAPP), Budapest 20IO, S. 5I-54. - M. KemÉNY, A Magyar Tudományos Akadémia palotája, Budapest 2015. 


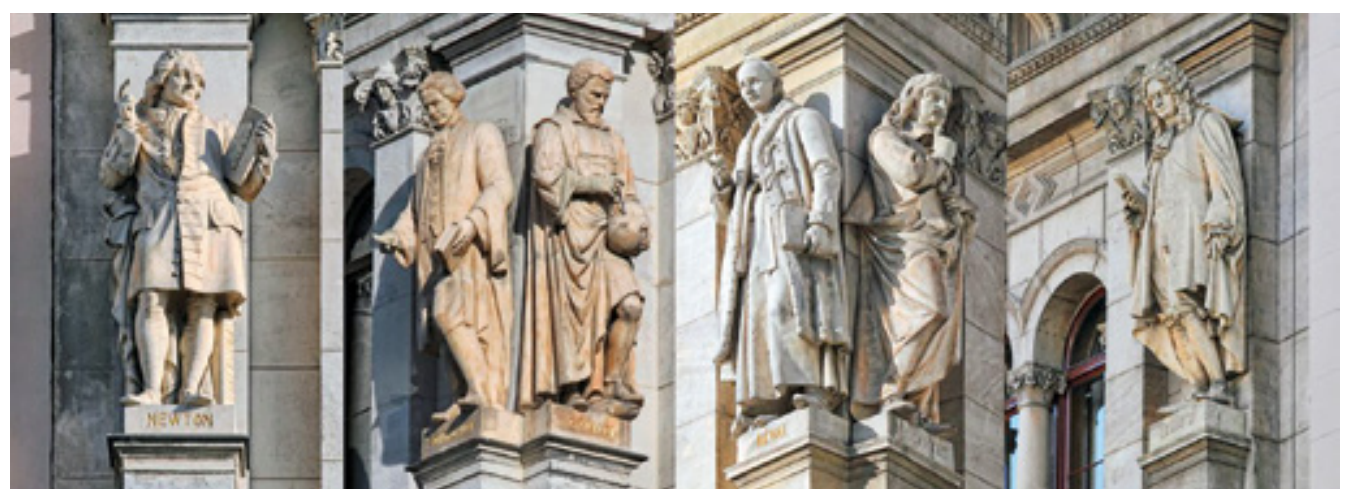

Abb. 6: Gelehrtenporträts an der Hauptfassade des Palastes der Ungarischen Akademie der Wissenschaften, Budapest.

Man bestellte alle Terrakottastatuen und die Verzierungselemente der Fassade bei der Fabrik Ernst March und Söhne in Berlin-Charlottenburg. ${ }^{\text {Io }}$ Die allegorischen Wissenschaftsskulpturen wurden anhand von in der Fabrik vorhandenen Mustern ausgeführt, und Modelle deutscher Bildhauer (Albert Wolff, Bernhard Afinger, Hermann Schievelbein, Hermann Wittig und Rudolf Siemering) und eines ungarischen Meisters (Miklós Izsó) dienten zur Ausführung der Gelehrtenstatuen.. ${ }^{\text {II }}$ Das Budapester Gebäude von Stüler zeigt dem Stil, der Raumanordnung und den Verzierungselementen der Fassade nach enge Beziehungen auch mit den früheren öffentlichen Gebäuden des Architekten: mit dem schwedischen Nationalmuseum in Stockholm und der Universität Königsberg (I860 und I862). ${ }^{12}$ Während aber die gleichen Berliner Bildhauer an der figuralen Verzierung der Gebäudefassaden von Budapest und Königsberg tätig waren, verfertigten am Nationalmuseum Stockholm örtliche
Künstler die Porträts der großen Gestalten der schwedischen Kultur. Stüler verwendete das Motiv der Profilbüsten von Gelehrten und Künstlern in Tondoform auf kreative Weise auch an den Fassaden in Stockholm und in Königsberg. ${ }^{13}$ Diese bauplastische Form wird im nachfolgenden halben Jahrhundert an den öffentlichen Gebäuden verschiedener Wissenschaftszweige die gemeinsame Berufsidentität kennzeichnen und die Trägerin der Gelehrtenmemoria auch für die Außenwelt sein. ${ }^{14}$ Die frühesten Beispiele in Ungarn erscheinen an den Wänden des Treppenhauses und des Vorlesungssaals des ehemaligen Chemischen Instituts der Budapester Universität. Sie entstanden I868, drei Jahre nach der Vollendung des ungarischen Akademiegebäudes. Sie sind ohne Ausnahme Tondoporträts ausländischer Gelehrter (Abb. 7). Das Programm stammt von einem Fachkundigen, dem bekannten ungarischen Chemiker Károly Than, der seine Ausbildung in Heidelberg bei Robert Wilhelm Bunsen

Io Zur Tonwarenfabrik March: C. A. Wolf, Studien zur Tonwarenfabrik March in Charlottenburg, phil. Diss., Technische Universität Berlin, Berlin I990.

II KemÉny, A Magyar Tudományos Akadémia palotája (zit. Anm. 9), S. I22.

I2 www.bildindex.de (abgerufen am 23. Jänner 2017.): Neue Universität, Königsberg (Aufnahme-Nr.: Foto Marburg I.I99.I44; 212.482; Deutsche Fotothek FD 352 582; FD 20 161; FD 52482; FD 52 483; FD 352 583; FD 352 584).

I3 Börsch-Supan/Müller-Stüler, Friedrich August Stüler (zit. Anm. 7), S. 23I, S. 945. - Ethos und Pathos. Die Berliner Bildhauerschule I786-I9I4 (Ausstellungskatalog Staatliche Museen zu Berlin), Berlin 1990, S. 557, S. 580-58I.

I4 Zum Beispiel: 1875, Jernkontoret (Haus des Metallkontors) in Stockholm: Tondos renommierter schwedischer Naturwissenschaftler von Johan Frithiof Kjellberg - Herzlichen Dank für den Hinweis an Fredrik Krohn Andersson; I892, Allgemeine Poliklinik in Wien, mit I3 Keramikmedaillons berühmter Wiener Ärzte. 

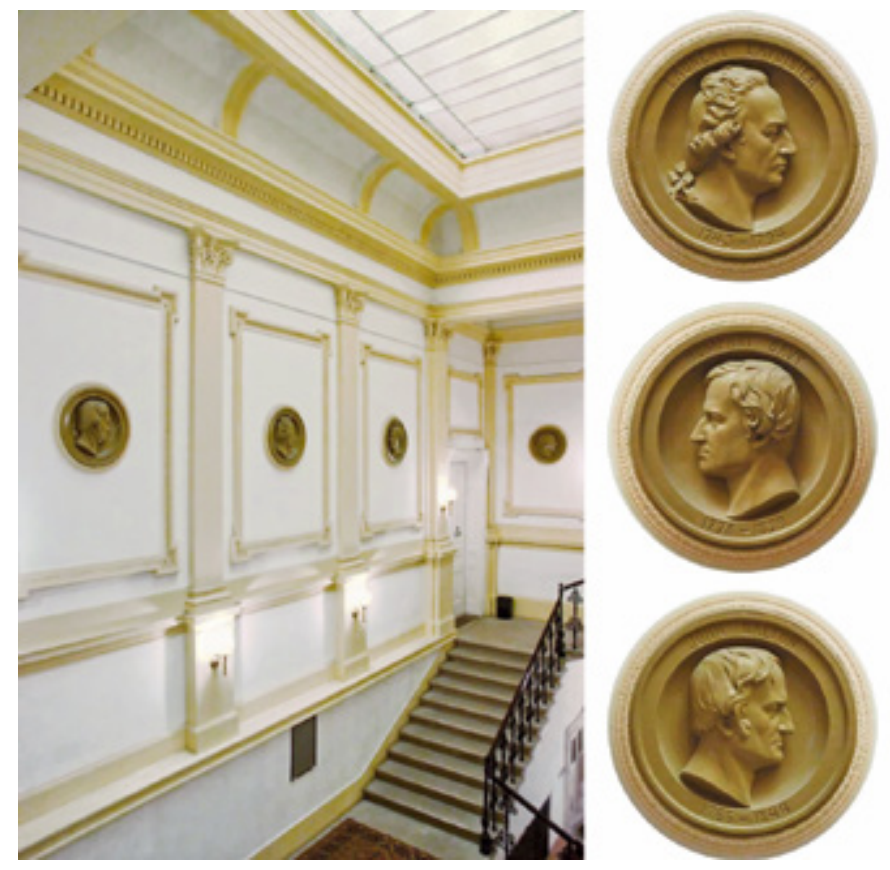

Abb. 7: Treppenhaus des Chemischen Instituts der Pester Universität/Wissenschaftlerporträts von Tonwarenfabrik Ernst March und Söhne, I868.

erhalten hatte und in Pest das Chemische Institut gründete. Nicht nur mangels ungarischer Vorläufer, sondern auch um den internationalen Charakter der Wissenschaft zu betonen, bestellte Than die Profilporträts von fünf deutschen, fünf französischen, vier englischen und zwei schwedischen Chemikern - höchstwahrscheinlich durch Vermittlung des Berliner Architekten des Gebäudes Friedrich Zastrau - wiederum bei der Fabrik March in Charlottenburg. ${ }^{\text {Is }}$ Die Aussage der Serie von Gelehrtenporträts ist unmissverständlich: Die nachfolgenden Generationen Ungarns können dank des fachgerechten Unterrichts - nach dem Vorbild des Auslands - in die Kreise der großen (europäischen) Gestalten der Wissenschaft eintreten.
Die in Berlin bestellte Gelehrtengalerie des Chemischen Instituts fand in den I88oer-Jahren auch an anderen Budapester Universitätsgebäuden Nachfolger. Deren Gelehrtenbildnisse in Tondoform wurden aber schon in ungarischen Werkstätten (Marchenke - Budapest, Zsolnay Pécs) ausgeführt. Man verwendete im Innenhof der Technischen Universität (I882), die in der Nähe des Chemischen Instituts liegt, und später an der Außenfassade des Neugebäudes des Chemischen Instituts (I9OI) noch immer denselben Tondotyp der Bildnisse - eher nur zeichenartig, mit den Porträts von fünf berühmten Chemikern. ${ }^{16}$

Die charakteristische Erscheinung der Gattung verziert die Fassade des Empfangsgebäudes des St.-Stephan-Krankenhauses in Budapest, das

I5 C. v. Than, Das chemische Laboratorium der k. ungarischen Universität in Pest, Wien I872.

I6 Zs. MendöL, Zsolnay Ceramics in the Service of Architecture, in: Hungarian Ceramics from the Zsolnay Manufactory, I853-200I (hrsg. von É. Csenkey/Á. SteinerT), New Haven/London 2002, S. I69-I80, S. I70. - M. MillisITs, A Fechtig-háztól a Városligeti fasori református templomig, in: Budapest színes város. Zsolnay épületkerámiák. (Ausstellungskatalog Budapest, Ernst Múzeum), Budapest 2006, S. 5I-79, S. 54. 


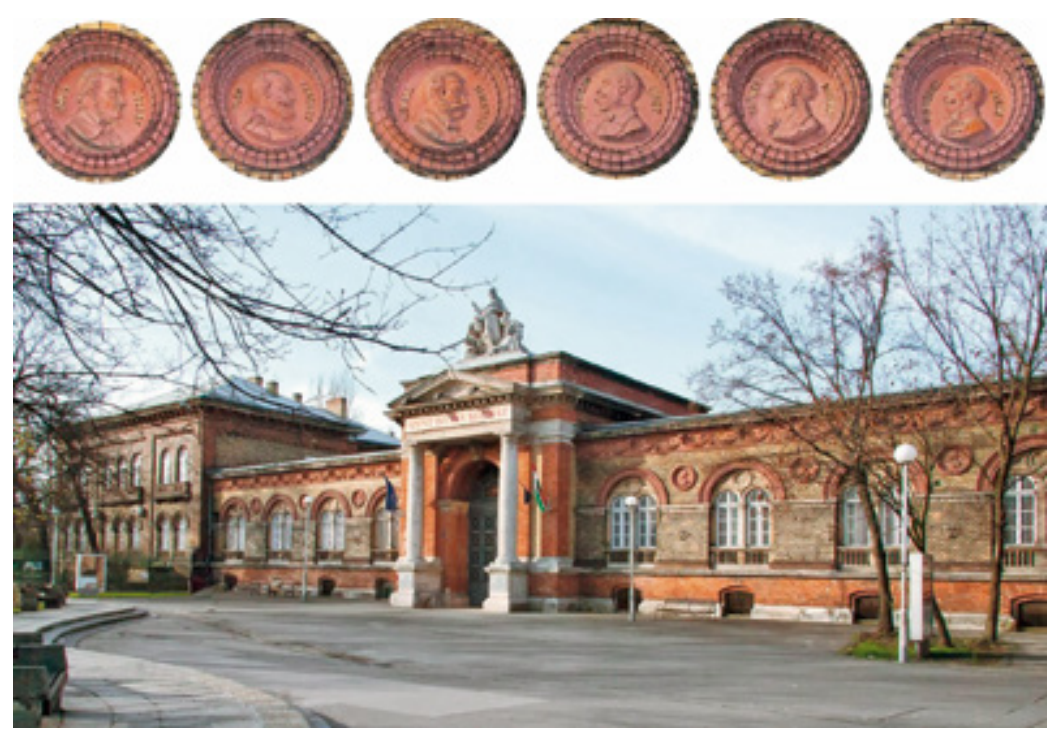

Abb. 8: Hauptfassade des St.-Stephan-Krankenhauses/Medizinerporträts von Tonwarenfabrik Marchenke, um I885.

nach I88I von dem in Berlin ausgebildeten ungarischen Architekten Alajos Hauszmann konzipiert wurde. Die Tondo-Bildnisse von sechs berühmten ungarischen Ärzten (Abb. 8) wurden zwischen den Fensterbogenfeldern an der Fassade im Neorenaissancestil angebracht. ${ }^{17}$ In der Auswahl und beim Anbringungsort des Motivs zeigt sich die Inspiration des Renaissancevorbildes, des Ospedale degli Innocenti in Florenz, besonders deutlich. In beiden Fällen sind die zwischen den Rundbögen angebrachten Tondos die Visualisierungen der Funktion des Gebäudes. Dies war die erste Porträtreihe, die in aller Öffentlichkeit die Memoria ausschließlich ungarischer Gelehrter heraufbeschwor. Sie stellt Ärzte dar, und das ist kein Zufall. In der zweiten Hälfte des 19. Jahrhunderts erfasste nämlich ein einzigartiger Fortschritt die Heilkunde. Die neuen Kenntnisse und Verfahren wurden „ad hominem" überliefert und angewandt, und für die großen, humanistisch gut gebildeten Arztpersönlichkeiten, die dabei die Hauptrollen spielten, hegte die nachfolgende Ärztegeneration eine so große Achtung, dass sie ihr Andenken auch durch Kunstwerke und ihre Porträts verewigen wollte. Diese Attitüde der Heilwissenschaft bildete sich im letzten Drittel des i9. Jahrhunderts heraus und wurde von den nachfolgenden Generationen bis heute fortgeführt.

Ganzfigürliche Gelehrtenstatuen als Bauplastik erschienen nur selten in Ungarn. An der Fassade der Poliklinik der Budapester Barossstraße (I90I) stehen zum Beispiel die Nischenskulpturen von vier ungarischen Ärzten und Professoren, darunter die von Ignaz Philipp Semmelweis und János Balassa. ${ }^{18}$ Die Darstellung eines gelehrten Arztes als selbstständiges Denkmal erschien in Ungarn erstmals Anfang des 20. Jahrhunderts mit dem Denkmal für Ignaz Semmelweis (Abb. 9). ${ }^{19}$ Seine Statue im öffentlichen

I7 A. DÉRY, Budapest eklektikus épületszobrászata, Budapest I991, S. 76, S. 80-8I.

I8 Ebd., S. 71, S. 86.

I9 E. Liber, Budapest szobrai és emléktáblái, Budapest 1934, S. 263-265. - Zur deutschsprachigen Biografie des Künstlers: http://kulturportal-west-ost.eu/biographien/strobl-alois-2, abgerufen am 23. Jänner 2017. 


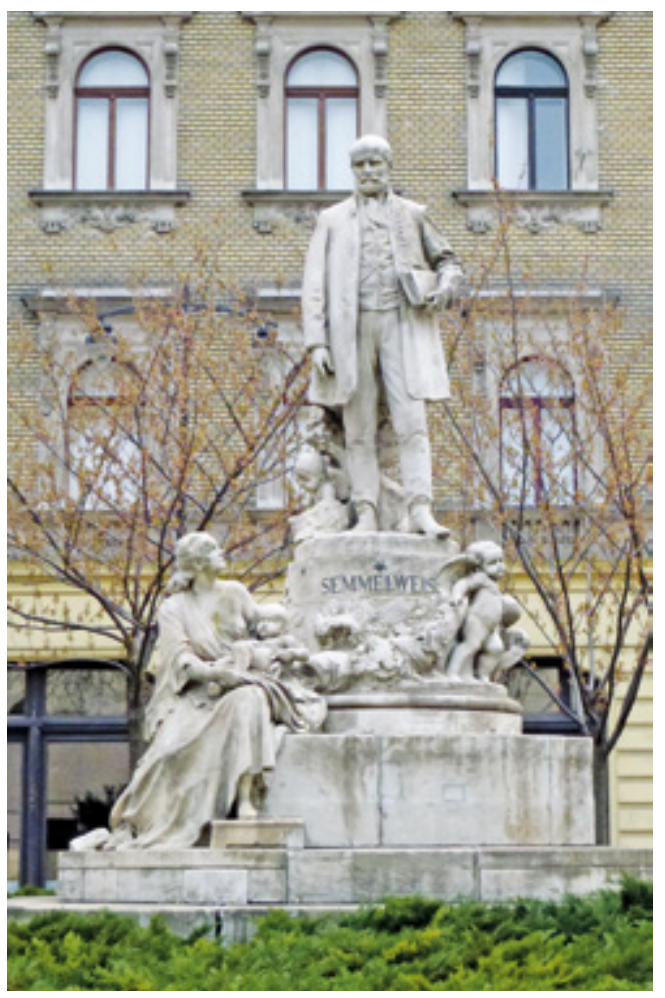

Abb. 9: Alajos Stróbl, Ignaz Semmelweis, Igos, Budapest, Gyulai Pál utca.

Raum ist zugleich auch das Zeichen seiner gesellschaftlichen Rehabilitation, und daran zeigt sich auch eine der besonderen Funktionen der Gelehrtendenkmäler. Seiner Zeit voraus hatte Semmelweis - bekanntlich - entdeckt, dass die Ärzte selbst, durch mangelnde Hygiene, das für die Gebärenden oft tödliche Kindbettfieber verursachten. Seine Theorie und damit die Möglichkeit zur Vorbeugung wurde aber vom Großteil der Ärzteschaft seinerzeit rundweg abgelehnt. Erst nach seinem Tod mit der Entdeckung des krankheitserregenden Bakteriums wurde die Bedeutung seiner Entdeckung klar, seine Ansichten wurden rehabilitiert und seine Person in den wissenschaftlichen Kanon aufgenommen. ${ }^{20}$ Dem „Retter der Mütter“ wurden in mehreren Ländern durch Filme, Briefmarken ${ }^{21}$ und Statuen Denkmäler gesetzt. In Ungarn genießt die Gestalt von Semmelweis außerordentliche Popularität, sein Geburtshaus beherbergt das Medizinhistorische Museum, die Medizinische Universität Budapest trägt seinen Namen und zahlreiche Skulpturen von ihm wurden im ganzen Land aufgestellt. Da er Student und dann Lehrer der Universität Wien gewesen war, bekam er auch im Arkadenhof der Wiener Universität ein spätes Denkmal, ${ }^{22}$ ferner wurde die Wiener Frauenklinik, in deren Garten auch eine Semmelweis-Statue steht, nach ihm benannt.

In der Zwischenkriegszeit erbaute man in Ungarn die seinerzeit größte und repräsentativste Ehrenhalle Mitteleuropas in der am Ufer der Theiß liegenden südungarischen Stadt Szeged. Der Komplex, der auch durch seine Abmessungen imposant wirkt, wurde Ende der I920er-Jahre, innerhalb weniger Jahre, errichtet - die Einweihung erfolgte 1930. Der Platz vor der neoromanischen Votivkirche wird auf drei Seiten von einer jeweils hundert Meter langen Arkadenreihe umrahmt (Abb. Io). Man plante schon beim Entwurf, in den Arkaden die Denkmäler von hundert bedeutenden Persönlichkeiten der ungarischen Geschichte und Kultur aufzustellen. Das Ziel bestand in Szeged nicht nur darin, eine nationale Ruhmeshalle an sich zu errichten, sondern auch ein politisches, städteplanerisches, wissenschaftliches und kulturelles Programm zu verwirklichen. Weil Ungarn durch den Friedensvertrag von Trianon (I920) bedeutende Gebiete mit großen Universitätsstädten und Bischofssitzen verloren hatte, muss-

20 Über Ignaz Semmelweis: I. BenedeK, Ignaz Philipp Semmelweis (I818-I865), Wien 1985 - S. B. Nuland, Ignaz Semmelweis. Arzt und großer Entdecker, München 2006.

2I Zur Popularisierung und Popularität von Ignaz Semmelweis siehe: https://de.wikipedia.org/wiki/Ignaz_Semmelweis, abgerufen am 23. Jänner 2017. - Zu den Wissenschaftler-Briefmarken siehe: http://www.sma.org.sg/ smj/470I/470ImsI.pdf, abgerufen am 23. Jänner 2017.

22 Durchsuchbar: https://monuments.univie.ac.at/index.php?title=Hauptseite, abgerufen am 23. Jänner 2017. 


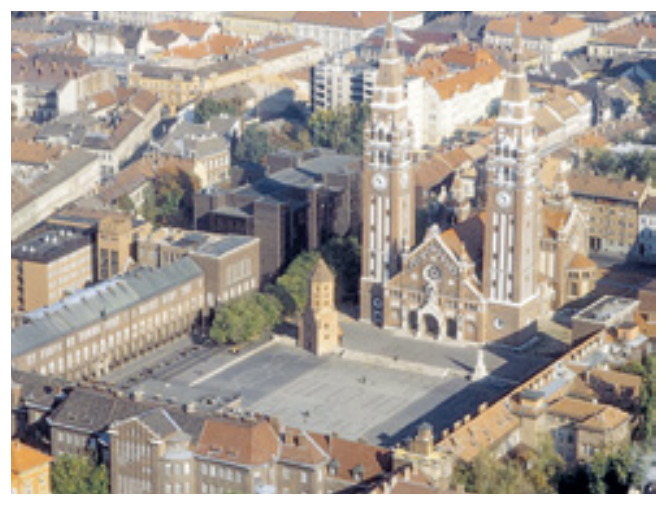

Abb. Iо: Szeged, Domplatz.

te es neue regionale Zentren schaffen. In diesem Prozess kam der Stadt Szeged eine bedeutende Rolle zu. Das Programm dazu hatte der beeindruckende Kulturpolitiker Kuno Klebelsberg, Minister für Religions- und Unterrichtswesen, ersonnen. ${ }^{23}$ Nach seinem Konzept sollte Szeged zunächst eine Stadt mit hoher Einwohnerzahl, mit administrativer, kultureller und wissenschaftlicher Anziehungskraft, ein Gegengewicht zur kulturellen (und politischen) Dominanz von Budapest werden. Als Modelle für Szeged dienten die mittelgroßen europäischen Städte, wie z. B. Augsburg, Bologna, Toulouse und Graz. Es wurde ein Wettbewerb für das ganze Stadtzentrum ausgeschrieben, um die neuen Gebäude für die von Kolozsvár (heute Cluj-Napoca, Rumänien) hierher geflüchtete Universität ebenso wie für den neuen Sitz des Bistums Csanád (früher in Temesvár, heute Timişoara, Rumänien) und für sein Priesterseminar aufbauen zu können. In der Ausschreibung wurde vorgegeben, dass die Erdgeschosse der neuen Bauten mit Arkadenreihen versehen sein müssen, um der Idee des „ungarischen schöpferischen Genius“ und der „ungari- schen Kulturdominanz" auch visuell Ausdruck zu verleihen. ${ }^{24}$

Der Gewinner des Wettbewerbs war der Budapester Architekt Béla Rerrich (I88I-I932), der Klinker als Baumaterial der Gebäude wählte. Vorbildlich waren hierfür die modernen Klinkerbauten zeitgenössischer nordeuropäischer Architekten (Fritz Höger, Ragnar Östberg), die Rerrich während seiner Studienreisen nach Skandinavien und Norddeutschland auch persönlich getroffen hatte. ${ }^{25}$ Die zeitgenössische kunsthistorische Rezeption setzte die Gebäude aus Szeged in Parallele zu den Rathäusern und den Palazzi der italienischen Renaissance (Palazzo Pubblico, Siena), die Ausgestaltung des Platzes zum Markusplatz in Venedig. In den drei aneinandergefügten Flügeln, die den Platz umrahmen, erinnern Reliefs und Büsten auf Konsolen und auf vor die Wand gestellten Postamenten an die großen Gestalten Ungarns. Zur Betonung des nationalen (und christlichen) Charakters der Ruhmeshalle fanden hier in der ersten Zeit auch Skulpturen von Herrschern und (auch kirchlichen) historischen Persönlichkeiten neben Künstlern und Gelehrten ihren Platz. Bei Ausbruch des Zweiten Weltkriegs standen schon fast achtzig Denkmäler, reich an Formen und typologischer Vielfalt (Abb. II). ${ }^{26}$

Die neueren Erweiterungen nach dem Weltkrieg und nach der letzten politischen Wende sind Belege dafür, dass sich der in den I93oerJahren gestaltete Platz für die Metamorphosen der ursprünglichen Erweiterungskonzeption des Denkmalensembles als geeignet erwies. Man konnte ihn mit immer neuen Inhalten füllen. In der Ära des Sozialismus erhielten in erster Linie Literaten und Gelehrte, deren Präsenz für das nationale Gedächtnis eine wichtige Rolle spiel-

\footnotetext{
23 K. Klebelsberg, A szegedi gondolat, in: Magyar Iparművészet, XXXV, I932, S. 2-7. - Zur Kulturpolitik Klebelsbergs: „A legnagyobb álmú magyar kultuszminiszter”, gróf Klebelsberg Kuno (hrsg. von G. UjváRY), Budapest 2013. 24 Ebd. S. 2-3.

25 The Architecture of Historic Hungary (hrsg. von J. Sisa/D. Wiebenson), Cambridge, Mass./London 1998, S. 247249.

26 A. ZwickL, A szegedi Dóm tér, in: Művészet, I988, 4. S. 2-5, S. 6I-62.
} 


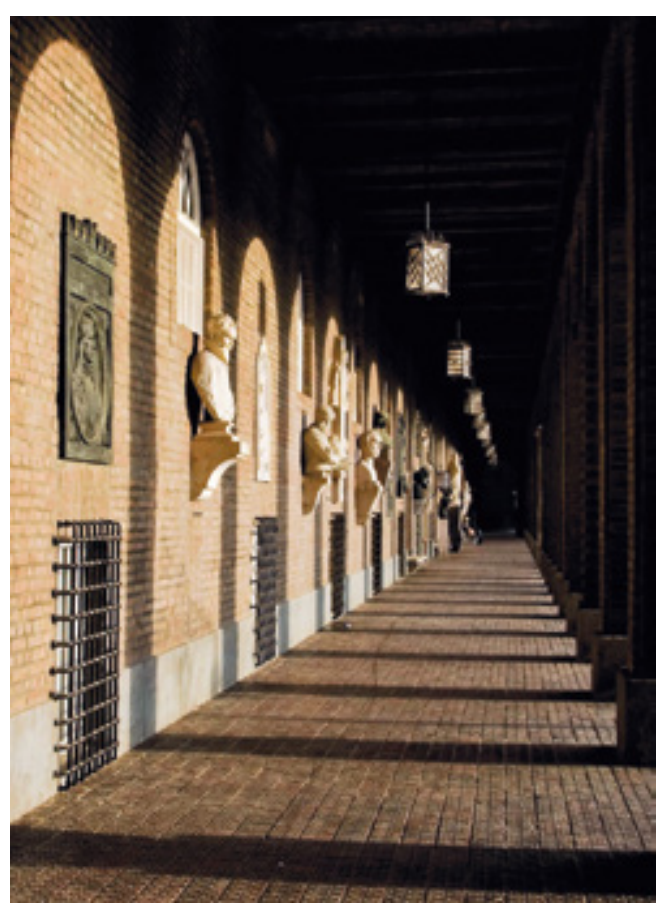

Abb. II: Szeged, Arkadenhof des Domplatzes mit Denkmälern.

te, Denkmäler in diesem Pantheon. Nach 1989 veränderte sich wiederum die Erweiterungsstrategie. In den beiden letzten Jahrzehnten wurden Monumente vor allem für Persönlichkeiten errichtet, die auf irgendeine Weise mit der Stadt Szeged verbunden sind (dort geboren wurden, dort arbeiteten oder eben an der Universität unterrichtet haben). ${ }^{27}$

Seit dem Ende des Zweiten Weltkriegs richtete sich das politische System Ungarns gegen die politische Ideologie der Zwischenkriegszeit und dies übte eine Wirkung auch auf die Gedenkpolitik dieser Ära aus. Nach 1945 wurden nämlich die Denkmäler derjenigen aus der Ruhmeshalle entfernt, die nicht in den Gedankenkreis der „progressiven Traditionen Ungarns“ einzugliedern waren. An ihre Stelle rückten Skulpturen von Schriftstellern und Dichtern, die bis dahin vernachlässigt worden waren. Da Ungarn nach dem Zweiten Weltkrieg zum sowjetischen Einflussbereich gehörte und in ihm vier Jahrzehnte verblieb, brachte diese Lage auch in der Memorialpolitik extreme Lösungen hervor, besonders in den I95oer-Jahren. Im Zeichen der sowjetischungarischen Freundschaft musste beispielsweise auf der Fassade der Ungarischen Akademie der Wissenschaften auch ein russischer Gelehrter Platz finden, und der wurde in der Gestalt von Lomonossow anstelle der Raffaelskulptur angebracht (Bildhauer: Gyula Palotai Szkalos, 1963).28

Erst während der Ära der Konsolidierung nach der Niederschlagung der Revolution von 1956, ab dem Ende der 196oer-Jahre, ergab sich die Möglichkeit, dass die verschiedenen Wissenschaftsgebiete - aufgrund der Traditionen ihres eigenen Fachgebiets - thematische Gelehrtenensembles errichten durften. Fortschrittlich waren darin die Museen. Schon 1969 wurde zum Beispiel das erste Gießereimuseum Europas in einer geschlossenen Gießerei in der Innenstadt von Budapest eröffnet. Im Garten des Museums reihen sich die Büsten hervorragender Gestalten der ungarischen Metallurgie und Gießerei bis in die jüngste Vergangenheit. ${ }^{29}$ Eine ähnliche Initiative des Landwirtschaftsmuseums war das Büstenensemble der bedeutenden Persönlichkeiten der ungarischen Landwirtschaft im Garten des historisierenden Gebäudekomplexes der Burg Vajdahunyad im Stadtwäldchen von Budapest. Aber der würdigste Gedenkort desselben Gelehrtenkreises wurde nicht dies, sondern die äußere Arkade des Agrarministeriums, das sich am repräsentativsten Platz von Budapest, gegenüber

27 A. Tóth, The National Pantheon, in: Ders., A Nemzeti Emlékcsarnok, Szeged 2009, S. I4-16. (Fotos und englischsprachige biografische Daten aller porträtierten Persönlichkeiten). - Zu den Denkmälern: http://panteon.szegedvaros.hu, abgerufen am 23. Jänner 2017.

28 SisA, A Magyar Tudományos Akadémia székháza (zit. Anm. 9), S. 53.

29 K. Lengyelné Kiss, 40 éve a köz szolgálatában, in: 40 éves az Öntödei Múzeum 1969-2009 (hrsg. von K. LengYelNÉ KIss/A. SCHUdich), Budapest 2009, S. 8-35, S. I6. 


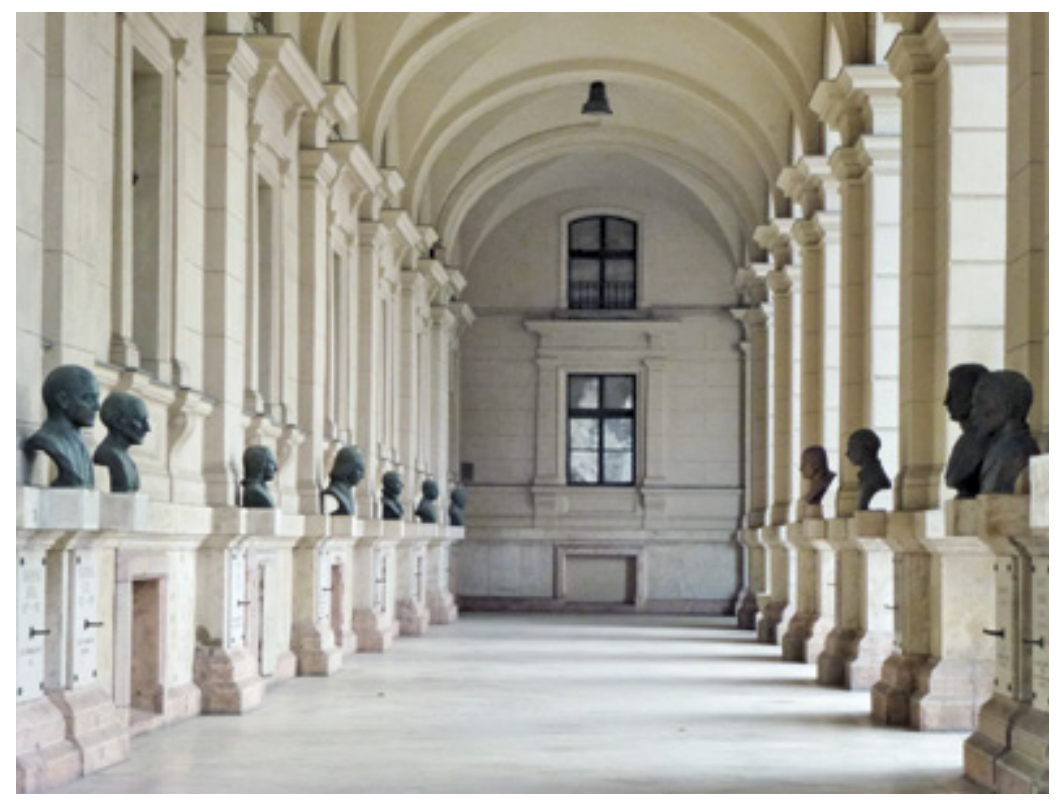

Abb. I2: Budapest, Arkaden des Agrarministeriums.

dem Parlament, befindet (Abb. I2). Ein gelehrter Ackerbauminister mit historischem Interesse, Pál Romány, hatte den Blick für den architektonischen Raum in der Arkade des 1885 errichteten Gebäudes, der dann auf Konsolen die Büsten der hervorragenden Vertreter der ungarischen Landwirtschafts- und Tierzuchtkultur aufnahm. Man begann 1977 die Skulpturengalerie der bedeutendsten Agrarfachleute Ungarns bis in das I8. Jahrhundert zurückgehend aufzustellen. Zur politischen Konzeption der zentralistischen sozialistischen Industrie und Landwirtschaft passte die Idee, die Vorbilder gelehrter Fachleute zu beschwören - und nicht nur auf der Ebene der Denkmalsetzung. Ausgezeichnete Experten beschäftigten sich auch mit der wissenschaftlichen Aufarbeitung der Werke der Vorgänger und mit der Nutzbarmachung ihrer Ergebnisse. Bei der Zusammenstellung des Gelehrtenensemb- les spielten ausschließlich die wissenschaftlichen Verdienste der Porträtierten eine Rolle. Die beiden Denkmalgalerien in Szeged und Budapest sind bis heute lebendige Beispiele der Initiativen der I970er-Jahre, die immer wieder mit neuen Gelehrtenskulpturen erweitert werden..$^{\circ}$

Diese beiden Gruppen von Kunstwerken zeigen, vor welchem Hintergrund sich die Gelehrtenmemoria in Ungarns sozialistischer Ära entfaltete. Darüber hinaus gibt es noch zahlreiche Beispiele dafür, dass die verschiedensten Fachgebiete - in Erinnerung an die ungarischen Gelehrten - ab den I97oer-Jahren in Ungarn ihren Vorläufern Denkmäler setzten. Typischerweise erfolgte dies an den Universitäten. Am aktivsten waren neben der Technischen Universität Budapest die Universität für Forstwissenschaft und Holztechnik in Sopron ${ }^{31}$ sowie die Universitäten von Debrecen und Pécs und besonders die me-

30 Zum Anfang der Gelehrtengalerie siehe: o. V., Szoborgaléria a magyar agrárgazdaság nagyjainak emlékére, in: Magyar Mezőgazdaság, XXXII, I977, 35, S. 2.

3I Wissenschaftler-Denkmäler im Botanischen Garten: http://www.nyme.hu/index.php/6252/?\&L=I, abgerufen am 23. Jänner 2017. 


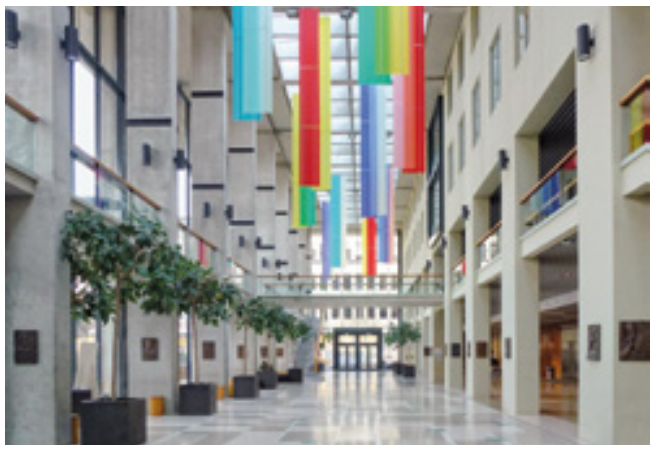

Abb. 13: Budapest, Aula des Unterrichtszentrums der Semmelweis-Universität (Elméleti Orvostudományi Központ), 2009.

dizinische Universität von Budapest. In der Symbiose von Forschung und Heilung fand man die Formen, durch welche die Denkmäler der Gelehrtenmemoria wieder und wieder an den Wänden von Kliniken, Krankenhäusern und Universitätsgebäuden auftauchen. Hier knüpft auch die neueste großzügige Unternehmung der ungarischen Medizin an. Zwischen 2007 und 2009 wurde in Budapest, in der Nähe der Kliniken, ein modernes Unterrichtszentrum von imposanten Ausmaßen erbaut. Das prägende Strukturelement des Neubaus bildet die doppelte Pfeilerreihe, welche die Struktur der mehrgeschossigen Aula trägt. Die Vorsitzenden der SemmelweisUniversität beschlossen, die Pfeiler mit den Porträtreliefs der berühmtesten gelehrten Medizinprofessoren aus den letzten hundert Jahren der ungarischen Heilkunde zu zieren. Bisher wurden 34 Reliefs gefertigt (Abb. 13). ${ }^{32}$

Die traditionelle Erscheinungsform des Gedenkens in einem modernen Gebäude kann sogar die Antwort auf die Frage liefern, ob die Gattung noch lebt, die das Andenken an die bedeutendsten Vertreter einer Disziplin durch ihre Porträts der Nachwelt beispielgebend präsentiert. Das neue Unterrichtszentrum der SemmelweisUniversität belebt ohne Zweifel die Gattung der

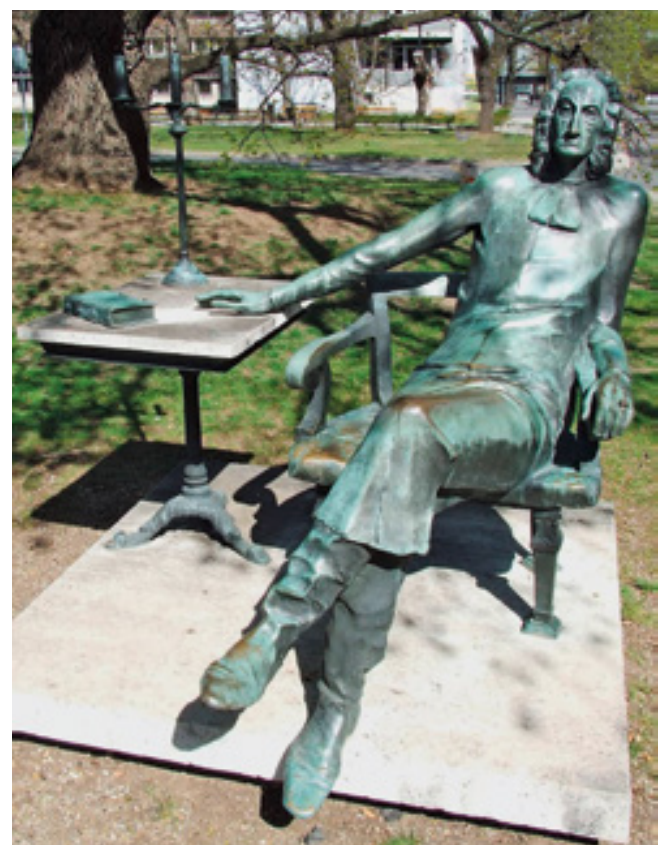

Abb. I4: Imre Varga, István Hatvani, I97I, Debrecen, Egyetem tér.

traditionellen Porträtreliefs weiter. Gleichzeitig gibt es auch Bestrebungen, die Erscheinungsform einer Büste auf Postament durch neue Formen abzulösen. Dazu gehören die Lösungen, die man pflegt „Straßenstatuen“ zu nennen. In diesen Fällen steigt die ganzfigürliche lebensgroße Statuengestalt vom fiktiven Postament hinab und trifft auf der Straßenebene stehend oder sitzend ihr Publikum. In Ungarn wurde schon 1971 eine Skulptur dieser Art in der Nähe der Universität der Stadt Debrecen konzipiert. Sie stellt den berühmtesten Physiker und Polyhistor der Stadt des I8. Jahrhunderts dar: István Hatvani (Abb. I4). In der Stadt Szeged, wo der ungarische Medizinforscher und Nobelpreisträger Albert von Szentgyörgyi tätig war, verkörpert ihn seit 2013 eine ganzfigurige Bronzestatue vor dem Universitätsgebäude, wie er mit der Pfeife in der

32 http://semmelweis.hu/eok/eok/tortenet, abgerufen am 23. Jänner 2017. - Über die Errichtung des Unterrichtszentrums: http://ujsag.semmelweis.hu/se200808/2008083I.html, abgerufen am 23. Jänner 2017. 


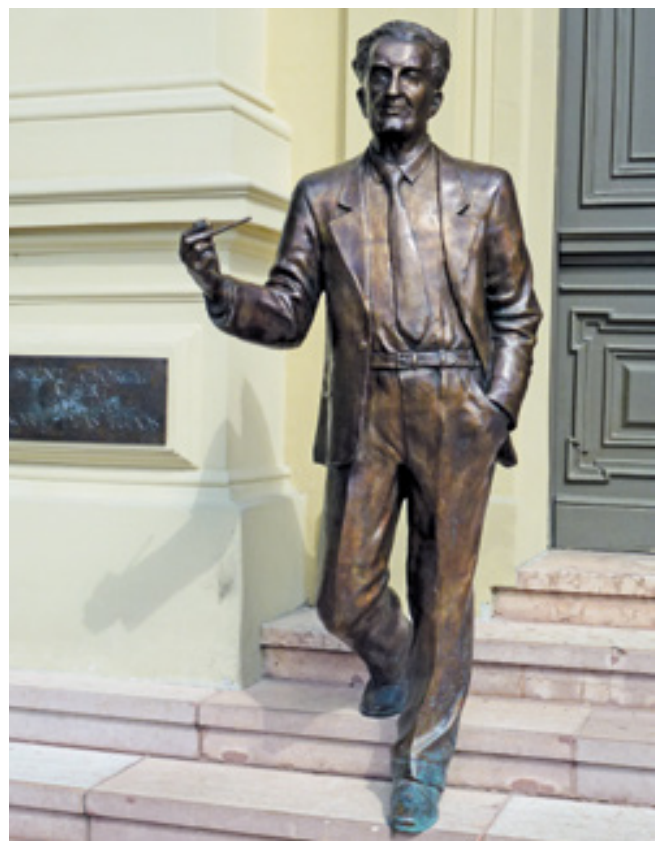

Abb. I5: Lajos Biró, Albert Szentgyörgyi, 2013, Szeged, Dugonics tér.

Hand, mit einer leichten Bewegung die Treppe der Universität herabsteigt (Abb. I5). Aufgrund seiner Popularität wird er in einer Situation gezeigt, in der er den einfachen Menschen nahe erscheint, was allerdings die Gefahr in sich birgt, als „spazierende Statue” in dem großstädtischen Raum viel an symbolischer Bedeutung eines Gelehrtendenkmals zu verlieren.

Es ist eindeutig, dass die Räume der Memoria da eine Zukunft haben, wo sie keine geschlossenen Systeme bilden, sondern geeignet sind, die Bildnisse weiterer bedeutender Gelehrter aufzunehmen. Die Campus sind Gedenkorte solcher Art, wo es noch Raum für weitere Kunstdenkmäler gibt. Die Ehrenhallen in architektonischen Räumen bleiben aktive Gedenkorte, wenn die Möglichkeit besteht, weitere Monumente einzufügen, wie zum Beispiel unter den Arkaden des Budapester Agrarministeriums. Ebenso bei der Ruhmeshalle des Domplatzes von Szeged, wo schon vor langer Zeit das Streben der Gründer nach der Veranschaulichung der ungarischen Kulturdominanz schwand und die moderne Architektur des Platzes ein ikonischer Raum wurde, den die Denkmäler in den Arkaden mit geistigem Inhalt erfüllen. Was die modernen Medien in Ungarn betrifft, gilt die Praxis der Universität für Forstwissenschaft in Sopron als beispielhaft, wo Fotos sämtlicher dortiger Gelehrtendenkmäler auf der Homepage der Universität zu finden sind und man neben dem Foto auch die Daten, die Laufbahn, die wissenschaftlichen Erfolge des Dargestellten ablesen kann. ${ }^{33}$ Neben dem wirklichen Denkmalensemble entsteht also ein anderes, im virtuellen Raum zugängliches.

Man könnte sich an dieser Stelle fragen, ob die traditionellen Formen der Bewahrung der Gelehrtenmemoria im Zeitalter des Internets noch einen Sinn haben. Unserer Meinung nach ist es durch nichts ersetzbar, dass Studenten und Professoren Tag für Tag den Bildnissen der berühmten Wegbereiter begegnen, in deren Fußstapfen sie treten möchten und die im gegebenen Fach mit ihren Erfolgen sich, ihrer Profession und der Universität einen Rang verschafft haben. Das Gelehrtendenkmal im öffentlichen Raum ist ein Bestandteil der kollektiven Identität der Auftraggeber, und durch die Errichtung des Kunstwerks wird es sogar zum symbolischen Repräsentanten der Selbstbestimmung einer größeren Gemeinschaft. Und wenn die Kunstwerke, welche die Gestalten von Gelehrten heraufbeschwören, in öffentlichen und in Gemeinschaftsräumen stehen und sich in die Textur der Stadt einbetten, können sie ihre Wirkung über die Bedeutung der Gelehrten und der Wissenschaften in noch breiteren Kreisen der Gesellschaft ausüben.

Abbildungsnachweis: Abb. ı: Martin Mádl, Ústav dějin umění Akademie věd České republiky; Abb. 2, 5, 6, 7, 8, 9, I2, 13, I5: Verfasser und Péter Hámori, MTA Böl-

33 http://www.nyme.hu/index.php/6252/?\&L=I, abgerufen am 23. Jänner 2017. 
csészettudományi Kutatóközpont Művészettörténeti Intézet; Abb. 3: Szépművészeti Múzeum, Budapest; Abb. 4: András Kovács, Facultatea de Istorie şi Filosofie, Universitatea Babeş-Bolyai, Cluj-Napoca; Abb. Io: http://hir- portal.sikerado.hu. (abgerufen am 23. Jänner 2017.); Abb. II: www.sulinet.hu/oroksegtar. (abgerufen am 23. Jänner 20I7.); Abb. I4: Pál Zsamboki 


\title{
EWIGE PRÄSENZ DER WISSENSCHAFTLER IM ÖFFENTLICHEN RAUM. GELEHRTENDENKMÄLER IN LAIBACH
}

\author{
Barbara Murovec
}

S tatuen im öffentlichen Raum zählen zu den Kunstwerken, die am direktesten und unmittelbarsten von den politischen Interessen und Zielen der jeweiligen herrschenden Elite abhängig sind. Erst in der neuesten Zeit werden auch im slowenischen akademischen Milieu, das sich fast fünfzig Jahre lang im Einparteiensystem entwickelte, fachgemäß die Fragen über die Funktion der Monumente im öffentlichen Raum und deren historisch-politischen Kontext gestellt. ${ }^{I}$ Die Divergenz zwischen der nach dem sowjetischen Vorbild realisierten Monumentalpropaganda der jugoslawischen Führungsspitze, die den Befreiungskampf gegen die Okkupation als Legitimierung der kommunistischen Nachkriegsrepression ausnutzte, und der bisherigen Forschung und Bewusstmachung der Funktion und des Kontexts der Denkmäler im öffentlichen Raum ist wesentlich. Der Grund für eine solche gesellschaftliche und fachliche Einstellung stimmt mit den in den Jahrzehnten nach dem
Zweiten Weltkrieg an der Laibacher Universität gelehrten kunsthistorischen Methoden überein, die sich in der Regel lediglich auf die bloße Identifizierung des Künstlers, der Datierung und den Stil/die Form des Kunstobjektes beschränkte. ${ }^{2}$ Nur in geringem Maße versuchte man dem Auftraggeber, seinen Absichten und Zielen nachzugehen, den Zusammenhang von Denkmal und Gedächtnis festzustellen, die Folgen einer bestimmten Erinnerungsweise zu ermitteln, zu erfassen, ob und wie die Distanz zur Vergangenheit inszeniert wurde, und sich mit weiteren Fragestellungen zu beschäftigen, die zum Verständnis der Kunstwerke in ihrem (politischen) Kontext wesentlich hätten beitragen können. Nicht zuletzt sind für das Verständnis der Monumente die Untersuchung ihrer Rezeption in der Gegenwart und das Dilemma individueller nationaler - auch in Abhängigkeit von den politisch vorherrschenden Strömungen - Narrationen der Geschichte bedeutend. ${ }^{3}$

I In Slowenien wird dieses Thema noch immer stark politisch instrumentalisiert; in der letzten Zeit oft durch „Veranschaulichung" der Geschichte in künstlerischen Performances und Ausstellungen; wie z.B. erst kürzlich in einer Ausstellung über den Sozialistischen Realismus: Heros we love, Umetnostna galerija Maribor (20. März - 30. August 2015) - wo die Grenze zwischen wissenschaftlicher bzw. (kunst-)historischer Analyse und (künstlerischer) Nutzung der Geschichte bewusst verwischt wird.

2 Der Plastik im öffentlichen Raum widmete sich systematisch Špelca Čopič, besonders für die erste Hälfte des 20. Jahrhunderts (ک̌. ČopIČ, Javni spomeniki v slovenskem kiparstvu prve polovice 2o. stoletja, Ljubljana 200o); mit der Skulptur des Historismus befasst sich Sonja Žitko (S. Žıтко, Historizem v kiparstvu I9. stoletja na Slovenskem, Ljubljana 1989 (Zusammenfassung: Der Historismus in der Bildhauerei des I9. Jahrhunderts in Slowenien)).

3 Vgl. J. E. Young, Memory/Monument, in: Critical Terms for Art History. Second Edition (hrsg. von R. S. Nelson/R. ShIFf), Chicago/London 2003, S. 246. 
Im 20. Jahrhundert wurden öffentliche Denkmäler in den slowenischen Ländern insgesamt dreimal grundlegend geändert, beseitigt oder sogar vernichtet. Entscheidende Wendepunkte stellen I. der Zerfall Österreich-Ungarns im Jahr I9I8 mit der Entfernung der Habsburgermonumente und der Inszenierung der serbischen Dynastie dar, 2. die Okkupation im Jahr 194I mit der Beseitigung der königlichen Familie Karadjordjević aus dem öffentlichen Raum und 3. das Ende des Zweiten Weltkrieges mit der Realisierung tausender Denkmäler zum Sieg der Befreiungsfront und der Partisanen, der Statuen von Marschall Tito (1892-1980) und von anderen kommunistischen Revolutionären bzw. Trägern der neuen politischen Macht. ${ }^{4}$ Alle Veränderungen der „monumentalen Landschaft“, die jeweils mit dem Regimewechsel korrespondieren, indizieren, dass die staatlich festgelegte Erinnerungskultur in den Denkmälern eindeutig bestimmt und aus ihnen ablesbar wird.

Der Zerfall Jugoslawiens im Jahr 1991 brachte im Vergleich zum Ostblockende im Jahr 1989 keine eindeutige Umformung der visuellen Narrative und Gedächtnispolitik des Landes. Lediglich die Statuen von Tito wurden entfernt, die Denkmäler von Boris Kidrič (19I2-1953) und Edvard Kardelj (I9IO-I979) als den slowenischen Hauptvertretern des kommunistischen Regimes sind hingegen noch immer Teil der monumentalen Propaganda des politischen Stadtteils von Laibach (slow. Ljubljana). Die Unabhängigkeit Sloweniens brachte auf Denkmalebene keine evidente Trennung (oder bewusste Distanzierung und fundierte Aufarbeitung) von einem politischen System, in dem nach dem Zweiten Weltkrieg die kommunistischen Sieger Massenmorde begingen. ${ }^{5}$ In der kritischen Auseinandersetzung mit der Denkmal- und Erinnerungskultur stellte die Universitätsebene - wie aus dem folgenden Text klar wird - hier wenigstens teilweise eine Ausnahme dar. ${ }^{6}$

Die slowenischen Länder entwickelten ihre nationale Identität in der zweiten Hälfte des I9. Jahrhunderts - als in diesem Zusammenhang auch die ersten slowenischen öffentlichen Denkmäler errichtet wurden - und am Beginn des 20. Jahrhunderts historisch mittels Skulpturen von Dichtern und Wissenschaftlern, wobei die Trennung zwischen den Vertretern beider Gruppen, die als nationale kulturelle Elite zu verstehen sind, nicht ganz eindeutig ist. Bisher wurden die slowenischen öffentlichen Denkmäler noch nicht hinsichtlich ihrer spezifischen wissenschaftlichen und universitären Ikonografie untersucht. Während der Erforschung zeigte sich, dass eine hohe Zahl individueller Denkmäler und ganzer Denkmalalleen kaum bekannt

4 Die in Stein bzw. Bronze gehauene Monumentalisierung des Kultes lebender Personen war allein für Tito reserviert; alle anderen Politiker bekamen ein Denkmal mit ihrem Porträt erst nach dem Tod. Boris Kidrič, der früh starb, schon ab den I950er-Jahren, Edvard Kardelj erst nach 1979. In den I990er-Jahren wurden nur die Monumente Titos beseitigt - als Akt der Trennung von Jugoslawien, nicht aber von dem politischen System; vgl. B. Murovec, The Statue of the Communist Revolutionary Boris Kidrič (1912-1953). Art, Ideology and Ethics in Public Space, in: Acta historiae artis Slovenica, XVIII/2 (= Visualizing Memory and Making History. Public Monuments in Former Yugoslav Space in the Twentieth Century), 2013, S. I49.

5 Vgl. z. B. P. Vodoprvec, Von den Anfängen des nationalen Erwachens bis zum Beitritt in die Europäische Union, in: P. Šтıн/V. Simoniti/P. Vodopıvec, Slowenische Geschichte. Gesellschaft - Politik - Kultur, Graz 2008, S. 384397 (Kapitel: Der Triumph der Sieger).

6 Slowenien präsentierte sich im europäischen Raum, wie das Referat des Repräsentanten des Kultusministeriums belegt, als das Land, das keine Denkmäler zerstört (vgl. G. Zupan, Les monuments et l'espace public Slovene de 1945 à I99I, in: Bildersturm in Osteuropa. Die Denkmäler der kommunistischen Ära im Umbruch. Eine Tagung des Deutschen Nationalkomitees von Icomos, des Instituts für Auslandsbeziehungen und der Senatsverwaltung Berlin in der Botschaft der Russischen Föderation in Berlin, I8.-20. Februar 1993 (hrsg. von F. Fiedler/M. Petzet), München 1994 (ICOMOS-journals of the German National Committee, I3), S. 54-55). 
und eigentlich unbearbeitet sind, sodass sie ein kunsthistorisches Desideratum darstellen. Für die Auftraggeber, häufig die jeweiligen Ortsgemeinden (z. B. Skulpturen in den Geburtsorten) war lediglich die visuelle Präsenz des (bedeutenden) Landsmannes als Identifikationsmoment relevant, da damit auch die Bedeutung des eigenen lokalen Milieus erhoben wurde, weswegen die genauen kunsthistorischen Daten (auch der Name des Künstlers) bei den Denkmaleinweihungen und in Medienberichten wiederholt unerwähnt blieben. Zahlreiche Büsten wurden erst in neuester Zeit hinsichtlich Entstehungskontext, Urheberschaft, Raumeinordnung und Rezeption untersucht. ${ }^{7}$
Der Aufsatz beschränkt sich auf die Analyse der Vorgeschichte und der Entstehung der Porträtbüsten von Wissenschaftlern bzw. Gelehrtendenkmälern im öffentlichen Raum Laibachs. Der Gedächtnisweg, der sich vom Universitätshauptgebäude bis hin zur National- und Universitätsbibliothek (NUK) mit der Porträtallee auf der Vegovastraße erstreckt, bildet als ein Gelehrtenraum in der Hauptstadt Sloweniens einen wissenschaftlichen Gegenpol zum politischen Areal Laibachs, repräsentiert durch das Parlament und den Präsidentenpalast sowie die zugehörige Plastik (u.a. Revolutionsdenkmal, Hauptportal des Nationalversammlungsgebäudes, Heldengrabstätte, Kidrič-Denkmal, Kardelj-Denkmal).

\section{GEMALTE VORGE S CH ICHTE}

Obwohl die Anfänge des Hochschulwesens in Laibach mit dem jesuitischen Engagement am Anfang des 17. Jahrhunderts verbunden sind, ${ }^{8}$ wurde die erste slowenische Universität erst nach dem Zerfall der Habsburgermonarchie im Jahr I9I9 gegründet. Bis dahin studierten Slowenen am häufigsten an der Wiener Universität, aber auch in vielen anderen Städten wie Rom, Bologna, Graz oder München und in den sla- wischen Ländern vor allem in Prag. Die erste Akademie, die Academia Operosorum, eine Vereinigung von Laibacher Gelehrten, wurde 1693 vor allem nach italienischem Vorbild konstituiert und gilt als Vorgängerin der Slowenischen Akademie der Wissenschaften und Künste, die erst 1938 gegründet wurde. ${ }^{9}$

Eine frühe Visualisierung der Bedeutung von Ausbildung und Wissenschaft in einem öffentli-

7 Die Recherchen zum Thema finden im Rahmen des Forschungsprogramms über slowenische Kunst im europäischen Kontext (Slovenian Artistic Identity in European Context) statt und in der Kooperation mit anderen Ländern (z. B. mit Serbien, vgl. zwei thematische Nummern der Zeitschrift Acta historiae artis Slovenica, I8/I-2, 20I3; hrsg. von B. Murovec/N. Makuljević, 20I3). Viel Material zu dem Projekt über Denkmäler im öffentlichen Raum wurde auch in den anderen Projekten des France Stele Institutes für Kunstgeschichte des Forschungszentrums der Slowenischen Akademie der Wissenschaften und Künste (UIFS ZRC SAZU) sowie der Kunsttopografie Sloweniens und Kunst in Maribor (Visual Arts and Architecture in the Spatial Context of the City of Maribor) gesammelt.

8 J. Ciperle, Jezuitski učni program in njihovi študiji v Ljubljani, in: Jezuiti na Slovenskem. Zbornik simpozija, Ljubljana 1992 (Redovništvo na Slovenskem, 3) (Zusammenfassung: Das Jesuitische Lehrprogramm und ihre Studien in Ljubljana), S. I74.

9 Zur Academia Operosorum siehe vor allem: J. KoruzA, E. Cevc, Academia operosorum, in: Enciklopedija Slovenije, I, Ljubljana 1987, S. 5-6; Academia Operosorum. Zbornik prispevkov s kolokvija ob 30o-letnici ustanovitve, Ljubljana 1994; A. LaVRIČ, Janez Gregor Dolničar in njegova Zgodovina ljubljanske stolne cerkve, in: I. G. THALNITsCHer, Historia Cathedralis Ecclesiae Labacensis, Labaci I7OI-I7I4/J. G. DolniČAr, Zgodovina ljubljanske stolne cerkve, Ljubljana I70I-I7I4 (hrsg. von A. Lavrič), Ljubljana 2003, S. 3I-35; L. VIDmar, Ljubljana kot novi Rim. Akademija operozov in baročna Ljubljana, Ljubljana 20I3 (Zusammenfassung: Ljubljana as the New Rome. The Academy of the Industrious and Baroque Italy).

io Vgl. z.B. G. Bergamini, Giulio Quaglio, Tavagnacco I994. 
chen Gebäude stellt das Fresko in der ersten allgemein zugänglichen Laibacher wissenschaftlichen Bibliothek (jetzt Seminarbibliothek) dar, ein Werk von Giulio Quaglio (I668-175I) aus Laino im Val d'Intelvi bei Como. ${ }^{\text {IO }}$ Im Jahr I70I wurde die Bibliothek von dem Laibacher Bischof Sigismund Christoph Herberstein, dem Dompropst Johannes Prešeren und dem Domdechanten Johann Anton Thalnitscher (Dolničar) gegründet. ${ }^{\text {II }}$ Die beiden Letztgenannten waren auch die antriebsstärksten Mitglieder der Academia Operosorum, die im ersten Viertel des I8. Jahrhunderts künstlerische und wissenschaftliche Bemühungen der Laibacher Gelehrten bündelte. Zuerst befand sich der Bibliotheksraum über der Sakristei in der Kathedrale des hl. Nikolaus, der aber nicht den Sicherheits-, Räumlichkeits- und Repräsentationsbedürfnissen entsprach. Deshalb wurde der neue Bibliothekssaal im Priesterseminar Collegium Carolinum, das ab I708 erbaut wurde, geplant. ${ }^{12}$ Das erste Programm für die Ausstattung war eine ambitionierte Invention des Bruders des Dechanten, dem sehr gut in der Kunst bewanderten Juristen Johann Gregor Thalnitscher (Dolničar) (1655-1719), der sich nach dem Studium und Reisen in Italien mit dem Vorhaben beschäftigte, Laibach in eine moderne barocke Stadt umzubauen. ${ }^{\mathrm{I}}$ In seinem unvollen- deten Manuskript mit den beiden Titeln Bibliotheca Labacensis publica Collegii Carolini Nobilium und Ectypon Bibliothecae Publicae Labacensis stellte er in Dialogform das Programm für die künstlerische Ausstattung als bereits realisiert dar - indem er Agesilaus, Präfekt im Collegium Carolinum, seinen italienischen Gast Lentulus durch die Bibliothek führen lässt. ${ }^{14}$ Thalnitscher plante Porträts von den drei Bibliotheksstiftern und den wichtigsten krainischen Vertretern von insgesamt einundzwanzig Wissenschaften und Kunstgattungen (I. Theologi, 2. Canonistae, 3. Sacri oratores, 4. Ascetae, 5. Historici, 6. Geneologici, 7. Iuristae, 8. Medici, 9. Chimici, I0. Philosophi, II. Mathematici, I2. Geographi, 13. Astrologi, 14. Geometrae, I5. Musici, I6. Picturae, sculpturae et architecturae cultores, 17. Arithmetici, I8. Politi$c i$, 19. Oratores et humaniorum litterarum scriptores, 20. Poetae, 2I. Philologici), teils als Marmorstatuen, teils als Gemälde (statuae marmoreae et icones; coloribus expressam intueris effigiem). ${ }^{\text {Is }}$ In seiner Handschrift stellte er mehr als 190 krainische Gelehrte und Künstler dar und legte eine Liste mit denjenigen an, die für die einzelnen der einundzwanzig Fächer stehen könnten. ${ }^{16}$ Bei Johann Ludwig Schönleben konnte sich Thalnitscher nicht entscheiden, ob er die Theologie vertreten oder als Historiker die erste Stelle

II Die Stiftungsurkunde wurde mehrmals transkribiert, vgl. Thalnitscher, Historia (zit. Anm. 9), S. I73-I74 (De Bibliotheca publica: S. 177-180), S. 329, Anm. 663.

I2 A. LAVRIČ, „Štiri fakultete“v ljubljanski Semeniški knjižnici. Prispevki k ikonografski interpretaciji Quaglieve poslikave, in: Acta historiae artis Slovenica, XII, 2007 (Zusammenfassung: The „Four Faculties“ in the Seminary Library of Ljubljana. Contribution to Iconographic Interpretation of the Ceiling Fresco by Giulio Quaglio), S. I67.

I3 Vgl. Lavrič, Janez Gregor Dolničar (zit. Anm. 9), S. 40, Anm. I65. Das Programm wird besonders aus seinen als Discursus politicus de bono statu et requisitis excollendae et qualificandae Civitatis Labac., Metrop. Carn. betitelten Notizen ersichtlich.

I4 Handschrift I4 (Seminarbibliothek, Laibach); Transkription: J. G. DoLNIČAR, Bibliotheca Labacensis publica Collegii Carolini Nobilium, in: Trubar, Hren, Valvasor, Dolničar. O slovstvu na Kranjskem. Znanstvenokritična izdaja (hrsg. von L. Vidmar), Ljubljana 2009, S. I8I-293; Fr. Ks. Lukman, Pripombe o Dolničarjevi „Bibliotheca publica Labacensis“, in: Zbornik za umetnostno zgodovino, n. F. V/VI, I959 (Zusammenfassung: Bemerkungen über Thalnitschers „Bibliotheca Lab. Publica“), S. 469-470, 476; vgl. auch V. STESKa, Dolničarjeva „Bibliotheca Labacensis publica“, in: Izvestja Muzejskega društva za Kranjsko, X, I900, S. I34-I40, I45-I74; LaVRIč, Janez Gregor Dolničar (zit. Anm. 9), S. 45; Lavrič, Štiri fakultete (zit. Anm. I2), S. I67-I68.

I5 Hs. I4, S. 20-I4I; DolniČAr, Bibliotheca (zit. Anm. I4), S. 195, 250; Lukman, Pripombe (zit. Anm. I4), S. 470.

I6 Hs. I4, S. 20-I4I; DolniČAR, Bibliotheca (zit. Anm. I4), S. 195-289.

I7 Diese Figur wurde in der älteren Literatur erst als Theologie (Fr. STELE, K zgodovini bibliotečnih stavb v Ljublja- 


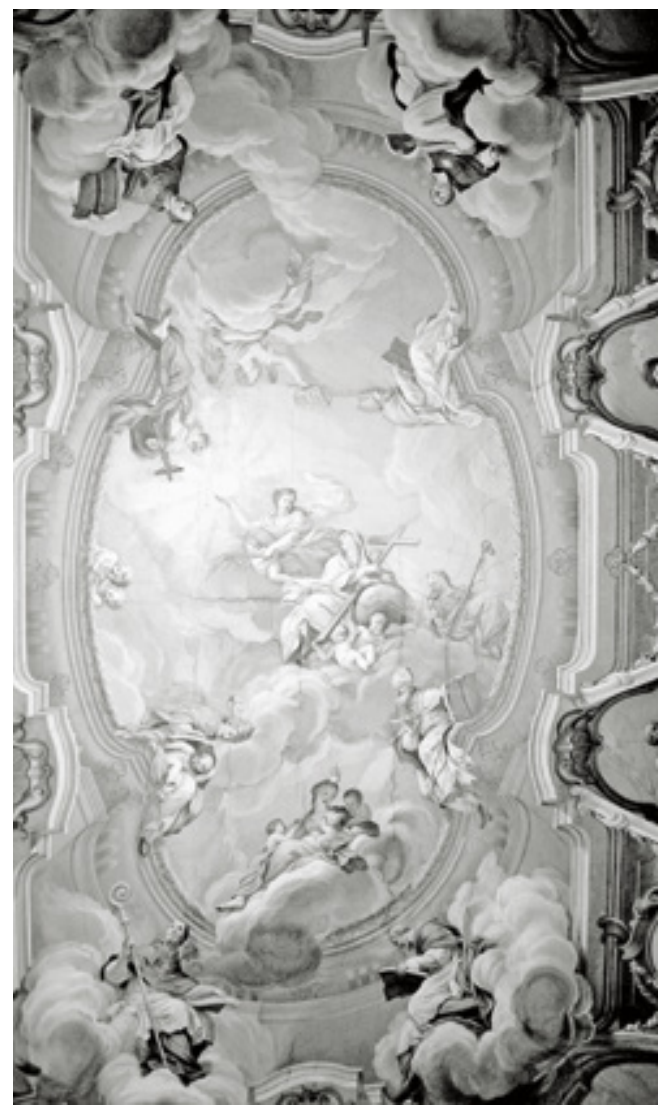

Abb. I: Giulio Quaglio, Deckengemälde der Seminarbibliothek, Laibach, I72I, Fresko.

statt Johann Weichard Valvasor übernehmen solle; Protestanten ließ er völlig unberücksichtigt. Nach dem Tod der beiden Thalnitschers blieb das Konzept unrealisiert. Statt einer Porträtgalerie bedeutender krainischer Gelehrter malte Quaglio I72I an die Decke des Bibliothekssaales eine klassische barocke Allegorie mit der Personifikation der Wahrheit ${ }^{17}$ - als Leittugend aller Wissenschaften - im Zentrum (Abb. I). Das auf den Ort und die Stadt bezogene Konzept und sein Kontext blieben unrealisiert. Unter dem Kanoniker Gregor Andreas Gladich (I659-I725), Domdechant nach dem Tod von Johann Anton Thalnitscher I7I4, der die Bauvollendung des Seminars und der Bibliothek leitete, schuf der Künstler Quaglio den Bozzetto, in dem die Raumfunktion zwar berücksichtigt wurde; aber eine solch unspezifische Ausmalung ohne Auftraggeber, krainische Gelehrte und Mitglieder der Academia Operosorum, die Bücher für die erste öffentliche wissenschaftliche Bibliothek stifteten, hätte jede Decke in Europa zieren können. Im gleichen Jahr, I725, als Gladich starb und die Academia Operosorum sich auflöste, war die Bibliothek vollendet, und die geschenkten Bücher wurden in die neuen Regale übertragen. ${ }^{18}$ Statt der visuellen Repräsentation der Stifter und krainischen Autoritäten, die Laibach nach römischem Vorbild in eine moderne künstlerische und wissenschaftliche Stadt verwandelt hatten, wurde die Bedeutung der Wissenschaft durch die Personifikationen der vier Fakultäten (Theologia, Philosophia, Medicina, $I u s),{ }^{19}$ die zu dieser Zeit in Laibach jedoch noch überhaupt nicht existierten, dargestellt (Abb. 2). Unter der Führung der Wahrheit und der drei katholischen Tugenden sitzen die vier großen westlichen Kirchenväter und die vier katholischen Kirchenlehrer (hl. Bonaventura, hl. Thomas von Aquin, hl. Karl Borromäus und hl. Franz von Sales), begleitet von vier Denkern, Putten mit Attributen und vier gemalten Büsten antiker Gelehrter, auf die dadurch als Referenz verwiesen wird.

Erst im letzten Viertel des 19. Jahrhunderts wurde in den slowenischen Ländern ein Bildprogramm realisiert, das die Gelehrten-

ni, in: Projekt univerzitetne biblioteke ljubljanske, Ljubljana I933, s.p.) und später auch als Sapientia interpretiert (M. SмоLıк, Umetnine v ljubljanskem Semenišču, in: Vis imaginis. Baročno slikarstvo in grafika. Jubilejni zbornik za Anico Cevc (hrsg. von B. Murovec), Ljubljana 2006 (Zusammenfassung: Works of Art in the Diocesan Seminary in Ljubljana), S. 139). Zuletzt analysierte die Ikonografie der Decke Ana Lavrič, die auch die vier Personifikationen als die vier Fakultäten überzeugend identifizierte (LAVRIČ, Štiri fakultete (zit. Anm. I2), S. I7I-I78).

I8 M. Sмоцıк, Semeniška knjižnica, Celje/Ljubljana 20I0, S. 3I.

I9 LaVRIČ, Štiri fakultete (zit. Anm. I2), S. I73-178.

20 Freiherr von Schmidburg zieht konkrete Parallelen zwischen der Academia operosorum und ähnlichen Bestrebungen 

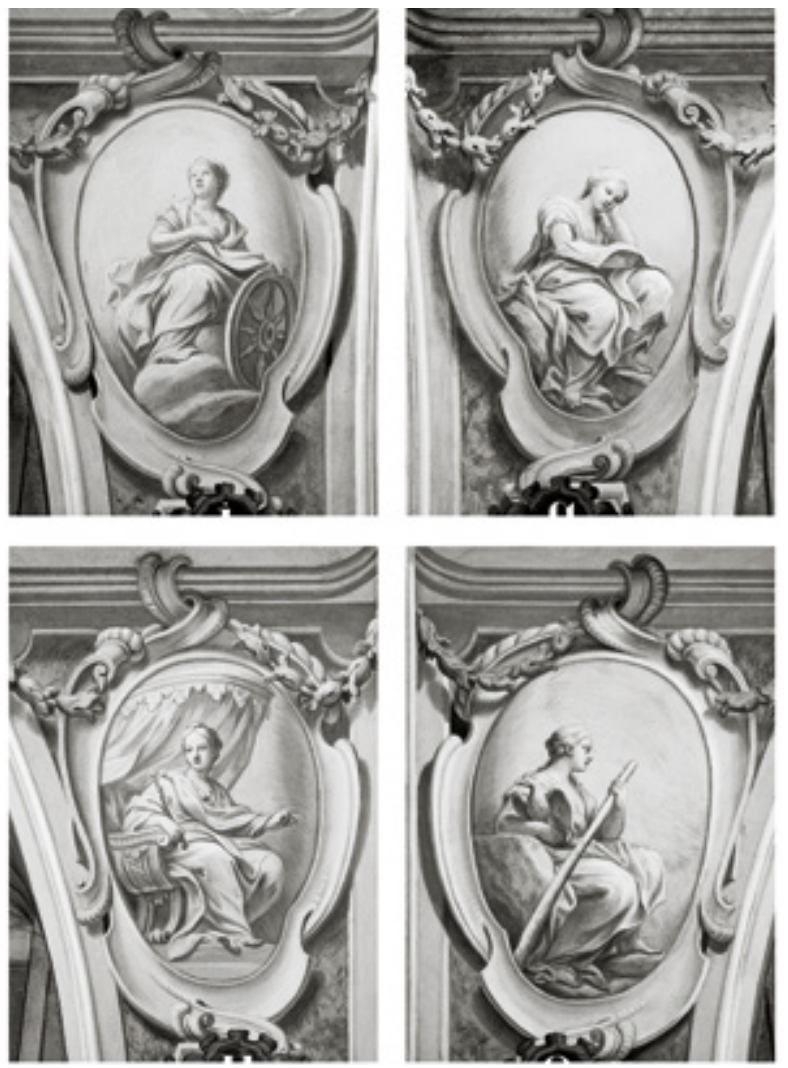

Abb. 2: Giulio Quaglio, Vier Fakultäten, Seminarbibliothek, Laibach, I72I, Fresko.

porträts abbildet und sich zugleich auf die lokale Geschichte bezieht. In dem neuen Gebäude des ersten allgemein zugänglichen Museums, in der Eingangshalle des Krainischen Landesmuseums (gegründet I826, zwischen I882 und I92I Krainisches Landesmuseum Rudolfinum, heute Nationalmuseum Sloweniens), wurde mit vier historischen Personen ein viel bescheideneres Konzept als das ursprünglich von Thalnitscher geplante ausgeführt. Schon am I5. Februar 1823 betitelte der Landesgouverneur und Präsident der Stände Joseph Camilo Freiherr von Schmidburg seinen gedruckten Aufruf, der das Konzept und die Aufgaben des Museums, der ersten For- schungsinstitution in Krain, erläuterte: An die vaterländischen Freunde der Wissenschaften. ${ }^{20}$ I888, drei Jahre nachdem das Museum ein eigenes Gebäude bekommen hatte und ausgestattet wurde, konnte es „anlässlich der Jubiläumsfeier der 4O-jährigen Regierung Sr. Majestät des Kaisers Franz Josef I. “" ${ }^{21}$ eröffnet werden und wurde noch im selben Jahr von dem Initiator des Neubaus und damaligen Kustos Karl Deschmann (I82I-I889) im Führer durch die Sammlung mit folgenden Worten beschrieben:

„Auf dem Plafond des Vestibuls befindet sich ein grosses Oelgemälde des heimischen Malers Johann Šubic, Professor an der Gewerbeschule

im I9. Jahrhundert, wenn er erläutert, dass „Krain in gewisser Hinsicht früher als manches andere Erbland [...]“ war. (Nach der Kopie des gedruckten Textes in der Bibliothek des Nationalmuseums, s.p.)

2I K. Deschmann, Führer durch das Krainische Landes-Museum Rudolfinum in Laibach, Laibach I888, S. I7. 


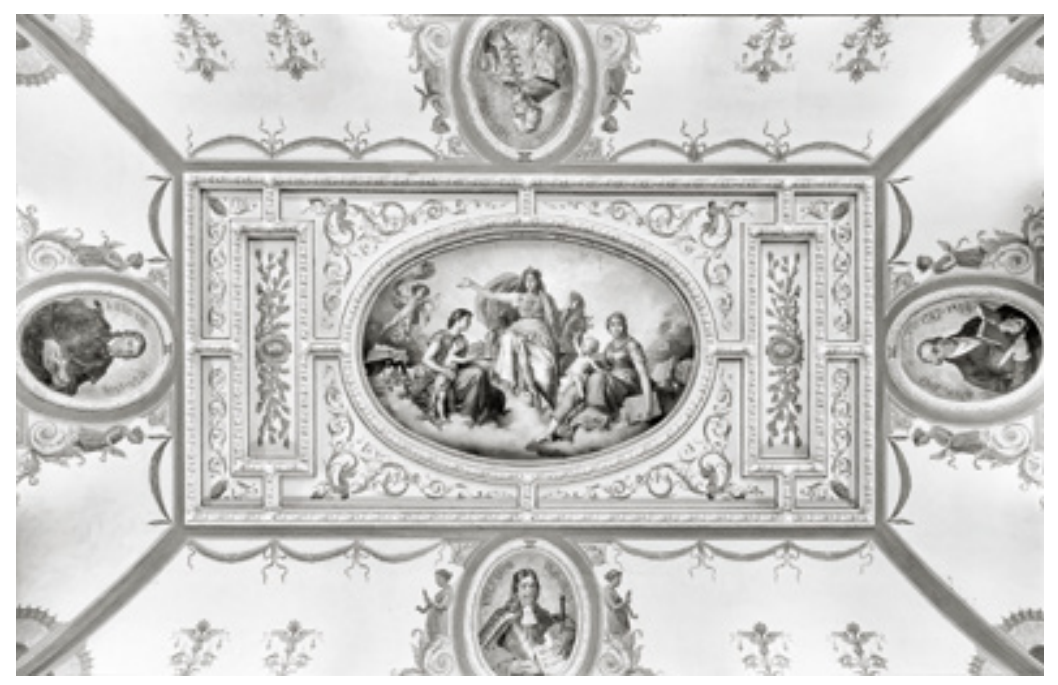

Abb. 3: Janez Šubic, Carniolia mit Porträts von vier Krainischen Gelehrten, Deckengemälde, Laibach, Slowenisches Nationalmuseum.

in Kaiserslautern, darstellend die thronende Carniolia, welcher die Kunst und die Wissenschaft huldigen. An den Hohlkehlen der vier Wände wurden in Medaillonform die Bildnisse vier berühmter Krainer vom Bruder des oben genannten Künstlers, Georg Šubic, gemalt, und zwar gegenüber dem Portale der Chronist Valvasor, Verfasser der ,Ehre des Herzogthums Krain“, links von demselben der erste krainische Dichter Valentin Vodnik, rechts der berühmte Mineralog und Montanist Sigmund Freiherr von Zois, ober dem Mittelthore ist das Porträt des berühmten Staatsmannes Sigmund von Herberstein, eines geborenen Krainers, in diesem findet die Geschichtsforschung und Ethnographie einen würdigen Vertreter" (Abb. 3). ${ }^{22}$

\section{ERSTE GELEHRTEN SKULPT UREN}

Der Neubau und die Ausstattung des Landesmuseums trugen entscheidend zum Eintritt der Gelehrtenskulptur im öffentlichen Raum Laibachs bei. Für die Analyse der Wissenschaftlerporträts und der Gelehrtendenkmäler ist die Berücksichtigung der Deckenmalerei in der Vor- halle genauso wichtig wie die Büsten, die in den Achtziger- und Neunzigerjahren des 19. Jahrhunderts für die Innenräume bestellt wurden.

Im Museum wurde schon am 24. Mai I890, ein Jahr nach dem Tod Deschmanns, die Büste dieses einflussreichen Politikers (eines Geg-

22 Deschmann, Führer (zit. Anm. 2I), S. 13. Bei der Erforschung der Tätigkeit Karl Deschmanns kommt immer wieder betont die aktuelle Frage nach der relevanten Sprache in den Geisteswissenschaften zum Ausdruck. Deschmann war zwar bemüht, heimische Künstler zu engagieren, für die Forschung vertrat er allerdings die Ansicht, dass die Wissenschaft zur Qualitätssicherung mit dem Wiener Raum eng verbunden bleiben müsse und deshalb die deutsche Sprache verwendet werden solle (vgl. A. Pirjevec, Karel Dežman, in: Slovenski biografski leksikon (hrsg. von Iz. Cankar/Fr. Ks. Lukman), Ljubljana 1925, S. 132-I33). Zur Ausstattung vgl. auch P. Petru/M. Žargi, Narodni muzej v Ljubljani, Ljubljana 1983 (Kulturni in naravni spomeniki Slovenije, I23), S. 22-38 (mit deutschem Einleger Führer durch das Slowenische Nationalmuseum/Narodni muzej, S. I-XXVII, und weiterführender Literatur).

23 S. Žıтко, Fernkorns und Tilgners Werke für Ljubljana, in: Österreichische Zeitschrift für Kunst und Denkmalpflege, LI, I997, S. 408-4I4. 


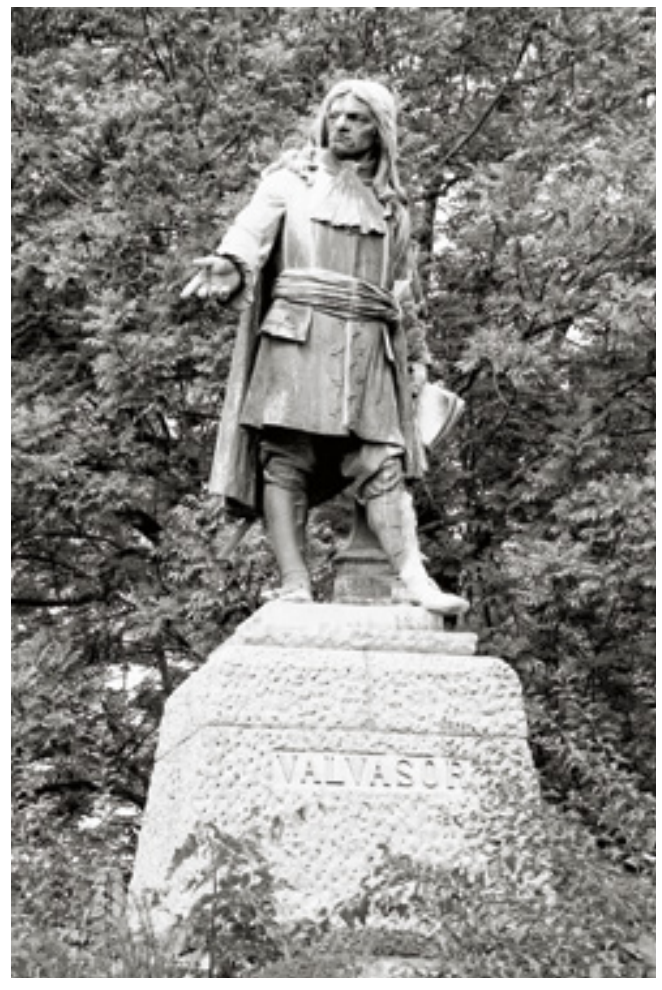

Abb. 4: Alois Gangl, Valvasor-Denkmal, I903, Bronze, Laibach, Trg narodnih herojev.

ners der slowenischen Bewegung) und Naturwissenschaftlers enthüllt. Sein Denkmal war bei dem Wiener Bildhauer Victor Tilgner (I844I896) bestellt worden. ${ }^{23}$ Ein Jahr später wurde im Lesesaal die „überlebensgroße“ Gelehrtenbüste Johann Weichard Valvasors (I64I-I693) von dem Salzburger Bildhauer Josef Müllner (I84OI9II) aufgestellt. ${ }^{24}$ Das Ausstattungskonzept des Landesmuseums visualisierte erstmalig die Forschungserfolge der krainischen Gelehrten und führte damit noch in der Habsburgermonarchie die Bestrebungen der Academia operosorum und besonders von Thalnitscher nach wissenschaft- licher Repräsentation aus.

In dieser Zeit entstanden für Wissenschaftler auch die ersten Denkmäler im öffentlichen Raum, zunächst in Laibach mit dem Denkmal des schon im Landesmuseum zweifach porträtierten Johann Weichard Valvasor vor dem neuen Museumsgebäude (Abb. 4). Die Idee, die Statue Valvasors in der Stadt aufzustellen, ging auf das Rudolfinum zurück. ${ }^{25}$ Die zeitgenössischen nationalen Auseinandersetzungen zwischen Slowenen und Deutschen spiegelten sich aber in der Errichtung der Denkmäler von historischen Personen genauso stark wie in der Politik wider. Die Betonung der eigenen (wissenschaftlichen) Leistungsfähigkeit sollte womöglich identitätsstiftend wirken. Nach einem Bericht der Laibacher Zeitung (7. Mai 189I) war „das Ministerium für Cultus und Unterricht bereit, auf Rechnung des diesfälligen, ihm zur Verfügung stehenden Credites durch einen heimatlichen Künstler eine Statue des als Geschichtsschreiber und Topographen Krain's sowie als Patrioten“ bekannten Gelehrten „[...] herstellen zu lassen." Sie soll [...] einem öffentlichen Platze in Laibach zur Ausschmückung [...] dienen. ${ }^{\text {"26 }}$ Die verwendeten Worte zeigen, wie vorsichtig bzw. diplomatisch die deutsche Seite versuchte, ihre Absichten durchzusetzen. Trotzdem vergingen vom Auftrag I894 bis zur Errichtung der Statue, die der krainische Bildhauer Alois Gangl (I859-1935) ausführte, insgesamt zehn Jahre. Das Denkmal Valvasors, eines Mitglieds der Royal Society in London, ${ }^{27}$ der wegen seiner Investitionen in das Land verherrlichende Forschungs- und Buchprojekte (unter anderem schrieb er auch die grundlegende Landesgeschichte in vier Büchern, Die Ehre deß Hertzogthums Crain, I689) in ernste

24 A. Müllner, Ein Denkmal für den Freiherren Johann Weichard Valvasor, in: Argo, III, Mai I894, Sp. 97-98 (mit Tafel); vgl. auch ČopIč, Javni spomeniki (zit. Anm. 2), S. 42.

25 Čopıč, Javni spomeniki (zit. Anm. 2), S. 42.

26 Zitiert nach Müllner, Ein Denkmal (zit. Anm. 24), Sp. 97.

27 Seine Biografie in Deutsch: I. Palladino/M. Bidovec, Johann Weichard von Valvasor (I64I-I693). Ein Protagonist der Wissenschaftsrevolution der Frühen Neuzeit. Leben, Werk und Nachlass, Wien/Köln/Weimar 2008 (mit weiterführender Literatur). 
finanzielle Schwierigkeiten geriet - wurde größtenteils ablehnend aufgenommen, ganz im Gegensatz zu dem in der Laibacher Zeitung als unzweifelhaft positionierten Gedanken, „dass die Idee dieser Denkmalerrichtung sowie die Munificenz der Unterrichtsverwaltung in allen Kreisen der Bevölkerung mit Freude begrüsst werden wird [...]“. Um 1900 wurden die Leistungen von
Valvasor und seine Person selbst (auch weil er in Deutsch schrieb) weitgehend negativ rezipiert. So fand beispielsweise 1903 nach der Errichtung seiner Statue, die gleichzeitig das erste öffentliche Gelehrtendenkmal in Laibach darstellte, keine feierliche Enthüllung statt - vorgeblich wegen des ungünstigen Wetters. ${ }^{28}$

\section{FRANZ VON MIKLOSICH (FRAN MIKLO ŠI Č́) $S$ TATT KAISER FRANZ JOSEPH I.}

Im Jahr I895 wurde Laibach durch ein Erdbeben stark beschädigt und wegen dieser Katastrophe besuchte Kaiser Franz Joseph die Hauptstadt Krains. Ihm zu Ehren wurde am Slowenischen Platz ein Kaiserdenkmal geplant und I908 enthüllt. Svetoslav Peruzzi (I88I-1936) gewann den ersten Preis in dem schon 1903 ausgetragenen Wettbewerb, an dem neun Bildhauer teilnahmen. ${ }^{29}$ Nach dem Zusammenbruch Österreich-Ungarns wurde die Büste von Franz Joseph wie die anderen mit der Monarchie verbundenen Denkmäler beschädigt und abgetragen. Die restlichen Denkmalbestandteile mit der Personifikation Laibachs, die dem Kaiser huldigt, und der Sockel mit dem Relief, auf dem die Erdbebenopfer abgebildet sind, blieben auf dem Platz. Üblicherweise wurden die Habsburgerbüsten durch die aktuellen Vertreter des neuen Königreichs der Serben, Kroaten und Slowenen, die Karadjordjevićs, ersetzt, wie beispielsweise vor der Kadettenschule in Marburg an der Drau (Maribor) Franz Joseph durch das Bildnis von König Peter I., was hier allerdings unterblieb. ${ }^{30}$
Der Slowenische Platz in Laibach wurde nach I9I8 in König-Peter-Platz umbenannt, das Podest des früheren Kaiserdenkmals blieb jedoch anfangs leer. Später wurde eine Vase aufgestellt und erst bei der Renovierung des Platzes 1926 kam darauf eine Büste des slowenischen Wissenschaftlers Franz von Miklosich (I8I3-I89I), ${ }^{31}$ dem wichtigsten Philologen slawischer Sprachen seiner Zeit und Inhaber des neu gegründeten Lehrstuhls für Slawistik an der Wiener Universität, wo er u.a. Rektor war sowie Mitglied der Österreichischen Akademie der Wissenschaften (Abb. 5).

Für Miklosichs Büste wurde kein Wettbewerb ausgeschrieben, den Zeitungsnotizen nach wurde das Projekt rasch zu Ende geführt und die Gründe für die Auswahl der abgebildeten Person blieben undokumentiert. Die Entscheidung wurde ohne große Vorbereitung getroffen und knüpft höchstwahrscheinlich an ein Ereignis im selben Sommer an. Am 8. August 1926, einen knappen Monat vorher, wurde das erste slowenische Miklosich-Denkmal in Luttenburg (slow. Ljutomer), wo Miklosich seine Jugend verbrachte, enthüllt. An der festlichen Veranstaltung nahmen auch viele Repräsentanten aus den politi-

$28 \mathrm{Vgl}$. ČopIČ, Javni spomeniki (zit. Anm. 2), S. 42, 44.

29 Vor allem B. Hudales-Kori, Kipar Svetoslav Peruzzi, in: Zbornik za umetnostno zgodovino, n. F. VIII, I970, S. I65-199, bes. I74-I78; ČopIČ, Javni spomeniki (zit. Anm. 2), S. 255-259.

30 Vgl. Podstavek za cesarjev spomenik pred Kadetnico v Mariboru, in: Spomenik Franca Jožefa I. pred Kadetnico v Mariboru. Njegov pomen in materialna dediščina, Virtuelle Ausstellung (hrsg. von B. Murovec), http://www. mariborart.si/razstava/-/article-display/kip-franca-jozefa-za-mariborsko-kadetnico, abgerufen am 23. Jänner 2017.

3I Notiz in: Slovenec, 26. August I926, LIV/I93, S. 4. 


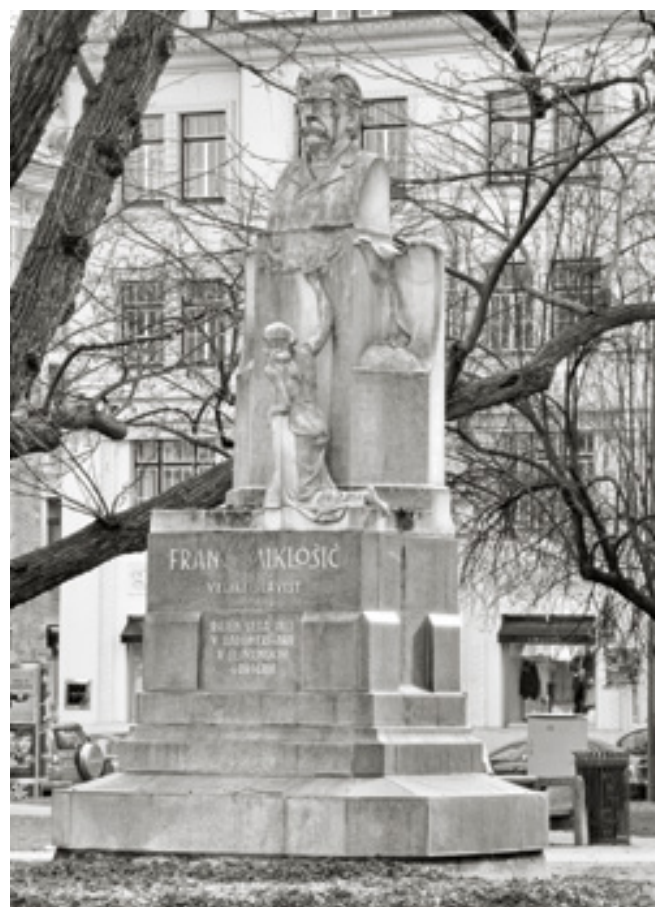

Abb. 5: Svetoslav Peruzzi/ Tine Kos, Miklosich-Denkmal, 1908, 1926, Marmor, Laibach, Miklošičev park.

schen, wissenschaftlichen und universitären Kreisen teil. Aus Laibach kamen unter anderen Dr. Dragotin Lončar aus dem Unterrichtsministerium, Prorektor Prof. Karel Hinterlechner und Prof. Rajko Nahtigal von der Universität sowie der Schriftsteller Fran Govekar als offizieller Vertreter der Stadt Laibach. Die Eröffnungsrede hielt der Slawist Prof. Nahtigal, der neben dem wissenschaftlichen Beitrag von Miklosich auch betonte, wie dieser sich für die slowenischen Schulen einsetzte. Er beschrieb dessen Rolle bei den österreichischen Schulreformen, was ihm auch den Platz neben dem Monument von Leo Graf Thun Hohenstein und den Büsten von Prof. Hermann Bonitz und Prof. Franz Exner im Arkadenhof der Universität Wien sichere. Nicht zuletzt hob der Laudator hervor, dass Miklosich Volksschulen nur in der slowenischen Sprache fordere, im Gegensatz zum Bischof Anton Martin Slomšek (I80o-I862), der sich für zweisprachige Schulen einsetzte. ${ }^{32}$ Beim anschließenden Bankett folgten noch weitere Reden, besonders interessant ist der Bericht in der Zeitung Slovenec über die Bemerkung Govekars, der erwähnte, dass „Laibach vielleicht schon in diesem Herbst ein Denkmal Miklosichs bekommen wird." 33

In so kurzer Zeit wäre es unmöglich gewesen, ein komplettes Denkmal zu errichten, wenn nicht das alte Podest des Franz-Joseph-Denkmals verwendet worden wäre. Für die Hauptstadt und ihre Universität war es aber 1926 nicht nur wichtig, den berühmten Landsmann im öffentlichen Raum angemessen zu würdigen, sondern vor allem waren seine Ansichten auch höchst aktuell. Wie Nahtigal am Ende seiner Rede in Luttenburg betonte:

„Ich komme zum Schluss! Ich denke, dass ich ausreichend die allgemeinmenschliche Monumentalität des wissenschaftlichen Oeuvres von Miklosich skizziert habe und den noch immer andauernden Nutzen für die slawischen $\mathrm{Na}$ tionen zeigte, für die es in ihrer kulturellen Entwicklung nicht nur erforderlich sein wird, das wesentliche Merkmal eigener nationaler Individualität, die Muttersprache, zu pflegen, sondern sie könnten in seinem Werk wissenschaftliche Förderung und Hinweise für ihre immer größere und enge Einheitlichkeit finden. [...] $]^{\text {‘3 }_{3}}$

Diese Rede wurde vollständig publiziert und könnte als Botschaft eines slowenischen Intellektuellen in Bezug auf die Frage der Sprachen und im Kampf für Erhaltung der slowenischen (gegenüber der serbokroatischen) Sprache verstanden werden. Die slowenische nationale

\footnotetext{
32 R. Nahtigal, Franc Miklošič (Slavnostni govor o priliki odkritja spomenika v Ljutomeru dne 8. avgusta I926.), in: Ljubljanski zvon, XLVI/Io, I926, S. 565 .

33 Odkritje Miklošičevega spomenika v Ljutomeru, in: Slovenec, Io. August 1926, LIV/I79, S. 4.

34 Nahtigal, Franc Miklošič (zit. Anm. 32), S. 572.
} 
Frage war in den I920er-Jahren im Königreich der Serben, Kroaten und Slowenen (SHS) das dringendste Problem der slowenischen Intelligenz, die in diesem Zusammenhang keine Unterstützung bei den kroatischen und serbischen Kollegen, insbesondere nicht bei den Linguisten, fand. ${ }^{35}$ Am Ende des Jahres 1925 und 1926 einigte die Drohung einer gewaltigen Universitätsreform die ansonsten tief zerstrittenen Organisationen und Parteien zur Herausgabe einer gemeinsamen Resolution „Für die Autonomie der Laibacher Universität" . ${ }^{36}$ Und der bedeutende slawische Gelehrte aus Slowenien wurde eine der wichtigsten Referenzen, die für die slowenischen Bestrebungen sprachen und durch Denkmäler präsent waren.

Die Miklosich-Büste für Luttenburg wurde bei dem Wiener Bildhauer und Akademieprofessor Johann Scherpe, dem Autor des Miklosich-Denkmals im Arkadenhof der Universität Wien (enthüllt I897), bestellt. ${ }^{37}$ Sie ist eine exakte Kopie des Wiener Denkmals und wurde nach der Enthüllung von dem zu dieser Zeit noch studierenden Literaturhistoriker und Schriftsteller Bratko Kreft (1905-1996) wegen der Auswahl des Künstlers stark kritisiert: „Überall soviel Slowenentum, überall soviel Nationalismus und die Gewohnheit, dass den Auftrag ein Fremder bekommt und dass man die Arbeit nicht dem slowenischen Künstler zu- traut. ${ }^{{ }_{38} 8}$ Von den slowenischen Bildhauern, die gegenwärtig gute Denkmäler anfertigen würden, hebt er den jungen Tine Kos (I894-1979) hervor, insbesondere dessen Monument von König Peter I. in Krain. ${ }^{39}$ Und eben diesem Bildhauer wurde der Auftrag der Miklosich-Büste für Laibach anvertraut. Das Denkmal wurde Anfang September 1926 errichtet, der Vergleich mit den Porträts Miklosichs zeigt, dass der Bildhauer höchstwahrscheinlich nach der Fotografie der Wiener „k. k. Fotografin“ Rosa Jenik arbeitete, mit der sogar der Anzug des Gelehrten übereinstimmt. ${ }^{\circ}$ Der Schriftsteller Fran Govekar, der auch in Luttenburg anwesend war, fand später das Monument „geschmacklos“, weil es „als Überrest des ehemaligen kaiserlichen Denkmals noch immer Symbole des österreichischen zweiköpfigen Adler" trage. ${ }^{41}$ Und tatsächlich ist das Antlitz mit dichtem Schnurrbart und buschigen Augenbrauen auch visuell dem FranzJoseph-Porträt von Peruzzi (jetzt Stadtmuseum Laibach) sehr nahe. ${ }^{42}$

Das Denkmal auf dem Laibacher KönigPeter-Platz war eine eher ungewöhnliche, wenn nicht sogar politisch unkorrekte Anknüpfung an die habsburgische Monarchie bzw. eine bewusste Rückbesinnung und Würdigung des Universitätszentrums in Wien. Auch wenn in diesem Fall ein slowenischer Künstler beauftragt wurde. Der Entscheidung, die Miklosich-Büste auf

35 E. Dolenc, „The Generation at a Closed Door“. Slovenian Intellectual Issues Between the Two World Wars, in: Slovene Studies, I-II, 200I, S. I9.

36 E. Dolenc, Kulturni boj. Slovenska kulturna politika v Kraljevini SHS. 1918-1929, Ljubljana 1996, S. $223-225$.

37 T. Maisel, Gelehrte in Stein und Bronze, Wien/Köln/Weimar 2007, S. 58, Nr. 55; M. Fleming, Denkmal Franz von Miklosich, https://monuments.univie.ac.at/index.php?title=Denkmal_Franz_von_Miklosich (abgerufen am I7. Juli 2015).

38 B. Kreft, Miklošičev spomenik in slovenski umetniki, in: Mladina, III/I, I926, S. 24.

39 KREFT, Miklošičev spomenik (zit. Anm. 38), S. 24.

40 Vgl. https://commons.wikimedia.org/wiki/Category:Franc_Miklo\%C5\%Ari\%C4\%8D\#/media/File:Rosa_Jenik_-Franc_Miklo\%C5\%Ari\%C4\%8D.jpg (abgerufen am I7. Juli 20I5). In der Zeitung Slovenec (LIV/202, 5. September 1926, S. 5) wurde berichtet, dass Kos mehrere Gemälde und Fotografien studiert habe und sich auch das Denkmal im Wiener Arkadenhof anschaute.

4I Platon (= Fr. Govekar): Napoleonov spomenik v Ljubljani, in: Slovenski narod, 2I. Juni I929, S. 2.

42 Vgl. Več glav ... Iz kiparske zbirke Mestnega muzeja Ljubljana ... več ve / Many Heads Are Better than One (hrsg. von A. Pokrajac Iskra), S. 62, Abb. I8. 
das ehemalige Franz-Joseph-Denkmal zu setzen, müssen auch zeitliche und finanzielle Abwägungen zugrunde liegen. Im Jahr 1926 war es wichtig, unbedingt ein Monument für Miklosich zu errichten. Seine Persönlichkeit und linguistische Sicht bekräftigten die aktuellen politischen und universitären Bemühungen der Slowenen im Königreich der Serben, Kroaten und Slowenen. Franz von Miklosich, I848 Präsident des Wiener Verbands „Slowenien“ und einer der Verfasser des Nationalprogramms für das „vereinigte Slowenien“, vertrat den slowenischen Standpunkt der I92oer-Jahre mit dem aufkommenden $\mathrm{Na}$ tionalbewusstsein und ,agierte“ gegen die Einführung der serbokroatischen Sprache und die zunehmende Dominanz der Serben. Gleichzeitig - wie auch Prof. Nahtigal betonte - war Miklosich in seinen slawischen Forschungen am engsten „mit dem Serbentum und Kroatentum verbunden “43 und diese auch in Belgrad gut bekannte Tatsache deproblematisierte die Präsenz des slowenischen Gelehrtendenkmals auf dem König-Peter-Platz in Laibach.

Auf Miklosich als slowenischen Spitzenwissenschaftler wird in der jüngsten Zeit besonders in Nordostslowenien (Steiermark) verstärkt Bezug genommen. Besonders in der Universitätsstadt Maribor/Marburg an der Drau, wo u. a. die Bibliothek an der Philosophischen Fakultät nach ihm benannt ist und seine Statuen sowohl in der Universitätsbibliothek (1997) als auch vor dem Universitätshauptgebäude als Teil der Gelehrtenallee (1998-2000) stehen, ${ }^{44}$ wird die Erinnerung an Miklosich auch in Abgrenzung zur Laibacher Universität gepflegt und mit Verweis auf den renommierten Wissenschaftler zur eigenen Profilschärfung verwendet. ${ }^{45}$

\section{WISSENSCHAFTLER VOR DER NATIONAL- UND U N I VER S T T̈̈TS B I B L I O T H E K}

Den Schlüsselbeitrag zur Positionierung der Gelehrtendenkmäler im öffentlichen Raum Laibachs leistete der Architekt Josef Plečnik (I872-1957) mit dem Bau der National- und Universitätsbibliothek sowie seiner Neu- bzw. Umgestaltung der Vegovastraße (Abb. 6). Sie wurde an der Stelle des zugeschütteten Grabens neben der mittelalterlichen Stadtmauer zwischen 1929 und 1942 angelegt und u.a. mit einer Allee slowenischer Komponisten und Gelehrter versehen. Plečnik plante der Universitätsbibliothek entlang eine Ehrenallee von Wissenschaftlern, ähnlich der Allee mit Komponistenhermen vor der Slowenischen Musikalischen Gesellschaft Glasbena matica, die in den 1930er-Jahren im Auftrag der Stadt Laibach nach seinen Plänen ausgeführt worden war (die ersten acht wurden 1932 enthüllt). ${ }^{46}$ Auf Initiative der Slawistischen Gesellschaft wurde die Wissenschaftlerallee als spezifische Slawistenreihe angelegt (Abb. 7). Dies stand im Einklang mit der

43 Nahtigal, Franc Miklošič (zit. Anm. 32), S. 566.

44 Vgl. M. Berdič, Javna plastika Viktorja Gojkoviča, in: Viktor Gojkovič. Kipar in restavrator (hrsg. von A. GAČNIK), S. I20, I29.

45 Mehr über die Funktion von Miklosich-Denkmälern in Slowenien in: B. Murovec, Slovenski znanstvenik. Funkcija in transformacija Miklošičeve podobe na javnih spomenikih, in: Patriae et Orbi. Essays on Central European Art and Architecture. Festschrift in Honour of Damjan Prelovšek/Študije o srednjeevropski umetnosti. Jubilejni zbornik za Damjana Prelovška (hrsg. von A. Lavrič/F. LaZarini/B. Murovec), Ljubljana 20I5, S. 667-688 (Opera Instituti Artis Historiae).

46 Das Vorbild dafür stellte das Projekt der Ehrenallee für die Wiener Universität (Hermen vor der TU Wien) des Architekten Max Fabiani (I865-I962) dar; vgl. Š. ČopIČ/D. PrelovšEK/S. ŽıtKo, Outdoor Sculpture in Ljubljana, Ljubljana I99ı, S. 36, Nr. 33; A. Hrausky/J. KožElJ/D. Prelovšek, Plečnikova Ljubljana. Vodnik po arhitekturi, Ljubljana 1996, S. 3I; vgl. auch M. Pozzetтo, Max Fabiani. Ein Architekt der Monarchie, Wien 1983, S. 85-86. 


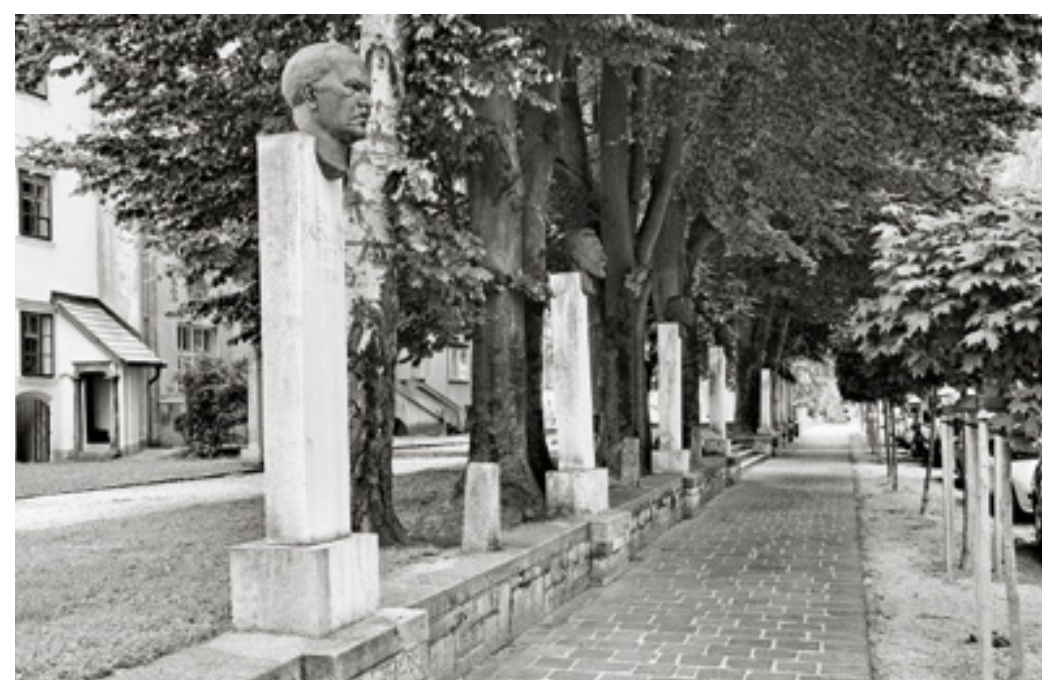

Abb. 6: Vegovastraße mit Komponistenhermen, Konzept von Joseph Plečnik, ab 1929, Laibach.

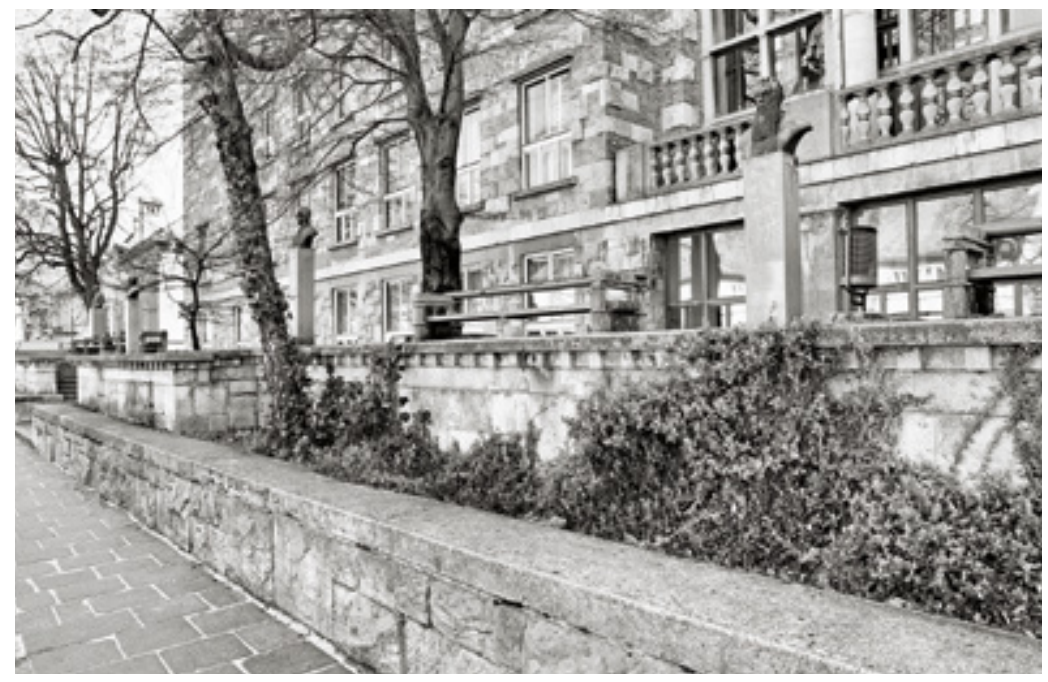

Abb. 7: Slawisten-Reihe vor der National- und Universitätsbibliothek, 1942, 1961, Laibach.

historisch mehrfach bestätigten Position, dass für die Slowenen die eigene Sprache grundlegend für eine nationale Eigenständigkeit (auch im wissenschaftlichen Kontext) war und daher im Selbstverständnis als primäres Verteidigungsmittel gegen die unitaristische Politik Jugoslawiens gese- hen wurde. Das Denkmal für Ivan Prijatelj (I875I937) wurde 1942 als erstes enthüllt. Der Geehrte war einer von zwei Professoren, die Plečnik zur Planung der neuen Universitätsbibliothek anregten und als Mitinitiatoren in der Buchausgabe der Pläne genannt werden (Abb. 8). ${ }^{47}$

47 J. PleČNIK, Projekt univerzitetne biblioteke ljubljanske, Ljubljana I933, s.p. 


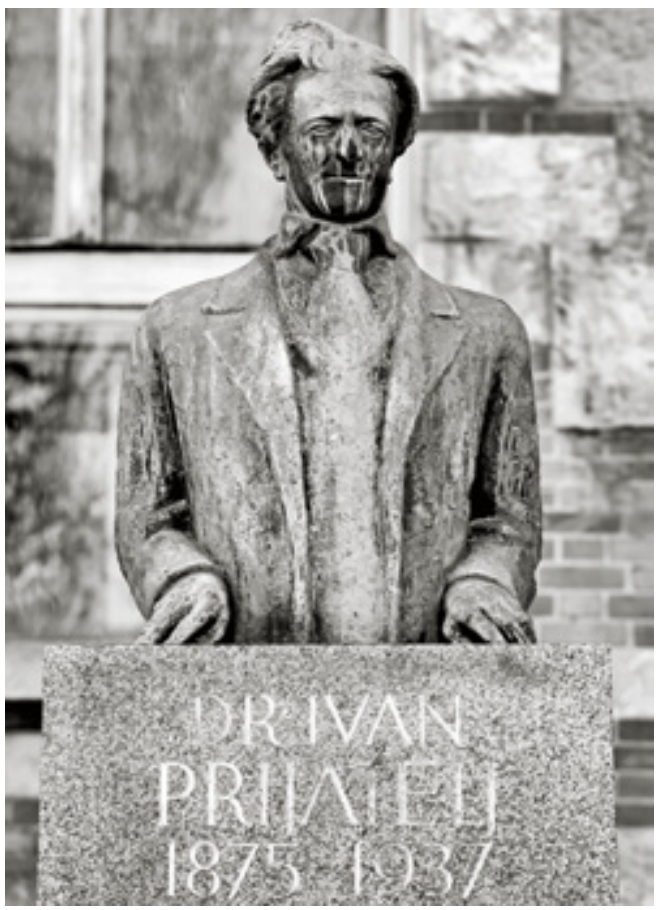

Abb. 8: Franc Goř̌e, Ivan Prijatelj, 1942, Bronze,

Slawisten-Reihe vor der Nationalbibliothek, Laibach.

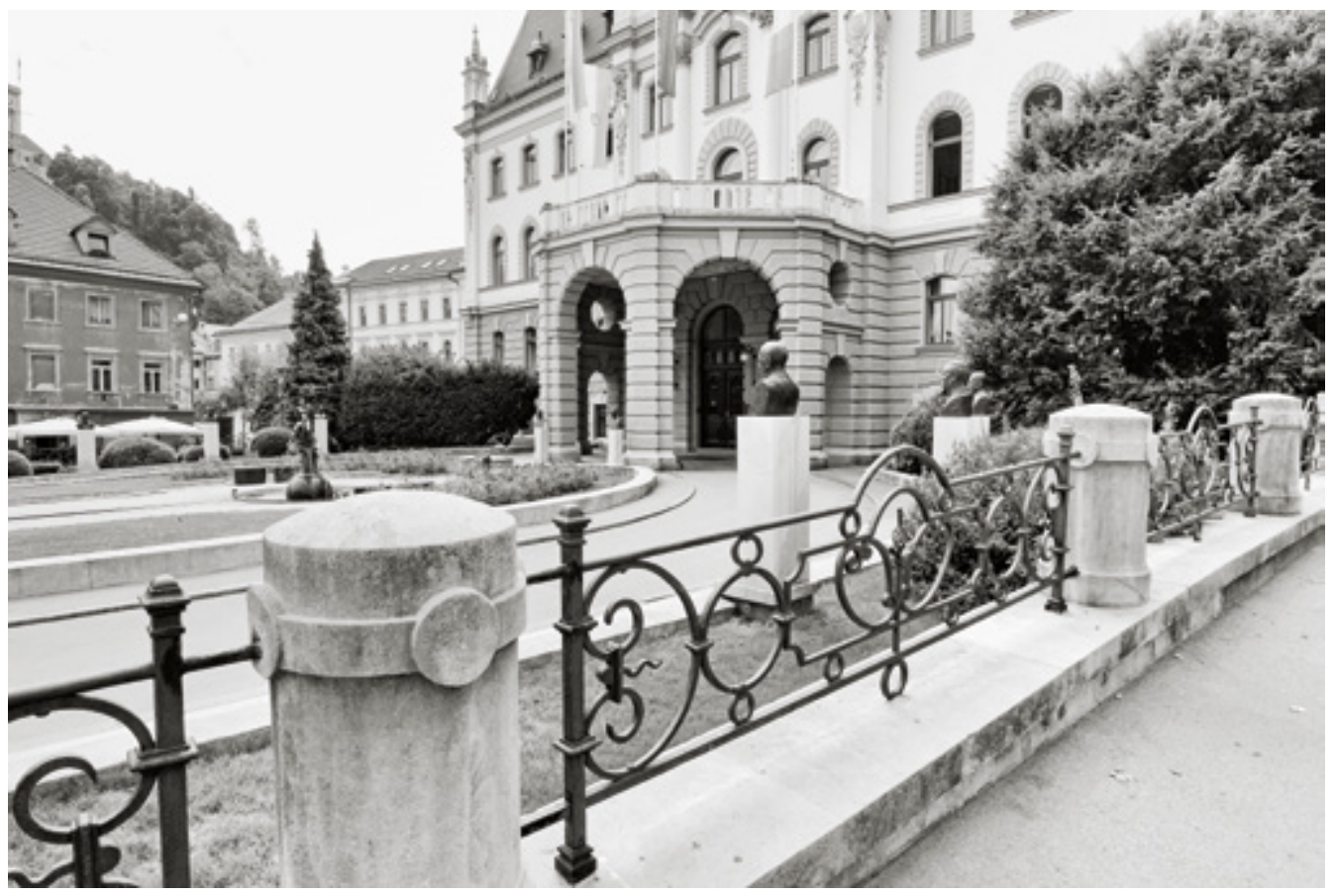

Abb. 9: Büsten vor dem Universitätshauptgebäude, 1969-2012, Laibach. 
Seine Halbfigur ist ein Werk des Bildhauers Franc Gorše (I897-1986). In der Zeit des Kongresses der Slawistischen Gesellschaften 196r in Laibach wurden noch drei Büsten slowenischer Slawisten von dem Bildhauer Boris Kalin (1905-1975) errichtet: France Kidrič (I880-1950), Rajko Nahtigal (I8771958) und Fran Ramovš (I890-I952). ${ }^{48}$

\section{B ÜSTEN VOR DEM UNIVERSITÄTSHAUPTGEB ÄUDE: "ONGOING PROJECT"}

In Laibach gibt es mehrere einzelne Gelehrtendenkmäler, am häufigsten ist ihr Standort mit einzelnen Fakultäten in der unmittelbaren Umgebung verbunden. Die wichtigste Reihe aus der Zeit nach dem Zweiten Weltkrieg befindet sich vor dem Hauptgebäude der Universität, das am Ende der Vegovastraße mit der Hauptfassade zum Kongressplatz steht (Abb. 9). Mit dieser Gelehrtengalerie, auf dem teilweise eingezäunten Platz und in Form des Halbkreises angelegt, wurde in der Vegovastraße Plečniks Konzept für die Denkmäler im öffentlichen Raum nicht mehr weiterentwickelt. Bis heute wurden acht Büsten errichtet, die nicht nach einem einheitlichen inhaltlichen Entwurf entstanden sind. ${ }^{49}$ Die Auswahl der mit einem Denkmal geehrten Personen bzw. Wissenschaftler war (und ist) vor allem von dem jeweiligen Rektor abhängig. ${ }^{50}$ Zum 50-jährigen Gründungsjubiläum der Universität 1969, als die ersten Statuen ihren Platz vor dem Universitätsgebäude bekamen, wurde festgelegt, dass nur „die Personen, die für die Universitätsgründung verdienstvoll waren",, ne Statue direkt vor dem Hauptgebäude bekommen könnten. Damit wurde auch auf die ursprüngliche Idee verzichtet, vor der Universität das Denkmal des berühmten slowenischen Mathematikers Jurij Vega (I754-I8O2) zu errichten und sich enger an die Auffassung der Vegovastraße als Gelehrtenareal Laibachs zu halten. Vega bekam schließlich seinen Ehrenplatz vor der Elektrotechnischen Fakultät. ${ }^{52}$ Die letzte Büste (für den Maler Božidar Jakac (I899-I989), den ersten Rektor der 1945 gegründeten Akademie der bildenden Künste, von Drago Tršar) wurde erst 2012 enthüllt.

Gerade der Einfluss bzw. das Primat der Politik über die Wissenschaft zeigte sich in der Geschichte der Universität insbesondere an zwei Denkmälern. In der Universitätsaula stand die Statue von König Alexander I. Karadjordjević, das Werk des Bildhauers Nikolaj Pirnat (19031948), errichtet $1935 .{ }^{53}$ Die zentrale Position vor dem Gebäude nahm ab 1979 das Denkmal des wichtigsten slowenischen kommunistischen Politikers Edvard Kardelj ein, das noch im Jahr seines Todes enthüllt wurde (beide waren $\mathrm{Na}$ mensgeber für die Universität). Dem Typus nach war das Denkmal von Kardelj eines von wenigen (wie Prijatelj vor der National- und Universitätsbibliothek), das nicht nur eine Büste, sondern eine Halbfigur zeigt (Abb. Io). Obgleich die Mehrheit der Denkmäler von Politikern des kommunistischen Regimes, Kidrič und Kardelj, nach der Selbständigkeit Sloweniens I99I auf ihrem Platz geblieben ist, wurde das Denkmal

48 Š. Čopič/D. Prelovšser/S. Žıtro, Outdoor Sculpture (zit. Anm. 46), S. 34, Nr. 30.

49 Eine Studie zu den Gelehrtendenkmälern mit einer genaueren Analyse der Büsten vor dem Universitätshauptgebäude und in der Slowenischen Akademie der Wissenschaften und Künste ist in Vorbereitung.

so A. Benedetič, Postavljanje in odstranjevanje spomenikov, in: Delo, XXXIV/264, I4. November 1992, S. 34.

5 I Ebenda.

52 Ebenda.

53 I. SteInER, Rektorji Univerze v Ljubljani/Rectores Universitatis Labacensis. I5. rektor. Dr. Maks Samec, in: J. CiperLE, T. DekLeva, T. AnžUr, I. SteIner, Univerza in njeni rektorji, Ljubljana 2006, S. 22. 


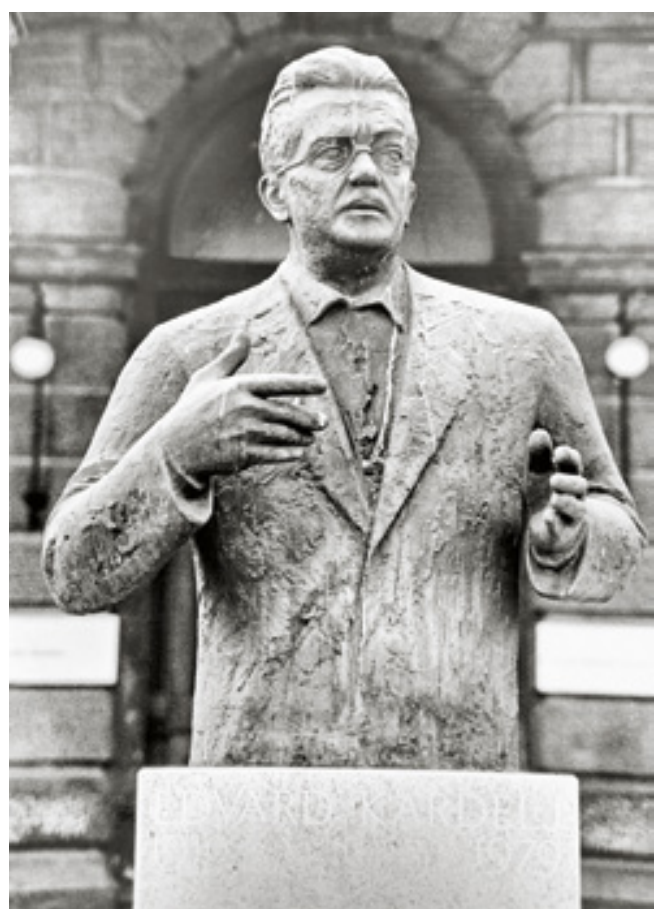

Abb. Iо: Zdenko Kalin, Edvard-Kardelj-Denkmal vor dem Universitätshauptgebäude, I979, Bronze, Laibach, entfernt.

bereits im September 1990 von seinem Standort vor der Universität entfernt. ${ }^{54}$ In der Mitte der Anlage errichtete die Stadt Laibach 1992 mit dem Raub von Europa ein Werk des Bildhauers France Kralj (eine Stiftung von dessen Sohn
Zlat), eines Künstlers der unter dem kommunistischen System besonders gelitten hatte. 5

Diese Beispiele zeigen, wie deutlich politische und historische Strömungsänderungen im öffentlichen Raum wahrnehmbar sind, wie sehr sich Systemwechsel tatsächlich im Entfernen oder Aufstellen von Kunstwerken äußern und wie sehr die Aufstellung von Denkmälern bzw. die Auswahl der auf diese Weise Geehrten nach einem nachvollziehbaren Konzept von den unterschiedlichsten Interessen und der Durchsetzungsstärke ihrer Vertreter abhängig ist. Die Gelehrtendenkmäler, ihre Auswahl und Transformationen veranschaulichen nicht nur die Bedeutung einzelner Wissenschaftler, sondern insbesondere auch ihre jeweilige (politische) Rezeption. ${ }^{56}$

Abbildungsnachweis: Abb. I, 2: Umetnostnozgodovinski inštitut Franceta Steleta ZRC SAZU, Ljubljana (Foto: Ana Lavrič); Abb. 3-9: Umetnostnozgodovinski inštitut Franceta Steleta ZRC SAZU, Ljubljana (Foto: Andrej Furlan); Abb. Io: Arhiv in muzej Univerze v Ljubljani, Ljubljana.

54 Benedetič, Postavljanje (zit. Anm. 50), S. 34.

55 I. Kranjc, Zbirka v Kostanjevici na Krki, domovanje umetnosti Franceta Kralja. Prispevek ob donaciji petdesetih del iz zapuščine umetnikovega sina Zlata/Collection at Kostanjevica na Krki, a Home for the Art of France Kralj. A Contribution to Commemorate the Donation of 50 Works from the Estate of the Artist's Son Zlat, in: France Kralj. Donacija/Donation 20I3. Zlat/Jasna Kralj (Ausstellungskatalog Kostanjevica na Krki, Galerija Božidar Jakac), Kostanjevica na Krki 20I4, S. 82-IO3 (Kapitel: Izvor originalne umetniške oblike in njena usoda v časih enoumja/The Origin of the Original Artistic Form and Its Fate in a Time of Single-Mindedness).

56 Der Text wurde im Rahmen des Forschungsprogramms Slovenian Artistic Identity in European Context am France Stele Institut für Kunstgeschichte des Forschungszentrums der Slowenischen Akademie der Wissenschaften und Künste erarbeitet. Für die Einladung und Bereitschaft, auch slowenische Gelehrtendenkmäler in den Sammelband einzubeziehen, sei Prof. Dr. Ingeborg Schemper-Sparholz und der Forschungsgruppe Ge(l)ehrte Köpfe gedankt. Der Aufsatz wurde durch Gespräche mit meinen Kollegen Vesna Krmelj und Dr. Ana Lavrič sowie Hilfe in mehreren Institutionen, wo die Dokumentation über die Denkmäler aufbewahrt wird, bereichert, vor allem durch das Universitätsarchiv und Museum der Universität Ljubljana (Tatjana Dekleva, Tea Anžur), die Dokumentationsabteilung der Modernen Galerie (Jana Intihar Ferjan) und die Bibliothek des Slowenischen Nationalmuseums. Insbesondere verpflichtet bin ich Andrej Furlan für die Vorbereitung der Fotografien und Anke Schlecht für die Verbesserung des deutschen Textes, die viel mehr als reine sprachliche Korrekturen war. 


\title{
FRANTIŠEK PALACKÝ IM PRAGER PANTHEON UND AUF DEM PLATZ*
}

\author{
Martin Krummholz
}

\section{M PA N THEON STEHEN D}

Um die Entstehung des tschechischen Nationalmuseums ${ }^{1}$ im Jahr I8I8 machte sich maßgeblich der Historiker, Politiker und führende Initiator der Erneuerung des tschechischen Kulturlebens und des Nationalselbstbewusstseins, František Palacký, (I798-1876) verdient. ${ }^{2}$

Als Zentralraum im Neorenaissance-Neubau des Nationalmuseums, das man in den Jahren 1885 bis 1890 nach Entwurf des Architekten Josef Schulz in der oberen Achse des heutigen Wenzelsplatzes anstelle des 1875 abgerissenen Rosstors baute, entstand das sogenannte Pantheon (Abb. I). Dieser durch die zentrale Kuppel ausgeleuchtete Festsaal ist mit skulpturalen Porträts der prominenten Persönlichkeiten der böhmischen Geschichte und der patriotischen Elitenmitglieder des I9. Jahrhunderts ausgeschmückt. Verspätet errichtete man hiermit in Prag ein tschechisches Nationalheiligtum im Geiste der europäischen Romantik des 19. Jahrhunderts. Obwohl sich dessen Bezeichnung zu den französischen Aufklärungsidealen bekennt, war die ursprüngliche Inspiration des böhmischtschechischen Pantheons die bayerische Walhalla (fertiggestellt I842). Schon im Jahr I837 beabsichtigte der Grundbesitzer und Mäzen Anton Veith (I793-I853), ein Förderer der romantisch patriotischen Tendenzen, auf seinem mittelböhmischen Gutsbesitz in Tupadly bei Liběchov eine Ruhmesstätte (Slavin) mit den plastischen Bildnissen der bedeutendsten Persönlichkeiten der tschechischen Geschichte zu errichten. Im Jahr I845 beauftragte Veith den Münchener Bildhauer Ludwig von Schwanthaler (I8O2-I848) mit der Anfertigung von insgesamt 2I Statuenmodellen. Jedoch führte der Künstler bis zu seinem Tod nur acht von diesen historisierenden Figuren aus. Deren Bronzeabgüsse (I847-I867) schmücken heute das Eingangsvestibül und das Stiegenhaus des Nationalmuseums. ${ }^{3}$

František Palacký, der jahrelang als Geschäftsführer der Gesellschaft des Patriotischen

* Dieser Aufsatz entstand im Rahmen des Projektes Stopy tvorby. Dědictví velkých sochařů první poloviny 2o. století. Restaurování a péče o sochařské památky ze sádry (NAKI, 2016-20I9, reg. Nr.: DGI6Po2Bo52) dank der Unterstützung des tschechischen Kulturministerium (Ministerstvo kultury ČR).

I Ursprünglich Vaterländisches/Patriotisches Museum in Böhmen, seit I848 Böhmisches Museum, I854-I9I9 Museum des Königreichs Böhmen.

2 František Palacký, in: ÖBL I815-I950, Band. 7 (Lfg. 34, I977), S. 294 ff.; J. STAIF, František Palacký. Život, dílo, mýtus, Praha 2009.

3 Zur Museumsgeschichte: V. Denkstein, Vývoj a koncepce Panteonu a umělecké výzdoby Národního muzea v Praze v 19. století, in: Časopis Národního muzea. Historické muzeum, CXLII, 1973, S. 65-87; L. SRŠEň, Budova Národního muzea v Praze I89I/I99I. Architektura, umělecká výzdoba a původní uměleckořemeslné vybavení, Praha I99I. 


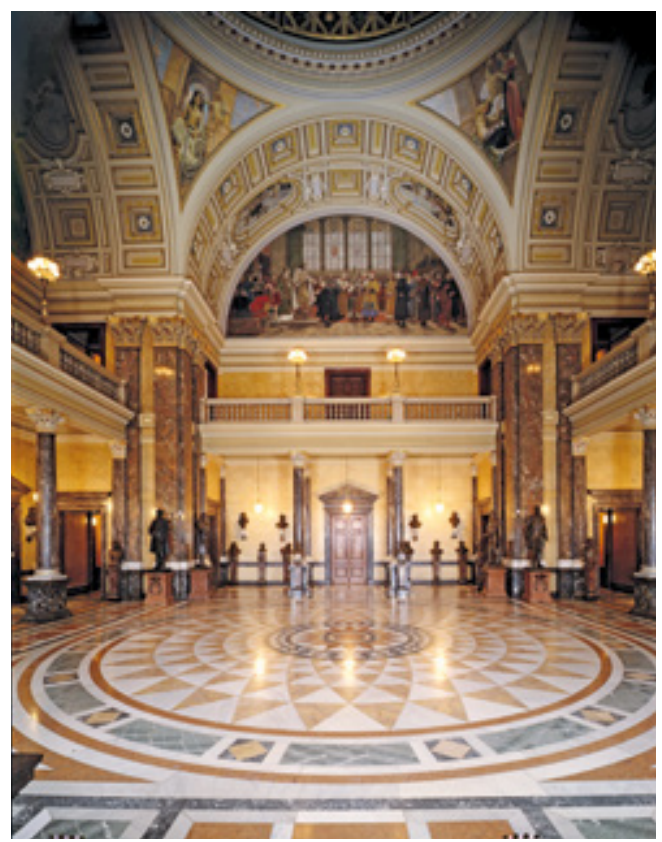

Abb. I: Pantheon des Prager Nationalmuseums.

Museums (damals im Palais Nostitz am Graben residierend) wirkte, formulierte schon in den Jahren I839/I842 den Vorschlag, einen neuen, repräsentativen Monumentalbau zu errichten, der zu Ehren des kurz vorher verstorbenen
Kaisers Franz II./I. Francisceum genannt werden sollte. In diesem sollten die wichtigsten nationalen Kulturinstitutionen samt Patriotisches Museum untergebracht werden. Gerade Palacký rechnete schon damals mit „einer Art von böhmischer Walhalla“, die er sich als einen zweistöckigen, von oben beleuchteten, kreisrunden Saal mit plastischen Porträts der größten Söhne der Nation - im Sinne eines Ehrentempels - vorstellte. Seiner Idee nach sollte es sich aber nicht um ein traditionelles Ensemble historisierender Figuren der Herrscher und anderer hervorragender Persönlichkeiten der böhmischen Geschichte handeln, sondern um einen Zyklus, der auch die Schlüsselvertreter der böhmischen Wissenschaften, Kunst und Kultur umfasst. Die ursprüngliche, großzügige Vision Palackýs wurde schließlich auf die Verwirklichung eines Reiterdenkmals des Kaisers auf dem neu errichteten Altstädter Kai beschränkt. Das eigene Museumsgebäude wurde am Kopf des Wenzelsplatzes erst ein halbes Jahrhundert später ausgebaut (Abb. 2). ${ }^{4}$

Die Bedeutung des Pantheons als ein Festsaal des Nationalmuseums unterstrich dessen prominente Platzierung unter der zentralen

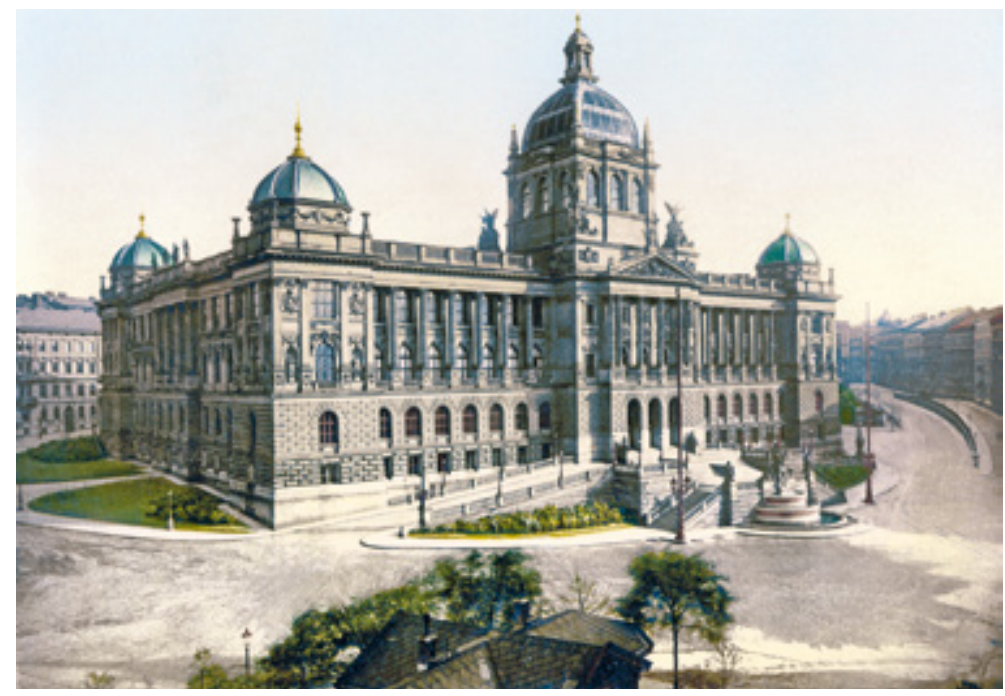

Abb. 2: Josef Schulz, Prager Nationalmuseum, I885-1890, Gesamtansicht.

4 Der Museumsbau wurde vom Böhmischen Landtag finanziert und mittels Landesausschuss geleitet. 


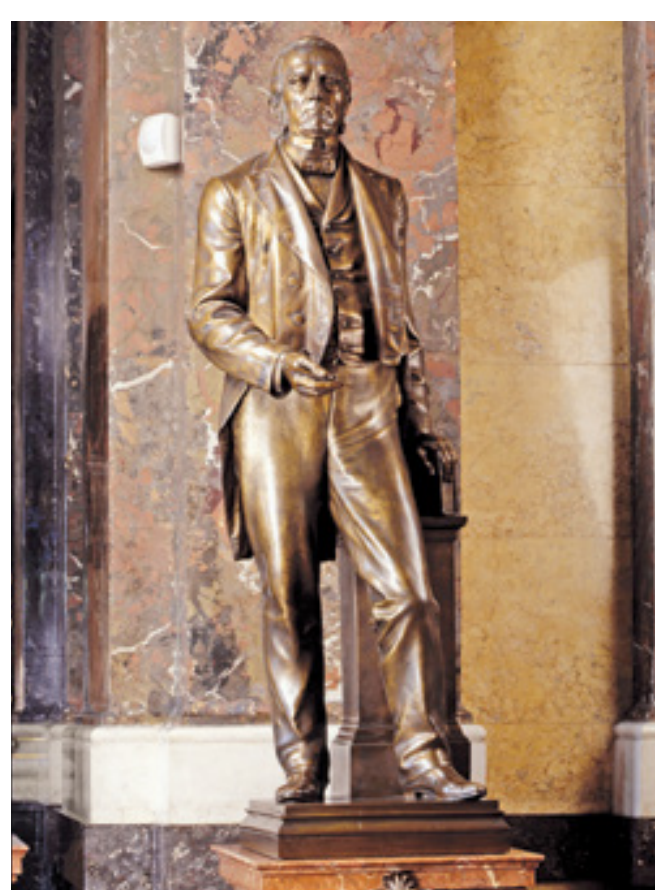

Abb. 3: Statue des František Palacký im Pantheon, Antonin Popp, 1897 .

Kuppel in der Fassadenmitte. Neben der aufwendigen künstlerischen Ausschmückung sowie der fortschrittlichen elektrischen Ausstattung (aus den Jahren I890/I89r!) ist die Tatsache auffallend, dass einzig dieser Raum „des NationalHeiligtums“ bis zur zweiten Hälfte des 20. Jahrhunderts in der Zuständigkeit des Staates blieb: zuerst in der des Landesausschusses, dann des Bildungs- respektive Kulturministeriums.

Die ursprüngliche Interieurplanung des Architekten Schulz umfasste im Pantheon die Aufstellung von vier freistehenden Statuen sowie die Anbringung von I6 Büsten auf den Sockeln und I6 weiteren Büsten auf den Wandkonsolen. Im Dekorationskonzept des Gebäudes aus dem Jahr I893 betonte man die Differenzierung der ikonografischen Programme von Stiegenhalle (Geschichte der Nation) und Pantheon, für das man das Lob der tschechischen Kultur, Bildung und
Wissenschaft vorgesehen hatte. Nachfolgende langwierige Diskussionen bezüglich der Auswahl der Persönlichkeiten wurden - trotz zahlreicher Fachkomitee-Expertisen - kompliziert und erheblich politisch beeinflusst. Eine Reihe von deutlich protschechisch auftretenden Literaten, die heute als die prominenten Schöpfer der tschechischen Literatur des 19. Jahrhunderts gelten (Mácha, Tyl, Němcová, Borovský, Neruda u.a.), wurde a priori bei der Auswahl ausgeschlossen. Letztendlich vergab man in den Jahren I898 bis I90I den Auftrag der insgesamt 34 Büsten an die im Voraus ausgewählten Bildhauer Emanuel Halman, Antonín Popp, František Rous, Bohuslav Schnirch, František Stránský, Stanislav Sucharda, Ladislav Šaloun, Bohumil Vlček und Čeněk Vosmík. In der Mitte der Seitenwände befanden sich zwei Heißluftkamine mit den Marmorbildnissen des Kaiserpaares (beide Anton Wagner, Wien, I89I). Von den vier freistehenden Hauptfiguren des Pantheons wurden als Erstes die Statue des František Palacký (Abb. 3) und die des Johann Amos Komenius (beide Antonín Popp, I897) aufgestellt. Etwas später fügte man die zwei übrigen Gestalten hinzu: die des Grafen Heinrich von Clam-Martinic, Präsident der Museumsgesellschaft (Milan Havlíček, I898-1900), und die des Museumsgründers, Graf Kaspar Maria von Sternberg (Josef Kvasnička, 1900). Als einer der Schlüsselorte des tschechischen Nationalgedächtnisses veränderte sich das Pantheon mehrmals während der folgenden Jahre und Jahrzehnte. Die Veränderungen des politischen Regimes sowie der gesellschaftlichen Verhältnisse spiegelten sich auch in der Besetzung dieser „tschechischen Walhalla“ wider, die man nach den jeweiligen Bedürfnissen entweder ergänzte oder reduzierte.` Dennoch, „der Vater der Nation" - wie man František Palacký schon seit dem I9. Jahrhundert titulierte ${ }^{6}-$ überlebte alle Turbulenzen und verblieb bis heute stehend im Pantheon-Saal.

5 So z. B. entfernte man I9I8 die beiden kaiserlichen Büsten. SRšEň (zit. Anm. 2), S. 20.

6 So z. B. Ottův slovník naučný, Band I9, Praha 1902, S. 39. 


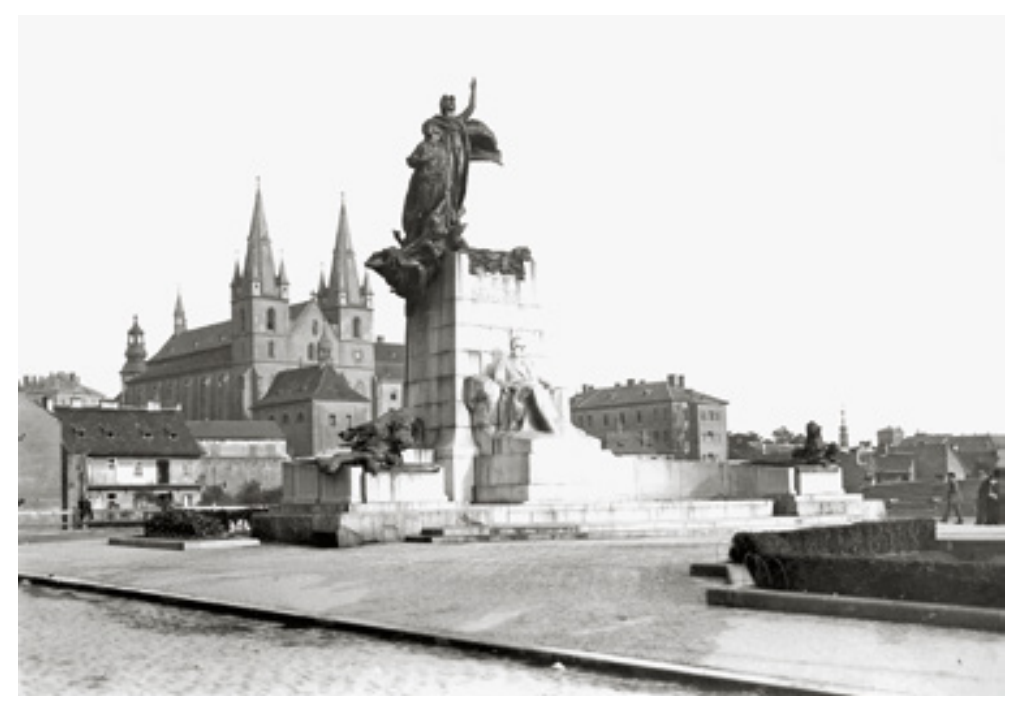

Abb. 4: Palacký-Denkmal kurz nach der Enthüllung.

\section{AUF DEM PLATZ SITZEND}

Während sich der Bau und die Ausstattung des Nationalmuseums als eine konsensuelle politische Angelegenheit dem korrekten, patriotischen Landes- Utraquismus unterordnen musste, begleiteten das etwa zeitgleich entstehende František-Palacký-Denkmal (Abb. 4) diametral gegensätzliche Umstände. Die Ursache dafür war die Tatsache, dass die Initiatoren im radikal protschechischen Prager Rathaus von Wien unabhängig waren. Das Palacký-Denkmal war eines der drei parallel entstandenen Prager Monumente, die man - in der Folge der gipfelnden nationalen Bewegung - in der Landeshauptstadt den wichtigsten Persönlichkeiten der tschechischen Geschichte widmete. Deren Realisierung akzentuierte die Bedeutung der tschechischen Geschichte und sollte so zugleich die aktuellen tschechischen Staatlichkeitsansprüche legitimieren. Besonders im Fall des Palacký-Denk- mals handelte es sich um ein höchst interessantes Kunstwerk, das in vielen Facetten die ehemaligen schwierigen - politischen wie künstlerischen -Verhältnisse anschaulich illustriert.

Die großen damaligen Denkmälerwettbewerbe stimulierten maßgeblich die Bildhauerinvention, die im Fall der tschechischen Künstler weiter durch eine intensive Suche nach einem spezifischen, von Wien und dem deutschen Milieu unabhängigen künstlerischen Ausdruck gefördert wurde. ${ }^{7}$ Die beiden, für die tschechische Bildhauerei um 1900 ausschlaggebenden Pole stellten die Namen Auguste Rodin und Josef Václav Myslbek dar. ${ }^{8}$ Myslbek (I848-1922) entwickelte sich zur herausragendsten Persönlichkeit der tschechischen Bildhauerei dieser Zeit: einem allgemein anerkannten Künstler und einem ungeheueren autoritären Professor, unter dem (fast ohne Ausnahme) mehrere Bildhau-

7 Z. Hojda/J. Pokorný, Pomníky a zapomníky, Praha/Litomyšl i996; K. Kuthanová/H. Svatošová (Hg.), Metamorfózy politiky. Pražské pomníky I9. století, Praha 2013.

8 P. Wittlich, Scuplture of Czech Art Nouveau, Praha 200 .

9 V. Volavka, J. V. Mylsbek, Praha 1942; P. Wiтtlich, České sochařství ve XX. století, Praha I978, S. I3-22; Z. DvořÁková, Josef Václava Myslbek: Umělec a člověk uprostřed své doby, Praha I979. 
ergenerationen studierten. Den charakteristischen Ausdruck Myslbeks nannte man „monumentalen Realismus".9 Das Werk von Auguste Rodin (I840-1917) und dessen essenzielle Bedeutung für die moderne europäische Bildhauerei braucht man an dieser Stelle nicht auszuführen. ${ }^{\text {IO }}$ Das tschechische Milieu konnte sich mit der Kunst Rodins erstmals in den Jahren 1900 und I902 unmittelbar bekannt machen. Im Jahr 1900 wurde ihm eine Ausgabe der Zeitschrift Volné Směry (Freie Richtungen) gewidmet und zwei Jahre danach fand in Prag eine große Ausstellung von Gipsabgüssen seiner Werke statt. Initiiert wurde beides von einem Zusammenschluss junger tschechischer Künstler und Intellektueller, dem Verein der bildenden Künstler Mánes, einem Partnerverein des Wiener Hagenbundes. Die bedeutenden Aktivitäten des Vereins begannen in den 9oer-Jahren des I9. Jahrhunderts, zeitgleich mit der kräftigen Abgrenzung gegen die vorangegangene sogenannte Nationaltheater-Generation. ${ }^{\text {II }} \mathrm{Zu}$ eben dieser Generation gehörte auch Myslbek. Von der im Sinne des Modernismus radikal gesinnten jungen Generation wurden die realistisch beschreibenden Kunstformen sowie das patriotische Sentiment und $\mathrm{Pa}$ thos als Zeichen des Provinzialismus kategorisch abgelehnt. Für die jungen tschechischen Künstler war es natürlich Frankreich, wohin man die Studienreisen unternahm und woher man die Inspiration schöpfte.

Der Bildhauer Stanislav Sucharda (I866I9I6) stammte aus der kleinen ostböhmischen Stadt Nová Paka (Neupaka), aus einer Familie, deren handwerklich-künstlerische Tradition bis ins Jahr 1790 zurückreicht. ${ }^{\mathrm{I2}}$ Das tschechisch-patriotische Familienmilieu sowie die einheimische Landschaft mit der alten Tradition der Sandsteinskulpturen prägten Suchardas Mentalität. Ein patriotischer (oder vielleicht national gesinnter) Aspekt war also seit Suchardas Kindheit präsent. Nová Paka war der letzte tschechischsprachige Ort in der sonst vollkommen deutschsprachigen Riesengebirge-Region. Sein Vater, der Bildhauer Antonín Sucharda (I843-I9II), gründete hier den zweitältesten Sokol-Gau (patriotisch-militärischer Turnverein) in Böhmen. An dem Bau sowie der Ausschmückung des neuen Familienhauses mit Atelier beteiligten sich in den 9oer-Jahren des 19. Jahrhunderts in Nova Paka alle Mitglieder der Sucharda'schen Familie: Eltern sowie alle Kinder. Im Rahmen eines gemeinsam durchdachten patriotisch-künstlerischen Konzepts bevorzugte man natürlich die sogenannte „tschechische Neorenaissance“- einen Stil, den die tschechische Intelligenz als ,angemessener" erachtet; im Gegensatz zum disqualifizierenden Neobarock, den man hier gewöhnlich mit der Tragödie am Weißen Berg, der Rekatholisierung und mit den Habsburgern verband. Es gab aber nicht nur solche rein ideellen Stereotypen: Die Beziehungen zwischen der tschechischen Umwelt und dem zentralistisch und antislawisch wirkenden Wien waren wirklich nicht freundschaftlich. Ein umso größerer Erfolg war es, als Sucharda im Jahr I892 - als frischer Absolvent der Prager Kunstgewerbeschule - beim Wettbewerb des Wiener Künstlerhauses für sein

io Z. B.: P. Wittlich, Auguste Rodin et la modernité tcheque, in: Opera Facultatis philosophicae Universitatis Carolinae Pragensis, I, 2006, S. II7-I37; M. Kuhlemann (Hg.), Vor Ioo Jahren. Rodin in Deutschland, München 2006; A. Husslein-Arco/S. Koja (Hg.), Rodin und Wien, München 2oro; D. Viéville, Rodin, les métaphores du génie, Paris 2014.

II D. h. gegen die an der Ausschmückung des Prager Nationaltheaters - eines wichtigen Symbols der tschechischen kulturellen Emanzipation - sich beteiligenden Künstler (vor allem Vojtěch Hynais, František Ženíšek, Václav Brožík und J. V. Myslbek).

I2 P. Wittlich, Scuplture of Czech Art Nouveau (zit. Anm. 6), S. I82-215; Martin Krummholz, Stanislav Sucharda (I866-I9I6), Nová Paka 2006; derselbe: Stanislav Sucharda, in: Österreichisches Biographisches Lexikon I815-1950, Band 63, Wien 20I2, S. 26-27; derselbe, Apoteóza národních hrdinů a českého pohanství. Pomníkové vize Stanislava Suchardy, in: Kuthanová/Svatošova (zit. Anm. 7), S. 76-94, 315-317 (deutschsprach. Zusammenfassung). 
Relief Das Wiegenlied (Ukolébavka) den goldenen Reichel-Preis bekam. Für seinen Professor Myslbek war es - in seinen eigenen Worten - eine größere Genugtuung als sein eigener Erfolg einer Silbermedaille in einem Pariser Salon einige Jahre zuvor. ${ }^{13}$ Dieser außergewöhnlich frühe Erfolg brachte Sucharda eine Assistentenstelle und später die Professur an der Prager Kunstgewerbeschule sowie eine Reihe von Aufträgen ein. Die Kunstgewerbeschule war damals viel progressiver als die eher konservative Prager Akademie. Zu den Kollegen Suchardas zählten da beispielsweise der Architekt Jože Plečnik (I8721957), mit dem Sucharda mehrmals zusammenarbeitete. ${ }^{I 4}$ Von wesentlicher Bedeutung war dort die Ankunft von Jan Kotěra (I87I-I923), der als junger Absolvent Otto Wagners I899 von Wien nach Prag kam, wo er zunächst eine Professur an der Prager Kunstgewerbeschule erhielt. Kotěra gilt zu recht als Bahnbrecher der modernen Architektur Böhmens. ${ }^{\text {Is }}$ Kotěra befreundete sich bald mit Sucharda, der mit ihm an mehreren bedeutenden Bauten als Bildhauer kooperierte. Kotěra entwarf auch das zweite Prager Wohnhaus (1904-1906) Suchardas mit dem Atelier, in dem das Palacký-Denkmal entstand. Und gerade Kotěra und Sucharda waren die gemeinsamen Initiatoren der wichtigsten Aktivitäten des Mánes-Vereins in der ersten Dekade des 20. Jahrhunderts.

Im Vorstand dieses Vereins war Stanislav Sucharda länger als zwölf Jahre tätig. Paradoxerweise führte er also eine Opposition gegen Myslbek, aus dessen Schule er selbst als Künstler hervorgegangen war. Der frühe Erfolg des Wiegenlied-Reliefs und damit die Brandmarke des „rein tschechischen, lyrischen Ausdrucks“ empfand Sucharda, besonders im Mánes-Milieu, als eine immer größere Bürde. Denn sein Stil wandelte sich um die Jahrhundertwende grundsätzlich infolge der Begegnung mit dem lockeren und leidenschaftlichen Duktus von Auguste Rodin. Die bisherige Unbeweglichkeit wurde von Dynamik und Leidenschaft, tschechische Volkstrachten von nackten Körpern, klare Konturen von skizzenhaften Zeichnungen abgelöst.

Hinsichtlich der ungefälligen Stellung Wiens gegenüber den Forderungen der tschechischen Eliten spielte der pro-tschechische Prager Stadtrat die Rolle einer tschechischen Quasi-Ersatzregierung. So war es die Stadt Prag, die die Entstehung von zwei der insgesamt drei bereits erwähnten größten „tschechischen“ Denkmäler initiierte. Nur das erste, das des Heiligen Wenzelslaus (Wenzelsplatz, ehem. Rossmarkt), war ein Staatsauftrag, mit dem man den zuverlässigen Myslbek betraut hatte. Die zwei folgenden, jenes des „Nationalhelden und Märtyrers“ Jan Hus (an einer programmatischen Prestigelokalität des Altstädter Rings) und schließlich jenes des František Palacký, ${ }^{16}$ entstanden als städtische Aufgaben parallel und unter dem Einfluss ähnlicher Umstände. Im Kontext der europäischen Denkmalproduktion stellen diese zwei Prager Monumente eine gewisse, die Grundregeln der Monumentalität verletzende Anomalie dar. Eine extrem dynamisierte Komposition in beiden Fällen (beim Hus-Denkmal sowie bei Palacký) belegt einerseits die Faszination für Rodin, andererseits eine programmatische Negation des Kunstgeschehens im deutschsprachigen Raum. Stattdessen prägte sich die moderne tschechische Kunst (mit dem Mánes-Verein im Kopf) ganz kategorisch aus. Jede Verbindung,

I3 Brief des J. V. Myslbek an Josef Supecký, I6. April I892, Archiv Národní galerie v Praze, Sign. AA 775/63.

I4 D. Prelovšek, Josip Plečnik. Život a dílo, Brno 2002; M. Krapež/D. Prelovšek (Hg.), Architect Jože Plečnik (I872-I957), Ljubljana 2008.

I5 V. Šlapetka (Hg.), Jan Kotěra. The Founder of Modern Czech Architecture I87I-1923, Prague 2003.

I6 Das vierte kolossale Denkmal Prags, des hussitischen Heerführers Jan Žižka, wurde zwar auch seit Ende des I9. Jh. beabsichtigt. Die Realisierung dieses Monuments hat sich jedoch lange Zeit geschleppt, enthüllt wurde es erst im Jahr 1950. Siehe dazu: P. Wittlich, Bohumil Kafka (I878-I942). Př́iběh sochaře, Praha 2014. 
jede Kommunikation mit deutschen, österreichischen oder Wiener Künstlern oder deren Stilen (außer in der Architektur) war für einen protschechischen Künstler a priori disqualifizierend. Stanislav Sucharda selbst wurde im Sommer 1907 in der tschechischen Presse Opfer solcher übler Kampagnen, deren Ursache es war, dass er - respektive der Mánes-Verein - nicht sofort und entschieden eine Initiative des in Wien gegründeten Künstlerverbandes österreichischer Bildhauer ablehnte. Dies betrachtete der Tschechische Nationalrat als „Verrat an den nationalen Interessen ". Sucharda war aber mit mehreren Wiener Künstlern befreundet, der Mánes-Verein kooperierte intensiv vor allem mit dem Wiener Hagenbund. Im Kontext der national verschärften Beziehungen ist Suchardas Freundschaft mit dem erfolgreichsten deutsch-tschechischen Bildhauer Franz Metzner höchst signifikant. Sucharda beobachtete sehr sorgfältig Metzners Werk, das er auch hoch schätzte. „Schade, dass man es hier nicht laut sagen kann ..." - liest man in Suchardas Tagebuch. ${ }^{17}$

Im Gegensatz zu Karl IV., dem heiligen Wenzelslaus und Jan Hus handelt es sich im Fall von František Palacký (1798-I876) um einen relativ „jungen“ Einwohner der tschechischen Ruhmeshalle. Palacký war zweifelsohne der bedeutendste tschechische Politiker des I9. Jahrhunderts, ein führender Historiker und wichtiger Initiator der Gründung der zentralen nationalen Kulturinstitutionen, u.a. des Nationalmuseums und des Nationaltheaters. Im Revolutionsjahr I848 lehnte Palacký als der wichtigste tschechische Politiker die Teilnahme an der Frankfurter Nationalversammlung (und den Anschluss slawischer Gebiete an ein Deutsches Reich) ab. Eines seiner Hauptwerke stellt die fünfbändige Geschichte von Böhmen (erst auf Deutsch, dann Tschechisch herausgegeben) dar, die er mit höchster wissenschaftlicher Erudition und Akribie schrieb. Für seine großen Verdienste wurde František Palacký

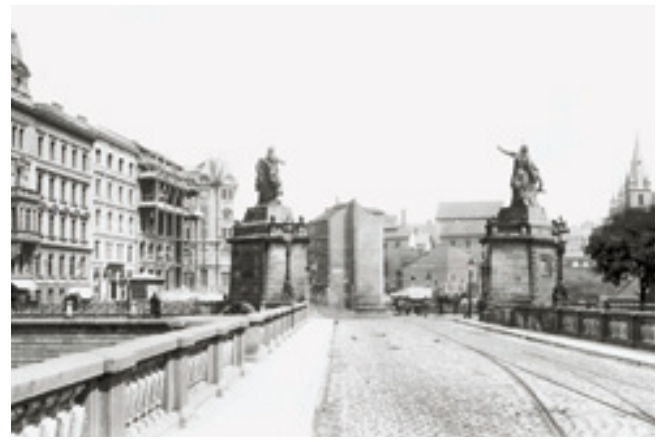

Abb. 5: Ostteil der Palacký-Brücke mit dem künftigen Palacký-Platz, Ende des I9. Jahrhunderts.

- neben Kaiser Karl IV. (dem „Vater der Heimat") - als „Vater der Nation“ verehrt. Seine Doppelprofession als Historiker und als Politiker spiegelte sich auch in der Gestalt seines Denkmals. Hier verknüpft der Künstler diese genannten Aspekte mit dem damaligen Nationalismus, den Antagonismen zu Wien und last but not least mit der eindeutigen stilistischen Orientierung an Rodin.

Die Idee des František-Palacký-Denkmals tauchte kurz nach dem Tod des Politikers (I876) auf: $\mathrm{Zu}$ seinen Ehren wurde I878 eine neue, die Prager Neustadt mit dem industriellen Vorort Smíchov verbindende Brücke nach ihm benannt (Abb. 5). An deren Brückenkopf sollte im Rahmen der laufenden Uferregulation ein neuer Platz entstehen. Auf diesem, damals aber noch nicht existierenden Platz (es war tatsächlich noch lange Zeit eine riesige Baustelle) legte man im Sommer 1898 - „vor den Augen aller Slawen“ (in Anwesenheit der Delegationen aus anderen slawischen Ländern) - den Grundstein. Die ungünstige Lage dieser Lokalität gab während der folgenden I5 Jahre Anlass zu verschiedensten Polemiken.

In der ersten Runde des Wettbewerbs für das Palacký-Denkmal (I898) bewertete man zwei Entwürfe, und zwar denjenigen Suchardas (gemeinsam mit dem Architekten Alois Dryák)

I7 Aus dem Privatnachlass von Stanislav Sucharda - unsortiert. 


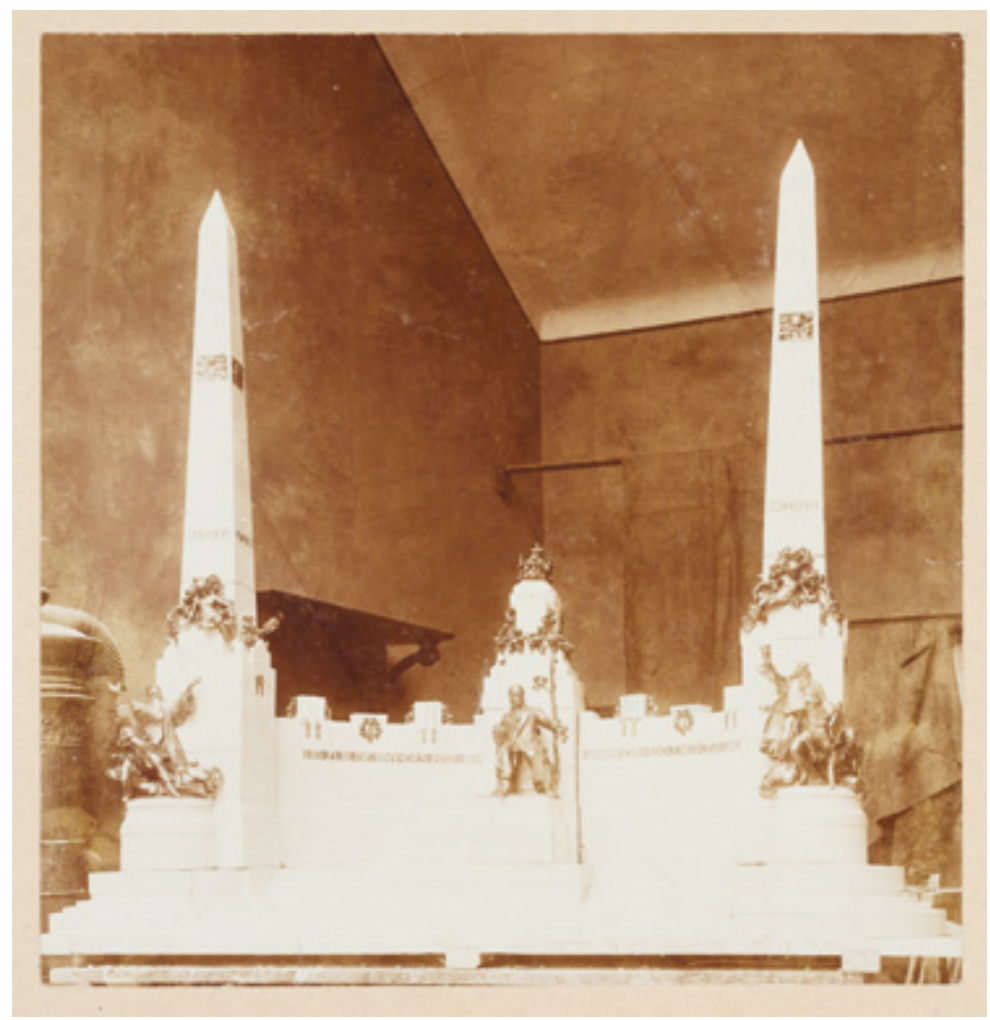

Abb. 6: Stanislav SuchardalAlois Dryák, Erster Entwurffür das Palacký-Denkmal, I898.

und denjenigen von Ladislav Šaloun (mit dem Architekten Alois Dlabač). Beide trafen einander fast gleichzeitig auch im Wettbewerb des JanHus-Denkmals, das letztlich Šaloun realisierte. ${ }^{18}$ Während Šaloun 1898 eine eher konservative zentralisierte Kombination mit einem Obelisken vorlegte, präferierte Sucharda eine bipolare Exedrakomposition mit zwei Seitenpylonen (Abb. 6). Die Mitte akzentuierte er mit einem von einem Politiker gehaltenen Lindenast unter der böhmischen Wenzelskrone (die Linde gilt als tschechischer Nationalbaum). Vor den beiden Obelisken befanden sich zwei dynamisch aufgefasste Figuralgruppen: das tschechische $\mathrm{Hei}$ dentum und das Hussitentum - also zwei allegorisch dargestellte historische Perioden, in denen
Suchardas Meinung nach die Nation den größten Aufstieg genoss. Auf die hintere Exedraseite - die der Bildhauer selbst als "großen architektonischen Ballast" empfand - platzierte er die Reliefs mit Szenen aus der tschechischen Geschichte, die Sucharda, der u.a. ein Erneuerer der tschechischen Medaillenkunst war, später in dem intimen Maßstab als separate Plaketten behandelte. Das einzige dreidimensionale Element hier war die Gruppe der Geschichte, die als eine erzählende weibliche Figur mit einem Jungen dargestellt ist. Die atypische bipolare Komposition des Denkmals reagierte auf die asymmetrische Lage des Ortes (Abb. 7), denn die Brücke trifft nicht rechtwinkelig auf den Kai und dadurch auch nicht axial auf den Platz. Stattdessen

I8 P. ŠámaL, Od podobizny k podobám symbolu. Pomníková tvorba Ladislava Šalouna do první světové války, in: Kuthanová/Svatošová (zit. Anm. 7), S. 95-IO5. 


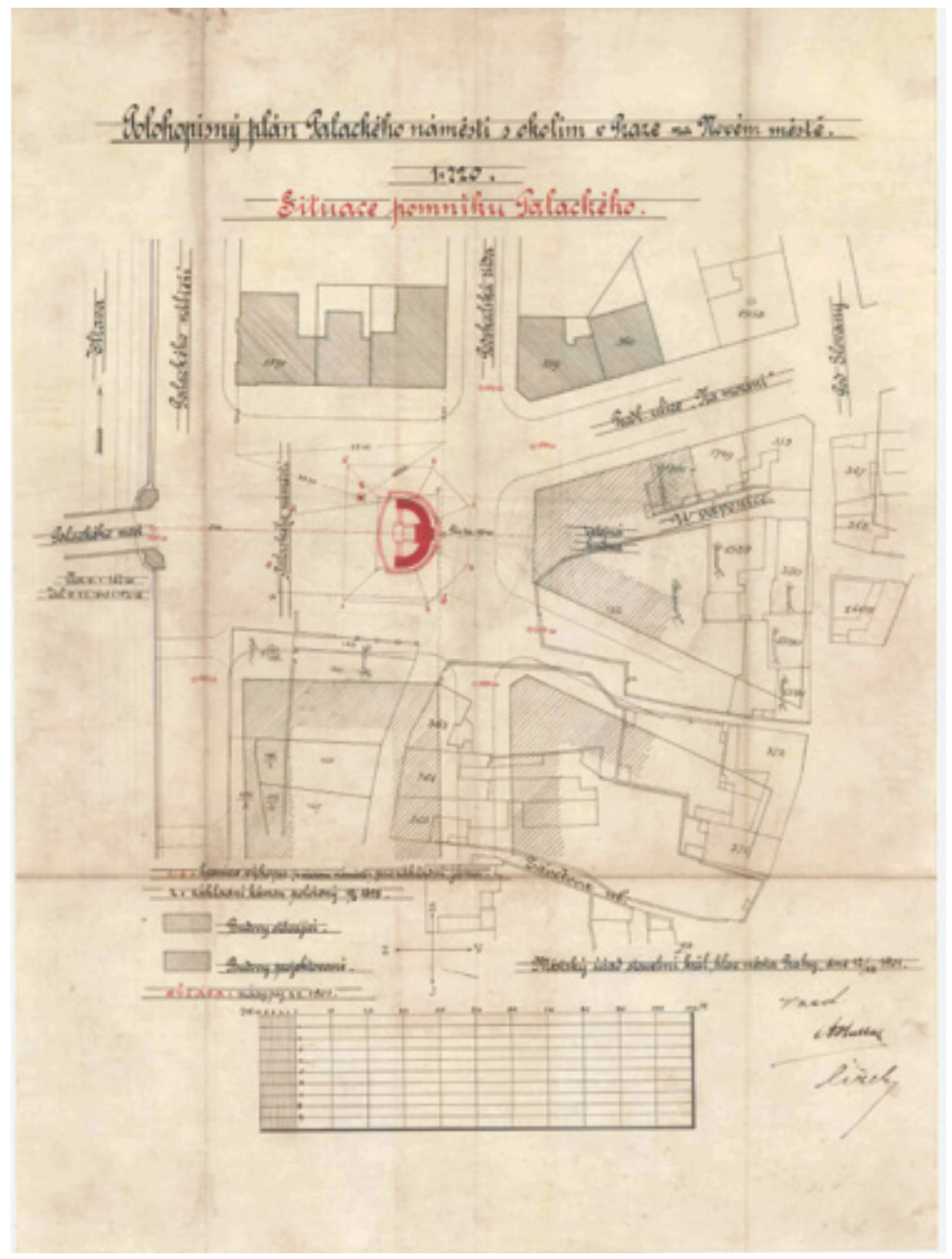

Abb. 7: Ursprünglicher Regulierungsplan des künftigen Palacký-Platzes aus dem Jahr I9oI.

bildet der linke Obelisk einen Punkt auf der verlängerten Brückenachse.

In der für den zweiten Wettbewerb (I9OI) vorgelegten Fassung (bezeichnet als ,Der Erwecker der Nation'), die schließlich den Sieg davontrug, reduzierte Sucharda die architektonische Komponente radikal (Abb. 4). Sehr originell und mit einer einzigartigen Dynamik - eine Folge des Einflusses Rodins - ließ er den Historiker und Politiker Palacký mit den Ursachen sowie den Folgen seines Wirkens verschmelzen. Er schuf hiermit de facto ein Monument der tschechischen Nationalemanzipierung (oder der nati- onalen Wiedergeburt). Im Vergleich mit den bisher gewöhnlichen Denkmalkonventionen zeigt sich - unabhängig von qualitativen Urteilen Suchardas Lösung als höchst originell. Der vor dem zentralen Pylon sitzende Palacký (Abb. 8) ist die einzige in Stein realisierte Figur. Eine der Tradition widersprechende Ausführung der Hauptgestalt des Monuments in „minderwertigem" Material (d.h. nicht in Bronze) musste Sucharda vor dem Denkmalkomitee, das gegen diese Materialwahl war, hart verteidigen. Sucharda bemühte sich damit um eine Vereinheitlichung des Denkmals, denn der ursprünglich 


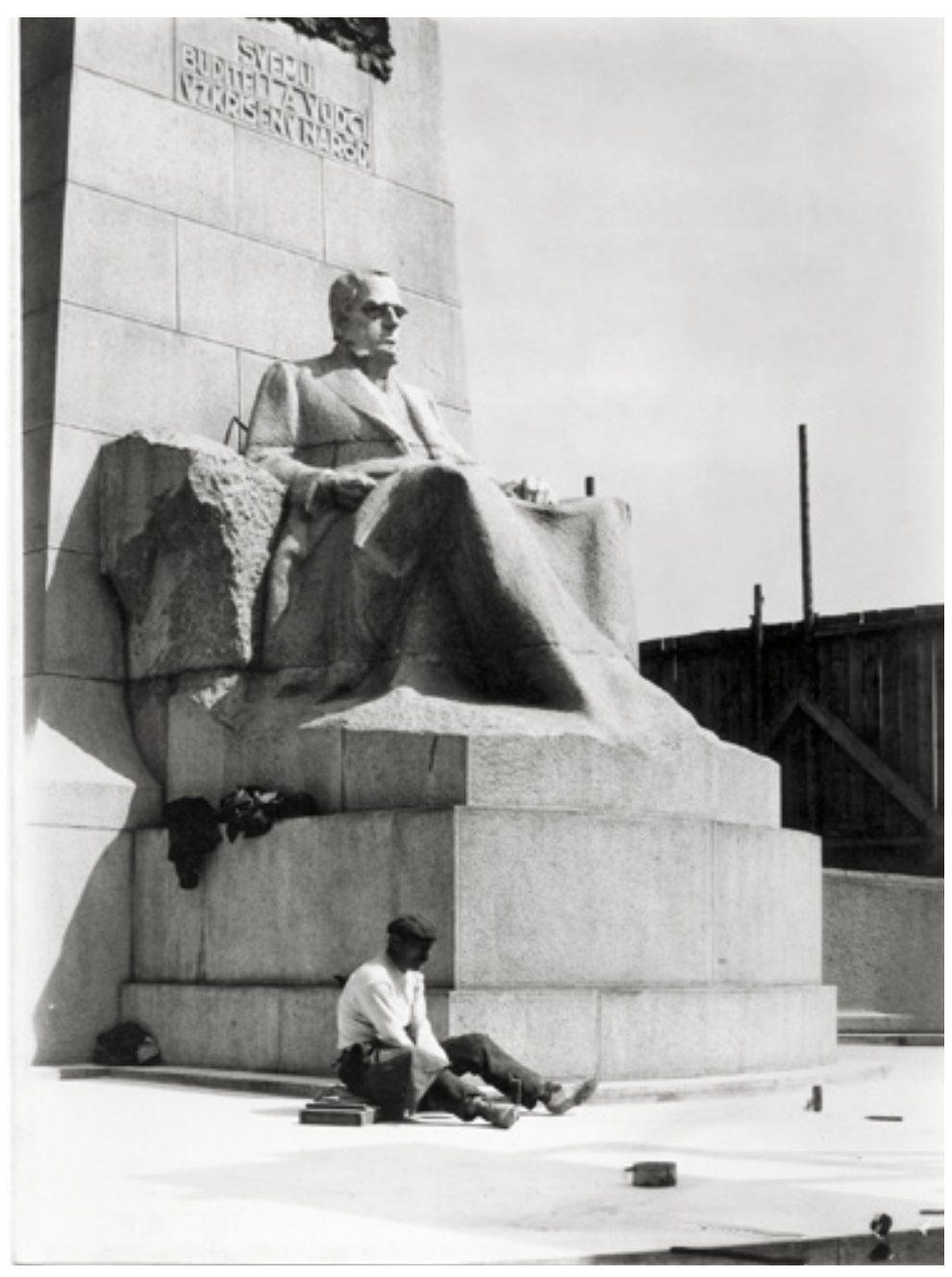

Abb. 8: Sitzender František Palacký, Monument-Detail, kurz vor der Vollendung.

bronzene Palacký riss (in Suchardas Worten) ein Loch ins Denkmal. ${ }^{19}$ Den Granit betrachtete er, aufgrund der von Mythen umwitterten böhmischen Berge, als den „tschechischsten“ (oder „ur-tschechischen“) Stein. Die Ruhe des überlebensgroßen, wie eine Sphinx im ewigen Nachdenken sitzenden Palacký, kontrastiert scharf mit der Dynamik der seitlichen Bronzefiguren. Diejenigen in der Front stellen die Ursprünge des Lebenswerkes des Historikers und Politikers dar. Direkt am Fuß des Sockels befindet sich die Allegorie der Schlacht am Weißen Berg (mit der fatalen Folge für die tschechische Staatlichkeit) - ein in Ohnmacht schlafender Genius der tschechischen Nation mit gebrochenen Flügeln. Die Unterdrückung (Abb. 9) der (tschechischen) Nation wird durch das zweiköpfige, von dem kaiserlichen Wappen abgeleitete Untier der Germanisation mit „deutschen“ Eichenlaubflügeln und „habsburgischer" Physiognomie dargestellt, das die tschechische Nation würgt. Das Gegenstück dieser Gruppe ist die Allegorie der tsche-

I9 S. Sucharda, Historie pomníku Fr. Palackého v Praze. K slavnosti odhalení vydal Stan. Sucharda, Praha I9I2, S. I7. 


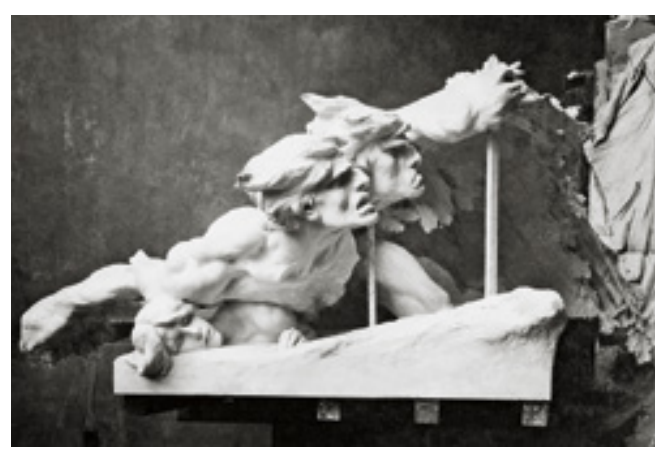

Abb. 9: Das Finalmodell der Unterdrückung in Suchardas Atelier in Prag-Bubeneć, I907. chischen nationalen Wiedergeburt: zwei liegende, männliche Akte, von denen sich einer bereits erhebt und sich in Richtung des nationalen Aufstiegs und der Emanzipation wendet. Der hintere, obere Teil des Denkmals allegorisiert „die Folgen“"von Palackýs Tätigkeiten als Historiker sowie als Politiker: Die erwachte Nation steigt in einer monumentalen Spirale hinauf zu einer Krönung ihrer Emanzipationsbestrebungen. Diese ist durch die Gipfelgestalt eines triumphierenden Genius der Nation dargestellt. Zusätzlich steht die Allegorie der Sehnsucht (nach nationaler Freiheit; ein Porträt der Tochter des Bildhauers)

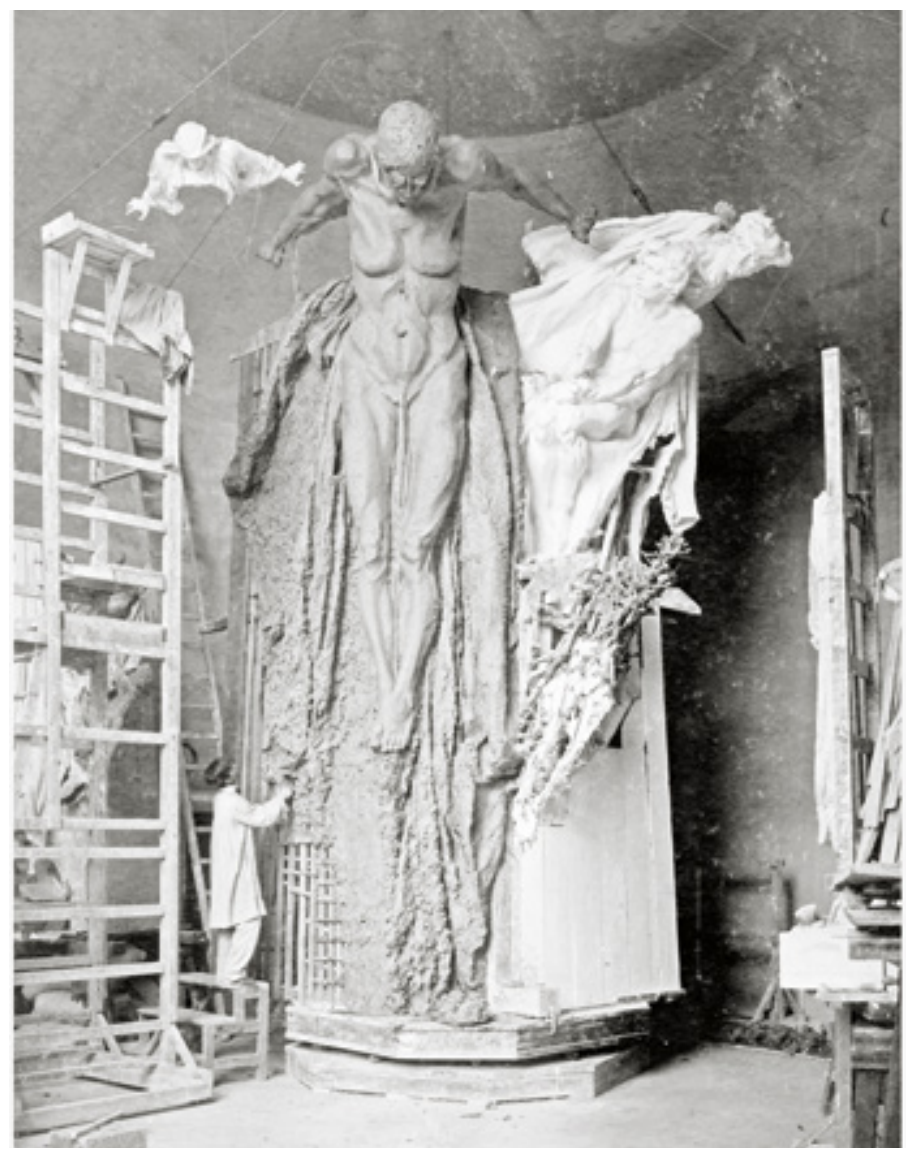

Abb. Iо: Das Finalmodell der Weissagerin in Suchardas Atelier in Prag-Bubeneć, 1907. 


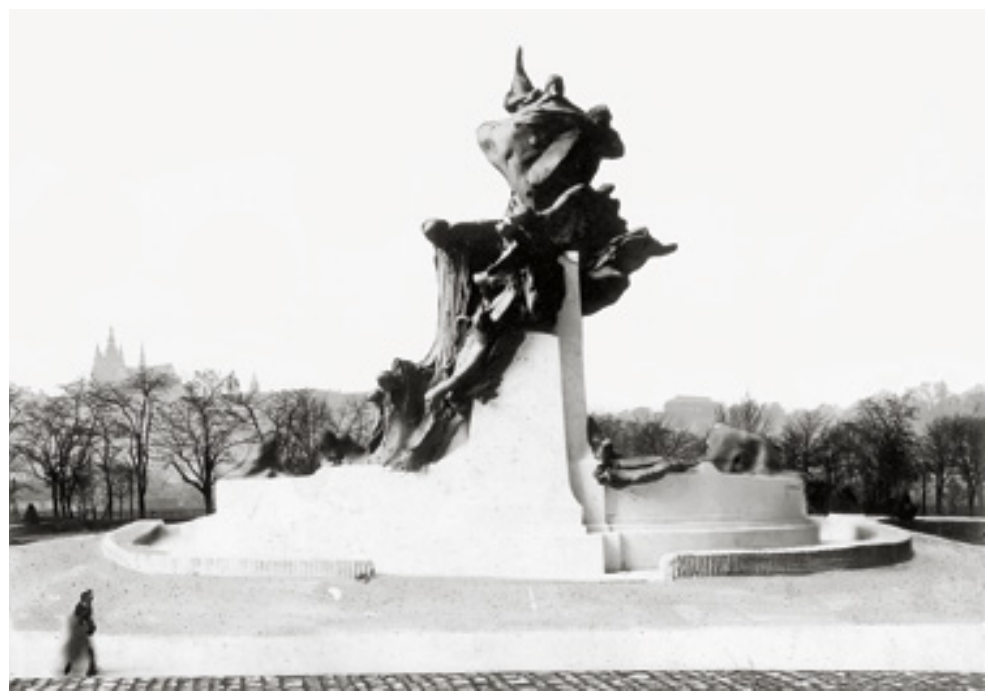

Abb. II: Stanislav Sucharda, fotografische Simulation der Platzierung des Palacky-Denkmals vor dem Rudolfinum (auf heutigem Palach-Platz), I906/1907.

für die Zukunft der jungen Nation: insbesondere die fünf Meter hohe Figur einer Weissagerin (Abb. Io), die eine weitere Paraphrase Suchardas Lieblingsmotivs der Geschichte/der Erzählungl des Unterrichtes darstellt. Am Fuße der Gipfelgruppe findet sich eine markante horizontale Gestalt des fliegenden, anrufenden Politikers. Diese Wiedergeburtsikonografie Suchardas ist vollkommen originell. Das Palacký-Denkmal ist aber hinsichtlich weiterer Aspekte ein merkwürdiges Werk.

Die asymmetrische Komposition reagiert analog zum ersten Entwurf aus dem Jahr I898 - auf die ungünstige Lage des Ortes (Abb. 7). Die nach links verschobene obere Gruppe (mit dem gerade erwähnten Politiker) wird in die Brückenachse gerückt. Das Gesamtkonzept sowie die Proportionen der monumentalen Figuren (Höhe 3-4,5 m) des Denkmals korrespondierten mit den Skulpturen der Palacký-Brücke (I887-I897) (Abb. 5). Dort standen bis Ende des Zweiten Weltkriegs vier Statuengruppen von J. V. Myslbek, die verschiedene Themen aus den tschechischen slawischen Mythen (einschließ- lich der Fürstin Libuše) allegorisieren und die sich heute im Park am Vyšehrad befinden. Ihre Entfernung von der Brücke (1945) führte zu einer Verschleierung der räumlichen Beziehungen und des ursprünglichen Gesamtkonzepts des Palacký-Denkmals.

Während der langen Realisierungszeit versuchten mehrmals die Kommunalpolitiker die Aufwendigkeit des Monuments zu verringern, u.a. durch die Reduktion einiger „überflüssiger“ Teile. Nach dem verbindlichen Modell im Maßstab I : 8 entstand in Suchardas neuem von Kotěra entworfenen Atelier ein finales Modell in halber Größe. Ein kaschiertes Modell vor Ort führte 1906 zu vehementen Bemühungen Suchardas für einen anderen Aufstellungsort. Für eine Alternative vor dem Konzerthaus Rudolfinum (heutiger Palachplatz) fertigte Sucharda daher Fotomontagen (Abb. II). Ganz logisch klang in diesem Zusammenhang ein Argument, dass hier das Denkmal des bedeutendsten tschechischen Historikers mit dem damals gegenüber projektierten Neubau der Prager Philosophischen Fakultät hätte korrespondieren können. ${ }^{\circ}$ Der Stadtrat

20 M. Krummholz, in: Kuthanová/Svatošová (zit. Anm. 7), S. 83. 
beharrte dennoch auf der ursprünglichen Lokalität am (zukünftigen) Palacký-Platz, obwohl klar war, dass dort nie eine geschlossene Platzanlage entstehen würde. Völlig fatal wirkte nämlich die Veränderung des originalen Regulierungsplans (Abb. 7), nach dem man auf der Ostseite ursprünglich mit zwei diagonal führenden Straßen rechnete. Die endgültige Situation zeigt das Denkmal in einer kommunikationsmäßig tauben Ecke der Platzrampe (Abb. 4), was die Wirkung des Werkes maximal beeinträchtigt. Die sehr bemerkenswerte hintere Partie (inklusive der monumentalen Allegorie der Weissagerin oder der Geschichte) kommt daher gar nicht zur Geltung. Das Denkmal wurde realisiert und I9I2 enthüllt an einem Ort (de facto noch längere Zeit eine Baustelle), den man als „eine Kreuzung“ oder sogar als „die Müllkippe“ bezeichnete.

Der instabile Untergrund des Moldauufers forderte eine sehr anspruchsvolle Konstruktion; eine tschechische Premiere war die Verwendung eines massiven Stahlbetonrosts: mehr als vier Meter tief, auf der Grundlage von III Betonpfählen, die bis zu 8,5 Meter tief eingeschlagen wurden. Für den Sockel brauchte man 55 Waggons Granit und eine riesige Menge an Betonfüllung. Aus Stahlbeton war auch die Armatur der oberen asymmetrischen Figurengruppen, die sich ursprünglich gegenseitig ins Gleichgewicht brachten. Die finalen Bronzegüsse wurden in der Gießerei von Tomáš Bohdan Srpek in Brandýs nad Labem (Brandeis an der Elbe) gefertigt. Srpek gewann den Auftrag dank dem niedrigsten Dumpingpreis, den er letztendlich nicht einhalten konnte. ${ }^{2 \mathrm{~T}}$ Gründlichst überprüfte man zuvor, ob Srpek wirklich ein Tscheche war, wie es die Auftragsbedingungen strikt verlangten. Der Hauptsitz seiner Gießerei befand sich nämlich in Wien-Hietzing. Die Firma Srpeks genoss damals ein erhebliches internationales Renommee und realisierte Denkmäler in Wien, Lemberg, Kra- kau, Berlin und sogar Persien (General Khans Monument in Teheran). Eine komplizierte Weise der Verankerung der Bronze erprobte Srpeks Firma schon bei der Realisierung des MickiewiczMonuments von Antoni Popiel in Lemberg (1898-1904). Statt einer Standard-Bronzelegierung (93\% Kupfer à $7 \%$ Zinn) nützte Srpek eine eigene, geheime Mischung: $88 \%$ Kupfer, $3 \%$ Nickel, $2 \%$ Zinn und $7 \%$ Zink. In einer besonders unangenehmen Situation befand sich der Fabrikbesitzer im Juli I9ıo, als unerwartet der Erzherzog (später Kaiser) Karl seine Brandeiser Gießerei besichtigte. ${ }^{22}$ Der Erzherzog befragte mehrmals den beinahe verstummten Srpek über die Bedeutung der gerade finalisierten Denkmalteile der Unterdrückung und der Germanisation (Abb. 9) - also des oben erwähnten zweiköpfigen Untieres mit den Eichenlaubflügeln und der „habsburgischen“ Physiognomie.

Obwohl das Palacký-Denkmal schon im Frühjahr I9II fertig war, wurde politisch beschlossen, es erst im Juni I9I2 im Rahmen der slawischen Sokol-Feier offiziell zu enthüllen. Länger als ein Jahr wurde also das fertige Werk hinter einem sechs Meter hohen Holzzaun versteckt. Die feierliche Enthüllung wurde als ein Nationalfest von mehreren Politikern ausgenützt (u.a. Prager Bürgermeister Karel Groš und dem Abgeordneten Karel Kramáŕ). Die Tschechische Akademie der Wissenschaften und die Prager Universität organisierten gemeinsam am 29. Juni I9I2 eine Jubiläumstagung und im Nationaltheater wurde die "tschechische Nationaloper" - also Smetanas Libuše - aufgeführt. Nach der Enthüllungszeremonie fand ein opulentes Festessen im Prager Gemeindehaus statt. Die Gesamtsumme des Denkmals - zur Zeit seiner Entstehung das größte Bronzedenkmal Europas - war kolossal: 525.000 Kronen.

Das Monumentalwerk, das während der langen Zeit von I4 Jahren (I898-I9II) - in der

2I Bohdan Srpek realisierte auch das Prager Jan-Hus-Denkmal.

22 In Brandeis besaßen die Habsburger ein Schloss. M. Krummholz, in: Kuthanová/Svatošová (zit. Anm. 7), S. 85. 
Zeit entstand, die eine der intensivsten Perioden in der Entwicklung der modernen Kunst war wurde gleich nach seiner Enthüllung zum Gegenstand unterschiedlichster und heftiger Kritik. Sucharda selbst schloss seine eigene, die Entstehung und Gestalt erklärende Publikation mit bezeichnenderweise skeptischen Worten: Das Leben vergeht schnell - die Kunstrichtungen verändern sich - vielleicht hätte ich (jetzt) selbst etwas an der Gestalt meines Werkes verändert. ${ }^{23}$ Die Kritik kam von allen Seiten. Die Anhänger der Moderne fanden das Denkmal als formal überholt und zu narrativ, für die konservative Mehrheit hingegen war die Uneinheitlichkeit der Komposition und die Unruhe des Ausdrucks störend. Das Monument wurde als „antiakademisch“ bezeichnet. Schließlich wurde auch das „germanisch-übermenschliche" Aussehen Palackýs angegriffen, das mit dem Stil Franz Metzners verglichen wurde. Die deutsche sowie österreichische Kritik wurde schließlich durch das Unterdrückungsmonster mit seiner antihabsburgischen Konnotation provoziert. Daher wurde das wegen Form und Symbolik umstrittene Denkmal während des Protektorats (1942) entfernt und sollte zerstört werden. Aber die demontierten Bronzeteile wurden gerettet und versteckt, sodass das Denkmal einige Jahre nach dem Krieg wieder zusammengesetzt werden konnte.

Aus der heutigen Perspektive jedoch erscheint es im Vergleich mit anderen europäischen Monumenten um die Wende zum 20. Jahrhundert als eine äußerst originelle, von allen Denkmalklischees und Zeitkonventionen befreite Schöpfung. Die gewählte Form ist interessant und die dynamisierte Masse evoziert suggestiv den organischen Prozess der tschechischen Nationalwiedergeburt. Das Rodin'sche leidenschaftliche Sujet wurde von Sucharda monumentalisiert und in Form einer kolossal nach oben gesteigerten
Spirale auf das ganze Volk erweitert. Mit seiner Erzählung knüpfte Sucharda an die ähnlich (obgleich mit weniger Dynamik) dargestellte, geschichtliche Szene des Hus-Denkmals von Šaloun (von den ersten Slawen bis zur Schlacht am Weißen Berg) an. Beide Denkmäler entstanden gleichzeitig in enger Interaktion. Höchst originell ist zudem die Ikonografie des PalackýDenkmals, so treffen wir fast keine etablierte allegorische Figur. Schließlich kann man anmerken, dass die gar nicht sentimentale „slawische“ Gestaltung Suchardas (vor allem zahlreiche Variationen der Fürstin Libuše) ein vollwertiges Gegenstück zur damaligen „germanischen Kunst“ darstellte, wie sie beispielsweise sein Zeitgenosse und Landsmann Franz Metzner repräsentierte.

Den markanten Unterschied zwischen den beiden in Prag fast gleichzeitig entstandenen Palacký-Monumenten kann man im Hinblick auf die Bedeutung dieser konkreten künstlerischen Aufgabe erklären. Die traditionell konzipierte Figur des Pantheons im Nationalmuseum war nur ein Teil des einheitlich und konventionell gefassten formalen Innenraumes, der unter Aufsicht einer offiziellen und konservativen Landesinstitution entstand. Demgegenüber folgte das großzügig subventionierte Palacký-Denkmal u.a. dem Ziel, die Ambitionen des selbstbewussten Prager Rathauses zu erfüllen. Dieses war bereit, eine vollkommen unkonventionelle Lösung zu fördern, die als Demonstration eines kühnen künstlerischen Talents gelten konnte, dessen konstruktiv-technologische Fähigkeiten die Erfolge und die Vitalität der wiedergeborenen Nation repräsentierten.

Abbildungsnachweis: Abb. I, 3: Foto: Jaroslav Kvíz (2000); Abb. 2: Foto ÚDU AV ČR; Abb. 4, 5, 6, 8, 9, Io, II: Archiv des Autors; Abb. 7: Archiv hlavního města Prahy. 


\section{PLAN DES ARKADENHOFS}

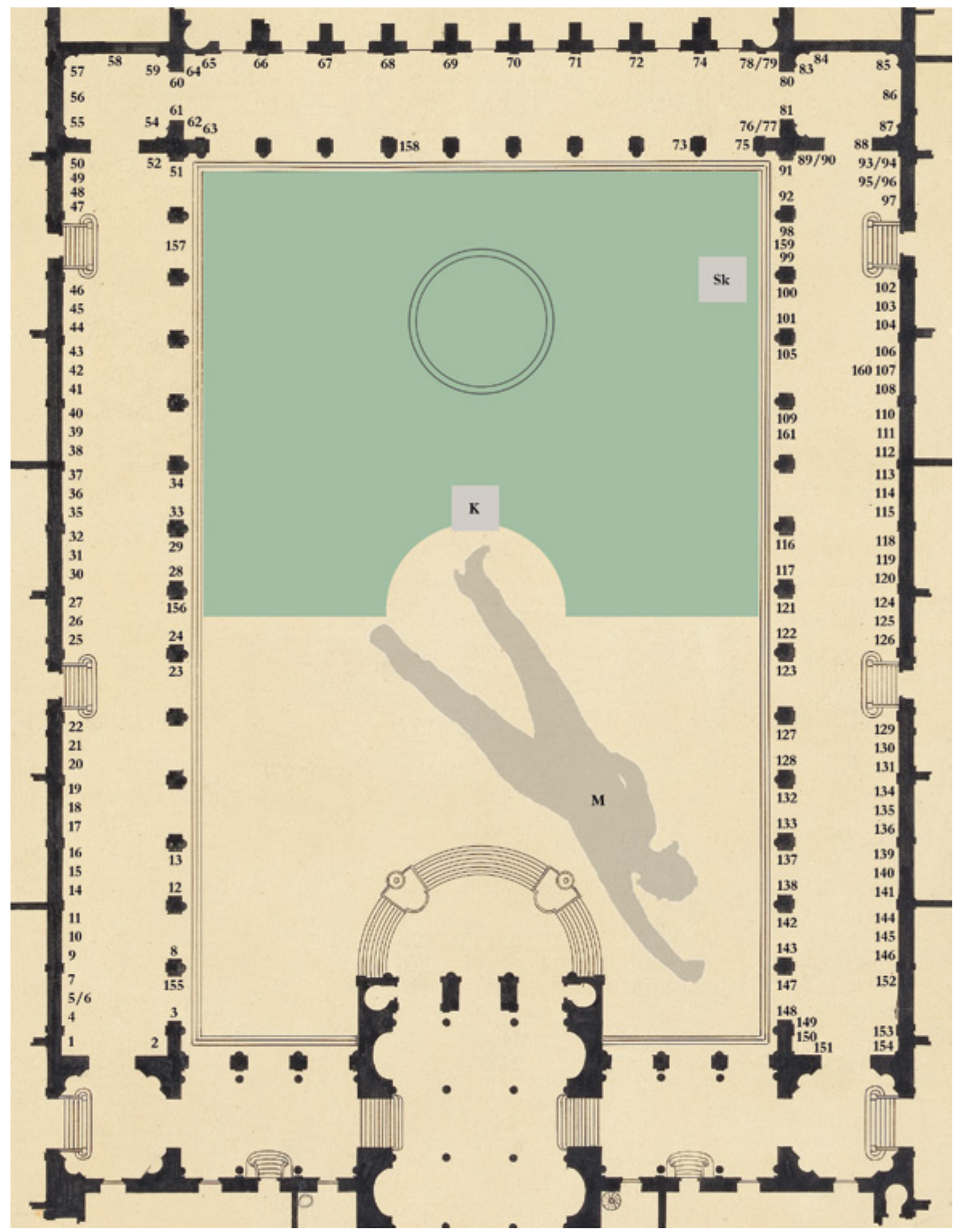

Plan des Arkadenhofs mit Nummerierung der Denkmäler nach Maisel 2007 und chronologischer Ergänzung der 2016 aufgestellten Ehrungen für Wissenschaftlerinnen, Montage A. Mayr, Wien 2016. 


\section{Nr. Denkmal}

2

Sternegg

Arnesberg
Denkmal Karl von Czyhlarz

Denkmal Andreas Josef von Stifft

Denkmal Carl Menger

Denkmal Josef von Sonnenfels

Denkmal Gustav Demelius

Denkmal Franz Anton von Zeiller

Denkmal Josef Kudler

Denkmal Eugen von Böhm-Bawerk

Denkmal Wilhelm Emil Wahlberg

Denkmal Franz Brentano

Denkmal Karl Theodor von Inama-

Denkmal Friedrich von Wieser

Denkmal Max Hussarek von Heinlein

Denkmal Anton Menger

Denkmal Lorenz von Stein

Denkmal Heinrich Siegel

Denkmal Hans Kelsen

Denkmal Franz Hofmann

Denkmal Heinrich Lammasch

Denkmal Karl Ludwig Arndts von

Denkmal Albrecht Schrauf

Denkmal Robert von Zimmermann

Denkmal Adolf Merkl

Denkmal Richard Wettstein von

Westersheim

Denkmal Hans Molisch

Denkmal Anton Bruckner

Denkmal Wilhelm Dantine

Denkmal Gustav Tschermak

Denkmal Friedrich Becke

Denkmal Stephan Ladislaus Endlicher

Denkmal Anton Kerner von Marilaun

Denkmal Franz Unger

Denkmal Franz Serafin Exner

Denkmal Josef Maria Pernter

Denkmal Nikolaus Joseph Freiherr von Jacquin

Denkmal Gerard van Swieten
Künstler

Alfred Hofmann

Franz Klein

Alfred Hofmann

Alois Düll

Wilhelm Seib

Emanuel Pendl

Wilhelm Seib

E. Delug

Melanie Horsetzky

von Hornthal

Theodor Georgii

Edmund Klotz

Rudolf Schmidt

Michael Drobil

Richard Kauffungen

Friedrich Steger

Melanie Horsetzky

von Hornthal

Ferdinand Welz

Theodor Khuen

Josef Humplik

Theodor Charlemont

Franz Seifert

Edmund Klotz

Ferdinand Welz

Hans Bitterlich

Franz Seifert

Josef Tautenhayn

Josef Zenzmaier

Rudolf Marschall

André Roder

Johann Kalmsteiner

Edmund Hofmann

von Aspernburg

Jakob Gruber

Michael Powolny

Michael Drobil

Leopold Schrödl

Franz Xaver Messerschmidt
Enthül- Tätigkeit

lungsjahr

1927 Jurist

I889 Mediziner

I929 Nationalökonom

I89I Jurist

I897 Jurist

I89I Jurist

I89I Nationalökonom

I950 Nationalökonom

1908 Jurist

1952 Philosoph

1917 Historiker

1957

Nationalökonom

Jurist

Jurist

Jurist

Jurist

Jurist

Jurist

Jurist

Jurist

Mineraloge

Philosoph

Jurist

Biologe

Biologe

Musikwissenschaftler

Theologe

Mineraloge

Mineraloge

Biologe

Biologe

Biologe

Physiker

Mathematiker

Biologe

Mediziner 
Denkmal Jan Ingen-Housz

Denkmal Rudolf Wegscheider

Denkmal Ferdinand Lotheissen

Denkmal Hans von Arnim

Denkmal Ernst Späth

Denkmal Carl Claus

Denkmal Thomas Garrigue Masaryk

Denkmal Adolf Mussafia

Denkmal Anton Josef Hye von

Gluneck

Denkmal Eduard Hanslick

Denkmal Ludwig Barth von Barthenau

Denkmal Melchior Neumayr

Denkmal Adolf Exner

Denkmal Karl Anton von Martini

Denkmal Ignaz Seipel

Denkmal Julius Glaser

Denkmal Richard Heinzel

Denkmal Carl von Rokitansky

Denkmal Franz von Miklosich

Denkmal Leopold Hasner von Artha

Denkmal Franz Exner

Denkmal Leo Graf von

Thun-Hohenstein

Denkmal Hermann Bonitz

Denkmal Viktor von Lang

Denkmal Adolf Lieben

Denkmal Guido Goldschmiedt

Denkmal Rudolf Much

Denkmal Zdenko Hans Skraup

Denkmal Josef Unger

Denkmal Friedrich Jodl

Denkmal Otto Benndorf

Denkmal Franz Klein

Denkmal Robert Ultzmann

Denkmal Heinrich von Bamberger

Denkmal Julius von Wiesner

Denkmal Josef Seegen

Denkmal Karl Landsteiner

Denkmal Edmund von Neusser

Denkmal Karl Schenkl

Franz Seifert
Heinrich Zita
Hans Bitterlich
Franz Barwig?
Heinrich Zita
Richard Kauffungen
Vincenc Makovsky
Kaspar von Zum-
busch

Kaspar von Zum-

busch

Viktor Tilgner

Heinrich Natter

Carl Kundmann

Hans Bitterlich

Hans Mauer

Josef Engelhart

Kaspar von Zum-

busch

Carl Kundmann I9I4

Alexius von Swoboda 1898

Johann Scherpe

I897

Kaspar von Zum-

busch

Carl Kundmann

Carl Kundmann

1893

I893

Carl Kundmann

Hans Bitterlich

I893

Carl Kundmann

1929

Franz Seifert

1922

1923

Franz Pixner

1952

Ilse Twardowski-

1920

Conrat

Kaspar von Zum-

1928

busch

Hans Mauer

I924

Hella Unger

Hermann Haller

K. Selinger

Richard Kauffungen

Franz Seifert

Richard Kauffungen

Arnold Hartig

Heinrich Karl Scholz

Stefan Schwartz
Biologe

Chemiker

Philologe

Philologe

Chemiker

Biologe

Philosoph

Philologe

Jurist

Musikwissenschaftler

Chemiker

Paläontologe

Jurist

Jurist

Politiker

Jurist

Philologe

Mediziner

Philologe

Jurist

Philosoph

Politiker

Philologe

Physiker

Chemiker

Chemiker

Philologe

Chemiker

Jurist

Philosoph

Archäologe

Jurist

Mediziner

Mediziner

Biologe

Mediziner

Mediziner

Mediziner

Philologe 
76 Denkmal Julius Tandler

77 Denkmal Friedrich Hasenöhrl

78 Denkmal Hans Horst Meyer

79 Denkmal Leopold von Dittel

80 Denkmal Ferdinand von Arlt

8I Denkmal Nikolai Sergejewitsch

Trubetzkoy

82 Denkmal Adalbert Duchek

83 Denkmal Vatroslav v. Jagić

84 Denkmal Ernst Fleischl von Marxow

85 Denkmal Emil Zuckerkandl

86 Denkmal Wilhelm von Hartel

87 Denkmal Julius Wagner-Jauregg

88 Denkmal Johann Heinrich

Dumreicher

89 Denkmal Johann von Oppolzer

90 Denkmal Theodor von Oppolzer

9I Denkmal Eduard Albert

92 Denkmal Gustav Riehl

93 Denkmal Josef Stefan

94 Denkmal Julius von Schlosser

95 Denkmal Joseph Johann von Littrow

96 Denkmal Karl von Littrow

97 Denkmal Sigmund Freud

98 Denkmal Rudolf Chrobak

99 Denkmal Ernst Ludwig

Ioo Denkmal Jakob Schipper

IoI Denkmal Leopold Schrötter von

Kristelli

IO2 Denkmal Josef von Skoda

IO3 Denkmal Theodor von Sickel

IO4 Denkmal Karl Popper

IO5 Denkmal Karl Luick

Io6 Denkmal Ferdinand von Hebra

I07 Denkmal Johann Radon

Io8 Denkmal Karl Langer von Edenberg

I09 Denkmal Rudolf Pöch

IIo Denkmal Theodor Meynert

III Denkmal Christian Doppler

II2 Denkmal Erwin Schrödinger

II3 Denkmal Josef Hyrtl

II4 Denkmal Carl Braun von Fernwald

II5 Denkmal Franz Schuh

II6 Denkmal Robert Reininger

II7 Denkmal Alfons Dopsch
Josef Ried

Franz Seifert

Grete Hartmann

Rudolf Bachmann

Hans Bitterlich

Vanja Radauš

Josef Grünhut

Ivan Meštrović

Emil Fuchs

Anton Hanak

Heinrich Karl Scholz

Josef Müllner

Adalbert Eduard Saff

1956

1923 ?

1953

1908

I896

1974

I9OI

1954

I898

1924

I9I2

I95I

I9OI

Viktor Tilgner

I890

Viktor Tilgner

I890

Arthur Kaan

1909

Arnold Hartig

1954

Anton Schmidgruber

I896

Josef Thorak

1955

Hans Bitterlich

1892

Hans Bitterlich

I892

Paul Königsberger

1955

Edmund Hellmer

1927

Kaspar von Zum-

1932

busch

Josef Müllner

1928

I937

Zumbusch

Carl Kundmann

I898

Josef Kassin

1930

Christine Pillhofer

2002

Heinz Satzinger

1956

Viktor Tilgner

I89I

Ferdinand Welz

1987

Alfonso Canciani

I903

Gustav Schütz

I933

Theodor Khuen

I9OI

Georg Leisek

I9OI

Ferdinand Welz

I984

Johann Kalmsteiner $\quad$ I889

Theodor Charlemont $\quad$ I894

Josef Beyer

I889

Günther Baszel

Arnold Hartig
Mediziner

Physiker

Mediziner

Mediziner

Mediziner

Philologe

Mediziner

Philologe

Mediziner

Mediziner

Philologe

Psychiater

Mediziner

Mediziner

Physiker

Mediziner

Mediziner

Physiker

Kunsthistoriker

Physiker

Physiker

Mediziner

Mediziner

Chemiker

Philologe

Mediziner

Mediziner

Historiker

Philosoph

Philologe

Mediziner

Mathematiker

Mediziner

Mediziner

Psychiater

Physiker

Physiker

Mediziner

Mediziner

Mediziner

Philosoph

Historiker 
II9 Denkmal Hermann Nothnagel

I20 Denkmal Heinrich Obersteiner

I2I Denkmal Karol Kuzmány

I22 Denkmal Ján Kollár

I23 Gedenktafel zur Erinnerung an 1938-

I945 vertriebene Angehörige der Medizinischen Fakultät

I24 Denkmal Josef Quarin

I25 Denkmal Ernst Wilhelm von Brücke

I26 Denkmal Ludwig Mauthner

I27 Denkmal Eduard von Hofmann

I28 Denkmal Ernst Fuchs

I29 Denkmal Karl Stoerk

I30 Denkmal Theodor Billroth

I3I Denkmal Hermann von Widerhofer

I32 Denkmal Anton von Eiselsberg

I33 Denkmal Marie von

Ebner-Eschenbach

I34 Denkmal Clemens Pirquet von Cesenatico

I35 Denkmal Adam Politzer

I36 Denkmal Richard von Krafft-Ebing

I37 Denkmal Johann Sölch

I38 Denkmal Eduard Jäger von Jaxtthal

I39 Denkmal Constantin von Economo

I40 Denkmal Rudolf von Eitelberger

I4I Denkmal Paul Kretschmer

I42 Denkmal Rudolf von Scherer

I43 Denkmal Franz Martin Schindler

I44 Denkmal Otto Kahler

I45 Denkmal Joseph Maximilian Petzval

I46 Denkmal Leopold Oser

I47 Denkmal Ignaz Philipp Semmelweis

I48 Denkmal Hugo Weidel

I49 Denkmal Heinrich Swoboda

I50 Denkmal Gustav W. H. Bickell

I5I Denkmal Josef Böhm

I52 Denkmal Karl Werner

I53 Denkmal Ludwig Boltzmann

I54 Denkmal Josef Loschmidt

I55 Denkmal Elise Richter

I56 Denkmal Marie Jahoda
Johannes Benk I908

Richard Kauffungen I9IO

Richard Kauffungen $\quad 1997$

Ludmila Cvengrošová 1998

Ludmila Cvengrošová 1998

Günter Wolfsberger $\quad 1998$

Johann Martin

Fischer

Otto König $\quad$ I894

Rudolf Weyr

1947

Josef Müllner

I95I

Johannes Benk $\quad 1907$

Kaspar von Zum- $\quad 1897$

busch

Richard Kauffungen

1907

\section{0}

1925

Josef Riedl

József Kampfl $\quad$ I983

Richard Kauffungen

Viktor Hammer

1908

Gertrude Dengg

Max Kremser

Kaspar von Zum-

busch

-

Arnold Hartig

Arnold Hartig

Richard Kauffungen

Anton Brenek

Carl Wollek

Alfred Hrdlicka

Alfonso Canciani

Franz Strahammer

Karl Nickmann

Johannes Benk

Franz Koch

Leopold Brandeisky

Anton Schmidgruber

Catrin Bolt

Catrin Bolt
I889

I899

1962

1965

I9IO

1966

I889

Mediziner

Mediziner

Mediziner

Theologe

Archäologe

Mediziner

Mediziner

Mediziner

Mediziner

Mediziner

Mediziner

Mediziner

Mediziner

Mediziner

Mediziner

Schriftstellerin

Mediziner

Mediziner

Psychiater

Geograph

Mediziner

Psychiater

Kunsthistoriker

I968 Linguist

I95I

I95I

1904

I9OI

I9I7?

1967

1906

1956

I92I

I895

I897

I9I2

I899

2016

2016
Theologe

Theologe

Mediziner

Mathematiker

Mediziner

Mediziner

Chemiker

Theologe

Philologe

Biologe

Theologe

Physiker

Physiker

Romanistin

Sozialwissenschaftlerin 


$\begin{array}{ll}\text { I57 } & \text { Denkmal Charlotte Bühler } \\ \text { I58 } & \text { Denkmal Grete Mostny-Glaser } \\ \text { I59 } & \text { Denkmal Berta Karlik } \\ \text { I60 } & \text { Denkmal Olga Taussky-Todd } \\ \text { I6I } & \text { Denkmal Lise Meitner } \\ \text { K } & \text { Kastalia-Brunnen } \\ \text { M } & \text { Der Muse reicht's } \\ \text { Sk } & \text { Siegfriedskopf }\end{array}$

\begin{tabular}{|c|c|c|}
\hline Thomas Baumann & 2016 & $\begin{array}{l}\text { Entwicklungspsycho- } \\
\text { login }\end{array}$ \\
\hline Karin Frank & 2016 & Archäologin \\
\hline Thomas Baumann & 2016 & Physikerin \\
\hline Karin Frank & 2016 & Mathematikerin \\
\hline Thomas Baumann & 2016 & Physikerin \\
\hline Edmund Hellmer & 1910 & - \\
\hline Iris Andraschek & 2009 & - \\
\hline Josef Müllner/Marx & $1923 / 2006$ & - \\
\hline
\end{tabular}

E R G Ä N Z U N G
Im Mai 2017 wurde aus feuerpolizeilichen Gründen die Schaffung von Fluchtwegen in beiden Arkadengängen als notwendig erachtet. Im Zuge dieser baulichen Maßnahmen müssen einzelne Denkmäler neu verortet werden. Diese maßgeblichen Veränderungen in der ursprünglichen
Konzeption und derzeitigen Aufstellung der Denkmäler im Arkadenhof waren bei Drucklegung dieses Werks noch nicht näher ausgeführt und konnten daher nicht mehr berücksichtigt werden. 


\section{PERSONENREGISTER}

Abel, Othenio 13

Abel, Wolfgang 13

Adam, Gottfried 146-147

Adamovich, Ludwig 128, 137, 145

Adler, Guido 34

Ackermann, Astrid 307

Afinger, Bernhard 341

Albert, Eduard 26, 32, 384

Alberti, Leon Battista 8

Albrecht III., Herzog von Österreich 24

Albrecht V., Herzog von Bayern 202

Alciato, Andrea 20, 242

Alexander der Große (the Great) 151

Alexander I. Karadjordjević, König der Serben,

Kroaten und Slowenen 365

Algardi, Alessandro 198

Algarotti, Francesco 18

Alma Tadema, Lawrence 224

Amoretti, Maria Pellegrina 34

Andraschek, Iris 7, 31, 133, 386

Aranzio, Giulio Cesare 172

Arditi, Andrea 157-158

Arlt, Ferdinand von 384

Arndts von Arnesberg, Karl Ludwig 382

Arneth, Alfred von 91, 93

Arnim, Hans von 135, 138, 383

Assmann, Aleida 233-234, 403

Assmann, Jan 233, 403

Avanzini, Nikolaus 23

Ayres, Sarah 9

Bachmann, Rudolf 384

Baciocchi, Elisa 275

Bacon, Francis 204-205, 209-210

Baillet-Latour, Vincenz Graf von 91

Baker, Malcolm 9, 151, 198-199, 201, 204-205, 211, 403

Balassa, János 343

Bamberger, Heinrich von 124, 127, 383

Barlach, Ernst 329

Barozzi, Giacomo > Vignola 240-241, 247-249, 254

Barta, Ilsebill 55-56, 403

Barth von Barthenau, Ludwig 283
Bartholoni, François 275, 387

Bartoletti, Fabrizio 172

Bartolini, Lorenzo 275, 278, 284-285, 406

Barwig, Franz 138, 383

Bassi, Laura 34, 176

Baszel, Günther 384

Batthyány, Ignác 337-338, 411

Bauerschmidt, Marie Luise 327-328

Baumann, Thomas 34, 386

Baxandall, Michael 199, 403

Becke, Friedrich 135, 382

Becker, Johannes B. 306

Beethoven, Ludwig van 73, 91, 108

Begas, Reinhold 323

Bellano, Bartolomeo 235-236

Bellini, Giovanni 189, 194

Bembo, Pietro 239

Benedikt XIV., Papst (Benedict XIV, Pope) 173-174

Benjamin, Walter 7

Benk, Johannes 385

Benndorf, Otto 22, 87, 91-95, 383

Bentham, Jeremy 9, 213-217, 220-221

Bentley, Thomas 206-209

Bernardi, Giuseppe 186, 193-194

Bernatzik, Edmund 32

Bernini, Gianlorenzo 198

Bessel, Gottfried 53, 56

Bettelheim, Anton 32-33, 404

Beuth, Christian Peter Wilhelm 213, 322, 331

Beyer, Angelina 18, 404

Beyer, Josef 384

Bèze, Thédore de 283

Biasutti, Costante 195

Bickell, Gustav W. H. 124-125, 127, 385

Bieber, Margarete 317

Billroth, Theodor 8, 18, 29, 31-32, 73, 103-118, $138,257,385,404,407,417$

Bíró, Lajos 349

Bitterlich, Hans 73, 382-384

Blaschke, Hanns 116

Block, Benjamin von 52, 58

Blumenberg, Hans 233

Blümer, Heinrich Angelus 52-53, 59, 65 
Bock, Hieronymus (genannt Tragus) 239

Böckh, Franz Heinrich 37, 43, 404

Bode, Wilhelm von 140

Böhm, Josef 382

Böhm-Bawerk, Eugen von 135-136, 382

Boldrini, Francesco 254

Bolt, Catrin 34, 385-386

Boltzmann, Ludwig 322, 385

Bonaparte, Napoleon 21, 173-174, 180, 185, 190, 275, 279

Bongiovanni, Bartolomeo 183, 194

Bonitz, Hermann 8, 11, 16, 23, 25, 87-102, 360, $383,409,412,417$

Bonnet, Charles 273-275, 278-279

Boodewyns, Jacob 64, 66

Bormann, Eugen 28, 91, 94

Börne, Ludwig 316

Borovský, Karel > Havlíček Borovský, Karel 369

Borro, Luigi 189, 193-194

Borsato, Giuseppe 183, 194

Bortotti, Gerolamo 192, 195

Bosa, Antonio 185

Bouchard, Henri 283

Boyle, Richard 250, 252

Bracci, Giuseppe 263, 265

Bracciolini, Poggio 162, 198, 404

Brahe, Tycho 338-339

Brambilla, Alessandro 20-21

Bran, Friedrich Alexander 213

Brandeisky, Leopold 385

Braun von Fernwald, Carl 26, 384

Breker, Arno 140

Brenek, Anton 385

Brentano, Franz 135, 137, 382

Brindle, Peter 226, 231-232

Brougham, Henry 216

Brown, William 223-224, 230

Brücke, Ernst Wilhelm von 29, 31, 80, 385

Brücke, Franz 81

Brucker, Johann Jakob 15

Bruckner, Anton 382

Bruni, Leonardo 154, 162

Brütt, Adolf 324, 326

Büchner, Georg 316

Bühler, Charlotte 34, 386

Bunsen, Robert Wilhelm 341

Burger, Fritz 150, 152, 154, 156

Burgheim, Hedwig 317
Burhenne, Thomas 316

Butades 149

Butler, Reg 227

Caffieri, Jacques 202

Calvin, Jean 271-273, 276, 283, 416

Camerarius, Joachim 291

Campbell, Colen 252-253

Canciani, Alfonso 31, 384-385

Candolle, Augustin Pyrame de 270, 276, 278 279, 405

Canova, Antonio 179, 181-187, 193-194, 274$276,278,405,414$

Cantalamessa, Giulio 179

Carducci, Giosue 169-170

Carl, Erzherzog von Österreich-Teschen 41

Carlini, Giulio 192-193, 195

Caroline von Brandenburg-Ansbach, Königin von Großbritannien 200-201, 405

Casanova, Giovanni Battista 256

Catra, Elena 8, 179, 405

Cattaneo, Danese 236, 239

Cattaneo, Raffaele 192-193, 195, 236

Caylus, Anne-Claude de 9, 257, 268, 405, 416

Celtis, Konrad 23

Caesar, Julius 151, 170

Cestius, Caius 170

Chabrey, Dominique 278

Charlemont, Theodor 73, 382, 384

Chellini, Giovanni 156, 412

Chotek, Johann Rudolf Graf 40-41

Chrobak, Rudolf 76, 384

Ciardi, Gugliemo 191-193

Cicero 150, 240

Cicognara, Leopoldo 179, 182-185, 193-194, 405

Clam-Martinic, Heinrich von 369

Claus, Carl 383

Clemens XIV., Papst 36

Conradis, Franz Karl 242

Contarini, Girolamo 181

Conte, Pietro 9

Conze, Alexander 95

Cornaro Piscopia, Elena Lucrezia 33

Cornelius, Peter von 314

Corti, Francesco 20

Cotton, Robert 206-207

Crescimbeni, Angelo 174 
Creti, Donato 172, 516

Croke, Edward 158

Curie, Marie 321

Cuspinian, Johann 23

Cvengrošová, L̉udmila 385

Czyhlarz, Karl von 382

Dal Zotto, Antonio 189, 192-193, 195

D'Andrea, Giovanni 162, 166, 171

D'Anger, David 294

Dantine, Wilhelm 146-147

D‘Argelata, Pietro 172

Darwin, Charles 29

David, Benno von 91

Davies, B. R. 277, 280

De la Rive, Auguste 275, 278

De' Liuzzi, Mondino 172, 178

De Logu, Giuseppe 193, 196

De Maria, Giacomo 174-175

De Paula von Triesnecker, Franz 338

De Piles, Roger 66

Delug, E. 382

Demelius, Gustav 382

Demus, Otto 136, 142

Dengg, Gertrude 385

Denk, Wolfgang 113

Dériaz, Jean-Jacques 273, 275

Descartes, Réné 340

Deschmann, Karl 356-357, 406

D`Este, Antonio 185-187, 194

D'Estouteville, Guillaume 163-165

Deym, Joseph Graf von 41

D'Hancarville, Pierre-François 9, 257, 260-261, 264-268, 408-409, 414

Diedo, Antonio 185, 187-188, 190, 193-194

Dietmayr, Berthold von 56-60

Dittel, Leopold von 26, 384

Dlabač, Alois 374

Donatello 152, 158, 411, 415

Doppler, Christian 384

Dopsch, Alfons 74, 384

D'Oultremannus, Henricus 244

Drake, Friedrich 322

Drobil, Michael 105, 113-114, 116-117, 137138, 382, 385

Druml, Christiane 116

Duchek, Adalbert 384

Dufour, Guillaume-Henri 279, 281
Düll, Alois 22-23, 28, 382

Dumreicher, Johann Heinrich 384

Duttenhoefer, Thomas 316

Dyck, Johann Gottfried 256

Ebel, Johannes 309-310

Ebenbauer, Alfred 135, 146

Ebendorfer, Thomas 23

Ebner-Eschenbach, Marie von (geb. Dubsky) 32-33, 385

Economo, Constantin von 385

Egger-Möllwald, Alois von 91, 99

Eimmart, Georg Christoph 68-69

Einstein, Albert 321

Eiselsberg, Anton von 135, 385

Eitelberger von Edelberg, Rudolf 15-18, 22, 27, 70, 73, 385, 404, 406

Eitingon, Max 132

Ekhart, Walter 118

Elgin, Thomas Bruce 181

Endlicher, Stephan Ladislaus 382

Engel, Martin 7-8, 10, 14

Engelhart, Josef 136, 383

Engl, Heinz W. 7

Ennius, Quintus 244-245

Erasmus von Rotterdam 288

Ernst Ludwig, Großherzog von Hessen und Rhein 208

Ernsting, Bernd 9

Eszterházy, Károly Graf von 335-337

Eugen IV., Papst (Eugene IV, Pope) 154, 163

Exner, Adolf 32, 91, 101, 383

Exner, Franz 11, 23, 25, 32, 87, 90, 92-95, 97-99, 101, 360, 383, 409, 412, 417

Exner, Franz Serafin 32, 89, 382

Extermann, Grégoire 9, 271, 275, 278, 285, 406, 416

Eybel, Joseph Valentin 36

Eynard, Jean-Gabriel 275, 279, 281, 284-285

Fadiga, Domenico 195

Farel, Guillaume 283

Fassetto, Fabio 178

Fassler, Manfred 149

Favre, Guillaume 273-276, 281

Favretto, Giacomo 191-193, 195

Fea, Carlo 261-262

Ferdinand I., römisch-deutscher Kaiser 24, 50, 169 
Ferdinand II., römisch-deutscher Kaiser 24

Ferdinand III. von Habsburg 219

Ferdinand IV. von Habsburg 48

Ferrari, Luigi 189-195

Ferstel, Heinrich von 15-18, 21-22, 25-26, 91, 406-407

Feuerborn, Justus 310-311

Fiesole, Mino da 152-167

Fillitz, Hermann 145

Firmian, Karl Joseph Graf von 19

Fischer, Heinz 145

Fischer, Johann Martin 16, 36, 385

Fischer, Joseph 40

Fissell, Mary E. 104-105, 407

Fleischl von Marxow, Ernst 32, 124, 127, 384

Fogolari, Gino 193, 196

Folin, Bartolomeo 256

Fracassati, Carlo 172

Fraccaro, Plinio 19, 21, 407

Fragiacomo, Pietro 192-193, 196

Fraisl, Johann Joseph 66-67

Franz Joseph I., österreichischer Kaiser (Francesco Giuseppe, Imperatore) 22, 24, 73, 189-190, 194, 359-362

Franck, Adam 310-311

Franck, Philipp 310-311

Francke, Christoph Bernhard 294

Franco, Giacomo 192-193, 195

Frank, Johann Peter 16, 19, 21, 23

Frank, Karin 386

Frank, Karl Friedrich von 53, 407

Frankl, Paul 30

Franz I. Stephan, römisch-deutscher Kaiser 44, 420

Franz II. / I., römisch-deutscher / österreichischer Kaiser 368

Frederick II of Swabia (Friedrich II., Herzog von Schwaben) 170

Freyer, Stefanie 307

Freud, Sigmund 129-135, 384

Friedrich August I., König von Sachsen 290-291, 295

Friedrich I. von Preußen 219-220

Friedrich II., römisch-deutscher Kaiser 50

Frisch, Otto Robert 321

Frisch, Otto von 117-118

Fuchs, Emil 385

Fuchs, Ernst 135, 385
Füger, Heinrich Friedrich 38-39, 43-44, 410

Füssel, Marian 49, 53, 110, 304, 407

Gaggio, Luigi 195

Gajassi, Vincenzo 254

Galavics, Géza 9, 336, 407

Galen 172

Galilei, Galileo 336, 340

Gall, Franz Joseph 28-29, 31, 217

Galle d. Ä., Cornelis 245

Galle, Theodor 244-245, 247

Galleni-Pellegrini, Rosa Maria 236, 238-239, 407

Galli, Giovanni Antonio 173-174

Galvani, Luigi 174-175

Gambello, Vittore 189

Gangl, Alois 358

Garforth, Edmund 206-207

Gascoigne, John 210, 507

Gasser, Lorenz 23

Gautsch von Frankenthurn, Paul 90, 95, 97-98

Gaxotte, Pierre 319

Gellert, Christian Fürchtegott 291

Georg II., Landgraf von Hessen-Darmstadt 305-306

George I., König von England 251

Georgii, Theodor 137

Geutebrück, Albert 290, 292, 296

Geyser, Christian Gottlob 262

Giaccarelli, Antonio 179

Giannotti, Silvestro 172

Giorgio III d'Inghilterra (George III., König von England) 181

Giovanni, Matteo di 165

Giovio, Paolo 198

Girardon, François 202

Gladich, Gregor Andreas 355

Glaser, Julius 11, 22, 25-27, 34, 71, 73, 76, 92 , $124,127,383$

Glaser, Wilhelmine 22, 25, 27, 408

Globocnik, Odilo 119

Goethe, Johann Wolfgang von 29-31, 213-215, 266, 294, 296-298, 300, 314, 404, 406-408, 416

Goldenbaum, Laura 162, 408

Goldschmiedt, Guido 122, 124, 127-128, 139, 383

Gomperz, Theodor 91

Gorše, Franc 364-365 
Gottsched, Johann Christoph 287-290, 295, 300-301, 408, 415

Goujon, Jean 240

Govekar, Fran 360-361

Gozzoli, Benozzo 165

Gran, Daniel 335

Grandi, Gian Gerolamo 237-238

Grandi, Renzo 170-172, 408

Grandi, Vincenzo 238

Grigoletti, Michelangelo 189, 193, 195

Grillich, Ludwig 77, 79

Groš, Karel 379

Grosholtz, Marie > Tussaud, Marie 217

Grosley, Pierre-Jean 201

Gruber, Jakob 382

Gruber, Max 82

Grün, Anastasius 25

Grüner, Laurentius 54, 65, 70

Grünhut, Josef 384

Guérard, Bernhard von 42

Guérard, Eugene 42

Guglielmi, Gregorio 335

Guldener, Eduard 37

Gunschmann, Carl 308

Haberkorn, Peter 310-311

Hadrian 258

Hagenauer, Johann Baptist 41, 411, 417

Hahn, Otto 320-321

Hähnel, Ernst Julius 295-296, 299

Haid, Johann Jakob 15

Forster-Hahn, Françoise 197, 412

Hahn, Cynthia 158, 408

Halbig, Johann 72

Halblechner, Vencel 336

Haller, Hermann 383

Halley, Edmond 201

Halman, Emanuel 369

Hamilton, James 226, 408

Hamilton, William 261, 264, 266, 405, 409

Hammer, Viktor 385

Hanak, Anton 29, 384

Hannl, Maximilian Josef 66-67

Hanslick, Eduard 122, 125, 127, 383

Harreither, Reinhardt 84

Hartel, Wilhelm von 91, 93-94, 97-100, 384

Hartig, Arnold 72-74, 79-86, 383-385, 416

Hartmann, Grete 384
Hartmann, Karl 37

Hasenöhrl, Friedrich 384

Hasner von Artha, Leopold 22, 73, 101, 383, 413

Hatvani, István 348

Hauszmann, Alajos 343

Havlíček Borovský, Karel 369

Havlíček, Milan 369

Hayden, Hieronymus 54, 63

Hayek, Heinrich 83

Hayzer, Geoffrey 223-224, 230, 234

Heberden, William 209

Hebra, Ferdinand von 18, 81, 384

Heiliger, Bernhard 325-326

Heinrich IV. von Navarra 273

Heinzel, Richard 383

Hell, Maximilian 338

Hellmann, Maria Felicita Berand 181

Hellmer, Edmund 76, 138, 384, 386

Helmholtz, Hermann von 319, 324, 326, 328329, 331, 334

Helmshoysen, Roman 53, 56

Hepworth, Barbara 227

Herberstein, Sigismund Christoph 354, 357

Herder, Johann Gottfried 263, 268, 409

Herter, Ernst 324, 326

Herzig, Josef 122, 126

Hesse, Fabian 328-329

Hiesmayr, Ernst 142-143

Hill Burton, John 216

Hinterlechner, Karel 360

Hippokrates (Hippocrates) 172

Hirschhorn, Thomas 10

Hitler, Adolf 140

Hlosta, Wilhelm 81

Hoffmann, Emanuel 91

Hofmann von Aspernburg, Edmund 31, 73

Hofmann, Alfred 74, 382

Hofmann, Eduard von 135, 137-138, 385

Hofmann, Franz 382

Höger, Fritz 345

Holzhausen, Adolf 98-99

Homer 197, 256, 273

Hönes, Hans Christian 9, 265, 268, 409

Hormuth, Stefan 308

Horsetzky von Hornthal, Melanie 382

Houdon, Jean Antoine 269, 273, 275, 282

Hoyer, Jörg 147

Hrdlicka, Alfred 141-142, 146, 385 
Huber, Michel 256, 261, 263, 419

Hugo von Tuszien, Markgraf 152, 154

Hugo, Victor 280, 282

Humboldt, Alexander von 16, 319, 322-324, 331

Humboldt, Wilhelm von 16, 319, 323, 331

Hume, David 199

Humplik, Josef 136, 140, 382

Hus, Jan 372-374, 379-380

Hussarek von Heinlein, Max 135, 382

Hye von Gluneck, Anton Josef 73, 383

Hyrtl, Josef 11, 24, 26-28, 30-31, 384

Inama-Sternegg, Karl Theodor von 382

Ingen-Housz, Jan 13, 27-28, 34, 383, 419

Istvánffy, Miklós 336

Jacquet, Jean 273-275, 278, 281-282, 407, 413

Jacquin, Joseph Franz von 38-39, 41, 44

Jacquin, Nikolaus Joseph von 8, 13, 28, 35,

$38-45,407,415-416$

Jäger von Jaxtthal, Eduard 385

Jagić, Vatroslav von 135, 140-141, 384

Jahoda, Marie 34, 386

Jakac, Božidar 365, 366

Jenik, Rosa 361

Jobst, Christoph 304

Jobst, Heinrich 313

Jodl, Friedrich 383

Jones, Ernest 133

Jones, John 223, 410

Jones, Ian 268

Jones, Inigo 249-250

Joseph II., römisch-deutscher Kaiser 19-21, 44

Jury, Hugo 115

Kaan, Arthur 32, 384

Kahler, Otto 385

Kalin, Boris 365

Kalin, Zdenko 366

Kalmsteiner, Johann 26-27, 382, 384

Kampfl, József 385

Kaposi, Moriz 124, 127, 385

Kardelj, Edvard 352-353, 365-366

Karl IV., römisch-deutscher König und Kaiser 373

Karl VI., römisch-deutscher Kaiser 50-51, 53, 60, $63,67,69,410$
Karlik, Berta 34, 386

Kassin, Josef 384

Kauffungen, Richard 382-385

Kaunitz-Rietberg, Wenzel Anton Fürst von 19, 255

Kees, Johann Georg von 61, 65

Kelly, Brendan 223, 226, 230

Kelsen, Hans 145, 382

Kent, William 200-201, 252, 405

Kepler, Johannes 338-339

Kerner von Marilaun, Anton 39, 382

Kerner, Adelheid 39

Keune, Angelika 9, 16, 109, 322, 410

Keyser, Hendrick de 288

Khuen, Theodor 382, 384

Kidrič, Boris 352-353, 365, 414

Kidrič, France 365

Kiss, August 322

Kiss, Jernyei 335, 410

Kiss, K. Lengyelné 346, 412

Kleanthes von Assos 243

Klein, Dagmar 303, 309, 315, 318

Klein, Franz 382-383

Klenze, Leo von 340

Klinger, Max 299

Klotz, Edmund 382

Knapp, Johann 42-43, 407, 416

Knaur, Immanuel August Hermann 292-296

Knoll, Fritz 119-121, 123-128

Knöll, Pius 91

Knöll, Stefanie 307, 312, 410-411

Knox, John 283

Koblicek, Ruth 116

Koch, Dietrich 299, 411

Koch, Eckehard 299, 411

Koch, Franz 385

Koch, Linda A. 154, 411

Köchlin, Karl 15, 22-24, 91-92

Kohl, Jeanette 8, 149-150, 158, 411

Kohler, Alfred 50, 411

Kollár, Ján 146, 385

Kolumbus, Christoph 336

Komenius, Johann Amos 369

König, Carl (Carl) 13, 21, 24, 28

König, Otto 31, 385

Königsberger, Paul 131-133, 384

Kopernikus, Nikolaus 338

Kos, Tine 360-361 
Kotěra, Jan 372, 378, 418

Kovachich, Martin Georg 337-338, 405

Kracker, Johann Lucas 336, 410

Krafft-Ebing, Richard von 385

Kräftner, Johann 40

Kralj, France 366

Kralj, Zlat 366

Kramár, Karel 379

Kreft, Bratko 361

Kremser, Max 385

Kretschmer, Paul 385

Kris, Ernst 220, 411

Kronsteiner, August Stefan 17

Krummholz, Martin 10, 371, 378-379, 411

Kudler, Josef 28, 382

Kundmann, Carl 21-22, 25, 87-96, 98, 383-384

Kupelwieser, Leopold 38

Kupetzky, Johann 56-57, 59-62, 65-66, 414, 417

Kurz, Otto 220, 411

Küster, Georg 219-220, 411

Kuzmány, Karol 146, 385

Kvasnička, Josef 369

Lammasch, Heinrich 135-136, 140, 142, 382

Lampi, Johann Baptist 43

Landovski, Paul 283

Landsteiner, Karl 74, 82-85, 383, 418

Lang, Karen A. 197, 412

Lang, Viktor von 383

Lange, Hildegard 153-154, 160-161, 412

Langenbeck, Bernhard von 106, 112

Langenstein, Heinrich von 23

Langer von Edenberg, Karl 31, 111, 384

Langhans, Victor 91

Langsteiner, Karl 85

Larese, Lorenzo Moretto 189, 195

Lavater, Johann Caspar 29

Lavin, Irving 150, 157, 160, 403, 412

Lebzeltern, Karl Wolfgang 61, 63, 65

Lechner, Georg 60, 410

Ledoux, Claude-Nicolas 249

Leibniz, Gottfried Wilhelm 9, 287-301, 340, 404, 406, 415, 419

Leisek, Georg 384

Lejeune, Fritz 115

Lelli, Ercole 172-173

Lemot, François-Frédéric 278
Leoni, Giacomo 249-251

Leopold I., römisch-deutscher Kaiser 48, 57, 59

Lessing, Gotthold Ephraim 289, 297, 298, 300

Levanti, Antonio 172

Lieben, Adolf 122, 125, 127, 383

Lieben, Ida von 137

Liebig, Justus 312-317

Liebknecht, Wilhelm 316

Linck (Linckh), Sebastian 64, 66

Lindberg, Erik 84

Linné, Carl von 43

Lipparini, Ludovico 189, 193, 195

Lipsius, Justus 198, 243-247, 412

Lister, Joseph 107

Littrow, Joseph Johann von 384

Littrow, Karl von 384

Locke, John 199-200, 208

Lombardo, Cristoforo 20

Lomonossow, Michail Wassiljewitsch 346

Lončar, Dragotin 360

Lorenzetti, Carlo 195-196

Loschmidt, Josef 385

Lotheissen, Ferdinand 383

Luckhardt, Fritz 75-76

Ludwig IV., Landgraf von Hessen-Marburg 311, 314

Ludwig V., Landgraf von Hessen-Darmstadt 304, 308, 311, 315

Ludwig, Ernst 73-76, 78-79, 85, 97-98, 384

Luick, Karl 384

Lullin, Anne 284-285

Mácha, Karel Hynek 369

Macho, Thomas 149, 412

Macro, Cox 211

Maderna, Marianne 134

Maganza, Giovanni Battista 254

Magdalena von Brandenburg 311

Maiano, Benedetto da 156

Maisel, Thomas 8, 13-14, 43, 71, 73, 75, 80, 91, $101,108,111,120,127,361,381,413$

Maiwald, Simone 315

Makovsky, Vincenc 383

Malpighi, Marcello 172, 176

Malton, James 201

Malvezzi, Prospero 174-175

Mampieri, Antonella 8, 18, 177, 413

Mandelstam, Osip 332 
Manetti, Giannozzo 157

Manfrin, Giacomo 81

Mang, Caroline 14, 33, 413

Manteuffel, Ernst Christoph Graf von 287

Manzolini, Giovanni 173

Maria Theresia, Erzherzogin von Österreich 19, 22-23, 24, 28, 35-36, 73, 91

Marie Karoline, Erzherzogin von Österreich 70

Marolois, Samuel 241-242

Marschall, Rudolf 382

Marsili, Emilio 189, 195

Marsili, Luigi Ferdinando 173-174

Marsuppini, Carlo 154

Martin, Jean 240

Martini, Giacomo de 179, 182, 185, 194

Martini, Karl Anton von 23, 383

Marx, Bele 133

Masaryk, Thomas Garrigue 146, 383

Massimiliano I Giuseppe > Maximilian I. Josef, König von Bayern 181

Matteini, Teodoro 186-187, 193-194

Mauer, Hans 383

Maulbertsch, Franz Anton 335

Mauthner, Ludwig 18, 127, 385

Maximilian I., römisch-deutscher Kaiser 24, 50

Maximilian II. Josef, König von Bayern 50

Mayr, Andrea 7-8, 10, 14, 135, 381

Mazza, Giuseppe Maria 172

McIntyre, Chris 226-229, 234

McNeil Whistler, James 224

Mead, Richard 201

Medici, Cosimo de 163

Meister, Richard 13-14, 90, 135-136, 138-139, 413

Meitner, Lise 9, 34, 319-334, 386

Mellini, Pietro 156

Menger, Anton 125-127, 382

Menger, Carl 125-127, 382

Menghin, Oswald 78, 120

Menn, Barthélémy 275

Merkl, Adolf 382

Merkel, Ursula 288, 293-294, 413

Messerschmidt, Franz Xaver 28, 35-36, 337-338, 382, 405, 415

Meštrović, Ivan 140-141, 384

Metzner, Franz 373, 380

Meyer, Hans Horst 135, 384

Meynert, Theodor 384
Miklosich, Franz von 9, 26, 87, 90-95, 101, 359-362, 383

Millais, John Everett 224

Milton, John 200-201

Mol, Hans 233

Molin, Girolamo Ascanio 180-181, 194

Molisch, Hans 135, 138-139, 382

Molmenti, Pompeo Gherado 191, 195

Molmenti, Pompeo Marino 192-193

Mommsen, Theodor 319, 324, 326, 329, 331, 334

Monico, Giuseppe 182

Montagu, Elizabeth 203-204

Montenari Vicentino, Giovanni 254

Morandi, Anna 173, 413

Moretus, Balthasar 245, 247

Morton, George 201

Mostny-Glaser, Grete 34, 386

Mozart, Wolfgang Amadeus 16, 28, 30, 41, 411

Much, Rudolf 135, 383

Mühlberger, Kurt 11-12, 14, 47-48, 50-53, 59, 65, 69, 72, 99, 101, 120, 147, 409, 414, 420

Müller, Albert 120-122, 126

Müller, Robert 121, 125

Müller-Deym, Joseph Graf von > Deym, Joseph Graf von 41

Müllner, Josef 73, 78, 358, 384-386, 414

Munk, William 215-216, 414

Murovec, Barbara 9, 101, 352-353, 355, 359, $362,414,418$

Mussafia, Adolf 73, 122, 124, 127, 383

Mussard, Gilles 133, 386

Myslbek, Josef Václav 370-372, 378, 406

Nahtigal, Rajko 360, 362, 365

Natter, Heinrich 383

Natter, Günter (Tobias) 35-39, 42, 48, 52, 56, 63, 66, 69, 414

Naudé, Gabriel 202, 210, 414

Necker, Jacques 269

Nelli, Mario 195

Němcová, Božena 369

Nemon, Oscar 132-133, 147

Neroni, Diotisalvi 160-161

Neruda, Jan 369

Nettinghofen (Nettekoven), Johann Adam von 63-66

Neumayr, Melchior 383 
Neusser, Edmund von 383

Nevile, John 211

Newton, Isaac 199-201, 204-205, 209-212, 340

Nicholas V, Pope > Nikolas V. 154

Nicholson, Ben 227

Nickmann, Karl 385

Nicolai, Thomas 328-329

Niedzielski, Julian 25

Niemann, George 87, 89, 93, 95, 404, 418

Nikolas V., Papst 154

Nikolaus II., Zar von Russland 276

Nipperdey, Thomas 105, 414

Nobel, Alfred 84

Nono, Urbano 192, 195

Nono, Luigi 190, 192-193

Nothnagel, Hermann 385

Obersteiner, Heinrich 385

Odofredo (Odofredus) 170

Oeser, Friedrich Adam 256, 261-263, 268

Oppolzer, Johann von 24, 384

Oppolzer, Theodor von 24, 28, 384

Oreffice, Pellegrino 192, 195

Orsi, Tranquillo 187-188, 194

Oser, Leopold 125, 127, 385

Östberg, Ragnar 345

Otterbeck, Christoph 306

Öttl, Anton von 51, 55, 64-65

Otto, Paul 323

Ovid 158

Özel, Cigdem 14

Pachtner, Dagmar 327, 330

Palacký, František 10, 367-380, 418

Palladio, Andrea 238-239, 247, 249-255

Palmieri, Giovanni Battista 178

Palotai, Gyula 346

Panfili, Pio 173

Pannolini, Francesco 174

Paoletti, Pietro 152, 188

Passeggeri, Rolandino de 170

Pasteur, Louis 107

Paul V., Papst 243

Pázmány, Péter 336

Pedrini, Filippo 176-177, 413

Pendl, Emanuel 17, 73, 382

Penker, Elisabeth 134

Perger, Ernest 57, 65-66
Pernkopf, Eduard 119, 127

Pernter, Josef Maria 138, 382

Perrault, Claude 240-241, 415

Peruzzi, Svetoslav 359-361, 409

Peter der Große 220

Peter I. Karadjordjevic, König der Serben, Kroaten und Slowenen 359, 361

Petrarch 162

Petzek, Joseph Anton 38

Petzval, Joseph Maximilian 385

Peuerbach, Georg von 23

Pfund, Roger 284-285

Philipp I., der Großmütige, Landgraf von Hessen 304, 309

Pictet, Marc-Antoine 271, 279, 281

Piermarini, Giuseppe 19

Pietschmann, Herbert 143

Pignatori, Carmine 263, 265

Pillhofer, Christine 131, 384

Piombo, Sebastiano del 189, 195

Pirnat, Nikolaj 365

Pirquet von Cesenatico, Clemens 385

Pisani, Almorò 179

Pius VII., Papst 174

Pixner, Franz 383

Pizzi, Angelo 181-182, 187, 190-194

Planck, Max 319-320, 325-327, 334

Platner, Ernst 291

Plečnik, Jože 9, 362-363, 365, 372, 409, 411, 415

Plinius der Ältere (Pliny the Elder) 149, 418

Pöch, Rudolf 29, 384

Politi, Odorico 186, 188, 193-194

Politzer, Adam 385

Pollack, Leopoldo 19, 21

Pompe, Ilse 385

Pope, Alexander 199-201, 403

Popiel, Antoni 379

Popp, Antonín 369

Popper, Karl 129-131, 133, 146, 384

Posch, Leonhard 40-41, 45

Posch, Wilfried 147

Pötzl-Malikova, Maria 8, 17, 35-36, 337-338, 415

Powolny, Michael 382

Pradier, James 269, 271, 278-279, 281-283, 285, 412

Prem, Josef 47-48, 67, 70

Prešeren, Johannes 354 
Prijatelj, Ivan 363-365

Pronner, Christoph Maximilian 305-306, 417

Pross, Helge 316

Ptolemäus, Claudius 339

Quaglio, Giulio 353-356, 404

Quarin, Josef von 11, 36-37, 44, 73, 385

Radauš, Vanja 384

Radetzky, Josef Wenzel von 92

Radon, Johann 145, 384

Raffael 340, 346

Rainer, Erzherzog von Österreich 70

Ramovš, Fran 365

Rastrelli, Francesco Bartolomeo 220

Rauch, Christian Daniel 294, 322

Ray, John 204, 210

Rayne, Max 233

Rechperger, Christian 52-53, 56-58, 65

Rechperger, Wilhelm von 56-58

Redlich, Oswald 23

Reininger, Robert 384

Renner, Karl 141

Rerrich, Béla 345

Reuter, Erich F. 137, 315, 318

Révai, Miklós 340

Ricci, Sebastiano 250-251

Richter, Elise 34, 385

Richter, Horst-Eberhard 316-317

Riedl, Josef 136, 384-385, 416

Riehl, Gustav 74-76, 78-81, 85, 183, 384, 414

Rietschel, Ernst 290-292, 294

Rigaud, Jean-Jacques 275, 285

Rinaldi, Rinaldo 179, 181-182, 194, 414

Ringel, Erwin 147

Rintelen, Anton 13

Ripa da Sannazaro, Francesco 20

Ripa, Cesare 176

Riviera, Tarsizio 176

Roccabonella, Pietro 235

Roder, André 382

Rodin, Auguste 108, 370-373, 375, 380, 410411, 419-420

Roeder, Emy 315

Rohan, Duc de 271, 408

Rohling, August 124-125

Rokitansky, Carl von 18, 24, 31, 101, 106, 383, 416, 419
Romány, Pál 347

Röntgen, Conrad W. 315, 317-318, 418

Roßbach, Arwed 297-298, 300

Rosselino, Antonio 155-156

Rossellino, Bernardo 115

Rosselli, Cosimo 153, 155, 159

Rossi, Giovanni Antonio de (genannt Rubeus) 237-238

Rossi, Pellegrino 278, 407

Roubiliac, Louis-François 151, 198-199, 201, 203-207, 210-211, 403

Rous, František 369

Rousseau, Jean-Jacques 9, 269, 271, 275, 278, 280-283, 405

Rubens, Peter Paul 244-247

Ruby, Sigrid 9, 307, 318, 409

Ruckh, Christoph 64, 66

Rüdiger, Julia 8, 14, 31, 73, 138, 416

Rudolf II., römisch-deutscher Kaiser 304

Rudolf IV., Erzherzog von Österreich 22, 24, 50, 69

Rudolf, österreichischer Kronprinz 109

Rysbrack, Michael 200, 250, 252, 419

Saccenti, Luigi, 178

Saff, Adalbert Eduard 384

Salmons, William 253

Šaloun, Ladislav 369, 374, 380

Salucci, Giovanni 275

Salutati, Coluccio 8, 149, 152-167

Salutati, Leonardo 152-167, 408

Sandrart, Joachim von 219, 417

Sanmicheli, Michele 239

Sancta Clara, Abraham 51, 237

Santi, Raffael > Raffael 346

Satzinger, Heinz 384

Saurau, Franz Graf von 37

Saussure, Horace-Bénédicte de 276, 278

Sbaraglia, Gerolamo 172

Scamozzi, Ottavio Bertotti 254-255

Scarpa, Antonio 19, 21

Scarpa, Carlo 31, 188

Schadow, Johann Gottfried 294

Schaper, Fritz 313-315, 404

Schatter, Serenus 237, 417

Scheemakers, Peter 200-201, 403

Schemper-Sparholz, Ingeborg 21, 33-34, 36-37, $62,151,366,417$ 
Schenkl, Karl 91-92, 383

Scherer, Rudolf von 74, 79, 135, 385

Scherpe, Johann 361, 383

Schickh, Georg Friedrich 51, 60-63, 65, 67

Schievelbein, Hermann 341

Schiller, Friedrich 25, 30, 322

Schindler, Franz Martin 74, 79, 385

Schinkel, Karl Friedrich 289-290, 322, 331

Schipper, Jakob 78, 384

Schirach, Baldur von 116

Schlittern, Paul Christoph von 50-51, 53, 59, 63-65, 67

Schlosser, Julius von 135, 139-140, 218, 220, 384, 417, 419

Schmidburg, Joseph Camilo von 355-356

Schmidgruber, Anton 384-385

Schmidt, Burghart 7

Schmidt, Gerhard 142

Schmidt, Rudolf 382

Schmitt-Maass, Silvia 9

Schmutzer, Ferdinand 130, 409

Schnirch, Bohuslav 369

Scholz, Heinrich Karl 383-384

Schomburg, Christoph 66-67

Schönbauer, Leopold 81, 110, 113-114, 403, 417

Schönleben, Johann Ludwig 354

Schopenhauer, Arthur 29

Schrauf, Albrecht 382

Schrauf, Karl 70, 97, 99, 417

Schrödinger, Erwin 142-144, 384

Schrödl, Leopold 28, 43-44, 382

Schrötter von Kristelli, Leopold 73-74, 77-79, 85,384

Schuh, Franz 11, 24, 26, 384

Schulz, Josef 367-369

Schupp, Johann Balthasar 307

Schuricht, Christian Friedrich 40

Schuschnigg, Kurt 13, 137

Schütz, Gustav 384

Schwanthaler, Ludwig von 112, 367

Schwartz, Stefan 73, 383

Schwarzbach, Anna Franziska 319, 330-333

Schwerczek (Schwerzek), Carl 25

Seebacher, Felicitas 107-108, 280, 417

Seegen, Josef 383

Seffner, Carl Ludwig 297

Seib, Wilhelm 382
Seifert, Franz 27-28, 138-139, 382-384

Seipel, Ignaz 14, 135, 383

Selinger, K. 383

Sellius, Gottfried 261

Selva, Giannantonio 185, 193-194

Selvatico, Pietro 188, 191

Semmelweis, Ignaz Philipp 141-142, 343-344, $348,385,404,414$

Sénebier, Jean 278

Seneca 243-247

Serra, Luigi 169, 420

Settignano, Desiderio da 154

Shakespeare, William 200-201

Sickel, Theodor von 29, 32, 384

Siegel, Heinrich 382

Siemering, Rudolf 341

Signorelli, Luca 165

Sigrist, Franz 335-336, 410, 413

Singer Sargent, John 224

Skoda, Josef von 24, 106, 384

Skraup, Zdenko Hans 383

Slomšek, Anton Martin 360

Smetana, Bedřich (Friedrich) 379

Smith, Robert 203-204, 206-211

Sölch, Johann 385

Sonnenfels, Josef von 23, 28, 36, 41, 69, 124, 127, 382

Sorbait, Paul 23

Southwood Smith, Thomas 215-216

Sozzini, Mariano 162, 408

Späth, Ernst 383

Spaun, Franz Anton 64-67, 69

Sperges, Joseph Freiherr von 19

Spiera, Giacomo 180-181, 189-190, 194

Spurzheim, Johann Gaspar 217

Srbik, Heinrich von 13, 135

Srpek, Tomáš Bohdan 379

Staël, Germaine de 285

Starhemberg, Guido Graf von 61-62

Stefan, Josef 29, 384

Steger, Friedrich 382

Stein, Anton 38

Stein, Lorenz von 382

Stemolak, Karl 116-117

Sternberg, Kaspar Maria Graf von 369

Stieger, Rolf 308

Stifft, Andreas Josef von 11, 29-30, 36-37, 44, 73, 106, 382 
Stoerk, Karl 26, 125, 127, 385

Stoll, Maximilian 23

Strahammer, Franz 385

Stránský, František 369

Straßmann, Fritz 321

Stróbl, Alajos 343-344

Strobl, Julia 14

Studniczka, Franz 298

Stüler, Friedrich August 340-341, 404

Šubic, Georg 357

Šubic, Johann (Janez) 356-357

Sucharda, Antonín 371

Sucharda, Stanislav 369, 371-378, 380, 411, 418

Suess, Eduard 11, 14, 34, 91,122, 126

Suetonius (Gaius Suetonius Tranquillus) 202

Sutherland, Graham 233

Swieten, Gerard van 11, 13, 26, 28, 30, 35-37, $73,106,338,382$

Swoboda, Alexius von 31, 383

Swoboda, Heinrich 135, 385

Szemethy, Hubert D.8, 15, 23, 89, 418

Szent-Györgyi, Albert von 348-349

Tagliacozzi, Gaspare 172

Talrich, Jacques 216

Tambroni, Clotilde 176

Tandler, Julius 135-136, 384

Taussky-Todd, Olga 34, 386

Tautenhayn, Josef 382

Tebaldeo, Antonio 150

Telesko, Werner 50, 69-70, 108, 410, 414, 418

Temanza, Tommaso 193, 254

Tenerani, Pietro 278

Thaer, Albrecht 322, 331

Thalnitscher (Dolničar), Johann Anton 353-356, 358,412

Than, Károly 341-342, 418

Thelusson, Madame de 269

Thorak, Josef 139-140, 384

Thubières, Anne-Claude-Philippe de, Comte de Caylus > Caylus 9, 257-268, 405, 416

Thun-Hohenstein, Leo Graf von 8, 11, 15, 23 , 87-102, 360, 383

Tieck, Friedrich 285

Tilgner, Viktor 22, 25, 28, 31, 357, 384, 420

Timanthes 245

Tito, Josip Broz 252

Tizian 179, 181-182, 194
Treischke, Heinrich von

Trembley, Abraham 278

Trenkwald, Josef Mathias 91-93

Trippel, Alexander 296

Tronchin, Théodore 269

Tršar, Drago 365

Trubetzkoy, Nikolai Sergejewitsch 384

Tschermak, Gustav 382

Tussaud, Marie 217

Twardowski-Conrat, Ilse 383

Tyers, Jonathan 205, 207

Tyl, Josef Kajetán 369

Tynjanow, Jurij Nikolaevic 220, 418

Ugry, Balint 9

Ultzmann, Robert 383

Umberto I of Savoy, König von Italien 174, 190, 195

Unger, Franz 382

Unger, Hella 383

Unger, Josef 25, 73, 125, 127, 383

Valvasor, Johann Weichard 354-355, 357-359, 414-415

Van Dyck, Anthonis 250

Varga, Imre 348

Varignana, Bartolomeo da 172

Varolio, Costanzo 172

Vasari, Giorgio 157, 161, 164, 167, 255

Vaucher, Samuel 279

Vega, Jurij 365

Vegio, Maffeo 162

Veith, Anton 367

Vermenoux, Madame de 269

Veronese, Paolo 251

Vignola > Barozzi, Giacomo 240-241, 247-249, 254

Vignoli, Farpi 177-178

Vincenzo, Rinaldo 195

Vinci, Leonardo da 110

Vio, Romano 196

Virchow, Rudolf 322-323

Vitruv 240-241, 247, 252-253

Vittorio Emanuele II, Re d'Italia 174, 190,195

Vlček, Bohumil 369

Vodnik, Valentin 357, 362, 409

Vogl, Annette 322

Vogt, Carl 316 
Volta, Alessandro 19

Vosmík, Čeněk 369

Wagner, Anton 369

Wagner, Otto 372

Wagner-Jauregg, Julius 29, 82, 135, 384

Wagner-Rieger, Renate 140, 142-143, 419

Wahlberg, Wilhelm Emil 21, 25, 382

Wakil, Mitra 328-329

Walker, Richard 206, 208-210

Warburg, Aby 266

Watts, George Frederick 224

Weber, Cornelia 226

Wegscheider, Rudolf 135, 138-139

Weichselbaum, Anton 80, 82

Weidel, Hugo 385

Weigel, Johann Christoph 51, 61

Weigler, Georg Leopold 64-66

Welz, Ferdinand 142-146, 382, 384

Wenzel, Matthias 311, 304

Werbőczy, István 336

Werner, Karl 385

Wettstein von Westersheim, Richard 382

Weyr, Rudolf 18, 385

Widerhofer, Hermann von 385

Wieser, Friedrich von 14, 135-136, 382

Wiesner, Julius von 28, 122, 124, 126-127, 383, 419

Wilczek, Hans Graf von 69-70

Wilhelm I., deutscher Kaiser 16, 323

Wilhelm II., deutscher Kaiser 324

Willoughby, Francis 204-210

Wilson, Tim 223-224

Winckelmann, Johann Joachim 9, 255-257, 261-268, 405, 409, 415-416, 419
Winckelmann, Johannes 306, 309-310

Winckler, Georg 101, 135, 146, 419

Wittig, Hermann 341

Wolf, Christa 334

Wolf, Erich 91

Wolff, Albert 341

Wolff, Christian 287

Wolff, Christine Alexandra 341, 419

Wolff, Ruth 162

Wolfsberger, Günther 133, 385

Wollek, Carl 48

Wren, Christopher 203-204, 403

Zaccagnini, Raffaele 33

Zahn-Harnack, Agnes von 317

Zandomeneghi, Luigi 184-185, 188-190

Zannoni, Ugo 195

Zastrau, Friedrich 342

Zauner, Franz Anton 21, 28, 41, 405

Zeiller, Franz Anton von 17, 28, 37, 382

Zenon von Kition 243

Zenzmaier, Josef 146-147

Ziegler, Caspar 239

Zimmermann, Robert von 382

Zita, Heinrich 138-139, 383, 417

Zois, Sigmund von 357

Zschokke, Hermann 91

Zuckerkandl, Emil 29, 111, 123-124, 127, 384

Zumbusch, Kaspar von 21-22, 25, 27, 71-80, 82, 85, 91-92, 103-104, 108-110, 112, 114, $118,383-385,412$

Zumbusch, Leo von 80

Zweig, Stefan 147 


\section{ORTSREGISTER}

Alba Iulia 338-339

Alba Iulia, Sternwarte 338-339

Alba Iulia, Trinitarierkirche 338

Altdorf, Universität 287

Amsterdam 282

Athen, Parthenon (Partenone) 181

Augsburg 72, 345

\section{Bamberg 43}

Basel 51, 307

Berlin 9, 16, 41, 70, 89, 106, 140, 213, 219-220, 276, 314, 320, 322-328, 330, 332-334, 340-343, 352, 379

Berlin, Charité 106, 109

Berlin, Humboldt-Universität 16, 319-334

Bologna 8, 18, 19, 31, 33, 145, 162, 169-178, 195, 202, 345, 353

Bologna, Accademia Clementina 174

Bologna, Anatomisches Theater (Anatomy Theatre) 172

Bologna, Archiginnasio 18, 171-173, 176, 178

Bologna, Biblioteca Universitaria 173-174

Bologna, Charter House (Kartause) 174

Bologna, Cimiterio Municipale 8

Bologna, City Hall 169

Bologna, Istituto delle Scienze 172-174

Bologna, La Certosa 174-178

Bologna, Modern Art Gallery 178

Bologna, Municipal Archive 176, 178

Bologna, Municipal Cemetery 169, 175-178

Bologna, Museo Civico Medievale 171, 178

Bologna, Museo delle Navi 173

Bologna, Palazzo Poggi 173-176, 178

Bologna, Pantheon 169, 176-178

Bologna, San Domenico 170, 171

Bologna, San Francesco 170

Bologna, Santi Vitali ed Agricola 31

Bologna, Specola 173

Bologna, Town Hall 169, 177-178

Bologna, Universität (University) 169-173

Brand bei Tannwald 73

Brandeis an der Elbe, > Brandýs nad Labem 379

Brandýs nad Labem 379

Buda > Budapest 9, 337-338, 340-348, 350
Budapest, Agrarministerium 346, 347, 349

Budapest, Burg Vajdahunyad 346

Budapest, Königlicher Palast 337

Budapest, Medizinhistorisches Museum 344

Budapest, Medizinische Universität 344

Budapest, Nationalbibliothek 338-339

Budapest, Poliklinik 343

Budapest, Semmelweis-Universität 348

Budapest, St.-Stephan-Krankenhaus 342-343

Budapest, Szépművészeti Muzeum 338, 350

Budapest, Technische Universität 342, 347

Budapest, Ungarische Akademie der Wissenschaften 339-341, 346

Budapest, Ungarisches Nationalmuseum 340

Budapest, Universität 341-342, 344, 347

Cambridge 201

Cambridge, Darwin College 223-224, 232-234

Cambridge, Trinity College 9, 151, 198, 201, 203, 204-208, 210, 212

Cambridge, University 201, 203, 205, 208-210, 212, 224

Carrara 278

Cluj-Napoca 345, 350

Debrecen, Universität 347-348

Děčín 89

Dresden, Staatliche Museen 290, 301

Dublin 201

Eger 335-337

Fiesole 8, 150-155, 157-158, 163, 165-167

Fiesole, San Girolamo 163

Fiesole, San Romolo 152-153, 155, 160, 165

Florenz (Florence) 152-154, 157-158, 165-167, 213, 244, 255, 275

Florenz (Florence), Badia Fiorentina 154, 161

Florenz (Florence), Museo del Bargello 162

Florenz (Florence), Ospedale degli Innocenti 343

Florenz (Florence), San Miniato al Monte 153-154

Florenz (Florence), Santa Croce 154

Florenz (Florence), Santa Maria del Fiore 157

Freising 72 
Gablonz an der Neiße > Jablonec nad Nisou 73

Genf 9, 269-270, 275-283, 285

Genf, Akademische Bibliothek 279

Genf, Bibliothèque de Genève 272-279, 281

Genf, Botanischer Garten 276, 280

Genf, Friedhof von Plainpalais 271-272

Genf, Île Rousseau 282

Genf, Kathedrale Saint-Pierre 271

Genf, Musée Rath 278-279

Genf, Orangerie 269-270, 276, 278-283, 285

Genf, Palais Eynard 275, 279, 284-285

Genf, Parc des Bastions 269-270, 279, 281-283, 285

Genf, Société des Arts 275, 279

Genf, Uni-Dufour 284-285

Genf, Universität 278, 285

Gießen 9, 303-318

Gießen, Alter Friedhof 309-311

Gießen, Altes Schloss 316

Gießen, Festungswälle 309, 313

Gießen, Friedhofskapelle 311-312

Gießen, Justus-Liebig-Universität 303, 315

Gießen, Ludoviciana 304, 309, 312

Gießen, Neues Schloss 316

Gießen, Ostanlage 313-316

Gießen, Universitätsarchiv 306, 318

Gießen, Universitätshauptgebäude 305-306, 308, 314-315

Göttingen 106

Graz 345, 353

Greifswald 106

Gjölbaschi-Trysa 95

Gyulafehérvár > Alba Iulia 338-339

Hamburg 41, 282

Hannover 87, 288-289

Heidelberg 341

Hertfordshire, University 223, 224-231, 234

Jablonec nad Nisou 73

Jena 307

Kaliningrad, Universität 341

Karlsburg > Alba Iulia 338-339

Kolozsvár > Cluj-Napoca 345

Krakau 379

Kiel 329

Königsberg, Universität > Kaliningrad, Universität 341
Kutná Hora, Schloss Kačina 40

Kuttenberg > Kutná Hora 40

Laibach > Ljubljana 9, 351-366

Landshut 327

Langensalza 89

Leiden 307,312

Leipzig 9, 287-289, 292-300, 307

Leipzig, Karl-Marx-Universität 289, 296-297, 299

Leipzig, Altes Rathaus 287, 289

Leipzig, Augusteum 9, 287, 289-291, 297, 300

Leipzig, Campus am Augustusplatz 299

Leipzig, Neues Augusteum 300

Leipzig, Stadtgeschichtliches Museum 289, 292, 297-298, 301

Leipzig, Universität 80, 287, 289-293, 296-301

Leipzig, Universitätsarchiv 288, 296, 299, 301

Leipzig, Universitätskirche St. Pauli 289, 299

Lemberg > Lwiw 379

Limyra 22

Linz, Kunstuniversität 147

Ljubljana 9, 352, 361-362, 366

Ljubljana, Collegium Carolinum 354

Ljubljana, Gedächtnisweg 353

Ljubljana, Kathedrale Hl. Nikolaus 354

Ljubljana, Krainisches Landesmuseum Rudolfinum > Nationalmuseum 356, 358

Ljubljana, National- und Universitätsbibliothek 353, 362-363, 365

Ljubljana, Nationalmuseum 356-357, 366

Ljubljana, Parlament 353

Ljubljana, Präsidentenpalast 353

Ljubljana, Seminarbibliothek 354-356

Ljubljana, Stadtmuseum 361

Ljubljana, Universität 353, 360-362, 365-366

Ljubljana, Universitätshauptgebäude 353, 362, 364-365

Ljutomer 359-360

London 9, 201, 207, 212-213, 216, 224-225, 249, 252, 254, 256, 276, 358

London, British Museum 204, 205, 207, 256

London, Chiswick House 250

London, Royal Academy of Sciences 173

London, University College London 214, 216, 221

London, University's Botanic Garden 208

London, Vauxhall Gardens 205

London, Victoria \& Albert Museum 156, 207 
London, Westminster Abbey 17

Luttenburg > Ljutomer 359-360

Lwiw 379

Mailand (Milano) 9, 19, 188, 242

Mailand (Milano), Universität 19, 180, 184

Marburg an der Drau > Maribor 359, 362

Marburg 304-307, 309, 311

Maribor 351, 353, 359, 362

Mödling, Waisenhaus 27

München 8, 72, 96, 256, 313, 328-329, 340, 353, 367

München, Polytechnische Schule 72, 108

New York, Rockefeller Institute for Medical Research 82, 84-85

Niederösterreich 60, 79

Niederösterreich, Schallaburg 44

Niederösterreich, Stift Melk 56-60, 65, 70

Nová Paka 371

Nürnberg 51, 58, 65, 69, 164

Oxford (Universität) 201, 266, 307, 312

Oxford, Bodleian Library 198

Padua 19, 33, 89, 235, 247-248

Padua, Basilica del Santo 237-239

Padua, Palazzo Bo 18

Padua, San Francesco Grande 235-236

Pannonhalma, Benediktinerstift 339

Paris 41, 202-203, 240, 276, 278, 372

Paris, Académie des savants (Académie des sciences) 173

Paris, Bibliothèque Sainte Geneviève 202-203, 210

Pavia 16, 19-21, 34

Pavia, Anatomisches Theater 21

Pavia, San Epifanio 20

Pavia, Universität 19-21, 31

Pécs 342

Pécs, Universität 347

Pest > Budapest 9, 337-338, 340-342, 344-348, 350

Pisa, Campo Santo 18

Prag 10, 62, 97, 102, 353, 367, 370-373, 377-380

Prag, Chotek-Archiv 41

Prag, Kunstgewerbeschule 371-372
Prag, Nationalmuseum 367-368, 370, 373, 380

Prag, Pantheon 367-369, 380

Prag, Patriotisches Museum/Palais Nostitz 367-368

Prag, Vyšehrad 378

Regensburg, Walhalla 18, 367

Richmond 200-201

Rom 33, 151, 154, 164, 170, 174, 182, 185, 187, 221, 239, 244, 256, 261-262, 264, 353

Rom, Lateransbasilika 66

Rom, Museo Nazionale del Risorgimento 190, 196

Rom, Museo Nazionale Palazzo Venezia 163

Rom, Pantheon 17-18

Rom, St. Paul vor den Mauern (San Paolo fuori le mura) 66

Rom, St. Peter (San Pietro) 16

Rom, Santa Maria del Popolo 16

Rom, Santa Maria Maggiore 163-164

Rotterdam 288

Salzburg, Benediktiner-Universität 237

Samothrake 22, 95

Siena, Palazzo Pubblico 345

Sopron, Universität 347, 349

Stockholm, Nationalmuseum 341

Stowe, Temple of British Worthies 200-201

Sankt Petersburg 220, 276

Szeged 344-348

Szeged, Domplatz 345-346, 349

Teheran 379

Temesvár > Timişoara 346

Tetschen $>$ Déčín 89

Timişoara 346

Toulouse 345

Trient 336

Tübingen 307, 312

Venedig 8, 43, 141

Venedig, Accademia di Belle Arti 8, 179-180, 182, 184-187, 190-193, 195-196

Venedig, Ai Frari 16, 184

Venedig, Fondazione Giorgio Cini 188

Venedig, Gallerie di Venezia 179

Venedig, Markusplatz 345

Venedig, San Giovanni e Paolo 16 
Venedig, San Marco 182-183, 189

Venedig, Santa Chiara 185

Venedig, Santa Maria dei Frari 278

Venedig, Santissimo Nome di Gesù 185

Versailles, Trianon 344

Vicenza 254

Vicenza, Basilica Palladiana 254

Vicenza, Villa Valmerana 254

Wien (Vienna) 8, 11, 15-16, 18-22, 28-32, 35-37, 40-45, 47-48, 50-51, 53-55, 58, 60, $65,70,72,74-76,79-80,82-83,87,89-$ $100,103,105,107-110,112,116,125-126$, 141, 151, 335, 369-373, 379

Wien, Akademie der bildenden Künste 25, 28, 44, 72, 87, 91, 95, 140, 145

Wien, Allgemeines Krankenhaus 16, 19, 26, 30 , 37, 80, 103, 105-107, 111, 113-115, 118

Wien, Alte Universität 30, 50, 69

Wien, Arkadenhof 7, 8, 11-14, 16-34, 43-44, 71-75, 77-91, 93, 95, 98, 100-104, 106, 108-113, 119-131, 133-136, 138-139, 141, 143, 145-147, 151, 198, 212, 257, 300, 344, 360-361

Wien, Augustinerkirche 16

Wien, Belvedere 35-36, 42, 45, 61-62, 69-70, 111,118

Wien, Billrothhaus 115

Wien, Botanisches Institut 38-39, 41, 44-45

Wien, Freud Museum 133

Wien, Grinzinger Friedhof 139

Wien, Hauptgebäude der Universität Wien 7, 12, $14,17,52,55-57,59,61-62,64,67,73,85$, 99-100, 119-120, 126, 128

Wien, Haus der Gesellschaft der Ärzte in Wien > Wien, Billrothhaus 18, 115

Wien, Hernalser Friedhof 18

Wien, Hofbibliothek 51, 335

Wien, Hofburg, Leopoldinischer Trakt 145
Wien, Josephinum 21, 29, 31, 116, 118

Wien, Juridicum 142

Wien, Kaiserliche Gemäldegalerie 43

Wien, Karlskirche 16

Wien, Kunstgewerbeschule 73-74

Wien, Kunsthistorisches Museum 52, 58, 140

Wien, Künstlerhaus 73-74, 371

Wien, Medizinische Universität 116, 118

Wien, Naturhistorisches Museum 15, 30, 43-45

Wien, Neue Aula > Alte Universität 30, 50, 69, 335

Wien, Niederösterreichisches Landhaus 27

Wien, Oberes Belvedere 43

Wien, Österreichische Akademie der Wissenschaften 359

Wien, Österreichische Nationalbibliothek 29, 34, 86-87, 111, 118, 147

Wien, Österreichisches Staatsarchiv 38, 51, 53 , 87,91

Wien, Ringstraße 14-15, 73, 85, 87, 108, 141

Wien, Rudolfinerhaus 103, 106-107, 109, 118

Wien, Schillerplatz 25

Wien, Semmelweis-Frauenklinik 344

Wien, Sonnenfelsgasse 68-69

Wien, St. Marxer Friedhof 30

Wien, Universitätsarchiv 8, 24, 68, 35, 37, 47, 70, 72, 75, 78, 99, 101, 126, 135

Wien, Universitätskirche (Jesuitenkirche) 17, 37, 40

Wien, Universitätskirche (Votivkirche) $>$ Wien, Votivkirche 16

Wien, Votivkirche 16

Wien, Wienbibliothek im Rathaus 87, 95, 97, 102

Wien, Zentralfriedhof 16, 18, 72, 79, 85, 103, 140

Zürich, Universität 106, 109, 111 


\section{BIBLIOGRAFIE}

M. Aaronberg Lavin, Giovannino Battista: A Study in Renaissance Religious Symbolism, in: Art Bulletin 37, I955, S. 85-IOI.

S. Abend, Götter in Weiß. Arztmythen in der Kunst, Hilden 20I0, S. 130-I36.

A. Ackermann/ St. Freyer (Hg.), Standesgemäß? Jenaer Professorenporträts zwischen Adel und Neuzeit, Weimar 20I5.

J. Amann-Bubenik, Merkur besucht die Universität Wien. Zur Dichterkrönung des Petrus Paganus, in: Neulatein an der Universität Wien (hrsg. von C. Gastgeber und E. Klecker), Wien 2008, S. 143-175.

Ch. Aichner/B. Mazohl, La riforma scolastica di Thun-Hohenstein I849-1860, in: La scuola degli Asburgo. Pedagogia e formazione degli insegnanti tra il Danubio e il Po (I773-1918) (hrsg. von S. Polenghi), Torino 20I2, S. I79-209.

Anonym, Das Augusteum und dessen Übergabe an die Universität Leipzig am dritten August I836, Leipzig 1836.

I. ArIAS, Die Medizinische Fakultät von 1945 bis 1955: Provinzialisierung oder Anschluss an die westliche Wissenschaft?, in: Zukunft mit Altlasten. Die Universität Wien 1945 bis 1955 (hrsg. von M. Grandner et al.), Innsbruck/Wien u. a. 2005 , S. $68-88$.

I. ArIas, Felix Mandl. Chirurg im Wiener Gemeinderat/Leopold Schönbauer. Chirurg und Abgeordneter zum Nationalrat, in: Universität - Politik - Gesellschaft (hrsg. von M. Ash/J. EHMER), Göttingen 2015, S. 319-328.

D. Angeli, Mino da Fiesole, Florenz 1905.

G. ANSAldi, Cenni biografici die personaggi illustri della città di Pescia e suoi dintorni, Pescia 1872.

K. Arnold-Forster, ,A Developing Sense of Crisis': A New Look at University Collections in the United Kingdom, in: Museum International, 52:207, 2000, S. IO-I4.

A. Assmann, Texts, Traces, Trash: The Changing Media of Cultural Memory, in: Representations, 56, I996, S. I23-I34.
J. Assmann, Collective Memory and Cultural Identity, in: New German Critique, 65, 1995 , S. $125-133$.

J. J. Bachofen, Die Sage von Tanaquil. Eine Untersuchung über den Orientalismus in Rom und Italien (1870), Basel I95I.

M. Baker, The Portrait Sculpture, in: The Making of the Wren Library (hrsg. von D. McKiтTERICK), Cambridge I995, S. IIO-I37.

M. BAKER, The making of portrait busts in the mid-eighteenth century: Roubiliac, Scheemakers and Trinity College, Dublin, in: Burlington Magazine, CXXXVII, 1995, S. 82I-83I.

M. Baker, Busts and Friendship: The Identity and Context of William Murray's Version of Roubiliac's Bust of Pope, in: Sculpture Journal, XXII, 20I3, S. 65-76;

M. Baker, The Marble Index. Roubiliac and Sculpted Portraiture in Eighteenth-Century Britain, New Haven 2014.

M. Baker, Fame and Friendship. Pope, Roubiliac and the Portrait Bust, Waddesdon 2014.

F. Bargilli, La Cattedrale di Fiesole, Florenz I883.

I. Barta, Familienporträts der Habsburger. Dynastische Präsentation im Zeitalter der Aufklärung, Wien 2008.

E. BAssi, La Regia Accademia di Belle (vedi n. 6), S. 48. La targa recitava: RELIQVAE PHIDIACI OPERIS / E PARTHENONE ATHENARVM GYPSO DESVMPTAE / MDCCCXX. / EX MVNIFICENTIA REGIS ANGLIAE. Cfr. Antonio Emmanuele Cicogna, Corpus delle iscrizioni di Venezia e delle isole della laguna veneta di Emmanuele Antonio Cicogna ovvero riepilogo sia delle Iscrizioni edite pubblicate tra gli anni 1824 e 1853 che di quelle inedite conservate in originale manoscritto presso la Biblioteca Correr di Venezia e dal I867, anno della morte dell'insigne erudito, rimaste in attesa di pubblicazione (hrsg. von P. Pazzi), Venezia 200I. 
M. BAXANDALL, Patterns of Intention, New Haven/ London 1985.

I. Beier, Carl Kundmann, ungedr. Dipl.-Arb., Univ. Wien 1994.

P. Bellettini (Hg.), L’Archiginnasio: il Palazzo, l'Università, la Biblioteca, Bologna 1987; Biblioteca Comunale dell'Archiginnasio, Florenz 200I.

I. Benedek, Ignaz Philipp Semmelweis (I8I8I865), Wien 1985 .

J. Bentham, Codicil to Bentham's Will, 29 March and 9 October 1824, in: Bentham's Auto-Icon and Related Writings (hrsg. von J. E. CRIMMINS), Bristol 2002.

M. BERDIČ, Javna plastika Viktorja Gojkoviča, in: Viktor Gojkovič. Kipar in restavrator (hrsg. von A. Gačnik), Ptuj 2005.

G. Bergamini, Giulio Quaglio, Tavagnacco 1994.

A. Bettelheim, Marie von Ebner Eschenbach. Wirken und Vermächtnis, Leipzig 1920.

M. Bettini, Antropologia e cultura romana. Parentela, tempo, immagini dell'anima (1986), Rom 1999.

A. Beyer, Das Haus der Gesellschaft der Ärzte in Wien. Billroth-Haus. Eine Untersuchung zur Baugeschichte und Ausstattung, MA-Arbeit, Universität Wien 2016.

Th. Billroth, Ueber die Verwendung vom Bildhauermeissel bei Osteotomien, in: Wiener Medizinische Wochenschrift, Nr. I8 (I2. März I870), Sp. 28I.

Th. Billroth, Über das Lehren und Lernen der medicinischen Wissenschaften an den Universitäten der deutschen Nation. Eine Culturstudie, Wien I875.

D. Bindman, The Skeleton in the Cupboard: Jeremy Bentham's Auto-Icon, in: The Old Radical. Representations of Jeremy Bentham (hrsg. von C. Fuller), London 1998. S. 9-I5.

L. Blondel, Le cimetière de Plainpalais, Genève 1957.

F. De Boni, Biografia degli artisti, Venezia I840.

U. Boeck, Der Leibniztempel, in: Herrenhausen: die Königlichen Gärten in Hannover (hrsg. von M. vON KöNIG), Göttingen 2006, S. 245-246.

F. H. Вöскн, Wiens lebende Schriftsteller, Künstler und Dilettanten im Kunstfache. Ein Hand- buch für Einheimische und Fremde, Wien I822.

L. Bоенм, Libertas Scholastica und Negotium Scholare. Entstehung und Sozialprestige des akademischen Standes im Mittelalter, in: Universität und Gelehrtenstand I400-I800, Büdiger Vorträge 1966 (hrsg. von: H. RössKer/G. Franz ), Limburg 1970, S. 15-6I.

E. Börsch-Supan/D. Müller-Stüler, Friedrich August Stüler I800-I865, München/Berlin 1997.

J. BorchHardt, Georg(e) Niemann I84I-I9I2, in: Archäologenbildnisse. Porträts und Kurzbiographien von Klassischen Archäologen deutscher Sprache (hrsg. von R. Lullies/W. Schiering), Mainz I988, S. 80.

T. von BorodajKewicz, Aus der Frühzeit der Wiener Schule der Kunstgeschichte. Rudolf Eitelberger und Leo Thun, in: Festschrift für Hans Sedlmayr (hrsg. v. K. Oettinger/M. Rassem), München 1962.

P. Bracciolini, De vera nobilitate (hrsg. von D. Canfora), Rom 2002.

Ch. Brandhuber/U. Schachl-Raber (Hg.), Gymnasium Mortis. Das Sacellum der Universität Salzburg und seine Sitzgruft, Salzburg/ Wien/Berlin 2014.

H. Bredekamp, Vom Wachskörper zur Goldkrone. Die Versprechung der Effigies, in: Preußen I70I. Eine europäische Geschichte, 2 Bde., Berlin 200I.

K. Brenm, Das Goethe-Denkmal in Berlin, in: Fritz Schaper (Hg.), Die Wiederentdeckung des Denkmals, Goch 2000, S. 39-53.

H. Brocкhaus, Forschungen über Florentiner Kunstwerke, Leipzig 1902.

E. Broscheк, Matthias Wenzel. Ein Beitrag zur mittelhessischen Bildhauerkunst im 17. Jahrhundert, in: Mitteilungen des Oberhessischen Geschichtsvereins 8I, 1996, S. 227-260.

R. BRowning, The Bishop Orders his Tomb, verse 98, cit. The Poems of Browning. Volume Two: I84I-I846 (hrsg. von J. Woolford/D. Karlin), New York 199I.

J. Browne, Looking at Darwin: Portraits and the Making of an Icon, in: Isis, I00:3, 2009, S. 542570. 
R. BRUCK, Arwed Rossbach u. seine Bauten, Berlin 1904.

W. BRÜCKNER, Bildnis und Brauch. Studien zur Bildfunktion der Effigies, Berlin 1966.

A. Brulhart/E. Deuber Pauli, Ville et canton de Genève, in: Art et monuments, Genève 1985 .

M. BüCKLIng, Der Historiker Martin Georg Kovachich (I782), in: Franz Xaver Messerschmidt I736-I783 (Ausstellungskatalog Wien, Österreichische Galerie Belvedere), Wien 2002, S. 278-279.

T. BukLijas, Surgery and national identity in late nineteenth-century Vienna, in: Studies in History and Philosophy of Biological and Biomedical Sciences, 38 (2007), S. 756-773.

H. Burg, Der Bildhauer Franz Anton Zauner und seine Zeit, Wien I9I5.

F. Burger, Geschichte des florentinischen Grabmals von den ältesten Zeiten bis Michelangelo, Strassburg 1904.

R. Burgstaller/H. Posch, Zeitgenössische Kunst und Geschichte im Alten Allgemeinen Krankenhaus. Eine Dialogführung durch den Campus der Universität Wien, in: Update! Perspektiven der Zeitgeschichte (hrsg. v. L. ERKER et al.), Innsbruck/Wien/Bozen 20IO, S 748-753.

J. H. Burnett/D. Howarth/S. D. Fletcher, The University Portraits: Second Series, Edinburgh I986.

D. Buyssens, Galerie de portraits et collections iconographiques, in Patrimoines de la Bibliothèque de Genève: un état des lieux au début du XXIe siècle (hrsg. von D. Buyssens), Genf 2006.

D. Buyssens, La question de l'art à Genève. Du cosmopolitisme des lumières au romantisme des nations, Genf 2008.

A. P. de Candolle, Second rapport sur la fondation et l'état du Jardin Botanique de Genève, fait à l'assemblée générale des Souscripteurs et Donataires de l'Etablissement, le 30 avril I82I, Genf I82I.

D. CARL, Benedetto da Maiano. A Florentine Sculptor at the Threshold of the High Renaissance, Turnhout 2005, 2 vols.

C. C. Carus Gretschel, Die Universität Leipzig in der Vergangenheit und Gegenwart, Dresden I830.

E. Catra, Canova come Fidia: le metope e i fregi per il Tempio di Possagno, in: Canova. L'ultimo capolavoro. Le metope del Tempio, (catalogo della mostra di Milano, Galleria di Piazza Scala, 3 ottobre 20I3-6 gennaio 20I4), (a cura di M. Ceriana/F. Mazzocca E. Catra), Cinisello Balsamo 20I3, S. 35-5I.

A. C. De Caylus, Recueil d'Antiquités, Egyptiennes, Etrusques, Grecques Et Romaines, vol. VII (Supplement), Paris 1767.

I. Cerman, Chotkové. Př́iběh úřednické šlechty, Prag o. J.

E. Chapuisat, Jean-Gabriel Eynard et son temps, Genf 1952.

L. Cicognara, Prolusione, in: Discorsi letti nella grande aula dell'I. R. Accademia di Belle Arti in occasione della solenne apertura di una delle sue nuove Gallerie, e della pubblica distribuzione dei Premii ..., Venedig I8I7.

J. Ciperle, Jezuitski učni program in njihovi študiji v Ljubljani, in: Jezuiti na Slovenskem. Zbornik simpozija, (Redovništvo na Slovenskem, 3), Ljubljana 1992.

J. Ciperle/T. Dekleva/T. Anžur/I. Steiner, Univerza in njeni rektorji, Ljubljana 2006.

C. Clement, Musei sive bibliothecae, I635.

J. Colton, Kent's Hermitage for Queen Caroline at Richmond, in: Architectura, II, 1974, S.I8II90.

D. Constantine, Winckelmann and Sir William Hamilton, in: Oxford German Studies 22, 1993, S. 55-83.

Š. Čopič D. Prelovšek/S. Žitko, Outdoor Sculpture in Ljubljana, Ljubljana I99I.

Š. Čopič, Javni spomeniki v slovenskem kiparstvu prve polovice 20. stoletja, Ljubljana 2000.

A. Corboz, La place Neuve, composition progressive, in: Le Musée Rath a I5O ans (hrsg. von M. Pianzola), Genf 1976, S. 9-36, 23-24.

A. Corboz, Le palais Eynard à Genève: un „design" architectural en 1817 , in: Genava, 23, S. 195-275.

A. Corboz, La „refondation“ de Genève en I830 (Dufour, Fazy, Rousseau), in: Genava, 40, 1992, S. $55-85$. 
W. Davis, Winckelmann Divided, in: Ders. (Hg.), Replications. Archaeology, Art History, Psychoanalysis, University Park, Penn. I996, S. 257-265.

E. Décultot, Winckelmann et Caylus. Enquête sur les rapports de l'histoire de l'art au savoir antiquaire, in: Le Comte de Caylus. Les Arts et les Lettres (hrsg. von N. Cronk/K. Peeters), Amsterdam/New York 2004, S. 59-78.

V. Denkstein, Vývoj a koncepce Panteonu a umělecké výzdoby Národního muzea v Praze v I9. století, in: Časopis Národního muzea. Historické muzeum, CXLII, 1973.

A. DÉry, Budapest eklektikus épületszobrászata, Budapest I99I.

K. Deschmann, Führer durch das Krainische Landes-Museum Rudolfinum in Laibach, Laibach I888.

G. Didi-Huberman, Ähnlichkeit und Berührung. Archäologie, Anachronismus und Modernität des Abdrucks, Köln I999.

D. Döring (Hg.), Der junge Leibniz und Leipzig. Ausstellung zum 350. Geburtstag von Gottfried Wilhelm Leibniz im Leipziger Alten Rathaus, Ausstellungskatalog Leipzig, Rathaus der Stadt Leipzig, Berlin 1996.

E. Dolenc, „The Generation at a Closed Door“. Slovenian Intellectual Issues Between the Two World Wars, in: Slovene Studies, I-II, 200I, S. I5-I9.

E. Dolenc, Kulturni boj. Slovenska kulturna politika v Kraljevini SHS. I918-1929, Ljubljana I996.

J. G. DolničAR, Zgodovina ljubljanske stolne cerkve, Ljubljana I7OI-I7I4 (hrsg. von A. LAVRIČ), Ljubljana 2003.

F. Druffner, Identität statt Ähnlichkeit. Jeremy Benthams „Auto-Icon“, in: Zeitschrift für Ideengeschichte I/3, 2007, S. 84-96.

L. Drysdale, A World of Learning: University Collections in Scotland, Edinburgh 1990.

T. H. von Der Dunk, Das Deutsche Denkmal. Eine Geschichte in Bronze und Stein vom Hochmittelalter bis zum Barock. Köln/Weimar/ Wien I999.

F. Dupont, L'autre corps de l'empereur-dieu, in: Ch. Malamoud/J.-P. Vernant (Hg.), Corps des dieux, Paris I986.
Z. Dvořáková, Josef Václava Myslbek: Umělec a člověk uprostř̌ed své doby, Prag 1979.

J. Eckel, Der Sinn der Erzählung. Die narratologische Diskussion in der Geschichtswissenschaft und das Beispiel der Weimargeschichtsschreibung, in: J. Eckel/Th. Etzemüller (Hg.): Neue Zugänge zur Geschichte der Geschichtswissenschaft, Göttingen 2007, S. 20I-230.

R. von Eitelberger, Ferstel und die Votivkirche, in: Gesammelte Kunsthistorische Schriften, I, Wien I879, S. 27I-348.

R. von Eitelberger, Die Plastik Wiens in diesem Jahrhundert, in: Gesammelte Kunsthistorische Schriften, I, Wien I879, S. I04-I55.

R. von Eitelberger, Das Porträt, Vortrag gehalten im n.ö. Ständehaus in Wien I860, in: Gesammelte Kunsthistorische Schriften, III, Wien I884, S. I89-220.

N. Etienne/V. Chenal, Les demoiselles Rath \& l'institution artistique à Genève autour de I80o, in: Post tenebras luxe (hrsg. von D. Bernardi), Genf 2009, S. 66-87.

K. Eustace, Stowe and the Development of the Historical Portrait Bust, in: Apollo, CXXXXVII, I998, S. 3I-40.

G. Extermann, Attività di Lorenzo Bartolini in Svizzera, in: Neoclassico, 27-28, 2005 (2007), S. 44-89.

G. Extermann, Iguel, Charles, in: Artistes à Genève: de 1400 à nos jours (hrsg. von K. Tissot), Genf 2010, S. 332-333.

W. Eckart, Illustrierte Geschichte der Medizin: Von der französischen Revolution bis zur Gegenwart, Berlin/Heidelberg 20II.

J. ENDres, Knochenreste. Versuch einer begrifflichen Differenzierung (im Anschluss an Goethe), in: Kritische Berichte, 3, 2008, S. 7-18.

L. Erba/A. Morani, Monumenti e Lapidi conservati nel Palazzo Centrale dell'università di $\mathrm{Pa}$ via, Pavia 1977.

L. Erba (Hg.), Il Cortile di Medici e degli Artisti e il Teatro Anatomico dell'Università di Pavia (Katalog: Ch. Pagani), Pavia 2012. 
P. FARA, Framing the Evidence: Scientific Biography and Portraiture, in: The History and Poetics of Scientific Biography (hrsg. von T. Söderqvist), Aldershot 2007, S. 7I-92.

P. FARBAKY, Pálos könyvtár vagy nemzeti könyvtár? in: Művészettörténeti tanulmányok Mojzer Miklós hatvanadik születésnapjára (hrsg. von I. TAkÁcs et al.), Budapest I99I, S. 237-244.

D. Fassman, Leben und Thaten des Allerdurchlauchtigsten und Großmächtigsten Königs von Preußen Friederici Wilhelmi, 2 Bde., Hamburg/Breßlau I735-I74I.

E.-M. Felschow/C. Lind/N. Busse, Krieg, Krise, Konsolidierung. Die „zweite Gründung“ der Universität Gießen nach 1945, Gießen 2008.

E.-M. Felschow/C. Lind, Ein hochnutz, nötig und christlich Werck. Die Anfänge der Universität Gießen vor 400 Jahren. Gießen 2007.

H. von Ferstel, Bauten und Projekte für Wien (Ausstellungskatalog Hermesvilla), Wien 1984.

M. E. Fissell, Making Meaning from the Margins. The New Cultural History of Medicine, in: Locating Medical History. The Stories and Their Meanings (hrsg. von F. Huisman/J. H. WARNER), Baltimore/London 2004.

Fitzwilliam Museum (Hg.), Cambridge Portraits: from Lely to Hockney, Cambridge 1978.

W. Fleischhauer, Die ,Imagines Professorum Tubingensium'. Entstehungsgeschichte und Bildnisse, in: Erhard Cellius Imagines Professorum Tubingensium I596 (hrsg. von H. DeCKer-Hauff/W. Setzler, Bd. 2 (Kommentar und Text in Übersetzung), Sigmaringen I98I, S. $2 \mathrm{I}-32$.

H. Flower, Ancestor Masks and Aristocratic Power in Roman Culture, New York 1996.

C. Fontaine-Borgel, A la mémoire du sculpteur Jean Jacquet: 1754-1839, Genf I887.

A. Forschler-Tarrasch, Leonhard Posch, Porträtmedailleur und Bildhauer 1750-I83I, Berlin 2002.

E. Forssman, Goethezeit. Über die Entstehung des bürgerlichen Kunstverständnisses, Berlin 1999.

P. Fraccaro, L'Università di Pavia, Pavia 1957.

K. F. von Frank, Standeserhebungen und Gnadenakte für das deutsche Reich und die Österreichischen Erblande, Bd. I-5, Schloss Senftenegg 1967-1974.
D. Freedberg, The Power of Images. Studies in the History and Theory of Response, Chicago/ London 1989.

O. von Frisch, Billroth als Kriegschirurg während des Sommers 1870, in: Wiener Medizinische Wochenschrift 98, N.R. 3/4, 20. Jänner 1944

G. Frodl, Der Wiener Blumenmaler Johann Knapp und die botanische Illustration seiner Zeit, in: Johann Knapp (Hg.), Jacquins Denkmal, In: Österreichische Galerie, Bildheft I, 1976, S. 30-50.

M. FüsSel, Ritus Promotionis. Zeremoniell und Ritual akademischer Graduierungen in der frühen Neuzeit, in: Examen, Titel, Promotionen. Akademisches und staatliches Qualifikationswesen vom I3. bis zum 2I. Jahrhundert (hrsg. von C. Schwinges), Basel 2007, S. 4II-450.

M. Füssel, Akademische Rituale. Deposition, Promotion und Rektorwahl an der vormodernen Universität, in: Spektakel der Macht. Rituale im Alten Europa 800-I80o (hrsg. von B. Stollberg-Rilinger et al.), Darmstadt 2008, S. 39-43.

M. FüsSEL, Talar und Doktorhut. Die akademische Kleiderordnung als Medium sozialer Distinktion, in: Frühneuzeitliche Universitätskulturen. Kulturhistorische Perspektiven auf die Hochschulen in Europa (hrsg. von B. KRUGRichter/R. E. Mohrmann), Köln/Weimar/ Wien 2009, S. 245-27I.

M. FüsseL, Gelehrtenkultur als symbolische Praxis. Rang, Ritual und Konflikt an der Universität der Frühen Neuzeit, Darmstadt 2012.

G. Galavics, Die letzten Mäzene des Barock ungarische Kirchenfürsten, in: Künstlerischer Austausch. Akten des XXVIII. Internationalen Kongresses für Kunstgeschichte/Artistic Exchange. CIHA I5.-20. Juli 1992 Berlin (hrsg. von T. W. Gaehtgens), Berlin I993, Band II. S. $185-198$.

R. M. Galleni Pellegrini/C. Andrei/L. PassegGIA (Hg.), Scultore, poeta, architetto, 2 Bde. und CD-ROM, Fosdinovo 2013.

G. GANDOLFI, Imagines Illustrium Virorum: la collezione dei ritratti dell'Università e della Biblioteca Universitaria di Bologna, Bologna 2010.

F. Gardy, Les bustes de Rossi et de Cavour conser- 
vés à la Bibliothèque de Genève, in: Genava, 8 , I930, S. I2I-I27.

J. Gascoigne, Cambridge in the Age of Enlightenment: Science, Religion and Politics from the Restoration to the French Revolution, Cambridge 1988 .

P. Geimer, Die Vergangenheit der Kunst, Weimar 2002.

W. Genschorek, Wegbereiter der Chirurgie. Johann Friedrich Dieffenbach/Theodor Billroth, Leipzig 1982.

W. Gerabeck, Enzyklopädie Medizingeschichte, Berlin 2005.

O. H. Giglioli, La mitria del vescovo Leonardo Salutati nel Duomo di Fiesole, in: Rivista d'Arte 9, I916, S. 5.

O. H. Giglioli. Catalogo delle cose d'arte e di antichità d'Italia - Fiesole, Rom 1933.

W. Von Glaser, Julius Glaser. Bibliographisches Verzeichniß seiner Werke, Abhandlungen, Gesetzesentwürfe und Reden, Wien I888.

J.-A. Godoy, Le mausolée du duc Henri de Rohan (I579-1638): notes sur son effigie et son armure posthumes, in: Genava, 53, 2005, S. I23-153.

J. W. von Goethe, Plastische Anatomie, in: Goethe's Werke. Vollständige Ausgabe letzter Hand, 6o Bde., Stuttgart/Tübingen I827I842, Bd. 44.

E. Golay, Révolutions à Genève: une chronologie, in: Révolutions genevoises (Ausstellungskatalog Genf, Maison Tavel), Genf 1989.

L. Goldenbaum, Der Zeugniswert des Körpers oder anima forma corporis. Der quattrocenteske Bronzegisant des Sieneser Rechtsgelehrten Mariano Sozzini, in: kunsttexte 4, 20IO, S. I-24.

J. C. Gottsched, Das Andenken des vor Ioo Jahren in Leipzig gebohrnen Freyherrn Gottfried Wilhelms von Leibnitz, welches in hoher Gegenwart Ihrer Kön. Hoheiten, Beyder ältesten Kön. u. Chursächs. Prinzen, auf der PaulinerBibliothek zu Leipzig 1746 den Io May vorgelesen worden, in: Ausgewählte Werke (hrsg. von J. Birke/Ph. M. Mitchell), Bd. I-II, Berlin I968-I995, Bd. I, S. I88-203.

S. Grabner/M. Krapf (Hg.), Aufgeklärt bürgerlich: Porträts von Gainsborough bis Waldmüller I750-I840, München 2008.

C. Graepler, Imagines professorum Academiae
Marburgensis. Katalog von Bildnissen Marburger Hochschullehrer aus 5 Jahrhunderten, Marburg 1977.

F. Graf-Stuhlhofer: Opportunisten ..., in: Wiener Klinische Wochenschrift IIO, I998, S. I52I57.

R. Grandi, Le tombe dei dottori bolognesi: ideologia e cultura, in: Università e Società nei secoli XII - XVI, Atti del IX Convegno Internazionale di studio (Pistoia, 1979), o. O. 1983, S. 429-445.

R. Grandi, La Scultura nel Medioevo, in Storia Illustrata di Bologna, Repubblica di San Marino I987, vol. 2, S. 26I-280.

R. Grandi, Dottori, scultori, pittori: ancora sui monumenti bolognesi, in: Skulptur und Grabmal des Spätmittelalters in Rom und Italien, Akten des Kongresses, Scultura e monumento sepolcrale del tardo Medioevo a Roma e in Italia'(Roma 1985), Wien I990, S. 353-365.

R. Grandi, ,Ad modum doctoris': nuove considerazioni ai margini dei monumenti funerari del medioevo bolognese, in Di fronte all'aldilà. Testimonianze dall'area bolognese, atti del convegno di studi (Bologna 2002), Bologna 2004, S. I69-I85.

M. Grandner/G. Heiss/E. Klamper, Im Kampf um das Haupt des deutschen Helden Siegfried, in: FORUM, 37/444, I5. Dez. I990, S. 57-63.

S. Greenblatt, The Swerve. How the World Became Modern, New York 20II.

P. Griener, Le Antichità etrusche greche e romane I766-I776 di Pierre Hugues d'Hancarville, Rom 1992.

P. Griener, La République de l'oeil. L'Expérience de l'art au siècle des Lumières, Paris 20 o.

E. Griffey/B. Jackson, The Portrait as Leader: Commissioned Portraits and the Power of Tradition, in: Leadership, 6:133, 2010, S. I33-I57.

A. Grisebach, Römische Porträtbüsten der Gegenreformation, Leipzig 1936.

B. Grois, Das Allgemeine Krankenhaus in Wien und seine Geschichte, Wien I965.

M. GrütTner, Biographisches Lexikon zur nationalsozialistischen Wissenschaftspolitik, Heidelberg 2004.

P.-A. Guerretta, Pierre-Louis De la Rive ou la belle nature: vie et oeuvre peint, Genf 2002. 
H. Guest, On the shoulders of Giants: Portraits from the University of Cambridge, Cambridge 2008.

E. Guthey/B. Jackson, CEO Portraits and the Authenticity Paradox, in: Journal of Management Studies, 42:5, July 2005, S. I057-1080.

C. HaHN, Speaking Reliquaries, in: Gesta 36, no. I, 1997, S. 20-31.

J. Hamilton, The Role of the University Curator in the r99os in: Museum Management \& Curatorship, I4:3, I995, S. 73-79.

B. Намм, Hieronymus-Begeisterung und Augustinismus vor der Reformation. Beobachtungen zur Beziehung zwischen Humanismus und Frömmigkeitstheologie (am Beispiel Nürnbergs), in: Augustine, the Harvest, and Theology (1300-1650). Essays Dedicated to Heiko Augustinus Oberman in Honor of his Sixtieth Birthday (hrsg. von K. HaGen), Leiden I990, S. $127-235$.

P.-F. D’Hancarville, Antiquités étrusques, grecques et romaines, tirées du cabinet de M. Hamilton, vol. II, Naples 1766.

P.-F. D'Hancarville, Essay de Politique et de Morale Calculée, London 1752.

A. Hanreich, Ferdinand Schmutzer (I870-I928): der fotografische Nachlass, Diss. Wien 2012.

R. Hanslik, Das österreichische humanistische Gymnasium in seinem Werden und gegenwärtigen Sein. Festvortrag anläßlich der Hundertjahrfeier der Reform durch Franz Exner und Hermann Bonitz, gehalten an der Wiener Universität, Wien 195I.

M. Hansmann, Die Kapelle des Kardinals von Portugal in S. Miniato al Monte. Ein dynastisches Grabmonument aus der Zeit Piero de'Medicis, in: Piero de'Medici ,il Gottoso' (I4I6-69). Kunst im Dienste der Mediceer (hrsg. von A.Beyer/B. Boucher), Berlin I993, S. 29I-3I6

F. Hartt, The Chapel of the Cardinal of Portugal, I434-I459, at San Miniato in Florence, Philadelphia 1964 .

F. Haskell, The Baron d'Hancarville: An adventurer and art historian in eighteenth-century Europe, in: Oxford, China and Italy. Writings in Honour of Sir Harold Acton on His Eightieth
Birthday (hrsg. von E. Chaney/N. Ritchie), London 1984, S. I77-191.

F. Haskell, History and its Images, New Haven/ London I991.

F. von Hauer, Jahresbericht für I887, in: Annalen des k. k. naturhistorischen Hofmuseums, Bd. III, I888.

H. Haupt/G. Lehnert, Chronik der Universität Gießen, 1607-1907, Gießen 1907.

W. Heindi/M. TichY, „Durch Erkenntnis zu Freiheit und Glück ...". Frauen an der Universität Wien (ab 1897), Schriften des Universitätsarchivs, Universität Wien, 5, Wien 1990.

J. G. Herder, Lobschrift auf Winckelmann, in: Die Kasseler Lobschriften (cit. n. 17), S. 3I-63.

N. Heringman, Sciences of Antiquity, Oxford 2013.

V. Herremans (Hg.), Voorbeldige busten. Het borstbeeld in de Nederlanden 1600-1800, Ausst.-Kat. Antwerpen, Koninklijk Museum voor Schone Kunsten I2. 9.-I4. I2. 2008, Köln 2008.

C. G. Heyne, Lobschrift auf Winckelmann, Leipzig 1778.

R. Hiller von Gaertringen/N. Horsch, Incitamenta animi. Die Professorengalerie des 17. und I8. Jahrhunderts der Universitätsbibliothek Leipzig, in: Das Porträt als soziale Praxis (hrsg. von E. Krems/ S.Ruby), Berlin [im Druck].

L. Hölbling, Medaillen der Wissenschaft, Die Sammlungen des Archivs der Universität Wien, (Schriftenreihe des Universitätsarchivs, Universität Wien, I3. Band, Hrsg. von Kurt MüHLBerger/Franz Skacel), Wien 1998.

H. Ch. HöNEs, Kunst am Ursprung. Das Nachleben der Bilder und die Souveränität des Antiquars, Bielefeld 2014.

Z. Нојda/J. РокоRnÝ, Pomníky a zapomníky, Prag/Litomyšl 1996.

S. and J. Horner, Walks in Florence, Florenz I884.

M. Horster, Dem ,Florentiner Wanderer', in: Beiträge zur Ikonographie und Hermeneutik. Festschrift für Nikolaus Himmelmann, Mainz I988, S. 5II-5I4.

A. Hrausky/J. Koželj/D. Prelovšek, Plečnikova Ljubljana. Vodnik po arhitekturi, Ljubljana 1996. 
M. Hubensdorf, Medizinische Fakultät 1938I945, in: Willfährige Wissenschaft. Die Universität Wien 1938 bis 1945 (hrsg. von G. Heiss et al.), Wien 1989, S. 233-282.

A. von Hülsen-Esch, Gelehrte im Bild: Repräsentation, Darstellung und Wahrnehmung einer sozialen Gruppe im Mittelalter, Göttingen 2006.

A. von HülsEN-EsCH, Kleider machen Leute. Zur Gruppenrepräsentation von Gelehrten im Spätmittelalter, in: Die Repräsentation der Gruppen: Texte, Bilder, Objekte (ed. O.G. Oexle/A. von Hülsen-Esch), Göttingen 1998 , S. 225-258.

B. Hudales-Kori, Kipar Svetoslav Peruzzi, in: Zbornik za umetnostno zgodovino, n. F. VIII, 1970, S. 165-199.

G. Hufenreuter, Völkischer Antisemitismus, in: Handbuch des Antisemitismus (hrsg. von W. Benz), Bd. 3, Berlin/New York 20Io, S. 342.

A. Husslein-Arco (Hg.), Barocke Meisterwerke im Belvedere, Wien 2008.

A. Husslein-Arco/S. Koja (Hg.), Rodin und Wien, München 2010.

A. Husslein-Arco/G. Lechner (Hg.), M. Meytens der Jüngere, Wien 2014.

A. Janda-Bux, Die Entstehung der Bildnissammlung an der Universität Leipzig und ihre Bedeutung für die Geschichte des Gelehrtenporträts, in: Wissenschaftliche Zeitschrift der Karl-MarxUniversität Leipzig, Gesellschafts- und Sprachwissenschaftliche Reihe 4, 1954/44, S. I43-168.

A. Janda-Bux, Katalog des Kunstbesitzes der Universität Leipzig mit besonderer Berücksichtigung der Gelehrtenbildnisse, in: Wissenschaftliche Zeitschrift der Karl-Marx-Universität Leipzig. Gesellschafts- und Sprachwissenschaftliche Reihe 4, 1954/44, S. 169-197.

A. Jávor, Johann Lucas Kracker. Ein Maler des Spätbarock in Mitteleuropa, Budapest 2005.

J. Jernyei Kiss, Recentior Philosophia. A bölcsészeti fakultás ábrázolása Franz Sigrist egri mennyezetképén, in: „Ez világ, mint egy kert ...” Tanulmányok Galavics Géza tiszteletére (hrsg. O. Bubryák), Budapest 20Io, S. 67I-684.

J. Jones, The Portraits of Balliol College, Oxford I990.
L. Jordanova, Defining Features. Scientific and Medical Portraits 1660-2000, London 2000.

R. Jungblut, Hieronymus. Darstellung und Verehrung eines Kirchenvaters, Tübingen 1967.

F. M. Kammel, Charakterköpfe. Die Bildnisbüste in der Epoche der Aufklärung, Nürnberg 2013.

E. Kandel, Das Zeitalter der Erkenntnis. Die Erforschung des Unbewussten in Kunst, Geist und Gehirn von der Wiener Moderne bis heute, München 2012.

W. Kansteiner, Finding Meaning in Memory: A Methodological Critique of Collective Memory Studies, in: History and Theory, 4r:2, 2002, S. 179-197.

R. Kanz, Dichter und Denker im Porträt. Spurengänge zur deutschen Porträtkultur des I8. Jahrhunderts, München 1993.

D. R. Kelley, Vera Philosophia: The Philosophical Significance of Renaissance Jurisprudence, in: Journal of the History of Philosophy $14 / 3$, July 1976, S. 267-279.

H. Karner/W. Telesko, Die Jesuiten in Wien. Zur Kunst und Kulturgeschichte der österreichischen Ordensprovinz der Gesellschaft Jesu im 17. und I8. Jahrhundert, Wien 2003.

I. KeIBLINGer, Geschichte des Benedictiner-Stiftes Melk in Niederösterreich, seiner Besitzungen und Umgebungen, Bd. I, Wien I85I.

R. KeIL, Heinrich Friedrich Füger 175I-I818, Wien 2009.

M. KemÉny, A Magyar Tudományos Akadémia palotája, in: A Magyar Tudományos Akadémia és a művészetek a XIX. században - The Hungarian Academy of Sciences and the Fine Arts in the Nineteenth Century (Ausstellungskatalog Budapest, Magyar Nemzeti Galéria), Budapest 1992, S. II8-I25, English: S. 286-290.

A. Keune, Gelehrtenbildnisse der Humboldt-Universität zu Berlin. Denkmäler, Büsten, Reliefs, Gedenktafeln, Gemälde, Zeichnungen, Graphiken, Medaillen, Berlin 2000.

R. KINK, Geschichte der kaiserlichen Universität zu Wien, 2 Bde. Wien I854.

W. Kılıтsснка, Grabkult \& Grabskulptur in Wien und Niederösterreich, St. Pölten/Wien 1987.

K. Klebelsberg, A szegedi gondolat, in: Magyar Iparművészet, XXXV, 1932, S. 2-7. 
E. KLECKER, Universität und Hofbibliothek unter Karl VI, in: biblos 20I4, 2, S. 5-19;

D. KLeIn, Die Gießener Friedhöfe. Erinnerungsorte der Universitätsgeschichte, in: Panorama - 400 Jahre Universität Gießen - Akteure, Schauplätze, Erinnerungskultur (hrsg. von $\mathrm{H}$. Carl et al.), Frankfurt a. M. 2007, S. 250-255.

D. KLEIN, Röntgenstrahlen durchdringen Körper [= Denk-mal: unikunst 2], in: uniforum 3/2006, S. 8.

G. Klingenstein, Vorstufen der theresianischen Studienreform in der Regierungszeit Karl VI., in: MIÖG 76 (1968), S. 327-377.

$S$. KNöLL, Creating academic communities. Funeral monuments to professors at Oxford, Leiden and Tübingen: $1580-1700$, Equilibris $\mathrm{Pu}-$ bl. 2003 .

S. KNöll, Die Grabmonumente der Stiftskirche in Tübingen, Stuttgart 2007; dies., Vom Ruhm des Geistesadels: Professorengrabmäler in Oxford, Leiden und Tübingen, in: B. KRUGRichter/R.-E. Mohrmann (Hg.), Frühneuzeitliche Universitätskulturen, Köln et al. 2009, S. 273-284.

S. KNÖLL, Funeral monuments to professors in I7th century Oxford, in: Creating Identities. Die Funktion von Grabmalen und öffentlichen Denkmalen in Gruppenbildungsprozessen (hrsg. von R. SöRRIES), Norderstedt 2007, S. 23I-24O.

D. Косн/E. Косн (Hg.), Kulturkampf in Leipzig. Denkschrift zur Wiederaufbaudebatte Universitätskirche St. Pauli, Leipzig 2006.

L. A. Косн, The Early Christian Revival at S. Miniato al Monte: The Cardinal of Portugal Chapel, in: Art Bulletin 78, 1996, S. 527-555.

J. Kонц, Talking Heads. Reflexionen zu einer Phänomenologie der Büste, in: Kopf/Bild. Die Büste in Mittelalter und Früher Neuzeit (ed. J. KoHL/R. MülLER), München/Berlin 2007, S. 9-30.

J. КонL, Gesichter machen. Büste und Maske im Florentiner Quattrocento, in: Marburger Jahrbuch für Kunstwissenschaft 34, 2007, S. 77-I00.

J. KoHL, Sichtbar sein. Materialität und Facialität frühneuzeitlicher Porträts, in: Trajekte I7 (Zeitschrift des Zentrums für Literatur- und Kultur- forschung: Ausdruck. Erscheinung. Affekte) Io, 2008, S. 17-24.

J. Koнl, No one in particular. Donatello's San Rossore, in: Inventing Faces. Rhetorics of Portraiture Between Renaissance and Modernism (ed. M. Körte/S. Weppelman et al.), Berlin 2013, S. $15-28$.

A. KoHLer, Bildung und Konfession. Zum Studium der habsburgischen Studenten an Hochschulen aus dem Reich 1560-1620, in: Bildung, Politik und Geschichte. Studien zur Geschichte des europäischen Bildungswesens vom 16 . bis zum 20. Jahrhundert. (Wiener Beiträge zur Geschichte der Neuzeit, Bd. 5) (hrsg. von G. Klingenstein/H. Lutz/G. Stourzh), S. 64-I23.

M. Kolisko, Caspar von Zumbusch, Wien 193I.

A. Kovács, Program és műalkotás a I8. század végi Erdélyben. A gyulafehérvári Batthyaneum csillagvizsgálója, in: Stílusok, művek, mesterek. Erdély művészete I690-I848 között. Tanulmányok B. Nagy Margit emlékére (hrsg. von J. ORBÁN), Marosvásárhely/Kolozsvár 20II, S. II7I36.

A. Kovács, The Batthyaneum Observatory of Alba Iulia: A less known iconographic program, in: Batthyaneum: Omagiu fondatorului Ignatius Sallestius de Batthyan (I74I-I798) (hrsg. von D. H. Biro), Bucureşti 20II, S. 195-2I2.

M. Krapež/D. Prelovšek (Hg.), Architect Jože Plečnik (I872-1957), Ljubljana 2008.

S. Krasa-Florian, Franz Klein, ein Bildhauer des Klassizismus, in: Mitteilungen der Österreichischen Galerie I4, I970, S. 99-I49.

W. Krause, Die Plastik der Wiener Ringstraße, Von der Spätromantik bis zur Wende um I90o, mit I87 Abbildungen und 4 Textfiguren, Wiesbaden 1980 .

W. Krause, Kundmann, Karl, in: Neue Deutsche Biographie I3, Berlin 1982, S. 289-290.

M. Kretzschmar, Herrscherbilder aus Wachs. Lebensgroße Porträts politischer Machthaber in der Frühen Neuzeit, Berlin 2014.

E. KRIS/O. KURZ, Die Legende vom Künstler. Ein geschichtlicher Versuch, Wien 1934.

T. Кroha, Großes Lexikon der Numismatik, Gütersloh 1997.

B. Krug-Richter/R.-E. Mohrmann (Hg.), Früh- 
neuzeitliche Universitätskulturen, Köln et al. 2009.

M. Krummholz, Stanislav Sucharda (I866-1916), Nová Paka 2006.

F. Kürnberger, Ein Aphorismus zur DenkmalPest unserer Zeit, in: Die Gegenwart. Wochenschrift für Literatur, Kunst und öffentliches Leben, Io (30. März 1872), S. 154-156.

G. G. Küster, Altes und neues Berlin, 4 Bde., Berlin $1737-1769$.

M. Kuhlemann (Hg.), Vor ioo Jahren. Rodin in Deutschland, München 2006.

O. Kurz, Hagenauer, Posch and Mozart, in: The Burlington Magazine, vol. IIo, Nr. 783 (Juni I968), S. 327-328.

K. Kuthanová/H. Svatošová (Hg.), Metamorfózy politiky. Pražské pomníky 19. století, Prag 20I3.

G. Lahusen: Zur Funktion und Rezeption des römischen Ahnenbildes, in: Mitteilungen des deutschen archäologischen Instituts, Römische Abteilung (Römische Mitteilungen) 92, 1985 , S. 26I-289.

J. de Landtsheer, Pius Lipsius or Lipsius Proteus?, in: Between Scylla and Charybdis. Learned Letter Writers navigating the Reefs of religious and political Controversy in early modern Europe (hrsg. von J. De Landtsheer/H. NeLLEN), Leiden u. a. O. 20II, S. 303-349.

H. Lange, Mino da Fiesole. Ein Beitrag zur Geschichte der florentinischen und römischen Plastik des Quattrocento, München 1928.

R. Lane Poole, Catalogue of Portraits in the Bodleian Library, completely revised and expanded by K. Garlick, Oxford 2004.

K. A. LANG, Monumental unease: monuments and the making of national identity in Germany, in: Imagining modern German culture, I889I9IO. Studies in the history of art (hrsg. von F. Forster-Hahn), Washington D. C. 1996, S. 274-299.

C. LAPAIre, La sculpture à Genève au XIXe siècle, in: Genava, 27, I979, S. IOI-I2I.

C. Lapaire, James Pradier (1790-1852) et la sculpture française de la génération romantique, Milano 2010 .

I. Lavin, On the Sources and Meaning of the Re- naissance Portrait Bust, in: The Art Quarterly XXXIII, no. 3, 1970, S. 207-226.

A. LAVRič, Janez Gregor Dolničar in njegova Zgodovina ljubljanske stolne cerkve, in: I. G. Thalnitscher, Historia Cathedralis Ecclesiae Labacensis, Labaci I70I-I7I4.

R. Leitner, Das Reformwerk von Exner, Bonitz und Thun: Das österreichische Gymnasium in der zweiten Hälfte des i9. Jahrhunderts - Kaderschmiede der Wiener Moderne, in: Zwischen Orientierung und Krise. Zum Umgang mit Wissen in der Moderne (hrsg. von S. RINOFNER-KReIDL), Wien u. a. 1998, S. 17-69.

M. LEMBERG, god erbarme dich uber mich / bruder des begere ouch ich. Die Grablegen des hessischen Fürstenhauses, Marburg 20IO.

S. Frommel/E. Leuschner (Hg.), Architekturund Ornamentgraphik der frühen Neuzeit. Migrationsprozesse in Europa, Ausst.-Kat. Erfurt, Universität, Forschungsbibliothek Gotha 5.6.-3I. 7. 20I4, Rom 2014.

M. A. Lewenz/K. Pearson, On the Measurement of Internal Capacity from Cranial Circumferences, in: Biometrika, III/4, 1904 .

E. Liber, Budapest szobrai és emléktáblái, Budapest 1934.

R. Lightbown, Il busto di Giovanni Chellini al Museo Victoria \& Albert di Londra, in: Bollettino dell'Accademia degli Euteleti 26, 1962/63, S. $13-24$.

J. Lipsius, De Bibliothecis Syntagma, Antwerp 1602.

K. LeNGYeLnÉ KISs, 40 éve a köz szolgálatában, in.: 40 éves az Öntödei Múzeum 1969-2009 (hrsg. von K. Lengyelné Kiss/A. Schudich), Budapest 2009, S. 8-35.

H. Lentze, Die Universitätsreform des Ministers Graf Leo Thun-Hohenstein, Wien 1962.

M. Lobban, A History of the Philosophy of Law in the Common Law World, 1600-1900, vol. 8 of A Treatise of Legal Philosophy and General Jurisprudence (hrsg. von E. PatTaro), Dordrecht 2007.

H. Lorenz, Die Landgrafengräber und der Hochaltar in der lutherischen Pfarrkirche zu Marburg, in: Marburger Jahrbuch für Kunstwissenschaft I, 1924, S. 99-194.

K. Lovecky/B. Panning, ... nicht einmal ein 
Tröpfchen Blut. Adalbert Seligmanns Gemälde „Der Billroth'sche Hörsaal im Allgemeinen Wiener Krankenhaus", in: Wiener Geschichtsblätter, 68. Jg., Heft 3 (2013), S. 229.

H. LÜTHY, La banque protestante en France, de la Révocation de l'Edit de Nantes à la Révolution, I, Paris 1959.

Ks. Lukman, Pripombe o Dolničarjevi „Bibliotheca publica Labacensis“, in: Zbornik za umetnostno zgodovino, n. F. V/VI, 1959 (Zusammenfassung: Bemerkungen über Thalnitschers „Bibliotheca Lab. Publica“), S. 469-470.

T. Масно, Das prominente Gesicht. Notizen zur Politisierung der Sichtbarkeit, in: Politische Inszenierungen im 20. Jahrhundert. Zur Sinnlichkeit der Macht (hrsg. von S. R. ARnold/C. Fuhrmeister/D. Schiller), Wien 1998, S. I7I-I84.

C. Magnusson, Jean Jacquet et ses émules obscurs: les sculpteurs d'ornement à Genève au XVIIIe siècle, Doktorarbeit, Université de Lausanne, 2 OII.

T. Maisel, Gelehrte in Stein und Bronze, Wien/ Köln/Weimar 2007.

A. Mampieri, Filippo Pedrini e la decorazione della Sala degli Uomini Illustri e Benemeriti del cimitero comunale della Certosa, in: Aperto. Bollettino del Gabinetto dei Disegni e delle Stampe della Pinacoteca Nazionale di Bologna, n. 2, http://www.aperto.gdspinacotecabo. it/?q=node/477, abgerufen am 26. Jänner 2017.

A. Mampieri, Roma-Bologna. Le statue dei santi Pietro e Paolo per il completamento della facciata della Metropolitana di S. Pietro, in: Benedetto XIV e la facciata della cattedrale di Bologna (ed. R. Terra/G. Cavina), Ferrara 2008, S. 39-53.

S. M. Marconi, Gallerie dell'Accademia di Venezia. Opere d'arte dei secoli XVII, XVIII, XIX, Rom i97o.

M. Marek, ,Virtus' und ,fama'. Zur Stilproblematik der Porträtbüsten, in: Piero de'Medici ,il Gottoso' (I416-69) (hrsg. von A. Beyer/B. BOucher), Berlin I993, S. 34I-368.

C. F. A. Marmoy, The „Auto-Icon“ of Jeremy Bentham at University College London, in: Medical History, 2 (1958), 77-86.
L. Martines, The Social World of the Florentine Humanists, 1390-I460, Toronto $201 \mathrm{I}$.

A. MÁrtonfi, Initia astronomica speculae Batthyanianae Albensis in Transilvania ..., Gyulafehérvár 1798 .

A. Massiczer, Die Situation an der Universität Wien März/April 1938, in: Forschungen und Beiträge zur Wiener Stadtgeschichte, 2, 1978, S. 222.

B. Matsche-von Wicht, Franz Sigrist, I727-I803: Ein Maler des 18. Jahrhunderts, Weissenhorn I977.

P. Matussek, Bewegte und Bewegende Bilder. Animationstechniken im historischen Vergleich, in: Kunst der Bewegung. Kinästhetische Wahrnehmung und Probehandeln in Virtuellen Welten (hrsg. von C. Lechtermann/C. Morsch/H. WenzeL), Bern 2004, S. I-I3.

U. MAY, Fundstücke zur Freud-Biographik in der Exilpresse, in: Luzifer Armor, Heft 38 (19. Jg. 2006): Blicke auf Freud, S. I44-I47.

M. T. Mazzilli Savini (Hg.), Il cortile di Volta dell'Università di Pavia. Maestri e studenti: arte e memoria, Mailand 201 .

J. G. Megerle von Mühlfeld, Österreichisches Adelslexikon des I8. und 19. Jh., enthaltend alle von I7OI bis I820 von den Souveränen Österreichs wegen ihrer Verdienste um den Kaiserstaat in die verschiedenen Grade des deutscherbländischen oder Reichsadels erhobenen Personen. Ergänzungsband, Wien I824.

St. Meissel/Th. Olechowski (Hg.), Bedrohte Intelligenz. Von der Polarisierung und Einschüchterung zur Vertreibung und Vernichtung im NS Regime, Publikation zur Ausstellung der Universität Wien aus Anlass des Jubiläumsjahres, Wien 20I5.

R. Meister, Ruhmeshalle der Wiener Universität. Geschichte der Wiener Universität, Wien 1934.

R. Meister, Entwicklung und Reformen des österreichischen Studienwesens, Wien 1963.

L. Meitner/ O.R.Frisch, Desintegration of Uranium by Neutrons: a New Type of Nuclear Reaction, in: Nature I43, London 1939, S. 239-240.

Zs. MendöL, Zsolnay Ceramics in the Service of Architecture, in: Hungarian Ceramics from the Zsolnay Manufactory, I853-200I (hrsg. von É. Csenkey/Á. Steinert), New Haven/London 2002, S. 169-180. 
U. Merkel, Das plastische Porträt im I9. und frühen 20. Jahrhundert. Ein Beitrag zur Geschichte der Bildhauerei in Frankreich und Deutschland, Berlin 1995 .

R. Messbarger, The Lady Anatomist: the Life and Work of Anna Morandi Manzolini, Chicago 2010.

U. Middeldorf, A Forgotten Florentine Tomb of the Quattrocento, in: Raccolta di Scritti, that is Collected Writings, vol. III: 1974-1979, Florenz I98I, S. 69-74.

H. L. Mikoletzky, Hasner Ritter von Artha, Leopold, in: Neue Deutsche Biographie 8, Berlin 1969, S. 38.

M. Millisits, A Fechtig-háztól a Városligeti fasori református templomig, in: Budapest színes város. Zsolnay épületkerámiák. (Ausstellungskatalog Budapest, Ernst Múzeum), Budapest 2006, S. 5I-79.

C. Montandon, Le développement de la science à Genève aux XVIIIe et XIXe siècles. Le cas d'une communauté scientifique, Vevey 1975.

S. B. Montgomery, The Use and Perception of Reliquary Busts in the Later Middle Ages, Ann Arbor 1997.

J. Moore, History as Theoretical Reconstruction? Baron D'Hancarville and the Exploration of Ancient Mythology in the Eighteenth Century, in: Reinventing history: the enlightenment origins of ancient history (hrsg. von J. Moore et al.), S. 137-I67.

P. Moraw, Kleine Geschichte der Universität Gießen, Gießen 1990.

H. Morgenstern, Riehl Gustav, Dermatologe, in: Österreichisches Biographisches Lexikon. I815I950, 9 (42, 1985), S. I55.

M. A. G. [Giovanni Antonio Moschini], Alla ornatissima signora T. C. E., a Padova, in: Giornale sulle scienze e lettere delle provincie venete, VIII/7, I825 e M. S. Lilli, Rinaldo Rinaldi, in: Antologia delle Belle Arti, IV, I3-I4, 1980, S. 94-100.

K. MüHlberger, Dokumentation Vertriebene Intelligenz 1938. Der Verlust geistiger und menschlicher Potenz an der Universität Wien von 1938 bis 1945, Wien, 2. Aufl. 1993, S. 7-9

K. MüHLberger, Universität und Jesuitenkolleg, in: H. Karner/W. Telesko, Die Jesuiten in Wien, Wien 2003, S. 2I-37.

K. Mühlberger, Palast der Wissenschaft. Ein historischer Spaziergang durch das Hauptgebäude der Alma Mater Rudolfina Vindobonensis, Wien/Köln/Weimar 2007.

K. Mühlberger, Promotion und Adelsverleihung im frühneuzeitlichen Österreich. Zur Nobilitierungspraxis der Wiener Philosophischen Fakultät im I7. und I8. Jahrhundert, in: Examen, Titel, Promotionen. Akademisches und staatliches Qualifikationswesen vom I3. zum 2I. Jh. (hrsg. von R. C. Schwinges), Basel 2007, S. 575-624.

K. Mühlberger, Das „Antlitz“ der Wiener Philosophischen Fakultät in der zweiten Hälfte des 19. Jahrhunderts. Struktur und personelle Erneuerung. In: Eduard Suess und die Entwicklung der Erdwissenschaften zwischen Biedermeier und Sezession, hrsg. von J. SeIDL (= Schriften des Archivs der Universität Wien I4), Göttingen 2009, S. 67-104.

A. MüLler, Dynamische Adaptierung und „Selbstbehauptung". Die Universität Wien in der NSZeit, in: Geschichte und Gesellschaft, 23/4, 1997, S. 595-607.

A. Müllner, Ein Denkmal für den Freiherren Johann Weichard Valvasor, in: Argo, III, Mai I894, Sp. 97-98.

W. Munk, The Roll of the Royal College of Physicians of London, 3 Bde., London 1878.

B. Murovec, The Statue of the Communist Revolutionary Boris Kidrič (I912-I953). Art, Ideology and Ethics in Public Space, in: Acta historiae artis Slovenica, XVIII/2 (= Visualizing Memory and Making History. Public Monuments in Former Yugoslav Space in the Twentieth Century), 2013, S. I47-158, I86-187.

M. Natale, Le goût et les collections d'art italien à Genève du XVIIIe au XIXe siècle, Genf 1980.

G. (T.) Natter, Die Gemälde der Universität Wien. Eine historische Dokumentation, Ms., Wien 1988.

G. (T.) NatTeR, Icones Rectorum. Werden und Eigenart der Rektorengalerie an der Universität Wien, Ms. (Phil. Diss. an der Leopold-FranzensUniversität Innsbruck), Wien/Innsbruck 1988. 
G. NAude, Advis pour dresser une bibliothèque, Paris 1627; the English quotations used here are from John Evelyn's translation: J. Evelyn, Instructions concerning erecting of a library, London I66I.

Th. NipPERDEY, Nationalidee und Nationaldenkmal in Deutschland, in: Historische Zeitschrift, Bd. 206, H. 3 (Juni 1968), S. 529-585.

E. NoÈ, Il Monumento a Canova dell'Accademia di Venezia, in La mano e il volto di Antonio Canova. Nobile semplicità, serena grandezza, (catalogo della mostra, Possagno, Museo Gipsoteca Antonio Canova), (a cura di M. Guderzo), Treviso 2008, S. 93-97.

S. B. Nuland, Ignaz Semmelweis. Arzt und großer Entdecker, München 2006.

A. NyARI, Der Porträtmaler Johann Kupetzky. Sein Leben und seine Werke, Wien/Pest/Leipzig I889.

W. Ogris, Die Universitätsreform des Ministers Leo Graf Thun-Hohenstein. Festvortrag anläßlich des Rektorstages im Großen Festsaal der Universität Wien am I2. März 1999, Wien 1999.

T. Olechowski/T. Ehs/K. Staudigl-CiechowiCz, Die Wiener Rechts- und staatswissenschaftliche Fakultät I918-1938 (Schriften des Archivs der Universität Wien 20), Göttingen 2014.

D. Orrells, Burying and excavating Winckelmann's History of Art, in: Classical Receptions Journal 3, 20II, S. I66-I88.

F. Otтen, Neue Quellen zur Datierung einer Wachsfigur Friedrichs. I, in: Zeitschrift des Deutschen Vereins für Kunstwissenschaft, XLII, 1988, S. 77-8I.

R. Отто, Gottscheds Leibniz, in: Pluralität der Perspektiven und Einheit der Wahrheit im Werk von G. W. Leibniz: Beiträge zu seinem philosophischen, theologischen und politischen Denken (hrsg. von F. Beiderbeck/S. Waldhoff), Leipzig 20II, S. 19I-264.

I. Palladino/M. Bidovec, Johann Weichard von Valvasor (I64I-I693). Ein Protagonist der Wissenschaftsrevolution der Frühen Neuzeit. Leben, Werk und Nachlass, Wien/Köln/Weimar 2008.

J. T. Paoletti/G. M. Radke, Art in Renaissance Italy, London 1997.
M. Papenheim, En ce monde chacun a sa politique: Aspekte einer Begriffsgeschichte von ,politique in Frankreich vom 16. bis 19. Jahrhundert, in: Politik: Situationen eines Wortgebrauchs im Europa der Neuzeit (hrsg. von W. Steinmetz), Frankfurt a. M. 2007, S. 162-205.

C. Perrault, Abrégé des dix livres d'architecture de Vitruve, Paris I674.

D. Pescarmona, I monumenti commemorativi, in Le raccolte storiche dell'Accademia di Brera, (hrsg. von G. Agosti/M. Ceriana), Florenz 1997.

G. Pesci (Hg.), La Certosa di Bologna: immortalità della Memoria, Bologna 1998.

T. Petercsák (Hg.), Az egri Domus Universitatis és Líceum. Oktatás, tudomány, művészet I7632013, Eger 2013.

P. Petru/M. Žargi, Narodni muzej v Ljubljani, Ljubljana 1983 (Kulturni in naravni spomeniki Slovenije, I23), S. 22-38 (mit deutschem Einleger: Führer durch das Slowenische Nationalmuseum/Narodni muzej, S. I-XXVII).

M. Petz-Grabenbauer, Zu Leben und Werk von Nicolaus Joseph Freiherr von Jacquin, in: Wiener Geschichtsblätter, Jg. 50, 1995, H. 3, S. I40I44.

W. Pichler/R. Ubl, Bildtheorie zur Einführung, Hamburg 2014.

J. Plečnik, Projekt univerzitetne biblioteke ljubljanske, Ljubljana 1933.

A. Pöllmann, Von der Entwicklung des Hieronymus-Typus in der älteren Kunst, in: Benediktinische Monatsschrift 2, 1920, S. 438-522.

M. Росн-Kalous, Wiener Plastik im 19. Jahrhundert, in: Geschichte der bildenden Kunst in Wien, Wien I970.

J. Poeschke, Donatello. Figur und Quadro, München 1980.

J. Poeschke, Die Skulptur der Renaissance in Italien, vol. I: Donatello und seine Zeit, München I990.

M. Pötzl-Malikova, Franz Xaver Messerschmidt, Wien 1982.

M. PötZl-Malikova, Franz Xaver Messerschmidt, Monographie und Werkverzeichnis, Belvedere (hrsg. von A. Husslein-ArCo), Wien 2015.

H. A. Pohlsander, National Monuments and 
Nationalism in 19th Century Germany, Bern 2008.

F. Polleross, „Damit mein Contrefait zur Gedachtnuss in Hauss verbleibe“. Adelsporträts des 17. und I8. Jh., in: Adel im I8. Jh. Umrisse einer sozialen Gruppe in der Krise (hrsg. von G. Ammerer/E. Lobenwein/M. Scheutz), Innsbruck 20I5.

J. Pope-Hennessy, Italian Renaissance Sculpture, London 1958.

C. Poppi/E. Farioli (Hg.), I concorsi Curlandesi: Bologna Accademia di Belle Arti 1785-1870, Bologna 1980.

H. Posch/D. Ingrisch/G. Dressel, „Anschluss“ und Ausschluss 1938. Vertriebene und verbliebene Studierende der Universität Wien (Emigration - Exil - Kontinuität. Schriften zur zeitgeschichtlichen Kultur- und Wissenschaftsforschung, hrsg. v. F. Stadler, Bd. 8), Wien/Berlin 2008, S. II4-II5.

M. Pozzetto, Max Fabiani. Ein Architekt der Monarchie, Wien 1983.

D. Prelovšek, Josip Plečnik. Život a dílo, Brno 2002.

B. Prokisch, Der Nachlass Arnold Hartig im Museum Lauriacum in Enns, Katalog, Teil r: Das Medaillenwerk, Linz/Wien 2005

B. ProKisch, Der Nachlass des Medailleurs Arnold Hartig (I878-1972). Bericht über eine Lehrveranstaltung, in: Mitteilungsblatt des Instituts für Numismatik und Geldgeschichte, SoSe 2005, Wien 2005, S. 24-25.

F. QueYrel, Caylus, de l'antiquaire à l'archéologue: une méthode différente de celle de Winckelmann, in: L'idée du style dans l'historiographie artistique (hrsg. von S. Frommel/A. BRucCULERI), Rom 20I3, S. 23I-239.

G. Raspini, Gli Eremi nella Diocesi di Fiesole, Fiesole I98I

O. RathкоLв, Die Rechts- und Staatswissenschaftliche Fakultät der Universität Wien zwischen Antisemitismus, Deutschnationalismus 1938, davor und danach, in: Willfährige Wissenschaft. Die Universität Wien 1938-1945 (hrsg. von G. Heiss/S. Mattr/S. Meissl/E. Saurer/K. StUhlpfarrer), Wien 1989, S. 197-200.
O. Rathkolb (Hg.), Der lange Schatten des Antisemitismus. Kritische Auseinandersetzungen mit der Geschichte der Universität Wien im I9. und 20. Jahrhundert (Zeitgeschichte im Kontext, 8), Göttingen 2013.

O. Rathкоlв, Gewalt und Antisemitismus an der Universität Wien und die Badeni-Krise 1897. Davor und danach, in: Der lange Schatten des Antisemitismus: Kritische Auseinandersetzungen mit der Geschichte der Universität Wien im 19. und 20. Jahrhundert (hrsg. von O. RathKоlв), Göttingen 2013, S. 69-92.

J. Rees, Die Kultur des Amateurs: Studien zu Leben und Werk von Anne Claude Philippe de Thubières, Comte de Caylus (I692-I765), Weimar 2006.

E. F. Rice, Saint Jerome in the Renaissance, Baltimore/London 1985.

B. Ridderbos, Saint and Symbol. Images of Saint Jerome in Early Italian Art, Groningen 1984.

R. RiedL (Hg.), Leben und Schaffen des Bildhauers Josef Riedl, Frankfurt a. M. 2005.

D. Ripoll, Ci-gît J. C.: la tombe de Jean Calvin au cimetière des Rois, in: Il più dolce lavorare che sia: mélanges en l'honneur de Mauro Natale (hrsg. von F. Elsig/G. Extermann/N. Etienne), Mailand 2009, S. 453-457.

G. Ring, Saint Jerome Removing the Thorn from the Lion's Paw, in: Art Bulletin 27, 1945, S. 190.

L. Ritter Santini, ,Auf dunklen Grund gezogen.' Das Gedächtnis der Bilder, in: Geheimster Wohnsitz. Goethes italienisches Museum (hrsg. von H. Mildenberger et al.), Berlin 1999, S. 4I-73.

S. Rösch, Die Professorengalerie der Gießener Universität. Ikonographische und genealogische Betrachtungen, in: Ludwigs-Universität, Justus-Liebig-Hochschule: I607-1957. Festschrift zur 350-Jahrfeier, Gießen 1957, S. 433-442.

R. Roli, Il Creti a Palazzo: il lascito Collina Sbaraglia al Senato di Bologna (1744), in: Arte a Bologna: Bollettino dei Musei Civici d'Arte Antica, I, I99I, S. 47-57.

M. Rosa di Simone, Die Zulassung zur Universität, in: Von der Reformation bis zur französischen Revolution (hrsg. von W. RuegG), S. $235-262$.

H. Rumpler/H. Denk (Hg.), Carl Freiherr von 
Rokitansky (I804-I878). Pathologe, Politiker, Philosoph. Gründer der medizinischen Schule des 19. Jahrhunderts. Gedenkschrift zum 200. Geburtstag, Wien/Köln/Weimar 2005.

J. B. Rupprecht, Jacquins Denkmal durch den Blumenmaler Knapp. Aus: Wanderung durch die Ateliers hiesiger Künstler, in: Archiv für Geographie, Historie, Staats- und Kriegskunst, Jg. I2, Wien I82I.

A. Rubbiani, La chiesa di San Francesco e le tombe dei Glossatori, Bologna I899.

A. Rubbiani, i veri e i falsi storici (exh. cat. Bologna 198I), Casalecchio di Reno 198I.

J. RüDIGER, Begegnung mit dem steinernen Autor. Die Gelehrten an der Fassade der Wiener Universität, in; Autorschaft. Konzeptionen, Transformationen, Diskussionen (hrsg. von $\mathrm{H}$. BANNert/E. KleCKer), Wien 20I3, S. 223-246.

J. Rüdiger/D. Schweizer, Stätten des Wissens. Die Universität entlang ihrer Bauten I365-20I5, Wien 20I5.

D. Russo, Saint Jérome en Italie. Étude d'Iconographie et de Spiritualité (XIIe-XVe siècle), Paris/Rom 1987.

E. A. SAfarik, Johann Kupetzky (I666-1740). Gesamtwerk (hrsg. von Z. KAZLEPKA), Brno 2014.

F. SAlomon, Graf Leo Thun-Hohenstein, Franz Exner und Hermann Bonitz. Beiträge zur Geschichte der österreichischen Unterrichtsreform, Wien I893.

D. Salter, Holy and Noble Beasts: Encounters with Animals in Medieval Literature, Cambridge 200 .

S. Salvini, Catalogo Cronologico de' Canonici della Chiesa Metropolitana Fiorentina, Florenz 1782.

J. von SAndrart, Academie der Bau-, Bild- und Mahlerey-Künste (1675), hrsg. von A. R. PeltZER, München 1925 .

R. SсhacheL, Österreichisches Biographisches Lexikon 7, Wien 1978, S. I21.

S. Schatter, Fama Sancta Oder Heiliger Rueff. Das ist: Lob- und Ehren-Predigen, [...], sambt zweyen Leich-Predigen, Augsburg 1728.

I. Schemper-Sparholz, Ge(l)ehrte Köpfe, Zu den Anfängen ehrenhalber aufgestellter Büsten in Wien, in: Blickwechsel. Die Bildnisbüste in der Epoche der Aufklärung, Wissenschaftlicher Beiband zum Anzeiger des Germanischen Nationalmuseums (hrsg. von M. KAMMEL), in Druck.

I. Schemper-Sparholz/C. Mang, „Gedächtniswerk" - Zu den plastischen Bildnissen der Marie von Ebner-Eschenbach, in: Innsbrucker Beiträge zur Kulturwissenschaft N. F. I4, erscheint 2017.

M. Scheu, Johann Baptist Hagenauer (I732-I8IO) und sein Schülerkreis. Wege der Bildhauerei im I8. und 19. Jahrhundert, phil. Diss., Wien 2014.

Th. SсHLich, Asepsis and Bacteriology: A Realignment of Surgery and Laboratory Science, in: Medical History, Vol. 56/3 (2012), S. 308-334.

J. von Schlosser, Geschichte der Porträtbildnerei in Wachs. Ein Versuch, in: Jahrbuch der Kunsthistorischen Sammlungen des Allerhöchsten Kaiserhauses, XXIX, I9IO-I9II.

E. G. Sснмidt, Marmorbüsten der Universitätsaula. Nachbetrachtungen zu einer Ausstellung, in: Mitteilungen und Berichte für die Angehörigen und Freunde der Universität Leipzig, $\mathrm{H}$. 7, 1998, S. 19-20.

E. Sснміdт, Die Gießener Universitätsmaler Christoph Maximilian Pronner und Friedrich Johann Ludwig Berchelmann und der Kunstmaler Johann Nikolaus Reuling, Gießen 1968.

I. SchNack, Beiträge zur Geschichte des Gelehrtenporträts (= Historische Bildkunde 3), Hamburg 1935.

L. Schönbauer, Das Medizinische Wien. Geschichte - Werden - Würdigung, Berlin/Wien I944.

L. Schönbauer, Das Medizinische Wien. Geschichte - Werden - Würdigung (überarbeitete Fassung), Wien 1947.

G. Schörner, Der österreichische Realismus am Beispiel eines Künstlerlebens - Heinrich Zita. Der Bildhauer und seine Zeit, Wien (Eigenverlag) 1987.

R. Scholl, Die Bildnissammlung der Universität Tübingen I477-1927, Stuttgart 1927.

K. Schrauf, Die Gedächtnistafeln der Wiener Universitäts-Rectoren. 1365-I893, Wien I893.

P. Schubring, Die italienische Plastik des Quattrocento, Berlin I9I9.

K. Schulz, Künstler, Graveure, Medailleure, in: 
Geld. 8oo Jahre Münzstätte Wien, (Kat. zur Ausstellung im Kunstforum Bank Austria Wien, 27. Juni-2I. August 1994), Katalogredaktion Ch. Bauer, E. Benesch, Wien 1994.

C. Schwinges, Rektorwahlen. Ein Beitrag zur Verfassungs-, Sozial- und Universitätsgeschichte des alten Reiches im I5. Jahrhundert, Sigmaringen 1992.

G. C. Sciolla, La scultura di Mino da Fiesole, Turin 1970 .

L. Sebregondi, Tre confraternite fiorentine, Florenz I99I.

F. Seebacher, „Der operierte Chirurg“. Theodor Billroths Deutschnationalismus und akademischer Antisemitismus, in: Zeitschrift für Geschichtswissenschaft 54 (2006), S. 317-338.

F. SeEbacher, Das Fremde im „deutschen“ Tempel der Wissenschaften. Brüche in der Wissenschaftskultur der Medizinischen Fakultät der Universität Wien, Wien 201 .

J. SISA, Klassizistische Bauten des I9. Jahrhunderts. Die Bibliothek und der Turm von Pannonhalma, in: Acta Historiae Artium, XXXVIII, 1996, S. $167-184$.

J. Sisa/D. Wiebenson (Hg.), The Architecture of Historic Hungary, Cambridge, Mass./London I998.

J. SisA, A Magyar Tudományos Akadémia székháza, in: Épített örökség a magyar tudomány szolgálatában. (hrsg. von G. Gy. PApP), Budapest 20IO, S. 5I-54.

V. Šlapetka (Hg.), Jan Kotěra. The Founder of Modern Czech Architecture I87I-I923, Prag 2003.

M. Sмоцıк, Umetnine v ljubljanskem Semenišču, in: Vis imaginis. Baročno slikarstvo in grafika. Jubilejni zbornik za Anico Cevc (hrsg. von B. Murovec), Ljubljana 2006 (Zusammenfassung: Works of Art in the Diocesan Seminary in Ljubljana).

M. SMolıK, Semeniška knjižnica, Celje/Ljubljana 2010.

G. B. Soria, Li cinque libri di architettura di Gio. Battista Montani Milanese, Rom I684.

P. Speiser/F. G. Smekal (Hg.), Karl Landsteiner. Entdecker der Blutgruppen und Pionier der Immunologie, Biographie eines Nobelpreisträgers aus der Wiener Medizinischen Schule, mit I26 Abbildungen, 2. Aufl., Wien 1975.
P. Speiser/F. G. SMeKal (Hg.), Karl Landsteiner. The discoverer of the blood-groups and a pioneer in the field of immunology, Biography of a Nobel Prize winner of the Vienna Medical School, engl. Übersetzung von R. RicкETT, Wien 1975.

W. SpeitKamp, ,Sinnbild für unsere wieder aufgebaute Stadt'? Das Röntgen-Denkmal in Gießen, in: Panorama - 400 Jahre Universität Gießen - Akteure, Schauplätze, Erinnerungskultur (hrsg. von H. CARL et al.), Frankfurt a. M. 2007, S. 272-277.

L. SRŠEŇ, Budova Národního muzea v Praze I89I/I99I. Architektura, umělecká výzdoba a původní uměleckořemeslné vybavení, Prag I991.

J. STAIF, František Palacký. Život, dílo, mýtus, Prag 2009.

W. Steguweit, Europäische Medaillenkunst von der Renaissance bis zur Gegenwart, Münzkabinett Staatliche Museen zu Berlin - Preußischer Kulturbesitz, Berlin 1995.

V. Steska, Dolničarjeva „Bibliotheca Labacensis publica“, in: Izvestja Muzejskega društva za Kranjsko, X, I900, S. I34-I40, I45-174.

S. Sucharda, Historie pomníku Fr. Palackého v Praze. K slavnosti odhalení vydal Stan. Sucharda, Prag I9I2.

N. Suthor, Caius Plinius Secundus d. Ä.: Trauerarbeit/Schatten an der Wand, in: Porträt (hrsg. von R. Preimesberger/H. BaAder/N. Suthor), Berlin 1999, S. II7-I26.

D. Syndram, Ägypten-Faszinationen: Untersuchungen zum Ägyptenbild im europäischen Klassizismus bis I800, Frankfurt a. M. 1990.

H. Szemethy, From Samothrace to Spalato/Split. The architectural drawings of ancient buildings and sites by George Niemann (I84II9I2), in: Cogitata Tradere Posteris. Figurazione dell'Architettura antica nell'Ottocento/The representation of ancient architecture in the XIXth century: Atti della Giornata Internazionale di Studio „La documentazione grafica dei monumenti antichi nell'Ottocento. Tra tecniche e ideologia (Catania, 25 novembre 2009)“ (hrsg. von F. Buscemi), Rom 20IO, S. 87-IO9. 
D. Tацвот Rice, The University Portraits, Edinburgh 1957.

V. TANDy, Boom and Bust: Why we Can't Afford to be Complacent about Local Authority Museums and University Collections, in: Museums Journal, I07:II, 2007, S. I6-I7.

K. TASChwer, Geheimsache Bärenhöhle. Wie ein antisemitisches Professorenkartell der Universität Wien nach I9I8 jüdische und linke Forscherinnen und Forscher vertrieb, in: Alma mater antisemitica. Akademisches Milieu, Juden und Antisemitismus an den Universitäten Europas zwischen 1918 und 1939, Wien 2015.

W. Telesko, Die Wiener Hofburg I835-1918. Der Ausbau der Residenz vom Vormärz bis zum Ende des „Kaiserforums“, Wien 2 oI2.

C. von Than, Das chemische Laboratorium der k. ungarischen Universität in Pest, Wien 1872.

L. Thévenaz, Histoire du collège de Genève, Genf I896.

G. Tibiletti, Monumenti e Cimeli dell'Ateneo Pavese, Pavia I96r.

A. То́тн, The National Pantheon, in: Ders., A Nemzeti Emlékcsarnok, Szeged 2009, S. I4-I6.

J. Tynjanow, Die Wachsperson (1930), deutsche Übersetzung in: Aufzeichnungen auf Manschetten. Sonderbare Geschichten von Bulgakow bis Schukschin, Leipzig 1987.

L. VIDMAR, Ljubljana kot novi Rim. Akademija operozov in baročna Ljubljana, Ljubljana 2013.

D. Viéville, Rodin, les métaphores du génie, Paris 2014 .

P. Vodopivec, Von den Anfängen des nationalen Erwachens bis zum Beitritt in die Europäische Union, in: P. Štih/V. Simoniti/P. Vodopivec, Slowenische Geschichte. Gesellschaft - Politik - Kultur, Graz 2008, S. 384-397.

V. Volavka, J. V. Mylsbek, Prag 1942.

R. Wagner-Rieger, Julius von Schlosser - zur hundertsten Wiederkehr seines Geburtstages (23. September), in: Neue Züricher Zeitung, 26. 9. 1966, Nr. 4045 (IO8).

R. WAlter, Bleibende Erinnerungszeichen an eine Rechtslehre, in: T. OlechowsKi u. a. (Hg.), Grundlagen der österreichischen Rechtskultur.
Festschrift für Werner Ogris zum 75. Geburtstag, Wien 2010, S. 552-553.

A. WandruszKa, Österreich und Italien im I8. Jahrhundert (Österreich Archiv. Schriftenreihe des Arbeitskreises für Österreichische Geschichte), Wien 1963.

J. Weatherburn Goodison, Catalogue of Cambridge Portraits, Cambridge 1955.

M. I. Weвв, Michael Rysbrack. Sculptor, London I954.

I. Weibezahn, Das Leibnizdenkmal in Hannover. Geschichte, Herkunft und Wirkung, in: Niederdeutsche Beiträge zur Kunstgeschichte, XI, I972, S. I9I-248.

B. Werche, Kräuters Skizze des Rokokosaales der Großherzoglichen Bibliothek, in: Anna Amalia, Carl August und das Ereignis Weimar (hrsg. von H. Th. Seemann), Göttingen 2007 (Klassik Stiftung Weimar, Jahrbuch 2007), S. 24427I.

N. Werner, Die Professoren-Galerie und ihre Portraitmaler, in: Panorama - 400 Jahre Universität Gießen - Akteure, Schauplätze, Erinnerungskultur (hrsg. von H. CARL et al.), Frankfurt a. M. 2007, S. 244-249.

N. Werner, Professoren-Galerie, in: 375 Jahre Universität Gießen I607-1982. Geschichte und Gegenwart. Ausstellungskatalog, Gießen 1982, S. 50-54.

H. White, Metahistory. The Historical Imagination in Nineteenth-Century Europe, Baltimore/ London 1973.

C. Wiebel, Askese und Endlichkeitsdemut in der italienischen Renaissance, Weinheim 1988.

E. L. Wiemers/G. Wiemers, Planung und Entstehung der Sächsischen Akademie der Wissenschaften zu Leipzig. I704-I846, Göttingen I996.

J. Wiesner, Jan Ingen-Housz. Sein Leben und Wirken als Naturforscher und Arzt, Festgabe zum II. internationalen botanischen Kongreß in Wien 1905, Wien 1905.

J. J. Winckelmann, Histoire de l'art de l'antiquité (übers. von M. Huber), Paris I78I.

J. J Winckelmann, History of the Art of Antiquity (trad. von H. F. Mallgrave), Los Angeles 2006.

G. WINCKLER, Carl von Rokitansky als Rektor der 
Wiener Universität, in: Carl Freiherr von Rokitansky I804-1878. Pathologe, Politiker, Philosoph, Gründer der Wiener Medizinischen Schule des 19. Jahrhunderts (hrsg. von H. Rumpler/H. Denk), Wien u. a. 2005, S. 4550.

G. WINTER, Zwischen Individualität und Idealität. Die Bildnisbüste. Studien zu Thema, Medium, Form und Entwicklungsgeschichte, Stuttgart 1985 .

R. WitT, In the Footsteps of the Ancients: The Origins of Humanism from Lovato to Bruni, Boston 2000.

P. Wittlich, České sochařství ve XX. století, Prag 1978.

P. Wittlich, Scuplture of Czech Art Nouveau, Prag 200I.

P. Wittlich, Auguste Rodin et la modernité tcheque, in: Opera Facultatis philosophicae Universitatis Carolinae Pragensis, I, 2006, S. II7-I37.

P. Wittlich, Bohumil Kafka (I878-I942). Př́běh sochaře, Prag 2014.

C. A. Wolf, Studien zur Tonwarenfabrik March in Charlottenburg, phil. Diss., Technische Universität Berlin, Berlin 1990.

R. Wolff, Zur ,Gruppe` der Gelehrtengrabmäler des Mittelalters in Oberitalien, in: Creating Identities. Die Funktion von Grabmalen und öffentlichen Denkmalen in Gruppenbildungsprozessen, Kassel 2007, S. 219-230.

W. Wordsworth, The Prelude [1850], in: The Poetical Works of Wordsworth (hrsg. von T. Hutchinson/E. De Selincourt), Oxford I936, Book III.

J. Wrba, Der Orden der Gesellschaft Jesu im alten Universitätsviertel von Wien, in: Das alte Universitätsviertel in Wien 1385-1985 (hrsg. von K. Mühlberger/G. Hamann/F. Skacel), Wien I985, S. 47-74.

C. Wurzbach, Biografisches Lexikon des Kaiserthums Österreich, IV, Wien I858.

J. E. Young, Memory/Monument, in: Critical Terms for Art History. Second Edition (hrsg. von R. S. Nelson/R. Shiff), Chicago/London 2003 , S. 246.
A. ZACCHI, Temi sacri, storici e allegorici, in: Il Segno e il colore. Nell'atelier di Luigi Serra (exh. cat. Bologna, Galleria d'Arte Moderna), Cinisiello Balsamo 2003.

H. Zedelmaier/M. Mulsow (Hg.), Die Praktiken der Gelehrsamkeit in der Frühen Neuzeit, Tübingen 200I.

R. Zedinger (Hg.): Lothringens Erbe. Franz Stephan von Lothringen (1708-1765) und sein Wirken in Wirtschaft, Wissenschaft und Kunst der Habsburgermonarchie (Ausst.-Kat. Schallaburg 29. April-29. Oktober 2000).

Josef Zenzmaier. Zum 70. Geburtstag, (Ausstellungskatalog hrsg. vom Salzburger Museum Carolino Augusteum), Salzburg 2003.

S. Žitko, Historizem v kiparstvu I9. stoletja na Slovenskem, Ljubljana 1989.

S. Žitko, Fernkorns und Tilgners Werke für Ljubljana, in: Österreichische Zeitschrift für Kunst und Denkmalpflege, LI, 1997, S. 408-4I4.

P. Zitzlsperger, Die Büste als Porträt. Historische und theoretische Überlegungen, in: Die obere Hälfte. Die Büste seit Rodin (hrsg. von D. Brunner et al.), Heidelberg 2005 .

G. Zupan, Les monuments et l'espace public Slovene de 1945 à 1991, in: Bildersturm in Osteuropa. Die Denkmäler der kommunistischen Ära im Umbruch. Eine Tagung des Deutschen Nationalkomitees von Icomos, des Instituts für Auslandsbeziehungen und der Senatsverwaltung Berlin in der Botschaft der Russischen Föderation in Berlin, I8.-20. Februar 1993 (hrsg. von F. Fiedler/M. Рetzet), München 1994 (ICOMOS-journals of the German National Committee, 13), S. 54-55.

S. Zuraw, The Sculpture of Mino da Fiesole, New York 1993.

S. Zuraw, The Public Commemorative Monument: Mino da Fiesole's Tombs in the Florentine Badia, in: Art Bulletin 80, 1998, S. 452-477.

H. Zwahr, Geschichte der Universität Leipzig I409-2009, Bd. 2, Das neunzehnte Jahrhundert 1830/3I-1909, Leipzig 2010, S. I59 ff.

A. ZwICKL, A szegedi Dóm tér, in: Művészet, I988, 4. S. 2-5, S. 6I-62. 


\section{AUTORINNENVERZEICHNIS}

Dr. SARa Ayres

National Portrait Gallery, London, sayres@npg.org.uk / ayressara@hotmail.com

Malcolm Baker, PhD

Distinguished Professor, Department of Art History, University of California, Riverside, malcolm.baker@ucr.edu

Elena Catra, PhD

Dipartimento di Filosofia e Beni Culturali, Università Ca’ Foscari Venezia, elena.catra@gmail.com

Dr. Pietro Conte

Centre for Philosophy of Science (CFCUL), University of Lisbon, pietro.conte@fc.ul.pt

Dr. Martin Engel

Institut für Kunstgeschichte, Universität Wien, martin.engel@univie.ac.at

Dr. Bernd ERnsting

LETTER Stiftung, Köln, vorstand@letter-stiftung.de

Grégoire Extermann, PhD

Département d'Histoire Art, Université de Genève, Gregoire.Extermann@unige.ch

Univ.-Prof. Dr. GÉza Galavics / Bálint Ugry, MA

Institute for Art History, Research Centre for the Humanities, Hungarian Academy of Sciences, Budapest, galavics.geza@btk.mta.hu, ugry.balint@btk.mta.hu

Dr. Hans Christian Hönes

Research Group “Bilderfahrzeuge”, The Warburg Institute, London, hoenes@bilderfahrzeuge.org

Dr. Angelika Keune

Humboldt-Universität, Berlin, angelika.keune@ub.hu-berlin.de

Jeanette Kohl, PhD

Associate Professor, Department of Art History, University of California, Riverside, jeanette.kohl@ucr.edu

PhDr. Martin Krummholz, PhD

Ústav dějin umění Akademie věd ČR, v.v.i (Institut für Kunstgeschichte, Akademie der Wissenschaften der Tschechischen Republik, Prag), krummholz@udu.cas.cz / Krummholz@seznam.cz 
HR Mag. Thomas Maisel MAS

Universitätsarchiv, Universität Wien, thomas.maisel@univie.ac.at

Dott.ssa Antonella Mampieri

Archivio fotografico e catalogo, Musei Civici d'Arte Antica Bologna,

antonella.mampieri@comune.bologna.it

Mag. Andrea Mayr

Münzkabinett, Kunsthistorisches Museum Wien, Andrea.Mayr@khm.at

Dr. Barbara Murovec

Znanstvenoraziskovalni center, Slovenske akademije znanosti in umetnosti, Umetnostnozgodovinski inštitut Franceta Steleta (Zentrum für wissenschaftliche Forschung, Slowenische Akademie der Wissenschaften und Künste, Ljubiljana), bm@zrc-sazu.si

Prof. Dr. Maria Pötzl-Malikova

Furtwänglerplatz 37/1, 1130 Wien, poetzlma@aol.com

Mag. Heidrun Rosenberg

Institut für Kunstgeschichte, Universität Wien, heidrun.rosenberg@univie.ac.at

Univ.-Prof. Dr. Sigrid Ruby

Institut für Kunstgeschichte, Universität des Saarlandes, Saarbrücken, sigrid.ruby@uni-saarland.de

Ass.-Prof. Dr. Julia Rüdiger

Institut für Kunstgeschichte, Universität Wien, julia.ruediger@univie.ac.at

Institut für Geschichte und Theorie der Architektur, Katholische Privatuniversität Linz,

j.ruediger@ku-linz.at

Ao. Univ.-Prof. Dr. Ingeborg Schemper-Sparholz

Institut für Kunstgeschichte, Universität Wien, ingeborg.schemper@univie.ac.at

Dr. Silvia Schmitt-MaAss

Wilhelm-Reinecke-Sr. 22, 21225 Lüneburg, s.schmitt.maass@gmail.com

Ass.-Prof. Mag. Dr. Hubert D. Szemethy

Institut für Alte Geschichte und Altertumskunde, Papyrologie und Epigraphik, Universität Wien, hubert.szemethy@univie.ac.at 


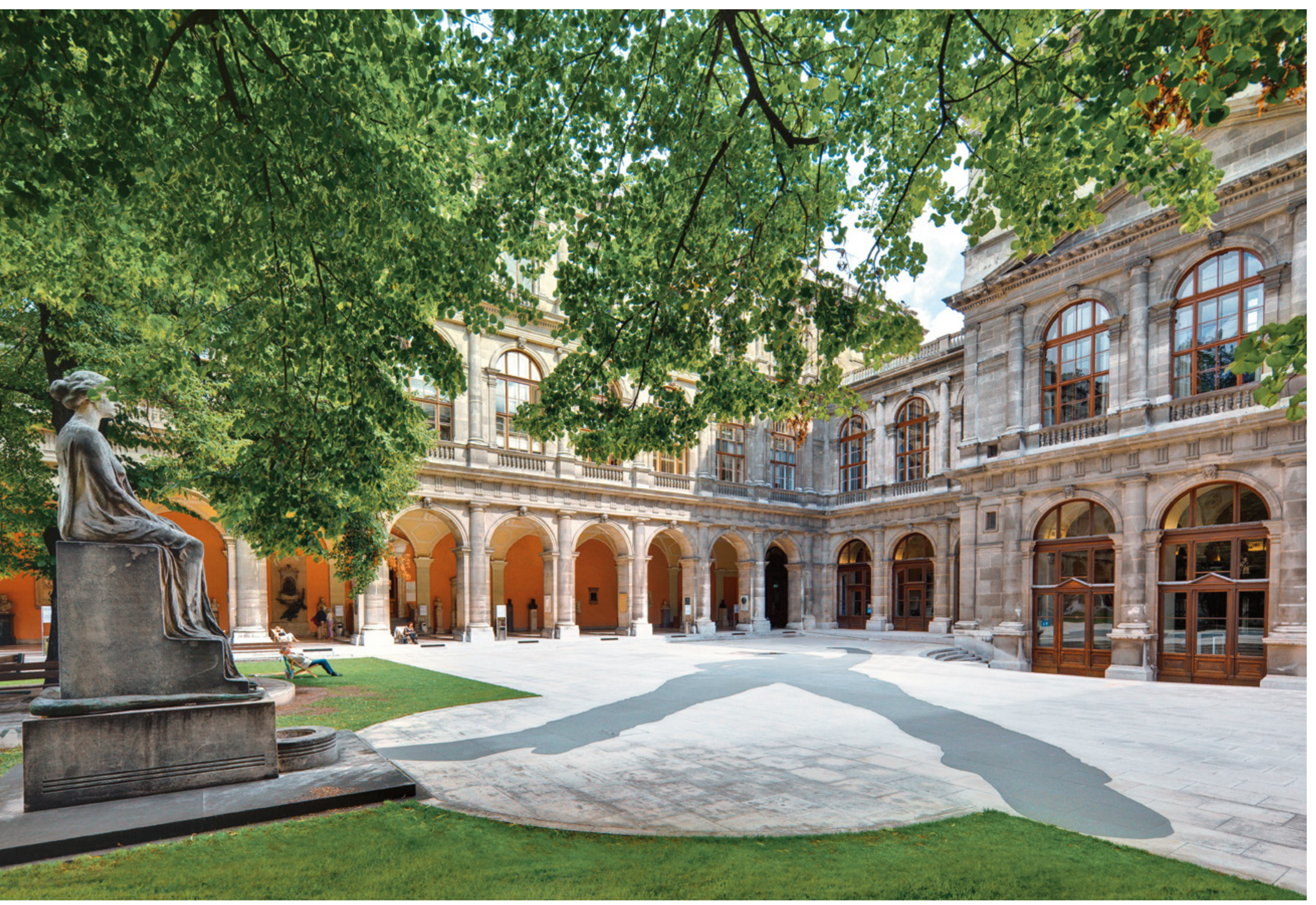


Ausgehend von dem Denkmäler-Ensemble im Arkadenhof der Universität Wien, widmet sich dieser Themenband der Tradition der Gelehrtenmemoria im europäischen Vergleich. In 24 Expertenbeiträgen spürt der Band der Entstehungsgeschichte der Denkmäler der Universität Wien in den wechselnden kulturellen und politischen Kontexten nacbound bettet dieses herausragende Beispiel in das europäische Umfeld historischer Ehrenhallen und Pantheons ein.

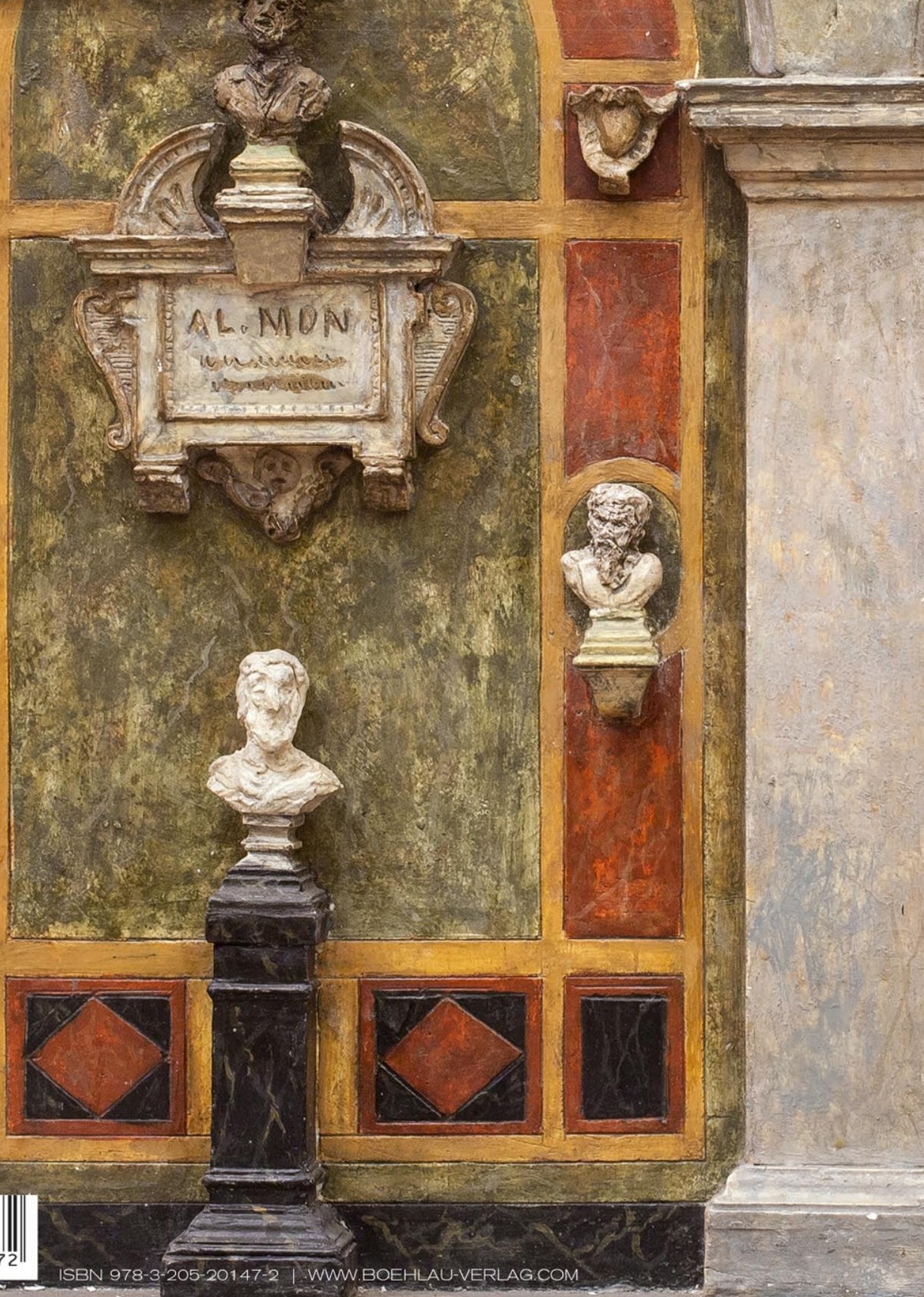

